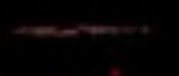

? 



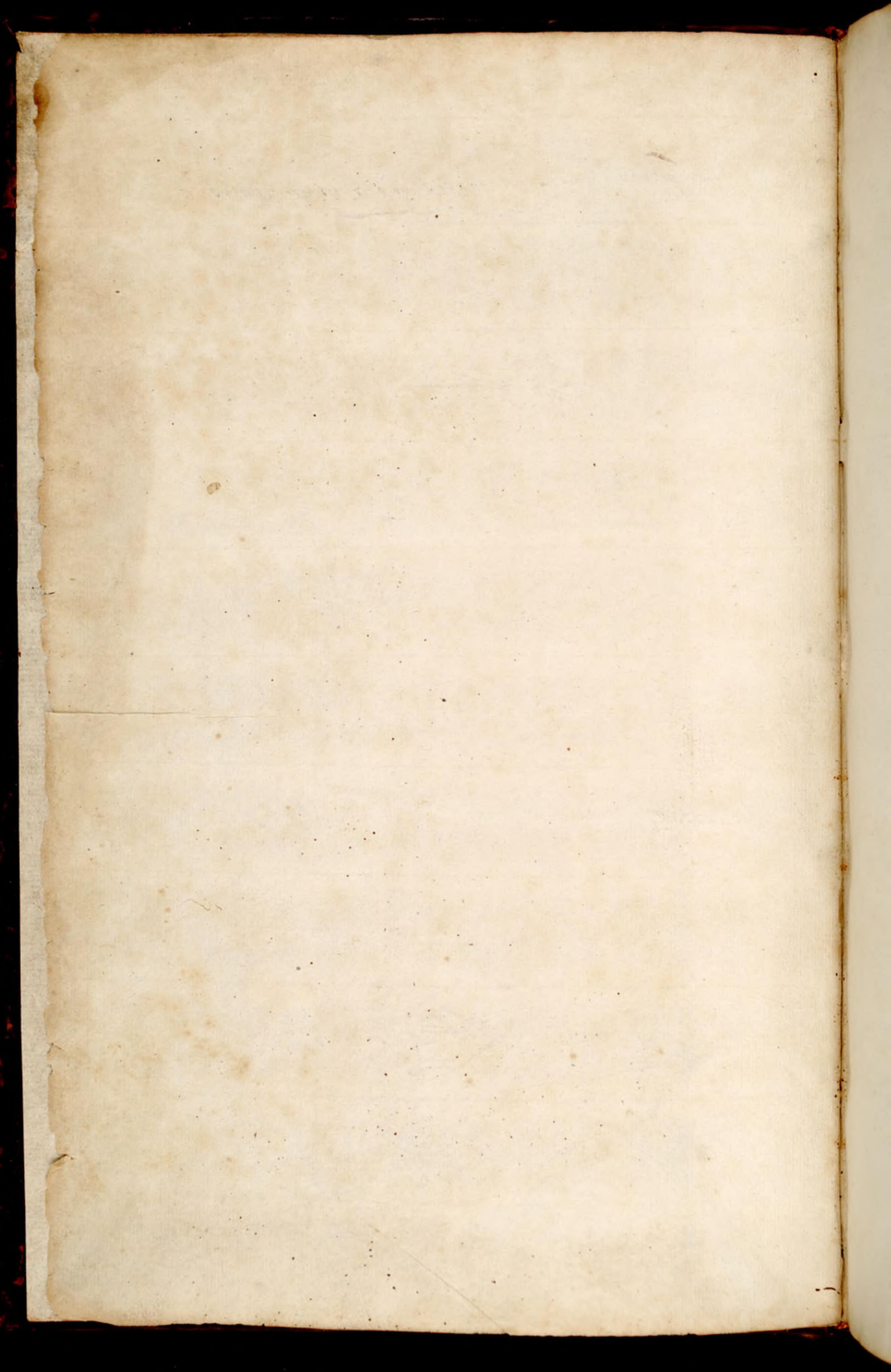




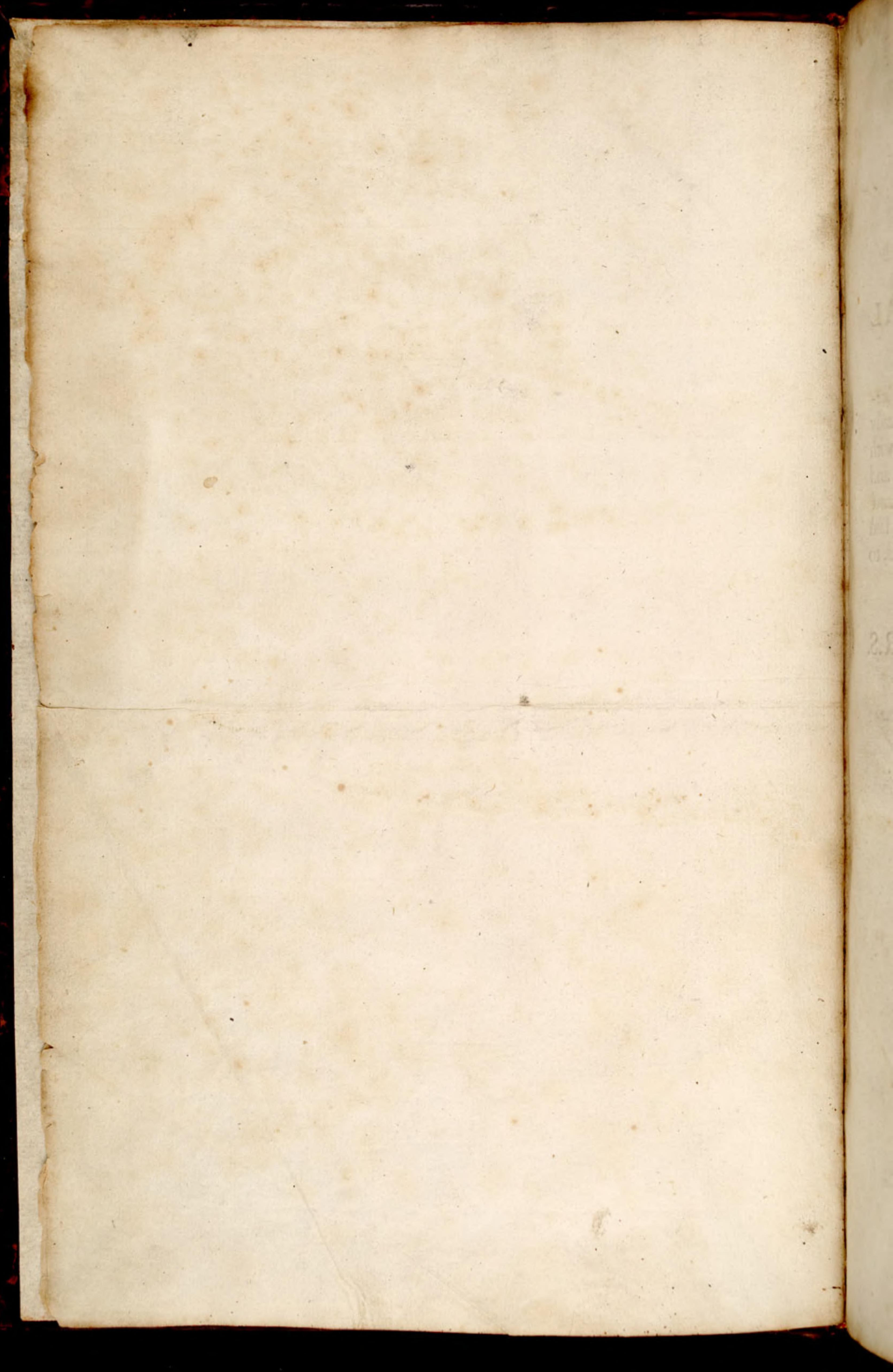



At a Meeting of the Council of the ROY AL SOCIETY, Feb.22. 168:

D. Grew having read feveral Lectures of the Anatomy of Plants, fome whereof have been already printed at divers times, and fome are not printed; with feveral other Lectures of their Colours, Odours Tafts, and Salts; as alfo of the Solution of Salts in Water; and of Mixture; all of them to the fatisfaction of the faid Society: It is therefore Ordered, That $\mathrm{He}$ be defired, to caufe them to printed together in one Volume.

CHR. WREN P.R.S. 


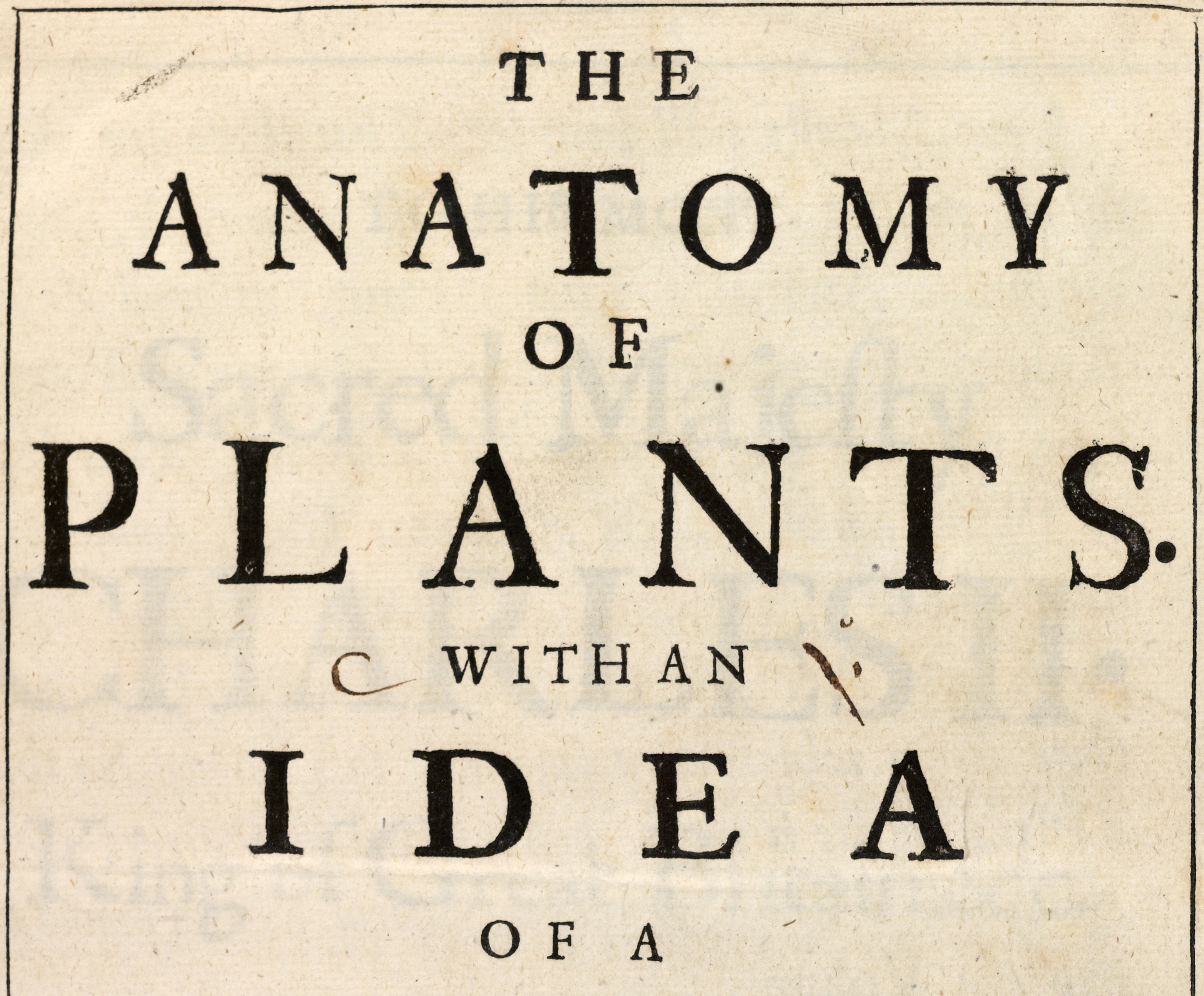

Philofophical Hiftory of Plants.

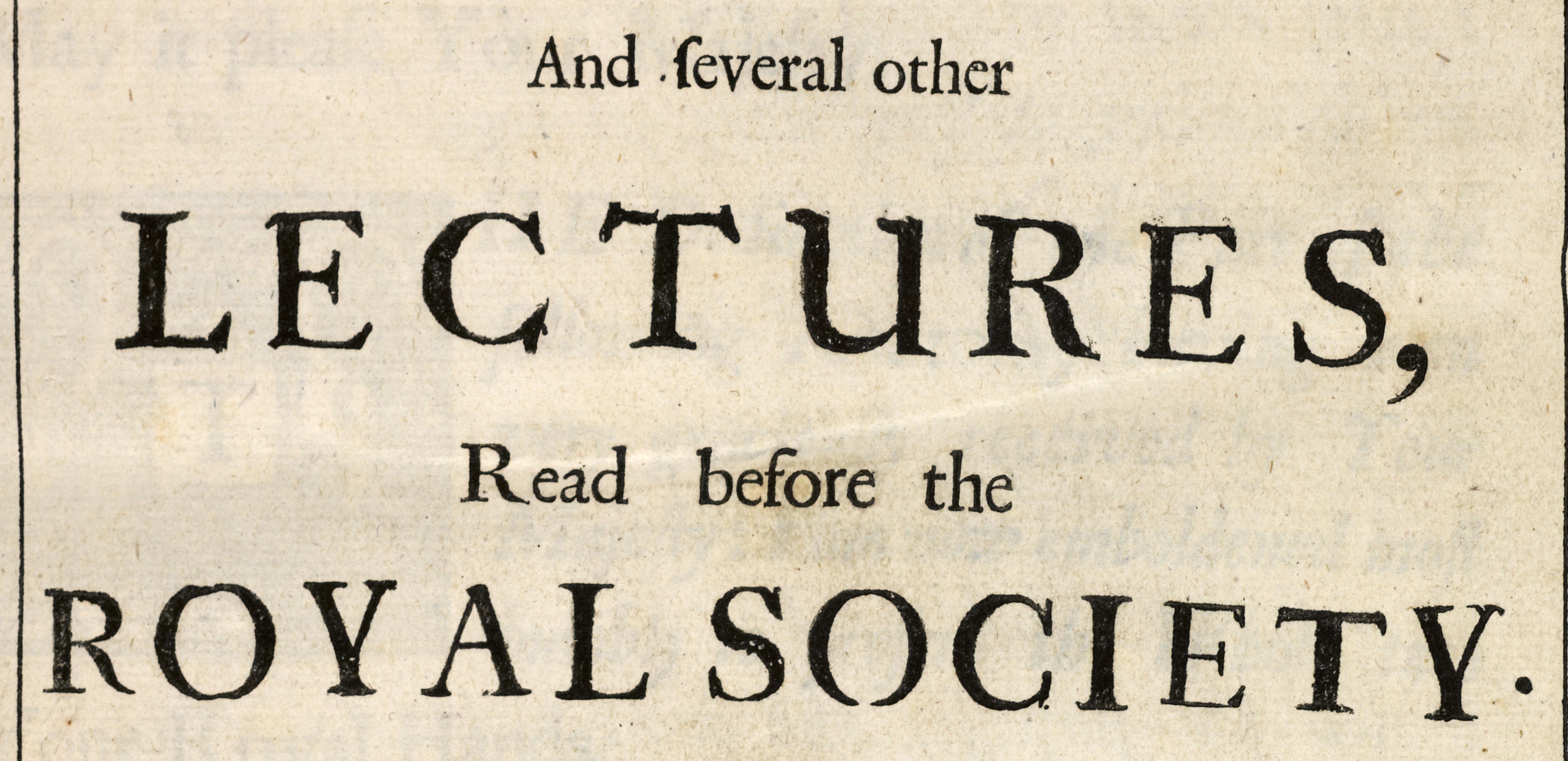

By $N E H E M F A H G R E W$ M.D. Fellow of the ROYALSOCIET $r$, and of the COLLEGE of PHYSICIANS.

Printed by $W$. Ranolins, for the Author, 1682. 


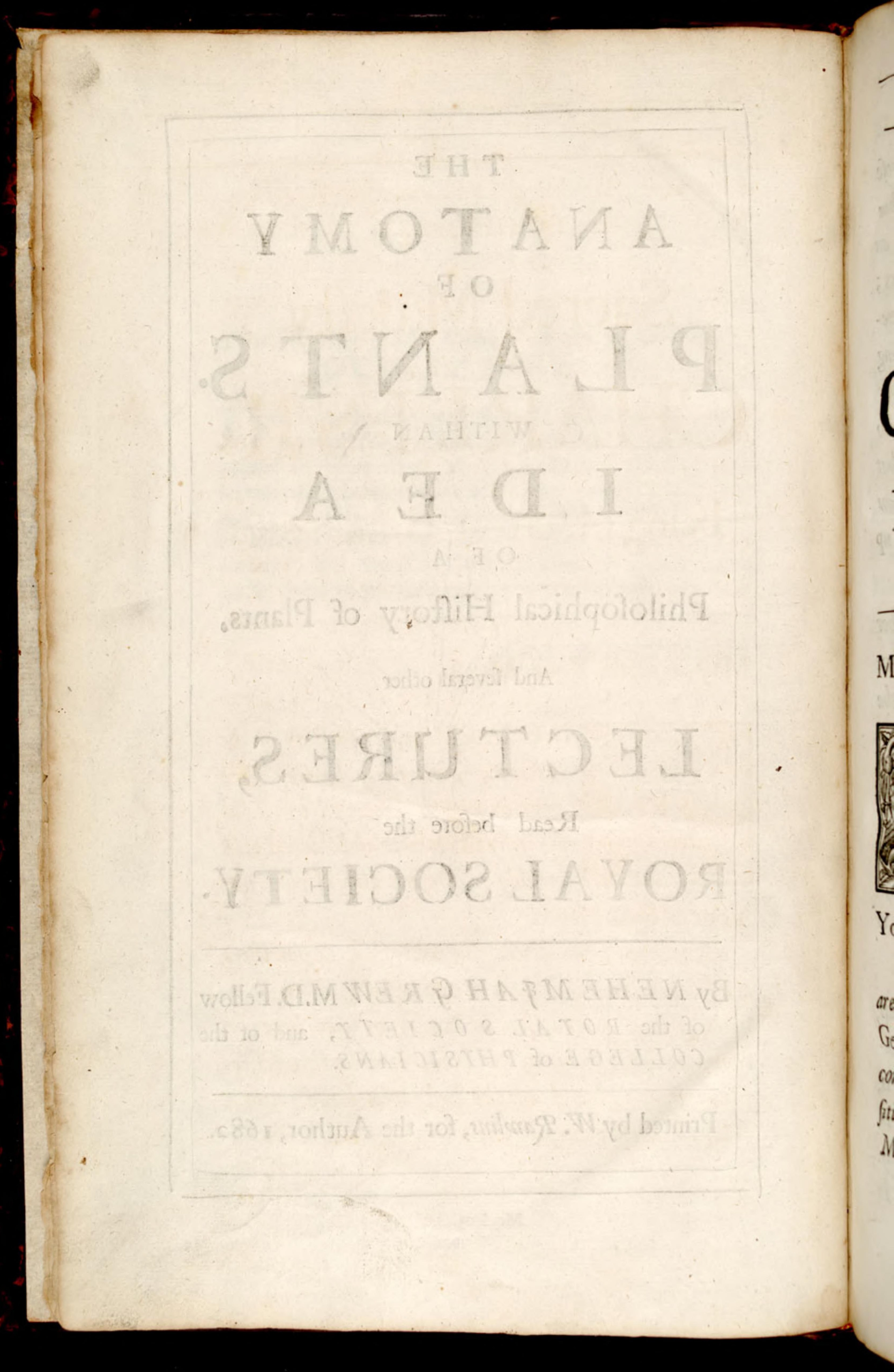




\section{TOHIS MOST}

\section{Sacred Majefty}

\section{CHARLES II.}

\section{King of Great Britain,\&c.}

May it pleafe Your Majefty,

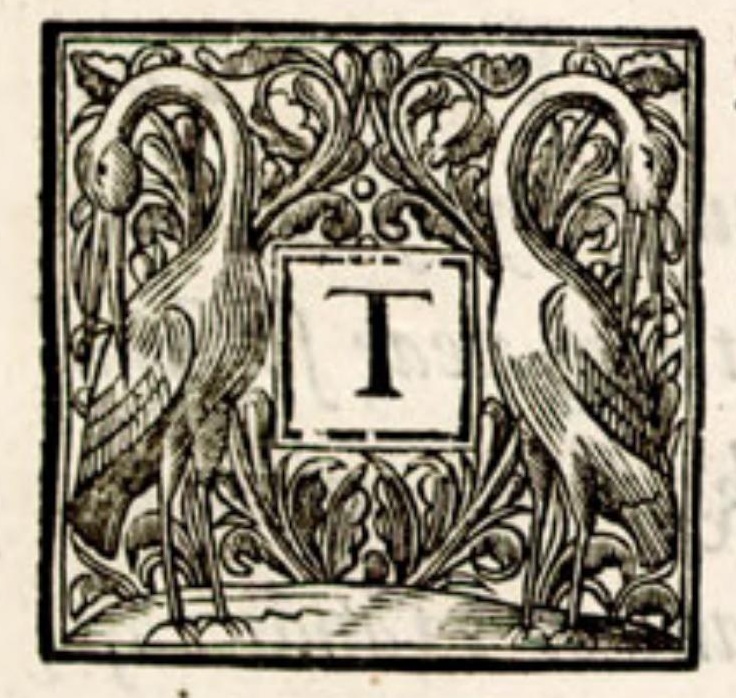

HE Dedication of one Part of the following Anatomy baving been very gracioufly received by $\Upsilon_{\text {our }}$ Majefty: I am nows emboldened moft bumbly to prefent the Wbole into Your R oyal Hands.

By wbich Your OMajesty mill find, That there are Terræ Incognitæ in Philofophy, as soell as Geography. And for fo much, as lies bere, it comes to pafs, I know not bow, even in this Inquifitive Age, That I am the firft, who bave given a Map of the Country. 


\section{The Epiftle Dedicatory.}

Tour Majefty will bere fee, T bat there are thofe tbings witbin a Plant, tittle less admirable, tban witbin an Animal. That a Plant, as well as an Animal, is compofed of ferveral Organical Parts; fome zobereof may be called its Bowels. That eveyy Plant bath Bowels of divers kinds, conteining divers kinds of Liquors. T bat even a Plane lives partly upon Aer; for the recoption wobereof, it bath thofe Parts wobicb are anfwerable to Lungs. So that a Plant is, as it were, an Animal in Quires; as an Animal is a Plant, or ratber feverat Plants bound up into one Volume.

Again, that all the faid Organs, Bowels, or otber Parts, are as artificially made; and for tbeir Place and Number, as puncually fet togetber; as all the Mathematick Lines of a Flower or Face. Tbat the Staple of the Stuff is fo exquiftely fine, that no Silk-worm is able to dram any tbing near $\int 0$ fmall a Thred. So tbat one who walks about woith the meaneft Stick, bolds a Piece of Natures Handicraft, zobich far furpafjes the most elaborate Woof or Needle-Work in the World.

That by all the/e Means, the Afcent of the Sap, the Diftribution of the Aer, the Confection of $f e-$ veral forts of Liquors, as Lympha's, Milks, Oyls, Balfames mith otber parts of Vegetation, are all contrived and brought about in a Mechanical way. 


\title{
The Epiftle Dedicatory.
}

In fum, Your oMajefty will find, that woe are come afbore into a new World, wobereof wo fee no end.

It may be, that fome will Say, into anotber Utopia. $\Upsilon_{\text {et not }} I$, but Nature peaketh the e t tbings: the only true Pallas, wherewith it is treafonable for the most courioufly banded Arachne to compare. In zobofe Name, I, the meanef of ber Pupils, do in all bumility crave Your Majesties Gracious Patronage.Whereof I cannot doubt, fince Your Majesty batb been pleaSed to be the Founder, and to fyle Tour Self the Patron of that Society, of wobicb $I$ bave the bonour to be a Member. Tour Majefly deeming it to be a more Noble $\mathcal{D}_{\text {efgn, }}$ To enlarge the Territories of Knowledge, tban thofe of Dominion: and the Higheft Pitch of Human Glory, not to rule, in any fort, over many; but to be a Good Prince overWife o Men. I am

\author{
Your Majefties \\ moft humble \\ and \\ moft obedient \\ Subject
}




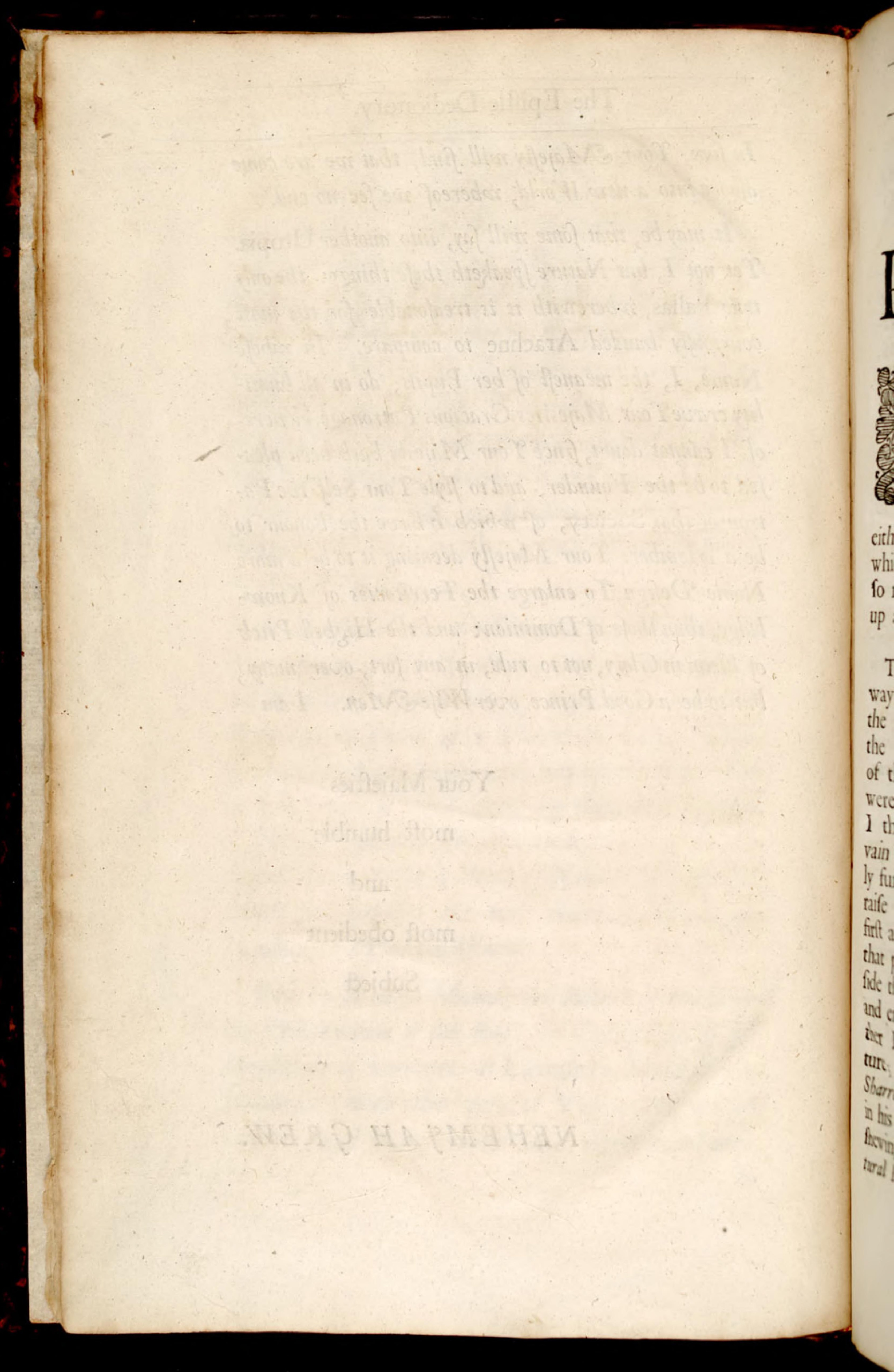




\section{T H E}

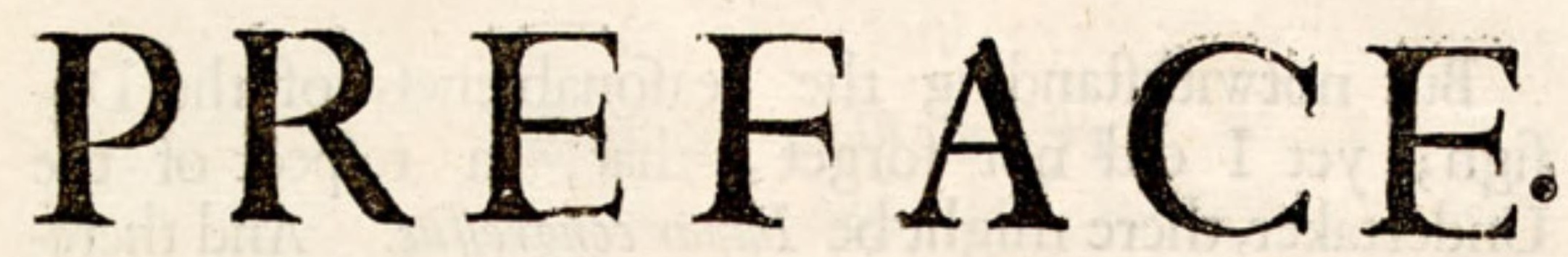

$\mathrm{T}$ is a Politick or Civil Virtue in every prudent mans Eye, To fet himfelf an example, in what he doth, unto others. And in fo doing, he looks upon himfelf as accountable, in fome fort, to all Men. To thofe therefore, who may either exprefly, or tacitly, expect the Reafons, upon which I firt undertook the Anatomy of Plants, and alfo made the after-progrefs therein; I fhall fumme them up as follows.

The firt occafion of directing my Thoughts this way, was in the Year 1664 , upon reading fome, of the many and curious Inventions of Learned Men, in the Bodies of Animals. For confidering, that both of them came at firt out of the fame Hand; and were therefore the Contrivances of the fame Wifdom: I thence fully affured my felf, that it could not be a vain Defign; to feek it in both. And being then newly furnithed with a good ftock of Seeds, in order to raife a Nurfery of Plants; I refolved, befides what I firlt aimed at, to make the utmolt ufe of them for that purpofe: that fo I might put fomewhat upon that fide the Leaf which the bett Botanicks had left bare and empty. And in which, notwithitanding fome other Learned Men had inferted fomewhat of this nature; as Dr. Highmore in his Book of Generation, Dr. Sharrock of the Propagation of Plants, and Mr. Hook in his Micrography: yet but collaterally, and whithout fhewing any purpofe of managing this Part of $\mathrm{Na}$ tural Hiftory. And although it feemed at firt an $\mathrm{Ob}-$ 


\section{The Preface.}

jection in my way, That the firft projectors feldome bring their bufinefs to any good end : yet I alfo knew, That if Men fhould ftay for an Example in every thing; nothing extraordinary would ever be done.

But notwithftanding the reafonablenefs of the Defign; yet I did not forget, that, in refpect of the Undertaker, there might be Impar congreffus. And therefore, before I had ventured very far, in the Year 1668 , I imparted it to my Brother-in-Law, the Learned Dr. Henry Samplon, now Fellow of the Colledge of Phy $\mathrm{L}_{\mathrm{L}}$ cians in London. Who not only very well liked the fame; but alfo excited me to a vigorous and accurate profecution of it. Which he did, partly, by mentioning a very pertinent paffage of Dr. Gliffon, in the Preface to (a) Ch.r. his Book de Hepate, (a) which I had not then read.

Plante quoque in bunc cenfum (fc. Anatomicum) veniunt, variâ enim Partium texturâ, \& differentiis conftant: $\sigma$ proculdubio, ex acurata earundem diffectione, utiles valde obfervationes nobis exurgerent: praftaretque in illis (inferioris licet ordinis) rebus examinandis operam impendere, quam in tranfcribendis ut fape fit, aliorum laboribus, inutiliter atatem tranfigere. Quippe hoc pacto, ignavarum apum more, aliena duntaxat alvearia expilamus,nibilque bono publico adjicimus.

After I had finithed the Firft Book, that I might know the fenfe alfo of other Learned Men, whether the fteps $I$ had already taken, would warrant me to proceed any further: I put fome part of it into the fame Hand; who, in the Year 1670 , communicated the fame to Mr. Oldenburge, then Secretary to the Royal Society: and after he had read it over, it was, upon his motion, delivered to that excellent Perfon Dr. Fobn Wilkins then Bifbop of Chefter; who produced it at a Meeting of the Royal Society, and defired, they might fee the reft. Which, or the greateft part, being alfo prefented to them, the Right Honourable the Lord Vicount Brouncker, then Prefident of the Royal Society, was pleafed to perufe the fame. Prefently, after which, at a Meeting of the Council 


\section{The Preface.}

of the faid Society, the following Order was made, and entred in their Council-Book with this Date, and in thefe words:

\section{May $11^{\text {th }} 1671$.}

Then was Licenfed $\mathcal{D} r$. Nehemjah Grew's Book, Entituled, The Anatomy of $V$ egetables begun; togetber mitb an account of Vegetation grounded tbereupon. And Ordered to be Printed by the Printer to the Royal Society.

Hereupon, I was obliged to fend the Book to the Prefs. And upon the $9^{\text {th }}$ of November following in the fame Year 1671 , when it was near being printed, my Lord Brouncher figned the forementioned Order: the Printer, whofe Name was to be inferted therein, not having received his Diploma till that time.

The Book being quickly after printed off ; I ordered it to be Prefented to the Royal Society; which was accordingly done at one of their Meetings December 7, 1671. And alfo to be fent to the Bihop of Chefter ; who was pleafed to fignifie his acceptance thereof by a Letter dated at Chefter, December $26^{\text {th }} 167 \mathrm{I}$. now filed amongft others in the Cuftody of the Royal Society: part whereof, in regard it relates to matter of Fact, I hall here recite.

\section{Sir,}

I did yefterday receive your Book; and am very Senfible of the Honour you bave done me in the $\mathcal{D} e$ dication of it. You woas very bappy in the choice

a 2 


\section{The Preface.}

of tbis Subject to worite upon; one of the moft Noble and the moft Copious parts of Philofophy; and fucb an one, as batb bitberto lain uncultivated. And you bave been very fuccefsful in your first Attempt about it, in fo many remarkable Obfervations and Difcoveries, as you bave made already. I could beartily zoifh that you would still apply your Jelf to this kind of Enquiries. Tou poill find that $A d-$ ditionals will come in more copiougly and eafily. And it is not fit, that any one Bould, by bis Superfructions, carry ansay the praife fram bim, whoo was the first Inventor, and wobo laid the Foundations, wherein the greatest difficulty dotb confist, \&c.

Having thus fubmitted my felf to the Judgment of many Learned Men; I faw that my Journey muft not here end. So that, like one who is got into a Wood, I thought I might as fairly find my way out, by going on, as by making a retreat. Whereupon, I began to draw up a Scheme of the whole Defrgn.

While I was doing this, I received news from London, that the fame day, December $7.167 \mathrm{I}$, in which my Book, then printed, was prefented to the Royal Society: there was alfo prefented a Mamufcript (without Figures) from Seignior Malpighi, upon the fame Subject; dated at Bononia, November, $\mathrm{I}^{\mathrm{ft}}$ 167 r. the fame, which Mr. Oldenburge, when it came to be printed, calleth his Idea. And of this, entry was made in their Journal Book. So that the Royal Society having now a Profpect of the good fervice of an Ancient Member, and one, who had highly merited by his Works then extant ; from thence forward, I looked upon my felf to be excufed.

But foon after, receiving another Letter from the Bifhop of Chefler, dated at London, Febr. 18. 1672. I 


\section{The Preface.}

found the matter otherwife; and that the Society were pleafed to engage me to proceed. Whereof entry was made by the Secretary in their Journal Book, at one of their Meetings, April, 18. 1672, in thefe/words:

The Society was made acquainted woitb one particutar lately paffed in the Council; fc. I bat the Bi/hop of Chelter bad there propofed Dr. Grew to be a Curator to the Royal Society for the Anatomy of Plants : and that the Conncil bad approved of that Propofal. Vpon which, it was Ordered, That the Thanks of the Society be returned to the Lord Bißhop of Chefter, for this Propofal, and to the Council for their Approbation of the fame.

This they might be induced to do ; upon confidering, that it would be no difadvantage to the credit of thofe matters, which were fo new and ftrange, to be offered to the World from a double Authority. For one, although he may have no mind to deceive; yet is it more likely for one, than for two, to be deceived. Likewife, that the fame Subject, being profecuted by two Hands, would be the more illuftrated by the different Examples produced by both. And that, as in other matters, fo here, the defects of both, would mutually be fupplyed.

Whether for thefe, or other Reafons alfo, they were pleafed to pafs the forementioned Order; that being done, it had been very ill manners in me, not to have anfwered their expectation therein. And therefore reaffuming the Defign I had laid by, and having reduced it to fome intelligible Idea, it was fubmitted to the Cen ${ }^{4}$ fure of the Royal Society: and it was thereupon ordered it thould be printed. 


\section{The Preface.}

Not long after, I received a Curious and Learned Book from Monf. Dodart, Arcbiater to the Prince of Conde, and Fellow of the Royal Academy at Paris; in perfuance of whofe Order, it was by him compofed and publined. Which being a Defign of a like Import, I was glad to fee it fo far juftify'd by that Illuftrious Society, as well as by our own.

In this Idea, one principal Thing I infilt upon, for a Philofophical Hiftory of Plants, is Anatomy. And, agreeing to the Method therein propofed, all the Obfervations conteined in the Firft Book, except one or two, were made with the Naked Eye. To the end, I might firt give a proof, How far it was poffible for us to go, without the help of Glaffes: which many Ingenious Men want; and more, the patience to manage them. For the Truth of thefe Obfervations, Seignior Malpighi, having procured my Book to be tranflated into Latin for his private ufe, fpeaks his own fenfe, in fome of his Letters to Mr. Oldenburge, printed at the end of his Anatomy of Plants. And fome of them, have fince been confirmed, both by our Learned Country-men Dr. Wallis, and Mr. Lifter; and by the Ingenious Mr. Lewenboeck, abroad.

Having thus begun with the bare Eye; I next proceeded to the ufe of the Microfcope. And the Obfervations thereby made, firft on Roots, and afterwards on Trunks and Branches, together with the Figures, were all exhibited to the Royal Society at feveral times from May 15. 1672. to April 2. 1674; being the Materials for the Second and Third Parts: and hereof Memorials were inferted in their Journal Books.

After this, the Royal Society received from Seignior Malpigbi his Second Part of the Anatomy of Plants, together with the Figures therein defcribed, and his Letters to their Secretary, dated at Bononia Aug. $20^{\text {th }}$ of the fame year 1674. when, and not before, he gave leave that the two faid $P$ arts fhould be printed. 


\section{The Preface.}

So foon as I had finifhed the Second and Third Parts, I proceeded to the Laft, fc. of Leaves, Flowers, Fruits and Seeds: and thofe Things I met with, more remarquable, were prefented to the faid Society in the Years 1676 $\& 1677$. And the publining of the former Parts fucceffively, as well as of all together, hath been done in purfuance of their feveral Orders for the fame.

Having concluded the Hiftory of Perfect Plants; I intended to have fubjoyned the Defcription of thofe which are Imperfect. As alfo of Parafitical, Marine, and Senfitive Plants. Aud laftly, a view of the chief Particulars, wherein the Mechanifme of a Plant, is different from that of an Animal. But thefe things I leave to fome other Hand.

The Firft Book, a little after it came forth; was tranflated into the French Tongue, by Monf. Le Vaffeur an Ingenious Gentleman in Paris; elegantly, and in the Judgment of thofe who are well skilled in that Language, with much exactnefs, as to the fenfe. He having taken fpecial care, to have all the difficulties of our own, by Me, cleared to him. And in a late Book. Entituled, Philofophia vetus do nova printed at Noriberg 1682. the Learned Author feems to have made ufe of this Tranflation, for all that he hath taken notice of in that my Firft Book.

By the Ingenious Collectors of the German Ephemerides, both my Firft, Second, and Third Books, are all publifhed in Latine. But their unskilful Interpreter doth often fail of the Grammatical Senfe. Whofe Errors, many of them very grofs, I defire may be imputed neither to them, nor to my felf.

Befides thefe, the Second Lecture of Mixture is alfo tranflated into French, by Monf. Mefmin a Learned Phyfician in Paris: whofe Verfion is very well approved by thofe who are competent Judges hereof. 


\section{The Preface.}

This, and the reft which follow, are placed, not in the order of Time; but more according to their Nature or Relation one to another. All of them intended as a Commentary upon fome particulars mentioned, either in the Firft Lecture, or in the Idea,

In the Plates, for the clearer conception of the Part defcribed, I have reprefented it, generally, as entire, as its being magnified to fome good degree, would bear. So, for inftance, not the Barque, Wood, or Pith of a Root or Tree, by it felf; but at leaft, fome portion of all three together: Whereby, both their Texture, and alfo their Relation one to another, and the Fabrick of the whole, may be obferved at one View. Yet have I not every where magnify'd the Part to the fame degree; but more or lefs, as was neceffary to reprefent what is fpoken of it. And very highly, only in fome few Examples, as in $T a b$. 40. which may fuffice to illuftrate the reft. Some of the Plates, efpecially thofe which I did not draw to the Engravers hand, are a little hard and ftiff: but they are all well enough done, to reprefent what they intend. 


\section{A N}

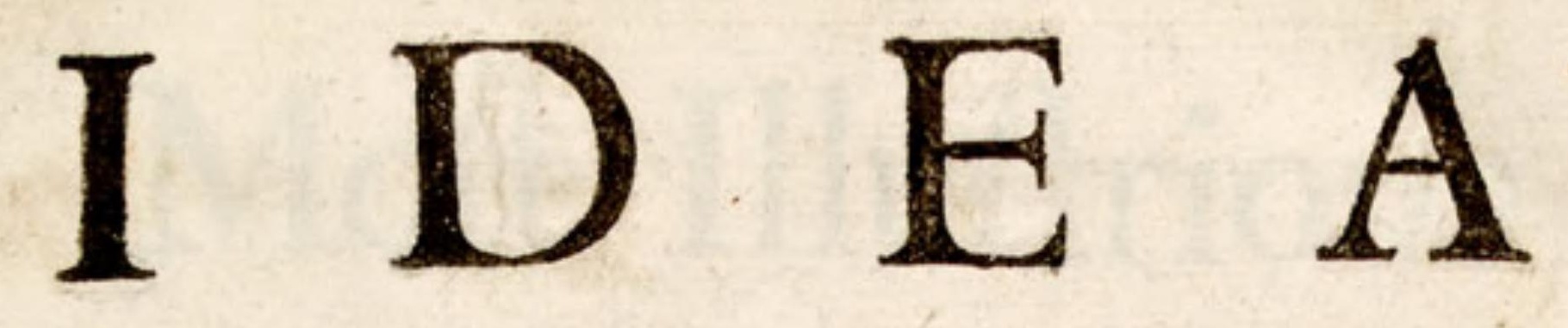

O F A

\section{Philofophical Hiftory}

O F

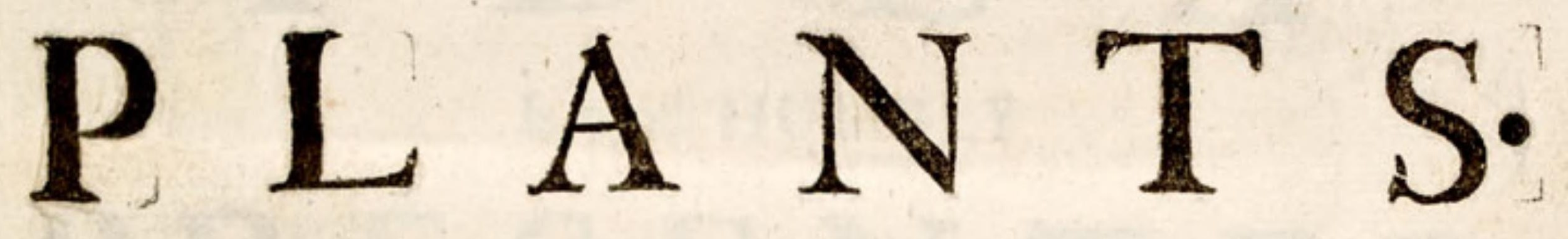

Read before the

\section{ROYAL SOGIETY, Fanuary 8. and fanuary 15. 1672 .}

By NEHEMfAH GREW M.D. Fellow of the Royal Society, and of the College of Phyficians.

Tye SECOND EDition.

$$
\text { LONDON, }
$$

Printed by $W$. Rawlins, 1682 . 


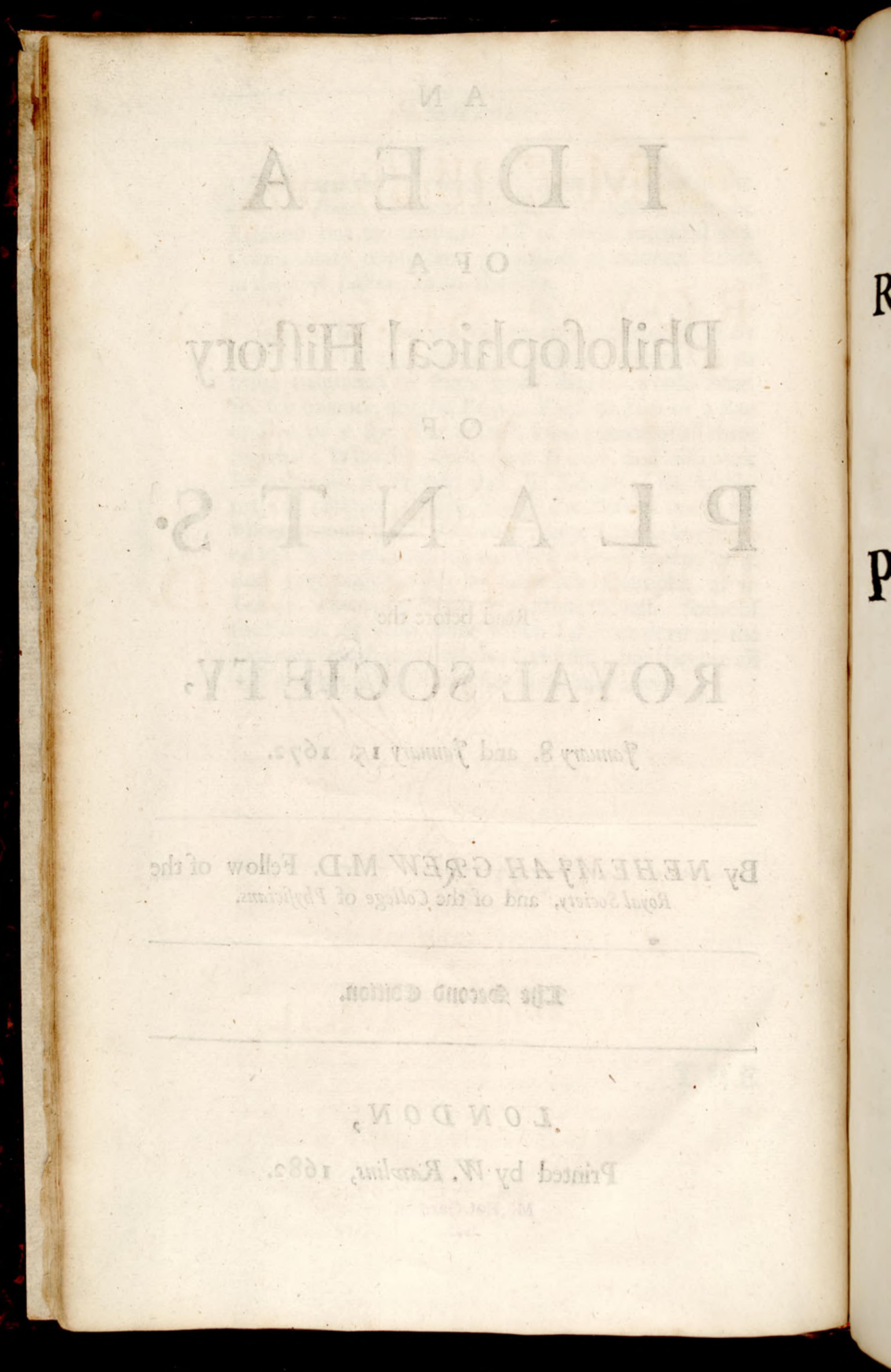


TO THE

\section{Moft Illuftrious}

T H E

\section{ROVAL SOCIETY,}

The following

I
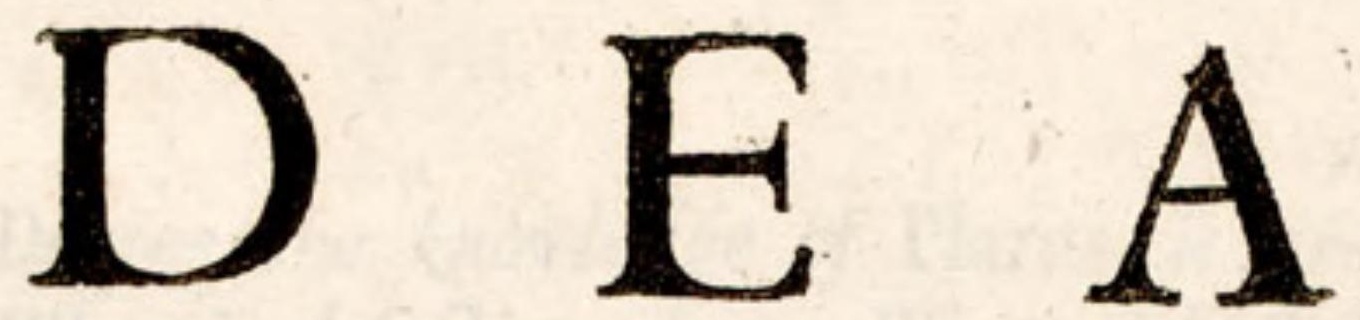

Is moft $\mathrm{HUMBLY}$

PRESEN T E D. A N D,

In their NAM ES alfo

P R O P O S E D

TO THE

CONSIDERATION

Of other

Learned Men.

By the AUTHOR

$\mathcal{N} E H E M g A H$ GREW 


\section{2uoinfullt: floM}

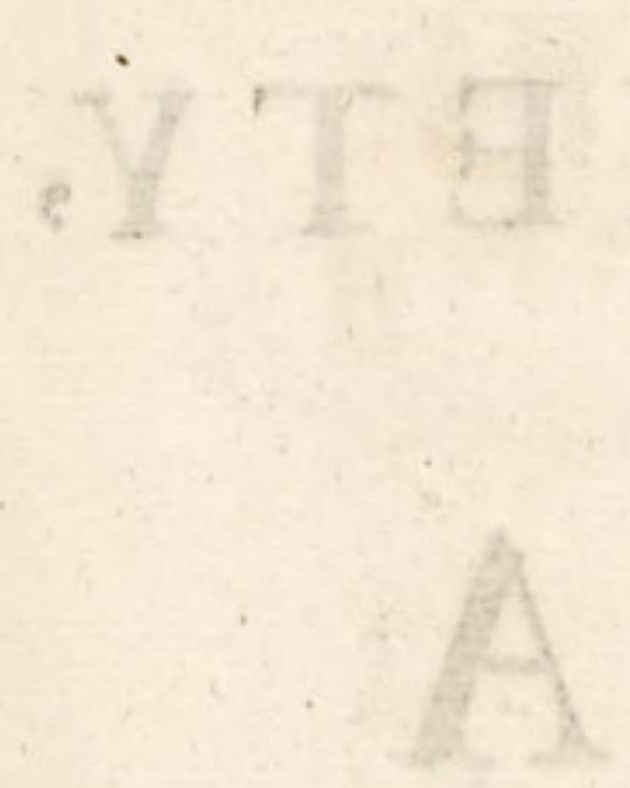

502
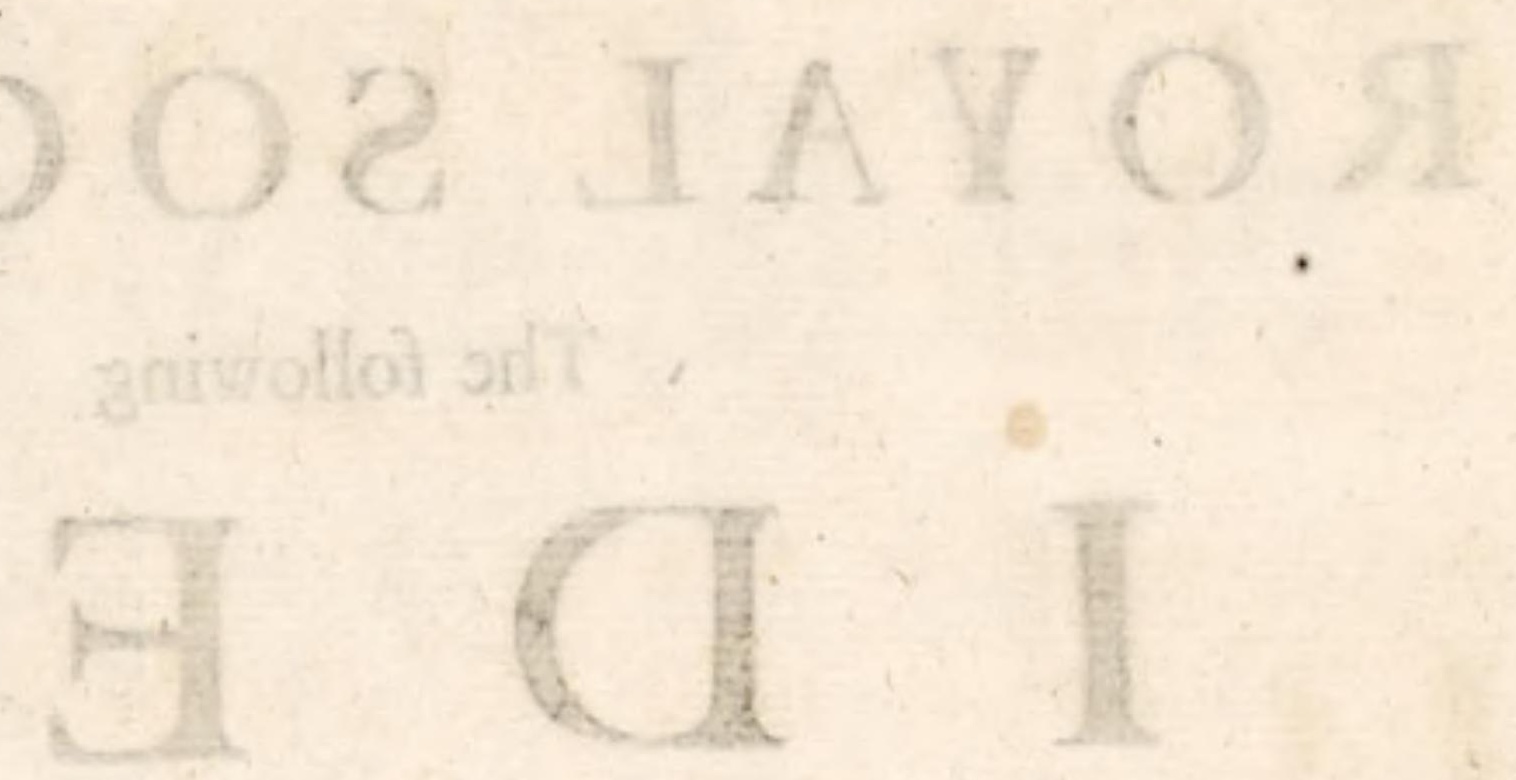

\section{XIANUII flom aI}

(1) IVA2 IRI

(1. VA

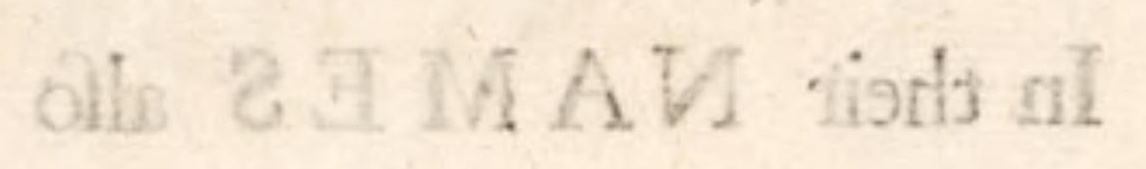

a. 3.2090 .9 .9

$$
\text { ant, OT }
$$

MOLA

w 10

- IJM bon'iso I

SOHTUA orl YU

WISP HAEMAHAY 


\section{T H E}

\section{CONTENTS.}

U N 10 what Degree the knowledge of Plants is arrived, $\$$. . . Wherein defective, \$. 2. Why concluded to be $\int 0, \$ \cdot 3$. Yet capable of Improvement, $\$ .4$. And worthy of it, $\$ \cdot 5$.

Divers Inftances given, wherein; firft of the Organical Parts, as to their external Accidents and Oeconomical V fes, 6. Then of their Contents, Qualities, and Powers, 7. And an Improvement of this Part, will furtber that of divers other parts of knowledge; whereof Inftances are given, 8.

In order whereto, Five General Means are propounded, 9. The Firit, a particular and comparative Survey of whatever is of more External confideration about Plants, Io. Inftanced as to their Figures, I I, 1 2. Proportions, 13. Seafons, 14. Places, 15. Motions, 16.

The Second, A like Survey of the Organical Parts by Anatomy, as that which is very neceffary, I 7. In what manner to be profecuted, both without, and with the Microfcope, 18. What thereupon to be obferved, 19. And what, from obfervantion made, probably attainable, 20.

The Third, A like Survey of the Contents of Plants; their feveral Kinds, 2 1. Of all which, their Receptacles, 22. Motions, 23. Qualities, 24. Confiftence, 25. Colours, Smells, and Taftes, 26. Where alfo the fame Qualities are to be inquired inte, as generally belonging to Plants, 26. As their Colours; 27. Odours, 28. Taftes, 29. Alfo their Faculties, 30. All theje to be further examined, 31. By Contufion, 32. Agitation, 33. Frigifaction, 34. Infufion, 35. Subfeffion, 36. Digeftion,37,38. Decodtion,39. Deftillation,40. Arefaction,4t.

Af]dition, 


\section{The Contents.}

Affation, 42. Uftion, 43. Calcination, 44. By Compofition with other Bodies, 45 . And by Compounding the Experiment it Jelf, 46. What bence attainable, 47.

The Fourth, A like Survey of the Principles, as well as of the Contents, of the Organical Parts, 48. The Diffculty bereof, in fome refpects cleared, 49. Further, by two Inftances, 50, 51. Some Remarques bereupon, of the Principles of Plants, 52. From hence will be attainable a further knowledge of the Modes of Vegetation, 53. Of the Qualities of Vegetables, 54. And of their Powers, 55, 56.

The Fifth, A like Survey of thofe Bodies, either from which the e Principles are derived, or wherewith they have any communion, 57. Which are Four in general, fcil. Earth, and all folid Receptacles, 58. Water, and all liquid Receptacles, 59. Aer, 60. And Sun, 6r.

A Sixth General Inquiry, only binted, 62 .

The Conclufion, 63 . 


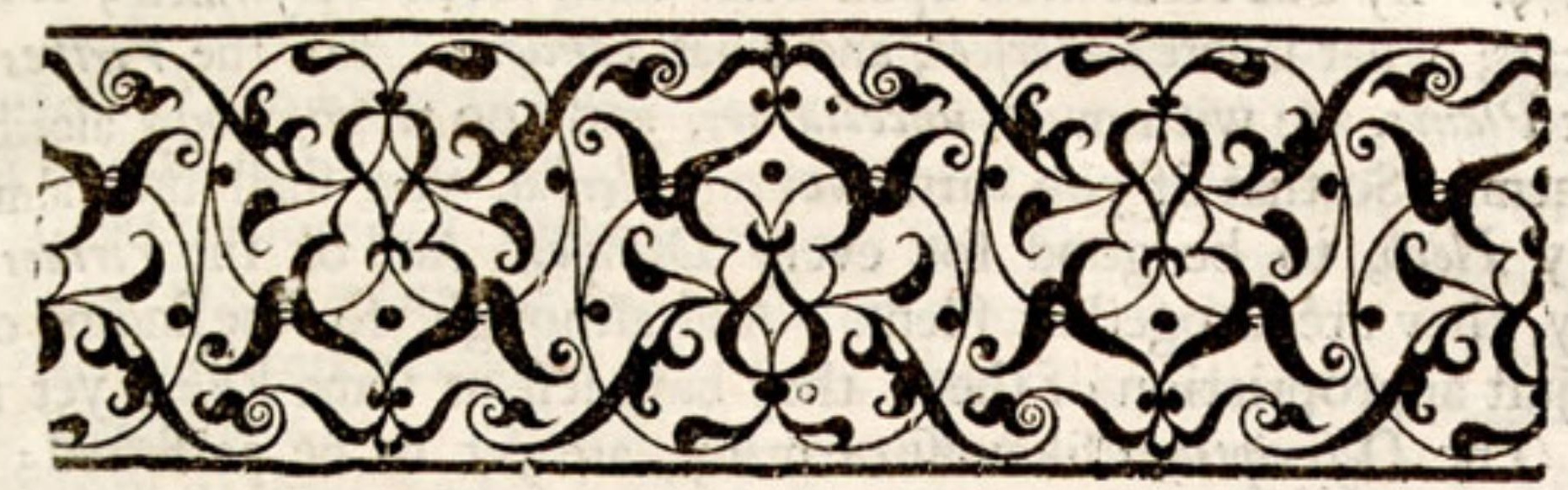

A $\mathrm{N}$

I $\quad \mathrm{D} \quad \mathrm{E} \quad \mathrm{A}$

O F A

\section{Philofophical Hiftory}

O F
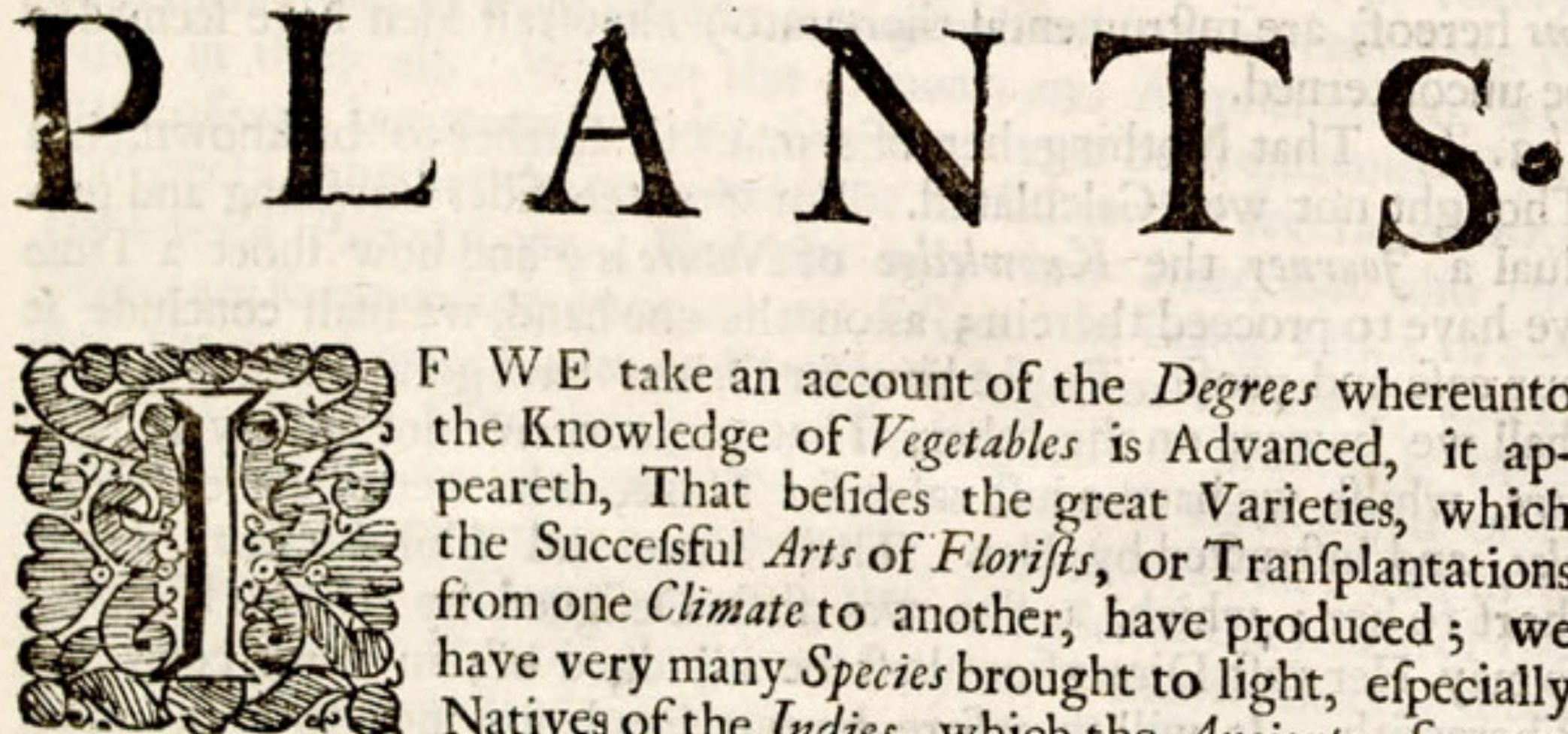

W E take an account of the Degrees whereunto the Knowledge of Vegetables is Advanced, it appeareth, That befides the great Varieties, which the Succefsful Arts of Florifts, or Tranfplantations from one Climate to another, have produced; we have very many Species brought to light, efpecially Natives of the Indies, which the Ancients, for any thing that appears in their Writings now extant, were ignorant of. In which particular Clufius, Columna, Baubinus, Boccone, and others, have performed much. Withall, That their Defcriptions (of all Parts above ground) their Places and Seafons, are with good diligence and precifenefs fet before us. Likewife their Order and Kindred: for the adjufting whereof our Learned Countryman Mr. Ray, and Dr. Morrifon, have both taken very laudable pains. As alfo the ordering of them with refpect to their Alimental and Mechanick Ufes; for which, amongtt others, Mr. Evelyn and Dr. Beal have deferved many thanks, and great praife. We are alfo informed, of the Natures and infallible Faculties of many of them. Whereunto fo many as have affifted, have much obliged their Pofterity. 
2. §. By due Reflection upon what hath been Performed; it alfo appears, what is left Imperfect, and what Undone. For the Virtues of moft Plants, are with much uncertainty, and too promifcuoufly afcribed to them. So that if you turn over an Herbal, you thall find almoft every Herb, to be good for every Difeafe. And of the Virtues of many, they are altogether filent. And although, for the finding out, and juft appropriation of them, they have left us fome Rules, yet not all. The Defcriptions likewife of many, are yet to be perfected; efpecially as to their Roots. Thofe who are very curious about the other Parts, being yet here too remis. And as for their Figures, it: were much to be wilhed, That they were all drawn by one Scale; or, at molt, by Two; one, for Trees and Shrubs; and another for Herbs. Many likewife of their Ranks and Affinities, are yet undetermined. And a great number of Names, both Englifh and Latine, not well given. So what we call Goat's-Rue, is not at all of kin to that Plant, whofe Generical Name it bears. The like may be faid of Wild-Tanfy, StockFuly-Flowers, Horfe-Radifh, and many more. So alfo when we fay Bellis Major, \& Minor, as we commonly do, thefe Names would intimate, That the Plants to which they are given, differ (as the great double Marigold, doth trom the le(s) only in Bulk: whereas, intruth, they are two Species of Plants. So we commonly fay, Centurrium $\mathrm{Ma}$ jus or Minus, Cbelidonium Majus \& Minus, and of others in like manner, which yet are diftinct Species, and of very different Tribes. But for the Reafon of Vegetation, and the Canfes of all thofe infinite Varietics therein obfervable (I mean fo far as Matter, and the various Affections hereof, are inftrumental thereunto) almoftall Men have feemed to be unconcerned.

3. \$. That Nothing hereof remaineth further to be known, is a Thought not well Calculated. For if we confider how long and gradual a Yourney the Knowledge of Nature is; and how fhort a Time we have to procced therein; as on the one hand, we fhall conclude it our eafe and profit, To fee how far Others have gone before us: fo fhall we beware on the other, That we conceive not unduly of $\mathrm{Na}$ ture, whilft we have a juft value for Thofe, who were but her Difciples, and inftruqued by Her. Their Time and Abilities both, being Thort to her; which, as She was firtt Defigned by Divine Wiflom; fo may Her vaft Dimenfions beft be adjudged of, in being compared Therewith. It will therefore be our Prudence, not to infift upon the Invidious Queftion, Which of Her Scholars have taken the faireft meafure of Her; but to be well fatisfied, that as yet She hath not been Circumfribed by Any.

4. \$. Nor doth it more behove us to confider, how much of the Nature : of Vegetation may lie before us yet unknown; Than, to believe, a great part thereof to be knowable. Not concluding from the acknowledged, mach lefs fuppofed Infuccefsfulnes, of any Mens Undertakings a but from what may be accounted Poffible, as to the Nature of things themfelves; and from Divine Providence, by Infinite Ways condacting to the knowledge of them. Neither can we determine how giveat a part This may be : Becaufe, It is impo/fible to Meafure, what zoe See not. And fince we are molt likely to under-meafure, we fhall hereby but intrench our Endeavours, which we are not wont to carry beyond the $I_{d e a}$, which we have of our Work. 


\section{Pbilofopbical Hifory of Plants.}

5. \$. And how far foever this kind of Knowledge may be attainable, its being fo far alfo worthy our attainment will be granted. For beholding the Many and Elegant Varieties, wherewith a Field or Garden is adorned; Who would not fay, That it were exceeding pleafant to know what we See: and not more delightful, to one who has Ejes, to difcernthat all is very fine; than to another who hath Reafon, to underftand how. This furely were for a Man to take a True Inventory of his Goods, and hisbeft way to put a price upon them. Yea it feems, that this were not only to be Partaker of Divine Bounty; but alfo, in fome degree, To be Copartner in the Secrets of Divine Art. That which were very defireable, unlefs we fhould think it impertinent for us to defign the Knowing of That, which God hath once thought fit to $D_{0}$.

6. \$. If for thefe, and other Reafons, an inquiry into the Nature of Vegetation may be of good Import; It will be requifite to fee, firft what our Scope is. making, and having to doing, we may take our aim the better Amongft other Inquiries, in applying our Obfervations thereunto. pofed. Firft, by what means it is , fuch as thefe deferve to be proto Grow, a Seed to put forth a Root and Trunk, or any Part of it,comes Parts, to the Seedagain; and all and Irunk; and this, all the other trition ftill to be increafed. How theing formed, by continual $\mathrm{Nu}$ fed, is duly prepared in its feveral Parts; unto them; and in what manner it is affs; which way it is conveyed tures in them all. Whence this afsilated to their refpective $\mathrm{Na}$ made of one, but many differing Growth and Augmentation, is not and great; whether the comparifores, unto both extremes of fmall the feveral Parts of one. How not madebetwixt feveral Plants, or Shapes are fo exceeding various not only their sizes, but alfo their der, Short or Long, Entire or Roots, in being Thick or Slenlike: of Trunks, fome being Parted, Stringed or Ramified, and the Shrub'd: of Leaves, which more Entire, others Branched, others callop'd, and many other ways differg or Round, Even-edg'd or Efthe other Parts. Then to inquire, Wh, yet always Flat: and fo for various Motions; that the Root fhould de fhould be the reafon of their fometimes be perpendicular, fometimes moend; that its defcent fhould afcend; and that the afcent thereof, as to level: That the Trunkdoth it is made, is of different meafures: an to the fpace of Time wherein they are obfervable in the Roots $:$ and of divers other Motions, as Whence again, thefe Motions have Trunks, and other Parts of Plants. that Plants have their fet and their Different, and Stated Terms ; Birth, for their Full Growth, and for their Tons for their Spring or Furtber, what may be the Caufes as of the Teeming; and the like. fo of the Periods of their Lives; for the Seafons of their Growth; others Perennial; fome Perennial fome being Annual, others Biennial, and fome as to their Roots only. Thoth as to their Roots and Trunks? veral Seafons of their Lives, in when, as they pafs through thefe feboufing, cloatbing or protection otherwife, is their convenient feeding, kind and harmonious Oeconomy, one Part, may bed; wherein, in this for the prefervation of the health what care is taken, not only for themflife of the sobole. And laftly, C but for their Posterity; in what 


\section{CAn Idea of a}

what manner the Seed is prepared, formed and fitted for Propagation: and this being of fo great concernment, how fometimes the other Parts alfo, as Roots, in putting forth Trunks; Trunks in putting forth Roots; yea in turning oftentimes into Roots themfelves; whereof, in the Second Book of the Anatomy of Plants, I thall give fome inftances. With other Heads of Inquiry of this kind.

7. 6. Nor are the Natures, Faculties, and Contents of Vigetables lefs various, or a particular Infpection hereinto, of lefs concernment. For fince All, or Moft, feem to grow in the fame manner, with one Sun, one Rain, indifferently well upon one Soil, and, to outwardappearance, to have the fame Common Parts; it may be asked, How it comes to pafs, that their Liquors, or other Contained Parts, are of fuch different Kinds; one being Watry, another Winy, a third Oily, a fourth Mil$\mathrm{ky}$, and the like. How alfo there is fuch a variety in their Senfible 2ualities, as their Colours, Taftes, and Smells; what thofe Materials are, which are neceffary to the Being of thefe 2ualities; and thofe Formalities, wherein their Effence doth confift; as what it is that makes a Plant, or Flower, to be white or red; fragrant or fetid; bitter or fweet; or to be of any other Colour, smell, or Tafte. In like manner, their Faculties and Powers, what that is, or thofe things are, by which they are conftituted; as whence one becomes Purgative, another Vomitory, a third Diaphoretick, \&c, Thefe, I fay, with many other particular Inquiries depending hereupon; as they cannot but much oblige the Reafon of Man to be obfequious to them, fo by bringing in, at leaft, fome fatisfaction, will no lefs reward it. Efpecially, if it be withal confidered, that befides our fatisfaction as to the Nature of Vegetation; fome further Light, to divers other parts of Knowledge, may likewife hence arife.

8. §. For fince the prefent Defign will ingage us, to an accurate and multifarious Obfervation of Plants; we may hereby be enabled to range and fort them with morecertainty, according to the Degrees of their Affinity. And all Exoticks, Plants or Parts of Plants, may probably be reduced to fome fuch Domefticks, unto which they may bear the beft Refemblance. Again, it may frequently conduct our minds to the confideration of the State of Animals; as whether there are not divers material Agreements betwixt them both; and what they are. Wherein alfo they may confiderably differ, and what thofe things are which are more effential to their diftinguifhment. And befides, not only to compare what is already known of both; but alfo, by what may be obferved in the one, to fuggeft and facilitate the finding out of what may yet be unobferved in the otber. So alfo the confideration of the Colours, smells and Taftes of Vegetables, may conduce to the Knowledge of the fame 2ualities in General; or of what it is, that conftitutes them fuch, in any other Body: not as they are aifually received by Senfe; but fo far, as fuch Materials or external Circumftances, are requifite to their becoming the Adequate Objects thereof. Ii may lead us alfo to inquire into further Ways of Cultivation, with refpect to the whole Plant, or to the Flower, Fruit, or other Part: To amend them as to their Sizes, Colours, Taftes, Fruitfulneß, or otherwife: To think of other Ways of Propagation; or to apply thofe already known to other Plants than hath been ufed. Likewife the Knowledge of their Mechanical Ufes may hereby be enlarged; both as tothe 
Reafon of their ufe, in fuch particular Trades and Manufactures, already known; and the difcovery of other ufes yet unknown. As alfo their Alimental, with refpect both to Meats and Drinks; the preparation of fome, and the finding out of others. But efpecially their $\mathrm{Me}$ dicinal ; fome Plants which have hitherto been neglected, may be applied to ufe; the Perverted ufes of fome, and the Confufed ufes of others, may be rectified. What may beft correct their Malignancies, or inforce theirVirtues; When needful to add the preparations of Art to That of Nature; How to Enlarge thofe of Art, and Rectifie thofe which are indeed Inartificial, may hereby be better conjectured. The knowledge of all which, that we may know how far it is acceffible, and what probable Approaches may be made towards it; thofe feveral Means I have thought of, and fuppofe neceffary thereunto,are next to be propofed.

9. \$. Reflecting then upon the prefent Defign, and feeing this to lie wide; we fhall, in the firft place, conclude the Means attending thereon, fhould do fo likewife. Wherefore, although fome may prefent themfelves unto us as more promifing; yet let us fuppofe what feveral Perfons, were they hereunto engaged, each according to his Senfe and Genius, would poffibly make choice of. Believing, that although Confidering Men may vary, in the approval of their own Senfe and Notion; yet not always mearly, becaufe it is their own; but becaufe each, may probably fee fomewhat more in his own, than others do. Wherefore it will be our fureft Logick to conclude, Not becaufe no Mesn may be approved by all Men, that all Means fhould be rejected; but rather, becaufe each may be approved by fome, that therefore, all be made choice of. And thefe, I think, may be comprehended under Five General Heads of Enquiry. Firft, Of thofe Things, which are of more External Confideration about Plants, as their $F i$ gures, \&cc. Secondly, Of their Compounding Parts, as Veffels, \&uc. Thirdly, Of their Liquors, and other Contents. Fourtbly, Of their Principles, as Salts, \& $c$. Fiftbly, Of their Aliment, as Water, and other Means of Growth.

10. 5. AND FIRST of all, whatever is of more External Con- The Firf fideration, as the Figures, Proportions, Motions, Seafons, situations of General Vegetables, and of their feveral P.rts, fhould be obferved. In doing Mean. which, a particular furvey of all their Varieties fhould be taken. And then a Comparifon made betwixt thefe, and the feveral Plants, or Parts of Plants, whereof they are the Properties. To the end, We may, if poffible, be thereby conducted to find out, what other, either fenfible, or more reclufe Froperty, any of them may agree together in. For it is not more certain, that the three Angles of every Rectilinear Triangle, becaufe all ways equal to two Right Angles, are therefore, if put together, always the fame: than that one Property, agreeing to divers $V$ egetables, fhould have one Canfe: For although the Scope and End may vary; yet the Caufe, as it is the Carfe of that Property, muft be one: and confequently, muft alfo import fome Identity in the Nature of all thofe Vegetables wherein it Acts. Wherefore by thus comparing of them, we thall be able more exactly to ftate the Orders and Degrees of their Affinities; Better to underftand both the Caufes and Ends of their Varieties: And more probably to conjecture of their Natures and
$V$ ertues.

$$
\text { C } 2 \text { xx.5. Firft }
$$


11. 5. Firft then the various Figures of their feveral Parts fhould be obferved; and that with refpect both to the Forms, and the Pof tions, by which their Roots, Trunks, Branches, Leaves, Flowers, Fruits, and seeds may vary, or agree; and thofe feveral Lines, by which both the faid Varieties are determin'd. In which of thefe Parts, the agreement chiefly lies; this being both more obfervable, and more material in fome of them; lefs in the Root, more in the Flower, or Seed. And in how many of thefe Parts together; whether one, more, or all. By both which, the Orders and Degrees of Affinity, which are many, may be accounted; either as to what we ftrictly call $K i n$ dred, or elfe Analogy. For there are found, not only Herbs accounted of feveral Tribes, which are ally'd; and fome of the Smalleft, which are of kin to the Greateft : But there are allo, probably, fome Herbs, which have a particular Relation, to many Kinds of shrubs; and fome Shrubs, to many Kinds of Trees. Thus the feveral forts of Letuce, are of Kin, together in the Firft Degree; with Endive, in the Second.The feveral Clarys, amongft themfelves in the Firft; with Horebound, in the Second; with Lamium, in the Third. All Stramberries agree together, in the Firft Degree; with Cinquefoyl, in the Second; with Tormentil in the Third; and with Avens, $6 c$. in other Degrees more remote. So Agrimony, hath alike Analogy unto Stramberry; as GoatsRue, hath to Claver: And Strawberry, the like unto the Rafp; as Goosberry to the Vine; or Burnet, to the Rofe. Amongt the feveral Sorts of Grafs, there are fome which matchall thofe of Corn; which is but a greater kind of Graß. So again all Pulfe, are not only of kin, in their feveral Degrees, to one another; but likewife, to almoft all kinds of Trefoyls, as Melilot, Fanugreek, and the common Clavers themfelves; as by comparing not only their Leaves, but Flowers, Seeds, and Cods together, may be evident. For the feveral parts of the Flower of a Trefoyl, are fo many more Flowers, containing fo many Cods of mall seeds, all, in thape, agreeable to the Flowers, Cods, and seeds of $P_{k} l f e$. The fame Relation, which Trefoyls have to the Peas or other Pulfe; Colts-foot, hath to Buttyr-Bur; Chickweed to Leucanthemum; Groundfell, to Jacobea ; or Scorodonia, to Foxglove: Or, to go higher, as the Leguminous Kinds of Herbs, have to Sena, or fome other of the Lobed Shrubs and Trees. And, as among Animals, there arefome which conneet feveral Kinds; as the Batt doth Beafts and Birds: So, among plants, there are fome alfo, which feem to ftand between two Tribes; as Lappa, between Knapreeds and Thiftles; Lampfana, between the Iniybaceous Kind, and the Monfe-ears.

12. 5. From hence likewife, the Natures of Plants may be conjectured. For in looking upon divers Plants, though of different Names and Kinds; yet if fome affinity may be found betwixt them, then the Nature of any one of them being well known, we have thence ground of conjecture, as to the Nature of all the reft. So that as every Plant may have fomewhat of Nature individual to it felf; fo, as far as it obtaineth any $V_{i f i b l e}$ Communities with other Plants, fo far, may, it partake of Common Nature with thofe alfo. Thus the $W$ ild, and Garden Cucumers, have this difference; that the one purgeth ftrongly, the other, not at all: yet in being Diuretick, they both agree. The Natures of Umbelliferous Plants, we know, are various; yet 'tis moft probable, that they all agree in this one, fcil. in being Carminative. 
TEe feveral forts, both of Corn and Graßs, are all akin; there is no doubt therefore, but that the Seeds of Graß themfelves (of Rye and Oats it is tryed) if it were worth the while to order them, as Barley, would yield an inflammable Spirit. So likewife the feveral Kinds of Pulfe, have fome one community in their Form, as is faid: for which reafon, I queftion not, but that in fome Cafes, wherein Cicers are efteemed a good Medicine; a Decoction of the better fort of Peafe, efpecially that we call the sugar-Peafe, may go beyond them. As doth alfo the Flower or Meal of Beans, that of the seeds of Frnugreek; even there, where they are accounted excellent. So Tulips, Lillies, Crocufes, Facynths, and Onions themfelves, with meny others, in their feveral Degrees, are all allied. If therefore Crocufes, Onions, Lillies, agree in one or more Faculties, then why may not all the reft ? as in being Anodyne; or in fome other Common Nature; whereby, in their Vegetation, their Parts are Governed and Over-ruled, to one Common or Analogous Form.

13. 5. The Proportions likewife, amongt the feveral Parts of $V$ egetables, for the fame Reafons, deferve to be obferved; the comparifon being made, both betwixt the Parts of feveral Plants, and the feveral Parts of one. And here again, either betwixt any Two of the Parts, or any One of them, and the Whole befides, or all the reft put together. So fome larger seeds, produce a fmall Root; as thofe of Cucumer : and others fmaller, produce one very great; as thofe of Bryony. Some Plants, as the Melon, though themfelves but veryllender, yet have a vaft and bulky Fruit; others again, as Tbiflles, and many yet more fubftantial, have no otber Fruit, befides their Seed. So the Seeds of all Pulfe, and efpecially, the Gardon Bean, though large, yet produce but a fmall Plant: but thofe of Foxglove, Mullen, Burdock, Sun-flower, \&oc. being themfelves much lefs, do yet produce a far greater. And efpecially, thofe Seeds, which are inclofed in the Thicker fort of Cover, (analogous to that I have elfewhere called the Secondine) as that of Peony; whore seed, fo called, is only the Anat. Plant. Nest wherein the true and real Seed is lodged, no bigger than a little Book r..Chap: Pins head: which is alfo obfervable of the Seeds of divers other Plants. There, and the like Proportions, as they lie betwixt the feveral Parts, fhould be noted: and to what Plants or Parts efpecially, any of them may agree: comparing alfo in what other kind of Properties an agreement betwixt the faid Parts may be found : that fo doing,we may, if poffible, amongft all their Individual Natures, be inftructed to ing Properties. be confidered. Obferving at alfo of Plants, and of their Parts, fhould of them chiefly Spring, Early what particular Times of the Year, any minate; whether for Early or Late. The Times wherein they Gerin they Spring, after Sowing; only, or all the Year long. Whereflower. Which Flower after the Leaves are put the firf $t$ Year, or not till the fecond. Which the CrocusV Vernus, Bears-foot, Hepaticefore them; for fo, fome do, as at the time of their flowering being old, and others; all the Leaves, growth. So likewife the Maturation of the Fruit or Soing Year's after the Flower, and the like. All or fome of which Varieties, being

laid 


\section{$8 \quad$ An Idea of a}

laid together, we may probably conjecture the Cat fes thereof, whid the Natures of the Plants in which they are feen: foil. as fuch a Degree of Heat may be neceffary for the Fermentation, or the better Diftribution of the sap of fuch a Plant; or for the Impregnation of the Aer, to be mixed therewith; or the due Difpofing of the Soil, to render the moft convenient Aliment thereunto. So the Principles of fuch Plants, which flower all the Year, may be more equally proportion'd. Thofe which flower before the Leaves put forth, as the Crocus Vernus, and thofe which flower in Spring, may be accounted Rank, and full of Volatile Salt. But Autumn Plants efpecially, to abound with a Fixed : and the like.

15. 6 . The proper Places alfo of plants, or fuch wherein they have, from their Seeds, or other way of Propagation, a Spontaneous growth, thould be confidered. And that as to the Climate; whether in one Colder, Temperate, or more Hot. The Region; Continent, or Ifland. The Seat; as Sea, or Land, Watry, Boggy, or Dry ; Hills, Plains, or Vallies; Open, in Woods, or under Hedges; Againft Walls, rooted in them, or on their Tops: and the like. And perhaps the Seeds of fome plants, as of Moffes, (which, through their fmallnefs, will afcend like Moths in the Sun) may fly or fwim for fome time, in the Aer, viz. till they begin to fhoot, and fo become heavy enough, to fall down upon the Ground. From whence, in like manner, as from their Seafons, their particular Natures may be directed unto. In that, fo far as we may conjecture the nature of fuchan Aer, Soil, orseat, we may alfo of fuch a Plant, to which they are congenial.

16. 5. So likewife, thofe many Varieties obfervable in the Motions of Plants, and of their Parts, both Kinds and Degrees; Afcending, Defcending, and Horizontal; Rectilinear, and Spiral Motions, fhould be noted; to what Plasts they agree, and wherein any of thefe Motions may be analogous to thofe of Animals. And in a word, any other Forenfick Properties of Plants. And then, to Compare them all together; both being neceflary. For Thouglts cannot work upon noshing, no more than Hands. He that will build an Houfe, muft provide Materials. And on the contrary, the Materials will never become an Houfe, unlefs, by certain Rules, we joyn them all together. So, it is not, fimply, the Knowledge of many tbings, but a multifarious Copulation of them in the Mind, that becomes prolifick of further Knowledge. And thus much for the firft General Mean. 17. \%. THE NEX T which I propofe, and that a moft necef-
The Second fary one, is Anatomy. For when upon the Diffection of Vegetables, we Gencral Mean. fee fo great a difference in them, that not only their Outward $F_{i}$ gures, but alfo their Inward Structure, is fo Elegant; and in all, fo Various; it muft needs lead us thus to Think, That thefe Inward Varieties, were either to"no End; or if they were, we muft affign to what. To imagine the firft, were exceeding vain; as if Nature, the Handmaid of Divine Wifdom, fhould with Her fine Needle and Thred, ftitch up fo many feveral pieces, of fo difficult, and yet fo groundlefs a Work. But if for fome End, then either only to be looked upon, or fome other befides. If for this only, then this muft be fuch as in refpect whereof, Her Work is at no time, nor in any degree fruftrate; the contrary whereunto, is moft manifeft. For although Men do every where, with frequent pleafure, behold the Outward Elegancies of Plants; 


\section{Pbilofopbical History of Plants.}

Plants; yet the Inward Ones, which, generally, are as Precife and Various as the Outward; we fee, how ufual it is, forthe beholding of Thefe, to be omitted by them. And befides, when we bave obferved Nature's Work, as well as we can; it may be no impediment to our beft Endeavours, to believe, That fome Parts of it, will ftill remain behind, Unfeen. So that if to be Seen, were the only End of it, it muft needs be wholly fruftrate, as to the greater number of Men; and, in fome part, as to all. Wherefore, we muft fuppofe fome other Ends of the faid Varieties, which fhould have their Effect, and fo Thefe, not be in vain, whether Men beheld them or not; which, are, therefore, fuch as have refpect to Vegetation: That the Corn might grow, fo; and the Flower, fo, whether or no Men had a mind, leifure, or ability, to underftand how.

18. 6. If then the Anatomy of Vegetables be fo ufeful a Mean, we ought not to ftreighten it ; but to force this, as well as the reft, to its utmoft Extent. And therefore, firft of all, To go through all the Parts, with equal care; examining the Root, Trunk, Branch, Leaf, Flower, Fruit, and Seed. Then to Repeat or Retrograde the Diffection, from Part to Part : in that, although the beft Method of Delivery, for clear Difcourfe, can be but one, according to that of $\mathrm{Na}$ ture, from the seed forward, to the Seed: yet can it not but be ufeful, for That of Diffection, to proceed $t e$ and fro; fomewhat or other being more Vifible in each feveral Part, from whence ftill an Hint may be taken, for the ufhering in the obfervation of it in the others. To examine, again, not only all the Parts, but Kinds of $V_{\text {egetables, }}$ and comparatively, to obferve divers of the fame fize, Shape, motion, age, fap, quality, power, or any other way the fame, which may alfo agree, in fome one or more particulars, as to their Interiour Structure: and to make this comparifon, throughout all their Parts and Properties. To obferve them likewife, in feveral Seafons of the Year, and in feveral Ages of the Plants, and of their Parts; in both which, divers of them may be noted to change, not only their Dimenfions, but their Natures alfo; as Veffels, do into Ligaments ; and Cartilages, into Bones, fometimes, in Animals. And to do all this by feveral Ways of section, Oblique, Perpendicular, and Tranfverfe; all three being requifite, if not to Obferve, yet the better to Comprehend, fome Things. And it will be convenient fometimes to Break, Tear, or otherwife Divide, without a Section. Together with the Knife it will be neceffary to joyn the Microfiope; and to examine all the Parts, and every Way, in the ufe of That. As alfo, that both Immediate, and Microfcopical Infpections, be Compared: fince it is certain, That fome things, may be demonftrated by Reafon and the Eye conjunct, without a Glafs, which cannot be difcovered by it ; or elfe the difcovery is fo dark, as which, alone, may not be fafely depended on.

19. 6. By thefe feveral Ways of Infpection, it will be requifite, To obferve their Compounding Parts; as Simply confidered, and as varioully Proportioned, and Difpofed. As simply confidered, to note their Number; what, and whether the fame, in all: their Kinds, wherein different in the fame, or divers Vegetables : their Original, in part, or in whole: Strudure, as to their Contexture and their Cavities; Their Contexture, within themfelves feverally, and as joyned together: their Cavities, as to their size, Shape, and Number; in which a great va. 
riety will be found. Next their Pofitions one amongft another, which are alfo various; as Anterior, Pofterior, Collateral, Surrounding, Mediate, Immediate, Near, Remote; both as they refpect the feveral Parts, and the feveral portions of one: And all thefe, as few, or more; thefe or others of them, may be diverlly Compounded together. And then the Proportions they bear one to another; whether as to Minority, Equality, or Excefs; each Part compared with each, and that as to the feveral Degrees appearing in the faid Proportions; the Varieties whereof may be exceeding numerous. For if we thould fuppofe but Four confiderable Parts generally conftitutive of a Vegetable: Thefe Four, produce a Variety Four ways. Firft, when One is Unequal; and then it produceth only Four Varieties: and thofe two ways, fcil. when one is Greater, and the other three, Equal and Lefs; or when one is Lefs; and the other three, Equal and Greater. Secondly, when Two be Unequal; and then they produce Six Varieties. Thirdly, when Three be Unequal, which produceth Twelve Varieties. Or laftly, when all Four be Unequal; which produceth Twenty four : which general Varieties, may be further multiplied by their feveral Degrees.

20. 6 . From all which, we may come to know, what the Communities of $V$ egetables are, as belonging to all; what their Distinctions, to fuch a Kind; their Properties, to fuch a Species; and their $P_{e-}$ culiarities, to fuch Particular ones. And as in Metaphyfical, or other Contemplative Matters, when we have a diftinct knowledge of the Communities and Differences of Things, we may then be able to give their true Definitions : fo may we poffibly, here attain, to do likewife : not only to know, That every Plant Inwardly differs from a. nother, but alfo wherein; fo as not more furely to Define by the Outward Figure, than by the Inward Structure, What that is, or thofe things are, whereby any ${ }^{\bullet}$ Plant, or Sort of Plants, may be diftinguifhed from all others. And having obtained a knowledge of the Communities and Differences amongt the Parts of Vegetables; it may conduct us through a Series of more facile and probable Conclufions, of the ways of their Canfality, as to the Communities and Differences of $V_{e}$ getation. And thus much for the Second General Mean.

The Third 2I. \%. HAVING THUS far examined the Organical and ConGeneral taining Parts of Vegetables; it will be requifite, more defignedly, Mean. to obferve thofe alfo which are Fluid, or any others Contained in them: and that, for our better underftanding both of the Nature of $V$ egetation, and of the faid Contained Parts. And to make inquiry, Firft of their Kinds; as Spirits; both fuch as agree, in general, in being Vinows; and thofe that are Special, to particular Plants. Aers and Vapours; for the exiftence whereof, in all Vegetables, there are Arguments certainly concluding. And for the difference of their $\mathrm{Na}$ tures, in being more dry, or moift, more fimple or compounded, as they are exiftent in feveral Parts, there are probable ones. Lympha's or clear and watry saps; which molt Plants, in one Part or other, at fome time of the Year, do Bleed Mucilages; as in Mallow and Violet Leaves; in many Seeds, as of 2uinces, Clary; Fruits, as in Cucumers; diftinct from the watry $S a p$, as by permitting it to ftand and gelly upon the Veffels from whence it iffues, is plain: And in the young Berrys of White Bryony, when about the bignefs of a Pepper- 


\section{Pbilofopbical History of Plants.}

Corn; the juyce whereof is fo Vifcous, that the twentieth part of a Grain, will draw out above a $Y_{\text {ard }}$ in length. Oyles; not only in seeds, and fome Fruits, but other Parts; as in certain little cavities in the Leaves of Savine, vifibly collected while they are growing. Gumms or Refines; as in Pine, Fir, and others of this Kind. Milks; as in a vaft number of Plants, and amongft them, many not fufpected to yield any. For, of Herbs, not only moft of the Umbellijerous Kind, are Milky; but all or moft of the Intybous; Poppys; Tracheliums; Perwinkles; divers Thiftles; and even Onions, if cut at the bottome; with a great many more. Of Trees, not only the Little Maple, but the young shoots of Lawrel, efpecially being crufhed; as alfo thofe of Elder, and fome others. To which may be added, fuch Mucilages, which though not fo properly contained witkin the Parts, yet are found lying over them; as over the firft Spring-leaves of all kinds of Docks; betwixt the Leaves and the Veil wherein they are involved. That fine white Flower or Powder, which lies over the Leaves of fome Plants, as of Bears-Ear: And in Princes-Featber, about certain Aper-
tures only on the edges of the Leaves.

22. 6. Of all thefe thould be obferved, firft their Receptacles; fome of them, being proper to one; others, common to two or more of them : fince it is certain, that fome of them do Tranfmigrate from one, into another Receptacle, or that the fame Receptacle is filled with Fluid Bodies, of a quite different Nature, at the different Seafons of the $Y_{\text {ear }}$, and Ages of the $V_{\text {egetable. And it is alfo very probable, That }}$ two of fome of them, may, fometimes, be contained in one Receptacle, at the fame time; as in Animals, the Lympha in the D. Thoracicus, and that, and the Chyle, in the Sanguineous Veffels.

23. 5. Then their Motions; both Natural, and fuch as may be effected by Art : and thofe either by Defcent or Afcent; And in afcending, through what different Cbanels or Parts of the Trunk; fince it is certain, That there is a variety, both in refpect of the Seafon, and As alfo their Bleeding it will fall in, To obferve the Tapping of Trees. which it is, with what to what Trees it is proper to bleed: in thofe to Seafon: for none will bleed at all times fame. And then their Collaterll times; neither will all bleed at the their Tranfition from Collateral Motion, together with the Mode of 24.

is made betwixt feveral plants, or either of one; as the Comparifon the true Seed of all Plants, any of the other Parts. Orelfe of a proportion one to another in the fams as coexiftentand bearing fuch may be known by their fin the fame $P$ art: of moft of which, it on muft not be made from thective Receptacles. Yet the Computatibut as that is in conjunction with is proportioned to their fur with their Capacity; and as their Capacity leatt Capacity, being ufually as thich asdes; the Sides of thofe of the fuppofe Ten leffer, tolye within the as thofe of the greateft : fo that tent of thefe altogether within the compafs of One greater ; the Conthat One. 
25. 5. Alfo their Confiftence; fcil: of fo many of them as are difcriminable by Touch; in being Soft or Hard; Thin or Thick; Mucilaginous, Gummous, Glutinous, Friable, $b$ c. And thefe in their feveral Degrees;in which there is a Variety, as in the Milks of fome Plants, which are more Dilute, than that of others: Mucilages; which in fome, are very thick and $V_{i}$ cours, in others, more diluted and coming nearer to a watry Sap. And by This, to be compared in the fame manner, as by their 2 uantity.

26. 5. Likewife their Colours, Smells, and Taftes: The general and particular Kinds of all which fhould be noted. And to what $C$ ontained Parts, and in what Variety, they appertain. So moft Refinous Gumms are Tinctur'd, fome, not; as that which drops from the Domeftick Pine, is as clear as Rock-water. The Milks of fome Plants are Paler, as in Burdock; of others Wbiter, as in Dandeljon, Scorzonera; Citrine, as in the Root of Trachelium, Angelica; Yellow, as in Lovage. In fome Plants, Odorous, as in Umbelliferous; in others not, as inCichoraceous. That of Little Maple, Tajtleß; of Garden Chervil, Sweet; of Fenil, Hot; of Scorzonera, Aftringent; of Dandelion, Bitter; and generally, in other Plants; but with many Degrees of Strength, and in conjunction with other Tafts. But moft Mucilages, have little either Colour, Tafte, or Smell; and the like. Here alfo the fame Qualities are to be inquired into, as, in general fpeaking, they are faid to belong to a Vegetable. Since it is more than probable, that all Colours (excepting White, which is fometimes common both to $C_{\text {cntaining and }} C_{\text {ontained }}$ Parts) all Odours, and Tastes, which are more immediately, and without a refolution of their Effential Principles, perceptible in a Plant; are not afcribable either to the Organical, or Containing Parts; but only to Thofe, Contained in them; as from divers reafons hereafter may appear.

27. 6. And firf, their Colours; where, with refpect to feveral Plants and Parts, they are more Changeable; as Red, in Flowers; or Conftant, as Green, in Leaves.' Which, with refpect to feveral Ages of one Part, are more fading, as Green in Fruits; or durable, as Yellow in Flowers. In what Parts more single, as always in the Seed; or more Compounded, as in the Flower; and in what Plants more efpecially, as in Pancy. Which proper to Plants that have fuch a Tafte or Smell, as both, in Wbite Flowers, are ufually lefs ftrong. To Plants that flower in fuch a Seafon, as a Yellow Flower, I think, chiefly, to Spring Plants. And to Plants that are natural to fuch a Soil or Seat, as to Water-plants, more ufually, a wobite Flower. What, amongft all Colours, more Common to Plants, as Green; or more Rare, as Black. And what all thefe Varieties of Colours are upon Cultivation, but chiefly, in their natural soil. To obferve alfo with their fuperficial Colours, thofe within: fo the Roots of Docks, are Yellow; of Biftort, Red; of Avens, Purple; but of molt, White. Where the Inward, and Superficial Colours agree; as in the Leaves; or vary, as in the orher Parts frequently. And in what manner they are Situated; fome univerfally fpreading, others running only along with the Veffels, as in the Leaves of Red Dock, and the Flowers of Wood-Sorrel.

28. 6. Next their Odours; what may be their principal Seat; whether one or divers Seats in the fame Plant. What the chief Matter out of which they are continually bred. What fimilitude betwixt 
the smells of divers Vegetables; as betwixt Baume, and a Limon; the Green Leaves of Meadow-froeet, and the green Rinds of Walnuts. Or betwixt thofe of Plants and Animals; as the Smell of green and wellgrown Carduus, is like to that rank fcent, ab aliquorum axillis $j p$ ranti. Which have a more fenfible smell; as moft have; and which have lefs, as Corn. Where the green Leaf is the moft Fragrant Part, as in Musk-Cranesbill; where the Flower, as in Rofes; the Root, as in fweet Calamus. Where all the Parts have fome Odour, where fome, or one, only; as in Scurvy-graß, only the Flowers, unlefs the Leaves are bruis'd; and in Arum, the Peftil only; for neither the Leaf, nor Root hath any smell, unlefs cut; but this is ftrong enough, not much unlike to Humane Excrements.

29. 6. But efpecially their Taftes, which it much importeth us more precifely to diftinguifh ; Firft, by their general Kinds; for the number, even of thefe, may be computed greater than ufually it is. I remember not, that Heat and Acritude, with refpect to Taste, are diftinguifhed; yet Arum-Root is very Pungent, without any proper Heat; and Cloves, are very Hot, without any proper Pungency. So the White Roots of Yarrom, have a Taste, hardly any other way perceptible, than by caufing a gentle glowing and continued Warmth upon the Tongue. Alfo their Reppondencies one to another; as that of $Z e$ doary, and of the leffer Cardamoms, is fomewhat like to Camphire. Likewife their Degrees; in which there is a great latitude, and may be extended from One to Ten, or with eafie diftinction, from One to Five: So the Root of Sorrel, is Bitter in the firft; of Dock, in the fecond; of Dog-Rofe, in the third; of Dandelyon, in the fourth; of Gentian, in the fifth: obferving them, not only as they vary in feveral Kinds of Plants, but the feveral species of one, as in Cichory, Hawkweed, Dandelyon. And then their Compofitions; for Tastes are as truly conjunit in one Part, as Colours: by which, the latitude is ftill greater; In that all Kinds of Tastes, in all their Degrees, and in differing Numbers, may be varioully Compounded together: For the moft part, in Sorrel-Roots, Aftringent and Bitter , Dock, Aftringent, and Sowre; the one in the fifth, the and Bitter; and in Aloes, Bitter and Sweet; judiced tryal may be perceived: in the first Degree; as upon an unpreof any Land-Animal. Sometimes the more evidently in the Gall of any Land-Animal. Sometimes three, as in Agrimony, Bitter,Rough, perhaps more. The Agarick, Bitter, Rowgh, and sweet. And fometimes, as wide, as of Plonts thought ralhnefs, to themfelves. Wherefore, although it may be Dry, Tobin, Gros, and other aualities, in thions of Hot, Cold, Moift, the Ancients have affixed to particular Plants feveral Degree, which done it, to many of them, with much uncertintyet fince they have they are, more properly, wh much uncertainty; and that, withal, 2ualites; Practical Obfervation, add thefe Senfible Ones of varion, may therefore approve it ufeful, to Conjugations and Degrees of various Taftes, precifely diftinguifhing their ons, with refpect to the Subject wherein feveral Varieties and Mutatinoted, As, of th the Subject wherein they refide, fhould alfo be common; Sweet and found in Plants, Bitter and Sowr, are moft ceptible in fome sea-Plat, moft rare. Which latter, is not only perfome others, as upon the frefh 
Leaves of Tamurisk; which being licked while they grow, or when immediately gathered, are plainly saltifh. How they vary with the Age of the Plant, or Part; as the Roots of Radifles, growing up to Seed, lofe the ftrength of their Taft; fo moft Fruits are firft Sowre, then Sweet. What proper to the feveral Parts of any one Plant; fo the Leaves of Wormwood are extraordinary Bitter; the Root fcarcely fo at all; of an Hot, but quite different Tafte. What more Common,or Rare, to any Part; fo no Root that I ever tafted, is Sowre. And how they Alternate in feveral Plants; as the Root of Stock-Fuly-flower is biting, not the Leaves; on the contrary, the Leaves of the WaterArfmart, are Biting; but not the Root; and the like. To which we may add the difference of Time wherein the Taftes of Plants are perceived; as thofe of Arum, and Rape-Cronofoot, are both Biting; but that of the firft, as it is flowly perceived, fo it continues long; that of the other, quickly comes, and quickly goes.

30. 6 . Amongtt the other Adjuncts of the Contained Parts, though not of thefe only, the Faculties of Vegetables are to be reputed. For fo the Rofin of Falap, which is Purgative, is as truly contained in the Organical Parts of that Root, as Blood is in Veins : It.will be requifite therefore to make particular obfervation of thefe alfo. And firft, what Faculties chiefly may refide in Plants, above others: fo there is none of known ufe in Salivation, except by holding in the mouth: Although we may ask, Why fome amongft them, may not (being Taken inwardly) have a power to evacuate by This,as well as other Violent ways? Where the Faculty is more univerfally fpread over all the Parts of a Vegetable, as in Afarum. Where belonging chiefly or wholly to any particular Parts or Part; as chiefly to the Root of Rkubarb; and only to the true and proper Seed of Barbado Nuts. Whether fome Faculties, may be proper to fome Parts efpecially. What conjunction they may have with any fenfible 2 ualities. So, many Purgers, arenot only Refinows and Gummous; But alfo Mucilaginous; as Bryony, wild Cucumer, Lapatbum Sativum; and therefore probably Rhubarb, when growing; Mallows, Violets, \&uc. Such as are Purging and Vomitory, though fome of them have a ftrong Tafte, yet the greater part, and of thofe, many of the ftronger fort, have no Tafte, or not Great; as senna, Jalap, Scammony, Hellebore, Afarum, and others. Amongtt which, although Hellebore hath a very Durable Tafte, yet is it not very High or Great. So alfo, thofe that are moft fenfibly tafted, are, I think, for the moft part, more or lefs Bitter; either fimply, as Colocyntbis; or Bitter and Aftringent, as Rbubarb; or Bitter and Sweet, as Aloe; or Bitter, Aftringent, and Sweet, as Agarick. Few are Hot, as Iris. Or fimply Sweet. And though fome may be Subacid, that are Mollifying or Lenitive, yet no proper Purge or Vomit is Sowre. Such Plants as are of a foft and fweetifh Tafte, without Vifcofity, may beaccounted good Antifcorbuticks, efpecially againft the Sea, or other SaltScurvey; as are good fweet Peafe: And fometimes the $W$ ater or Spirit of the shells; which may eafily be drawn from them, being ffret duly fermented, and hath a true Vinows Tafte; but very mild, and not unpleafant. Thofe Plants, whofe Parts are not only Hot but Volatile, as Onions, are generally good for Burns. Such as have a Balfantick Tafte or smell, with a little Afringency, as Hypericum, Golden-Rod, Lamium Luteum, \&6. the beft Wound-Herbs. And fuch as are gently 
Bitter, and penetrant upon the Tongue, or in the Throat, as Daify, Anagallis, good Cleanfers. That fuch Bodys, principally, are Anodyne, which are Ycllow, I think, is more than a conceit; Yelks of Eggs, Fœnugreek Seeds, Lint-feed Oyl, May-Butyr, Marrow, Pinguedo Humana, Hyofcyamus luteus, Safron, Sulphur, Opium, all Anodyne and Yellow. How likewife their Faculizes and Qualities may vary their Degrees, either differently or together: fo Aloe and Colocyntbis, are both Bitter in the higheft Degree; yet Aloe, which is alfo sweet, Purgeth more moderately; Colocynthis, which is Bitter, but not $S$ weet, moit Violently. How far the Faculties of Vegetables, as well as their 2ualities, may be Compounded; where, and which chiefly; as Aftrictive and Purgative in Rbabarb. Where this Queftion may be put, Whether divers other, and yet more extreme Faculties, as well asthefe of Aftrictive and Purgative, may not fomewhere or other be alfo found, or made, to meet: whereby the fame Plant, or fome Preparation of it, may be moft Potent, and yet moft Innocent; the Malignity thereof exerting its Power, and the Dirtue its Soveraignty at the fame time. And laftly, what Affinity there may be betwixt them; as moft Plants, that are ftrong Purgatives, and elpecially Vomitories, I think, are'alfo Sternutatory; as white Hellebore, Falap, Tobacco : and on the contrary, fuch as are Sternutatory, are fome of the moft proper and moft potent Medicines for the Head, Brain, and Genus Nervojum, Taken inwardly, as Lilium convalle, orc. and the like.

31. \$. Thus far a particular obfervation of the 2ualities and $F_{a-}$ culties of the Contents of Vegetables may proceed, as they are exiftent in their Natural Eftate. From which, although fome probable Conjectures may be made, of their Material and Formal Effences, and of the Caufes of their determinate Varieties, or the Modes of Vegetation neceffary thereunto : yet will our Conceptions hereofbe more facile,clear, and comprehenfive, if by all other Ways of Obfervation, they be likewife examined, according as Experiment may be applicable to any of them.

32. 6. As by Contufion: fo fome Plants give their Smell, not without Rubbing, or not fo well; as the green Leaves of Stramonium,Scurvygra $\beta$, and many more: others lofe' it by Rubbing, as the flowers of Violets, Carnations, Borage, \& c c others yield it both ways, as Rofemary, \&c. So fome Apples mend their Tafte, by Scoaping, and Pears by Rowling, efpecially that called the Rowling Pear.

33. 6. By Agitation; which doth that, fometimes, by Force, which Digeftion, doth by Heat: fo any cold $O y l$ and a syrup being, in a due manner, agitated together, of two Fluid bodies will become one Confiftent, as is known.

34. 5. By Frigifaction; how far the Fuyces of Plants, either without or within them, may be any of them, or fome more than others, fubject to Cold: and thereby to be deprived of their Motion or natural Confistence, or may fuffer alteration in their Colour, Tafte, or Smell.

35. 5. By Infufion; where I mean Infufion only in Common Water; So both Cajjia Lignea, and Cinnamon are a little Mucilaginous; but the former moft. Some of the Contents of Plants, may be wholly diffolved in Common Water; fome but in part,others not at all; or very little; which is proper to fome Milks, as well as Gums. The $\mathrm{Co}_{0-}$ lours, Smells or Taftes they hereupon yield, are found various; and in 
fome very unexpected : So the green Leaves of Barm, being duly infufed in common Water, without any other Body added, tincture it with a clear and deep Red, near that of Claret Wine, as I have often tryed.

36. \$. By Subfiding; So the Juyce of Sorrel, being ordered as that of Grapes, will, in time, let fall a kind of Tartar or Efjential Salt. And fo perhaps will that of many other Plants, without any previous $D e-$ coction; although that be commonly thought to be neceffary.

37. 6. By Digeftion with Fermentation; either of the entire $V_{e-}$ getables, or of the $\mathcal{J}^{\text {uyces, }}$ or other Contents; and thefe by themfelves, or with common Water. And hereby to note, what difference may be in the Strength, Celerity, or Continuance of the Fermentation.Likewife, how their 2 ualities may thereby be altered; as the Smell of $V i o-$ let-flowers, from a moft excellent Fragrancy, may, by Digeftion, be reduced to an odious and abominable stink, like that of the black Mud of $\mathrm{Gutters.}$

38. \$. By Digeftion with Calefaction; fo the Colour of the fuyce of Limons, from Tranfparency (if that be a Colour) may be turned to a perfect Red. Whence it is that many are deceived in the Preparation called the Tincture of Corals; fuppofing the Corals to give the Menftrum its Colour. Whereas the Menstruum will obtain it, only by Digeftion, without any Corals, mixed with it.

39. 6. By Decoction; either of Vegetables themfelves, or of their Liquors; and to obferve what alterations follow. So Turpentine boiled becometh friable; Sugar, Bitter, and of a Brown Red. Turneps lofe their Biting Tafte ; Onions, their Picquancy; yet neither of them convey thofe felf fame 2 ualities to the Water. The fame maybe obferved in the Decoction of sweet-Fennel-feeds, Anifeeds, and others, lofing much of their Taftes themfelves, and yet conveying very little of them to the Liquors wherein they are boiled; the greater portion of their Volatile parts, and fo their Virtue and Tafte therewith, flying away. Whereof therefore it is much bettertomake an Emulfion, than to decoct them; or to make an Emulfion from them, with their own Decoction, efpecially if the Medicine be intended to be Carminative, as I have frequently obferved. The Decottion thould alfo be carried on throughout all degrees to that of an Extract; by which the Qualities thereof,fometimes, are much altered; as the Colour of all or molt green Leaves, from a kind of Yellow, deepens at laft into a dark one, as Black as Pitch.

40. 6: By Diftillations; both with the cold Still, Alembick, Chappel- and open Furnace : and to note what Vegetables thus give their Smell or Taste, and in what Degrees of ftrength, either under, or over their natural ones; as Mint, Pennyroyal, and the like, which are Aromatick and Hot, give their Taftes perfect: but Wormwood, which is Aromatick and Bitter; gives it but by halfs, pretty fully as Aromatick, little as Bitter. And Carduus, though alfo fo exceeding Bitter, yet not being Aromatick, yieldeth a much weaker Tafte. Alfo what Vegetables yield $O y l$ moft plentifully; and what difference may be in thofe. Oyls, as to their Colour, Weight, or otherwife; as that of Cloves is fometimes Red; of Cinnamon, limpid ; both Ponderous. So to diftil Juices; Gums, or other Contents, with an hot fire; and to fee, what Bodiesthey yield, and of what Qualities; as Turpentine is known to yield, befides 
its $0 y l$, a fubacid Water; Vinegar, an Eager Spirit; as that part may be called, which Chymists are wont to call the Pblegm.

41. 6. By Arefaction; fo Milks which are Liquid, and White in their Natural Eftate, in Standing, grow Gummous, Yellow, and otherwife different, fo doth that of Scorzonera; and that of Fenil becomes a Balfamical, but Limpid Oyl. The Roots of Angelica, being dry'd, and cut by the length, exhibit their fmall $V_{\text {eins }}$ fill'd with an Aromatick Rofin. In the whiter parts of Rhubarb, is gathered a kind of Saline Concret; by which, this Root, in chewing, feems as if it were a little gritty. Cabbage-stalks, fliced, and laid in the Shade to dry, gather on them a kind of Nitrous Hoar. Raifins and Corins contain, not only a fweet Juyce, but alfo a true Sugar, which lies curdled in the Pulp, as the more Saline parts do in Green Soap. And the like is gather'd on the out-fide of a Fig; faving, that it is more Nitrous, as lying next the Aer. The Roots of Arum, upon drying, lofe much of the ftrength of their Tafte; but the contrary maybe noted of many other Roots, which, upon drying, increafe it. Some, being cut and laid by, change their Natural Colours, into Red, Pnrple, Yellow, Green, or White; as Liquorifh, into White, in fome places; and Peony, into Red: and fometimes into two; as Patience, into Yellow and Red.

42. 6. By Affation; thus Apples, by roafting, eat more Sowre. The Root of Horje-Radifh, toafted, tafteth like a Turnep. Potatoes, Onions, and many other Roots, and Parts, have their Tafles, either Altered or Refracted; which chiefly, and in what manner, thould be obferved. There is onealteration, as remarkable, as commonly known; and is that which followeth upon roatting or baking in one kind of the Waldenfian pears, which, for a Walden, we corruptly call a Warden.

43. 6. By Uftion; wherein fome Plants, or Parts of them, burn very quietly; others, not without violent motions; fo Fenil-Seeds, held in the flame of a Candle, will fpit and fpurtle, like the serum of Blood. Some Vegetables lofe their Smell, as Rofes; others, keep it, as Rofemary; and others, mend it, as Lignum Aloes, To note, not. only the alteration of their 2ualities, but what they yield; as Turpentine, which, in Diftillation, yieldeth $O y l$ and $W$ ater, bothlimpid; upon Uftion, theweth nothing but a black soot. So Benzoine, by Diftillation, $O y l$; by Ustion, white Flowers, as is known.

44. 6 . By Calcination; and here to obferve, wherein the Caput Mortuum of one, may differ from, or agree in Nature with that of another; andalfo to compare thefe with thofe of Animal Bodies. As alfo in their 2uantities. And to compare them with what they yield by $D i$ fillation and Ustion as to both. Thus far they have been tryed fin$g l y$, or by themfelves. They fhould alfo be examined,

45. 6. By Compofition; not only with Water, as in fimple Infufions, cic. but with any other Bodies, which may have a power of acting upon them, or upon which, thefe may have a power to act. And fo to make Infufions, Deftillations, 'Decoctions, Digeftions, in divers kinds of Liquors, as Vinegar, Urine, Spirit of H.H. Wine, Blood, Milk, or others. So in Infuftons, fome Red Colours are heightned by Acids; Blews, turned Purple.So fetid Spirits (as of H.H.) maybe rendred much more grateful, by being Rectified, once ortwice, with frefh Aromaticks, To obferve alfo what follows, upon mixing the Liquors, or other Parts 
of Plants together; as $O_{y} l$ of Turpentine, by Digeftion with a Lixivial Salt, extracteth thence a Red Tincture. Or with Salts, Earths, Metals, or any other Bodies; as the Fuyce of the green Leaves of Rasberry, Primrofe, and divers other Plants (I think principally fuch as are Aftringent) expreffed upon Steel, as it drieth, becometh of a Purple Colour.

46. 5. Laftly, by Compounding the Experiment it felf, or joyning two or more of them, upon the fame matter : as Fermentation and $D_{e}$ stillation, as is ufed for fome Waters. Infufion and Fermentation, as in making of Beer. Fermentation and Coction, or rather AfJation, as in making of Bread. Arefaction and Deftillation, as may be tryed upon fome Herbs; and with what difference from what may be noted, upon their being diftilled, moift.

47. 6. Having proceeded thus far, by all the above particular Ways of Obfervation; a Comparative Profpect muft be taken of them: by which, at Jaft, the Communities and Differences of the Contents of Vegetables, may be difcerned; the manner of their Caufation and Original, partly, be judged of; and wherein it is, that the E/fence of their feveral Natures and 2ualities doth confift, in fome meafure compre. hended. And confequently, both from the knowledge of their particular Natures, and the Analogy found betwixt them; we may be able, better to conjecture, and try, what any of them are, or may be good for. For certainly, we fhall then know, more readily, to apply things unto, and more fitly to prepare them for, their Proper Ufes, when we firft know, what they are. Notwithftanding, fince the Faculties of Plants, do often lie more reclufe; it is beft, therefore, not wholly to acquiefce in fuch Conjectures, as their Tastes, or other Senfible Praperties may fuggeft; but to fubjoyn Experiment. In making of which, and in paffing a Judgment thereupon, many Cautions, both in reffect of the Plant whereof, and the Subject whereupon it is made, are requifite to be attended. Which yet, in regard they refult not fo directly from the Matterat prefent in hand; I fhall not, therefore, here infilt upon them, And thus much for the Third General Mean.

The Fourth 48. THE Contents of the Organical Parts of Vegetables, having General been thus duly Examined: it will be requifite to make the like Inquiry, into their Principles; or the Bodys, immediately concurrent and effential to their Being. And of thefe, we are to obferve, Firft, their Number; whether well reducible to five, fix, feven, or more, or fewer : and the Special Differences obfervable under any one General ; fince there are many Bodies, of very different Natures, confounded under one Name. Next their Conjugation; which they are, that either under or over thofe obfervable in animai, or other Bodies, are here joyned together in a Plant; How far common to the Organical Parts of divers plants; or to the feveral Organical Parts of one; or how far different in them. So the predominant Principle of the Parenchymous Parts of a Plant, that it is an Acid, feems evident, From the general Nature of Fruits; and of Corn; and moft Parenchymous Roots, which are either Spirituous, or Sower, or by Digeftion, do eafily become fuch. Likewife their Proportions; which ftand in the greatef, which in the leaft, or in the meaner Quantities, and in what Degrees; both in divers Vegetables, and in the feveral Organical Parts of one. And then the $C_{\text {encentration }}$ and Union of them altogether; as to the de- 
grees of their Clofenefs or Laxity; or the manner of their Implicationand Coherency; or as to their Location, one being more Central, another more Expofed and Rampant over the reft; or otherwife different. To examine thefe Principles, by their Colour, Tafte, Smell, Confiftence, Fixedneß, Volatility,Weight, Figures, or other Accidents. And to thefe purpofes, to go through the formentioned Ways of Experiment; as Uftion, Calcination, Deftillation, \&uc. as any iof them may appear applicable hereunto. So the Effential Salt of Wormwood, which may be obtained from the Lixivial; is Bitter, tranfparent, and commonly, of a Cylindrick figure: whereas that which is obtained by Coction, or from the Extract, is taftle $\beta$, greyifh, and almoft Cubick: and that in the Extract of the Green Leaves of Violets, appears in fine tranfparent Shoots, like fo many little Needles. And it is probable, That the Salts of moft Kinds of Plants, whether Lixivial or Eflential ; and of thefe, whether obtained by Decoction, or otherwife, have either their Figure, or other 2ualities, proper to themfelves, whereby they are all diftinguifhed one from another. And laftly, to make Experiment upon thefe Principles, mixing them with one another, or with other Bodies, or otherwife.

49. \$. I know it will be difficult to make obfervations of this kind upon the Organical Parts of Plants, feverally. Yet I have thought of fome Ways, whereby true and undeceivable ones may be made. And the better to illuftrate what I mean, I fhall give one or two Inftances of Tryal to this purpofe. For the making of which, and fome others of the like nature, I confidered, That upon the Anatomical Analyfis of all the Parts of a Plant, I had certainly found, (and thall hereafter fhew) That in all Plants, there are Two, and only Two Organical Parts Effentially distinct, viz. The Pithy Part, and the Lignous Part, 'or fuch others as are analogous to either of Thefe. So that, if we can think of any Plants, which will afford us either of thefe two, though not perfectly, yet in fome good meafure, fimple and unmixed: We may then fee, by putting them to a Chymical, Teft, what Principles and Proportion of Principles, concur to ppecifie their Subftantial Forms.

50. \$. To the Pithy Part, Starch, or pure Manchet is analogous, as having very little of the Lignous mixed with them. I therefore ordered to ij of Starcb to be put into a Retort, and with a Receiver affixed, to be fet in a Sand Furrace; and that all it would yield, fhould, by degrees, be forced over; which, befides what was evaporated at the Neck of the Receiver, was about it $j$. of an acid and eager Liquor, of a heavy and blackifh $O_{y} l \xi \mathrm{H}$, and of a light $O_{y} l ; \mathrm{j}$. The Caput Mortrum could not be reduced to Afines, by the ftrongeft heat which a naked fire in that Furnace would produce.

51. To the Lignous Part, Hemp or Flax is analogous, having very little of the Pithy mixed with them. I caufed therefore tb ij of Flax to be put into a Retort, and manag'd as the Starch: whereupon, it yielded a Liquor, as I remember, fomewhat like the former, and about the fame quantity; no $O_{y} l$ which remained liquid, when cold; but inftead of that a Butyr, almoft of the Confiftence and Colour of the $\mathrm{Oyl}$ of $\mathrm{Mace} ;$ and of this above $z$ iij, or near fix times the quantity of the $Q y l$ which was yielded by the starch. The Caput Mortuum being burned to a white $A \beta$, yielded fome portion of a Lixivial
Salt 
52. \$. From whence, I fhall, at prefent, only make thefe two Remarques; Firft, That although the chief portion, as to quantity, in both thefe Bodys, (as in molt Plants) is an Acid Liquor ; yet the latter, yields alfo fome of an Alkaly, which the other doth not. So that they are the Lignous Parts of a Plant, generally, which yield the Alkalick Salt, or at leaft in the greateft Proportion. Secondly, That the Sulphurieus or Oleous Principle, is alfo much more predominant in the Lignous Part, than in the Pithy. To thefe, the like Tryals upon other Plants, fhould be added; and other ways. So, in regard the Soot of moft Woods, yields a Volatile Alkaly; it were fit to examine, Whether the Soot which is made of the Pithy Parts and that, of the Lignous, afford the faid Alkaly, in equal qantity; or whether, as is moft likely, that of the Lignous doth afford it in a far greater : and the like.

53. 5. The profecution of what is here propofed, will be requifite, To a fuller andclearer view, of the Modes of Vegetation, of the Senfible Natures of Vegetables, and of their more Reclufe Faculties and Poxers. Firft, of the Modes of Vegetation. For fuppofe we were fpeaking of a Root; from a due confideration of the Properties of any Organical Part or Parts thereof; 'tis true, that the real and genuine Caufes may be rendred, of divers other dependent Properties, as fpoken generally of the whole Root. But it will be asked again, What may be the Canfes of thofe firft and Independent ones? Which, if we will feek, we mult do it by inquiring alfo, What are the Principles of thofe Organical Parts? For it is neceflary, that the Principles whereof a Body doth confift, fhould be, if not all of them the aitive, yet the capacitating Caufes, or fuch as are called Caufe fine quibus non, of its becoming and being, in all refpeets, both as to Subftance and Accidents, what it is : otherwile, their Exiftence, in that Body, were altogether filperfluous; fince it might have been without them : which if fo, it might then have been made of any other; there being no neceffity of putting any difference, if neither thofe, whereof it is made, are thought neceffary to its Being. Wherefore if we will allow a Body, and fo the Organical Parts of a Vegetable to have Principles, we mult allow thefe Principles their neceffary Ufe; and that the Shapes or other Properties of the faid Parts, are as much dependant upon the Nature of Thefe; as is the Roundnefs of a Drop of Ink, upon the Fluidity of Water, ingredient to it.

54. 5. Again, the Principles of the Organical Parts being known, we may from thence obtain a further knowledge of the Natures, and Caufation or Original of their Contents; fince thefe Contents are not only included in the faid Organical Parts, but alfo Created by them :and muft needs be fo, whether we will fuppofe the Principles of thefe Contents to be pre-exiftent to their reception thereinto, or not. For, if not pre-exiftent, what can be clearer, than that the faid Parts give them their Exiftence? And if pre-exiftent, yet in regard they are diftinguilhed, and fuch only of them admitted in fuch fort into an Organical Part, from amongft others, as are apt to combine and mix together in fuch a Form, and fo to conftitute fuch a Liquor; it is as clear, that the Exiftence, if not of thofe Principles, yet of that Liquor, is dependent on the faid Part. 
55. 5. And if by means of the faid Organical Parts, it is, that their Contents become fuch and fucb peculiar Mixtures; it is hence alfo manifelt, That, by the fame means, they are of fucb diftinct F aculties and Powers : Becaufe the Faculty or Power of a Body, lieth not in any of its Principles apart; but is a Refultance from them all; or from their being, in fuch peculiar fort and manner, United and Combined together. So the Principles of the Purgative Parts of a Root, as of Rbu$\mathrm{barb}$, although we lhould fuppofe them to be exiftent in the furrounding Earth, yet we cannot fay, That that Earth, or the Principles therein contained, are Purgative; but only that they are fuch, as by being combined together, in fuch a peculiarway, may become fo. So the feveral parts of a Clock, although they are and muft be all præ-exiftent to it, and it is their Form, by which they are, what they are; yet is it the fetting together of fuch Parts, and in fuch a way only, that makes them a Clock. And fince we fee that the Mixture of two Bodies of two different Qualities, as of $\mathbf{T}$ wo Colours, will produce a Third colour, differing from them both; as Blue and Red, do a Murrey : Why fhould not Two or More Bodies of different Natures, be fo combined together, as to produce a Third Nature? Or whereforemay not that be allowed to be performed by Nature, which by Artificial Compounding of Medicines, or other Bodies, is defigned, and oftentimes effected? III give but one Inftance; Water, Greafe, and an Alcalizate Salt, may be eafily fo ordered as to be invefted with new Qualities, Nature, and Pomers; the Salt, to lofe its extreme fiery Pungent Tafte; the Tallow, its Smell; and being before unfociable with the $W_{a t e r}$, to mingle therewith: neither Tallow, Salt, nor Water alone, will fetch out a fpot of Greafe; but all united eafily do it: the fame Three Bodys united, are, in fome Cafes, as in the faundies, no ill Medicine; any of which, given alone, may rather prove prejudicial, than a cure: and all this done, only by duly boiling them together into one Body, which we call Sope.

56. \$. Whence again, if it be fuch an Union, and Proportion, of fuch a Sort of Principles, which produceth fuch a Faculty; and that we may, by any means, come to know what thefe are; we may, poffibly, alfo attain to the knowledge of fuch Rules, whereby any kind of Faculty may be made; as to Compound fuch Bodies, which are neither Purgative nor Vomitory, fo together, as to be Invefted with thofe $\mathrm{Fa}$ culties. And if to Make them, then confequently, to Mend, Exalt, Strengthen, and Enoble them, with greater eafe and certainty. And thus much for the Fourth General Mean.

57. \$. HITHERTO, We have confidered the Materials of a $V_{e-}$ The Fifth getable, only as Ingredient to it : there yet remains a Fifth Story to be General
afcended; which is, to confider thefe afcended; which is, to confider thefe Materials as they are derived Mean.
from abroad: or as, after they are received and naturalized, they may,
with others yet abroad, have any kind of corref with others yet abroad, have any kind of correfpondence. And thefe are Four in general, fcil. Earth, Water, Aer, and Sun; all which, in that they contribute fo univerfally to Vegetation, and to whatfoever is contained in a $V_{\text {egetable, it is therefore requifite, that of Thefe likewife, }}$ Particular Obfervation hould be made.

58. \$. And Firft, of the Earth, and of all Solid Receptacles of Plants. Where we are to confider their feveral Kinds; as Mellow, Sandy, Clayie, Chalky, and others. Their Ingredients; as Rank and 
Mellow Earth, with Sand, or with Clay ; or Sand with Clay; or altogether; and in what Proportions. The Principles whereinto any one of thefe Ingredients, feparated from the reft, and put to the Teft of Diftillation, Uftion, Calcination, or other, either alone, or by mixture with other Bodies, may be Refolved. And by their 2ualities, as Colour, Smell, Tafte, \& c. both Ingredients and Principles to be examined. To make tryal of the growth of Plants, in all kinds of fimple soils; either Earthy or Mineral, as Clay, Marl, Oker, Fullers Earth, Bole Armeniac, Vitriol, Allum, Ecc. or Vegetable, as Rotten Wood, Brans, Starch, or Flower, \&uc. or Animal, as Dungs, pounded Fleth, dried and powdered Blood, and the like; that it may appear, how far any of thefe may contribute to the growth of a Plant; or to one,above another.

59. \$. Next of the Water, and of all Liquid Receptacles. Where the feveral kinds of Water, from Wells, Springs, Rain, and Rivers are, by their 2ualities and Faculties, to be examined; as thefe, and by thefe, their Principles, either in their Natural State, or upon Digeftion, or otherwife, may be obfervable : fince Common $W$ ater it felf, is undoubtedly compounded of feveral Principles; the fimplicity thereof, not being argued, f om its Clearnefs and Tranfparency; for a Solution of Alum, though it containeth a confiderable quantity of Earth, is yet very Clear : nor from its feeming to have neither $S_{m e l l}$ nor Tafte; for Water-drinkers will tell you of the varieties of both in different Waters. Befides, if thefe Qualities fhould be accounted rather Phanfie, than Senfe; the difference of $W$ aters is yet more manifeft, from their different Effects, obferved by Cooks, Laundrefjes, Brewers, and others, that have occafion to ufe them : for not to mix with Sope, without curdling; not to boil Meat tender, or without colouring it red; and the like, are the vices of fome Waters, not of others, which yet would feem, in Colour, Tafte, and Smell, to be the fame. Tryal fhould alfo be made of the growth of Plants in all kinds of Liquid Receptacles, as Common Water, snow Water, Sea Water, Urine, Milk, Whey, Wine, Oyl, Ink, \& c . Or any of thefe, with a folution of Salt, Nitre, Sal prunell $a$, Sope, or other body. And hereby to obferve what follows, either in the Liquor, or in the Plant it felf: as if any fixed Body, being weighed before its diffolution in Water; and if the Plant, fet herein, groweth; the Water, being then evaporated; whether the quantity of that diffolved body, continue the fame, or is leffened.So, whether any Vegetable will become Opiate, by growing a confiderable time in a plain Solution or Water-tincture of Opium; and the like. Which Experiments, what event foever they have, yet at leaft, for our further inftruction in the Nature of Vegetation, may be of ufe.

60. \$. Next of Aer, where it will be requifite to inquire, what fort of Bodies may be herein contained : It being probable, from the variety of Meteors formed herein; and of Vapours and Exbalations continually advanced hereinto; that fome or other of them, may bear an Analogy, to all Volatile Bodys, whether Animal,Vegetable, or Mineral. The flourithings alfo of Frozen Dew; and the Green Colour, which the Aer gives the Ground or Water, when, for fome time expored to it; and other effects; feem to argue, that it is Impregnated with Vegetable Prins. ciples. To confider alfo the peculiar Nature of that Body, which is ftrictly called, Aer, And of that true Aerial Salt, which to me, feemeth pro- 


\section{Pbilosopbical History of Plants.}

bable, that it is diffolved in the $\mathbb{E}$ ther, as other Salts are in Water, or in the Vaporousparts of the Aer. As alfo to try, what different Effects, a diverfity of Aer may have upon a Vegetable; as by fetting a Plant, or Seed, either exceeding Low, as at the bottom of a deep Well; or exceeding High, as on the top of a Steeple. Or elfe by expofing fome Soil to the Aer, which is affuredly free from any $S e e d$, and fo, as no Seed can light upon it ; and to obferve, whether the Aer hath a power of producing a Vegetable therein, or not: and the like.

6I. \$. Laftly of the Sun; as to which, it may be confidered, What Influence it may have upon the Plant it felf; upon the Soil; Or upon the Aer. Whether that Infuence is any thing elfe befides Heat : or may differ from that of a Fire, otherwife, than by being Temperate, and more Equal. That it doth, feems evident from an Experiment fometime fince given us, in one of the Parifian fournals des Scavans, and which I therefore think very applicable to our prefent purpofe. If you hold a Concave at a due diftance, againft a Fire, it will collect and caft the Heat into a burning Focus : but if you put a peice of plain Glafs between them, the Glafs will fcatter the Heat, and deftroy the Focus. Whereas the Sun-Beams, being gathered in like manner, will pafs through the interpofed Glafs, and maintain their Focus. Asfor That, of the Collection of the Sun-beams, by the help of Glajes, in the form of a Magistery, or of Flowers, and fuch like, I defire to fufpend my thoughts of them, till I fee them. I will only fay thus much further at prefent, That I do not underftand why the Sun fhould not have fome Influence upon Bodies, befides by Heat, if it may be granted, That the Moon hath; for which, it fhould feem, there are fome good Arguments.

62. \$. WE HAVE thus far examined the Principles neceffary to A Sixth Ge$V$ egetation. The 2ueftion may be put once more, In what manner are neral Mean. thefe Principles fo adapted, as to become capable of being affembled to- Only hinted. gether, in fuch a Number, Conjugation, Proportion, and $\mathcal{U}_{\text {nion, }}$ as to make a Vegetable Body? For the comprehenfion whereof, we mult alfo know, What are the Principles of thefe Principles. Which, although they lie in fo great anabyfs of obfcurity; yet, I think, I have fome reafon to believe, that they are not altogether undifcoverable. How far they may be fo, I am fo far from Determining, that $\mathbf{I}$ thall not now Conjecture.

63. \$. THIS isthe Defign, and thefe the Means I propofe in order The Conthereunto. To which, I fuppofe, they may all appear to be neceffary. clufion. For what we obtain of Nature, we muft not do it by commanding, but by courting of Her. Thofe that woo Her, may poffibly have her for their Wife; but She is not fo common, as to proftitute her felf to the beft behaved Wit, which only practifeth upon it felf, and is not applied toher. I mean, that where ever Men will go beyond Phanfie and Imagination, depending upon the Conduct of Divine Wifdom, they muft Labour, Hope and Perfevere. And as the Means propounded, are all neceffary, fo they may, in fome meafure, prove effectual. How far, I promife not; the Way is long and dark: and as Travellers fometimes amongft Mountains, by gaining the top of one, are fo far from their Journeys end; that they only come to fee another lies before them: fo the Way of Nature, is fo impervious, and, as I may fay, down Hill and up Hill, that how far foever we go, yet the furmounting of one difficulty, is wont ftill to give us the profpect of another. We may there- 
therefore believe, our attainments will be imperfect, after we have done all : but becaufe we cannot attain to all, that therefore we fhould endeavour after nothing; is an Inference, which looks fo much awry from the Prastical Senfe of Men, that it ought not to be anfwered. Nor with better Reafon, may we go about determining, what may be done. The greateft Defigns that any Men undertake, are of the greateft uncertainty, as to their Succefs: which if they appear to be of good Import, though we know not how far they are attainable, we are to propound the Means, in the utmoft ufe whereof only, we can be able to judge: A $W$ ar is not to be quitted, for the hazards which attend it; nor the Councils of Princes broken up, becaufe thofe that fit at them, have not the Spirit of Prophecy, as well as of Wifdom. To conclude, If but little thould be effected, yet to defign more, can do us no harm : For although a Man fhall never be able to hit Stars by fhooting at them; yet he fhall come much nearer to them, than another that throws at Apples. 


\section{TO THE}

RIGHT HONOURABLE

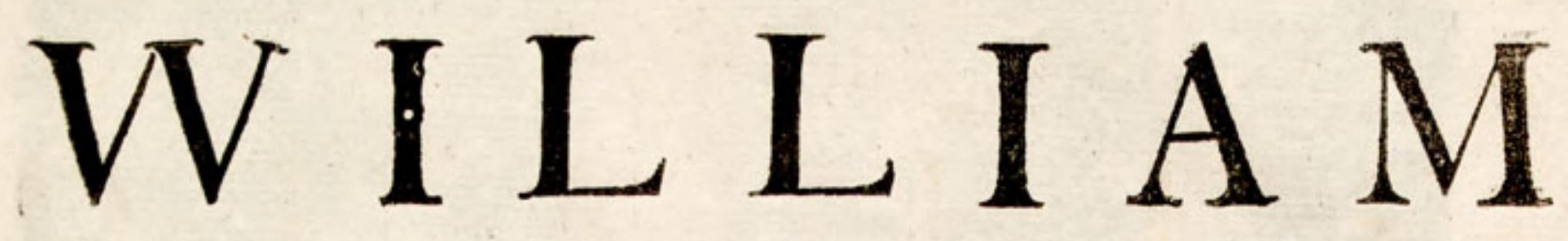

Lord Vi-Count Brouncker,

T H E

PRESIDENT,

And to the

Council and Fellows

OF T H E

ROY A L SOCIETY,

The following

A N A T OM Y

Is moft $\mathrm{HUMBLY}$

P R E S E N T E D

By the AUTHOR

NEHEMqAH GREW. 


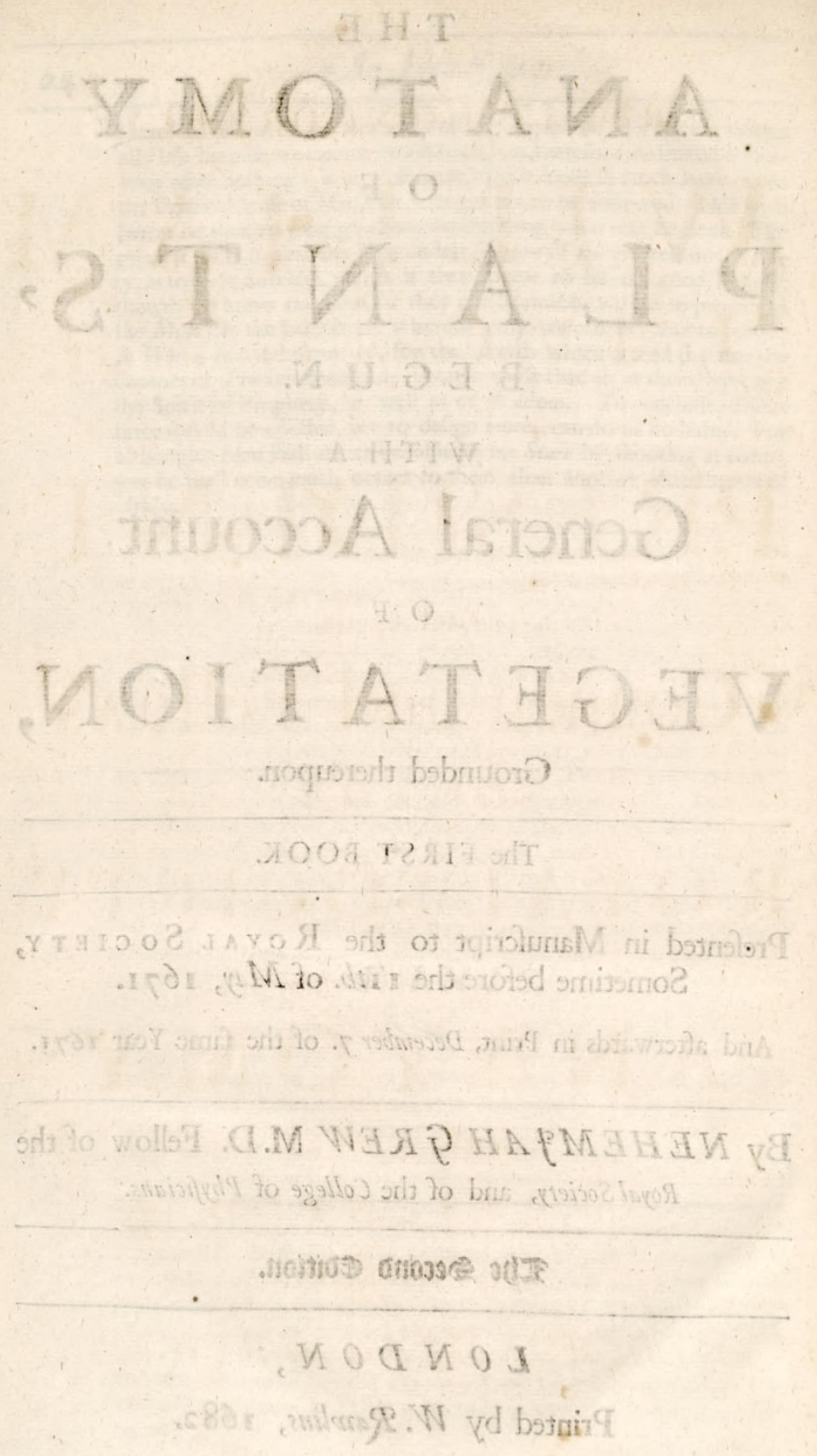




\section{T H E}

\section{A NAT OMY \\ O F}

P L
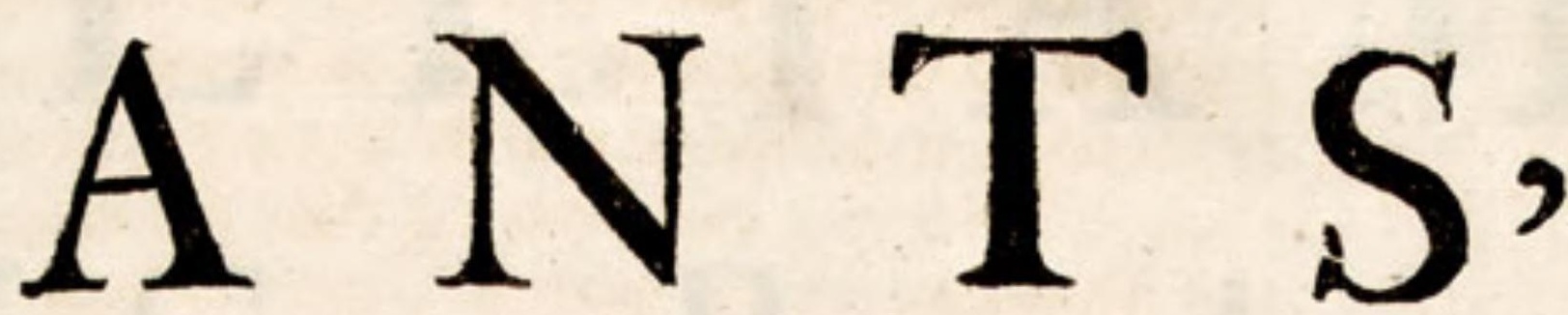

B E G U N.

WITH A

General Account

$\mathrm{O} \mathrm{F}$

VEGETA TION,

Grounded thereupon.

The FIRST BOOK.

Prefented in Manufcript to the Royal SocieTy, Sometime before the 11 th. of May, 1671 .

And afterwards in Print, December 7. of the fame Year $167 \mathrm{r}$.

By $N E H E M f A H G R E W$ M. D. Fellow of the Royal Society, and of the College of Phyficians.

The Second Edition.

$$
\text { LONDON, }
$$

Printed by $W$. Ranolins, 1682. 


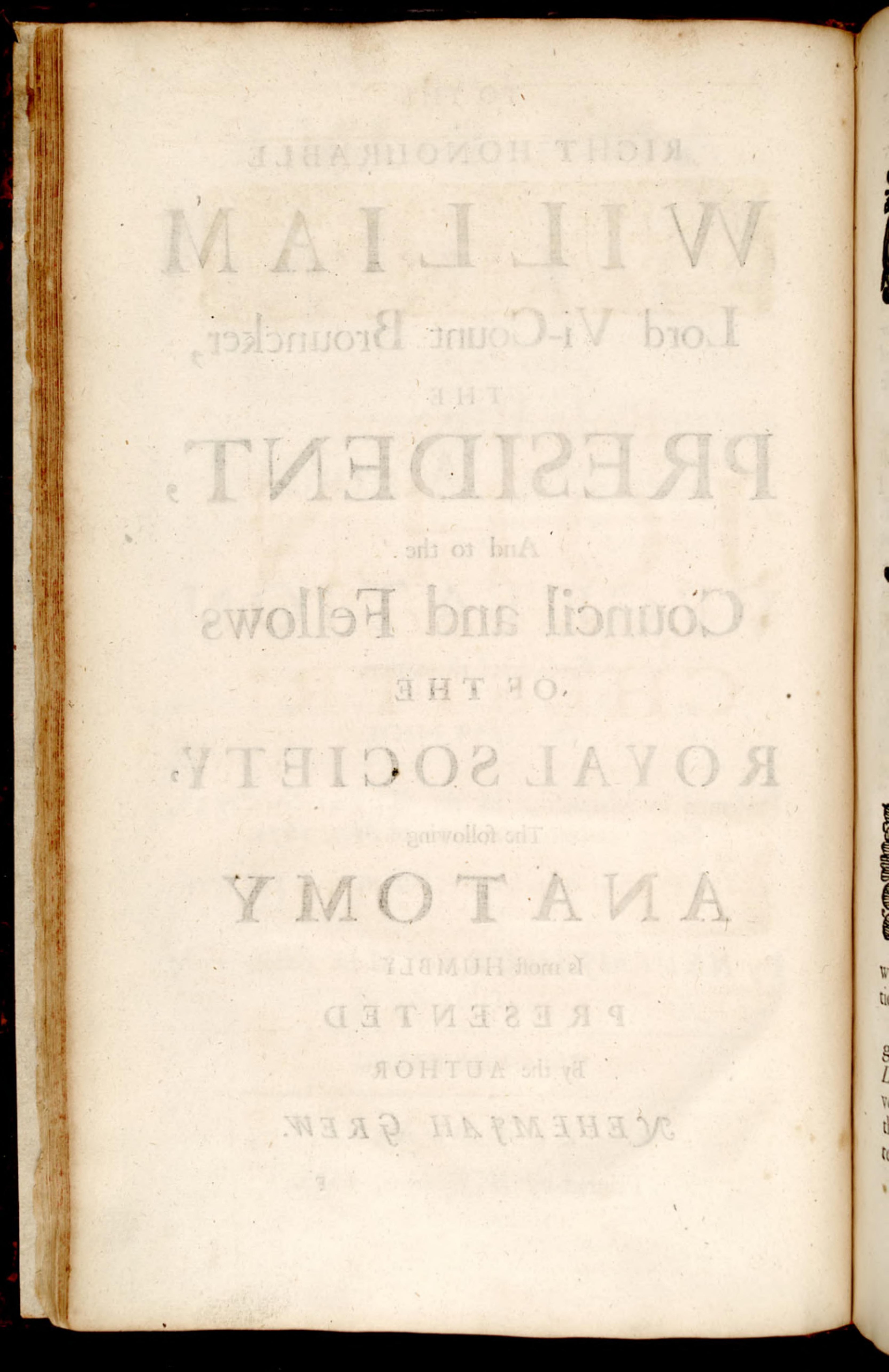


TO THE

\section{Right Reverend}
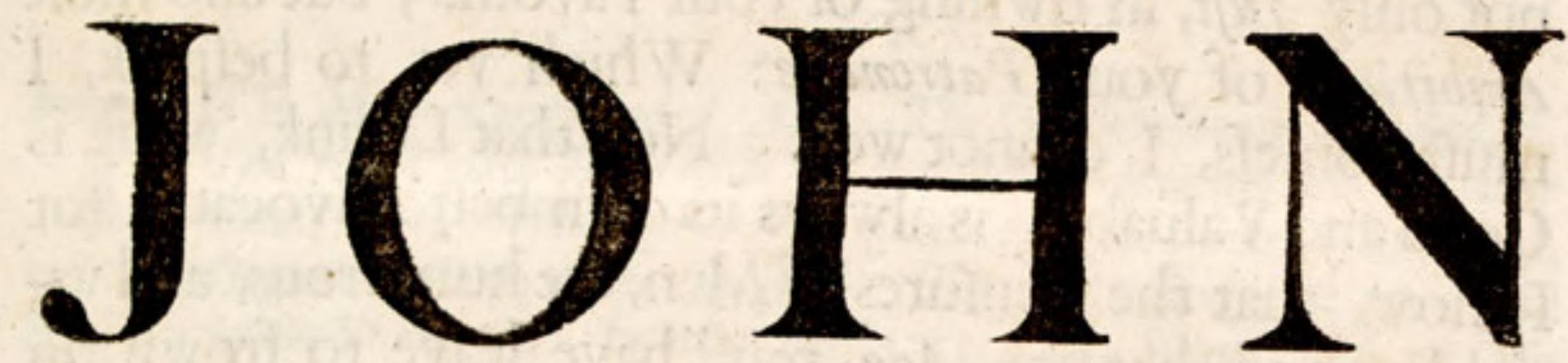

Lord Bifhop of

\section{CHES TER.}

$M T L O R D$,

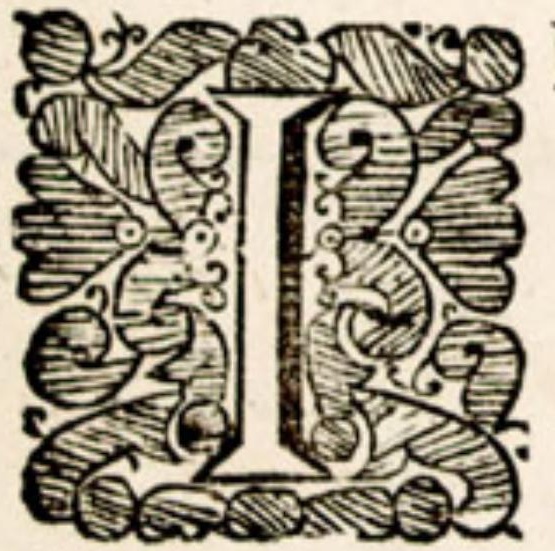

Hope your pardon, if while you are holding That beft of Books in one Hand, I here prefent fome Pages of that of Nature into your other: Efpecially fince Your LordJip knoweth very well, how excellent a Commentary This is on the Former; by which, in part, GOD reads the World his own Definition, and their Duty to him.

But if this Addrefs, my Lord, may be thought congruous, 'tis yet more juft; and that I hould let Your Lordfhip, and others knew, how much, and how defervedly, I refent Your extraordinary Favours. Particularly, that you were pleafed, fo far to animate my Endeavours, towards the Publifhing the following Obfervations. Ma* $\mathrm{F}_{2}$ ny 


\section{Epifle Dedicatory.}

ny whereof, and mott belonging to the Firft Chapter, having now lain dormant, near feven years; and might ftill, perhaps, have fo continued, had not Your Lordfbips Eye, at length, created Light upon them. In doing which, You have given one, amongft thofe many Tokens, of as well rour readinefs to promote Learning and Knowledge by the hands of others; as Your high Abilities to do it by Your Own: Both which, are fo manifeft in Your Lordship, that, like the firf Principles of Mathematical Science, they are not fo much to be afferted, becaufe known and granted by all.

The Confideration whereof, my Lord, may make me not only $7 u f t$, in owning of your Favours; but alfo moft Ambitious of your Patronage: Which yet, to befpeak, I muft confefs, I cannot well. Not that I think, what is Good and Valuable, is always its own bett Advocate : for I know, that the Cenfures of Men, are humorous, and variable; and that one Age, mutt have leave to frown on thofe Books, which another, will do nothing lefs than kifs and embrace. But, chiefly, for this Reafon, Left I fhould fo much as feem defirous, of Your Lordfbips Solliciting my Caufe, as to all I have faid. For as it is your Glory, that you like not fo to fhine, as to put out the leaft Star ; fo were it to Your Difhonour, to borrow Your Name, to illuftrate the Spots, though of the moft confpicuous. I am,

\section{My Lord,}

\section{Your Lordfbips}

Moft Obliged,

And

Moft Humble Servant

NEHEMJAH GREW.

Coventry,

fune 10. 1671 . 


\section{T H E}

\section{CONTENTS.}

\section{H A P. I.}

\section{Of the Seed in its State of Vegetation.}

$\mathbf{T}$

HE Method propounded, 5. I. The Garden-Bean, diffected, 2. The two Coats Defcribed, 3, 4. The Foramen in the outer Coat, 5, 6. What generally obfervable of the Covers of the Seed, 7. The Organical Parts of the Seed, 8. The Main Body, 9, ro. The Radicle in the Bean, I1. In other Seeds, 12. The Plume, 13, 14. The Similary Parts, 15. The Cuticle, 16, 17. The Parenchyma, 18, 19, 20. The Inner Body, 21, to 29. No folid Account yet given, of Vegetation, 30. The Coats bow in common fubfervient to the Vegetation of the Seed, 31. The Foramen, of what ufe herein, 32. The ufe of the Inner Coat, 33. Of the Cuticle, 34. Of the Parenchyma, 35. Of the Seminal Root, 36. How the Radicle firft becomes a Root, 37. By what means, the Plume all this while preferved, 38 . How after the Root the Plume vegetates, 39. How the Lobes, 40. But not in all Seeds, 41. That they do in moft, demonftrated, $42,43,44$. What bence refolvable, 45. The ufe of the Diffimilar Leaves, 46, to the end.

\section{H A P. II.}

Of the Root.

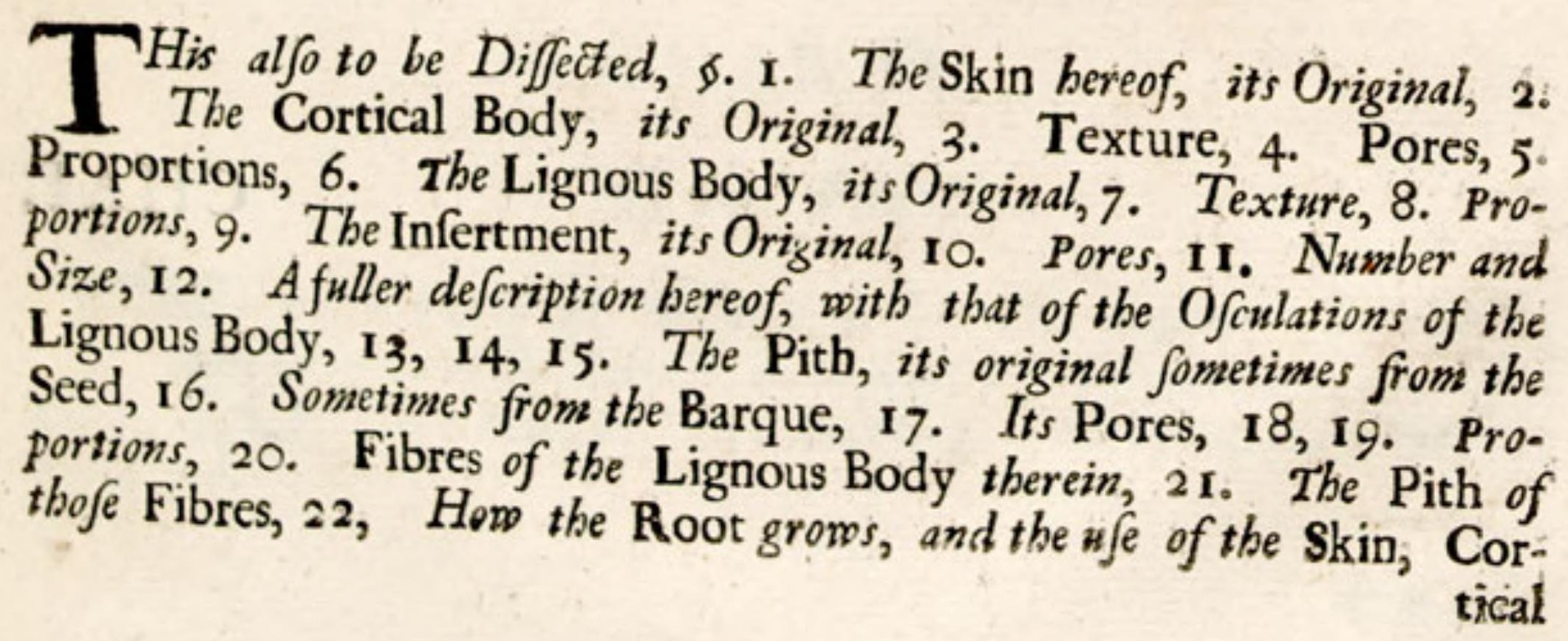




\section{The Contents.}

tical and Lignous Body thereto, 23. How it groweth in length, 24. By what means it defcends, 25. How it grows in breadth, 26. And the Pith, how thus framed, 27. The ufe of the Pith, 27. Of the Infertment, 28. The joynt Jervice of all the Parts. $29,30,3 \mathbf{I}$.

C H A P. III.

Of the Trunk.

THE Coarcture, 6. 1. The Skin, its original, 2. The original of the Cortical Body, 3. Of the Lignous, 4. Of the Infertment and Pith, 5. The Latitudinal Shooting of tbe Lignous Body, wherein obfervable, 6,7. The Pores of the Lignous Body, where and how moft remarkable, 8. A leffer fort of Pores, 9. A third fort only vifible through a Microfcope. Obferved in Wood or Charcoal, 10. Obferved in the Fibres of the Trunks of Herbs, II. The Infertions, where more vifible, 12, 13. Their Weftage with the Lignous Body, 14. The fmaller Infertions, only vifible through a Microlcope, 15. No Valves in a Plant, I6. The Ranks of the Pores of the Infertions, 17. The Pores of the Pith, 18 19, 20. How the Trunk afcends, 21 . The difpofition of its Parts confequent to that Afcent, 22. Confequent to the different Nature of the Sap, 23. The effects of the faid Differences, 24, to 28. Which way, and how the Sap afcends, 29, to the end.

\section{The Appendix. \\ Of Trunk-Roots and Claspers.}

Trunk-Roots of two kinds, 5. I, 2. Clafpers of one kind, 3. The U Jes of both, 4, to the end. 


\section{The Contents.}

\section{CHA P. IV.}

- Of the Bud, Branch, and Leaf.

$\mathbf{T}$

HE parts of the Germen and Branch the fame with thofe of the

Trunk, 6. 1, 2. The manner of their growth, 3. How nourijed, 4. And the ufe of Knots, 5. How fecur'd 6. The Parts of a Leaf, 7. The Pofitions of the Fibres of the stalks of Leaves, 8, For what 'U fes, 9,10 . The vifible caufe of the different circumference of Leaves, 11 . And of their being flat, 12. And filamentous, 13. The Foulds of Leaves, their Kinds and $\mathcal{U}_{f e}, 1_{4}, 15,16$. The Protections of Leaves, 17. The ufe of the Leaf, 18 , to the end.

\section{The Appendix.}

\section{Of Thorns, Hairs and Globulets.}

Thorns of two Kinds; the Lignous, 5.1 . The Cortical, 2. An aygument of the Magnetick Defcent of the Cortical Body, 3. Hairs of divers Kinds, 4, 5. Their USe,6. Globulets of two Kinds, 7,8.

\section{CHAP. V.}

Of the Flower.

Ts three Parts, 6. 1. The Impalement, of divers kinds, 2. Their ufe, 3, 4. The Foliation, its nature, 5. Foulds, 6. Protections, 7. Downs, 8, 9. Globulets, 10. Its $\mathcal{U} e, 11,12$. The Attire of two kinds. The Defcription of the first, $13,14,15,16$. Of the other, 17 , $18,19,20,2 \mathrm{I}$. Their ufe, 22, to the end.

\section{CHAP. VI.}

\section{Of the Fruit.}

$\mathrm{T}$ HE Vital Parts of all, the fame, 6. 1. The Number, Defcription, and Original of the Parts of an Apple, 2. Of a Pear, 3, 4. Of a Plum, 5, 6, 7. Of a Nut, 8. Of a Berry, 9. The infe of the Fruit, 10 , to the end. 


\section{The Contents.}

\section{CHA P. VII.}

\section{Of the Seed in its State of Generation.}

T Hat bere further obferved, not in the Firft Chapter, \&. I. The $\mathrm{Cafe}$, its Figures, 2. The outer Coat, its Figures, 3. Various Surface, 4. And Mucilages, 5. The nature of the outer Coat, 6. Its Apertures, 7. Next to which the Radicle ufually placed, 8. The Original of the Outer Coat, 9. The Original of the Inner, 10. Its Nature, 1 1, 12. The Effential Parts of a Plant, 13, 14. The Secondine, 15. The Colliquamentum herein, 16. The Navel Fibres, 17. In the Gene ration of the Seed, the Sap firft prepared in the Seed-Branch, $18,19$. Next in the inner Coat, 20. With the belp of the Outer, 21,22. The ufe of the Secondine, 23. Of the Ramulets of the Seed-Branch, 24. Of their Inofculation, 25. How the Colliquamentum becometh a Parenchyma, 26 , to the end. 


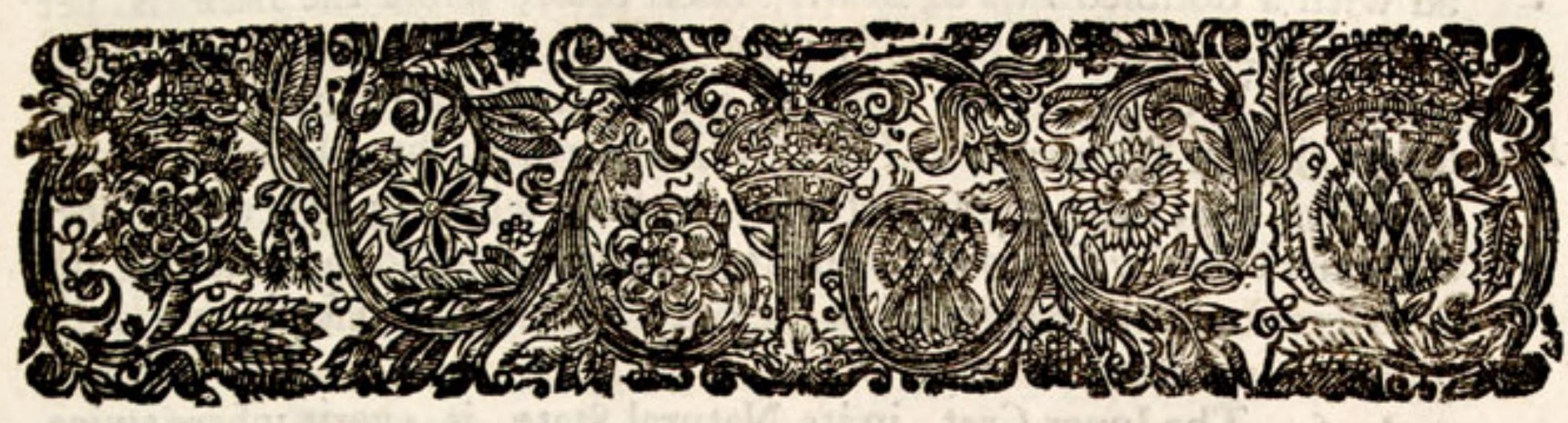

T H E

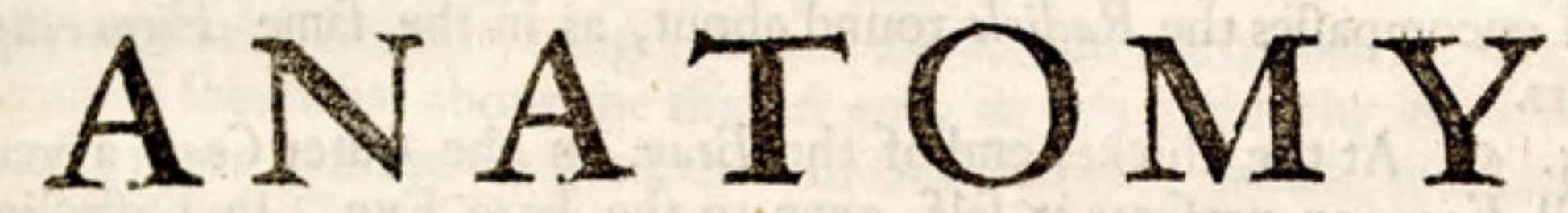

O F

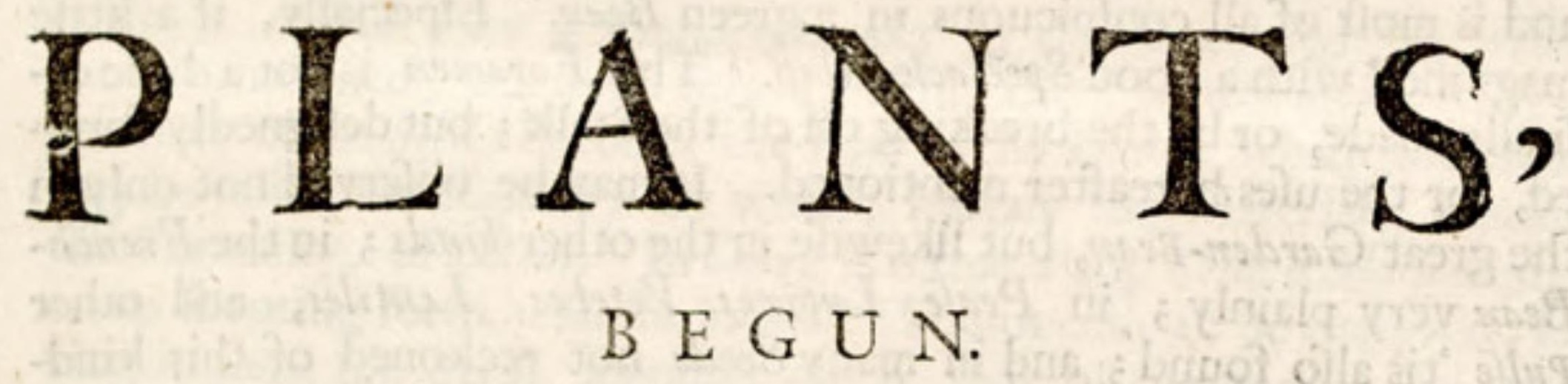

With a General Account of Vegetation, Founded thereupon.

\section{CHA P. I.}

Of the Seed in its State of Vegetation.

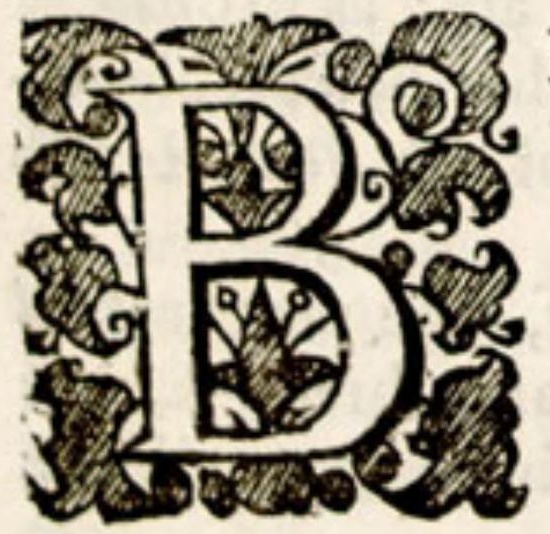

E I NG to fpeak of Plants; and, as far as Infpect $\mathrm{i}$ on, and confequent Reafon, may conduct, to enquire into the vifible Conftitutions, and $\mathcal{V}$ es of their feveral Parts: I choofe that Method, which, to the beft advantge, may fuit with what we have to fay hereon. And that is the Method of Nature her felf, in her continued Series of Vegetations; proceeding from the seed fown, to the formation of the Root, Trunk, Branch, Leaf, Flower, Fruit, and laft of all, of the seed alfo to be foren again; all which, we fhall, in the fame order, particularly fpeak of.

2. 5. The Effential Conftitutions of the faid Parts are in all Plants the

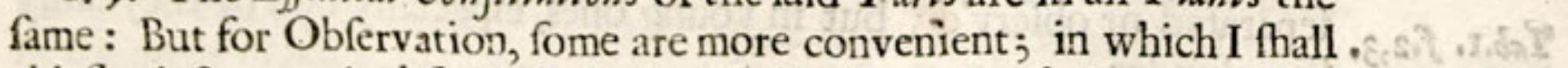
chiefly inftance. And firft of all, for the Seed, we choofe the great Garden-Bean, 
3. 6. If then we take a Bean and diffect it, we thall find it cloath. ad with a doubled $V_{e f t}$ or Coat. Thefe Coats, while the Bean is yet green, are feparable, and eafily diftinguifhed. Or in an old one, after it hath lay'n two or three days in a mellow Soil; or been foaked as

Tab. x. f.2. long a time in Water: as in Tab.1. When 'tis dry, they cleave fo clofely together, that the Eye not before inftructed, will judge them but one; the inner Coat (which is of the moft rare contexture) fo far fhrinking up, as to feem only the roughnefs of the outer, fomewhat refembling $W$ afers under Maquaroons.

4. \$. The Inner Coat, in its Natural State, is every where twice, and in fome places, thrice as thick, as the Outer. Next to the Radicle, which I fhall prefently defcribe, it is fix or feven times thicker; and encompaffes the Radicle round about, as in the fame Figure ap-

Tab.1.f. 2, pears.

5. 6. At the thicker end of the Bean, in the outer Coat, a very frmall Foramen prefents it felf, even to the bare Eye. In Diffection

$T_{a b}$ I. $f_{\mathbf{i}} \mathbf{I}-\mathrm{a}$ 'tis found to terminate againft the point of that Part which I call the Radicle. It is of that capacity, as to admit a fmall Virginal Wyer; and is moft of all confpicuous in a green Bean. Efpecially, if a little magnified with a good Spectacle-Glajs. This Foramen is not a hole cafually made, or by the breaking off of the Stalk; but defignedly formed, for the ufes hereafter mentioned. It may be obferved not only in the great Garden-Bean, but likewife in the other kinds; in the FrenchBean very plainly; in Peafe, Lupines, Vetches, Lentiles, and other Pulfe 'tis alfo found; and in many Seeds not reckoned of this kindred, as in that of Fenugreek, Medica Tornata, Goats-Rue, and others : In many of which, 'tis fo very fmall, as fcarcely, without the help of Glaffes to be difcovered; and in fome, not without cutting off part of the seed, which otherwife would intercept the fight bereof.

6. 6. That this Foramen is truly permeable, even in old SettingBeans, and the other Seeds above named, appears upon their being foaked for fome time in Water. For then, taking them out, and crufhing them a little, many fmall bubles will alternately arife and break upon it.

7. 6. Of all Seeds which have thick or hard Covers, it is alfo obfervable, That they have the fame likewife Perforated, as above faid, or in fome other manner. And accordingly, although the Coats of fuch Seeds as are lodg'd in Shells or Stones, being thin, are not vifibly perforated; yet the Stones and shells themfelves always are; as in Chap. $\%$ thall be feen how. To which Chapter, what is farther obfervable, either as to the nature and number of the Covers of the Seed, I alfo refer.

8. 6. The Coats of the Bean being ftripp'd off, the proper seed Thews it felf. The parts whereof it is compofed, are three $; f c$. the Main Body, and two more, appendant to it ; which we may call, the Three Organical Parts of the Bean.

9. 6. The Main Body is not one entire piece, but always divided, lengthwife, into two halves or Lobes, which are both joyn'd together at the Bafis of the Bean. Thefe Lobes in dry Beans, are but difficultly $\mathbb{T}_{a b} \mathbf{x}_{1} f_{* 2,3}$, feparated or obferv'd; but in young ones, efpecially boil'd, they eafily flip afunder. 
10. 5. Some very few seeds are divided, not into two Lobes, but into more; as that of Creffes into Six. And fome are not at all divi- Tab. r. f. 4. ded, but entire; as the Grains of Corn. Excepting which few,all other $f \cdot 5$. Seeds, even the fmalleft, are divided, like as the Bean, into juft two Lobes. Whereof, though in moft Seeds, becaufe of their minutenefs, we cannot by diffection be inform'd; yet otherwife, we eafily may, as in this Chapter fhall be feen.

II. \$. At the Bafis of the Bean, the two other Organical Parts ftand appendent ; by mediation whereof, the two Lobes meet and join together. The greater of thefe two Parts ftands without the two Lobes, and upon divefting the Bean of its Coats, is immediately vifible. 'T is of a white colour, and more gloffie than the Main Body, efpeci- Tab. r. f.2. ally when the Bean is young. In the Bean, and many other Seeds, 'tis o $3^{---a}$ fituated fomewhat above the thicker end, as you hold the Bean in its moft proper pofture for growth. In Oak.Kernels, which we call $A$ corns, Apple-Kernels, Almonds, and many other Seeds, it ftands pro- Tab.1.f.6-a-c minent juft from the end; the Bafis and the End being in thefe the
fame, but in the Bean divers.

12. 5. This Part is found not only in the Bean, and the Seeds above mentioned; but in all others: being that, which upon the Vegetation of the seed, becomes the Root of the Plant; which therefore may be called the Radicle: by which, I mean the Materials, abating the Formality, of a Root. In Corn, it is that Part, which Malfters, upon its thooting forth, call the Come. 'Tis not eafie to be obferved, faving in fome few seeds, amongtt which, that of the Bean is the moft fair and ample of all I have feen. But that of fome other Seeds, is, in proportion, greater; as of Fanugreek, which is full as big as one of $\tau_{a b .1 . f .7-\ldots e}$
its Lobes.

13. 5. The leffer of the two faid Appendents lies occult beeween the two Lobes of the Bean, by feparation whereof only it is to be feen. 'T is enclos'd in two fmall Cavities, form'd in the Lobes for its reception. Tab.r. $f_{3^{-b}}$ Its colour comes near to that of the Radicle; and it is founded upon the $B$ alis thereof, having a quite contrary production, $f_{c}$. ftowards the cone of the Bean; as being that very Part, which, in procefs, becomes the Body or Trunk of the Plant. In Corn, it is that Part, which after the Radicle is fprouted forth, or come, fhoots towards the fmaller end of the Grain; and by many Malsters, is called the Acropire.

I4. \$, This Part is not, like the Radicle, an entire Body, but divided, at its loofe end, into divers pieces, all very clofely couched toPlumer, as Feathers in a Bunch; for which reafon it may be called the Plume. They are fo clofe, that only two or three of the outmoft are at firft feen: but upon a nice and curious feparation of thefe, the more interiour ftill may be difcovered. In the Bean, this may be done: but in very few other Seeds; becaufe of the extreme fmallnefs of the Plume.
Now as the Plume is that Part which fo thefe pieces are fo many true, and already formed thunk of the Plant, play'd Leaves, intended frue, and already formed, though not difplicature, wherein upon the the faid Trunk, and foulded up in the fame pear. In a French Bean, and efpecing of the Bean, they afterwards apthe great Indian Phaleolus, efpecially in the larger white Kind, or in In the great Garden-Bean two extraordinary are very fair and elegant. always, ftand onden-Bean two extraordinary fmall Plumes often, if not $\tau_{a b . i . f .8-i b}$ great one now defcrib'd: From which, 
which, in that they differ in nothing fave in their fize, I therefore only here juft take notice of them. And thefe three Parts, $\int c$. the Main Body, the Radicle, and the Plume, are concurrent to the making up of a Seed; and no more than thefe

15. 5. Having thus taken a view of the Organical Parts of the Bean, and other Seeds; let us next examine the Similary, $f_{c}$. thofe whereof the Organical are compos'd: a diftinct obfervation of which, for a clear underftanding of the Vegetation of the seed, and of the whole Plant arifing thence is requifite: To obtain which, we muft proceed in our Anatomy.

16. 5. Diffecting a Bean then, the firft Part occurring is its $C_{\text {Cuticle. }}$ The Eye and firft Thoughts, fuggeft it to be only a more denfe and gloffy Superficies; but better enquiry difcovers it a real Cuticle. 'Tis fo exquifitely thin, and for the moft part, fo firmly continuous with the Body of the Bean, that it cannot, except in fome fmall Rag, be diftinctly feen, which, by carrying your Knife aflant into the Bean, and then very gently bearing upward what you have cut, will feparate, and fhew it felf tranfparent. This Cuticle is not only fpread upon the Convex of the Lobes, but alfo on their Flats, where they are contiguous, extending it felf likewife upon both the Radicle and Plume, and fo over the whole Bean.

17. 5. This Part, though it be fo far common with the Coats of the Bean, as to be like thofe, an Integument; yet are we in a quite different Notion to conceive of it : For whereas the Coats, upon fetting the Bean, do only adminifter the Sap, and, as being fuperfeded from their Office, then die; as fhall be feen : this, on the contrary, with the Organical Parts of the Bean, is nourifhed, augmented, and by a real Vegetation co-extended.

18. \$. Next to the Cuticle, we come to the Parenchyma it felf; the Part throughout which the Inner Body, whereof we thall fpeak anon, is diffeminated; for which reafon I call it the Parenchyma. Not that we are fo meanly to conceive of it, as if (according to the ftricter fenfe of that word, ) it were a meer concreted Juyce. For it is a Body very curioully organiz'd, confifting of an infinite number of extreme fmall Bladders; as in Tab. I. is apparent. The surface hereof is fome-

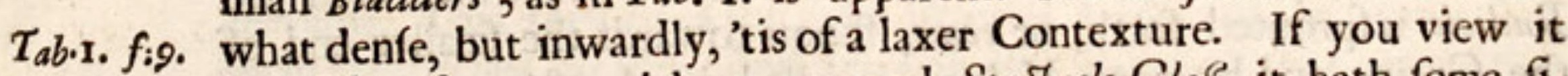
in a Microfcope, or with a very good Spectacle-Glaj, it hath fome fimilitude to the Pith, while fappy in the Roots and Trunks of Plants; and that for good reafon, as in $C h .2$. fhall be feen. This is beft feen in green Beans.

19. 6. This Part would feem by its colour to be peculiar to the Lobes of the Bean; but as is the Cuticle, fo is this alfo, common both to the Radicle and Plume; that is, the Parenchyma or Pulp of the Bean, as to its effential fubftance, is the fame in all three. The reafon why the colour of the Plume, and efpecially of the Radicle, which are white, is fo different from that of the Lobes, which are green, may chiefly depend upon their being more compact and denfe, and thence their different Tinctures. And therefore the Lobes themfelves, which are green while the Bean is young; yet when it is old and dry, become whitifh too. And in many other Seeds, as Acorns, Almonds, the Kernels of Apples, Plums, Nuts, \&cc. the Lobes, even frefis and young, are pure white as the Radicle it felf. 
20. 5. But although the Parenchyma be common, as is faid, to all the Organical Parts; yet in very differing proportions. In the Plume, where it is proportionably leaft, it maketh about three Fifths of the whole Plume; in the Radicle, it maketh above five Sevenths of the whole Radicle ; and in each Lobe, is fo far over-proportionate, as to make at leaft nine Tenths of the whole Lobe.

2I. \$. By what hath been faid, that the Parenchyma or Pulp is not the only conftituting Part, befides the Cuticle, is imply'd : there being another Body, of an effentially different fubftance, embofom'd herein: which may be found not only in the Radicle and Plume, but alfo in the Lobes themfelves, and fo in the whole Bean.

22. \$. This Inner Body appears very plain and confpicuous in cutting the Radicle athwart, and fo proceeding by degrees towards Tab.i.f. 10; the Plume, through both which it runneth in a large and ftrait Trunk, $11,812$.

In the Lobes, being it is there in fo very fmall proportion, 'tis difficultly feen, efpecially towards their Verges. Yet if with a harp Knife you fmoothly cut the Lobes of the Bean athwart, divers fmall Specks, of a different colour from that of the Parenchyma, ftanding thereinall Tab.1. f.13. along in a Line, may beobferv'd; which Specks are the Terminations of the Branches of this Inner Body.

23. \$. For this Inner body, as it is exiftent in every Organical Part of the Bean; fo is it, with refpect to each Part, molt regularly diftributed. In a good part of the Radicle 'tis one entire Trunk; towards the Bafis thereof, 'tis divided into three main Branches; the mid- Tab.r. f. 14: dlemoft runneth directly into the Plume; the other two on either fide it, after a little fpace, pafs into the Lobes; where the faid Branches dividing themfelves into other fmaller; and thofe into more, and fmaller again, are terminated towards the Verges of each Lobe; in which manner the faid Inner Body being diftributed it becomes in each Lobe a true and perfect Root.

24. \$. Of this Seminal Root, as now we'll call it, from the Defcription here given, it is further obfervable; That the two main Branches hereof; in which the feveral Ramifications in each Lobe are all united, are not committed into the Seminal Trunk of the Plume, nor yet ftand at right angles with That, and the Radicle, and fo with equal refpect towards them both : but being produced through part of the $\mathrm{Pa}_{\text {- }}$ renchyma of the Radicle, are at laft united therein to the main Trunk, and make acute Angles therewith: as may be feen in the fame. f.I4. Tab.r. f. I4.

25. 6. This seminal Root being fo tender, cannot be perfectly excarnated, (as may the Veffels in the Parts of an Animal) by the mott accurate Hand. Yet by diffection begun and continu'd, as is above declared, its whole frame and diftribution may be eafily obferv'd. Again, if you take the Lobe of a Bean, and lengthwife pare off its Parenchyma by degrees, and in extreme thin flices, many Branches of the Seminal Root, (which by theother way of Diffection were only noted by fo many (specks) both as they are fewer about the Bafis of the Bean, and more numerous towards its Verges, in fome good diftinction and entirenefs will appear. Forthis you muft have new Beans : or elfe foaked in Water, or buryed for fome tiuc.

26. 6. As the Inner Body is branched out in the Lobes, fo is it in the Plume: For if you cut the Plume athwart, and from the Bafis proceed along the Body thereof, you'll therein find, firf, one large Irunk. 
or Branch, and after four or five very fmall Specks round about it, which are the terminations of fo many leffer Branches therewith diftributed to the feveral parts of the Plume. The diftribution of the

Tab.I.f. I I-c Inner Body, as it is continuous throughout all the Organical Parts of the Bean, is reprefented,Tab.I.f.I 4 .

27. 6. This Inner Body is, by diffection, beft obfervable in the Bean and great Lupine. In other larger Pulfe it thews likewife fome obfcure Marks of it felf. But in no other seeds, which I have obferved, though of the greateft fize: as of Apples, Plums, Nuts, \&c. is there any clear appearance hereof, upon diffection, faving in the Radicle and Plume; the reafon of which is partly from its being, in molt Seeds, fo extraordinary little; partly from its Colour, which in moft Seeds, is the fame with that of the Parenchyma it felf, and fo not diftinguifhable from it. 28. 5. Yet in a Gourd-seed, the whole Seminal Root, not only its
Tab.I5 Main Branches, but alfo the Sub-divifions and Inofculations of the leffer ones, are without any diffection, upon the feparation of the Lobes, on their contiguous Flats immediately apparent.

And as to the exiftence of this Seminal Root, what Diffection cannot attain, yet an ocular infpection in hundreds of other seeds, even the fmalleft, will demonftrate; as in this Chapter fhall be feen how.

29. 5 . In the mean time, let us only take notice; That when we fay, every Plant hath its Root, we reckon fhort. For every Plant hath really two, though not contemporary, yet fucceffive Roots; its Original or Seminal-Root within the Lobes or Main Body of its Seed; and its Plant-Root, which the Radicle becometh in its growth : the Parenchyma of the Seed, being in fome refemblance, that to the Seminal Root at firft, which the Mould is to the Plant-Root afterwards; and the Seminal Root being that to the Plant-Root, which the Plant-Root is to the Trunk. For our better underftanding whereof, having taken a view of the feveral Parts of a Bean, as far as Diffection conducts we will next briefly enquire into the Ufe of the faid Parts, and in what manner they are the Fountain of $V$ egetation, and concurrent to the being of the future Plant.

An Account 30. 5. THE GENERAL Caufe of the growth of a sean, or other of the Vege-Seed, is Fermentation. That is, the Bean lying in the Mould, and a tation of the moderate accefs of fome moifture, partly diffimilar, and partly congenerous, being made, a gentle Fermentation thence arifeth. By which, the Bean fwelling, and the $S_{a p}$ ftill encreafing, and the Bean continuing ftill to fwell, the work thus proceeds : as is the ufual way of explicating. But that there is fimply a Fermentation, and fo a fufficient fupply of sap is not enough: but that this Fermentation, and the sap wherein 'tis made, thould be under a various Government, by divers Parts thereto fubfervient, is allo requifite; and as the various preparation of the Aliment in an Animal, equally neceffary: the particular procefs of the Work according whereto, we find none undertaking to
declare.

31. §. Let us look upon a Bean then, as a piece of Work fo fram'd and fet together, as to declare a Defign for the production of a Plant; which, upon its lying in fome convenient Soil, is thus effected. Firlt of all, the Bean being enfoulded round in its $\mathcal{C}_{\text {oats }}$, the Sap wherewith it is fed, muft of neceflity pafs through thefe: By which means, it is 
not only in a proportionate quantity, and by degrees; but alfo in a purer body; and poffibly not without fome Vegetable Tincture, tranfmitted to the Bean. Whereas, were the Bean naked, the sap muft needs be, as over-copious, fo but crude and immature, as not being filtred through fo fine a Cotton as the Coats be. And as they have the ufe of a Filtre to the tranfient $S a p$; fo of a $V e f f e l$ to that which is ftill depofited within them; being alike accommodated to the fecurer $F$ ermentation hereof, as Bottles or Barrels are to Beer, or any other Fermentative Liquor.

32. 5. And as the Fermentation is promoted by fome Aperture in the Veffel; fo have we the Foramen in the upper Coat alfo contrived. That if there fhould be need of fome more Aiery Particles to excite the Fermentation; through this, they may obtain their Entry. Or, on the contrary, fhould there be any fuch Particles or Steams, as might damp the genuine proceeding thereof, through this again, they may have eafie iffue. Or if, by being over copious, they fhould become too high a Ferment; andfo precipitate thofe foft and flow degrees, as are neceffary to a due $V$ egetation. The faid Aperture being that, as a common Pafport, here to the Sap, which what we call the Bung-bole of the Barrel, is to the new tunn'd Liquor.

33. 5. And the Radicle being defigned to fhoot forth firft, as prefently fhall be fhew'd how; therefore is it diftinctly furrounded with the Inner and more fucculent Coat. That being thereby fuppled on every fide, its eruption may be the better promoted.

34. 5. The Sap being paffed through the Coats, it next enters the Body of the Bean; yet not indifcriminately neither; but, being filtred through the Outer Coat, and fermented in the Body of the Inner, is by mediation of the Cuticle, again more finely filtr'd, and fo entereth the Parenchyma it felf under a fourth Government.

35. \$. Through which Part the Sap paffing towards the Seminal Root, as through that which is of a more fpatious content; befides the benefit it hath of a farther percolation, it will alfo find room enough for a more free and active fermenting and maturation herein. And being moreover, part of the true Body of the Bean, and fo with its proper Seminalities or Tinctures copioufly repleat; the $S_{a p}$ will not only find room, but alfo matter enough, by whofe Energy its Fermentation will ftill be more advanced,

36. § And the Sap being duly prepared here, it next paffeth into all the Brancbes of the Seminal Root, and fo under a fifth Government. Wherein how delicate 'tis now become, we may conceive by the proportion betwixt the Parenchyma and this Seminal Root; fo much only of the beft digefted sap being difchargedfrom the whole Stock in that, as this will receive. And this, moreover, as the Parenchyma, with its proper Seminalities being endowed; the Sap for the fupply of the $R_{a}$ dicle, and of the young Root from thence, is duly prepared therein, and with its higheft Tincture and Impregnation at laft enriched.

37. \$. The sap being thus prepared in the Lobes of the Bean, 'tis thence difcharg'd; and either into the Plume, or the Radicle, muft forthwith iffue. And fince the Plume is a dependent on the Radicle; the $\boldsymbol{s} a p$ therefore ought firft to be difpenced to this: which accordingly, is ever found to thoot forth before the Plume: and fometimes an inch or two in length. Now becaufe the primitive courfe of the sap into 
the Radicle, is thus requifite; therefore, by the frame of the Parts of the Bean is it alfo made neceffary. The two main Branches of the $S e-$ minal Root, being produced, as is before obferved, not into the Plume, but the Radicle. Now the Sap being brought as far as the Seminal Root, in either Lobe; and according to the conduct thereof continuing ftill to move: it muft needs immediately iffue into the fame Part,

Tab.1. f. 14. whereinto the main Branches themfelves do; that is, into the Radicle. By which Sap, thus bringing the feveral Tinitures of the Parts aforefaid with it, being now fed; it is no longer a meer Radicle, but is made alfo seminal, and fo becomes a perfect $R$ oot.

38. 6. The Plume, all this while, lyes clofe and ftill. For the fake of which, chiefly it is, that the Bean and other seeds are divided into Lobes, viz. That it might be warmly and fafely lodged up between them, and fo fecur'd from the Injuries fo tender a Part would fuftain from the Mould; whereto, had the Main Body been entire, it muft, upon the cleaving of the Coats, have lay'n contiguous.

39. 6. But the Radicle being thus impregnated and fhot into a Root; 'tis now time for the Plume to rouze out of its Cloyfters, and germinate too: In order whereto, 'tis now fed from the Root, with laudable and fufficient Aliment. For as the Supplies and Motion of Sap were firft made from the Lobes, towards the Root : fo the Root being well fhot into the Mould, and now receiving a new and more copious $S_{a p}$ from thence; the motion hereof muft needs be ftronger, and by degrees proceed in a contrary courfe, $f c$. from the Root toward the Plume: and, by the coutinuation of the Seminal Root, is directly conducted thereinto; by which being fed, it gradually enlarges and difplays it felf.

40. 9. The courfe of the Sap thus turned, it iffues, I fay, in a direct Line from the Root into the Plume : but collaterally, into the Lobes alfo; $f c$. by thofe two aforefaid Branches which are obliquely tranfmitted from the Radicle into either Lobe. By which Branches the faid Sap being disburfed back into all the seminal Root, and from thence, likewife into the Parenchyma of the Lobes, they are both thus fed, and for fome time augmenting themfelves, really grow : as in $\mathbf{L u -}$ pines is evident.

41: §. Yet is not this common to all seeds. Some rot underground; as Corn; being of a laxer and lefs Oleous Subftance, differing herein from moft other Seeds; and being not divided into Lobes, but one entire thick Body. And fome, although they continue firm, and are divided into Lobes, yet rife not; as the great Garden Bean. In which, therefore, it is obfervable, That the two Main Branches of the Lobes, in comparifon with that which runs into the Plume, are but $T_{a b . x}, f_{0} 14$. mean; and fo infufficient to the feeding and vegetation of the Lobes; the Plume, on the contrary, growing fo lufty, as to mount up without shem.

42. 6. Excepting a few of thefe TwoKinds, all other Seeds whatfoever, (which I have obferved) befides that they continue firm; upon the Vegetation of the Plume, do mount alfo upwards, and advance above the Ground together with it; as all seeds which fpring up with one or more Dilfimilar Leaves: Thefe Diffimilar Leaves, for the molt part Troo, which firft fpring up, and are of a different fhape from thofe that follow, being the very Lobes of the Seed,divided, expanded, and thus advanced. 
43. 6. The Impediments of our apprehenfion hereof are the Colour, Size and Shape of the Diffimilar Leaves. Notwithftanding, that they are nothing elfe but the Main Body of the Seed, how I came firft to conceive, and afterwards to know it, was thus. Firft, I obferved in general, that the Difjimilar Leaves, were never jagg'd, but even edg'd: And feeing the even verges of the Lobes of the seed hereto refpondent, I was apt to think, that thofe which were fo like, might prove the fame. Next defcending to particular Seeds, I obferved,firf, of the Lupine; that, as to its Colour, advancing above the Ground, (as it ufeth todo) it wasalways changed into a perfect Green. And why might not the fame by parity of Reafon be inferred of other seeds? That, as to its fize, it grew but little bigger than when firft fet.Whence, as I difcern'd (the Augmentation being but little) we here had only Tab. 2. f. i. the two Lobes: So, (as fome augmentation there was) I inferr'd the like might be, and that, in fartherdegrees, in other Seeds.

44. 5. Next of the Cucumber-Seed, That, as to its Colour, often appearing above ground, in its primitive white, from white it turns to yellow, and from yellow to green; the proper colour of a Leaf. That, as to its fize, though at its firft arife, the Lobes were little bigger than upon fetting; yet afterwards, as they chang'd their Colour, fo their di- Tab. 2, f.2. menfions alfo, growing to a three-four-five-fold amplitude above their primitive fize. But whereas the Lobes of the Seed, are in proportion, narrow, fhort and thick : how then come the Diffimilar Leaves, to be fo exceeding broad, or long, and thin? The Queftion anfwers it felf: For the Diffimilar Leaves, for that very reafon are fo thin, becaufe fo very broad or long; as we fee many things, how much they are extended in length or breadth, fo much they lofe in depth, or grow more thin; which is that which herebefalls the now effoliated Lobes. For being once dif-imprifoned from their coats, and the courfe of the $S_{a p}$ into them, now more and more encreafed; they muft needs very confiderably amplifie themfelves: and from the manner wherein the Seminal Root is branched in them, that amplification cannot be in thicknefs, but in length or breadth. In both which, in fome Diffimilar Leaves, 'tis very remarkable; efpecially in length, as in thofe of Lettice, Thorn-Apple, and others; whofe Seeds, although very fmall, yet the Lobes of thofe seeds growing up into Diffimilar Leaves, are extended an Inch, and fometimes more, in length. Though he that fhall attempt to get a clear fight of the Lobes of Thorn-Apple, and fome others, by Diffection, will find it no eafie Task; yet is that which may be obtained; and in the Laft Book fhall be fhew'd. From all which, and the obfervation of other seeds, I at laft found, that the Diffimilar Leaves of a young Plant, are nothing elfe but the Lobes or Main Body of its Seed. So that, as the Lobes did at firft feed and impregnate the Radicle into a perfect Root; fo the Root, being perfected, doth again feed, and by degrees amplifie each Lobe into a perfect Leaf.

45. 6. The Original of the Di/Jimilar Leaves thus known, we underftand, why fome Plants have none; becaufe the Seed either rifeth not, as Garden-Beans, Corn, \&c. Or upon rifing, the Lobes are little alter'd, as Lupines, Peafe, \&c. Why, though the proper Leaves are often indented round; the Diffinilar like the Lobes are even-edg'd. Why, though the proper Leaves are often hairy, yet thefe are ever fmooth. Why fome have more Diffimilar Leaves than two, as Creffes,

$$
\text { H which }
$$


Hift. of the which have fix, as the Ingenious Mr. Sharrock alfo obferves. The reafon Prop.of Vege. whereof is, becaufe the Main Body is not divided into Two, but Six, diftinct Lobes, as I have often counted. Why Radifhes feem at firft to have four, which yet after appear plainly two: becaufe the Lobes of the Seed, have both a little Indenture, and are both plaited, one over the other. To which, other Inftances might be added.

46. The ufe of the Diffimilar Leaves is, firt, for the protection of the Plume; which being but young, and fo but foft and tender, is provided with thefe, as a double Guard, one on either fide of it. For this reafon it is, that the Plume, in Corn, is truffed up within a mem-

Tab. 3. branous Sheath: and that of a Bean, cooped up betwixt a pair of Surfoyls: But where the Lobes rife, there the Plume hath neither of them, being both needlefs.

47. \$. Again, fince the Plume, being yet tender, may be injurd not only by the Aer, but alfo for want of Sap, the fupplies from the Root being yet but flow and fparing; that the faid Plume therefore, by the Diffimilar Leaves, may have the advantage likewife of fome refrefhment from Dew or Rain. For thefe having their Bafss a little beneath that of the Plume, and expanding themfelves on all fides of it, they often ftand after Rain, like a Veffel of Water, continually foaking and fuppling it, left its new accefs into the $A y r$, fhould fhrivel it.

48. \$. Moreover, that fince the Diffimilar Leaves by their, Bafis intercept the Root and Plume, the greater and groffer part of the sap, may be, by the way, depofited into thofe; and fo the pureft proceed into the yet but young and delicate Plume, as its fitteft Aliment.

49. 6. Laftly, we have here a demonftration of the being of the Seminal Root: which, fince through the colour or fmalnefs of the Seed, it could not by Diffection be obferv'd, except in fome few ; Nature hath here provided us a way of viewing it in the now effoliated Lobes, not of one or two Seeds, but of hundreds; the Seminal Root vifibly branching it felf towards the Cone or Verges of the faid Lobes, or now Diffimilar Leaves. 


\section{CH A P. II. \\ Of the $R O O T$.}

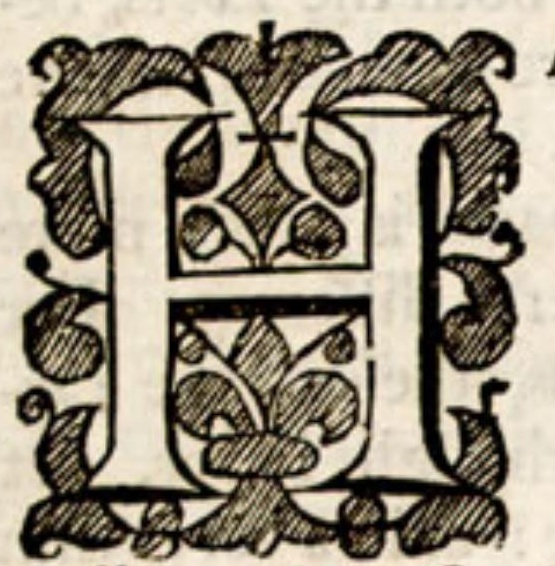

A V I N G Examin'd and purfu'd the Degrees of $V$ egetation in the Seed, we find its two Lobes have here their utmoft period: and, that having conveyed their Seminalities into the Radicle and Plume; there therefore, as the Root and Trunk of the Plant, ftill furvive. Of thefe, in their order, we next proceed to fpeak; and firft, of the Root: whereof, as well as of the Seed, we muft by Diffection inform our felves.

2. \$. In Diffection of a Root then, we fhall find it with the $R a$ dicle, as the Parts of an Old Man with thofe of a Fatus, fubitantially, one. The firft Part occurring is its Skin, the Original whereof is from the Seed: For that extreme thin Cuticle which is fpread over the Lobes of the Seed, and from thence over the Radicle, upon the fhooting of the Radicle into a Root, is co-extended, and becomes its skin.

3. 5. The next Part is the Cortical Body. Which, when it is thin, is commonly called the Barque. The Original hereof, likewife is from the Seed; or the Parenchyma, which is there common both to the Lobes and Radicle, being by Vegetation augmented and prolonged
into the Root, the fame becomes the Parenchyma of the Barque.

4. 5. The Contexture of this Parenchyma may be well illuftrated by that of a sponge, being a Body Porous, Dilative and Pliable. Its Pores, as they are innumerable, fo, extream fmall. Thefe Pores are not only fufceptive of fo much Moifture as to fill, but alfo to enlarge themfelves, and fo to dilate the Cortical Body wherein they are : which by the fhriv'ling in thereof, upon its being expos'd to the Air, is alfo feen. In which dilatation, many of its Parts becoming more lax and diftant, and none of them fuffering a folution of their continuity; 'tis a Body alfo fufficiently pliable; that is to fay, a most exquifitely fine-

5. \$. The Extention of thefe Pores is much alike by the length and breadth of the Root; which from the fhrinking up of the Cortical Body, in a piece of a cut Root, by the fame dimenfions, is argu'd.

6. 6. The proportions of this Cortical Body are various : If thin, than as is faid, called a Barque; and thought to ferve to no other end, If a Bulky Body, in componceit. Roots of Cicbory, Aparagus \& with That within it, as in the young fore taken for the prime Part \&c. 'tis here, becaufe the faireft, thereit is; yet, as to the private ufe of the though, as to Medicinal ufe, hereof, though it be private ufe of the Plant, not fo. The Colonr the Root, divers Tincturinally white, yet in the continued growth of into introduced. 
7. 5. Next within this Part ftands the Lignous Body: This LigTab.2.f 4.b. nows Body, lyeth with all its parts, fo far as they are vifible, in a Circle or Ring. Yet are there divers extreme fmall Fibres thereto parallel, ufually mixed with the Cortical Body; and by the fomewhat different colour of the faid cortical Body where they ftand, may be noted. Thefe Fibres the Cortical Body, and Skin, altogether, properly make the Barque. The Original of this Lignows Body, as of the two former, is from the seed; or, the Seminal Roots of both the Lobes, being united in the Radicle, and with its Parenchyma co-extended, is here in the Root of the Plant, the Lignous Body.

8. §. The Contexture hereof, in many of its parts, is much more clofe than that of the Cortical; and their Pores very different. For whereas thofe of the Cortical are infinitely numerous, thefe of the Lignows are in comparifon nothing fo. But thefe, although fewer, yet are they, many of them, more open, fair and vifible: as in a very thin Slice cut athwart the young Root of a Tree, and beld up againft the light, is apparent. Yet not in all equally; in Coran-Tree, Goosberry-

Tab.2.f.5. Tree, Ecc. lefs, in Oak, Plums, and efpecially Damajcens, more; in Elder, Vines, $\boldsymbol{\sigma}_{c}$. moft confpicuous. And as they are different in number and fize, fo alfo (whereon the numeroufnefs of the Pores of the Cortical Body principally depends) in their fhape. For whereas thofe of the Cortical Body are extended much alike both by the length and breadth of the Root; thefe of the Lignous, are only by the length; which efpecially in Vines, and fome other Roots is evident. Of thefe Pores, 'tis alfo obfervable, that although in all places of the Root they

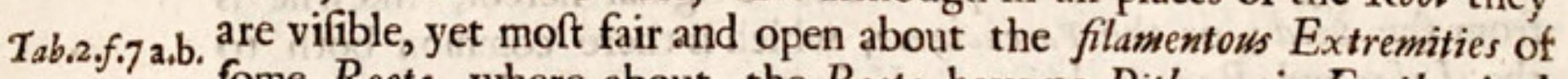
fome Roots, where about, the Roots have no Pith; as in Fenil. And in many Roots, higher.

9. 5. The proportion betwixt this Lignous Body and the Cortical, is various, as was faid; yet in this, conftant, $f c$. that in the filamentous and fmaller Parts of the Root, the Lignows Body is very much the lefs; running like a lender $W$ yer or Nerve through the other furrounding it. Whereas in the upper part, it is often times of far greater quantity than the Cortical, although it be encompafs'd by it. They ftand both together pyramidally, which is moft common to Infant Roots, but alfo to a great many others.

10. The next Part obfervable in the Root, is the Infertment. The exiftence hereof, fo far as we can yet obferve, is fometimes in the Radicle of the Seed it felf; I cannot fay always. As to its fubftantial natnre, we are more certain; that it is the fame with that of the Parenchyma of the Radicle; being always at leaft augmented, and fo, in part, originated from the Cortical Body, and fo, at fecond hand, from the faid Parenchyma. For in diffecting a Root, I find, that the Cortical Body doth not only environ the Lignous, but is alfo wedg'd, and in many Pieces inferted into it; and that the faid inferted Pieces make not a

$\tau_{a b}$. 2. f. 5. meer Indenture, but tranfmit and fhoot themfelves quite through as far as the Pith: which in a thin Slice cut athwart the Root, as fo many lines drawn from the Circumference towards the Center, fhew themfelves.

II. 6. The Pores of the Infertment are fometimes, at leaft, extended fomewhat more by the breadth of the Root, as about the top of the Root of Borage may be feen; and are thus different from thofe of 
the Cortical Body, which are extended by the length and breadth much alike; and from thofe of the Lignous, being only by its length.

12. 6. The number and fize of thefe Infertions are various. In Hawthorn, and fome others, and efpecially Willows, they are moft extream fmall; in Cberries and Plums they are Biger; and in the Vine and fome other Trees, very fairly apparent. In the Roots of moft Herbs they are generally more eafily difcoverable; which may lead to the obfervation of them in all.

13. 6. Thefe Infertions, although they are continuous through both the length and breadth of the Root; yet not fo in all Parts, but by the feveral hootings of the Lignous Body they are frequently intercepted. For of the Lignows Body it is (here beft) obfervable; That its feveral Shootings, betwixt which the Cortical is inferted, are not, throughout the Root, wholly diftinct, ftrait and parallel: but that all along being enarch'd, the Lignous Body, both in length and breadth, is thus difpored into Braces or Ofculations. Betwixt thefe feveral Shootings of the Lignous Body thus ofculated, the Cortical thooting, and being alfo ofculated anfwerably Brace for Brace, that which I call the Injertment is framed thereof.

14. \&. Thefe $O$ fculations are fo made, that the Pores or Fibres of the Lignous Body, I think, notwithftanding, feldom or never run one into another; being, though contiguous, yet ftill diftinct. In the fame manner as fome of the Nerves, though they meet, and for fome fpace are affociated together, yet 'tis moft probable, that none of their Fibres are truly inofculated, faving perhaps, in the Plexures.

15. \$. Thefe Ofculations of the Lignous Body, and fo the interception of the Infertions of the Cortical, are not to be obferv'd by the traverfe cut of the Root, but by taking off the Barque. In the Roots of Trees, they are generally obfcure; but in Herbs often more diftincty apparent; and efpecially in a Turnep: the appearance whereof, the Barque being ftripp'd off, is as a piece of clofe-wrought Network, fill'd up with the Infertions from thence.

16. \$. The next and laft diftinct Part of the Root is the Pith. The fubitantial nature thereof, is, as was faid of the Infertment, the fame likewife with that of the Parenchyma of the seed. And according to the beft obfervation I have yet made, 'tis fometimes exiftent in its $R_{a}$ dicle; in which, the two main Branches of the Lobes both meeting, and being ofculated together, are thus difpos'd into one round and tubular Trunk, and fo environing part of the Parenchyma, make thereof P Pith; asin either the Radicle, or the young Root of the great Bean or Lupine, may, I think, be well feen.

17. \%. But many times the Original hereof is immediately from the Barque. For in diffection of divers Roots, both of 7 rees and Herbs, as of Barberry or Mallows, it is obfervable, That the Cortical Body and Pith, are both of them participant of the fame Colour; in the Barberry, both of them tinged yellow, and in Mallows, green. In cutting the fmaller Parts of the Roots of many Plants, as of Borage, Mallows, ParJey, Columbine, \&c. 'tis alfo evident, That the Lignous Body is not there, in the leaft Concave, but ftandeth Solid, or without any Pith, Tab.2.f.9. -a
in the Center; and that the Infertions being gradually multiplied afterwards, the Pith, at length, towards the thicker parts of the Root, fhews and enlarges it felf. Whence it appears, that in all fuch Roots, 
the Pith is not only of the fame fubftantial nature, and by the Infertions doth communicate with the Barque; and that it is alfo augmented by it; which is true of the Pitb of all Roots; but is moreover, by mediation of the faid Infertions, wholly originated from it; that is to fay, from the Parenchymous Part thereof. The various appearances of the Infertions and Pith from the filamentous Parts to the

Tab. 2. f. 9. top of the Root, fee in Tab. 2. The Pores of the Lignous Body, as it ftands entire in the faid filamentous Parts, are beft feen when they have lain by a night to dry, after cutting.

18. 6. A farther evidence hereof are the Proportions betwixt the Cortical Body and Pith. For as about the inferiour Parts of the Root, where the $P$ ith is fmall, the Cortical Body is proportionably great; fo about the top, where the Pith is enlarged, the Cortical Body (now more properly becoming a Barque) groweth proportionably lefs, $f c$. becaufe the Infertions do ftill more and more enlarge the Pith. Likewife the peculiar frame of fome Roots, wherein befides the Pith, the Lignous Body being divided into two or more Rings, there are alfo one or more thick Rings, of a white and foft fubftance, which ftand betwixt them; and are nothing elfe but the Infertions of the Cortical Body collected into the faid Rings; but, towards the top of the Root, being inferted Tab.2.f.8. again, thus make a large and ample Pith; as in old, Turnep, and fome other Herbs, is feen.

19. \$. The Pores of the Pith, as thofe of the Cortical Body, are extended both by the breadth and length of the Root, much alike; yet are they more or lefs of a greater fize than thofe of the Cortical Body.

20. \$. The Proportions of the Pith, are various; in Trees, but fmall ; in Herbs, generally, very fair; in fome making by far the greateft part of the Root; as in a Turnep: By reafon of the wide circumference whereof, and fo the finer Concoction and Affimilation of its Sap; that Part which in moft old Trunks is a dry and harlh Pith, here proves a tender, pleafant meat.

2I. б. In the Roots of very many Plants, as Turneps, Carrots, \&uc, the Lignous Body, befides its main utmolt Ring, hath divers of its ofculated Fibres difperfed throughout the Body of the Pith; fometimes all alike, and fometimes more efpecially in, or near, its Center; which Fibres, as they run towards the top of the Root, ftill declining the Center, at laft collaterally ftrike into its Circumference; either all of them, or fome few, keeping the Center ftill. Of thefe principally, the Succulent part of the Lignous Body of the Trunk is often originated.

22. \$. Some of thefe Pith-Fibres, although they are fo exceeding flender, yet in fome Roots, as in that of Flower de liz, they are vifibly concave, each of them, in their feveral Cavities alfo embofoming a very fmall Pith; the fight whereof, the Root being cut traverfe, and laid in a Window for a day or two todry, may without Glafjes be obtain'd. And this is the general account of the Root; thedeclaration of the manner of its growth, with the ufe and fervice of its feveral Parts, we fhall next endeavour.

An Account 23. 5. I SAY THEN, That the Radicle being irspregnate, and of the fhot into the Moulds, the contiguous moifture, by the Cortical Body, be-

Growth of ing a Body laxe and Spongy, is eafily admitted : Yet not all indiferimithic Root. nately, but that which is more adapted to pafs through the furrounding 
Cuticle. Which tranfient sap, though it thus becomes fine, yet is not fimple; but a mixture of Particles, both in refpect of thofe originally in the Root, and amongft themfelves, fomewhat heterogeneous. And being lodg'd in the Cortical Body moderately laxe, and of a Circular form; the effect will be an eafie Fermentation. The sap fermen. ting, a feparation of Parts will follow ; fome whereof will be impacted to the Circumference of the Cortical Body, whence the Cuticle becomes a Skin; as we fee in the growing of the Coats of Cheefes, of the Skin over divers Liquors, and the like. Whereupon the $S_{a p}$ paffing into the Cortical Body, through this, as through a Manica Hippocratis, is ftill more finely filtred. With which sap, the Cortical Body being dilated as far as its Tone, without a folution of Continuity, will bear; and the fupply of the Sap ftill renew'd : the pureft part, as moft apt and ready, recedes, with its due Tinctures, from the faid Cortical Body, to all the parts of the Lignous; both thofe mixed with the Barque, and thofe lying within it. Which Lignous Body likewife fuper-inducing its own proper Tinctures into the faid $s a p$; tis now to its higheft preparaton wrought up, and becomes (as they fpeak of that of an Animal) the Vegetative Ros or Cambium : the nobleft part whereof is at laft coagulated in, and affimilated to the like fubftance with the faid Lignous Body. The remainder, though not united to it, yet tinctur'd therein, thus retreats, that is, by the continual appulfe of the sap, is in part carried off into the Cortical Body back again, the sap whereof it now tinctures into good Aliment. So that whereas before, the Cortical Body was only relaxed in its Parts, and fo dilated; 'tis now increas'd in real quantity or number of parts, and fo is traly nourifh'd. And the Cortical Body being faturate with fo much of this Vital sap as ferves it felf; and the fecond Remainders difcharged thence to the $S$ kin; this alfo is nourifh'd and augmented therewith. So that as in an Animal Body there is no inftauration or growth of Parts made by the Bloud only, but the Nervous Spirit is alfo thereunto affiftant; fo is it here: the sap prepared in the Cortical Body, is as the Bloud, and that part thereof prepared by the Lignous, is as the Nervous Spirit; which partly becoming Nutriment to it felf, and partly being difcharged back into the Cortical Body, and diffufing its Tincture through the Sapthere, that to the faid Cortical Body and skin, becomes alfo true Nutriment, and fo they all now grow.

24. ๖. In which growth, a proportion in length and breadth is requifite: which being rated by the benefit of the Plant, both for firm ftanding and fufficient Sap, muft therefore principally be in length. And becaufe it is thus requifite, therefore by the conftitution of one of its Parts, $\int_{c}$. the Lignous Body, it is alfo made neceffary. For the Pores hereof, in that they are all extended by its length, the $S a p$ alfo according to the frame and fite of the faid Pores will principally move; and that way asits sap moves, the fame way will the generation of its Parts alfo proceed; $f c$. by its length. And the Lignous Body firf (that is by a priority caufal) moving in length it felf; the Cortical alfo moves therewith. For that which is nourifh'd, is extended: but whatever is extended, is mov'd : that therefore which is nourifh'd, is mov'd: The Lignous Body then being firft nourifh'd, 'tis likewife firft mov'd, and fo becomes and carries in it the Principle of all Vegetative motion in the Cortical; and fo they both move in length. 
25. 6. Yet as the Lignous Body is the Principle of Motion in the Cortical; fo the Cortical is the Moderator of that in the Lignous: As in Animal Motions, the Principle is from the Nerves; yet being once given to the Mufcle or $L i m b$, and that moving proportionably to its ftructure, the Nerves alfo are carried in the fame motion with it. We fuppofe therefore, that as the principal motion of the Lignous Body is in length, fo is its proper tendency alfo to Afcend. But being much exceeded both in Compals and Quantity by the Cortical, as in the fmaller parts of the Root it is; it muft needs therefore be over-born and governed by it; and fo, though not lofe its motion, yet make it that way wherein the Cortical Body may be more obedient to it ; which will be by defcent. Yet both of them being fufficiently pliable, they are thus capable, where the Soyl may oppofe a direct defcent, there to divert any way, where it is more penetrable, and fo to defcend obliquely. For the fame reafon it may alfo be, that though you fet a Bean with the Radicle upward; yet the Radicle, as it thoots, declining alfo gradually, is thus arch'd in form of an Hook, and fo at laft defcends. For every declination from a perpendicular Line, is a mixed motion betwixt Afcent and Defcent, as that of the Radicle alfo is, and fo feeming to be dependent upon the two Contrary Tendencies of the Lignous and Cortical Bodies. What may be the caufe of thofe Tendencies (being moft probably external, and a kind of Magnetifme) I fhall not make my Task here to enquire.

26. \$. Now although the Lignous Body, by the pofition and fhape of its Pores, principally groweth in length; yet will it in fome degree likewife in breadth: For it cannot be fuppofed that the pureft Sap is all received into the faid Pores; but that part thereof likewife, ftaying about its Superficial Parts, is there tinctur'd and agglutinated to them. And becaufe thefe Pores are prolonged by its length; therefore it is much more laxe and eafily divifible that way; as in flitting a Stick, or cleaving of Timber, and in cutting and hewing them athwart is alfo feen. Whence it comes to pafs, that in thooting from the Center towards the Circumference, and there finding more room, its faid original Laxity doth eafily in divers places now become greater, and at length in open Partments plainly vifible. Betwixt which Partments, the Cortical Body, being bound in on the one hand, by the furrounding Skin and Moulds, and preffed upon by the Lignous on the other, muft needs infert it felf, and fo move contrary to it, from the Circumference towards the Center. Where the faid contrary motions continued as begun, they at laft meet, unite, and either make or augment the Pith. And thus the Root is fram'd, and the Skin, the Cortical and Lignons Bodies, fo as is faid, thereuntoconcurrent. We fhall next fhew the ufe of the twoother Parts, $f c$. the Infertment and Pith; and firft of the Pith.

27. \$. ONE true ufe of the Pith is for the better Advancement of the sap, whereof I fhall fpeak in the next Chapter. The ufe I here obferve, is for the quicker and higher Fermentation of the sap: For although the Fermentation made in the Cortical Body was well fubfervient to the firft Vegetations, yet thofe more perfect ones in the Trunk which after follow, require a Body more adapted to it, and that is the Pith; which is fo neceflary, as not to be only common to, but confiderably large in the Roots of molt Plants; if not in their inferiour 
parts, yet at their tops. Where though either deriv'd or amplify'd from the Cortical Body, yet being by its Infertions only, we may therefore fuppofe, as thofe, fo this, to be more finely conftituted. And being alfo from its coarctation, while inferted, now free; all its Pores, upon the fupply of the Sap, will more or lefs be amplified: Upon which accounts, the sap thereinto received, will be more pure, and its fermentation therein more active. And as the Pith is fuperiour to the Cortical Body by its Constitution, fo by its Place. For as it thus ftands central, it hath the Lignous Body furrounding it. Now as the skin is the Fence of the Cortical Body, and that of the Lignous; fo is the Lignous again a far more preheminent one unto the Pith; the Sap being here a brisk Liquor, tunn'd up as in a wooden Cask:

28. \$. And as the Pith fublerves the higher Fermentation of the Sap; fo do the Infertions its purer Diftribution; that feparation which the parts of the Sap, by being fermented in the Pith, were difpos'd for; being, upon its entrance into the Infertions, now made: So that as the skin is a Filtre to the Coritical Body, fo are the Infertions a more preheminent one to the Lignous. And as they fubferve the purer, fo the freer and fufficient dittribution of the $S_{a p}$ : For the Root enlarging, and fo the Lignous Body growing thicker, although the Cortical and the $\boldsymbol{P}$ ith might fupply $S a p$ fufficient to the nutrition of its $P$ arts next adjacent to them; yet thofe more inward, muft needs be fcanted of their Aliment; and fo, if not quite ftarv'd, yet be uncapable of equal growth: Whereas the Lignous Body being through its whole breadth frequently difparted, and the Cortical Body inferted through it; the Sap by thofe Infertions, as the Bloud by the diffeminations of the Arteries, is frecly and fufficiently convey'd to its intimate Parts, even thofe, which from either the Barque or from the Pith, are moft remote. Laftly, as the confequent hereof, they are thus affiftant to the Latitudinal growth of the Root; as the Lignous Body to its growth in Length; fo thefe Infertions of the Cortical, to its better growth in Breadth.

29. 5. Having thus feen the folitary ufes of the Several Parts of the Root, I thall laftly propound my Conjectures of that Defign whereto they are altogether concurrent, and that is the Circulation of the Sap.

30. 6. That the sap hath a Double, and fo a Circular Motion, in the Root; is probable, from the proper Motion of the Root, and from its Office. From its Motion, which is Defcent: for which, the Sap muft likewife, fome where, have fuch a Motion proper to it. From its Office, which is, To feed the Trunk: for which, the Sap muft alfo, in fome Part or other, have a more efpecial Motion of Afcent.

31. б. We may therefore fuppofe, That the Sap moving in the Barque, towards the Pith, through the Infertions, thereinto obtains a pafs, Which paflage, the upper Infertions will not favour; becaufe the Pith ftanding in the fame heigth with them, is there large, the fermenting and courfe of the sap quick, and fo its oppofition ftrong. But through the lower it will much more eafily enter; becaufe there, from the fmalnefs of the $P$ ith, the oppofition is little, and from the fhortnefs of the Infertions, the way more open. So that the Sap here meeting with the leaft oppofition, here it will beftow it felf (feeding the Lignous Body in its paffage) into the Pith. Into which, frefh sap ftill entring, this being yet but crude, will fubfide : that 
firft receiv'd, and fo become a Liquor higher wrought, will more eafily mount upwards.And moving in the Pith,efpecially in the Sap-Fibers there difpers $d$, as in the Arterys, in equal altitude with the upper-Infertions; the moft volatile parts of all will ftill continue their direct afcent towards the Trunk. But thofe of a middle nature, and, as not apt to afcend, fo being lighter than thofe beneath them, not to defcend neither; they will tend from the Pith towards the Infertions in a Motion betwixt both. Through which Infertions (feeding the Lignous Body in its paffage) it is, by the next fubfequent $S a p$, difcharged off into the Cortical Body, and fo into the Sap-Fibres themfelves, as into the $V_{\text {eins, }}$, back again. Wherein, being ftill purfu'd by frefh $S_{a p}$ from the Center, and more occurring from the Circumference, towards the lower Infertions, it thus defcends. Through which, together with part of the sap afrefh imbib'd from the Earth, it re-enters the Pith. From whence, into the Cortical Body, and from thence into the Pith, the cruder part thereof, is reciprocally disburs'd; while the molt Volatile, not needing the help of a Circulation, more direct. ly afcendeth towards the Trunk. 


\section{H A P. III. \\ Of the $T R \cup N K$.}

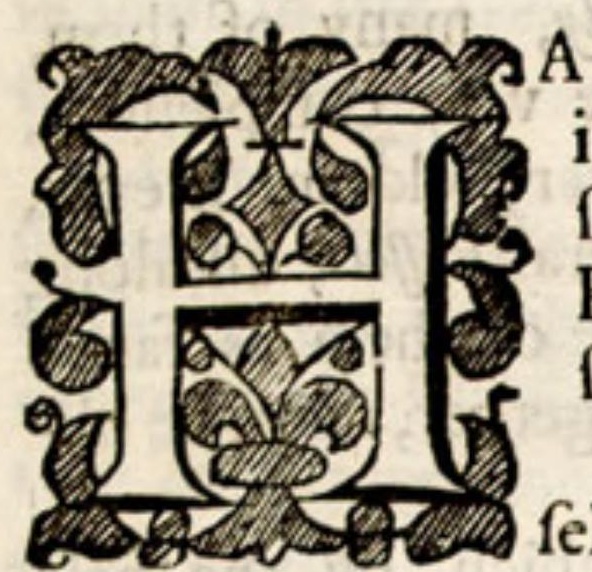

A V I N G thus declar'd the degrees of Vegetation in the Root; the continuance hereof in the Trunk fhall next be fhew'd: in order to which, the Parts whereof this likewife is compounded, we fhall firlt obferve.

I. 6. That which without diffection thews it nor of the Trienk; but what I choofe here to mention, as ftanding betwixt them, and fo being common to them both; all their Parts being here bound in clofer together, as in the tops of the grown Roots of very many Plants, is apparent.

2. 5. Of the Parts of the Trunk, the firft occurring is its skin : The Formation whereof, is not from the Air, but in the Seed, from whence it is originated; being the production of the Cuticle, there invefting the two Lobes and Plume.

3. 5. The next Part is the Cortical Body; which here in the Trunk is no new fubftantial Formation; but, as is that of the Root, originated from the Parenchyma of the Plume in the Seed; and is only the increafe and augmentation thereof. The skin, this Cortical Body Tab.3.f. $\boldsymbol{I}_{2}$ or Parenchyma, and (for the molt part) fome Fibers of the Lignons 4 . mixedherewith, alltogether make the Barque.

4. \$. Next, the Lignous Body, which, whether it be vifibly divided into many fofter Fibers or fmall Threads, as in the Bean, Fen$n e l$, and moft Herbs; or that its Parts ftand more compact and clofe, Thewing one hard, firm and folid piece, as in Trees; it is, in all, one and the fame Body; and that not formed originally in the Trunk, but in the Seed; being nothing elfe but the prolongation of the $\mathrm{Se}_{e-}$ minal Root diftributed in the Lobes and Plume thereof.

5. 5. Laftly, The Infertions and Pith are here originated likewife from the Plume, as the fame in the Root, from the Radicle: So that as totheir subftantial Parts, the Lobes of the seed, the Radicle and Plume, the Root and Trunk are all one.

6. 6. Yet fome things are more fairly obfervable in the Trunk: Firft, the Latitudinal thootings of the Lignous Body, which in Trunks of feveral years growth, are apparent in fo many Rings, as is commonly known. For feveral young Fibers of the Lignous Body, as in the Tab. 3. f. s, Root, fo here, fhooting in the Cortical one year, and the fpaces be- $\& 8$.

twixt them being after fill'd up with more (I think not till) the next, at length they become altogether a firm compact Ring; the Perfection of one Ring, and the Ground-work of another, being thus
made concomitantly. 
7. 5. From thefe Annual younger $F$ ibers it is, that although the Cortical Body and Pith are bothof of the fame fubftantial nature, and their Pores little different; yet whereas the Pith, which the firft year is green, and of all the Parts the fulleft of sap, becomes afterwards white and dry: The Cortical Body, on the contrary, fo long as the Tree grows, ever keepeth green and moift, $f_{c}$. becaufe the faid $S a p-F i$ bers, annually grow therein, and fo communicate with it.

8. 5. The Pores likewife of the Lignous Body, many of them, in well-grown Timber, as in Oaken boards, are very confpicuous, in cutting both lengthwife and traverfe. They very feldom, if ever, run one into another, but keep, like fo many feveral $V_{e} \int f e l s$, all along

Tab.3.f:2. diftinct; as by eutting, and fo following any one of them as far as o 3. you pleafe, for a Foot or half a Yard, or more together, may be obferv'd. And fo, the like, in any Cane.

9. 5. Befides thefe, there are a leffer fort; which, by the help only of a good Spectacle Glafs may be obferv'd.

10. 6. And thefe are all the Pores vifible without a Microfcope. The ufe of which, excepting in fome few particulars, I have purMicrography. pofely omitted in this firft Book. Mr. Hook theweth us, befides thefe, a third, and yet fmaller Sort; and (as a confirmation of what, in

C.2.5.8. the Second Chapter, I have faid of the Pores of the Lignous Body in general) that they are all continuous and prolonged by the length of the Trunk, as are the greater ones: whereof he maketh Experiment, by filling up, in a piece of Char-coal, all the faid Pores with Mercury: which appears to pafs quite through them, in that by a very good Glas it is vifible in their Orifices at both ends; and without a Glafs, by the weight of the Coal alone, is alfo manifeft. All thefe I have feen, with the help of a good Microfcope, in feveral

Tab. 3.f. 7. forts of Woods. As they all appeare in a piece of Oak, cut tranfverfely, See Tab. 3 .

II. S. Upon further Enquiry, I likewife find, That the Pores of the Lignous Body in the Trunks of Herbs, which at firft I only fuppofed, by the help of good Glajfes, are very fairly vifible: each $F_{i}$ bre being fometimes perforated by $30,50,100$, or hundreds of Pores. Or what I think is the trueft notion of them, That each Fibre, though it feem to the bare eye to be but one, yet is, indeed, a great number of Fibres together; and every Pore, being not meerly a f pace betwixt the feveral parts of the Wood, but the Concave of a Fiber. So that if it be asked, what all that Part of a Plant, either Herb or Tree, which is properly called the Woody-Part; what all that is, I fuppofe, That it is nothing elfe but a Clufter of innumerable and moft extraordinay

Tab.3. f.6. fmall Veffels or Concave Fibers : as in a Slice of the Trunk of Bur-

12. 5. Next the Infertions of the Cortical Body, which in the Trunk of a Tree faw'd athawrt, are plainly difcerned as they run from the Circumference toward the Center; the whole Body of the Tree being vifibly compounded of two diftinct Subftances, that of the feveral Rings, and that of the Infertions, running crofs; fhewing Tab. 3. f. 5. that in fome refemblance in a Plain, which the Lines of Latitude and
of 8.
of the Meridian do in a Globe. The entrance of the Infertions into the $W_{o o d}$, is alfo, upon ftriping off the Barque, very apparent; as in the fame Fig. 8. 
13. \$. Thefe Infertions are likewife very confpicuous in Sawing of Trees length-ways into Boards, and thofe plain'd, and wrought into Leaves for Tables, Wainfiot, Trenchers, and the like. In all which, as in courfe Trenchers made of Beech, and Tables of Oak, there are many parts which have a greater fmoothnefs than the reft; and are fo $\tau_{a b} .3 . f_{\text {. }}$. many inferted Pieces of the Cortical Body; which being by thofe of ${ }^{\infty} \mathcal{T}_{a b}$. $4 \mathrm{f} \cdot \mathrm{f}$. the Lignous, frequently intercepted, feem to be difcontinuous, although in the Trunk they are really extended, in continued Plates, throughout its Breadth.

14. 6. Thefe Infertions, although as is faid, of a quite diftinct fubftance from the Lignous Body, and fo no where truly incorporated with it, yet being they are in all parts, the one as the $W$ arp, the other as the Woof, mutually braced and intersooven together, they thus conftitute one ftrong and firmly coherent Body; as the Timber Tab. $4, f, x$. of any Tree.

15. \$. As the Pores or Veffels are greater or lefs, fo are the Infertions alfo: To the bare eye ufually the greater only are difcernable: But through an indifferent Microfcope there are others alfo, much more both numerous and fmall, diftinctly apparent, as in a tranfverfe piece of Oak

16. \$. In none of all the Pores can we obferve any thing which $T_{a b}, 3 \cdot f \cdot 7$. may have the true nature and ufe of $V$ alves, which is, Eafily to admic that, to which they will by no means allow a regrefs. And their nonexiftence is enough evident, from what in the firft Chapter we have C. x. S.42. faid of the Lobes of the Seed: in whofe seminal Root, were there any $V_{\text {alves, }}$ it could not be, that by a contrary Courje of the $S_{a p}$, they fhould ever grow; which yet, where-ever they turn into Diffimilar Leaves, they do. Or if we confider the growth of the Root, which oftentimes is upward and downward both at once. And being cut tranfverfely, will bleed, both the fame ways, with equal freedom.

17. \$. The Infertions here in the Trunk give us likewife a fight of the pofition of their Pores. For in a plained piece of Oak, as in Wainfcot, Tables, Es 0 . befides the larger Pores of the Lignous Body, which run by the length of the Trunk; the Tract likewife of thofe of Tab.3.f. 2 . the Infertions may be obferved to be made by the breadth, and fo directly crofs. Non are they continuous as thofe of the Lignous Body, but very fhort, as thofe both of the Cortical Body and Pith, with which the Infertions, as to their fubltance, are congenerous. Yet they all ftand fo together, as to be plainly ranked in even Lines or Rows throughout the breadth of the Trunk: As the Tract of thofe Pores appears to the naked Eye, fee in Tab. 3.Fig. 9. The Pores themfelves may be feen in the Root of a Vine deferibed and figured in the Second Book, as it appears through a good Microfcope.

18. .. The Pores of the Pith likewife being larger here in the Trunk, are better obfervable than in the Root: the width whereof, in comparifon with their sides fo exquifitely thin, may by an HonyComb be grolly exemplified; and is that alfo which the vaft difproportion betwixt the Bulk and Weight of a dry Pith doth enough declare. In the Trunks of fome Plants, they are fo ample and tranfparent, that in cutting both by the length and breadth of the Pith, fome of them through the tranfparency of the skins by which they are bounded, or of which they confift, would feem to be confidera- 
bly extended by the length of the Pith; but are really difcontinuous and fhort, and as tis faid, fomewhat anfwerable to the Gells of an Hony-Comb. This is the neareft we can come to them, by the bare Eye without the affiftance of a good Microfcope. Mr. Hook, fheweth in his Micrography, That the Pores of the Pith, particularly of Elder-Pith, fo far as they are vifible, are all alike difcontinuous; and that the Pith is nothing elfe but (as he calls them) an heap of $B u b$ bles. Although, in regard they are not fluid, but fixed Parts, I fhall choofe rather to call them, Bladders. As they appear through a good $T_{a b}$ 3. f. 6.' Glafs, in a piece of Burdock, See in $T a b$. 3. But a more particular Defcription of the Sizes, Figures, and admirable Textures hereof, I have given in feveral places in the following Books. 19. \%. Befides what this Obfervation informs us of here, it
C.2. $6.3,16$, farther confirms what in the Second Chapter we have faid of the 17. Original of the Pith and Cortical Body, and of the famenefs of both their natures with the Parenchyma of the Seed: which is noC. 1. 5. 18. thing elfe but a Mafs of Bladders; as in the Firtt Chapter hath been 6. Tab.r.f.g. faid.

20. 5. In the Piths of many Plants, the greater Pores or Bladders have fome of them leffer ones within them, and fome of them are divided with crofs Membranes: And betwixt their feveral fides, have, I think, other fmaller Bladders vifibly interjected. However, that they are all permeable, is moft certain. They ftand together not confufedly, but in even Ranks or Trains; as thofe of the Infertions by the breadth, fo thefe by the length of the Trunk. And thus far there is a general correfponding betwixt the parts of the Root and Trunk. Yet are there fome confiderable Difparities betwixt them; wherein, and how they come to pafs, and to what efpecial Ufe and End, fhall next be faid. An Account 21 . WE SAY then, that the Sap being in the Root by Filtra-
of the tions, Fermentations (and in what Roots Growth of the Trunk. tions, Fermentations (and in what Roots needful, perhaps by Circulationalfo ) duly prepar'd; the prime part thereof paffing through the intermediate Coardure, in due moderation and purity is entertaind at laft into the Trunk. And the Sap of the Trunk being purer and more volatile, and fo it felf apt to afcend; the motion of the Trunk likewife will be more noble, receiving a difpofition and tendency to afcend therewith. And what by the Sap the Trunk is in part dipos'd to, by the refpective pofition and quantity of its Parts it is effectually enabled. For whereas in the Root the Lignous Body being in proportion with the Cortical, but little, and all lying clofe within its Center; it muft therefore needs be under its controul : on the contrary, being here comparatively of greater quantity, and alfo more dilated, and having divers of its Branches ftanding more abroad towards the Circumference, as both in the Leaves and Body of the young Trunk and Plume, is feen; it will in its own magnetical tendency to afcend, reduce the Cortical Body to a compliance with it.

22. 5. And the Trunk thus ftanding from under the reftraint of the Ground in the open Air, the difpofition of its Parts, originally different from that of the Parts in the Root, will not only be continued, but improved. For by the force and preffure of the $S_{a p}$ in its collateral Motion, the Lignous Body will now more freely and farther be di- 
lated. And this being dilated, the Cortical Body alfo, muft needs be inferted; and is therefore in proportion always, more or lefs, fmaller here in the Trunk, than in the Root. And as the Cortical Body leffens, fo the Pith will be enlarged, and by the fame proportion is here greater. And the Pith being enlarged it felf, its Pores (the Lignous Body, upon its dilatation, as it were tentering and ftretching out all their fides) muft needs likewife be enlarged with it; and accordingJy, are ever greater in the Pith of the Trunk, than of the Root. And the dilatation of the Lignous Body ftill continued, it follows, that whereas the Pith defcendent in the Root, is not only in proportion lefs and lefs, but alfo in the fmaller extremities thereof, and fometimes higher, altogether abfent: Contrariwife, in the Trunk, it is

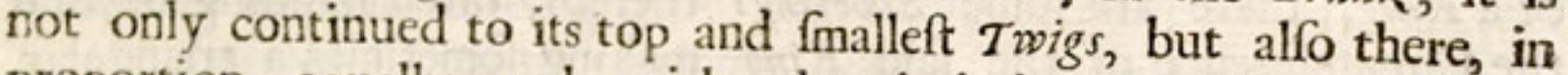
proportion, equally ample with what it is in any other inferiour part.

23. 6. But although the opennefs of the Aer permitting, be allways alike; yet the Energy of the $S a p$ effecting, being different; as therefore that doth, the dilatation of the Trunk, will alfo vary. If that be lefs, fo is this; as in the Trunks of moft Trees: If that be greater, fo this; as in Herbs is common; the Lignous Body being ufually fo far dilated, that the utmoft Shootings thereof may eafily be feen to jut out, and adjoyn to the Skin. And if the Sap be ftill of greater energy, it fo far dilates the Lignous Body, as not only to amplifie the Pith and all its Pores; but alfo fo far to ftretch them out, as to make them tear. Whereupon either running again into the Cortical Body, or Shrinking up towards it, the Trunk thus fometimes becomes an ballow Stalk, the Pith being wholly, or in part voided. But generally it keeps entire; and where it doth, the fame proportion and refpect to the Lignous and Cortical Bodies, as is faid. The Confequences of all which will be, the Sirength of the Trunk, the Security and Plenty of the Sap, its Fermentation will be quicker, its $D_{i-}$ fribution more effectual, and its Advancement more fufficient.

24. 6. Firft, the Erect Growth and Strength of the Trunk; this being, by the pofition of its feveral Parts, effected : for befides the flendering of the 7runk ftill towards the top, the Circumferential pofition of the Lignows Body, likewife is, and that eminently, hereunto fubfervient. So that as the Lignous, Body, in the fmaller parts, of the Root ftanding Central, we may thence conceive and fee their pliablenefs to any oblique motion; fo here, on the contrary, the Lignous Body ftanding wide, it thus becomes the Strength of the Trunk, and moft advantageous to its Perpendicular Growth. We fee the fame Defign in Bones and Feathers: The ftrongeft Bones, as thofe in the Legs, are hollow. Now fhould we fuppofe the fame Bone, to be contracted into a Solid; although now it would be no heavier, and in that refpect, as apt for motion; yet would it have far lefs ftrength, than as its Parts are dilated to a Circumferential pofture. And fo for Quills, which, for the fame Reafons, in fubferviency to flying, as they are exceeding light; So, in comparifon with the thinnefs of their Sides, they Solid Cylinder. and much lefs apt to bend, than if contracted into a is, that Jogners and Carpenters only in Nature, but Art. For hence it pieces and feveral Works oftentimes with double Joynts; which, although 
though they are no thicker, than a fingle one might be made ; yet ftanding at a diftance, have a greater ftrength than That could have. And the fame Architecture, will have the fame ufe, in the Trunks of Plants; in moft whereof 'tis very apparent; as for inftance, in Corn. For Nature defigning its sap a great Afcent; for its higher maturity, hath given it a tall Trunk: But to prevent its ravenous defpoiling either of the Ear, or Soyl; although it be tall, yet are its fides but thin: And becaufe again, it thould grow not only tall and thriftily, but for avoiding propping up, ftrongly too; therefore, the fame proportion as its heigth bears, to the thinnefs of its fides, doth the greatnefs of its $\mathrm{Cir}$ cumference alfo; being fo far dilated as to parallel a 2 uil it felf.

25. \$. Befides the pofition of the Lignous Body within the compafs of a Ring, there are fome shootings thereof, often ftanding beyond the Circumference of the faid Ring, making fometimes a triangular, oftner a quadrangular Body of the Trunk. To the end, that the Ring, being but thin, and not felf-fufficient, thefe, like Splinters to Bones, might add ftrength and ftability to it.

26. \$. Next, the fecurity and plenty of the sap. For fhould the Lignows Body, as it doth in the fmaller Parts of the Root, ftand Central here alfo, and fo the Cortical wholly furround it: the greater part of the Sap would thus be more immediately expos'd to the Sun and Aer; and being lodged in a laxe Body, by them continually be prey'd upon, and as faft as fupplied to the Trunk, be exhautted. Whereas, the Pith ftanding in the Center, the sap therein being not only moft remote from the Aer and $S u n$, but by the Barque, and efpecially the Wood, being alfo furrounded and doubly immur'd, will very fecurely and copioufly be convey'd to all the Collateral Parts, and ( as fhall be faid how ) thetop of the Trunk.

27. 5. And the Sap by the amplitude, and great porofity of the Pith, being herein more copious, its Fermentation alfo will be quicker; which we fee in all Liquors, by ftanding in a greater quantity together, proceeds more kindly: And being tun'd up within the Wood, is at the fame time not only fecur'd from lofs, but all extream mutations; the Day being thus, not too hot; nor the Night, too cold for it.

28. 5. And the Fermentation hercof being quicker, its motion alfo will be ftronger, and its Diftribution more effectual, not only to the dilatation of the Trunk, but likewife the fhooting out of the Branches. Whence it is, that in the Bodies of Trees, the Barque of it felf, though it be Sappy, and many Fibres of the Lignous Body mixed with it, yet feldom fendeth forth any; and that in Herbs, thore with the leaft Pitb (other advantages not fupplying this defect) have the feweft or fmalleft Branches, or other collateral Growths: and that Corn, which hath no Pith, hath neither any Branches.

29. 5. Laftly, the Advancement of the Sap will hence alfo be more ready and fufficient. For the underftanding where, and how, we fuppofe, That in all Trunks whatfoever there are two Parts joyntly hereunto fubfervient. In fome, the Lignous Body and the Cortical, as in older Trunks; the Pith being either excluded, or dried: But in moft, principally, the Lignous Body and Pitb; as in moft Annual Growths of Trees; but efpecially Herbs, where the Cortical Body is ufually much and often wholly Inferted. 
30. 6. Of the Lignous Body it is fo apparent by its Pores, or rather by its Veffels, that we need no farther Evidence. For to what end are $V e f e l s$, but for the conveyance of Liquor? And is, that alfo, which upon cutting the young Branch of a Sappy Tree or Herb, by an accurate and fteady view may be obferved. But when I fay the $V_{e}$ fels of the Lignous Body, I mean principally them of the younger footings, both thofe which make the new Ring, and thofe which are mixed with the Cortical Body in the Barque: that which afcendeth by the Pores or Veffels of the Wood, being probably, becaufe in lefs quantity, more in form of a Vapour, than a Liquor. Yet that which drenching into the fides of its Pores, is with all thereunto fufficient Aliment; as we fee Orpine, Onions, \& $c$. only ftanding in a moyfter Aer will often grow. And being likewife in part fupplied by the Infertions from the younger Shoots: But efpecially becaufe as it is but little, fo (confidered as Aliment) it ferveth only for the growth of the Wood, and no more; whereas, the more copious Aliment afcendent by the younger shoots, fubferves not only their own growth, but the generation of others; and is befides with that in the Cortical Body the Fountain of Perfpirations, which we know even in Animals are much more abundant than the Nutritive Parts; and doubtlefs in a Vegetable are ftill much more.

3I. \$. But thefe Pores, although they are a free and open way to the afcending Sap; yet that meer Pores or Veffels fhould be able of themfelves to advance the Sap with that fpeed, ftrength and plenty, and to that height, as is neceffary, cannot probably be fuppofed. It follows then, that herein we muft grant the $P_{i t h}$ a joynt fervice. And why elfe is the $\boldsymbol{P}^{\mathrm{ith}}$ in all Primitive Gromths the moft Sappy part, why hath it fo great a ftock of sap, if not, after due maturation within it felf, ftill to be disburfed into the Fibres of the Lignous Body? Why are the Annual Growths of all both Herbs and Trees, with great Piths, the quickeft and the longeft? But how are the Pores or Bladders of the Pith permeable? That they are fo, both from their being capable of a repletion with $S_{a p}$, and of being again wholly emptied of it, and again, inftead thereof fill'd with Aer, is as certain as that they are Pores. That they are permeable, by the breadth, appears from the dilatation of the Lignous Body, and from the production of Branches, as hath been, and fhall hereafter be faid. And how elfe is there a Communion betwixt This and the Cortical Body? That they are fo alfo, by the length, is probable, becaufe by the beft Microfcope we cannot yet obferve, that they are vifibly more open by the breadth, than by the length. And withall are ranked by the length, as thofe of the Infertions by the breadth of the Trunk. But if you fet a piece of dry Elder-Pith in fome tinged Liquor, why then doth it not penetrate the Pores, fo as to afcend through the Body of the Pith? The plain reafon is, becaufe they are all fill'd with Aer. Whereas the Pith in a Vegetating Plant, as its Parts or sladders are ftill generated, they are at the fame time alfo fill'd with $S_{a p}$; which, as 'tis gradually fpent, is ftill repaired by more fucceeding, and fo the Aer ftill kept out $;$ as in all Primitive Growths, and the Pith of Elder it felf: Yet the fame Pith, by reafon of the following Winter, wanting a more copious and quick fupply of $S_{a p}$, thus once become, ever after keeps dry. And fince in the aforefaid Trial the Liquor only afcends by the fides of the Pith, that 
is of its broken Bladder, we fhould thence by the fame reafon conclude that they are not penetrable by the breadth neither, and fo no way; and then it need not be ask'd what would follow. But certainly the $S_{a p}$ in the Bladders of the Pith is difcharged and repaired every moment, as by its fhriv'ling up, upon cutting the Plant, is evident.

32. 6. We fuppofe then, that as the Sap afcendeth into the Trunk by the Lignous Body, fo partly alfo by the Pith. For a piece of Cotton with one end immers'd in fome tinged Liquor, and with the other erect above, though it will not imbibe the Liquor fo far as to overrun at the top, yet fo as to advanee towards it, it will. So here, the Pith, being a porous and fpongy Body, and in its Vegetating ftate, its Pores or Bladders being alfo permeable, as a curious Filtre of Natures own contrivance, it thus advanceth, or as people ufe to fay, fucks up the sap. Yet as it is feen of the Liquor in the Cotton; fo likewife are we to fuppofe it of the Sap in the Pith; that though it rifeth up for fome way, yet is their fome term, beyond which it rifeth not, and. towards which the motion of the afcending $S_{a p}$ is more and more broken, weak and flow, and fo the quantity thereof lefs and lefs. But becaufe the sap moveth not only by the length, but breadth of the Pith; at the fame time therefore as it partly afcendeth by the $P$ ith, it is likewife in part preffed into the Lignous Body or into its Pores. And fince the motion of the Sap by the breadth of the Pitb not being far continued, and but collateral, is more prone and eafie, than the perpendicular, or by its length; it therefore follows, that the collateral motion of the $S_{a p}$, at fuch a height or part of the $P$ ith, will be equally ftrong with the perpendicular at another part, though fomewhat beneath it; and that where the perpendicular is more broken and weak, the collateral will be lefs; and confequently where the perpendicular tendency of the $S a p$ hath its term, the collateral tendency thereof, and fo its preffure into the Pores or Vefels of the Lignons Body, will ftill continue. Through which, in that they are fmall, and fo their fides almoft contiguous, the sap as faft as preffed into them willeafily run up; as in very fmall Glaffe Pipes, or betwixt the two halves of a Stick firft flit, and then tyed fomewhat loofely together, may alfo any Liquor beobferved to do. By which Advantage the facility and ftrength of that afcent will be continued. higher in the faid $V_{e} \iint_{l} s$, than in the Pith. Yet fince this alfo, as well as that in the Pith will have its term; the $S_{a p}$, although got thus far, would at laft be ftagnant, or at leaft its afcent be very iparing, flow and feeble, if not fome way or other re-inforced. Wherefore, as the $S a p$ moving by the breadth of the Pith, preffeth thence into the Veffels of the Lignous Body; fo having well filld thefe, is in part by the fame Collateral motion disburfed back, into a yet higher Region of the Pith. By which partly, and partly, by that portion of the $S_{a p}$, which in its perpendicular afcent was before lodged therein; 'tis thus here, as in any inferiour place equally replenifhed. Whereupon the force and vigour of the perpendicular motion of the Sap herein, will likewife be renew'd; and fo its Collateral motion alfo, and fo its preffure into the VefJels of the Lignous Body, and confequently itsafcent therein: and fo by a preffure, from thefe into the $P$ ith, and from the $P$ itbinto thefe, reciprocally carried on; a moft ready and copious afcent of the Sap will be continued, from the bottom to thetor, though of the higheft Tree. 
en Appendix.

Of Trunk-Roots and Clafpers.

$T^{1}$

$\mathrm{HE}$ diftinct Parts whereof thefe are compored, are the fame with thofe of the Trunk, and but the continuation of thers.

I. 6. Trunk. Roots are of two kinds: Of the one, are thofe that vegetate by a direct defcent : The place of their Eruption is fometimes all along the Trunk; as in Mint, \&c. Sometimes only at its utmolt point, as in the Bramble.

2. 2. The other fort are fuch as neither afcend nor defcend, but fhoot forth at right Angles with the Trunk; which therefore, though as to their Office, they are true Roots, yet as to their Nature, they are a Middle Thing betwixt a Root and a Trunk.

3. 5. Claspers, though they are but of one kind, yet their $\mathrm{Na}-$ ture is double; not a mean betwixit that of the Root and that of the Trunk, but a compound of both; as in their Circumvolutions, where. in they often mutually afcend and defcend, is feen.

4. 6. The ufe of thefe Parts may be obferved as the Trunk Mounts, or as it Trails. In the mounting of the Trunk, they are for Support and Supply. For Support, we fee the Clafpers of Vines: the Branches whereof being very long, fragile and flender; unlefs by their Clapers, they were mutually contain'd together, they muft needs by their own weight, and that of their Fruit, undecently fall; and be alfo liable to frequent breaking. So that the whole care is divided betwixt the Gardener and Nature; the Gardener, with his Ligaments of Leather, fecures the main Branches; and Nature, with thefe of her own finding, fecures the Lefs. Their Conveniency to which end, is feen in their Circumvolutions, a motion, not proper to any other Part: As alfo in their toughnefs, though much more flender than the Branches whereon they are appendent.

5. The Clafpers of Bryony have a retrograde motion about every Third Circle, to the form a Doublet-Clafp. Probably for the more certain hold; which, if it mifs one way, it may be fure to take
another.

6. 6. For Supply, we fee the Trunk-Roots of Ivy. For mounting very high, and being of a clofer or more compact Subftance than that of a Vine; the sap could not be fufficiently fupplied to the upper Sprouts, unlefs thefe, to the Mother-Root, were joyntly affiftant. Yet ferve they for fupport likewife; whence they thoot out, not as in Creffes, Brook-lime, \&cc. recipocrally on each fide, but commonly, all on one; that fo they may be faftned at the neareft hand.

7. 5. In the Trailing of the Trunk, they ferve for ftabiliment, propagation and thade. For ftabiliment, the clapers of Cucumbers are of good ufe. For the Trunk and Branches being long and fragile, the Brufhes of the Winds would injurioully hoife them to and fro, to the dammage both of themfelves and their tender Fruits, were

$$
\text { K } 2 \text { they }
$$


they not by thefe Ligaments brought to good Affociation and Settlement.

8. §. As for this end, fo for Propagation, the Trunk-Roots of Chamamile do well ferve. Whence we have the reafon of the common obfervation, that it grows better by being trod upon: the Mould, where too laxe, being thus made to lie more conveniently about the faid Trunk-Roots newly bedded therein; and is that which is fometimes alfo effected in Rowling of Corn.

9. 6. For both thefe ends, Serve the Trunk-Roots of Siranberries; as alfo for fhade; for in that all Strawberries delight; and by the trailing of the Plant is well obtain'd. So that as we are wont to tangle the Twigs of Trees together to make an Arbour Artificial; the fame is here done to make a Natural one: as likewife by the Clapers of Cucumbers. For the Branches of the one by the Linking of their Clapers, and of the other by the Tethering of their Truwk-Roots, being couched together; their tender Fruits thus lie under the Umbrage of a Bower made of their own Leaves.

\section{CHA P. IV. \\ Of the GERMEN,BRANCH, and LEAF.}

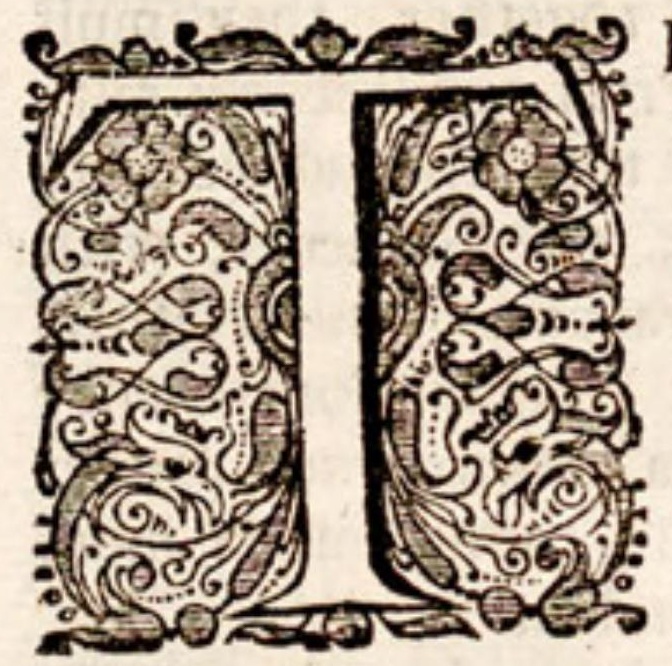

HE Parts of the Germen and Branch, are the fame with thofe of the Trunk; the fame Skin, Cortical and Lignous Bodies, Infertment and Pith, hereinto propagated, and diftinctly obfervable herein.

2. \$. For upon Enquiry into the Original of a Branch or Germen, it appears, That it is not from the Superficies of the Trunk; but fo deep, as to take, with the Cortical, the Lignous Body into it felf: and that, not only from its Circumference, but from in Inner or Central Parts; So as to take the Pith in alfo. Divers of which Parts may commonly be feen to fhoot out into the Pith; from which Shoots, the furrounding and more fuperiour Germens are originated; in like manner as the Succulent Part of the Lignous Body of the Trunk is fometimes principally from thofe Fibrous shoots which run along the Pith in the Root.

3. 6 . The manner wherein ufually the Germen and Branch are fram'd, is briefly thus: The Sap (as is faid, Chap. 3.) mounting in the Trunk, will not only by its length, but by its breadthalfo, through the Infertions partly move. Yet, its Particles being not all alike qualified, in different degrees. Some are more grofs and fluggifh; of which we have the formation of a Circle of Wood only, or of an Ammual Ring. Others are more brisk; and by thefe, we have the Germen propagated. For by the vigour of their own motion from the Center, they imprefs anequal tendency on fome of the inner Portions of the Lignous Body next adja- 
cent to the Pith, to move with them. And fince the Lignous Body is not entire, but frequently difparted; through thefe Difpartments, the faid interiour Portions, upon their Nutrition, actually fhoot; not only towards the Circumference, fo as to make part of a Ring; but even beyond it, in order to the production of a Germen. And the Lignous Body thus moving, and carrying the Cortical along with it; they both make a force upon the Skin. Yet their motion being moft even and gradual, that force is fuch likewife; not to caufe the leaft breach of its parts, but gently to carry it on with themfelves; and fo partly, by. the extenfion of its already exiftent parts, as of thofe of Gold in drawing of Guilded $W_{y e r}$; and partly, by the accretion of new ones, as in the enlarging of a Bubble above the Surface of the Water; it is extended with them to their utmolt growth. In which growth, the Germen being prolonged, and fo difplaying its feveral parts, as when a Prospective or Telefcope is drawn out, thus becomes a Branch.

4. 5. The fame way as the propagation of the Parts of a Germen is contriv'd, is its due nutrition alfo. For being originated from the inner part of the Lignous Body, 'tis nourifhed with the beft fermented sap in the Trunk, $f c$. that next adjacent to it in the Pith. Befides, finceall its Parts, upon their fhooting fortb, divaricate from their perpendicular, to a crofs Line, as thefe and the other grow and thrive together, they bind and throng each other into a Knot: through which Knot the Sap being ftrain'd, 'tis thus, in due moderation and purity delivered up into the Branch.

5. \& And for Knots, they are fo neceffary, as to be feen not only where collaterl Branches put forth; but in fuch Plants alfo, as thoot up in one fingle Trunk; as in Corn. Wherein, as they make for the ftrength of the Trunk; fo by fo many percolations, as they are Knots, for the trafmiffion of the sap more and more refined towards the Ear. So that the two general ufes of $K_{\text {nots }}$ are, For fimer ftanding, and finer growth.

6. 6. Laftly, as the due Formation and Nutrition of the Germen are provided for, fo is its fecurity alfo; which both in its pofition upon the Trunk, and that of its Parts among themfelves, may be obferved. The pofition of its Parts fhall be confidered in fpeakimg of the Leaf. As to its ftanding in the Trunk, tis alwayes betwixt the trunk or older Branch, and the Bafis of the Stalk of a Leaf; whereby it is not only guarded from the Injuries of any contingent Violence; but alfo from the more piercing affaults of the Cold; fo long, till in time 'tis grown larger, and more hardy. The maner and ufes of the pofition of every Germen, confidered as after it becomes a Branch; hath already been, by the Ingenious Mr. Sharrock.Hift. of the very well obferved; to whom I refer.

7. \$. UPON THE prolongation of the Germen into a Branch, its Leaves are thus difplay'd. The Parts whereof are fubftantially the fame with thofe of a Brancl. For the Skin of the Leaf, is only the ampliation of that of the Branch; being partly by the accretion of new, and partly the extention of its already exiftent parts, dilated (as in making of Leaf-Gold) into its prefent breadth. The Fibres or Nerves difperfed through the Leaf, are only the Ramifications of the Branct's Wood, or Lignous Body. The Parenchyma of the Leaf, 
which lies betwixt the Nerves, and as in Gentlewomens Needle-works, fills all up, is nothing elfe, but the continuation of the Cortical Body, or Parenchymous part of the Barque from the Branch into it felf, as in moft Plants with a thick Leaf, may eafily be feen.

8. 5. The Fibers of the Leaf neither fhoot out of the Branch, or the Trunk, nor ftand in the Stalk, in an even Line; but alwayes in either an Angular or Circular pofture; and ufually making either a Triangle, or a semi-Circle, or Chord of a Circle; as in Cichory, Endive,

Tab.4. f. 2. Cabbage, \&c. may be obferved. And if the Leaf have but one main $F_{i}$. to $f . \mathbf{I}$. ber, that alfo is poftur'd in a bowed or Lmar Figure; as in Mint and

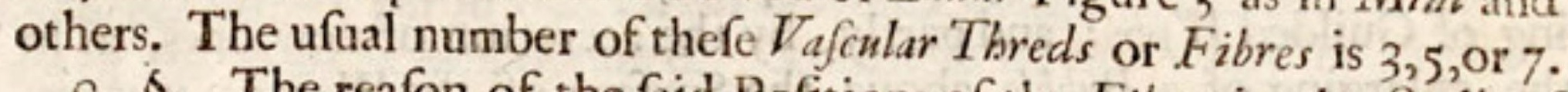

9. \$. The reafon of the faid Pofitions of the Fibers in the Stalk of the Leaf, is for its more Erect growth, and greater Strength: which, were the pofition of the faid Fibers in an even Line, and fo the Stal/s it felf, as well as the Leaf, flat; muft needs have been defective; as from what we have faid of the Circumferential pofture of the Lignous

C. 3. 5.24. Body in the Trunk, we may better conceive.

IO. $\delta$. As likewife for the fecurity of its $s a p$ : For by this means it is, that the feveral Fibers, and efpecially the main or middle $F$ iber of the Leaf, together with a confiderable part of the Parenchyma, are fo difpofed of, as to jut out, not from its upper, but its back, or neither Side. Whence the whole Leaf, reclining backward, becomes a Canopy to them, defending them from thofe Injuries which from colder Blafts, or an hotter Sun, they might otherwife fuftain. So that by a mutual benefit, as Thefe give fuck to all the Leaf, fo that
again protection to Thefe.

II. 6. Thefe Fibers are likewife the immediate Vifible Caufe of the Shape of the Leaf. For if the nethermoft Fiber or Fibers in the Stalk (which thence runs chiefly through the length of the Leaf) be in proportion greater, the Leaf is long; as in Endive, Cichory, and others: If all of a more equal fize, it ipreads rounder, as in Ivy, Doves-foot, Colts foot, \&c. And although a Dock-Leaf be very long, whofe Fibers notwithftanding, as they ftand higher in the stalk, are difpofed

Tab. 4. Fibres, ftanding, in or equal fize; yet herein one or more peculiar Fibres, ftanding, in or near the Center, betwixt the reft, and running
through the length of the Leaf, may be obferved.

I2. 6. In correfpondence alfo to the fize and fhape of thefe Fibres, is the Leaf flat. In that either they are very fmall, or if larger, yet

Tab. 4. in Borage, or at moft three parts of Ring; but either half of one, as For if either they were fo big parts of one, as in Mullen, may be feen. to include a Pith, the Energy of the $S$, or fo entire, as perfectly the faid Lignous Ring to fhoot forth $S_{a p}$ in that Pith, would caufe Root or Trunk: But the faid Fibers being not fide, as it doth in the Ring, but fo as to be they cannot fhoot any thing directly from themfelves, becaufe there through the faid opening, againt the $S$ ap having alfo a free vent unto oppfite, it can have no force; and fo neither will is thereforth on that hand; and fo will they confequen will they fhoot which the force of the sap directs, which is only on the right and
left. 
13. \$. The feveral Fibers in the stalk, are all Inofculated in the Leaf, with very many Sub-divifions. According as thefe Fibers are Inofculated near, or at, or thoot directly to the edge of the Leaf, is it Even, or Scallop'd. Where thefe Inofculations are not made, there we have no Leaves, but only a company of Filaments; as in Fensel.

14. \$. To the Formations of Leaves, the Fouldings immediately follow. And fometimes they have one Date, or are the contemporary works of Nature; each Leaf obtaining its diftinct fhape, and proper pofture together; both being perfect, not only in the outer, but Central and minuteft Leaves, which are five hundred times fmaller than the outer: both which in the Cautious opening of a Germen may be feen.

15. 6. Nor is there greater Art in the Forms, than in the Foulds or Poftures of Leaves; both anfwerably varying, as this or that way they may be moft agreeable. Of the 2uincuncial pofture, fo amply in- Treat. of the ftanc'd in by the Learned Sir Thomas Brown, I thall omit to fpeak. 2uincunx.

Others there are, which though not all fo univerfal, yet equally neceffary where they are, giving two general advantages to the Leaves, Elegancy and secnrity, $f c$. in taking up, fo as their Forms will bear, the leaft room; and in being fo conveniently couch'd, as to be capable of receiving protection from other Parts, or of giving it one to another; as for inftance,

16. 6. Firf, There is the Bow-Lap, where the Leaves are all laid fomewhat convexly one over another, but not plaited; being to the length, breadth and number of Leaves moft agreeable; as in the Buds of Pear-tree, Plum-tree, \&c. But where the Leaves are not fo thick fet, as to ftand in the Bow-Lap, there we have the Plicature, or the Flat-Lap; as in Rofe-Tree, Strawberry, Cinquefoyl, Burnet, \&c. For the Leaves being here plaited, and fo lying in half their breadth, and divers of them thus alfo collaterally fet together; the thicknefs of them all, and balf their breadth, are much alike dimenfions; by which they ftand more fecure within themfelves, and in better confort with other Germen-Growths in the fame Trufs. If the Leaves be much indented or jagg'd, now we have the Duplicature; wherein there are divers Plaits in one Leaf, or Labels of a Leaf, but in diftinct Sets, a leffer under a greater; as in Soucbus, Tanfey, \&c. When the Leaves ftand not collaterally, but fingle; and are moreover very broad; then we have the Multiplicature; as in Goofeberries, Mallows, \&c. the Plaits being not only divers in the fame Leaf, but of the fame set continuant, and fo each Leaf gather'd up in five, feven or more Foulds, in the fame manner as our Gentlewomens Fans, Where either the thicknefs of the Leaf will not permit a Flat-Lap, or the fewnefs of their number, or the fmalnefs of their Fibers, will allow the Rowl,there This may be obferved. Which is fometimes fingle, as in Bears-Ears, Arum, Flammula, Jerufalem Comflip, \&c. Sometimes double, the two Rowls beginning at each edge of the Leaf, and meeting in the middle. Which again, is either the Fore-Rowl, or the BackRowl. If the Leaf be defign'd to grow long, now we have the BackRowol, as in Docks, Sorrels, and the reft of this Kindred: as alfo in Primrofe, and other like Plants. For the main Fibers, and therewith a confiderable part of the Cortical Body ftanding prominent from the Back-fide of the Leaf, they thus ftand fecurely couch'd up be-

twixt: 
twixt the two Rowls; on whofe fecurity the growth of the Leaf in length depends. But thofe of Bears-Ears, Violets, Doves Foot, Warden, and many more, upon contrary refpects, are rowled up inwards. Laftly, there is the Tre-Rowl, as in Fern; the Labels whereof, though all rowled up to the main stem, yet could not ftand fo firm and fecure from the Injuries either of the Ground or Weather, unlefs to the Rowls in breadth, that by the length were fuper-induc'd; the stalk or main Stem giving the fame Protection here, which in other Plants by the Leaves, or fome particular Mantling, is contriv'd. Thefe, and other Foulds, See in the Figures belonging to the Firsit joat of the Fourth 2300 k.

17. 5. According to the Form and Foulding of every Leaf or Germen, is its Protection order'd; about fix ways whereof may be obferv'd; $f$. by Leaves, Surfoyls, Interfoyls, Stalks, Hoods and Mantlings. To add to what we have above given, one or two Inftances. Every Bud, befides its proper Leaves, is covered with divers Leafy Pannieles or Surfoyls; which, what the Leaves are to one another, are that to them all: For not opening except gradually, they admit not the Weather, Wet, Sun or Aer, to approach the Leaves, except by degrees refpondent, and as they are gradually inur'd to bear them. Sometimes, befides Surfoyls, there are alfo many Interfoyls fet betwixt the Leaves, from the Circumference to the Center of the Bud; as in the Hafel. For the Fibres of thefe Leaves ftanding out fo far from a plain furface; they would, if not thus fhelter'd, lie too much expos'd and naked to the severities of the Weather. Where none of all the Protections above-named, are convenient, there the Mesubranes of the Leaves by continuation in their firf forming (together with fome $F_{i}$. bres of the Lignous Body) are drawn out into fo many Mantles or $V_{\text {eils; }}$ as in Docks, Snakemeed, \&c. For the Leaves here being but few, yet each Leaf and its Stalk being both exceeding long; at the bottom whereof the next following Leaf ftill fprings up; the form and pofture of all is fuch, as fuperfedes all the other kinds of Protection, and fo each Leaf apart is provided with a $V$ eil to it felf. There, and other Protedions, See in the Figures belonging to the Firft yatt of the Fourth 23aok.

18. 5 The Ufies of the Leaves, I mean in refpect of their fervice to the Plant it felf, are thefe: Firft, for Protection; which, befides what they give one to another, they afford alfo to the Flower and Fruit. To the Flower in their Foulds; that being, for the moft part, born and ufher'd into the open Aer by the Leaves. To the Fruit, when afterwards they are difplay'd, as in Strawberries, Grapes, Rapss, Mulberries, \&c. On which, and the like, fhould the SunBeams immediately ftrike, efpecially while they are young, they would quite fhrivel them up; but being by the Leaves fcreened off; they imprefs the circumjacent Aer fo far only as gently to warm the faid Fruits, and fo to promote their Fermentation and Gromth. And accordingly we fee, that the Leaves above-named are excceding large in propotion to the Fruits: whereas in Pear-trees, Apple-lrees, \&ce. the Fruit being of a folider Parenchyma, and fo not needing the like protection, are ufually equal with, and often wider in Diameter than the Leaves. 
19. 5. Another ufe is for Augmentation; or, the capacity for the due fpreading and ampliation of a Tree or other Plant, are its, Leaves. For herein the Lignous Body being divided into fmall Fibres, and thefe running all along their lax and fpongie Parenchyma; they are thus a Body fit for the imbibition of Sap, and eafie Growth. Now the sap having a free reception into the Leaves, it ftill gives way to the next fucceeding in the Branckes and Trunk, and the voyding of the sap in thefe, for the mounting of that in the Root, and ingress of that in the Ground. But were there no Leaves to make a free reception of Sap, it muft be needs be ftagnant in all the Parts to the Root, and fo the Root being clogg'd, its fermenting and other Offices will be voyded, and fo the due Growth of the whole. As in the motion of a $W a t c h$, although the original term thereof be the spring, yet, the capacity for its continuance in a due meafure tbroughout all the Wheels, is the free and eafie motion of the Ballance.

20. 6. Laftly, As the Leaves fubferve the more copious advance. ment, fo the higher purity of the Sap. For this being well fermented both in the Root, and in its Afcent through the Trunk, and fo its Parts prepar'd to a farther feparation; the groffer ones are ftill depofited into the Leaves; the more elaborate and effential only thus fupplied to the Flower, Fruit and Seed, as their convenient Aliment. Whence it is, that where the Flowers are many and large, into which the more odorous Particles are copioufly receiv'd, the green Leaves have little or no fmell; as thofe of Rofe-tree, Carnations, FrenchMarigold, Wood-bind, Tulips, \&c. But on the contrary, where the Flowers are none, or fmall, the green Leaves themfelve are likewife of a ftrong favour; as thofe of Wormwood, Tanfie, Baum, Mint, Rue, Geranium Mofchatum, Angelica, and others.

\title{
An Appendix.
}

\section{Of Thorns, Hairs and Globulets.}

\begin{abstract}
$T^{\prime}$
Horns are of two kinds, Lignous and Cortical. Of the firft are fuch as thofe of the Hanthorn, and are conftituted of all the fame fubftantial Parts whereof the Germen or Bud it felf, and in a like proportion: which alfo in their Infancy are fet with the refemblances of divers minute Leaves. Of affinity with thefe are the Spinets or Thorny Prickles upon the Edges and Tops of divers Leaves, as of Barbery, Holly, Thiftle, Furze, and others; all which I think are the filamentous extremities of the Lignous Body fheathed in the Skin. But this principal differnce betwixt a Bud and thefe Lignous Thorns, is ob. fervable; That the Bud hath its Original from the Inner part of the Lignous Body, next the Pith: But thefe Thorns, from the outer, and Jefs fecund Part; and fo produceth no Leaves, but is, as it were, the
Mola of a Bud.
\end{abstract}


2. 5. Cortical Thorns are fuch as thofe of the Rasberry Bufh, being not, unlefs in a molt extraordinary fmall and invifible proportion propagated from the Lignous Body, but as, it feems, wholly from the Cortical and Skin, or from the exteriour part of the Barque.

C.2. 6.25. 3. 6. The Growth of this Thorn may farther argue what in the second Chapter we fuppofed; $\int c$. That as the proper Tendency of the Lignous Body, is to Afcend; fo of the Cortical to Defcend. For as the Lignous Thorn, like other Parts of the Trunk, in its Growth afcends; This, being almoft wholly Cortical, pointeth downdward. The ufe of Hift. of the Thorns the Ingenious Mr. Sbarrock hath obfeved.

Prop.ofVeget. 4. \$. Upon the Leaves of divers Plants two Produdions thew themfelves, $f c$. Hairs and Gloubulets. Of Hairs, only one kind is taken notice of ; although they are various. Ordinarily they are of a Simple Figure; which when fine and thick fet, as on moft Hairy Buds; or fine and long, as on thofe of the Vine, we call them Down.

5. 5. But fometimes they are Branched out, from the bottom to the top, reciprocally on every fide, in fome refemblance to a Stags Horn; as in Mullen. And fometimes they are Aftral, as upon Lavender, and fome other Leaves, and efpecially thofe of Wild Olive; wherein every Hair rifing in one round entire Bafis a little way above the furface of the Leaf, is then difparted, Star-like, into feveral, four, five or fix Points, all ftanding at right Angles with the faid perpendicular Bafis.

6. \$. The Ufes of Hairs are for Diftinction and Protection. That of Diftinction is but fecondary, the Leaves being grown to a confiderable fize. That of Protection is the prime, for which they were originally form'd together with the Leaves themfelves, and whofe fervice they enjoy in their Infant-eftate: For the Hairs being then in form of a Down, always very thick fet, thus, give that Protection to the Leaves, which their exceeding tendernefs then requires; fo that they feem to be vefted with a Coat of Frize, or to be kept warm, like young and dainty Chickens, in Wool.

7. 5. Globulets are feen upon Orach, both Garden and Wild; and yet more plainly on Mercury or Bonus Henricus. In thefe, growing almoft upon the whole Plant, and being very large, they are by all taken notice of.

8. 6. But ftrict Obfervation difcovers, that thefe Globulets are the natural and conftant Off-fpring of very many other Plants. Both. thefe Globulets, and likewife the diverfity of Hairs, I find that Mr.

Micrography. Hook hath alfo obferved. I take notice, that they are of two kinds; Tranfparent, as upon the Leaves of Hyfop, Mint, Baume, and many more White, as upon thofe of Germander, sage, and others. All which, though the naked Eye will difcover, yet by the help of Glaj/es we may obferve them moft diftincly. The ufe of thefe we fuppofe the fame, in part, with thofe of the Flower, whereof we hall fpeak. 


\section{CHA P. V. \\ Of the FLOWER.}

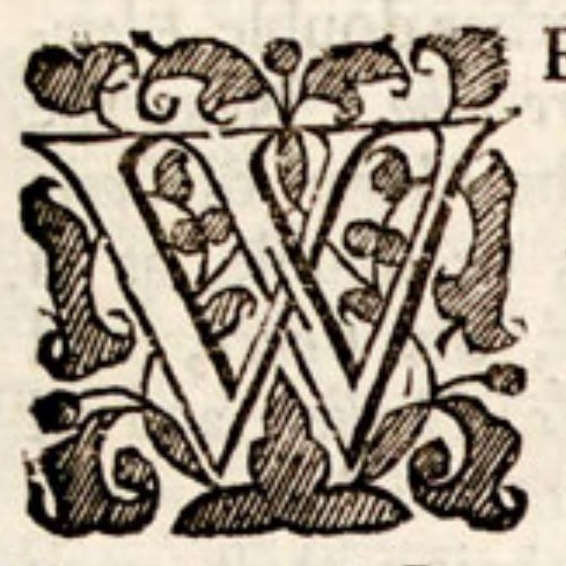

E next proceed to the Flower. The general Parts whereof are molt commonly three; $f c$. the Empalement, the Foliation, and the Attire.

2. 6. The Empalement, whether of one or more pieces, I call that which is the utmolt Part of the Flower, encompaffing the other two. 'Tis compounded of the three general Parts, the Skin, the Cortical and Lignous Bodies, each Empaler (where there are divers) being as another little Leaf; as in thofe of a 2uince-Floner, as of as they happen to be overgrown, is well feen. As likewife in the Primrofe, with the green Flower; commonly fo calld, though by a miftake: For that which feems to be the Flower, is only the more flourihing Empalement, the Flower it felf being White. But the continuation of all the three aforefaid Parts into each Empaler, is difcoverable, I think, no where better than in an Articboke, which is a true Flower, and whofe Empalers are of that amplitude, as fairly to fhew them all: As alfo, that the Original of the skin of each Empaler or Leaf is not diftinct from that of the reft; but to be all one piece, laid in fo many Plaits or Duplicatures, as there are Leaves, from the outermoft to the inner and moft Central ones.

3. 5. The Defign of the Empalement, is to be Security and Bands to the other two Parts of the Flower: To be their Security before its opening, by intercepting all extremities of Weather: Afterwards to be their Bands, and firmly to contain all their Parts in their due and moft decorous poftnre: fo that a Flower without its Empalement, would hang as uncouth and taudry, as a Lady without her Bodies.

4. §. Hence we have the reafon why it is various, and fometimes wanting. Some Flowers have none, as Tulips; for having a fat and frim Leaf, and each Leaf likewife ftanding on a broad and ftrong $\mathrm{Ba}$ fis, they are thus fufficient to themfelves. Carnations, on the contrary, have not only an Empalement, but that (for more firmitude) of one piece: For otherwife, the Foot, of each Leaf being very long and flender, moft of them would be apt to break out of compafs: yet is the top of the Empalement indented alfo; that the Indentments, by being lapp'd over the Leaves before their expanfion, may then protect them; and by being fpread under them afterwards, may better fhoulder and prop them up. And if the Feet of the Leaves be both long and very tender too, here the Empalement is numerous, though confifting of feveral pieces; yet thofe in divers Rounds, and all with a counterchangeable refpect to each other (which alfo the Learned Sir Thomas Brown obferves) as in all Knapweeds, and other Flowers; whereby, how commodious they are for both the aforefaid Treat. of the ends, myy eafily be conceiv'd; and well enough exemplified by the Scales of Fifbes, whereunto, as to their pofition, they have not an unapt refem'slance.

L 2 
5. 6. THE FOLIATION alfo, is of the fame fubftantial Nature with the green Leaf; the Membrane, Pulp, and Fibres whereof, being, as there, fo here, but the continuation of the Skin, the Cortical and Lignous Bodies.

6. 6 . The Foulds of the Flower or Foliation are various, as thofe of the green Leaf; but fome of them different. The moft general are, Firft, The Clofe-Couch, as in Rojes, and many other double Flowers. Then the Concave-Couch, as in Blattaria flore albo. Next the Plait, as in fome of the Leaves of Peafe-Blooms, in the Flowers of Coriander, \&c. which is either fingle, as in thofe nam'd; or double, as in Blew-Bottle, facea, and more of that rank. Next, the Couch, and Plait together in the fame Flower, as in Marigolds, Daifres, and all others of an agreeing form: where the firft apparent Fould or Compofture of the Leaves is in Couch; but the Leaves being erect, each likewife may be feen to lie in a double Plait within it felf. Then the Rowl, as in the Flowers of Ladies-Bower, the broad top of each Leaf being by a double Rowl foulded up inwardly. Next, the Spire, which is the beginning of a Roml; and may be feen in the Flowers of Mallows, and others. Laftly, the Plait and Spire together, where the Part analogous to the Foliation, is of one piece, the Plaits being here laid, and fo carried on by Spiral Lines to the top of the Flower, as is in divers, and I think, in Convolvulus Doronici folio, more elegantly feen. Thefe and other Foulds, See in the Figures belonging to the Second J Patt of the Fourth 230ok. The reafon of all which varieties, a comparative confideration of the feveral Parts of the Flower may fuggeft. I'le only mention, That no Flower, that I find, hath a Back-Rowl, as hath the green Leaf. For two Reafons; becaufe its Leaves have not their Fibres ftanding out much on their backfide, as the green Leaves have; and becaufe of its Attire, which it ever embofomes, and cannot fo well do it by a Back-Rowl.

7. 6. The ufual Protections of Flowers by the Precedents are expref'd, $\int c$. Green Leaves and Empalements. Some have another more peculiar, that is a double Veil; as the Spring-Crocus. For having no Empalement, and ftarting up early out of the Mould, even before its Green Leaves, and that upon the firft opening of the Spring; left it fhould thus be quite ftarved, 'tis born fwath'd up in a double Blanket, or with a pair of sheets upon its Back.

8. 6. The Leaves of divers Flowers at their Bafis have an bairy Tuft; by which Tufts the Concave of the Empalement is filled up; That, being very choice and tender, they may thus be kept in a genthe and conftant Warmth, as moft convenient for them.

9. 5. The Leaves of the Flower, though they are not hairy all over, yet in fome particular parts they are often fet with a fine Downy Velvet; that, being by their fhape and pofture in thofe parts contiguous to their delicate and tender Attire, they may thus give it a more foft and warmer touch. Thus in the Flower of Ladies Bower, thofe parts of its Leaves which rowl inward, and lie contiguous to the Attire, are Downy; whereas the other Parts are fmooth or bald : So the Flowers of Peafe, spanifo Broom, Toad-Flax, and many others, where contiguous to their Attires, are deck'd with the like Hairy Velvet. 
I0. अ. As upon the Green Leaves, fo upon the Flowers are Globulets fomtimes feen; as upon the backfide of that of Enula. On none more plainly than that kind of Blattaria with the white Flower where they are all tranfparent, and growing both on the Stalk and Leaves of the Flower, each fhewing likewife its Peduncle whereon it is erected.

II. 6. The ufe of the Flower, or the Foliation whereof we now fpeak, (that is, as to its private fervice) is for the protection of the Attire; This, as its under, and the Empalement as its upper Garments. As likewife of the Fruit: The neceffity of which Service, in fome Cafes, by the different fituation of the Flomer and Fruit, with refpect to each other, is evident; Apples, Pears, and feveral other Fruits, ftanding behind or under the Flower; but Cherries, Aprecots, and divers others, within it. For thefe. being of a very tender and pulpous Body, and withal putting forth with the colder part of the Spring; could not weather it out againft the Variations and Extremities of the Air, (as thofe of a more folid Parenchyma can) except lodged up within their Flowers.

12. 5. And as the Flower is ferviceable to the fafety of the Fruit, fo is it to its growth; $f c$. in its Infancy, or Embryo-eftate; for which purpofe, as there is a Flower, fo that Flower is greater or lefs, according as the nature of the Fruit to which it belongs, and the plenty of the $S a p$ by which the Fruit is fed, doth require, Thus, where the young Fruit is of a folider Subftance and the afcent of the Sap lefs copious, were there here no Flower to promote the faid afcent thereof into the Fruit (in the manner as is effected by the Green Leaves) it muft needs pine and die, or prove lefs kindly. On the contrary, fhould the Flower be over-large, it would not only promote the afcent of the Sap up to the Fruit, but being as yet overproportionate to it, would likewife it felf exhauft the fame $s a p$, as faft as afcendent; like a greedy Nurfe, that prepares the Meat for her Child, and then eats it up her felf. Thus we fee Apples and Pears, with a Flower of a moderate Size; like their Body, of a middle Conftitution, and their sap, of a middle quantity: But 2 uinces, being more folid, befides that they have as great a Flower, the Imqalers of their Flower alfo thrive fo far as to become handfom Leaves; continuing alfo after the Flower is fallen, firm and verdent a great while; folong, till the Fruit be able to provide for it felf. On the other hand, Plums being more tender and Sappy than Appels and Pears, befides that their Empalers are much alike, their Flower is lefs. and Goofberries and Currans, which are ftill more Pulpy, and the courfe of the $\mathrm{Sap}$ towards them more free, have yet a Flower far lefs. And Grapes, whofe sap is ftill of quicker Afcent, have fcarce any Flower at all; only fome fmall refemblance thereof, ferving juft upon the fetting of
the Fruit, and no longer.

13. 6. THE ATTIRE, I find to be of two kinds, Seminiforme, and Florid. That which I call Seminiforme, is made up of two general take leave to call them, ) have the appearance, efpecially in many
Flowers, of fo many little seeds: but a For, upon enquiry, we find seeds : but are quite another kind of Body. 
be folid, and for fome time after their firft formation, are entire; yet are they really hollow; and their fide, or fides, which were at firft entire, at length crack afunder: And that moreover the Concave of each Semet is not a meer vacuity, but fill'd up with a number of minute Particles, in form of a Powder. Which, though common to all Semets, yet in fome, and particularly thofe of a Tulip or a Lilly, being larger,

Tab. 4.f.r2. is more diftinctly obfervable.

14. 6. Thefe Semets are fontimes faftned fo, as to ftand erect above their Chive, as thofe of Larks-heel. Somtimes, and I think ufually, fo as to hang a little down by the midle, in the manner and figure of a Kidney; as in Mallows. Their Cleft or Crack is fometimes fingle, but for the moft part double: At thefe Clefts it is that they disburfe f. 12. -a. their Powders; which as they ftart out, and ftand betwixt the two Lips of each Cleft, have fome refemblance to the common Sculpture of a Pomegranate with its Seeds looking out at the Cleft of its Rind. This muft be obferv'd when the Clefts are recently made, which ufually is before the expanfion of the Flower.

15. 5. The Particles of thefe Powders, though like thofe of Meal or other Duft, they appear not eafily to have any relugar fhape; yet upon ftrict obfervation, efpecially with the affiftance of an indifferent Glafs, it doth appear, That they are a Congeries, ufually, of fo many perfect Globes or Globulets; Sometimes of other Figures, but always regular. That which obfcures their Figure is their being fo fmall : In Dogs-Mercury, Borage, and very many more Plants, they are extreamly fo. In Mallows, and fome others, more fairly vifible.

16. S. Some of thefe Powders, are yellow, as in Dogs-Mercury, Goats-Rue, \&c. and fome of other Colours: But moft of them I think are white; and thofe of yellow Henbane very elegant; the disburs'd Powers whereof, to the naked eye, are white as Snow; but each Globulet, through a Glafs, tranfparent as Cryftal; which is not a fallacy from the Glafs, but what we fee in all tranfparent Bodies whatfoever, lying in a Powder or fmall Particles together The Parts of this Attire, fee in Tab. 4. But efpecially, in the Figures belonging to the Second joatt of the Fourth 2Book.

17. \$. The Florid Attire, is commonly known by the blind and rude Name of Thrums; as in the Flowers of Marigold, Tanfle, \&c. How in adequate its impofition is, obfervation will determine. For the feveral Thrums or rather suits, whereof the Attire is made up, howcver elfe they may differ in various Flowers, in this agree, that they

Tab.4.f.I3.a. the moft part of Three Pieces (for which I call them Suits) and each
( Piece of a different, but agreeable and comely form.

18. 6. The outer Part of every Suit, is its Floret: whofe Body or Tube is divided at the top (like that of the Comflip) into five
diftinct Leaves. So that a Floret, is the Epitome of a Flower: and

f. 13.b. is all the Flower that many Plants, as Mugwort, Tanfie, and others, have. What the Learced Sir Thomas Bromn obferveth of the Treat. of the number Five, as to the Leaves of the Flower, is ftill more univerfally
Quincumx. holding in thefe of the Floret.

19. 6. Upon the Expanfion of the Floret; the next Part of the Suit is from within its Tube brought to fight; which we may (with re-

f. 13.c. fpect to that within it) call the sheath. For this alfo, like the Floret, 
is a Concave Body; in its thape very well refembling the Fiftulous Pouches of Wake-Robin, or of Dragon. .

20. 6. The Sheatb, after fome time, dividing at the top, from within its Concave the Third and innermole part of the Suit, fc. the Blade advanceth and difplayes it felf. This Part is not hollow, as Tab.4.f.i3.d the other two, but folid; yet at its Point, is commonly, divided into two halves.

21. 5. About the faid Point efpecially, there appears, Globulets, which are of the fame nature with thofe of a semet, though not fo copious. So that all Flowers have their Powders or Globulets. The whole Attire may in After Per, Blewbottle, \&c. where the Suits are large, be plainly obferved without a Glafs. The Parts of this Attire, See in Tab. 4. But efpecially in the Figures belonging to the second Datt of the Fourth $2300 \mathrm{k}$.

22. \$. The ufe of the Attire, how contemptibly foever we may look upon it, is certainly great. And though for our own ufe we value the Leaves of the Flower, or the Foliation, moft; yet of all the three Parts, this in fome refpects is the choyceft, as for whofe fake and fervice the other two are made. The ufe hereof, as to Ornament and Diftinction, is unqueftionable; but is not all. As for Diftinction, though, by the belp of Glaffes, we may make it to extend far ; yet in a paffant view, which is all we ufually make, we cannot fo well. As for Ornament, and particularly in reference to the Semets, we may ask, If for that meerly thefe were meant, then why fhould they be fo made as to break open, ${ }^{2}$ or to contain any thing within them? Since their Beauty would be as good if they were not hollow; and is better before they crack and burft open, than afterwards.

23. 5. Other ufes hereof therefore we muft acknowledge, and may obferve. One is, for food; for Ornament and Diftinction to us, and for Food to other Animals. I will not fay, but that it may ferve even to thefe for Diftinction too, that they may be able to know one Plant from another, and in their flight or progrefs fettle where they like beft : and that therefore the varieties of thefe fmall parts are many, and well obferved by them, which we take no notice of. Yet the finding out of Food is but in order to enjoy it: Which, that it is provided for a vaft number of little Animals in the Attires of all Flowers, obfervation perfwades us to believe. For why elfe are they evermore here found? Go from one Flower to another, great and fmall, you fhall meet with none untaken up with thefe Guefts. In fome, and particularly the Sun-Flower, where the parts of the Attire, and the Animals for which they provide, are larger, the matter is more vifible. We muft not think, that God Almighty hath left any of the whole Family of his Creatures unprovided for; but as the Great Mafter, fome where or other carveth out to all; and that for a great number of thefe little Folk, He hath ftored up their peculiar provifions in the Attires of Flowers; each Flower thus becoming their Lodging and their Dining-Room, both in one.

24. \$. Wherein the particular parts of the Attire may be more diftinctly ferviceable, this to one Animal, and that to another, I cannot fay : Or, to the fame Animal, as a Bee, whether this for the Honey, another for their Bread, a third for the Wax : Or whether all only fuck 
from hence fome Fuice; or fome may not alfo carry fome of the Parts, as of the Globulets, wholly away.

25. 6. Or laftly, what may be the Primary and Private Ufe of the Attire ( for even this abovefaid, though great, yet is but Secondary ) I now determine not.

\section{H A P. VI.}

\section{Of the FRVIT.}

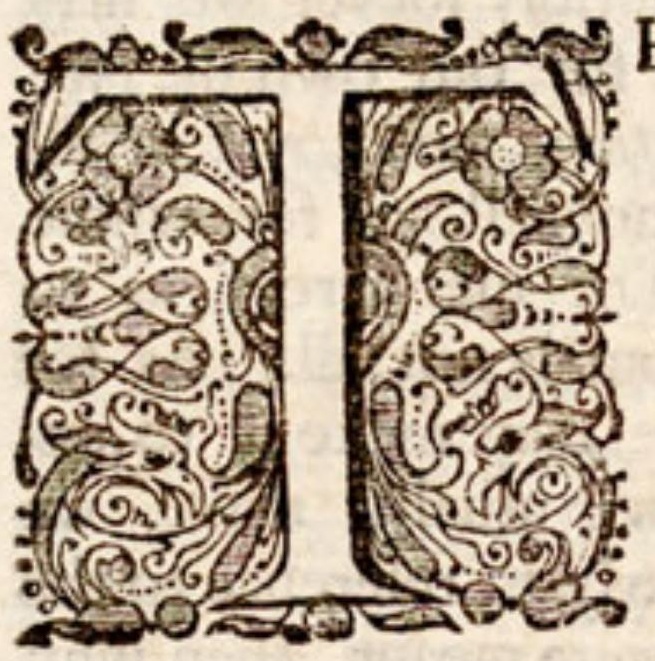

HE general compofition of all Fruits is one, that is, their Effential and truly Vital Parts, are in all the fame, and but the continuation of thofe which in the other Parts of a Plant, we have already obferved. Yet becaufe by the different Conftitutions and Tinctures of thefe Parts, divers confiderably different Fruits refult; I fhall therefore take aparticular view of the more known and principal of them, $\int c$. Apples, Pears, Plums, Nuts and Berries.

2. §. AN APPLE, if cut traverfe, appears conftitued of four diftinct Parts, the Pilling, the Parenchyma, Branchery, and Coare. The Pilling is only the fpreading and dilatation of the skin, or utmoft part of the Barque in the Branch. The Parenchyma, when full ripe, is a tender delicate Meat. Yet as the Pilling is but the Continuation of the utmoft part of the Barque; fo is this, but the continuance and ampliation, or ( as I may call it ) the fwelth and fuperbience of the $I n$ ner Part thereof; which upon obfervation of a young and Infant-Apple efpecially, is evident. Thus we fee the Pith, which is often tough; in many Roots, as Parjneps, Turneps, \&c. is tender and edible. So here, the Parenchyma, though originally no more than the Barque, yet the copioufnefs and purity of its $S_{a p}$ being likewife effectual to the largnefs and finenefs of its growth, it thus becomes a foft and tender meat. The Branchery is nothing elfe but the Ramifications of the Lignous Body throughout all the parts of the Parenchyma; the greater Branches being likewife by the Inofculations of the lefs (as in the Leaf) united together. The main Branches are ufually Twenty : Ten are fpred and diftributed through the Parenchyma, moft of them enarching themfelves towards the Cork or Stool of the Flower: The other Ten, running from the stalk in a directer Line, at laft meet the former at the faid Cork; and are there ofculated with them. Of thefe latter, five are originated from one; which running along the Center of the Stalk, and part of the Parenchyma of the Fruit, is therein at laft divided. To thefe the Coats of the Kernels are faftned. So that whereas moft of thefe Branches were originally extended even beyond the Fruit, and inferted into the Flower for the due growth 
thereof; the Fruit afterwards growing to fome head, and fo intercepting and preying upon the Aliment of the Flower, ftarves that and therefrom fuperfedes the fervice of the faid Branches to it felf, fifteen for its Parencbyma, and five for its $S_{e e d}$. The Coar is originated from the Pith; for the Sap finding room enough in the Parenchyma, through which to difpence it felf all abroad, quits the Pith, which thereby hardens into a Coar. Thus we fee the Infertions, alchough originate from the Cortical Body, yet their Parts being, by the Inofculations of the Lignous, fo much comprefs'd and made to co-incide together, they become a Body very compact and denfe. And in the Barque the fame thing is effected by Arefaifion only, or a meer voydance of the Sap; the Inner Part whereof, though foft and fappy, yet its fuperficial Rind is often fo hard and fmooth, that it may be fairly writ upon. The Parts of an Apple, See in the Figures belonging to the Thind 1 Datt of the Fourth $2300 k$.

3. \$. IN A PEAR there are five diftinct Parts, the Pilling, the Parenchyma, Branchery, Calculary, and Acetary. The three former are here and in an Apple much alike; faving that here the Inner or SeedRranches ordinarily ftand double. The Calculary (moft obfervable in rough-tafted, or Choak-Pears) is a Congeries of little ftony Knots. They are many of them difperfed throughout the whole Parenchyma: But lying more continuous and compact together towards the Center of the Pear, furround the Acetary there, in a fomewhat Globular Form. About the stalk they ftand more diftant; but towards the Cork or Stool of the Flower, they ftill grow clofer, and there at laft gather (almoft) into the firmitude of a Plum-ftone it felf. Within this lies the Acetary; 'tis allways four, and by the bounding of the Calculary of a Globular Figure. 'Tis a fimple Body, having neither any of the Lignous branched in it, nor any $C_{\text {alculous }} K_{\text {nots. }}$. It is of the fame fubftantial nature with the outer Parenchyma; but whether it be abfolutely one with it, or bederived immediately from the Pith, my Enquiries yet made, determine not.

4. \$. The Original of the Calculary I feem to have neglected. But hereof we may here beft fay, that whereas all the other Parts are Effential and truly Vital; the Calculary is not: but that the feveral Knots whereof it confifts, are only fo many meer Concretions or Precipitations out of the Sap; as in Urines, Wines, and other Liquors, we often fee. And that the Precipitation is made by the mixture and re-action of the Tinctures of the Lignous and Cortical Bodies upon each other: Even as all Vegetable Nutrition or Fixation of Parts is alfo made by the joynt efficiency of the two fame Tinctures, as hath been faid. Hence we find, that as the Acetary hath no Branehes of the Lignous Body, fo neither hath it any Knots. Hence likewife it is, that we have fo different and contrary a taft in the Parenchyma beyond the Calculary, from that in the Acetary: For whereas this is four, that, wherein the faid Precipitations are made, is fweet; being much alike effect to what we find in mixing of Corals, \&os with Vinegar or other acid Liquors. The Parts of a Pear, See in Tab. 4. But efpecially in the Figures belonging to the Third joatt of the Fourtb $2300 \mathrm{k}$. 
5. \$. IN A PLUM (to which the Cherry, Apricot, Peach, Walnut, \&c. ought to be referr'd) there are four diftinct Parts, the Pilling, the Parenchyma, Branchery and Stone. The Pilling and Parenchyma are, as to their Original, with thofe of an Apple or Pear, both alike. As likewife the Brunchery; but differently ramified. In Plums (I fuppofe all ) there are five main Out-Branches, which run along the Surface of the Stone from the Bafis to the point thereof, four of them by $\tau_{a b .4 . f . I 5}$ one Ridge, and one by the other oppofite to it. In an Apricot there is the fame number, but the fingle Branch runs not upon the surface, but through the Body of the Stone. There are likewife two or three fmaller Branches, which run in like manner under the other Ridge for fome fpace, and then advancing into the Parenchyma, therein difperfe themfelves: Thefe latter fort in Peaches are numerous throughout.

6. 6. But notwithftanding the different difpofition of the Branches of the Fruits aforefaid; yet is there one Branch difpos'd in one and the fame manner in them all. The entrance hereof into the stone is at its Bafis; from whence running through its Body, and ftill inclining $I_{a b}$ 4.f.I5. or arching it felf towards its Concave, is at laft, about its Cone, thereinto emergent, where the Coats of the seed are appendent to it. Of the seed-Branch 'tis therefore obfervable that after its entrance into the Fruit, itis always prolonged therein to a confiderable length; as is feen not only in Apples, \&c. where the Seed ftands a good diftance from the Stalk; but in Plums likewife, where it ftands very near it ; in that here the Seed-Branch, as is faid, never ftrikes through the stone into the Coats of the Seed directly, but runs through a Chanel cut in the Stone, till it iffues, near the Cone, into the Concave thereof.

7. 5. The Stone though it feem a fimple Body, yet it is compounded of different ones. The Inner Part thereof, as it is by far the thinneft, fo is it the moft denfe, white, fmooth and fimple. The Original is from the Pith; difficult, but curious to obferve: For the seedBranch, not ftriking directly and immediately quite through the Bafis of the Stone, but in the manner as is above defcribed, carries a confiderable Part of the Pith, now gather'd round about it, as its $P a-$ renchyma, along with it felf; which upon its entrance into the concave of the Stone about its farther end, is there in part fpread all over it, as the Lining thereof. The outer and very much thicker Part, confifteth partly of the like Precipitations or concrete Particles, as in a $\boldsymbol{P}_{\text {ear }}$; being gathered here much more clofely, not only to a Contiguity, but a Coalition into one entire Stone; as we fee in Pears themfelves, efpecially towards the Cork, they gather into the like Stoninefs; or as a stone, Mineral, or Animal, is oftentimes the product of accumulated Gravel. But as the Parenchyma is mixed with the Concretions in the Calculary, fo is it alfo, though not vifibly, with thefe in the stone, the ground of the stone being indeed a perfect Parenchyma; but by the faid Concretions fo far alter'd, as to become dry, hard and undiftinguifhable from them. All which Particulars, are obfervable only in the feveral degrees of Growth in the young Fruit. And are reprefented in Tab. 4. But efpecially by the feveral Figures belonging to the Third and Fourth 2 arts of the Fourth $2500 k$. 
8. 6. IN A NUT (to which an Akern is analogous) there are three general Parts, the Cap, Shell, and Pith. The Cap is conftituted of a Pilling and Parenchyma, derived from the Barque; and Ramulets from the Lignous Body of the Branch. The Shell likewife is not one fimple Body, but compounded. The Superficial Part thereof is originated from the Pilling or Skin of the Cap, from the infide whereof it is, in a Duplicature, produc'd and fpred over the Shell. Which, if you look at the Bafis of the Shell, is farther evident: for that being continuous with the Parencbyma of the $C a p$, without the interpofure of the Skin, the faid fuperficial $P$ art is there wanting. The thicker and inner Part of the shell confifteth of the fame Parenchyma as that of the Cap, with a Congeries of Precipitations filled up, as in a stone. And as the Lignous Body is branched in a Stene, fo, with fome difference, in a shell. The outer Branches or Ramulets are numerous, each iffuing out of the Parenchyma of the Cap, and entring the shell at the Circumference of its $B a f i s$, and fo running betwixt its fuperficial and inner Parts towards the Cone, round about. The Inner or Seed-Branch is fingle, entring in, as do the other, at the Bafis of the shell, but at the Center thereof: from whence it runs, not through the Shell, as in Plums through the Stone; but through the Pith, as far as the Cone, where the Coats of the seed hang appendent to it. The Pith whether derived from the fame part both in name and nature in the Branch and Stalk; or from the Cortical Body, I yet determine not. The Parts of a Nut, See in the Figures belonging to the Third 1Patt of the Fourth 2300k.

9. 5. A BERRY, as a Goofeberry (to which Corinths, Grapes Hips, \&c. are to be referr'd) confifteth, befides the Seed, of the three general Parts, Pilling, Parenchyma and Branchery. The Pilling is originated as in the foregoing Fruits. The Parenchyma is double, as likewife in fome other Berries. The outer is commonly, together with the Pilling, call'd the skin, and is that part we fpit out, being of a four taft. Now as the Pilling is originated from the outer, fo this from the inner Part of the Barque; and accordingly the Pores thereof may be obferved plainly of a like fhape with thofe both of the Cortical Body and Pith. The Inner or Pulp is of a fweet tafte, and is the Part we eat: It is of a Subftance folaxe and tender, as it would feem to be only a thicker or jellied fuice; although this likewife be a true Parenchyma, fomething like that of an Orange or Limon, with its Pores all fill'd up with Liquor. The Branchery is likewife double: The Exterior runs betwixt the Pilling and Outer Parenchyma in arched Lines, from the Stalk to the Stool of the Flower. Thefe outer Branches, though of various number at the stalk, yet at the Cork are ufually ten principal ones; five for the five Leaves of the Flower, and five for the Attire. The Inner muin Branches are two, diametrically oppofite to each other, and at the cork with the other inofculated. From thefe two are branched other fmaller, every one having a Seed appendent to it, whofe coats it entreth by a double Filament, one at the Bafis, the other at the Cone. They are all very white and turgent, and by a flaunt cut, may be obferv'd concave; thus reprefenting themfelves analogous to fo many true Jpermatick $V_{e} / f e l s$. The

$$
\mathrm{M} 2 \text { Parts }
$$


Parts of a Goofeberry, See in the Figures belonging to the Third that of the Fourth $2300 k$.

10. 6. The Ufes of Fruits are for Man, (fometimes alfo other Animals, as are Akerns and Haws) and for the Seed. For Man, they are fo varioufly defirable, that till our Orchards and store-Chambers, Confectioners-Stoves and Apothecaries-Shops, our Ladies Clofets, their Tables or Hands are empty of them, I fhall not need to enquire for what. If it be asked, how the Fruit becomes, generally above all the other Parts, fo pleafant a Meat? It is partly from the Sap, the groffer portion thereof being depofited in the Leaves, and fo the purer hereunto referved. Partly from the Globular Figure of the Fruit. For the sap being thus in a greater quantity herein, and in all Parts equally diffus'd, the Concoction hereof, as in a $V_{e} / f e l$, is with greateft advantage favoured and promoted. Wherefore all Fruits, which we eat raw, how fmall foever, are of a Globular Form, or thereunto approaching; and the nearer, the delicater; amongft Apples, the Pipin; amongft Pears, the Burgundian; and amongft all Fruits, the Grape; and amongft Grapes, the roundeft, are of all, the moft dainty.

II. 5. The vifible caufe of this Globular Figure, is the Flower; or the Inofculation of all the main Branches at the Stool of the Flower? and upon the fall of the Flower, the obtufenefs, and with Wind and sun, as it were the feaing of their feveral ends: For thus the Sap entering the Fruit, being not able to effect, either a Difunion, or a fhooting forth of the faid Branches, and fo to carry on their Growth in length; they muft of neceffity be enarch'd, and with the Parenchyma more and more expand themfelves. Whereas were they difpofed and qualified otherwife, than as is faid; inftead of forming a Fruit within bounds, they would run out into all extravagance, and even into another little Iree or Leafy Growth.

12. 5. To the Seed, the Fruit is ferviceable; Firft, in order to its being fupply'd with a due and moft convenient $S a p$, the greater part thereof, and that which is lefs elaborated, being, in its paflage towards the seed, thereinto received; the Fruit doing the fame office to the Seed, which the Leaves do to the Frwit; the Sap in the Fruit being, in a laxe comparifon, as the Wine; and that for the seed, a Imall part of the higheft Spirit rectified from it.

13. 6. So likewife for its Protection, in order to the profperous carrying on and perfecting of its generation, and fecurity being perferted. Which protection it gives not only to the Seminal sap and Seed it felf; but ever alfo to its seed-Branch. Thus we fee an Apple, befides that it is it felf of ample compafs, for the fake of its seed, hath likewife its Coar; as if it were not fufficient, that the Walls of their Room are fo very thick, unlefs alfo wainfcoated. In a Pear again, where the Parenchyma is of lefs compafs than that of an Apple, to what protection this affords, that of the Calculary is fuper-added. But in a Plum, where the Parenchyma is exceeding tender, and in a Peach, which hangs late, and till Autumn Frofts approach, we have not only the Rubbifh of a Calculary, but ftout Stone-Walls. Within which alfo, not only the Seed it felf, but the Seed-Branch is evermore immur'd. Laftly, in a Nut, where the shell being not furrounded with a Parenchyma, that protection is wanting without, 'tis anfwer'd by an ample 


\section{Book I.}

of Plants.

Pith within it; and the seed-Branch likewife included, not meerly in the Body of the Shell, as in a Plum, but within the Pith it felf. So neceffary is this defign, that what the Hen by Incubation of Hovering, is to the Egg or Chick; that the whole Fruit, by comprehenfion, is to the Seed.

\section{CHA P. VII.}

\section{Of the SEED, in its State of Generation.}

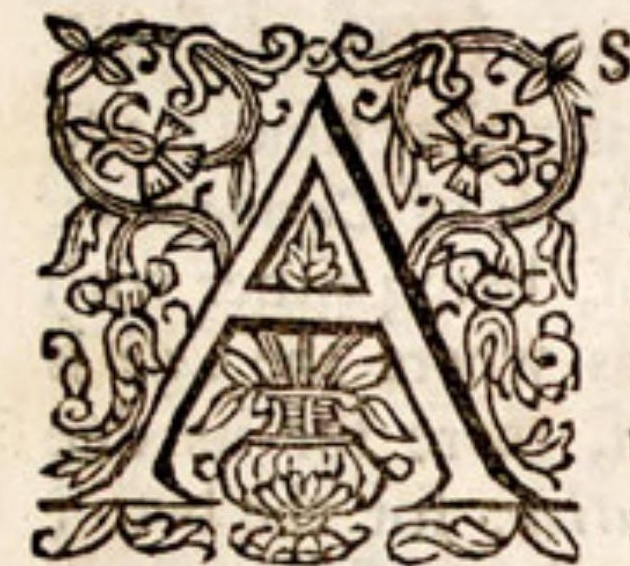

the Original, fo the Ultimate end and Perfection of Vegetation is the seed. How it is the former, and in its ftate apt for Vegetation, hath already been feen. How the Jatter, and in its ftate of Generation, we fhall now laftly enquire. In doing which, what in the other ftate, was either not diftinctly exiftent, or not fo apparent, or not fo intelligible, will occur.

2. \$. The two general Parts of the seed are its Covers and Body. The Covers in this eftate are ufually Four. The outmoft, we may call the $C a \int e$. 'Tis of a very various form; fometimes a Pouch, as in Nafturtium, Cochlearia; a Cod, as in all Pulfe, Galega; fometimes not entire, but parted, or otherwife open, as in sorrel, Knotgrafs; withmany other forms: I think alwaies more heterogeneous to that of the Seed, by which it differs from the proper Coats. To this the Caps of Nuts, and the Parenchyma's of other Fruits are analogous.

3. 5. The two next are properly the Coats. In a Bean efpecially, and the like; from whence, to avoyd Confufion, the denomination may run common to the refponding Covers of other Seeds. The Colour of the outer, is of all degrees, from White to the Blacknefs of fett. It's Figure fometimes Kidney'd, as in Alcea, Beben, Poppy; Triangular, as in Polygonatum, Sorrel; Spherically triangular, in Mentba, Melifja; Circular, in Leucoium, Amarantbus; Globular, in Napus, Afperula; Oval, in Speculum Veneris, Tithymalus; half Globe, in Coriander; that which we take for one fingle round Seed, being a Conjugation of two ; half Oval, in Anife, Fennel; Haftal, in Lactuca; Cylindrical, as, if I miftake not, in Facobaa; Pyramidal, in Geranium Althese fol. with many other differences. But the Perfection of one or two of the faid Figures lieth in the $C$ afe. So that, as all Lines and Proportions are in the Leaf and Flower; fo all Regular solids in the Seed; or rather in its Covers.

4. 6. ' $T$ is fometimes gliftering, as in Speculun Veneris; Rough-caft, in Catanance; Studded, in Beben, Balttaria; Favous, in Papaver, Antirrbinum, Lepidum annuum, Alced Veficaria, Hyofcyamus, and many more, before the Seeds have lain long by ; Pounced, in Phalangium Crete, Lithospermum; Ramified, in Pentaphyllum fragifersm Erectum majus, refembling 
refembling the Fibers of the Ears of the Heart; fome juft Quinguenerval, as in Anifum, and many more, the Lignous Body being in five main $\mathrm{Fi}_{i-}$ bers branched therein. The Figures, and Surface, of Thefe, and other Seeds, See in the Tables belonging to the Fourth J Patt of the Fourth 2 20ok.

5. \$. The covers of not only Quince-Seeds, and thofe of Pfyllium (more ufually taken notice of) but thofe alfo of Horminum, Nafturtium, Eruca, Camelina, Ocymum, and divers others, have a Mucilage. Which, though it be not vifible when the Seeds are throughly dry; yet lying a while in fome warm Liquor, or only on the Tongue, it fwells more or lefs, and upon them all fairly fhews it felf, On that of Ocymum it appears grayilh; on the other, tranfparent ; and on that of Nafturtium Hortenfe very large; even emulous of the inner Pulp furrounding a Goofeberry-Seed. The putting of Clary-seed into the Eye, may have been brought into ufe from this Mucilage, by which alone it may become Medicinal. And thus far of the Superficies,

6. §. The sature of the outer Coat is alfo various, Membranous, Cartilaginous and Stony; the like Precipitations being fometimes made herein, as in a Stone or shell; as in that of the Seeds of Cartbanum, Lithoßpermum and others. The Defignment hereof, being either with refpect to the Seed in its ftate of Generation; as where the $C_{a j e}$ is either wanting, or at leaft infufficient of it felf, there for its due protection and warmth. Or, in its ftate of Vegetation, for the better Fermenting of its Tinclures and Sap; the Fermentations of fome Seeds not well proceeding, unlefs they lie in their Stony Casks in the Ground, like Bottled Liquors in Sand.

7. \$. All seeds have their outer Covers open; either by a particular Foramen, as in Beans, and other Pulfe, as is faid; or by the breaking off of the Seed from its Peduncle or Stool, as in thofe in Cucumber, Cichory; or by the entering and paffage of a Branch or Branches, not only into the Concave thereof near the Cone, but alfo through the Cone it felf; as in Shells and stones.

8. \%. For the fake of this aperture it is, that Akerns, Nuts, Beans, Cucumbers, and moft other seeds, are in their formation fo placed, that the Radicle ftill ftandeth next to it; That So, upon Vegetation, it may have a free and ready paffage into the Mould.

9. $\$$. The Original of the outer Coat, though from Parts of the fame fubftantial nature, yet is differently made. In a Plum, the seedBranch which runns, as is defcribed, through the Stone, is not naked, but, as is faid, invefted with a thin Parenchyma, which it carries from the Stalkalong with it ; and which, by the Ramification of the faid Branch within the Stone, is, in part, dilated into a Coat. That of a Bean is from the Parenchyma of the Cod; the fuperficial part of which Parenchyma, upon the large peduncle of the Bean becoming a thin $\mathrm{Cu}_{\mathrm{H}}$ ticle, and upon the Bean it felf a Cartilaginous Coat.

Io. \$. The Original of the inner Coat of the Bean is likewife from the inner part of the faid Parenchyma; which firft is fpred into a long Cake, or that which with the Seed-Branch maketh the Penduncle of the Bean; under which $C_{a k e}$, there is ufually a black part or f fot ; by the length of which, the inner part of the $C$ ake is next inferted into the outer $C_{o a t}$, and fpred all over the Concave thercof, and fo becomes the inner. 
I I 6. Of this Inner Coat it is very obfervable, That allthough when the Seed is grown old and dry, 'tis fhrunk up, and in moft Seeds, fo far, as fcarcely to be difcern'd; yet in its firft and juvenile Conftitution, it is a very Spongy and Sappy body; and is then likewife (as the Womb in a Pregnant Animal) in proportion, very thick and bulky. In a Bean, even as one of the Lobes it felf: And in a Plum or Apricot, I think I may fafely fay, half an hundred times thicker than afterwards, when it is dried and thrunk up, and can fcarcely be diftinguifhed from the upper Coat. Upon which Accounts it is, in this eftate a true and fair Parencbyma. The Delineation hereof, See in the Figures belonging to the Fourth patt of the Fourth 2500 k.

12. \$. In this Inner Coat in a Bean, the Lignous Body or SeedBranch is diftributed : Sometimes, as in French-Beans, throughout the whole Coat, as it is in a Leaf. In the Great Garden-Bean, upon its firft entrance, it is bipartite, and fo in fmall Branches runs along the Circumference of the Coat, all meeting and making a kind of Reticulation againft the Belly of the Bean. In the fame manner the main Brancbes in the outer Coat of a Kernel, circling themfelves on both hands from the place of their firft entrance, at laft meet, and mutually inofculate; as the Veins in the Kidneys of a Man or any Quadrupede; Or the Carotick Arteries in the Braine.

13. F. So that all the Parts of a Vegetable, the Root, Trunk, Branch, Leaf, Flower, Fruit and Seed, are ftill made up of Two Subftantially different Bodies.

14. 6. And as every Part hath Two, fo the whole Vegetable taken together, is a compofition of Troo only, and no more: All properly Woody Parts, Strings and Fibers, are One Body: All fimple Barques, Piths, Parenchyma's and Pulps, and as to their fubftantial Nature, Pills and Skins likewife, all but One Body: the feveral Parts of a Vegetable all differing from each other, only by the various Proportions and Mixtures, and variated Pores and structure of thefe Troo Bodies. What from thefe two general Obfervations might reafonably be inferr'd, I fhall not now mention.

15. 5. The Fourth or Innermoft Cover we may call the Secondine. The fight of which, by cutting off the Coats of an Infant-Bean, at the Cone thereof, in very thin Slices, and with great Caution, may be obtain'd. While unbroken, 'tis tranfparent; being torn and taken off, it gathers up into the likeness of a Jelly, or that we call the Tredle of an Egg, when rear-boyl'd. This Membrance in larger or elder Beans, is not to be found diftinct. But ( as far as our Enquiries yet difcover) it may in moft other Seeds, even full grown, be diftinctly feen; as in thofe of Cucumber, Colocyntbis, Burdock, Carthamum, Gromwel, Endive, Mallows, \&c. 'Tis ufually fo very thin, as in the above-nam'd, as Tab.4.f.16. very difficultly to be difcover'd. But in fome Kernels, as of Apricots, 'tis very thick; and moft remarquably fuch, in fome other Seeds. That all thefe have the Analogy of one and the fame Cover, which I call the Secondine, is moft probably argu'd from their alike Natures; being all of them plain fimple Membranes, with not the leaft Fibre of the Lignous Body or Seed Branch, vifibly diftributed in them: As alfo from their Texture, which is in all of them more clofe. See this Part in Tab. 4. As alfo amongft the Figures belonging to the Fourth joatt of the Fourth 2300k. 
16. 6. The Concave of this Membrane is filled with a moft traniparent Liquor, out of which the Seed is formed; as in cutting a petite and Infant-Bean, may be feen; and yet better in a young Walnut. In Beans I have obferved it to turn, upon boyling, into a tender white Coagulum.

17. \$. Through this Membrane, the Lignous Body or Seed-Branches diftributed in the inner Coat, at laft thoot downright two flender Fibres, like two Navel-strings, one into each Lobe of the Bean.

$T_{a b}$ 4.f.18. The places where the faid Fibres fhoot into the Lobes, are near the Bafis of the Radicle; and by their Blackifonefs well enough remark'd: but the Fibers themfelves are fo very fmall, as fcarcely to be difcern'd. Yet in a Lupine, of the larger kind, both the places where the NavelFibres thoot into the Lobes (which here from the Bafis of the Radicle is more remote) and the Fibres themfelves, are fairly vifible. For the Seed-Branch, upon its entrance into the Coat of the Lupine, is prefently divided into two main Branches, and thofe two into other lefs; whereof fome underly, others aloft, run along the Coat, and towards its other end meet and are inofculated: where about, two oppofite,

Tab.4.f.17. Thallow, round, and moft minute Cavities, anfwerable to two specks of a Cartilaginous glofs, one in either Lobe, may be obferved; which Specks are the ends of the faid Navel-Fibres, upon the ripening of the seed there broken off. Thefe Fibres from the superficies of each Lobe, defcend a little way directly down: prefently, each is divided into

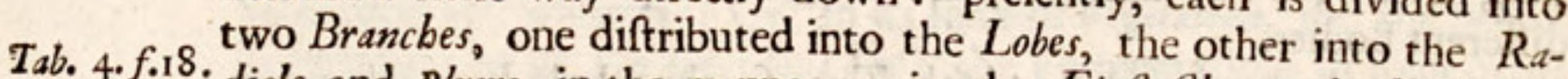
dicle and Plume, in the manner as in the Firft Chapter is defcribed. And thus far the Hiftory. I thall now only with a brief account of the Ceneration of the seed, as hereupon dependent, conclude this Difcourfe.

An Account 18. 5. LET US fay then, that the $S_{x p}$ having in the Root, Trunk and of the Gene- Leaves, paffed divers Concodtions and Separations, in the manner as they ration of the are faid to be perform'd therein; 'tis now at laft, in fome good ma-
Seed. turity, advanced towards the Seed.

19. 6. The more copious and cruder part hereof is again feparated by a free reception into the Fruit, or other Part analogous to it : being either fufficiently ample to contain it, or at leaft laxe enough for its tranfiration, and fo its due difcharge. The more Effential part is into the Seed-Branch or Branches entertian'd. Which, becaufe they are evermore of a very confiderable length, and of aConftitution very fine, the faid $S a p$ thus becomes in its Current therein as in the Spermatick
$V$ effels, ftill more mature.

20. \& In this mature eftate, from the Seed-Branch into the Coats of the seed, as into the Womb, 'tis next delivered up. The meaner part hereof again, to the Outer, as Aliment good enough, is fupplied. The finer part is tranfmitted to the Inner; which being, as is faid, a Parenechymous and more fpatious Body, the Sap therefore is not herein, as in the Outer, a meer Aliment ; but in order to its being, by Fermentation, farther prepared.

2I. 6. Yet the Outer Coat, being on the contray hard and denfe; for that reafon, as it admitteth not the Fermentation of the Siap fo well within it felf; fo doth it the more promote and favour it in the Inner; being Bounds both to it and its Sap; and alfo quickneth the process of the whole Work in the formation of the seed. 
22. 5. Nor doth the Outer Cost, for the fame reafon, more promote, than declare the purity of the $S a p$ now contained in the Inner : For being more hard and denfe, and fo not perfpirable, muft needs fuppofe the Parts of the sap encompaffed by it, fince thus uncapable of any evacuation, to be therefore all fo choice, as not to need it.

23. 6. The Sap being thus prepared in the Inner Coat, as a Liquor now apt to be the Subftratum of the future Seed-Embrio; by frefh fupplies, is thence difcharg'd. Yet that it may not be over-copious; which, becaufe of the laxity of the Inner $C_{o z t}$, from whence it iffues, it might eafily be : therefore, as the faid Inner Coat is bounded without, by the upper coat; fo by the secundine, is it bounded within. Through which secundine the sap being filtr'd, or, as it were, tranfiring; the depofiture hereof, anfwerable to the Colliquamentum in an Egg, or to the Semen Mulibre, into its Concave at laft is made.

24. 5 . The other part of the pureft sap embofom'd in the Ramulets of the Seed-Branch, runs a Circle, or fome progrefs therein; and fo becomes, as the Semen Mafculinpm, yet more elaborte.

25. 5. Wherein alfo, left its Current fhould be too copious or precipitant, by their co-arifure and divarication where they are inofculated, it is retarded; the nobleft portion only obtaining a pafs.

26. S. With this pureft $s a p$, the faid Ramulets being fupplied, from thence at laft, the Navel-Fibres fhoot (as the primitive Artery into the Colliquamentum ) through the Secundine into the aforefaid $L i$ quor depofited therein.

27. 5. Into which Liquor, being now fhot, and its own proper sap or Tinctures mixed therewith, it frikes it thus into a Coagulum; or of a Liquor, it becomes a Bods confiftent and truly Parenchymous. And the fupply of the faid Liquor ftill continu'd, and the fhooting of the Navel-Fibres, as is above defcribed, ftill carried on, the faid Coagulation or Fixation is therewith likewife.

28. \$. And in the Interim of the Coagulation, a gentle Fermentation being alfo made, the faid Parenchyma or Coagulum becometh fuch, not of any Texture indifferently, but is thus raifed (as we fee Bread in Baking ) into a Congeries of Bladder's: For fuch is the Parencbyme of the whole Seed.

\section{$F$ I $N$ I S.}

Mo.Bot. Garcen, 1902. 


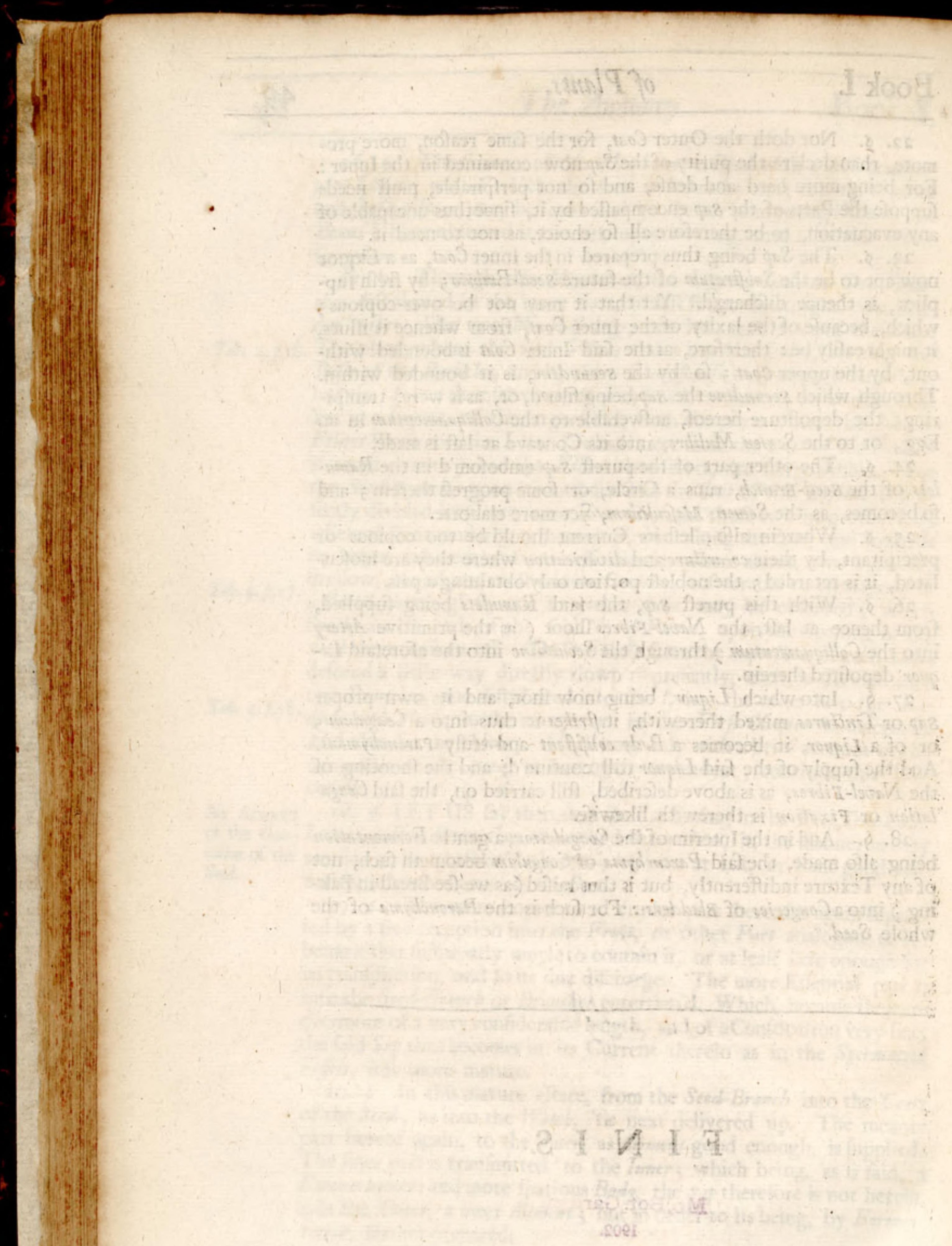




\section{T. H E}

\section{A NATOM Y}

$\mathrm{O} F$
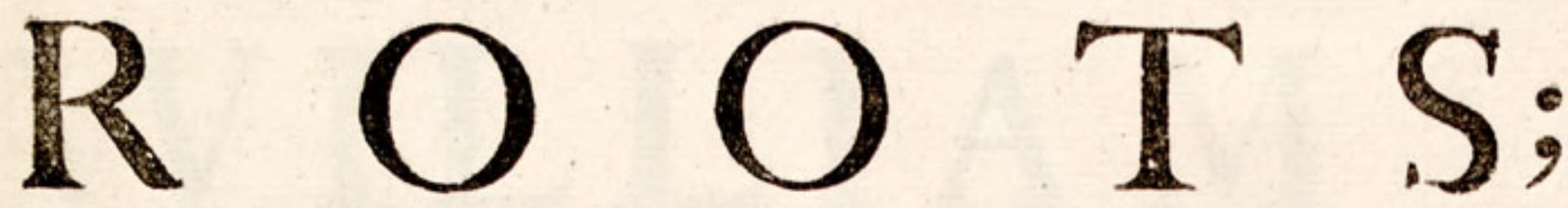

Prefented to the Royal Societr at feveral times, in the Years, $1672 \& 1673$.

With an Account of the

\section{VEGETATION OF ROOTS,}

Grounded chiefly hereupon.

The SECOND BOOK.

By $N E H E M^{f} A H G R E W^{\prime} M$. D. Fellow of the Royal Society, and of the College of Phyficians.

The Second Edition.

$$
\text { LONDON, }
$$

Printed by $W$. Ramolins, 1682。

Mo.Bot. Garclen, $\quad N_{2}$




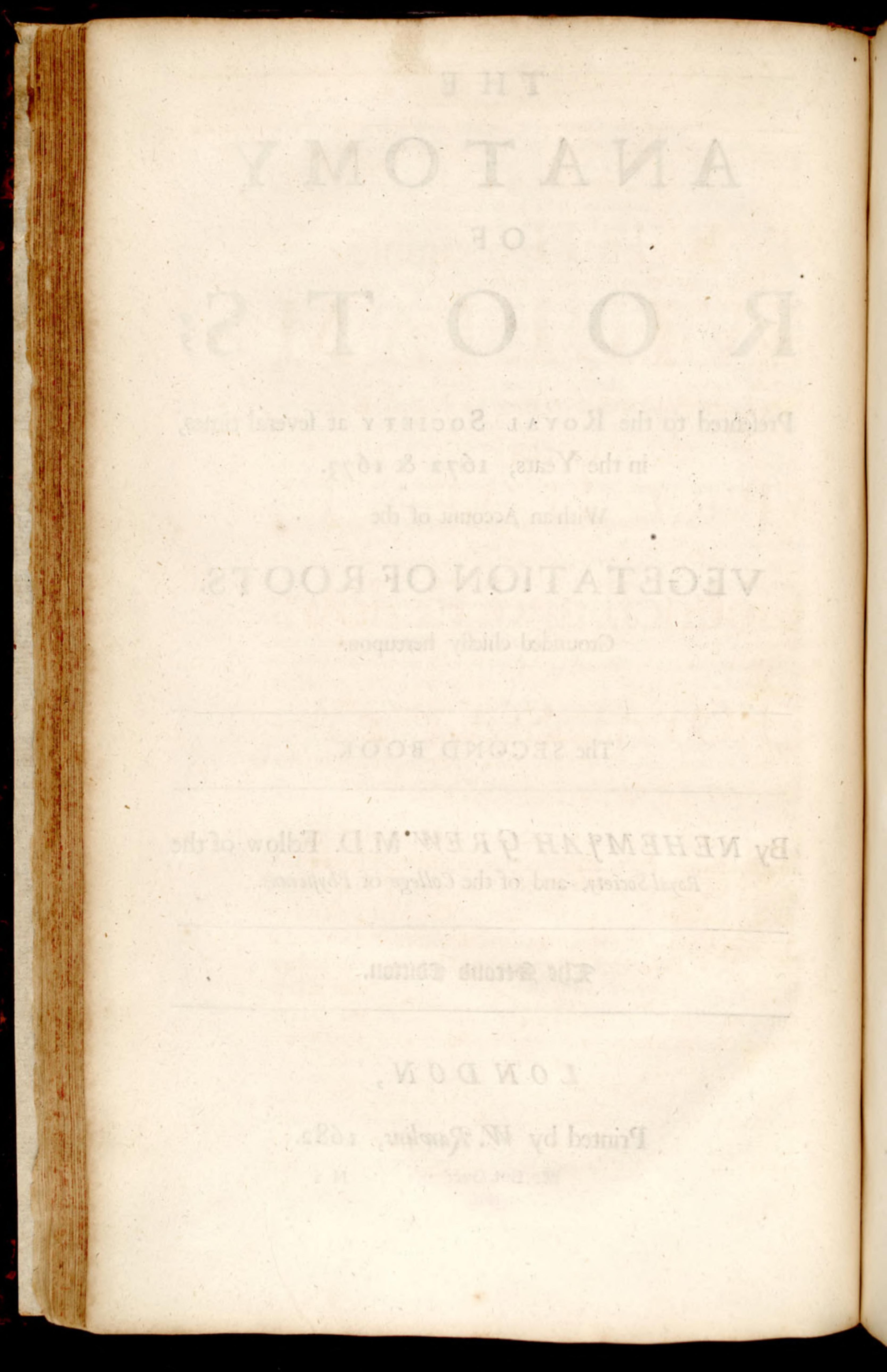


T O TH E

Right Honourable

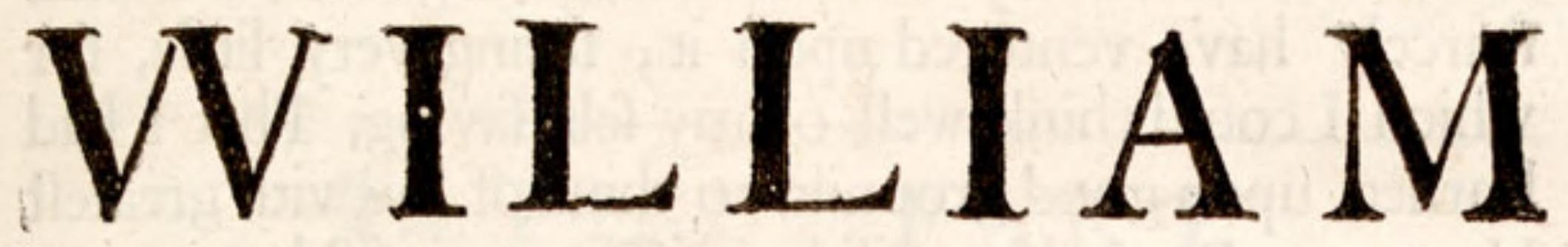

Lord Vi-Count BROVNGKER

$\mathrm{T} \mathrm{HE}$

\section{P R E S I D E N T \\ AND TO THE}

\section{Council and Fellows}

O F T HE

\section{ROYAL SOGIETY.}

MYLORD,

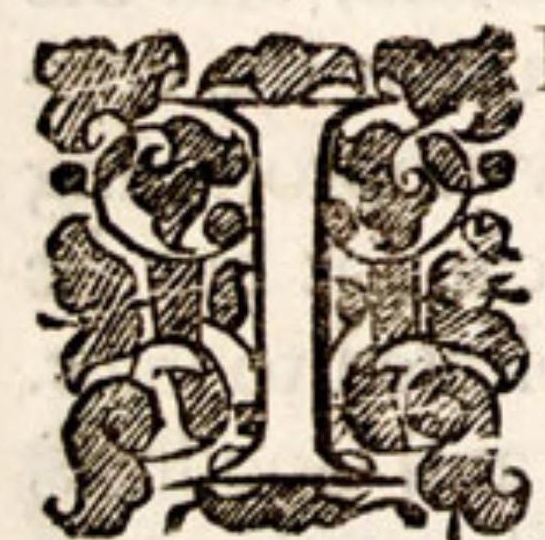

$F$ the Dedication of Books were not in ufe; yet here, I think, I might have been a Precedent. The promotion of Phytological Science is one Part of Your Work; and 'tis You have called me to the management of this Part; for fome time, have intrufted me herein; and by Your moft favourable and candid acceptance of what I have performed thus far, have encouraged me hereunto: I therefore prefent but rour Own, into Your Hands.

The great Honour and Advantage of Your Fellowhip I firft obtained, by Mediation of Dr. Wilkins, the late moft Reverend Bifbop of Cbefter. Whom I cannot name, without faying thus much of him, That He was a Per- 


\section{The Epifle Dedicatory.}

fon of that eminent and happy Worth, which, as it was too good, to fear envy; fo is it too great, to need an Elogie.

With Him, it was, You were pleafed to commit to Me, the further profecution of this Work; the Beginnings whereof, were by Your Order formerly made publique. Had I confulted my own Abilities altogether, I fhould farcely have ventured upon it; feeing very little, for which I could think well of my felf, faving, That I had learned, upon good grounds, to think of $Y_{0}$ with greateft Honour. But I alfo confidered, That to infift hereon too much, might be a reflection upon Your Judgments, who had thought fit to make choice of Me. And, That You were not more the Patrons of Wit, than of Induftry; and of All, who fhall endeavour to find out, or to confirm the Truth of Things. Withal, I looked upon Nature, as a Treafure fo infinitely full; that as all Men together, cannot exhauft it ; fo no Man, but may find out fomewhat therein, if he be refolved to Try.

In compliance therefore with $Y_{\text {our }}$ Commands, I have hereunto devoted a very confiderable part of my Time. Thefe,adding force to my own Defires, of being fomewhat inftrumental to the Improvement of Medicinal, and other wholefom Knowledge: if peradventure, as we increafe herein, we may become better, and more happy. As to which Improvement, though I could not hope; yet, I would not difpair. I have already prepared the Soil, and made fome Plantation : what remaineth behind, and the Vintage of the whole, will depend much upon the continued Influence of Your Beams: for how unpromifing foever the Stock may be; yet the Fruit cannot but be fomewhat matured, upon which $r_{0 u}$ are pleafed to fhine. I am alfo confident, that the fame Nobilty and Goodnefs, which accept the endeavours, will likewife pardon the faults, of,

September 1 . 1673 .

$$
\begin{aligned}
& \text { My Lord, } \\
& \text { Your Lordfbips moft bumbly } \\
& \text { and moft fincerly } \\
& \text { devoted Servant }
\end{aligned}
$$

NEHEMJAH GREW. 


\section{T H E}

\section{G O N T E N T S.}

\section{The F IRST PAR T.}

\section{H A P. I.}

F the Original of Roots, 5. 1, 2, 3. Of their Figures, 4, to
8. Of their Motions, 9, to 15. And of their Ages, 16, to the end.

\section{H A P. II.}

O

F the Skin. Its external Accidents, and Original, \&. I, 2. Compounding Parts. Whereof the one Parenchymous, 3. The other Lignous, 4, to the end.

\section{H A P. III.}

As to

F the Barque. Its Original and external Accidents, 5. ז. Size, 2. Compounding Parts: Whereof the one Parenchymous, 3 7, to II The other Part I2, to 17 Of feveral, Lignous, confifting of long Pipes or Veffels, 24, 25. And in different and, 18, to 23. In different Proportion, 24, 25. And in different and elegant Pofition. 26, to the end.

\section{H A P. IV.}

O

$F$ that Part of the Root next witbin the Bark; in Trees and Shrubby Plants, called the Wood. Hereof the Parenchyma, 5. 1, 2, 3, \& 7. The Lignous Portion : of which, the Sap-Veffels, 4 Latter Aer-Veffels, 5, 6. The Pofition of the Former, 8, 9. Of the Latter, 10, I1, 1 2. Their Proportion, 13, 14, I5. The Latter, fometimes a little tapering. 16. Their Texture, 17, to 22. Content, 23. 


\section{The Contents.}

\section{H A P. V.}

C $F$ the Pith. Found in the upper part of moft Roots, \&. x. Its fize and Sape, 2. Sap-Veffels, 3. Original, 4, 5. Bladders, 6, Fibres and Texture, 7,to II. That of the Infertions and Barque the fame, 12. Hence, the Original of the Aer-Veffels conjectured, 13. What the wohole Body of a Root, concluded, 14, 15. The Contents of the Pith, 16.

\section{The SECOND PART.}

Heology, the Beginning and End of Philofophy, 6. I, to 6. If we
The Divine Wifdom seen in the Growoth of Plants, 7. If we How the Ground is Prepared, 8, to 14.

How the Sap is Imbibed, and Diftributed to the feveral Parts of the Root, 15, to 28.

How the feveral Parts are Nourifhed and Formed, 29, to 35 .

How the everal Parts receive their refpective Situation, 36, to 40.

How Roots receive their different Size and Shape, 4I, to 47.

How Roots receive their different Motions, 48, to 53.

How Roots are differently Aged, 54, 55, 56.

How the Liquors and other Contents of the feveral Parts are made 571063.

How the Odors of Roots are made, 64 .

How their Colours, 65, to 67 .

How their Tafts, 68, to the end. 


\section{T H E}

\section{A N A T O M Y}

$\mathrm{OF}$
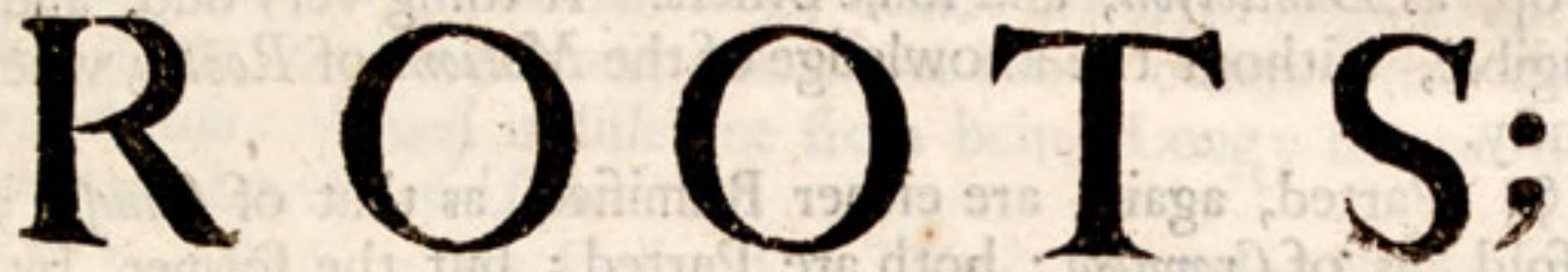

PROSECUTED

With the bare EY E,

A NDWITH THE

MICR OSCOPE.

\section{P A R T I}

\section{CHAP. I}

Of the ORIGINAL, FIGURES, MOTIONS, and $A G E S$ of ROOTS.

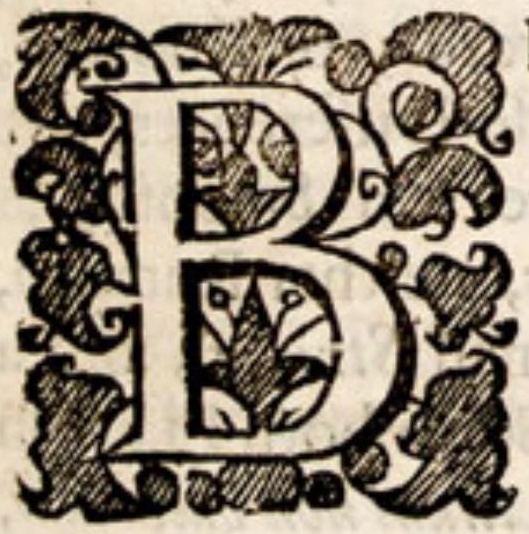

E ING T O rpeak of Roots; it is requifite, for our better underftanding of what follows, that fome things, as to their Original, Figures, Motions and Ages, be premifed.

I. 5. Roots, taken altogether, have a Threefold Original. Either from the Radicle; as all Roots which come of the Seed: or from the Trunk or Caulis, above ground; as in Strawberry, Chamemile, and many other Creepers: or from the Trunk or Caulis, after it is funk under ground; as in Primrofe, Biftort, and many others; and prefently fhall be fhewed how.

2. 5. In the Growth of a Bud, and of a Trunk-Root, there is this obfervable difference; That the former, carries along with it, fome portion of every Part in the Trunk or Stalk; whereof it is a Compendium. The latter, always fhoots forth, by making a Rupture in the Barque, which it leaves behind, and proceeds only from the inner part
of the Stalk. 
3. 6. As alfo, That in a Bud, the Lignous Part is fpread abroad, fo as to encompafs a Pith. Whereas in a Trunk-Root, it makes a fo. lid Thred ftanding in the Center. Which is the Caufe of its defcend. ing into the Ground: as is already, in the Firf $2300 k$, and thall in This be further fhewed.

4. 6. ROOTS are generally diftinguifhed, as to their Figures, in being more Entrie, as is that of Liquiriß ; or Parted, as of St. Fohnswort. Parted or Forked, either at the Bottom, as moft Roots; or at the Top, as Dandelyon, and fome others. A thing very odd, and unintelligible, without the knowledge of the Motions of Roots; whereof prefently.

5. 6. Parted, again, are either Ramified, as that of Cumfry ; or Manifold, as of Cromfoot : both are Parted; but the former, by the fubdivifion of greater Branches, into leffer; thefe, when divers strings, have all their diftinct original from one Head. Some are Straight, as a Radifh; others Crooked, as Biftort. Smooth, as Bugloss; or Stringy all round about, as Columbine. And to Carnations, this feems to be peculiar, That fometimes many of the Strings run parallell with the Wood of the great Root, through the Barque, or betwixt the Wood and the Barque.

6. 6. Again, fome are Thick, as Rbubarb; Slender, as the Vine. Long, as Fenil; Short, as a Turnep : which are diftinct from Great and Little; in that thefe, are fo called with refpect to feveral Roots; thofe, with refpect to the feveral Dimenfions of one. Short, are Stubbed, as Iris tuberofa; or Round, as Dracontium. Round are Tuberous, or Simply Knobbed, as Rape-Crowfoot; Bulbous, that is Scaled, as fome Lilys; or Shell'd, as an Onion. Where note, That all Bulbous Roots, are, as it were, Hermaphrodites, or Root and Trunk both together: for the Strings only, are abfolute Roots; the Bulb, actually containing thofe Parts, which fpringing up, make the Leaves or Body; and is, asit were, a Great Bud under ground.

7. 6. Roots, again, are Even or Uneven; Even, are Cylindrical, as Eryngo; or Pyramidal, as Borage. Growing fmaller Downwards, as do moft; or U Uwards, as skirrets. Uneven, are Pitted, as Potato's, where the Eyes or Buds of the future Trunks lie inward; or Knotted, as Jerufalem-Artichoke; where they ftand out. Thefe Differences, are alfo Compounded: fo fome Roots are both Entire and Smooth, as Peony; others Entire, but Stringy, as Clary: that is, neither Ramifid, nor yet Brufhy, or divided at the Top into feverall fmall Strings; but a Single Root furrounded with many Hairy Threds. Some both Plain in fome parts, and Knobbed in others, as Filipendula, Lilium non bulbofum, and others.

8. 5. Some alfo have two or more Roots; and thofe of one Kind : of which, fome are diftinctly faftend to the bottome of the Stalk, as in Dogftones; fome ftand one under another, fo as only the uppermoft is faften'd to the Stalk, as in Dragon, Crocus, and others. And there are fome, which have not only two Roots, at the fame time; but thofealfo of two diftinct Kinds, as in Biftort; one of them, a flender ftrait Cylindrick and horizontall Root; the other large and crooked, and bred of the Defcending Trunk; as in fpeaking next of the Motions of Roots, will be underftood, how. All which, with other Differences 
by Thofe that undertake the Defcriptions of Plants, are accurately to be Noted. But the Differences, above mentioned, will ferve for our prefent Purpofe.

9. צ. THE MOTIONS of Roots are alfo divers. Sometimes Level, as are thofe of Hops, Ammi, Cinquefoyle; and all fuch as properly Creep. Sometimes Perpendicular, as that of Parfnep: Which is different from Straightnefs; for fome Straight Roots, are Level. Both of them are either Shallow or Deep: fome run Level, and near the Turf, as Woodbind, Wild Anenomy; others lower, as Dogs-Grafs. Some frrike down, but a littleway, as Stramonium; others grow deep, as Horfe-Radifls: Which is different from being Long; for many long Roots, are Level, as Hops.

II. 5. Some again Defcend, as Tulips, and other Bulbous Roots, which differs from growing only Downwards; in that here, the Head of the Root is Immoveable; but in Defcending, the whole Root obteineth different Places, running deeper, time after time, into the Earth. Some alfo Afcend, fometimes, and in fome part, appearing above ground, as Turneps.

II. 6. Thefe Motions are alfo Compounded; both in refpect of the feveral Parts of the Root, and of feveral Times. So the main Root of Primrofe, is Level; the Strings are Perpendicular. The Roots of moft seedlings grow Downward and Upward, or fhoot out in length at both Ends, at the fame time. Thofe of Biftort, Iris, and fome others, grow, in part, both Downward and Upward at feveral times: Whence it is, that Biftort is Crooked, with fome refemblance to an S, according to its Name; And that fome Parts of IrisRoot appear oftentimes above the ground.

I2. 5. There is alfo another Motion, in fome Roots, not heeded; and that is Contortion: whereby, without being moved out of their Place, they are Writhed or Twifted; as a piece of Cloath is, when the Water is wrung out of it; as in Carduns, Soncbus, and others: whether always I cannot fay. This Mation cannot be noted, without ftripping off the Barque; whereby the $V$ effels may be feen, fometimes, to make two or three Circumvolutions. This Motion feems to be governed by the winding of the Stalk; and therefore to begin at the Head, and terminate at the Poynt or lower end of the Root, which
is immoveable.

13. 5. BUT ABOVE all the Motions of Roots, not obferved, the molt remarkable is that of DESCENT. Which, although it hath been noted, by fome Botanicks, of Bulbous Roots; yet of thefe only: differeas it is the Property, of a great many more; and thofe, of very of Herbs Kinds; probably, of the far greater number of Perennial Roots foot, Tanfy, as of Arum, Rape-Cromfoot, Valerian, Brownwort, Bearfsfoot, Tanfy, Lychnis, Sampier, Primrofe, Ammi, Avens, Wood-forrel, their Root is annull Of which Plants, it is very obfervable, That it felf. That isnually renewed, or repaired, out of the Trunk or stalk infenfible Degrees fay, The Bafis of the Stalk continually, and by hiding it felf therein ed into a true Root is thus, both in Nature, Place, and Office changthe continuance of the faid O 2

Motion 
Motion of the Stalk, alfo Defiends; and fo, according to the durablenefs of its Subftance, becomes a fhorter or longer Root; the Elder or Lower Portion thereof, Rotting off, by the fame Degrees with the Generation of the Upper, out of the Stalk. So in Brownwort, the $B a$ is of the stalk finking down by degrees, till it lies under Ground, becomes the upper part of the Root; and continuing ftill to fink, the next year, becomes the lower Part ; and the next after that, rots away; a new Addition being ftill yearly made out of the Stalk, as

$T_{a b}$. 5. f. 6, the elder Parts yearly rot away. So in Dragon, Crocus, and the like,

6. 7. where the Root is double; the Bafts of the Stalk, this year; the next, becomes the Upper-Root; after that, the Lower-Root; and at the length dies and is confum'd.

14. 6. The Demonftration hereof, is taken, more evidently, from fome Roots, than from others; as from the Level and Knobed Roots

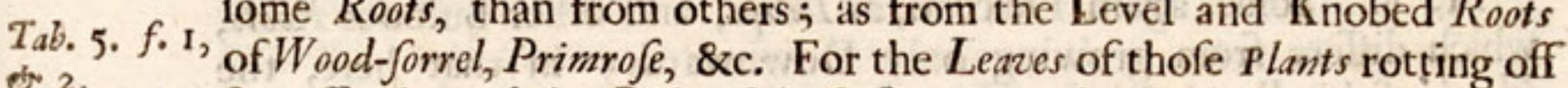
fucceffively, and the Bafes of thofe Leaves gradually defcending into the Ground; each Bafis is thus nourifhed with a more copious Sap, and fo fwelled into fo many thick Knots. It may likewife be gather'd in fome, from the like Pofition of the $V_{e}$ fjels or Woody Parts, in the Root, as in the Trunk; as in Bares-foot, As alfo, from the Root of the Iris

Tab.5.f. 4. Tuberofa: where, although the Leaves fall off clofe to the Surface of the Stalk; yet after that is funk down, and fwell'd into a Root, the Seats of the perifhed Leaves, and the Ends of the Veffels belonging to them, are not obfcurely vifible; whereby the Root is wrought, as it were, with feveral seames and Prickt. Lines; the seams fhewing the fetting on of the Leaves; and the Pricks, the Terminations or broken Ends of the Veffels: which ends, are ftill more apparent, upon the ftripping off the Barque. I confidered likewife, That as among Animals, there are many, which are not Bred of Eggs, immediately; but are Transformed, one Animal into another : $\mathrm{So}_{\text {, }}$ it is more than probable, That among Plants, there are not a few Inftances of the like Transformations; whereof, this is one.

15. 6. The Caufe of this Defcent, fo far as it is dependent on the Inward Conformation of the Root, I fhall fhew in the following 19att. But the Immediate Vifible one, are the String-Roots, which this kind of Trunks frequently put forth: which, defcending themfelves directly into the Ground, like fo many Ropes, lug the Trunk after them. Hence the Tuberous-Roots of Iris upon the rotting or fading away of the String-Roots hanging at them, fometimes a little Re-afcend. Hence alfo the Shape of fome Roots is Inverted: For whereas moft are parted downwards, into feveral Legs; fome are parted upwards into

Tab.5.f.5. divers Necks, as Dandelyon, and others. For thefe Roots fending forth at the top feveral Trunk-Buds, the faid Buds fucceffively put forth new, and caft their old Leaves; and continually alfo making their Defcent, are at length formed into fo many Necks, of three, four, five, or more Inches long, under Ground.

16. 6. HENCE ALfo we underftand, in what particular way, fome Roots become Perennial. Some are wholly fo, as thofe of Trees, slorubs, and divers other woody Plants. Others, in part, or by a new Progenies of Roots, from the old Head or Body, in the room of thofe that die yearly, or after a certain Time; as of Lilimn non bulbo- 


\section{Book II.}

fum, Ferraflem Artichoke, Potato, Dog-fones, Monks-bood, little Celandine, and others. In which Plants, one or more of their Roots are firm, the other fpongy and fuperannuated; and partly, by the ravine of the Trunk, and other younger Roots, reduced to a Confumption and Death.

17. \$. With thefe,Tulips, and other Bulbous-Roots confort : For the feveral Rindes \& shells, whereof chiefly, the Bulb confifts, fucceffively perifh and fhrink up into fo many thin and dry skins: betwixt which,and in their Centre, other Leaves and Shells, being fucceffively formed, the Bulb is thus perpetuated. In the fame manner the String-Roots alfo fucceed one another annually. So that at the end of divers Years, although it be ftill looked upon as the fame Individual Root, yet it is, in truth, Another, as to every particle thereof.

18. F. Laftly, many other Roots are perpetuated by the aforefaid Defcent of the Trunk; out of which, it is ftill annually Repaired, as by the gradual perifhing of its lower parts, it is Diminifhed; as hath been faid. Whence alfo we fee the reafon of the Rugged and Blunt extremities of thefe, and fome other Roots, as of that Plant fuperftitioufly called Devils-bit: becaufe the end of it feems to be bitten off. Yet doth it not appear fo originally; but the Lower part thereof rotting off, as the Upper defcends; the living remainder, becometh ftumped, or feemeth Bitten. Thus far of the Original, Shapes, Motions, and Ages of Roots.

\section{H A P. II.}

\section{Of the $S K I N$.}

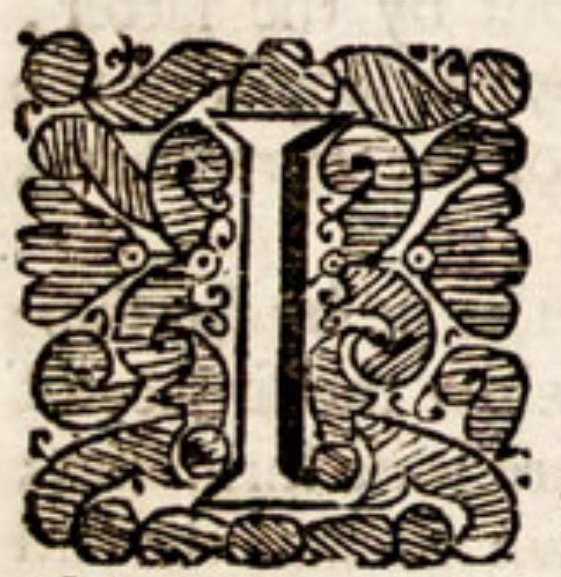

N EX T proceed to the feveral Parts whereof a Root is Compounded. The outer Part of all is the Skin; which is common to all Roots. 'T is diverlly Coloured: Whiter in Skirrets; Yellow, in Dock; Red, in Potato; Brown, in Lovage; Black, in Buglofs. Its Surface, fometimes Smooth, as in Horfradifh; Rough, as in Scorzonera. And the Skins of the feveral Sheils of a Tulip-Root, taken up frefh, look as if they were perforated with a great many fmall holes. 'Tis of various Size; very Thin, in Parfnep; fomewhat Thick, in Bugloss; very Thick in Iris. Sometimes it is Opacous, as in Thiftle; and fometimes Tranfparent, as
in Madder.

2. \$. Every Root hath fucceffively two kinds of Skins: the one, Coëtaneous with the other Parts; and hath its original from that which involveth the Parts of the seed it felf. The other, Poltnate, fucceeding in the room of the former, as the Root ageth; and is orinated from the Bark. So in Dandelyon, the old skin, looked upon about the beginning of May, feems to have been one of thofe feveral 


\section{2

Rings, which the precedent year compofed the Cortical Body of the

Root : but by the Generation of a new Ring, next the $W_{o o d}$, is now thruft off and thrunk up into a Skin. So alfo in the Roots of Bugloss Tab. 14, 15. and Horfe-Radifh, as far as the Bladders in the former, and the Veffels in the latter are Radiated; the Cortical Body feems either annually or oftener, to fhrink up into another new $s$ kin, as, the old ones fall off.

Tab. 10. And fometimes, perhaps, as in Asparagus, the whole body of the Perpendicular Roots, except the woody Fibre in the Centre, becomes the fecond skin. So that the wearing away of the old Skin, fucceeds the derivation of the new one; as in Defcending Roots, the Confumption of the Lower Parts, doth the Generation of the U Uper. Becaufe the Barque fwells, and grows fometimes fafter than the Skin can fall off, or give way to it : therefore are the Roots of many Herbs, Barquebound, as well as the Trunks of Trees.

3. 6. This Skin is ufually, if not always, compounded of two Kinds of Bodies : which alfo is probable of the Coëtaneous. The one, Parenchymous, and frequently conftructed of exceeding little $C_{e} l l s$ or Bladders; which in fome Roots, as of Afparagus, cut traverfe, and viewed through a Microfcope, are plainly vifible. Thefe Bladders are

Tab. 10.

Tab. 14 . of different Sizes; in Buglos, larger ; in Afparagus lefs; and fometimes they coincide and difappear. But in thefe, and all other Roots, even where thefe Bladders appear not, the Parenchyma of the skin, is of the fame Subftantial Nature, with that other more vivid and bulky one of the Bark: As is manifeft, from its being thence Originated and alike Conformed, as fhall be feen; and not only adjacent to it, as a Glove is to the Hand; but continuous therewith, as the parts of 2 piece of flefh, are one with another.

4. \$. OF THIS Parenchymous Body, the skin confifteth chiefly, but not wholiy; there being many Lignous Veffels which are Tubulary, mixed therewith : which, though hardly by the Microfcope, yet otherwife, is demonftrable. For in tearing the Skin, you fhall do it more eafily by the length, than bredth; becaufe, by the firft way, the continuity only of the Parenchyma, is diffolved; but by the latter, both of this, and of the $V_{e} / f e l s$, thefe being pofited by the length of the Root: So that, as by the fmalnefs of the Bladders of the Parenchyma, the Skinis Denfe; fo by thefe $V e \int f e l s$, is it Tough.

5. 6. Again, if you cut a Root traverfe, and let it lie by for fome time, all the parts, where there are no $V_{e} \iint e l s$, hrink below the furface of the cut-end; but where-ever Thefe are pofited, there is no fhrinking; which oftentimes, evidently appears alfo in the Skin : becaufe the faid $V e f f e l s$, though, as the Bladders, they may coincide; yet they cannot vilibly fhorten or fhrink up in length; no more than a Straw, whofe fides may yet be eafily crufhed together.

6. \$. Further, the Root being cut traverfe, if, near the cut-end, you very gently prefs the fide of the Root with the edge of your Nail, the $s a p$ will thereupon arife fometimes from the Skin; in the fame manner, as from any other part of the Root, where the like Veffels are pofited. And although the Sap may likewife be expreffed from the Pith, and other Parts where fometimes, there are none of thefe $V$ efels; yet not without a folution of there continuity; which here doth not follow; as appears, from the difappearing of the $S_{a p}$, together with the in- 
termifilion of the preffure; the faid $V_{e} / f e l s$ then dilating themfelves by aMotion of Reftitution, and fo fucking up the sap again.

7. 6. Hereunto may be added the Teltimony of fight; the very $V$ effels themfelves, in many Roots, coming under an apparent view, and ftanding in the utmoft furface of the Root all round about, as in that of Liquirith, Columbine, Scorzonera, and others. Which Experiments, I have here, once for all, more particularly fet down; becaufe I fhall have occafion, hereafter, to refer to them.

\section{H A P. III. \\ Of the BARQUE.}

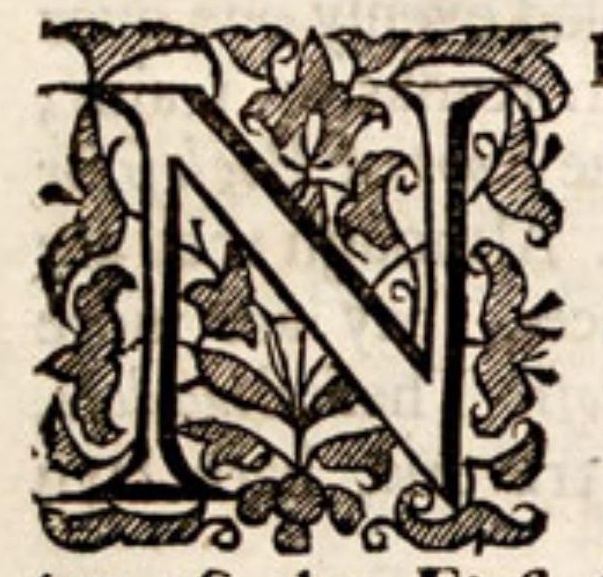

ter of the Firft $23 \mathfrak{s o l k}$.

EXT WITHIN the Skin lieth the Barque. 'T is fometimes Yellow, as in Dock; Red, in Biftort; but ufually, and in seed-Roots, I think, always White. It is derived from the seed it felf; being but the extenfion or prolongation of the Parenchyma of the Radicle; One of the three Organical Parts of the Seed, defcribed in the First Chap.

2. I It is varioufly Sized; fometimes very Thin, as in ferufalem Artichoke, Goats-beard, and in moft Trees; where it alfo retains the Name of a Barque or Rind. Sometimes 'tis more Thick, and maketh up the far greateft protion of the Root, as in the String-Roots of Afparagus, in Dandelion, and others. The thinneft and the thickeft ar e all analogous, and obtain the fame general Ufes. The degrees of its Size, amongit all Roots, may be well reckoned about Twenty, and feen in the following examples, $f c$. Beet, Droproort, ferufalem Artichoke, Tab. 7, 8, g. Orpine, Valerian, Goats-beard, Nettle, Bromnwort, Columbine, Celandine, Afparagus, Horfe-Radifh, Peony, Bryony, Eryngo, Borage, Lovage, Dandelion, Parfnep, Carrot, \&uc. In the Root of Beet, fcarce exceeding a good thick Skin: but in a Carrot, half the Semidiameter of the Root, or above half an Inch over in fome places : and that of Dandelion, fometimes, in proportion with the woody Part, twice as thick: the reft of Several intermediate Degrees: And to moft Roots, this is common, To have their Barque proportionably thicker, at the bottome than at the top.

3. \$. IT IS Compounded of two Bodies. The one Parenchymous; Continuous throughout; yet fomewhat Pliable without a folution of its Continuity. Exceeding Porous; as appeareth from its fo much Thrinking up, in drying. The Pores hereof are extended much alike both by the length and bredth of the Root; therefore it thrinketh up, by both thofe Dimenfions, more equally. And they are very Dilative; as is alfo manifeft from its reftorablenefs to its former bulk again, upon 
its infufion in Water: that is to fay, It is a moft curious and exquifitely fine wrought Sponge. Thus much the Eye and Reafon may difcover.

4. \$. The Microfcope confirms the truth hereof, and more precifely fhews, That thefe Pores are all, in a manner, Spherical, in moft Plants; and this Part, an Infinite Mafs of little Cells or Bladders. The fides of Tab. 10, none of them, are Vifibly pervious from one into another; but each is o fequent. bounded within it felf. So that the Parenchyma of the Barque, is much the fame thing, as to its Conformation, which the Froth of Beer or Eggs is, as a fluid, or a piece of fine Manchet, as a fixed Body. The Sides alfo of thefe Bladders are as tranfparent, as thofe of Water; or the Bodies of fome Infects.

6. 6. But their Size is ufually much fmaller; and their Pofturemore Regular than thofe in Bread or Water. In all Roots they are fo fmall, as fcarcely, without the Microfcope, to be difcerned: yet are they of different Size, both in the fame, and in divers Roots; the varieties whereof, amongft all Roots, may be reduced to about Ten or Twelve Tab. 13, 14, according to the Standard, in Tab. 11. Some of thofe in Dandelion, being of the Smalleft; and in Bugloss, of the Greateft. They are pofited, for the moft part, at an Equal Height; and piled evenly one over another: So that, oftentimes, they vifibly run in Ranks or trains, both by the length and breadth of the Roots, as in the Root of Buglofs, or of Dandelion, fplit through the middle, may be feen. Although they are ufually Spherical, yet fometimes, and in fome places, they are more

Tab. 14. oblonge, as in the outward part of the Barque of Buglofs. Thefe Bladders, are fometimes beft feen, after the Root, being cut traverfe, hath layn by a while, to dry.

6. \$. They are the Receptacles of Liquor; which is ever Lucid ; and I think, always more Thin or Watery. They are, in all SeedRoots, filled herewith; and ufually, in thofe alfo which are well grown, as of Borage, Radifh, \&c.

7. 6. THIS Parenchymous Part, in many Roois, is of one Uniform Contexture; as in Afparagus, Horf-Radifh, Peony, Potato, and others. In many others, it is, as it were, of a Diverfified Woof; the Bladders being, though every where Regular, yet either in Shape, Size, or Situation, different in fome Parts hereof, from what they are, in other intermediate ones. For thefe Parts, are like fo many White Rays, ftreaming, by the Diameter of the Root, from the inward Edge toward the Circumference of the Barque; as in Lovage, Melilot, Parfnep, \&c.

Tab. 8, 9. cut tranfverlly, is apparent. They are, though not in direct Lines, continued alfo by the length of the Root; fo that they are, as it were, fo many Membrances, by which the other Parts of the Barque, are difterminated.

8. §. The Continuation of thefe Diametral Rays, or Portions, is divers: fometimes, but half through the Barque, or fomewhat more,

Tab. 9. or lefs, as in Melilot. And it is probable, that to the Roots of all or moft Trefoyls, and alfo of the Leguminous Kind, this is proper, To have their Diametral Rays come fhort of the Circumference. Sometimes, they run quite through to the very $S$ kin, as in Lovage. And I think, in the Roots of all Umbelliferous Plants: In which therefore, the Skin feems to have a clofer Communion with the Diametral Rays, and to be originated efpecially therefrom. They ufually ftand at an Equal Diftance in the fame Root: But with refpect to divers Roots, their Di- 


\section{Book II.}

of Roots.

ftance varies; fo lefs, in Parfnep, greater in Bugloss. They are commionly $T_{a b .7,8 .}$ Rectilinear, as in Lovage; but fometimes winding to and fro, as in
a Carrot.

9. \$. They are not always of one Size: in a Carrot near the Tab.8. Inner Edge of the Barque, exceeding Slender, and fcarcely difcernable; in others, Thicker, as in the Three greater ones of Melilot, and in common Chervil. Both by their Diftance, and Size, they are alfo Tab. 8, 9. lefs or more Numerous; fome, only as they are nearer; fome, as fmaller ; others, as both. And 'tis proper, I think, to the Intybous kind, either to have none, or but a few. Sometimes they are of the fame Thicknefs quite, through the Barque from edge to edge, as in Mar/s. Mallow. And fometimes are confiderably pread or dilated as th. Tab. 7 . aproach the Skin, wherewith they are joyned, and whereinto they more vifibly run, as in Par/ley, or the fmaller part of the Root of Lovage. And in fome Roots, as of scorzonera, at fome times of the $T_{a b} .8$. year, when lefs fucculent, almoft the whole Parenchyma feems to be of the Nature of the Diametral Rays, in other Roots. The Bladders of thefe Diametral Portions, are fometimes, greater than thofe of the other Parenchymous Parts, as in Parley; and I think fometimes lefs. Yet as there, fo here, varioully fized; to about fix or eight Degrees; and thofe of Parfley about the third, fourth, and fifth. Their Figure is Sometimes more oblong; and their direction or refpect more
towards the Center of the Root.

I I. F. As the other Parenchymons Parts of the Barque, are the Receptacles of Liquor; fo thefe, (where they are) of Aer. This is argued, From their being more White, and not Tranfparent, as fuch Roots and Parts ufe to be, which are more copioufly and equally filled up with Liquor: as the Pith of Elder, which, in the old Stalks, is White; was once, and by being well foaked, will become, again Tranfparent. And from their being more dry and voyd of Liquor; whereupon their Bladders, which cannot be Vacuities, muft be filled with more or lefs Aer, mixed with the Sap or the Vaporous parts thereof. This is more obfervable in thofe Diametral Portions, which terminate upon, and run into the Skin.

12. THE BARQUE is not only of a divers Woof, but as is Lignous $V_{e} / f l_{s}$, fewer the Parenchymous Part abovere, in fome place or other, mixed with demonfrable in all Roots pulled by the length. By the vifible Continuation the Barque, when through the length of the Barque, in the refemblance the faid $V_{e} / f e l s$ And by the rifing up of the sap , in the refemblance of fmall Tbreds. Tab. 6: fuch places of the Barque, where in the traverfe cut of the Root, in iftence of the fame $V_{e}$ fels in the thefe Threds terminate: as the exchaptet.

13. Thefe Tubulary Threds, run not through the Barque in direct lines; but are frequently Braced together in the form of NetWork; The Parencbymous Parts every where filling up the fpaces betwixt the Braced Threds; as in Burnet, Scorzonera, \&c. the Barque
being paired or ftriped off, is apparent. 
19. ซ. Oftentimes thefe Succiferous $V$ effels yield a Milky or White Sap; and fometimes Yellow, and of other colours as in Sonchus, and molt Cichoraceous Plants; in Angelica, and moft Umbelliferous; in Burdock; and divers Thiftles, to which that is 'akin: in scorzonera, Common Bells, and many other Plants, not commonly taken notice of to be snilky. The Milky Saps of all which, although they differ in Colour Thicknefs, and other Qualities; yet agree, in being more $O y l y$ than any of the Lymphous Saps. It being the mixture of the $O_{y l y}$ parts with fome other Limpid Liquor, but of a different Nature, which caufeth them to be of a Milky, or other Opacous Colour, in the fame manner as common $O y l$, and a ftrong Liquamen of Tartar, fhaked in a Bottle together, prefently mix into a White Liquor. And although they will, for the greateft part, feparate again ; yet fome of their parts, without any Boiling, or fo much as the leaft Digeftion with Heat, by Agitation only, or ftanding together for fome time, incorporate in the form of a Thin Milky-Sope, which will alfo diffolve in Water. I fuppofe, therefore, That it is the Volatile Salt, chiefly, of thefe Plants, which being mixed with their $O y l$, renders this Liquor of a White or other Opacous Colour.

20. 6. Sometimes the $O y l$ will feparate and difcover it felf: for if you cut a Fenil-Root traverfe, after it hath layn fome days out of the

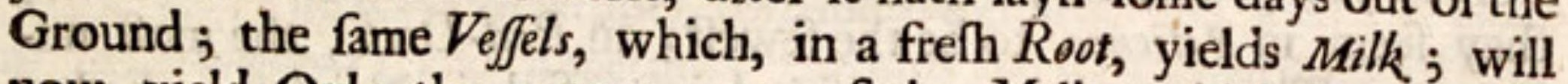
now, yield Oyl: the watery parts of the Milk, which in the drying of the Root are more evaporable, being fpent.

21. \$. All Gums and Balfams are likewife to be reputed the proper Contents of thefe $V$ effels: for Thefe and Milks, are very near akin. So the Milk of Fenil, upon ftanding, turns to a Clear Balfam; of Scorzonera, Dandelion, and others, to a Gum. In the dryed Root of Angelica, \&c. being fplit, the Milk, according to the Continuation of thefe $V$ effels, appeareth, as Blood clodders in the Veins, condenfed to an hard and thining Rofin. And the Root of Helenium cut Tab.9. tranfverfely, prefently yields a curious Balfame of a Citrine Colour, and fometimes of the Colour of Balfame of sulphur. I call it a Balfame; becaufe it will not diffolve in Water. Yet not a Terebinth; becaufe, nothing near fo vifcid or tenaceous as that is. But the Root of Common Wormwood, bleeds, from large $V_{e} \iint e l s$, a true Terebinth, or a $T_{a b} .10 . \mathrm{E}$. Balfame with all the defining properties of a Terebinth; although that word be commonly ufed only for the Liquors of fome Trees.

22. 5. There is yet another kind of Sap-Veffels, which may be called $V_{\text {aponr-Veffels; }}$ as in Docks, at leaft fome of them. For by the Sap-Veffels it is, that the Barques of Roots do Bleed. Of which, fome Bleed quick and plentifully, as the Umbelliferous and the Cicboraceous Kinds. Some, very flowly and fcarce vifibly, as all or moft Trefoyls, and of the Leguminous Kind. And fome feem not to Bleed, as the Dock. Yet that this Root, hath alfo $V_{e}$ ffels diftinct from thofe that carry Aer; doth partly appear, from the different Colour they produce where they ftand; as will better be underftood anon, in fpeaking of the Caufes of the Colours of Roots. As alfo from the Toughnefs of the Barque, in pulling it by the length; neither the Parenchyma nor the Aer-Vefels, being of themfelves Tough. But becaufe the Succus or sap they carry, feems to be a kind of Dewy Vapour, therefore, they may not improperly be called Roriferous or Vapour-Veffels.

$$
\mathrm{P}_{2}
$$


23. \$. THE sap-Veffels, are not only of divers Kinds, in divers Roots, but in the fame. Whether in all, I doubt : but in fome it is certain they are: For if you cut a Fenil-Root traverfe, both Milk and

Tab.9. Limpid $S_{a p}$, will prefently afcend, and, upon accurate infpection, appear thereupon dinftinctly. So the Roots, both of Trachelium and Enula, Bleed both a Lympha, and a Citrine Balfame: and Wormwood, both a Lympha, and a Terebinth, at the fame time. So alfo the Root of Dandelion being cut in November, feems to bleed both a Milk and a Lympha; the latter being drowned by the former at another time when it is more copious. Whether all Roots have Lymphaducts, is doubtful ; but 'tis moft probable, that they have, more or fewer; ftanding, for the moft part, in a Ring, at the Inner Verge of the Barque: the $S a p$ whereof, I fuppofe, is fo far of common Nature in all Roots, as to be Clear, and lefs Oily.

24. 6. THE Quantity of thefe Veffels is very different: In Borage, Peony, Biftori, but few; in Afparagus, fewer : in Parfnep, Celandine, many; in Fenil, Mar/h-mallow, many more: and betwixt thefe ex$T_{a b} .7,8,9$. treams, there are many Degrees, as by comparing the Roots of HorfeRadifh, Turnep, Briony, Skirrets, Parley, Goats-Beard, and as many more as you pleafe, may be feen. Amongtt the feveral Sorts of Docks, they feem in Patience, to be the feweft; in Red-Dock, the moft numerous. There are two ways of judging of their Number; Either as their Extremeties are vifible upon the traverfe cut of the Barque; or as the Barque is diverfly Brittle or Tough; being fo, from the various Number of thefe Vefels therein, as in the Second Chapter hath been faid.

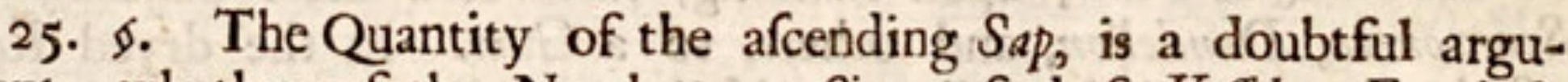
ment, whether of the Number, or Size of thefe Vefjels. For it is common to moft Milky-Roots, for the Milk to afcend more copioufly: yet in fome of them, the Veffels feem, in proportion with the Parenchymous Part, not to be fo numerous, as in fome other Roots, where the afcending Sap is lefs; as by comparing the Lacteals of Dandelion, and the Lympheducts of Fenil together, may appear: fo that it fhould feem, that the bore of the Lacfeal Veffels, is greater than that of the Lympheducts.

26. 5. THE Situation of thefe $V_{e}$ fels, as they appear, even to the naked Eye, in the tranfverfe Section, is Various and Elegant. Sometimes they are pofited only at the Inner Edg of the Barque, where $T_{a b} .7,8,2$, they make a Ring, as in Afparagus. In which place and pofition, they 6. 10. - ftand in moft, if not in all, Roots, how varioully foever they are pofited alfo otherwife. The Common Crow -Foot with numerous Roots, hath a Ring of Sap-Veffels next the Skin. So the Barque of MonksHood, is encompaffed with a tranfparent Ring of Sap-Veffels. The Ring is either more Entire, as in Eryngo, Brown-Wort, Valerian, Hop, Madder, Ecc. Or it is a Prick'd Ring, as in Buttyr-Bur. Sometimes they are chiefly poftur'd in a Prick-Ring, towards the outward part of the Barque, as in Peony: and fome Roots are pricked all over the Barque, as of Melilot. In others, they ftand not fo much in Prioks, as Portions or Colums, as in Cumifry- 
27. \$. In others, again, they all ftand in more continued Lines, either Rays or Diametral, as in Borage; or Peripherial, as in Celandine. The Vafcular Rays are not equally extended in all Roots: in Parfnep, towards the Circumference of the Barque; in Bugloss, about Tab.7, 8, . half way. In all Docks, and Sorrels, the Rays are extended through about $\frac{3}{4}$ of the thicknefs of the Barque, towards the Circumference, whereabout, divers of them are always arched in, two and two together. In all or many Trefoyls, and of the Leguminous Kind, they are extended through no more than $\frac{1}{3} \mathrm{~d}$ of the Barque. In the Umbelliferous, they are Ralled in betwixt the Diametral Portions of the Parenchyma. In Borage, the Rays are more Continuous; in a Carrot, more Pricked. Here alfo the Pricks ftand in Even Lines; in Lovage, they are Divaricated. Of which, and thofe of fome other Roots, it is alfo Obfervable, That they are not all meer Pricks, but moft of them fmall, yet real Circles; which, after the Milk hath been frequently licked off, and ceafeth to afcend, are vifible, even without a Glafs. And note, that in obferving all Milk-Veffels, the Milk is to be taken off, not with the Finger but the Tongue; fo often, till it rifeth no more, or but little. And fome Roots may alfo be foaked in Water ; whereby the Pofition of the Milk-Veffels, will be vifible by the darker $\mathrm{Co}$ lour of the Barque, where they ftand.

18. 5. The Rays fometimes, run more Parallel, and keep feveral, as in Monk/bood; and fometimes, towards the Circumference of the Barque, they are occurrent; as not only in Docks, but other Plants: In Eryngo, in a termination more Circular; and in Bryony, angular, or in the form of a Glory, as alfo in Horfradifh, through a Microfcope. ThePeripherial Lines are in fome, more entire Circles, as in Dandelion; in others, made up of fhorter Chords, as in Potato, Cumfry, and the fmaller part of the Root of Monks-hood. In fome, the Pricks are fo exceeding fmall, and ftand fo clofe, that, to the bare eye, they feem to be continous Rings, which yet, through the Microfcope, appear diftinct, as in Mar/s-mallow and Liquirifh.

29. \$. Sometimes Columns and Chords are compounded, as in Burnet; Pricks and Chords, in Potato ; Rays and Rings, in Monkfood; where the Ring is Single. In Fenil, there is a double or treple order both of Rays and Rings, the Lympheducts ftanding in Rays and the Lacteals in Rings. And in Marjh-mallow, the $V_{e j f e l s}$ are fo pofited as to make both thofe kinds of Lines at once.

30. 6. In Celandine, they feem all, to the bare eye, to ftand in numerous Rings lying even one within another. As alfo in Dandelion; in which yet, being viewed through a Microfcope, there is an appear- Tab.13. ance of very many froall Rays; which ftreaming from the Inner Verge of the Barque, crofs three or four of the fmaller Rings, and are there terminated. Whence it fhould feem that Lymphatick Rays and Milky Rings, are in thatRoot, fo far mixed together. Only the Lympha, being confounded with the Milk, cannot be difcerned. And where the Milky.Vefels are evacuated, or at fuch Seafons, wherein they are lefs full, divers Milky Roots will yield a clear Liquor at the Inner Verge of the Barque, where, at other times, they feem to yield only Milk. And this is the Defcription of the Barque. 


\section{H A P. IV. \\ Of the WOOD.}

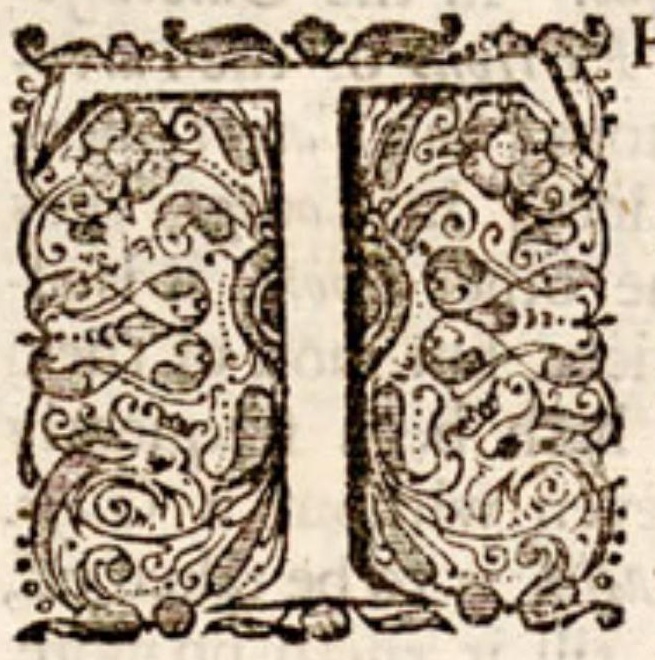

A T Portion of the Root which ftandeth next within the Barque, and in Trees, and Sbrubby Plants, is the Weod; is alfo compounded of Two Subftantially different Bodies, Parenchymous and Lignous. The Parenchymous, is of the fame Subftantial Nature with that of the Barque. And is originated from it ; being not only adjacent to it, but all round about continuous therewith; even as that, is with the Skin; the Parenchyma of the Barque, being diftributed, from time to time, partly outward into the skin, and partly inward, into the Wood.

2. 6. The Pofition of the feveral parts hereof, is different. For the moft part it hath a Diametral Continuation, in feveral Portions, running betwixt as many more of the Lignous, from the Circumference towards the Center of the Root: all together, conftituting that, which in the second Chapter of the Firf $22300 \mathrm{k}$, I call the Infertment. In the Roots of many Herbs, thefe Diametral or Inferted Portions are more

Tab.9. obfervable, as in Cumfry; which leadeth to the notice of them in all others, both of Herbs and Trees. Sometimes part of this Parenchymous Body is difpofed into Rings, as in Fenil. The Number and Size of which Rings differ: In Fenil, when the Root is grown large, they

$T_{a b}$. 8, 9. are in fome places broader, but fewer; in Beet they are narrower, but more. The Diametral Portions are here, in like manner, much varied; in Cumfry, Celandine, larger; in Beet, Bugloss, meaner; in Borage, Parfnep, more, and fmaller; and in moft Woody-Roots, ftreaming betwixt the Pith and the Barque, as fo many fmall Rays. Their Continuation is alfo different ; in fome Roots, to the Centre, as in Columbine; in others not, as in Parfnep. And fometimes different in the Tab. 17. fame Root, as in the $V$ ine.

3. 5. The Contexture of thefe Parenchymous Portions is fometimes Uniform, as in Bugloss, Peony; and fometimes alfo, as it is in the Barque, different ; in part, more fappy, and tranfparent; in part, more white, dry, and aery, as in Carrot, Lovage, Scorzonera, and others; which yet cannot be obferved without a wary view. But their general Texture is the fame being all made up of many fmall Bladders. Which are here of different Sizes, like thofe of the Barque, but for the moft part fmaller. Their Shape likewife, is ufually Round; but fometimes Oblong and Oval, as in Borage; or Oblong and Square, Tab. 17. as in the Vine.

4. 5. The Lignous Part, if not always, yet ufually, is alfo Compounded of TwoKinds of Bodies, fiil. Succiferous or Lignous and Aer$V e f f e l s$. The Lignous as far as difcernable, are of the fame Conformation and Nature with thofe of the Barque, and in the tranfverfe cut 
of the Root, do oftentimes, as thofe, emit a Liquour. They are alfo Braced; and many of them run in diftinct Threds or Portions, collaterally together.

5. \$. The Aer Veffels I fo call, becaufe they contain no Liquor, bnt an Aery Vapour. They are, more or lefs, vifible in all Roots. They may be diftinguifhed, to the bare Eye, from the Parenchymous Parts, by their Whiter Surface; and their ftanding more prominent, wheras thofe fhrink below the tranfverfe level of the Root, upon drying. They are frequently Conjugated divers of them together, fometimes fewer, and $\tau_{a} b . \mathrm{yo}_{\text {, }}$ for the moft part fingle, as in Afparagus; fometimes many, as in Horf- $\mathbf{1 5}$. Radifh. And their Conjugations are alfo Braced, as the Threds of the Succiferous Veffels. But they are no where Inofculated: nor Twifted one about another; but only Tangent or Collateral. Neither are they Ramified, the greater into lefs; but are all diftinctly continued, as the Nerves in Animals, from one end of the Root to the other.

6. 6. Their Braces, as thofe of the Succiferous $V_{e} \int j e l s$, are alfo of various number: in Ferufalem Artichoke, Cumfry, Scorzonera, more rare; in Borage, Burnet, more frequent; as by ftripping off the Barque of fuch Roots, where it is eafily feparable, may be feen. And they often Tab. 6 . vary in the fame Root; fo in Borage, Scorzonera, \&c. they are more frequent in the Centre, and next the Barque, than in the Intermediate fpace, as by fplitting thofe Roots down the middle doth appear. They alfo vary from thofe of the succiferous Vefjels; thofe being ufually more $T_{a b .} \sigma_{\dot{\alpha}}$ frequent, as in Jerufalem Artichoke, than thefe of the Aerial.

7. 6. Betwixt thefe Braced Aer-Veffels, and the reft, which make the true Wood, run the Parenchymous Parts above defcribed; as they $\tau_{a b} .6$. do betwixt the Succiferous in the Barque: and fo make up two Pieces of Net Work, wherof one is the filling up of the other.

8. 5 . The Pofition of both thefe Kinds of $V e \int f e l s$, is Various. The Succiferous or Lignous, are fometimes pofited in diametral lines or portions; as in the Vine, and moit Trees. Sometimes, oppofitely to the $T_{a b .17}$ Aerial, as in Beet; each Ring herein being double, and made both of $T_{a b} .8$.
Sap-and Aer-Veffels.

9. 5. In Nettle the Pofition is very peculiar, from what it is in the $T_{a b} .8$. Roots of other Herbs; being curiously mixed; the succiferous running crofs the Aerial, in feveral, viz. Five, Six, Seven, or more Rings.
In Bryony the feveral Conjugations of the Aerial, are diftinctly furrounded with the Succiferous. In Patience, the Succiferous are difpofed, Tab. \% befides Rays, into many fmall Rings, of different Sizes, fprinkled up and down, and not, as in other Roots having one common Centre; within divers whereof, the Aer-Veffels are included: efpecially within thofe which are drawn, not into Rings, but, as it were, into little ftragling Hedges.

10. S. That alfo of the Aer-Veffels, is Various and Elegant : efpecially in the upper part of the Root. In Ammi, Lilium-non-bulbofom, they make a Ring. In thefe, a Prick'd-Ring; in Peony, a Ring of Rays; in Valerian, a Ring of Pricks and Rays. In others, they make $\tau_{a b}, 7,8 ; q$. not Rings, but longer Rays, extended either towards the Centre, as in Scorzenera; or meeting in it, as in Columbine. In the Common Dock, they ftand more in fingle Rays: in the other Species of $D_{\text {ocks, }}$ both in Rays, and collateral Conjugations between.

11. 6 . 
II. \$. In Beet, they ftand in feveral Rings; and every Ring, made of Rays. In Cumfry, the Rays and Rings are feparate; thofe

$T_{a}$. 8, 9. Itand without, thefe next the Centre. In Dandelion, they ftand altogether, and make a little Rope, in the Center it felf. In Geranium, and others of that Kindred, they make a little Thred, in the fame place. And in Skirret, they ftand in two Threds, near the Centre.

12. \$. In Celandine, they ftand in almoft parallel Lines. In

Tab. 8, 9. Monks-hood, of a wedged Figure; divided in the fmaller part of the Root, into Three little Wedges, with their poynts meeting exactly in the Centre. In Cinquefoyle, and Strawberry, they are alfo poftur'd in three Conjugations, triangularly. In the young Roots of $\mathrm{Oak}$, they ftand neither in Radiated, nor otherwife ftrait, but Winding Lines. And in Borage the pofition, of many of them, is Spiral. As likewife, fometimes, in Mercury, or Lapatbum uncuofum. In Horfe-

Tab. 15. Radih, they ftand more confufed neither in Rings nor in Rays; yet their feveral Conjugations, are radiated: with very many other differences.

13. 5. The Quantity of thefe $V_{\text {effels, }}$ as to the fpace they take up in the Root, is to be computed Two ways, By their Number, and Size. Their Number may, in fome Roots, and in fome meafure, be judged of, by the bare Eye; having, frequently, a whiter furface than the other Parts. As alfo their Size; the Bore of thefe $V$ effels being greater than that of the Lignows in all Roots; efpecially in fome. For if you take the Roots of Vine, Fenil, Dandelion, Plum-tree, Elder, Willow, \&c. and lay them by, for fome time, to dry; and then, having cut off a very thin Slice of each, tranfverfely; if you hold up thofe Slices before your Eye, fo as the Light may be trajected through the faid $V$ effels, they hereby become vifible, as notably different, both in Number and Size.

14. 5. But undeceitful and accurate Obfervation of both their Number, and Size, muft be made by the Microfcope; and fo they will appear to be much more various. In Biffort, Skirret, they are very few; in Beet, very many: betwixt which extreams there are all Degrees; as in Orpine, Venus Looking-Glafs, Scoizonera, Great Celandine, Peony, Boragc, Fenil, \&c. may befeen. So their Size, in fome is extream Imall, as in Strawberry, Biftort, Valeriun; in others very great, as in Afparagus, Buglofs, Vine. They are alfo of feveral Sizes in one and the fame Numerical Root; but in fome, are lefs varied, as in $\mathbf{L i}$ -

Tab. 10. to lium non bulbofum, Afparagus, Buglo $\beta$; in others, more, as in Bryony,
the 17. the 17 as by comparing the Roots of Vine, Thorn-Apple, Bryony, Lovage, Fenil, Wild Carrot, saxifrage, Parfley, Peony, Hore-hound, Cinquefoyl, strawberry, \&c. together, may be feen. Some of thofe in the Vine, being of the greatelt Size; appearing through a good Gla $\int_{s}$, at leaft one Third of an Inch in Diametre: thofe in Strawberry, and that Kind, of the fmalleft; moft of them appearing, in the fame Gla/s, no bigger, than to admit the poynt of a fmall Pin, according to the Standard, in Tab. 12. See alfo the Figures of fo many of them as are drawn. 
15. 6. In fome Roots, they are Small, and Few; as in ferufalem Artichoke; in others Small, but Many, as in Horfe-Radifis: in Buglofs, Tab. 11, $1_{4}$, they are Great, but Few; in the Vine, Great and Many. So that the $15,17$. proportion, which thofe of a Vine, their Number and Size being taken together, bear to thofe of ferufalem Articboke, may be, at leatt, as Fifty, to One. Of the fmalleft Kinds, as thofe of Cinquefoyl, Jerufalem Artichoke, and the like; It is to be noted, That they are fcarce ever vifible in the frefh Slices of thefe Roots; but after they have layn by a while, at laft, by a good Glajs, Clear Light, and fteddy View, are difcernable.

16. 6. In fome Roots, the greater of thefe Veffels ftand in or next the Centre, as in Taraxacum, or Dandelion; in others next the circum. Tab.13, 15. ference, as in Horfe-Radiffs. Sometimes each of them is from one end of the Root to the other, of a more equal Size, or more Cylindrical, as in Mar/h-mallow ; but ufually, they widen, more or lefs, from the Top, to the Bottom of the Root, as in Thorn-Apple: about the Top of which, they are, for the moft part, but of the Sixth, Seventh, and Eighth, Magnitude; fome of the Fifth, but none of the Third; but about the Bottome, they are moft of the Third, and Fifth: whence it is manifelt, That fome of them are, in the manner of Veins, fomewhat Pyramidal. Yet is it obfervable, That theirampliation proceedeth not towards, but from their Original, as in Nerves.

17. 5. Of thefe Veffels Seignior Malpighi hath obferved; Componuntur (faith he) expofite fiftule Zona tenui \& pellucida, velut argentei coloris lamina, parum lata; que, Jpiraliter locata, \& extremis lateribus unita, Tubum, interius of exterius aliquantulum afperum, efficit.

18. 5. To whofe Obfervation I further add, That the Spiral Zone, or Lamina, as he calls it, is not ever one Single Piece; but confifteth of Two or More round and true Fibres, although ftanding collaterally together, yet perfectly diftinct. Neither are thefe Single Fibres themfelves flat, like a Zone; but of a round forme, like a moft fine Thred. According as fewer or more of thefe Fibres happen to break off, from their Spiral location, together; the Zone is narrower, or broader: ufually, Narrower in the Trunk, and Broader in the Root.

19. 5. Of thefe Fibres I alfo Obferve, That they are not Inofculated fide to fide, but are $K_{n i t}$ together by other fmaller Fibres; thofe being, as it were, the Warp, and thefe the Woof of the Aer-Veffels. Yet I think the feveral Fibres are not interwoven juft as in $\mathrm{Web}$; but by a kind of Stitch, as the feveral Plates or Bredths of a Floor-Mat. A clear and elegant fight of thefe Fibres, and of their Interwoftage, by fplitting a Vine-Root, or a piece of Oal, may, with a good Glafs in the fides of their Greater Aer-Veffels, be obtained; having much of the refemblance of Clofe Needle-work: 20. 5. The Spiration of the Fibres of thefe Vefjels, may more eafily
be obferved in the Trunk, than in the Root. And better in younger
Plants, than Plants, than other. And not fo well by Cutting as by Splitting, or by Tearing off fome fmall Piece, through which they run: their Conformation being, by this means, not fpoiled. Yet this way, the Veffels are
feen, chiefly, Unrefolved.

2I. 6. But in the Leaves and Tender Stalks of all fuch Plants, as fhew, upon breaking, a kind of Doune or Wool; they may be feen
Refolved and Drawn out, and that fome times even to the naked Eye, 
an Inch or two Inches in length. This Wool being nothing elfe, but a certain number of Fibres Refolved from their Spiral pofition in thefe $V$ effels, and Drawn out in Length; and fo cluftred together, as fo many Threds or little Ropes: appearing thus more or lefs, in the Leaves and fome other Parts of moft Plants; but more remarquably in fome, as in the Vine, Scabious, and others. As alfo in the Scales of a squill. In which laft, for example, they are fo eafily feparable, as further to fhew, what before was obferved; viz. That the Plate or Zone, into which the Aer-Veffels are ufually Refolved, is not one Single Piece, or meer Plate; but made up of feveral Round Fibres, all ftanding and running parallel, and fo knit together by other fmaller ones, tranfverlly, in the form of a Zone. For if you break or cut a Leaf or shell of a frefh Squill, till you come to the Aer-Veffels, and having foftly drawn them out, for about an Inch or more (to the naked Eye) in length, you then fingle out one or two of them from the reft, and rowl them, as they hang at the Shell, eight or nine times round, each $\mathrm{VeJel}$ will appear, through a Glafs, to confift of 8,10 , or 12 mall Fibres; which, in the Unrefolved Veffel, run parallel; but by this means, are all feparated one from another. See the Figures belonging to the Third and Fourth $2300 \mathrm{~kg}$.

22. \$. The Procefs of their Spiration, is not, fo far as I have obferved, accidental, but conftantly the fame; fcil. In the Root, by South, from $W_{e f t}$ to Eaft: But in the Trunk, contrarily, by South, from $E a f t$ to $W e f$.

23. 5. The Content of thefe Vefjels, is, as hath already been intimated, more Aery. The Arguments for which, are, That upon a tranfverfe Cut of the Root, the sap afcendeth not there, where Thefe ftand. Being alfo viewed through a Microfcope, they are never obferved to be filled with Liquor. Befides a Root cut and immerfed in Water, till the Water is in fome part got into thefe Vefels, and then the Root taken out and crufhed; the other Parts will yield Liquor, but Thefe, only Bubbles: which Bubbles are made, by fome fmall quantity of Liquor mixed with the Aer, before contained in the faid $V e f f e l s$. To which, other Arguments will arife out of thofe Things that follow in the Second joatt. As alfo for this Content, its not being a pure or fimple, but Vaporous Aer. Whether thefe Veffels may not, in fome Vegetables, and at fome times, contain Liquor, is doubt.

(a) See ful. (a) Thus far of the Lignous Part.

Book 3 .

CHAP. 


\section{H A P. V. \\ Of the P I TH.}

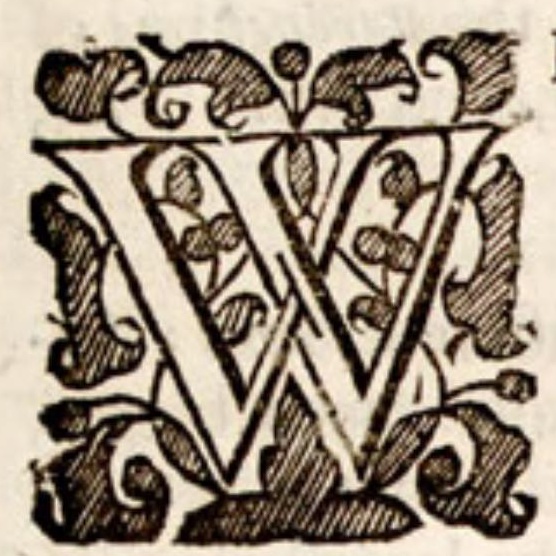

I THIN the Lignous Part lyeth the Pith. This Part is not common to all Roots, for fome have none, as Nicotian, Srtamonium, and others. Yet many which have none, or but little, throughout all their lower parts, have one fair enough about their tops, as Mallow, Bourage, Dandelion, and the like. See the Roots. And in many others there Tab.6. are Parenchymous Parts, of the fame fubftantial nature with the $P i t h$, diftributed betwixt the feveral Rings of $V_{e} / \int e l s$, and every where vifible, from the top to the bottom, as in Beet, Fenil, \&c.

2. 6. The Size of the Pith is varied by many Degrees, eafily recTab. 8. koned an Hundred; in Fenil, Dandelion, Ajparagus, but fmall; in Horfe-Radifh, Valerian, Biftort, great. The Shape hereof, in the lower parts of moft Roots, is Pyramidal ; but at the tops, Various, according to the different Diftribution of the Vefels, as in Carrot, Hyper- $\tau_{a} b .6$, bolick, in Parley, Oval; as appearetb, in cutting the Roots lenght-
ways.

3. 5. The Pith, for the moft part, efpecially in Trees, is a simple Body: but fometimes, it is, as the Barque, compounded; fome certain number of succiferous $V$ effels being mixed herewith; as in Ferufalem Artichoke, Horfe-Radifh, \&c. upon a traverfe cut, by a ftrict view, may be $T a b .6,6.8$. difcerned. Their Pofition is fometimes Confufed, as in a Carrot; and fometimes Regular, as in Parfley; appearing, by the traverfe cut, in Rings, and in cutting by the length, in Arches. And fometimes the $T_{a b} .6$. Pith is hollow 3 as in the Level-Roots of Bifhops-Weed: thefe Roots being made out of the Stalk, as in the First Chaptet hath been fhew- S. 13,14,15.
ed, how.

4. 5. As all the other Parts of the Root, are originated from the Seed; fo, fometimes, is the Pith it felf. But fometimes, it hath its more immediate Derivation from the Barque. Hence it is, that many Roots, which have no Pith in their lower parts, have one at their top, as Columbine, Lovage, \&c. For the Parenchymous Parts of the Barque being, by degrees, diftributed into Diametral Portions, running betwixt thofe of the Lignous Body, and at length, meeting and uniting in the Centre, they thus conftitute the Pith. In the fame manner, at the top of fome Roots, the $P$ ith is either made or augmented, out of the Parenchymous Rings above defcribed; thefe being gradually diftributed to, and embodied in the Centre; as in Fenil, and fome other Roots, their lower and upper parts compared together, may be feen. Even as in Animals, one Part, as the Dura Mater, is the original of divers others. 
5. \$. From hence, it alfo appears, That the Pith is of the fame Subftantial Nature with the Parencbyma of the Barque, and with the Diametral Portions; and that therefore they are all one body, differing in no Effential Property, but only in their Shape and Place. The fame is alfo evident from the Continuity of the Pith with the Diametral Portions, as of Thefe, with the faid Parenchyma. And from their Contexture, which, by a Microfcope, appeareth to be of one and the fame general kind, in all Plants, both in the Parenchyma of the Barque, in the Infertment or Diametral Portions, and in the Pith, all being made up of Bladders. 6. 5. The Bladders of the Pith, are of very different Sizes; fel-
$T_{a b .9,}$. T 15. dom lefs, than in the Barque, as in Afparagus; ufually much bigger, as in Horfe-Radiff. They may be well reckoned to about fifteen or twenty degrees; thofe in Ferufalem Artichoke, of the largeft; in $\mathrm{Ve}$ lerian, Hor e-Radifh, of the meaner; in Biftort, Peony, of the fmalIeft. Their Polition is rarely varied, as it is oftentimes, in the Barque; but more uniform, and in the tranfverfe Cut, equally refpective to all parrs of the Root: yet being piled evenly, one over another, in the long cut, they feem to run, in Direct Trains, by the length of the Root. Their Shape alfo is, ufually more orbicular; but fometimes,

Tab. II. fomewhat angular, in the larger kinds, as in Jerufalem Artichoke.

7. 6. THUS FAR the Contexture of the $P$ ith is well difcoverable in the Root. In the Trunk, farther, and more eafily. Whereof therefore, in the next Book, I hall give a more particular Defcription and Draught. Yet fince I am fpeaking of it, I fhall not wholly omit: here to obferve, That the sides, by which the aforefaid Bladders of the Pith are circumfcribed, are not meer Paper-skins, or rude Membranes; but fo many feveral Ranks or Piles of exceeding fmall $F_{i-}$ brous Threds; lying, for the moft part, evenly one over another, from the bottom to the top of every Bladder; and running crofs, as the Threds in the Weavers Warp, from one Bladder to another. Which is to fay, That the Pith is nothing elfe but a Rete mirabile, or an Infinite Number of Fibres exquifitely fmall, and admirably Complicated together: as by cutting the Pith with a Razor, and fo viewing it with a good Glafs, may be feen. See the Figures belonging to the Third 23ook.

8. 6. All Plants exhibit this Spectable, not alike diftincty; thofe beft, with the largeft Bladders. Nor the fame Pith, in any condition; but beft, when dry : Becaufe then, the $S a p$ being voided, the fpaces betwixt the Fibrous Threds, and fo the Threds themfelves, are more diftinctly difcernable. Yet is it not to be dryed, after Cutting; Becaufe its feveral parts, will thereupon coincide and become deformed. But to be chofen, while the Plant is yet growing; at which time, it may be often found dry, yet undeformed; as in the Trunks of Common Thifle, Ferufalem Artichoke, \&c.

9. 6. Neither are thefe Tbreds, fo far as I can obferve, Single $F_{i-}$ bires; but ufually, confift of feveral together. Nor are they fimply Collateral, but by the weftage of other Fibres, in their natural Eftate, knit together; much after the fame manner as the Spiral Fibres of the 
Aer-Veffels. This Connexion I have no where fo well feen, as in the White Bottoms of the Bladders of a Bulrufh, being cut traverfe; wherein they have the appearance, of very Fine and clofe Needle-work.

10. 5. The Fibres by which the faid Threds are knit together, I think are all Single: and are feldom and fcarcely vifible, except by obliquely Tearing the Pith; by which means, they will appear through the Glafs, broken off, fometimes, a quarter or half an Inch, or an Inch in Length; and as fmall as one Single Thred of a Spiders Webb. In a Bulrufl, they are fometimes difcernable in cutting by the Length. Thefe Fibres, and the Threds, they knit together, for the moft part; are fo pellucid, and clofely fituate, that they frequently feem to make One entire Body, as a picce of Ice or a film of Water it felf: or even as Animal skins fometimes thew, which yet are known to be Fibrous.

i1. \$. The Situation of thefe Threds, is contrary to that of the $V e \int f e l s$, as thofe by the Length, fo thefe, chiefly, by the Bredth of the $R o o t$, or horizontally, from one edge of the $P$ ith to the other. They are continued circularly; whereby, as oft as they keep within the compafs of the feveral Bladders, the faid Bladders are Round: But where they winde out of one Bladder, into another, they mutually Interfect a $C$ hord of their feveral Circles; by which means, the Bladders become Angular.

12. 5. The Contexture, likewife, both of the Parenchymous Part of the Barque, and of the Diametral Portions inferted betwixt the Lignous; is the fame with this of the Pith, now defcribed; that is, Fibrous, Whence we underftand, How the feveral Braces and Threds of the Vef fels are made: For the $V$ effels running by the length of the Root, as the Warp; by the Parenchymons Fibres running crofs or horizontally, as the Woof: they are thus knit and as it were fitcbed up together. Yet their weftage feemeth not to be fimple, as in Cloath; but that many of the Parenchymous Fibres are wraped round about each $V_{e f f e l}$; and, in the fame manner, are continued from one $V_{e f f e l}$ to another; thereby knitting them altogether, more clofely, into one Tubulary Thred; and thofe Threds, again, into one Brace: much after the manner of the Needle work called Back-Stitch or that ufed in Quilting of Balls. Some obfcure fight hereof, may be taken in a Thred ofCambrick, through a Microfcope. But it is moft vifible, in the Leaves and Flowers of fome Plants. The Delineation of thefe Things I thall therefore omit, till we come hereafter to fpeak of the other Parts.

13. 6. From what hath been faid, it may be conjectured; That the Aer $V_{e} \int f e l s$ fucceffively appearing in the Barque, are formed, not out of any Fluid Matter, as are the original ones: But of the Parenchymous Fibres; $f c$. by changing them from a spherical to a Tubulary
Forme.

14. 6. From the precedents, it is alfo manifeft, That all the Parenchymous Parts of a Root, are Fibrous.

15. 5. And laftly, That the whole Body of a Root, confifteth of $V e f e l s$ and Fibres. And, That thefe Fibres themfelves, are Tubulous, 
or fo many more $V e f f e l s$, is moft probable: There only wanteth a greater perfection of Microfcopes to determine.

16. 5. The Contents of the Pith are, fometimes Liquor, and fometimes a Vaporous-Aer. The Liquor is always Diaphanous, as that of the Parenchymous Part of the Barque; and in nature, not much differing from it. The Aer is fometimes lefs, and fometimes more Vaporous, than that of the Barque. By this Aer I mean, that which is contained in the Bladders. Within the Concaves of the Fibres which compofe the Bladders, I fuppofe, there is another different Sort of Aer. So that as in the Bladders is contained a more Aqueous; and in the Veffels, a more Effential Liquor: So fometimes, in the fame Bladders, is contained a more Vaporous; and in the Fibres, a more Simple and Effential Aer. 


\section{An Account of the}

\section{VEGETATION}

$\mathrm{OF}$
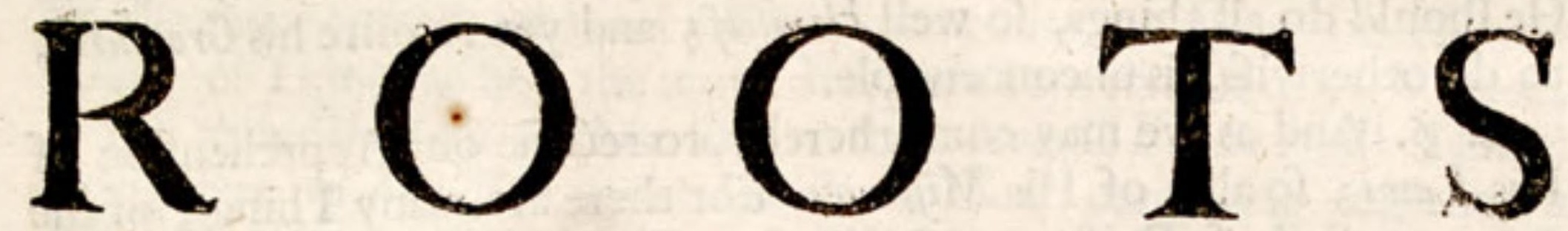

Grounded chiefly upon the foregoing

\section{A N A T OM Y.}

\section{P A R T II.}

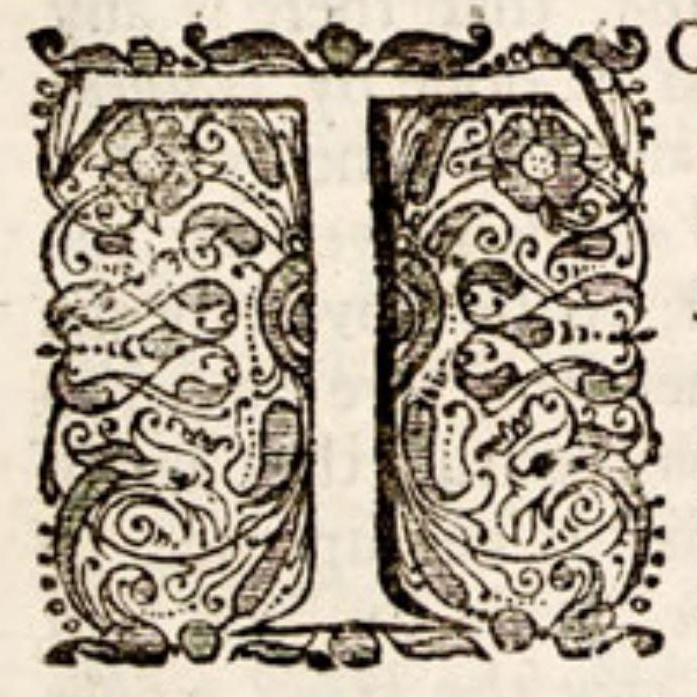

Pbilofophize, is, To rendar the Caufes and Ends Thoology the of Things. No man, therefore, that denieth God Beginning can do this, Truly. For the taking away of the and End of firft Caufe, maketh all things Contingent. Now, Pbilosopby. of that which is Contingent, although there may be an Event; yet therecan be no Reafon or End: fo that Men fhould then ftudy, That, which is not. So the caufes of Things, if they are Contingent, they cannot be Conftant. For that which is the Canfe of This, now; if it be fo Contingently, it may not be the Caufe hereafter : and no Phyfical Propofition, grounded upon the Conftancy and Certainty of Things, could have any foundation. He, therefore, that philofophifeth, and denieth God, playeth a childith Game.

2. \$. Wherefore Nature, and the Caufes and Reafons of Things, duly contemplated, naturally lead us unto God; and is one way of fecuring our Veneration of Him: giving us, not only a general Demonftration of his Being; but a particular one, of moft of the feveral 2ualifications thereof. For all Goodnefs, Righteoufnefs, Proportion, Order, Truth, or whatever elfe is Excellent and Amiable in the Creatures; it is the Demonftration of the like in God. For it is impoffible; that God 
fhould ever make any thing, not like Himfelf, in fome degree or other. Thefe Things, and the very Notions which we have of them, are Conceptions iffuing from the $W$ onab of the Divine. Nature.

3. 5. By the fame means, we have a greater affurance of the Excelency of his Sacred Word. That He, who hath Done all things fo tranfcendently well; muft needs Speak as well, as he hath Done. That $\mathrm{He}$, who in fo admirable a manner, hath made Man; cannot but know beft, What his true Principles and Faculties are; and what Actions are moft agreeable thereunto: and, that having adorned him with fuch Beauteous and Lovely ones; it is impoffible, He fhould ever put him upon the Exercife of thofe Faculties, in any way Deformed and Unlovely. That He fhould do all things, fo well Himelf; and yet require his Creatures,
to do otherwife, is unconceivable.

4. 5. And as we may come, hereby, to rectifie our Apprehenfion of His Laws; fo allo, of His Mifteries. For there are many Things, of the Manner of whofe Exiftence, we have no certain Knowledge. Yet, of their Exiftence, we are as fure, as our Senfes can make us. But, we may as well deny, what God hath Made, To be ; as, what he hath Spoken, Things being gradually attained wot bow. And the knowledge of Things we occalion to reflect, That fome gible. I know, therefore, what I underftand we once thought unintelliwhat is unintelligible: what I know ntand not; but, I know not, not I, another; or if no Man, or ow I may hereafter; or if God fully underfandeth Himfelf. It Creature, it is fufficient, That of Nature, but they are the manton is not, therefore, the $K$ nomledge them, either to Forget God, or to Think of Mens minds, that difpofe

5. 8. Nor have we reafon to fear going too

ture; more than the entring into going too far, in the Study of $\mathrm{Na}$ the true Knowledg and dus into it: Becaufe, the higher we rife in and due Contemplation of This; the nearer we Contradiction, when Philo hopby which Religion, and to be done by Nature; no more, next Wheel; is to deny that Wheel and of $W$ atch is moved by the Spring; and that both the spring, and the reft, to be moved by the move together by the This Effect, although a Ther of them. So God may be truly the Canfe of intervene: For all Nature is as other Canfes fhould be fuppofed to in His Hand. And as it is the Watch-makers Engine, made by, and held regurt, that the Hand moves regularly, fromhour to hour, although he put not his Finger ftill to it : So is it the Demonftration of Divine Wifdome, that the Parts of Nature are fo harmonioufly contrived and fet together; as to confpire to all kind of Natural Motions and Effects, without the Extraordinary and Immediate Influence of the Author of it.

6. 6. Therefore, as the Original Being of all Things, is the moft proper Demonftration of Gods Power: So the fucceffive Generations, and Operations of Thingsare the moft proper Demonftration of his Wifdom. For if we fhould fuppofe, that God did now make, or do any Thing, by any Thing; then, no Effect would be produced by a Natural Canfe: and confequently, He would ftill be upon the Work of Creation: which yet Sacred Scripture affureth us, He reftet b from. And we might exfpect 
the Formation of a Cbild, in an Egg, as well as in a Womb; or of a Cbick en, out of a Stone, as an Egg: And all Sorts of Animals, as well as Plants, might propagate their Species, without Coition: and the like. For Infinite Poner, needeth not make any difference in the Things it undertakes to manage. But in that, thefe Things are not only made, but fo made, that is, according to fuch certain Natural Laws, as to produce their Natural Effects; here is the Senfible and Illuftrious Evidence of his Wifdom. Wherefore as the Wifdom of Government, is not feen, by the King his interpofing Himfelf in every Cafe; but in the contrivance of the Laws, and Conftitution of Minifters in fuch fort, that it thall be as effectnally determin'd, as if he did fo indeed: So the more complicated and vaftly Numerous, we allow the Natural Caufes of Things to be; the more duely we conceive of that Wifdom, which thus difpofeth of them all, to their feveral Effects: All Things being thus, as Minifters in the Hands of God, confpiring together a Thoufand $W$ ays, towards a Thoufand Effects and Ends, at one time; and that with the fame certainty, as if he did prepofe to each, the fame Omnipotent Fiat, which he ufed at the Creation of the World.

7. 6. THIS Univerfal Monarchy, as it is eminently Vifible in all other Particular Oeconomies; fo is it, no lefs, in that of Vegetables. The Divine Infinite Occurrences, and fecret Intrigues, 'tis made up of; of which Wifdom we cannot skill, but by the help of manifold Means; and thofe, in feen in the the foregoing Idea, have been lately propofed. Wherein, although Growth of fome Experiments have been briefly touch'd: yet that which I have Plants; if hitherto chiefly prove obferve, hitherto chiefly profecuted, hath been the Anatomical Part ; and that not throughly neither. Notwithftanding, fo far as Obfervations already made will conduct us, I fhall endeavour to go. And if, for the better clearing of the way, I have intermixed fome Conjectures; I think they are not meerly fuch, but for which I havelayd down fome Grounds, and of which, the Series alfo of the following Difcourfe, may be fome further proof.

8. \$. LET US fay then, that the Rooi of a Plant being lodged in Firft, fome Soil, for its more convenient growth; 'tis neceffary the Soil How the fhould be duly prepared for it. The Rain, therefore, falling and foak-Ground is ing into the Soyl, fomewhat diluteth the Diffoluble Principles there-prepared. in containéd; and renders them more eafily communicable to the Root: Being as a Menftruum, which extracteth thofe Principles, from the other greater and ufelefs part of the Soil.

9. 6. And the warm $\delta$ n, joyned with the diluting Rain, by both, as it were a Digeftion of the Soil, or a gentile Fermentation amongt its feveral Parts, will follow : whereby the Diffoluble Parts therein, will rot and mellow : that is, thofe Principles which as yet remained more fixed, will now be further refolved and unlocked, and more copioufly and equally fpread themfelves through the Body of the Soil.

10. 6. Thefe Principles, being with the growth of Plants continually exhaufted, and needing a repair; the fucceffions, therefore, of Wet, Wind, and other Weather, beat down and rot the Leaves and other Parts of Plants. Whereby thefe ( as Weeds which are wont to be buried under ground) bicome a natural Manure, and Re-impreg- 
nate the Soil : Being thus, in part, out of their own Refolved Prin ciples, annually Compounded again.

I I. §. Many of thefe Principles, upon their Refolution, being by the Sun more attenuated and volatilized; continually afcend into the Aer, and are mixed therewith. Where, although they lofe not their Veyatable Nature, yet being amongft other purer Principles; themfelves alfo, depofiting their Earthy feculencies, become more fubtile, fimple and Effential Bodies.

12. \$. And the Aer being of an Elastick or Springy Nature, preffing, more or lefs, uponall Bodies; it thereby forceth and infinuateth it felf into the Soil, through all its permeable Pores. Upon its own entrance, it carries alfo many of the faid Vegetable and E/fential Principles along with it; which, together with the reft, are fpread all over the Body of the Soil. By which means, though a lefs Vehement, yet more Subtil Fermentation, and with the leaft advantage of warmth, continuable, will be effected.

13. 5. The Principles being thus farther refolved and fubtilized, would prefently exhale away, if the Rain, again, did not prevent. Which, therefore, falling upon and foaking through the Ground, is as a frefh Menftruum, faturate or impregnate with many of them. And as it ftill finketh lower, it carries them along with it felf, from the Superficial, to the Deeper parts of the Ground : thus, not only maturing thofe parts alfo, which, otherwife, would be more lean and cold; but therein likewife, laying up and fecuring a store, more gradually and thriftily to be beftowed upon the Upper parts again, as they need.

14. 6. And Autumn having laid up the Store, Winter following thereupon, doth, as it were, lock the doors upon it. In which time, fome warmer Intervals, ferve further and gradually to mature the ftored Principles, without hazard of their being Exhaled. And the Spring returning, fets the doors open again, with warmer and more conftant Sun, with gentle and frequent Rain, fully refolves the faid Principles; and fo furnifheth a plentiful Diet, for all kinds of Vegetables : being a Compofition of Water chiefly, wherein are refolved, fome portions of Earth, Salt, Acid, Oyl, spirit, and Aer; or other Bodies of Affinity herewith.

Then, How 15. \$. THE ROOT ftanding in the Ground thus prepared, and bethe Sap ing always furrounded with a Barque, which confifteth chiefly of a is imbib'd, Parenchymous and spongy Body; (a) it will thus, as Sponges do, natuand diftribu- rally fuck up the watry parts of the soil impregnate ,with the faid ted to the fe- Principles. Which Principles notwithftanding, being in proportion (a) P.r.c.3. With the watry parts, but few, and alfo more E/fential; $(b)$ therefore 5. 3. in this Parenchymous Part, are they never much difcovered, either by (b) $5.11_{12}$ Colour, Tafte, or Smell. As it is probable, that fome diftilled Waters, which difcover nothing, to Senfe, of the Plants from which they are diftilled, may yet, in part, retain their Faculties. And it is known, that many Bodies; as Crocus Metallorum, convey many of their parts into the Menftrum, without any fenfible alteration thereof. So Froft and snow have neither Tafte nor Smell; yet from their Figures, 'tis evident, that there are divers kinds of Saline Principles incorporated with them; or at leaft, fuch Principles as are common to them and divers kinds of salts.

16. \$. 
I6. 6. The entrance of this Impregnate Water or Sap is not without difference, but by the Regulation of the intervening skin; being thereby frained and rendred more pure : the $S_{k}$ in, according to the thicknefs (a) or clofenefs thereof, becoming fometimes only as a brown paper, fometimes as a Cotton, and fometimes as a Bag of Leather to (a) P.r.c.2. the tranfient Sap, as the nature of it doth require. By which it is al- $\$$. fo moderated, left the Barque, being fpongy, fhould fuck it up too faft, and fo the Root fhould be, as it were, furcharged by a Plethora. And divers of the succiferous Veffels being mixed herewith (b) and lying next the Soil, ufually more or lefs mortified, and fo their Principles (b) P.r.c.2. fomewhat refolved; the $S_{a p}$ is hereby better specified, and further $\$ .4$. tinctured; fuch parts of the $\mathcal{S} a p$ beft entring, as are moft agreeable to thofe Princtples; which the Sap alfo carries off, in fome part, as it paffeth into the Barque.

17. §. The Sap thus frained, though it be pure, and confifteth of Effential parts; yet being compounded of heterogeneous ones; and received into the Parenchyma of the Barque a laxe and fpongy Body, they will now eafily and mildly ferment. Whereby they will be yet further prepared, and fo more eafily infinuate themfelves into all the Bladders of the faid Parenchyma; fwelling and dilating it as far as the Continuity of its parts will bear. Whereupon, partly from the continued entrance of frefh $S a p$, and partly by a Motion or Preffure of $R e$ fitution in the fwollen and Tenfed Bladders of the Parenchyma, the Sap is forced thence into the other parts of the Root.

18. 6. And becaufe the Parenchyma is in no place openly and Vifibly Pervious, but is every where compofed of an Infinite Number of fmall Bladders (c); the $S a p$, therefore, is not only fermented therein, and fitted for Separation; but, as it paffeth through it; is every part $(c)$ P.r. c. . of it, ftrained an Hundred times over, from Bladder to Bladder.

19. 6. The Sap thus fermented, and frained, is diftributed to the other Organical Parts, according as the feveral Principles of This, are agreeable to thofe whereof the faid Organical Parts confift. As the $S_{a p}$ therefore paffeth from Bladder to Bladder, fuch Principles as are agreeable to thofe of the Fibres of the faid Bladders, will adhere to, and infinuate themfelves into the Body of the Fibres; $\int c$. Watry chiefly, next Acid, then Jpirituous, Earthy, Aery, and Oleous. (d)

20. 5. And the sap by its continual appulfe and percolation as it leaveth fome parts upon leaveth fome parts upon the faid Fibres; fo as it is fqueezed betwixt them from Bladder to Bladder, it licks and carries off fome others from them, in fome union together with it; and fo is Impregnate herewith : as Water, by pafing through a Mineral $V_{\text {ein }}$, becomes tinctured with that Mineral.

21. \$. The Sap thus Impregnate with fome united Principles of the Parenchymons Fibres, paffeth on to the Lignous Veffels, whereinto their correfpondent Principles alfo enter; $f c$. Watry, Saline, Oleous and Earthy chiefly. (e) And becaufe the Parenchymous Principles mixed with (e) Idea, $\zeta_{\text {: }}$ them, are in fome degree united, and fo more ready to fix; fome of $51,5^{2}$. thefe therefore will likewife enter into the faid $V$ effels. Whereupon,the Alkali oleofum of the one, and the Acidum pirituofum of the other,meeting together; Thefe, with the other Principles, all concentre, and of divers fluids, become one fixed Body, and are gradually agglutinated to the Veffels; that is, The Vefjels are now nourified.

$$
\begin{array}{ll}
\mathrm{R} 2 & \text { 22. }
\end{array}
$$


22. 6. The fupply of the Sap ftill continued, the Principles thereof will not only enter into the Body of thefe Parts, but alfo their Concaves.

(a) P.r.c.5. And the Parenchymous Fibres being wrapped about the $V_{e} \int e l s$, (a) as

5. 12. often as the faid Fibres are more turgid with their own contained Fluid, they will thereby be fomewhat fortned, or contract in length; and fo muft needs bind upon the $V$ effels, and thereby, as it were, fqueeze fome part of the Fluid, contained both within themfelves and the Veffels, back again into the Bladders.

23. 5. And the Sap herein, being thus tinctured with fome of the united Principles of the $V$ effels, divers of them will now alfo infinuate themfelves into the Parenchymous Fibres, and be incorporated with them: Whereby, the faid Fibres, which before were only relaxed and dilated, are now alfo nourified, and not till now. Some portion of the united Principles both of the Parenchymous and Lignous Parts, being neceffary to the true nutrition of Each: As the Confufion and joynt affiftance of both the Arterious and Nervous Fluids, is to the nourifhment or coagulation of the Parts in Animals.

24. 5. Some portion of the Sap thus doubly tinctured, is at the fame time tranfmitted to, and enters the Body of the Aer-Veffels; confitting chiefly of Water, Aer, and Acid; and, in like manner, as in the other Parts is herein agglutinated. And the appulfe and preffure of the sap ftill continued, fome portion hereof is alfo trajected into the Concaves of the faid $V_{e} \iint_{e} l s$; exifting therein as a moft compounded Fluid; partaking, more or lefs, both of the Principles and Tindures of the other Organical Parts, and of the Aer-Veffels themfelves; being as it were, a Mixed Rejolution from them all.

25. 5. And the Parenchymous Fibres being wrapped about Thefe, (b) P.1.c.5. as about the other $V e f e l s$, (b) and, in like manner, binding upon them; 6. 2. $^{2}$ they thus frequently Jqueeze part of the faid contained Fluid out again: As neceffary, though not to the immediate Nourifhment of the Parts, yet the due Qualification of the Sap; being a Conftant Aerial Ferment, fucceffively ftored up within the Aer-Veffels, and thence tranffufed to the Sap, in the other Organical Parts.

26. $\$$. And that there may be a better Tranfition of the sap thus tindired, to the feveral Organical Parts; therefore, none of them are clofe fet and compact within themfelves, feverally: For fo, they would be inacceffible to the $S_{a p}$, and their inward Portions, wanting a due fupply of Aliment, would be ftarved. But the $V e f j e l s$, both of Aer and Sap, being every where divided into Braced Portions, and other Parenchymous Portions, filling up the fpaces every where betwixt (c) P.r.c.3. them (c); there is therefore a free and copious communication of the 5. I3. \& c.4. Sap, (and fo of all the Tinctures fucceffively transfufed into it) from 8.4,557. Part to Part, and to every Portion of every Part: The Parenchymous Portions, running betwixt the Braces, as the fmaller Veffels do throughout the Vifcera, in Animals. Whereby, none of them want that Matter, which is neceffary either for their Nutrition, or for the good Eftate of their Contents, or for the due period of their Growth.

27. \$. For the better Tempering of the feveral parts of the Sap, ferve the Diametral Portions of the Parenchymous Body whichrun fometimes directly through the Barque, as in Lovage, Parfley, \&c. is defcribed (d) P.x.c.3. and figur'd (d) Which being, all or moft of them, continued be 8.7,8. twixt both the Succiferous and the Aer-Veffels, from the Circumference 
to the Centre; they hereby carry off a more Copious and Aerial Ferment from the One, and communicate it unto the Other. For as the sap enters the Barque, the more liquid part, ftill paffeth into the fucculent Portions thereof; the more Aery, is feparated into thofe White and Dryer Diametral ones; and in its paffage betwixt the Portions of the Aer-Veffels, is all along communicated to them. Yet is it not a pure or fimple Aer, but fuch as carries a Tincture with it, from the succiferous Veffels. And therefore it is obfervable, That when the Diametral Portions are more diftant, the Sap.Veffels run not in a Straight Line betwixt them, but are Reciprocally fo inclined, as to touch upon them; as in Lovage is vifible: Thereby communicating their Tincture to the Aer, as it paffeth by them, through the faid Diametral Portions.

28. 5. By the continual appulfe of frefh Sap, fome, both of the aery, and of all the other parts thereof are tranfmitted into the Pith; where, finding more room, it will yet more kindly be digested. Efpecially having the advantage herein of fome degree of Warmth; being herein remoter from the soil, and, as it were, Tunn'd up within the Wood, or the Mafs of furrounding Veffels. So that the Pith, is a Repofitory of better Aliment gradually fupplied to thofe Succiferous $V e f f e l s$, which are frequently fcattered up and down therein, and which afcend into the Trunk. (a) But where no fucciferous Veffels are mixed, herewith, it ufually becomes Dryer, and is replenifhed with (a) P.x.c.5. more Aerial and Warmer Sap; whereby the growth of the Caulis is promoted,as by an Hot Bed fet juft under ir. And in many Plants with divers knobbed Roots, the younger are more fucculent, ferving chiefly to feed the Stalk: the Elder are fpongy and fill'd with Aer, for the fermenting of the Sap, and more early growth of the Stalk: as in little Celandine, Dogftones and all of that Kindred. And thus all the Parts have a fit Aliment provided for their Nourifoment

29. \$. IN THIS Nourifbment, the Principles of the sap are, as is How the fefaid, concentred and locked up one within another: $(b)$ Whence it is, veral Parts that the Organical Parts, being cleanfed of their Contents, have none of are Nouthem any Tafte or Smell, as in the Piths of Plants, Paper and Linen rifh'd and Clotb is evident. (c) Becaufe till by Digeftion, violent Deftillation, or Form'd. fome other way, they are refolved, they cannot act upon the Organs (b) S. 21. of thofe Senfes. For the fame reafon, they are never tinctured, ex- (c) Idea, $\zeta$. cepting by their Contents: and although, to the bare Eye, they fre- $49,5 \mathbf{I}$. quently fhew White, yet viewed through a Microfcope, they all appear tranfparent. In like manner, as the serum of Blood, Whites of Eggs, Tendons, Hairs and Horns themfelves are tranjparent, and without much Smell or Tafte, their Principles being, in all of them, more or lefs concentred: But when ever thefe Principles, are forcibly refolved, they are ever varioufly invefted with all thofe Qualities.

30. 5. And as from the Concentration of the Principles, in every Organical Part, the faid Parts do thus far, all agree: So, from the Predominion of the Principles of each Part, the reft are controuled, not only to a Concentration, but an AJjimilation alfo; whereby, the specifick Differences, of the feveral Organical Parts, are preferved. Hence the fucciferous $V$ effels are always Tough and very Pliable; for fo are all Barques, wherein thefe $V_{e} / f e l s$ abound ; fo is a Handful of Flax, which is nothing elfe but a heap of the fucciferous Veffels in the Barque of that 
that Plant. For befides Water, and Earth, an Alkaline Salt and $O y l$ are,

(a) $5.2 \mathrm{I}$. as is faid, the predominant principles of thefe Vefjels. (a) It is then the $O y l$, chiefly, by which thefe $V e f f e l s$ are Tough: for being of a tenacious Nature, by taking hold of other Principles, it marries them together ; and the Alkaline Salt and Earth, concentred with it, addeth to it more strength. Hence the Caput Mortuum of moft Bodies, efpecially thofe that abound with $O_{y} l$ and a sal Alkali, is brittle and friable; thofe Principles, which were the Ligaments of the reft, being forced away from them. From the fame Caufe, the Parencbymons Parts of a Root, even in their Natural State, are brittle and friable; $f c$. Becaufe (b) 6. 19. their Earthy, and efpecially Oleous and Saline Principles are, as is faid, (b) fo very few. Therefore all Piths and more fimple Parenchyma's, break fhort, fo Corn, and the Roots of Potato's, and divers other Plants, being dryed, will eafily be rub'd to $M e a l$; and many Apples, after Frofts, eat mealy; the Parenchymous Parts of all which, are not only (c) Lib. 1, by Analogy, but in Subftance or Effence, the felf fame Body. (c)

c.7.5. 14. 3I. 6. And as the Confiftence of the feveral Organical Parts, is dependent on their Principles; fo are their Figures. And firft, the

(d) P.2. S. Succiferous Veffels, from their Alkaine Salt, (d) grow in Length. For
2I. moveable Principle than the reft, and fo apt more fpeedily to fix or fhoot: It thus overrules them to its own Figure. And even as the Shape of a Button dependeth on he Mould, the Silk and other Materials wrought upon it, being always conformable thereunto: fo here; the $s$ alt is, as it were, the Mould; about which, the other more paffive Principles gathering themfelves, they all confort and fafhion to it, Hence alfo the fame Sap.Veffels are not pyramidal, as the Veins of Animals; but of an equal bore, from end to end; the footings of the faid Salt, being alfo figured more agreeably to that Dimenfion. And (e) Ib. as by the Saline Principle, thefe Veffels are Long; fo by the Oleous, (e) they are every where Round, or properly Cylindrical; without fome joynt Efficacy of which Principle, the faid Veffels would be Flat, or fome way Edged and Angular, as all faline fhoots, of themfelves, are; as thofe of Alum, Vitriol, sal Ammoniac, Sea Salt, Nitre, \&c. And becaufe the Spirituous and more Fluid part of the Principles, is leaft of all apt to fix ; while therefore, the other parts fix round about, This will remain moveable in the centre; from whence every $V e f f e l$ is formed, not into a folid, but hollow Cylinder; that is, becomes a Tube.

32. 6. The Lactiferous Veffels are tubulary, as the Lymphaducts, but of a fomewhat wider Concave or Bore. For being their Principles are lefs Eartby and Oleous, and alfo more loofely Concentred; as from their eafie corruption or Refolution by the Aer, it appears they are : they are therefore more tender, and fo more eafily dilative, and yielding to the faid spirituous part in the Centre. And by this means, obtaining a wider Bore, they are more adapted to the free motion of the Millyy Content : which being an Oleous and Thicker Liquor, than that in the Lympheducts; and having no advantage of pulfation, as the Blood hath in Animals; might fometimes be apt to ftagnate, if the $\mathrm{P}_{e} f \mathrm{els}$, through which it moves, were not fomewhat wider.

33. $\$$. 


\section{Book II.}

of Roots.

33. 6. As the Saline Principle is the Mould of the Succiferous, fo is the Aerial of the Aer-Veffels. (a) Now the Particles of Aer ftrictly fo (a) P.i.c.4. called, at leaft of that part of it concerned in the Generation of the $5.23 . \&$ P.2. Aer-Ve/fels, I fuppofe, are crooked: and that by compofition of many $\$ .24$. of thofe crooked ones together, fome of them become Spiral, or of fome other winding Figure: and that thereupon dependeth the Elafick Property of the Aer, or its being capable of Rarefaction and Condenfation by force. Wherefore, the faid crooked Particles of the Aer, firft flooting and fetting together, as the Mould, the other Principle cling and fix conformably round about them. So that, as by force of the Saline Principles, the reft of them are made to fhoot out in Long continued Fibres; fo by force of the Aerial, thofe Fibers are ftill difpofed into spiral Lines, thus making up the Aer-Veffels. And according as there are fewer of thefe Acrial Particles, in proportion to the Saline, the Concave of the Aer-Vefels is varioufly wider,or the Fibres continue their frooting by wider Rings; as thofe that come nearer to a right Line, and fo are more complient to the Figure and fhooting of the Saline parts. And whereas the Lympheducis, fhooting out osly in length, are never fenfibly amplified beyond their original fize: Thefe, on the contrary, always, more or lefs, enlarge their Diameter; becaufe their Fibres, being difpofed into Spiral Lines, muft needs therefore, as they continue their growth, be ftill dilated into greater and greater Rings. And being at the bottom of the Root more remote from the Aer, and fo having fomewhat fewer Particles purely Aerial, there ingredient to them, then at the top; they fall more under the government of the Saline, and fo come nearer to a right Line, that is into greater Circles; and fo the Aer-Veffels, made up of thofe Circles, are there generally wider. (b)

34. 6. By mediation of their Principles, the Parenchymous Parts Y.16.

likewife of a Root have their proper Contexture. For from their $A$ cid Salt they are Fibrous; from their Oyl, the Fibres are Round, and in all parts even within themfelves; and from their spirit, it is moft probable, that they are alfo hollow. But becaufe the spirit is, here, more copious than the Aer; and the saline Principle an Acid, $(c)(c)$ 5. 19. and fo, more under the government of the spirit, than is an Alkali; therefore are not the faid Fibres continued in fraight Lines, as the Sap-Veffels; or by one uniform motion, into Jpiral lines, as the Fibres in the Aerial; but winding, in a circular manner, to and fro a thoufand ways, agreeable to the like motions of the spirit, that moft active, and here moft predominant Principle. And the Spirituous Parts being, as is faid, here more copious and redundant, they will not only fuffice to fill up the Concaves of the Fibres, but will alfo gather together into innumerable little fpaces, without them: whence the $F i$ bres cannot wind clofe together, as Thred, in a Bottom of Yarn; but are forced to keep at fome diftance, one parcel from another, and fo are difpofed, as Bread is in baking, into Bladders. (d)

35. \$. And the under Fibres being fet firft, as the Warp, the Jpi- 5.4 . ritueus parts next adjacent, will incline alfo to $f(x$, and fo govern an over work of Fibres, wrapping, as the Woof, in ftill fmaller Circles round the other: whereby they are all knit together. (e) For the (e) P.1. c.5. fame reafon, the Lympheducts, being firf formed, the Parenchymous S.9. Fibres fet and wrap about Thefe alfo: $(f)$ And the Aer-Veffels being $(f)$ P.i.c.5: fortined 5.12 . 
formed in the Center, the fucciferous run along thofe likewife (as volstile salts froot along the fides of a Glafs, or Froft upon a Window) and fo are, as it were, Incruftate about them in a Ring.

How the fe- 36.6. SOME OF THE more Ættherial and Subtile parts of the Aer, veral Parts as they ftream through the Root, it thould feem, by a certain Magnicome to be tifme, do gradually difpofe the Aer-Veffels, where there are any fore Situate or of them, into Rays. This Attraction (as I take leave to call it) or Difpos'd. Magnetick power betwixt the Aer and thefe $V_{e} / f e l s$, may be argued, From the nature of the Principles common to them both: From the Electral nature of divers other Bodies; the Load-ftone being not the (a) $L_{i b}$. 1. only one which is attractive: And from other Effeets, both before (a) c.2. $9.25 . \&$ and hereafter mentioned. Wherefore in the inferiour parts of the c.4. Append. Root, they are lefs Regular; (b) becaufe more remote from the Aer. (b) P.I. 2.4. And in the upper parts of many Roots, as Cumfery, Borage, Parfnep, (b) Io. . $1 . c .4$ where thofe that are next the Centre are confufed, or differently Tab.7,8,9. difpofed; thofe next the Barque, and fo nearer the Aer, are poftured more Regularly, and ufually into Rays. For the fame reafon it may be ; that even the sap-Veffels in the Barque, as often as the Aer $V e f f e l s$ are more numerous, are ufually difpofed into Rays, as following the direction of the Aer-Veffels. And that the Parenchyma of the Barque, is difpofed into Diametral Portions: and that where the Aer $V$ efels are fewer or fmaller, thefe Portions are likewife fmaller or none; as in Chervil, Afparagus, Dandelion, Orpine, Biftort, Horfe-Radifh, $T_{a b}, 7,8,9$, Potato's, \&c.

\&c. $\quad 37$. \$. The faid Ætherial parts of the Aer, have a Power over the Aer-Veffels not only thus to Difpofe them; but alfo to Sollicite and $\int$ pread them abroad from the Center towards the Circumference of the Root. By which means, thofe Roots which have no Pith in (c) P.1. c.5. their lower parts, obtain one in their upper. (c) And the fame Pith, 5. I. which in the lower part, is ratably, fmall, in the upper, is more or (d) 1 b. 5.4 . lefs enlarged. (d)

38. 5. The Spreading of thefe Veffels is varied, not only according to the Force the Aer hath upon them, but alfo their own greater or lefs Aptitude to yield thereto. As often therefore, as they are Slen. derer, they will alfo be more Pliable and receffive from the Centre, towards the Circumference. Hence, in fuch Roots where they are

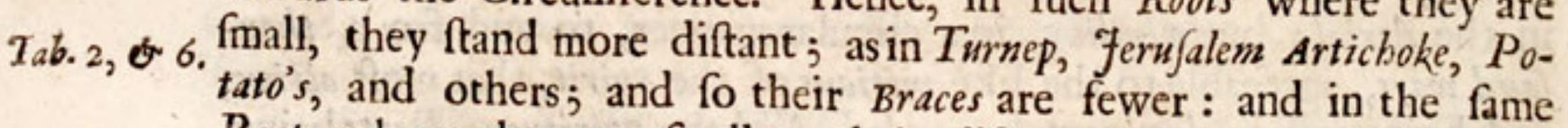
Root, where they are fmaller, their diftance is greater. Befides, in thefe fmaller Aer-Vefjels, the Rings being lefs, and the spiral Fibres whereof they are made, continuing to fboot; the faid Rings therefore, muft needs be fo many more, as they are fmaller; and fo take up more fpace by the length of the Root; and fo, not being capable of being crowded in a right line, every $V e f f e l$ will be forced to recede to a crooked or bowed one.

39. \$. The Sap Veffels, being by the Parenchymows Fibres knit to the e, will likewife comply with Their motion, and fpread abroad with them. (e) P.1.c.3. Yet being ftill fmaller (e) and more pliable than the Aer-Veffels, and fo 6.16. more yielding to the intercurrent Fibres of the Parenchyma, their

Tab.6. braced Threds will, fometimes, be much more divaricated, than thofe of the Aer-Veffels; as in Ferufalem Artichoke. And becaufe the Succiforous 
Veffels, although they are joyned to the Aerial by the Parenchymous Fibres, (a) yet are not continuous with them; neither fall under (a) P.x.c.5. the like Attractive Power of the Aer, as the Aerial do; the Aerial 5.12. therefore, upon their fpreading, do not always carry all the succiferous along with them; but often, if not always, leave many of them behind them fprinkled up and down the Pith; as in Parfley, Carrot, Tab. 6. Ferufalem Artichoke, Turnep, \&c. may be feen.

40. §. The Jpreading of the Aer-Veffels ftill continued, feveral of them, at length, break forth beyond the circumference of the Root; and fo are diftributed, either in the lower parts, into Brancbes and strings; or at the top, into Leaves. And left they fhould all fpread themfelves into Leaves, and none be left for the Caulis; as where they are very fmall, or the $S a p-V_{e} \int f e l s$ to bound them, are but few, they might; therefore divers of them are, oftentimes, more frequently braced in the Centre; for which reafon, they cannot fo eafily feparate and fpread themfelves from thence, but run more inwardly up into the Caulis, as in Borage.

41. 5. FROM THE various sizes, Proportions, and Difpofitions How the of the Parts, Roots are varioufly fized, Maped, moved and aged. Thofe whole Root which, by their Annual Growth, are large; have fewer, both Aerial, is differently and Sap.Veffels, and a more copious Parenchyma. So that the Aer- fized and $\bar{V}_{e} \int e l s$, or rather, the Aery Ferment contained in them, volatilizing thaped: only a fmaller portion of the $S_{a p}$; the faid $S_{a p}$ is lefs capable of advancement into the Trunk; and fo muft needs remain and fix more copioufly in the Root, which is thereby more augmented. And where the Sap-Veffels alone, are but few, the Root is yet, ratably, fomewhat large: but where they are numerous, it is never fo, as to its Annual Growth, in any proportion to their Number: Becaufe their Tincture, which is Alkaline, will go farther in fetting the Parencbymous Parts: than the Tinalure of Thefe, which is Acidulate, will go, in fetting Them. (b)

42. 6. When the Aer-Iefts are Attraction of the Aer, and fo Spread themfelves, and the Succiferous together with them, more abroad; in the manner as hath been faid; the Root alfo will grow more in Breadth; the nutrition of the Parenchymous Parts, to which the $V_{e}$ fels. are adjacent, being thus, by the $T_{a} b .2, \& 7$ 。 fame dimenfion, more augmented; as in Turnep, feriffalem Artichoke, \&c. Tab. $7, \&$ \&. But where thefe are not fpread abroad, the Root is but flender; as in Afparagus, Dandelion, \&c.

43. 6. If the Aer-Veffels be contracted into, or near the Centre, and are fomewhat Large or Numerous; and the Succiferous, alfo more copioufly mixed with, or furrounding them; the Root grows very Long; as do thofe of Fenil, Vine, Liquirift, \&c. For the Aer-Veffels

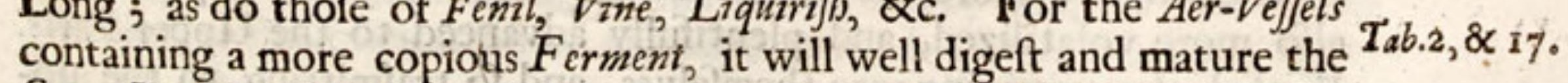
Sap : Yet the Succiferous being over proportioned to them; the Sap will not therefore, be fo far volatilized, as to afcend chiefly into the Trunk; but only to fubferve a fuller Growth of their Veffels: which being more numerous, and fo more fturdy, and lefs fequent to the expanfive motion of the Aerial; this their own Growth, and confequently, that of all the other Parts, cannot be fo much in Breadth, as Length. 
44. \$. Where the fame AerialVeffels are Fewer,or more Contracted, or theathed in a Thicker and Clofer Barque; the Root is fmooth, and

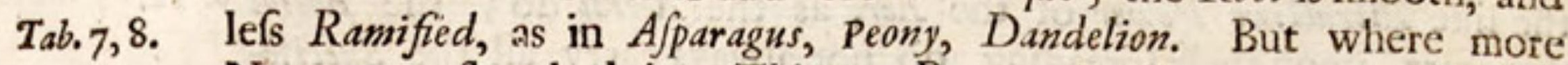
Numerous, fheathed in a Thinner Barque, Smaller, or more Dilated;

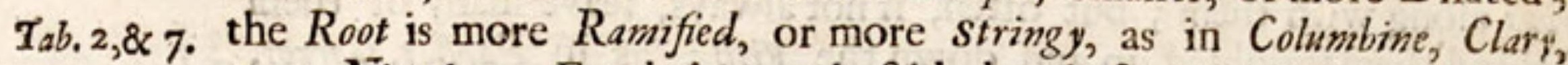
Beet, Nicotian. For being, as is faid, by thefe means, more fequent to the Attraction of the Aer; approaching ftill nearer the circumference of the Barque, they at laft ftrike through it, into the Earth. And the Parenchymous Fibres being wrapped about them, and the (a)P.r.c.5. Succiferous $V_{c f j e l s}$ knit to them by thofe fibres; (a) therefore they צ. 12. never break forth naked, but always invefted with fome quantity of thefe Parts as their Barque : where by, whatever Conftitutive Part is in the main Body of the Root, the fame is alfo in every Branch or string.

45. \$. From the fame Expanfion and Pliability of the Aer-Veffels, the Root oftentimes putteth forth Root-Buds; which gradually fhoot up and become fo many Trunks. In the Formation of which Buds, they are pliable and receffive all kinds of ways; being not only invited Outward, toward the Circumference of the Root, as in Rootfrings, but alfo fpread more Abroad every way, fo as to make a RootBud: Where as in the faid Root-ftrings; they are always more Con-

Tab. 6. tracted. Which, in refpect of the Difpofition of the Parts, is the principal difference betwixt the Root and the Trunk, as hath been (b) P.I.c.I. faid. (b) Hence, thofe Roots, chiefly, have Root-Buds, which have 5. 2, 3. the fmalleft Aer-Veffels; (c) thefe, as is faid, being the moft pliable Tab. II. (e) P.1.c.4, and Expanfive.

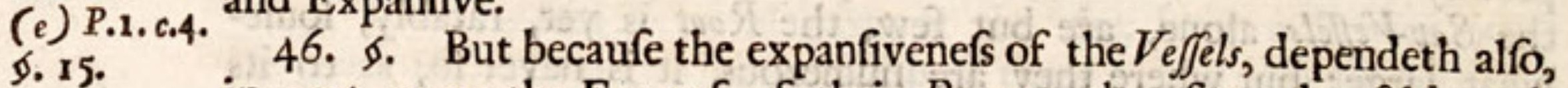
in part, upon the Fewnefs of their Braces; therefore the faid Buds thoot forth differently, in divers Roots. Where the Braces are fewer, the Buds fhoot forth beyond the Circumference of the Root, as in Fe-

Tab. 6. rufalem Artichoke; where more clofe, as in Potato's, the Buds lie a little abfconded beneath it; the Aer-Veffels being here, by their Braces, fomewhat checked and curbed in, while the Barque continueth to fwell into a fuller Growth.

47. 5. If the Aer-Ve/fels are all along more equally fized, the Root is fo alfo, or Cylindrical; as are thofe of Eryngo, Horfe-Radifh, Marfbmallow, Liquirifh, \&c. But if unequal, growing ftill mider towards the bottom of the Root; then the Root is unequal alfo: But groweth, as is obfervable, quite contrarily to the Aer-Veffels; not Greater, as They do; but ftill fmaller, or pyramidally; as in Fenil, Borage, Nettle, Patience, Thorn-Apple, \&c. is apparent. For the Aer$V e f f e l s$ peing confiderably wider about the bottome of thefe Roots; they there contein a more Copious Ferment: Whereby the Sap is there alfo more volatilized, and plentifully advanced to the U Uper Parts. Withal, thus receiving into themfelves, and fo trafmitting to the upper Parts, a more plentiful Vapour, they hereby rob the Parenchymous Parts of their Aliment, and fo ftint them in their Growth.

How Roots 48. 6. FROM THE different Proportions and Situation of the are diffently Parts, the Motions of Roots are alfo various. For where the Are-Veffels Mov'd.

$T_{a b} .8$. are fpread abroad and invelted with a thinner Barque; the Root runs or lies Level, as in the level-Roots of Primrofe, Bifhops-weed, Anewone, \&c. 
may be feen. So that thefe Roots, as by the Perpendicular strings, which fhoot from them into the Earth, and wherein the Aer-Veffels are contracted into their Center, they are Plucked down $(a)$ : So by $(a) P . \mathbf{r}$.c. I. the Aer-Veffels, which ftand nearer the Aer, and more under its At- $\$ .15$. tractive Power (b) they are invited uppoards; whereby they have (b) P. 2. neither afcent nor defcent, but keep level, betwixt both.

5. 36.

49. 5. But if thefe Veffels are Contracted, ftanding either in, or near the Centre, and are invefted with a Barque proportionably Thick; the Root ftriketh down perpendicularly, as doth that of Dandelion, Buglofs, Parfnep, \&c. And therefore the faid $V_{e} f f e l s$, although $T_{a b}, 7,8$. they are fpread abroad in the level Roots, yet in the perpendicular ones of the fame Plant, they are always contracted; as by comparing the Level and Down-right Roots of Ammi, Primrofe, Ferufalem Articboke, Com lip, and others, is manifeft.

50. \$. If the Aer.Veffels are Contracted, and Environed with a greater number of Succiferous, the Root grows deep; that is, perpendicular and long. (c) Perpendicular, from the Contraction of the Aer- (c) P.i.cit. $V e f f e l s ;(d)$ and long, from the Predominion of the Succiferous, which 5.9. in their growth, are extended only by that Dimenfion as in $L$. Eryngo, \&c.

5I. 5. If the succiferous are over proportioned to the Parenchymous Parts, but under to the Aer-Veffels; the Root is perpendicular ftill, but groweth fallow: The succiferous being fturdy enough to keep it perpendicular; But the Aer-Veffels having a predominion to keep it from growing deep; as in Stramonium, Nicotian, Beet, \&c.

52. §. If, on the contrary, the Parenchymous Parts are predominant to the Aer Veffels; and that, both in the Root and Trunk; then the whole Root changeth place, or defcends. (e) For the faid Aer-Veffels, having neither in the Trunck, nor in the Root, a fufficient Power to (e)P.r.c.i. Draw it upsoards; it therefore gradually yields to the Motion of 5 . ro. Lib.i. String-Roots; which, as they ftrike into the Soil, Pluck it down after 4 . Append.
A them. And becaufe the old Strings annually rot off, and new ones S. 10. P. 2. fucceffively fhoot down into the Ground, it therefore annually ftill de- 5.36 . fcendeth lower; as in Tulip, Lily, \&c, may be obferved.

53. 5. Where the Aer-Veffels are much fpread abroad, and alfo numerous, the Root oftentimes, as to its feveral parts, defcends and afcends both at once. So Radifhes and Turneps, at the fame time, in which their nether parts defcend; their upper, (where the faid Veffels are more loofely braced, and spread more abroad than in the lower parts) do Tab. 2 i afcend, or make their Growth upmard. Hence alfo, the upper part of molt young Roots from Seed, afcends: Becaufe the firt Leaves, being proportionably large, and ftanding in a free Aer, the Aer-Veffels therein, have a dominion over the young Root; and fo themfelves yielding to the folicitation of the Aer, upowards; they draw the Root, in part, after them.

54. S. BY THE situation and Proportions of the Parts, the Age How Roots of the Root is alfo varied. For if the Sap-Veffels have the greateft are differentProportion, the Root, is Perennial, and that to the fartheft extent, as ly Aged. in Trees and shrubs. Becaufe thefe Veffels containing a more copious $\mathrm{O}_{y} ;(f)$ and their feveral Principles being more clofely concentred, they are lefs fubject to a Refolution, that is, a Corruption or Mortificati- $(f)$ P, 2 , on by the Aer. 
55. 5. If the Parenchymous parts have much the greateft, the Root feldom liveth beyond Two Years; but afterwards peritheth either in whole, or in part; as do divers bulbous, tuberous, and other Roots; whether they are more Porous and Succulent, or more Clofe and Dry. If Porous, all the Liquid Principles ftanding herein more abundant, either by a ftronger Fermentation, or otherwife, Refolve the fixed ones of the Organical Parts; whence the whole Root, rots; as in Potato's. So alfo Parfneps, and fome other Roots, which, in a hard and barren soil, will live feveral years, in another more rank, will quickly rot. If the Parenchyma be Clofe, then the Aer, chiefly, entring in and filling it up,thus mortifies the Root; not by Rotting the (a) P.r.c.1. hood, \&c. (a)

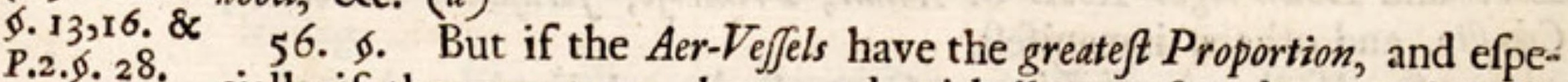
P.2.6. 28. cially if they are more large, and withall, are fpread more abroad:

Tab.9. the Root is Annual, as in Thorn-Apple, Nicotian, Carduns Ben. \&c. And of the fame Kindred, if any, thofe are Annual, which have the molt Aer-Veffels. So Endive and Soncbus, which have ftore of Aer.Veffels, are both Annual: whereas Cichory, in which they are fewer, is a Perennial Root. For hereby a more copious Aer being Tranf(b) P. 2. 6. fufed into all the other Parts; (b) they are thus, by degrees, hard25, 26. ned, and become fticky; and fo impervious to the Sap, which ought to have a free and univerfal Tranfition from Part to Part. As Bones, by Precipitations from the Blood, at length, ceafe to grow. Or the fame more abundant Aer, fo far volatilizeth the Liquors in the Root; that they are wholly advanced into the Trunk, and fo the Root is ftarved. Whence alfo the Aer-Veffels of the Trunk; where they are numerous, and over proportioned to the Bulk of the Root, as in Corn; they fo far promote the advance of the $s_{a} p_{2}$ as to exhauft the Root, fucking it into a Confumption and Death.

How the 57. 5. FROM THE Principles of the Parts, their Contents and Contents of the feveral Qualities hereof are alfo various; $(c)$ the Fluid of each the feveral Organical Part, being made, chiefly, by Filtration through the fides Parts are thereof; fuch of the Principles in the $S_{a p}$, being admitted into, and made. $I_{d e a}$, s. tranfmitted through them, as are apteft thereunto. In the like manner, 54. ${ }^{\text {(c) }}$. 5 as when $O y l$ and Water, being poured upon a Paper, the Water paffeth through, the $O_{y l}$ fticks : or as the $C$ byle is ftrained through the Coats of the Guts, into the Lacteal Veffels: or as Water in Purgations, is ftrained through the Glands of the fame Guts, from the Mefenterical.

58. \$. The Principles therefore of the Parenchymous Fibres being fpirituous, acid, and aerial, they will alfo admit the like into them;

(d) P. 2. excluding thofe chiefly which are Alkaline and Oleous. (d) And as by
S. 19. 8. 19. admittance into their Body: fo the Proportion and Union of the fame Principles, regulates the tranfmiffion hereof into their Concave. Wherefore, the predominant Principles of the Fibres being chiefly acid, next fpiritueus, and aery, the more acry ones will be tranfmitied. For if more of them fhould fix they mult do fo by fimilitude and adhefion: But where there are fewer fimilary parts to adhere to, fewer muft adhere. The Fibres therefore contain fo many parts of Aer, as to admit 
many more into their Body ; but not to fix them; which therefore muft needs, upon admiffion, pafs through into their Concave; where, together with fome other more $\beta$ pirituous parts, they make an \#therial Fluid. And becaufe fome aqueous or vaporous parts will alfo ftrain through with them ; hence it is, that as more and more of thefe enter; they by degrees ftill thruft out the aery ones; which quitting the more fucculent Fibres of the Parenchyma, are forced to betake themfelves to the dryer ones, fcil. all thofe, whereof the Diametral Portions do confift. For the fame reafon the Aery parts being gradually excluded the fucculent Fibres of the Barque; they are forced to recede and tranfmigrate into thofe of the Pith. And the Fibres of the Pith themfelves being filled, aud the Aery parts ftill forced into them; they at length alfo itrain through the Fibres into the Bladders: whenve it comes to pafs, that while the Barque is fucculent, the $P$ ith is often times filled with Aer.

59. 6. The Lymphaducts being more earthy, Salinous ; oleous, and (a) P.2. aqueous, will both admit and copioufly fix the like Principles, as their $\$ .21$. proper Aliment, The $W$ ater being more perfluent than the reft, will therefore ftrain, with a lighter Tincture of them, into their Concave. Efpecially the Oleous parts of thefe being rampant, and lefs apt to $f i x$ and feize the aqueous, upon their entrance, than the faline.

6o. 5. The Lactiferous, appearing to be made, chiefly, by the Conftipation of the Parenchymous Parts all round about their Sides; the Liquor conteined in thofe Parts, although it may eafily enough be transfufed into the Hollow of thefe $V_{e} / f e l s$; yet feems it not, with equal facility, to be refunded thence: So that the thinner and more aqueous Portion only, paffing off; the remainder, is, as it were, an oleous Elixyr, or extract, in the form of a Milk.

6r. \$. The Fluid Ferment contained in the Aer-Vefjels, is alfo in part, dependent on the Principles of thofe $V_{e} / j e l s$, being in their percolation tinctured therewith. But becaufe the percolation is not made through the Body of the Fibres whereof the $V_{e}$ fels are compofed, but only betwixt them; therefore the tranfient Principles more promifcuofly, yet with an over porportion of dryer Particles, pafs into the Concaves of thefe $V_{e}$ fels, and fo are herein all immerfed in a Body of Aer. (b) The Fibres themfelves, in the mean time, as thofe of the (b) P. 2. Parenchyma, admitting and containing a more Aery and Fitherial S.24.
Fluid.

62. \$. The Contents are varied, not only by the Nature, wut alfo the Proporition and situation of the Parts, whereby the faid Contents are with different Facility and Quantity, communicated one toanother. Hence it is, partly, that a Vine, or that Corn, hath fo little $O_{y} l: f c$. Becaufe their Aer-Veffels, in proportion with the other Parts, are fo Great and Numerous: in Corn, the Stalk being alfo very hollow, and fo becoming as it were, one Great Aer-Veffel. For the Oily parts of the Sap, are fo exceedingly attenuated (c) by the Aery Ferment contained in (c) P. 2. 5. thefe $V$ effels; that they are, for the moft part, fo far immerfed in the $25, \& 56$. spirit, or mixed therewith, as not, by being collected in any confiderable Body, to be diftinguifhable from it. And the affinity that is betwixt Spirits and Oils, efpecially Effential, is manifeft: Both are very inflammable; Both will burn all away; The Odors, which we call the Spirits of Plants, are lodged in their effential Oyl; Both, being duly 
duly Rectified, will mix as eafily together, as Water and Wine. So that, although $O y l$, by the feparation of its earthy and Saline parts, which give it its fenfibly oleous Body, may not be fo far attenuated, as to produce a spirit; yet that it may fo far be attenuated, and fo be mixed therewith, as not to be difcerned from it, as in the forementioned Plants, will be granted.

63. 6. Hence it is, that the Lactiferous ftanding more remote from (a) Tab. 9. the Aer-Veffels, and the succiferous interpofing; (a) the Liquor, there2 16. fore, contained in them, is not fo much under the government of the Aerial Ferment, and is thence, partly, more Oily. For the fame reafon, all Roots which are Milky, fo far as I have obferved, have an under-proportion of Aer-Vefels; thefe being either Fewer or Smaller.

How the 0 - 64. 6. FROM what hath been faid, we may receive fome dours of information, likewife, of the Odours, Colours, and Taftes of Plants are Plants. And for Odours, I fuppofe, That the chief Matter of them, made. is the Aerial Ferment contained in the Aer-Veffels. Not but that the other Parts do alfo yield their fmell; but that the fe yield the frongeft and the beft, and immediately perceptible in frefh, undryed and unbruifed Plants. For the Aer entring into, and paffing through the Root, and carrying a Tincture, from the feveral Organical and Contained Parts, along with it, and at laft entring alfo the Concaves of the Aer-Veffels; it there exifts the moft Compounded and Volatile Fluid, of all others in the Plant, and fo the fitteft matter of Odour: and fuch an Odour, as anfwers to that of all the Odorous parts of the

(b) P. 2. Plant. (b) Wherefore the Organical Parts, being well clenfed of their 6.24. Contents, fmell not at all; Becaufe the Principles hereof are, as hath been faid, fo far fixed and concentred together. Hence alfo the Contained Parts themfelves, or any other Bodies, as their Principles are any way more fixed, they are lefs Odorous : So is Rofin, lefs than Turpentine, and Pitch, than Tar; and many the felf fame Bodies, when they are coagulated, lefs than when they are melted. So alfo Musk, which is not fo liquid as Civet, is not fo ftrong; nor Ambergreece, as Musk: For although it hath a more excellent fmell, than Musk hath, yet yieldeth it not fo eafily; fince it is a more fixed Body, and requireth fome Art to be opened. Hence alfo the Leaves of many plants lofe their Odour upon rubbing: Becaufe the Aer-Veffels being thereby broken, all their contained odorous Fluid vanifheth at once: which before, was only ftrained gradually through the Skin. Yet the fixed Parts themfelves, upon drying, are fo far altered by the Sun and Aer, as to become refoluble, and volatile, and thence odorous.

How their 65. 6. SO ALSO of their Colours. As whence the Colours of the Colours. Skins are varied. For divers of the Sap-Veffels, together with the Parenchymous Parts fucceffively falling off from the Barque into the
(c) P.r.c.2. Skin (c) by their proximity to the Earth and Aer, their Sulphureous or 6. 2, 4. Oleous Principle is more or lefs refolved, and fo produceth divers $C_{0}$ lours. So thofe Roots which turn purple any where within, have ufually a blacker skin; the one of thofe two Colours being, by a refolution and corruption of parts, eafily convertible into the other, as in Cumfry, Thiftle, \&c, So the Milk of scorzonera, contained in the Veffels of the Barque, upon drying, turneth into a brown Co- 
lowr: Wherefore the $s k i n$, in which there are divers of thofe $V e f-$ fels, is of the fame. So both the Milk and Skin of Lovage is of a brownith yellow. But Parfnep hath a clearer $S_{a p}$ in all its Veffels, and a whiter Skin. So Potato's, being cut traverfe, after fome time out of ground, have divers red fpecks up and down where the Veffels ftand, and their skin is accordingly red.

66. 6. The reafon, I fay of thefe Colours, is the refolution or referation of the Principles of the feveral Parts, chiefly, by the Aer, and a lighter mixture of them confequent thereupon: whereby the Sulphureous or Oyly Parts, which were before concentred, are now more or lefs rampant, difcovering themfelves in divers Colours, according as they are diverfly mixed with the other principles. Hence thefe $C_{0}$ lours are obfervable, according to the nature of the Parts wherein they are, or whereunto they are adjacent : So where the Lympheducts doe run, there is a Red, or fome other Sulphureous Colour; the Oleous Principles being, as is faid, (a) more copious in thefe Veffels; as (a) P. i. in the Bark of Peony, the inward parts of Potato's, \&c. may be S.2I. feen. But the Parenchymons Parts, where more remote from the faid $V e f f e l s$, they are ufually White, or but Yellow: the Sulphureous Principle of thefe Parts, being, as hath been faid, but fparing. (b) The fame is feen in thofe Roots which thew both Red and Yellow. The (b) P. 2: Parts, principally, where the Succiferous Veffels run, being Red; but thofe Parts, where only the Aer-Veffels are mixed with the Parenchymous, being $Y_{\text {ellow }}$; as in Patience. So likewife the pithy part of a Carrot, where the Aer-Veffels have very few Succiferous mixed with them, is Yellow; but the Barque, where the Succiferous are very numerous, is Red. For the fame reafon, many Roots, which are Whiter in their upper parts, are Purple or Reddifs in their inferiour, as Avens, strawberry, \&c. Becaufe thofe lower parts, having lain longer $(c)$ under ground (thefe being defcending Roots) their $(c) \vec{P}$. Principles are, thereby, fomewhat more refolved, and fo the Oleous, ramp S. I3. and fpread all over the reft in that Colour.

67. 6. And that the Refolution of the Sulpbureous and other Principles is partly effected by the Aer, appears, In that, where the Aer hath a free accefs to the Succiferous Vefjels, the Colours are there, chiefly produced, or are more confpicuous. So in Potato's, where the succiferous Veffels are either next to the external Aer, as in the Skin; or contiguous with the Aer-Veffels, as in the Ring within the Barque; there, they produce a Red: but where more remote from both, as in the middle of the Barque, and Centre of the Root, there they produce none. Hence alfo it is, that the Leaves and Flowers of fome Plants, as Bloodwort, Wood-sorrel, Radifh, Facea, \&c. although Green or White in the greateft portion of their $\mathrm{Pa}_{\text {- }}$ renchymous Part; yet where the succiferous and Aer-Veffels run together, they are of Red, Blue, and other Colours; the Oleous parts of the one, being unlocked and opened, by the aery of the otber.

68. 6. AND LASTLY, of their Tafts. Moft Roots which are thow their acres or bitting, have a very copious Parenchyma in proportion with $T_{a f f e s}$. the Succiferons Veffels, as of Arum, Dragon, and others: Becaufe the Saline and other Principles are not fo much hot, by any fufficient quantity of Sulphureous, from thofe Veffels, in which the Sulpbir, as is faid, is more abundant; (a) but tendred rather pungent, from (a) P. 2 : fome 
fome Spirit and Aer. But divers Umbelliferous Roots, efpecially which abound with Lactiferous Veffels, are hot; as Fenil, Lovage, Angelica, \&c. Yet is it not their $O y l$ alone that makes them hot, but the combination thereof with the Saline Parts: as is manifelt, from the na. ture of the Seed of thefe Plants; wherein, as the $O y l$ is moft copious; So being held to a Candle till they burn, conftantly fpit; which cometh to pafs, by the eruption of the saline Parts: and is the very fame effect, with that which followeth upon burning of Serum or Blood. And therefore, as thefe seeds are more bot, they alfo fpit the more; So thofe of Cumine, which, though fulfom, yet are not fo bot, Jpit lefs; Fenil and Dill, which are hotter, more; there being a greater quantity of volatile Salt contained herein. Hence all Effential Oyls are hot, the Spirit and volatile salt, being incorporated herewith. And fome of them will froot, and cryftallize as Salts do, as that of Anife; which argues a mixture of a confiderable quantity of volatile salt. As alfo doth the Nature of thefe Oyls, in being amicable to the Stomach, Carminative, and fometimes Anodyne; fcil. as they kill fome fetid, or corrofive Acid: for volatile salts themfelves will have the like operation in fome cafes as thefe Oyls.

69. \$. Many Lactiferous Roots, as Taraxacum and others of that kind, are not fo much bot, as bitter. For although by the Lactiferous $\nabla_{e f f e l s}$ they are very $O_{y} l y ;$ yet thofe $V_{e}$ fels being pofited in Rings, and not in Rays, and having no Diametral Portions running through ab. 13. their Barque to the Aer-Veffels; the Acido-Aerial Parts do hereby, although not mortifie, yet fo far refract the faline, lightly binding up the Oleous therewith, as to produce a bitter Tafte. So, many fweet Bodies, upon burning, become bitter; the Acid Parts, now becoming rampant, and more copioufly mixed with the Oleous.

70. The Roots, or other Parts, of many Umbelliferous Plants, have a fweetifh Tafte, as both the sweet, and Common Chervil; both the Garden, and woild Carrot; Parfnep, Fenil, \&c. the Saline Principles being concentred in the $O y l y$, and both of a moderate quantity with refpect to the reft. For by the $O y l y$, the saline is rendred more fmooth and amicable; and both being moderate, they are not therefore bot, as in fome other Umbelliferous Roots; but by the predominion of the other Principles, made mild. Hence it is, that Sugar it felf is frpeet, fcil. becaufe it is an Oleous salt; as is manifeft, from its being highly inflammable; itseafie diffolution by a moderate, Fire, without the ad. dition of Water; and in that, being melted with Turpentine, and other Oily Bodies, it will mix together with them. So alfo the Acid Parts of Vinegar, being concentred in the Salino-fulphureous of Lead, produce a sugar. Hence Barley, which upon Diftillation or Decoction yeildeth only an acid; being turned into Mault, becomes fweet. Becaufe, being fteeped, couched, and fo fermented, the oleous parts are thereby unlocked, and becoming rampant, over the other Principles, altogether produce that $T_{a} f t e$. And the Bile it felf, which, next to Water and Earfb, confifteth moft of oily parts, and of many both faline and acid is a bitter-froeet. Wherein, as fome of the Saline and Acid parts, fmoothed by the Oleous, produce a Sweet: So, fome of the Oleous, impregnated with the Saline, and the Acid, doe hereby produce a Bitter. 


\section{T H E}

\section{A N A T OM Y}

$\mathrm{OF}$

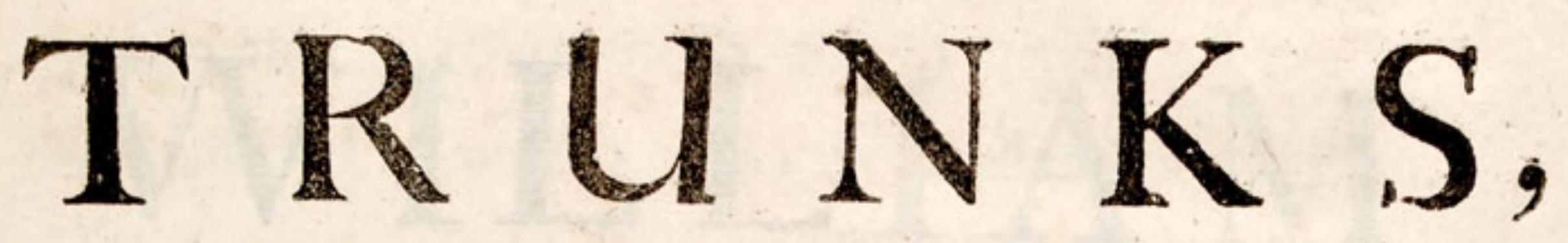

With an Account of their

\section{VEGETA T I ON.}

Grounded thereupon.

The Figures hereunto belonging, Prefented to the R o y a t SocIETY in the Years, $1673 \& 1674$.

The THIRD BOOK.

By NEHEMfAH GREW M.D. Fellow of the Royal Society, and of the College of Phyficians.

The Second edition.

$$
L O N D O N
$$

Printed by $W$. Ramolins, 1682 .

Mo.Bot. Garcion, 1902. 


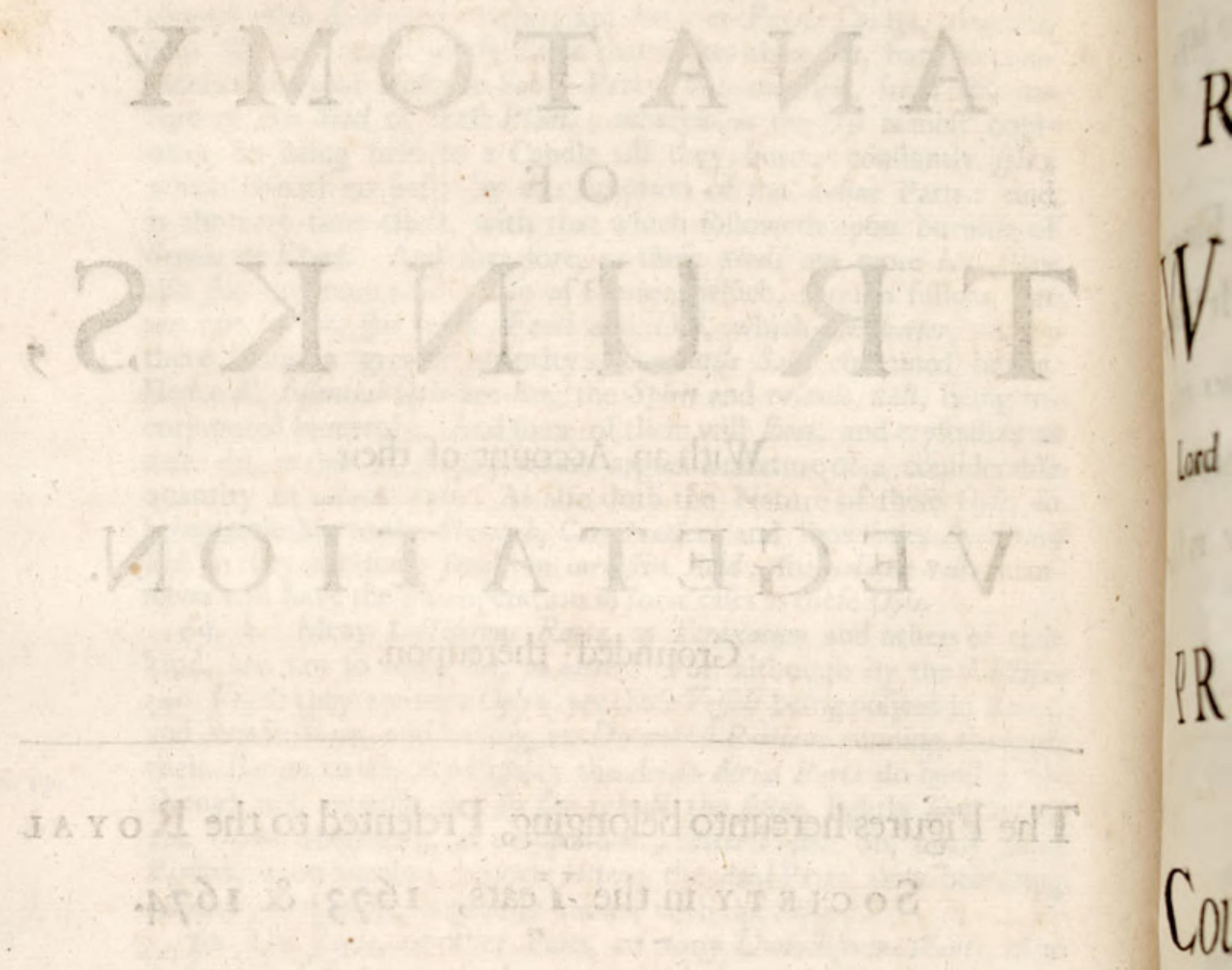

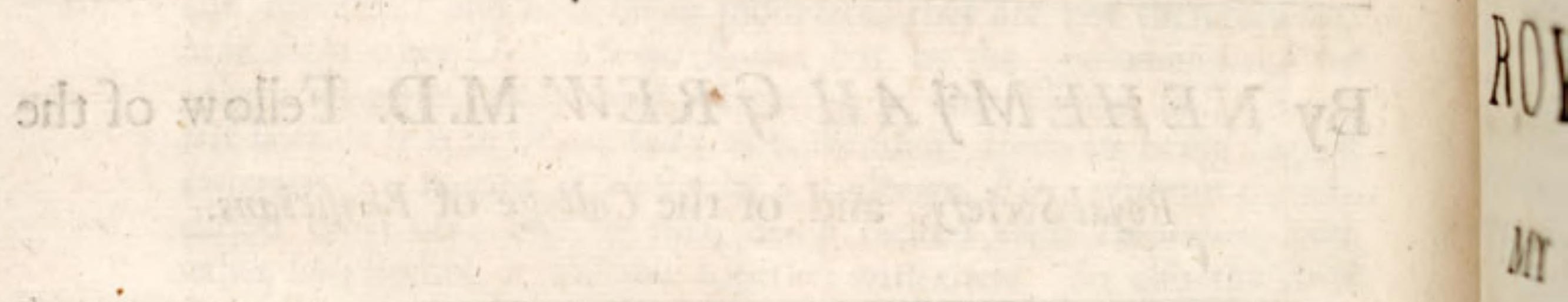

The
64
4
4 


\section{T O THE}

\section{Right Honourable}

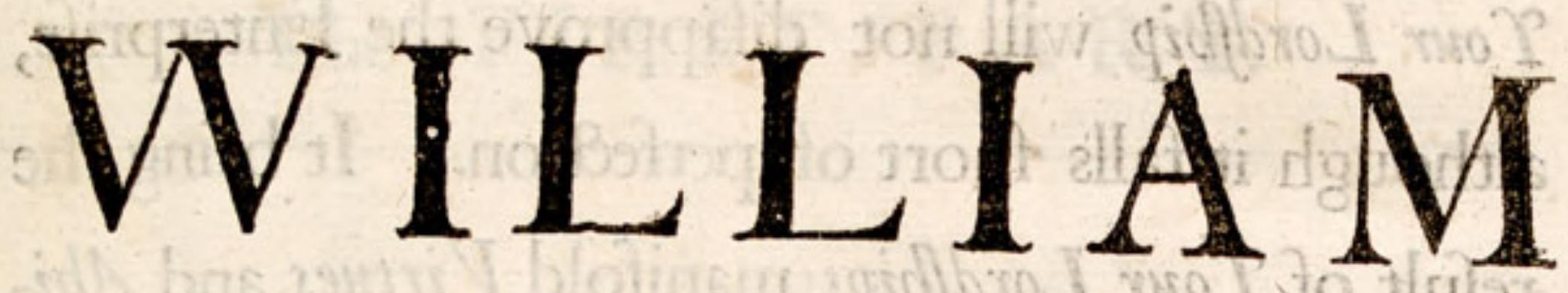

Lord Vi-Count BROUNCKER

\section{T H E}

PR ESIDEN T;

AND TO THE

\section{Council and Fellows}

O F THE

\section{ROYAL SOCIETY:}

$M Y L O R \mathcal{D}$,

H E Commands I received from $\Upsilon_{\text {our }}$ Lord:

A Sip, and the Royal Society, To profecute the Subject treated of in the Two former Books; have produced This which follows. And I humbly fubmit the fame to Your Lordfbips Judg-

$$
\text { T. } 2
$$

ment: 
The Epistle Dedicatory.

ment: which muft needs be Candid and Benign, becaufe it is Great. I have only this to fay,

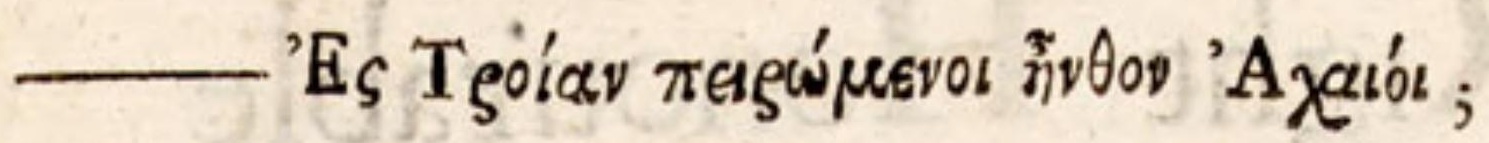

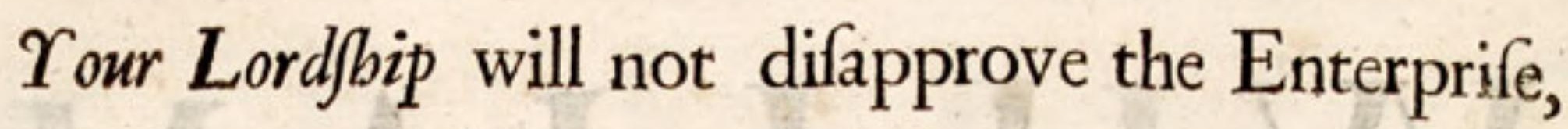
although it falls thort of perfection. It being the refult of $\Upsilon_{\text {our }}$ Lord/Bips manifold $V$ irtues and $A b i$ lities, That $\Upsilon_{0}$ know how far to Encourage the meaneft Attempts; as well as rightly to Value and Affift the greateft Performances.

$$
\text { I am, }
$$

My Lord,

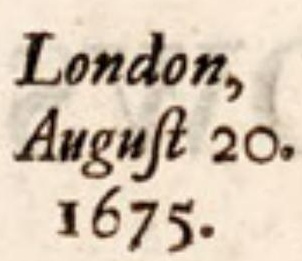

Your Lordsips

moft humble

and

moft obfequious

Servant

NEHEMJAH GREW.

THE 


\section{T H E}

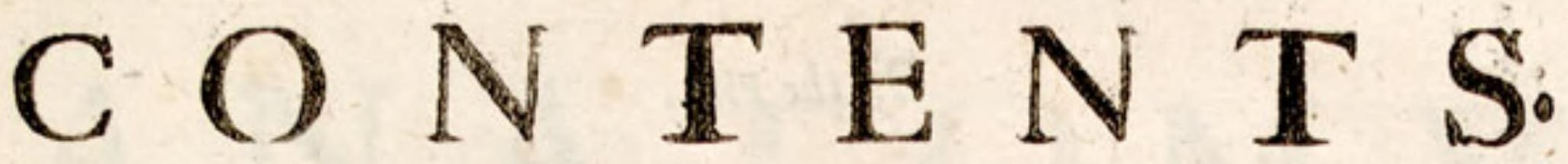

\section{The FIRST PART.}

\section{CHAP. I.}

ADefcription of feveral stalks or Trunks, as they appear to the Naked Eye.

$\mathrm{O}$

$F$ the stalk of Maze, 5. I, 2. Of Dandelion, 3, to 6. Of Borage, 7, to 10. Of Colemort, in, to 16. Of Holyoak, 17, to 20. Of Wild Cucumer, 21,to 23. Of scorzonera, 24, to 26. Of Burdock, 27, to 29. Of Endive, 30,31. Of Vine, 32, to 35. Of sumach, 36, to 38. Cautions to be had in obferving the Parts, 39. Some Particulars better obferved in cutting by the length, 40,41 .

\section{H A P. II.}

Of the Barque, as it appears through a good Microfcope.

DIrft, a General Defcription of the feveral Parts of the Barque, 2, to 9. Next, a Particular Defcription of the Barques of 8 feveral Trunks; fc. Of Holly, Hazel, Barbery, Apple, Pear, Plum, Elm, Afls; The Veffels of all whose Barques are Lympheducts: and thofe of two kinds, IO, to 13. Of 3 more, fc. Wallnut, Fig, and Pine: the Veffels of the Barques of the Troo firft, being Lymphaducts and Lactiferous, of the next, Lympheducts and Refiniferous, 14, to 20. Of 3 more, fc. Oak, Common Sumach, and Common Wormowood; the Veffels of whofe Barques are of 3 Kinds, 2 I, to 29. Some further Obfervations and Conjectures of the Sap-Veffels, 30, to 37 .

\section{H A P. III.}

\section{Of the Wood.}

W Hat in all Trunks, 6. 1. A. Defcription of its Parts, in the feveral Trunks aforefaid. Of the Parenchymous Part, or Infertions, 2, to 9. Of the true Wood, 10, to 15. Of the Aer-Veffels, 16, to 26. Some further Obfervations and Conjectures of their Form, 27. Texture, 28, to 32. Nature, 33, 34. And Original, 35 . 


\title{
The Contents.
}

C H A P. IV.

Of the Pith.

A Defcription of the Pith, in General, G. I. In the feveral Trunks Parenchyma and Bladders or Brances aforefaid. As of the Size, 2, 3. Veffels, 4. Parenchyma and Bladders, 5, to 9. Apertures or Rupturss, 10. Some further objervations of the Pith. And of all the Pithy and Parenchymous Parts. And thence of the True Texture of a Plant, II, to 15.

\section{The SECOND PART.}

\author{
C H A P. I.
}

Of the Motion and Courje of the Sap.

\section{CH A P. II.}

Of the Motion and Course of the Aer.

C H A P. III.

Of the structure of the Parts.

$$
\text { C H A P. IV. }
$$

Of the Generation of Liquors.

$$
\text { C H A P. V. }
$$

Of the Figuration of Trunks.

$$
\text { C H A P. VI. }
$$

Of the Motions of Trunks.

$$
\text { C H A P. VII. }
$$

Of the Nature of Trunks, as varioufly fitted for Mechanical $\mathcal{U} e_{\text {. }}$ 


\section{T H E}

\section{A N A T O M Y \\ O F}

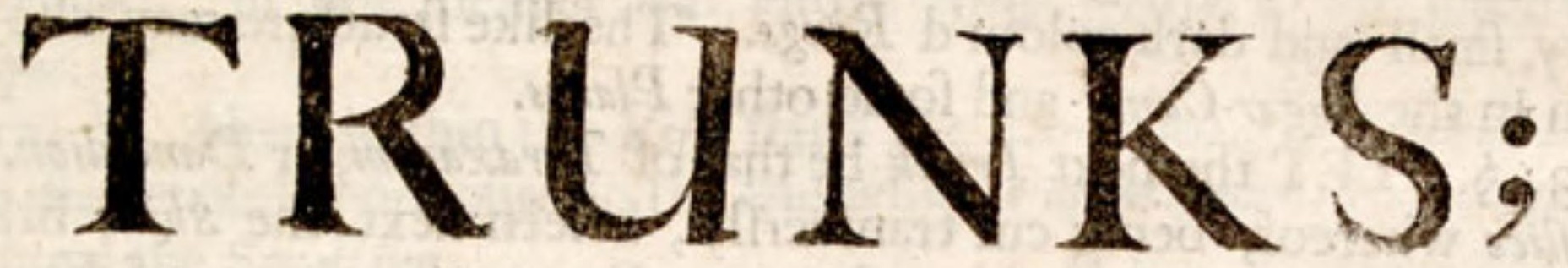

PROSECUTED.

With the bare EYE,

And with the

\section{MICR OSCOPE.}

\section{P A R T I.}

\section{H A P. I.}

The Defcriptions of feveral Trunks, as they appear to the bare Eye.

the end we may clearly underftand, what the

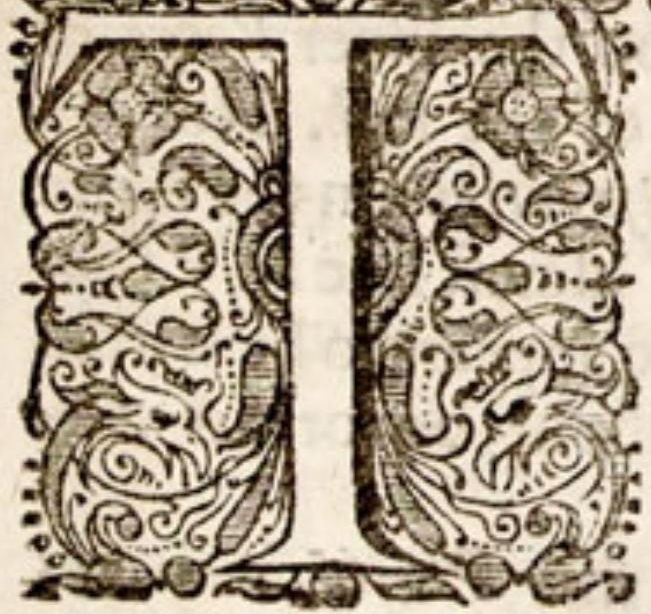

Trunk, Stalk, or Brancb of a Plant, is; I thall by thefe Figures here before us, Defcribe the feveral Parts, whereof it is compounded.

I. 6. And for examples fake, I fhall in the firft place, Defcribe the Trunks of fome Plants, as being cut tranverfly, and accurately obferv'd, they appear to the naked Eye. And fome others, as by the length. Which having done, I thall next proceed to a more particular Defcription of divers other Trunks and Branches as they appear through a good Microfcope. In both fhewing, not only what their feveral $P_{\text {arts }}$ are, as generally belonging to a Branch; but alfo, by a Comparative Profpect, in what refpects they are specifically diftinguifhed one from another, in the fe-
veral Sorts of Branches: 
2. 6. I SHALL begin where the Work of Nature appears lefs Diverfify'd: as in the Stalk of Maze or Indian Wheat. In which, although there are the fame Parenchymous and Lignous Parts, as in all

Tab. 18. other Plants; yet is there neither Barque, nor Pith; the Veffeis being difperfed and mixed with the Parenchyma, from the Circumference to the Centre of the Stalk: Saving, that in and next the Skin, there feems to be no Aer-Veffels. Every where elfe, they run up, like fine Threds, through the length of the stalk: Each Thred being alfo furrounded with Sap.Veffels; which in a Slice cut tranfverfly, appear in very fmall and dark colour'd Rings. The like ftructure may alfo be feen in the Sugar-Cane, and fome other Plants.

3. \$. LET the next Trunk be that of Taraxacum, or Dandelion. In a fice whereof, being cut tranfverfly, is feen next the skin, firft, a

Tab. 18. Fimple, white, and clofe Parenchyma or Barque; made up of $V_{e}$ ficles; but fuch as are exceeding fmall; and hardly vifible without a Glafs.

4. §. Within This, ftand Milk-Veffels in feven or eight diftinct $C_{0}-$ lums, of different fize: each Colum being alfo made up of feven or eight Arched Lines. Betwixt thefe Colums, run as many Diametral Portions, derived from the Barque, into or towards the Pith.

5. §. Next within Thefe, ftand the Aer-Veffels. Which are likewife divided, by the faid Diametral Portions, into divers Arched Lines. The fize of thefe $V_{e} \int f e l s$, as well as their number, is fmall.

6. 6. Within Thefe, ftands the Pith, confifting of very fmall $V_{e-}$ ficles or Bladders, as the Barque. 'Tis very fmall, the Diameter hereof, being farce one fifth, of that of the Pith of Borage. But the Barque of Borage is not half fo thick as this of Dandelion.

7. 6. FOR a Third stalk, we may take that of Borage; wherein there is fome further Variety. For in a fice hereof, cut tranfverfly, there appears, firft a Tough, yet Thin and Tranfparent Skin. Within this Skin, and Continuous therewith, there is alfo a Thin Ring of Sap-

Tab. 18. Veffels: which, without being crufhed in the leaft, do yeild a Lympha.

8. 6. Next ftandeth the Parenchyma of the Barque. Which is made up of a great number of very. fmall Veficles or Bladders. Upon the inner Verge of this Parenchyma, ftandeth another Ring of Sap-V Veffels: which alfo yield a $L y m p h a$; and that different, as is probable, from the Lympha in the utmolt Ring. Hitherto goes the Barque.

9. 6. Adjacent to the Ring of Sap-Veffels, on the inner Verge of Barque, ftand the Aer-Veffels on the outer Verge of the Pith. Not in a Ring; but in feveral Parcels; fome Parcels or Conjugations, in the figure of little Specks; others, in little Arched Lines, almoft like an V Confonant. And being viewed in a good Glafs, there appears to be within the compafs of every larger Speck or Parcel, about 20 or 30 Aer$V e f j e l s$ and within the fmalleft, about 8 or 10.

10. 5. The Pith, in a well grown Stalk of this Plant; is always bollow. But originally, it is entire. It is likewife wholly made up of a great number of Veficles: of which, through a Glafs, fome appear Pentangular, others Sexangular, and septangular. Moft of them are larger than thofe of the Barque; fo as to be plainly vifible to a naked Eye.

II. §. A FOURTH Trunk, thall be that of Colewart, which feems likewife, to have at leaft, two Sorts of Lymphaducts. For being cut tranfverly, as the former, we may obferve, next the Skin, a 
very clofe Parenchyma, of a darkith Green. Wherewith are mixed fome few sap Veffels, which give it that Colour.

12. 6. Within This, ftands a falloped Parenchymous Ring, or a Ring of many fhort and flender white Arches. Which all round about Tab. 18. the Barque, meeting together, run in fo many white Diametral Portions, or extream fmall Rays, into the Pith.

13. \$. Betwixt thefe white Rays, and next of all to the faid white Arches, ftand asmany fmall Parcels of Sap-Veffels, like fo many little Half-Ovals. Within each of which, is included a white Parenchyma.

14. \$. On the inner Verge of the Barque, ftands another Sort of sap-Veffels, in one flender and entire Ring. And fo far goes the Barque.

15. \$. Next within this Ring ftand the Aer-Veffels, in feveral Parcels, diametrically oppofite to the faid white Parencbymous Parcels next without the Sap-Ring.

16. 5. Laft of all, and more within the Pith, ftand the fame kind of Sap-Veffels, as thofe of the Half-Ovals. Both thefe, by fmall lines, run one into another; thus, on both fides, hemming in the Aer-Veffels, and fo making altogether, fo many little Pyramids.

17. 5. LET a Fifth be that of Holyoake. In which, the Curiofity of Nature, is ftill more copious : prefenting us, as it is feems, with Three forts of Lymphaducts; Of which, two yield a Thin; the Third, a Thick Lympha. For being cut, as before, next to the Skin, ftands the Barque; fomewhat clofe, and, in proportion, Thick.

18. 5. Towards the inner Verge hereof, ftand one fort of sap-Veffels, poftur'd in thort Rays. Thefe Veffels yield a Mucilage. And on the inner Verge of the Barque, ftands a Thin Ring of other sap-Vefels,
which yield a thinner Liquor.

19. ऊ. Next within the Barque ftand the Aer-Veffels, pofturd likewife in fhort Rays, diametrically oppofite to thofe in the Barque. In every Ray, there are about twelve or fixteen $V$ effels.

20. 5. Laftly, and more within the Pith, there ftand other Sap$V$ effels, all in very Thin or Slender Arched-Lines; thus hemming in the ral Parcels of Aer-Veffels.

2 I. 5. FOR a Sixth, I will take that of Wild Cucumer: Wherein is alfo found a Mucilaginous Lympha. For firft of all, next to the skin, there is a Ring of Sap-Veffels. Which Ring is alfo radiated, the Rays, all poynting towards, and moft of them terminating on, the Skin.

22. §. Next of all, there is a thick, and fimple Parenchymous Ring. On the inner Verge whereof, there are other Sap-Veffels ftanding in Parcels, alfo in a Ring. So far goes the Barque.

23. 6. Next within, ftand the Aer-Veffels, in as many Parcels, contiguous to thofe of the sap-Veffels aforefaid. To which likewife are adjoyned as many more Parcels of Sap-Veffels within the Pith, oppofite to the faid $S_{a p}-V_{e} \int f e l s$ within the Barque.

24. ซ. FOR a Seventh, we may, choofe that of scorzonera. In which, the $V_{e}$ Jels are both Lympheducts, and Laitiferous. All of them, with the Aer-Veffels, in a radiated pofture. For firt next the outer Edg of the Barque, ftand the Lactiferous, in little Specks. Next to Tab. 18. thefe, on the inner Edg of the Barque, ftand the Lympheducts, in the fame form. 
25. 5. Hereunto adjacent, on the outer Edg of the Pith, ftand the Aer-Vefels, fome in Specks, and fome in extream fhort Lines; hardly diftinguifhed, without a very nice Infpection.

26. 6. Within Thefe, are placed other Lymphadudts, oppofite to thofe in the Barque. And within thefe Lympheducts, ftill in the fame radiated Line, run more of the Milk. $V_{\text {effels. }}$.

27. 5. AN EIGHTH, may be that of Eurdock; Wherein firf, there are a Sort of Lympheducts, which ftand in Arched Parcels, round

Tab. 18. the Trunk, adjacent to the Skin.

28. 6. Within thefe, about the middle of the Barque, run the Milk-Veffels, in the form of fmall round Specks.

29. 5. Next to thefe on the inner Edg of the Barque are placed other Lympheducts. Which, together with more of the fame in the Pith, and the Aer-Veffels betwixt them, ftand all in Radiated Lines, of feveral Lengths, and all harpning towards the Centre.

30. 6. LET the Ninth, be that of Endive: In which there is al-

Tab. 18. fo much curious Work. Next to the $S$ kin, there is, firft, a thick and fimple Parenchyma. Then there is a kind of Undulated Ring of MilkVefels. Within which ftand a Sort of Lympheducts, in feveral Parcels; fome, in Arched Half-Ovals; others, in thort flender Rays. Betwtxt. thefe Parcels, many of the Milk-Vefjels likewife ftand.

31. \$. Next there is an undulated Ring of other Lymphaducts, parting as in moft Trunks, betwixt the Barque and the Pith. Within which, are the Aer-Veffels. And within Thefe, more Sap-Veffels. Both of them, in fmall Specks, anfwerable, or oppofite to the Rays in the Barque.

Tab. 18. 32. S. I SHALL give alfo one or two Examples of Trees, or Arborefcent Plants; the Vine and Common Sumach. In a Slice of the former cut tranfverly, next the $s k i n$, there is a Thin Barque. In the inner part whereof, adjacent to the Wood, ftand the Lympheducts in feveral Half-Oval Parcels, oppofite to fo many Radiated Pieces of the Wood.

33. 5. The Wood is divided into the faid Pieces, by as many $\mathbf{P a}$ renchymous Rays, inferted from the Barque, and fo continuous therewith.

34. 5. Within thefe Radiated Pieces of Wood, ftand the Aer-Veffels; the largeft of which, efpecially if held up againft the light, are plainly vifible to the bare Eye.

35. 8. Within the hollow of the Wood, ftands the Pith; in the young Growths always large. In the utmolt Verge whereof, adjacent to the Wood, ftand a few more $S a p-V e f f e l s$ of the fame Sort with thofe in the Barque.

Tab. 18. 36. 5. IN A like Slice of Common sumach, contiguous to the hairy Skin, there is a Ring of Lympheducts. Next to this a Simple Parenchyma. Then feveral Arched Parcels of Lympheducts. Within thefe, a Ring of Milk-Veffels. And then a Ring of other Lympbeducts. Thus far the Barque.

37. 5. Within the Barque, ftands the Wood, divided into feveral Portions, by the Diametral Infertions divided from the Barque. In the Body of the Wood, ftand the Aer-Veffels, very much fmaller than in the Vine. 
38. 6. The hollow of the Wood is filled up with the Pith. In the Circumference of which, ftands a Ring of Lymphaditus, of the fame fort with thofe next to the Wood without.

39. 6. All the Parts of thefe Trunks, may, as I have now defcribed them, be obferved without a Microfcope : excepting the Bladders and number of Aer-Veffels. Yet Three things are hereunto neceffary; viz. a good Eye, a clear Light, and a Rafor, or very keen Knife, wherewith to cut them with a fmooth furface, and fo, as not to Diflocate the Parts.

40. 6. UPON $\ln$ pection alfo by the length, there are fome particulars, common, more or lefs, to moft Plants, yet better obfervable in fome, than in others. As firft, the Reticulation of the $V$ e f els, (formerly defcribed ) not only in the Wood, but in the Barque : which is evident in a young Branch ofCorin, upon the very Surface thereof, when fome of the $V_{\text {effels }}$ begin to be caft off into the Skin. And fo, by ftripping off the $S k$ in , upon the Surface of the Wood.

41. 6 . In cutting by the length, as well as tranfverlly, the young Fibres, which grow within the Wood in the Edg of the Pith, are alfo feen. As likewife the manner of the Derivation of the Parts of the Bud from the Branch or Stalk; as in Sonchus. There are alfo many Varieties in the Pith, fuch as thofe hereafter mentioned (a) which fall un- (a) Chap.4. der obfervation only in cutting by the length.

\section{H A P. II.}

\section{Of the Barque, as it appears through a good Microfcope.}

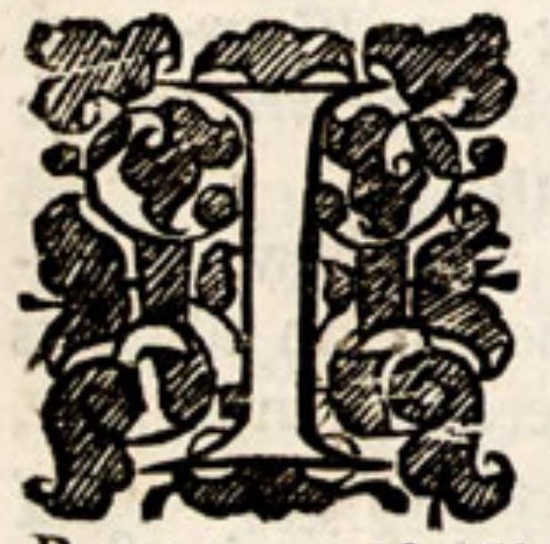

NOW proceed to a more particular Defcription of feveral Trunks and Branches, as they appear through good Glafes.

I. S. Now the Trunk, or Branch of every Tree, hath Three General Parts to be defcribed; $f c_{0}$ the Barque, the Wood, and the Pith. That likewife of every Horbaceous Plant, hath either the fame Three Parts; or elfe Three Parts Analogous; $f c$. the Cortical, the Lignons; and the Pitby Parts.

2. 5. The Barque confifteth of two Parts, $f c$. the outmoft or $s k$ in, and the Main Body. The skin is generally compofed, in part, of very fmall $V e f$ icles or Bladders, clufter'd together. That is, originally it is fo; but as the Plant grows, the Skin dries, and the faid Bladders, do very much fhrink up and difappear.

3. 5. Amongft thefe Bladders of the Skin, there are ufually intermixed a fort of Lignous Fibres, or Veffels, which run through the length $T_{a b} .20$; of the Skin; as in Mallom, Nettle, Borage, Thiftle, and moft Herbs. Which is argued not only from the Toughnefs of the skin by means of the faid $V_{e f f e l s ;}$ but in fome Plants, may be plainly feen, as in Teafle. In which,

$$
\mathrm{U}_{2} \text { the }
$$


the feveral Fibres, which run by the length of the Stalk, are alfo conjoyned by other fmaller ones, which ftand tranfverfly.

4. 6. Whether they are Aer-Veffels, or Sap-Veffels, is dubious. For, on the one hand, becaufe they emit noSap, or bleed not, and alfo ftand adjacent to the Aer; 'tis probable that they are Aer-Veffels. On the other hand, they may be Sap-Veffels; notwithftanding that they bleed not: Becaufe the non-emiffion of Sap is not an infallible and concluding argument of an Aer-Veffel. For there are fome Plants which bleed not. Which yet are furnifhed with $s a p-V e f f e l s$, as certainly as any others (a) B. 2. which bleed. (a)

P. I. c. 3. 5. 6. The Skin of the Trunk is fometimes vifibly porous. But no 5.22. where more, than in the better fort of walking Canes; where the Pores are fo big, as to be vifible even to the naked Eye: like to thofe, Tab. 20. Which are obfervable in feveral parts of the Ball of the Hand, and upon the ends of the Fingers and Toes.

6. 6. THE Main Body of the Barque confifteth likewife of two Parts, fc. Parenchyma, and Veffels. The Parenchyma is made up of an innumerable company of fmall Bladders clufter'd together. Differing
$T a b .22 . \mathcal{H}$ in nothing from thofe aforefaid in the Skin; faving, that they are much Sequent. larger; and generally rounder.

7. 5. This Parenchyma of the Barque is the fame, as to its Sub. ftance, both in the Root and Trunk. Yet as to the Texiure of its Parts, in the one, and in the other, there is This obfervable difference, viz. That in the Barque of the Root, cut tranfverlly, the faid Parenchyma (as hath been thew'd) is ufually, more or lefs, difpofed into Diametral $T a b .7,8,9$. Rays; running through the Barque, after the fame manner, as do the the Hour-Lines through the Margin of the Diul-plate of a Clock or Watch: as in Marßh-Mallow, Lovage, Melilot, and others. Whereas here in the Barque of the Trunk, the faid Parenchyma is rarely thus Tab. 22. difpofed into Dimetral Rays: Nor when it is, are thofe Rays continued d. Seq. to the Circumference of the Barque; as in the Barque of the Root they frequently are. So in Rhus or Sumach, although part of the Paren-
Tab.3 1,34, chyma be difpos'd into Diametral Rays: yet are thofe Rays extended oc. not half way through the Barque. So alfo in Fig-tree, Worm-wood, Thiftle, and others. What is further obfervable in the Texture of the Parenchyma, I fhall thew in the defription of the Pith.

8. \$. THE Vefjels of the Barque, are, as I fhall alfo fhew, diverfifyed many ways. But there are fome Things, wherein, in all Sorts of Plants, they agree. Firft, in ftanding, moft numeroufly, in or near, the inner Margin of the Barque. Secondly, in being always, and only sap. Veffels. I have viewed fo many, that at leaft, I can fecurely affirm thus much, That if there be any Heteroclital Plants, wherein they are found otherwife, there is not One, in Five Hundred. Thirdly, in being always Conjugated or Braced together in the form of Net-mork. Al-

Chap. 3. though the Number and Diftances of the Braces, are very different: as Tab. 6 . I have already fhewed in the Anatomy of Roots.

9. §. THE Properties, whereby the faid $V_{e} \iint e l s$ of the Barque are fpecificated and diftinguifhed one from another, both in the fame Plant, and in the feveral Species of Plants, are very many. Which Properties, are not Accidental, but fuch as thew the Conftant and Univerfal Defign of Nature. All which thall be demonftrated by the Defription of feveral 2uarters of the Slices, of fo many Kinds of Branches 
Brancbes, cut Tranfverlly : and by the feveral Figures which reprefent them.

10. \$. FIRST then, for the Eleven firft Quarters, the Veffels of Tab.22. the Barque are only of Two Kinds. And thefe, in the firft Eight, feem seq. to be Roriferous (defcribed alfo in the Anatomy of Roots) (a) and (a) $P$. I. thofe which are common to moft, if not to all Plants, fe. the Lymphe- $c .3 . \$ .23$.
duds. Yet in all the Eight, they are, in refpect both of their Proportion, and Pofition, very different. So in $\mathrm{Haxel}$ and $A / b$ they are but few. In Holly and Barberry more. In Apple, Pear, Plum, Elm, fill more numerous. And of thofe three Frnits, in an Apple, or Plum, more than in a Pear.

I I. 5. Again, as their Proportion, fo likewife their Pofition is divers. For in Holly, the Lymphreducts or inner Veffels next to the Wood, ftand in Rays. Yet fo numerous and clofe together, as to make one Tab. 22, Entire Ring. In Hazel, they ftand more in Oblong Parcels. In Bar- 23, 24. berry, they ftand likewife in Parcels, but they are fo many Half-Ovals. The utmoft $I^{\prime}$ effels or Roriferous of all Three, make a Ring.

12. 5. Again, in Apple, Pear, and Plum, the Lymphaducts are Radiated. The Roriferous are neither Radiated, nor make an entire Ring; Tab. 25, to
but ftand in Peripherial Parcels. Much after the fame manner, they 28 . alfo ftand in Elm. In $A f h$, the $V_{e} f f e l s$ make Two Rings; but neither Tab. 29. of them Radiated: the inmot Ring or Lympbeducts, confifting of $A r$ ched Parcels, and the utmoft or Roriferous Veffels, of Round ones. And whereas in all the foregoing, the Lympheducts are ftill contiguous to the Wood; and the Roriferous more or Jefs, diftant from the Skin: here, on the contrary, the former are diftant from the Wood, and the latter contiguous to the $S k i n$.

13. \$. And that thefe Veffels in each Barque of the faid Eight Branches, are of $\mathrm{T}$ wo diftinct Kinds, feems evident, as from fome other reafons, fo from hence; In that their Pofitions are altogether Heterogeneous: Yet in both Conftant, Regular and Uniform. I fay, there feems to be no Reafon, why the felf fame Kind or Species of Veffels, fhould have a different, yea a contrary Pofition in one and the fame Plant; and that Contrariety, not Accidental, but Regular and Conftant.

14. 5. FOR the Three next Quarters fc. the Ninth, Tenth and Eleventh, the reffels of the Barque are alfo different in Number, Pofution, Tab: 30 , Size and Kind. In Pine, which is the Eleventh, they are fewer. In $3 \mathbf{I}, 32$. Walnut the Ninth, more. In Fig, the Tenth, moft numerous.

15. \$. So for their Poftition. In Pine, the inmolt make a Radiated Ring. The utmoft ftand stragling up and down, without any certain order. In Wallnut the inmoft make alfo a Radiated Ring; The utmoft make a Double Ring; not Radiated, but of Round Parcels. In $F_{i g}$, the inmoft make alfo a Radiated Ring. But the utmoft make a Double and fometimes Treble Ring, not of Radiated, nor Round, but
Arched Parcels.

16. \$. Thirdly, they are alfo different in Kind. Thofe, I think, of the two former, Wallnut and Fig, are thus different: thofe certainly, of the Fig, are fo; being Lympheducts and Laiteals. The Lymphaducts makethe inmoft Radiated Ring. The outmoft which make the other Rings in Arched Parcels, are the Lactifers.

17. \$. That they are diftinct Kinds of Veffels, is evident for two Reafons. Firft, from their Pofution in the Barque; which is altoge- 
ther different, as hath been faid. secondly, from the moft apparent Diverfity of the Liquors or Saps, which they contain, and which, upon cutting the Branch tranfverlly, do diftinctly Bleed from them. Which is one way, whereby we do diftinguith the Veffels of Animals themfelves. As in the Liver, it were hard to fay, which is a Blood-Veffel, and which is a Bile- $V_{e} \int e_{0}$, where they are very fmall, if it were not for the Contents of them both.

18. 6. Thofe in the Barque of Pine, are likewife of Two Kinds. The inmoft are Lympheducts, as in the two former. The utmoft are not Milk-Veffels, but Gum-Veffels, or Refiniferous; which ftand ftragling, and fingly, about the midle of the Barque. Out of thefe $V$ effels all the clear Turpentine, that drops from the Tree, doth iffue.

19. 6. Few, but very great. So that befides the difference of their Number and Pofition, and of the Liquors which they contain, and Bleed; there is yet a Fourth, and that is, their Size. Moft of thefe Turpentine Veffels, being of fo wide a bore, as to be apparent to the naked Eye: and, through a good Glafs, above $\frac{1}{3} \mathrm{~d}$ of an Inch in Diametre. Whereas that of the Lympheducts, can hardly be difcovered by the beft Microfcope.

20. 5. The fame Turpentine. Veffels of Pine, are likewife remarkably bigger, not only than the Lympheducts, but many times, than the Milk-V $\hat{V}_{\text {jels }}$ themfelves: as thofe of the Fig, which, in comparifon, are exceeding fmall; every Arch, not being a fingleVeffel, but a Parcel or Clufter of Veffels; Whereas one fingle Gum-Veffel in Pine, is fometimes as big as two whole Arched Clufters, that is, as fome Scores of the Milk $V e \int f e l s$ in a Fig-tree. And the faid Gum-Deffels of Pine, being compared with the Iympheducts of the fame Tree, one Gum-Veffel, by a moderate eftimate, may be reckoned three or four bundred times wider than a Lymphaduct. The like prodigious difference may be obferved in the Size of the feveral Kinds of Veffels of many other Plants.

21. 5. THE Three next Quarters of Branches, are of Oak, Common sumach, and Common Wormwood. In the Barque-Ve]els whereof, there is obfervable fome farther Variety. For in all or in moft of the above named, there are only Two Kinds of Veffels in the Barque. But in Each of thefe, there are, at leaft, Three Kinds.

22. 5. And firft, in that of Oak there are Lymphaducts, Rorife-

Tab.33. rous, and a Sort of Refiniferous. The inmoft or Lymphaducts, make a Radiated Ring, contiguous to the Wood. The utmolt or the Roriferous make alfo a Ring, but not Radiated. Thofe which are a fort of Rofin-Veffels, ftand in Round Parcels; the greater Parcels betwixt the Two Rings of Roriferous and Lymphaducts; and the leffer, betwixt the Roriferous and the Skin.

23. 5 . That thefe laft are different VefJels from both the other, feems evident, from the difference of their Pofition, as aforefaid. And that they are a fort of Refiniferous, is argued from hence; In that, not only Galls are very full of Rofin, but that the Barque of $O a k$ it felf is alfo fomewhat Refinous. For the conveyance of whofe Refinous parts, it is moft unlikely that any other Veffels fhould fubferve, but a peculiar Kind; which may therefore be properly called Refiniferous.

Tab. 34. 24. \$. The next is a Branch of Common Sumach. In the Barque whereof, there are likewife Three Kinds of Veffels. Firft of all, there is a thick Radiated Ring of Lympheducts; ftanding on the inner Mar- 


\section{Book III.}

of Trunks.

gin of the Barque, contiguous with the Wood. Thefe Veffels exhibit their Lympha very apparently. A fecond kind of $V e f f e l s$, fc. Roriferous, are fituate towards the outer Margin of the Barque, and are compofed into diftinat Arched Parcels, all ftanding in a Ring.

25. 5. Betwixt thefe Two Kinds ftand the Milk-Vefjels. Every fingle Milk-Veffel being empaled or hemmed in with an Arch of Roriferous. The Milk-Veffels are extraordinary large, almoft as the Gum$V e f f e l s$ of Pine; fo as diftinctly to be obferved without a Microfcope; after they are evacuated of their Milk; and without difficulty will admit a Virginal $W y e r$; being two or three hundred times as big as a Lympbeduct. Befides thefe Three forts of Vefjels, there is alfo a Ring, adjacent to the Skin; which feems to be another fort of Roriferous.

26. 5. The Laft, is a Branch of Common Wormwood. In the Tab.35. Barque whereof, there are likewife Three Kinds of Veffels. Firft of all, there is a thin Radiated Ring of Lympheducts, contiguous with the Wood or on the inner Margin of the Barque. Yet the Ring is not entire, but made up of feveral Parcels; which are intercepted by as many Parenchymows inferted into the $P$ ith.

27. 5. A Second Sort of Veffels, which feem to be Roriferous, are fituate about the middle of the Barque : and are compofed into Arched Parcels, which likewife ftand all even in a Ring.

28. 6. Beyond thefe Arches, and towards the outer Margin of the Barque, ftand a Third Sort of Veffels. Different from the Milk-Veffels in Sumach, both as to their Situation, Size and Content. For in Sumach, the Milk-Veffels ftand within the Arched Lymphreducts : whereas thefe in Wormwood, ftand without them. Likewife, being the Veffels of an Herb, they are far lefs; $f c$. about the compals or width of a fmall Wheat-straw. Their Content, is not a Milk, but a liquid, molt Oleous and vifcid Gum. Or which, for its pleafant Flavour may be called an Aromatick. Balfom. For it perfectly giveth whatever is in the Smell and Tafte of Wormwood: being the Effence of the whole Plant, which nature treafureth up in thefe Veffels. So that they are, in all refpects, analogouss to the Turpentine Veffels in Pine. There are divers other Herbs and Trees, which in the like Veffels, contain a Turpentine, or rather Aromatical Balfom; as Angelica, Helenium and others; the Veffels being fo very large, that they may be eafily traced with a knife, in cutting by the length of a Branch or Saltk.

29. \$. Whether in fome Plants, there are not more sorts of $V e f-$ fels, in the Barque, than have been now mentioned, I cannot fay: Though we have not much reafon to doubt of it. Becaufe we fee, there is fo great variety in the Vifcera of Animals. For what the $V i f c e r a$ are in Animals; the Veffels themfelves are in Plants.

30. 5. CONCERNING the Form and Texture of the Lymphreducts, there are fome things, which though they are beft obferved in the Wood, yet in regard $\mathbf{I}$ am now defcribing the faid $V_{e} \int f e l s$, I fhall here therefore add. I have already faid, and thewed, in the former Books, That the Lignous and Towy Parts of all Plants, are Tubulary. And that the Lympha is conveyed, by the length of a Plant, through an innumerable company of fmall Tubes or Pipes.

31. 6. The 2ueftion may be yet further put: If the Towy Parts of the Barque are made of Tubes, What are thefe Tubes themfelves made up of ? I anfwer, That thefe Tubes or Lymphaducts, are not only themfelves 
themfelves Organical; but their very Sides alfo, feem to be compofed

Tab. 40. of other Parts, which are Organical, $f c$. of Lignous or Towy Fibres. Which Fibres, ftanding clofe or contiguous in a round Figure, they make one Tubulary Body, which I call the Lymphaduct of a Plant. And it is probable, That thefe Fibres themfelves, are alfo Tubulary. That is, that a Lymphaduct, is? a fmall Tube, made up or compofed of other, yet much fmaller Tubes, fet round together in a $C_{y}$ lindrick $F_{i-}$ gure. As if we thould imagine a company of Straws, which are fo many fmall Pipes, to be joyned and fet round together, fo as to make another greater Pipe, anfwerable to a bollow Cane. The Cane, I fay, is as the Lymphaduct; and the strams are as the Fibres whereof it is compofed. By which alfo appears, the admirable fmallnefs of thefe Fibres. For there are fome Lymphaducts, which may be reckoned fifty times fmaller than a Horfe-Hair. Allowing therefore but Twenty of the aforefaid Fibres to make a Thred fo big as one Lympheduct; then one of the faid Fibres, muft be a Thoufand times fmaller than a HorjeHair. That thefe Fibres, whereof the Lympheducts are made, are themfelves made up of other Fibres, is not altogether improbable.

32. \$. Thefe Fibres, although parallel; yet are they not coalefcent, but only contiguous; being contained together in a Tubulary Figure, by the Weftage of the Cortical Fibres, as in Chapter the Fourth will better be underftood.

33. \$. The firft notice I took of the Compofition and Texture of thefe Veffels, fo far as the beft Glaffes yet known, will admit; was in a very white and clear piece of $A / b$-wood torn, with fome care, by the length of the Tree, and objected to a proper Light. They feem alfo fometimes difcernable in fome other clear Woods, as in very white Fir, occ. And having formerly demonftrated, that the Lignous Part of a Plant, is annually made or augmented out of the inner part of the Barque, wherein the Lympheducts always ftand: we may reafonably fuppofe the fame Lymphaducts to have the like Conformation in the Barque, as in the Wood.

34. 5. And I am the rather induced to believe, that I am not miftaken in this Defcription, upon thefe two Confiderations. Firft, that herein the Analogy betwixt the Veffels of an Animal and a Plant, is the more clear and proper. For as the Sanguineous Veffels in an Animal are compofed of a number of Fibres, fet round, in a Tubulary Figure, together : fo are thefe Lymphaducts of a Plant. Secondly, in that herein, there is a more genuine refpondence betwixt thefe, and the other $V e f f e l s$ of a Plant it felf; $f c$, the Aer-Veffels; which are made up of a certain number of Round Fibres, ftanding collaterally, or fide to fide as I have already obferved in the Anatomy of Roots. So that it is the lefs ftrange, that the Lympheducts fhould be made up of Fibres, fince the Aer-Veffels are eviden tly fo made. Only with this difference, that whereas in the Aer-Vefels, the Fibres are poftured or continued Spirally: here, in the Lymphaducts, they ftand and are continued only in fraight Lines.

35.5. THE STRUCTURE of the Ladtiferous and Gum-Veffels, which

Tab.20. have a very ample Bore, is more apparent. And, by the beft Glaffes I have yet ufed, they feem to be made, chiefly, by the Conftipation of the Bladders of the Barque. Thatis to fay, That they are fo many 
Chavels, not made or bounded by any walls or fides proper to themfelves, as a 2uil thruft into a Cork, and as the Aer-Veffels are in the Wood: but only by the Bladders of the Parenchyma; which are fo poltured and crouded up together, as to leave certain Cilyndrick spaces, which are continued by the length of the Barque.

36. $\%$. One difference betwixt the Veffels or Chanels now defcrib'd, and the Tubulary Hollows and other Apertures in the Pith, is this; That thefe never exift originally with the $P$ ith; but are fo many Rupe tures fupervening to it in its Growth. Caufed, partly, by the Stretch or Tenter it fuffers from the Dilatation of the Wood: (a) and partly, the drying, and fo the Shrinking up of its Bladders, and of the Fibres whereof they are compofed. Whereas the faid $V_{e}$ fjels in the Barque, 3. $5.22,6$. are many of them originally formed therewith. And thofe which are poft-nate, not made by any Rupture, but only fuch a Difpofition of the Parenchymous Fibres, and Conftipation of the Bladders, as is thereunto convenient.

37. 6. In paring the Barque of a Branch of Pine, Sumach, \&c. they appear, neither parallel, nor any where Inofculated: but run, with fome little obliquities, diftinct one from another, through the length of the Branch: and fo, we may believe, through the length of the Tree.

\section{H A P. III.}

$$
\text { Of the } W 000 \text {. }
$$

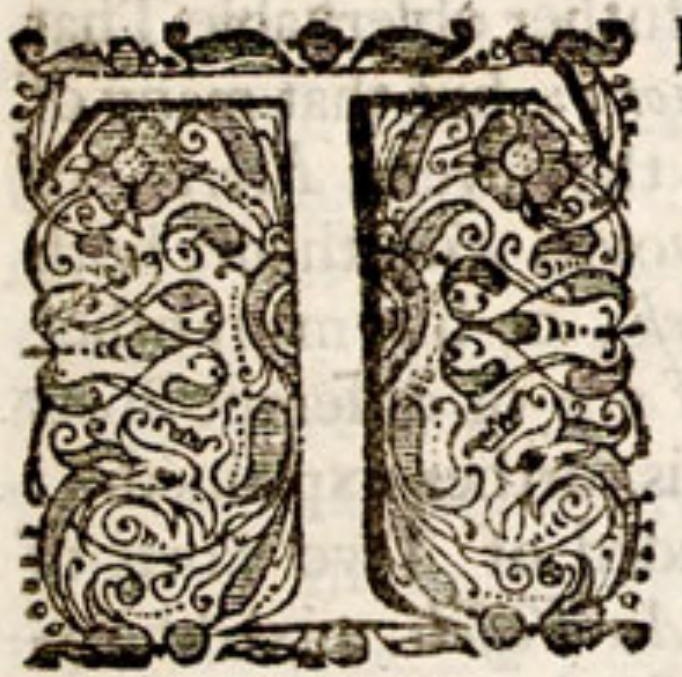

HE next general Part of a Branch, is the Wood; which lyeth betwixt the Barque and the Pith. And this likewife evermore confifteth of Two General Parts, $\int c$. of a Parenchymous Part, and that more properly called Lignous. The $\mathrm{Pa}$ renchymous $P$ art of the Wood, though much diverfifyed, yet in the Trunks of all Trees whatfoever, hath this property, To be difpofed into many Rays, or Diametral Infertions, running betwixt fo many Lignous Portions, from the Barque to the Pith: as in any of the 2uarters here before us may appear.

2. 5. But thefe Infertions are much diverfifyed, according to the feveral Sorts of Plants. So in Barberry, A $h$, Pine, Worm-wood, they Tab. 22, are lefs numerous. In Elm, Wallnut, Fig, Sumach, they are more. to 35 . And in Holly, Pear, Plum, Apple, Oak, Hazel, are moft numerous.

3. 6. The fame Infertions, in Barberry, Wormwood, and fome in $\mathrm{Oak}$, are very Thick. In Pine, Fig, $A j$, of a middle Size. In Pear, Holly, and moft of them in Oak, are exceeding Small. Again, in Bar- Ibid. berry, Elm, $A f$, sumach, Fig, they are of an Equal size. In Holly, Hazel, Pear, Plum, Oak, they are very Unequal: fome of thofe in Holly, being Four or Five times thicker than the reft; in Plum, Six or Seven times; and inOak, Ten times at leaft.

$$
\text { X 4. } \S \text {. }
$$


4. 5. In fome Plants, they are Equidiftant; in others, not: in fome, the Great ones are Equidiftant ; in others, the Leffer ; in others, both; in fome, neither. Which Varieties are not accidental; but conftant to the species in which they are feverally found.

5. 6. They are not always vifibly continued from the Circumference to the Centre of the Wood: but in fome Branches, as of Sumach;

Tab.34. under or over, from a Level, are thereby, upon a Tranfverfe Section, in part cut away.

6. \$. They have yet one more Diverlity, which is, That in divers of the aforefaid Branches, they run not only through the Wood;

Tab. 28, but alfo thoot out beyond it, into fome Part of the Barque, as in 34, 35. Elm, Sumach, Wormmood, \&c. Whereas in Pine, and fome of the Tab. 32. reft they either keep not diftinet from the other parts of the Parenchy$m a$ of the Barque; or are fo fmall, as not to be diftinguifhed there form.

7. 5. The Texture likewife of thefe Infertions is fomewhat various.

Tab. 35. For in Wormmood, and moft Herbs, they are manifently compofed of fmall Bladders: differing in nothing from thofe of the Barque or Pith, faving, in their being much lefs. Yet in Herbs, they are much larger Tab. 36, than they are in Trees. And in many Trees, as Apple, Pear, Plum, Pine, 37. \&c. they are either quite loft, or fo fqueezed and preffed together by the hard $W_{\text {ood }}$ ftanding on both fides, as to be almoft undifcernable.

8. S. So that although the Parenchyma of the Barque or Pith, and the Infertions in the Wood, are of the fame specifick Nature or Subftance: yet there is this difference betwixt them; That the Fibres of the former, are fo Netted together, ås to leave feveral round Vacuities; or to make a great many little Bladders, whereas, in the latter, they are ufually fo far crowded up, as to run (as when a Net is ftretched out) like a Skein of Parallel Threds.

9. 5. Of thefe Infertions in the Wood, it is futher obfervable, That they do not only run betwixt the Lignous Portions; but that many of

Tab. 40. their Fibres are likewife all along diftributed to the feveral Fibres, of which the Lignous Portions confilt, and are interwoven with them; both together thus making a piece of $\operatorname{Linfy}-$ Woolfy Work, or like many other Manufactures in which the Warp and the Woof are of different Sorts of Stuff: as in the end of the Fourth Chapter is further explained.

I0. \$. THE WOOD is likewife compounded of Two Sorts of Bodies; That which is ftrictly Woody; and the Aer-Veffels mixed herewith. The true Wood is nothing elfe but a mafs of antiquated Lymphaducts, viz. thofe which were originally placed on the inner Margin of the Barque. For in that place, there grows, every year, a new Ring of Lymphaducts. Which lofing its original foftnefs by degrees, at the latter end of the year, is turned into a dry and hard Ring of
perfect Wood.

II. \$. So that every year, the Barque of a Tree is divided into Two Parts, and diftributed two contrary ways. The outer Part falleth off towards the Skin; and at length becomes the $S_{k i n}$ it felf. In like manner, as hath been obferved of the Skin cf the Root. Or as the $C_{u-}$ ticula in Animals, is but the efflorefcence of the $C_{u t i s}$. I fay, that the elder $s$ kin of a Tree, is not originally made a skin; but was once, fome of the midle part of the Barque it felf, which is annually caft off, and 
and dryed into a Skin: even as the very skin of an Adder, upon the gradual generation of a new one underneath, in time,becomes a slough. The inmoft portion of the Barque, is annually diftributed and added to the Wood: the Parenchymous Part thereof making a new addition to the Infertions within the Wood; and the Lymphaducts a new addition to the Lignous pieces betwixt which the Infertions ftand. So that a Ring of Lympheducts in the Barque this year, will be a Ring of Wood the next; and fo another Ring of $L y m p h a d u c t s$, and of Wood, fuccefively, from year to year. So the Table, for an Apple-Branch, fheweth a Tab.25. quarter of a Slice of a Branch cut tranfverfly, of Three years growth: $24,34,28$. That of Barbery, of Two; That of Sumach, of One only; That of Elm, of Five.

12. \$. Hereby two things maybe the better noted. Firft, the difference betwixt the degrees of the annual growths of feveral Trees: three years growth in an $\mathrm{Oak}$, being as thick as five in an Elm. Secondly, Tab. 33, the difference betwixt the Annual growths of the fame Tree; being 28 . not of a conftant proportion, but varying in thicknefs, as it fhould feem, according to the feafon of the year: whereby it may appear, what feafon, or kind of year, doth moit of all favour, the latitudinal growth, or the thickening of any Tree.

13. 5. The Lympheducts thus antiquated or turned into Wood, do rarely, if ever, Bleed: but only tranfmit a kind of Dewy or Vaporous Sap. And fome of them, as in the Heart of fome Trees, it is probable, That they tranfmit not any Sap, either in the form of a Liquor, or a Vapour: and fo being gradually deprived of their Watery Parts, become the Heart.

14. 6. There is this further variety in the Wood; reprefented in Walnut, Fig and Oak. That fome certain parcels hereof, make either feveral fmall and white Rings, as in $\mathrm{Oak}$; or elfe divers white and crooked Parcels, tranfverfe to the Infertions, as in Wallnut and $F$ ig. For it feemeth, that, at leaft, inimany Trees, fome portion of all the Kinds of VefJels in the Barque, are not only annually diftributed to the Wood, but do likewife therein retain the fame, or fomewhat like Pofition, which they originally had in the Barque. So that as all thofe bigger aud darker Portions of the Wood, were originally, the Radiated Lymphaducts of

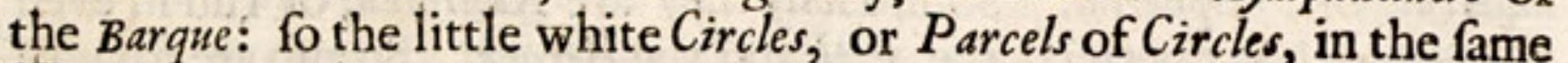
Wood, were originally another fort of Sap-Veffels in the Barque, $f_{c}$. thofe which have a circular Pofition therein.

15. 8 . In the Branches of Fir, Pine, and others of the fame Kindred, there are fome few Turpentine-Veffels feattered up and down the Wood; Tab. 3 ż $_{\text {: }}$ and reprefented by the larger Black Spots. Which $V e f f e l s$ are eadem numero, the felf fame, which did once appertain to the Barque; and do even here alfo in the Wood, contain and yield a liquid Turpentine. Only, being pinched up by the Wood, they are become much fmaller Pipes.

16. \&. THE Aer-Veffels, with the Infertions, and true Wood, altogether make up That, which is commonly called, The Wood of a Tree. The Aer-Veffels I fo call, not in that they never contain any Liquor; but, becaufe all the principal time of the growth of a Plant, when the $V$ efjels of the Barque are filled with Liquor, thefe are filled only with a Vegetable Aer.

17. 5. In almoft all Plants, not one in fome hundreds excepted, this is proper to the Aer-Veffels; To have a much more ample Bore or $C_{a}$; $X: 2$ 
vity, than any other in the Wood. In the Wood, I fay; for in the Barque, there are many Sap.Veffels bigger than the biggeft Aer-Veffels that be.

I8. \$. The Varities hereof are very many; in refpect both of their Number, Size, and Pofition; being, 'as to thefe, the fame, in no two Sorts of Plants whatfoever. Firft in refpect of their Number. So in Tab. 23, Hazel, Apple, Pear, they are very numerous; but in different degrees: 25,26 . and are reprefented in the Figures already referred to, by all the black 22, 24, 27. fpots in the Wood. In Holly, Plum, Barberry fomewhat numerous. In 29,30,33. Oak, Afl, Walnut fewer. In Pine, and others of that Kindred, very 32.

few; $f c$. fewer than in any other kind of Plant.

19. 5. Secondly, in refpect of their Size; which from the firft or greateft, to the leaft, may be computed eafily to about Twenty Degrees. Thus, many of thofe in $E l m, A \S, W$ allnut, Fig, Oak, are very large. In Tab. 28, Barberry, Plum, not fo large. In Hazel, Sumach, fmaller. In Holly, 33. Pear, of a ftill fmaller Size. So that many of thofe in Elm, or Oak, 22, 26. are Twenty times bigger, than thofe in Holly or Pear.

20. $\$$. In an ordinary joynted Cane, they are fo wide, that if you take one a yard, or a yard and $\frac{1}{2}$ long, and putting one end into a $\mathrm{Ba}$ fin of Water, you blow ftrongly at the other; your Breath will immediately $\mathrm{g}_{\mathrm{p}} \mathrm{P}$ fs, through the Aer-Veffels, the length of the Cane, fo as to raife up the Water into a great many Bubbles.

21. \$. And as they have a different Size in divers Kinds of Plants; fo likewife, according to the place where they ftand, in the felf fame.

Tab. 22, So in Holly, Hazel, Apple, their Size is more equal throughout the 23, 25. bredth of the Tree. But in Barberry, Elm, Oak, Alh, very different: $24,28,29$. Not fortuitoully, but always much after the fame manner. For in all 33. the laft named Branches, the Aer-Veffels that ftand in the inner margin of each annual Ring, are all vaftly bigger, than any of thofe that ftand in the outer part of the Ring.

22. 5. Thirdly, thefe Aer-Veffels are alfo different in their SituaTab. 25, tion. So in Apple, Wallnut, Fig, they are fpread all abroad in every 30, 3r. annual Ring; not being pofited in any one certain Line. In others, they keep more within the compafs of fome Lise or Lines; either Di-

Tab. 22. 23,32 . ametral, or Peripherial. So in Holly they are Radiated, or run in even Diametral Lines betwixt the Pith and the Barque. So alfo are fome of of them in Hazel; and fome few in Wallnut.

23. 6. Whether they ftand Irregularly, or are Radiated, it is to be noted, That Nature, for the moft part, fo difpofeth of them, that many of them may ftill ftand very near the Infertions. So in Apple, fhe will rather decline making an even Line; or in Holly, will rather break that Line into Parcels, than that the Acr-Veffels fhall ftand remote from the Infertions. To what end this is done, fhall be faid hereafter.

24. 5. Again, in $A h_{3}$, the Aer-Veffels are none of them Radiated, Tab. 24. al Ring. Which Circle is fometimes very thick, as in $A / B$ and Barberry. 29. In others but thin, the Veffels ftanding, for the moft part, fingle 28. throughout the Circles; as in Elm. Sometimes again, they both make 26, 27. a Circle, and are alfo fpread abroad; as in Pear and Plum.

25. 6. Thofe likewife which are fpread abroad, are fometimes Re-

Tab.24. gularly pofited. So in Barberry, befides thofe larger, that make the Circle, there are other fmaller ones, that ftand, in oblique Lines, 
athwart one another; almoft like a Bend, or fometimes, an entire or broken Saltyr in an Efcutcheon. In Oak, they make rather certain Tab. 33 . Columns, in the pofture of the Pale. And in Elm, they make, as it 38. were, many crofs parcels, in the polture of the $\mathrm{Fe} e s$.

26. 6. This great difference in the size and Pofrtion of the Aer$V_{e} / f e l s$, in the fame individual Plant, is one ground, for which, I think it probable, That there are divers Kinds of Aer-Veffels, as well as of Sap-Veffels. Even as in Animals, there are divers Kinds of Organs for Spiration, and the feparation of Aer: Filhes having their Branchie; Land-Animals their Lungs; and thofe in Frogs, Gc. being of a fomewhat peculiar $K$ ind.

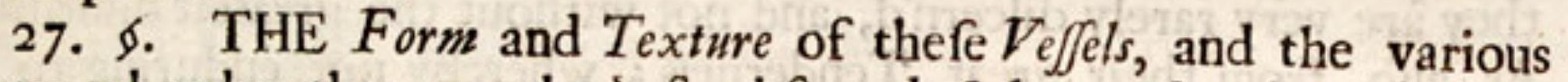
ways whereby they may be beft obferved, 1 have already defcribed and thewed in my Anatomy of Roots. As to their Form, one thing P. I.c. 4 . remarqued was this; That they are never Ramified, but diftinctly continued from one end of a Plant, fmall or great, to the other: as the Nerves are in Animals. A further and eafie proof whereof, may be made, only by holding up a piece of an ordinary Cane, about $\frac{x}{2}$ a foot long, cut very fmooth at both ends, againft a full light: whereupon, if you keep it in a ftraight Line betwixt the Ligbt, and the caft of your Eye, and then look fteadily, you may fee quite through it, that is, through the Aer- $V_{e} / \int_{e} l s$, which run ftraight along the $C$ ane from end to end.

28. 6. As to their Texture; whereas, oftentimes, the Aer-Veffels appear to be unroaved in the form of a very fmall Plate, it is to be noted, That it is not only of different bredth, in divers Plants, and ufually much broader in the Root, than in the Trunk: but alfo, that in the Trunk, many times, the faid $V_{e} \int l_{l} l$ are unroaved or refolved, not in the form of a Plate, but of a Round-Thred. The Caufes of which Diverfity, are principally Three; viz. The Weftage of the Fibres of which the Aer-Veffels confilt; The deference betwixt the faid Fibres, or betwixt the Warp and the Woof; And the different Kinds of Woof.

29. \$. By the Weftage of the Fibres, it is, That the Veffels, oftentimes, unroave in the form of a Plate. As if we thould imagine a piece of fine narrow Ribband, to be woun'd f pirally, and Edg to Edg, round about a Stick; and fo, the Stick being drawn out, the Ribband to be left in the Figure of a Tube, anfwerable to an Aer.Veffel. For that which, upon the unroaving of the $V_{e} \int \mathrm{fel}_{\text {, }}$ feems to be a Plate, Tab.39. or one fingle Piece, is, as it were, a Natural Ribband, confifting of feveral Pieces, that is, a certain number of Threds or Roundy Fibres, ftanding parallel, as the Threds do in an Artificial Ribband. And as in a Ribband, fo here, the Fibres which make the Warp, and which are Spirally continu'd; although they run parallel, yet are not coallefcent; but conteined together, by other Tranfverfe Fibres in the place of
a Woof.

30. 5. And as the faid Fibres are tranfverfly continued, thereby making a Warp and Woof: So are they (as in divers woven Manufactures ) of very different Bulk; thofe of the Former, being much bigger, and therefore much ftronger, than thofe of the Latter. By which means, as Cloth or silk will often Tear one way, and not another ; fo here, while the Warp or thofe Fibres which are Spirally continued? 
tinued, are ufually unroaved without breaking; thofe fmaller ones; by which they are ftitched or woven together, eafily tear in funder all the way.

31. And becaufe the Fibres of the Woof, are themfelves alfo of different Bulk; therefore it is, That where they are more fturdy, as ufually in the Root, they require a greater quantity of $W a r p$, that is, a broader Plate, to overmatch them. Whereas, where they are more extream fmall, as in the Trunk and Leaves, one Thred of the Warp, that is, one Spiral Fibre, will be ftrong enough of it felf, and fo, fometimes, be fingly unroav'd.

32. 5. From the extream Tenuity of thefe Fibres, it is, That they are very rarely difcern'd, and not without the greateft difficulty. As alfo, from their great Tendernefs; whereby not enduring to be drawn out, they all break off clofe to the Sides of the spiral ones. In the Pith, the like Tranfverfe Fibres are a little more vifible: which firft conducted Me to the notice of them here alfo.

33. \$. All the Fibres of the Aer-Veffels, both the Warp and the Woof, are of the fame Subftantial Nature with the Pith and the other Parenchymous Parts of a Plant. From whence it is, That whereas the Tomy Parts of a Plant, whereof all Linen Manufactures are made, are very Strong and Tough; thefe, as is abovefaid, are extream Tender and Brittle, like thole of the Pith and all the Pithy Parts. To which therefore, the Aer-Veffels are tobe referr'd. And the Content of both, is oftentimes the fame.

34. 5. From whence, we have a further proof of what I have B. 1. c. 7. formerly afferted, which is, That in all Plants, there are Two Sub-

9. 13, 14. the Towy or Lignous Parts.

35. \$. From hence alfo we have fome ground to conjecture, That fo many of the Aer-Veffels, at leaft, which are not formed with the feed, but poft-nate, are originated from the Parenchymous Parts; which feem by fome alteration in the 2uality, Pofition and Texture of the Fibres, to be Transformed into Aer-Veffels, as Caterpillars are into Flies. And as the Pitb it felf, by the Rupture and Shrinking up of feveral Rows of Bladders, doth oftentimes become Tubulary: So is it alfo probable, that in the other Parenchymous Parts, one fingle Row or File of Bladders evenly and perpendicularly piled; may fometimes, by the fhrinking up of their Horizontal Fibres, all regularly breakone into another and fo make one continuedCavity; or a Tube, whofe Diametre is the fame with that of the Bladders, wherof it is compofed. All which, will appear more probable, and what hath been faid, be yet better underftood, when we come, in the next Chapter, to the Defcription of the Pith. 


\section{CH A P. IV. \\ Of the PIIH.}

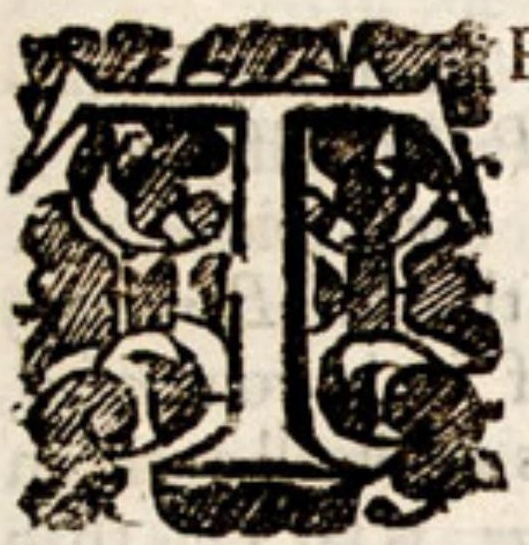

HE Third General Part of a Branch is the Pith. Which though it have a different name from the $P_{a}$. renchyma in the Barque, and the Infertions in the Wood; yer; as to its Subftance, it is the very fame with them both. Whereof there is a double evidence, $f c$. their Continuity, and the famenefs of their Texture. Their Texture thall be thewed prefently. As to their continuity, it is to be noted, That as the $s$ kin is continuous with the Parenchyma of the Barque; and this Parenchyma likewife, with the Infertions in the Wood; fo thefe Infertions again, running through the Wood, are alfo continuous with the Pith. So that the Skin, Parenchyma, Infertions, and Pith, are all One entire piece of Work; being only filled up, in divers manners, with the Veffels.

2. 5. The size of the Pith is various, being not the fame in any two Branches here reprefented. In Wormopood, Sumach, Fig, Barbery, Tab. 24, 'tis very large; $f c$. betwixt 5 , and 7 Inches Diametre, as it appears $31,34,35^{\circ}$ through the Microfcope. In Pine, $A \beta_{3}, H_{0}$ lly $_{3}$ Walnut, not fo large; 22, 29, from 3 Inches Diameter to 4. In Oak, Apple, Pear, Hazel, leffer, fcarce 30, 32. from 2, to 3. In Damafcene, not above an Incb and half. And in Elm, 23, 25, fcarce an Inch Diameter. Note alfo, that of all Plants, both Herbs, 26, 35. and shrubs, have generally the largeft Piths, in proportion with the 27. other Parts of the fame'Branch, 2s in Sumach, Fig, Barbery, is ma- 28. nifeit.

3. 5. It is alfo worth the noting, That wheras, in moft Plants, the Barque and Wood do both grow thicker every year: the Pith, on the contrary, groweth more flender ; So that in a Brancb of one years growth, it is apparently more ample, than in one of two; and in a Branch of two, than in one of three; and fo on.

4. 5. The Pith, for the moft part, if not always, in the Branch, as well as the Root, is furnifhed with a certain number of sap-Vefsels. They are here ufually fo poftur'd, as to make a Ring on the Margin of the Pith. Where they are more numerous, or large, they are more evident; as in Walnut, Fig, Pine, and others. They are alfo of divers Kinds, anfwerable to thofe in the Barque; as in Wallnut, Lymphaducts; in Fig, Lacteals; in Pine, Refiniferous.

5. \$. The Parenchyma of the Pith is compofed of Bladders. Which are the very fame with thofe in the Barque, and oftentimes in the Infertions within the Wood. Only thefe in the Pith, are of the largeft Size; thofe in the Barque, of a leffer; and thofe of the Infertions leaft of all : for which reafon they are lefs obvious than in the Pith.

6. 6. The Bladders of the Pith, though always comparatively Great; yet are of very different Sizes. Being eafily diftinguifhed, even Tab. 24, as to their Horizontal Area, to Twenty Degrees. Thofe of Fig, Barberry, and fome others, are fomewhat large. And of many Herbs, as $3 \mathbf{I}$. 
2ab. 39. of Tbiftle, Borage, and others, three times as big again; appearing in the Microfcope, like to the largeft Cells of an Hony-comb. Thofe of

Tab.32. Plum, Worm-wood, Sumach, lefs. Of Elm, Apple, Pear, leffer. Of Holly and Oak, ftill lefs. So that the Bladders of the Pith in Borage or Common Thiftle, are of that Size, as to contain, within the compafs only of their Horizontal Area, about twenty Bladders of the Pith of Oak. Wherefore one whole Bladder in Thiftle, is, at leaft an hundred times bigger, than another in $\mathrm{Oak}_{\text {. }}$

7. \$. Of the size of thefe Bladders of the Pith, 'tis alfo to be noted, That it doth not at all follow the size of the Pith it felf; but is ftill varied, according as Nature defigneth the Pith for various ufe. Thus, whereas the Pith of Sumach, is Larger than that of Barberry; it might be thought, that the Bladders, whereof it is compofed, fhould be likewife Larger: Yet are they Three times as Small again in Tab. 24, Sumach, as they are in Barberry. So the Pith of Plum, is far Lefs, than 34 . $26,27$. that of Pear; yet the Bladders of the former are Four or Five times as big, as thofe of the latter. So the Pitb of Hazel is almoft Three times as Little again, as that of Holly; yet the Bladders in Hazel, are Ten times bigger, than in Holly.

8. 9. The Shape of the Bladders hath alfo fome Variety. For although, for the moft part, they are more round; yet oftentimes they are angular : as in Reed-grafs, a Water-plant; where they are Cubical; and in Borage, Thistle, and many others, where they are pentangular,
fexangular and feptangular.

9. 5. Of the Texture of the Bladders, tis alfo to be noted, that many times, the Sides of the greater Bladders are compofed of leffer; as is often feen in thofe of Borage, Bulrufh, and fome other Plants. In the fame manner, as the Sap-Veffels, are but greater Fibres made up of
leffer.

10. 5. The Pith, though always originally compofed of Bladders, and fo One Entire Piece; yet in procefs, as the Plant grows up, it hath divers openings or Ruptures made in it :roftentimes very regularly, and always for good ufe,and with conftancy obferved in the fame species of Plants. In Sharp-poynted Dock, many of the Poresare confiderably pro-

$T a b$. 19. longed by the length, like fmall Pipes. In Walnut it fhrinketh up into tranfverfe Filmes or Membranes; as likewfe fometimes in Spanifh-Broom. Sometimes the Pith is hollow or Tubulary :either throughot the Trunk, as in Thiftle, Endive, Scorzonera, Marh-Mallow: or fo, as to remain entire at every joynt ; as in Sonchus, Nettle, Teafle; in which it is divided as it were into feveral Stories : and divers other ways.

I1. \$. I SHALL conclude this difcourfe with a further illuftration of the Texture of the Pith, and of the whole Plant, as confequent thereupon. I fay therefore, (and have given fome account hereof in the Anatomy of Roots) That as the $V e \int j e l s$ of a Plant, $\int c$. the Aer-VefJels and the Lymphaduits are made up of Fibres; according to what I have in this Difcourfe above faid; fo the Pith of a Plant, or the Bladders whereof the Pith confifts are likewife made up of Fibres. Which is true alfo of the Parenchyma of the Barque. And alfo of the Infertions in the Wood. Yea, and of the Fruit, and all other Parenchymous Parts of a Plant. I fay, that the very Pulp of an Apple, Pear, Cucumber, Plum, or any other Fruit, is nothing elfe but a Ball of moft extream fmall tranjparent Threds or Fibres, all wrapped and 
fitcb'd up (though in divers manners) together. And even all thofe Parts of a Plant, which are neither formed into vifible 7 ubes, nor into Bladders, are yet made up of Fibers. Which, though it be difficul to obferve, in any of thofe Parts which are clofer wrought and principally in the Infertions of fome Trees: yet in the Pith,efpecially of fome Plants, which confifteth of more open work, they are more vifible. Which introduceth the obfervation of them in all other Parenchymous Parts. So in the Pith of a Bulrufh of the Common Thistle, and fome other Plants; not only the Threds of which the Bladders; but alfo the Tab. 38. fingle Fibres, of which the Threds are compofed; may fometimes with the help of a good Glafs, be diftinctly feen. Yet one of thefe Fibres, may reafonably be computed to be a Thoufand times fmaller than an Horfe-Hair.

12. 5. The Fibrofity of the Parenchyma is alfo vifible in fome Woods, in which, it is apparently mixed with the Lignous Parts, not only by Infertions, but perwinimas Partes organicas. That is to fay, The Parenchymous Fibres, like fmaller Threds, are either wraped round about both the Lignous and the Aer-Veffels, or at leaft interwoven with them, and with every Fiber of every Veffel: as in very white $A B$ or Fir-Wood with an advantagious pofture and light, may be obferved.

13. 6. WHENCE it follows, that the whole subftance, or all the Parts of a Plant, fo far as Organical, they alfo confift of Fibres. Of all which Fibres thofe of the Lymphaducts, run only by the Length of the Plant : thofe of the Pith, Infertions, and Parenchyma of the Barque, run by the breadtb or horizontally : thofe of the Aer$V e f f e l s$, fetch their Circuit by the Breadth, and continue it by the Length.

14. \$. By which means, the faid Parenchymous Fibres, in fetching their borizontal Circles, do thus weave, and make up the Bladders of the Pith, in Open.Work. And the fame Fibres being thence continued; they alfo wpeave and make up the Infertions, but in clofe-Work. Betwixt which Infertions, the $V$ effels being likewife tranfverfly interjected, fome of the fame Fibres wrap themfelves alfo about thefe; thus tying many of them together, and fo making thofe feveral Conjugations and Braces of the Vefels, which I have formerly defcribed. And as fome of thefe Horizontal Fibres are wraped about the $V_{e} \iint_{e l s}$; fo alfo about the Fibres, whereof the Vefjels are compofed. By which
means it is, that all the Fibres of the Veffels are Tacked or stitched up clofe together into One Coherent Piece. manner, as the Perpendicular Splinters or Twigs of a Basket, are, by thofe that run in and out Horizontally. And the fame Horizontal Fibres, being ftill further produced into the Barque; they there compofe the fame work over again (only not fo open) as in the $P$ ith.

15. \$. SO THA T the moft unfeigned and proper refemblance we can at prefent, make of the whole Body of a Plant, is, To a piece of fine Bone-Lace, when the Women are working it upon the Cufbion, For the Pith, Infertions, and Parenchyma of the Barque, are all extream Fine and Perfect Lace-Work: the Fibres of the Pith running Horizontally, as do the Threds in a Piece of Lace; and bounding the feveral Bladders of the Pith and Barque, as the Threds do the feveral Holes of the Lace; and making up the Infertions without Bladders, or with very fmall ones, as the fame Threds likewife do the clofe Parts of 
the Lace, which they call the Cloth-Work. And laftly, both the Lignous and Aer-Defels, ftand all Perpendicular, and fo crofs to the Horizontal Fibres of all the faid Parenchymous Parts; even as in a Piece of Lace upon the Cufbion, the Pins do to the Threds. The Pins being alfo conceived to be Tubular, and prolonged to any length; and the fame Lace-Work to be wrought many Thoufands of times over and over again, to any thicknefs or hight, according to the hight of any Plant. And this is the true Texture of a Plant: and the general compofure, not only of a Branch, but of all other Parts from the Seed to the Seed.

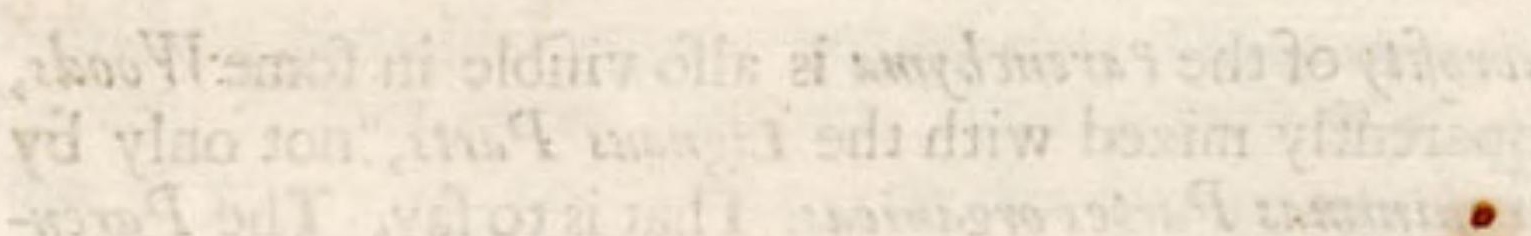




\section{An Account of the \\ VEGETA T I O N \\ $\mathrm{O} F$}

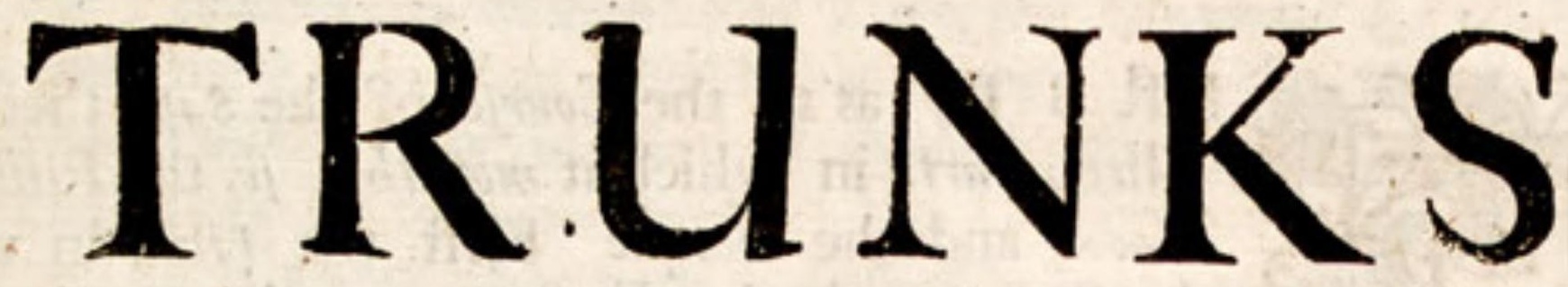

Grounded upon the foregoing

\section{A N A T OM Y.}

\section{P A R T I I.}

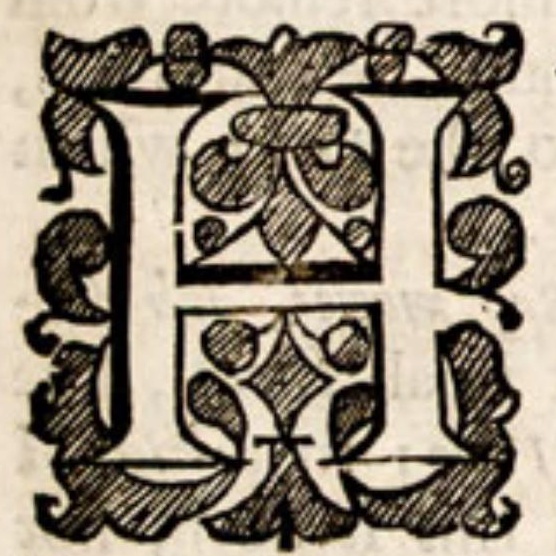

A V I N G before given the Anatomy of Trunks; I thall next proceed to fee, what $\mathcal{U}_{e}$ may be made thereof; and principally, to explicate the manner of their Vegetation. In doing which, that former Method, which I ufed in thewing the manner of the Growth of Roots, I thall not exactly follow. For fo, in regard the Organical Parts of the Root and Trunk are the fame, and confequently their Nutrition and Conformation are effected in the fame way; I thould hereby be obliged to a naufeous and unprofitable repetition of many things already faid. The Explication therefore of all thofe Particulars, which more efpecially belong to the Trank, or are more Apparent therein, and not fpoken of, or not fo fully, in the former Books, will be my prefent Task. The chief Heads whereof, thall be thefe Seven following, viz.

FIRST, the Motion and Courfe of the Sap.

SECONDLY, The Motion and Courfe of the Aer.

THIRDLY, The Structure of the Parts.

FOURTHLY, The Generation of Liquors.

FIFTHLY, The Figuration of Trunks.

SIXTHLY, The Motion of Trunks.

SEVENTHLY, And laftly the Nature of Trunks as varioufly fitted for Mecbanical Uje.

$$
\mathrm{Y}_{2} \mathrm{CHAP} \text {. }
$$




\section{H A P. I. \\ Of the Motion and Courfe of the Sap.}

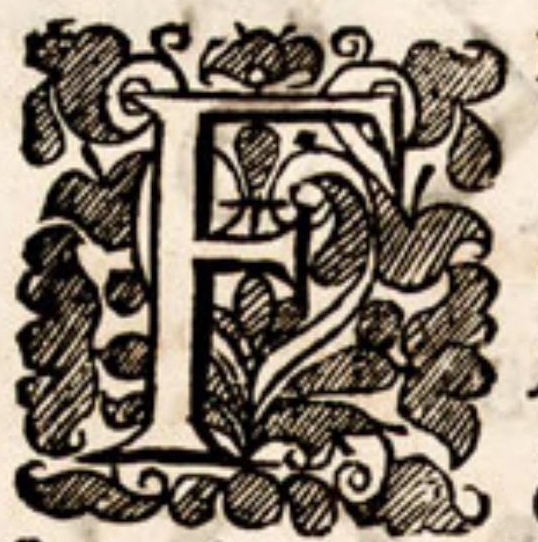

I R S T, as to the Course of the sap, there are Three Parts in which it moveth; $f c$. the Pith, the Wood, and the Barque Firft the Pith; in which the Sap moveth the Firft year, and only the Firft year. Or, it is Proprium quarto modo, to the Pith of every Annual Growth, and to the Pith of fuch a Sprout Growth only, To be fucculent. That is, whether of a Sprout from a seed, or of a Sucker from a Root, or of a $C_{y o n}$ from a Branch; The Pith is always found the Firft year full of sap. But the Second year, the fame individual Pith, always becomes $d r y$, and fo it continues ever after.

2. 5. One caufe whereof is, that the Lymphaducts in the Barque, being the firf year adjacent to the Pith; they do all that time, tranffufe part of their Sap into it, and fo keep it always Succulent. But the fame Lymphaducts, the year following, are turned into Wood; and the Veffels which are then generated, and carry the Sap, ftand beyond them, in the Barque. So that the Sap being now more remote from the Pith, and intercepted by the new Wood, it cannot be transfufed, with that fufficient force and plenty as before, into the Pith; which therefore, from the firft year, always continues dry.

3. 6. THE SECO ND Part in which the Sap moves, fub forma liquoris, is the Wood. Which yet, it doth not in all Plants, but only in fome; and vifibly, in very few; as in the Vine: In a Vine, I fay, the Sap doth vifibly afcend by the Wood. And this it doth, not only the firft year, but every year, fo long as the $V$ ine continues to grow. But although this afcent, in or through the Wood, be every year; yet it is only in the Spring, for about the fpace of a Month; $f c$. in Marcls and April.

4. $\$$. There are many other Trees, befides the Vine, wherein, about the fame time of the year, the Sap afcendeth, though not fo copioufly, yet chiefly, in the Wood. For if we take a Branch of two or three years growth, fuppofe of Sallow, and having firft cut the fame tranfverfely; if the Barque be then alfo tranfverfely, and with fome force, preffed with the back of the knife, near the newly cut end; the Sap will very plainly rife up out of the utmoft Ring of Wood. And if it be preffed in the fame manner, or a little more ftrongly, about an Inch lower, the sap will afcend out of every Ring of Wood to the Center. Yet at the fame time, which is to be noted, there arifeth no $\mathcal{S}_{a p}$ at all
out of the Barque.

5. \$. Whence appears the Error of that fo Common Opinion, That the Sap always rifeth betwixt the Wood and the Barque. The contrary whereunto is moft true, That it never doth. For the greater part of the year, it rifeth in the Barque, $\int c$. in the inner Margin adja- 
cent to the Wood, and in Spring, in or through the Wood it felf, and there only.

6. 5. THE THIRD Part in which the sap afcends, is the Barque, as was above hinted, and may be observ'd in almoft any Branch, if cut crofs, in the late Spring and in Summer; either as the sap iffueth fpontaneoufly, or upon preffing, as aforefaid. So that: when the Sap ceafeth to afcend, fub forma liquoris, by the Wood, then it begins to afcend by the Barque.

7. 5. Befides the difference of Time, the Organical Parts likewife, in which thefe two saps afcend, are divers. For in the Barque, it afcendeth vifibly, only in the Succiferous, whereas in the Wood, it afcendeth only by the Aer-Vefels.

8. 5. F R O M what hath been faid, we may underftand, what is meant by the Bleeding of Plants. If we take it generally, it properly enough expreffes, The eruption of the sap out of any Veffels. And fo, almoft all Plants, in Summer time, do Bleed, that is, from sap-VeJels, either in the Barque, or in the Margin of the Pith: the Saps they Bleed, having either a sower, Sweet, Hot, Bitter, or other Tast. At which time, the Veffels alfo, in the Barque of a Vine-Branch, do Bleed a Sower Sap.

9. 5. But that which is vulgarly called Bleeding, as in a Vine, is quite another thing; both as to the Liquor which iffueth, and the Place where it iffues : that is to fay, it is neither a sweet, nor sower, but Tafteless sap; iffuing, not from any Veffels in the Barque, but from the Aer-Veffels in the Wood. So that there is as much difference betwixt Bleeding in a Dine, or the Rifing of the Sap in any other Tree, in March, and in fuly; as there is betwixt Salivation and an Hemorrbage? or betwixt the Courfe of the Chyle in the Lactiferous reffels, and the
Circulation of the Blood in the Arteries and Veins.

10. 6. N O W the Caufe from whence it comes to pafs, that the early spring-Sap of a Vine, and other Trees, afcendeth by the wood, is, In that the Generation of the young sap-Vefels in the Barque, by which the $S a p$ afcendeth all the Summer; is, in the beginning of spring, but newly attempted. So that the Sap having not yet thefe $T_{e}$ effels to receive it, it therefore (pro bac vice) runs up the Aer-Veffels in the Wood. But fo foon as the faid Veffels in the Barque begin to be confiderably encreafed, the sap, declining the Aer-Veffels, betakes it felf to
These, as its moft proper Receptacles.

11. 5. THE CAUSE alfo, why the Veffels of almolt all Plants, upon cutting, do yield Sap, or Bleed; is the Preffure which the Parenchyma makes upon them. For the Pith and other Parenchymous Parts of a Plant, upon the reception of Liquor, have always a Conatus to dilate themfelves. As is manifeft from sponges, which are a Subftance of the fame Nature, and have a fomewhat like ftructure. As alfo from Cork, which is but the Parenchyma or Barque of a Tree. I fay therefore, that the Parencbyma being fill'd and fwell'd with Sap, hath thereby a continual Conatus to dilate it felf; and in the fame degree, to prefs together or contract the Veffels which it furroundeth. And the faid $V e f j e l s$ being cut, their actual Contraftion and the Eruption of
the Sap, do both immediately follow.

1 2. §. IT may be alfo noted, That the Trunk or Branch of any Plant being cut, it always bleeds at both ends, or upwards and downwards, alike 
alike freely. Which, as well as divers other Experiments plainly fhews, That in the Sap-Veffels of a Plant, there are no Valves.

13. 6. F ROM what we have now above, and elfewhere formerly faid, we may alfo underftand the manner of the Afcent of the Sap. As to which, I fay, Firft, That confidering to what heigth and plenty, the Sap fometimes afcends; it is not intelligible, how it fhould thus afcend, by virtue of any one Part of a Plant, alone; that is neither by virtue of the Parenchyma, nor by virtue of the Veffels, alone. Not by the Parenchyma alone. For this, as it hath the Nature of a sponge or Filtre, to fuck up the $S_{a p}$; fo likewife, to fuck it up but to a certain heigth, as perhaps, about an Inch, or two, and no more.

14. 5. Nor by the Vefjels alone, for the fame reafon. For allthough we fee, that fmall Glass-Pipes immerfed in Water, will give it an afcent for fome Inches; yet there is a certain period, according to the bore of the Pipe, beyond which it will not rife. We muft therefore joyn the Veffels and the Parenchyma both together in this Service; which we may conceive performed by them in the manner following.

15. 5. Let A B be the Veffel of a Plant. Let C E D F be the Bladders of the Parenchyma, wherewith, as with fo many little Cifterns,

$T a b$. 39. it is furrounded. I fay then, that the $S a p$, in the Pipe B A, would, of it felf, rife but a few Inches; as fuppofe, from D to L. But the Bladders D P, which furround it, being fwelled up and turgid with Sap, do hereby prefs upon it; and fo not only a little contract its bore, but alfo transfufe or ftrain fome Portion of their sap thereinto: by both which means, the Sap will be forced to rife higher therein. And the faid Pipe or $\mathrm{Veffel}$ being all along furrounded by the like Bladders; the Sap therein, is ftill forced higher and higher: the Bladders of the Parenchyma being, as is faid, fo many Cifterns of Liquor, which transfufe their repeated Supplies throughout the length of the Pipe. So that by the fupply and preffure of the Cifterns or Bladders F D, the the $S$ ap rifeth to $L$; by the Bladders $Q_{2} L$, it rifes to $M_{\text {; }}$ by the Bladders N M, it rifes to I ; by the Bladders $\mathrm{O} I$, it rifes to $\mathrm{K}$; by the Bladders $\mathrm{PK}$, it rifes to $\mathrm{E}$; and fo to the top of the Tree. And thus far of the Motion of the Sap. 


\section{H A P. II.}

\section{Of the Motion and Courfe of the Aer.}

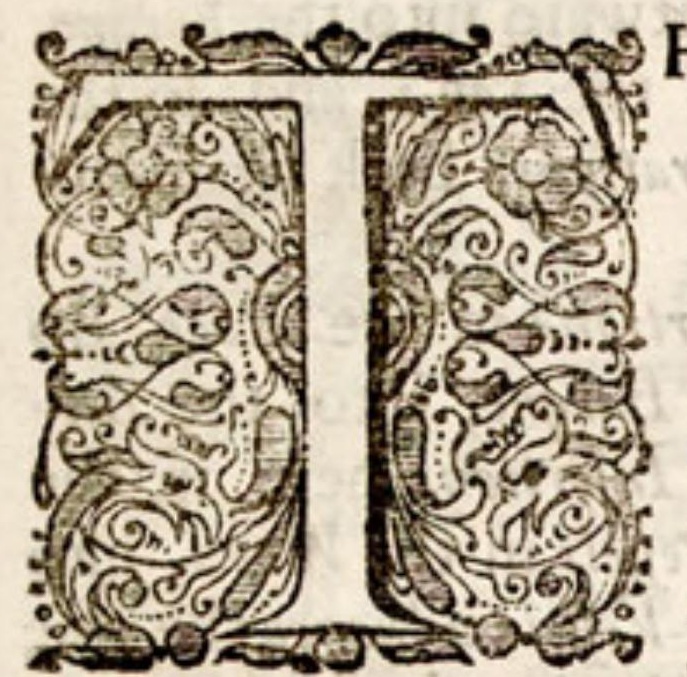

HE NEX T enquiry to be made, is, into the Motion and Courfe of the Aer. Where this queftion will firft of all be asked; $\int c$. Which way the Aer firlt enters the Plant; whether at the Trunk, Leaves, and other Parts above ground; or at the Root? I anfwer, That it enters in part, at them all. For the Reception, as well as Extramilfion whereof, the Pores are fo very large, in the Trunks of fome Plants, as in the better fort of thick walking Canes, that they are vifible, to a good Eye, without a Glafs; but with a Glafs, the Cane feems, as if it were ftuck top Tab. 19. full of holes with great Pins: being fo large, as very well to refemble the Pores of the Skin in the end of the Fingers and Ball of the Hand.

2. 5. In the Leaves of Pine, they are likewife through a Glass, a very Elegant Show; ftanding all mot exactly, in rank and file, throughout the length of the Leaves. The Figure whereof thall be given hereafter, when we come to the Anatomy of the Leaf.

3. \$. But although the Aer enters, in part, at the Trunk and other Parts, efpecially in fome Plants; yet its chief entrance, is at the Root. Even as fome Parts of Aer, may continually pafs into the Body and Blood, by the Habit, or Pores of the Skin; but the chief entrance hereof, is at the Mouth. And what the Mouth is, to an Animal; that the Root is to a Plant.

4. 5. Again, if the chief entrance of the Aer,were at the Trunk; then, before it could be mixed with the sap in the Root, it muft defcend; and fo move not only contrary to its own Nature, but likewife in a contrary Courfe to the $S a p$, throughout the Plant. Whereas, by its Reception at the Root, and fo its Tranfition from thence; it hath a more natural and eafie motion of Afcent. For while the sap afcends, that the Acr, in the fame Plant, fhould continually defcend, cannot reafonably be fuppofed.

5. 6. The fame is further argued, From the fewnefs and fmallnefs of the Diametral Portions in the Trunk in comparifon with thofe in the Root. In which Nature hath plainly defigned the fame, for the Separation of the Aer from the $S a p$, after they are both together received thereinto. So that the Reception and Courfe of the Aer, is made on this manner following.

6. 5. THE Aer being a springy Body, it infinuates into all the Holes and Cranies of the Earth; and fo is plentifully mixed therewith. Whereupon, as the Sap enters the Root, more or lefs Aer ftill intrudes it felf together with it. The Liquid Portion of the Sap, fwells and fills up the Succulent Parts of the Barque. The Aery Part, is, as was faid, feparated from the Liquid, into the Diametral Portions. Which running; 


\section{8}

running from the Barque towards the Centre of the Root, and fo paffing along betwixt the Aer-VefJels; do hereby convey the Aery Pare of the Sup from the Barque, into the fame.

7. 5. Being thus received into the Aer-VefJels, and the Reception thereof, by the fame means continued; it is by them advanced into the Irunk. In which advance, it is again, more or lefs, disburfed into all the Parts of the Trunk, as it goes. Partly, inwards to the Pith. From whence, the $P$ ith is always, at length, filled with Aer. Partly, into the Infertions; by which it is conveyed outward into the Barque. Wherein, it is in fome part, transfufed through the Sap: and fo the reft, with part of the Sap, remitted, in perjpirations, back again into the Aer.

8. S. So that, whereas the Diametral Portions in the Root, do ferve to convey the Aer from the Sap in the Barque, into the Aer$V_{e} \int e l s$, in the Wood: on the contrary, the Infertions here in the Trunk, ferve to convey the Aer from the Aer-Ve/Jels in the Wood, into the $S_{a p}$, in the Barque. Wherefore, as the Aer-Veffels advance the Aer, or the Aery Part of the Sap, and fo convey it by the length of the Trunk; fo the Infertions filter it, and convey it by the breadth.

9. 5. AND that the Infertions have this Office or Subfervience unto both $K$ inds of $V$ efjels; doth yet further appear, if we confider, That the Aer-Veffels are always fo poftured, as to touch upon the faid Infertions, or at leaft to ftand very near them. For either they are large, and fo do frequently touch upon them on both fides; as in

Tab. 28. Elm, $A j$, $W$ allnut, \&c. Or if they are fmall; then they either run 29. along in even lines collateral and oftentimes contiguous with the faid 22. Infertions, as in Holly : or at leaft, are reciprocally, fome on one fide, and fome on another, inclined to them; as in Apple. By all which

25. means, the Aer is more readily conveyed from the $V_{e} \int f e l s$ into the $I_{n}$ fertions.

I0. 6. A further evidence hereof is this, That generally, the bigger and the more numerous the Aer. $V_{e} \int j e l s$ be; the bigger, or at leaft, the more numerous alfo are the Infertions: Efpecially, if the comparifon be made ( as in all other cafes it ought to be, as well as here) betwixt the feveral species of the fame Kind. So corin, which hath

Tab. I7. fmall Aer-VefJels, hath alfo very fmall Infertions. But the $V_{i n e}$, hath both very large: and fo for others.

I I. Wherefore, the Infertions minifter betwixt the Aer-Veffels, and the Succiferous; in the fame manner, as the $V_{e}$ ficule of the Lungs, do betwixt the Bronchic and the Arteries. That is to fay, as in an Animal, the Broncbia depofite the Aer into the Veficule of the Lungs; which adminifter it to the Arteries: fo in a Plant, the Aer-Vefjels depofit the Aer into the Infertions, that is into the Veficule of the Infertions; by which it is gradually filtred off into the Barque and the Sap-Vefjels therein. 


\section{H A P. III.}

\section{Of the Structure of the Parts.}

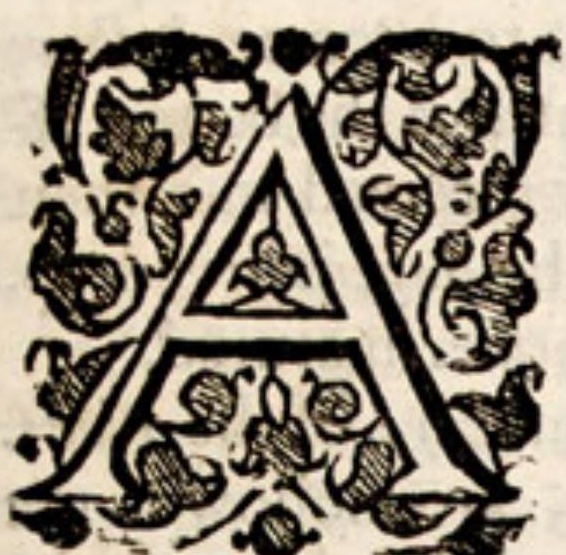

THIR D enquiry, is into the Generation and Structure of Parts. The manner whereof I have already endeavoured to explicate (a) from the $A-(a) L i b .2$. natomy of the Root, throughout all particulars. P.2. Some whereof I thall yet further clear.

I. 5. As Firft, the Union of the Barque to the Body of the Tree, Contrary to the common Opinion, That they are not continuous; but that the Barque only furrounds the Body, as a Scabbard does a Sword, or a Glove the Hand. As allo feemeth to be proved, by the eafy slipping of the Barque of Willop, and molt other Trees, when full of Sap, from the Wood.

2. 5. But, notwithftanding this, they are as truly continuous, as the skin of the Body is with the Flefh : fc. by means of the Parenchy$m a$; which is one entire Body, running from the Barque into the Wood, and fo uniting both together; as in a Branch of Vine or Corin-Tree, Tab. I9. when the Barque is ftripped off, is apparent ; the Spaces between the feveral Parts of the Wood, being filled up with the Parenchymous, inferted from the Barque.

3. 5. Now the reafon why the Barque neverthelefs flips fo eafily from the Wood, is plain, viz. Becaufe mott of the young Veffels and Parenchymous Parts, are there every year fucceffively formed; that is, betwixt the Wood and Barque : where the faid Parts newly formed, are as tender, as the tendereft $V$ efjels in Animals. And we may imagine, how eafie it were at once to tear or break a thoufand Vefjels or Fibres of an Embrio, of a Womb or Egg.

4. 6. THE fame Veffels of the Barque being always braced, and gradually falling off, together with the Parenchyma, into the utmoft Rind: Hence it is, that the Barques of many Trees, are as it were, lat- Tab. 19: ticed with feveral $C$ racks of divers Sizes, and fometimes in the Figure of Rombs: the faid Fiffures reprefenting the Poftion and Trait of the $V e f j e l s$ in their Braces. Hence alfo it is, that the Barque of fome Trees, as of Corin, Cberry, \&c. falleth off in Rings, $\int c$. becaufe the Sap-Defels are pofited in the fame manner in the Barque.

5. 5. The $S a p-V e f f e l s$, as they are generated at the inner Verge of the Barque : fo likewife, in a fmall quantity, at the utmoft Verge of the $P$ ith. Thefe being not only fed with a more vigorous Sap, but with great caution, fecured within the Wood, for the propagation of the fucceeding Buds.

6. $\$$. Hence alfo it is, that is, by the annual accretion of thefe $V$ effels, that the Pith is fometimes lefs in the Trunk, than in the Branches; Tab. 18. and lefs in the elder Branches, than in the younger; and fometimes 'tis allmoft wholly filled up. By which means, as the Branches carry every year a greater burthen; fo they become ftill more fturdy the better to fupport it.

7. 5. SOMETIME S alfo the Pithbreaks and fhrinks up, thus making the Trunk a Pipe. The caufe whereof, is either the Largeness of its Pores, or the Thinnefs of the sides of the faid Pores; upon both 
which accounts, the Pith doth more eafily tear, and upon tearing fhrink up, and fo become hollow: as in Cichory, Lampjana, Sonchus, Teafel, Bromnmort, and others; wherein the Pores of the Pith are Large, and the Sides of the Pores, Thin. Whereas, upon contrary accounts, the Piths of moft Trees, remain perpetually entire.

8. 6. T HE Reafon why Plants are made thus to become bollow, is partly, for the ripening of the Fruit or Seed; which is the better effected by a more plentiful fupply of Aer continually received into their hollow Trunks. For by means of that Aer, part of the $S_{a p}$, is dryed up, and the remaining part of it made warmer, and fo fooner matured.

9. \$. Partly, for the better determining the due Age of the Plant. Hence it is, that the greater part of Annual Trunks, are hollow: the Aer contained in that hollow, drying up the $S a p$, and thrinking up the Sap-Ve/els. fo far, as to hinder the free motion of the Saptherein; from whence the Plant muft needs perifh. So that as the Content of the Aer-Veffels, is a kind of Vegetable Aer, whofe Office is to Attenuate, and Ferment the Fuyces of Plants : fo the Content of thefe Cavities, cometh nearer to a more common Aer, defigned chiefly, fo foon as it is conve-
nient, to $d r y$ them up.

I0. \$. A G A I N, as to the Aer-Vegfels, divers queftions may be asked. As how it comes to pafs, that they are generally lefs in the Trunk of the fame Plant, than in the Root? The Caufe whereof is, that here in the Trunk they are more under the power of the Aer; both that which entreth in at the Trunk, and that which of its own Nature afcendeth up into it from the Root. For the Aer, as we have elfewhere faid, is the Mould of the Aer-Veffels; to whofe crooked or at leaft, Acid Parts, the Saline, and other Principles concurring to their generation, do conform. To which they do beft, the fmaller they are: the Fibres of the larger Aer-Vc/Jels making greater Circles, and fo coming nearer to a right Line, anfwerable to the Figure of the Particles, not of the Aerial, but of the saline Principle.

I1. 6. Wherefore as the Aer-Ve/fels may be obferved ftill to be dilated or widened towards the lower parts of the Root; the Aerial Principle being there lefs predominant, and the Saline more: So towards the upper part of the Trunk, to be contracted or grow fmaller; the Aerial Principle being here more predominant, and the Saline lefs.

12. 6. FOR the fame caufe it may be obferved, That the Aer-Veffels of the Second years Growth, and the feveral years fucceeding, are ufually nearer of one Size, than thofe of the Second and Firft; all being under a lefs power of the Aer, than the Firft. For the firt year the Pith being full of Liquor, the Aer-Veffels themfelves, are the only Repofitories of the Aer. Whereasjafterithe firft year, the P ith becoming dry, or another great Repofitory for the Acr; the Aer-Veffeles are henceforth filled with a moifter or more Vaporous and saline Aer, and fo made to
grow wider.

13. \$. Hence the very Size of the Pith, hath much influence upon the Aer-Vefjels, and the manner of Nutrition, and the Generation of $L i$ -
quors in Plants.

14. \$. BUT for the moft part, the Aer-Veffels are fomewhat, more or lefs, amplified in every new Annual Ring; or at leaft to a certain number of years. Probably, becaufe in the elder Branches, the Spiral Fibres, of which the Vefjels confift, are more bulky; and fo make a Velfel 
Veffel of a wider, as a more agreeable bore. Nature obtaining hereby, that the Quantity of Aer, thall always be anfwerable to the Growth of the Plant, or at leaft, be fufficient to maintain its Vegetable Life and Vigour.

15. 8. And therefore, as is above hinted, it feems likely, That after a certain number of years, the Aer-Veffels are no longer amplified, but ftand at a ftay, and perhaps may grow fmaller, according as the Tree is lefs or more Longave; and that after this period, it is fome way or other in its Declining State.

16. 6. LASTLY, from the Content and Governing Principle of the Aer-Veffels, the Time, when they begin every year to be formed, or to appear, is always later; at leaft with refpect to the feafon of the Tree. So that whereas the Sap-Veffels begin to be formed in Spring : thefe, not till the latter end of Summer, or there about; at leaft not till about that time to appear. That is, when the $S_{a p}$ begins to decreafe, and to grow more Aery; and fo more fit matter for the Generation of the faid Aer-Veffels.

\section{H A P. IV. \\ Of the Generation of Liquors.}

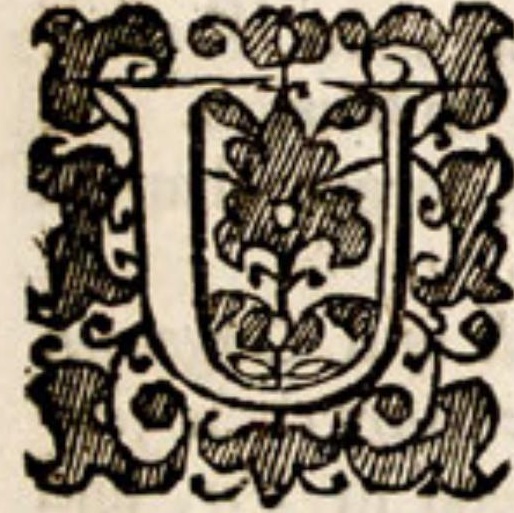

P ON the Structure and Formation of the Parts, dependeth the Generation of Liquors, as was lately intimated. The manner whereof I have formerly Shewed, in difcourfing of the Root. Yet fome things I thall here further explicate. And Firft, what we have formerly afferted, $f c$. That the concurrence of two spocifically diftinct Fluids, is as neceffary to Nutrition in Plants, as in Animals. Which appears, as from divers other confiderations, fo from the very structure of a Plant: where in all the Organical Parts, or the Parenchyma and the Veffels, are every where mixed together per minima, that is, per minimas partes organicas, or Fiber with Fiber of feveral Kinds. Every fmall part of a

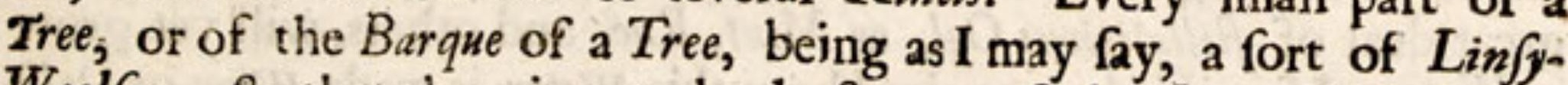
Woolfey. So that there is not the leaft part of the Sap, which is not impregnate with divers Effential Tinctures, as it is continually filtred from the Fibres of one Kind, to thofe of another; ftanding every where monn'd and ftitch'd up together for the fame purpofe.

2. 5. F R OM the fpecial Nature and Structure of the Parts, the Liquors of plants are likewife Jpecified. The Vefels being the chief $V$ ifcera of a Plant. For all Liquors in a Plant, are certainly made by that Plant. And fince the Plant hath no Vifcera (fo called) I would then know, what its feveral Liquors are made by ? If in the Parenchyma, furely by that parenchyma. If in the Veffels, by the Veffels., And if of divers Kinds by divers Kinds of Veffels. So that what the $V i f c e r a$ are in Animals, the Vefjels themfelves are in Plants. That is to fay, as the Vifcera of an Animal, are but $V e f f e l s$ conglomerated: fo the Vefjels of a Plant, are Vifcera drawn out at length.

$$
\mathrm{Z}_{2}
$$

3. \$. 
3. 6. A G A I N, as the specifying of the sap dependeth chiefly on the fpecial Neture of the Parts: fo partly, upon the Structure of the Whole. Whereby every Part is ftill better accomodated with its own Fayce. Thus the Aer-Veffels are neceffary, not only and barely for a Jupply of Aer; but alfo by their Number, Size, and Pofition to adjuft the quantity of that Aer, to the government of Nutrition, and the Generation of the specifick Liquors of every Plant. Which is evident from hence, in that they do not follow the size of the Plant; but are great and many, in fome fmall Plants; and fmall and few, in fome others that are large. So Vines, and Corn, as we have formerly obferved, have proportionably a great number of Aer-Veffels, and thofe very large. By which means the Sap is attenuated and less $O y l y$, and more copioufly impregnated with a Subtle, Volatile and Winy Spirit.

4. 6. For the fame reafon, the Stalk of Maze or of Indian Wheat, which when it is Green yieldeth a very fweet Fuyce; and the Canes; whereof sugar (which aboundeth with a volatile and inflammable spirit ) is made ; thefe, I fay, obtain the like over proportion of Aer$V$ efjels, to what we fee in moft other Plants. Hence alfo it is, that none of the faid Plants have any confiderable Barque; that fo the attenuating and fubtilizing Aer, may have a more eafie and plentiful admiffion at the Trunk alfo. For which reafon likewife the Pores of the Skin of fome Canes are, as hath been faid, remarkably wide.

5. 5. Hence alfo it is obfervable, that of the fame Species or $K_{i n-}$ dred, thofe Plants which have the moft, and efpecially the largeft Aer$V e f j e l s$; have alfo the greateft abundance either of a fweet, or of a $2 \mathrm{wi}-$ ny Liquor. So in Apple; they are larger than in crab; In Warden; larger than in 2nince; and in Pear-Tree, larger than in Warden. So alfo in Corin, larger than in Goofeberrey; and in Vine, larger than in Corin: and fo in others.

6. 6. AND as the Aer-Veffels, by their Multitude and Largenefs, are accommodated to the better making of a Winy sap: fo by their fewnefs and fmallnefs, of an Oylie. As is remarkably feen in Fir, and other Refiniferous Trees: thefe having, if not the fmalleft, yet the femeft Aer-Veffels of all other Trees.

7. 5. IF it be asked, how a Plant comes to have any $O_{y} l$ at all in any Part? Since we fee, that the Sap by which the Root is fed, feemeth to be nothing elfe but Water ; and that many Plants which yield a great deal of ftillatitious $O y l$, as Mint, Rue, and others, will yet grow in Water: I fay, if it be enquired how this Water, is made Wine or Oyl? I anfwer, that there is no fuch matter. But that the $O y l$, and all other

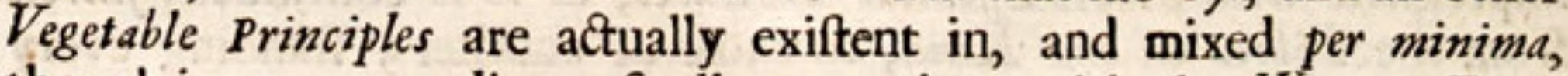
though in an extraordinary fmall proportion, with the Water. Even as we fee the diftilled $W$ aters of Anife Seeds, Penyroyal, and the like to be impregnated with their own Oyls, which give the Tafte and Smell to fuch Waters.

8. 5. Wherefore,as a certain quantity of any Salt may be diffolved in Water; beyond which, it will not mix therewith, but remains under its own Form: So is there a certain proportion of $O y l$, though far lefs, which may alfo be perfectly mixed with Water; and is certainly fo, more or lefs, with all the Water in the world. But if that proportion, or degree of impregnation be once exceeded; the particles of Oyl do then, and not till then, gather into a body, and appear under their own Form. 
9. \$. I fay therefore, that all kinds of Vegetable Principles, are either in or together with the Water, with lefs difference firft received into a Plant. But when they are once therein; they are then Separated, that is to fay, filtred, fome from others, in very different Proportions and Conjunctions by the feveral Parts; the Watery by one Part, the Aery by another, the $O y l y$ by another, and fo the reft: and fo every Part is the Receptacle of a Liquor, become peculiar, not by any Transformation, but only the Percolation of Parts out of the common Mass or Stock of Sap. And fo all thofe parts of the Sap, which are fuperflous to any kind of Plant, are at the fame time, difcharged back by Perfpirations, into the Aer.

10. 5. A ND, that Nature, in the various Percolations and Sepations of the Sap, may ftill the better anfwer her end; hence, it is, that fhe carefully feeth, not only to the fpecial Nature and Proportion of the Organs, by which the doth her work ; but likewife to their very Pofition. Thus it is obfervable, That whereas the Lympheducts, which carry a more Watery Liquor, are ftill placed on the inner Verge of the Barque, next to the Aer-Veffels: the Lactiferous and Refiniferous Veffels of Plants, to whofe Oylie Liquor a mixture of much Aer is incongruous; do ufually ftand, neither on the inner, nor the outer verge of the Barque; but in the midle. By which means, they are at the greateft diftance, and fo moft fecure, from the Aer; either that which enters the Barque at the Circumference, or from the Wood and pith.

I I. 5. AN D becaufe the Refinous Liquors of Plants are more Oily, than their Millyy; their fecurity therefore, from the approach of the Aer, is yet further contrived. In that in Pine, and other Refinons Trees, the Diametral Infertions are never found; or at leaft, not vifible: which yet in other Trees, are confpicuous; being thofe Parts, whore office it is, to introduce the Aer from the Aer-Veffels into the Barque.

12. 5. A G A I N, the Milky Liquors of Plants being thinner than the Refinous, and having a confiderable quantity of Water mixed with their $O y l$; hence it is, that in Milky Plants, as in Rbus, there are a greater number of Lymphadncts; and thofe ftanding nearer to the Milky $V_{e} \int e l s$, than they do in Pine and the like, to the Refinous. By which means they are better fitted to affufe their Aqueous Parts more plentifully to the faid Milly Liquor.

i3. 6. F R OM the Mixture of Watery Parts with the Oylie, it comes to pafs, that whereas all Lympha's, Mucilages, and Rogins are tranfparent ; the Aque-oleous Liquors of Plants are Milky or white. or otherwife Opacous. For the fame thing is the caufe of the whitenefs of Vegetable, as of Animal-Milk : that is to fay, a more copious mixture of Watery and Oily Parts per minima, or into one Body. For even the Serous and oylie Parts of Animal Milk, when throughly feparated one from the other, they become very tranfparent. So the Stillatitious Oyl of Anife Seeds, is moft tranfparent and limpid, even as $W a-$ ter it felf: yet there is a known fort of Wbite Anife-seed Water, as it is commonly called: that it is to fay, wherein the $O y l$, in diftillation, arifeth and is mixed more plentifully with the Water. And the $\mathrm{Wa}$ $t e r$, wherein the ftillatitious $O y l$ of any $V$ egetable is diffolved, becomes a perfect white Milk; as in this Honourable and Learned Prefence, I (a) See the have formerly had occafion to thew the Experiment.

$$
\text { 14. 5. of Mixture }
$$


14. 5. AND that the Milky Liquors of all Vegetables what foever, are more $O_{y l i e}$ than their $L y m p h a^{\prime}$, is moft certain. For all thofe Gums, which diffolve either in $O_{y} l$ or in Water, as Galbanum, and the like, are originally the Milky "fuyces of Plants. And if you take the Milk of any Plant, as for inftance, the Milk of common Sumach, or of any Tafte, Bitter, Aftringent, Hot, Cold, or any other whatfoever; and having well dryed it, and then fired it at a candle ; it will thereupon burn with a very bright and durable flame, even like that of Tar or Turpentine it felf.

15. 6. FR OM what hath been faid, we may likewife gather the moft genuine import of the word Gum, and the diftinction thereof both from a Rofin and a Mucilage. Firft, a $R o f i n$, is originally a Turpentine, or Acidoleous Liquor, having an exceeding fmall quantity of Watery Parts mixed therewith; and which, for that reafon, will not be diffolved in Water, but only in $O y l$. Of this kind are Maftick, Benzoine, Taccamabacca, and divers others, commonly, in our Bils to Apothecaries, called Gums. Yet in ftrit fpeaking they are all fo many Rofins.

16. 5. Secondly, a Gum, and every Oylie Gum, is originally a Milky Liquor, having a greater quantity of Water mixed with its Oyly Parts; and which for that reafon, will be made to diffolve either in Water or Oyl. Of this kind are Sagapen, 'Opopanax, Ammoniac, and others.

17. \$. The third fort of Gum, is that which is Unoylie, and which therefore diffolveth only in Water, as Gum-arabick, the Gum of Cherry-Tree, and others fuch like. This Gum, though commonly fo called, yet is properly but a dryed Mucilage : being originally nothing elfe but the Mucilaginous Lympha iffuing from the Veffels of the Tree. In like manner, as it doth from Cumfry, Mallow, and divers other Plants: and even from the $C$ ucumer. The $V$ effels whereof, upon cutting crofs, yield a Lympba, which is plainly Mucilaginous, and which being well dryed, at length becomes a kind of Gum, or rather a hardened Mucilage. In like manner, the Gums of Plum-tree, Cherrytree and the like, are nothing elfe but dryed Mucilages. Or, if we will take the word in its wideft fenfe, then all Gums are originally, either a Terebinth, or a Milk, or a Mucilage.

18. \$. I have likewife made divers Obfervations of the Tafts, Smells, and Colours of Plants, and of their Contents, fince thofe I laft publifhed: and that both for the finding out the true Canfes of their Generation, and alfo the applying of them unto Medical and other Ujes. Of which hereafter. 


\section{H A P. V. Of the Figuration of Trunks.}

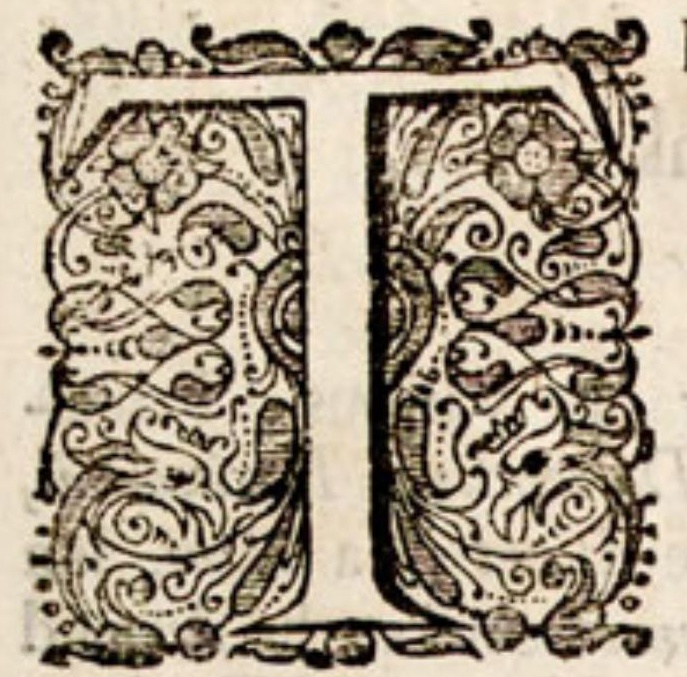

HE Fifth Head, fhall be, of the Figuration of Trunks. Which alfo, as well as the making of Liquors, dependeth upon the Structure of the Parts. As Firft, almoft all Sbrubs (cateris paribus) have a greater number of Aer-Veffels; and thofe of a fmaller Size; and confequently much fpread abroad, as moft eafily yielding to the magnetick Power of the Aer, according as we have more fully demonftrated, in fpeaking of the Vegetation of Roots: as in Elder, Hazel, Fig, Sumach, and the like. By which fpreading, the faid Aer-Veffels do fooner, and more eafily ftrike into the Barque, and fo produce collateral Buds and Branches, and that upon the firft rifing of the Body from the Root: that is, the Plant becomes a Sbrub.

2. 5. B U T if the faid Aer-Veffels are very large, they will not yield fo eafily to fhoot out collaterally; and fo the Trunk grows up taller and more entire: as in Oak, Wallnut, Elm,\&c. wherein they are exceeding large, is feen. Hence alfo the $V$ ine, if fupported, willgrow to a prodigious length. And Hops and Bryony, are fome of the talleft,amongt all Annual Growths: the Aer-Veffels of all which, are very large. Whereas Borage, and many other like Plants, although the Pores of their Paren. chyma, are vaftly wide, and filled with $S_{a p}$; yet becaufe their Aer-VeJels are fmall, they are therefore but Dwarf-Plants. Wherefore the tallnefs or advancement of a Plant or Tree, dependeth not upon the Plenty of Sap, how great foever, but on the Largenefs of the Aer-Veffels.

3. 6. AGAIN, as a Plant or Tree grows either Shrubby, or Tall and Entire, according to the Size of the faid Veffels : fo from their Pofition, doth it grow slender or Thick. So, where they keep more within the compafs of a Ring, as in Elm, and $A f$, , the Tree, in proportion, ufually grows taller, and lefs thick. But where the faid $V e \int f e l s$ are fpread more abroad, and efpecially are poftured in Rays, as they are in $O a k$, the Tree grows very thick. Becaufe the faid $V_{e}$ ffels thus ftanding all along nearer to the Infertions, there is a more teady and copious paffage of the Aer out of the one into the other; and fo the Diametral growth of the Wood is mote promoted.

4. 5. LASTLY, from the fame general caufe it is, That the Trunks of Vegetables are either Round or Angular. Thole of all Trees are Round. Becaufe the Barque, being here thicker, and the Aer-Veffels bound up with a greater quantity of Wood; the Aer hath not fufficient power to move them, and the Barque with them, into thofe various Pofitions or Figurations, as the Trunks of Herbs do yield to.

5. \%. Yet the caufe of the various fapes of the Trunk, is not the Aer alone; but partly, the Principles of the Plants themfelves, in conjution therewith; according to the predominion whereof, and chiefly of fome certain kind of Salt or Salts, as 1 thall hereafter (a) more particularly explicate) the Trunk is Square, Triangular, Pentangular, (a) B.4. $P_{i}$ or otherwife Figured. And thus much in general of the Figuration $1 . C b \cdot 6$ : of Trunks: 


\section{H A P. VI.}

\section{Of the Motions of Trunks.}

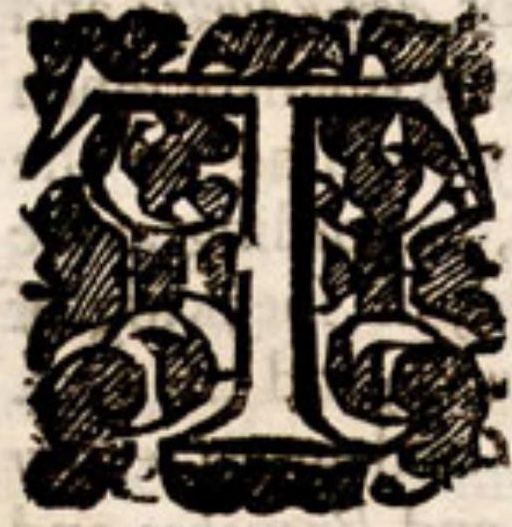

HE Motions alfo of Trunks are various. Principally Four; fc. Afcending, Defcending, Horizontal, and spiral. The caufe of the Afcent of a Plant, is a certain Magnetick Corre Jpendence betwixt the Aer and the Aer-Veffels of a Plant; the Motion and Tendency whereof, the whole Plant follows. This I have afferted, and I think, clearly demonftrated in my Firft and Second $2300 k$ kg of the Anatomy of Plants. I will here add this plain Experiment.

2. \$. Take a Box of Moulds, with a hole bored in the bottom, wide enough to admit the stalk of a Plant, and fet it upon ftilts half a yard or more above ground. Then lodg in the Mould fome Plant, for Example a Bean, in fuch fort, that the Root of the Bean ftanding in the Moulds may poynt upwards, the stalk towards the ground. As the Plant grows, it will follow, that at length the stalk will rife upward, and the Root, on the contrary, arch it felf downward. Which evidently fhews, That it is not fufficient, that the Root bath Earth to fhoot into, or that its Motion is only an Appetite of being therein lodged, which way foever that be: but that its nature is, though within the Earth already, yet to change its Pofition, and to move Downwards. And fo likewife of the Trunk, that it rifes, when a Seed fprouts, out of the Ground, not meerly becaufe it hath an Appetite of being in the open Aer; for in this Experiment it is fo already; yet now makes a new Motion upwards.

3. 5. BUT although the Natural Metion of the Trunk be to Afcend; yet is it forced oftentimes to Defcend. For the Trunk-Roots growing out of fome Plants near the ground, and fhrinking thereinto, like fo many Ropes, do pluck the Trunk annually lower and lower into the ground together with them; as may be feen in Scropbularia, Facobea, and many other Plants.

4. \$. I F thefe Trunk-Roots break out only about the bottom of the Trunk, as in the aforefaid Plants, then the Trunk gradually Defcends into the Earth, and is turned into a Root. But if itbe very fender, and the Trunk-Roots break forth all along it, then it Creeps horizontally; the faid Roots tethering it, as it trails along, to the ground; as in Strawberry, Cinquefoyl, Mint, Scordium, \&c.

5. 5. A S to their Spiral Motion, it is to be noted; That the Wood of all Convolvula's or Winders, ftands more clofe and round together in or near the Center, thereby making a round, and flender Trunk. To the end, it may be more tractable, to the power of the external Motor, what ever that be : and alfo more fecure from breaking by its winding Motion. 
6. 6. Wherefore, convolvula's do not wind by any peculiar $\mathrm{Na}$ ture or Genius, which other Trunks have not ; but becaufe their $P$ arts are difpofed fo, as to render them more fequaceous to the external Motor. Even as the Claspers of a Vine, having the like structure, have alfo a Motion of Convolution: whereas the Branches themfelves upon a contrary account, move in a fraight Line.

7.5. The Convolution of Plants, hath been obferved only in thofe that Climb. But it feems probable, that many others do alfo wind; in which, the main Stalk, is as the Axis to the Branches round about. Of which number, I conceive, are all thofe whofe Roots are twifted; a Motion we obferved in fpeaking of the Root. Whether it be fo, or not the Experiment may eafily be made by tying a Thred upon any of the Branches; fetting down the refpect it then hath to any Quarter in the Heavens : for, if it fhall appear in two or three Months, to have changed its Situation towards fome other Quarter; it is a certain proof hereof. And that hereby the Roots of many Plants become twifted; the Motion beginning in the Stalk, and ending at the bottom of the Root, which ftands always fixed in the fame place.

8. \$. The Convolution of Trunks, is made not one, but divers ways ; fome moving by South from Eaft to Weft; and others fromWeft to Eaft. Wherefore it feemeth, that as the Efficient Canfe of Convolution, is not within the Plant, but external: fo alfo, that it is not One, but that there are Two Great Efficients of this Motion; $f c$. the Sun and the Moon. Some winding together with the Sun, in its Diurnal Motion, (or, if the the Earth moves, then, Inclining to the Sun) by South from Eaft to Weft. And others winding with the Moon, in its Monthly Motion, from Weft to Eaft.

9. 5. This poffibly, may alfo be one fenfible way of diftinguifhing betwixt Solar, and Lunar Plants. Thus far, in general, of the Motions of Trunks.

\section{H A P. VII.}

\section{Of the Nature of Timber or Trunks, as they ferve for Mechanick Ufe.}

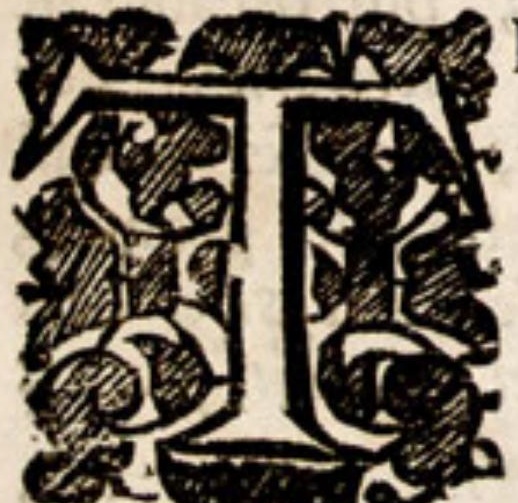

HE laft thing I purpofed to fpeak of, is, Thofe feveral 2ualities of Timber or of Trunks, by which they are fitted for Mechanical USe. As Hardne $s_{\text {, }}$ Softne $s_{s}$ Faftne $\int s$, Clevefomene $\int s$, Toughnefs, Brittle$n e f s$, Durablene $s s$, or any of the fame Qualities compounded. The Vifible Caufes. whereof are obfervable, Partly, in the Structure of the feveral Parts; $\int c$. the Infertions, sap-Veffels and Aer-Veffels; as to the Number, Size, or Pofition of any of them. And partly, in the Nature of the Parts; I mean fuch as is manifeft to fenfe. According to our clear and diftinct obferving of all which Caufes, we may underftand, Wherefore any Wood is made ufe of for any certain purpofe. And alfo, wherein fitly to apply it to further $U_{j e}$. In order to which, a

$$
\mathrm{A} \text { a compleat }
$$


compleat Hiftory of the Mechanical $\mathcal{U}$ es of Vegetables would very much conduce. I thall for the prefent give fome Inftances.

2. \$. AS First, fome Woods are foft, as Deal, and sallow. Yet from different Caufes. Deal, from the great Porofity of the Wood it felf, or the large Pores amongft the Sap-IefJels. But Sallow, from the great number of Aer-Veffels fpread all over it. And therefore, though they are both $\int o f t$, yet will not ferve for the fame purpofes; Sallow being well wrought upon, which way foever you cut it: but Deal, efpecially the white Deal, if it be cut crofs, it tears, and will never polifit or work fmooth.

3. \$. Again, in sallow, by the equal fpreading of the Aer-Veffels, the softnefs is equal or alike in all Parts. For which caufe it maketh an excellent Coal for Painters Scribets. Becaufe it doth not only make a light Stroak, but every where certain; and fo doth not difturb the even Motion of the Hand. For the fame caufe, shoomakers alfo make ufe of it for their Carving boards. Becaufe being every where equally foft, it turns not the edge of their Knives, Which Deal would prefently do; becaufe though very foft in fome places, yet in others 'its hard; that is to fay, on the inner Verge of every annual Ring of Wood, where the old sap-Veffels grow much more compact and clofe together.

4. 6. A G A I N, fome Woods are foft, but not fast; others are both, as Linn: its Softnefs, depending on the numeroufnefs and equal fpreading of the Aer-Veffels : its Faftnefs, on the clofenefs of the true Wood, and the thortnefs, and fmallnefs of the Infertions. For which caufe, it is of excellent ufe for many purpofes; and particularly, for fmall Sculpture: fuch as may fometimes be feen for the Frames of Looking-Glafes, or of fmaller Pidtures in Water-Colours.

5. 6. SOME Woods, again, are faft, and hard, as Elm. Its hardnefs depending upon the clofenefs of the Wood. Its faftnefs, Partly, upon the fame caufe; and partly, on the fmalnefs of the Infertions; as alfo on the fewnefs of the Aer-Ve/els in proportion with the Wood; and on the thwart and crofs Pofition of many of them. Hence it is, that Elm, of all others, is the moft Crofs-grain'd Timber; that is, cleaveth fo unevenly, to and fro, according to the cross Pofition of the
faid Veffels.

6. 6. Hence alfo it cleaveth the moft Difficultly. Even then, when it is without any Knots. For which reafon it is always ufed, as beft for the Hub of a great Wheel. As alfo for Water-Pipes, and for Pumps. Not becaufe it is the moft durable Wood; but becaufe it will not fplit or crack, either in the working, or afterwards. For the very fame reafon, it is ufed for Coffins; that is, becaufe, it will not Jplit in working: not becaufe it will endure longeft under ground; for Pales are always made of Oak. So alfo the Ladles and Soles of a Mill-wheel are always made of Elm; as alfo the Keel ofa Boat, $\int c$. left they fhould $\int p l i t:$ but the other Parts are made of $O a k$.

7. \$. It may here alfo be noted, That the Planks commonly called Groaning-Boards, lately expofed, as a kind of Prodigy, to the view and hearing of many People, were of Elm. The Aer-Veffels of this Wood, being, though not more numerous, yet more ample, than in any other Timber. So that upon the application of the Red-bot-Iron, as was ufual, and thereby the Rarifaction of the Aer and Watery Parts in the Timber; every Veffel became, as it were a little Wind-Pipe for 
their Expiration. And as a great many Drops falling together in a Thowr of Rain; fo a great many of thefe Pipes playing together, might make a kind of big or groaning noyfe.

8. 5. AS Elm, of all Woods, is one of the fafteft; So, on the contrary, of all bard Woods, Oak is the moft Cleavefome, or Jplitteth the moit eafily. The caufe whereof is, partly, the Largenefs of the Infertions ; and partly, the Diametral or Radiated Pofition of moft of the Aer-freffels: upon both which accounts, wherever a crack is once begun, 'tis eafily continued throughout the Diameter of the Trunk.

9. 6. AGAIN, fome Woods are hard, faft, and tough. So is $A f h$, and efpecially Beech. Hard and faft, from fome of the fame Caufes, as Elm. Tough not from the struiture, but from the Nature of the Parts; whofe Principles are united in a more exact proportion. Wherefore London-Cars have the Rings of their Wheels of Beech; becaufe it tears more difficulty than even $A$ f it felf. Whence alfo for large $S$ crezos, there is no Wood like it. But for Small Screws, of about an Inch Diameter, Birch is the beft; as being, though not fo hard, yet more tough.

10. 5. T HE more Brittle a Wood is, 'tis likewife ufually the more durable. So Oak, which, with refpect to its hardnefs, is not a tough, but very brittle Wood, is almoft as durable as any. Whereas Beech, Birch, and the like, although very tough; yet for Duration, are of no fervice; for there are no Woods will rot fooner: and therefore, though ftrong enough, yet unfit to make any standing Parts of Building, or of Furniture; efpecially in wet and moift places. Becaufe, thefe Woods, having a lefs proportion of $0 y l$, than there is in $O_{a k}$; they are apter to imbibe the moifture even of a dank Aer; by which moifture, they either Rot, or breed Worms, which deftroy them.

11. 6. HENCE it is, that what we call the Heart of Timber, as it is more brittle, fo alfo more durable; fc. Becaufe more Oylie. So that which is called the sap of Oak, is much more tough than the Heart, although the Heart be more durable. That is to fay, the older the Wood is, the Watery Parts are the more evapourated, whillt the Oylie ftill remaine, as a kind of Tincture or Extract in the Wood. Even as we fee, that the older seeds of any one Kind, are more $O y$ lie than thofe that are green and young. So that the Oylie or Rofinous Parts of the $S a p$, are a kind of Embalming to the Heart, or older Part of a Tree, fecuring it from the deftructive impreffions of the Aer. For which Caufe it is, that $O_{a k}, Y_{e m}, C_{o c u s}$, Guajacum, \&c. which are Oylie Woods, have always much Heart, whereas Birch, Alder, Beech, Maple, which are very Unoylie, have never any Heart.

12. 5. F R O M hence likewife we may underftand the Caufe of the Toughnefs of Flax: what we call Flax, being only the sap.Veffels, or Lignous Fibres of the Barque. And generally, the Barque of any Tree, as of Willow (whereof are ufually made a fort of Ropes) is very tough. The $V$ effels being here younger, and lefs $O$ ylie than in the Wood. So likewife Hemp, is nothing elfe but the sap-Veffels of the Barque of the Plant fo called. And Scotch-Cloath, is only the Houfewifery of the fame Parts of the Barque of Nettle.

13. \$. WHENCE it is very probable, that there are many other Plants, as well as the above named, whereof might be made good Tonv. And of fome, efpcially in fome refpects, better than of Flax it felf. Becaufe that even Hemp, although it will not make fo $\mathrm{A} \mathrm{a}_{2}$ fine 
fine a Staple, as Flax (for all our fine Hollands are made of Flax) yet Flax, which is but of the fame finenefs as Hemp, will never, by all the Art yet known, be made fo white as Hemp is made. The Qualities therefore of the beft Tow, that can be in Nature, are that the Staple be long, fmall, tough, and wobite. So that if in the Barque of any Plant, we can find thefe 2 ualities, or any of them, to excell; we may be fure, it will be of better ufe, in fome refpects, for the making of cloath, or other purpofe, than Flax it felf.

14. \$. I W I L L conclude with one Inszance more, and that is as to Grafting. The good and happy fuccefs whereof, doth certainly depend upon the fuitablenefs or refpondence betwixt the feveral Part', of the Stock and $C_{y o n}$; as the Barque, Wood, and Pith; and that both as to the Number, size, and Pofition of the faid Parts, and of their feveral Pores or Veffels : according to the degrees whereof, the Conjunction (cateris paribus) will be more or lefs profperous. So that of all fuch conjunctions as are found to be apt and taking, and which fome have learned not without long Practice and Experience; another, only by comparing the Branches of Trees together, may with little trouble, and in much lefs time, inform himfelf. By the fame means, fome Conjundions which feem to be ftrange, as 2uince and Pear, White Thorn and Medlar, \&c. do yet, by the refpondence of their Parts, as well as by Experience, appear to be good. And there is no doubt, but that many Conjunctions not yet tryed, or not known to have been fo, may upon the fame ground, be tryed with good fuccefs.

15. 6. The chief Ufe of Grafting and Inoculation, is, That they Accelerate the growth of Good Fruit. The Caufe whereof, is the Knot, which is always made in the Conjunction. By means of which, all the Sap is ftrained, and fo afcendeth up into the Graff or Bud, both Purer and in lefs Quantity; and is therefore better and fooner concocted. Hence, the fmaller the Fruit of any Tree, though it be not the beft, yet the $S$ ap being there, in lefs 2antity, is the fooner ripe. On the contrary, where the Sap afcendeth too freely, it doth not only retard the growth of the Fruit, but produceth Barrennefs; as is feen in thofe luxuriant Branches, where it runs all up to Leaves. Hence alfo Vines, by Bleeding, become more Fruitful: that is, by the Effufion of Part of the $s a p$, there is a more eafier melioration of that which remains. Even as Pblebotomy doth oftentimes produce a more healthful and better Habit of our own Bodies. To conclude, the leffening the Quantity, and thereby the melioriation of the afcending sap, by Knots, is Natures own contrivance; as is feen in sugar-Cane, Corn, and other Plants. 


\title{
THE \\ A N A T O M Y \\ $\mathrm{OF}$ Or \\ LEAVES, FLOWERS, \\ FR U I T S and S E E D S \\ In Four Parts. \\ The FOURTH BOOK.
}

By $N E H E M \mathcal{F} A H G R E W$ M.D. Fellow of the ROYAL SOCIETY, and of the COLLEGE of PHYSICIANS.

$$
\text { LONDON, }
$$

Printed by $W$. Rawlins, 1682 .

\author{
Mo.Bot.Garc'en,
}

1902. 


\section{T H E \\ CONTENTS. OF THE \\ Firlt Part.}

C H A P. I.

Of the Protections and Folds of Leaves.

CHAP. II.

Of those Things which appear upon the Surface of the
Leaf.

\section{CHAP. III.}

Of the Figures of Leaves; and the Apparent Pofition of the Fibres.

\section{H A P. IV.}

of the Parts and Texture of the Leaf.

\section{CHA P. V.}

Of the Duration of Leaves, and the Time of their Generation.

\section{CH A P. VI.}

Of the Manner of the Generation of the Leaf. Where alfo, that of the Two General Parts of a Plant, $f c$. the Lignous and Parenchymous, is further explain'd. 


\section{To the Honourable}

\section{Robert Boyle Efq;}

S I R,

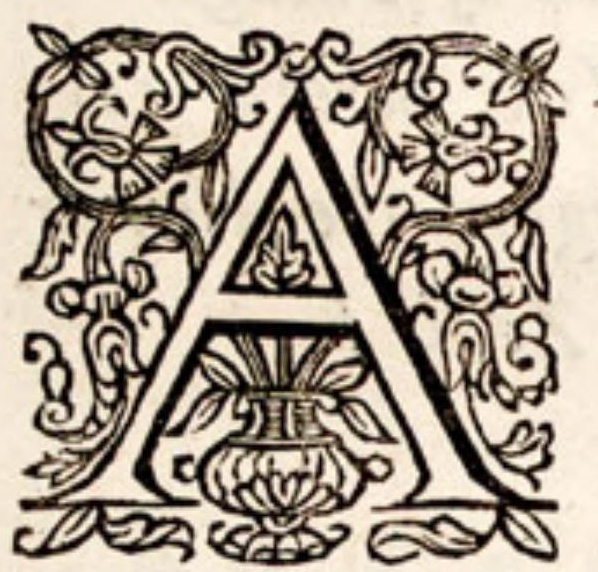

FTER I bad finifhed the foregoing Books, In which, I conceive, as far as Glaffes will yet lead us, I bave clearly Defrib'd and Delineated the Structure of a Plant; and have endeavour'd, in foms part, to Vufold the Reafon and Scope of Nature there. in: I was willing to fit down, and leave what remained, to the Improvements of the Prefent and Succeeding Ages.

But in Difcourfe upon this Subject, You bave been pleafed frequently to infift, That I Sould by no means omit, to give likewife, fome Examples of the Mechanifme of Nature in all the other Parts. The Performance whereof therefore, next to the Obedience I owe to the Royal Society, is to be looked upon, as a Due to the Authority which Your fudgment bath over me.

This I bave Said, that, if what is herein done, Shall prove acceptable unto Learned Men; they may knom, To whom they are oncemore to give their Thanks: After they havie fo often done it, upon (a better fcore) the Publibing of Your omn Excellent Works. In which, there feems to be a Queftion, Whe. ther Your Continual Endeavours, to enlarge the Bounds of Natural Knowledge, or Your Succelfes therein, have*been the Greater. So that, whereas Nobility in fome, doth only 


\section{The Epiftle Dedicatory.}

only ferve to lift them, like Jupiter's Satellits, out of fight: You, by giving a greater Light, have drawn all Mens Eyes upon You. And whileft there are many, in all Ages, fond of Prebeminency in the Conduct of Popular Affairs; who yet rarely bit the Mark they aim at; or aim at That they pretend: You bave thought fit, rather to leparate Your Self, to that more Innocent, and more Noble Sort of Wifdom, which lieth, not in the Arts of Conceiling, but in Difcovering, the Truth of Things.

That we may have many to imitate You berein, cannot but be heartily wifh'd by all, who regard the-Honour of their own Country; as it is, with much Zeal, by

Sir,

Your moft obedient

Servant

NEHEMFAH GREW. 


\section{T H E}

\section{A N A T O M Y \\ O F}

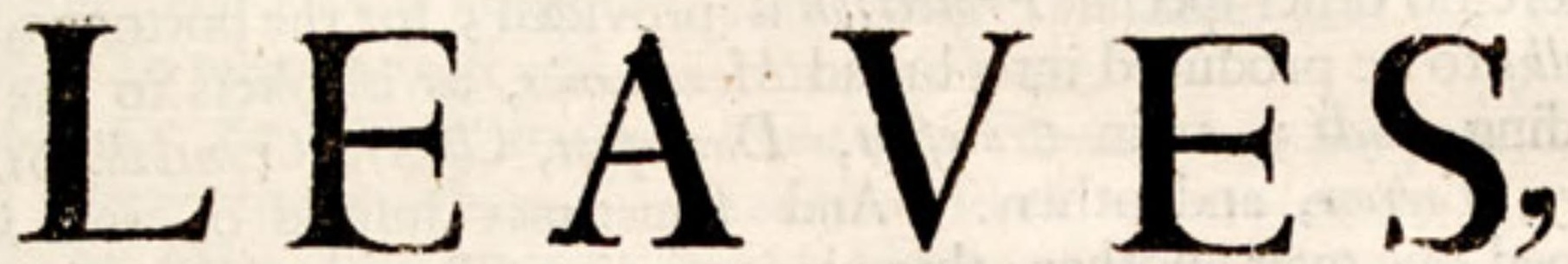

P R O S E C U T E D

With the bare EYE,

And with the

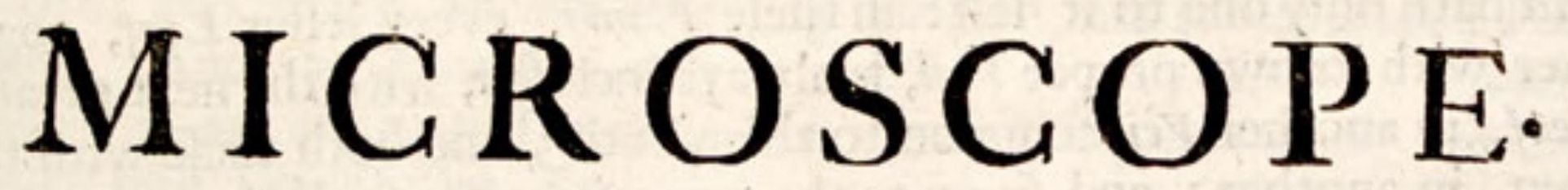

Read before the Royal Society, OCtob. 26. 1676.

\section{P A R T I.}

\section{H A P. I.}

\section{Of the Protections and Folds of Leaves.}

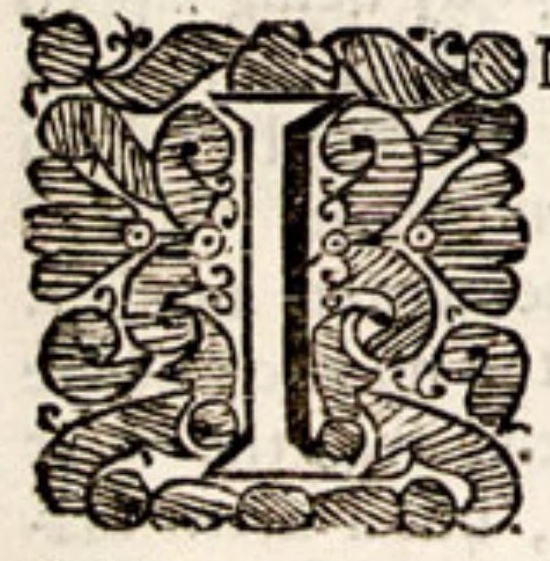

N T HE General Anatomy of Plants, I have affigned one whole Chapter (a) to the Germen and (a) Lib. $\dot{1}_{\text {. }}$ Leaf. Since then, I have occafionally made divers $C h .4$. Remarques of the fame; both with the Naked Eye, as there, and alfo with the Microfcope. The Principal whereof, I thall here fet down; without repeating any from thence; or obliging my felf ftrictly to the Order there ufed.

2. \$. That which in a Germen, firft occurs to the Eye, is the Protection of the Leaves, or the various Methods which Nature takes to preferve them from the Injuries both of the Ground, and of the Weather. To the Inftances formerly given, I fhall add thefe that follow. 
3. 5. AND Firft, it is obfervable of the young Buds of Ammi, that left they thould be bruifed, or ftarved, upon their firft Eruptiward; each Bud, againft they are couched, as Firn is rowl'd, inLeaves, and moft exactly laid up within stalk of the foregoing duced: Juft as the Child in the Womb, the Membranes thence proKnees; or as it is afterwards Womb, lies with his Head againft his Nurfe. And it is a general Rule of Nature whe Armes of the the Leaves are fo long that they of Nature, where the stalks of where no other fpecial Protection cannot lap one over another, and stalks to be produced into broad is provided; for the bottoms of the ceeding Buds; as in Cromfoot, Doveranes, as Blankets to the fucberry, Tarrow, and others. And fometimes laver, Cransbill, Strawlapped one over another, there is one entire Skin, produced from the
Stalk, in which as within a secundine, the which, in its Growth, it gradually 4. 6. THE fame is alfo obly breaks open.

all other Plants of this Kindred, win Dock, Sorrel, Biftort, and $V$ eil or Secundine is not Kindred; with this difference, That every hath its Original Distinct from it. And the Stalk of the Leaf; but

Tab. 41. Bud hath only one to it felf: in thefe Plants, every leffer $L$ er, every ther with its own proper $V$ eil, is always inclofed, with ther Leaf, togeLeaf, in another Veil common to them next, in another; and fo on to them thin, and have very few Vefjels; being fo Thefe $V_{\text {eils }}$ are extream Skins. For which reafon, there is always found meer tranfparent Gelly, between every Leaf, and its $V_{e} i l_{\text {, }}$ and a Mucilage or clear The one, thus preferving the branes of the Eye) from drying and (as do the Humors and Membecoming ufelefs for the Protection of the Plant.

5. 5. THE Orchis, and other Plants of this kindred, becaufe they Shring and Flower early, when the mornings are cold, have a double having no Hairs growing on them, are of fome Herbs (as of Plantain) the Nettle hath Bastard-Leaves, or Interfogl with Hairy Thrums. And for the prefervation of its Stings.

6. 5. A NOT HER Sort of Protection is feen in Wild Clary,
White Archangel, and other Plants of a like Shape. In which,

Tab.41. $\begin{aligned} & \text { greater Leaves do ftill cover and inclofe the leffer, not by being lapped } \\ & \text { over them, as where the Leaves are more }\end{aligned}$ Double Fore-Curl at the bottome more numerous, is ufual; but by a the little Under-Bud is embraced every two greater Leaves; by which 7. \$. THE Leaves of Onions are kept fafe and warm.

Thefe Pipes are every where entire, are all Pipes one within another.

Tab. 42. they have a fmall Aperture; comm, faving about the middle, where minute in the Centre: not ginally formed, for : not being a forced Crack, but a Door ori-

8. 6. THE LAS T Ing of every leffer Pipe, out of a greater. Common sumach. The Buds whell give, is that which is remarkable in

Tab. 4i. appears follicitous in a peculiar mann, being exceeding tender, Nature whereas in other Plants, peculiar manner, for their prefervation. For behind thestalks oflants, they are well enough fecured only by ftanding very 
very Body of the Stalk; as entirely, as a Kernel is within an Apple, or a Fotus in the Womb. From whence it comes to pafs that the Bafis of every stalk is extreamly fwelled, as going Great with a Bud.

9. 5. U PON THE removal of thofe Parts, which are contrived for the Protection; the Foulds and Compofture of the Leaves do next appear : all which are moft aptly fuited both to the Number and Shape of the Leaves, and alfo their Pofition upon the Branch. In the Firft $2300 k$ (a) I have given Examples of thefe Eight Sorts, fc. the (a) Ch. 4. Plain Lap, the Plicature, the Duplicature, the Multiplicature, the Single Roll, the Double Back-Roll, the Double Fore-Role, and the Treble-Tab.42. Roll. To which I thall add Four or Five more.

10. 6. And Firft, in fome Plants, as Ground-Ivy, St. Fobns Wort, and divers others, where the Leaves are fmall, pretty numerous, and grow by pairs, they have no Fould, but ftand Flat and Tangent, like a pair of Battledores clapt together.

11. S. They have the like Pofture in Baum; faving, that here the Edges of the Leaves are a little curled backward. Not Rolled, a Curl being but the beginning of a Roll. So the feveral Labels of a Grounfel-Leaf are all laid in a Back-Curl.

12. \$. The Leaves of fome Plants, as Horehound, Whito Lamium, Nettle, and others, are likewife only Tangent, but are fet with a ForeCurle. And the feveral Labels or Scallops of the Leaf of Common Crounfoot, are all $C_{u r l e d}$ Inward. But thofe of Hepatica aurea, are compofed into Double Fore-Rolls.

13. 5. THE Leaves of Sage, Scabious, Red Lamium, Lychinis Sylveftris, and others, are neither couched one over another, as in the Bow-Lap; nor plated, as in the Flat Lap; but being loofely foulded, of every pair of Leaves, the half of one is reciprocally received between the two halfs of another, and may therefore be called the Cleep. $T a b_{0} \mathbf{4 2}^{2}$ A Poftion very well fuited to the Smalnefs of their Number, and the Equality of their Size, not fo well agreeing with the Bow-Lap; and the fomewhat inward Pofture of the Fibres, not allowing the Flat Lap. Sometimes, as in Syringa, where the Leaves are broader, the Cleep is joyned with a Fore-Curle.

14. 5. THE laft I thall mention, is the Plaite-Roll, as in the $\mathbf{L} a$ patbum Alpinum, which fome call Englifh Rhubarb. The Leaves whereof are fo very large, and the $s i b r e s$ fo prominent; that befides and under the two Back-Rolls, they are alfo laid in feveral Plaits, and under thofe Plaits, again with leffer ones, all moft exquifitely Tucked up between the faid Fibres: So, as neither to bruife the fame, nor yet to leave any Vacuity: whereby every Leaf, and the whole Bud, lie clofe and round within their Veils. 


$14^{8}$ The Anatomy BookIV.

\section{H A P. II.}

\section{Of thofe things which appear upon the Surface of the Leaf.}

$T a b .43$.

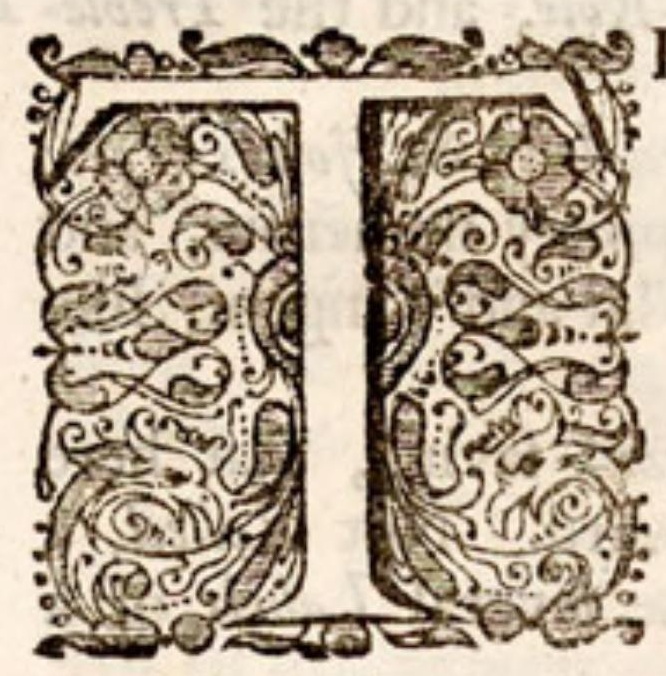

HES E are Globular Excrefcences, Spots, Hairs, Thorns and Prickles: of all which, except spots, I have fpoken in the Appendix to the Chapter of Leaves in the Firft 2300 k.

2. 5. Of the Globulets, it may here be further noted, That thofe which are white, and lie fometimes like a fine Powder upon the Leaf, were once tranfparent, as in Bears-Eear; their cleer Liquor beeing now evaporated to anExtract or White Flowers. This, if licked off, will give you the Taft of the more E/fential Content of the Plant; different from that perceived in chewing the Leaf.

3. 5. For the obferving of them, it may alfo be noted, That although they often grow on both fides the Leaf alike; yet fometimes, as in Ground-Ivy, only or chiefly on the Back-Side. And that in many Plants, where the elder Leaves have none; on the young Buds they are very numerous; as in Corin Tree, Sorrel, and others.

4. 5. A S for spots, the fmaller ones are obfervable not only in st. Fohns-morts, (in which Plant only they are commonly taken no-

Tab. 43. tice of) but alfo in Rue, Ground-Ivy, Pympernel or Anagallis, and divers other Plants, when held up againft the Light. The original whereof feems to be, at leaft in fome, from the Globulets above mentioned; that is, when they break and dry away. So the Spots of RueLeaves, which in the Reflection of Light look black, but upon the Trajection thereof are transparent, are fo many little Holes, pounced half way through the thickners of the Leaf, and feem as made, by the breaking and drying away of as many Globulets. Whence alfo, as the Globulets are beft feen in the younger Leaves, fo thefe Spots in the elder.

5. 5. BESI DE S thefe, and fome others (as thofe in LadiesThiftle) which are Natural to the Leaf; there are alfo fome $S$ pots, or

Tab. 43. rather Streaks, which are Adventitious; as thofe in the Leaves of Sonchus. The Caufe whereof, is a fmall flat Infect, of a grey Colour, and about $\frac{1}{6}$ th of an Inch long. Which neither ranging in bredth, nor ftriking deep into the Leaf; eats fo much only as lies juft before it, and fo runs fcudding along betwixt the skin and the Pulp of the Leaf; leaving a whitifh Streak behind it, where the skin is now loofe, as the meafure of its Voyage.

6. 5. THE Original and feveral kinds of Thorns, Thave deferib'd in the above faid Appendix. I only add, that the very Leaves of fome Plants, if they ftand till the fecond year, are changed into fo many Thorns, as in the Furz. 
7. \$. They are of Ufe, not only for the Protection of the Bud; but likewife, forthe fupport of the Plant; as is obfervabie in thofe Climbers, which are neither ftrong enough to ftand of themfelves; nor yet, from their fragility, are capable of winding about another, without being torn all to pieces. For which end alfo, thefe Thorns grow not like Buds, erected; but poynt all downwards, like fo many Tenters or Hanging-books: as in the Bramble, chiefly on the stalks; and in Clivers, Tab. 43 . alfo on the Leaves themfelves; whereby they catch at any Thing that ftands next them; and fo, although fuch 0 im and feeble Plants, yet eafily climb to a very great hight.

8. \$. OF T HE feveral Figures of Hairs, and their Ufe, I have B. r.Ch.4. alfo fpoken. As to one Ufe, $f c$. the Protection they give to the Leaf, Tab. 43 . I thall here further note, That the defign of Nature, is the more evident if we confider, That all Leaves are not alike Hairy, nor at all times, nor in every part : but differently, according to their Age, Subfance, Texture, and Foulding up. Their Age; for there are many young Buds covered with a thick warm Hair, which afterwards dries up and difappears, as ufelefs; as thofe of the Vine, Golden Liverwort, \&c. Their Subftance; fo thofe Buds which are tendereft, and would fooner feel the cold, if naked, have the fulleft Hair; as of Thiftle, Mullen, Burdock, and others. Their Structure; therefore thofe Leaves, whofe Fibres ltand more prominent or above their surface, left the cold thould nip them, are covered with greater Store of Hair; as in Motb-Mullen, Garden-clary, and the like. And their Fould; it being obfervable, That thofe Leaves which are folded up inward, have little or no Hair on their inner, but only on their Back-Sides, which are open to the Aer; as is vifible in Corin, Warden, Golden Liverwort, and others.

9. 5. Add hereto, That where there is Store of Hair, Nature is the lefs follicitous for other Covers; and where there is not, the is more. So the Leaves of Beans and Peajen, of Nettle, Plantain, \&c. not being Hairy, have each a Surfoyl, or elfe certain Hairy Thrums, to protect them. And thofe Plants which have neither, are fuch as have a Hotter Fuyce, and folefs fubject to the impreffions of $C_{\text {old }}$, as Speerwort, Scurvygrafs, Watercrefs, Fenil, and moft of the Umbelliferous Kind.

I0. 5. Hair is of ufe to preferve young Buds, not only, from the cold Aer, but alfo from too much Wet; which, if it were contiguous, efpecially in Winter, would often rot and deftroy them. But being made to ftand off in drops at the ends of the Hair, doth not hurt but refrefh them. Thus doth Nature make the meaneft Things fometimes fubferve to the beft Ends. 


\section{HA P. III.}

\section{Of the Figure of the Leaf; and the Apparent Pofition of the Fibres.}

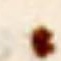

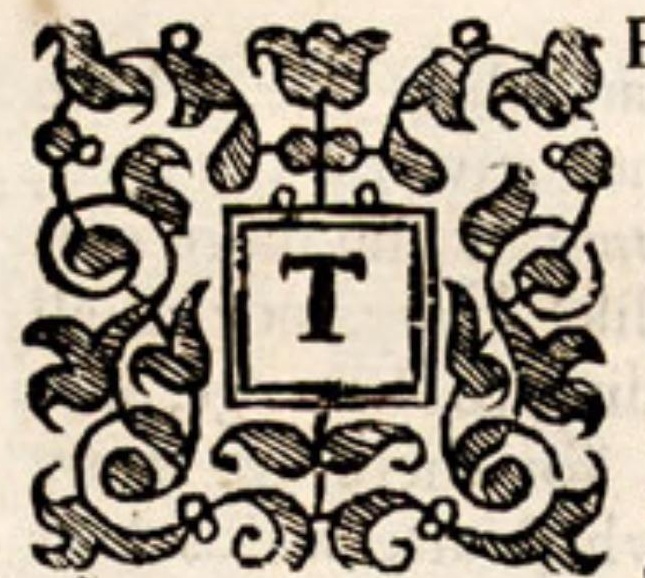

H A T which in the Leaf offers it felf next to be obferved, is its Figure. This is infinitely varied with the feveral Kinds of Plants: and there are fome, which have Leaves (befides the two firft Diffimilar ones) of Two Kinds or Two diftinct Figures; as the Bitter-Sweet, the common Little Bell, Valerian, Lady-Smocks, and others. For the Under Leaves of Bitter-Sweet, are Entire; the Upper, with two Lobes : the Under Leaves of the Little Bell, like thofe of Pancy; the Upper, like thofe of Carnation, or of Sweet-William. And in fome Plants, Nature affecteth a Kind of Irregularity; the Leaves whereof are of no one certain Figure; as in Dragon, Peony, Biflops-Weed, \&c.

2. \$. B U T the Leaves of moft Plants, have a Regular Figure; and this Regularity, both in Length and Circuit, always defineable. In Length; by the Proportion between the feveral Leaves upon one

Tab.46. Stalk, or between the feveral Lobes upon one Leaf. So the Leaves of Clematis sylv. major, which ftand by Ternaries, fhorten by equal Proportions, that is to fay, if, the chief Fiber of each, be divided into equal Parts; their feveral Lengths are not as Ten,Eight, and Four; but as Ten, Eight, and Six. So the Lobes and Fibers of Clematis Virginiana Hedere folio, of Artenuifa, \&c. Thorten in like manner by equal Proportions. The fame is obfervable in meafuring, upon a Goofeberry-

Tab.46. Leaf, from the Poynt of the firft Lobe, to the firft Angle; from thence, to the fecond Poynt; from thence, to the fecond Angle; and from
thence to the third Poynt.

3. \$. But in many, the Proportion is different. So in the Leaves of the LefJer Maple; the fhortning of the fmaller Lobes, with refpect to the middelmoft; is not Equal, but Double to that of the middlemoft, with refpect to the Greater. For if their chief Fibres be divided into Equal Parts, they are as Eleven, Nine, and Five. On the contrary, in the Leaves of Althaa fruticofa Pentaphylloidea, the middlemoft Lobes fhorten by a greater Proportion than the Leaft; all three being as $\mathbf{T e n}_{2}$
Fourteen, and Twenty.

4. 6. W I T H refpect to the Circumference, the Figure of moft Leaves is very Complex. Yet $\mathrm{T}$ wo things are evident. Firft, that all Regular Leaves, are defined or meafured out by Circles; that is, by the Arches or Segments of feveral Circles, having either the fame, or divers Centers and Diameters. Secondly, That the Length of the Leaf, or of the chief Fiber thereof, is the standard Meafure for the Diameters of thefe Circles: thefe being either its full Length, or certain equal parts fubftracted, or multiplied; as half its Length, or its Length
and half, \&c. 
5. 6. TO make this appear, I thall give feveral Inftances: of fome, where both the Edges are of one Meafure; and of others, where they are different: And of both kinds, where they are meafured by fewer'
and where by more Circles.

6. \$. The Leaf of Lagopus major fol. pennat. is meafured by One Circle, the fame on both Edges, whofe Diametre is Thrice the Length
of the Leaf.

7. \$. That of syderitis Salvie fol. by Two Circles: the Diameter of the Lower, being Twice the Length of the Leaf; of the upper, Tab. 4 s: that is, with their Centers fome where Circles are drawn Outward; Fiber of the Leaf

8. \$. That of Orange-Tree, is alfo meafured by $\mathbf{T}$ wo Circles : but one of them repeated with Oppofite Centers. That next the Cone of the Leaf, is drawn Inward; that is, with the Center no where upon the Leaf, but without it. The Diameter hereof is juft the Length of the Tab. 44 . Leaf. The midle part of the Edge is meafured by the fame Circle, only drawn Outward. The lower Circle next the stalk, is drawn Inward, as the upper; and its Diameter Three times the Length of the
Leaf.

9. 5. The Leaf of the Venetian Vetch, is meafured by Three Circles. That next the Cone, drawn Inward; the Diameter whereof, is Twice the Length of the Leaf; the next is drawn Outward; where- Tab. 44\% of the Diameter, is juft the Length. The third or lowermoft, is drawn alfo Outward; and its Diameter, half the Length. So that they all leffen by an Equal Proportion.

10. 5. The Leaf of Great Laferwort, is alfo meafured by Three Circles; all drawn Outward, and one of them Repeated. The Diameter of that next the Cone, is Half the Length of the Leaf; of the Tab. 45 : next, Thrice the Length; of the Third, juft the Length; the lower-
moft, is the fame with the Firft.

I8. 5. That of Broad Leav'd Laferwort, is alfo meafured with Three Circles; and one of them repeated with oppofite Centers. The Diameter of the Firft, is Half the Length of the Leaf; of the Second, Twice Tab. 44 .
the Length; of the Third, juft the Length: all of ward. That next the Stalk, is the Length: all of them drawn OutInward.

12. \$. The Figure of the Leaf of the Cornelian Cherry, is exactly that of the foregoing, Inverted: the fame meafure there beginning at the Tab. 44. at the Bafe: as by comparing their Draughts together may be ob-
ferv'd.

I3. 5. IN A L L, the foregoing Examples, both the Edges of the Leaves have the fame Meafure. But they have oftentimes, different
ones; as in thefe that follow.

14. \$. The Leaf of Althea fruticofa, is meafured by ThreeCircles. The left Edge (as the Leaf lies with the backfide upward) by One Circle, but Twice repeated. For the Diasneter of the Firft, is the Length of Tab. 48 : the Leaf; the Second is the fame, but drawn upon another Center; the Third alfo the fame, but drawn Inward. The right Edg, is mea-
fur'd by Two Circles: the Diameter of the Firft, being the Length of
the Leaf; of the Second, Half the Length. the Leaf; of the Second, Half the Length. 
15. 6. That of slack Poplar, by Three; and each Edge by Three repeated. On the left, the Diameter of the Firft, is the Length of the

Tab. 45. Leaf; of the Second, Half the length; of the Third, the Length and Half. The Meafure of the right Edge, is that of the left, Inverted: the fame Meafure there beginning at the Bafe, and ending at the Cone; which here begins at the $C_{o n e}$, and ends at the Bafe.

16. \$. That of Doronicum, is meafured by Three Circles, whereof, one is repeated Once; and another Thrice. The right Edge by Two, and One repeated. For the Diameter of the Firft or that next the Cone; is the Length of the Ieaf; the next is the fame, but drawn Outward;

Tab. 45. the Diameter of the Third, is Half the Length. The left Edge, by Three Circles; whereof One is repeated on the fame Edge, and Two, the fame, as on the other. For the Diameter of the firft, is the Length of the Leaf; of the Second, Four times the Length; the Third, the fame as the Firft; and of the Fourth, Half the Length.

17. \$. Laftly, that of Mountain Calamint is meafured by Four

Tab.45. Circles. The left Edge, by Three Circles, of which, the lowermoft is once repeated: the right Edge alfo by Two; whereof the nether is likewife once repeated.

18. 5. It may feem, even from thefe Inftances, no very unobvious Conclufion; That all Crooked Lines, Spiral, Helick, Elliptick, Hyperbolick, Regular, or Irregular; are made up of the Arches of Circles, having either the fame, or divers Centers and Diameters. And, as otherwife, fo from the Contemplation of Plants, men might firft be invited to $\mathrm{Ma}$ thematical Enquirys.

19. 5. T OGETHER with the Figure of the Leaf, the Pofition of the Fibers, as it is apparent before Diffection, is obfervable; efpecially on the back of the Leaf. Whereof I thall add, to what I have faid in the Firft $2300 k$, the following Remarques.

20. \$. Firft, that there are fome Leaves, in which the firft Collateral Fibres make Right Angles with the Great one in the midle: as the Great-Maple, the Great Celandine, Chondrilla, and the reft, or many, of the Intybous Kind; with fome few others. But that generally all the chief Fibers of a Leaf, make Accute Angles together : both where they ftand collateral with the midle Fiber, as in Strawberry; and where they all part at the Stalk, as in Mallow.

2 I. 6. Again, that of thefe, there are fome few, any two of whofe Tab.46, o Defining Fibres making two Rays of equal Length, take in One Eighth Part of a Circle, as in Mallow; and in fome one Tenth: but in moft 47. they take in either one Twelfth part, as in Holy-Oak; or one Sixth, as in Sirynga. So that where the Fibres ftand Collateral with one in the the midle, if you fuppofe them to be drawn out at Oppofite Angles; or where the chief Fibers part at the Stalk, you only take in the Stalk; you will thereby divide a Circle into Eight, Twelve, or Six equal Parts; as in sirynga, the Vine and others. And fo likewife, where there are

Tab.46,47. feveral Sprigs upon one Stem, as in Fenil, Hemlock, and the like: as will beft be underftood by the Figures. 


\section{H A P. IV.}

\section{Of the Parts and Texture of the Leaf.}

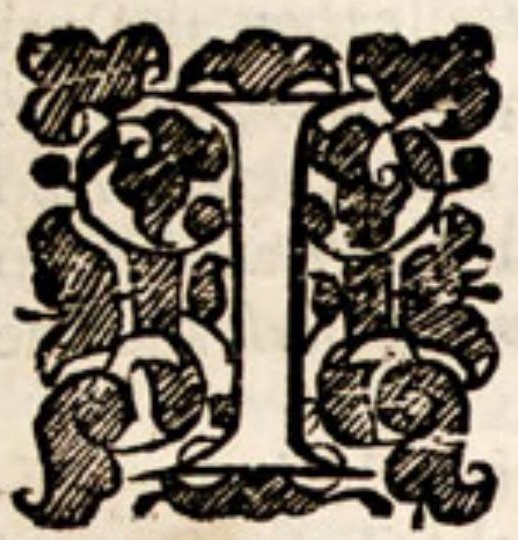

COME next to obferve the feveral Parts, whereof the Leaf is compoled : and firft the skin. This being ftript off the Leaf, although to the bare Eye it looks no otherwife than a skin of Ifinglafs: yet being viewed through a good Glafs, with a clear and true Light, and in an advantagious Pofition; it appears to confift not only of Organical Parts, as do the skins of Animals; but thefe alfo Regularly mixed together; that is, of Parenchymous and Lignous Fibres, all very curionfly interwoven as it were, into a piece of admirably fine white Sarcenet : as in Flag, Tab.48. Tulip, and the like.

2. 6. From hence, it is eafy to conceive how the Shins of all Plants, as well as thofe of Animals, are perfpirable; $f c$. between the feveral Fibers of which they confift. But as the Skins of Animals, efpecially in fome Purts, are made with certain open Pores or Orifices, either for the Reception, or the Elimination of fomething for the benefit of the Body: fo likewife the Skins, of at leaft many Plants, are formed with feveral Orifices or Pafs-ports, either for the better Avolation of Superfluous Sap, or the Admiffion of Aer.

3. 6. THESE Orifices are not in all Leaves alike; but varied in Bigness, Number, Shape, and Pofition: Serving to the different Nature of the Plant, or Leaf; and giving the Leaf, as it were, a different Grain. Princes Feather, i.e. a Sort of Sanicle, they ftand only on the Edges of the Leaf; but are very ample. In the White Lily, they are Oval, very white, and each furrounded with a flender white Border. They ftand about a $6^{\text {th }}$ or $8^{\text {th }}$ part of an Inch diftant,as they appear through Tab. 48 . a good Glass, all over the Leaf, but not in any regular Order. Thefe Orifices are the caufe of the Greyilh Glofs on the upper fide the Leaf: for the Back-fide, in which there are none of them, is of a dark Sea-Green.

4. 5. In the Leaf of Pine, they are alfo Oval, and about the fame Bignefs and Number, as in that of a Lily; yet without a Border. But their Pofition is very Elegant, ftanding all, moft exactly, in Rank and $T_{a} b .48$. File from one end of the Leaf to the other.

5. 6. NEXT TO the skin,lies the Pulpy part of the Leaf; which by the fame latitude, as $\mathcal{U}_{\int e}$ hath taught us in many other Words, $\dot{I}$ call the Parenchyma. This Parenchyma or Pulp of the Leaf, like the Pith, and all other Parenchymous Parts of a Plant is made up of incomparably fmall $C_{y}$ lindrick Fibres: and thefe Fibres, in moft Leaves, woven and woun'd up into little Bladders.

6. 5. The Bladders are here of feveral Sizes, as in the Pith : but generally more vifible in the Stalk, than in the Body of the Leaf. Va-Tab. 49 ;
ried, as in the Pith, fo here, not according to the Size, but the Nature of the Leaf. So in Common Dock, and Moth Mullein, both Great

$$
\text { C c leaves, }
$$




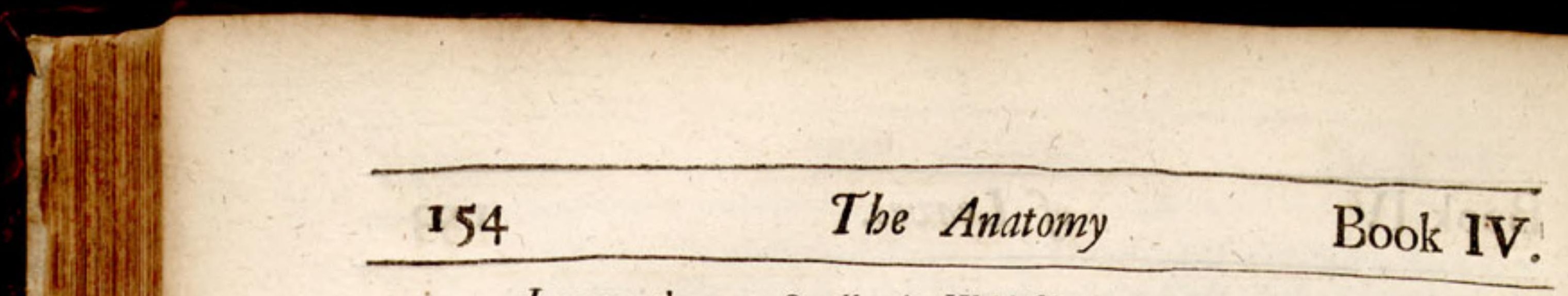

Leaves, they are Small; in Wild Clary, a Lefler Leaf, they are very Tab. 50. Large. In the Body of the Leaf, fometimes the Sides of the greater
Bladders, are made up of leffer ones; as in Borage.

7. §. In fome Leaves, thefe Parenchymous Fibres are all drawn clofe up together. In the Former, they are as the Threds in the Open-work of Bone-Lace; in Thefe, as the fame Threds, in the Cloth-work.

8. 5. The Pithy Part, in the Stalk, and almoft up to the Top of the chief Fiber, in many Leaves, is Tubular; even whilft they are yet Young and Sappy: as in Sweet Chervil, Hemlock, Endive, Cichory, Lampfana, Dandelion, Burdock, Daifje, Scorzonera, and others. And fometimes the faid Pithy Part is opened into feveral little $P_{i p e s,}$ like fo many Aer-Veffels, above $\frac{x}{3}$ a Foot long; as in the Common Dock and the Little spurge, by fome called Wart-Wort.

9. 6. THE Strings of the Leaf, or thofe Fibres which are vilible to the bare Eye, are compofed of Veffels of the Two General Kinds, $\int c$, for $S_{a p}$, and for Aer. They are joyntly diftributed throughout the Leaf: Yet not fo, as to run meerly parallel; as in Animals, every Artery hath its $V$ ein : but the Aer-Vefels are every where Inclofed,
or as it were Jheathed in the Sap-Veffels.

IO. 6. THEIR Pofition is various and regular, not only in the Body of the Leaf, as is above fhewed; but likewife in the stalk: of which alfo I have given feveral Inftances in the Firft $2300 \mathrm{k}$. I fhall here note, and more particularly defcribe, One or Two more. In the Stalk of a Mallow-Leaf, they ftand in Six Oblong Parcels of equal Size,

Tab. 49. and in a Ring near the Circuit. Whereby the Stalk is ftronger, the Growth hereof, before and behind, more equal, and fo the poiture
of the Leaf more erect.

II. 6. In Dandelyon, they ftand in Five Parcels: of which the Greater ftands a little bebind the Centre of the Stalk; figured into a very fmall Half-Moon or Semi-Tube, whofe Diametre, through a Glafs, is not above ${ }^{\text {th }}$ of an Inch. The other Four, are extream fmall $C_{y-}$;

$T a b$. 49. linders. Altogether make an Angle, twice as big as that of a V Confonant. Whereby, although the stalk be ftrong enough to fupport the younger Leaves; yet thofe which are grown longer, and fo not only by their Bulk, but their farther Extenfion from the Center of Gravity, are become more weighty; commonly lie flat on the Ground.

12. \$. In Wild Clary, they fand alfo in Five Parcels, the Greater ftands not behind, but before the Center; making an Arch, whofe Chord in a Glafs, is above $\frac{*}{2}$ an Inch long; and belongeth to a Circle, whofe

Tab. 49. Diameter is an Inch and half. The other Four, are fmall $C_{y} l i n d e r s$, alfo different from thofe in Dandelion; the two bigger, there ftanding hindmoft; but here, the two Lefs, and the two Bigger, within the two round Ridges of the Stalk.

13. 6. From hence it is, that the Leaves of this Plant have not only a Prone or Horizontal Pofture, but alfo make that Forceable Preffure on the Ground, which can by no means be imputed to their Weight. For the Great Arched-Fibre ftanding before the Centre of the Stalk, and the two Longer Round ones being uppermoft, in the Ridges of the stalk; they put on the upper parts thereof to a more full and forward Growth, and fo to bow the Leaf back-ward. And the Fibrous Arch being, though broad, yet almoft flat, doth hereby the more ea-
fily yield to that Motion. 
14. ऊ. In Borage, and Moth-Mullen, they ftand alfo in Five Parcels. In the former, the largeft maketh ftill a more bulky Arch, than $T a b .49$. that of Clary; being thicker, as broad, and of a leffer Circle or more bowed. But in Mullein, it maketh almoft an entire Oval.

15. 5. By means of this Figuration, a fufficient number of $V$ effels for fuch large Leaves, are not only more conveniently Diftributed into them ; but alfo ftand more fafely in the Stalk. For were the $A r c h$ contracted into a folid cylinder, it could not fo prefently be refolved into fmall Fibers. And were it laid into a flat Plate, or ftraight out, either the Figure of the Stalk, and fo of the Leaf, muft be altered; or elfe, the two ends of the Plate, would come too near the Circumference of the stalk, and fo be more liable to the Impre/fions of the Weather : as may be obferved in cutting the Stally tranfverly, and by the Figures.

16. \$. IN the Body of the Leaf, befides, the Pofutions of the Fibrous strings r. Threds; above expeffed, there is one Thred, bigger or lefs, which in all Plants, runs round the Edge of the Leaf, and hems in all the reft; but can hardly be well obferved in any, without ftripping off the skin of the Leaf. When the Fibres of the Leaf, are bigger,or lefs tender, Tab. 50 . as in Holly, the skin and the Pulp are fometimes found either rotted off, or eaten away with Infects; whereby, both the faid furrounding
Fiber, and the reft, are all very fairly viffble.

17. \$. THE Veffels feem to be continu'd, in the Leaf, by being Ramified out of Greater into Lefs, as Veins or Aiteries are in Animals. But if the Skin and Pulp of the Leaf, as fuppofe a Borage-Leaf be taken off, and the $V$ effels laid bare; by the help of a good Glafs, it will appear; That they are all of the fame Size, every where in the Leaf; Tab. 50. and alfo continued throughout the fame, all feveral and diftinct Pipes one from another, as the Threds in a Skein of Silk. And that therefore the Diftribution of the Threds which the $V_{e} \int f e l s$ compofe, is not the Ramifying of Greater Pipes into Lefs; but the dividing a greater Clufter of
Pipes, into feveral leffer Clufters, till at laft they come to be fingle; as
in the Diftribution of the Nerves. in the Diftribution of the Nerves.

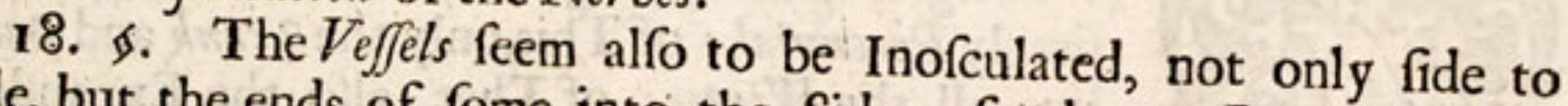
fide, but the ends of fome into the Sides of others. But neither is this ever really done : the leffer Threds, being only fo far diducted, as $T a b .50$. fometimes to ftand at Right-Angles with the greater. So that they are Inolculated only End to End or Mouth to Mouth, after they are come
at laft to their final diftribution.

19. 5. The Aer-Veffels, are not only, as is faid, Exiftent in the Leaves of all Plants; but are herein alfo difcoverable without the help of Glaffes: For upon breaking the stalk or chief Fibers of a Leaf; the likenefs of a fine Woolly Subftance, or rather of curious fmall Cobwebs, may be feen to hang at both the broken Ends. This is taken notice of, only in fome few Plants, as in Scabious, where it is more vifible. But may alfo be feen more or lefs, in moft other Plants, if the Leaves be ve- Tab.5 I, d. ry tenderly broken: as I have noted near twenty years fince; and 52. thence conjectur'd them a Sort of $V$ effel common to Plants. Now this fine $W_{o o l}$, is really a Skein of Aer-Veffels, or rather of the Fibers of the Aer-Veffels, unroaved from their Spiral Pofition, and fo drawn out in Length. As they appear thus unroaved and drawn out at Length, both to the bare Eye, and through a good Microfcope, I have reprefented in two Exemples, the one a Scabious Leaf, the other that of a Vine.

$$
\begin{aligned}
\mathrm{Cl} 2 & \text { 20. } 5 .
\end{aligned}
$$




\section{6

20. \$. THE Weftage of the Strings and Parenchymous Fibers together, is here made in the fame manner, as hath been defcribed in the Anatomy of the Root, and Trunk: the former being in fome Sort as the Warp, the latter as the Woof of the Leaf.

21. \$. And one Example we have (it may be more than one) wherein Nature fhews, though not a greater, yet a different $A r t ;$ and that is the Palm-Net. For whereas in other Plants, the Webb is made betwixt the Lignous-Strings and the Fibers of the Parenchyma, only vifible through a Microfcope : here the faid Strings themfelves are Interwoven, and the Weftage apparent to the bare Eye. Of thefe PalmNets or Sacks, there are feveral Sorts. One of them is compofed in this manner. It hath a Fivefold Series of Lignous Strings or Fibers. The greateft whereof fwell out above the reft; and like fo many $R i b s$, are obliquely produced on both hands, fo as to encompafs the Sack. Along each of thefe Ribs, on the infide the sack, runs a fmall Whitifs Line; being a Thread of Aer-Vefjels growing thereto. Betwixt thefe Ribs or larger Strings, there are others much lefs, Two or Three betwixt Rib and Rib, Parallelly interjected. On the infide, there is a Third series, which is alfo obliquely produced; but tranfverlly to the former. The Fourth and Fifth, confift of the fmalleft strings; not only Tranfverly produced, but alfo Alternately, from the outfide to the infide of the sack, \& vice verfa. By thefe two laft, all the reft are moft elaborately woven into one entire and ftrong piece of Work.

\section{CHA P. V. \\ Of the Duration of Leaves, and the Time of their Generation.}

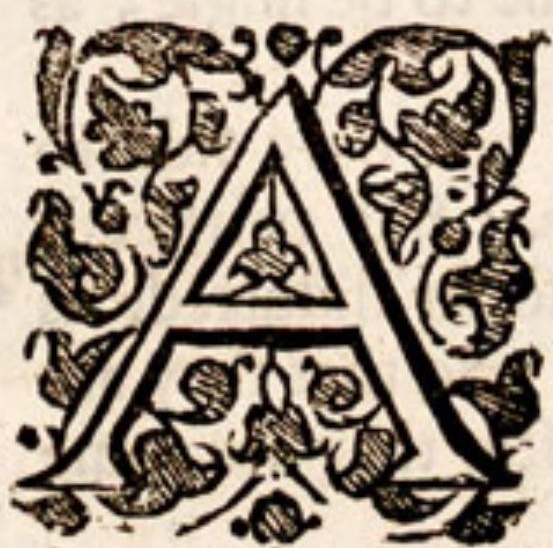

N Evergreen, is one degree above a Plant which is fimply Perennial: of This,only the Trunk and Buds live all the Winter; of That, alfo the Expanded Leaves. And an Evergrox, is a degree above an Evergreen: here, the Buds and young Sprigs, do only live; there, they grow and are put forth.

2. \$. An Evergreen, is made fuch, either by the Toughness of the Skin, and Closeness or Denfity of the Parenchyma, whereby the Leaf is better able to endure Cold; as in Holly: or by the extream Smalnefs or Fevoness of the Aer.Vefels, whereby the Sap is lefs dryed up, and fo fufficient, even in Winter, for the Nourifhment of the Leaf; as in Box, and $\Upsilon_{\text {ew }}$, as alfo Fir, and all Refiniferous Plants.

3. 6. The perpetual Growth of a Plant, feemeth to depend chiefly on the Nature of the Sap. For all Fuyces will not ferment alike, nor with the fame degree of Heat. So that whereas many Plants require a greater Heat, as that of Summer, for the fermenting and diftribution of their fuyces, and fo their growth; the Warmth of Spring is fufficient for many others; and for fome few, that of Winter it felf.

4. 5. A S T O the Time wherein the Leaves are formed; Firf, it is very probable, That in thofe Plants which have Leaves (befides the DifJimilar) of Two diftinat Figures, as hath the Little Common 
Bell, and fome others; the Under-Leaves, which differ in Shape from the reft, are all at firft formed in the Plume, before it begins to Jprout; and the reft afterwards; That is to fay, that the former Leaves, are all formed (out of sap from the Trunk) with the Seed it felf, and fo compofe one Principal Part thereof, $f c$. the Plume: the latter, not till after the Seed is fow'n, and fo the Plume fupply'd with $S_{a p}$ immediately from the Root. Which sap, it feems, is fo far different from the former, as fometimes to produce a different Sort of Leaves.

5. 5. S E C O NDL Y, of the Buds of all Trees, and of PerenniStalks, it appears, That they confift of a great number of Leaves, all perfectly formed to the Centre; where, notwithftanding, they are fometimes, not half fo big as a Cheefe-Mite. So that all the Leaves which ftand upon a Branch or Cien of one whole Years Growth, were actually exiftent in the Bud. It is alfo very obfervable, That al though thefe Buds begin to be expanded not till Spring, yet are they entirely Formed, as to all their Integral Parts, in the Autumn foregoing. So that the whole Stock of Leaves which grow upon a Tree, or any Perennial Stalk, this year; were made, or actually in being, the laft year. A greater Heat, more fubtilized Aer, and better concocted Fuyce, being requifite for their Generation, than for their bare Expan-
fion and Growth.

6. 5. L A S T L Y, of all Annual Plants, in which there are feveral Succeffive Generations of Buds, one under another in one year; although I have not made the Remarque, yet am apt to believe, That as the Leaves in every Bud are all formed together, as in other Plants: fo likewife, that the Succeffive Generations of the Under-Buds, begin at certain ftated Terms : as in fome Plants, at every New Moon; in others, at the Full Moon; and in fome perhaps; with both, or every
Fourt'night.

\section{CH A P. VI.}

\section{Of the Manner of the Generation of the Leaf. Where alfo, that of the Two General Parts of a Plant, $\int c$. the Lignous and Parenchymous, is further explain'd.}

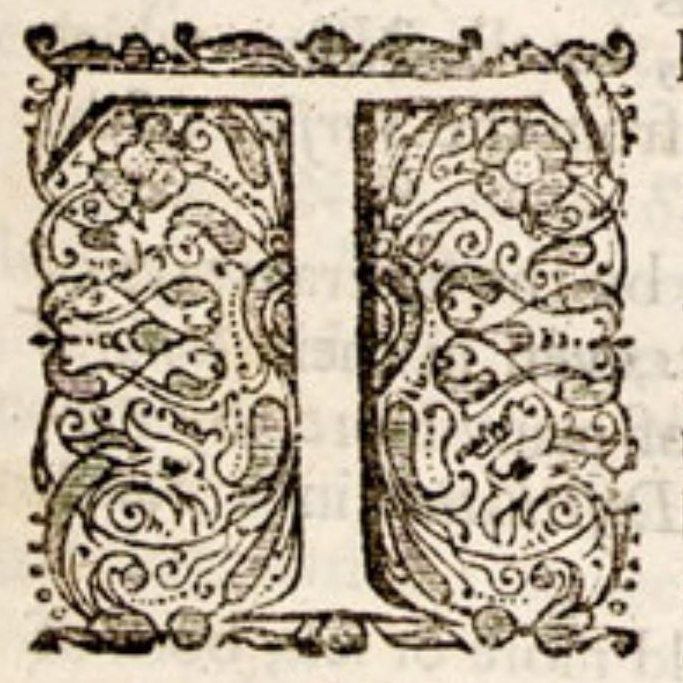

H E Vifrble Caufes of the Figures of Leaves, have B.I. Ch. 4 . been formerly mentioned. It may here be further noted, That the greater Fibers of the Leaf, being never Braced in the Stalk; it is a good preparative for their better fpreading in the Leaf. As alfo, that the fame is much favour'd, by the extream fmainefs of the Aer-Veffels herein : whereby they are more eafily divaricated, in the leffer Fibers, and fo the Leaf dilated.

2. 6. B U T thefe and the like are to be reckoned a fecondary $\mathrm{Or}$ der of Caufes; which ferve rather to carry on and improve, that which Nature hath once begun. And therefore, we muft not only confider the vifible Mechanifm of the Parts; but alfo the Principles of which Idea, 8.53 . they are compofed; wherewith, Nature feems to draw her firft Strokes. 
3. 5. Now of thefe, I have formerly, and as I conceive upon good Lib. 2.P.2. ground, fuppofed, the chief Governing Principle, to be the saline, 5. 3 I, \&c. whether Alkaline, Acid, or of any other Kind: being in fome fort as the Mold of a Button, to which the other Principles, as its Attire, do all conform. Or the Salts are, as it were, the Bones; the other Principles, as the Flefs which covers them.

4. 6. A further Argument hereof may be deduced from the Cuticular and other Concretions, commonly called Mothers, in Diftill'd $W_{a-}$ : ters, Vinegar, and other Liquors. For in thefe Concretions, there is allways a tendence to Vegetation; and many of them are true Vegetables in their Kind; as thall hereafter be feen. Now the Liquors, in which thefe are generated, do always, wholly or in part, lofe their Taft and smell, and fo become Vapid. The more fenfible Principles therein: having made their Tranfit from the Fluid, into the Concrete Parts. So, I have known, fometimes, Vinegar it felf, to become by thefe Concretions, almoft as Taftless as Common Water. Whereby it feems evident, That of Vegetable Principles, there are fome, more Mafterly than others: and that of thefe, the Saline is the chief. The fame is likewife argued, from the frequent Experiment of many good Husband-men; that molt Bodies which abound with Salt, are the greateft Nouriflers of Plants.

5. \$. This saline Principle, as is above hinted, is to be underftood, a Generik Name, under which divers species are comprehended; and of fome whereof, it is always compounded, as in other Bodies, fo in Plants. As thall be made to appear, by divers Experiments, when we come, hereafter, to fpeak of Vegetable salts. Whereby we are conducted, yet further to enquire, What are the Princinples of this Principle?

6. 6. NO W thefe feem to be Four; a Nitrous, an Acid, an Alkaline, and a Marine. The Admixture of the Firft, is argu'd from the Place, which Nature hath affigned for the Generation and Growth of moft Plants, $f \hat{c}$. neither in Caverns under Ground, as for Minerals; nor above it, as for Animals; but the Surface of the Earth, where this Sort of Salt is copioufly bred. And doth therefore prove, not only a Mixture, but a good Proportion hereof with the other Principles of a Plant. Hence it is, that Dew or Water on Windows or Plain and Smooth Tables, by virtue of a Nitro-Aerial Salt, is often frozen into the refemblance of little shrubs. And the like Figure I have often feen in a well filtred Solution of the salt of any of our Purging Waters, as of Epfom, \&c. being fet to fhoot. Produced, as I conceive, by the Nitre, which with the Rain or other Waters, is waherd down from the Surface of the Earth, and fo mixed with the Mineral Salts.

7. \$. The other Three Salts are exhibited, by the feveral ways of Refolving the Principles of a Plant. Many Plants, even in their Natural Effate, do yield an Acid Fuyce. And the Fuyces of many more, by Fermentation, will become Acid. And molt, by Diftillation in a SandFurnace, yield an Accid Liquor.

8. 5. By Calcination, all Sorts of Plants, yield more or lefs, both of a Fixed and a Volatile Alkaly: the former, in the Afhes; the latter, in the Soot. And, at leaft the generality, by Fermentation alfo, yield a Volatile one; or fuch a kind of Salt, which, whether we call an Urinous, or otherwife, hath the like Odour and $T_{\text {aft }}$ with that of Urine, HartsHorn, Soot, and the like. 
9. 6. The Marine, is obtained no other way, that I know of, but from a Solution of the Alkaline, upon its being expofed to the Aer. The procefs wherof, I thall particularly fet down in a following $D_{i-}$ alfo Impregnated wath, mixed in a certain proportion, together, and and Impregnated with fome of the other Active Principles of a Plant, that which I call the $E$ fentixt of fome Parts from the Aer; I fuppofe, an account in the fame Difcourfe.

10. 5. ALL THE Four salts above mentioned, feem in their $O r$ der, to have a thare in the Formation of a Leaf, or other Part of a Plant: And firft of all, the Marine. For all Generations are made in fome Fluid: But in every Fluid there is a perpetual Inteftive Motion of Parts be difpofed to Ref. are none hereunto more Now of all the Principles of a Plant, there being figu'rd with plain Sidpoled, than their Salts; whofe Particles, two Marbles exquifitely polifhed, they as they touch Side to Side, like Particles of Marine Salt, being Cubich; will adhere together. And the sure, of greater Bulk than tho of $\mathrm{Cny}$ and fo, with refpect to their $\mathrm{Fi}_{i}$ moft and firft of all difpofed to Rether Salt; they will hereby, be Foundation of the following Superftrif and fo become, as it were, the

II. THE Second Intention of Nature is, That the Particles be brought to Reft, in a certain Poftion, agreeable to the Figure of the Parts which are to be formed. And therefore in the next place, all with the affiftance of the All truly Lignous, by the Marine Salt, made to fhoot out in Length, or into an innumerable come Nitrous, are Cylindrick Fibres : thefe salts being annumerable company of fmall thofe Impulfes which might incline, altogether, fturdy enough to refift $T a b .53$.

12. \$. THE next Intention is, That thefe Fibres, at the fame time in which they are formed, may likewife receive fuch a Pofture as will beft anfwer the indented shape of the Leaf. Which Pofture, although in the Generation hereof, feems to be Govern'd by the Aer-VefJels; yet tioned Salts, according to their feverirt determined by the foremenferently applicable one to another.

13. 5. Now all the Sides of the Marine Salt, and the Sides and the Ends of the Nitrous, properly fo called, ftand at Right Angles. And it is very probable, from the Figure of the Cryftalls in spirit of Blood, and fome other Bodies, that the Particles of the Alkaline are Square at Tab. 53 one End, and Poynted at the other. And thofe of the Acid, at both;
And that, withal, they are Shorter and more Slender.

14. 6. It fhould therefore feem, That where the Alkaline Salt is End; there the Lignous $F$, wat the Particles thereof are placed End to declining their parallel Growth, begin to larger ones in many Leaves ) Tab.53. gles one with another, and thofe Acute. 
15. 6. If the fame Salt be predominant, and fome of its Particles $T_{a}$. 53. placed, with the Pointed End of one, to the Side of another, or the Square End of one, to the Poynted End of another; there the faid $\mathrm{Fi-}$ bres begin to thoot at Angles lefs Acute.

16. 5. But if either the Marine or Nitrous $S_{a l t}$ is predominant ; or fome Particles of the Alkaline, are placed with the Square End of one, Tab.53. to the Side of another; there the Fibres begin to make, not Acute, but Right Angles; as do the greater Fibres, in fome Leaves; and the fmaller, in all.

17. 6. IN the fame manner, the Fibre in the Circumference of the Leaf is alfo governed; the Particles of the faid Salt, being reduceable, not only to any Angle, but alfo to any Circle, or other Crooked Line, as they are varioufly applyed. For if the major part be applied.

Tab. 53. End to End, and only every Third or Fourth applied End to Side, they produce a great Circle. But if the Poynted End of each, be fet to the Side of another, they make a lefs. And if the Application be the fame, but to the contrary Side, they thence begin a new Circle with the fame Diameter, but with another Center, anfwerable to the intended shape of the Leaf.

18. 6. AFTER the fame manner, the Aer-Veffels may be formed by the Particles of the Acid Salt. Which, without being fuppofed to be crooked (as thofe of the Aer, at leaft the compounded ones, probably be ) only by applying the leffer Side of one, to the greater Side of another, will alfo be reduced to any either Gircular or Spiral Line.

$T a b$. 53. And fo, likewife, for the production of the winding Fibres, which compofe the Bladders of the Pith and other Parenchymous Parts of a Plant.

19. ऊ. Thus doth Nature every where $\gamma \varepsilon \omega \mu \varepsilon т \varepsilon \varepsilon \tilde{i v . ~ F o r ~ w h a t ~ S h e ~ a p-~}$ pears in Her Works, She muft needs be alfo in their $C$ anfes. 
T H E

ANATOMY

$\mathrm{O} F$

FLOWERS,

PROSE C U TE D

With the bare EYE,

And with the

MICR OSCOPE:

Read before the Royal Society, Novemb. 9.1676

The SECOND PART.

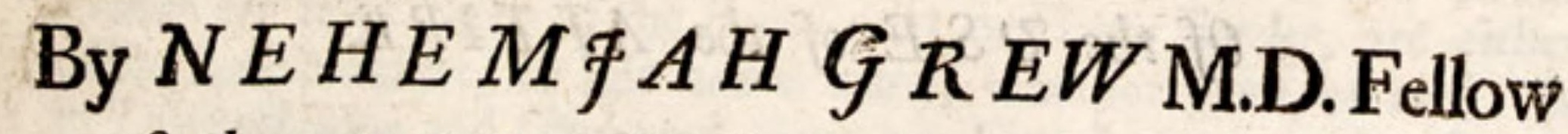
of the ROYAL SOCIETY, and of the COLLEGE of PHYSICIANS.

LONDON,

Printed by $W$. Ramolins, 1682.

Mo.Bot.Garćon, D d 


\section{T H E \\ C O N T E N T S A OF THE \\ Second Part. \\ C H A P. I. \\ Of the EMPALEMENT. \\ CHA P. II. \\ Of the FOLIATURE. \\ C H A P. III. \\ Of the ATTIRESEMINIFORM. \\ C H A P. IV. \\ Of the FLORID ATTIRE. \\ CHA P. V. \\ Woll I. Of the USE of the ATTIRE. \\ CH A P. VI. \\ Of the TIME of the Generation of the Flower. \\ Tbe Appendix.}

Being a MET HOD propofed, for the ready finding, by the Leaf and Flower, to what Sort any Plant belongeth. 


\title{
Book IV.
}

\section{T H E}

\section{ANA TOMY}

$\mathrm{OF}$

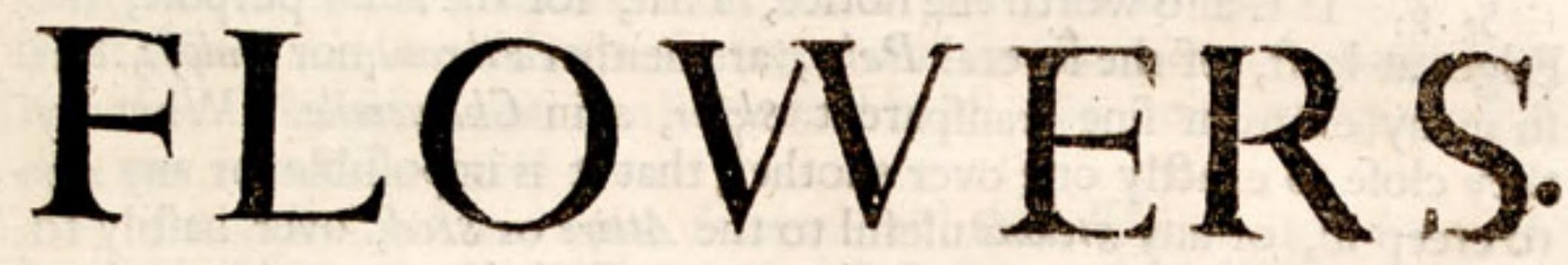

P A R T II.

\author{
C H A P. I. \\ Of the EMPALEMENT.
}

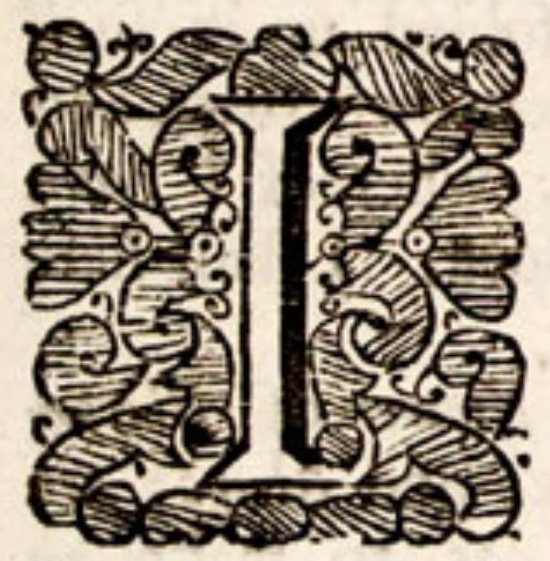

NE X T proceed to the Flower. Where I intend not to repeat thofe things, which have been by Me already noted in the First $2300 k$. And the foregoing Difcourfe of Leaves, will excufe me from di- $C h .5$. vers particulars, common to Theje and the Flomer. I thall here therefore remarque fome things not before mentioned, or but in tranfitu, and fuch as are moreparticular to the Flower.

2. 6. And Firft, it may be noted; That where the Leaves of the Flower are few; thofe of the Empalement or Green Border, are either of the fame Number, or juft half as many, whether even, or odd. So in Leucanthenum and Chickpoed, there are Five Leaves; in the former Five Empalers; in the latter, Ten. In Great Celandine, there are Four Leaves, and but Two Empalers; and fo in Poppy. The Arithmetick of Nature being every where fuitable to Her Geometry.

3. 6, Of this Part of the Flower it is likewife obfervable, That it is rarely, if ever, entire or one piece, but parted into divers little Leafy Pales, efpecially in all Flowers with the Florid Attire, as of Marigold, Daify and the like; being fo numerous, as to make a Double, and often a Treble, Quadruple or 2 uintuple Border. Whereby they are aptly defigned, not only to protect the Leaves of the Flomer in the Bud; and after their Expanfion, to keep them tite: but alfo, by receding, Bredthways, one from another, and fo making a greater Circle, gradually to give way for the full Growth and fafe fpreading of the Attire. Which, in regard it confilts of Parts fo exquifitely tender, were 
it pinched up too clofe, would be killed or fpoyled before it came to the Birth. As Teeming Women, gradually flaken their Laces; or as Taylors ufe to fplit their Stomachers into feveral Lappets, to fpread, as their Belly rifes.

4. 5. Nor is the Pofture of the Parts in the Empalement lefs fuitable: not being filed one juft over another, but alternately. Whereby the Pales or Pannciles of every Under-Order, ferveto ftop up the gaps

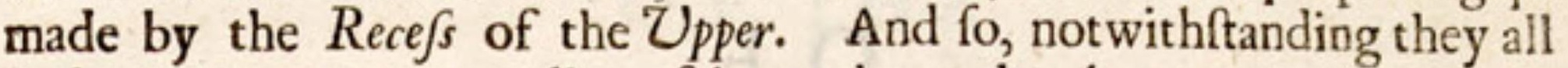
make more roome, yet all confpire to keep the Aer out.

5. 5. It is alfo worth the notice, That, for the fame purpofe, the Edges at leaft, of the feveral Pales, are neither Fibrous, nor Pulpy; but fo many extream fine tranfparent skins, as in Chamemile. Whereby they clofe fo exactly one over another, that it is impoffible for any Aer to creep in, or any steams ufeful to the Attire or Seed, over haftily to perfpire. As we ufe, when we have put a Cork into a Botile, to tie a Bladder over it.

\section{CHAP. II.}

$$
\text { Of the FOLIATURE. }
$$

Tab.54.

Ch. 5 .

Tab.54.

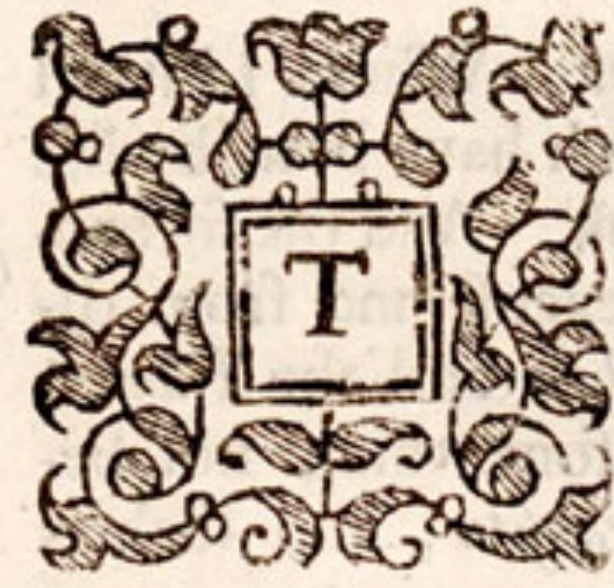

Equilateral Pentangle.

$\mathrm{H} \mathrm{E}$ Leaves of the Flower are folded up in fuch Sort, as is moft agreeable to their own shape, and that of their inclofed Attire: whereof I have given Inftances in the Fift 2500k. I fhall here add fome further Remarques.

2. 6. The Leaves of the Flower of Blattaria, although of different Size and Shape; are fo lapped one over another, as to make an

3. \$. The Spiral Fold, which is proper to the Flower, and never

Tab.54. feen in the Green Leaves; as it is it felf immediately vifible on the Surface, fo by cutting off the top of the Flower before it is expanded, fcems alfo to make a Helix; as in Perwincle, the larger Convolvulus, \&c.

4. 6. In fome Flowers, where the Attire is lofty or fpreading, as in Holioak, together with the Spiral Fold, the Leaves are all at the top tacked down a little; thereby making a blunter $C_{0}$ ene, and fo a more ample Pyramid for the inclofed Attire.

5. \$. In POPDy, although the Leaves are extraodinary broad, yet being but few, and inclofing a fmall Attire; they could not be well re-

Tab. 54. duced to any regular Fold, without leaving fuch a Vacuity, as by being filled with Aer, might be prejudicial to the seed. For which reafon, they are cramb'd up within the Empalement by hundreds of little Wrinckles or Puckers; as if Three or Four fine Cambrick Handcbercbifs were thrult into ones Pocket. 
6. 5. In Ladies-Bower, the Leaves are neither laped one over another, as is moft ufual; nor fet Edge to Edge, as fometimes, but Side Tab.54 to Side, anfwerable to their Stsape, and the Diftribution of their Fibres. Their broad Tops being alfo rowled up fo as to make a Cone. In Ladys-Looking-Glafs, they ftand alfo Side to Side, but in a different manner: in the Former with the Sides ftanding inward, but here, bearing outward.

7. 6. In the Marvel of Peru, the Fold is likewife very peculiar. For, befides the feveral Plates, about Six, whereby the Flower is ga- Tab. 54. thered in the Midle; the Top of it is alfo gathered up by as many diftinct Plates, underneath the former; and thefe rowled or wreathed up together fo exactly, that the like could hardly be imitated by a very dextrous Hand.

8. 6. OF the Hairs upon Flowers and their $\mathrm{U}_{\mathrm{e}}$ to the Attire, I Ch. 5. have alfo fpoken in the Firft $2300 k$. I thall here add, That they are likewife of Uje to the Leaves themfelves, that is, for their clofer and fafter Conjunction. For of fome Flowers it is obfervable, That they are all over fmooth, faving on their Edges, which are border'd with Fringes of Hair; as of spanifh Broome, Dulcamara, and others: In Tab. 55 . which, the Hairs on the Edge of one Leaf, are fo complicated, or at leaft indented, with thofe of another, that all the Leaves feem to be but one piece. Nature feeing it fit, by this meanss to tie them together, left they fhould be expanded before it be due time.

9. 5. Many Flowers inftead of Hairs, are befet round about, with a great Number of fmall Parts, not ending in a Poynt, but having a Head. Sometimes oval, as in Snap-Dragon, like the Horns of a Butterfly, or a Plummers Sodering-Iron. But ufually Globular, as in Deadly Night/hade, like fo many little Mufbrooms fprouting out of the
Flower.

10. 5. Out of thefe Heads, doth fometimes iffue a Gummy or Balfamick Fuyce. From whence proceeds that Clamminefs of fome Flowers, whereby, being handled they ftick to our Fingers, as do thofe of Blataria, and of Marigold; and thofe of Colus Fovis, where the faid Heads are fo foft and fucculent, that they refemble fo many little Drops of Balfane. The Clamminess which is felt upon frefh Carduws, may perhaps proceed from the like Caufe.

II. \$. THE Number of the Leaves of the Flower hath been noted by the Learned Sir Thomas Brown, to be ufually Five. And this Treat. of Nature fo far affecteth, that many times where the Leaves of the fame the 2uinc. Flower are of a different Size, yet they keep to this Number, as in Tab. 54.
Blattaria.

12. 5. I alfo add, That even thofe Flowers, which are not properly parted into Leaves, have yet their Tops ufually divided into Five great Scallops; as thofe of Toad-Flax, Snap-Dragon, Coded-Arfmart, Clary, Broom, and others. And when the Flower hath more than Five, even many times Five Leaves; yet the Top of each Leaf is indented into Five Parts; as in Scorzonera, Cichory, and all the Intybous Kind, with Tab. 54.
many others.

I3. 5. From whence and other like Inftances, it may feem, That there is fome certain Species of Salt in Nature, and that in moft Plants, of whofe Agency there are fill fome Footfeps or other in the
Flower. 
14. \$. The Number of the Leaves, as hath been faid, is commonly Five. Yet fome Flowers have fewer, and fome more, and that with Conftancy, in divers Numbers, from One to One and Twenty; perhaps in all, fo far. The Flower of Acantbus Syriacus, is in a manner one fingle Leaf, that of Monks-Rubarb, Three-Leav'd; of Poppy, Crofswort, Radifh, and many others, Four-Leav'd; the greater Number of Flowers, Five-Leav'd; of White Hellebore, Tulip, Onion, and moft Plants with Bulbous Roots, Six-Leav'd; of Wild-Crowfoot, SevenLeav'd; of French Marigold, commonly Eight-Leav'd; of Flower-deluce, Nine-Leav'd; of chickweed, Ladies.Mantle, Ten-Leav'd; of St. Fames's Wort, Thirteen-Leav'd; and I think of Febrifuga, Cotula, Ageratum, Corn-Marigold, with others; and of Chamemile, Buphthalmum, and fome few more, the Leaves are commonly One and Twenty. In that of St. Fames's Wort, the Number is fo conftant that there is Tab. 55. fcarce OneFlower in Forty, wherein the Leaves are more or fewer than Thirteen. Divers of which Numbers, feem alfo to have fome relation to the Number 5. For 9, is Twice; 13, Thrice; and 25, Five times 5 running into it felf.

15. 6. THE Conftituent Parts of the Flower are the fame asthofe of the Leaf, $f c$. the Parenchyma or Pulp, and the $V_{e} \int j e l s$. But in the Bafis or bottom of the Flower, the Parenchyma is commoniy much more ßpon$g y$ and $d r y$, than in the Leaves ; conteining, after the Flower is open'd, little or no Sap, but only a dry and warm Aer. Which ftanding continually under the Seed, haftens the Maturation or due Exiccation thereof: as we ufe to dry Maulted Barly over a warm Killn.

16. \$. The Veffels of the Flower, are both for Sap and for Aer, as well as in other Parts. And both of them fometimes, even in the $s$ kin of the Flower; as may be argued from its being ftained with divers

B. 2.P. 2. Colours; produced as hath formerly been fhewed, by the mixed $5.65,66$, Tinctures of the faid $V_{\text {effels. }}$ Thefe Colours, in many Flowers, as Tu67. lips, as they are in the Skin it felf, fo therein only; the Pulp of the leaf being white.

17. 5. The Lignous or Sap-Veffels are fewer, and the Aer-Veffels fmaller in the Flower, than in the Leaf. And therefore it is very difficult to obferve the latter by Glafes; efpecially the Proportion which they hold to the other Parts. But if you break the Leaves of fome Flowers, with very great gentlenefs; they may hereby be Unroaved or drawn out, as in the Green Leaves, to fome vifible length; and their different Number in divers Flowers may be difcerned.

18. 6. THE $\mathcal{U}$ Se of the Flower or of the Foliature whereof we B. I. Ch.5. are fpeaking, is various; as hath formerly been thewed. I now only add, That one $U_{j}$ hereof feemeth to be, for the Separation of the more Volatile and ftronger Sulpbur of the plant. That fo the Seed, which lyeth within or next it, may be fo much the milder,and the Principles thereof more fixed and concentred. And this, both for its better Duration till the time of Sonving; and alfo, that its Fermentation, when it is fow'n, may not be too hot and precipitate; but fuitable to fo flow and equal a motion, as is the Vegetation of a seed.

19. 5. And that this Sulphur is feparated and difcharged by the Flower, feems evident, not only from the Strength of its Odour, above that of the other Parts; but likewife, in that many times where there is no Flower, or that very fmall, the Seed, that is its Cover, as in the Z $\mathrm{m}$ - 
belliferous Kind, is the more odorous. And therefore alfo, the Vine hath no Flower, partly, that the molt Volatile Spirit and Sulphur might all run into the Fruit.

20. б. THE Figure of the Flower, although it is often much more complex, than that of the Leaf: yet there is no doubt, but that the Meafure hereof may be defined in fome way, anfwerable to that exemplified in the foregoing 1 Patt. The difference is only this, That whereas the Green Leaves, and the Plain Leaves alfo of the Flower, are all meafured by the parts of feveral Circles: thofe Flowers which are Bellyed, and thofe Leaves of the Flower which are not Plain, but $C$ onvex, are all meafured by the parts of feveral spheres. And as the Diametres of thofe Circles, bear a certain proportion to the midle Stemm of the Leaf; fo the Axes of thefe spheres, to an imaginary one in the Centre of the Flower.

21. 6. NOW the reafon why the Figure of the Flower is more multiplex, than that of the Leaf; may be, partly, becaufe it is under the Command and Government of thofe Salts, which are here more refined and depurate, than in the Leaf; and fo more free to lay the Foundation of any kind of Figure, for which, of their own Nature, they are adapted. Partly, for that as the Nitrous and Alkaline Salts are chiefly regnant in the Leaf; fo in the Flower, in which the Parenchyrious Part hath a greater (a) proportion than in the Leaf; it is moft reafonable, (a) $\mathcal{S}_{0} \times$ \% to affign the Predominion to the $A c i d(b)$ : the Particles whereof,both as (b) Idea, they are lefs, and alfo poynted at both ends, $(c)$ feem to be more eafily 5.52 . applicable one to another for the making of any Sort of Line or Figure (c) P. I.

\section{CHA P. III.}

\section{Of the Attire, and firft of that fort which may be called Seminiform.}

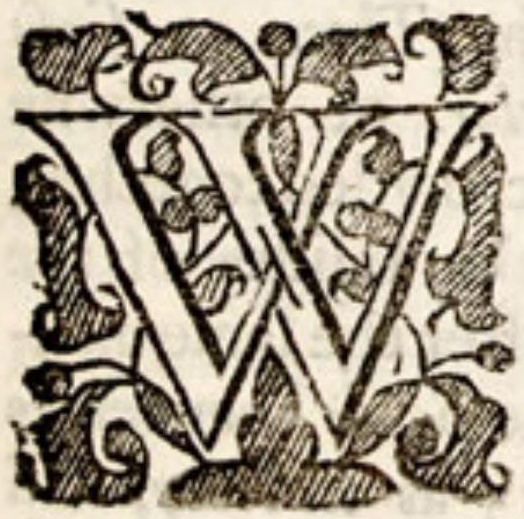

I T H IN the Foliature ftands the Attire; which is of $\mathbf{T}$ wo general Kinds, every where Various and Elegant; according to the Defcription I have given of them in the Firft 23aok. I fhall here add fome $C_{2} .5$. further Remarques.

2. \&. And firft, of that Sort of Aitire, which may be called Seminiform; being ufually, as it were, a little Sheaf of seed-like Particles; ftanding on fo many $P_{e-}$ dicills, as the Ear doth upon the End of the Straw.

3. 5. Of their Colour it is obfervable, That for the molt part, they are White or Yellow; fometimes Blew; but never Red, let the Flower or Foliature be of what Colour it will. Neither doth their Colour allways follow that of the Foliature, although that be not Red. Whereby it appears, how very Curious and Critical Nature is, in the Separation of the Fuyces in Plants: that fuch fmall Parts as thefe of the Attire, and fo near the Leaves of the Flower, fhould yet receive a different Tincture. 
4: 6. Thefe Parts differ alfo in their Pofition; ftanding fometime

Tab. 55. double upon each Pedicil, as in Toad-fiax, Snapdragon, and fome others; but ufually fingle, as in Blattaria, Clematis Auftriaca, \&c. Sometimes faftned to their Pedicils at their middle, ftooping down after the manner of Poppy and other hanging Flowers; as in Spani/h-Broom, Hyfop, Scabeous, Behen, \&c. Sometimes they ftand erected, as in Clematis Austriaca, Ladyes-Looking-Glafs, Rape-Cromfoot, \&c. Thofe of Coded Arfmart have no Pedicils, but ftand upon a large Bafe.

5. 6. Of the Pedicils themfelves, it is to be noted, That they are rarely faftned to the Top of the Repofitory or Cafe of the Seed, but round about the Bottom. Partly, That hereby they may the better intercept and feparate the Incongruous Parts of the Sap from the Seed. Yet in the Coded Arfmart they ftand at the Top. Which is not the only thing peculiar in that Plant; it being the property thereof, to ejaculate its Seed, upon the leaft touch. Which property feemeth to depend, partly, upon the Pofition of the faid Pedicils, as thall be fhewed in fpeaking of the Seed.

6. 5. Thefe seed-like Parts are alfo of different Number. In Great Celandine, Rofe, Rape-Crowfoot, numerous; in Great Plantaine, and fome other Herbs, much more confpicous than the Foliature it felf. In Germander-Cbickweed, they are always Two, and no more. Sometimes they follow the number of the Leaves, efpecially in the number $5 ;$ as in Blattaria, Black Henbean, \&c. In Stichwort and Lychnis Sylveftris, they are 10 , juft double to the number of the Leaves.

7. 6. They differ alfo in their Bignefs, being in fome fmaller Flowers, large; as in Borage, Ladys-Looking-Glafs, and others: and in fome larger Flowers, lefs; as in the Rofe.

8. \$. But efpecially in their Shape, which is always very Elegant, and with much Variety. In Borage, like the point of a spear. In Blattaria, like a Horfe-foooe. In clematis Auftriaca, like the Spatula, wherewith Apothecaries make their Mixtures. In Mallow, like a Head-Roll. In $H_{y} f_{o p}$, they have one Cleft before; in Blattaria, one round about ; in Water Bettony, one at the Top; in Scabious, they have a double Cleft,

Tab. 56. one on each fide; and fo in St. Fohns Wort, Hyofcyamus, and others; before they open, in the Shape of a double Purfe.

9. 6. Thefe Parts, are all hollow; each being the Theca or Cafe of a great many extream fmall Particles, either Globular, or otherwife Convex; but always regularly figur'd. They are all crowded together, and faftned in clofe Ranks, without any Pedicils, to the Infides of the Theca, like other leffer Seeds within a greater; or after the fame manner as in Hyofcyamus and fome other Plants, the true Seeds themfelves

Tab.55,56. grow all round about clore to the Bed of the Cafe; as in Clary, and the Figures now referred to, may be feen. And when they are ripe, the Cafe alfo opens and admits them to the Aer, as the seed-Cafe doth the seed. The whole Attire, together with the Foliature and Seed-CaJe,

Tab. 57. See in one Example, amongft the Figures.

10. \$. The Colour of thefe fmall Particles conteined in the Theca, is alfo different. But as That is ufually White or Yellow, fo are Thefe: fometimes Blewifh; but never Red. And fometimes not of the fame Colour with that of the Theca. Which further fhews how fcrupulous Nature is, in differencing the Tinctures of the feveral Parts. 
II. 6. They are alfo of different Bignefs and Figure. Thofe in Snap-dragon, are of the fmalleft size I have feen; being no bigger Tab. 58 .
through a good Microfcope, than the leaft Cheefe-Mite to the naked Eye. In Plantain, alfo through a Glafs, like a Scurvy-grafs-seed. In Bears-foot, like a Muftard-feed. In Carnation, like a Turnep-seed. In Bindweed, like a Peper-Corn. In all thefe of a Globular Figure.

12. In Devils-bit, they are alfo Round, but depreffed, like the Seed of Goof-grafs, or a Holland Cheefe. In the Bean and all forts of Puls, and Trefoyls, as alfo in Blew-bottle, \&c. they are Cylindrick. In Orange Tab. 58. Lilly, Oval, one $5^{\text {th }}$ of an Inch long,like an Ants-Egg. In Deadly-Nightfrade, alfo oval, but fmaller at both Ends. And thofe of Pancy, Cubick. In all thefe and the former, they are smooth.

13. 5. But in Mallow, Holyoak, and all of that kind, they are befet round about with little Thornes; whereby each looks like the seedBall of Roman Nettle, or like the Fruit of Thorn-Apple, or the Fifb cal-Tab. 58 . led Pifcis orbis minor, or the Murices, ufed antiently in Wars. They are alfo very great, fhewing, through a Glafs, of the bignefs of a large White Peafe; being 200 or 300 times biger than thofe in Snapdragon; of which there are about a Thoufand in each Theca, that is, in the fpace of about $1000^{\text {th }}$ Cubical Part of an Inch.

15. 5. In fome Plants, as in Deadly Night-fuade, where thefe Partiales are White, they feem, by a very good Glafs and advantagious Pofrtion, to be compofed of Parenchymous and Lignous Fibres, ftitched up together, as in the other Parts.

15. \$. In Colocyntlis, (and with fome Analogy in Wild Cucumer, and I fuppofe all of that kind ) the Attire is very peculiar, not confifting of feveral little Thece, upon fo many Pedicils, as is defcribed; but is all one entire Part, like a thick Columna in the midft of the Flower; having feveral little Ridges, and Furrows winding from the Top to the Bottom round about. In the midle of each Ridge runs a Line, where the Skin, after fometime, openeth into two Lips, prefenting the Globular Particles conteined in the hollow of every Ridge.

16. \$. Where the Attire confifts of feveral seed-like Parts, as is defcribed there, another Part diftinct, like a little Columna or Pinacle, ftands on the Top of the Uterus or true seed-cafe. Which is alfo regularly and variounly Figured. In Bindweed, it hath a round Head, like that of a great Pin. In the Common Bell, St. Fobns mort, it is Tab.56,5\% divided into Three Parts. In Gerarium, into Five; In Afarum, into Six. Sometimes, the Head is Smooth, and fometimes befet with litthe Thorns, as in Hyofcyamus. Of the $v \int e$ of thefe Parts, anon. 


\section{H A P. IV.}

\section{Of the FLORID ATIIRE.}

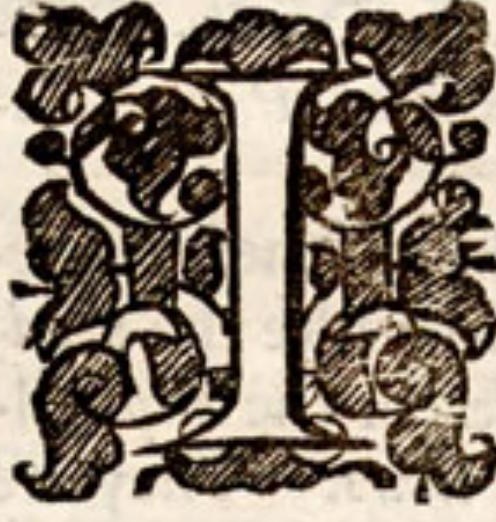

N THIS Attire there is alfo much Elegant Variety, according to the Defcription we have given of it in the Firf $21300 k$. It always confifts of feveral suits; Ten, Twenty, Fourty, a Hundred, or more, according to the Bigness of the Flower. And every Suit moft commonly, of three diftinct Parts, all of a Regular, but Different $F_{i}$ gure. The utmoft Part, is always like a little Flower with Five Leaves and a Tubular Bafe, like that of Cowplip. So

Tab.59. that every Flower with the Florid Attire, Embofomes, or is, a Pofy. of perfect Flowers.

2. 6. In fome Flowers, every one of thefe Florets, is encompaffed with an Hedg of Hairs; and every Hair branched on both fides

Tab.59. almoft like a sprig of Fir; as in Aster Atticus, Golden-Rod, and others.

3. \$. The Bafe of the Floret is ufually $C$ ylindrick, but fometimes Tab.60. Square, as in French Marigold. And the Leaves hereof which, for the moft part, are Smooth on the Infide, in the fame Flower are all over Hairy. And the Edges of thefe little Flowers, are frequently Ridged, or as it were, He mid, like the Edge of a Band.

B.r. Ch. 5. 4. S. The midlemoft of the Three Parts, which I call the Sheath, $T a b .60$, is ufually faftened towards the Top, or elfe at the Bottom of the Floret.

61, 62. This is rather indented, than parted into Leaves. The surface feldom Plain or Even, but wrought with Five Ridges, and as many Gutters running almoft Parallel from the Top to the Bottom.

B.1. Ch.5. 5. \$. The Inmoft Part, which I call the Blade, runs through the hollow of the Two Former, and fo is faftned, with the Floret, to the convex of the Seed-CaJe. The Head and Sides of this Part, is always befet round about with Globulets, commonly through a Glafs, as big as a Turnep-eed, or a great Pins-Head. In fome Plants growing clofe

Tab.60, to the Blade, as in the common Marigold; in the French, and others,

61, 62. upon Pedicils or little flender Stalks. Thefe, as the Blade fpringeth up from within the Sheath, are ftill rubed off, and fo ftand like a Powder on them both. And fometimes, as in Cichory, they feem to grow on the Infide the $s h e a t h$, if it be fplit with a fmall Pin: as alfo in Knapweed, in which they are numerous. Yet in the seed-like Attire, always more numerous, than in the Florid.

Tab. 58, 6. The Head of the Blade is al ways divided into Two, and fome\&c. times into Three Parts, as in Cicbory; which, by degrees, curl outward, after the manner of Scorpion-Grafs.

7. 5. The Defcription now given, agrees principally to the Corymbiferous Kind, as Tanfy, Chamemile, and the like. But in Scorzonera, as alfo Cichory, Hawk-Weed, Moufear and all the Intybous Kind, with many 
more, the Attire is not feparate from the Foliature, fo as to ftand within that in one entire Pofy; but every Leaf of the Flower hath its own Attire apart. For the fake of which, the Bafis of every Leaf is formd into a little Tube or Pipe, whereby it embofomes its own Attire within Tab.62. it felf. Confifting commonly of 7 wo Parts, a Sheath and a Blade: the Leaf it felf anfwering to the Floret in other Flowers.

8. \$. In fome Plants, befides the Attire or Pofy in the midle of the Flower; the Leaves alfo have each their own to themfelves, as in Marigold: yet this, as I take it,confifting only of one fingle Part, which Tab. 6ז. anfwers to the Blade; the Leaf it felf being as the sheath.

9. 6. In many Plants, this Florid Attire is very large; fo that not only the Suits, but alfo the feveral Parts whereof every suit confifts, Tab. $6 \mathrm{E}$. being throughly ripe and well blown open, are all vifible to the bare Eye, as in Knapweed, and all the Thiftle Kind. This Attire is all the Flower, that this fort of Plants have; being, though Empal'd, yet without any Foliature.

10. \$. And fometimes, there is little or no Flower befides this Attire, although extream fmall, as in Golden Rod, Wormwood and others. Where it may be noted, That the Medicine called Wormfeed or Semen Santonici, is no Sort of Seed, but the Buds of fmall Flowers, or of the Florid Attire of that Plant.

\section{CHA P. V. Of the Ufe of the Attire.}

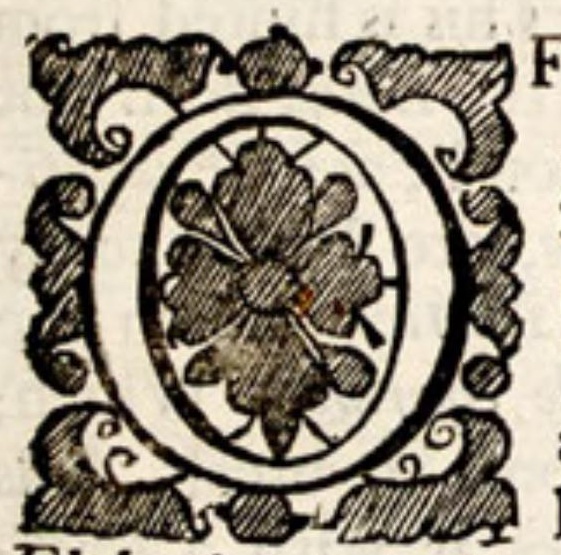

F the Secundary $\mathbb{U}$ e hereof, I have fpoken in the First 23aok; and particularly, of the Globulets or fmall Particles within the Theca of the Seed-like Attire, and upon the Blades of the Florid, I have conjectur'd, That they are that Body which Bees gather and carry upon their Thighs, and is commonly called their Bread. For the Wax they carry in little Flakes in their Chaps : but the Bread is a Kind of Powder; yet fomewhat moift, as are the faid little Particles of the Attire.

2. 5. But the Primary and chief $\mathcal{U} \mathcal{J}_{e}$ of the Attire is fuch, as hath refpect to the Plant it felf; and fo appears to be very great and neceffary. Becaufe, even thofe Plants which have no Flower or Foliature, are yet fome way or other Attir'd; either with the Seminiform, or the Florid Attire. So that it feems to perform its fervice to the Seed, as
the Foliature, to the Fruit.

3. \$. In difcourfe hereof with our Learned Savilian Profefior Sir Thomas Millington, he told me, he conceived, That the Attire doth ferve, as the Male, for the Generation of the Seed.

4. \$. I immediately reply'd, That I was of the fame Opinion; and gave him fome reafons for it, and anfwered fome Objections, which

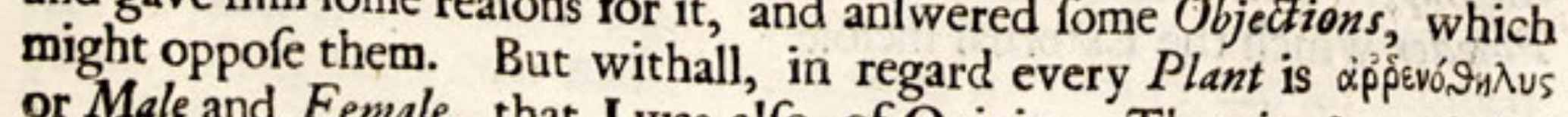
or Male and Female, that I was alfo of Opinion, That it ferveth for $\mathrm{E} \mathrm{e}_{2}$ 
the separation of fome Parts, as well as the Affufion of others. The fum the refore of my Thoughts concerning this Matter, is as follows.

5. 5. And Firf, it feems, That the Attire ferves to difcharge fome redundant Part of the Sap, as a Work preparatory to the Generation of the Seed. In particular, that as the Foliature ferveth to carry off the $V_{0}$ latile Saline Sulphur: So the Attire, to minorate and adjuft the Aereal; to the end, the Seed may become the more Oyly, and is Principles, the better fixed. And therefore the Foliature generally hath a much ftronger Odour, than the Attire: becaufe the Saline Sulphur is ftronger, than an Aerial, which is too fubtile to affect the Senfe. Hence alfo it is, that the Colour of the Parts of the Attire, is ufually Wbite, or Yellow, never Red: the former, depending upon a greater participation of Aer; the latter, of Sulphur. I add further, That the moft Volatile and Aerial Sulphur; being by means of thefe Parts much difcharged; it may hereby come to pafs, not only that the Seed is more Oylie, and its Principles more fixed; but alfo, that the Body or Parenchyma thereof, is fo compact and clofe: For although it confifts of Bladders, yet fuch, as are Twenty times fmaller than in any other Part of a Plant of the like bignefs. Whereas, were the Aer copioufly mixed with the sap here, as in the Pith, Fruit, and other Parenchymous Parts; it would give fo quick a Ferment to the $S a p$, as to dilate and amplify the Bladders of the Seed, beyond its prefent compact and durable Texture; and fo expofe it, either to a precipitant Growth, or fudden Rot. Wherefore, as the Seed-Cafe is the Womb; fo the Attire (which always ftands upon or round about it ) and thofe Parts of the $S a p$ herinto difcharged; are, as it were, the Menfes or Flowers, by which the Sap in the Womb, is duly qualified, for the approaching Generation of the Seed.

6. \$. And as the young and earlv Attire before it opens, anfwers to the Menfes in the Femal: fo is it probable, that afterward when it opens or cracks, it performs the Office of the Male. This is hinted from the Shape of the Parts. For in the Florid Attire, the Blade doth not unaptly refemble a fmall Penis, with the Sheath upon it, as its Preputium. And in the Seed-like Attire, the feveral Thece, are like fo many little Tefticles. And the Globulets and other fmall Particles upon the Blade or Penis, and in the Thece, are as the Vegetable Sperme. Which, fo foon as the Penis is exerted, or the Tefticles come to break, falls down upon the seed-Cafe or Womb, and fo Touches it with a Protifick Virtue.

7. 5. Confentaneous hereto it is alfo obfervable, That thofe Herbs generally have the Seed-like Attire, which either produce a greater Quantity of Seed, or a Perennial Root: and that there is no Tree, with the Florid Attire. As if the other, becaufe it contains a far greater Proportion of the abovefaid Particles, that is, of Sperm; 'tis able to beget a more Numerous, Vivaceous, or Gigantick Birth.

8. 5. That the fame Plant is both Male and Female, may the rather be believed, in that Snails, and fome other Animals, are fuch. And the Parts which imitate the Menfes, and the Sperm, are not precifely the fame: the former, being the External Parts of the Attire, and the $S a p$, which feeds them; the latter, the fmall Particles or moyft Powder which the External inclofe. 
9. \$. And that thefe Particles, only by falling on the Uterus, fhould communicate to it or to the Sap therein, a Prolifuck Virtue; it may feem the more credible, from the manner wherein Coition is made by fome Animals; as by many Birds, where there is no Intromilfion, but only an Adofculation of Parts: And fo in many Fifhes. Neither in others, doth the Penis ever enter any further than the Neck of the Womb. Nor doth perhaps the semen it felf: or if it doth, it can by no means be thought, bodily or as to its grofs Subftance, to enter the Membranes, in which every Conception, or the Liquor intended for it, before any Coitiou, is involved; but only fome fubtle and vivifick Efflsvia, to which the vifible Body of the Semen, is but a Vebicle. And the like Effluvia may be very eafily transfufed from the above faid Particles into the Seed-Cafe or Womb of a Plant.

Io. 6 . If any one thall require the Similitude to hold in every Thing; he would not have a Plant to refemble, but to be, an Animal.

\section{CH A P. VI.}

\section{Of the Time of the Getheration of the Flower.}

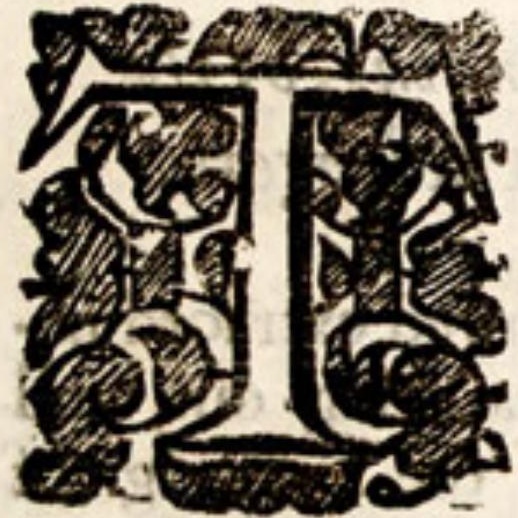

HE Time in which the Flower is Generated or Formed is a Providence in Nature, whereof, I do a little wonder, that no one, amongit fo many obfervers of Plants, hath ever yet taken any notice. It is therefore to be remarked, That all Flowers are formed or perfectly finifled, in all their Parts, long before they appear in fight; ufually Three or Four Montbs, and fometimes half a year, or more. And that in all Perennial Plants, thofe Flowers which appear and are called the Flowers of any one year; are not formed in that year; but were actually in Being, and entirely formed in all Parts, the year before; as in many
Herbs, and in all Shrubs and Trees.

2. \$. This will beft be feen by fome Inftances. So the Flower of Mezereon, which opens in Fanuary, is entirely formed about the midle of Auguft in the year foregoing. At which time, the Green Leaves of the Bud being cautioufly removed, the Leaves of the Flomer, and the Tab. 63 . Theca Seminiformes or Seed-like Attire, encompaffing the Seed-Cafe,
through an indifferent Glass, are all diftinctly vifible.

3. S. The like may be feen in Sirynga, and other Shrubs, and in Trees. In as many of which, as are Frugiferous, the Fruit alfo, which
anfwers to the Seed-Cafe in other Plants, is about the fame time entire-
ly formed. y formed.

4. \$. And fo in Herbs; as the Flower of Afarum, which appeareth in April or May, is entirely formed in Auguft or Fuly of the foregoing
year. For there are here, as well as in Trees, Two Sorts of Buds; fome Tab.64.
which are compoled only of Geen which are compofed only of Green Leaves; and fome which alfo contein a Flower and the Seed-Caje. So in Bears-foot, by fome called the fanuary Rofe, the Flower-Buds, which open in fanuary are all formed in or before the Month of Auguft in the year preceding. 
5. 6. The fame may alfo be feen about the end of Auguft or the be-

Tab.63. ginning of September in a Tulip-Root. In which, the Two Inmoft Shells dryer than the reft, ftand hollow, with the little young Flower (which appears in March or April following) inclofed now in their Centre. Being thus kept warm and $d r y$, left it fhould either perifh, or be precipitated upon the Winter, by fprouting too foon.

6. 5. From hence it is plain, That although the Flower appears before the seed; yet if the comparifon be made betwixt the Flower and Seed of the fame year; the Seed is firft formed, and afterward the Flower. That is, the seed, for which Nature choofes the Firftborn Sap, is formed in the fore part of the year: which work being finifhed, out of the lefs fecund part of the Sap, the Flowers intended for the Sire and Matrix of the next years Seed; is afterwards produced.

7. 5. THE true Time of the Generation of the Flower being know'n, it may alfo be an Inducement to make Tryal, for the bringing of many Flowers to grow fairly in Winter, which are ufed to grow, that is, to appear, only in the spring and summer: $\int c$. by keeping the Plants warm, and thereby enticing the young lurking Flowers to come abroad.

\section{The Appendix.}

\section{Being a Method propofed, for the ready finding, by the Leaf and Flower, to what Sort any Plant belongeth.}

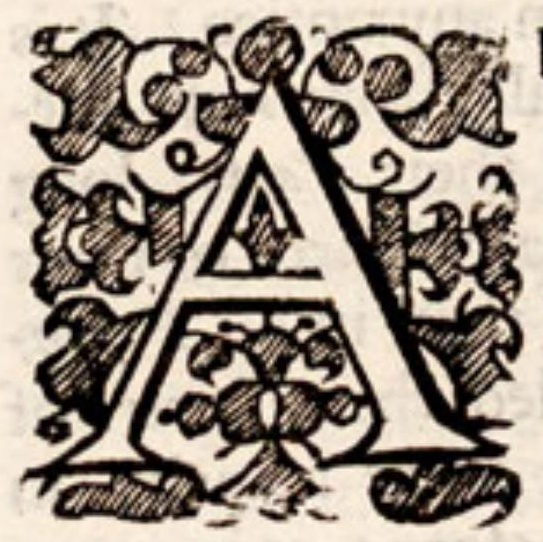

L T HOU G H many have beftowed extraordinary Care and Induftry upon the fearching out, and Defription of Plants; and for the reducing of them to their feveral Tribes: yet I will take leave, here to propofe a fhort Method whereby Learners, feeing a Plant they know not, may be informed to what Sort it belongs, and fo be directed where to find it defcribed and difcourfed of. For, except they have a Mafter to conduct them, which few have; they muft needs, by feeking at random, lofe a great deal of time, which by a regular Enquiry might be faved. Befides, that what is learned by their own Obfervation, will abide much longer on their mind, than what they are only Poynted to, by another.

2. 5. Now the moft Pbilofophick way of diftinguifhing or forting of Plants, were by the Characteriftick Properties in all Parts, both Compounded, Conftituents, and Contents. But of the Compounded, the Seeds, and fome other Parts, are oftentimes very minute: and the Roots always lie hid. As alfo the Conftituent Parts, every where, without cuting and the ufe of Glafjes. Nor can the Contents be accurately obferved otherwife. So that for the $\mathcal{U}_{\int}$ here intended, thofe Properties are the fiteft to be infifted upon, which are the moft Conspicuous, and in thofe Parts, where the Learner may the moft readily and without any difficulty take notice of them; as in the Flower and Leaf. The Flower hath Varieties enough of it felf. But in regard it is often wanting, when the Green Leaf is not; it is therefore convenient, that he be affifted 
by both, and that the Varieties of both be diftinaty reduced unto $T_{a-}$ bles. Which may be done, after the following, or fome other like manner.

3. \$. And Firft for the Leaves. The moft obvious Varieties of which, are in their Pofition, Size or Shape.

4. 6. Leaves are faftned with, or without a Stalk. Without, only clofe to the Branch, as in Soutbiftle; or furrounding it, as in Thorow-Wax.

5. 5. Both thefe ways, they ftand either fingly, that is, but one at the fame height ; or more together.

6. \$. More together, in Even or Odd Numbers. In Even Numbers, commonly Two and Two, as in Sage, Polium; Sometimes Four, as in Crofs-wort, Madder, Herb True-Love, Pomum Maje; or more, as, I think, in Woodrofe, \&c. In Odd Numbers, Three, as in all Trefoyls, stramberries; Five, in Pentaphil, Caftanea Equina; Seven,in Tormentil.

7. 6. The Sizes of Leaves are innumerable. It is therefore neceffary to reduce them to a Standard. And fo, they may be reckoned, Three; Small, Mean and Great: with refpect to the Length of the Leaf, the Breadth, or both. From one Inch and under, all Leaves may be accounted small; from one Inch and over, to five Inches, Mean; from five and over, Great.

8. 6. The shapes of Leaves are alfo numberlefs. But the moft obvious diftinctions which they admit of, are fuch as thefe;

9. 6. Leaves are Membraneous, as the greater part ; squameous, as Abies, or Filamentous. Which are folid, as in Fenil, Meum, Buphthalmum, Chamemile, Groundpine; or hollow, as in Onion.

10. 5.. Membraneous, have all their main Fibres produced either from the Stalk, as in Holyoak; or from the middle Stem of the Leaf, as in moft. From the midle Stem, reciprocally, as in Scabious, or oppofitely, that is, one over againft another, as in Rofe : and both ways, at Acute Angles, as in molt; or Right, as in Dandelion.

I I. 5. Again, they are different with refpect to the Top, the Bottom, and the Sides. The Top is Thorny, as in Furz; or Unarmed. Unarmed, either Produced, that is, Poynted, or at leaft, Roundifh, as in Lamium, Ironwort; or elfe Reduced, as in Woodforrel. And fo the Bottom, is either Reduced towards the Top, as in Ground-Ivy; or Produced upon the Stalk, as in Poplar, Bay, \&c.

12. 5. The Sides or Edges of the Leaf, are either of one and the fame Meafure, as commonly; or of divers, as in Doronicum. Both ways they are Even, as in Syringut, Mous-ear; or Uneven. The Uneven, are Prickly, as Holly, Eryngium, Thifle; or Unarmed. Unarmed, are Infected, or Refected. Infected deeply, that is, Lobed, as Golden Liverwort, Clematis Peregrina; or with fhallow Infections, as in moft. And fo, Indented, or Scallopped: the former, when the An$g l e$ is made with Straight Lines, as in Dandelion; the latter, with Crooked, as in Thalictrum. Refected, that is, both Lobed, and Infected, or when upon the greater Infections, there are other leffer ones, as in Wild-Clary, Lovage, Mafterwort.

13. \$. THE moft Confpicuous Varieties of Flowers, are in their Pofition, size, shape, and Colour.

14. \$. Moft are faftned with stalks; but many without. Sometimes, they are placed round about the Branch, that is, Coronated, as 
in Pulegium; and fometimes, all on one fide; either in Ranks only, as in Bawm; or in Rank, and File, as in Foxglove. In Saxifraga Aurea, they grow on the Leaf.

15. 5. Again, they either ftand Singly, as in Corn Marigold; or Cluftur'd. And fo, either all upon one $B r a n c h$, or on feveral little $R_{a-}$ mificated Sprigs. On one Branch, prolonged like a Tail, as in Blattaria; or Contracted. And fo, either without Stalks, that is, Capitated, as in Scabious; or with Stalks, that is, Umbellated, as Fenil, \&c. On feveral Sprigs, as in Tanacetum, Tarrom.

16. 5. The Sizes of Flowers, as of the Leaves, may be reduced to Three. From $\frac{1}{2}$ an Inch and under, in Diameter or Length, may be accounted small. From $\frac{1}{2}$ an Inch and over to an Inch and $\frac{1}{2}$, may go for Mean. And from an Inch and $\frac{2}{2}$ and over, Great.

17. In refpect of the Shape, Flowers are Open or Belly'd. Open have both Leaves and Attire, as moft; or elfe are all Attire, as of Burdock, Beta Cretica.

18. \$. The Open, confift of a Certain Number of Leaves, One, Two, Three, Four, Five, Six, Seven, Eight, Nine, Ten, Tbirteen, or One and Twenty. Uncertain, commonly called Double. Thofe of a Certain Number, either Uniform, that is, all of a certain size and Shape, as ufually; or Biform, or Triform, as in Iris, Blattaria. And thefe again, Even Edged or Notched; with Three Poynts, as in Marigold; or Five, in Cichory.

19. 5. The Bellyd, are either fo in whole; or in Part, that is, with the Top divided into Leaves, and the Bottom, Hollow: The former, are alfo Even Edged, as inConvolvulus; or Notched, as in Trachelium. The latter have their Leaves diftinguifhed as before. Their Bottom or Bafe, either faftned to the Seed-Cafe, as in Snap-dragon; or ftanding below it. And fo, either Straight, as I think in Toad-flax; or Crooked, as in Violet, Lark-heel.

20. 5 . In all thefe, the Attire is either Seminiform, or Florid. And both, Cluftur'd, or Divided; as in Mallow, St. foluns woort ; Starwort, Hawkweed.

21. 6. The Colours of the Flower, are White, as in Water-Cromfoot; Red, as Lychnis; Blew, as Borage; Purple, as Stock-Fuly. Flower; Black, as in fome Anemones; Yellow, in Wall-Flower; Tawny, in Colus fovis; Green, in Laureola. Which are either Single, or Mixed: Two together, as in Butyr-Bur, White and Red; in White Hellibore, White and Green; in Monks Rubarb, Red and Green; \&c. Or Three together, as in Pancy, Yellow, Blero, and Black, i. e. atro-purpureus.

22. 5 . How far thefe, and fome other like Diftinctions, being reduced to Tables, would ferve for the finding out of any Sort of Plant, may be conceived, if we confider, how great a Variety, a few Bells, in the ringing of Changes, will produce. And the fearch will be eafy, and fuccefffull, if in every foregoing Table, reference be made to thofe that follow; and in the Tables conteining the laft Divifions, the Names of the Plants therein poynted out, be expreffed. 


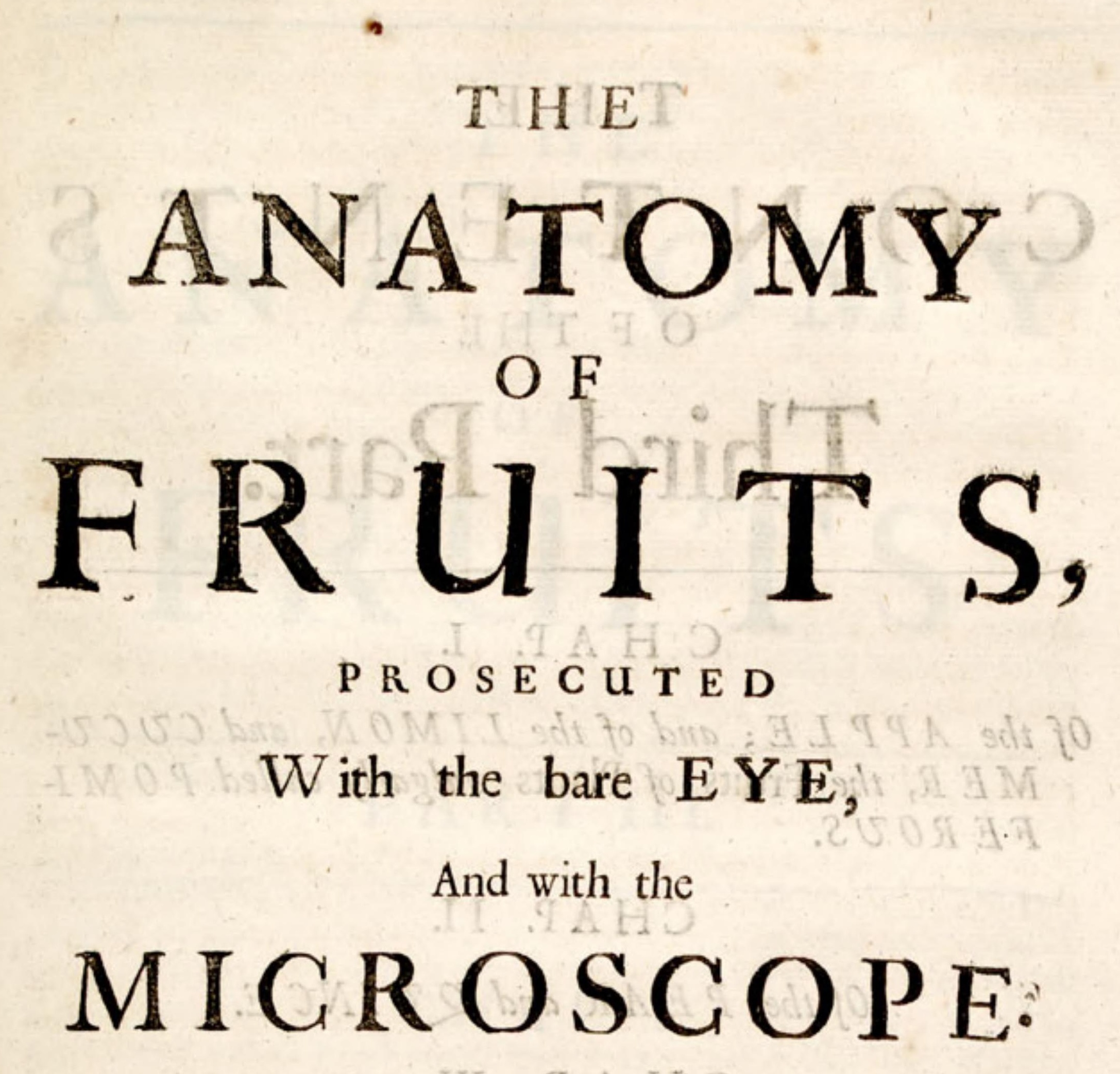

Read before the Royal Society, in the Tear $1677^{\circ}$

The THIRD PART.

By $N$ E HE $M \mathcal{F} A H \mathcal{G} R E W$ M.D. Fellow of the ROYALSOCIETY, and of the COLLEGE of PHYSICIANS.

\section{$L O N D O N$}

Printed by $W$. Ramlins, 1682. Mo.Bot.Garcin, $\mathbf{f} £$ 


\section{T $\mathrm{HE}$}

\section{O N T E N T S}

O F THE

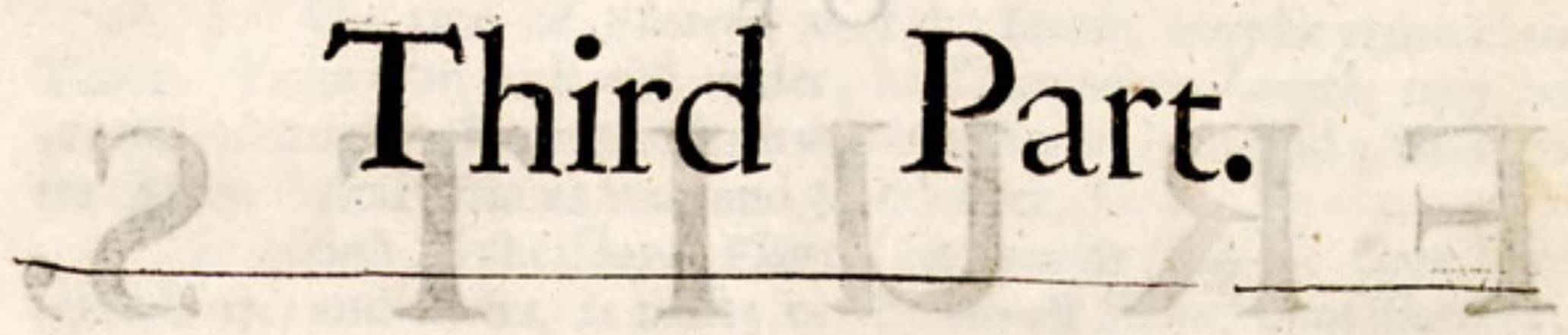

C H A P. I.

Of the APPLE; and of the LIMON, and CVCV$M E R$, the Fruits of Plants vulgarly called POMIFEROUS.

CHA P. I I.

1) Of the PEAR and QVINCE. C H A P. III.

of the P LUM, and fome other Fruits of the fame Kindred C H A P. IV.

Of the GRAPE, and HAZEL-NVT; with fome other Fruits analogous to each of them.

\section{wollo' OMA GHA P. V.}

Of the SEED-CASE or MEMBRANEOUS UTERUS:

\section{CH A P. VI.}

Of the USE of the Parts to the Fruit.

C H A P. VII.

Of the US E of the Parts to the Seed. And the T IME, in which, the Uterus or Fruit and Seed-Cafe are formed. 


\section{T H E}

\section{A N A T OM Y}

$\mathrm{OF}$

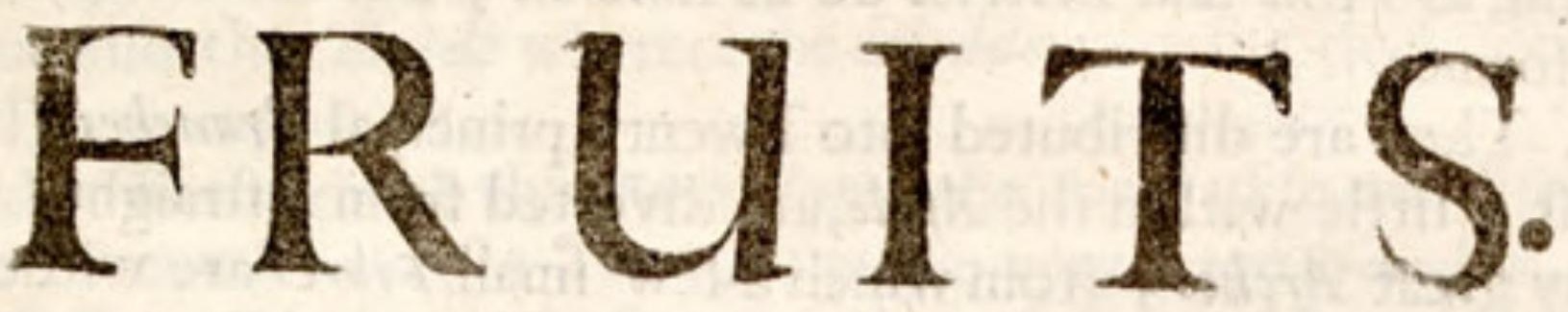

\section{H A P. I.}

Of the APPLE; and of the LIMON, and CVCV. $M E R$, the Fruits of Plants vulgarly called $P O M I$ FEROUS.

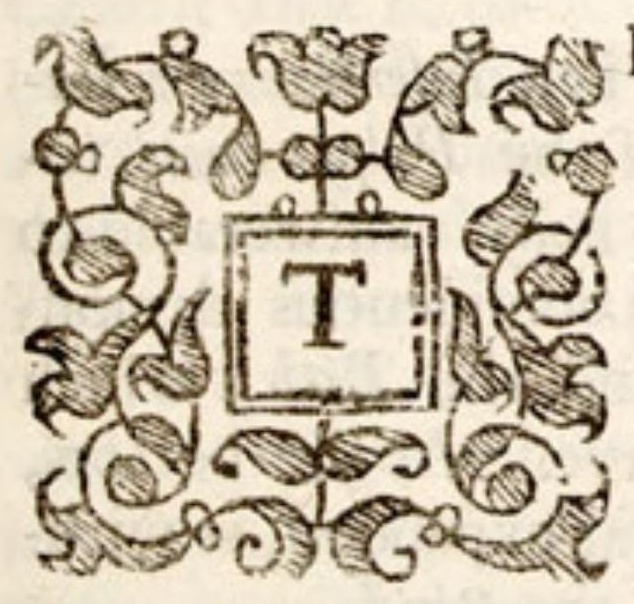

$\mathrm{H} \mathrm{E}$ Defription and $\mathcal{U} \int \mathrm{e}$ of Leaves and Flowers, together with the Figures thereto belonging, were prefented to this Honourable Society, the laft year. I fhall conclude this Subject with Fruits and seeds; beginning withFruits, which will take up the prefent Difcourfe.

2. 5. And Firft, I thall defcribe the ComWhich pounding Parts of forme, more generally known. Which having done, I thall next obferve the U fes of the fame; either for the Fruit it felf, or for the Seed. Some of the Defcriptions, the Reader may be pleafed to compare with thofe in the Firft 2300 k. Ch. 6 , I begin with the Apple; to which I thall fubjoyn the Limon, and $C u$ cumer, commonly reduced to the Pome Kind.

3. 5. A N A P PL E, befides the Skin, confifteth of a Parenchyma, $V e f f e l s$, and Coar. The Parenchyma or Pulp, is the fame with that of the Barque of the Tree. As is apparent, not only from the vifible continuation thereof from the one, through the Stalk, into the other: but alfo from the Structure common to them both; being both compofed of Bladders. In which, notwithftanding, there is this difference,

$$
\text { Ef } 2 \text { That }
$$


That whereas in the Barque, they are $\int$ pherical, and very fmall, moft of them, through a good Glass, not exceeding $\frac{1}{10}$ th of an Inch in Diametre, and fome of them, lefs: here, they are oblong and very large, moft

Tab.65. Of them about $\frac{\mathrm{d}}{3} \mathrm{~d}$ of an Inch in Length, or more, according to the largenefs and tendernefs of the Fruit; being all uniformly tenter'd or ftretched out, by the arching of the Veffels, from the Coar towards the Circumference of the Apple.

4. 5. The VefJels, as in the other Parts of a Plant, are Succiferons, and for Aer. Both the Branches of the former, and the fingle Veffels of the latter, are extream fmall. They run every where together, not

Tab. 65. collateral, as Veins and Arteries do in Animals; but the latter, fheathed in the former.

5. 5. They are diftributed into Twenty principal Branches. The Ten outmoft, a little within the Apple, are diverted from a ftraight Line, into fo many great Arches; from which a few fmall Fibres are without any order difpearfed through the Apple. The Five middlemoft, and the Five inmoft, run in a ftraight Line as far as the Coar, and are there di-

Tab.65. verted into as many leffer Arches; the former, at the outer, and the latter at the iner Angles of the Coar. Upon thefe Five inmoft hang all the seeds.

6. 6. Thefe Ten, and the other Ten abovefaid, do all meet together at the top of the Apple, where originally, they all ran into the Tab.65. Flower. But betwixt them, there are fcarce any intercurrent Fibres; of the Apple.

7. 6. A LIMON hath a Threefold Parenchyma; which feem to be derived one from another : the Texture, upon every derivation, being fomewhat altered, and fo made more clofe and elaborate. The utmoft, called the Rind, hath the moft open, and the courfeft Texture; being compofed of the largeft Threds, and thofe Threds woven up into larger Bladders. Thofe little $C_{e}$ ells, which contein the Effential Oyl of the Fruit, and ftand near the Surface of the Rind, are fome of the faid Bladders much more dilated.

8. 5. From this utmoft Parenchyma. Nine or Ten Infertions or Lamells are produced, betwixt as many Portions of the Pulpy Part, towards the Centre, where they all unite into one Body, anfwerable to the Pith in the Trunk or Root of a Tree; and is a confpicuous demonftration, of the communion betwixt the Barque and the Pith; which

Tab. 66. there, is much more obfcure and difficult to obferve. At the bottom, but efpecially the top of the Fruit, the Pith is fo far expanded, as without the mediation of any Lamels, to be joyned to the Rind.

9. 5. Throughout this Parenchyma, the $V e f f e l s$ are difpearfed. But the chief Branches ftand on the iner Edge of the Rind, and the outer

Tab. 66. Edge of the Pith, juft at the two extremities of every Lamel. From thofe Branches on the Edge of the Pith, other little and very thort ones thoot into the Pulp of the Fruit, upon which the seeds are appendant. In the Centre of the Pith, are Eight or Nine, in a Ring, which run through the Fruit up to the Flower.

10. 6. Between the Rind and the Pith and thofe feveral Lamels, which joyn them together, ftands the fecond Sort of Parenchyma, different from the former, in being fomewhat clofer, and finer wrought Divided, by the Lamels, into feveral diftinct Bodies; every one of them a great and entire Bag. 
II. 6. Within every great Bag, is conteined a Third Parenchyma, which is alfo a Clufter of other little Bags, about the bignefs of an Oate, all disjoyned one from another, and having their diftinct Stalks, Tab.66. of feveral Lengths, by which they are all faftned to the utmoft Side of the great Bag, wherein they are conteined. Within each of thefe leffer Bags are conteined many hundreds of Bladders, confifting of moft extream fine Threds woven up together into that Figure. Within thefe Bladders lies the Acid Fuyce of the Limon.

12. 6. A CUCUMER, hath alfo a Threefold Parenchyma. The Utmolt, is derived, from the Barque. In this, being expofed for fome time to dry, and then cut tranfverfly with a Rafor; not only the Bladders, but alfo the Threds whereof the Bladders confift, through a good Microfcope, are apparent.

13. 6. Throughout this Parenchyma the Sap-Veffels are difperfed; near the Circumference, in Ten or Twelve very large Branches. Each Tab. 66, of thefe larger Branches, embofoms another of Aer-Vefjels in its Centre. Adjacent to the Midle Parenchyma, they ftand in Cluftres of much fmaller Branches, but more numerous.

14. 6. Out of all thefe Sap-Veffels, iffues a tranfparent and vifcous Mucilage; which being dryed, becomes as hard and tough as Gum Tragacanth. Analogous to which, I fuppofe, is the truly purgative part of Elaterium.

15. §. The Midle Parenchyma is derived from the Pith; and divided into Three Colums, ftanding triangularly, and having each of them Tab. 66 . a Triangular Figure. Within thefe Colums ftand a diftinct Sort of Sap$V e f f e l s$ : from whence, feveral fmall and fhort Fibres thoot into the Inmoft Parenchyma, whereupon the Seeds do hang. So that thefe Columns are as it were the Beds on which the Seeds grow. With each of the Seed-Branchs or Fibres,goes fome part of the faid Parenchyma or Colum, out of which, the Covers of the Seed are formed.

16. 5. The Inmott Parenchyma wherein the Seeds lie, and which anfwers to the Pulp of a Limon, feems likewife to be derived from the Tab.66.
Colums, that is, to be originally thence produced upon the Seed-Fibres, and afterwards fpread and augmented into a Pulp. By Three Infertions from the Colums, and as many from the Utmoft Parenchyma, and thefe re-inferted; it is divided into Six Triangular Bodies; and every Triangle, into Three Ovals.

17. 6. A near refemblance betwixt the Garden and Wild Cucumer, with refpect to the Inward Structure, as well as the Outward Figure, Tab.66. may be obferved: Both of them having a Threefold Parenchyma. Yet with this difference, That the Three Wbite Triangular Bodies or $\mathrm{Co}_{0}$ lums in the one, is anfwered by a White Ring or Tube in the other. 


\section{H A P. II. \\ Of the PEAR and QUINCE.}

Tab.67.

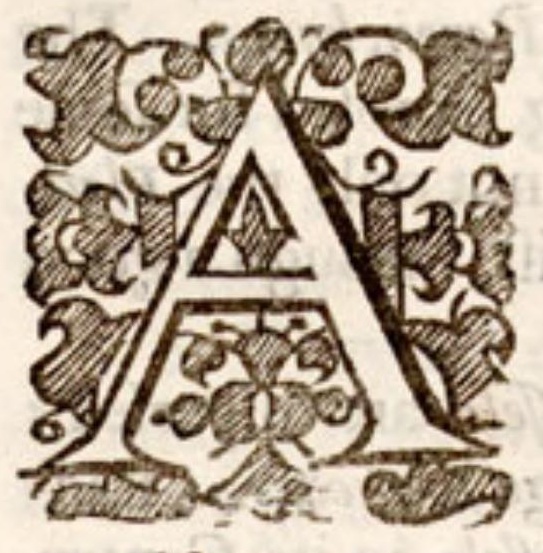

PE A R, befides the $S$ kin, confifteth of a Twofold Parenchyma, of Veffels, Tartareous Knots or Grains, and a Coar. The Skin is lined with a great number of the faid Tartareous Grains, through a Glass, about the bignefs of fmall Shot: whereby it looks withinfide, like the Skin of the Scate and fome other Fifles. Befides thofe which grow to the $s$ kin, there are alfo many more ftanding near adjacent to it all round about the Fruit : altogether about $\frac{1}{3} \mathrm{~d}$ of an Inch in thicknefs, through a Microfcope; as in a Slice of a Pear cut tranfverfly is apparent. Somewhat more or lefs, as I take it, according to the Delicacy or Harfhnefs of the Fruit; as more in a Burgamy, or other foft and weet Pear, than in thofe which are called Strangulatoria. As all Vinous Liquors, and thofe efpecially which are the moft Tartareous, become more foft and fweet, according as they caft off their Tartar, in a greater quantity, upon the Sides of the Veffel.

2. 5. The Outer Parenchyma, is of the fame Original, and general Structure, as in an Apple. But the Bladders, anfwerable to the Shape of this Fruit, not altogether fo long, with refpect to their Bredth.

Tab.67. Throughout this Parenchyma, are alfo difperfed many fmall Tartareous Grains; moft of them fomewhat round, as thofe next the skin, and of a like Size; but nothing near fo numerous.

3. 6. The Bladders here, have alfo a different Pofition from that they have in an Apple: there, they are all fo ftretched out, as to have refpect to one common Centre, which is that of the Apple it felf. But

Tab.67. Gere, they every where bear a refpect to the faid Tartareous Grains, every
Grain being the Centre of a certain Number of Bladders; like a Star, in the midle of its Vortex. Whereby, fo many of the Tartareous parts of the Sap, as cannot well be thrown off upon the skin, are more commodioufly difcharged, upon every little Knot or Grain, nearer hand.

4. \$. Throughout this Parenchyma, the Veffels likewife are difperfed. Of the Two general Kinds, for Sap, and for Aer. The Aer-Veffels, are here extream fmall, as well as in an Apple; yet one degree, larger. They are both together diftributed into Fifteen principal

Tab. 67. Branches. The Five Utmoft make as many Arches, but commonly not near fo deep as in an Apple. From thefe, fome fmall Fibres, yet a little more numeroufly than in an Apple, are difperfed throughout the Parenchyma. The Ten Inmoft run along to the Seed, and from thence, with the other Five, to the Flower.

5. §. Next the Coar, ftands the Inner Parenchyma, in divers refpects different from the Outer. The Bladders of the latter, as hath been faid, large and long; of the former, fmall and round, anfwerable to thofe of the Pith, of which it feems to be derived. Throughout that, 
the $V_{e} \int f e l s$ and Tartareous Grains are difperfed; in this, there are neither. The Effect whereof is, that is fweet, this fower; for which Tab. 6\%. reafon, I have taken leave to name it, the Acetary.

6. 6. Betwixt this and the outer Parenchyma, the faid Tartareows Grains begin, firft to ftand nearer together, to grow biger, and of a more unequal Surface; and by degrees, to unite into a Body, in fome Pears, and efpecially towards the Cork, almoft as hard as a Plum-Stone; Tab. 67. which I have thereupon, named the Calculary. So that a Pear, is $\mathrm{Na-}$ tures Preface or Introduction to a Plum.

7. \$. This Tartareous Body, and thofe fmall Grains above faid, I have formerly fuppofed, to be precipitated out of the $S a p$, by virtue of $B . x^{-C h .6 .}$ the $V$ effels. Which is not only argued from their growing, where the Veffels, only in the outer Parenchyma : but in that the very Bounds or Figure of the Calculary, is determined by the situation of the chief of $T a b .67$ thofe Veffels; as in cuting a Pear fmoothly through the Centre and by the Length, is apparent.

8. 6. The Coar as well as the Acetary, feems to be derived from the Pitb. And is therefore leffer here, than in an Apple, where the whole Pith of the stalk, goes to the making of the Coar only.

9. 6. In molt Pears, at the bottont of the Coar, and a little below the Centre of the Fruit, there is a kind of fmall Umbelical Knot; from Tab.67. whence is extended a ftraight Chanel or Ductus, which opens at the midle of the Cork or Stool of the Flower, fcarce wide enough to admit the fmalleft Pin. Made for the $\mathcal{U} f$ hereafter mentioned.

I0. 5. A QUINCE, is nearly allyed to a Pear. The differences betwixt them are thefe; In the 2uince, the outer Parenchyma is more clofe, that is, the Bladders are fmaller. The Veffels more numerous, and more deeply enarched; the Calculary greater, and more $T_{a} b .6 \%$ fpread; according to the Shape of the Fruit : but the Acetary, lefs: The Coar ftands higher or nearer to the Cork; divided, not into Five, but Four Celis. And the Ductus from the bottom of the Coar to the top of the Fruit, much more open and obfervable.

\section{H A P. IIİ.}

\section{Of the PLUM, and fome other Fruits of the fame Kindred.}

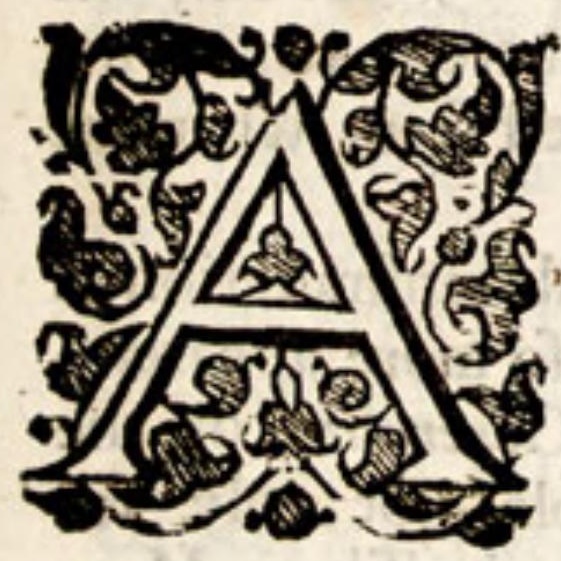

PLUM confifteth of a Parenchyma, the $\mathbf{T}_{\text {wo }}$

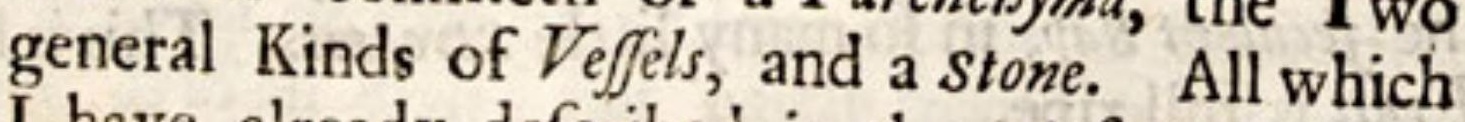
I have already defcribed in the Firft $2 b_{00 k}$, I $C b .6$. thall here add, and further clear fome things. And Firft, it is to be noted, That, in Proportion to the Bulk of the Fruit, there are more $V e f f e l s$ in a Plum, than in an Apple, Pear, or Quince. As alfo, That in Plums, all the Veffels are braced together into one Uniform Piece of Net-Work, every where terminating at an equal diftance from the Circumference, $\int_{i}$. 'th of an $T a b .68$. Inch or thereabout. And asfor the Bore of the Aer-Ve $\int e l s$, although
the Glass I ufed, when I examined this Fruit, would not reach it ; yet 
is it to be prefumed, that they bear a juft Proportion to thofe in the Trunk of the fame Tree; and that therefore they are here larger, than in an Apple or Pear. The Skin likewife of a Plum, is more fibrous, thick, and tough, than in thofe Fruits. The Ends of thefe Diverfities, we fhall prefently fpeak of.

2. 5. Of the stone, amongft other particulars wherein the conB.I. Cb.6. trivance of Nature is very admirable, I have formerly fhewed, That it is compoled of Two or rather Three diftinct Bodies. One of them, the Lining; which anfwers to the Coar in a Pear. And is originated from the Parenchyma, which the Seed-Branch brings along with it, through the Chanel in the Side, and at laft into the Hollow, of the Stone; and is there fpread all over it: as when a fmall Glass-Pipe, is blown and expanded into a Bubble. Or as if a Bladder, being ftretch-

Tab.68. out, and put through the Neck of a Bottle; were then blown up, fo as to be every where contiguous to the Sides, and become, as it were, the Lining of the Bottle.

3. 5. The Foundation or Ground of the Outer and more Bulky Part of the stone, is the Iner Part of the Parenchyma; and anfwers

Tab. 68. to the Acetary in a Pear. As the Fruit grows, the Tartareous Parts of the $S_{a p}$, being continually precipitated upon this Parenchyma, it is hereby petrify'd. As will beft be feen, by comparing the feveral $A$ ges of the fame Fruit together. And in fome Stones; on the Surface

Tab. 68. whereof, fome of the faid Tartareous Parts appear in diftinct Grains. So that whereas in a Pear, the Calculary and the Acetary are diftinit, here in a Plum, they are thrown one into the other. Or, as fome Mineral Waters only make a Cruft about a Stick or other Bodies immerfed in them; but others, by finking into thefe Bodies, do hereby petrify them: So in a Pear, the Tartareous Parts of the Sap, only make a Cruft about the Acetary; but in a Plum, they fink into the Body thereof, or that Part of the Parenchyma, which ftands in the place of it, whereby it is converted into a stone. The Figures of stones fhall hereafter be fpoken of, when I come in the next 1 (Datt, to the $C_{0}$ -
vers of the Seed.

4. 5. A N A PRECOCK is of the Plum-Kind. But fome things are herein better obferved. As firft, the Pofition of the Bladders of the Parenchyma. For the Tartareous Parts of the $S_{a p}$ not being here difperfed, in little Grains, throughout the Fruit, as in a Pear; but all thrown off into the Stone: the Bladders therefore are fo difpo-

Tab.68. fed, as not to have refpect to feveral Centres, as in a Pear; but only the stone, to which they all do moft exactly radiate; thereto conveying the feculent sap, in fo many little streams. This is beft feen, when the Fruit is full ripe.

5. 5 . In this Fruit, while it is young, the gradual tranfmutation of the Inner Part of the Parenchyma into a Stone, is alfo more apparent. And fo are the Three $C_{\text {oats }}$, which ferve for the Generation of the Seed; being now all very diftinct; and remarkable, not only for their Bulk; but alfo, the Analogy which they bear to the Three Membranes in many Viviparous Animals. Whereof I thall give a more particular Defcription, when I come, in the following 1 Patt, to the $\mathrm{Co}^{2}$
vers of the Seed.

6. \$. A PEA CH hath a much bigger stone, than either a Plum, or an Aprecock: and hath therefore, when full ripe, and efpecially in 
hot Countries, a more defecated or better fined Fuyce. For the reafon why the stone is fo great, is becaufe the VefJels run fo very numeroufly through the Body of it; and fo caufe a more copious precipitation of the Lees of the Sap thereinto.

7. 5. A CHEERY is likewife near related to a Plum. But the Bracement or Reticulation of the Veffels, is here carried out further, fo as to be all round about contiguous to the $s k i n$. And as the Aer- Tab.69. $V$ effels in the Branch of a cherry-Tree, are larger than thofe of an $A p$ ple-Branch, but lefs than thofe of a Plum-Branch; fo may they be prefumed, to bear the fame Proportion here in the Fruit,

8. \$. A WAL NUT, is a Nuciprune; or betwixt a Plum and 2 Nut, as a Bat is betwixt a Beaft and a Bird. For the Rind, anfwers to the Pulp; and the Shell, as the stone, is alfo lined. But the seed-Veffels, which in a Plum run through a Chanel made on purpofe in the Stone; do here enter, as in a Nut, at the Centre of the Shell. By which means, they are invefted with a more fair Parenchyma; which Nature hath provided, as her cloth, for the making of the Coats wide enough
for fo vaft a Kernel.

\section{H A P. IV.}

\section{Of the GRAPE, and HAZEL-NVT; with fome other Fruits, analogous to each of them.}

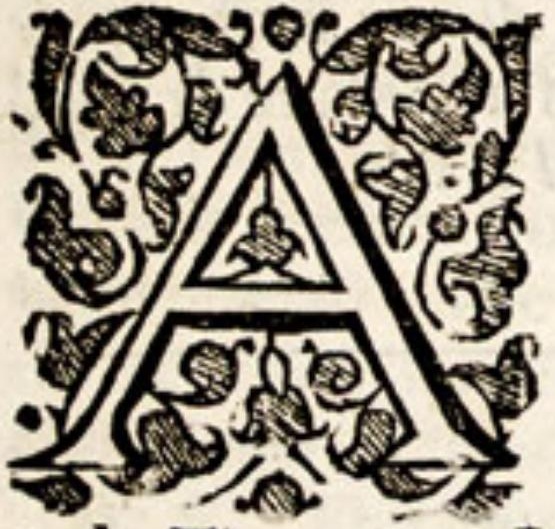

GRA PE, is a plum with two stones; for their thicknefs, as hard as any other. The Diftribution of the Veffels is alfo fomewhat different. For the Tab.69. principal Fibres running up directly betwixt the Stones; and the fmaller, making cnly one fingle Net, near the Circumference; they all meet togeted, That many Lignous Fibres are vifibly mixed It is alfo to be nowhereby it becomes very thick and tough. And as the Aer-Vefels in So is it to be prefumed Fruits of thofe Trees.

2. \$. The Parenchyma or Pulp of a Grape, feems to be derived, not from the Barque, as in an Apple; nor partly from the Barque, and partly from the Pith, as in a Gooskerry: but wholly from the Pith; at leaft, as far as the Reticulation of the Fibres; and the skin only from the Barque; whereby the $P$ ulp becomes fo tender and delicate a Meat. 3. 5. A GOOSBER R Y, hath a Threefold Parenchyma. The Utmoft is derived from the Barque; of a Greener Colour, and very sappy. The midlemoft, from the pith; fomewhat wbite, and more Bladders are very al Infertions in fome Roots. In both of them, the prefent think of confpicuous, above what they are in any Fruit, I at G good Eye without a Glass. 
Tab.69. 4. 6. Betwixt thefe Two Parenchymas, do run moft of the principal Fibres, or Vafcular Threds. From which feveral fmaller ones are branched into the Inmolt Parenchyma; upon which, the Seeds do hang.

5. 5. Each of thefe fmaller Branches is invefted with fome part of the midle or white Parenchyma. Serving partly to make the Covers of the Seed; and partly, the Pulp, that is, the Inmoft and fineft Parenchyma of the Berry, in which the seed lies.

A white C O R IN, without taking off the skin, fheweth not unpleafantly how the Seeds are faftned. For as the Trunk of the Tree continues not to any confiderable Length, entire, as in a Plum, but is prefently divided into feveral Boughs; nor are the Edges of the Leaf entire, as alfo in a Plum, but flit into feveral Lobes; and the Fruit, into a great many Corins in a Bunch: So again, the seeds do hang upon the Fibres, like Two other Buncbes, in every Corin. As by Refraction, Objects of all Sizes are reprefented on the Walls of the Eye. The Operations of Nature being every where Uniform: and fometimes the fame in fmall, tranfcribed from a greater Copy.

7. 5. A N U T, is a Plum inverted, or turned infide outward. For the Shell, ftanding naked, includes the Parenchyma: the bearded $C_{a p}$, not precifely anfwering to that, but to the Empalement of the

Tab.69. Flower; which likewife in many other Plants, out-lives the Foliature and Embofomes the Uterus of the Seed. And whereas the stone of a Plum is not Faced, but Lined with a Parenchyma derived at fecond hand from the Pith: The shell of a Nut is not Lined, but Faced with the iner Skin of the Cap.

8. \$. A N AKERN, is the $N u t$ of an oak. Yet with this difference; That befides the Cup, it ftands in, it hath only a Leatbern or Parchment Cover inftead of a Shell. From whence it come to pafs, that whereas the Kernel of a Nut is fweet; that of an Akern, is of a very rough Taft: the Auftere Parts of the Sap, which in a Nut are drained off into the Shell, being here imbibed by the Kernel it felf.

\section{H A P. V. \\ Of the SEED.CASE or MEMBRANEOUS VTERVS.}

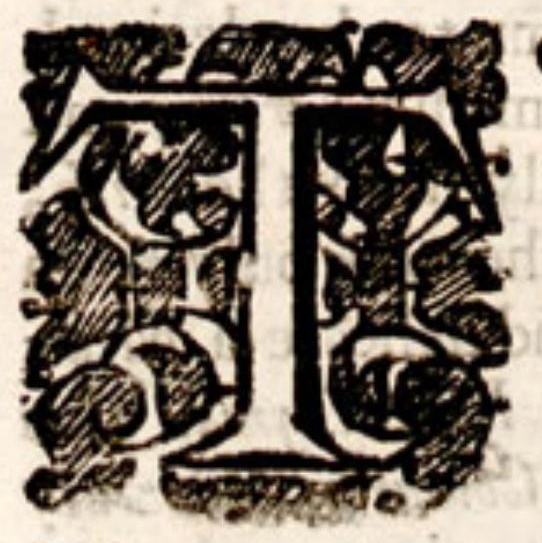

O the forementioned Fruits, I fhall fubjoyne, in fome Examples, the Defcription of the Seed-Cafe, which is analogous to the Fruit. For the Fruit, ftrictly fo called, is, A Flefy Uterus, wobich grows more moift and Pulpy, as the Seed ripens. But the Seed-Cafe, whether it be called a $C_{o d}, P_{0}$, or by any other name, is, $A$ Membraneous vterus, which as the Seed ripens, fill grows the more dry and bard: as in moft Plants.

2. 5. T HE SEE D-CA S E, is either originally open; Or only when the seed is ripe; Or never opens at all, till the Seed be fown: Of the firft Sort, is that of Luteola; as alfo of Clary, Sage, Hyfop, and 
the like: wherein one and the fame Part, is both the Empalement of the Flower, and when that is gone, furvives as the Cafe of the seed.

3. 6. Of the Laft, is that of Myagrum Monfpermon, Lithofperme, all the Stones of Fruits, with divers others. And fome Cafes, which are foft, as, I think, that of Garden Radifh. The former, by cleaving in fome part or other; thefe only by roting under Ground.

4. \$. THA T of Garden Radifh, is a Light and Spongy or Pithy Body; originally, every where entire. But, as it ripens, breaks within, into feveral White and Dry Membranes round about the Seed. By Tab. 70 the Length and about sch of an Inch diftant from the Sides of the Cafe,
do run a pair of little Vafoular Ropes. thefe tranfmitted to the sides of the $C a f e$; by which they are from titę and fteady. Upon divers others produced towards the $C$ are kept the Seeds, like Two Ropes of Onions.

5. \$. Of thofe which open fo foon as the seed is ripe; fome are made to open at the Top, as Popy Heads; Some on the Side, as molt Cods; and fome at the Bottom, as that of Coded Arfmart. 6. \$. THE Popy-Head, is a little Dove Cost; divided by Eight
or Ten Partitions, into fo many Stalls. On both Sides the Partitions, hangs a moft numerous Brood of Seeds. The Partitions and sides of Tab. 70 . the Head, are made of the Barque, and Lined with the Pith. While young, they are very thick and Spongy; and together with the Seeds, do then fill all up.The Head is then alfo every where entire; but as it dries, it gradually opens at the Top, into feveral Windows, one for every stall: which are all covered with a very fair Canopy. A Fabrick defigned for
feveral purpofes, as thall hearafter be faid.

7. \$. Of thole which open on the side; fome are made to open, only on One Side; fome, on both Sides; fome, with Three Sides; fome, with more; and fome horizontally or round about.

8. 5. THE COD of Garden Bean (and fo the reft of the Leguminous kind) opens on one side. It hath a Twofold Parenchyma. The Utmoft derived from the Barque: in which ftand all the Veffels, in fe-Tab. 70.
veral Parcels; than the reft, haped like a Copula ufed in of the Cod, is much larger thofe leffer Fibres upon which the Beans do grow.

9. \$. The Inner Parenchyma is derived from the Pith. U U its Nativity, and for fome time afterwards, entire and wholly compofed of
enlarged, fo as to compor. From the Bafe of the Cod they are gradually enlarged, fo as to compofe this Parenchyma into a very foft and delicate
Sponge. In which (the Cod being well grown ) the very Threds whereof the Bladders were woven, are many of them fo loofe and ample, as $T a b .70$. eafily to be drawn out (as in the uroaving of Knit-work) to a confi. derable Length, fairly vifible through an ordinary Glafs.

10. 6. This may further confirm all that I have formerly faid of the Fibrous Texture of the Pith, and of all the ot Plants.

II. \$. THE Seed-Cafe of Medica, is a Cod wound up: in the Ch. $5 . \& B$. Echinata, spirally; in the Tornata, by an Helix. Not finifhed all toge.P.I.Ch.4. ther; but, upon the fall of the Flomer, beginning to wind, continues
its Circles, till it be come to its full Growth.

$$
\mathrm{Gg}^{2} \quad \text { 12. } 6 .
$$


12. 6. THE Seed-Cafe of Yellow Henbean opens on both Sides.

Tab. 70. On the Top, is erected a Colum, about $\frac{1}{2}$ an Inch long; which, as the Cafe fwells, gwros lefs, and at laft falls off. On the Sides of the Zterus or $C a f e$, Two Vafcular Fibres run oppofitely from the bottom to the top, and fo into the Colum. Along the Tract of thefe Fibres, the Cafe, as it ages, gradually cleaves on both Sides afunder.

13. 5. The Cafe is lined with a dry and thin Parchment, as fmooth as Glafs. In the Centre of the Cafe, ttands a great Parenchymous

Tab. 70. Bofs, which is, as it were, the Bed or Placentula of the seeds; which lie all over it, as in a strawberry. And fo in many other Plants. Throughout this Bed, the Veffels for the Generation and Nourifoment of the Seeds, are diftributed; one very fmall Fibre, fhooting, from the direct ones, obliquely into each seed.

14. \$. THE Seed-Caje of Tulip, opens with Three Sides; being, when young, a Prifm or long Triangle. From the midle of each Side, a Partition or Boord is produced; all three meeting in the CenTab.7 I. tre of the Cafe; and fo parting it into Six Stalls for the Seed. The infides hereof, are, lined with a thin fmooth and gloffy Parchment, like that in Hen-bean; derived from the Pitb; as the outfide, from the Barque: and fo in many other Seed-Cafes.

I5. 5. The Veffels, after they rife above the Stalk, are difpofed with great artifice. For firft, they are divided into Three principal Branches, which run a long the Three Angles of the Cafe; where the

Tab.71. Three sides, as it ages, gradually cleave afunder. From thefe chief Branches, at the Three Angles, divers leffer ones run horizontally, and meet at the midle of each Side. From whence again, many yet fmaller ones are produced through the bredth of each Partition to their Edges in the Centreof the $\mathrm{Cafe}$. Where, once more, they are diftributed into very fine and fhort Threds, whereupon hang the seeds.

16. \$. THE Seed-Cafe of Stramonium or Thorn Apple, is divided into Four Clofets : Not open one into another, as in Poppy, Tulip, \&c. but fo many diftinct Inclofures. In the midtt of each Clojet ftands a the Length of the Colums run feveral greater and leffer Branches of $V_{e} \int j e l s$, from whence others are obliquely produced, upon which the seeds grow.

17. 5. T HE Seed-Cafe of Anagallis or Pimpernel, is a little Globe; which opens not by its Meridian or Vertically, as do the former; but by its Horizon. For divers very fmall Fibres, being produced from the Stalk to the midle of the $C_{a} \int_{e}$; do there fetch a $C_{\text {ircle, }}$, and fo divide it exactly into Two Hemispheres: the Uppermoft of which, when the Seeds are ripe, falleth off; and fo the wind fowes them.

18. 5. TH E Seed-Caje of Coded Arfmart, neither opens at the Top, nor on the sides, as do all the former; but at the Bottom. It is compofed of Four Sides: the Outer Part of which, is fofter and more

Tab. 71. fucculent; the Inner a tite and ftrong Membrane. In the Centre of the Cafe, is erected a Pole or Colum upon which the seeds do all hang very loofely.

19. \%. From this Mechanifm, the manner of that violent and furprifing Ejaculation of the Seeds, is intelligible. Which is not a motion originally in the seeds themfelves; but contrived by the Structure of the $C$ aje. For the seeds hanging very loofe, and not on the Sides of 
the $\mathrm{Cafe}$, as fometimes, but on the Pole, in the Centre, with their thicker end downward, they ftand ready for a difcharge : and the Sides of the $C a f e$ being lined with a ftrong and Tenfed Membrane, they hereby perform the office of fo many little Bons : which, remaining faft at the Top, and (contrary to what we fee in other Plants) opening or being lett off at the Bottom, forceably curle upward, and fo drive all the Sieeds before them.

\section{CHAP. VI.}

\section{Of the USE of the Parts to the Fruit.}

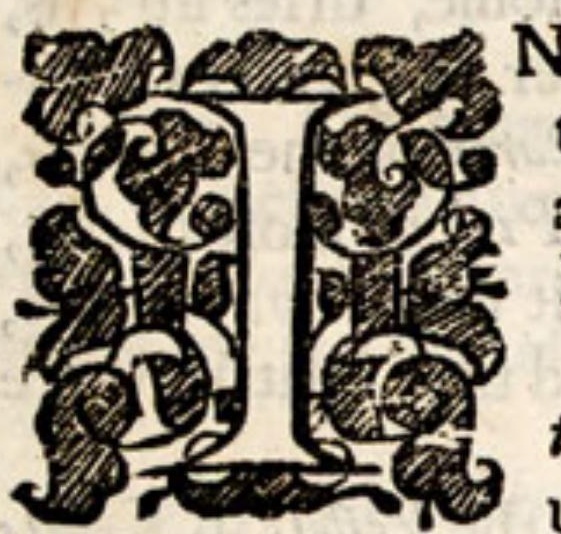

$\mathrm{N}$ the forgoing Defcriptions, I have already mention'd the $\mathcal{U} \int e$ of the Parts in fome particulars. I thall now a little further explain the manner of their fervice, both to the Fruit, and to the Seed.

2. 5. And firft, the Veffels ferve for the Figuration of the Fruit. So in an Apple, the Ten great and utmoft Branches ferve not only to nourifh and feed it; but alfo, by the Arched Lines they draw, to direct and govern the Growth thereof into an orbicular Figure. The Dilatation of thefe $V e f j e l s$, not being hindred by any Braces or Conjunction with the Interior ones. By the Slendernefs of the Aer-Veffels, as in the Root, fo here in the Fruit, much promoted. And by their Saline Principle, firft begun.

3. 5. The Five midlemoft and the Five Inmoft ferve together, to figure the Coar; the former bounding the Outer, the Latter, the Iner Angles. For were they only Five, or were all Ten in the fame Circle, they would only make a round Cavity like that of a hollow Pith. Hence it is that Apples, in which fome fmall Threds of the $V_{e} / \int e l s$ ftrike out into the Circumference, are very Uneven with divers $K$ nobs and Ridges. But Plums, Cherries, \&c. where the $V_{e f f}$ els all terminate at an Equal diftance from the $S_{k i n}$, are Even all round about.

4. \$. The Bulk of the Fruit dependeth alfo on the Braces of the Vefjels. For in Plums and Cherries, they are more numerous; but in Apples and Pears they are very loofe one from another, and fo have liberty left them to fpread abroad.

5. 5. As alfo on their Size; that is, on the Size of the Aer-Veffels. Which, the lefs they are themfelves, they ferve to make a bigger $F$ ruit. As the lefs they are in any Root, they ferve to make it the more ample. For the lefs they are, the more pliable to the Attraction of the Aer: and in their Gronth muft make fo many more fpiral Rings: by both which means, they make the greater Arches. And therefore a Pear is commonly a fmaller Fruit than an Apple; a Plum than a Pear; and a Grape, than a Plum; in all which the Aer-Veffels are ftill greater and greater. 
6. \$. From the fame Caufe, it is alfo moft agreeable, That the Fruit thould not come before the Leaves or Flower, but laft of all. For the Aer-Veffels, as hath been often noted, are not exactly $C_{y}$ lindrick, but tapered; that is, not only the Fibres confifting of divers of thefe $V_{e} \int f e l s$, but the Veffels themfelves, as they afcend into the Trunck, Branches, Leaves, Flower, and Fruit, grow ftill more and more flender. So that the fmalleft coming laft, and being the moft pliable; they are alfo beft accommodated for the Expanfion of the Parenchyma into that we call the Fruit.

7. 5. It is likewife a proper Queftion to be asked, How it comes to pafs, That fome Plants bear a Fruit, and not all ? I anfwer, That as the Size of the Aer-Vefjels conduceth to the Bulk of the Fruit, and the Order of its Growth : So the Number of them, to their being, or not being, any Fruit at all. For the Fruit, as we have already defined it, is an Uterus, which grows moyfter and fofter, as the Seed ripens. The reafon therefore, why the Uterus in fome Plants, continues moift and foft after the Seed is ripe; and in fome, dries up; is, Becaufe in the former, there is a fmaller, in the latter, a greater Quanty of the Aer-Veffels in proportion to the other Parts of the Uterus, and fo a greater quantity of Aer. Which as in the Pith of moft Plants, fo here, by degrees excludes the $S a p$, or rendring it more evaporable, comes in the room of it; and fo the Uterus is dryed up : that is, there is no Fruit produced, but only a seed-CaJe.

8. \$. From the Size, Number, and Pofition of all the Veffels in Fruits a reafon alfo may be given, for the diverfity of their Tafts. Some Inftances have before been given; to which $I$ thall add one or two more. So the Rind of an Orange, is bitter; the $P u p_{p}$, fower. Becaufe the former is furnifhed with many Lignous Veffels, the Sulpbureous or Oyly Tincture whereof, being copioully mixed with the Acid of the Parenchyma, produce that Taft. Whereas the Pulp, which is very fower, is void of all manner of $V$ effels. But if the $s a p-V$ effels are either lefs numerous or lefs Sulphureous; they give fo mild a Tincture to the Parenchyma, as not to produce a bitter, but a fweet or foft Taft; as in Apples, Grapes, Goosberries, \&c. And of a Goosberry, it is particularly to be noted, that whereas, in a Limon, the Pulp only is fower, as being void of $V$ effels: here, on the contrary, the Pulp only is fweet, whereinto all the Veffels ftrike, and the Rind fower.

9. 5. The diverfities of the Skin it felf, have their $\mathcal{U}_{\int}$. And therefore, the more tender and delicate the Fruit is; the Skin, on the contrary, is thicker and more tough. So Apples have a thicker Skin, than Pears; Plums, than Apples; and Grapes than Plums; thofe having as it were, only a Coat of Kid, but this of good thick Buff. And therefore fome Fruits, although tender, yet either not having fo rich a Fuyce, or coming early, and fo not being expofed to exceflive heats, have a very thin Skin, as Mulberries, Stramberries, \&c. 


\section{CH A P. VII.}

\section{Of the US E of the Parts to the Seed. And the TIME, in which the Uterus or Fruit and Seed-Cafe are formed.}

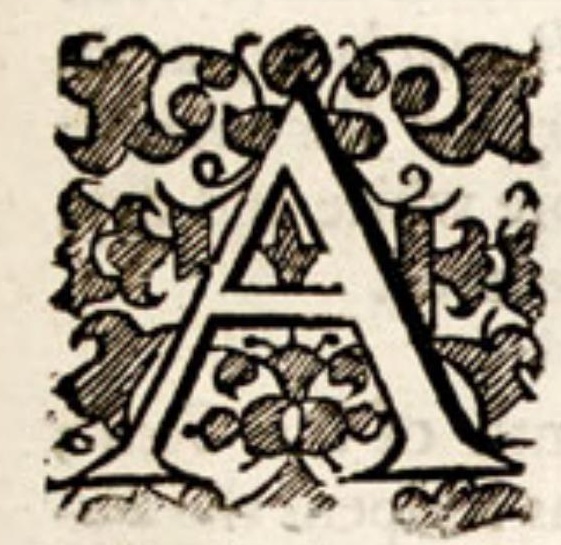

ND firft, for example, in an Apple, the Five Inmoft Branches, do beft ferve for the Generation of the seed; thefe running into the Attire of the Flower, and fo carrying off the moft Aerial spirit from the Seed; by which means, it becomes a more compact and denfer Body, than the Fruit, and fo hath formerly been fhewed.

more accommodate to the procefs of Vegetation; as P. 2.Ch. 5 .

2. 5. The Elongation likewife of the Seed-Veffels, in the Fruit and Cafe, fometimes directly, as in Plums and Nuts, and fometimes by fe. veral Ambages before they thoot into the Seeds, as in Tulip; Thewes a defign for the higheft refining and maturation of the seminal Sap.

3. 5. Chiefly by means of the Inmoft Veffels, is made that chanel in fome Pears, and efpecially in 2uinces. For thefe perilhing with the Flower, the circumjacent Parenchyma (hrinks up, leaving the faid Chanel in the midft. Defigned for an inlet to the Aer, for the better drying of the seeds; which here ftand the more in need of it, becaufe encompaffed with a Mucilage.

4. \$. For the better drying of the seed, and the disburfing or fowing of it in due time, the opening of the $C$ aje is, in the fame manner, alfo contrived: either at the Top, as in Popy; or on the Sides, as in Tulip, Pimpernel; or at the Bottom, as in Codded Arfmart. All which openings are effected by the running of the Aer-Veffels along thofe places: for by drying the Parenchyma next adjacent, they caufe it to chop and cleave afunder.

5. 5. Of the seed-Cafe of Poppy, it is particularly to be noted, That as the feveral Windows, ferve to let in $\mathrm{Aer}$, for the drying of the Seeds, after their full Growth: So the Canopy over them, ferves to keep out Rain. For here, the Cafe not cleaving down the Side, as it ufually doth; fhould the Rain get in, it would ftand in it, as in a Pot, and fo rot the Seeds. And as the Canopy ferves to preferve the Seeds; fo the feveral Partitions or Walls, for their better Stowoage. For by an eafie furvey of this little piece of Ground, it is plain, that as they ftand on both Sides every Wall, there is as much more Ground for them to ftand upon, as if there were no parting Walls, but the Seeds ftuck all round about upon the Ambit or Sides of the Cafe; or upon a great Bed or Placenta within it, as in Hyofcyamus, Anagallis, \&c. where there is a lefs nume rous Brood. 
6. 5. The Coar likewife, by ftanding betwixt the moyft Parenchyma and the Seed, and being hollow and fo filled with Aer; doth much conduce to the ripening and drying of the seed, and its greater fitnefs both for keeping, and fowing. So the Parcbment Lining of the SeedCafe, as in Hyofcyamus, \&c. is anfwerable to a Coar.

7. 5. The Parenchyma ferveth, amongit other purpofes, for the Generation of the Covers of the seed; as in fome inftances hath been fhewed. For which intent, fometimes the Exterior Parenchyma, as in a Limon; fometimes the midlemoft, as in a Goosberry or Cucumer, is fubfervient; both of them, in thofe Fruits, being more white and dry; than the reft, and fo fiter to make the Covers of the seed.

8. 6. The Parenchyma is alfo of ufe for the warmth of the Seed; as in the Seed-Cafe of Garden Radifh. Wherein, as it ripens the $\mathrm{Pa}_{a}$ renchyma gradually drys, breaks, and fhrinks up into feveral foft Membranes, in which the Seeds, in the Centre of the Cafe, lie fwadled, as in fo many fine Calico Clowts.

9. I S H A L L conclude with obferving the Time of the Generation of the Fruit and seed-Cafe. This hath hitherto been thought to be initiated upon the opening, I fay not, the forming, but the opening of the Flower, or not long before. Notwithftanding which, what I have formerly faid of the Flower; I now do the like, of the Uterus it felf; fc. That in very many Plants, tis formed, with the Flower, the year before it appears and comes to its full Growth. As for inftance, in $A$ -

Tab.71. zarum, not only all the Parts of the Flower, but the Uterus it felf, and there in allo the outer Cover of the seed of any one year, are perfectly formed in Anguft or September of the year foregoing. The like may be feen in Tulip, Mezereon, Corin, and many other Perennial Plasts. 
T H E

\section{ANATOMY \\ $\mathrm{O} \mathrm{F}$}

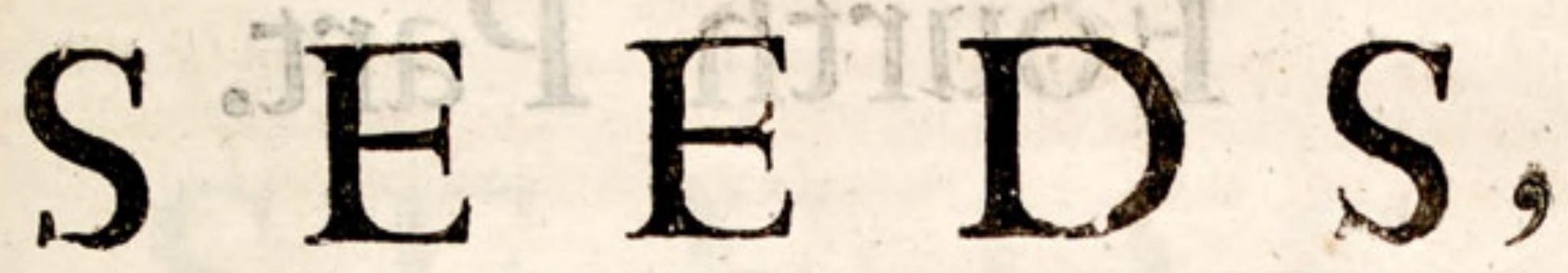

P R O S E C U T E D

With the bare EYE,

the Grotin And with the

\section{MICR OSCOPE.}

The Figures prefented to the Royal Society, in the Year 1677 .

The FOUR TH PART.

By $N E H E M \mathcal{F} A H G R E W$ M.D. Fellow of the ROYALSOCIETY, and of the COLLEGE of PHYSICIANS.

\section{$L O N D O N$}

Printed by $W$. Ramolins, 168: 


\title{
T H E
}

\section{CONTENTS O F T H E \\ Fourth Part.}

\author{
C H A P. I. \\ Of the FIGURES of Seeds. \\ C H A P. II.
}

Of the NUMBER and MOTIONS of Seeds.

C H A P. III.

Of the feveral C OVERS of Seeds, and of the VITELLVM.

C H A P. IV.

Of the FOET US or true $S E E D$ : and firf of the $R A D I C L E$ and LOBES.

C H A P. V.

Of the BU DS of Seeds. And of the P ART S of which the fe, the Radicle and Lobes are compounded.

C H A P. VI.

Of the GENERATION of the Seed. 


\section{T H E}

\section{A N A T OM Y \\ O F}

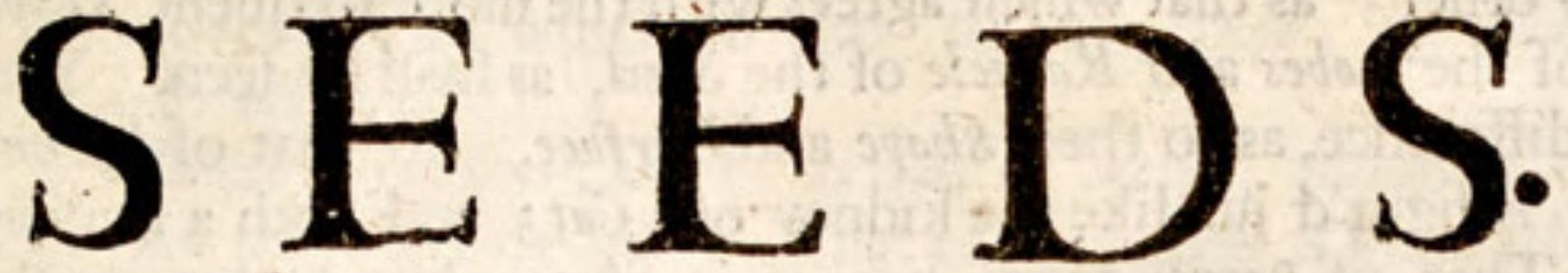

\section{P A R T IV.}

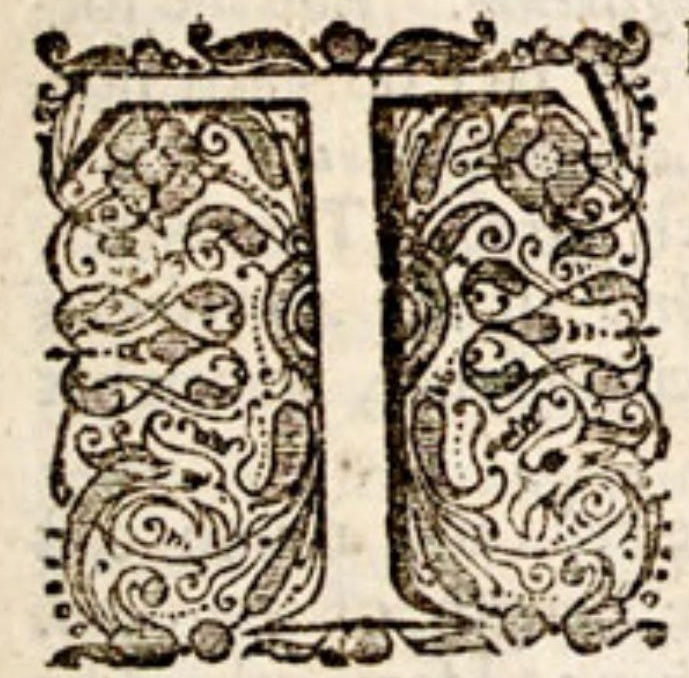

HE Figures of Seeds, or rather of their out: ward Covers, are made fuitable, Partly to their Collocation in the Uterus, as the End. So thofe of Mallow, ftanding like a Coronet round the Stalk, are of a wedged Figure; whereby their fharp Edges do all meet together in one Centre. Partly, to the various diftribution of the $V_{e f f e l s}$ or Fibers, as one Caufe: by which the Meafures and Surface of Seeds, as well as of the Leaves of Plants, are diverfified. And partly, to the Nature of the Saline and other Principles regent in a Plant, as another principal Caufe. And therefore the more ftony, brittle, or full of salt the covers of any seeds are, they are generally more angular, and their Figure, whether angular or not, more conftantly obferved. So the Tartareous stone of a Plum, is not only more angular, but alfo more regular than the Husk of the Kernel of a Pear or Apple.

2. \$. For all Stones are meafured by feveral $C$ ircles, whofe Diametres hold a certain proportion to the Length of the Stone; in the fame manner as hath been thewed in the defcription of the Leaf. So P.1.Cb.3; the Stone of the Peafe-Cod-Plum, is meafured by two Circles. That of the Turkey-Plum with Four. That of the Aprecok-Plum, with Two Tab. 7a。 repeated oppofitely; being perfectly Rhomboid. To which, thofe alfo of the Wheat-Plum, Damafceen, and fome others, allude. And fome are meafured be four $C$ ircles, and one repeated.

$\mathrm{Hh} 2$

5. 3 . 
3. \$. The Figsres, not only of the larger fort of Seeds, but even of the fmalleft, have much and elegant variety. We will take the pleafure of comparing thefe which follow.

4. §. And firft of all,fome are perfectly Spherick, and with an even

Tab. 73. Surface; as that of little Century. That of spergula is alfo Spberick; but hath a knobed Surface, and is encompaffed with a Membraneous Rimm, like the Horizon of a Globe. That of little Celandine is Circular, but compreffed like a Cheefe.

5. 6. Others are Nephroideoss, or as it were Hemijpherick. Of which Figure, and hereunto approaching, there are a greater number than of any other; as that which agrees with the more frequent shape and Fold of the Lobes and Radicle of the Seed, as thall be feen. Yet with fome difference, as to their shape and Surface. So, that of Lycbnis SylTab. 73. veftris is figur'd juft like the kidney of a Cat; and hath a knobed surface. That of Poppey comes near it in Shape; but hath a surface exactly like that part of the Paunch of a sheep, called the Hony-Coome. That of great Celandine, is a little more oblong; and fo, like the Kidney, not of a $C_{a t}$, but of a sheep : chequered with parallel Rings and other thort Lines placed alternately betwixt them.

6. 5. Where, by the way, we may fee, as well by the Seed, as by the other Parts, of how different kinds, the Great and Little Celandine, notwithitandig their Names, are to be efteemed.

Tab. 73. 7. \%. The Seed alfo of Ben or Spatling Poppey is fomewhat like a Kidney: but hath its Circumference raifed up into a double Ridg: to which feveral fmall Ridges do in fome fort alfo radiate frome one Centre $f c$. the Bafe of the Seed.

Tab. 73. 8. 5. The Seed of Cbickweed, is partly like a Kidney, and partly like a little Retort. As alfo that of Pentaphil. fragiferum. But the former is rough caft with fmall pieces having as it were feet on each fide, like little Infects. With which, the Seed of Leucbantbemum (which may be called, the Giant-Chickneed) doth much agree. The latter, hath feveral Fibrous Ridges, refembling the Fibres in the Auricles of the Heart; or runing from the nofe to the Circumference, fomewhat like the Azymuth Lines on a 2 uadrant.

Tab.73. 9. S. Some are Oval; as that of the little Bell, and rough caft with Fibres almoft parallel and produced by the Length of the Seed. In which latter refpect, the Seeds alfo of Tracbelium and fome other like Plants, are agreeable. That of Brooklime, is alfo Oval, but encompaffed with a thick Rimm, narrowing all the way to the Bafe of the Seed.

10. 8. The Seed of Dovesfoot hath an oval Cone, and a flat Bafe. Its Surface favous, like that of Poppy, Toad-flax, and fome other Seeds.

Tab. 73. That of Sedum minus aftivum luteum, is in a manner the Figure of the former inverted, being flat, not at the Bafe, but on the Top. And whereas that rifes with a blunt AngIe, this hath only a Ridg, raifed above the Surface of the Seed.

I 1. 8. The Seeds of divers forts of Grass, are more Conick, as particularly of that, which for the likenefs its Seed hath to a Barly Corn, may be called Barley-Grafs. And I little doubt, but that among the

Tab.73. feveral forts of Grafs, there are fome which anfwer to all the kinds of Efculent Grains, as Oat-Grafs, Rice-Grafs, Wheat-Grafs, Rye-Grafs. And accordingly, that they may be more profitably fown in one Ground, than in another; and ufed with diftinction, for the higher, or more wholfome 
wholfome feeding of Cattle. A $R u h$, though it feems an imperfect plant, yet befides its Flower, hath alfo a plentiful brood of Seeds of a Conich Figure.

12. 5. Some Seeds are Cylindrick, as that of St. Fohns-wort, as alfo of Tutfan, and fome other like Plants, with fome little diverfity in the Shape or Surface of the Seed. That of Vervain, is in a manner, half a Cylinder: the true Seed lying in the Covers, like a Child, in a Cradle without an head.

13. 6. Others are rather $C_{\text {onico-Cylindrick, as that of Facobea; }}$ having a Coronet on the top, and feveral furrows by the Length round $T a b .73$. about. Anfwerable to which, is that of Erygerum; in Sbape not unlike to a Rowling-pin.

14. 6. Some are Plani-Conick, as that of Nettle, which is thaped fomewhat like the end of a Speer. That of Eye-bright is more Eliptick; with feveral Ridges running by the Length; and joyned together with fhort pieces trarfverly, as in the looping of Lace. That of Worm-Tab.74. mood not very unlike a little flat Effence-Glajs: in which, the Fibres are produced by the Length, as the Ridges are in Ege-tright. And fo in rarrow, which is alfo encompaffed with a Membraneous Rimm. That of Dandelyon, is Plani-Conick towards the Bafe. And fo thofe of Lettice, Sonchus, and fome others. To which, thofe alfo of Hieraceum, Tragopogon, Scorzonera, \&c. with refpect to their Surface, do all allude.

15. \$. And fome are conico-Triangular. Of which, that of Sorrel is Conick at both ends; the fides equal; and upon every Angle, hath a narrow and fharp Rimm. As alfo that of Anagallis; but the Sides are Spheri-conick, and fo the ends are blunt. They are alfo Tab. 74 pounced with many little round Cavities. But have no Rimm upon the Angles.

16. \$. The Seed of Nigella is Triangular, and Conick only at the Top. On every Angle, hath a narrow Rimm; the three Sides equal, and spheri-conick; furrounded with feven or eight Ridges by the girth, joyned together in fome places with others tranfverfy. That of $A r-T a b .74$ fmart, is alfo Triangular and Conick at the Top. But one of the sides is almoft equal to the other two; which ftand low. That of KnotGrass hath three sides, one lefs than another; being as 5, 3, and 2, or thereabout.

17. \&. The next (which 1 take to be the Seed of a fort of Buglofs ) is very oddly figured. The Bafe, oval; the Top, conick; the Back, fwelling and round as an $E_{g g}$; the Belly allo fwelling, but rifing up into an obtufe Angle higheft in the midle, fomewhat like a Breaft- Tab. 74. piece of Armour: and is encompaffed with a Rimm floaped upward.

18. \$. That of Moldavian Bamm, is Triangular, and Conick only at the Baje. The place where it is faftned, fhaped like the Beard of a Dart. Two of the Sides are Plani-conick, the Third Sphericonick, Tab.74. and near as big as both the other two. The Head flat, with a Rimm erected upon each side, fo as to make a Spherical Triangle. Approahing to this, are thore of sage, Horehound, Clary, \&x.

19. 5. That alfo of Bellis Tanaceti folio, hath two sides Planiconick, and a third sphericonick. The two firt have feveral Ridges run- Tab. 74. ning to the Bafe. Which is not perfectly conick, but a little dilated into two obtufe Angles. The Head Triangular, with one Side convex, 
the other Two ftraight, a little hollowd, and having a fmall pinacle in the Center.

20. 6. That of Stechas Arabica, as, the former, faving, that the Head is oval, and the Bafe loaped into a little Triangle. That of Wartwort or Sun-Spurge, hath a very complex Figure. The Belly con-

Tab. 74. Fifteth of two Planiconick Sides, as the former; the Back, Splecriconick.

The whole Seed, in a manner, Conick-oval. Yet the Bafe and Head both flat. In the midle of the former, a Peg by which the seed is faftned; and of the latter, a poynted Knob. The midle of the BellySides, hollowed, fo as to make a flat Rimm of equal Bredth; and the hollows filled up with Bladders like thofe in all the Parenchymus Parts of a Plant.

21. \$. Laftly, there are fome seeds which are fquare. Whereof

Tab. 74. fome are ftraight, as that of Fox-glove; which hath alfo an even Surface: And that of Blattaria, in which there are feveral little hollows in even Rows. And fo in Brounwort.

22. \$. And fome Convex, as that of Chryfanthemum Americ. 'Tis Quadrati-conick, or fquare and tharp at the Bafe, and big at the

Tab. 74. Head. The sides all plain; and a thin Rimm erected upon every $A n$ gle. As alfo on the four sides of the Head, which is flat, with a little pinacle in the midle.

23. 5. The seed alfo of Tanfey, is a conick and bended fquare not Tab. 74. with the Angle forward, as the former, but the Side. And in the place of every Rimm, hath a round Ridge. Somewhat like to this, are thofe of Febrifuga, Mayweed, and fome others. Thus far of the $F_{i-}$ gures of Seeds.

\section{H A P. II.}

\section{Of the NVMBER and MOTIONS of Seeds.}

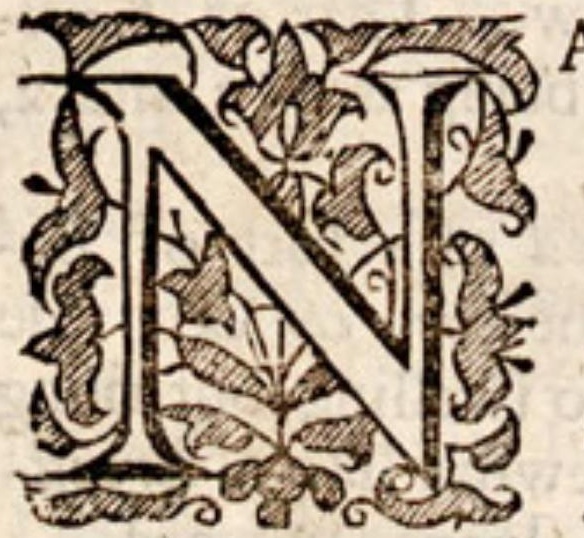

A T UR E hath fecured the Propagation of Plants feveral ways, but chiefly by the Seed: for the Production of which, the Root, Leaves, Flower, and Fruit, do all officiate, as hath been thewed. And according as the Plant, or the Seed it bears, is more liable to be deftroyed, Provifion is made for Propogation, either by a greater number of Seeds, or other ways. So the Seeds of Strawberry, being gathered, or eaten by Vermin, with the Fruit; the Plant is therefore eafily propagated by Trunk-Roots. So Poppy, being an annual Plant, is highly prolifick: for inftance, the White Poppy; which commonly bears about four mature Heads, in each of which, there are at leatt ten Partitions, on both fides whereof, the seeds grow; and upon th part of one fide, about I0o' seeds; that is, 800 on one Partition: which being multiplied by 10 (the number of Partitions ) makes 8000 ; and 8000 again by 4 (the number of Heads) makes 32000 Seeds, the yearly product of that Plant. 
2. 5. So in Typha major, the Seeds being blow'n off and low'n (as the Eggs of many Fijhes fpawn'd) with great hazard, they are ftrangely numerous. For as they ftand aitogether upon the $S_{p i k e}$, they make a $C$ ylinder at leaft fix Inches long, and near sths of an Inch in $\mathrm{Di}$ ametre, or an Inch and $\frac{3}{4}$ about. Now 9 of thefe seeds, fet fide to fide, as they ftand on the spike, make but th of an Inch; fo that 72 make a line of an Inch in Length. But becaufe upon the spike, the Hairs belonging to the seeds come between them; we will abate I0, and count but 62 . To which ${ }_{4}^{3}$ ths of 62 , that is (without the Fraction ) 46 . being added, makes 108 for the Circuit of the $C_{y}$ linder. And the $C$ ylinder being fix Inches long, there are fix times 62 , that is, 372 , for a Line the length of the $C_{y} l i n d e r$. Which number being multiplied by 108 , produceth 40176 the number of Seeds which ftand upon one Stalk; and fo, upon three Stalks, which one Plant commonly bears, there are in one year, above a hundred and twenty Thoufand seeds.

3. \$. SO SOON as the seed is ripe, Nature taketh feveral Methods for its being duly fow'n : not only in the opening of the Uterus, as in fome Inftances (a) hath already been feen; but alfo in the make (a) $P$. 3. of the Seed it felf. For Firft, the Seeds of many Plants, which affect Ch. 5. Tab. a peculiar Soil or Seat, as of Arum, Poppy, \&c. are heavy and fmall $70,8 \times 7$ i. $_{0}$ enough, without further care, to fall directly down into the Ground: and fo to grow in the fame place where themfelves had their Birth.

4. 6. But if they are fo large and light, as to be expofed to the wind, they are often furnilhed with one or more Hooks; To ftay them from ftraying over far from their proper place, till by the fall of $L$ eavs or otherwife, they are fafely lodged. So the Seeds of Avins have one fingle Hook, thofe of Agrimony and Goofe-grafs, many; both the for- Tab. 72 . mer, loving a Bank for warmth, the latter, a Hedge for its fupport.

5. 5. On the contrary, many Seeds are furnifhed with Wings or Feathers. Partly, with the help of the Wind to carry them, when they are ripe, from off the Plant, as thofe of $A\}$, Maple, Orach, \&c. leaft ftaying thereon too long, they fhould either be corrupted, or mifs their feafon. And partly, to enable them to make their flight, more or lefs, abroad: that fo they may not, by falling together, come up too thick; and that if one fhould mifs a good Soyl or Bed, another may hit. So the Kernels of Pine have wings not unlike to thofe of fome Infects; yet very fhort, in refpect of the weight of the Seed; Tab. 726 whereby they flye not in the Aer, but like domeftick Forols, only flutter upon the Ground. But thofe of $T_{y p h a}$, Dandelion and moft of the Pappous kind, with many more, have very long and numerous Feathers, by which they are wafted every way, and to any diftance neceffary for the aforefaid purpofes.

6. 6. Again, there are fome Seeds, which are fattered not by flying abroad, but by being either Spurted, or Slung away. The firft are thofe of Woodforrel; which having a running Root, Nature fees it fit to fow the seeds at fome diftance. The doing of which is effected by a white thick and fturdy Cover of a Tendinous or Springy Nature, in Tab. 72 : which the seed lies within the Cafe. This Cover, fo foon as it begins to drye, burfts open on one fide, in an inftant, and is violently turned infide outward, as you would turn the Gizard of a Fowl; and fo fmartly throws off the seed. 
7. §. The Seeds of Harts-tongue, and of all that Tribe, are Slung or Shot away. The doing of which is performed by the curious contrivance of the Seed-Cafe; as in Codded Arfmart, and fome other like Plants. Only there, the spring moves and curles up inward; but here it moves outward. I thall defcribe it, as well as the Weather (which when I obferved it was cloudy) would permit. Every Seed-Cafe, as

Tab. 72. it appears through a good Glafs, ftands upon a Pedicle from $\frac{1}{2}$ an Inch to an Inch or more in Length; at the bottom about as thick again as a Horje.bair, and a little thicker at the Top, on which ftands the $C_{a}$ e, of a Silver Colour; about the bignefs of a Cherry-ftone, of a spherick $F_{i-}$ gure, and girded about with a fturdy Tendon or Spring, of the Colour of Gold: the whole Machine looking not much unlike a little padlock. The Surface of the Spring refembles a fine Screw, or fome of the Aer-Ve/fels in the Wood of a Plant. So foon as by the Innate Aer of the Plant, or otherwife, this Spring is become ftark enough, it fuddenly breaks the $C_{a j e}$ into two halfs, like two little cups, and fo flings the Seed.

8. \$. Thefe Cafes grow in oblique Furrows or Trenches on the back Tab. 72. fide the Leaf, from $\frac{1}{4}$ of an Inch to an Inch in Length, and about $\frac{1}{8}$ th of an Inch broad. In one of thefe Trenches an Inch long are more than 300 of the Cajes above defcribed; and allowing but IO Seeds to every Cafe, above 3000 Seeds. Which being multiplied by the number of Furrows in one Leaf, with allowance for the leffer Furrows; and that fumm by the number of Leaves commonly growing upon one Root, comes to above Ten Hundred Thoufand Seeds, the annual product of this Plant. The Sced is of a Tawny Colour, through a good Glafs about $\frac{1}{2}$, th of an Inch long, flat, and fomewhat oval. Of thefe, ten Thoufand are not fo big as a white Pepper Corn.

\section{H A P. III.}

\section{Of the feveral COVERS of Seeds, and of the VI- TELLUM.}

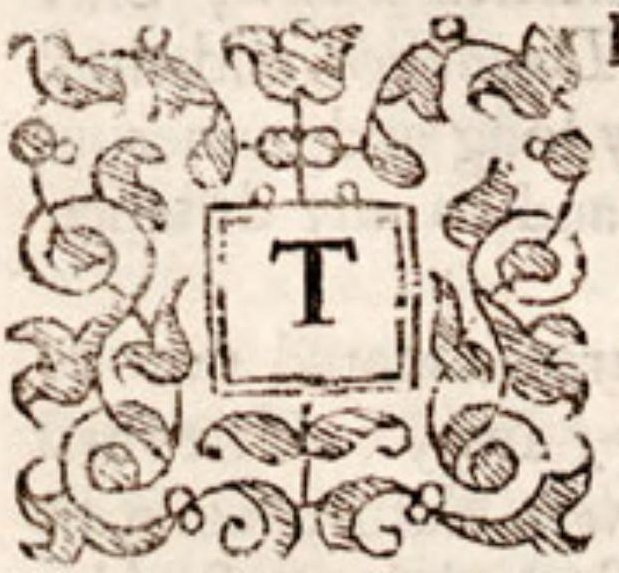

H E next Ptep of Natures Managery, relates chiefly to the Growth of the Seed when it is fow'n. For which purpofe, the outer Covers are fomewhere furnifhed with Apertures fufficient for the reception of Alimental Moyfter from the Ground; and Divifions, for the frooting forth of the young Root into it. As in the Seed of a Gourd, at the Bottom; in a Bean, on the Side; and in a Chef-

Tab.72, nut, at the Top: in which places the Radicle or young Root always lies and puts forth, in the faid feveral Seeds. And the Seed of Palma

Tab.72. Chrifti; which falls to the Ground not only in the ufual Covers, but alfo in the Seed-Cafe, for the more plentiful admiffion of Aliment, hath a double Aperture. Not much unlike to this, is that found fometimes 
in larger parcels of Euphorbium ; for which Caufe, I fufpect it to be the Gumm of a Plant of the Tithymal kind.

2. 6. If the Cover of the Seed be ftony and very hard, it is alfo diftinguifhed into feveral Pieces; whereby they eafily cleave afunder without much refiftance to the eruption of the Root. So the Shell of a Hazel-nut eafily cleavs on the edg; and the cleft begins beft at the poynt, where the Root ftands and fhoots forth. The Shell of fome Walnuts cleavs into three Parts; and the Stone of the Bellerick Myro- Tab.75. balan int o five : that fo, being very thick and hard, if one piece fhould not yield, another may not fail to do it. And the Covers or Husks of fome forts of Grain, as of Millet, are only folded or laped one over another, the better to give way to their tender Sprouts.

3. 6. Eefides the Kernels of Plums and fome other Fruits, there are very many Seeds, even of the fmaller fort, which have alfo ftony Covers; as of Carthamum, Myagrum monopermon, Beet, Borage, Lithosperme, Amaranthus, Violet, \&c. Sometimes, for the reception of the harher and lefs matured Principles from the Seed, in its Generation, as in Borage. Commonly, to keep it warmer before and after its fow'n. For which purpofe, the outer Covers of fome Seeds, are as it were Lined with Fur: in that of Great Maple, Short; of Golfipium, Long. And if the Seed requires a longer ftay under ground, the hardnefs of the Cover ferves to ftint the Aliment; left too much, fhould either rot it, or caufe it to germinate, before its properfeafon, or full time for a more Mafculine Growth.

4. \$. On the contrary, many Seeds, as thofe of Clary, Carden. Cress, and others of that Tribe, have their upper Covers faced with a Mucilage: which being eafily receptive of any Moyfture in the Ground, gradually fwells, till it lies like a Gelly round about the Seed. Either for a more plentiful fupply of Aliment; or at leaft, to foften the Covers, the better to accelerate the Growth of the Seed.

5. $\$$. The procefs of Nature in the feveral fteps of the Vegetation of the Seed, hath formerly been explained. (a)

6. 5. THE COVERS of all, or at leaft the far greater num- (a) B. 1. ber of Seeds, are Three; fome way or other derived from the $P_{i t b}: C h$. I. as fhall hereafter be feen. And fometimes, Four : even thofe of fton'd Fruits, have Three, befides the Stone. In that of Golfipium, there are Two Coats under that lined with the Cotton. The Seeds of Cucumer, Goats-beard, Broom, Scabious, Lettice, \&c. although fo fmall, have Tab.75. plainly Three Coats. But in fome of thefe, and many more, there are only Two diftinctly vifible, except in the State of Generation.

7. \$. In the Upper Coat, the Seed-Veffels are diffeminated. The Second, is firft a meer $P$ ulp; but afterwards fhrinks up and fticks clofe to the upper. The Third or Inmoft is more denfe; and if it be thin, for the moft part, tranfparent; whereby the Seed feems fometimes to be naked while it lies therein; as in Almonds, Cucumers, and the like. Tab. 76. For this fticks not to the midle Coat, as that doth to the outer; but commonly, remains entire, after thofe are ftripp'd off, being as it were, the Smock of the Seed.

8. 6. In Meliffa and fome other fmall Seeds, it comes finely off upon foaking in warm Water or on the Tongue. In Fenugreek, 'tis foft, and of an Amber-Colour; and being moyftened, looks almot like fine Glew. But commonly, tis a prety tough Membrane, and often with I i fome 
fome thicknefs, as in Plums, Borage, Scabious. Yet always extream thin at the Tip of the Radicle; the more eafily to break and yield to it, as the Secundine to the Fatus, when it firft Shoots into the Ground. And fometimes, as in the Seeds of an Orange, it bath at cne end, the

Tab. 75. refemblance of a Placenta. But of this, and the two upper Coats, I thall give a further Defcription in the laft Chapter.

9. \$. AS ALL Seeds are exOvo; fo there are many with thin Covers, as of Orach, Spinage, Beet, and the reft of that Tribe, \&c. which befides the Albumen or clear Liquor out of which they are bred; have alfo, a Vitellum, or a Body thereunto Analogus: being neither part of the Seed, nor part of the Covers, but diftinct from them both. With

Tab.75. refpect to the Bulk of the Seed, very large, as white as Starch, and pret-
ty friable, like good Rice or Barley: of a roundifh Figure, and grooved on the Girth, fo as to have a double Edge; Whereby the Sced, which is long and flender, lies round it, as a Sack of Corn upon a Pack-Saddle or a Rope upon a Pully-mbeel. Upon my firft notice hereof, it feemed to anfwer to a Placenta. But upon further confideration, the Analogy doth not hold betwixt them. For the Placenta lies without the Membranes in which the Fatus is conteined: whereas this body lies within the Covers contiguous to the Seed, and fo becomes its firft and fineft $A$ liment, as the $Y_{e l k}$ doth to the Chick. For which purpore, as in the Generation of the Seed, it is a pure Milky Chyle; So in its Vegetation, it is converted into the like again.

10. 5. The fame Body for Suftance, is obfervable in the seeds of

Tab.75. Rhapontick, Dock, Sorrel, and the reft of that kindred, with this difference; That whereas in Orach, \&c. the Seed only lies upon it; here, the main Body or Lobes of the Seed are immerfed therein, the Radicle ftanding naked or above it. So that the faid Lobes, and therein the Seminal-Root are beded herein, as in a Tub of Meal or a little pot of pure refirid Mould, neceffary for the firft $V$ egetation of the Radicle.

II. \$. B Y T H E S E midle Steps, Nature proceeds from the Thiner Covers of Seeds; or thofe, which after the Generation of the Seed is finifhed, Thrink up; to the Bulky Kind, or thofe which keep their Bulk after they are dry. Wherein, not only the Lobes, as in Dock, but the whole Seed is immediately lodged. Different in Subftance, Shape and Bulk; but always many times biger than the true Seed within it: for which it is commonly miftaken; but is no more the Seed, than is the Stone of a Plum, the Kernel.

12. 6. In the Barbado Nut, 'tis White, Soft, conick-oval, and taking all its Dimentions, 8 or 10 times bigger than the $S_{e e d}$ within it. In Afhen Keys, 'tis of a fad Colour, hard, yet fomewhat $O y l y$, Oval and flat, and of the fame Bignefs as in the Barbado Nut, with refpect to the

Tab.76. Seed. In the Fruit commonly called $N u x$ Vomica Officinarum, 'tis of the Colour and Hardnefs of a Cows-Horne; and makes almoft the whole Body of the Fruit, being about 14 or 15 times the Bulk of the Seed.

Tab. 77. In Goofgrafs or Cliver 'tis of the like Horny subftance, but fhaped fome-
what like a Bonet with the Rimm tuckt in. And fo in a Coffee-Berry; but rowled or foulded up into a kind of Oval Figure, with a Notch or Rima through the Length, where the two Ends meet. With other diverfities which will beft be underftood, when I come prefently to the $D e$ fription of the Seed herein contained. 
13. 5. With refpect to the ufe of this Cover, it is obfervable, that where there is a Stone or shell over it, as in the Barbado Nut, it is foft; but where there is none, as in Nux Vomica, Afl, \&c. 'tis hard; and fo it felf inftead of a stone. As alfo, That it becomes bard, only by the proper Nature of its Parenchyma, and the exquifite finallnefs of the Bladders of which it confifts. Whereas a Stone, is alfo hardened by the Lees or Tartar of the Sap which finks into it, and thereby petrifies it (a) as hath been faid. So that whereas a Stone, as it lies in the Ground, (a) P.3. only cleavs in certain Places, but continueshard: This $C_{o v e r}$, like forne $\mathrm{Ch} .3$. Horns, upon the due acceffion of Moifture, doth gradually become foft. Whereby, as while it is hard, it performs the Office of a stone, in guarding the Seed til the proper seafon for its Growth: So afterwards when it is $\int o f t$, it anfwers, as in Orach or Dock, (b) to a Vi-(b) Ch. 3 . tellum, from whence the Seed receiveth its firft and pureft Aliment. $\quad 5.8,9$.

$$
\begin{gathered}
\text { CHAP. IV. } \\
\text { Of the FOETUS or true SEED: and firt of the } \\
R A D I C L E \text { and LOBES. }
\end{gathered}
$$

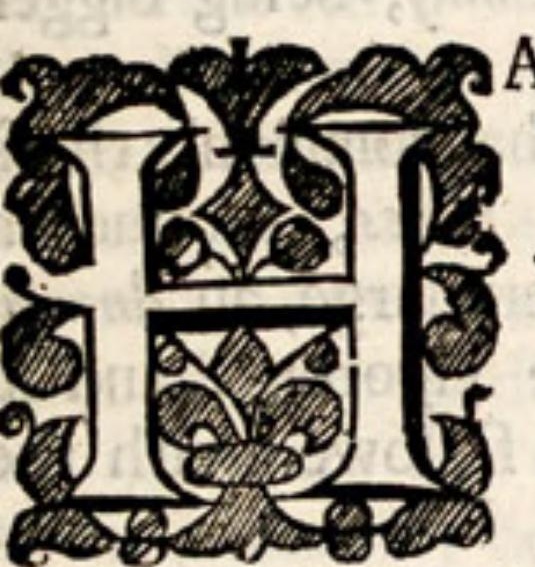

A V I N G difcourfed of the Covers, I come next to the Seed or Fatus it felf. Of the Shape and $\mathrm{Po}_{0}$ fture whereof, I thall give fome Examples, firft, among thofe with the thinner fort of Covers; and then, of thofe with the Bulky one: where I fhall fpeak only of the Lobes, or Main Body, and the Radicle. Next, I thall defcribe the feveral forts of Nodes or Buds of Seeds. And laftly, the feveral Parts, of which the Lobes, Radicle, and Buds are compounded.

2. \$. Among Seeds with the Thinner Covers, are thofe of all forts of Corn and Grafs, Of a different make, from that of moft other Seeds : The Main Body being not divided into Lobes, but one entire Piece, doubled in the form of a Pair of Lipps. And whereas commonly, the whole Seed is very $S$ oft and Oyly; here, only thofe two minute Parts, which become the Root and Stalk, are fo: The Main Body being of a different Subftance; when the Corn is ripe, bard and friable; but when it is fown, eafily colliquable into a kind of Milk or Cbyle, fo that, in fome refpects, it hath a near Analogy to a Vitellum. For as that is gradually melted into a fort of Chyle, and by the Branches of the $D u$ Cus Inteftinalis carryed into the Bowels of the Cbick: So is this, into a like Substance, and by the Branches of the Seminal Root (formerly defcrib'd ) conveyed to thofe Parts, which become the future Plant. B. I, Ch. Is

3. 4. Of Relation to this Kind, the Seeds of Dates, and of fome other like Plants, may be efteem'd. For that which is commonly called the Stone, feems indeed to be the Main Body of the Seed, doubled or folded up in the fame manner as in Corn. To which that Part which becomes the Plant, is annexed. But whereas in Corn, 'tis placed at Tab. 75. I i 2 the 
the Bottom of the Main Body; here it lies in a fmall round Cavity in the middle of the Back. The Stone, or Main Body, where this Part grows to it, is not fo hard, as more remote from it : and is therefore probably in fome part diffolved, by lying in the Ground, as in Corn.

4. 6. But for the moft part, the Main Body is divided, as hath been faid, into two Lobes; and thofe in Subftance Homogeneous to the oTab. 75. ther Part or Parts, plainly diftinguilhed in moft Kernels and other large seeds; and not difficultly in many leffer ones, as in that of Viola Lunaris, Scabious, Doves-Foot, \&c. if flipped out of their Covers before they are full ripe.

5. . . In Hounds-Tongue, they are of a circular figure, and very large in Proportion to the Radicle. In Cucumer, oblong, with fome vifible Branches of the Seminal Root; and the Radicle fomewhat bigger. But

Tab. 75. in Scorzonera, very long, like the Leggs of a Pair of Compafes : and the two firft, or diffimular Leavs of the Plant into which they are converted, are of the fame shape. Of thefe and many more, the Radicle is fhort and pointed; and lies in one ftraight Line with the Lobes.

6. \$. In Viola Lunaria, they are very large; and the Branches of the Seminal Root, fairly apparent, fo as to refemble a Pair of Leavs. The Radicle pretty long, equally thick from end to end, and couched

Tab.75. down upon the two Lobes, each of them having a little Shoulder for it to lie upon. In Woad, where it hath the like Pofture and shape, as alfo in Chamalina, Eruca, and many others, it is very Bulky, being bigger than both the Labes put together.

7. 6. Of this Part, I think it may be obferved, That commonly thofe Seeds, wherein it is very fmall with refpect to the Lobes, produce a Perennial Plant: And fo, vice verfa, where it is very Jarge, an Annual one. In the latter, the Seminal Virtue being more vigoious, and fo tending more haftily to the Bufinefs of Generation, followed with the Death of the Plant. Ilis:

8.9. IN THE former Seeds, the Lobes lie flat one againft another.
Tab.75. But in Garden-Radifh, they are folded up, fo as to receive the Radicle into their Bofome: as when a Chicken tucks his Head under his Wing.

Tab.75. 9:\%. In Holyoak, the Labes are plated upwards, and re-plated down again. Being moft agreeably compofed to the Shape of the Covers, as thofe are to their Pofture on the Plant. In Maple, they are plated one over another, and fo rouled up.

Io. \$. Inthe Cotton-Seed, which confifteth almoft wholly of two very

Tab. 75. broad and thin Lobes or Leaves, the Folds are yet more numerous; all curioufly reduced to an exact and folid $O$ val.

I I. 5 . It happens now and then, that inftead of two, there are three Lobes, as in the Kernels of Plums, Apples, and other Fruits, and the fmaller forts of Seeds, will fpring up fometimes with more than two diffimilar Leaves, originally the Lobes of the seed. Thefe are ob. ferved by fome, more frequently to produce a double Flower, which

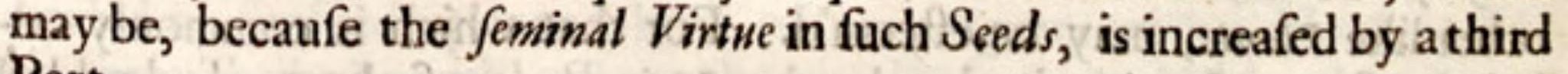
Part. 
12. \$. IN many Seeds, the Radicle is of one and the fame Colour from end to end. But in others, as in the Lupine, it is obfervable, That the upper and greater half, is White; the Lower to the Point, hath a kind of Horny Glofs, and feems to be of a fomewhat different make. Tab.75. Whereby it comes to pafs, that after the Radicle is fhot forth a little way, only this lower half defcends and becomes the Root: The upper half is produced or raifed above ground, as a Pillar upon which the Lobes, or diffimilar Leaves are erected.

13. 5. This seed, on the out fide of each Lobe, and near the Radicle, hath a very fmall and round Node, like a Navel; whereof, in the firft Book: the whole Seed looking not much unlike a Pidgeons Head; Ch. 7 . the Radicle refembling the Bill, and the Navel the Eye.

14. 5. IN the Seed of Garden-Orach, both the Radicle and Lobes Tab.75. are very long and flender, and lie almolt in a compleat Circle round about the Vitellum before defcrib'd. The Lobes of Rbapontick are Thaped like the Bitt of a Spade; and the Radicle ftands erected above $\mathrm{Cb} .3$. them like the Handle.

15. 5. OF SEEDS alfo with the Bulky Cover, there are many not divided into Lobes; being in a manner, all one Piece; as all of the Bulbous-Kind. In fome of which, though the inmoft $C$ over be thin; yet compared either with the other Covers, or with the Seed it felf, it may very well be accounted of the Bulky-Kind.

16. \$. In Flag, it is above twenty times bigger than the Seed within it. Confifting of Bladders all Radiated towards the Seat of the Seed. The Seed it felf is thaped fomewhat like a Penknife. The lower Part Tab, 76. which becoms the Bulb, as the Haft, is thick, and cometh near to a $C$ glindrick Figure, and the end, round. The upper Part which becomes the firtt years Leaf, as the Blade, is rather flat, double edged, and pointed, and the Point a little bent. The Fibers and Bladders of which it confifts, are all difpofed into Parallel Lines running by the length. In Lily, where this Cover is thinner and more Transparent, without being cut, but only held up againft the Light, the Seed may be feen within it.

17. 5. B U T THE greater number of Seeds alfo with the Bulky Cover, are divided into two Lobes; which, for the moft part, refemble a pair of little Leavs. In the Purging Nut of Angola, the Shell being taken off, the upper Covers (dry'd and fhrunk up ) feem to bebut one. Tab. ๆ\&. In thefe, the Spermatick $V_{\text {ejels }}$ are Branched. Under thefe, lies the Thick and Inmoft $C$ over; which being cut down the middle, exhibits the true Seed : Confifting of a couple of fair Leavs, Veined, and as white as Milk, joyned together with the Radicle at their Bafe; and let into a Hollow, made in the Cover, of an anfwerable thape. The like is obfervable in the Barbado-Nut, Ricinus Americanus, and fome other Indian Fruits; wirh fome little difference in the Shape of the Root and Leavs.

18. 6. IN the foregoing Fruits, the Bulky Cover is very foft. But in the Nux Vomica officinarum, tis near as hard as a Date-ftone. Tab. 76. In this, befides the hollow made for the reception of the seed, or the two Leavs and Root; the sides are feparated or diftinct almoft to the Edge of the Cover round about, ef pecially towards the Root : So that it may not unaptly be compared to a little Pouch with the Sides clapt together.

18. 6. In 
19. 6. IN this and the Nuts above mentioned, the seeds are all very

Tab.77. large. But in fome other Plants, they are extream fmall, fo as to be hardly vifible without a Glafs; as in Staphifagria, Peony, \&c. In staphifagria, the Thick or Inmoft Cover, is commonly a Spherical Triangle, conick towards the Bafe. At the poynt of which, there is a little $C a v i-$ $t y$, in which the Seed, about as big as a fmall pins head, is lodged. The Root whereof is a little ppynted, and the two Lobes rounded at the Top.

20. \$. In Peony, the fame Cover is Soft, White, and of an Oval FiTab. 77. gure; the part ufed in Medicine. Ufually thought to be the Seed it felf. But is near two hundred times biger than the true Seed, which is almoft invifible. It lies in a little Cavity near the bottom of the Cover; with a thick and blunt Root, and two poynted Lobes or Leavs.

23. 5. IN the Coffee-Berry, the Seed lies in the Inner or Cartilagi-

Ch. 3 .

Tab. 77 . nous Cover (formerly defcribed) where one would not expect to find it, $f c$. near the Top or Surface of the Back. The Lobes of the Seed are veined like two very minute Leaves, and joyned to a long Root like a Stalk. The end of which comes juft to the bottom of the $C_{\text {over, ready }}$
for its exit into the Ground.

22. \$. In Goofgrafs, where the Inner Cover is alfo Cartilaginous or Tab. 77. Horney, the Seed is poltured in much a like manner, and looks juft like a couple of poynted Leavs with a very long Stalk.

23. 5. T HE Seed of Stramonium, is alfo inclofed in a Bulky Cover. Which being foaked in warm water, and very warily cut about

Tab. 77. the edges, with a Rafor, the Seed may be taken out of it entire. Shaped like that of Orach, but muoh longer. For the Reception whereof, the Cover is formed with a hollow, which runs round about it near the Edge; where in the Seed lies like a little winding Snake.

\section{CH A P. V.}

Of the BUDS of Seeds. And of the PARTS, of which the e, the Radicle, and Lobes are compounded.

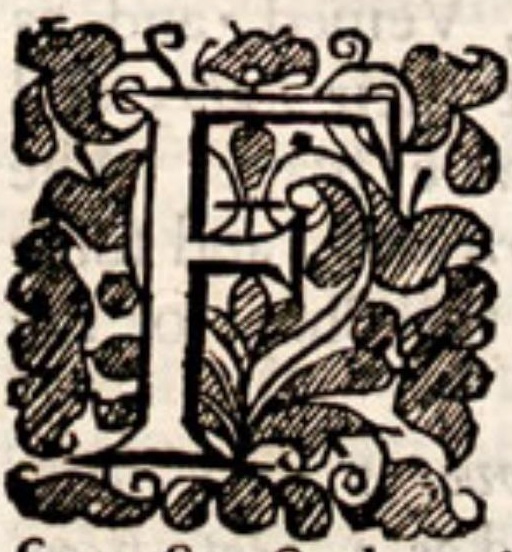

R OM between the two Lobes, rifes up the Stalk of the Plant. The original whereof, either to the naked Eye, or by a good Glafs, is always vifible in the Seed.

2. 6. In many Plants, Nature fees fit only to lay the foundation hereof in a fmall round Node; where upon the Leavs, in the Vegetation of the Seed, are fuperftructed: as in Viole Lunaria, and others.

3. \$. But in the greater number of Seeds, is formed a true Bud, confifting of perfect Leavs; different from thofe, which grow upon the stalk, only in Bignefs; and fo far in shape, as the fame Parts of an Animal Fetus, in its feveral ages in the Womb. In many seeds, as well 
fmall as great, and as well of Herbs as Trees, it is very apparent. But oftentimes lyeth fo deep between the Lobes as to be almolt undifcernable, as in Maple.

4. б. The Leaves of the Bud, in different Plants, are of a different Number; in fome, Two; in others, Four, Six, and fometimes more. In the Bay-Berry, they are only two; very fmall, but thick or fat, and finely veined. In the seed of Carduss Benedictus, they are alfo Tab. 78 . Two; almoft invifible; broad at the Bottom, poynted at the Top. thick or fat, yet plated inward, and poftured a little diftant one from the other; for the two next to rife up betwcn them. The like may be feen in Carthamum; and fo, I fuppofe, in all the Carduns Kind.

5. \%. In fome Herbs, although the Bud confifteth but of two perfeet Leaves, yet they are very confpicuous. Not only in larger Seeds, Tab. 78 . as in the Phafeolus or French Bean; but in thofe which are fmall, as in the Seed of Hemp. In this, the two Leaves are both plated, and fo fet Edge to Edge, with mutual Undulations. Of that Length, as to be extended beyond a third part of the Lobes.

6. 5. In the Seed of Sena, the Bud confifteth of Four Leaves; of Tab. 78. which, the greater pair is the outer, and guards the lefs. Shaped not much unlike thofe in the Seed of Carduns; but are a little more vifrble.

7. §. In the Bud of an Almond, we may eafily count fix, or eight Leaves, and fometimes more; the Inermoft being laid bare by a dexterous Tab. 78 . Separation of the Outer. Thefe are by much the greateft, doubled Inward, and fo laped one over another; whereby they embofome all the reft, as a Hen fpreads her Wings over her Cbickens. The like is obfervable in many other large Kernels, as alfo in the Garden Bean, and fome other Plants. With refpect to which, I have taken leave (a) to (a) B. t. call this Part the Plume.

8. 6. THE LOBES of the Seed, and fo likewife the Radicle and Bud confift of a Skin, Parenchyma, and Branched Veffels: all which I have formerly defcribed. (b) I fhall now add the following $R e-$ marques.

9. 5. And firft of the skin, which in fome Seeds, as the French-Ch. $\mathbf{x}$. Bean may eafily be feparated from the Parenchyma: efpecially if the Bean be foaked in water for fome days; for then it will flip off, like the $S$ kin in any part of ones Body where it is bliftered. 'Tis woven into Bladders, as the Parenchyma; but into fmaller ones, and upon the Tab. 79.
Lobes of a Garden Bean, all radiated towards the Center. With Lobes of a Garden Bean, all radiated towards the Center. With there Bladders, there are alfo mixed a fort of Lignous Fibres, incomparably fmall, which give a Toughnefs to the Skin, and by which the Bladders are directed into Rays.

10. \$. The Bladder's of the Parenshyma, as is faid, are much larger than thofe of the Skin, efpecially in the Lobes. In thofe of a Garden Bean, fomewhat oval, about ; of an Inch Diametre by their Bredth, Tab. 79. and directed towards the Branches of the Seminal Root. In the Radicle, they are twenty times fmaller, than in the Lobes: and fo in the Plume.

11. 5. Throughout the Parenchyma run the Branched Veffels, which Tab. 79. in the Lobes make the Seminal Root; in the Radicle and Plume, the Wood of the Root and stalk. In all of them, diftributed as hath been $(c)(c) B$. I. formerly hewed. 
12. \$. I thall here further note, That the utmolt divifions are no

Tab. 79. where extended to the Circumference of the Lobes, but are all inofculated together at a confiderable diftance from it, as in the Leaves of fome Plants.

13. 6. In the Lobes they all meet in one folid Nerve. But in the Radicle, are dilated into a hollow Trunk, filled up with a Pith; comTab. 79. pofed of Bladders fomewhat bigger than thofe which make, as it were, the Barque of the Radicle. In the Radicle of a Freñch Bean, the Pith is very confpicuous.

14. 5. The $V_{e} \iint e l s$ are of two kinds, as in the other Parts of a Plant; for Sap, and for Aer. Not running collateral, as Arteries and Veins; but the latter every where theathed in the former. From the Aer-Veffels it is, that if a Bean be fteeped in water, and then the $R a$ dicle cut tranfverfly and prefled, it will yield Bubles as well as Liquor.

Tab. 79. Thefe $V e f e l s$ are admirably fmall, yet through a very good Glafs be-

15. 5. The Liquor conteined in the Seed, when full ripe is chiefly $\mathrm{Oyl}$; generally, found in a greater proportion here, than in any other part of a Plant. Being as the Pickle, in which the Seminal Virtues, i. e. the more volatile and aftive Principles of the Seed, are immerfed for their Prefervation: and to curb them from too great a Luxuriance in the Vegetation of the Seed. 


\section{H A P. VI.}

\section{Of the GENERATIO N of the SEED.}

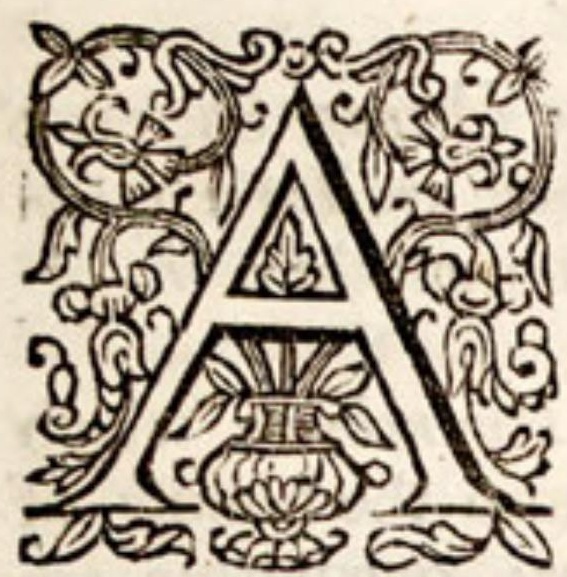

$S$ I made choice of a Garden-Bean, to thew the manner of the Vegetation of the seed: fo I thall take an Aprecock, as very apt and convenient, to obferve and reprefent the Method which Nature taketh in its Generation.

2. 6 . In order to this, the firft thing that is to be done, is to make a fit $\bigcup_{\text {terus. }}$. Both to keep the Membranes of the Fotus warm, and fucculent, till it be formed : and to preferve and fecure the Fatus it felf afterwards, till it comes to be born into the Ground.

3. \$. For this purpofe, the Pulp and Stone of the Fruit are both neceffary; but primarily the Stone : the Meat or Pulp being no otherwife neceffary, but becaufe the Stone cannot be made without it; the petrifying of that Parenchyma which is the Ground of the Stone, being effected, by the finking of the Tartar from the Pulp thereinto.

4. 5. And that, at the firt, the Ground of the Stone, is a diftinct, but foft Parenchyma; is evident in the cuting of a young Aprecock. Of which, alfo a flice cut off, with a Rafor, and viewed through a good Glafs, theweth it to be compofed of Bladders, as the Pulp it felf. Only, whereas many of thofe of the Pulp are large, now about as big as a white Pepper-Corn: thefe are no bigger than a MuftardSeed. But as the Parencbyma hardens into a stone, thefe Bladders are all gradually filled up, and difappear.

5. \$. This Parenchyma is derived immediately from the $P$ ith, as the $P u l p$ is from the Barque; and makes the far greater part of the Stone. 'Tis covered all over within, with a very thin Lining; derived, not from the Pith but the Parenchyma which covers the Seed-Branch, upon its firft entrance within the hollow of the stone. This Lining is of a clofe fubftance; yet compofed of Biadders, exquifitely fmall and hardly vifible. By which means, it foon becomes a very hard and dry Body; and is Tab.80. hereby fitted, both to promote the induration of the reft of the Stone; and the feafonable drying, and fo, the fhrinking up, of the Covers of the Seed, to make room for its Growth.

6. 5. The Stone being made hard and dry ; it could never be fo fufficiently foftned by lying under gtound, but that, it would keep the Seed a perpetual prifoner, unlefs it were alfo made pretty eafily to cleave in two. For which purpofe, the Skin of the Fruit doth obfervably $\tau_{a b}$. 80, conduce. For in a slice of a young Aprecock cut tranfverfly with a very tharp knife, it may be feen, efpecially with the help of a Glafs, to be doubled inward from the two Lips of the Fruit, and fo to be con- 
tinued, not only through the $P u l_{p}$, but alfo through the Stone it felf, into the hollow of the fame, where it meets, and is united with the Lining thereof. Whereby, as it further helps to the drying and hardning of the Stone; fo alfo renders it cleavable in that part, where it runs through it. And therefore, whereas towards the Stalk, it goes no farther than to the Seed-Branch, and fo but half way through the Stone: towards the Top of the Fruit, where the Radicle ftands, and where the Stone begins to cleave, it runs quite through it.

7. 5. Nature having thus provided a convenient $U_{\text {terus, }}$ She next taketh care about the Membranes of the Fatus. Thefe are Three apparently diftinct, and in many refpects different one from another.

8. 5. The outer Membrane is derived from the Parencbyma which furrounds the Seed-Branch; which, upon its entry into the hollow of

Tab. 80. the Stone, is expanded, as it were, into two Bladders, one within an-
other; whereof, one becomes the Lining of the Stone; the other, this outer Membrane : as is beft feen by cuting a young Aprecock, when it is about half an Inch long, down through the midle, or from the Seat of the Flower to the stalk, between the two Lips.

9. 6. This outer Membrane, at this age, hath a good full and frim $B o d y$, about $\frac{1}{12}^{\text {th }}$ of an Inch thick, or through an ordinary Glass, half an Inch, where it is thickeft, as at the Sides and the greater end: the

Tab. 8o. Poynt being thinner, for the more eafy errption of the Radicle into the Earth. Compofed of Bladders, through an ordinary Glafs, about as big, as a Colewort-Seed.

10. 6. Throughout this Membrane, the Veffels conteined in the seed-Branch are diftributed. Beginning a little below the fmaller end of the Coat or Membrane, they thence fetch their circuit both ways round about, juft beneath the Surface of the Membrane, and at laft, meet in the midle of the greater end, where they are all inofculated, fo as to

$T a b$. 80. make a kind of umbilical Node. From whence they ftrike deeper into it, and at laft, into the midle Membrane, in which they prefently become invifible. By thefe Vefels, the Sap is brought and fpewed into the midle Membrane. So that the outer Membrane feemeth, in fome refpects, to be anfwerable to the Placenta in Animals.

I I. \$. The midle Membrane, is derived from the bottome of the Outer. From whence efpecially, but alfo round about, the Bladders hereof (all angular) are more and more amplified towards the Centre; $T a b$, 80, moft of them being at leaft two hundred times biger, than thofe of the Outer Membrane: whereby it looks, through a Glafs, not unlike a Coome full of Hony; or in regard of their great tranfparency, like a company of little Crgftal Pans full of a pure Lympha.

12. 5. This Midle Membrane, is properly fo called, from the ftate and condition it hath, upon the Augmentation of the Seed, at which time, it obteins the nature of an Involucrum. But originally, it is every where entire, without any Hollow, filling up the Cavity of the Outer Membrane, like a foft and delicate $P_{m l p}$. After a fhort time, 
there appears in it a fmall Ductus or Chanel; which runs from the bottom to the top, like an Axis, through the midle of it. At firft, Tab. $8 \mathbf{t}_{\text {。 }}$ no wider than to receive the Hair of a Mans Head; not vifible, except in a flice hereof cut tranfverfly, and viewed in a Glafs. Being grown a little wider, it may be feen, if the Membrane be dexterounly cut by the length. At which time, it is alfo dilated into two Oval Cavities, one at each end : which are as two little Cisterns, whereinto a molt pure $L y m, h a$ continually owzeth, and is therein referved for the nourifhment of the Seed; and through the Chanel which runs between the Cifterns is emptied out of one Ciftern into another, according as the seed or the Inmolt Membrane hath need of it; i. e. as the $W e a$ ther and other Circumftances do more or lefs accelerate their Growth, and fo render the Lympha ufeful to them.

13. 6. A few days after this, the Innermoft Membrane begins to appear; growing, like a foft Node or Bud, out of the upper Ciftern; to the lower end of which it is joyned by a fhort and tender Stalk, from Tab. $8 \mathbf{f}_{\mathrm{o}}$ whence it is produced into a Conick-oval Figure, anfwerable to that of the Ciftern.

14. §. This Membrane, though foft and full of Sap, yet being compared with the midlemoft, is a clofe and compact Body, compoled of Bladders above 300 times fmaller than they are in that. Whereby, as the Seed is fo well guarded, as not to be fupplyed with any part of the Lympha, but the pureft : fo neither with any more of this, than will fuffice, without the danger of making an Inundation out of fo great a Lake.

15. \$. This Membrane, if it be pulled with a moft fteady hand,and very gently, upwards, it will draw a fmall tranfparent string after it to the bottom of the Midle Membrane: The faid String though for the greater part, Parenchymous, yet being ftrengthened with the admixture of fome Lignous Fibres; no otherwife vifible in either of thefe two Membranes. So that they feem, to be a fmall portion of thofe which are inofculated at the bottome of the Onter Membrane, and thence produced through the midlemoft, underneath the $\mathrm{Cbanel}$, till at laft they break forth into the upper Ciftern, where they form this Inner Membrane : a piece of clofe-wrought Work, fuitable to the incomparable finenefs of all the stuff out of which it is made.

16. 6. The fame Membrane is originally entire, as the Midlemoft: but being grown to about the bignefs of a Carvi-Seed, becomes a little hollow near the Cone. And the Lignous Fibers abovefaid, fetching their Tab. 81 . compafs from the Baje, fhoot forth into the Cone; and fo make a very fmall Node therein, for the firft E/fay towards the Generation of the Seed. The faid Fibers being thus fpun out, to the utmoft degree of finenefs for this purpofe.

17. 5. This Node, being grown about th part as big as a CheefeMite; it begins next to be divided by a little indenture at the Top. Tab. 8ז. Which growing by degrees ftill deeper, the Node is hereby at length diftinguilhed into two Lobes or thick Leavs. 
18. 5. So foon as thefe are finifhed, their Bafis begins afterwards

Tab. 81. to be contracted, and fo to be formed into a Radicle or that part of the Seed which becomes the Root. As the Stalks of Fruits do grow leffer, while the Fruits themfelves are expanded. So that in this eftate, the Radicle is, as it were, the stalk of the Seed.

19. 6. At this time, the seed being extream fmall, the Lobes are not fo manageable as to be feparated one from the other. Butit is moft reafonable to fuppofethat fo foon as the Radicle is finifhed, the next ftep, is the pufhing forth of another Node, between the Lobes, in order to the making of a Bud, and fo the perfection of the Seed.

20. 5. This being done or in doing, the Radicle or Stalk of the Seed, contracting ftill more and more at the bottome, hangs at the Inner Membrane, only by an extream fmall and thort Ligament or Navel-String. Which at laft, alfo breaks; and fo the Seed, as Fruits when they are

Tab.81. ripe, falls off and lies loofe in the Iner Membrane; this gradually fhrinking up and fo becoming more hollow, to make room for the further Growth of the Seed. 


\section{Several}

LECTURES

Read before the

\section{ROYAL SOGIETY.}

By $N E H E M F A H G R E W$ M.D. Fellow of the ROYALSOCIET $X_{2}$ and of the COLLEGE of PHYSICIANS.

\section{LONDON,}

Printed by $W$. Rawolins, 1682.

Mo.Bot. L 1, 


\section{T H E \\ T I T L E S \\ Of the following \\ LECT U R E $S$.}

I. F the Nature, Caufes, and Pomer of MIXTURE. The
fecond Edition.

II. Of the LUCT ATION arifing upon the Mixture of feveral Menftruum's with all forts of Bodies. The fecond Edition.

II I. An Effay, Of the various Proportions, wherein LIXIWIAL SALTS are found in Plants.

IV. Of the ESSENTIAL and MARINE SALTS of Plants.

V. Of the COLOURS of Plants.

V I. Of the Diverfities and Caufes of TASTS, cbiefly in Plants. With an Appendix, Of the ODOURS of Plants.

VII. Experiments in Confort, upon the SOLVTION of $S A L T S$ in Water. 
TO THE

S

Right Honourable

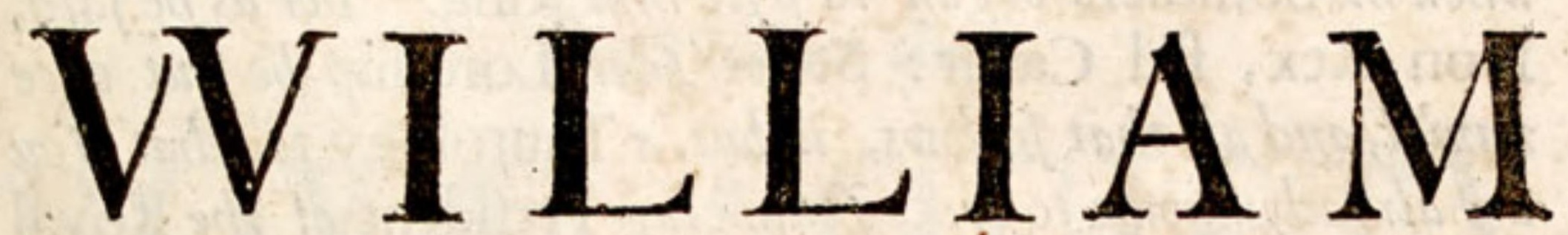

Lord Vi-Count BROVNCKER,

\section{PRESIDEN T \\ O F THE}

Royal Society.

MY LORD,

reir LIXI.

IS of Plans

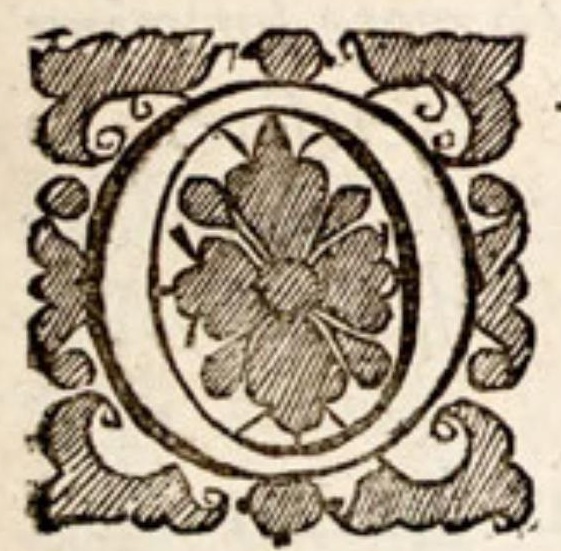

NE Reafon why I Dedicate the following Difcourfes to Your Lordhip, is, For that by Your great und undeferved Refpects, You bave obliged me to do no lefs.

Another, my Lord, is, Becaufe I could not but Publickly return Your Lordhip S: bliffin in Thanks, for minding the Royal Society of fo good a Way, they are lately refolved upon, for the Management of a great part of their Bufiness. Wherein, my Lord, I do more than prefume, that I alfo fpeak the Senfe of the whole Society; I think, not any one excepted.

I may with the fame Confidence intimate, my Lord, how happy they account themfelves, in baving a Perfon fo fit to prefide their Affairs, as Your Lordhip. The Largeness of your Knowledge, the Exactness of Your fudgment, the Evenness of Your Comport; being fome of thofe neceffary Qualifications, which His Majefty bad in His Eye (as right well underftanding what He did) when He fixed His Choice upon Your Lordhip.

I know, my Lord, that there are fome men, who bave $\mathrm{L}_{2}$ 
juft fo much Underftanding, as only to teach them how to be Ambitious: The Flattering of whom, is fomewhat like the Tickling of Children, till they fall a Dancing. But I alfo know, that Your Lordhip unconcernetb Your felf as much, in what I even now Jpake; as Cafar did bimelf, when bis Souldiers began to ftyle bim King. For as he faid, Non Rex, fed Cafar: So let Your Lordhip be but once namid, and all that follows, is but a Tautology to what $Y_{0 u}$ are already known to be. Your being Prefident of the Royal Society, Your being the Firft that was Chofen, and Chofen by fo Knowing a Prince; becomes fo real a Panegyrick to Your Lordhip, as leavetb Verbal ones without any found.

Whence, my Lord, I bave a third Reafon moft naturally emergent, which is, That I dare to fubmit my felf, as to what I have bereafter faid, to Your Lordfhips Cenfure. You being fo able and juft an Arbiter betwixt the fame and all thofe Perfons therein concern'd; that You can neither be deceived, nor corrupted, to make a fudgment in any Point, to the Injury of either.

And truly, my Lord, were it only from a Principle of felfIntereft, yet I could not defire it Sbould be otherwife. For the World, if it lives, will certainly grow as much more knowing than it is; as it is now more, than it was beretofore. So that we have as little Reafon to defpife Antiquity; as we can bave willingnefs, that we our felves Sbould be defpifed by Pofterity.

$Y_{e}$ fome difference there is to be made; viz. betwixt thole of all Ages, who have been modefly ignorant; and thofe who bave thought, or pretended, that they were Omnifcient. Or if knowing and acknowledging that they were Ignorant; baze yet not been contented to be $\int 0$; unlefs, with as good manners, as fenfe, they did conjure all Mankind not to offer at the knowing any more than them felves.

Upon the whole, my Lord, I defire not You fbould be a Patron, any further than You are a Judge. For if this fmall Eflay bath deferved the leaft acceptance, I am fure, that in being one, rou will be both. $I \mathrm{am}$,

My Lord,

Your Lordfbips moft Faithful and Obedient Servant, NEHEMFAH GREW. 


\section{A \\ DISGOURSE \\ Read before the \\ ROY AL SOCIETY \\ Decemb. 10. 1674 .}

Concerning the

NATURE, CAVSES, and POWER

\section{O F}

M IX T URE.

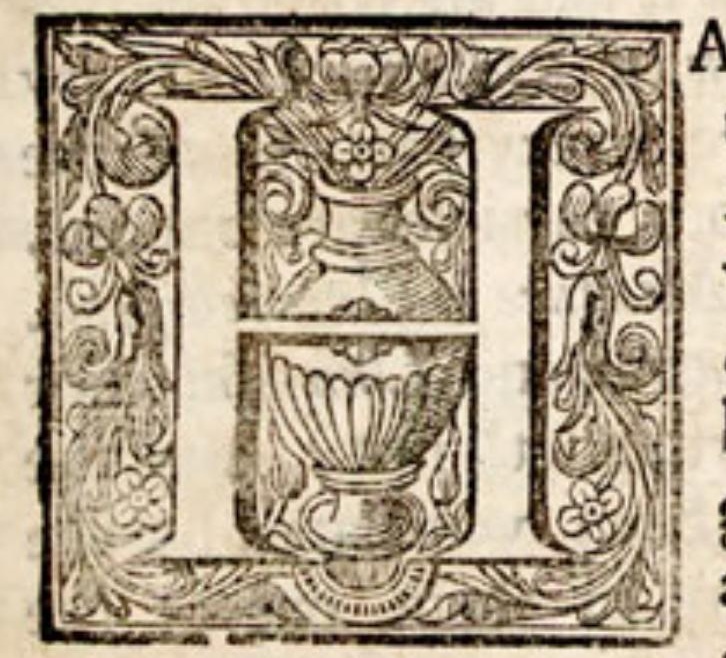

A V I N G the honour to perform the Task of this day; I thall endeavour to conform to the Phylofophy, which this society doth profefs; which is, Reafoning grounded upon Experiment, and the Common Notions of Senfe. The former being, without the latter, too fubtle and intangible; the latter without the former, too grofs and unmanageable: but both together, bearing a true analogy to our felves; who are neither Angels, nor meer Animals, but Men.

The Subject I have chofen to fpeak of, is Mixture. Whereof, that our Difcourfe may be the more confiftent, and the better intelligible; all I have to fay, fhall be ranged into this Method; viz.

I. Firft, I hall give a brief account of the received Doctrine of Mixture.

2. Next, lay down fome Propofitions of the Principles whereof all Mixed Bodies confift.

3. Then, open the true Nature of Mixture; or fay, what it is.

4. And then enumerate the Caufes of Mixture; or fay, How it is made.

5. Laftly, I thall thew the Power of Mixture; or, What it can do. 


\section{H A P. I. Of the received Doctrine of Mixture.}

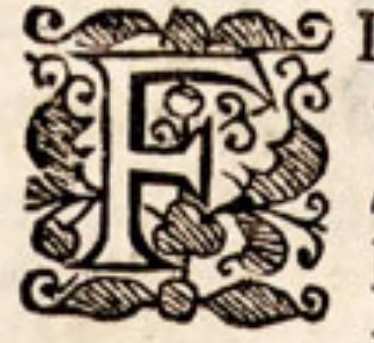
R S T, As to the received Doctrine of Mixture; not to trouble you with tedious quotations of what Ariftotle, $\mathrm{Ga}$ len, Fernelius, Scaliger, Sennertus, Riverius, and other Learned men fay hereof; we may fuppofe the whole fummed up in that Definition which Ariftotle himfelf hath given of it, and which the greater number of his Followers, have almoft religioufly

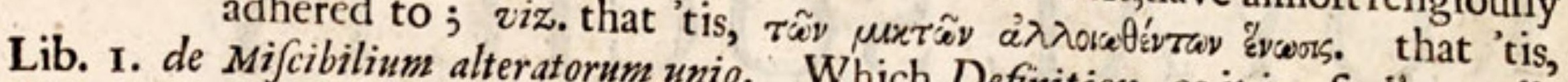
Generat. cated, is both Unintelligible, and Znueful. EC Corrupt. Cap.ult.

2. 6. Two things are unintelligible; what they mean by AlteratiForms of the Elements. In this Alteration, they fay, That the very Forms of the Elements are altered. And therefore lay it down for an let us fee the confequence. Forme Elementares tantum fint in potentia, But Elements are but in potentia. For if in a mixed body, the Forms of the potentia: for we all fartia; then the Elements themfelves are but in Elements, are only in potentia that effe. And if the Compounding be only in potentia in potentia; then the Compounded Body it felf can .

it fuch, As for the Union of Elements in a mixed Body; they make that the Zenetration of Bodies, and in fuch fort that every fay it is made Nature of the ted 2ualities of the four Elemeture, arileth from the contemperaevery particle of the mixed Body ments. Which is plainly to aff, containeth in it felf all the four EleElement is, at leaft, on Bodies. For every mixed Body, containe particle; if therefore every particle of the I conclude then That our Elements ; then four particles are but one.

4. 6 . Whence it follows who can make any ufe of experience of fo many difputes of men, pry years, wherein it hath been ventilated by the Learned sennertus, fhould come to underftand themfure upon Experiment, for fear they

5. \$. It is confeffed, that many gallant things have been found out by artificial Mixture. But no thanks to this Definition of it. For as an Ignorant Man may make bad $W$ ork, and a good $R$ ule be never the worfe; fo one that is Ingenious may make good Work, and a bad Rule be never the better. The queftion is not, what have men done? but what have they done upon this foundation, 2uod Mixitio fit mifcibilium alteratorum unio. Had this ever taught them to do any thing, even fo much as to make the Inke wherewith they have wrote, all their Difputes; I confefs, they would have had fomething to thew for it. But the truth is, their notions of Mixture, have been fo far from doing us any good, that they have done us much harm: being, through their fecming fubtlety, but real abfurdity, as fo many phantaftick spedrums, ferving only to affright men from coming near them, or the Subject whereof they treat. 
5. 6. I thall therefore endeavour to open the true Nature of Mixture. And I thall build my. Doctrine upon the Common Notions of Senfe: which none can deny; and every one may conceive of. In order to which, I thall take leave to lay down fome Propofitions, of the Principles of all mixed Bodies.

\section{H A P. II. of the Principles of Bodies.}

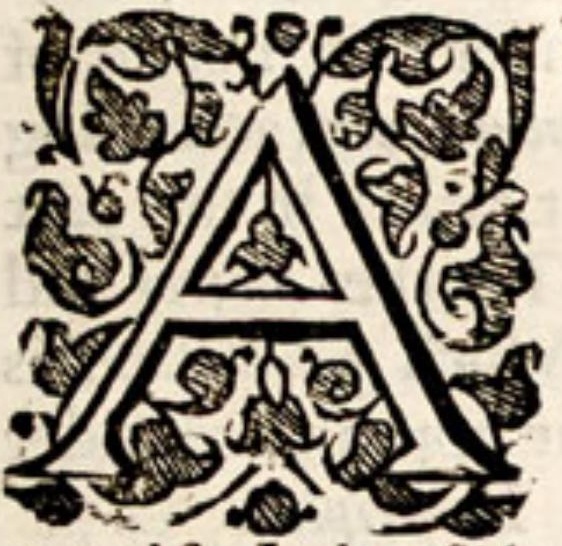

ND firft, by Principles, I mean Atomes, or certain Sorts of Atomes, or of the fimpleft of Bodies. For otherwife they would not be Principles; for a compounded Principle, in ftrict fpeaking, is a Contradiction. Even as Fives, Threes, or Two's are not the Principles of Number, but Unites.

2. 6. Whence, fecondly, it follows, that they are alfo Indivifible. Not Matbematically; for the Atomes of every Principle have their Dimenfions. But Phyfically; and fo, what is but one, cannot be made two. If it be asked, Whether a Stick cut with a Knife, be not of one, made two? I fay, that a Stick, is not one Body, but many millions of Bodies; that is, of Atomes; not any one whereof is divided within it felf, but only they are feparated one from another, where the Knife forceth its way. As in the drawing of a mans Finger through a Heap of Corn; there is no Divifion made in any one Grain, but only a feparation of them one from another, all remaining ftill in themfelves entire. I fay, therefore, that what is Pbyfically one, is alfo molt firm, and Indivifible, that is, Impenetrable : for Penetration is but the Separation, not the Divifion of Atomes.

3. 5. Hence, thirdly, they are alfo Immutable. For that which cannot be divided, cannot be chang'd. So that of the whole World of Atomes, not any one hath ever fuffer'd, or can fuffer the leaft $m u$ tation. Hereupon is grounded the Conftancy of Caufes and Effects. So that, in all Generations, it is not lefs certain, that the felf fame Principle is ftill propagated from the fame; than, that Man is from Man. Wherefore, compounded Bodies are generated; but Principles are not, but only propagated; that is, in every Generation, they pafs, in themfelves unaltered, from one Body, into another.

4. \$. If Principles, or Atomes are all Immutable; it again follows, That they are of Divers Kinds. For one and the fame Principle, or Kind of Atomes, will ftill make the Same Thing, and have the fame Effect : fo that all Generations would then be the Same. Wherefore, fince they are Immintable, they muft be Divers.

5. 5. This Diverfity, for the fame reafon, is not fmall, but very Numerous. For as the World, taken together, is Natures Shop; fo the Principles of Things are her Tools, and her Materials. Wherefore, as it fpeaks the goodness of a Shop; fo the Perfection of the Univerfe, That it is furnifhed with many Tools wherewith,and many Materials whereupon to work. And confequently, that Pbilofophy beareth beft its own name which doth not ftrain all totwo or three Principles; like two or three 


\section{4

Bells in a Steeple, making a pitiful Chime: but tryeth to rife up to Natures own Number, and fo to ring all the Changes in the World.

6. 6. Yet doth not this valt Diverfity take away the Regiment and Subordination of Principles. There being a certain leffer number of them, which either by their greater quantity, or other ways, have Rule and Dominion, in their feveral Orders, over all the reft. For where-ever the Subject is Multitude, Order is part of its Perfection. For Order is Proportion. And how can Nature be imagin'd to hold Proportion in all things elfe, and not here? Wherefore, as certainly, as Order and Government are in all the Parts of the Rational; fo certainly, of the Material World. Whence it is, That although the species of Principles be very numerous; yet the Principles called Galenical, Chymical, or any others, which do any way fall under the notice of Senf, are notwithftanding reduceable to a fmaller number : viz. according to the number of $f$ redominant Principles in Nature; or, rather in this part of the Univerfe which is near and ronnd about ws. To the Power and Empire whereof, all other Principles do fubmit. Which submilfzen, is not the quitting of their own Nature; but only their appearance under the external Face or Habit of the fard Predominant Principles.

7. 6. As there can be no Order of Principles, without Diverfity; fo no Diverfity, but what is originally made by thefe two ways; $j c$. by size and $F$ zgure. By the fe they may be exceeding different : and all other Properties befides, whereby they differ, muft be dependent upon thefe Two.

8. 6. Nor therefore, can they be of any other Figures, than what are Regular. For Regularity, is a Similitude continuid. Since therefore all kinds of Atomes are divers only by their Size and Figure; if the felfe fame Size and Figure were not common to a certain number of Atomes, they could not befaid to be of any one kind : and confequently, if there were no similitude of Atomes, there could be no Diftindion of Principles.

9. \$. Hence alfo, thefe two Modes of Atomes, viz. their Size and Figure, are the true, and only original 2ualities of Atonses. That is, an Asome is fuch or fuch, becaufe to is of fuch a certain size and $F_{i-}$ gure.

10. 5. Laftly, As thefe two Modes, taken feverally, are the 2ualities of an Atome: fo confider'd together, they are its Form. A jubftantial Form of a Body, being an unintelligible thing. I fay of a Body; for although the Rational Soul be a Jubltantial Form, yet is it the Form of a Man, and not of a Body. For the Form of a Body, we can conceive of no otherwife, than as of the Modification of a Body, or a Complexion of all the Modes of a Body. Which alfo agrees with that Definition of a Form, which amongft the Peripatetick Philofophers is well enough accepted, viz. 2uod fit, Ratio ejus Efentie, que cuique Rei competit. Which Ratio, if it be referred to a Body, what isit, but the Modification of that Body? Having thus propofed a Summary of my Thoughts about Principles; I thall next proceed to thew what their Mixture is. 
Lect. I. The Nature of Mixture.

\section{H A P. III. \\ Of the NATURE of Mixture.}

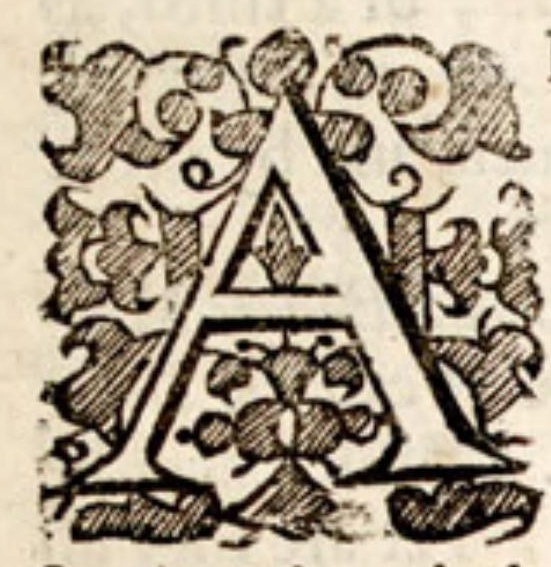

N D firft of all, from the Premiffes, we arrive at this Conclufion; $f c$.That the Formation and Transformation of all Bodies, can be nothing elfe, but the Mixture of Bodies. For all Principles are immutable; as we $\mathrm{Ch} .2 .5 .3$. have above proved: and therefore not generable, formable, or transformable. And the Forms of Principles, being but their Modes, are alfo immutable. Ch.2.\$.10: So that the whole Bufinefs of the Material World, is nothing elfe, but Mixture.

2. 6. Again, as Nature worketh every where only by Mixture; fo is this Mixture every where but one tbing, and can be but one. For whether it be the Mixture of great Bodies, or of fmall; of Compounds, or of Atomes; it is every where Mixture, and the Mixture of Bodies. Wherefore, Mixture is either an intelligible Affection of all Bodies, or of none; which later, no man will fay. As many ways therefore, as we can fee, or conceive the Mixture of any grofs Bodies, which we hold in our hand; fo many ways, we may, of the fubtileft Mixtures which Nature maketh, or of Atomes themfelves; and no other ways.

3. S. Now all the ways we can diftinguifh Mixture by, are, in general, thefe $T w o$; either in refpect of the Bodies Mixed, or elfe of the Modes of the Mixture it felf.

4. 5. In refpect of the Bodies Mixed, Mixture is diftinguithed alfo two ways; viz. by Conjugation, and by Proportion.

5. 5. By Conjugation, I mean, a Mixture of fome certain Principles, and not of others. Which is threefold. First, As to Number: as when one Body may be compounded of two Principles, another of three, a third of four, a fourth of five, and fo on. Secondly, As to Kind: where, though there be a conjunction of the fame Number, yet not of the fame Kind. Thirdly, When they differ from one another both in Number and Kind. So many ways the Principles of Bodies may be conceived to be Conjugated; and therefore are: for here, that which may be, is. The Confequence is clear. For frift, Nature hath various Materials wherewith to make thefe Mixtures; as we have fhewed. sccondly, By thefe Mixtures fhe may, and without the concurrence of any imaginary Forms, muft produce all the varieties in the material world; as likewife hath been faid. Where- $C b, 3 . \S . t$. fore, fince all imaginable Mixtures may be made, and thac to fome purpofe; if hey thould not be fo, Natwre would be Imperfect: becaufe we our felves can think, how fhe might put her Materials to further ufe, then $f o$ the would do. To think therefore, that all Kinds of Principles, or all Elements go to make up every Compounded Body, as by the Peripatetick, Philofophy we are taught; is a conceit, no more to be credited, than one that fhould tell us, all Kind of Wheels and other $\mathrm{M} \mathrm{m}$ 
parts of a Watch, were put into a clock; or that there were no other Materials wherewith to build an Houfe, then for a Tent or a ship. For why flsould Nature, the great Artificer by which all perfect Works are made, be feigned to cram and ram all things into one, which we our felves look upon as abfurd?

6. 5. Secondly, The Mixture of Principles is diverfifid, as by Conjugation, fo alfo by Proportion. That is, by the divers Quantities, of the feveral Principles or Parts mixed together. As if the Quantity of one, were as five to ten; of a fecond, as five to fifteen; of a third, as five to twenty, \&c. Or if that of one, be as five to $f i x ;$ of a fecond, as fix to feven; of a third, as feven to eight. By which, and by other Proportions, Mixture may be varied innumerable ways.

7. 6. Again, As Mixture is varied with refpect to the Bodies Mixed; fo likewife in refpect of the Mixture it felf, which I call the Location of Principles, or the Modes of their Conjunction. Which may be various, as well as their Conjugation and Proportion. Yet are they all reduceable unto two general Modes: all Bodies, and therefore all Prin-

Ch. 2. 5.2. ciples, being mixed either by Mediation, or by Contact.

8. \$. Now all Contact, whether of Compounds, or of Atomes, can be no other way, than fuch as is anfwerable to their Figures. Whereof, therefore, we can conceive but three general ways, viz.

Firft, By Contract in a Point, or fome fmaller part: as when two Atomes meet, which are globular or otherwife gibbofe. secondly, By Contait in a Plain: as in the conjunction of the fides of Triangular or Quadrangular Atomes, or otherwife flat. Thirdly, By Coniact in a Concave: as when one Atome is admitted into the Concave or bole of another ; as a Spigot is into a Foffet. The firft may be called, Appofition; the fecond, Application; the third, Reception or Intrulion.

9. S. In the two laft ways, Atomes may be joyned by Mediation; but beft of all the laft. As when the two extreams of one Atome are received into the Concaves or the holes of two others.

I0. 6 . And thefe are all the general ways, whereby we can conceive Bodies to be Mixed together; $f c$. by their various Conjugation, Proportion and Location. So that the Compofition of Atomes, in Bodies; is like that of Letters, in Words. What a Thunderclap would fuch a Word be, wherein all the four and twenty Letters were pack'd up? One therefore is compounded of more, another of fewer : this of fome, and that of others: and both the Conjugation, Proportion, and Location of Letters is varied in every Word: whereby, we have many thoufands of differing Words, without any alteration at all, in the Letters themfelves; and might have ten times as many more. In like manner, therefore, or in the felf fame analogous way, as the Letters of the $\mathrm{Al}$ phabet, are the Principles of Words; fo Principles, are the Alphabet of Things.

II. \$. What we have faid of Principles; and of Mixture as confequent thereupon; may be a foundation for an intelligible account, of the Nature and Caufe of moft of the Intrinfick Properties, and 2ualities of Bodies: as of Gravity, Levity, Fixity, Fluidity, Angularity, Roundnefs, Heat, Cold, Blacknefs, Whitenefs, Sowernefs, Sweetrefs, Fragran$c y$, Fetidnefs, and very many more. I fay an intelligible account ; $f c$. fuch as is grounded upon the Notions of Senfe, and made out Mechanically. But the exemplification hereof, being too large a field 
for this, or any one Lecture, I fhall, before I come to the Caufes of Mixture, only deduce from the Premifes, thefe following Corollaries.

12. \$. Firft, That there is no alteration of Principles or of Elements, in the mort perfect Mixture of Bodies. It cannot be; for Principles are Immutable, as we have faid. And if it could be, yet it needeth not Ch. 2. 6.30 to be: for they are alfo many, and compoundable infinite ways; as hath been thewed. So that we have no need to perplex our felves $c h .2 . \$ .5$. with any of thofe difficulties, that arife from the Doctrine of the Ch.3.8.10\% Alteration of Elements. The ground of which conceit, is that, of three being but four Elements, and all in every particle of the mixed Body. And fo men being puzeled, how from thence to make out the infinite variety of Bodies, they feigned them to be alterable, and altered, upon every perfect Mixture. Not confidering, that if their four Elements be alterable; as few as they are, no fewer then ibree of them may be fpared : for one Element, if alterable, may belmade any.

13. 5, Hence, secondly, may be folved that great Difpute, Whether fuch as we call Lixivial Salts, are made by the fire? For firft, No Principle is made by the fire: all Principles being unalterable; and therefore unmakable. Secondly, We muft therefore diftinguifh betwixt the Principle, and its various Mixture with other Principles; from whence it may receive different Shapes and Names. Wherefore, a Lixivial Salt, qua Lixivial, is certainly made by the fire. But quatewus Salt, it is not: that Principle being extractable out of moft Bodies; and by divers other ways, then by the fire. For whether you Calcine a body, or elfe Ferment it, (after the manner thewed by the curious Improver of Chimical Knowledg, Dr. Daniel Cox) or putrifie it under ground, or drown it in the Sea; it ftill yieldeth fome kind of Salt. All which Salts are made, not by making the Saline Principle; but only by its being differently Mixed, by thofe feveral ways of the Solution of Bodies) with other Principles: from which its different Mixture, it receives the various Denominations, of Marine, Nitrous, Volatile, or Lixivial.

14. 6. Hence, Tbirdly, the moft perfect Mixture of Bodies, can go no higher than Contact. For all Principles are unalterable; and all Ch.2. 5. 3. Matter is impenetrable; as hath been faid. In the molt vifible and laxe $C h .3 .8$. 2. Mixture, there is Contact; and in the moft fubtile and perfect, as in $\mathrm{Ge}$ neration it felf, there is notbing more.

15. 5. Hence, Fourthly, we eafily underftand, how divers of the fame Principles, belonging both to Vegetables and many other Bodies, are alfo actually exiftent in the Body of Man. Becaufe even in Generation orTranfmutation, the Principles which are tranflated from one Body to another, as from a Vegetable to an Animal, are not in the leaft alter $d$ in themfelves; but only their Mixture, that is, their Conjugation, Proportion and Location, is varied.

16. \$. Hence alfo the difference of Mixture, arifing from the difference of Contact, is intelligible; $f c$. as to thofe three degrees, Congregation, Union, and Concentration.

Congregation, and Inconfiftent Mixture, is when the feveral Atomes touch but in a Point, or fmaller part. In which manner, I have divers $C b_{0} 3.8 .8$. arguments, inducing me to believe the Atomes of all Fluid Bodies, qud 'Fluid, do touch; and in no other.

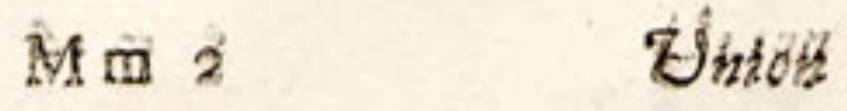


Cb.3.5. 8. Union, is when they touch in a Plain. As in the Cryftals and shootings of all Salts, and other like Bodies. For if we purfue their divided and fubdivided parts, with our eye, as far as we can; they fill terminate, on every fide, in Plains. Wherefore, 'tis intelligible, That their very Atomes do alfo terminate, and therefore touch, in Plain.

Concentration, is when two, or more Atomes touch by Reception

Ch.3. 5. 8. and Iutrufion of one into another: which is the clofeft, and firmeft Mixture of all; as in any fixed unodorable, or untaftable Body: the Atomes of fuch Bodies, being not able to make any Smell or Tafte, unlefs they were firft diffolved; that is to fay, unpin'd one from
another.

17. \$. Hence, Sixtbly, we underftand, how in fome cafes, there feemeth to be a Penetration of Bodies; and in what fenfe it may be admitted: viz. if we will mean no more by Penctration, but Intrufion. For the Intrufion of one Atome into the Concave or bole of another, is a kind of Penetration; whereby they take up lefs room in the mixed Body, then they would do by any other way of Contact. As a naked knife and its fheath, take upalmoft double room, to what they do, when the knife is theathed. Whence we may affign the reafon, Why many Liquors being mixed; take up lefs room or fpace, then they did apart; as the Ingenious Mr. Hook hath made it to appear by Experiment, that they do. I fay the plain reafon hereof, or at leaft one reafon, is the Intrufion of many of their Atomes into one ancther. Which yet is not a Penetration of Bodies ftrictly fo called.

Ch. 3. 5. I. 18. 5. Seventhly, If all that Nature maketh, be but Mixture; and

Cb.3.5.14. all this Mixture be but Contact 'tis then evident, That Natural and Artificial Mixture, are the fame. And all thofe feeming fubtilties whereby Pbilofophers have gone about to diftinguifh them; have been but fo many Scarcrows to affright Men from the Imitation of Nature.

19. 5. Eightbly, Hence it follows, That Art it felf may go far in doing what Nature doth. And who can fay, how far? For we have nothing to Make; but only to mix thofe Materials, which are already made to our hands. Even Nature her felf, as hath been faid, Cb. 3. S. x. Makethnothing new ; but only mixeth all things. So far, therefore,
as we can govern Mixture, we may do what Nature dotb.

20. 6. Which that we may ftill the better underftand; let us before, and in the next place, fee the Canjes of Mixture. For fince

Ch.3.5.18. Natural and Artificial Mixture are the fame; the immediate Canfes of both, are and muft be the fame. 


\section{H A P. I V.}

\section{Of the C A USES of Mixture.}

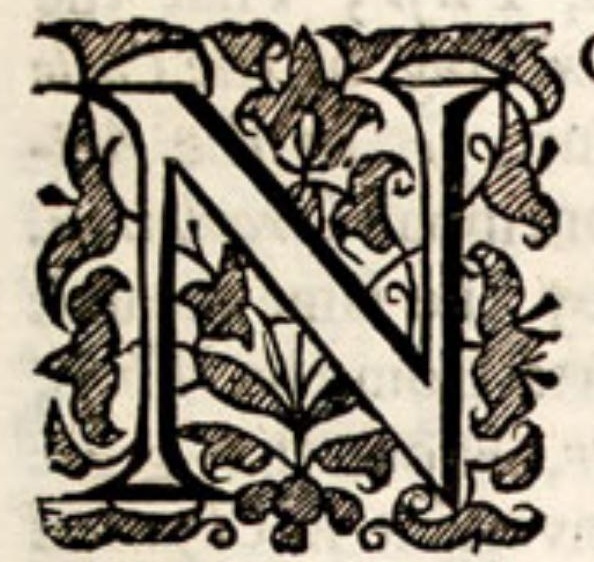

OW all the Canfes of Mixture we can conceive of, muft, I think, be reduced to thefe $f i x$ in general; viz. Congruity, Weight, Compreffion, Solution, Digeftion, and Agitation.

I. ك. Congruity, or aptitude and refpondence betwixt the Sizes and Figures of Parts to be mixed: whereby Bodies may be truly called the Inftrumental Caufes of their own Mixture. As when a Plain anfwers to a Plain, a Square to a Square, a Convex to a Concave, or a Lefs to a Greater or an Equal, \&x. according to which Refpondencies in the parts of Bodies, they are more or lefs eafily mingleable.

2. 6. Weight, by means whereof all Fluid Bodies, upon fuppofition of the Congruity of their parts, mutt nnavoidably mingle.

3. 6. Compreffion; which either by the Air, or any other Body, added to Weight, muft, in fome degree, further Mixture. Becaufe, that Weight it felf, is but Preffion. For further Proof of all the faid Caufes, I made this Experiment; Let Oyle of Anifeeds, and Oyl of Vitriol be put apart into the Receiver of an Air-Pump. And, having exhaufted it of the Air, let the two faid $O y l s$ be then affufed one upon the other. Whereupon, Firft, It is vifible, that they here mix and coagulate together; that is, their parts are woedged and intruded one into another, without the ufual compreffion of the Air; for that is exbaufted, and therefore only by the Congruity of their receiving and intruding parts; and by their Weight; by wobich alone they are fo compreffed, as to make that Intrufion. Secondly, It is alfo evident, That although they do $C_{0-}$ agulate; yet not altogether fo much, as when poured together in the fame manner, and quantity, in the open Air. Wherefore, Compre/fion, whether made by the Air, or any thing elfe, as it doth further the Diffolution of fome Bodies, fo the Mixture of others, and the greater the Compreffion, the more.

4. 5. Solution; For all Bodies mix beft, in Forma fluida. And that for two reafons. Firft, Becaufe the parts of a Body are not then in a ftate of Union, but of Separation; and therefore, in a more capable ftate, for their Mixture and Union with the parts of another Body. Secondly, becaufe then they are alfo in a ftate of Motion, more or lefis; and therefore, in a continual tendency towards Mixture; all Mixture being made by Motion. Wherefore all Generations, and moft perfect Mixtures in Nature, are made by Fluids; whether Animal, Vegetable, or Mineral. Which is alfo agreeable to the Dodtrine of the Honourable Mr. Boyle, in his Excellent Treatife of the Nature and Vertues of Gems. And it is well known, That Bodies are ordinarily petrified, or Stones made, out of Water.That is,out of petrifying parts diffolved per minima in Water, as both their Menftrum and their Vebicle. Wherefore, if we will talk of making Gold; it muft not be by the Philofophers Stone, but by the Philofophers Liquor. 
5. \$. Digeftion. For which there is the fame reafon, as for Mixture, by solution. For, Firft, All heat doth attenuate, that is, ftill further Separate the parts of a Body; and fo render them more mingleable with the parts of another. And therefore, secondly, Doth alfo add more Motion to them, in order to their Mixture.

6. 6. Agitation. Which I am induced to believe a great and effectual means of Mixture, upon divers Confiderations. As, Firft, That the making of Blood in the Bodies of Animals, and the mixing of the Chyle therewith, is very much promoted by the fame means; $f c$. by the Agitation of the parts of the Blood and Chyle, in their continual Circulation. Again, from the making of Butter out of Milk, by the lame means: whereby alone is made a feparation of the oleous parts from the Whey, and Conjunction of the Oleous together. Moreover, From the great Effects of Digeftion; well known to all that are converfant in Chymical Preparations. Which Digeftion it felf, is but a kind of infenfible agitation of the parts of digefted Bodies. 'Tis alfo a known Experiment, That the readieft way to diffolve Sugar in Wine or other Liquor; is to give the $V$ effel a bafty turn, together with a fmart knock, againft any bard and fteady Body: whereby all the parts of the Sugar and Liquor, are put into a vehement Agitation, and fo the Sugar immediately diffolved, and mixed with the Liquor. And I remember, that having (with intent, to make Mr. Matthews's Pill) put fome Oyl of Turpentine and Salt of Tartar together in a Bottle, and fent it up hither out of the Country; I found, that the continual Agitation upon the Road, forthree or four days, had done more towards their Mixture; than a far greater time of Digeftion alone had done before. And it is certain, That a vehement Agitation, efpecially, if continu'd, or joyned with Digeftion; will accelerate the Mixture of fome Bodies, ten timesmore, than any bare Digeftion alone; as may be proved by many Experiments. I will inftance in this one. Let fome $O y l$ of Turpentine and good spirit of Nitre be ftop'd up together in a Bottle, and the Bottle held to the Fire, till the Liquors be a little heated, and begin to bubble. Then having removed it, and the Bubbles by degrees increafing more and more; the two Liquors will of themfelves, at laft fall into fo impetuous an Ebullition, as to make a kind of Explofion; fending forth a finoak for the fpace of almolt two yards high. Whereupon, the parts of both the Liquors, being violently agitated, they are, in a great portion, incorporated into a thick Balfam in a moment: and that without any intenfe heat, as may be felt by the Bottle. And thus much for the Canfes of
Mixture. 


\section{CHA P. V.}

\section{Of the POWER and USE of Mixture.}

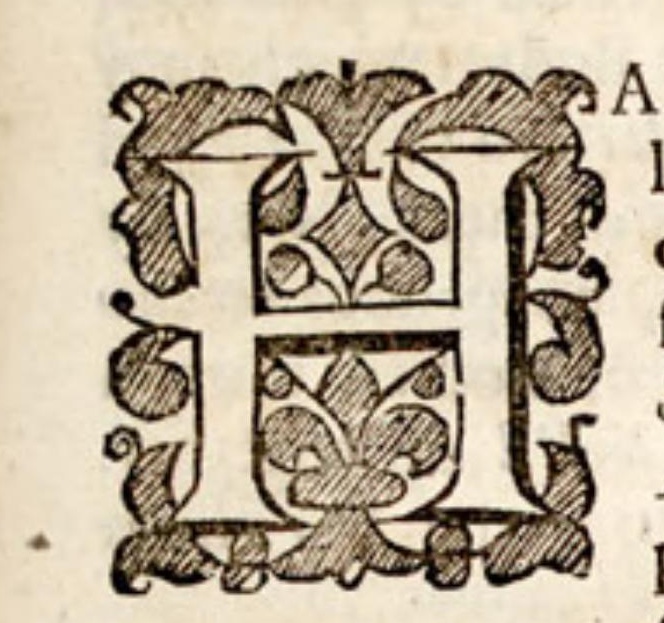

A V I NG enumerated the general Caufes, we fhall, laftly, enquire into the Power and U/e of Mixture; or, into what it can $D_{0}$ and Teach. And I fhall Inftance in $f l x$ particulars. First, to Renderall Bodies Sociable, whatfoever they be. Secondly, To Make Artificial Bodies in Imitation of thofe of Natures own production. Thirdly, to make or imitate the fenfible Qualities of Bodies; as smells, andTafts. Fourthly, To make, or imitate their Faculties. Fiftbly, It is a Key, to difcover the Nature of Bodies. Sixthly, Todifcover their $\mathcal{U} / e_{2}$ and the Manner of their Medicinal Operation.

\section{N S T A N C E I.}

$\mathrm{F}$ IR ST, To render all Bodies Sociable or Mingleable: as Water with Oyl, Salt with Spirit, and the like. For Natural and Artificial Mixture, are the fame; as we have before proved. If therefore Ch.3.5.18, Nature can do it, as we fee in the Generation of Bodies the doth, 'tis likewife in the Power of Art to do it.

2. $\$$. And for the doing of it, two general Rules refult from the Premiffes, $\int c$. The Application of Caufes, and the Choice of Materials. As for the Caufes, they are fuch as I have now inftanc'd in. And for Ch. 4 . the Application of them, I thall give thefe two Rules.

3. S. Firft, That we tread in Natures fteps as near as we can; not only in the Application of fuch a Caufe, as may be moft proper for fuch a Mixture; but alfo in allowing it fufficient time for its effect. For fowe fee Nature her felf, for her more perfect Mixtures, ufually doth. She maketh not a Flower, or an Apple, a Horfe, or a Man, in a moment; but all things by degrees; and for her more perfect and elaborate Mixtures, for the molt part, the requireth more time. Becaufe all fuch Mixtures are made and carri'd on per minima; and therefore require a greater time for the compleating of them.

4. 5. A fecond Rule is, Not only to make a due Application of the Caufes; but fometimes to Accumulate them. By which means, we may not only, imitate Nature, but in fome cafes go beyond her. For as by adding a Graft or Bud to the Stock, we may produce Fruit fooner, and fometimes better, than Nature by the Stock alone would do: So here, by accumulating the Caufes of Mixture, that is, by joyning $\mathrm{two}_{2}$ three, or more together; or by applying more in fome Cafes, where $\mathrm{Na}$ ture applyeth fewer; we may be able to make, if not a more perfect, yet a far more fpeedy Mixture, than Nature doth. As by joyning Compreffion, Heat, and violent Agitation, and fo continuing them all together, by fome means contrived for the purpofe, for the fpace of a THeek, 
Week, or Month, or longer, without ceffation. Which may probably produce, not only frange, but ufeful Effects, in the Solution of fome, and the Mixture of other Bodies. And may ferve to mix fuch Bodies, as through the fimall number of their congruous parts, are hardly mingleable any other way. Agitation being, as carrying the Key to and fro, till it hit the Lock; or within the Lock, till it hit the Wards.

5. 5. Secondly, For the Choice of materials, if they are not immediately, that is, of themfelves, mingleable; we are then to turn one Cb.3. 6.9. Species of Mixture into a Rule; which is, To mix them by mediation of fome third, whether more fimple or compounded Body, which may be congruous in part to them both: as Sulphurous salts are to Water and $O y l$; and are for that reafon mingleable with either of them. Or, By any two congruous Bodies, which are alfo, in part, congruous to two others: and other like ways. Whereby the parts of Bodies, though never fo beterogeneous, may yet be all bound and lock'd up together. Even as twenty Keys may be united, only by unising the two Rings whereon they hang.

6. 5. The Confideration of thefe things, have put me upon making feveral Experiments, for the mingling of heterogeneous Bodies. I fhall give two Examples of Tryal; the one upon Fluid, the other upon confiftent Bodies.

7. \$. For the firft, I took $0 y l$ of Anifeeds, and pouring it upon another Body ; I fo order'd it, that it was thereby turned into a perfect milk-white Balfam, or Butyr. By which means the faid $O g l$ became mingleable with any Winy, or Watery Liquor; eafily, and inftantaneoufly diffolving therein, in the form of a Nilk. And note, That this is done, without the leaft alteration of the Smell, Taft, Nature, or Operation of the faid $O y l$. By fomewhat the like means, not only Oyl of Anifeeds, but any other fillatitious Oyl, may be transformed into a milk-vobite Butyr; and in like manner be mingled with Water or any other Liquor. Which is of various ufe in Medicine; and what I find oftentimes very convenient and advantageous to be done.

8. 5. Again, not only Fluid but confiffent Bodies, which of themfelves will mix only with $O, l$; by due mixture with other Bodies, may be render'deafily diffoluble in Water; as may Rofin, and all refinous and friable Gums. As alfo $W a x$ : and this without changing much of their Color, Taft, or Smell. Whereof likewife, whatfoever others may do, the Phyjician may make a manifold $\mathcal{U}_{\int e}$.

\section{N S T A N C E II.}

RY Mixture alfo, we may be tanght to Imitate the Produdtions of Nature. As to which, from what we have before faid of Mix= ture, we may conclude; That there is no Generation of Bodies unorganical, but what is in the Power of Mixture to imitate. As of Animals, to Imitate Blood, Fat, Cbyle, Spittle, Flegm, Bile, \&c. Of Vegetables, to Imitate a Milk, Mucilage, Rofsn, Gum, or Salt. Of Minerals, to ImitateVitriol, Allom, and other Salts; as alfo Metals, and the like.

2. $\$$. I do not fay, I can do all this: yet if, upon good Premijes, we can conclude this poffible to be done; it is one feep to the doing of it. But I will alfo give an Instance of fomewhat that may be done in every kind. And, 
3. \$. Firf, For the Imitation of an Animal Body, I will inftance in Fat. Which may be made thus; Take Oyl Olive, and pour it upon high Spirit of Nitre. Then digeft them for fome days. By degrees, the $O y l$ becomes of the colour of Marrow; and at latt, is congealed, or hardned into a white Fat or Butter, which diffolveth only by the fire, as that of Animals. In converting $O y l$ thus into $F a t$, it is to be noted, That it bardens moft upon the exbalation of fome of the more $S u l$ phureous parts of the Spirit of Nitre. Which I effected, well enough for my purpofe, by unftopping the glafs after fome time of digeftion; and fo fuffering the $O_{y} l$ to diffolve and thicken divers times byfucceffive beat and cold. Hence, The true Congealing Principle, is a Spirit of Nitre feparated from its Sulphur. For the better doing whereof, the Aer is a mott commodious Menstruum to the faid Spirit of Nitre. Whence alfo, if we could procure fuch a Spirit of Nitre, we might congeal Water in the midft of Summer. We might alfo refrigerate Rooms herewith Artificially. And might Imitate all frofty Meteors. For the making of Fat, is but the Durable Congelation of Oyl: which may be done without frost, as I have fhewed how.

Hence alfo it appears, That Animal $F_{\text {at }}$ it felf, is but the $C_{\text {urdling of }}$ the $O_{\text {gly }}$ parts of the Blood; either by fome of its own Saline parts; or by the Nitrous parts of the Aer mingled therewith.

Hence likewife it is, That fome Animals, as Conies, and Fieldfares, grow fatter in frofty weather: the oily parts of the blood, being then more than ordinarily coagulated with a greater abundance of nitrous parts received from the Aer into their bodies.

For the fame reafon it is, That the Fat of Land-Animals is hard; whereas that of $F i$ lles is very $f o f t$, and runs all to $O y l, S c$. Becaufe the Water, wherein they live, and which they have inftead of breath, hath but very few nitrous parts in it, in comparifon of what the Aer hath.

4. 6. Secondly, For the Imitation of a Vegetable Body, I will give three Inftances; In Rofin, Gum, and a Lixivial Salt. The firft may be made thus; Take good Oyl of $V i t r i o l$, and dropit upon $O y l$ of $A n i f e-$ feeds; and they will forthwith incorporate together; and by degrees, will barden into a perfect Rofin; with the general and defining Properties of a truly Natural Refinous Gum. Being not at all diffoluble in Water; or at leaft, not any more, then any natural Rofin or Gum : yet very eafily by fire: as alfo higly inflamable: and exceeding friable. Although this Artificial Rofin, be the refult of two Liquors, both which very ftrongly affect the Senfe : yet being well wa/bed from the unincorporated parts, (which is to be done with fome care) it hath fcarce any Taft or Smell.

The Concentration of thefe two Liquors, is likewife fo univerfal; that the Rofin is not made by Precipitation, but almolt a total Combination of the faid Liquors; and that with farce fo much, as any vifible fumes.

5. \$. Again, Having taken a certain Powder and a Saline Liquor, and mixed them together in a bottle, and fo digefted them for fome time; the Powder was at laft tranfmuted to a perfect Oily Gum; which will alfo diffolve either in Oylor in Water; in the felf fame manner, as Galbanum, Ammoniac, and the like will do.

6. 5. And Lafly, A Lixivial Salt may be imitated thus; Take Nitre, Oyl of Vitriol, and high spirit of Wine, of each a like quantity. Of thefe three Bodies, not any two being put together, that is to fay

$$
\mathrm{N} n \text { neither, }
$$


neither the Nitre with the $O_{y} l$, nor the $O_{y l}$ with the Spirit, nor the Nitre with the Spirit, will make the leaft Ebullition: yet all three mingled together, make a very confpicuous one. The Spirit of Wine being as the Sulphur ; and fo that, and the Nitre together, ftanding, as it were, in the ftead of an Alkalizate, that is, a Sulphurious Salt, againt the Oyl of Vitriol. Divers other Experiments may be fhew'n of the like Nature.

7. 8 . In the laft place, for the Imitation of a Mineral Body, I will inftance in $t w o, \int c$. Nitre and Marine Salt; if I may have leave to reckon them amongft Mineral Bodies. As for Nitre, by mixing of four $\mathrm{Li}$ quors together, and then fetting them to foot; I have obtained Chryftals of true and perfect salt; which have had much of a nitrous taft; and would be melted with a gentle Heat, as Nitre is; and even as eafily as Butyr it felf; 1 mean not, by the addition of any fort of Liquor, or any other Body, to diffolve it; but only by the fire.

8. 6. And as for a Sea-salt, that I might Imitate Nature for the making thereof, I confider'd, That the faid Salt is nothing elfe but that of Animals and Vegetables, freed from its true spirit and sulphur, and fome Saline particles, Becifically Animal or Vegetable, together with them. For both Animal and $V$ egetable Bodies being continually carried by all Rivers into the Sea; and many likewife by shiporrack, and divers other waysimmerfed therein: they are at laft corrupted, that is, their Compounding parts are opened and refolved. Yet the Refolution being in the Water, is not made precipitately, as it is in the Air ; but by degrees, and very gently; whence the Sulphurious and other Volatile parts, in their Avolation, make not fo much bafte, as to carry themore fixed Saline parts along with them; but leaveth them behind in the Water, which imbibeth them as their proper Menftruum.

And the Imitation of Nature herein, may be performed thus; Put as much of a Lixivial salt as you pleafe, into a wide-mouth'd Bottle, and with fair Water make a ftrong Solution of it ; fo as fome part thereof may remain unrefolved at the bottom of the Bottle. Let the Bottle ftand thus for the fpace of about half or three quarters of a year, all the time unftopped. In which time, many of the Sulphurious and other Volatile parts gradually flying away; the top of the unrefolved Salt will be incruftate, or as it were frofted over, with many fmall and hard Concretions, which, in their nature, are become a true Sea-Salt. Whereof there is a double Proof; Firft, In that molt of the faid Concretions are of a Cubical, or very like Figure. Efpecially on their upper parts; becaufe having a fixed Body for their Bafis, their under parts, therefore, contiguousthereto, are lefs regular. Whereas the parts of the salt in the Sea, being environed on all fides with a Fluid; their $F i$ gure is on all fides regular. Secondly, In that a ftrong Acid spirit or Oyl being poured upon a full bodyd Solution hereof; yet it maketh herewith no Ebullition, which is alfo the property of Sea-Salt. And
thus much for the more General Imitation of Bodies. 


\section{N S T A N C E. I II, \& IV.}

FROM the aforefaid Premiffes, and by the aforefaid Means, there is $\mathrm{F}$ no doubt to be made, but that alfo the other fenfible Qualities of Bodies may be Imitated, as their Odors, and Tafts. And that not only the general ones, as Fragrant, or Aftringent: but alfo thofe which are Specifical and proper to fuch a species of Bodies.

17. 6 . Thus for Example, by mixing Spirit of Nitre or Vitriol with rectified $O y l$ of Turpentine, and fome other Vegetable Oyls, feverally, and in a due Proportion and Time, I have Imitated the Smells of divers Vegetables; as of Tanfy, of Lignum Rhodium, and others. And I conclude it feafable, To Imitate the Taft or Smell of Musk, or Ambergreece, or any otberbody in the world.

3. \$. Hence alfo we may be Tanght, How to Imitate the Faculties, as well as other 2ualities of Bodies. The reafon is, becaufe even the e have no dependance upon any fubstantial Form: but are the meer refult of Mixture; effected by the fame Canfes, whether in Nature or Art; as I think I have made to appear in the foregoing Idea. And Id. \$. 55 . as in the Premiffes of this Difcourfe hath been fhew'd.

\section{N S T A N C E V.}

Ch.2.5.10.

Ch.3.9.10.

A

R O M whence, again, it is likewife a Key to Difcover the Nature of Bodies. For how far foever we can attain to Mingle, or to Make them, we may alfo know what they are.

2. 6. For Bodies are mingleable, either of themfelves, or by fome Third. As to thofe which mingle of themfelves, we may certainly conclude, That there is a congruity betwixt them, in fome refpect or other. So upon various Tryals I find, That Effential Oyls do more eafily imbibe an Acid, then an Alkaly. Whence it is evident, That there is fome Congruity and Similitude betwixt Effentian oyls, and an Acid, which there is not betwixt the faid $O y l s$ and an Alkaly.

3. \$. As to thofe that mingle only by fome third; we may alfo certainly conclude, That though the two extreams are unlike; yet that they have both of them fome congruity with that third, by which they are united.

4. 6. Moreover, We may make a fudgment from the manner or Degree of Mixture. Thusthe Acid Spirit of Nitre, as is faid, will coagulate Oyl-Olive, and renderit confiftent. Whence it might be thought, That any other ftrong Acid will do the like; and that therefore, there is no great difference in the Nature of the faid Acid Liquors. But the contrary hereunto, is proved by Experiment. For having digefted the fame $O y l$ in the fame manner, and for a much longer time, with ftrong Oyl of Sulphur; although it thence acquired fome change of Colour, yet not any Confiftence.

5. 5. Again, Becaufe the faid Spirit of Nitre coagalates Oyl-Olive ; it might be expected, it fhould have the fame effect upon $O_{y} l$ of $A n i-$ feeds; or, at leaft, that if other Acids will Coagulate Oyl of Anifeeds, that this fhould do it beft. But Experiment proveth the contrary. For of all I have tryed, Oyl of Vitriol is the only Acid that doth it inftantaneoufly. Oyl of sulphur, if very ftrong, will do it; but not fo foon, 
nor fo much Aqua fortis, and Spirit of Salt, for the prefent, do not at all touch it. And Spirit of Nitre it felf will not coagulate it, under eight or ten hours at leaft.

\section{N S T A N C E VI.}

L As TLY, and confequently, It is a Key To Difcover the Medicinal $\mathcal{U}$ e and Operation of Bodies. Thus, for Example, by the Imitation of Refins and Refinous Gums, we certainly know what all of them are, and woben, and wherefore to be ufed. For what are Maftick, Frankincenfe, Olibanum, Benzoin, and other like Rofins, or Refinous Gums, for their principle and predominant parts, that is, quà Rofins; but Bodies refulting from Natural, in like manner, as I have fhewed, they may be made to refult, from Artificial Mixture? That is to fay, the oleous, and Acid parts of Vegetables, being both affufed and mingled together, per minima, in fome one fort of Veffels in a Plant, they thus incorporate into one confiftent and friable Body, which we call Rofin.

2. 5. Now from hence it is, That the faid Rofins, and Refinous Gums; as alfo Amber and Sulpibur for the fame Reafons; are of fo great and effectual $U_{j e}$ againft moft thin and falt Rheums; $/ c$. as they are Acidoleous Bodies. For by their Acid parts, which in all thefe Bodies are exceeding copious, they mortifie and refract thofe Salt ones, which feed the Rheum. And by their oleous parts, the fame salt ones are alfo Imbibed. Whence, they are all, in fome degree, incorporated together; that is, The Rbeum is thickned: which is the defired effect.

3. $\%$. Whereas, on the contrary, if the Cough proceed not from a thin, and fpecially a Salt Rheum, but from a Vifcous Flegm; the ufe of many other Bodies which are alfo more oleous, and abound not fo much with an Acid as thefe do, efpefcially fome of then, is more proper: fuch asthefe, in this Cafe, proving fometimes not only ineffectual, but prejudicial. Since the very $C_{\text {aufe }}$ of the faid Vifcoufnefs of Pblegm, is chiefly fome great Acidity in the Blood, or in fome other part, as may be proved by divers Arguments.

4. 5. Many more Instances might be hereunto fubjoyned : and may hereafter be offered to the acceptance of fuch, who are inquifitive into matters of this Nature. If I thall not herein anticipate, or reiterate the Thoughts and Obfervations, of thofe two Accurate and Learned Perfons Dr. Willis, and Dr. Walter Needham, as to what the one hath already publifhed, and both have put us in Expectation of. But the Inftances already given, are fufficient to evidence what I have faid. And, I hope, this prefent $D_{i}$ c cour $\int e$ to prove, in fome meafure, thus much; That $E x-$ periment, and the Common Notions of Senfe are prolifick; and that nothing is Barren, but Phanfie and Imagination. 


\section{An Appendix to the precedent difcourfe of Mixture.}

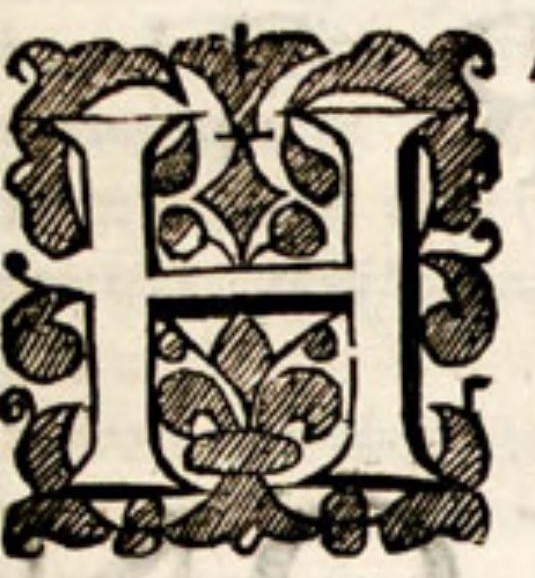

A V I N G, in the firft Edition of the foregoing Dif- Ch. $5 . \operatorname{In} f$. courfe, made mention of the preparation of EJJen- x. 6.8 : tial $O y l s$, fo as to become eafily mingleable with any unoyly Liquor. I fhall here acquaint the Reader, That this may be done, by digefting any of the faid $O y l s$ with about an equal quantity of the Yelk of an Egg, with a very foft heat, like that of the Meridian Sun in Summer, continued for the fpace of threeWeeks or a Month; and in the mean time, to be now and then ftirred a little together. The $Y_{e} l k$ will by degrees, imbibe the $O y l$, and at length be incorporated with it, and become a Balfam, as white as Milk, eafily diffoluble in any watery or winy Liquor.

2. \$. I confers, that it will be very difficult to prepare any good quantity for ufe, this way. But this being a fufficient proof of the poffibility of fuch a Mixture; I confidered, whether the application of fome other forementioned Caufe of Mixture, might not fupply the defect of this: and hereupon, have made feveral fucceffful tryals; not only for the mixing of the faid $O y l s$, but likewife of all forts of Rofins and Gums with any winy or watery Liquor, in great quantities, in a fhort time, and without much trouble. But for the mixing of fome of them, the Yelk of an Egg alone will not ferve, without the intervening of fome other fociable Body, according to one of the Rules given in the foregoing Difcourfe.

3. 6 . In the fame Difcourfe, upon certain premifes, I have laid down this following conclufion.

By accumulating the Caufes of Mixture, that is, by joyning

Ch. 5. Inft: I. $\$ .6$.

Ch. $5.5 \cdot 5 \%$ " two or three or more together; or by applying more in fome cafes, " where Nature applyeth fewer; we may be able to make, if not a more " perfect, yet a far more fpeedy Mixture, than Nature doth. As by joyn"ing COMPRESSIO N, Heat, and violent Agitation, and fo con"tinuing them altogether, by fome means contrived for the purpofe, for "the fpace of a Week or Month,or longer without Ceffation. Which " may probably produce, not only ftrange, but ufeful effects, in the "SOLU T ION of fome, and the Mixture of other Bodies.

4. \$. For the proof whereof, and that $I$ had throughly weighed what I have faid, Mr. Pappin hath fince given us an ingenious Inftance, in his new Digefter. Which is, a Balneum Marie claufum: all Infuffons and Digeftions made with Double Veffels, having hitherto been made with the outer $\mathrm{Veffel}$, open. So that whereas by the old way of $\mathrm{Di}$ geftion, their is no other Power made ufe of but that of Heat : in this way, that alfo of Compreffion is joyned therewith. 


\section{E X P E R I M E T S \\ I $\mathrm{N}$

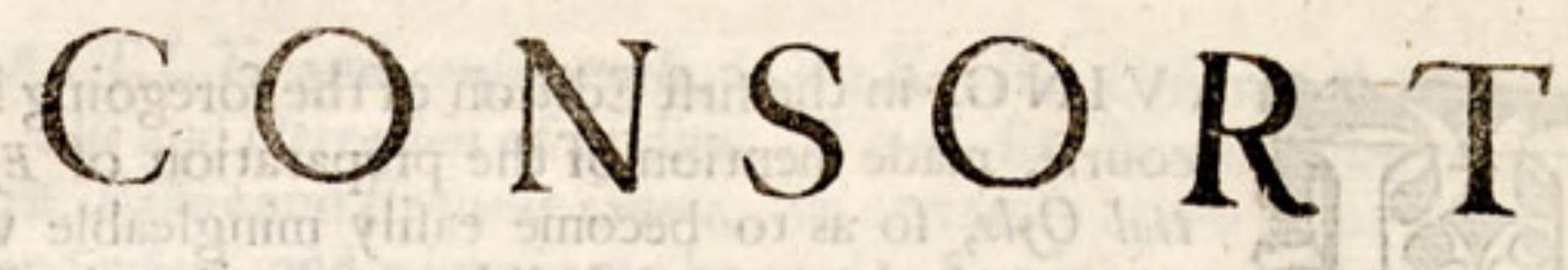 \\ O F T H E \\ LUCTATION}

Arifing from the Affufion of feveral

\section{MENSTRUUMS}

Upon all forts of

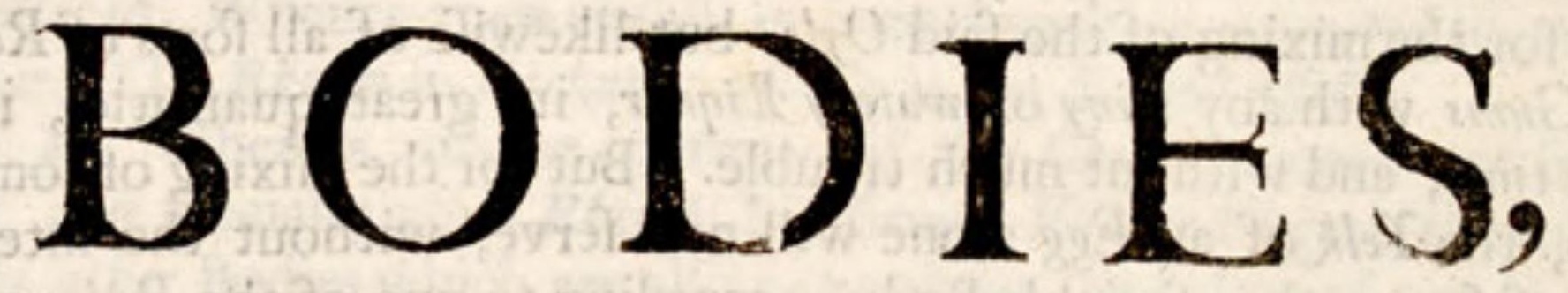

Exhibited to the Royal Society, April 13. and fune I. 1676 .

Ch.. . Inft. 5

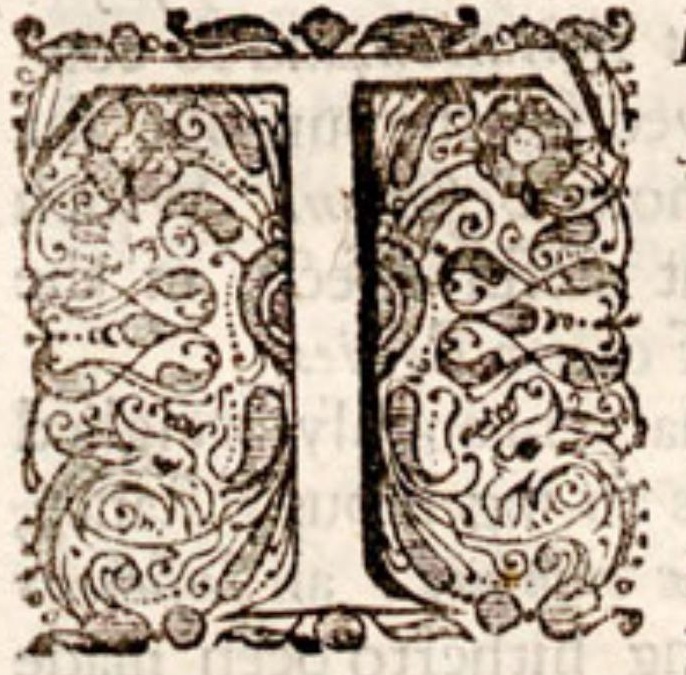

$H E$ intent of the following Experiments is twofold. The one, to be as a Demonftration of the Truth of one, amongft other Propofitions, laid down in the precedent Difcourses of Mixture, $f c$. That it would be a Key to let us eafily into the knowledge of the Nature of Bodies.

The other, and that conjequently, To be as a Specimen of a Natural Hiftory of the Materia Medica : that is to fay, a multifarious Scrutiny into the intrinfick Properties of all thofe Materials, which bave been, or may be ufed in Medicine: for the performance whereof, the following Method is exibited as one, amongft others, neceffary to be infifted upon. For what Dominion a Prince bath over the Moral, that a Phyfician bath, as one of God Almighty's Vice-Roys, over the Corporeal World. Whom therefore nothing can more import, than a particular knowledge of the $\mathrm{Ge}-$ nius of all bis Subjects, thofe feveral Tribes of Matter, juppofed to be under bis Command. 
There are fome known Obfervations of this nature : but there is no Anthor, I think, who hath given us a Syfteme of Experiments upon the Subject: The performance mbereof is bere intended.

The Experiments may feem too numerous to be of one make. But no leß a number mould bave anfwered the defign of an Univerfal Survey; which, though less pleafing, proves the more inftructive in the end: not being like angling with a fingle Hook; but like cafting a Net againft a Joole: with affurance of drawing. up fometbing. Befides the advantage of comparing many together; wbich being thus joyned, do oftentimes, like Figures, fignifie ten times viore, then fanding alone, they would bave done.

How far the Corollaries all along fubjoyned have made this good, is left to the Reader to judge. And alfo, to add to them, fo many more, as be pleafes : for I make my own Thoughts no mans Meafure.

\section{H A P. I.}

What is generally to be obferved upon the Affufion of the Menftruum; and what, particularly of Vegetable Bodies.

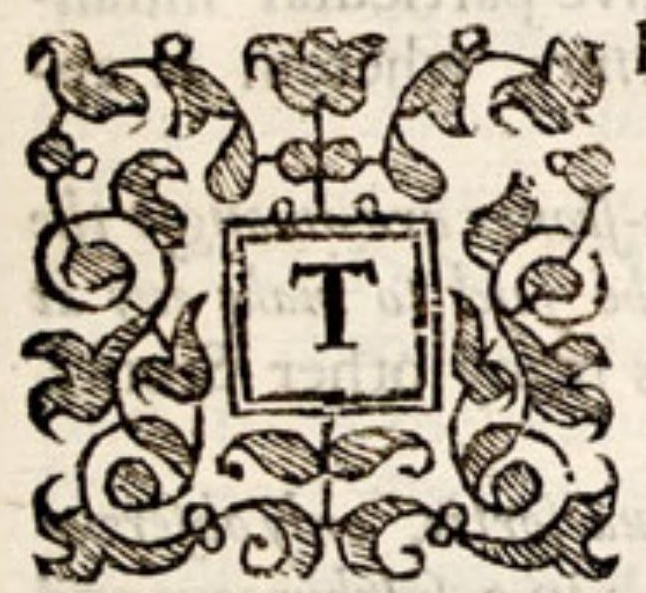

$\mathrm{HE}$ Bodies whereupon I made tryal, were of all kinds, Animal, Vegetable, and Mineral. Amongfi Vegetables, fuch as thefe, fcil. Date-ftones, Ginger, Colocgnthis, Pyretbrum, Hawnthorn-flones, Staphif. agria, Euphorbium, the Arenule in Pears, Semen Milii Solis, Tartar, Spirit of Scurvygrafs, Spirit of Wine, \&c.

2. 6. Amongt Minerals, feveral forts of Earths, Stones, Ores, Metals, sulphurs, and salts.

3. \$. Amongt Animals; fuch as thefe, foil. Hairs, Hoofs, Horns, shells, and ghelly Infects, Bones, Flegh, and the feveral Vifcera, Silk, Blood, Whites and Yellss of Eggs, sperma Ceti, Civet, Musk, Caftor, Gall, Urine, Dungs, animal Salts and Stones.

4. 6. The Liquors which I poured hereupon feverally, were thefe, fc. Spirit of salt Armoniac, Spirit of Harts-Horn, Spirit of Nitre, Aquia fortis, Oyl of Salt, Oyl of Sulpbur, and Oyl of Vitriol; commonly fo called.

5. 6. In the Mixture of thefe Bodies, two things, in general, are all along to be obferved, viz. Firft, which they are, that make any, or no Luiftation. For, as fome which feem to promife it, make none: So, many, contrary to expectation, make a confiderable one.

6. 5. Next, the manner wherein the Lutation is made; being with much variety in thefe five fenfible Effects. i. Bullition; when the Bodies mixed produce only a certain quantity of froth or bubbles: 2. Elevation; when, like Pafte in baking, or Barm in the working of Beer, they fwell and buff up. 3. Crepitation; when, they make a 
kind of hiffing and fometimes a crackling noife. 4. Effervefcence; then only and properly fo called, when they produce fome degree of heat. 5. Exhalation; when not only fumes, but vifible fteams are produced.

7. 6. Of all thefe, fometime one only happens, fometimes two or more are concomitant. Sometimes the Luttation begins prefently upon mixture, and fometimes not till after fome intermiffion. In fome bodies, it continues a great while; in others, is almoft inftantaneous: Examples of all which I fhall now produce; beginning with Vegetables, as affording the leaft variety.

8. 6. And firft, if we take Spirit or Oyl of Salt, Oyl of Vitriol, Spirit of Nitre, or Aqua fortis, and pour them feverally upon the feveral parts of Vegetables, as Roots, Woods, Stones, Goc. we Jhall find, that they are, generally far less apt to make a Luctation, than either Animal, or fubterraneal Bodies. Whence, as from one argument, it feemeth evident, That in molt Vegetables, and in molt of their parts, the predominant salt is an Acid. But that, on the contrary, the predominant Salt in moft Minerals, and parts of Animals, is an Alkaly: in the former, ufually a fixed; in the latter, a volatile Alkaly.

9. 6. Again, although the LuCtation which moft Vegetables, and moft of their parts make with Acids, be but Jmall, yet fome they make; efpecially with fome Acids, as with Spirit of Nitre and Aqua fortis. Whence it feemeth plain, That there is an Alkaline Salt exiftent in many $V_{\text {egeta }}$ bles, even in their natural eftate; and that it is not made Alkaline, but only Lixivial, by the fire. Or, there is fome quantity of a Salt, call it what we will, in the faid Bodies, which is fo far different from an $A$ cid, as to make a Luctation therewith. But to give particular inftances of the feveral proportions, or manner of Mixture, wherein it appears to be in feveral Plants.

10. \$. And firft, of all vegetable Bodies, Date-ftones are amongft the leaft apt to make a Luctation with Acids, if they may be faid to make any at all. Hence they are not fo potent Nepbriticks, as many other Stones, which make a more fenfible I uct ation.

I I. 6. Ginger mukes a fmall Bullition with Aqua fortis, only obfervable by a Glafs. Hence the pungency of Ginger lyeth in a fulphureous and volatile Salt, which yet is very little Alkalizate.

12. ऊ. Scurvygrafs-feeds make a very fmall Bullition with Aqua fortis, like that of Ginger. So doth alfo the seed of Purflane. Hence, although there is much more of a certain kind of volatile Salt in Ginger or Scurvygrafs, than in Purfane; yet there is little more of an Alkaly in any one, than in an other.

13. 6. The Pulp of Colocyntbis, Fruit-Stones, the ftony Covers of the Seeds of Elder, of white Bryony, of Violets, and others, with Aqua fortis make a Bullition juft perceivable without a Glafs. Hence it appears, That the great Cathartick power of Colocynthis lieth not fo much in an Alkaly, as an Acid; as making a much iefs Bullition, than fome other vegetable Bodies, which are lefs Cathartick. For which reafon likewife it is, That the beft Correctors, or Refractors of the force of Colocynthis, are fome kinds of Alkalies, as particularly that of $\mathcal{U}_{\text {rine, }}$ as Riverius hath fomewhere obferved.

14. 5. The Root of Pyrethrum, with Aqua fortis, makes a Bullition and buff; in a fort time. Hence, the Caufe of a durable Heat, upon the Tongue, is an Alkalizate Sulphur. For the Heat of Ginger, though 
greater; yet abideth notbing near fo long as that of Pyrethrum; which, as is faid, maketh alfo a more fenfible Bullition with Acids.

15. \$. Kermes-berries, commonly, but ignorantly, focalled, with the faid Liquor, buff up to an equal beight, but in a fomewhat longer time. Hence they are gently aftringent; fcil. as their Alkaly binds in with fome preternatural Acid in the ftomach.

16. \%. Hawthorn-ftones, with Aqua fortis, buff up equally with the former Body; but the Bullition is not fo vifible. The like is alfo obfervable of Medlar-ftones. Hence, as they contain a middle quantity of an Alkaly, they are not infignificantly ufed againft the Stone.

17. 6. Seeds of Staphifagria, with Aqua fortis, make a Bullition ftill more vifible. But it quickly ends. This confirms what was faid before, fc. That the caufe of a durable Heat is an Alkaline sulphur; thefe Seeds producing a durable Heat, as doth the Root of Pyrethrum.

18. \$. The Seeds alfo of red Rofes, Borage, and Comfrey do all with Aqua fortis make a confiderable Bullition and buff; and that very quickly. So that amongft all Shells and Stones, thofe generally make the greateft Bullition, which are the hardeft and the brittleft, and fo the fulleft of Salt.

19. 6. Eupborbium makes a Bullition yet more confiderable, with much froth, and very quickly. From which Experiment, compared with two of the former, it appears, That Euphorbium is not an Acid, but an $\mathrm{Al}$ kaline Gum. As alfo, that the caufe of its fo very durable Heat, is an alkaline Sulpbur, as of Pyretbrum and Staphifagria hath been faid. It feems alfo hence evident, that the power of all great Sternutatories lyeth not in their Acid, but their Alkalies.

20. 5. The Arenula or little ftones in Pears, clufter'd round about the Coar, with Aqua fortis, prefently buff up, and make a great Bullition and Effervefcence, much greater than do any of the Bodies above-named. Whence, althougb, fo far as I know, they have never yet been ufed in Medicine; yet it is probable, that they are a more potent and effectual Nepbritick, than any of the Bodies aforfaid, fome of which are ufually prefcribed. It is hence alfo manifert, That, according to what I have elfewere faid, for the fweetning of the Fruit and Seed, the Tartareous and Alkaline Anat. of parts of the Sap, are precipitated into their Stones, ftony parts, and Plants, $B_{\text {. }}$ Shells.

21. 6. The laft Inftance fhall be in the foells of the seeds of Milium I. $\mathrm{Ch} .6$. Solis; wbich not only with Aqua fortis, but fome other Acids, make a greater and quicker Bullition and Effervefcence, than any other vegetable Body, upon which I bave yet made tryal, in its natural eftate. Hence, as well as from divers of the laft fore-going Inftances, we have a clear confirmation of what $I$ have, towards the beginning of this Difcourfe, afferted; $f c$. That there is fome kind of Alkaline Salt in Plants, even in their natural eftate. As alfo, that they are as fignificantly ufed againft the Stone, quatenus alkalizate, as Millipedes, Egg-hells, or any other teftaceous Bodies of the fame ftrength. To thefe I hall fubjoyn one or two Examples of Vegetable Bodies which are more or lefs altered from their natural eftate.

22. 5. Neither Cryftals of Tartar, nor Tartar it felf (although they bave fome ftore of alkaline mixed with their acid parts) make any Effervefcence with Acids, but only with Alkalites, as spirit of Harts-Horn, \& c . Hence the calculous fediment or Arenula in Urine, may not fo properly be called 
the Tartareous part of the Urine; the events following the mixture hereof with the aforefaid Salts, being quite contrary ; as will be feen in the Laft Chapter.

23. 5. Spirit of Scurvj-grafs maketh no Luctation with any Acid. Hence (as from a former Experiment was above-noted) it feems, That there may be a kind of volatile Salt, which is neither acid, nor alkaline; fuch as this of Scurvygrafs and other like Plants feems to be: yet contrary to an acid; as experience fhews in their efficacy againft the acid Scurvy.

24. S. Rectified Spirit of Wine, both with Spirit of Nitre, and with Oil of Vitriol, feverally, maketh a little Luctation. Which argues, that there is contained, even in this Spirit, fome portion of a volatile Alkaly.

25. 5. Spirit of Wine, and double Aqua fortis, as the frongeft is called, make an effervefcence fo vehement, as plainly to boil.

26. 5. Befides the vehemency bereof, there is another furprizing circumfance. For whereas all other Liquors which make an Effervefcence together, will do it in any proportion affigned, although but one drop to a thoufand: thefe twoo, fc. rectified Spirit of Wine and Aqua fortis, require a certain proportion the one to the other. For if, fuppofe, into fix drops of Spirit of Wine you put but two or three of Aqua fortis, they fir no more than if you put in fo much Water: but drop in about feven or eight drops of Aqua fortis, and they prefently boil up with very great vehemency. Hence we may conceive the reafon of the fudden accefs of an acute Difeafe, and of its Crifis. Thefe not beginning gradually with the Caufe; but then, when the Caufe is arrived unto fuch an axum, or fuch a certain Proportion, as is ceceffary to bring Nature to the conteft. And thefe may ferve for Examples upon Vegetables.

\section{H A P. II.}

\section{What may be obferved of MINERALS.}

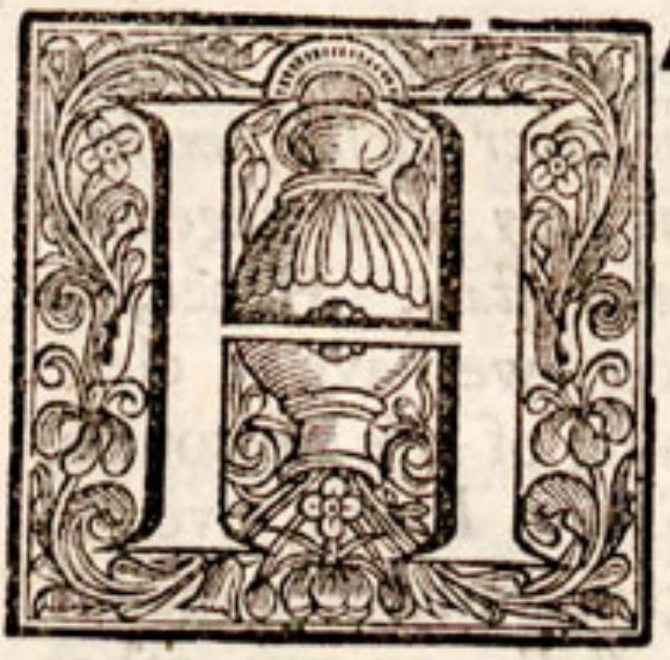

A V I N G given feveral Inftances of tryal upon $V$ egetables; I next proceed to Minerals, which, for fome orders fake, I thall diftribute into five or fix forts, fc. Earths, Stones Ores and Metals, Sulphurs, and Salts.

2. 5. Firft for Earths. Oyl of Vitriol upon Fullers Earth, doth not fir it, or caufe the leaft Bullition. Nor upon yellow Oker. Nor upon the Oker which falls from green Vitriol. The fame Oyl of Vitriol and Spirit of Harts-Horn poured feverally upon Bolus Armena of two kinds, and upon one kind of Terra figillata, fir none of them. Hence Bolus's are the Beds, or as it were, the Materia prima, both of opacous Stones, and Metals; into which the faid Bolus's are tranfmuted, by being concentred with divers kinds of Salts and Sulphurs, which fucceffively flow in upon them. 
3. 6. Aqua fortis, and $O y l$ of Vitriol being poured feverally upon another fealed Earth, which was vended by the name of Terra Lemnia; the) both made a very confiderable Effervefcence berewith. Whence it appears, That there is no fmall difference in the nature, and therefore the operation of Bolus Armena and Terra Lemnia. As alfo, betwixt the fealed Earths themfelves, one making a great Efferve/cence, another none at all. Whereto thofe that ufe them, are to have regard.

4. 6. Next for Stones. And firft, Irifs slat, with Spirit of Hartsborn, maketh a fmall, yet vifible Bullition: and it prefently ceafeth. So that it feems to be nothing elfe but a Vitriolick Bole. As is alfo argued from its tafte, which is plainly acid, and fomewhat rough. Whence alfo it is with good reafon given upon any inward Bruifes. Becaufe by coagulating the Blood, it prohibits its too copious afflux into the affected part. Yet being but gently aftringent, and fo the Coagulations it makes, not great; they are likewife well enough carried off from the fame part in the Circulation; by both which means an Inflammation may be either prevented, or the better over-ruled.

5. ६. Lapis Hematites maketh no Effervefcence at all either with Alkalies or Acids.

6. 6. Powder of the green part of a Magnet with Oyl of Vitriol ma* keth jome few bubbles, yet not vifible woithout a Glafs. But the powder of the black part of a Magnet, which is the faid ftone fully perfect, ftirreth not with any acid. Neither doth the calcined Magnet. Hence there is fome confiderable difference betwixt Iron and the Magnet.

7. 6. Lapis Lazuli, with Oil of Vitriol, and efpecially with Spirit of Nitre, maketh a conjpicuous Bullition. Hence its Cathartick virtuelyeth in an Alkaly. For which reafon it is alfo appropriate, in like manner as Steel, to the cure of Hypochondriacal Affections; originated from fome kind of fermenting Acid.

8. Ofteocolla, with Spirit of Nitre maketh yet a greater Effervefcence. How it comes to befo great a knitter of broken Bones, as it is reputed, is obfcure. It feemeth, that upon its'folution by a Nitrous Acid in the body; it is precipitated upon the broken part, and fo becomes a kind of Cement thereto.

9. 6. Lapis Tutbia, with spirit of Nitre, maketh an Effervefcence much alike. And with Oyl of Vitriol very confiderably. But Lapis Calaminaris with $O y l$ of Vitriol grows ftark; as the powder of Alabafter dots with water. With Spirit of Nitre it maketh a little Bullition, and quicklp. But with Aqua fortis, a great one; beyond any of the Stones above named. Hence both Tutty and Calamy are Ophtbalmicks from their Alkaly. Which is alfo confirmed, from the efficacy of fome Alkalies of the like ufe. Hence alfo Calamy feemeth to partake fomewhat of the nature of Silver: as by tryal made upon that alfo, will hereafter better appear.

10. \$. Chalk and Oil of Sulphur or Vitriol make as frong an Effervefcence as any of the reft. Whence it is fometimes well ufed againt a Cardialgia.

I I. 6. Whiting makes as great an Effervefcence as Cbalk. So that it feems the faline parts are not wafhed away with the water, whereia the Chalk, for the making of Whiting, is diffolved.

002 I2. है० 
12. 5. Talk will not ftir in the leaft either with Spirit of Nitre, or Oyl of Vitriol. But the Lead-Spar maketh a confiderable Effervefcence with both of them feverally. Hence, however this be alfo called Englifs Talk, yet there is no fmall difference betwixt this, and true Talk.

13. 5. To the fe Stones may be added petrified bodies. As petrified roood; which (that upon which I made tryal) no acid firreth in the leaft. Petrified fiells; upon four or five feveral forts whereof, Oyl of Vitriol being poured, produceth a great Effervefcence. The Root or rougher part of the stone called Gloffopetra, with Spirit of Nitre, makes a confpicuous Bullition. Afteria, the Stone fo called, and found in fome places in England, with Oyl of Vitriol, maketh an Effervefcence at the Jame degree. So doth the Belemnites, or Thunder-Stone, both the larger and the leffer kinds. So that none of thefe are acid, or vitriolick, but alkalizate Stones.

14. 6. Coraline, with Oyl of Vitriol, makes a confpicuous Bullition, yet mild and gentle; that is, with very little, if any beat, and woithout any vifible Fumes. And red and white coral do the like. Hence they are all of a very gentle operation, and fit for Children, as the cafe requires.

15. \$. Magiftery of Coral (prepared the ordinary way) ftirreth not in the leaft, either with Alkalies or Acids. Whence it is evident, That its active Principles are in its preparation deftroyed and wahed away: that is to fay, It is an elaborate Medicine good for nothing. And thus far of Stones.

16. 5. I next come to Metals and Ores. And firft for Lead; upon which spirit of Salt Spirit of Nitre, or Aqua fortis being dropped, it firreth not in the leaft with any of them: but with oyl of Sulphur, and efpecially with Oyl of Vitriol it maketh a flow Bullition and froth. Hence it feemeth to be the moft alkalizate Metal. Which is alfo confirmed by a foregoing Experiment upon the Lead-Spar, which maketh a confiderable Effervefcence with any fort of acid. And which likewife, being calcined, yieldeth a good quantity of Lixivial Salt.

17. \$. Lead-Ore stirreth not at all with Aqua fortis or Oil of Ditriol. But Spirit of salt makes it bubble, and Spirit of Nitre makes it boil. Hence there is a confiderable difference betwixt the perfect Metal and the Ore.

18. \$. Burnt Lead and red Lead, make a very fmall Bullition with Oyl of Vitriol, with Spirit of Nitre a far greater.

19. 5. Mercury, with Oyl of Vitriol, will not fir, nor with Oyl of Sulpbur. But with Spirit of Nitre prefently boyls up. Hence Mercury is a fubacid Metal; Spirit of Nitre being a fubalkaline Acid.

20. 6. The filings of Iron or Steel, with Oyl of Vitriol, make a fair Bullition, like that of Minium. But Spirit of Nitre makes them boil with much celerity. Hence Iron is likewife a fubacid Metal.

21. 5. Stcel prepared with Sulphur maketh a far less Effervefcence with the fame Spirit of Nitre, than do the filings. Hence there is a great difference in their ftrength. So that ten grains of thefilings unprepared, will go as far as fifteen grains or more of thofe which are prepared, as above-faid. Yet in fome cafes the weaker and milder may be the better.

22. \$. There is one Circumftance in the mixture of Steel and Aqua fortis, which is furprizing; and that is this, That frong Aqua fortis, dropped upon Steel, will not, of it felf, make the least Bullition: but if 
bereto you only add a drop or two of Water, they prefently boil up with very great vebemency. The Caufe is obfure; yet it is well known, that Water it felf will diffolve Iron: fo that it appeas, 'as well by this, as by fome other Experiments, that even in common Water, as mild as it is, there is fome kind of corrofive Principle.

23. 6. Antimony with Spirit of Nitre, and Aqua fortis feverally, maketh an Effervefcence; Somewhat lower than Iron. With Oil of $I_{i-}$, triol the Bullition is fo fmall, as difficulty to be perceived with a Glaes. Hence it feemeth to be of a very compounded nature; if I may fo call it, a fubacid-alkaline Metal.

24. §. Antimonium Diaphoreticum, with spirit of Nitre and Oil of Vitriol feverally, makes a confiderable Effervefcence. Wherefore it is not an ufelefs Preparation; as from the Calcination and Ablution ufed therein, fome have thought.

25. 6. Bezoardicum Minerale, (that upon wobich I made tryal) ftirreth not at all either with Alkalies or Acids. To which, let thofe who make ufe of it, have regard.

26. 6. Tin, with spirit of Nitre, makes so hot and vebement an Effervefcence, that it turns prefently, as it were, into a Coal. It makes alfo a fair Bullition with Oyl of Vitriol. And a gentle one with spirit of Salt. Wherefore, it hath fomething of the nature both of Iron, Lead, and Copper.

27. 5. The like remarkable circumftance is feen in the mixture of Aqua fortis with Tin, as with Iron. For Tin and strong Aqua fortis of themfelves will not stir; but add a few drops of water to them, and they boyl up with the greateft vibemency.

28. 6. Copper, with Spirit of Salt, and Oyl of Vitriol feverally, ftirs not at all. Spirit of Nitre, and Aqua fortis, both boil it ut vehemently. Neither Spirit of Harts-born, nor Spirit of Salt Armoniac maketh any Bullition therewith. But both of them, by a gentle folution, that is, gently separating its Sulphur from its Salts, turn it blue. Hence Copper hath a greater proportion of acid than any of the forementioned $\mathrm{Me}_{e}$ tals.

29. 5. Silver, neither with Spirit of Salt, nor Oyl of Vitriol makes any Bullition. With Spirit of Nitre it makes one, but tis foon over: and then continues to diffolve fowly into white Coagulations. It alfo maketh with Spirit of Harts-horn, or of Salt Armoniac, a full and deep blue. Hence there is a greater proportion of acid in Silver, than in Lead, Mercury, Iron, Antimony, Tin, or Copper.

30. \$. . Litharge of Silver maketh the greatel Effervefcence with oyl of Vitriol. Yet fome with spirit of Nitre: And with spirit of Salt Armoniac maketh fome little buff or elevation. And being mixed with spirit of Nitre and Spirit of Salt Armoniac both together, produceth a faint blue. Hence, although the far greater part of this Litharge be but lead; yet, it feems, it hath fome fmall mixture of silver. But that of Gold reemeth, for contrary reafons, not to have any Gold.

3I. S. Gold maketh no Effervefcence with any fingle salt I know of. But it is commonly diffolved with Aqua Regis, which is known to be an alkaline Liquor. Whence it feemeth, That as Lead is the mofr alkalizate, fo Gold the mogt acid of Metals. 
32. 5. Thefe things confidered, and other obfervations added hereunto, may poffibly give fome directions, not only for the ordering and ufing, but even for the making, imitating and tranfmuting of Metals. Thus far of Metals.

33. 5. I will next give one or two Inftances of tryal upon sulphurs. And firft sulphur vive, with Aqua fortis, maketh an apparent Bullition, but it is fome time, before it begins. But the factitious or common BrimA. ne, maketh fcarce any, if any at all. So that there is no fmall dif-
ference betwixt them.

34. \$. White and yellow Arsenick make no Bullition either with Alkalies or Acids. Wherefore the ftrength of its operation on the Body, lies more in a sulphar than a Salt; or in a Salt drowned in its Sulphure.

35. 5. The afhes either of Pit-Coal, or sea-Coal, make no Effervefcence with Alkalies or Acids. Whence the faline Principle is altogether volatile, and fublimed away by the fire.

36. Lastly for Salts. And first of all, Borax maketh no Effervefcence nor any Fumes with Oyl of Vitriol or Spirit of Nitre.

37. S. Oyl of Vitriol and Nitre make fumes or Jeams, thongh no Effervefcence.

38. 6. Green Vitriol, with Spirit of Harts-Horn, is fcarcely moved. White Vitriol, with the fame Spirit, maketh a conspicuous buff. And Roman Vitriol a vebement Effervefcence. Whence the former is the leaft acid, and the latter the moft of all. Which alfo confirms what I faid before of the like natures of the feveral Metals to which they belong.

39. \$. Salt of Vitriol, though a fixed Salt, and made by Calcination, yet maketh no Effervefcence with the ftrongeft acid; but only with Alkalies; as may be feen upon their mixtare, but much better heard by bolding the mixture to ones ear. Hence, there are fixed Acids. Which further confirms what $I$ have above afferted concerning the nature of Gold, $\int c$. That the predominant Salt thereof is a fixed Acid.

40. \$. Sal Martis, with Spirit of Harts-born, maketh a confiderable buff. Hence it is much more acid than green Vitriol; and is therefore a cooler body.

4I. 5. Almm and spirit of Harts-born make a plain Effervefcence.

42. \$. Saccharum Saturni, with Oyl of Yitriol, Airs not at all. With Spirit of Salt, buffs a little. With Spirit of Nitre much more. Hence the acid of the Vinegar, and not the Alkaly of the Lead, is the predominant Principle.

43. 6. Common Salt ftirs neither with Spirit of Salt, nor with Spirit of Nitre; nor with Aqua fortis. But with Oyl of Vitriol it inaketh. a great Effervefcence with noife and fleams. Hence, even common Salt, though it be not reckoned amongft alkaline salts, yet is far nearer in nature to that, than to an acid. Hence alfo the spirit of salt is a fubalkaline $A$ id, and of a very different nature from $O y l$ of $S u l p l u r$ or Vitriol.

44 , 6. Salt Armoniac, with Spirit of Nitre, firreth not. Bat with Oyl of Vitriol it maketh a great Effervefcence. Hence $S_{\text {pirit }}$ of Nitre is a jubalkalizate spirit.

45. 5. Oyl of Vitriol and Spirit of Nitre, though both acids, get make a great Jmoak; greater than that which the spirit maketh of it felf. Which confiu nos the laft prece Jent Corollary. 
46. 6. Oyl of Vitriol and Spirit of Salt, though both acids, yet make a ftrong Effervefence, with noife and fwmes. Which further confirms, what was noted before, $f c$. that Spirit of Salt is a fubalkaline Acid.

47. \$. Spirit of Salt Armowiac, with Oyl of Vitriol, makes an Effervefcence fo extraordinary quick, and as it were inftantaneous, that notbing feemeth quicker. Whence it is probable, That if Gun-powder were made of salt Armoniac, inftead of Nitre, or with both mixed together; it would be far ftronger, than any kind now in ufe. And thus far for Minerals.

48. 6 . I have only one Corollary to add, from the whole; which is, That whoever doth undertake the Natural Hiftory of a Country, ( fuch as that the Learned Dr. Plot hath exceedingly well done of $O x-$ fordßhire ) the foregoing Method, feemeth fo eafie, cheap, and indeceitful, for the finding out and well diftinguifhing the natures of all kinds of Metalls, Ores, Salts, Earths, Stones, or other fubterraneal Bodies ; as cannot, I think, be fupply'd, but by others of greater difficulty and expence.

\section{H A P. I II.}

\section{What may be obferved of the PARTS of Animals.}

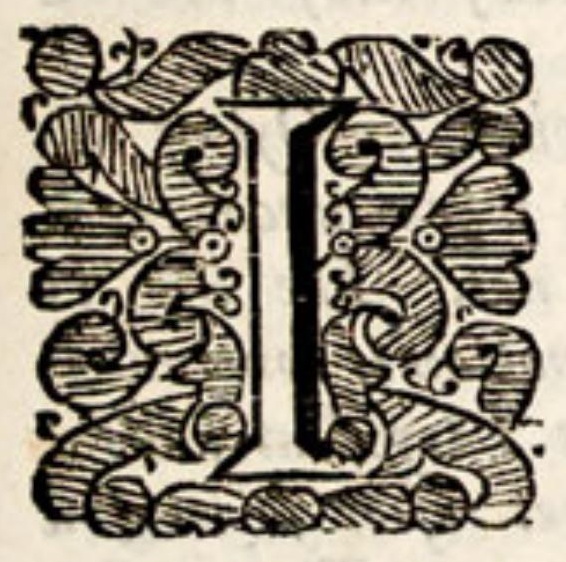

NO W proceed to the feveral Parts of Animals; as Hairs, Hoofs, Horns, Shells and Jelly Infeets, Bones, Fleß and the feveral Vifcere, Silk, Blood, Eggs, Musk, Caftor, Gall, Urine, Dungs, Salts and Stones.

2. \$. And firft of all, the Hair of a mans head, with Oyl of Vitriol, maketh no Bullition at all. Nor yet with Spirit of Nitre. So that although it contains a good deal of volatile Salt; yet it feemeth either not to be alkaline, or elfe is centred in fo great a quantity of $O y l$, that the acid menfruum cannot reach it.

3. S, Hares Fur, with pirit of Nitre, maketh, although a fhort, yet very plain Bullition and buff. Hence the Hair, and therefore the Blood, of fome Animals, is fuller of Salt, at leaft of an Alkaline Salt, than that of fome others. And perhaps the Hair of fome men, as of Black's, may be fo full of salt, as to make a Bullition like Hares Fur.

4. 6. The favings of Nails ftir not at all, either with Oyl of Vitriol, or Spirit of Nitre: only with the latter they turn yellow. But Elks Claws, with spirit of Nitre, meke a fmall and fow Bullition.

5. \$. Horfes Hoof, woitb Oyl of Vitriol, ftirs not of many bours. But with spirit of Nitre, allowing it fome time, makes a very plain Bullition, and buffs up very bigh.

6. 5. Cows Horn, neither with Oyl of Vitriol, nor with Spirit of Nitre, maketh any Bullition, only turnetb to a yellow colour.

7. §. Rams Horn ftirs not with Oyl of Vitriol; but with Spirit of Nitre, makes a fmall and foom Bullition.

8. 5. 


\section{8

8. 6. Harts-Horn makes a confiderable Bullition and buff, even with Oyl of Vitriol, which the rest of the Bodies abovefaid, will not do. But with spirit of Nitre, it makes yet a greater. From the foregoing Experiments, and almoft all that follow, what is before afferted of the salts of Vegetables and Minerals, is here alfo evident concerning that of Animals, fiil. That it is not made, but only feparated by the fire. It likewife hence appears, That the proportion of salt in the forementioned parts is very different; and that therefore fome of them are never, and none of them but with good difcretion, to be fubftituted one for another in Medicine. As alfo, that there is a different proportion of Salt in the feveral Animals themfelves, to which the faid Parts belong.

9. 5. Next for foells; as thofe of Lobfters, Eggs, Snails and Oifters: all wobich make an Efjervefcence, both with Oyl of Vitriol, and Spirit of tre. But with Spirit of Nitre the greatest. Lobfter-fbells make a confiderable Bullition and buff, but no noife nor fteams. Egg-fsells make a Bullition and buff, with fome noife, but no Jteams. Snail-hpells make an Effervefcence with noife and fteams. Oyfter-fhells make one with the gratejt noife and thickeft fteams. Hence we may judge, in what cafe to adminifter one more appofitely than another. As alfo in mhat proportion, according to their different ftrength. Some may be better for Children, as being milder. Or for a Body whole very fharp Blood or other Humors, are more eafily kindled into Ferments. Or elfe may be fafeft, to avoid a fudden precipitation of the Humors; or for fome other caufe.

10. 6. Oyfter-fhells, and the reft above-faid, make a quicker Effervefcence, not only with Spirit of Nitre, but even with spirit of Salt, than they do with Oyl of Sulpbur, or Ojl of Vitriol. So that the $\int e$ bodies, as well as Metals, have their proper Menftruums whereby they are be diffolved.

1 1. 6.. Egg-frelis calcined, make with Oyl of sulpbur, or Oyl of $V_{i}$ triol, or Spirit of Nitre, a greater Effervefcence, than when uncalcined. As alfo with feams, which uncalcined, they produce not. The like is feen in calcined $O_{y}$ fter-fiells. And the longer the Calcination is continued, the quicker and fronger will be the Effervefcence. This I trjed at feveral terms, from a quarter of an hour, to five hours. So that after fo long a Calcination, they make an Effervefcence almoft inftantaneous. The reafon hereof is, Becaufe the feveral Principles whereof the Shells confift, being relaxed, and the Sulphur for the greateft part, driven away by the fire; the remaining Salt lies now more open and naked to the attaque of the Menftruum, fo foon as ever they are mixed together. From hence it is plain, That Egg-תhells, and the others above-faid, being burnt, are far fronger Medicines, than when unburnt. It is hereby likewife evident, That a great portion of their Salt, is not a volatile, but a fixed Alkaly. Tothefe may be fubjoyned all kinds of thelly Infects. I will inftance in three or four.

12. \$. And firft Bees, with oyl of Vitriol, ftir not in the leaft. With Spirit of Nitre they make an exceeding fmall Bullition, without any elevation.

13. 6. Cocbinele (the Nefi of an Infect) makes fome Bullition with Oyl of Vitriol, but very fmall: for the bubbles are not to be feen without a Glafs. But with Spirit of Nitre the Bullition is more vifible, and joyned with fome elevation. 
14. 6. Cantbarides make no vifible Bullition with $O_{y} l$ of Vitriol. But with Spirit of Nitre they do, and huff up rather more than Cochinele. Yet is this done very flomly, and comparatively with many ot her bodies, is not much. Hence it is not the quantity, but the quality of their volatile Salt, which makes them fo ftrong an Epifpaftick. For moft of thofe Bodies above, and hereafter named, make a greater Bullition, and yet are neither Cauftick nor Epifpaftick in the leaft. It is hence alfo evident, as hath been before fuggefted, That there are divers kinds of Volatile Salts, eminently different; fome being highly alkaline, others very little, and fome fcarce any thing fo: fuch as thofe of Scurvy-grafs, Anemone, Cromfoot, and many the like Plants; to whofe saltr, this of $C$ antharides feemeth to be very near of kin.

15. 6. Millepedes make a Bullition and buff, mucls greater and quicker, than any of the Infects above-named: and that both with Spirit of Nitre, and Oyl of Vitriol it felf. $Y_{e t}$ is this In fect of a very temperate nature. Whereby is further demonftrated, That the being fimply alkaline, is not enough to make a body to be Cauftick:

16. 5. Again, although Millepedes make a Bullition, greater than any of the Infects above named: yet is it much lefs, than that of Oyfter, Snail, or even Egg-Shells; and of divers otber bodies above, and bereafter mentioned. Hence, being given to the fame intent, as any of thole bodies; it is the mildeft and gentleft in its operation of them all.

17. 6. Millepedes likewife calcined, makes a frronger Effervefcence, than when uncalcined, as do the Oyfter-foells, ofc. So that it appears, That all Teftaceous salts, are at leaft in part, fixed Salts.

18. \$. I next proceed to Bones. And firft Whale-bone maketh no Bullition at all with any acid. A Cartilage, with Spirit of Nitre, makes fome very fmall bubbles, not to be feen without a Glafs.

19. 5. The Bone in the Throat of a Carp, makes a little and Jow Bullition woith Spirit of Nitre. The Spina of a Fifh (that which I ufed was of aCod-fifh) maketb a Bullition one degree bigher.

20. 5. All forts of Teeth, as Dogs, Boars, the Sea-horfe, Elephant, make the like. As alfo the Bone of an Oxes beart. So that all thefe are very gentle in their operation, and fit for Children.

21. 6. Sheeps and Calves Bones both of them make a Bullition yet a little bigher, efpecially with Spirit of. Nitre. Cocks Bones fomewhat bigher than the former. Cranium humanum a little bigher than all the reft.

22. 5. Bones likewife, being calcined, make a Bullition with Acids. And fo doth alfo calcined Harts-Horn. But in neitber of them, is the Bullition advanced by Calcination, any thing comparab!e to what it is in foells. Whence it appears, That the Salt of Horns and Bones, is much more volatile, than that of shells.

23. 5. Next for Flefh and the feveral Vifcera. And firft, dryed and powdered Mutton, with Oil of Vitriol, firs not at all. But with Spirit of Nitre makes a fmall Bullition and buff. Sheeps Heart doth the like fomewhat more apparently. Vipers flefs produceth a froth, but buffs not, Powdered Earthsworms make a great froth, and buff a little. Powdered Tripe makes only a little Bullition. Lamb-ftones do the like. Kidney, Spleen, and Liver, with fome elevation. Lungs, with bubbles very large; becaufe extraordinary flowly. Dryed Brain makes alfo a little

$\mathrm{P} \mathrm{p}$ and


and flow Bullition. Hence there is a greater proportion of Sulphur or $O y l$, and lefs of an Alkaly in all thefe parts, than there is in Bones, Shells, and divers other parts hereafter mentioned. And in fome of them, as in the Brain, that Alkaline Salt which there is, may rather be lodged in fome fanguineous parts mixed with them, than in their own proper fubftance.

24. \$. I proceed to inftance in all forts of Animal Contents. And firft, raw Silk, with Spirit of Nitre, makes a very Jmall Bullition, but the elevation is confiderable.

25. 5. The grumous part of the Blood dryed, with Oyl of Vitriol, firs but little. But with Spirit of Nitre it buffs up confiderably.

26. 5. Serwm of Blood dryed, with the fame Spirit makes a plain elevation, with a little Bullition. Herewith may be reckoned the W bite of an Egg, which is nothing tut a pure Cryftalline Serum feparated from the common ftock. This being dryed, with Spirit of Nitre, buffs up rather more than even the grumous part of the Blood, the Bubbles are much larger, break oftner, and the elevation fooner made. Whence it feemeth, that there is a greater quantity of a volatile Alkaly in proportion to the sulphur, requifite to the Generation, than to the Nutrition of an Animal.

27. 6. The Yelk of an Egg is fcarce moved with spirit of Nitre, producing only a very few Bubbles. The salt being either little alkalizate, or elfe immerfed in fo great a quantity of $O y l$, that the Menftrum cannot reach it. For the fame reafon Sperma Ceti stirs not with any Acid. Neither doth Civet.

28. 5. Ruffian Caftor, with Oyl of Vitriol, stirs not. But with Spirit of Nitre makes a confiderable buff and froth. Yet it requires time. Wherefore it feemeth, That $C_{a}$ lor by virtue of its alkaline sulphur, becomes fo good a Corrector of the acid-alkaline sulpbur of Opium : fo I take leave to call it, having fome reafons to believe it fuch.

29. \$. Musk, with Oyl of Vitriol, ftirs not. But with Spirit of Nitre it makes a confiderable and quick Bullition, with large bubbles, which of ten break and rife again. Whence there is a very eminent difference betwixt Musl and Civet. Hence alfo, Musk is Cordial, not only from its Sulphur, but its Alkaly; by both directly oppofite to preternatural Acidities.

30. 6. Dryed Gall with spirit of Nitre, for fome time, is fill : but at length it makes a confiderable Bullition and froth. The reafon why it is fo long before it begins, is becaufe the salt, (as was obferved of fome other Parts) is locked up in fo great a quantity of $O y l$. The abundance whereof is manifert, not only from Deftillation, but alfo from hence, In that the dryed Powder, in lying by, incorporateth all together into one body, as Mirrh, and fome other fofter and oily Gums are ufed to do.

31. 5. Extract of Urine, with spirit of Nitre, makes a Bullition with fome Effervefcence, wbich continues for a confiderable time; and at laft it huffs up with great bubbles. The Bullition begins prefently: the salt being copious, and the $O_{y}$ l but little.

32. \$. The fame Extract of Urine makes a confiderable Bullition and froth, not only with Spirit of Nitre, but even with Oyl of Vitriol. Hence the salt of Urine is more alkaline than that in mott of the afore-faid 
Contents. From this and fome of the following Experiments, it alfo appears, That the salt which concurs to the generation of Gravel or of a Stone in the Kidneys or Bladder, is of a very different nature from the Salt of Urine.

33. \$. Next for Dungs. And firft, dryed Goats-dung makes with spirit of Nitre, a fmall Bullition, but no elevation. That of Mice the like. And that of Cows. So that of all I have tryed, thefe three ftir the leaft.

34. 6. Goofe-dung, with Spirit of Nitre, makes a very fmall Bullition and fome elevation. But it requires time. Oyl of Vitriol ftirs it not.

35. 6. Aibum Gracum, with Spirit of Nitre, befides innumerable fmall bubbles, rifes up with fome great ones, exactly refembling the buffing up of Yeft or Barm. Alfo with Oyl of Vitriol it maketh fome little froth, but flowly. So that it fhould feem, that the Bones are a little opened by fome acid Menstrumm in the Dogs ftomach (as the body of Steel is in its preparation with Sulphur) whereby it becomes a good mild Topick in Quinzies.

36. \$. Hens dung, with spirit of Nitre, makes a very great bullition and buff: greater and quicker, than any of the rest above-named.

37. 5. But of all I have tryed, Pigeons dung, with the Same Spirit, maketh the greateft and the quickeft Effervefcence and buff; and that not without feams. Yet neither the fame Dung, nor that of Hens, is moved in the least with Oyl of Vitriol. The Caufe of fo great an Effervefcence in thefe, more than in the reft, is that white part which is here mixed in a great quantity with the Dung. Which white part, defcendeth not from the Stomach, but is an Excrement feparated from the Blood (as the Urine in other Animals) by a peculiar Organ, which evacuates it into the Intestinum rectum; whence, together with the Stercus it is excluded. Hence it is evident, That in the faid mbite part of Hens, and efpecially Pigeons dung, is contained a great quantity of a volatile Alkaly.

38. 6. I proceed to Salts. And firf Salt of Blood and Urine both make a more durable Effervefcence woith Acids, than doth salt of Wormmood, or salt of Fern. Hence the former are more alkaline, than the latter.

39. 5. Again, though divers other Animal Salts will not ftir with Spirit of Salt, or with Oyl of Sulphur or Vitriol; yet the Salt of Blood will make an Effervefcence with all kinds of Acids. Whence it is further. argued to be highly alkaline, and very proper for the correction, of all forts of preternatural Acids in the body. There is little doubt, but that Spirit of Harts-horn will do the like.

40. \$. The Gravel which is precipitated out of Urine; with Oyl of Vitriol makes no bullition in the leaft. Nor with frong Spirit of Salt. But with Spirit of Nitre, it makes a very great one, with Effervefcence and fteams. From hence it appears, That there is much difference to be made in the ufe of asid Diureticks, Nephriticks, \&c.

4I. 6 . And that I may not altogether omit to mention, what may be fo much for the good of mankind, I do here declare, That for preventing (I fay not, the breaking, but preventing) the generation of the Stone, either in the Kidneys, or in the Bladder, there are not bet- 
ter Medicines in the world, than fome certain Preparations of Nitre, duly adminiftred. Whoever fhall think that any kind of acid, as $O_{y} l$ of Sulphur, Oyl of Vitriol, Spirit of Salt, or the like, will have the fame effects, will find themfelves much deceived in their practice.

42. 6. I conclude with Stones. And firft, Spirit of Nitre droped upon a Stone of the Kidneys or Bladder, produceth the very fame effect, as upon the Gravel in Urine. That is to Say, it makes it boil and buff up, until at length it is perfectly diffolved into a foft Pulp; which neither $O y l$ of Sulphur, nor Oyl of Vitriol, nor spirit of Salt will do; nor give the leaft touch towards its diffolution. This confirms what I faid before of the ufe of Nitre and Nitrous Spirits, if duly prepared and adminiftred, above any other Acids, againt the breeding of the Stone.

43. 5. Pearls, with any Acid, make the like Effervefcence, as do $\mathrm{O}_{\text {- }}$ fter-fhells. But Magistery of Pearls, as ufually prepared, ftirs not at all, with any Alkaly or Acid. So that as to the effect frequently intended by it, it is very infignificant; as of that of Corals bath been faid.

44. \$. Crabs Eyes, with any Acid, make an Effervefcence, almoft as quick as that of $\mathrm{Oyfter-ghells.}$

45. Crabs Eyes likewife calcined, make a fronger Effervefnence, than when uncalcined. So that the $\int e$, as well as Shells, contain a fixed Alkaly.

46. 9. The Stones in Whitings heads make a ftrong Effervefcence like that of $O y$ fter-gells.

47. S. Stone of humane Gall, stirs not with Oyl of Vitriol. But with Spirit of Nitre maketh a little bullition juft upon mixing, and after a confiderable time, a little froth. Much lefs than what was obferved before of the Gall it felf. So that it feemeth to be generated of the Gall coagulated by fome Acid, which hath already refracted the Alkaly wherewith the Gall abounds. This confirms the ufe of thofe Medicines in the Faundies, or any other bordering Difeafe, which deftroys thofe Acidities by which the Gall is curdled or coagulated, and fo rendred more difficulty feparable into the Guts.

48. 5. Since the firft publifhing of thefe Obfervations, Mr. William Matthews an Apotbecary in Ledbury, fent me part, as I take it, of a Stomach-ftone, as big as a Wallnut of the largeft Size, voided by a woman about 82 years of age, fometime after an Autumn Fever. It confifteth of the fame Strie, as the Bezoar Stone; and maketh fome Bullition with Spirit of Nitre.

49. 5. Bezoar, neither the Western nor the Eaftern, doth fir at. all with Oyl of Vitriol.

50. \$. Western Bezoar, with Spirit of Nitre, makes a very little thin froth, and that's all; and that it doth very flowly. But Oriental Bezoar, woith Spirit of Nitre, after fome time, maketh a very great Effervefcence, froth, elevation, noife, and fteams (as if you poured oyl of Vitriol upen $S_{a}$, of Tartar) till it be wholly diffolved by the affufed Spirit, and turned into almoft a blood-red. Hence it may feem to be no mean Remedy againft fuch fretting and venenate acids, as oftentimes in Fevers, and other $D_{i-}$ ftempers, lye about the stomach, and are thence frequently tranflated to the Heart, Brain, Nerves, and other parts. The difference likewife betwixt the Weftern and the Eaftern Bezoar, is fo great, that in any cafe of danger, and where the Bezoar is relyed upon, it is an unpardon; 
able fault, for the Apothecary, or any Perfon, to fubftitute the one for the other: unlefs he will take ten times as much, or ten times as little of the one, as he would havedone of the other: if that will ferve turn.

51. 6. The stones already mentioned, (except the great Stomachftone) are ordinarily generated in the bodies of Animals. I have one Inftance more of fome other stones which are extraordinary. In the City of Hereford lives a Maid, who often voids thefe Stones, and in the fpace of fome years laft paft, hath voided feveral pounds, of feveral Colours and sizes, not only per vias urinarias, but alfo by vomit, and by ftool. The firft mention made to me of them, was by Mr. Diggs, a worthy Gentleman of that City, as a thing that was there much wondred at. And fome of them, upon my defire, were fent me by Mr. Wellington, an Apothecary in the fame place. I have trged what feveral acid Menftruums will work upon them; and find, That with Oyl of Vitriol, and efpeially with Spirit of Nitre the great ones make a very quick and confpicnous Effervefcence. But the fmall ones, neither the white, nor the grey, make any Bullition in the leaft: for in truth, they are no other but little Pebbles and Grit-ftones.

52. §. This being confiderd, and the various colours and mixture of any one of the great Stones, being well obferved; it feemeth plain, That although fhe be fomewhat old (above thirty years) yet may the have a kind of rariaria, or difeafed Appetite to Stones, Bones, Woodafbes, Tobacco-Pipes, Chalk, and fuch like things; which fometimes fwallowing in little lumps, fometimes grofly, or finely ground betwixt her teeth; they are in her Stomach and Bowels, more or fewer of them, cemented together, either with a pituitous, bilious, or fome other more or lefs glutinous fubftance. And that by virtue alfo of the faid Cement, or any of the faid, or other like alkalizate Bodies, the greater stones, which confift of thofe partly, do make an Effervefcence with acid Liquors. Thus far of Inftances upon the parts of Animals. I thall clofe with fome Corollaries deduced from the whole.

53. §. And firft, fince we find, that amongt all the Menftuums we have made ufe of, Spirit of Nitre, or any very Nitrous Spirit, is the molt univerfal diffolver of all kinds of Animal Bodies; the beft diffolver of many others both Vegetable and Mineral, and the only diffolver of fome: Hence it is probable, That the great ftomachick Menftruum, which either diffolves, or opens almoft all Bodies which come into the Stomach, is a kind of Nitrous Spirit.

54. \$. Again, Spirit of Nitre being a fubalkaline Acid, and working more evidently upon Animal bodies, than other fimpler Acids do, which yet are as ftrong; It hence follows, That molt of the Salts of Animals are fubacid Alkalies. How far this conclufion may further inftruof us, I thall have occafion to thew in another Difcourfe.

55. \$. Laftly, there being fo many, fay twenty or thirty degrees, from the floweft to the molt vehement, in the Bullition of mixed Bodies; it feemeth, That Fermentation it felf, as to the formal notion of it, is 
nothing elfe : or that from the common Luctation of mixed Bodies whereof we have now been fpeaking, it differs not in ßpecie, but only in the manner of its caufation, and in degree: the Aer, or fome certain Menftruum lodged therein, being of no greater ftrength, than to produce a Bullition or Ludfation of that low and foft degree, which we
call Fermentation.

56. \$. I have thus endeavoured to prove, by various Inftances, how inftructive this moft eafie, plain and fimple Method in the Mixture of Bedies, may become to us: and that meerly by obferving the LuCtafions which thence arife betwixt them. How much more then, if a diligent remarque be made of all thofe various Colours, Smells, Taftes, Confiftencies, and other Mutations thereupon emergent? 


\section{A $N$ \\ E S S A Y \\ O F T H E \\ Various Proportions}

Wherein the

\section{I X I V I AL S A L T}

Is found in

\section{PLA N T S.}

Read before the Royal Society, March, 1676.

\section{H A P. I.}

Of the QV ANT IT IES afforded by feveral Plants calcined in grofs.

2 12 r $T$ is the part of a Phyfcian, knowingly and artiQo ficially to ufe and govern Nature. And therefore by every likely Method, to infpect the state and (3) I (a) Properties of all forts of Bodies. One Method, is I 15 that I have taken in the foregoing Experiments; As $s$. by mixing them with feveral Meftrums or $\mathrm{Li}$ Q 0150 quors: whereby we may be affited to judge, both of the Kinds and the Proportions of Principles in any Body; and of the manner of their Mixsure in the fame.

Another is byCalcining them; or, as it were, by mixing them with the Fire, a potent and almoft univerfalmenstruum. I fhall here only fet down fome Tryals for an EfJay, upon Plants; chiefly noting, The different Proportions of their Lixivial Salts. Of thefe Tryals, fome 
were made upon the whole Plant, or fome Portion of it wherein feveral Parts are mixed together: And others, upon fome one Part of a Plant diftinct from the reft. All of them anfwering to fuch Queries, as may feem proper to be propofed.

Query 1. As firft, Whether Trees or Herbs and Bufbes, quantity for quantity \& cxteris paribus, yeild the moft Lixivial Salt?

For this I took $A(b-B a r q u e$ and Rofemary of each tbj. The latter yielded 5 Scruples; the former but 32 Grains; which is three times lefs. I took alfo the fame quantity of the Barque of Black-Thorn, and of $A$ grimony. The latter yielded 5 Scruples and 6 Grains; the former, not above I Scruple and 5 Grains; which is four times lefs.

Although the Barque of a Tree be compounded of Pithy and Lignous Parts; yet to anfwer the Query exactly, the Wood of thefe Trees fhould be taken with the Barque, that there may be fome portion of every Part of the Tree, as well as of the Herb.

But thus far the Experiment is conclufive, That the fame quantity of Lixivial Salt, doth not always follow the fame Generical Taft. For the Barque of $A j$ and Rofemary, are both equally Bitter; and the Barque of Black-Thorn and Agrimony are both Aftringent and Bitter.

Quer. 2. Whether any Plant growing in a Garden or the Field, doth not yield a lefer quantity of Lixivial salt, than another of the fame kindred growing on the Sea-Coaft; and with what difference?

For this, I took Garden and Sea-Scurvygrafs, of each tbj. The former yields 2 Drachms and I scruple; the latter, being well wafhed, 9 Drachms, which is more than 4 times as much. The like may be tryed upon others.

Quer. 3. Whether the fame specifick Plant affords more Lixivial salt, being only dryed, and then calcin'd, or after it bath first been diftilled, it is then dryed and calcin'd?

For this, wastaken ftj of Mint only dryed and then calcin'd; and another firft diftilled. The former yielded $\frac{1}{2}$ an Ounce and $\frac{x}{2}$ a Drachm of Salt; the latter, 5 Drachms and a Scruple; which is almoft $i_{5}^{\text {th }}$ more. This alfo fhould be tryed on other Plants.

Quer. 4. How far the proportion follows the different Tafts of Plants? The firft Experiment, relates to the fame Tast in feveral Plants; this, to feveral Tafts. And fo,

Of Majorane, which is Aromatick, tibj affords but one Scruple of Lixivial Salt; which is but the $384^{\text {th }}$ part of the whole pound.

Of Oak-Barque which is Aftringent, tbj yields $\frac{1}{2}$ a Drachm of Salt; or the $25^{6 \text { th }}$ part of the whole.

Of Liquirifh, which is fweet, thj yields about the fame quantity. But Anife Seeds tbj yields 2 Scruples or a $192^{\mathrm{d}}$ part.

Of Sorrel, which is fower, tbj yields one Drachm, or the $128^{\text {th }}$ part.

Of Garden Scurvygrafs, which is Hot, ftj yields 2 Drachms and $\frac{1}{2}$ a Scruple; or the $59^{\text {th }}$ part.

Of Mint, which is Hot and Bitter, tbj yields 5 Drachms and a Scruple, or the $24^{\text {th }}$ part.

Of Sea Scurvygrafs, which is salt, thj yields 9 Drachms and a Scruple or 28 Scruples; which is near $\frac{1}{3}$ th part of the whole. A greater proportion of Salt, than in any other Plast upon which I have hitherto made Tryal: Or even in Tartar it felf. Yet is it not a Marine, but true Lixivial Salt: as is evident, both from its Tafte; and in that it 
maketh an Effervefcence with Spirit of Salt; which Sea-Salt will not do.

For the Experiment to be fully. âdequate to the 2uery; the Tryals fhouldbe made, either all on Trees, or all on Herbs; all on Roots, or all on Stalks, \&cc. Yet thus much is evident, That sorrel yields Thrice as much as Majorane; Sea-Scurvygrafs, Eight and Twenty times as much: Mint, Five times as much as Sorrel; and Sixteentimes as much Majorane, \&c.

Quer. 5. How far the Proportion follows the Faculties of Plants? And fo, it appears, that

Majorane, a Cephalick, hath a greater Proportion of Volatile Parts, than any of the Plants above mentioned, and fo far, is more agreeable to the Animal spirits, and Genus Nervofum.

Agrimony, (a) an Aperient, yields above Five times as much Lixivial Salt, as Majorane. Yet much lefs than many other opening Plants which are ftronger.

Mugwort (tbi) yields two Drachms and two Scruples; or above half as much more as Agrimony. So that this Plant, though it hath no confiderable Tafte, and in that refpect promifeth but little; yet yielding a good quantity of Lixivial Salt, feems no contemptible Medicine to fubdue thofe Acidities which either by caufing Obftructions, or immoderate Fermentations, frequently diforder the Female Sex.

Mint, yieldeth ftill a greater quantity; and is therefore, partly for the fame caufe fo excellent a Stomachick: And Rofemary, $(b)$ which is appropriated both to the Head and stomach, yieldeth a midle quantity of salt; more than the chief Cephalicks, and lefs than the chief stomachicks.

Common Mallow (tti) yields 5 Drachms and 2 Scruples. i. e. the $23^{\mathrm{d}}$ part of the whole. So that this Plant, though of a very mild Tafte, yet yieldsmore Salt than Mint it felf a Bitter Plant. Whereby it no Jonger feems ftrange, that a Plant of fo foft a Tafte, fhould be very Diuretick, and fo evidently affect the Reins.

$R h u b a r b$ ( 2 Ounces) yieldeth fcarce any fixed $S_{a l t}$, fo far as can be judged by the Tafte of the Aßses, not more than a Grain or two. So that its Salt is, in a manner, wholly volatile; and thereby apter to operate upon the Bilious parts of the Blood; which contein a far greater proportion of Volatile Salt, than do the Serous.

Of the Caput Mortunm or meer Earth, it is obfervable, that is was near $\frac{1}{2}$ an Ounce or $\frac{1}{4}$ th part of the whole; Which is almoft Six times as much as the Caput Mortuum of Common Dock: and much more than that of any other Root I have yet calcin'd. Whereby it feemetts probable that Rbubarb loofeth much of its Volatile Part, and therefore of its Virtue, before it comes to our Shops.

Sena (tbj) yields 4 Scuples and $\frac{1}{2}$ of Salt; or the $85^{\text {th }}$ part.

falap ( $\mathrm{tbi}$ ) yields but one Drachm and $\mathrm{I} 5$ Grains, or $102^{\mathrm{d}}$ part.

Colocynthis (ttij of the Pulp) yields an Ounce and half of $C_{a p u t}$ Mortuum, which is almoft all Salt. Yet allow half an Ounce of the Salt, and Earth to be wafted in filtring \&c. theremaining Ounce is no lefs than $\frac{1}{16}$ part of the whole. Which is more than in any of the above named Plants, except the Sea-Scurvygrafs. 


\section{H A P. II. \\ Of the QV ANTITIES afforded by the Parts of fe veral Plants diftinctly calcin'd.}

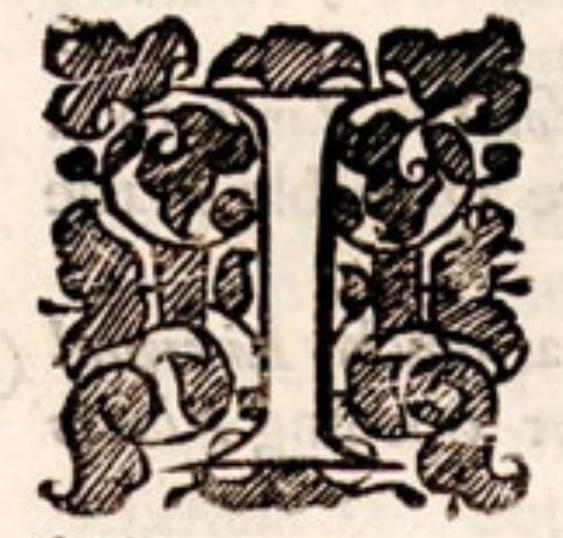

S HA L L next fet down fome Tryals, upon one Part of a Plant, as well Organick, as Content, feparated from the reft; in anfwer to thefe fuppofed 2ueries.

Quer. I. What Proportion doth the Lixivial Salt of the Pith or Pithy Part of a Plant, bear to that of the Fibrous, or of the Woody Part? Or whether is there a Fixed Salt always found in either of them? A fufficient Anfwer to which, muft be built upon many Tryals. At prefent I fhall mention only $\mathbf{T}_{\text {wo }}$; one upon Starch, anfwerable to the Pithy Parts; the other upon Flax, confilting almoft wholly of the Nervous or Tomy Fibres: of the Volatile parts whereof, chiefly, I have \$. 50, 5 I, given fome account in the foregoing Idea.

52. Of Starch, thj yieldeth about th $\frac{1}{4}$ not of Afhes, but of Black Coal. For though it be expofed in a Calcining Furnace to a vehement fire, for 5 or 6 hours, which is longer then will ferve to calcine moft Bodies: yet would it not in the leaft part, be reduced to Afhes; but to the laft continued (though the fiercenefs of the Fire confumed part of it) as black, as when it was firft burnt. So ftrangely was the remaining part of the Sulphur fixed to the Earth; that in flying away, it did volatilize and carry that away with it. In this Coal or Cinder, there is not the leaft of a Lixivial or other Tafte. And although, upon Tryal I find, That the Pith of many Plants, as of a Cabbage Stalk, will yield fome quantity of Lixivial Salt; yet it is probably, that generally, it yields lefs than the Wood.

Of Flax, tbj yields not above 50 Grains of Caput Mortum or white Afles, which are Salt. According to vulgar conceit, it would feem to be a very dry Body: yet of 153 parts, 152 are volatile, and being diftilled would have been collected into Liquor. Hence alfo appears the great and unexpected $V$ ariety in the Proportion of the Earthy Parts, as well as the other Principles of Bodies. Or elfe, that there are divers kinds of Earths, even in Plants, of which, as well as of Salts \&c. fome are volatile. For of $15 j$ of this Plant, there remaineth fixed but 50 Grains: whereas of thj of Rhubarb, there will remain near 1920 Grains, i. e. 88 times as much as the former.

Quer. 2. In what proportion is the Lixivial Salt found in the Gumms of Plants? and whether is it yielded, more or lefs, by all? For anfwer to which, I caufed the Eleven following, of each two Ounces, to be calcin'd, and fo obferved,

That Common Rofin, yields but one Grain and $\frac{1}{2}$ of Caput Mortumi: So that tffj will yield but 12 Grains. In this Caput Mort. there is not the leaft particle of Salt, it being altogether infipid.

Maftick yields gr. I 2 of Cap. Mort. But not the leaft part of salt. Of this Rogin, it is obfervable; That being fet, in a Crucible, within 
the fire, before it comes to have thick fumes, it boyls up with a very great foame or froath; and is the only Gum or Rofin (of the Eleven) that hath this property. So that I fufpect, there is a great quantity of fome kind of volatile Spirit, which then flies away; and fo, in breaking through the Oply parts, huffs them up to fo great a froath.

Olibanum yields half a Drachm of Caput Mortunm. But it is to be noted, That the weight is encreafed by certain little Spar-Stones, which in the burning of feveral parcels, I always found mixed with this Gumm. Thefe being picked clean out, the Cap. Mort. weigheth not much more than that of Maftick. And is in like manner infipid, when the faid Stones are picked out.

From hence it appears, how proper thefe Gums are for the Concoction of Salt Rheums; according to what I have formerly fuggefted Difcourfer from another Experiment.

It may alfo be noted, that Rofin and Maftick, feem to be more Cap. Ult purely Acidoleous Gums; not only.from their confiftence which is uniform; and their Smell, which is lefs ftrong and more pleafant : but alfo from the Acid Liquor they yield by Diftillation; and in that the young Leavs of Fir, and efpecially of Pine, are fower; and tis pro. bable that thofe of Maftick are fo likewife. Whereby thefe, and other like Gums are more efpecially fitted for the abovefaid purpofe. But Olibanum feems, befides its Acidity, to contein fomeVolatile Alkaly, and fo to be an Acid-Alkaline Gum. For as it hath a ftronger Smell than the former, fo a hotter Tafte; both the ordinary effects of an Alkaline Sulphur. And being infufed in feveral Menftruums, appears to conftift of two Bodies, one of them more Refinousthan the other. Of which, it is probable, that the one is made by the Acid parts as the other by the Alkaline. Whereby it is very well adapted in fome $C a \int e s$, as in a Pleurefie, for removing the Coagulations of the Blood, or its difpofition thereunto.

Afa fotida yileds no lefs than half its weight or an Ounce of $C_{a p u t}$ Mort. that is 8 times as much as that of the other Gumms, and 48 times as much as that of fome of them. Yet doth it not contein one grain of Salt, fo far as can be judged by its Taft. Yet the Strength and Loathfomnefs of the smell and Taft of the Gumm do argue it to be highly impregnated with fome kind of Volatile Alkaly proper to arreft thofe offenfive Vapours ( to ufe the vulgar word) which flying, either by the Blood or Nerves, from part to part, do often prove fo trouble-
fome.

Gum Arabick yields one Scruple of Cap. Mort. whereof, by the Tafte, about $\frac{2 \mathrm{~d}}{3}$ part is Salt.

Euphorbium yields one Drachm of Caput Mort. of which, by the ftrength of the Tafle, two Scruples feem to be Salt. Which confirms

a former conjecture (a) of its being an Alkaline Gumm. (a) Of the

Myrrb alfo yields a Drachm of Cap. Mort. and at leaft two Scruples Luctation of Salt. Of the Eleven, thefe two Gums have the greateft quantity of Bodies, of a fixed Alkaly.

Cb. $\mathrm{T}$.

Opium yields half a Drachm of Cap. Mort. whereof the one half is Salt. Salt.

Aloe yields a Drachm of $C_{a p}$. Mort, conteining about one Scruple of

Qq?

Scansmony 


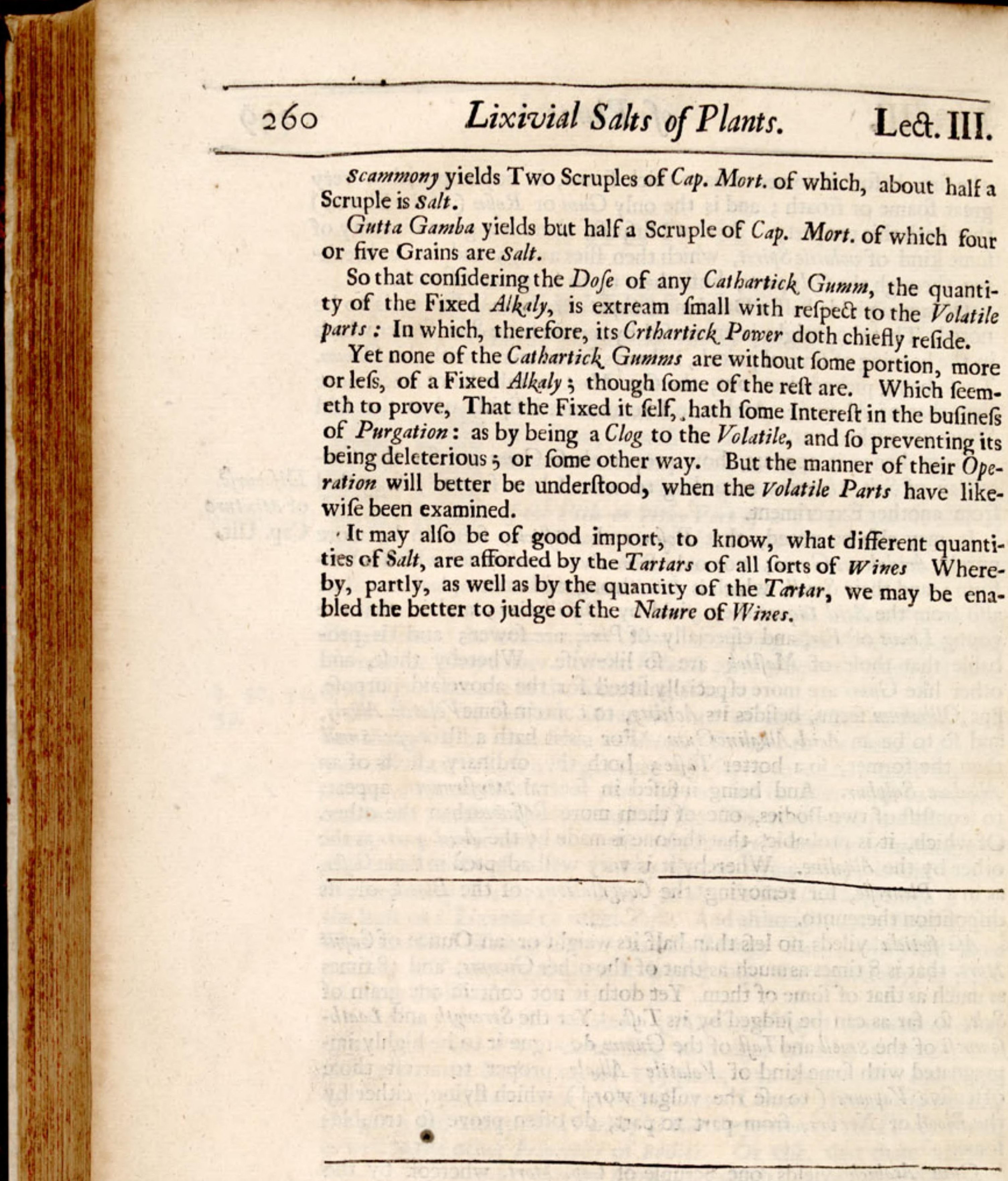




\section{A \\ D I S C O U R S E \\ Concerning the}

\section{ESSENTIAL and MAR I NE}

\section{Salts of Plants.}

\section{Read before the Royal Society, December 21. 1676.}

\section{CHA P. I.}

In which is Shewed the way of making both an ES SENTIAL and a MARINE Salt, out of the LIXI$V$ I A L Salt of a Plant.

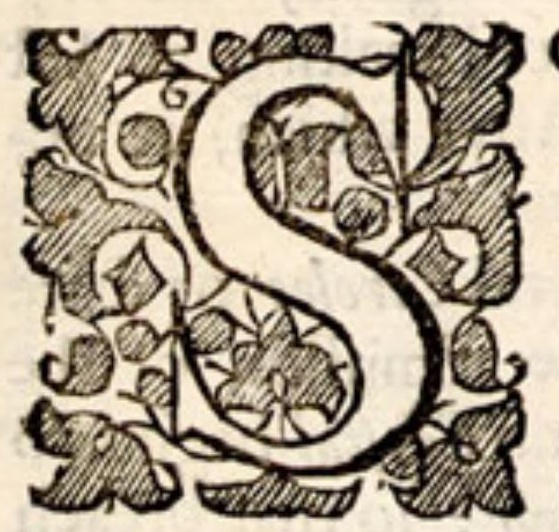

O MET I ME fince, I took the boldnefs to prefent my thoughts to this Honourable and Learned Body in a Difcourfe concerning Mixture. Wherein I have endeavoured to lay fuch a Foundation, as might hereafter reduce the Doctrine hereof to $E_{x-}$ perience and Practife; and to demonftrate, the Power and Uje of Artificial Mixture. And in further proof of what is therein afferted, I have fince made a continuation of Experiments upon the fame Subject, in Two Methods. One in the Mixture of feveral Menftruums, both Acid and Alkaline, with all Sorts of Bodies. The Other, by calcining them, or, as it were, mixing them with the Fire.

2. 6. I thall now proceed to a Third, which is, the mixing them with the Aer or expofing them to it; another of Natures grand Menfruums; which goes fometimes further than the Fire it $\mathrm{felf}_{\text {, }}$ in the dif- 
folution of Bodies. This I have formerly mentioned for the Imitation

Difcourfe of Nature, in producing a Marine or Muriatick Salt out of the Lixivial of Mixture Salt of a Plant. But fome Learned Perfons then prefent, feeming to Ch. 5. Inft. doubt of the Experiment; I thought it requifite to profecute the fame 2. a little further; that fo, if poffible, it might become clear and unqueftionable. And becaufe that Method wasimperfect, and required half a year, or a longer time: I bethought my felf of an other way; which proved far better, and more expedite. And which, withall, afforded me, not only a true Marine Salt, out of the Lixivial salt of a Plant; but alfo another kind of salt, different from them both: which may not be improperly called, an Effential salt or Nitre of Plants. The Hiftory or manner of the production of them both, is as follows.

3. 8. December 15. I 675 , I took about half a pound of a ftrong Solution of the Lixivial Salt of Firne: and pouring it into an Earthen Tab. 83. Pan, well glazed, broad and fhallow, expofed it therein to the open

4. 6. This Solution or Lee, although it was very clear before, and having ftood corked up in a bottle many days, had no fedement: yet ftanding now in the open Aer, within the fpace of 4 or 5 days, it began to let fall a very white Sedement, like fine Chalk; which encreafed daily for 8 or Iodays; amounting at laft to about half a Drachm of white, light and meer Earth, altogether infipid, and when it was weil wafhed, ftirring not upon the Affufion of Acids.

5. 5. Within the f pace of a day or two after this wobite Sedement began to fall to the bottom; there was alfo gatherd on the top, a kind of foft Scum or Cremor, wherewith the Solution was covered all over.

6. \$. Within 8 or 9 days after the firft expofing of the Liquor, or 2 or 3 days after the gathering of the Cremor; that Salt, which I take leave to call, an EJjential salt of Plants, began to appear; fhooting into feveral little $C$ rystals. Thefe Cryftals, as they grew bigger, began to fink, and at laft fell down to the bottom of the Pan.

7. 5. Upon their firft generation or fhooting, the faid $C$ remor pre.

Tab. 83. the bounds of every fpace is indented; about each $C_{r y} f_{t a l}$; and upon the bounds of every f pace is indented; the fpace growing bigger and bigger together with the Cryftal in the Centre. And fo, by that time the $C_{r y f t a l s}$ are grown to a confiderable number and bignefs, the $C_{r e-}$ mor vanifhes away, the feveral Circles or bare places breaking at laft one into another all over the Surface of the Lee. After which, it never comes again.

8. 5. From whence it feemeth, That the feveral Circles or bare

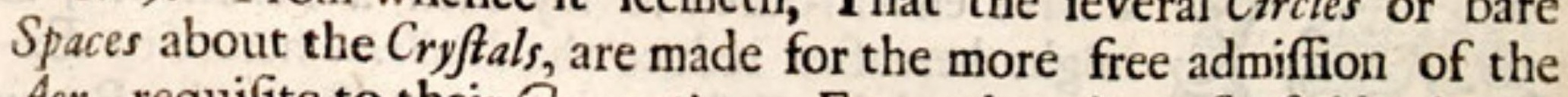
Aer, requifite to their Generation. For as there is no Cryftal begins to be formed before there is a breach made in the Cremor: fo that breach is enlarged together with the Cryftal. So that as the falling of the Sedement and the gathering of the Cremor, fheweth that the Aer, as a Menfruum feparates fome part from the Lee: fo the breaking of the Cremor afterwards, that as a Vebicle, it brings fomething to it: both in order to the Generation of the Cryftals. Nature taking a Method for the Generation of fimpler Bodies, as well as of thofe which are Compounded and
Organical. 
9. 6. The Figure of thefe Cryftals is angular and oblong, moft of them about the fifth, fixth or feventh of an Inch; but none of them very regular. Yet we are not hence to conclude, but that with the help of fome Circumftances which might be wanting in the fhooting of thefe; fome portion of regular ones may be obteined from this, as well as other Lixivial Salts hereafter mentioned.

10. \$. They are fomewhat tranfparent, and of a dark Ambar $C_{0}$. lor, or like that of brown Sugar-Candy. Of a quite different Tafte from that of the solution or Lee out of which they are bred; being not at all Lixivial, but very weak and mild; not Salt, but Bitter in a good degree.

I I. I. It is alfo obfervable; that Alkaline and Acid salts being both poured feverally upon thefe $C_{r y f t a l s}$, they ftir not, nor are any way affecied with either of them. So that thefe Cryftals are no fort of Tartar, or Tartareous Salt. As is plain, from the manner of their Generation; Tartar being ftill bred in clofe $V e f f e l s ;$ thefe never, but by expofing the Liquor to the Aer. As alfo from their Taste, being not fower, in the leaft, but bitter. And in that Tartar will make a Bullition with Alkaline Salts, which thefe will not do. Upon which accounts it appears, that they are a Salt different in Nature from all other Salts hitherto known, or a new Species added to the Inventory of Nature.

12. 6. Thefe crystals within the fpace of about a fortnight after their firft Generation, did alfo ceafe to fhoot any more, but only increafed a little in their Bulk. After which time, I dayly expected to fee the production alfo of a true Marine salt. And about two months after the faid EfJential Crystals had done thooting, and not before, this alfo began to fhoot, in many fmall Cryftals, and at the top of the Solution, as the other did, ftill falling to the bottom as they grew biger.

13. 6. The Size of moft of them was near that of the Flakes or Grains of Bay-Salt. The Colour of fome of them white, of others tranSparent; and of others white in the Centre, with tranfparent Edges; as is alfo ufual in the Cryftals of Common Salt.

14. 6. The Figure of moft is a perfect square, and of very many coming near to a Cube; which is alfo the Figure of Common Salt, and feldome an exact $C u b e$. An exact Cube, being the conftant property of no Marine Salt, that I know of, except that of the Dead Sea. Divers Tab. 83 . of them were alfo raifed as it were by feveral fteps from a deep Centre to the Top: as is often feen in the common fhooting of Common salt; and not in any other. Their Tafte is neither Lixivial, as that of the Solution out of which they fhoot; nor bitterilh, as that of the E/fential Cryftals; nor fowerifh, as that of Tartar; but the perfect Tafte of Common Salt.

15. F. It is alfo to be noted, That if Oyl of Vitriol, and fome other ftrong Acids, be poured upon this artificial sea-salt, they make an Effervefcence together: but if Spirit of Salt or Spirit of Nitre either be poured on it, though it be never fo ftrong it ftirreth it not. In both which, and all the formentioned refpects, it anfwers to the Properties of a Marine or Common Salt, which no other Salt doth. I conclude it therefore to be a true Marine Salt produced by Art in the imitation of $\mathrm{Na}^{*}$ ture. 


\title{
C H A P. II.
}

\author{
Wherein is Shewed, That the faid ESSENTIAL \\ and MARINE Salts of Plants are both of different \\ Sorts.
}

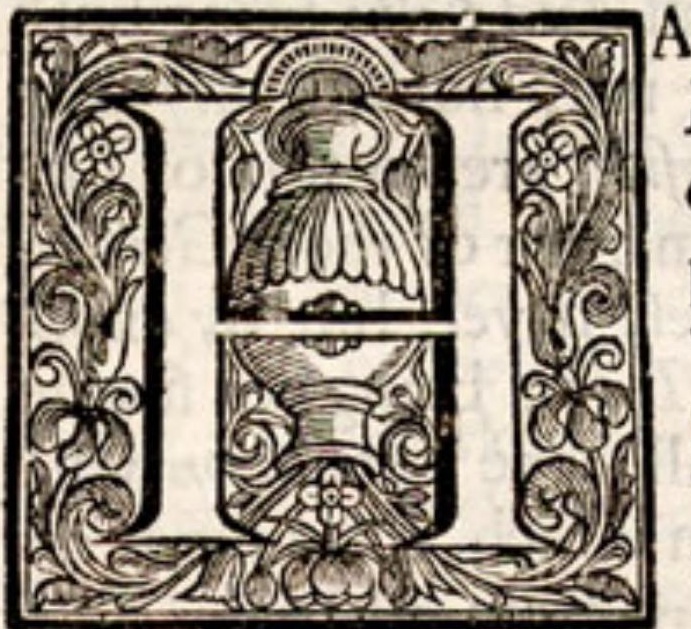

A VING made the Experiment, that both an EJjential and Marine Salt may be produced out of the Lixival Salt of a Plant. I thought it probable, that neither the one nor the other, was always the fame, but that as they had their general properties which made them to be of two general |kinds; fo they might have fome fpecial property, for the diftinguifhing of each kind into feveral Sorts. And withall, that in a warmer feafon, than before taken, the Tryal hereof might be finifhed in a fhorter time.

2. \$. For the making of which, I conceived it requifite to remove an Opinion which feemed to lye in my way $; c$. That there is little or no difference between the feveral Lixivial Salts of Plants, as fome Learned men have thought. But either there is a difference, or not: if not, it thould be proved : and if there be, it fhould then be juftly ftated, what that difference is. For the doing of which, I chofe this Method. I took an equal quantity of the whiteft and pureft Salts of divers Plants, all made by an equal degree of Calcination; and diffolved them all feverally in an equal quantity of water. And pouring likewife an equal quantity, as about 10 or 12 drops of each into a fpoon, I tafted them feverally. Whereby it was very evident, that they were not all of one Taft, but of very different ones, both as to ftrength and kind: and therefore different in Nature alfo. The Salts I made tryal of were thofe of Sorrel, Anife, Wormwood, Mallow, Afh, Tartar and others: and upon half a Drachm of each I poured $\xi_{\mathrm{ij} \beta}$ of water. The solutions are here prefent to be tafted. By which the differences will eafily be obferved, and particularly that the Salt of Wormowood or $S_{\text {cur- }}$ vygrafs, is almoft as ftrong again as the Salt of Anife, or Sorrel: and that the Salt of $A f b$ is above twice as ftrong, and that of Tartar above thrice as ftrong, as that of sorrel, and almoft thrice as ftrong ast that of Wormwood or Scurvygrafs. So that he who thall give half a Scruple, fuppofe of salt of Tartar; inftead of half a Scruple of Salt of Wormzood, or other like Salt; he may as well give a Scruple of Rofin of Jalap, for a Scruple of the powder, or almoft three' Drachms of $R b u-$ barb, or other like Purge, inftead of one. And the like is to be faid of other Lixivial Salts in their degrees.

1 3. 5. Having obferved thus much, I proceeded to repeat the former Experiment, with fome of the aforefaid, and fome other Vegetable Salts, the beft calcin'd, and the pureft, that could be made for this purpore, being thefe Six salts, $f c$. of Rofemary, Garden Scuryygrafs, 
Black Thorn, CommonWormwood, Afh, and Tartar. All which diffolved feverally in fair water, I expofed in a Chamber window, and not in Winter, as before, but in the heat of Summer, $f c$. on the 19 of $\mathcal{F}_{u l y}$, to evaporate of themfelves.

4. \$. The Effect was, That the third day after their being expofed, the Effential cryftals began to thoot in three of the Solutions, $f c$. in that of Rofemary, of Garden Scurvygrafs, and of Black Thorn. On the fouth day, in that of Wormwood. On the fifth day, in that of $A / b$. In that of Tartar, not at all.

5. \$. Thefe Effential Cryftals began, in all, to fhoot at the top, and then to fall to the bottome; as in the Experiment before. But as there was very little of the white Sedement before mentioned, that preceded; So no Scum or Cremor at all. Which although a more perfect Calcination, it feems, did here almoft prevent; yet did not in the leaft deftroy the aforefaid Effential Salt, but rather make way for its more fpeedy and copious Production: exhibiting likewife a diftinct Species in feveral of the Solutions.

6. 6. For firft, the Cryftals of Rofemary (the largeft of them) were about the bignefs of a Rice-Corn. In Figure almoft like a Tip-Cat, which Boys play with, fplit down the midle. Each Tip being cut into Tab.
5 fides all ending in a poynt: the midle part divided into 7 , all drawn by parallel Lines; the topmoft with the lowermoft but one, on each fide, beeing three exact $S$ quares.

7. 6. The Cryftals of Black Thorn are moft of them poynted with juft fix fides of Equal Meafure: very like to the thooting of true $C_{r y f t a l}$ it felf. From the topmoft of which fix Sides, a Line being drawn Tab. 83 . out, runs parallel to a broad $B a f e$, whereon each $C$ ryjal ial ftands. So that they are in fome fort of a Rbomboid Figure.

8. §. The Cryftals of Scurvygrafs have alfo a very elegant and regular Figure, which is in a manner compounded of the two former now defcribed. But they are nothing near fo bigg, the largeft of them, being no biger than a Grain of that which we call Pearl Barley.

9. 5. The Cryftals of Wormwood have alfo very many of them a regular Figure; but quite different from that of the Crystals before mentioned; each $C_{r y f t a l}$ being a little $C_{y}$ linder, faving that it is conftantly fomewhat fmaller at one end, than the other: as it were one half
of a Rowling-pin. And not evenly Circular, but cut out by Six Sides of equal Meafure: almoft as in the Cryftal of Nitre. So that contrary to what is feen in the forementioned Cryftals, the ends of thefe of Wormwood are not poynted, but flat; and cut at Right Angles with the Sides.

Iо. §. The Cryftals of $A f h$, though by their properties they appear likewife to be Efential; yet are nothing near fo regularly figur'd, as all the forementioned.

II. 5. The Colour alfo of the faid Cryftals is fomewhat different : Thofe of $A / 3$ being of a brown tranfparency, almoft like thofe of Firne. Thofe of Wormwood being alfo brownifh, but paler. Thofe of Rofemary and Scurvygrafs having fome little Tincture, yet very clear. But thofe of Black Thorn without the leaft Tincture, and as clear as Crystal it felf. 
12. \$. None of thefe Effential Cryffals have any hot fiery $T a f t e$, but are very mild, and fenfibly Bitter; efpecially, about the Root of the Tongue: as is alfo obfervable of fome Plants hereafter mentioned, in
fpeaking of the different Taftes of Plants.

13. \$. Oyl of Vitriol droped upon thefe Cryftals doth not affect them in the leaft: yet droped into the feveral Solutions out of which the $C_{\text {rgftals }}$ are produced, immediately caufeth a great Effervefcence.

14. \$. Of the Solutions above named, that, of Salt of Tartar was the $6^{\text {th. }}$ Whereof it is remarquable, That having waited feveral Months together, I could not obferve the leaft Effential Salt to be therein produced in all that time. Whether there be any other $V_{\text {ege- }}$ table Salts, befides this of Tartar, which will not yield the Effential above defcribed, I have not yet experimented.

15. \$. In the mean time, from the Premifes it is very probable, that moft of them afford more or fewer of the faid Cryftals. In regard they are Plants of a very different kind, which I made tryal upon: as Garden Scurvygrafs, very $H_{o t}$; Rofemary, very Aromatick. Wormmood very Bitter; Black Thorne, Aftringent and Sower. And it is alfo plain, That the faid Effential Salts contained in the Lixivial, are not altogether one and the fame, but of divers Sorts.

16. 6. ABOUT 7 or 8 days after the E/Jential Crystals were produced; the Marine Salt did alfo begin to hoot; firft in Rofemary; quickly after, in Scurvygrafs; Next, in Black Thorn and Wormwood, fc. after the face of a week or 10 days more. And in all of them with fome difference of Size and Figure.

17. 6. The plaineft of all, was that produced out of the Salt of Black Thorn, confifting for the molt part of very fmall $C_{\text {ryftals, not }}$ above the $15^{\text {th }}$ of an Inch fquare, as alfo thin, fhaped like a Duch Tile ufed for Chimies. Many others were very thick, and near to a

Tab. 83. Cube. Moft of which were a little hollowed in the midle, like a grinding Marble or Salt-Celler; and the hollow bounded by 4 plain and equal Sides, all defcending a little towards the Centre; and meafured by two crofs Lines, which ftaid upon the four Angles of the Square, and fo cut one the other at Right Angles. Both which Properties are likewife ufually feen in the Cryftals of Common Salt.

18. 6 . In Wormwood, many of thefe Cryftals, befides the plain

Tab. 83. times naked, and fometimes inclofed in a fquare andalmoft Cubical Box. Many others were figur'd into Sprigs made up of four chief Branches ftanding crofswife, and thofe fubbranched; and all the Branches made up of little fquare Crystals, cluftered together in that Figure. The sprigy Figure of thefe Cryjtals is not accidental, but hath conftantly come after they hadbeen three times diffolved, and the Solution expofed to evaporate.

19. \$. The Marine Salt of Rofemary hath alfo fome variety. For

Tab. 83. befides the plain ones above defribed, there are fome thick Squares, which have alfo a fquare hollow defcending by five, fix, or feven narrow fteps, towards the Centre; being in Figure, faving thefe Steps, fomewhat like the Hoper in a Mill.

20. \$. Upon a fecond Solution of the fame Salt, there fhoots another fort of fquare; which is not plain on the edges, as the aboveTab. 83. named, but fcalloped or florid all round about, not unlike the Leaves
of fome Plants. 
2x. 5. The Cryftals of Marine Salt of Scruvygrafs are fomewhat like to thofe of Rofemary now defcribed.

22. 6. As for the Lixivial Salts of $A f b$ and Tartar, though in a Month or Five Weeks Space, they yield fome Cryftals of very clear Salt: yet of Marine Salt neither of them yieldeth the leaft particle. So that of thefe Six Lixivial salts, $\int c$. of Rofemary, Scurvygrafs, Black Thorn, Wormwood, Afh and Tartar, all, but that of Tartar, yielded an E/fential salt. And all, but thofe of $A / l$ and Tartar, yielded a $M_{a}$. rine, fuch as is above defcribed. All which salts both Effential and Marine, together with their Models, made of white Alabaftre, I have here ready to be feen.

23. 5. Of thofe that yield thefe salts, or either of them, it is further to be noted, That there is a confiderable difference in the Proportion or 2uantities which they yield, The Rofemary yields ftore both of Effential and Marine, but more Effential. Wormwood and scurvygrafs more Marine. Black Thorn lefs of Either: The $A / f$ no Marine, and the Tartar neither the EJjential nor Marine, as hath been faid.

24. \$. From what hath been faid, I deduce only at prefent thefe Three Corallaie. Firft, That a Lixivial Salt, is not only a compounded Body $\int c$. ofSalt, Sulphur, Aer and Earth; but even a Compounded Salt, containing both a Vegetable Nitre, and a true Sea Salt.

25. 5. Secondly, That the Expofing of Bodies, in the manne? above fhewed, may juftly be accounted one Part of Chymiftry hitherto Deficient, and much farther to be improved for the Difcovery of the $\mathrm{Na}$ ture of Bodies. For as Nature chiefly compoundeth Bodies by Digefting them, and fo either fhutting out or keeping in the Aer: So the Diffolveth them by Expofing, and fo neither fhutting in the Aer, nor keeping it out, but leaving it free to come and go; and thereby to bring, and carry off whatfoever is neceffary for the Separation or Solution of Bodies. For the Sea it felf (to confine the fimilitude to our prefent cafe) is but as a Great Pan, wherein all kinds of bodies being long expofed, are throughly refolved, ultimately yielding from the reft of their vifible Principles, that which we call Sea Salt.

26. 5. Laftly, if by Expofing and Diffolving we can make oneSatl; then by Compounding and Digefting we may make another, yea any other Salt; either a Fixed of a Volatile, or a Volatile of a Fixed. That is to fay, a Volatile Salt may be fo feparated from other Bodies, as to become Fixed; or a Fixed salt may be fo mixed with other Bodies as to become Volatile. For that any Salt fhould of it felf become Fixed or Volatile, is a Fixion not grounded upon Experiment.

27. 6. As for the Virtue of the Effential salts above defcribed, I believe they will be found upon tryal, not contemptible in fome Cafes. For which amongft other reafons, I have been the more punctual 


\section{8

in relating the manner of their Generation; that others alfo may have the opportunity of making proof hereof.

28. \$. When I made the Experiments for this and the foregoing Difcoure, not having fo good conveniency at home for making the Salts I ufed: I procured them all (except that of Firne, which I made my felf ) to be purpofely prepared by Mr. Fobn Blackstone a London Apothecary, who affured me of his great care herein ; and particularly, that he added no Nitre to whiten any of the salts with, as is commonly done for that of Tartar.

I do declare, That all the Lixivial Salts mentioned in this and the foregoing Difcourfe except that of Firne, were faithfully prepared by me

Jobn Blackstone. 


\section{A \\ D I S C O U R S E \\ O F T H E}
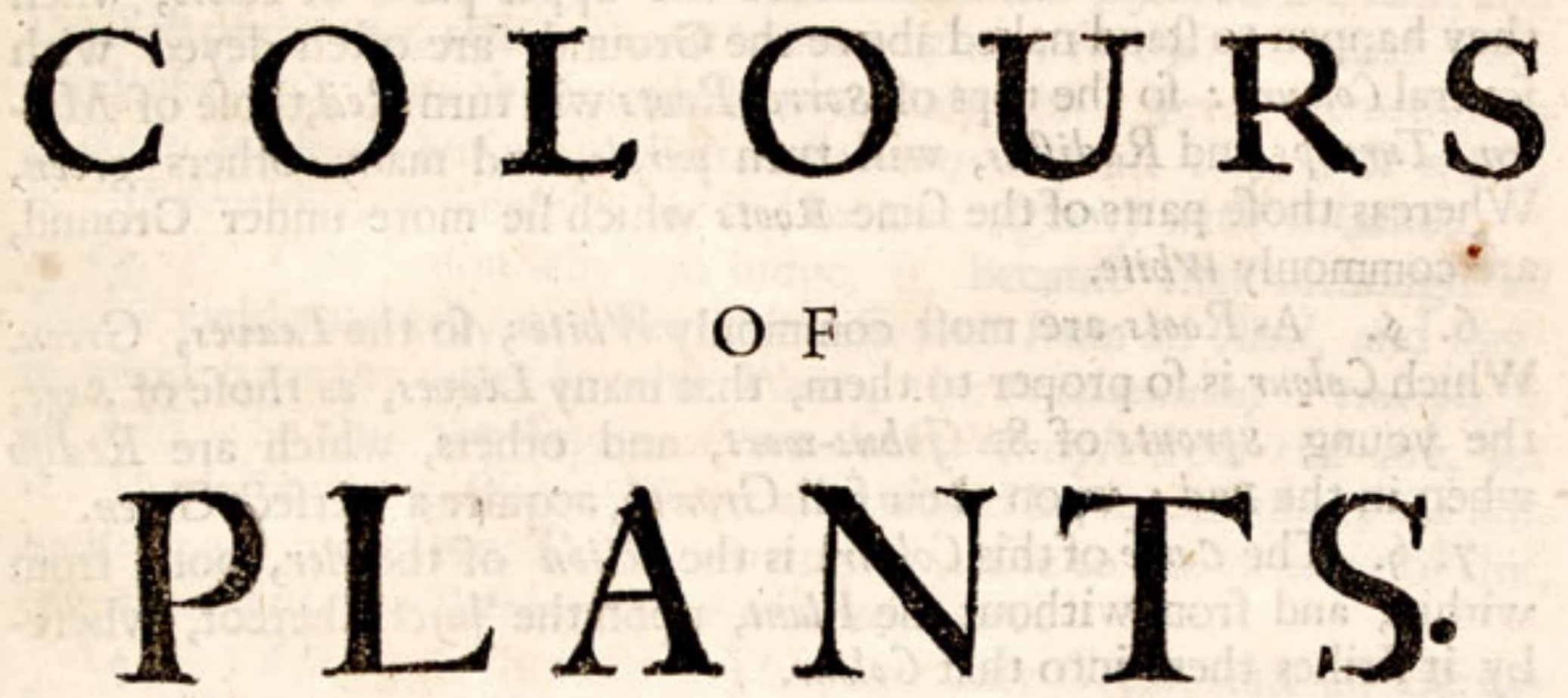

Read before the Royal Society, eMay 3.167\%

\section{CH A P. I.}

Of the COLOURS of Plants in their Natural Eftate.

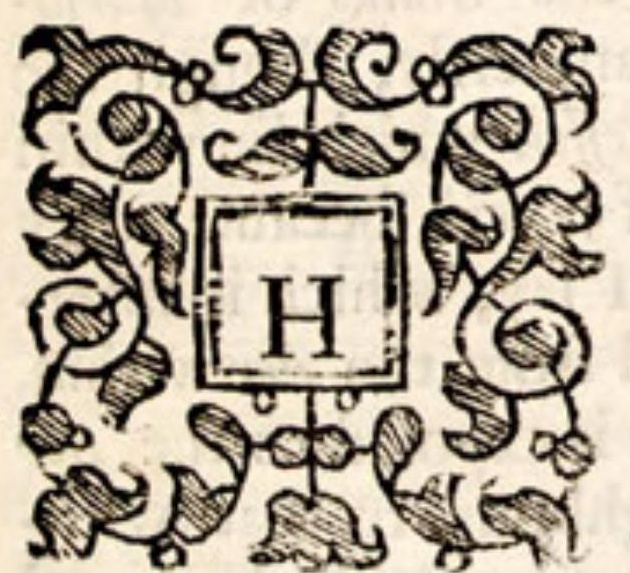

A V I NG formerly made fome Obfervations of the Colours of Plants; I thall now crave leave to Idea, 5.27 . add fome more to them of the like Nature. None of R.P. 2 . of which, nor any of the Conclufions thence deduced, will, if duly confidered, appear contrary to $6.65,8 \times c$ the Hypothefis and Experiments of Mr. Boyle, Mr. Des Cartes, Mr. Hook, Mr. Newton, or any other. concerning Colours. As not having refpect to the Colours of all Bodies in general. Nor to the Body of Colour, which is Light; Nor to the formal notion of Colours (ad extra) as the Rays of Light are moved or mixed: But to thofe Materials, which are principally necefiary to their Production in Plants. Concerning which, the prefent Difcourfe fhall be reduced to thefe Three general Heads, foil.

2. 6 . 
2. \$. Firft, Of thofe feveral Colours, which appear in Plants in their 3. 5. Secondly, As they appear upon the Infufion of Plants into
feveral Sorts of Liquors.

4. \$. Thirdly, As upon the Mixture of thofe Infufions, or of any one of them with fome other Liquor, or other Body.

5. 6. As they appear in the Plants themfelves, it may be obferved in the firft place, That there is a far lefs variety in the Colours of Roots, than of the other Parts: the Parenchyma being, within the Skin, ufu-

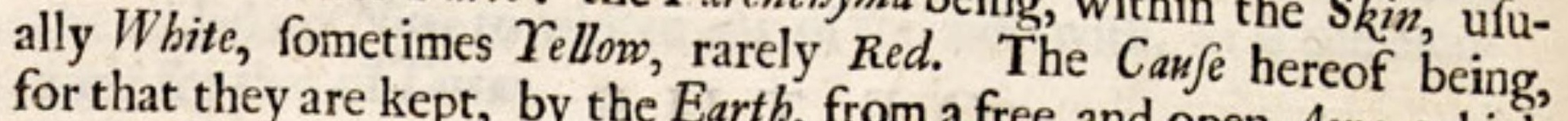
for that they are kept, by the Earth, from a free and open Aer; which concurreth with the fuyces of the feveral Parts, to the Production of their feveral Colours. And therefore the upper parts of Roots, when they happen to ftand naked above the Ground, are often deyed with feveral Colours : fo the tops of sorrel Roots will turn Red,thofe of Mul. len, Turneps and Radifhes, will turn purple, and many others green. Whereas thofe parts of the fame Roots which lie more under Ground,
are commonly White. 6. 6. As Roots are moft commonly White; fo the Leaves, Green.
Which Colour is fo proper to them, that many Leaves, as thofe of Sage,
the young sprouts of St. Fohns-mort the young sprouts of St. Fobns-wort, and others, which are Redifi when in the Bud; upon their full Growth, acquire a perfect Green.

7. 6. The Canfe of this Colour, is the action of the Aer, both from within, and from without the Plant, upon the Fuyces thereof, where-
by it ftrikes them into that $C_{\text {olour. }}$

8. \$. By the Aer from without, I mean that which furrounds the Body of the Plant: which is the Caufe of its Greenefs, not meerly as it is contiguous to it, but as it penetrates through the Pores of the $S$ kin, thereinto; and fo mixing with the Fuyces thereof, plainly deys
or ftrikes them into a Green.

9. \$. By the Aer from within, I mean, that which entring, together with the Aliment, at the Root, thence afcends by the Aer-Vefels, into the Trunk and Leaves, and is there transfufed into all the feveral Fuyces, thereby likewife concurring to their Verdure. Whence it is, that the Parts of Plants which lie under Water, are Green, as well as thofe which ftand above it ; becaufe, though the ambient Aer, conteined in the $W$ ater be but little, yet the want of it is compenfated, by that
which afcends from the Root.

I0. 6. And therefore it is obfervable, that the stalks of Mar/hMallow, and fome other Plants, being cut tranfverfly, thougin the Parenchyma in the Barque be white, yet the Sap-Veffels which lie within that Parenchyma, are as Green as the shin it felf; fcil. becaufe they ftand clofe to the Aer-Veffels. The Parenchyma, I fay, which is intercepted from the Aer, without, by the Skin; and from the Aer within, by the sap.VefJels, is white: but the $S k i n$, which is expofed to the Aer without, and the Sap-Vessels which are next neighbours to that within, are both equally Green. So likewife if a Carrot be plucked up, and fuffered to lie fometime in the open Aer; that part which ftandeth in and near the Centre, amongft the Aer-Veffels, will become Green as well as the $s$ kin, all theother Parts continuing of a Redifh $\Upsilon_{e} l l o w$, as before. The Aer therefore, both from without, and from within the Plant, together with the Fuyces of the Plant, are all the concurrent Caujes of its II. 6. 
I I. 6. B U T how doth the Aer concur to the Greenefs of Plants? I anfwer; Not as it is meerly either cold or dry, or moift, nor yet qudtenus Aer; but as it is a mixed, and particularly, a Saline Body: that is, as there is a confiderable quantity of Suline Parts mixed with thofe which are properly Aereal. It being plain from manifold Experience; That the feveral kinds of Salts, are the grand Agents in the Variation of Colours. So that, to fpeak ftrictly, although Sulpbur be indeed the Female, or Materia fubftrata, of all Colours; yet Salt is the Male or Prime Agent, by which the Sulphur is determined to the Production of one Colour, and not of another.

12. 5. If then it be the Aer mixed with the Fuyces of a Plant, and the Salt of the Aer, that makes it Green; It may further be asked, what kind of Salt ? But this is more hard to judge of. Yet it feemeth, that it is not an Acid, but a Subalkaline Salt; or at leaft fome Salt which is different from a fimple Acid, and hath an Affinity with Alkalies.

13. 5. One reafon why I fo judge, is, Becaufe that although all Plants yield an Alkaly, or other Salt different from an Acid, and fome in good quantity; yet in moft Plants, the Predominant Principle is an Acid. So that the Supply of an Acid Principle from the Aer, for the Production of a Green Colour, as it would be fuperfluous; So alfo ineffectual : a different Principle being requifite to the ftriking of this, together with the Sulphur, into a Green Colour.

14. 5. I fuppofe therefore, That not only Green, but all the $C_{0}$ lours of Plants, are a kind of Precipitate, refulting from the concurrence of the Saline Parts of the Aer, with the Saline and Sulphurious Parts of the Plant; and that the Subalkaline, or other like Saline Part of the Aer, is concurrent with the Acid and Sulphurious Parts of Plants, for the Production of their Verdure; that is, as they ftrike altogether into a Green Precipitate. Which alfo feemeth to be confirmed by divers Experiments hereafter mentioned.

15. 6. THE Colours of Flowers are various; differing therein not only from the Leaf, but one from another. Yet all feem to depend upon the general $C_{a u f e s}$ aforefaid. And therefore the Colours of Flowers, as well as of Leaves, to refult not folely from the Contents of the Plant, but from the concurrence likewife of the ambient Aer. Hence it is, that as they gradually open, and are expofed to the Aer, they fill either acquire, or change their Colour : no Flower having its proper Colour in the Bud, (though it be then perfectly formed) but only when it is expanded. So the Purple Flower of Stock-July Flowers, while they are in the Bud, are white, or pale. So Butchelors Buttons, Blew Bottle, Poppy, Red Daifies, and many others, though of divers Colours when blown, yet are all wobite in the Bud. And many Flowers do thus change their Colours thrice fucceffively; as the youngeft Buds of Ladys-Lookinglafs, Buglofs and the like, are all white, the larger Buds are purple or murrey, and the open Flowers, blew: according as they come ftill neerer, and are longer expofed, to the Aer.

16. 5. But if the colour of the Flower dependeth on the ambient Aer; it may be asked: How it comes to pafs then, that this Colour is various, and not one, and that one, a Green? that is to fay that all Flowers are not Green, as well as the Leaves? In anfwer to this Three things are to be premifed. 
17. 6. Firft, What was faid before, is to be remembred, that here the Aer is not a folitary, but concurrent Canfe. So that befides the Efficacy of this, we are to confider that of the feveral parts of the Plant, by which the Contents both Aereal and Liquid are fupplied to the Flower.

18. \$. Secondly, That in the Lympheduds of a Plant, Sulphur is the predominant Principle, and much more abounding than in any other part of a Plant, as alfo hath been formerly fhewed.

19. 5. Thirdly, That it appears, according to what we have obferved in the Anatomy of the Flower, That the quantity of Lymphaducts with refpect to the Aer-Veffels is greater in the Flower than in the Leaf.

20. 5. It femeth therefore, that the Aer-Veffels, and therefore the Aer, being predominant in the Leaf; Green, is therein alfo the predodominant Colour. I fay predominant, becaufe there are other Colours lye vailed under the Green, even in the Leafe, as will hereafter appear more manifeft.

2I. \$. On the contrary, the Lympheducts, and therefore the sulplour, being more, and the Aer-Veffels and therefore the Aer, lefs, in the Flower than in the Leaf; the ambient Aer alone is not able to controle the Sulphur fo far, but that it generally carrys the greateft port in the Production of the Colour. Yet in different degrees; For if the proportion betwixt the Lympheducts and the Aer-VefJels be more equal, the Flower is either White or elfe Yellow, which latter Colour is the next of kin to a Green. If the Sulpkur be fomewhat predominant, the Flower will thew it felf Red at firft; but the ambient Aer hath fo much power upon it, as gradually to turn the Red into a Blew. But if the Sulphur be much predominant, then the Acid of the ambient Aer will heighten it to a fixed Red.

22. Hence it is, that $Y_{\text {ellows }}$ and Greens are lefs alterable, upon the drying of Plants than other Colours; $f c$. Becaufe the Aer being predominant in their Production, they are the lefs lyable to fuffer from it afterwards. Whereas Reds and Purples, in the Production whereof Sulphur is predominant, are very changeable. So the Red Flowers of Lyfimacbia, upon drying, turn Purple, and the young purple Flowers of glofs turn Blew. Solikewife the Purple of Bilberries, and the Crimfon of baked Damafcens, both turn Blew. For being gathered, and fo wanting a continued fupply of frefh Sulphur, to bear up the Colour againft the force of the Aer; it ftrikes it down at laft from Red to purple or Blew. I conclude therefore, that one Principal Caufe of the Variety of Colours in the Flower, is the over proportion of the Lympheducts to the Aer-Veffels, and therefore the dominion of the Sulphur over the Aer, therein.

23. 5. If it be objected, that the Aer doth not deepen, but highten the Colour of the Blood: I anfwer, Firft, That I am not now fpeaking

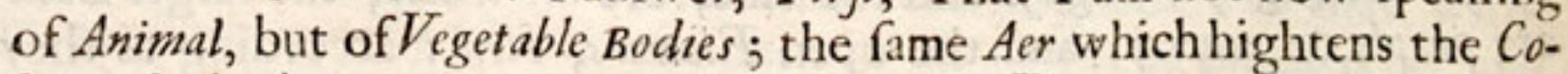
lour of Blood one way, may deepen that of a Flower, another: nay and may highten that of fome Flowers too, fome other way.

24. §. And therefore, Secondly, it is to be confidered, That as there is not one only, but divers Saline Principles in the Aer; fo are there alfo in the feveral Parts of one Plant; as in the Root, of one fort ; in the Leavs, of another; in the Flower, of another; and fo in the other Parts. For fince the Figuration of the Parts of a Plant dependeth 
chiefly upon the Saline Principles: and that the Flower hath a different Figure from that of the Leaf: it follows, that there is fome Saline Principle in the one, which is not in the other, efpecially, all in fuch Flowers, whofe Figures are cut out by a greater Variety and Complication of Lines. The Leavs therefore, though varioufly fhaped, yet agrecing fo far in one common Figure, as ufualy to be flat; it therefore feemeth plain, that there is a Saline Principle in them all, fo far one, as to be the chief Caufe of that common Figure: and in concurrence with the ambient Aer, to be likewife the chief $C a u f e$ of one common Colour, $f c$. a Green.

25. 6. Whereas the Figure of the Flowers, and therefore their Saline Principle, being more various, and commonly diftinct from that of the Leaf; it will eafily concur with as a great Variety of Salts in the Aer, whether Acid, Alkaline, Nitrous, Urinous, Armoniacal, of any other therein exiftent, to the Precipitation of the Sulphur into the like Variety of Colours. Thus far of the Colours of Plants as they appear in their Natural Eftate.

\section{H A P. II.}

\section{Of the COLOVRS of Plants by Infufion.}

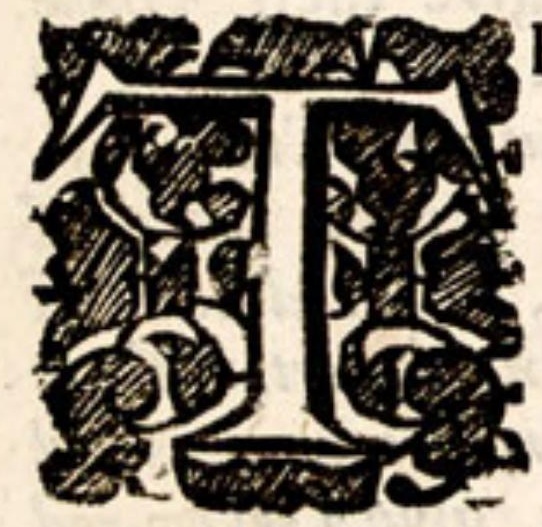

H E next general Inquiry, propofed to be made, was this, After what manner the Colours of Plants thew themfelves, upon their infufion into Liquors. The $\mathrm{Li}$ quors I made ufe of for this purpofe, were three, $f c$. Oyl of Olives, Water, and spirit of Wine. The Water I ufed was from the Thames, becaufe I could not procure any clear Rain Water, and had not leafure at prefent to diftill any. But next to this, that yields as little Salt, as any.

2. 5. As for $O y l$, it is known, that molt Plants either by Coction or long Infufion, will give it their Green Colour. I have likewife tryed fome $Y_{e} l l o w s$, and find they will do indifferently well; as Saffron, which, by Infufion in $O y l$, gives it a light golden Tincture.

3. 5. Divers Aromatick Plants, as Mint, Majorane, \&c. being dryed and infufed in $O y l$ give it a double Tincture, both green and yellow; one drop of the $O y l$ fhewing green; but a good quantity of it held up againft a candle looketh redifh or of a deep yellow.

4. \$. But there is no Vegetable yet known which gives a true Red to oyl, except Alkanet Root: with which, fome colouring either common or other $O y l$, vend it under the name of the Red Oyl of Scorpions.

5. 6. Thefe things confirm what we have faid concerning the $C_{a u}$ fes of Colours in the Leavs and Flowers of Plants, upon this twofold Confideration. First, that $O_{y} l$ is the moft proper Menstrumm of Sulphur. Secondly, that Oyls have a greater congruity with Acids than with Alkalies; as I have formerly fhewed. 
6. \$. I fay therefore, that in Blews, Purples and efpecially Reds, the predominant Principles being Sulphur and Acid, the Oyl either abftracts the Sulphur of it felf, or at leaft, unlocks it from the Acid Parts; whereby both of them are beftowed feperately to their like parts in the $O y l$; upon which their difunion the Colour vanifhes: that depending, not upon either of them alone, which of themfelves are $C_{o}$ lourle $\int_{s}$, but upon both united together.

7. 6. On the contrary, a Green Colour not depending on a pre. dominant Acid, but an Alkaly, or fome Saline Principle different from an Acid; this will not fo eafiely be imbibed feparately, into the Pores of the oyl, but only by mediation of their Sulphur. So that being both imbibed without any difunion, they ftill retein the fame green Colour they
had before in the Plant.

8. 6. Hence alfo it is, that red Rojes being dryed and infufed fome time in Oyl of Anije Seeds, a more potent Menftruum than Common Oyl; they wholly lofe their own Colour, and turn mbite; the $O y l$ remaining Limpid, as at the firft. That is the Sulphur or that part of it on which cheifly the Red depended, is abforbed feparately by the $O_{j} l$, and
fo the Colour vanifhes.

9. 6. A SECOND Menftruum I made ufe of, was Water. And Firft, Alkinet Root, which immediately tinctures $O f l$ with a deeper Red,
will not colour Water in the leaft.

I0. 5. Next it is obfervable

of plants in Infufon excer the Colours fuflon give a perfect Blew to $0 y l$; which, by Infufion will give a perfect Green is none, that I know of,

Colour, by Infulion in Water well as the Flowors themfelves give a Tincture no higher than to refemble Rbenifs of Cinquefoyl, give a Tincture no higher than to refemble Rbenifs wine; thofe of HyJop, Canary; of Strawberrey, Malaga; of Mint, Mufcadine; of Wood-Sorrel, Water and fome drops of Claret; of Blood-poort, Water and a dafh of Claret; and thofe of Bawm make a Tincture near as red as ordinary Claret alone. All Aromatick hot Plants, give a yellow-red Tincture, or colorem ex luteo rubrum. All Plants with a yellow Flower give either a pale citrine or yellowifl Tincture; and the like. Yet all give not their Tincture in the fame fpace of time; fome requiring a fortnight, others a week, others five, three or two days, and fome but one, or half a day. From hence it appears, that the Colours of molt Flowers are begun in the Leavs; only Green being therein the predominant Colour, as a veil fpred over them, conceils all the reft. But paffing on into the Flower, where the Aer-Veffels, as is aforefaid, are under the dominion of the Lymphaductss they fhew themfelves
diftinctly.

12. \$. A THIRD and the laft Menfrunm I made ufe of, was spirit of Wine. And here it is to be remarqued; That as $O_{y} l$ rarely takes a Red, there being but one known Inftance of it; nor Water, a Green: So neither spirit of Wine, a Blew. I have tryed with feveral blew Flowers, as of Lark-heel, Violet, Mallows, Burrage, and others, whereof it will not take the leaft Tincture.

13. 5. Again though no Blew Flowers, that I know of, will give a Blew Tincture to Spirit of Wine: yet having been for fome days iufufed 
Lect. $\mathbf{V}$.

$$
\text { of Plants. }
$$

in the faid spirit, and the spirit ftill remaining in a manner Limpid, and void of the leaft Ray of Blew; if you drop into it a little Spirit of Sulpbur, it is fomewhat fnrprizing to fee, that it immediately ftrikes it into a full Red, as if it had been Blew before: and fo, if you drop Spirit of Sal Armoniac or other Alkaly upon it, it prefently ftrikes it Green. Which further confirms what have been before faid of the $C$ ats fes of Vegetable Colours.

14. \&. It is alfo obfervable, That the Green Leaves of Bamm, which give a Mufcadine Red, with fome Rays of Claret, to Water, gives a pure and perfect Green to Spirit of Wine: and is the only Plani of all that I have yet tryed, which doth the like.

15. 6. It is likewife to be noted, That both Yellow and Red Flowers give a ftronger and fuller. Tincture to Water, than to spirit of Wine; as in the Tinctures of Comslip, Poppys, Clove-Fuly-Flowers and Rojes, made both in Water and spirit of Wine, and compared together, is eafily feen. So that for Tinctures made with Flowers, whether for $M_{e}$ dicines, or other purpofes, Water, with refpect to the Colour, is the better Menfrum. I fay for Tinctures made with Flowers; for there are fome other Paris, efpecially Gumms, as Gamboja, Myrrb and Alocs, which give their Tinctures full and clear, only to spirit of Wine. Some of which are ufed by Leather-Gilders, and others, for the wafhing over of Silver, fo as to give it the Colour of Gold. Thus far of the Colours of Plants as they appear upon Infufion.

\section{H A P. III.}

\section{Of the COLOVRS of Plants produced by their Mixture with other Bodies.}

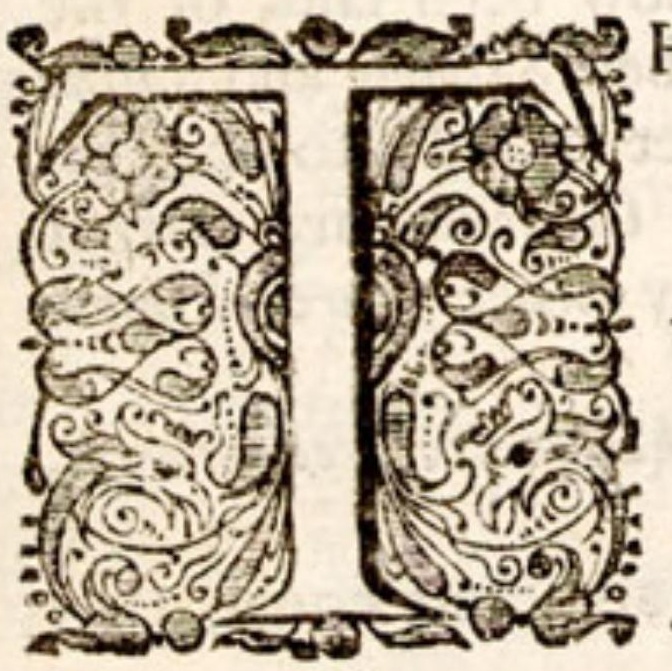

$\mathrm{H}$ E laft general Enquiry propofed to be made, was this, After what manner they would exhibite themfelves upon the Mixture of thofe Infufions, or of any one of them with fome other Liquor.

2. 6. A frrong Infufion, or the Fuyce of the Leavs of Rofe-Tree, Rajpis, Strawberry, Cynquefoyle, Goosberry, Primrofe, Ferufalem Comflip, Bearfeare, Bearsfoot, Peony, Bistort, Lawrel, Goats-beard, droped upon Steel, make a Purple Tindure. But that of $V_{i n e}$ Leaves fearce maketh any Tincture at all. So that there is fomething elfe befides Somernefs concurring to the Purple upon Steel.

3. \$. Saccharum Saturni droped on a Tincture of Red Rofes, turneth it to a faint pale Green.

4. 5. Salt of Tartar droped upon the fame Tincture, turneth it to a deeper Green. 
5. 6. Spirit of Harts Horn droped upon a Tincture of the Flower of Lark-heel and Borage turn them to a verdegreefe Green.

6. 5. Spirit of Harts Horn droped on moft green Leavs doth not change them at all. The like Effects have $A q$. Calcis, and spirit of
$S$. Armoniac.

7. 6. Thefe Experiments feem to confirm, That it is fome Alkaline or other like Salt in the Aer, which is predominant in the production
of Green in the Leavs of Plants.

8. 6. Salt of Tartar droped on the white Flowers of Daify, changeth them into a light Green. Which as it further confirms the aforefaid Pofition; folikewife argues, That Whitenefs in Flowers, is not always from the defect of Tincture: but that there may be White, as well as Yellow, Green, Red or Blew Tinctures.

9. \$. Spirit of Sulphur droped on the green Leavs of Adonis Flower, Everlasting Peafe, and Holy Oak, turns them all Yellow.

Ic. \$. Spirit of Sulphur on a Tincture of Saffron changeth it not.

II. \$. Spirit of Sulphur on the Yellow Flower of Crowfoot alters them not. Neither are they changed by the Affufion of Alkalies.

1 2. 5. So that it feemeth, that in all Yellows, the Sulpbureous Acid and Alkaline Parts are all more equal.

13. 6. Spirit of sulphur on a Tincture of Violets turns it from Blew to a true Lacke, or midle Crimfon.

14. \$. Spirit of Sulphur upon a Tincture of Clove-fuly-Flowers makes a bright blood Red. Into the like Colour, it hightens a Tincture of Red Rojes.

15. 5. So that as Alkalys, or other Analogous Salts, are predominant in Greens, fo Acids in Reds, efpecially in the brighter Reds, in the Leavs and Flowers of Plants. Hence it is, that Spirit of Nitre droped upon the Blew Flower of Ladies Looking-Glafs, Larkspur, Borage, turns them all Red, $f$ c. into the Red of Common Lychnis. But (which is particularly to be noted) being droped on the faid Red Flowers of Lychnis, alters them little or nothing: becaufe, that very Colour is therein produced by a copious admixture of the like Principle.

I6. 5. The Summ therefore of what bath now been faid, of the Canfes of Vegetable Colours, is this: That while their Sulphur and saline Principles, only fwim together, and are not as yet united into one Precipitate, no Colour refults from them, but the Contents are rather Limpid; as ufually in the Root, and many other Parenchymows
Parts.

17. 6. When they are united, and the Alkaline are predominant, they produce a Green. 18. 5. When the Sulpbur and the Alkaline are more equal, they
produce a Tauny.

19. \$. When the Sulpbur, Acid and Alkaline, there a Yellow.

20.5. When the Sulpbur predominant, and the Acid and Alkaline equal, there a Blew.

21. 6. When the Sulpbur and Acid are predominant to the Alkaline, then a purple.

22. 5. When the Sulphurpredominant to the Alkaline and the Acid to them both, a Scarlet. 
23. \$. Laftly, When the Acidpredominant to the Alkaline, and the Sulpbur to them both, a Blood-Red: which is the higheft and molt Sulphurious Colour in Nature.

24. 6. From the Premijes, divers Rules do alfo refult for the making of Tindures, either for Medicines, or for any other purpofes.

25. 6. I thall only add one or two Notes. As firft, that of all Colours, Yellows are the moft fixed and unfading. As for inftance, if you drop either a Solution of Tartar, or of Spirit of Sulpbur upon a Tincture of the rellow Flowers of Crowfoot, of Adonis, or of Saffron, neither of them will alter their Colour. Which thewes the ftrength of moft Yellows, to refift all manner of impreffions from the Aer.

26. 5. Again, that the ufe of Salts, is not only to highten or deepen Colours, but alfo to fix and make them permanent. As for Inftance, The Tindure of Clove-Fuly-Flowers, made either with Water or Spirit of Wine being expofed to the Aer, will often turn into a Blackifh Purple. But the addition of a few drops of Spirit of Sulphur, doth not only highten the Colour, but renders it ftable and permanent.

27. 6. Likewife, of Salts themfelves there is choice to be made. For there are fome, which although they fix the Colour, yet, will a little give, as we fay, and not hold throughly dry; as moft Lixivial Salts, and Stillatious Acids. But there are fome salts, which will not give in the leaft, as Alum, that in Lime-Water and fome others; which latter, is fo far from being moyftened, that it is rather petrified by the Aer. For which reafon I take it to be one of the beft Liquors for a ftable and permanent Green, and fome other Colours.

28. 5. Amongft all Water-Colours, the rareft, and moft difficult to make clear bright and permanent, is a Blew. There are many Flowers of an excellent Blew, as thofe of Bugloss, Lark-beel and others; but they eafily fade. And there are very few Flowers that will frrike into a Blew by any Liquor; being almoft all changeable into Green, Purple or Red. Yet fome few there are, in which this Colour may be produced. As for inftance, the Flower of Latbyrus or Parfeverlafting; which upon the affufion of Spirit of Harts-Horn is changed from a Peach, to as pure a Blem, as the beft Ultramarine : that which hitherto is, 1 think, wanting in Water Colours. Spirit of Harts Horn was the Liquor I ufed; but I queftion not, but that other.Alkalies, and particularly Lime-Water, will have the like Effect, and fo render it the
more ftable.

29. 5. From what hath been faid, we may likewife be confirmed in the ufe of the already known Rules, and directed unto others yet unknown, in order to the variation of the Colours of Flowers in their Growth. The effecting of this, by putting the Colour defired in the Flower, into the Body or Root of the Plant, is vainly talked of by fome: being fuch a piece of cunning, as for the obteining a painted face, to eat good ftore of white and Red Lead.

30. 5. The beft known Rules are thefe Two; Firft, that the Seed be ufed above any other part, if the variation of the Colour be intended. One reafon whereof is, becaufe that part being but very fmall, the Tinctures of the Soyl will have the greater over proportion to thofe of the seed. Befides, the tender and Virgin Seed, being committed to the Soyl, will more eafily take any peculiar Tincture from it, then an 


\section{8

other Part, which is not fo fufceptive, and hath been tinctur'd already. All the ftrange varieties in Carnations, Tulips, and other Flowers are made this way.

31. 5. The other Rule is, To change the Soyl, or frequently to tranfplant from one Bed to another. By which means, the Plant, is as it were, fuperimpregnated with feveral Tindures, which are prolifick of feveral Colours; which way is taken for Roots and Slips.

32. \$. The confideration whereof, and of the foregoing Experiments, may direct us not only in changing the Bed, but alfo in compounding the Soyl, as by mixing fuch and fuch Salts, or Bodies impregnated with fuch Salts, I fay by mixing thefe Bodies in fuch a proportion, with the $s o y l$, as although they have no Colour in themfelves, yet may be effectual to produce a great variety of Colours in the Plants they nourifh; fupplying the Plants with fuch Tinctsres, as thall concur with the Aer, to ftrike or precipitate their Sulpbur into fo many feveral Colours, after the manner above explicated: and fo to bring even Natures Art of Painting, in a great part, into our own power. 


\section{A \\ D I S C O U R S E \\ $\mathrm{O}$ F $\mathrm{TH} \mathrm{E}$}

DIVERSITIES and CAUSES

$\mathrm{O} F$

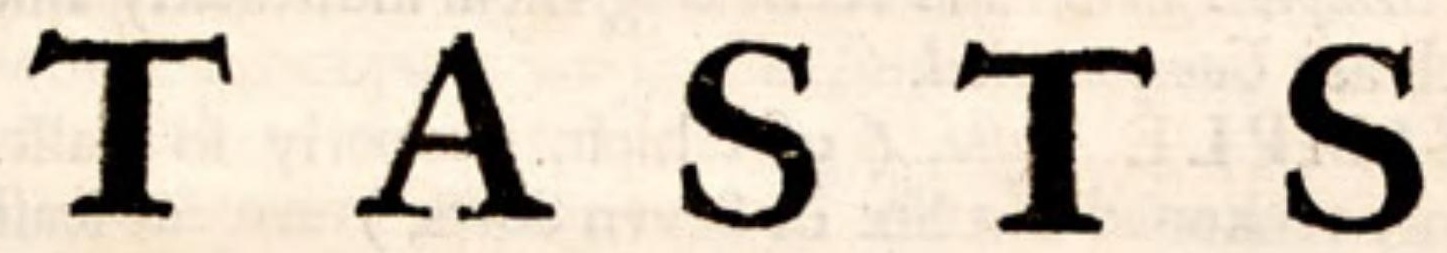

CHIEFL Y IN

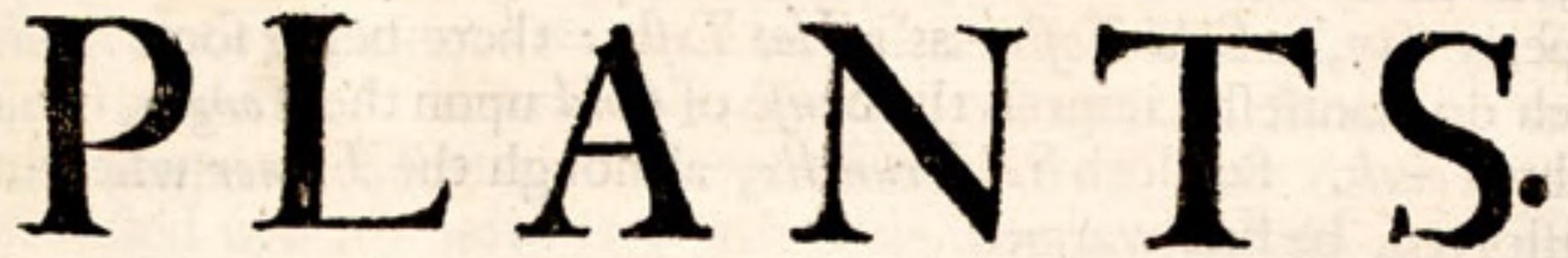

Read before the Royal Society, Marcb 25. 1675.

\section{CH A P. I.}

Of the feveral Sorts of SIMPLE and COMPOUN. $D E D$ Tafts; and the DEGREES of both.

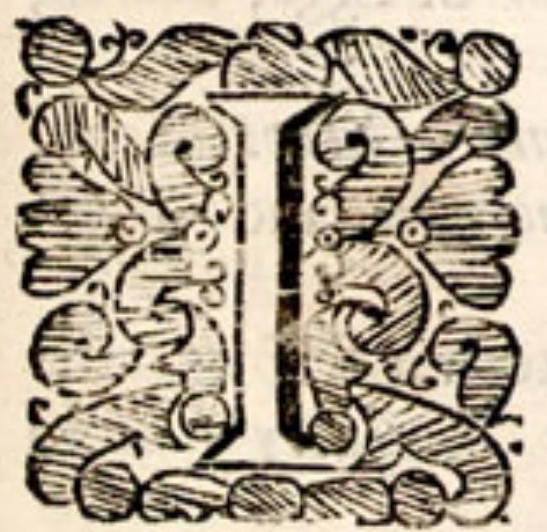

H A V E formerly publifhed fome Notes, concerning Tafts. Since then, I have made other Obferva- Idea, \$.29. tions upon the fame Subject: dive- of R. P.x. duced further Thoughts. I will fumm up all in giveing an account, Firft, of the Diverfities; and then, $5.68, \& c_{\text {。 }}$ of the Caujes of Tafts, chiefly in Plants.

2. \$. The Diverfities of Tafts are fo many, and fo confidcrable; that it feemeth ftrange, to fee the matter treated of both by Philofophers and Phyficians, with fo much fantnefs and defect. For the subject is not barren, but yieldeth much and pleafant Variety. And doth alfo appear to be of great import unto Medicine. Befides, it is prepofterous to difcourfe of the Caufes of Tafts, before we have taken an account of their Diver/ities; Whereof therefore I thall in the firft place, exhibit the following Scheme. 
3. 6. T A S T S may be difinguifhed by thefe Three general ways. Firft, with refpect to the Senfation it felf. Secondly, with refpect to its Duration and Terms. Thirdly, with refpect to its Subject.

4. 6. The Senfation it felf is differenced two ways, by its Species, and by its Degrees. With refpect to the Species, Tafts are simple, or Compounded. By Simple Tafts, I mean not fuch, as are never found in conjunction with other Tafts: but the Simple or Single Modes of Tast, although they are mixed with divers others in the fame Body. As for example, the Tafte of a Peppin, is Acidulcis; of Rbubarb, Amaraftringens; and therefore Compounded in both. Yet in the Peppin, the $A$. cid is one Simple Tafte, and the Sweet another; and fo in Rbubarb, the Bitter is one Simple Tafte, and the Aftringent is another.

5. 5. Two faults have here been committed; the defective Enumeration of Simple Tafts; and reckoning them indiftinctly among rome others which are Compounded.

6. §. S I MPLE Tafts, ( of which, properly fo called, there are commonly reckoned but Six or Seven Sorts, ) are, at leaft Sixteen. Fift,Bitter, as in Wormwood: to which, the contrary is Sweet, as in Sugar. Thirdly, Sower, as inVinegar: to which, the contrary is Salt. Fifthly, Hot, as in Cloves: whereto, the contrary is Cold. For we may as properly fay, a Cold Tafte, as a Hot Tafte : there being fome Bodies, which do manifeftly imprefs the Senfe of Cold upon the Tongue, though not by Touch. So doth Sal Prunelle, although the Liquor wherein it is diffolved, be firft warmed.

7. 6. Seventbly, Aromatick. For it doth not more properly agree to an Odour, than a Tafte, to be Aromatick. And that an Aromatick. Tafte, is dinftinct from an Hot, is clear; In that, there are many Bodies of a Hot Tafte, fome meanly and others vehemently $\mathrm{H}_{0}$; which yet are not in the leaft Aromatick: as amongft others, is apparent in Euphorbium. So that although an Aromatick Tafte be often conjoyned with Heat; yet it is not that Heat it felf, but another dinftinct Senfe.

8. \$. Eighthly, Naufeous or Malignant, contrary to the former. Such as is perceived, together with the Aftringent and Bitter, in Rbubarb; or with the Bitter, and Sweet, in Aloes. It may be called Malignant, becaufe diftaftul although mixed in a low degree with other Tafts: whereas other Tafts will render one another grateful.

9. 5. Again, Tafts may properly be faid, to be Soft or Hard. A Soft Tafte, is either Vapid, as in Watery Bodies, Whites of Eggs, Starch, Fine Boles, \&c. Or Unctuous, as in Oyls, Fat, \&c.

10. §. A Hard Tafte is Fourfold, $f c$. Penetrant, Stufifacient, Aftringent, Pungent. Contrary to a Vapid, are Penetrant and Stupifacient.

I I. \& Penetrant, is a kind of Tafte, which worketh it felf into the Tongue (as fome Infects into the Skin) without any Pungency; as in the Root and Leavs of Wild Cucumer.

12. \$. Stupifacient, as in the Root of Black Hellebore. Which being chew'd, and for fometime reteined upon the Tongue; after a few minutes, it feemeth to be benum'd and affected with a kind of Paralytick Stupor; or as when it hath been a little burnt with eating or fupping of any thing too hot.

13. 5. Contrary to an Unctuous Tafte, are Aftringent, and Pun$g^{e n t}$; as in Galls, and spirit of Sal Aromanick. 


\section{Lect. VI.}

of Tafts.

14. 6. Again, Tasts are either Continual, as molt commonly: or Intermittent; as that of Dracontium, efpecially in the Root. For after it feems to be loft and extinguifhed; it will then again (chiefly upon the Collifion of the Tongue and Goomes) be plainly heightened and reviv'd.

15. 5. Lafly, Tafts are either Still, as ufually ; or may be called Tremulous, as the Heat produced by Pyretbrum. Diftinct from that of Cloves, Ginger, and many other Hot Bodies, in that there the Heat is ftill; but here in Pyrethrum, "tis joyned with a kind of Vilration: as when a Flame is brandifhed with a Lamp-Furnace. Thus far of the Sorts of simple Tafts.

16. 6. COM PO U NDE D Tafts are very numerous; being made by the various Cowjundtion of simple Tafts, as Words are of Letters. Sometimes of two, as in Saccbarnin Saturni, of Aftringent and Sweet. Sometimes three, as in Aloes, Malignant, Eitter and Sweet; in Rbubarb, Malignant, Aftringent and Bitter. Sometimes four, as in Agarick, Malignant, Aftringent, Bitter and Sweet. And in fome Bodies, five or fix Species may be joyned together.

17. 6. For the more accurate $\mathrm{Obfervation}$ whereof, there are thefe eafie Rules. That not too many be tafted at one time: leaft the Tongue being furcharged, become lefs critical. That the Mouth be wafhed with warm water betwixt every tafting. And that thofe things be firft tafted which producc a lefs durable Tafte; that fo one may be throughly extinguifhed, before another be try'd.

18. \$. Of the numerous Conjunctions of Tafts, which may thus be obferved, there are only Six to which the penury of Language hath allowed (if I may call them) Proper Nanes, fc. Acerbus, Aufterus, Acris, Muriaticus, Lixivas \& Nitrofus. Moft of which are commonly taken in to make up the number of Simple Tafts. But very improperly; being all of them Compounded and Decompounded Tafts: to which Class they ought therefore to be refer'd. For

19. S. Auftere, is Aftringent and Bitter; as in the green and foft Stones of Grapes.

20. 5. Acerb, properly fo called, is Astringent and Acid; as in the Fuyce of unripe Grapes.

2I. 6. Acris, is alfo Compounded. For firft, fimply Hot, it is not: becaufe there are many Hot Bodies, which are not Acria; as the Roots of Zedoary, Yarrow, Contrayerva. Nor Secondly, is it fimply Pungent, becaufe there are alfo Bodies, which are Non-acria pungentia; of which kind is the Root of Arum. Wherefore Acritude, is Pungency joyned with Heat.

22. \$. Muriatick, is Salmess joyned with fome Pungency, as in common Salt.

23. 5. Lixivial, is Saltnefs joyned with Pungency and Heat

24. \$. Nitrous, is Saltnefs joyned with Pungency and Cold.

25. \$. Befides thefe Six, or perhaps one or two more, there are, as is faid, a great number of Conjudtions, for which we have no Prow per Names. For admit that there were but Ten species of Simple Tafts, fc. thefe Ten; Amarus, Dulcis, Acidus, saljus, Calidus, Frigidus, Aro. maticus, Malignus, Aftringens, Pungens. And of thefe Ten, but Troo, or at moft, but Three to be compounded together in any one Body. If only Two, they produce 45 Componnded Tafts. For the Firft, may 
be compounded with all the 9 following; the Second, with all the 8 following; and fo, the reft: which together make 45 . But if the fame Ten be compounded by Threes together; they produce no lefs than 120 Variations: as by the Table made of them all doth plainly appear.

25. 5. Some few of the Conjundions therein fet down, may not be found actually exiftent in Nature. The abatement of which, will be much more than compenfated two ways. Firft, by the other Six species of simple Tafts, which are alfo fometimes compounded. And by other more complex Conjunctions, as of many Quadruples, and perhaps fome 2uintuple or Sextuple ones. Thus far of the Simple Species, and Conjundtions of Tafts.

27. 5. THE DEGREES of Tafts are alfo numerous; and each species, in every Conjunttion, capable of Variation herein. For the more accurate obferving whereof, it will be beft, To take thofe Bodies, whofe Tafts are, as near as may be, the fame in specie : and that thofe be firft tafted, which are lefs ftrong; whereby the true $D_{e}$ gree will be more precifely taken.

28. \$. The Tafts of Bodies will thus appear to be varied, in moft Species unto Five Degrees; and in fome of them, unto Ten. So the Root of Turmerick, is bitter in the Firft Degree; of Gentian, in the Tenth. The Root of Carduns Benedictus, is Hot in the Firft Degree; the Green Pods or Seed.Cafes of Clematis peregrina, in the Tenth. So that, allowing fome to vary under Five; yet by a moderate eftimate, we may reckon every Species, one with another, to be varied by at leaft Five Degrees. Which being added to the feveral Species of Tafts, in all the Treble Conjunctions of the aforefaid Table, come to 1800 fenfible and defineable Variations of Tafte. And thefe are the Diver fities of Tafte, with refpect to the senfation it felf.

\section{CHAP. II.}

\section{Of the DURATION and feveral TERMES of Tafts.}

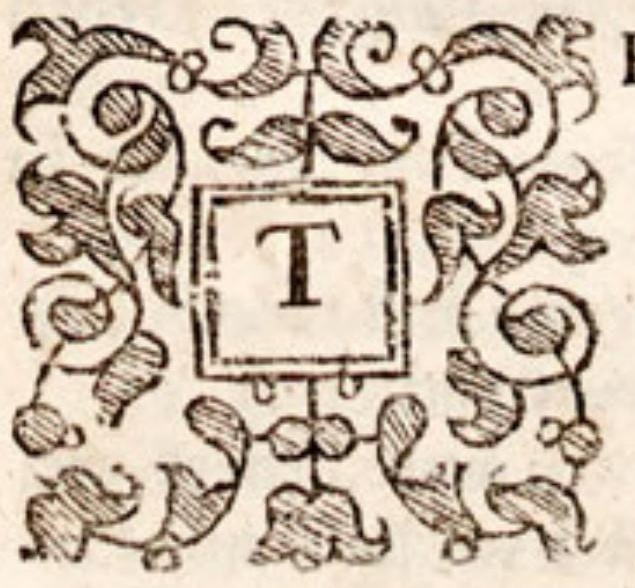

$\mathrm{HE}$ next general way of dinguifhing Tafts, is by their Duration, and their Terms, or their Motion of Intenfion and Remifjion from one Degree to another. For there are many Tasts, which have their Motions analogous to thofe of Difeafes; and by thofe may be diftinguifhed in the fame manner. For as of Difeafes, fo of Tasts, there are Four Times, as Phyficians call them, or Terms of Motion; fc. Principium, Angmentum, Status, \&. Declinatio.

2. \$. For the diftinat obferving of which, thofe Bodies which are hard, and fo their taftable parts lefs eafily extractable by the Tongue, fhould be reduced to a fine Pomder : otherwife, the true meafure of the 
Principinm will be loft. And for the precife meafuring of all the Four Termes, it fhould be done by a Minute-Watch or a Minute-Glafs. For fo it will appear, that the Variations of each, are divers and remarquable.

3. 5. To inftance firft in thofe of the Principium. Which I call, That fpace of time, betwixt the firft Contact of the Body to be tafted, and the firft manifeft Perception of the Tafie. For Example, thofe Bodies which are Acid, or Bitter, as Vinegar or Wormwood, are prefently perceiv'd, quatenus Acid or Bitter, upon the firft Contact; or have Principium breviffimum. Thofe Bodics which are Acria, have their Principium fomewhat longer. So the Seed-Cafes of clematis peregrina, although they have a vehement Acritude, even in the Tenth Degree; yet is not that Acritude fo foon tafted, as the Bitterne/s of Rofes, which is but in the fecond. But the Principium of Hot Tafts, is generally longer than that of any other. So the Bitterness of the Root of Black-Helebore, which exceedeth not the fecond Degree, is yet prefently tafted: but the Heat proceeding from the fame Root, and which afcendeth to the third Degree, is not perceived at all, till after two full Minutes. And fo the Bitterness of Enula, which exceedeth not the $4^{\text {th }}$ Degree, yet is fooner tafted than its Heat, which afcendeth to the 8 th.

4. 5. Next, in thofe of the Augment. Which I call, That fpace, betwixt the firft Perception of the Tafte, till it be come to the heighth. Sothe Heat of Galangale, is not only prefently perceived, but arifeth to the heighth within half a Minute. But the Heat of the Root of Enula, comes not to the heighth till after a whole Minute. And the Heat of Black-Hellebore, not till after four full Minutes from the firft Contact.

5. 5. The Status, or fpace wherein the Tafte continues in its heighth, is alfo divers. So the Heat of the Seed-Cafe of Helleborafter, comes to its heighth, and begins to decline within half a Minute; that of the Root of Garden-Scurvygrafs, not till after a Minute; and that of the Root of Afarum, not till after two full Minutes.

6 5. And Laftly, the Declination, or the fpace betwixt the firft Remiffion of the Tafte, and its total Extincton. For inftance, The Leavs of Millefolium, are Bitter in the $4^{\text {th }}$ Degree, and Hot only in the $\mathbf{I}^{\mathrm{ft}}$. yet the Heat continues for fometime, and the Bitter prefently vanifhes. Calamus Aromaticus, is Bitter in the $4^{\text {th }}$ Degree, Hot in the $\mathrm{I}^{\mathrm{ft}}$, and $A$ romatick in the $3^{\mathrm{d}}$ : yet the Bitter quickly vanifhes, the Heat continues two Minutes, and the Aromatick feven or eight. The Heat of the Root of Contrayerra, is extended, almoft to two Minutes; the Pungency of Falap, almoft to fix; the Heat of Garden Scurvygrafs, to feven or eight. And even the Bitteress of Wild Cucumer, to near a quarter of an hour. But the Heat of Euphorbium dureth much longer, as alfo that of Black Hellebore. $f c$. above half an hour.

7. 5. So that the Augmentum, is feldom extended beyond Four or Six Minutes, from the firft Contait: but the Declination, fometimes to Thirty, Fourty, or more. Thus far of the Terms of Taft, or the manner of their Intenfion and Remilfion.

$$
\mathrm{Tt}_{3} \quad \mathrm{CHA} \mathrm{P}_{\mathrm{d}}
$$




\section{H A P. III. \\ Of the SUBFECT or SEAT of Tafts.}

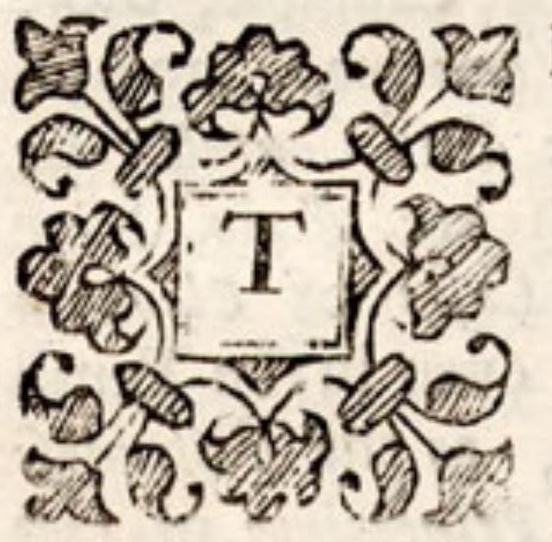

HE Tbird and Laft way of diftinguifhing Tafts, is by their Subject, or the Part or Parts where they are either wholly or chiefly perceived. And fo, Tafts are either Fixed, or Movable.

2. \$. A Fixed Tast, is that which keepeth within the compafs of fome one Part, all the time of its Duration; as upon the Tip, or the Root of the Tongue, or other Part.

3. 5. A Movable Tafte, is either Diffufive or Tranfitive.

4. 5. A Diffufive Tafte, I call that, which by degrees fpreads abroad into divers Parts, and yet in the mean time, adheres to that Part in which it is firft perceived. So the Bitternefs in the dryed Roots of Black Hellebore, is firt felt on the Tip of the Tongue; from whence it fpreads it felf to the midle of the fame. And the Bitternefs of the Leavs of Wild Cucumer, fpreads from the Tip, to the Root of the Tongue.

5. \$. A Tranfitive Tafte, is that, which after fometime, wholly quitting the Part wherein it is firft perceived, is thence transfered into fome other Part : as the Bitterness of Gentian, imediately from the Tip, to the midle of the Tongue. And moft of the Diffufive, are alfo Tranfitive.

6. 6. The feveral Parts which thefe ways become, and with fome latitude may be called, the Seats of Tafts, are, the Lips, Tongue, $\mathrm{Pa}_{a-}$ late, Throat and Gulet.

7. 6. Upon the Lips, the Root of white Hellebore, as alfo of Pyrethrum, being chewed, make a fenfible Impreffion; which continues (like the flame of a Coal betwixt in and out) for 9 or 10 Minutes. But the Heat in other Parts much longer.

8. 5. Upon the Tongue, Tafts are perceived in Three places, as - hath been intimated. On the Tip or Cone of the Tongue; as molt commonly. On or near the Bafis of the Tongue; where the Tafte of the Leavs of Wild Cucumer chiefly fixeth it felt. Or on the Vertex or midle of the Tongue; in which place it is obfervable, that the Taft of Gentian, Colocynthis, and divers other Bodies, is then confiderably ftrong, when not at all perceived at the Tip of the Tongue or in any other Part.

9. 5. Upon the Palate or Roofe of the Mouth, the Root, as I take it, of Deadly Night/bade maketh its chief Impreffion; and there continues about four Minutes in forne degree.

I0. \$. The Throat, or the Uvula, Larinx and other adjacent Parts are oftentimes the Seat of Tafte. For there are many Bodies, which although they have fearce any Taste upon the Tongue, or any other of the aforefaid Parts, yet make a ftrong Impre/fion on the Throat: as the Leavs of little Daify, little Celandine, and of Pimpinel; as alfo the Roots of falap, Mercury, Afparagus and others. Which being chewed makelittle or no Imprelfion on the Tongue, but their fuyce being fwal- 


\section{Lect. VI.}

lowed, caufeth a kind of pricking in the Throat; as when one is provoked by a tharp Rheum.

Ir. \$. And that this Tafte or Senfe, is truly diftinct from either the Heat, Pungency, or Acritude upon the Tongue, it is hence further manifeft; In that Pyrethrum, which is very Hot, and Cortex Winteranus which is very Pungent upon the Tongue; yet their Fuyce being fwallowed, caufeth no Heat, Pungency or Exafperation in the Throat.

I2. \$. Laftly, if we will take the word ( $T a f t)$ in a larger fenfe, the Oefophagus it felf may be faid to be fometimes the Subject thereof; as of the Heat produced by the Root of Common Wormwood. For of this Heat it is remarquable, that being firft perceived on the Tip of the Tongue, it thence maketh itstranfit to the Root of the Tongue, and fo into the Throat, and by degrees defcends into the very Gulet; where it feemeth to warm the Stomach; and fo continues, in fome degree, almoft $\frac{1}{4}$ of an hour. And the Tranfition and Defcent of this Heat is made, alchough none of the Fuyce be fwallowed. And in this maner

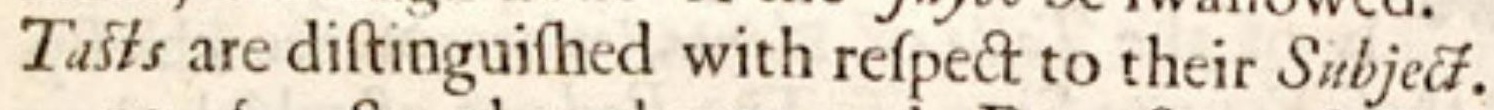

13. \$. So that the general Diverfities of Tafts are thefe. With refpect to their Species, they are Simplices vel Compofiti; To their Degree, Remiffi vel Intenfi; To their Duration, Breves vel Diuturni; To the Terms of their Motion, Celeres vel Tardi; and laftly, To their Subject, Fixi, Diffulivi \& Tranfitivi.

14. 9. I HAVE thus endeavourd to draw up a Scheme or Inventory of the feveral forts of Tafts. In which, fome may think, that I have over done: and that as Galen hath been cenfured for being too curions in the Diftindions of Pulfes; fo have I been, in thefe of Tafts. Not to enquire now, how far the Differences of the Pulfe may be extended, or be fit to be taken notice of; I flall only fay, That we have not fo much reafon to cenfure him, if he hath given us fome few which are coincident; as we have to thank him, for obferving fo many which are really diftinct.

15. 6. By the Scheme of Tasts here reprefented, we may be able, fo to enumerate the Modes of any Taft, as to make a Scientifick Definition of it. Which is pleafant Instruction to any inquifitive mind; thefe things being all matter of fenfe and demonftration; wherein lyeth, though not always the moft plaufible, yet the moft fatisfying Philofo$p h y ;$ and where men, after they are grown weary with turning round,
are oftentimes contented to reft.

16. \$. But the ufefulnefs of this Schem will further appear, in two refpects $; f$. In conducting us to a cleerer and more particular Explication of the Caufes of Tafts: and the Inveftigation of the Virtues of thofe Bodies in which they refide. Whereof in the following Chapters. 


\section{H A P. IV. \\ Of the CAUSES of Tafts.}

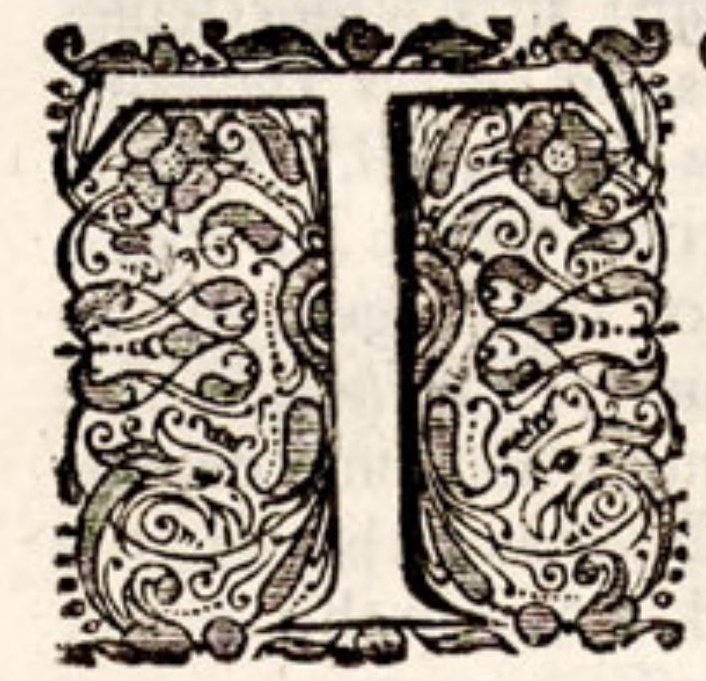

O fpeak of the Caufes of Tafts, before we have well enumerated and diftinguifhed them; is to provide Furniture for a Houfe, before the Roomes have been counted and meafured out. But the Varieties of Tafts having been firft laid down; it will induce us to believe, and invertigate as great a variety in their Caufes.

2. 6. Now the Caujes of Tafts, particularly of the Tafts of Plants, whereof we chiefly rpeak, are, in general, thefe Four or Five, $f c$. The Bed out of which they grow; The Aer in which they ftand; The Parts of which they confift; The feveral Fermentations under which their Juyces pafs; And the Organs by which their Taftable Parts are perceiv'd: as will appear upon
Inftance.

3. 5. But the immediate Caufes, befides the Organs of $T$ afte, are the Principles of Plants. As many of which, as come under the notice of Senfe, we have already fuppofed to be thefe Seven, Alkaline, Acid, Aer, Water, Oyl, spirit and Earth. The Particles both of Alkaline and Acid Salts, are all angular and poynted. Thofe of Aer, properly and ftrictly fo called, are Elaftick or Springy; and therefore alfo Crooked; as I have likewife formerly conjectured. And I find the Learned Borelli, in a Book of his fince then publifhed, to be of the fame Opinion. Thofe of all Fluid Bodies, quà Fluid, and therefore of Water, oyl and Spirit, I conceive to be Globular, but bollow, and with holes in their Sides. Thofe of Water, to be larger Globes, with more boles; thofe of $O y l$, to be leffer, with fewer boles ; and thofe of Spirit the leaft. Laftly, that the particles of Earth are alfo Round; yet angular; and nearer to a folid.

4. 5. Thefe Principles affect the Organs of Senfe, according to the variety of their Figures, and of their Mixture. So thofe which are fharp or poynted; and thofe which are fpringy; are fitted to produce any ftronger Tafte: and thofe which are round, are apt, of their own Nature, to produce a woeaker or fofter one. And fo by the diverfities of their Mixture; not only with refpect to their Proportion, but alfo the very Mode of their Conjundtion. Hence it is, that many Bodies which abound with Salt, as Ambar with an Acid, and the Bones of Land-Animals with an Alkaline, have notwithftanding but a weak Taft; the Saline Parts being in the former drowned in the $O_{y l} l$, and in the latter alfo buried in the Earth.

5. \$. The fame is further confirmed by an Experiment mentioned Of Mixt. in a former Difcourfe; $f$. . the Tranfmutation of Oyl of Anife-seeds, Ch. 5. with the help of Oyl of Vitriol, into a Rofin. For both thofe Liquors, though fo ftrongly tafted, apart; yet the Rofin made of them, being well wafhed, hath a very mild $T a f t e$, and without any fmatch of that 
in either of the Liquors. Whence it follows, that the very Mode of Mixture is fufficient, not only for the variation of the Degrees in any one species ef Taft; but alfo for the deftroying of one species, and the introducing of a nother.

6. \$. THESE things being premifed, I conceive, That as an Unctuous $T a f t$ dependeth upon $O_{y} l$; fo a Vapid either on Water, or Earth: or upon fuch an intimate Mixture of other Principles, as renders them indifioluble by the Saliva, and fo, in a manner, untaftable.

7. \$. That a Pungent, is made either by an Alkaly or an Acid fharpned or whetted; that is, cleared from the foyl of other Princt. ples; as in the spirit of Sal Aromoniac or of sulphur. And fo in thofe Plants which have a Pungent Taft; whofe Fuyces or Tindtures, although they confift of divers Principles, yet all fo loofely mixed, that being diffolved by the Saliva, the Saline are hereupon left naked. Where. fore biting Plants, qua biting, are Nitrous Plants. So that the fuyce of fuch Plants, is a kind of Spirit of Nitre, made by the feveral Parts of the Plant. Hence Arum grows beft under an Hedg; where the Ground, not being expofed to the Sun, but the Aer only, like thofe Rooms in Houfes, which are covered, is impregnated with a greater quantity of Nitrous Salt. And thofe Roots which are Biting, have but few or but fmall Aer-Veffels; whereby fewer parts of the nitroaereal sap are carryed off into the Trunk. For the fame Caufe, it is no wonder, that many Aquaticks are Biting; Water being, though it felf cold, yet the Menfruum by which all salts are imbibed moft eafily, and in laxer ftate of Commixture with other Frinciples.

8. 6. Penetrant (fomething flower than Pungent) is made by any salt that is alfo foiled or guarded with Earth. Sower, by an Acid only foyled with Earth. Salt, by an Acid guarded by an Alkaly, and foyled with Earth. Cold, by an Acid drowned in Water, and foyled with Earth.

9. \$. In all thefe, the Salts are predominant; In Heat the $O_{y} l$ or Sulphur. The particles whereof being Spberick and bored with holes; thofe of salt ftick in them, as the Spokes do in the Hub of a Wheel, or as the Quills in the $S$ kin of a Porcupine. Whereby, as in Common Fire the Sparks of sulphur being agitated and whirled about by the Aer; with the help of the Salts, which ftick in them, tear in pieces all kinds of Bodies : fo here, being agitated by the Circulation of the Blood, they make a kind of hurry or combuftion; and fo, according to the degree and ftrength of their Motion, tear in pieces fewer or more of the $\mathrm{Fi}$ bers of the Tongue; and in a greater quantity, would raife a Blifter upon it; the common Effect of Fire, or any ftrong Epispastick. So that a Hot Taft, is produced by Sulpbur toothed or armed with Salts. Wherefore all Stillatitious. Oyls are Hot; being ftrongly impregnated or armed with the Effential Salts of the Plants from whence they are diffilled. And as thofe Plants which are very Parenchymous, from the predominancy of their Volatile Acid, are biting: So thofe which are Lignows, that is, have a good quantity of Lymphednds, from the domiou of their Sulpbur are commonly Hot. For the fame reafon it is, that many both Biting and Hot Plants, as the Roots of Dragon, Garden-Radifh, Onion, Iris, Rape-Cromfoot, \&c. being corked up in a bottle with Water, and fet in a Cellar or other cool place; they do all of them turn sower in a few days: The fame Fermentation, at once 
fullying the Salts of the one, and difarming the sulphurs of the other. But fome, wherein the sulphureous parts are more copious, will hardly ever become Sower. Hence alfo, fome Plants, whofe Roots are neither Hot, nor of any ftrong Tafte, as thofe of Wild Anemone; yet their Leaves and Flowers are plainly Cauficks: So that it feems, that as their fuyces rife up into the Trunk or Stalk, and are therein further fermented, the Sulphureus Parts thereof, are at the fame time relaxed from the other Principles, and acuated with an Aereal salt.

IO. 6. A Stupifacient Taft (as the Impreffion which fome Hot Plants make upon the Tongue may be called) is in fome fort, analogous to the mortifying of any part of the Body by the application of a Cauftick. For as there the mortification fucceeds the burning pain, fo here, the Stupifaction, neither comes before, nor with the Heat, but follows it.

II. \$. Sweetnefs is produced; fometimes by an Alkaly; fmoothed either by a Sulphur, as in Lime-Water; or by both a Spirit and a Sulphur, as in the Stillatitious Oyls of Animals. But molt commonly, by a fmoothed Acid; as in Malt, sugar, Hony. Hence a Sweet Tafte, is generally founded in a Sower; So Sower Apples, by mellowing, and harfh Pears, by baking become fweet; the spirit and sulpbur being hereby at once feparated from the other Principles and brought to a nearer union with the Acid. So the Sower Leaves of Wood-Sorrel, being dry'd, become fweet: and thofe of a fower Codlin, while they hang on the Tree, and even of a Crab-Tree, are neither Astringent, nor fower, but fenfibly fweet. And fo commonly, wherever the faid Principles are a little exalted by a foft Fermentation; as in the Juyce of the Stalk of Maze or Indian Wheat, which is a fweet as Sugar; and in the green Stalks of all forts of Corn and Grafs, in feveral degrees. So likewife Tulips and fome other Roots, being taken up, in open weather, fometime before they fprout; if tafted, are as fweet as Liquirifh or St:gar; and at no other time: not only Fruits, but many Roots, Seeds, and other Parts, upon their firft or early Germination, acquiring a curious Mellownefs, wherein, all their Principles are refolved, and their moft Spirituous Parts exalted and fpread over the Acid. Wherefore alfo moft Roots, which are not meerly long, but grow deep in the ground, have at leaft fome of their $7 u$ yces of a fweet Taft; as Liquirifh, Eryngo, Hounds-Tongue, Garden-Parfnep, Black Henbeane, Deadly NightSade, Ec. Even the fuyce of Horje Radifh, which bleeds at the Lympheducts, is of a fweet Tafte. And of the fame kindred thofe which grow the deepeft, are the fweeteft; as a Parfnep is fweeter than a $C_{a r}$ root, efpecially if you taft the bleeding $S a p ;$ and the Root of Common Tall Trefoyl tafteth fomewhat like Liquirifh, but is not near fo fweet. For all deep Roots, are fed with a lefs Nitrous Aliment: and being remoter from the Aer, their Fuyces pafs under much more foft and moderate Fermentations.

12. 6. Bitternefs is produced by a Sulplur well impregnated,either with an Alkaline, or an Acid Salt, but alfo thackled with Earth. And therefore the Bittereft Plants, commonly yield the greateft quantity of Lixivial Salt. So alfo many Stillatitious Oyls digefted with any ftrong Acid, will acquire a Bitter Tafte. Wherefore this Tafte is ofren founded cither in a Hot Tafte, or a Sweet. Hence it is, that the Leaves of all fweet Roots are Bitter. And that the Fig-Tree, which bears a fweet Fruit, bleeds a Bitter Milk. So likewife thofe Plants, which bear a 
Bitter Stalk, have not Bitter, but Hot Roots, as in Yarrow, Primrofe, Wormwood, Rue, Carduus benedicius \&c. is manifeft. So the Coats of the Seeds of Viola Lunaria are of a hot and biting Taft; but the Seeds themfelves, in which the Salts, though copious, yet are alfo immerfed in a greater quantity of $O_{y} l$, are Bitter. And that the Earthy Parts do alfo contribute fomething more to this, than to moft of the forementioned $T_{a f t}$, is argued from its being more Fixed; that is, the Body in which it refides, is either more Fixed, or elfe flyeth not away in that fame ftate of conjunction, by which it maketh a Bitter Tafte. For whereas Hot, Biting, and divers other Plants lofe the ftrength of their Tafte, by drying; moft of thofe which are Bitter, do hereby increafe it. And although the Extract of Dandelion and fome other Roots, which are very Bitter, hath fearce any Taft; yet generally, they are Bitter Plants, which are beft for the making of Extracts. And the diftilled waters of Plants which are Hot and Bitter, notwithftanding that they always taft high of the Heat, yet rarely and very faintly of the Bitter.

13. 5. Aftringency, is niade, partly, by the further increafe and more intimate union of the Earth. And therefore this is feated ftill in a more Fixed Compofition, than a Bitter. And partly, by the diminution of the sulphur. And therefore the Acid Parts ingredient to it, either by Fermentation or otherwife, are eafily expofed. Afringency being the Womb or Bud of a Sower. For all or moft Aftringent Roots bear a fower Leaf, or a fower Fruit; as thofe of all Docks and Sorrels, Black-Thorn, Deg-Rofe, and others. Wherefore alfo, Aftringency is often found in conjuction with Bitter, Sweet, or Sower; but fcarce ever with Pungent, or Hot.

14. 5. An Aromatick Taft, feems to be produced, chiefly, by a pirituous, acid, and volatile Sulpbur; as in Ambar-griefe, CardamonSeeds, many Stillatitious oyls \&c. A Naufeous, by a Sulphur lefs Spirituos and Volatile, and more Alkaline; as in the Root of Dog-ftones, Sheepfcabiows, the young and green Leaves of Coriander, or the Seeds of $C u$ mine. The Spirit, as it enters the Nerves, carrying the Alkaline Sulpbur along with it; as when a City is betrayed by one of its Inhabitants to an Enemy.

25. 5. An Intermittent Tafte, as in Arum, feems to have its dependance upon a fimple and very pure Nitre, which by its fubtilty enters into the very Concaves of the Nervous Fibers of the Tongue: and fo being lodged there, is little affected or ftirred, by the Motion of the Blood; but only when the Tongue it felf is moved, at which time it caufeth a kind of pricking Tafte.

16. \$. A Tremulous Taste, as in Pyrethrum, dependeth probably, upon an Aercal Sulphur; which being agitated by the Blood in its Circulation, the jpringy Motion or Vibration of the Aereal Parts produce that Tafte.

17. 6. A Taft is Lingual, Guttural, \&c. according to the grofnefs or finenefs or other difference of the Membranes into which the taftable parts are admitted. For Tafts are made not meerly by the outward Contact, but the Ingre/s of the taftable parts. Now the outer Skin of the Tongue, which is commonly obferved to pill off in boyling, like the Cuticula in other Parts, hath either no finfe, or much lefs than that which lies under it; and is therefore, but a Seive or Strainer to the tastable parts. So that being of different finenefs in the feveral parts of the 
Tongue; it hereby comes to pafs, that according as the taftable parts of any Plant are more or lefs penetrant, fubtle, or diffoluble, they are admitted into one part of the Tongue, and not another. And in the Throat, the outer Skin it felf, feems to be the immediate Senfory; and fo, to be evidently affected with the Fuyces of fome Plants, from which the Tongue receiveth little or no fenfible Impreffion.

18. 6. When the Taft is Permanent and Fixed in fome one Part; it is a lign, either that the Guftable parts are lefs diffoluble; or more fubtle, fo as to enter the Concaves of the Fibers; and that there is an admixture of an Aereal Salt, or a like Sulpbur; fome of the parts whereof, beingcrooked, hang like Hooks on the Fibers of the Tongue. For the reception of fuch a Tast, is not to be looked upon as a wound made with a Lancet, and fo the Lancet taken away; but with the Lancet flicking in the wound; until in time, 'tis carryed off by the $C_{i r-}$ culation of the Blood; which like the Stream of a River in a Flood, carries all before it, but thofe things laft, which ftick in the Mud.

19. 5. But when the Taft, though Permanent, yet is Diffufive or Tranfitive; it feems probable, that as there is a lefs admixture of Aer; fo a greater fubtlety of the Taftable Parts, whereby they are conveyed, through the Nervous Fibers, from one Part to another.

\section{H A P. V. \\ Of the fudgment which may be made of the VIRTUES of Plants, from their Tafts.}

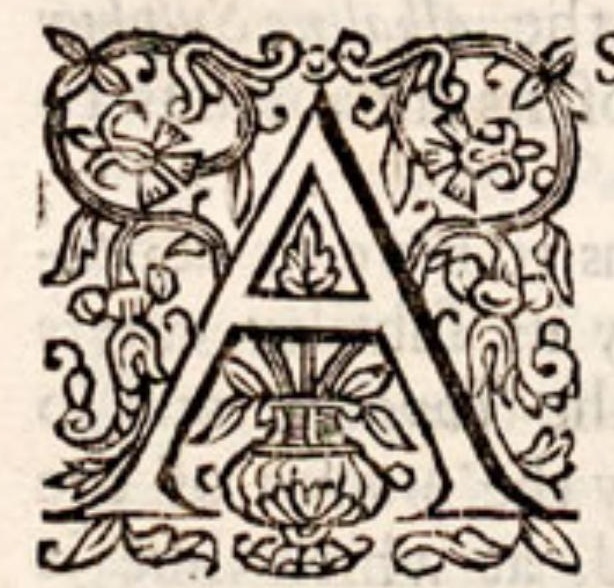

$S$ by duly obferving the Tafts of Plants, we may be directed to underitand their $C$ anfes. So alfo the $\mathcal{U}$ Se and Virtues of thofe Plants or Parts of Plants in which they refide. For the proof whereof, an Inftance might be fetched from every particular difference of Tast before fet down. But it may be enough, to give thefe which follow.

2. \$. And firft, we may make no ill guefs $e x$ Analogia, or where we find the fame Tast, that there the fame Virtue in fome kind, and in fome degree, may refide. So Jalap, Mercury, and Daify, have all of them that exafperating Taft in the Throat before defcribed; and they are all three more or lefs $C_{\text {athartick. }}$. Wherefore, we may believe, that other Plants which make the like Im. preffion on the Throat, and there are many others which do, that they are in fome degree alike Catbrtick. Thofe Plants which are reckoned amongft the chiefeft cepbalicks, caufe rather a ditrable, than a velement $H_{e}$ at upon the Tongue, as Prethrum, Euphorbium, Black-Hellebore, \&c. It feemeth therefore reafonable to rank with thefe, any other Plant, though not ufed, which produceth the like durable Heat. The young Roots of Tarrom, or Millefolium, 
have the fame Taste, as the Root of Contrayerva: and may therefore be ufed for the fame purpofe, with a probability of the like fuccefs; if not a better, becaufe they may be gotten frefher. But by drying the Root, the Taft and Virtue, which lie in its exhalible parts, are much loft. The Seeds of the leffer Cardamom, and of Zedoary Root, if found, have both a fmatch of the Taft of Camphire. They may therefore all, fo far, reach the fame Cafe.

3. 5. Again, as we may make no ill conjecture from the famenefs of $T$ afte in Plants of feveral Tribes; fo from the diverficy of Tafte, in thofe of the fame. So the Flowers of all the Docks are evidently Aftringent, and not Sower; except thofe of the Rha-pontick, which are extream fower, even in the $5^{\text {th }}$ degree. Which is no mean Signature of fome more than ordinary Virtue in it, befides what it hath in common with the reft of the Tribe. The Flowers of Pancy have a kind of fulfome Taft, plainly different from that of Violets : and in fome Hypochondriacal Cafes may be more ufeful.

4. 6. It likewife importeth much, to obferve the difference of Tafte in the feveral Parts of the fame Plant. So the Barque of saffafras is three times as ftrong, as the Wood: and the like may be obferved in any other commonly known Tree. If therefore we could obtein the Barques of Santalum, Lignum Rhodium, Lignum Aloes, \&c. they would doubtlefs, moft of them, be of much greater ufe. And as the Tafte is fometimes ftronger; fo, much more grateful, in one Part than in another : as in the Flowers or Yellow Attire in the Heads of Carduus Benedictus; which being infufed in spirit of Wine, or other convenient Liquor, make a pleafant Cordial. Nature having laped up the Virtue in the Leavs, as in a brown Paper; but in the Flowers, as in Leaf-Gold.

5. 5. As alfo, how far the Tafte of any Plant may alter, either in preferving, or preparing it. So the Root of Arum, when taken frefh out of the ground, is notably Pungent : but being throughly dryed, and efpecially kept for fome time, hath no more $\mathcal{T} a f t e$, and therefore in all likelyhood, no more Virtue, than a Lump of Starch. The like we are to judge of all other Plants, whofe Virtue lieth in their exhalible Parts. The Stillatitious Oyls of many Plants, are ftronger than the Leavs or other Parts from whence they are drawn: but fome there are, which are weaker; as is that of Euphorbium, in which the Heat is neither pertinaceous, as in the Gum it felf, nor fo great.

6. 6. We may make, moreover, a jugdment from the Nature of the Taft. So thofe Roots which are Bitter, and not Hot, as of Cichory, and the reft of the Intybous kind, may be accounted Nitro-Sulphureous; and fo, to be Abfterfive without any Heating Quality. The Marum Aufriacum, which is extream Pungent, as well as Aromatick, may be looked upon as the beft Cepbalick of that Tribe. Becaufe we find, that Falap hath a fpecial property of imitating the Glandulous Parts of the Mouth, and Throat; we may gather, That it is a better Purge to all the other Glandulous Parts, than moft other Catbarticks. Which is alfo one reafon of its operation, for the moft part, with at leaft a tendency to vomit; the Stomach it felf being Glandulous as well as the $T$ broat, and thereby anfwerably affected with it. A ftrong Infirfion of wbite Sarzaparilla in Water, botled up, and kept in a Cellar for the fpace of two montbs, becomes extream fower; far beyond any thing obferved in the Tafts of the Fuyces and Infufions of divers other

$$
\mathrm{U}_{\mathrm{u}} 2 \text { Plants }
$$


Plants kept as long and in the fame manner. Which fhews, how well Nature hath adapted a Plant of fo mild a Tafte, either by fimilitude of parts, for the carrying off of any preternatural Acid; or by contrariety, for the curbing of an exorbitant Salt. The Barque of the Root of common Wormwood, which impreffeth a pertinaceous and diffufive Tafte, which defcendeth from the Tongue into the Gulet, as is before defcribed; may be juftly ranked with the moft excellent Stomachicks; and upon tryal, I find it one of the beft: befides, that it is neither unpleafant, nor affecteth the Head, as the Leavs. Yet the Gardener, and every Body throws it away, as good for nothing.

7. 5. I fhall conclude with one note, which is this; That the Specifick Virtue of Medicines, which fome Phyficians pofitively deny, and moft difpute; from fome of the forementioned Differences of Tafte, as well as for other reafons, may feem, at leaft, to be probable. For why fhould not a Medicine make an ImprefJion upon one Part, and not upon another, within the Body, as well as we find it doth within the Mouth? efpecially, fince the Parts of the Mouth, are of a lefs different Nature, than fome of the Vifcera.

\section{An Appendix, \\ Of the ODOURS of Plants.}

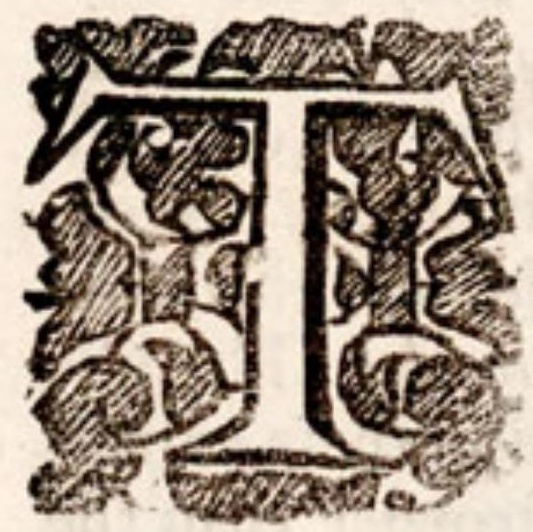

H E Senfes of Tafting and Smelling being fo nearly ally'd; many things already explained concerning the Diverfities and Caufes of Tafts in Plants, may eafily be transferr'd to thofe of their Odours. I fhall now therefore only remarque fome particulars, not commonly taken notice of hitherto, and leave them as a Specimen to be Improved by other Hands.

6. 2. The Root of Rape-Cromfoot being cut, and held to the Nofe, when it is newly taken out of the Ground, fmelleth almoft like Spirit of Sal Armoniac, or frelh Scurvygrafs fuyce. And hath the property of making the Eyes to water, as Onions do. Horfe-Radifs Root is not fo Pungent to the Nofe, but gets pretty much into the Eyes. But that of Dragon, doth neither affect the Eyes, nor the Nofe.

3. 5. The Succulent Roots of Dogftones, and moft of that Tribe, have a ranck $S$ mell. And that of Cromn Imperial, being rub'd a little, fmells as like a Fox, as one Fox fmelleth like another.

4. 6. The Root of Patience digefted with Water, in a warm Room, for the fpace of three weeks, fmels like Spirit of Harts Horn, or other Urinous Spirit. Of Red Dock, almoft like Aqua fortis or Spirit of $\mathrm{Ni}$ tre. That of Dragon bottled up with Water, and fet in a Cellar, about a Month, ftinks like the pus of the moft Fetid Ulcer. At the end of five Months, more abominably, than either to be endured or expreffed.

5. 6. The Leavs of Mountain Calamint, fmell like Peny Royal. Thofe of Ulmaria, like Walnut Pills. Of Yellow Lamium, like a Balfame. Of Sena, a good quantity being held to the Nofe, of a rank 


\section{Lect. VI.}

\section{of $T$ asts.}

Smell betwixt that of Sweat and Urine. Of Coriander, when green and young, ftink fo bafely, that they can hardly be endur'd. Sometimes the Leavs have a ftronger Smell, than the Flower, as in Borage, and fometimes the Stalk, a ftronger than the Leavs, as in Vlmaria.

6. \$. Rue Leavs corked up in a bottle and fet in a Cellar for about ten weeks, fmell like Spirit of Harts Horn, or of Urine. The green Leaves of Rofes infufed in water, have a mild, but pleafant Smell. Neither is that of Savine unpleafant, upon the like Infufion.

7. 6. Scurvygrafs Fuyce kept about $\frac{3}{4}$ of a year in bottles, with the green Sedement, in a warm Room, ftinks like Humane Excrements. And Scurvygrafs Wine, made only of the 'Juyce, fmells like fome I/Jues.

8. \$. The Flowers of Yarrow, fmell not much unlike to thofe of Southernwood. And the Flowers of Crowfoot almolt like thofe of Scurvygrafs. Some Flowers are of a weaker Smell in the Bud, as thofe of Mallow. But many have a ftronger, than when they are blown open;
as thofe of Lavender, Rofemary, \&c.

9. 5. The Buds of Vervaine Mallow, while they are young, and the Flowers unfeen, have a very pleafant Smell, like that of Geranium Mofchatum : but when afterwards they are opened they have an unpleafant Smell. Common Mallow Flowers dryed and bottled up for fome time, acquire, though not a ftrong, yet very noyfom Smell.

IO. 6. The Purple Pouch of Dragon which covers the Seed, being broken, fmells juft like a Lobfter. But permitted to lie in a warm Room for fome days, fmells exactly like Carrion; and fcents the Room with
the fame Smell.

II. \$. Some Seeds as thofe of Cumine, Daucus, being powdered and laped up only in Papers, do notwithftanding retein their Smello But many others, as of Sweet Fenil, in a fhort time, lofe it. Some Seeds, when they firft begin to fprout, become Odorous, which were
not fo before; as the Garden Bean. 
Tabula, quâ perfpicuè videre eft, quot Triplicati Sapores, ex folummodo decem Simplicibus numerantur.

Am.du.ac.

am.du.fa. am.ac.fa.

AMARUS am.du.ea. am.ac.ca. am.fa.ca.

am.du.fr. am.ac.fr. am.fa.fr. am.ca.fr.

am.du.ar. am.ac.ar. am.fa.ar. am.ca.ar. am.fr.ar.

am.du.ma. am.ac.ma. am.fa.ma. am.ca.ma. am.fr.ma. am.ar.ma.

am.du.af. am.ac.af. am.fa.af. am.ca.af. am.fr.af. am.ar.af. am.ma.af am.du.pu. am.ac.pu. am.fa.pu, am.ca.pu. am.fr.pu. am.ar.pu. am.ma.pu.

Du.ac.fa, (am.af.pu.

du.ac.ca. du.fa.ca.

du.ac.fr. du.fa.fr. du.ca.fr.

D U L C IS du.ac.ar. du.fa.ar. du.ca.ar. du.fr.ar.

du.ac.ma. du.fa.ma. du.ca.ma. du.fr.ma. du.ar.ma.

du.ac.af. du.fa.af. du.ca.af. du.fr.af. du.ar.af. du.ma.fa.

du.ac.pu. du.fa.pu. du.ca.pu. du.fr.pu, du.ar.pu. du.ma.pu.du,af.pu.

Aci.fal.cal.

aci.fal.fri. aci.cal.fri.

ACIDUS aci.fal.aro. aci.cal. ar. aci.fri.ar.

aci.fal.mal. aci.cal.ma. aci.fri.mal. aci.ar.mal.

aci.fal.aft. aci.cal.aft. aci.fri.aft. aci.ar.aft. ac.ma.aft.

ac.fal.pu. aci.ca pun. aci.fr.pun. aci.ar.pun. ac.ma.pu. ac.aft.pu.

Sal.cal.fri.

fal.cal.aro. fal. fri. aro.

S A L S U S fal.cal.mal. fal.fri.mal. fal.aro.mal.

fal.cal.aft. fal.fri.aft. fal.aro.aft. fal.ma.aft

fal.cal.pun. fal.fri.pun. fal.aro.pun. fal.ma.pu. fal.aft.pun:

Cal.fri.aro.

C A L IDUS cal.fri.mal. cal.aro.mal.

cal.fri.aft. cal.aro.aft. cal.mal.aft.

cal.fri.pun. cal.aro.pun. cal.mal.pun. cal.aft.pun.

Fri.aro.mal.

F R I G I D U S frig.aro.aft. frimal. aft.

fri.aro.pun. fri.mal.pun. fri.aft.pun.

AROMATICUS Aromal.aft. aro.mal.pun. aft. pun.

MALIGNUS

ASTRINGENS

PUN GENS 


\section{Tabula, qua Genericas omnes Saporum differentias comprenbedit.}

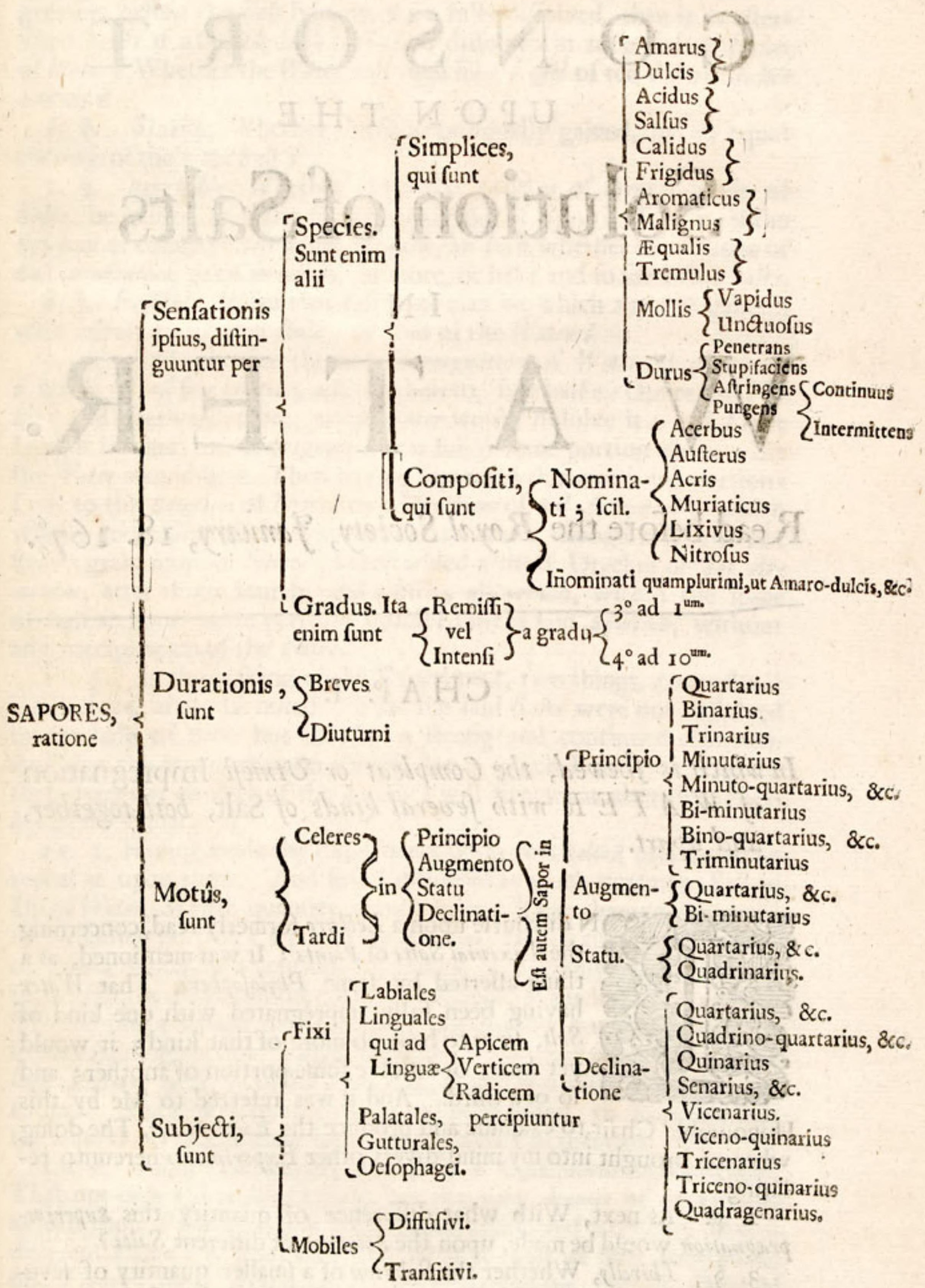




\section{Lect. VII}

\section{EXPERIMENTS}

\section{N \\ C O N S O R T \\ $\mathrm{UPON}$ T H E}

Solution of Salts

I $\mathrm{N}$
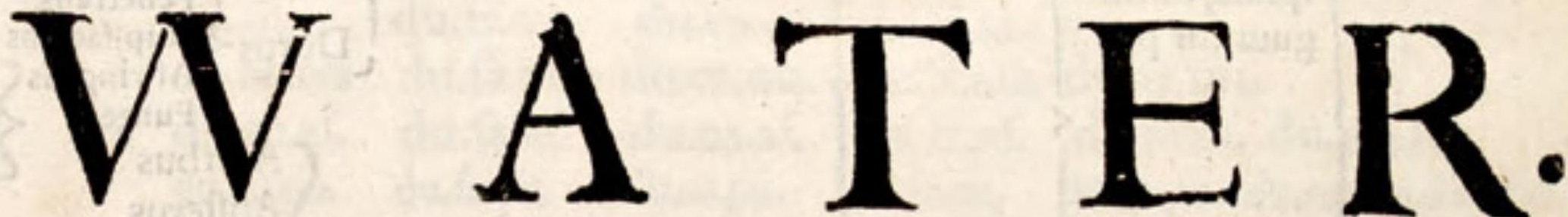

Read before the Royal Society, fanuary, I8. $167_{\%^{\circ}}^{\circ}$

\section{CHA P. I.}

In which is Shewed, the Compleat or Vtmoft Impregnation of W A T E R with feveral kinds of Salt, both together, and apart.

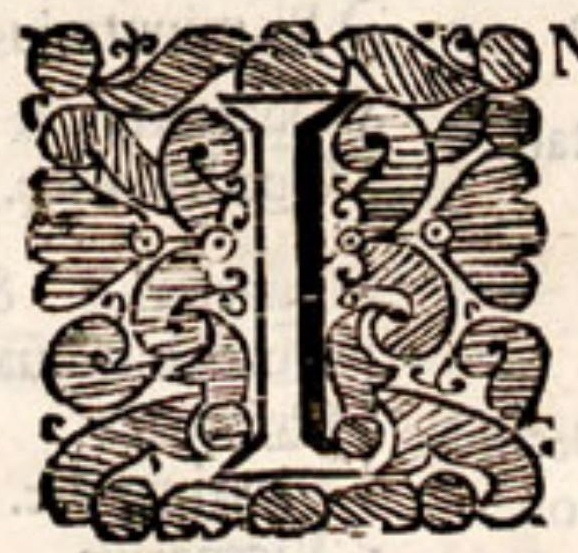

difcourfe upon a Lecture formerly read, concerning the Lixivial Salts of Plants; It was mentioned, as a thing afferted by fome Phylofophers, That Water baving been fully impregnated with one kind of Salt, fo as to bear no more of that kind; it would yet bear, or diffolve fome portion of another; and fo of a third. And it was referred to Me by this Honourable Chair,to examine and produce the Experiment. The doing whereof brought into my mind divers other Experiments hereunto relating.

2. 5. As next, With what difference of quantity this superimpragnation would be made, upon the Solution of different Salts?

3. \$. Thirdly, Whether the Solution of a fmaller quantity of feveral Salts, doth confift with the non-increafe of the bulk of the Water ? Becaufe this alfo is affirmed by fome. 
4. 5. Fourtbly, What quantity of the feveral kinds of Salt, may be diffolved feverally, in the fame quantity of Water ?

5. 5. Fifibly, Whether by diffolving a salt in Water, there be any Space gained, or not? That is, whether the Bulk of the Water be greater, before the Salt lying in it be fully diffolved, than it is afterwards? Or if a Cubick Inch of Salt be diffolved in nine Cubick Inches of Water; Whether the Water will then fill a $V e f f e l$ of ten $C u b i c k$ Inches content?

6. \$. Sixtbly, Whether the Space be equally gained, by an equal encreafe of the fame salt?

7. 5. Seventbly, Whether upon the solution of feveral kinds of Salts, be gained fo many feveral quantities of Space? That is, if the Solution of common Salt gains, fuppofe, an Inch, whether the solution of Salt Armoniack gains as much, or more, or lefs? and fo for other salts.

8. \$. Eighthly, What that juft fpace may be, which any salt gaineth with refpect to its own Bulk, or that of the Water?

9. 5. And firft, for the superimpregnation of Water; I put into a bottle 3 ij of fair Water; adding thereto, firft balf an Ounce of $\mathrm{Ni}$ tre; and afterwards more, as the Water would diffolve it ; and (that I might be fure the Impregnation was full ) fome portion above what the $W$ ater would bear. Then having feparated this remaining portion; I put to this Solution of Nitre, two Drachms of Sal Armoniac; which wholly and eafily diffolved in the faid solution; though it would not bear a grain more of Nitre. I then added a third Drachm of $s a l$ Armoniac, after that a fourth, and a fifth; all which, within the fpace of half an hour, were perfectly diffolved in the faid solution, without any precipitation of the Nitre.

10. 5. In the making of this Experiment, two things, to render it infallacious, are to be noted. That the faid Salts were not diffolved by the help of Fire, but only by a ftrong and continued Agitation. And that this was done upon a warm day : which I mention, becaufe that even the changes of the weather will fomewhat alter the solubility of the Salts.

I t. F. Having made the Experiment upon two salts, I proceeded to repeat it upon three. And firft I diffolved as much common Salt in $z_{i j}$ of $W$ ater, as that quantity would bear. Then having feparated the fubfiding portion; I put to the Solution, no lefs than five Drachms of Nitre, which by a continued Agitation, was wholly diffolved therein, neither the Nitre nor the common Salt being in the leaft precipitated. Then adding a Scruple more, it would not diffolve, but fubfided. This fecond fufiding portion, I again feparated; and then put to this $S_{u p e r-}$ impregnation, near $3 i$ of Sal Armoniac, which was alfo diflolved as the former. And if as many more salts had been added, tis probable that the fame Water would have born fome quantity of them all.

12. \%. From this Experiment, it is a Conclufion demonftrated, That not only the vifible Cryftals, but the very Atomes of every Salt, at leaft thofe Parizcles which are ultimately diffolved in Water, have a different Figure one from another. Becaufe that if they were all of one Figure; there would be no Superimpregnation, but the Pores of the fame Water, would imbibe as much of one salt, as anfwers to the total of two more Salts imbibed: that is to fay, it would as well imbibe two Ounces of common Salt, as one Ounce of common Salt and $\mathrm{X} \mathrm{x}$ another 
another of Nitre: which yet is contrary to the Experiment. And it is the fame thing, whether we fuppofe the Pores of Water to be alfo different, or not. Becaufe, that if the Figure of all the faid Atomes be the fame; then their refpect to the Pores of the Water muft be the fame, how different fo ever thofe Pores be: which is alfo contrary to the Experiment. Befides it is a great prefumption, to fay, that the Pores, and therefore the Atomes of Water have different Figures; and yet not thofe of Salts.

13. 6. From the fame Experiment we may go upon good ground in Compounded Infufions; whether of Purgative, or other Materials. As not doubting, but that the fame Menftrum may be highly impregnated with feveral Ingredients at once, whofe operative parts may be therein copioufly diffolved, without hindring either an Extraction, or caufing a Precipitation one of an other.

14. \$. The Second Enquiry is, With what difference this Superimpregnation of Water is made? which I find confiderable. For a solntion of above five Drachms of Nitre may be fuperimpregnated with no lefs quantity of Sal Armoniac. And a solution of five Drachms of common Salt, may be fuperimpregnated with as much Nitre. Yet neither a ftrong Solution (as of five Drachms) of common Salt, will bear above two Scruples of Sal Armoniac: nor will a ftrong Solution (as of five Drachms) of Sal Armoniac, bear above a Drachm of common Salt : for if above the faid quantities of either of them be mixed together: they are both copioully and forthwith precipitated to the bottome of the Glays.

I5. 5. Whence, notwithitanding the former Experiment, yet are we admonifhed, not to infufe all manner of Ingredients in any proportion. Becaufe though fome do not, yet others will precipitate one another.

16. 6. The Third Enquiry was this, Whether the Solution of a fmaller quantity of feveral Salts, doth confift with the non-increafe of the Bulk of the Water? For this I took a Bolthead with a flender Neck, conteining about a pint and a quarter of Water; and diffolved therein about $3 j \beta$ of Nitre. And marking the place to which the Water afcended in the Neck of the Bolthead: I then diffolved in the fame $\mathrm{Wa}$ ter about a Drachm of Sal Gemme: which little quantity, raifed the Water above half an Inch higher then it was before. The like I obferved in the addition of Nitre to a Solution of Sal Armoniac. So that to fuppofe the variation of the salt doth prevent the increafe of the Bulk of the Water, is a manifeft Error.

17. 6. From the fame Experiment it alfo appears, That the afcent of the Water upon a superimpregnation, is the fame, by whatfoever Salt the firft Impregnation be made. For inftance, Let a Solution of Nitre afeend in the Neck of the Bolthead, fuppofe, to ro Inches, then add $\frac{1}{2}$ an Ounce more of Nitre, fo as to raife the Water, fuppofe, 12 Inches or more, or lefs, according to the Bore of the Neck. In like manner, let a Solution of Sal Armoniac reach to ten Inches: then add again half an Ounce of Nitre; and it will reach juft 12 Inches, or more or lefs, as before.

18. 5. The Fourth Enquiry is, What quantity of the feveral kinds of salt, may be diffolved feverally in the fame quantity of Water: that is tofay, by agitation alone, without the help of fire, as I noted 
before. And upon tryal it appears, Firft, that two Ounces of Water will diffolve three Ounces of Loaf-Sngar and no more, except the Water be heated.

19. \$. The fame quantity of Water that is, two Ounces will diffolve above two Ounces of Salt of Tartar. I fay above, for how much more, want of a greater quantity of Salt which I could confide in, made me that I could not finilh the Experiment.

20. 6. The fame quantity, $f c$. two Ounces of Water, diffclveth an Ounce and a Drachm of Green Vitriol.

2I. 6 . The like quantity diffolveth fix Drachms and a Scruple or above $\frac{3}{4}$ of an Ounce of common Salt.

22. 5. Of Nitre, Five Drachms two Scruples and an half.

23. §. Of Sal Armoniac, five Drachms and two Scruples.

24. 5. Of Alum, not above two Drachms and a Scruple.

a5. 5. And of Borax, not above a Drachm and half a Scruple.

26. \$. Of thefe note, That although Common Salt be very diffoluble, and will prefently catch the moyfture of the Aer: yet a much greater quantity not only of Salt of Tartar, but even of Loaf sugar, and of Green Vitriol it felf, may be difiolved in Water than of Common Salt.

27. 6. Again, as the great Solubility of fome, fo the lefs Solubility of other Salts is alfo obfervable, as of Alum, and Borax. For the fame quantity of Water will diffolve near four times as much of Green Vitriol, as it will of Alum. And of Sugar more than ten times as much. OE Green Vitriol near eight times as much as of Borax; and of Sugar, twenty times as much.

28. \$. From this Experiment we are likewife cautioned, not only in the Infufion of feveral Ingredients together, but of any one fingly; that fuch a proportion thereof to the Menftrunm, be not exceeded. For all that is over and above what the Menftrum will bear, is either not extracted, or will be precipitated. As is evident not only in the Diffolution of the Salts above named, but in the Infufton of Plants themfelves: as, for inftance; of Senna; two Drachms whereof will impregnate four Ounces of Water as ftrongly, as if twice the quantity were infufed; becaufe the Water will bear no more of the Purgative Parts of that Body.

29. \$. There is only one Salt more remaineth to be fpoken of under this Experiment; and that is, the Cryftals of Tartar. Whereof, it is fomewhat ftrange to obferve, that it will fcarce at all diffolve in Water: not more, than even divers Refinous Gums, as Maftick, Tolu, Tacchamabacca, and fome others will do. For if two Drachms, fuppofe of thefe Cryftals, of Tartar (commonly fold for Cremor Tartari) be put to one Ounce of Water, fcarce five Grains thereof will, by Agi.. $^{3}$ tation, be therein diffolved.

$$
\mathrm{X}_{2} 2 \quad \mathrm{CH} \text { A P }
$$




\section{H A P. II.}

In which is Sbewed, that by the Solution of Salts in Water, fome certain fpace, more or lefs, is gained. That the Jpace is different according to the Nature of the Salt. And what the juft fpace is, which is gained.

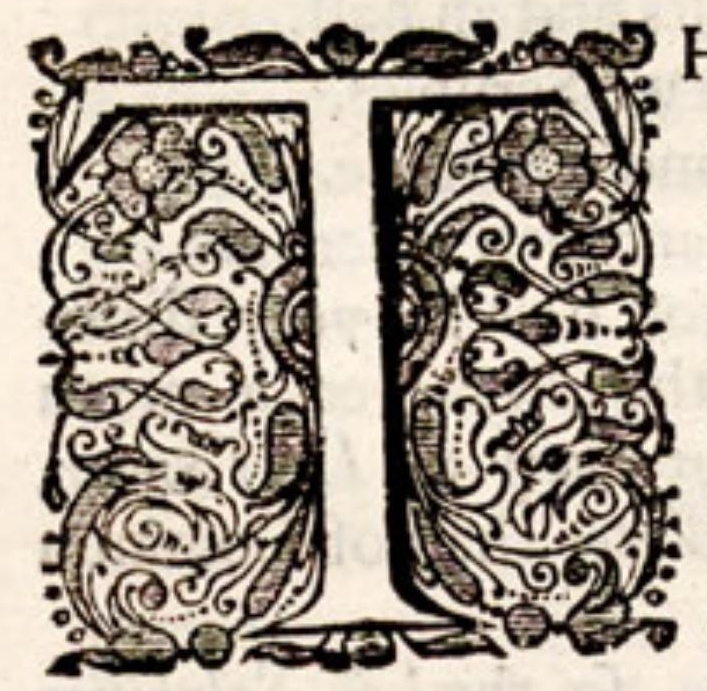

HE Fifth Enquiry is, Whether by diffolving of a Salt in Water, there be any fpace gained, or not. That is, whether the Bulk of the Water be greater before the Salt lying in it be fully diffolved, than afterwards. For tryal whereof, I took a Bolt-bead with a flender Neck, holding fomewhat more than a pint; and filling it up to a certain place in the Neck; I then put in an Ounce or two of Salt. And obferving the hight of the Water, both before it was diffolved, and afterwards; It plainly appeared, that there was fome, and that a confiderable fpace, gained by the Difolution; the Water thereby finking feveral Inches below the place, where it ftood after the Salt was firft put into it.

2. §. From this Experiment it is plain, that there are Vacuities in Water. That is to fay, that all the parts of $W$ ater are not contiguous, but that either betwixt, or in the Atomes of the Water themfelves, there are certain Pores, either abfolutely void, or at leaft filled up with another more fubtile body which is eafily excluded by the particles of Salt : by poffeffing the room of which the above faid fpace is gained.

3. 5. The Sixtb Enquiry is, Whether the fpace be equally gained, by an equal encreafe of the fame Salt.

4. 5. For this I made two tryals; the firft was this. Two balf Ounces of salt Armoniac, being fucceffively diffolved in the fame Water; both of them raifed up the Water in the Neck of the Bolt-bead, equally; the firft 3 Inches $\frac{7}{8}$, and fo the fecond.

5. \$. The other was this. Four half Ounces of Nitre, being fucceffively difiolved in the fame Water, they all of them raifed up the Water in the Neck of the Bolt-bead, equally; the firft a little above two Inches, and the $2^{\mathrm{d}}, 3^{\mathrm{d}}$, and $4^{\text {th }}$, juft as much.

6. \$. The Seventh Enquiry is, Whether upon the Diffolution of feveral kinds of Salts, be gained fo many feveral quantities of fpace. For this I made tryal upon Eleven feveral salts, fc. Salt of Tartar, Common Salt, Sal Gemmens, RomanVitriol, Nitre, Wbite Vitriol, Green Vitriol, Alum, Borax, Loaf.Sugar, and Sal Armoniac; of all which, I diffolved an equal quantity $f c$. two Ounces, in an equal quantity of Water, feverally; that is, taking frefh Water for every solution. The fuccefs was, That the sal Armoniac raifed the Water Is Inches. The Loaf-Sugar, I 3 Inches and sths. The Borax, a Foot. The Alum II Inches, and şrths. Green Vitriol, 9 Inches and sths. White Vitriol, 9 Ir:ches and $i^{\text {th }}$ Nitre, 8 Inches, and șths. Roman Vitriol, 7 Inches 
and sths. Sal Gemme, 6 Inches, and sths. Common salt, 6 Inches and ${ }^{3}$ ths. Salt of Tartar, not above 4 Inches and trth. All which differences are plain, and moft of them very remarquable: Two Ounces of $s a l$ Armoniac raifing the $W$ ater near four times as high, as the fame quantity of Salt of Tartar.

7. 6. From this and the fourth Experiment, compared, it alfo appears, That the feveral fpaces gained by the feveral salts, though fometimes they do, yet do not always anfwer to the Solubility of the faid Salts. As to give fome Inftances; Loaf-Sugar is the moft diffoluble of any other Salt; yet it gaineth lefs fpace than all the reft, fave only Sal Armoniac. So Green Vitriol is more diffoluble then either Nitre or Common Salt; yet gaineth lefs fpace than either, efpecially than the latter. And sal Armoniac, which is more diffoluble than Alum or Borax, yet gaineth lefs fpace than either of them. The Caufe whereof is not eafily affigned.

8. \$. Note alfo, that by the fame Experiment, as well as by the Tafte and other Circumftances, it is plain, That $S_{a l}$ Gemme is nothing elfe but Common Salt, coagulated or Cryftalliz'd under Ground.

9. 5. Again, as the Fifth Experiment Theweth, That there are Vacuities in Water : fo doth this Laft, that thofe Vacuities, are of differing kinds. Becaufe, otherwife, it fhould feem, That the Bulk of the Water would increafe, more or lefs, according to the Solubilitie of every Salt, and not be alternately differenced as it is; Some Salts, more diffoluble, increafing the Bulk of the Water lefs, and others lefs diffoluble, increafing it more. I fay, that this difference dependeth not only upon the different Figures of the Atomes of Salt; becaufe then every Salt which is more diffoluble, would (quantity for quantity) take up lefs room in the Water: which is contrary to the Experiment.

10. \$. From the fame Experiment, howfoever paradoxical it may reem, yet is it alfo manifeft, That although $W$ ater be a Fluid, yet the Particles thereof are hard and confiftent, and unalterable in their Figure. Otherwife it is plain, That all manner of salts would be diffolved in the fame manner, and take up the fame room in the Water. For let the Figures of the Salts be never fo various, yet if the Particles of Water were themfelves Fluid or Inconfiftent and Alterable, they would always fo conforme to thofe Figures, as to fill up all Vacuities; and fo upon the solution of feveral Salts, if of equal quantity, the Water would ftill retein an equal Bulk. As fuppofe an Ounce of Iron were drawn into Wyer, another beaten into Plates, a third made into Hooks, a fourth into Needles, a fifth into Nails; every one of thefe five Ounces, being put feverally into Water will encreafe its Bulk equally. I conclude therefore, That the Atomes of Water are hard and unalterable.

I I. \$. The Eighth Enquiry was this, What that juft fpace might be, which any Salt gaineth upon Diffolutiou, with refpect to its own Bulk, or the Bulk of the Water? For the making of this Experiment, Water will not ferve, nor yet Spirit of Wine; becaufe they both of them diffolve more or lefs of thofe Salts which are put into them; whereby the obfervation of the true Bulk of the Salt, and confequently of the juft fpace it gaineth by Diffolution is loft. I took therefore $O_{y} l$ of Turpentine, and pouring it into a Bolt-bead, marked the place of its afcent in the Neck. Then pouring likewife into it two Ounces of 
Common Salt, I marked the fecond afcent of the $O y l$; and found it to be $1 \circ$ Inches and 6 eighths. Repeating the Experiment in like manner with two Ounces of Nitre, I found the afcent of the $O y l$ to be I I Inches and sth. Repeating it again with two Ounces of Alum, the afcent of the $O_{y} l$ was 13 Inches and $\frac{2}{8}$ ths. And making it once more with $S_{a l}$ Armoniac, the $O_{y} l$ afcended to ${ }_{5} 5$ Inches : the faid feveral afcents of the $O y l$ being the true fpaces which the Four abovefaid Salts take. From which, the fpace which the fame Salts take up upon Diffolution, being deducted; the remainder is the fpace gained by that Diffolution. And fo it appears, firft, that Sal Armoniac gaineth notbing; being the only Salt of all I bave tryed, which caufeth the equal afcent both of the Water and the $O y l . \int c$. juft ${ }_{5} 5$ Inches in both. Alnm caufeth the afcent of the $O y l$ to 13 z ${ }^{2}$ ths, of the Water, to I I Inches and sths: So that it gains about $\mathrm{I}$ Inch and $\frac{1}{2}$ out of 13 . Nitre caufeth the afcent of the Oyl, to I I Inches and ${ }_{8}^{\text {th }}$; of the $W$ ater, to 8 Irches and ${ }^{3}$ ths. So that Nitre by Diffolution gets almoft the fpace of 3 Inches in I I. Common $S$ alt cuufeth the afcent of the $O y l$, toro Inches and $\frac{6}{8}$ ths ; of the Water, 6 Inches and $\frac{3}{8}$ ths. So that Common Salt gains by Diffolution 4 Inches in IO, which is very confiderable.

12. 5. By this way the Specifick Gravity of all kinds of Salts may be eafily taken, and the difference betwixt them is fomewhat furprizing. For it appears by the Afcent of the $O y l$, that Nitre, quantity for quantity, is about a $22^{\text {th }}$ part lighter than Common Salt. Alum about a $6^{\text {th }}$ part lighter. And Salt Armoniac, almoft a $4^{\text {th }}$ part lighter than Common Salt. The like eftimate may be made of the Gravity of all other Salts.

13. \$. By the fame Experiment it alfo appears, That according to the Specifick. Gravity of Salts they are many times at leaft more or lefs Volatile; as in the four laft Salts is plain. .For Common Salt which of all the four is the moft fixed, is alfo the heavyeft. Nitre which is fomewhat lefs fixed is fomewhat lighter. But Alum which is ftill lefs fixed is much lighter. And Sal Armoniac which is wholly Volatile, is the lighteft of all the Salts above mentioned. 


\section{H A P. III.}

\section{Wherein, from the Experiments in the foregoing Chapter, is Shewed, the Caufe of the Motion of the Mercury in the BAROMETER.}

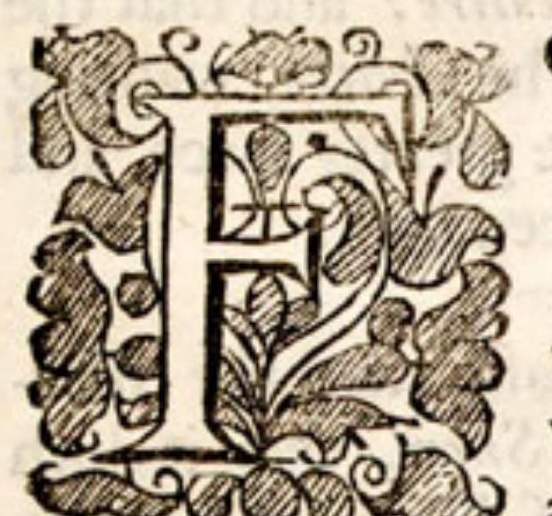

$\mathrm{O} R$ the doing of this, it will firft be acknowledg'd, That not only feveral forts of Sulphur, but alfo of Volatile Salts, are continually fublimed from moft Bodies into the Aer. So Lightning, from the celerity of the accenfion, appears to be made of a Meteor, which is Nitro-Sulphureous. Snow dependeth upon a Mixture of Nitrous, and other Salts; as is evident, from the regularly and differently Figur'd Parts, which compore the whole Body of a Snowy Cloud, before it clufters into Flakes. And one reafon, why Rain is the beft $W$ ater for any $s o y l$, is becaufe it is impregnated with divers Volatile and Fruitful salts. And fo from other Meteors.

2. 6. And next, that thefe Salts, are not always in the fame 2uantity, Proportion, and State, in the Aer : but that fometimes they are more copious; at others, lefs: fometimes, one more copious, than an other: fometimes, more plentifully diffolved; at others, more fpare: ingly : and that, either as they are more or lefs pure and diffoluble; or according to the quantity of the Vaporous Parts in the Aer, in which they are incorporated or diffolved.

3. 6. Thus much being granted, from the Experiments in the foregoing Chapter compared together, we may refolve our felves about fome Phenomena in the Barometre. Which feems to vary, not fo much with the meer Weight of the Aer, which hitherto hath been fuppofed : as by the different preffure it makes, in being crowded more at one time, than at another. That is, according as certain Nitrous, or other Saline Bodies, take up lefs space in the Aer, when diffolved in the Watery Parts therein, than while they are undiffolved.

4. 6. And therefore it is efpecially to be obferved, That as the Mercury commonly rifeth in the $C$ ylinder for fome days, but always for fome time, before the change of the Weather, whether for snow or Rain: So, that then it prefently falleth again, even before the Snow or Rain falls. Whereas, if the Weight of the Aer, were the only, or the chief Caufe of the afcent of the Mercury; than as it rifeth all the while the Weather is gathering, fo it would keep its ftanding or heighth, until the Weather breaks and falleth down: which yet it never doth, but always falls before it; fometimes no lefs than a whole day. The Caufe whereof is, in that all the while the Mercury rifeth in the Cylinder, the Aer is cromeded with more and more Saline Parts, which by 


\section{4

the Winds, or otherwife, are carryed into it; and fo caufeth it to prefs upon the Mercury in the Box: but after that in fome time the Salts are diffolved or incorporated in the Aqueous Parts of the Aer, as in Rain or Snow; fo foon as that is done, there is fome space gaind; and fo, before any Weather falleth, the Aer is lefs crowded, and preffeth Jefs upon the Mercury in the Box, which gives way to its defcent in the Cylinder.

5. 5. From hence alfo it is, that the Mercury rifeth higher with Cold Winds, than it doth with thofe which areWarme. Both becaufe that in cold Winds there is the greateft quantity of Nitre: and that the coldeft Winds, are ufually the dryeft. So that the Nitre wanting Moyfture fully to diffolve it; it takes up fo much the greater fpace, and fo caufeth a greater preffure in the Aer, as hath been faid.

6. 8. Laftly, For the fame reafon it comes to pafs, that the Mercury firft rifeth higher, and then falleth lower before Snow, than it doth before Rain. Becaufe that for the production of Snom, the Aer is crowded with a greater quantity of Nitre, or fome other like Salts; which before they are diffolved, take up fo much the more fpace; and afterwards fo much the lefs, even before the snow falls: as hath been proved. 


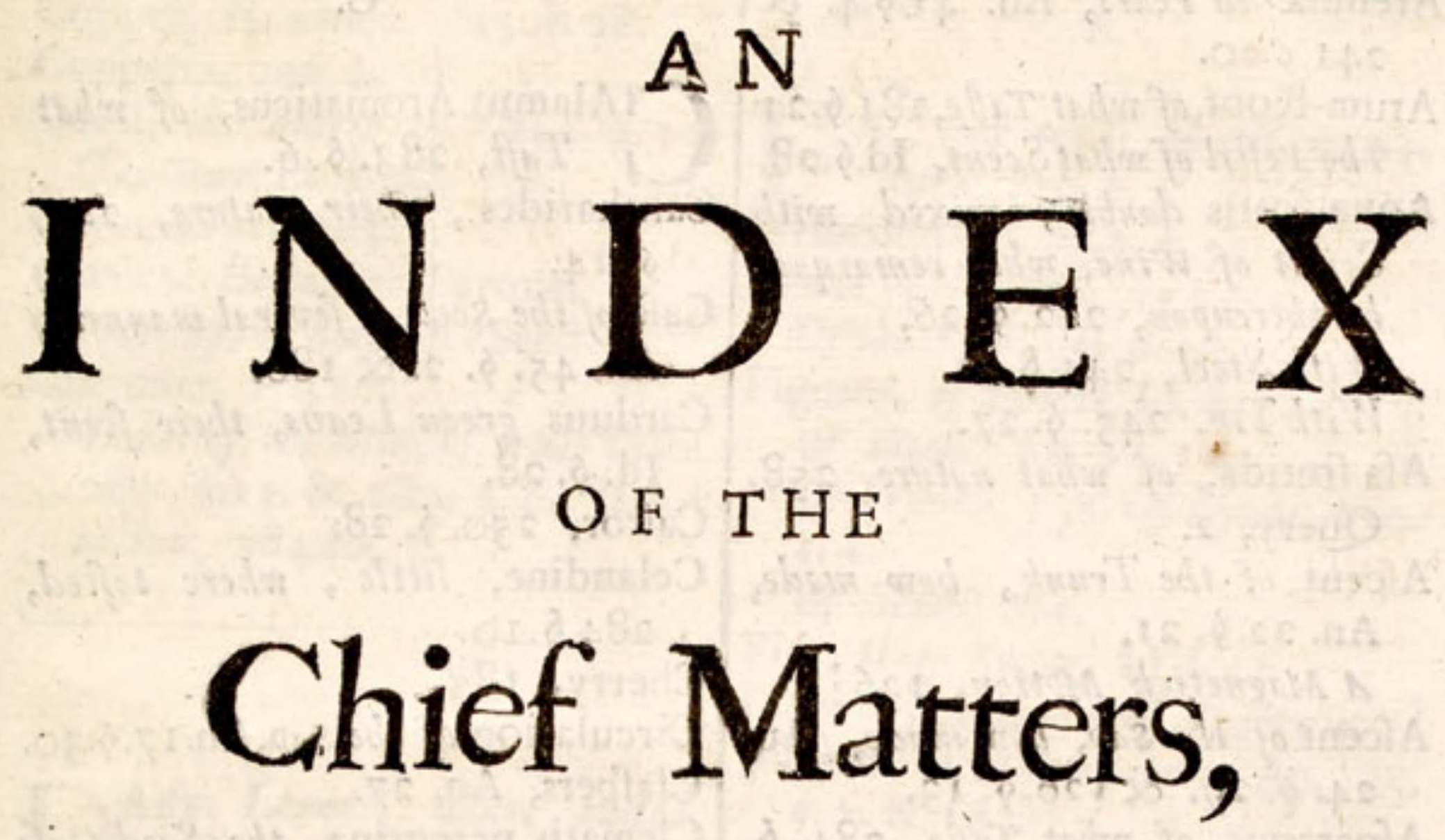

In which, Id. fignifies Idea. An. Anotmy. The Figuers before $\$$ the Page. The Figures following $§$. the Section in that Page.

A.

Cid, commonly the predominant Principle in Plants, 240.5.8. That is of the Parenchyma.

Id. 5.48.

Aer, how to be examined, as relating to Vegetation, Id.5.60.

Aer, in Plants, How made, An.93. \$.61.

Where it enters the Plant, 127. 5. I.

Its Motion and Courfe in Plants, ibid.

Aereal Salt, Id.b.6o.

Aer-Veffels, their structure, I 15. 6.16, \&c. See Root and other Parts.

Affinities of Plants, Id.6. S.II.

Age of Roots, see Roots.

Agitation, a Canje of Mixture, 230.6 .6 .

Akern, 186.

Albumen, see Seed.
Alkaline Salt, in many Plants ite their natural eftate. 240.5 .9$.

This the predominant Principle of the true Wood of a Plant, Id. 6.52.

Anagallis, of what Taste, 284. 6 . IO.

Angellica Roots, whben dry, full of Rofin, Id.. .4I.

Anatomy of Plants, why fit to be made, Id.S.17.

In what manner, s.18.

What to be obferved thereby, 6 . I9.

of what ufe, 6. 20.

Animals, their Parts mixed with Jeveral Menstruums, 247.to 253. Cantharides, of what nature, 2490

Antimony, of phat nature, 245 . \$.23.

Apertures of Seeds, An.2.6.5. \& 200.6.I.

Apple defcribed, An. 40. 6.2.8\% I79.

A precock, $\mathbf{1} 48$.

Arfmart, coded, bow its Seed ejacu- 


\section{The Index.}

lated, I88.6.18.

Arenula in Pears, An. 41. b.4. \& 24 I. 5.20.

Arum-Root, of what Ta?e,281.ל.2 I T be Peftil of wohat Scent, Id.乌.28.

Aqua-fortis double, mixed with Spirit of Wine, what remarquable thereupon, 242. \$. 26.

With Steel, 244 \$.22.

With Tin. 245 . 6. 27.

Afa fœtida, of what nature, 258 . Query, 2.

Afcent of the Trunk, bow made, An. 22.\$. 2 I.

A Magnetick Motion, 136:

Afcent of the sap, bow made, An. 24. 0.29. \& I 26.5. I3.

Afparagus, of what Tafle, 284. 6 . IO.

Attire of Plants fee Flower.

\section{B.}

B Arbado Nut, Id 6.30 .

Barque of the Rout, fee Root. f the Trunk, fee Trunk.

Bawme, its Tincture in Water, 274. S. II.

In Spirit of Wine, 275.6. 14.

Beams of the Sun, different from the Heat of Common Fire, Id. 6. 61 .

Bean difJect d, An. צ. I.

Beech-Wood, An 20.

Berry, fee Fruits.

Bezoar, its nature, 252.249.

Bezoardicum minerale, 245.6 .25 .

Bleeding of Plants, Id. 6. 23. An. I 24. 5.3 .

Bolus, what, 242. \$. 2 .

Bonus Henricus, of what Tafte. 284. P.10.

Bones, their different nature, 249. $8,18$.

Branch, how made, An. 28.6.3. Its Claspers, An. 27. fie Trunks.

Bud of a Branch, how originated, nourifled, and kept, An. 28. 乌. I. How kept, 145. \%. 2 . Bud of the Seed, fee Secd.

Butyr of Flax, Id. $\$ 5$ I.

\section{C.}

CAlamus Aromaticus, of what Taft, 283.6 .6 .

Cantharides, their nature, 249. 5. 14.

Cafe of the seed, of feveral manners, An. 45. 6. 2. \& 186.

Carduus green Leavs, their fcent, Id. 6. 28.

Caftor, 250.6 .28 .

Celandine, little, where tafted, 284 6. 10.

Cherry, 185 .

Circulation of the Sap, An.17.6.30.

Clematis peregrina, the Seed-Caje of what Taft, 283.6.3.

Colours of Plants, To what Parts

Convolution of the Trunk a Mag-
Clafpers, An. 27.

Coats of the Seed, fee Seed.

Colocynthis. Its nature, 240.6 . I3. \& 257. Query 5. Where tafted, 284.6 .8$. of Plants they belong, Id. 26.

How to be obferved, Id.6.27.

Colours of Roots, An. 94. D.65.

\& 270.6. 5 .

Of Leavs, 270. 6.6 .

Of Flowers, 27 I. 6.15 .

By In/ufion, in $\mathrm{Oyl}_{2}, 273$. In Water, 274. In Spirit of Wine, ibid. By their Mixture with other Bodies, 375 .

By Cultivation. 277.

7 beir Caufes fummed up, 276.

Compreffion a Caufe of Nixture; and of Dijolution, 229.6.3.232. 6. $4.8237 .6 .3,4$.

Contents of Plants, in what Method to be examined, Id. 6. 2 I to 26 . \& 3 t to 47 . of what kind, 6. 2 I.

Their Receptacles, \$.22. Motions, 4.23 . 2tantities, 6. 24. Confifience. 6,25 .

How made in the feveral Parts of a Plant, An.92.6.57.

What in the Seed, 208. \$.15.

Contrayerva, of what Tafte, 283. 6. 6.

Leso:

46. $\mathrm{i}$

itbe $\mathrm{K}$

Rayr,

atbe nat

lond. F

an of $B$

sin. 2

alusos,

mis, 59

a foums

-

on

ting $t$

ittare $p$

Pi PLE

esc, fer

Surat

xila

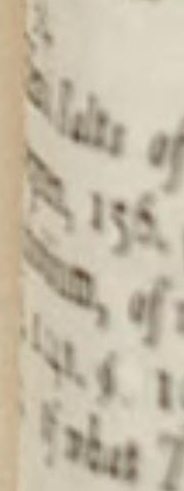




\section{The Index.}

netick Motion, 137.

Copper, its nature. 245. \$. 28.

Copperas, 246.6. 38 .

Coral, the Magiftery, 244. 6.15. Tincture, Id. \&. 28.

Corin white, 285.

Cortical Body, fee Barque.

Covers of the Seed, see Seed.

Cucumer, An. I8I. Leavs of the wild, of what Taste, 280. \$.II. \& 283. 6.6. Where tasted, $284.9 .4,8$.

D.

Aify Leaves, where tafted, Defcent of the Root, how made, An. $34 \cdot 8 \cdot 3$.

Diametral Rays, fee Roots.

Digefter, the nature of that invented by Monf. Pappin, 237.

Diffolution of Bodies promoted by Compreffion. 237.

Diffimiiar Leavs, Jee Leavs.

Dragon Root, 59. \$. 13.

Dung of Pigeons, $251 . \$ 37$.

\section{E.}

HArth, how to be exsmin'd, as 1- relating to Vegetation, Id. 9. 57.

How nature prepares it for the growth of Plants, I I. $\$ .8$.

Empalement, fee Flower.

Emulfionss, fometimes for Glyfers, Id. 39 .

Enula, of what Tafte; 283. S. 3,34 .

Effential Salts of Plants, fee Salts.

Evergreen, 156. 0.2.

Euphorbium, of what nat \$. I. 24 I. \%. 19. \& 258 . Query 2. Of what Tafte, 283.6 .6 .

\section{F.}

At, bow made by Art or NaA
ture, 233.4.3.

Fermentation, 253.4 .55

Fibers of the Leaf, fee Leavs. Of the Seed, fee Seed.

Figures, of Plants, Id. $\zeta$. I I. of Roots, An. 58. 6. 4 .

of Trunks, 135. Of Leavs, 150. b. I. of Steds, 195.

Figs, their Sugar. Id. \$.4I.

Flax, its nature, 258. Query r.

Flower, its Empalement, An. 35 . 6.2. \& 163.

Foliature, its Foulds, An. 36.5 . 5.\& 164.6.1. Protections, An. 36. 6. 7 . Hairs, An. 36. 6. 8. \& 168.夕.8. Globulets, An. 37. \$. 10. \& 165.6.9. Number of Leavs, 165.5.11. Parts of the Leavs, I66.3.15. ufe, An. 37. 夕. II. \& 166. 夕. 18. Shape or Figare, 167. \%. 20.

Attire, Seminiform, An. 37. $\$$. 13. \& 167. Florid, An. 38. 6 . 17. \& 170. Glebulets or Spermie of both, An.38.4. I 5. 39.6. 21 . 168 . $.9 . \& 170.5 .5$.

ufe of the Atire, An. 39.5. 22. \& I $I$ I.

Flower, when formed, 173 .

Colours of the Flower, $27 \mathrm{I}$.

How by the Flower to find out to what fort a Plant belonget $h, 175$. 6. 13.

Fœrtus, fee Seed.

Foulds of Leav's, fee Leavs.

Formation of the Root, fee Root.

Fruits; Apple, An.40.5.2. \& 179. Limon, 180. Crcumer, $18 \mathbf{I}$. Pear, An. 41. 5.3. \& 182. Quince, 183. Plum, An. 42. \$.5. \& 183. Aprecock, 184. Peach, 184. Cberry, 185. Walnut, ibid. Grape, ibid. Goofeberry, An.43.4.9.\&185. White Corin, 185. Filbert, An. 43.5. 8. \& 186. Akern, 186.

The USe of the Fruit, An. 44.

5. 10 . 


\section{The Index.}

6.IO. Of its Parts to its Self, |Lapis Tuthix, 243.5.9.

189. To the seed, 191, \& 209.

When the Fruit formed, 192.\$.9.

Furr of a Hare, $247 . \$ .3$.

\section{G.}

Y All-Stones, 252. \$. 47.

Generation of the Seed, and other Parts, fee the Seed, and other Parts.

Gentian Root, where tafted, 284 . 5. 5 .

Germen, fee Bud.

Glyfters, fometimes beft made of $E$ mulfions, Id. \$. 39 .

Globulets, fee Leavs and Flowers.

Gold, its nature, 245. $5.3 \mathrm{I}$.'

Goofeberry, 185 .

Grape, 185 .

Gravel, its nature, 25 1. $\$ .40$.

Gums, of three kinds, 134.5.15.

\section{H.}

$\mathrm{H}$ Airs, See Leavs and Flowers. Hares Furr, 247.5.3.

Harts-Horn, 248.5.8.

Hazel Nut, See Fruits.

Hellebore black, of what Tafte, $280.5 .12 . \& 283.5 .3$. \&c. where tafted, 284. 5.4.

Hoglice, 249.\$.15.

Horles Hoofe, 247.5.5.

I.

TAlap, of what Tafte, 283. 5. 6. 284. 5. 10.

Infertions, in the Root, and other Parts, fee Root and other Parts. Iris Root defcribed, 60. \.14. Irifh slate, its nature, 243.5 .4 . Iron, fee Steel.

L.

Apis Calaminaris, its nature, 1243.5.9.

Lapis Lazuli, 243.5 .7$.
Lead, its nature, .244. 5.16.

Lead Spar, 244.5.12.

Leavs, the two firft which come of every Seed, wohat, An. 8. \$. 42, \&c. Their Ufe, An. 10.5.46.

Leavs; their Protections, An. 32.5.17. \& 145.5.2. Foulds, An. 3I.6.I 4.\& I 47.9.9. Shapes and Meafures, An.30.5. 17. \& 150. 6.1. Globulets, An. 34. \$.7. \& 148. S.I. Hairs, An. 34. 5.4 . 149. 6. 8. Spots, 148. 5. 4. Thorns, 148.5. 6.

Their Compounding Parts, An. 29.6.7. Skin, 153. S.1. Parenchyma or Pulp, 153.5 .5 . Fibers or Veffels, Their Pofition In the Body of the Leaf, 152. \$. 19. In the Stalk, 154.5.9. The Lignous Veffels. 155. \$. 16. The Aer-Defjels, 155.5.19. Texture of a Palm Leaf or Bag, $\mathbf{1 5 6 . 5 . 2 0 .}$ Deration of the Leaf, 156.5 .2$.

Time and manner of its Genera. tion, I56.5.4. \& 174.

Colour of the Leaf, 270.

How by this to find out to what fort a Plant belongeth, 174 . \$. I:

Lignous Body, See Trunk and otber Parts

Lilium convalle, its nature, Id. 6. 30.

Limor, de fcribed, 180.

Lithofperm the Seed, its nature, $241.6 .2 \mathrm{I}$.

Lixivial Salts, fee Salts.

Lobes of the Seed, fee Seed.

Lympha out of which the Seed is first nouri/hed, fee Seed.

Lympheducts their Struiture, III. 6. 30.

\section{M.}

18

Agiftery of Corals, 244. 6.15 Of Pearls, $252 . \$ .43$.

Mallow, its nature, 257. Query 5. Marine Salt of Plants, fee Salts.

Maltick, its nat wre, 258 . Query. 2. Meafures of Leavs, I50.\$. I.

Mechanick ules of Timber, 137 .

Membranes 


\section{The Index.}

Membranes of the Seed, fee Seed.

Menftruum of the Stomach, 253. 653.

Metals; Lead, 244. $夕$ 16. Mercury, 244. \ 16. Steel, 244. 20. Antimony, 245.夕23. Tin, 245 . 26. Copper. $245 . \$ 28$. Silver, 245. \$29. Gold, 245. \$3I.

Milks of Plants, Id. $\$ 21, \& 26$. How made, An.67.\$19.\& 93. \$. 60. \& 133.612.

Milk-Veffels, therr Strudure, 112. 535 .

Millipedes, 249.\$ I5.

Minerals of all forts, how eafily try. ed, 247.648 .

Mixture; the received Dodtrine bereof, 222.

Its nature explained, 225. Cau. fes, 229. Power and Ufe, 23r. Mixture of the Parts of Plants with Jeveral Menftrums, 239, \&c. Of Minerals. 247, \&c. Of Animals, 247, \&c.

Motions, Of Plants, Id. 36. of Roots, and other Parts, See Roots, and other Parts.

of the Sap, fee Sap.

of the Aer, fee Aer.

Muciducts, An. 66. 618.

Mucilages, Id. $\$ 2$ I. \& An. 2 IO. 64 .

Musk, its nature, 250.\$. 29.

\section{N.}

Ature of Bodies, bow difcove-
rable, 235

Navel-Fibers, fee Seed.

Nighthade deadly, of what Taft, 284. $\$ 9$.

Nitre, of what Ta\}, $280 . \$ 6$.

Noli me tangere, how the Seed ejaculated, 188. \$ I8.

Number of Leavs in Flowers. 165. SII.

Number of Seeds, 198.

Nut Barbado, Id. \$30.\& 205.6

17. HazelNut, 43.\$8.\& 186.

O
AK-Wood, defcribed, An:
$20, \& 2 \mathbf{2}$.
Odors of Plants, how to be observed,
Id. \$2 28 .
Some Inftances bow made, An. 44
\$46. Imitated, 235 .

Olibanum, its nature, 258. Query, 2.

Oyls fillatitious, bow mingled with Water \&c. $232.67,8237$.

Oyly Sap, bow made, 132. $\$ 6$.

\section{P}

D Arenchyma or Cortical, Pithy, and Pulpy parts of a Plant, their predominant Principle, Id.

\$ 48. Defcribed in the Root and o. ther parts, fee Root, \&c.

How formed, fee Roots and Leavs.

Peach, fee Fruits.

Pear, fee Fruits

Pearls, their magifery, 252.\$ 43 .

Philofophy, tezins and ends with Theology. 79. \& I.

Pimpinel, where tasted, 284.5.10.

Pith, its ftructure, 76, $4.7 . \& 120$ $\&$ I I, \&c.

Plants, their Natural Hiftory how far cultivated, Id.5. 3. Wherein defective, \$2. Fit to be further improved, \&3. \& \&6 63. What to le enquired of, $\& 6$. The ufefulnefs bereof 5.8 .

Plants, their Nature and Virtue bow judged of, See Virtues.

Plants, their places of Growth, Id. 15.

Propotions, $\hat{\&} \mathrm{I} 3$.

Plants, their Parts only Two Ef. Sentially diflinit, $47 . \$ 14$.

Plants; the general fructure of their Parts, I 20. \$ I I, \&c.

Plants, their Pinciples hom to be obferved, Id. 6.48.

For wobat purpofe, \$53. What $\mathrm{Zz}$ predo- 


\section{The Index.}

predominant therein, 240. \$ 8. Rofin, bow made by Art, 233. 54 . Plants, bow to find out to what Rofin in dryed Roots of Angelica,

kind any one belong',

Plum, fee Fruits.

Principles of Bodys, 223. which predominant in the true mood of $a$ Plant. Id. $\$ 52$.

Principles of Principles. Id. \$62.

Protections of the Leaf and Flower. See Leaf and Flower.

Pyrethrum the Root, of what Taft, 281. \&... \& 284. \$7.

\section{R.}

$\mathrm{R}$ Adicle, fee Seed.

Raifins, their Sugar, Id. $\$ 4 \mathbf{I}$. Rings annual in the Trunk, An. 19. 56.

Roots; their Original, 57. \& . shapes or Figures, do sizes $58 . \$$ 4, 09.941 , Motions, An.15. \$2 24. \&c. 34. \$3. 59. \$9.8c. 90. $\$ 48$ \& c. Ages, 60. $\$ 16 . \&$ 9 I. 654 .

Parts, the Barque, its skin, An. II, \& 2. \& An. 6I.

Parenchyma defribed, An. I I. \& 3. \& 63.62 . How form' $d, 87.6$ 34. Its Diametral rays, 64, 6 7. Veffils, 65, 66, 67.

The Wood, Herein the Infertions, An, 12, $510 \& 17, \$ 28, \& 70$. \$2. Lignous Fibers or Veffels,70. \$ 4, 8, 9. Aer.Vefjels, An, 12. 5. 7. \& 71. \& 5, 6, 10, \&c. The Pith, An, 13. $916 . \&$ An, I6. \$ $27.8 \mathrm{An} .75,75.97$.

Root, bow it grows, An,14.\$23. The Sap, how imbibed and diftributed to its Several Parts, 82, 8 I5 \& c, Hoin circulated, An, I7. $\$ 29$.

How all the parts are form' $d, 85$. $526.00 c$. And differently difpofed, 88. \& 36, oc c The Colours of Roots, 170. 95 . How made, 94.665 .

Root of Wormwood, where tafted, 285.812 . Id. $\$ 4 \mathrm{I}$.

Common Rofin, its nature, 258 . Query 2.

\section{S.}

Alt aereal, Id, \$60.

Salt Alkaline, in many Plants in their natural eftate, 240. $\$ 9$.

Salt ammoniac, $246, \$ 44$.

Salt, effential of Plants, How made, $262+\& 3, \& c_{*} \& 265+\$ 3, \& c_{*}$ Of feveral forts, Id. \$ 48. In!anced alfo in thofe of Rofemary, Black Thorn, Scurvey-Grafs, Wormwood, $A f b, 865, \geqslant 6 \& c$. Taftable in good Rbubarb, Id. $54 \mathrm{I}$.

Salt fixed, of what ufe in Pu'gation, 260.

Salt Lixivial of Plants, bow imitated, 233. \$6. of different nature, 264,82 .

Salt of $A j h$, of what nature, 167.6 22. of Tartar. Ib, Yielded in different quantitys by the Barque of $A$ h, Rofemary, Black-Thorn, Agrimony, 256. Query 1. Garden and sea scurvy-grass, 256 . Query 2, Mint difill'd, and not, 256, Query 3. Majorane, Oak-Barque, Liquorifh, Anifeeds, Sorral, Garden Scurveygrafs, Mint, Sea Scurvegra/s, 256 . Query 4. Majorane, Agrimony, Nugwort, Mint, Mallow, Rbubarb, sena, Falap, Colocyntbis, 257, Query 5. Flax, $258, \mathrm{Qu}$. I. Gum Arabuck, Euphorbium, Myrrh, opium, Aloe, Scammony, Gutta gamba, 258. Query 2.

Salt Marine, its natwre, 246. \$43. Salt Marine of Plants, how made by Nature or Art, 234. \$8, 2635 I2, \&c, 266. \& 16. Of feveral forts, inftanced in thofe of Rogemary, Scurve) grafs, Black Thorn, Wormwood, 266.617 \&c.

Salt of the dead sea, 263 . \& 14 . 


\section{The Index.}

Saps of Plants, bow to be obferved, Id. $\ell_{21}$ to 26 . and 31 to 47. Their feveral kinds, S. 2I, Receptacles, $\$ 22$. Motions, 23 . Quantitys, 624 . Confiftence, 5 25.

Sap, bow imbibed, and diftributed to the feveral parts of the Root. An, 82, \& I5 \&c. Its Circulation therein, $A n+17 . \$ 29$. where, and bow it afcends in the Trunk, An. 24. 2 29. \& An. 124.

Sap and other contents of the feveral Parts bow made, An. 92. $\$ 57$ \&c. \& 131. How a Milky Sap, An.67.\$ 19.2293. $660.8 \times 133$. \& I $2 \& c$. How aWiny, $93 \$ 62$. $\& 132+53 \& \mathrm{c}_{*}$ How one very oyly, $\mathbf{1} 32+\$ 6 \&$ \&.

Scurveygrais Garden, of what Taft, $283 . \$ 6$.

Scurvey-grafs Sea, its Nature, 256. Query 4.

Seafons of Plants, Id, 8 I4.

Secundine fee Seed.

Seeds; their Cafe or Uterws, An. $45 . \$ 2$, of feveral manners, 186. Fighres, $\mathrm{An}+45+$ \& 3+ \&c. 195.

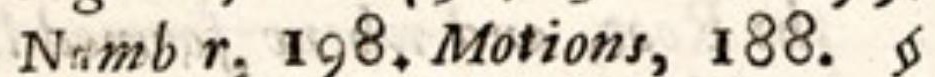
$18 \& 199$ \& 3, \&c.stones, 201. 62.8 209. Mucilages, 20I, 4 4. Coats or Membranes, An, 2. \&3. $45, \& 3$, \&c. 46 \& I0. 47 . $515 \& 201.96 .210$ \&c. Apertures, An 2. 85 , \& 200 \& I.

Virellum, 20.2.\$9. The Fatws, or true seed, its Radicle and Lobes, An. $2 \& 3 . \& 9$ to $12 . \& 203$. Plume or Bud, An. 3.6 $13 \& 206$. skin, An. 4. \& 16. \& 207. 69. Parenchyma, An+4. \& $8 . \& 207$. 510. Seminal Root or Veffels, An. 5. \& 21 , \&c. \& 207. \& II, \&c. Nuvle Fiber, An. 48. \$ I 7 . \& 2I2. Content. 208. \& I5. The

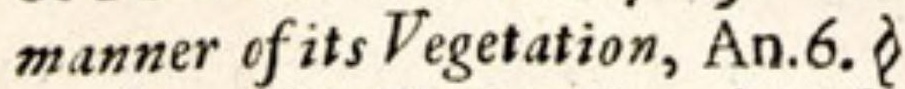
30, \&zc.Of its Generation, An.48. 18 \&c. \& 209 \&c.

Shape of Roots, and other Parts. fee Roots and otber parts.

Shells, their Nature, 248. \& 9, I0, II.
Skin, fee Seed and other Parts.

Silver, its Nature, $245 \$ 29$.

Smell of green Carduus, Id. \$28.of the Pestil of Arum. Ib.

Soyl. fee Earth.

Sperme of Plants. See Flower.

Spirit of Salt, 247.\$46.

Spirit of Salt Armoniac, $247 \% \oint$ 47.

Spirit of Peas-Cods, Id, $\$ 30$.

Spirits urinous, bow made lefs offenfive, Id, $\$ 45$.

Spirit of Wine mixed with Aqua fortis, what thereupon remarka ble, 242. $\$ 26$.

Stalks. Jee Trunks and Branches.

Steel, its nature, 244. 620 . Mixed with double Aqua fortis, what thereupon remarkable, 244. $\$$. 22.

Stillatitious Oyls, bow mixed with water, 232, 97.8237.

Stomachick menitruum, $253 . \$ 53$. Stones; a frange one bred in the stomach, 252. $\$ 48$. Others probably bred there, $253 . \$ 5 \mathrm{I}$. of the Kidneys or Bladder, of what nature, $251 . \$ 32$. How prevented, 251 . 4 I. 出 252. \$ 42. Gall Stone, its nature, 252.\$ 47. Bezoar, its nature, 252. $\$ 49$. Lead-Spar, 244. \& 12.

Lapis Calaminaris, 243.59. Tuthiæ, ibid.

Lazuli, 244 \& $\mathbf{2}$.

Structure of a Plant. I 20. $\$$ I $r_{\text {, }}$ 6.6.

Sugar of Raifins and Figs. Id. $\delta$ $4 \mathrm{I}$.

Sulphur predominant in the true wood of a Plant, id. $\$ 52$.

Sun, its Influence on Plants bow to be examined. Id. $\$ 6 \mathrm{I}$. 


\section{The Index.}

T.

$\therefore T$ Afts of Plants; bow to be cbserved, Id. $\&$ 29. simple, 280. \&6. Compounded, 281 . Their Degree, 282 . Motions or Terms, 283. Seat, 284. CauJes, An. 95. \$ 68 \&.c. \& 286 $\mathfrak{\sigma} c$.

Taft of Arum Root, 281. 5 Afparagus Root, 284. O 10. Bonus Henricus, 284. \& IO. Calamus Aromaticus, 283. \& 6. Celandine little, 284. $\$$ IO. Clematis peregrina the Seed-Cafe, 283. \$3. Colocynthis, 284. \$8 Contrayerva, 283. \& 6. Cwumer wild, the Leavs, 284. 64,8 . Daify Leavs, 284. \& Iо. Enula, $283 . \$ 3,4$. Euphormium, 283. 夕6. Gentian Root, $284.65,8$. Hellebore black, the Root, 280. \& I2. 283. \& 3. 284. \& 4 . Falap, $283 . \$ 6.284 . \& 10$. Night frade deadly, 284. 6 9.Nitre 280. \& 6. Pimpinel, 284. $\ell_{+}$ 10. Prretbrum the Root, $28 \mathrm{I}$. 5. \& 284. \& 7. TamariskLeavs, Id. \& 29, WormmoodRoot, 285. \&. 12, rarrow, $283 . \& 6$

Texture of a Plant, 120. \& II, \&c.

Thorns, their kinds. An. 33. 6 I. Timber, fee Trunk.

Tin, its nature, $245 . \$ 26$.

Tin mixed with ftrong Aqua fortis, what thereupon obfervable, 245. \$27.

Tincture of Bawme in Water, 274. S II. In Spirit of Wine, 275. 6. I4.

Tincture of Corals, a cheat, Id, \& 28 .

Trunks, and Branches feveral defiribed as they appear $t s$ the naked Eje, fc. of Indian Wheat, Dandelyon, Borage, Colemort, Holyoak, wild Cucumer, Scorzonera,
Burdock, Endive, Vine, Sumach IO3, \&c.

Trunk, skin, An, 19, \& 2, \& 107. $\$ 2$ to 5 .

The Barque, An, 19. 43.

Its Parenchyma, $108+6+7$.

Veffels, 108. 58 , to $\mathrm{p}_{+} \mathrm{I} \mathrm{I}_{3}$.

The Lympheducts their Structure, I I I+ $\eta_{+} 30$, \& c.

Milk-Veffels, their Structure, I I 2 , S 35, \&c.

Different Surface of the Barque bow made, 129.64 .

How united to the Wood, 129 , 6. 2,3. How this always keeps moyst, not the Pith, An, 20. \& 7.\& 93. 5 5. \& 124. र. 2.

The Wood, An. 19. $\$ 4$. to 11 . \& An. $20 \& 2$ I.

Its Annual Rings, An. 19. $\$ 6$. Infertions, An. 19. 6.5 . 12, to I5. $17 . \&$ I 28.68 . \&c.

True roood, I14. \& 10, \&c.

How dilated, An. 22. $\$ 22,23$. And woby, $\$ 24$, \&c.

Aer-Vefels, An, 20. $\$ 8,9 . \&$ I $5+$ 1 16, \&c.

How lefs in the Trunk, than in the Root, and whenc formed late in the year \&c, 130. \& 10. \& I3I. 6 I 6 .

The Pith, An. 19. \& 5, 18, 19, 20.\& II9. to I22 \& 129.95 . \&c.

Trunks, their different structure whence, I29.

Shapes, whence, 135.

Motions, whence, An. 22. \& 2 I. \& 136.

Trunks, bow fitted for Michanick ufe, 137 .

Trunks, of their Bbeeding, Id. \&23. \& I 24. \&.3, \&c.

Trunk-Roots, An. 27, 28.

Turnep, defcribed, An. 13. 


\section{The Index.}

V.

$\mathrm{V}$ Alves, no where in Plants, An. p. 21.6 .16$.

etables, fee Plants.

Vegetation of the Seed, fee Seed. The manner of Vegetation, how judged of, Id. \$. 53 .

Veffels of the Root and other Parts, fee Root and otber Parts.

Virtues of Plants, how to be obferved and judged of, Id. $6 . I_{2}, 30$, 47. \& p. 236.290.

Imitable, 235.

The reafon of them, how knowable, Id. \$. 55 .

Vitriols, their nature, 246. 9.38.

Uterus of Plants, flefhy or membraneous, 186.
W.

7 Allnut, 185.

Water, bow to be examined as relating to Vegetation.

Water, how mingled with fillatitious or other $O$ gls, 237.

Wood of the Root and other Parts. fee the Parts.

Wood of Beech, An. 20.\& $2 x$. Of Oak, Ibid.

Its predominant Principle, Id. 5. 52 .

\section{Y.}

Arrow Leavs, their Taft, 283 \$. 6 . 


\section{T H E}

\section{EXPLIGA TION \\ O F T H E}

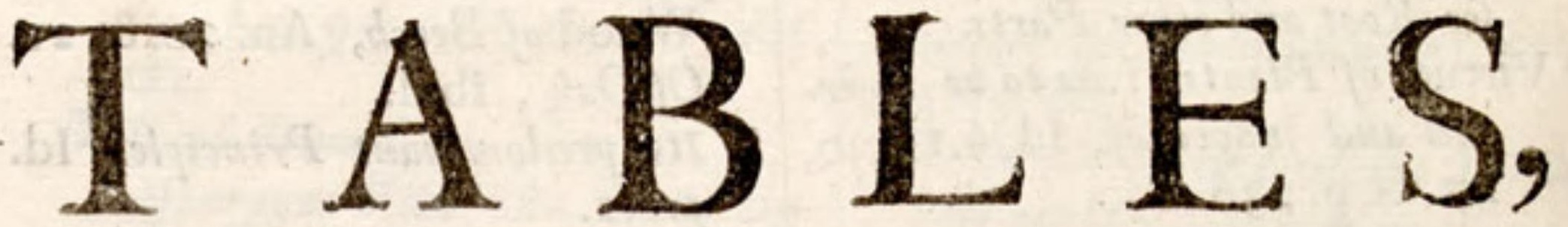

Reduced to a narrow compafs; as ferving to clear thofe Particulars, chiefly, which the Defcriptions before given, have not reached.

The TABLES to the Firft BOOK, are Four.

T A B. I. Figure $\mathrm{I}$, a, The FoF. 2, a, the Radicle lodged in the Body of the Iner Coat.

F. 3, a, the Radicle, b, the Plume or Bud.

F. 4 , the Seed covered; c, the Seed open; e, the fame magnified.

F. 5. a, the Corn covered; $\mathrm{c}$, naked and a little magnified.

F. 6. a, b, the two Lobes; e, the Radicle; c, the Radicle and Bud; $\mathrm{d}$, the Hollow in which the Bud lies.

F. 7. a, the Seed covered; c, naked; e, open.

F.8. a, one Lobe; --b, the Bud; $b$, magnified.

F. 9. the Slice a little magnified.

F. IO. The Radicle d, cut tranf verfly $\mathrm{c}$.

F. 18. The Plume or Bud a, cut tranfuerfly $\mathrm{c}$.
F. 12. Cut by the Length.

F. I3. A Lobe cut tranfverfly.

F. 14. Both the Lobes pared by the Length, to Shew the Seminal Root.

F. 15. a, the convex fide of one Lobe, ßhewing the Seminal Root without cuting; $\mathrm{c}$, the flat fide.

TAB. II. F.r, 2, \& 3. Shew the gradual converfion of the Lobes of the Seed, into Leavs.

F. 4. a, the Radicle cut by the len th; $b$, tranfverly.

F.5. The white Wedzes, are the Infertions; the black, are the Wood; the pricks are the Aer-Veffels; and the black balf ovals, the Lympheducts in the Barque.

F. 6. The three black Rings, are the terms of three years growth.

F. 7. a, the upper part; b, the lower.

F. 8. A Turnep cut tranfverfy, and part of the Rind cut off.

F. 9. Jieweth the gradual growth of the Pith.

T A B. III. F. r. The Bud cat tranfverfl, and part of the Radicle 


\section{The Explication of the Tables.}

by the Length, in a Bean newly sprung up.

F. 2. Sheweth the Wood as it appears to the naked Eye.

F. 3. the Cane Jplit down.

F. 4. the Corn newly fprouted.

F.5. A Branch of five years growth. From the Circumference, to the utmoft black Ring, goes the Barque.

F. 6. $a, a$ piece of the Staly; b, magnified.

F. 7. a, a piece of Oak.wood cut tranfuerfly ; b, the fame magnified. The wobite Lines are the leffer and greater Infertions. The Pricks, are the Wood. The little and great Holes two forts of Aer-Veffels.

F. 8. Part of a Branch ten years old, with the Barque Rripped off, and cut both tranfverfly and down the length, to fhew bow the Barque is inferted into the Wood.

T A B. IV. F. I. Shewing bow the In (ertions appear, in a piece of Beech-Tree Split down, to be braced or woven in togetber with the Wood.

F. 2. to II. Shew the different pofition and Figure of the Lignous Fibers.

F. 12. a, one of the Thece Seminiformes in a Lily, with the Jpermatick Powder therein, as apparent to the naked Eye.

F. 13. a, one of the fuits in the Florid Attire, as it appears to the naked Eye; b, the Floret; $\mathrm{c}$, the Sheath; d, the Blade.

F. 14. Wherein the white Pentangular Acetary is bounded by the Calculary.

F. 15. The Branches wbich run through the Stone to the Flower and Seed.

F. 16. The Innermot Cover of the seed, as fraped when it is ripe.

F. 17 . The Coats cut open.

F. I8. The Seminal Root.

The TABLES to the $S e$ cond $B O O K$ are Thirteen.

A B. V. Shemeth the generation of Roots out of the Defcinding Trunk. So F.6. is a treble Root of three years defcent $;$ the lowermoft, balf-roted off.

T A B. VI. F. I. Jueweth the sur. face of the Barque.

F. 2. the midle part.

F. 3. the Barque friped.

F. 4. the Root cut down the length.

F.5. the Barque friped off.

F. 6. the Network both of the Lympheduds, and of the Aer-Veffels.

F. 7. the Generation of a Bud.

F. 8, 9, 10, 1r. The Root split down, to fiew the Pofition of the $V_{e} \int f e l s$, and the Figure of the Pith as the top of the Root.

TA B. VII. The Roots all cus tranfverfly, and their Varieties defribed, in the fecond Book, as they appear to the naked Eye.

T A B. VIII. Otbir Roots cus $\operatorname{tranfver} f l y$, and the varieties of their Parts alfo defribed in the fecond Book.

TA B. IX. More Roots cut tranfverfly.

TAB. X. F. I. A Slice of the Root cut tranfverfly; but a litile too big for the life.

F. 2. AA, One balf of a like slice. b b, The skin.

A A D D, The Barque or all thas part of the Root analogous to it.

$\mathrm{GD}$, The Lympheducts on the inner edge of the Barque.

G G, The Wood.

GT, The Aer-Veffels th rein.

T T, The Pith.

T A B. XI. F. I. The Neck of 


\section{The Explication of the Tables.}

the Root cut tranfverfly. down.

F. 2. One balf of the fame fplit

F. 3. Magnified.

$A B, T$, Skin.

A E, The Barque.

$\mathrm{E} \mathrm{E}$, The Lympheducts.

The black Colnmns under them, are the Wood.

The Holes in the Columns are the Aer-Veffels.

The white Columns E L, are Infertions betwixt the Barque and the Pith.

L e, The Pith. Pith.

$\mathrm{e} e$, The angular Bladders of the

T A B. XII. A, one half of F. I. magnified.

A b, The Skin.

$A G$, The Barque, or all that part of the Root which anfwers to it.

In which the round black Spots, are the Muciducts.

D G, The coinmon Lympheducts.

DT, The Pithy Part of the Root.

T T, More Lympheducts.

In botb which, the black Holes are the Aer-Veffels.

T A B. XIII. A, One balf of F.I. magnified.

A C, The Skin.

$A G$, The Barque, or that part of the Root which anfwers to it.

DD, The Milk-Veffels placed in Rings.

E E, The Parerchymous Rings betwixt them.

$\mathrm{GT}$, The Bladders freaming in Rays, by the mixture of the Lymphedudts with the Lacteals.

G G, To the Centre, the Wood.

In wbich the Holes are the AerVeffels.

T A B. XIIII. A b., The kkin, which fould bave been thicker.

AF, The Barque.

$\mathrm{G} b$, The Bladders in the onter part of the Barque, oblong and

poftured circularly.

SS The Bladders in the inner part, ftanding in Arches.

F F, ARing of Sap-Ve/els.

d d, Parenchymous Infertions.

$\mathrm{dLd}$, The Wood.

In wobich, the Holes edged with

wbite Rings are the Aer-Vefels.

T A B. XV. A A, The Skin.

$\mathrm{AB}$, The Barque.

B L, The Sap-Veffels in the form of a Glory.

BE, The Wood.

In which, the Holes are the AerVeffels.

GE, ARing of more Sap-Veffels. $\mathrm{EE}$, The $\mathrm{P}_{i t h}$.

T A B. XVI. A b, The Skin.

$\mathrm{A} C$, The Barque.

In which the round Holes $\mathrm{B}$, are Balfame-Vefjels.

B. C. Parcels of Lymobeduts.

In wbich there aremore BalfameVeffels.

C D, Parenchymous Infertions.

DE, Parcels of Wood,

In which the Holes are the AerVeffels.

T A B. XVII. A, the Skin.

$A B$, The Barque.

L S, A parcel of Sap-Veffels.

Ll, A Parcel of Wood.

In which the Holes great and fmall are Aer-Veffels.

B B, Parenhcymous Infertions betwixt the parcels of Wood.

D D, Others within them.

The TABLES to the Third BOOK are 23 .

$\longrightarrow$ A B. XVIII. Hereof fee the Defcription in the Third Book, Chap. I.

T A B. XIX. F. I. A Branch of Corin Tree.

$A$, freweth the furface of the Barque. 


\section{The Explication of the Tables.}

\section{B, Of the wood.}

F. 2. stalk of Sonchus split down.

F. 3. Branch of vine jplit down In both, the feveral storys or Chambers of the Pith.

F. 4. Branch of Walnut. A. an older. B, a younger: in both, the Pith parted into tranfvers $M \mathrm{~cm}$ brans.

T A B. XX. F. I. Sheweth the Surface of a Walking $C$ ane.

And the Clusters of Aer-Veffels, furrounded with Rings of Succiferouss.

F. 2. The furface of the skin of Borage Stalk.

F. 3. The Turpentine Veffels run. ning through the length of the Barque; one of them cut down the middle, the other entire.

F. 4. The Milk-Veffels floewed in the fame manner.

T A B. XXI. Sheweth the Woody and Aer-VefJels by the length of the Branch, part of the Barque, and wood, being taken away.

T A B. XXII. A B, The Skin.

A C, the Barque.

$\mathrm{Q}$, the Pare chymous part. Ring.

$\mathrm{HI}$, Parcels of Muciducts in a

D C, Common Lymphedusts.

CDEF, the Wood of 3 years growth.

$K \mathrm{~L} M \mathrm{~N}$, The fecond years growth.

$\mathrm{O} \rho$, the reat In ertions.

$\mathrm{P} \rho$, the jmaller.

XX, Lignoms parcels. .

Within which the Holes are the Aer-Velfels.

E F G, the Pith.

T A B. XXIII. A B, the Skin.

A C, the Barque.

$\mathrm{Q}$ the fimple Parenchyma.

HI, a Ring of jpecial Vefjels.

$P$, common Sip.Veffels.

$\mathrm{CDEF}$, the Wood of 3 jears growth.

$\mathrm{KL} \mathrm{MN}$, one years growth.

$\mathrm{X}$, great Infertions.

$\mathrm{PO}$, leffer between them.

The black parcels are the rood.

In which the Holes are the Aer.Vefels.

E F G, the Pith.

T A B. XXIV. A B, the skin.

A B CD, the Bark.

$N \mathrm{~N}$, the Parenchyma. Sels.

$\mathrm{H}$ I, a Ring of Jpecial sap-Vef-

D M C, parcels of Lympheducts.

C DEF, the Wood.

E F L K, one years growth.

K PQL, the larger Aer-veffels in the feveral parcels of Wood.

$\rho \rho$, the lefJer Aer-vefJels.

MT, the infertions.

E F G, the $P_{i t h}$.

T A B. XXV. A B, the skin.

A B C D, the Barque.

H I, special sap Veffels in arch. ed parcels.

O O, the common Sap-reffels wbich begin to turn into Wood.

C.DEF, the Wood.

K L M N. one years growth.

The Holes are the Aer-veffels in the wood.

$\rho \rho$, the true wood.

$\mathrm{O} z, \mathrm{Oy}$, the Infertions.

E F, other sap-veffeis.

E F G, The Pith.

T A B. XXVI. A B, the skln.

$\mathrm{ABCD}$, the Barque.

QQ, the Parenchyma.

HI, special sap-veffels in arched parcels.

D C, a Ring of common Lympheducts.

DCFE, the Wood.

K L MN, one years growth.

The Holes are the Aer-Veßels.

$\mathrm{OO}$, the greater Infertions.

$\mathrm{P} O$, the fmaller.

E F, other Sap-veffels.

EF G, the Pith.

T A B. XXVII. A B, the skin.

$A$ B C D, the Barque.

W V, the Parenchyma.

$\mathrm{HI}$, round parcels of Sap $=V e \int f e l s$,

D C, the common Sap.Veffels.

DCEF, the Wood of 5 years growth.

$\mathrm{Bbb} \quad \mathrm{QRFE}$, 
QR F E, one years growth.

$\mathrm{XX}$, the true wood.

The Holes both great and fmall are the Aer-Veffels.

SS. The great Infertions.

$T S$, the fmaller.

EF G, the Pith.

T A B. XXVIII. A B, the skin.

A B C D, the Barque.

H T I, Special Sap.Vefels in round Parcels.

D SC, common Sap-Vefels.

DCE F, the Wood of five ysars growoth.

$\rho \rho$, the true rood.

K L \&c.the great Aer-Veflels.

D C, the fmaller.

$\mathrm{SS}$, the Infertions.

E F S, the Pith,

T A B. XXIX. A BCD, the Barque.

$\mathrm{AB}$, a Ring of Sap-Veffels in round parcels next the skin.

H I, the Parenchyma.

Another Ring of round parcels.

D O C, Common Lympheducts.

DCE F, the wood.

$\mathrm{MN} \mathrm{N} F$, one years growth.

$S S$, the true roood.

K L, the great Aer. Veffels.

$\mathrm{P} \mathbf{Q}$, the leffer.

$\mathrm{OO}$, the Infertions.

EF G, The Pith.

e, the Bladders of the Pith.

T A B. XXX. A B, the Skin.

A B CD, the Barque.

$\mathbf{R} \mathbf{R}$, the Parenchyma.

HR I, two Rings of Jpecial sapVeffels.

DC, Common Lympheducts.

DCE $F$, the mood of four gears growth.

d d, the true mood.

$\mathrm{Qd}$, part of it whiter, by the mixture of Special sap-Veffels reprefented by the tranfvers Lines.

$\mathrm{MN}$, the great Aer-Veffels.

ce, parcels of leffer ones.

$\mathrm{EF}$, a Ring of other Sap-Ve/fels.

E F G, the Pith.

T A B. XXXI. A B CD, the Barque. $\mathrm{m} \mathrm{m}$, the Parenchyma. cels.

$\mathrm{H} \mathrm{mI}$, Nilk Veffels in arched par-

D K C, Lympheducts.

D CE F, the wood of one years growth.

$\mathrm{ST}$, probably milk Veffels beretofore.

The Holes in the Aer-Veffels.

$\mathrm{K} \mathrm{K}$, the Infertions.

E v F, other Milk-Veff 6 ls.

EFG, the Pith.

T A B. XXXII. A B C D, the Barqne.

MN, The Parenchyma.

D L C, the Lympheduts.

H I, The Veffels which carry the Turpentine.

DCF E, the Wood.

$L \mathrm{~L}$, the Infertions.

E F G, the Pith.

Thegreater Holes both in the Wood and Pith, are more Turpentine VefSels.

T A B. XXXIII. A B CD, the Barque.

X Y. The Parenchyma.

K X Y L. Special Veffels in round parcels.

H I, others in a Ring.

D C, Common Lympheducts.

DCEF, the wood.

$\mathrm{S} Z \mathrm{ZT}$, probably one fort of SapVeffels beretofore in the Barque.

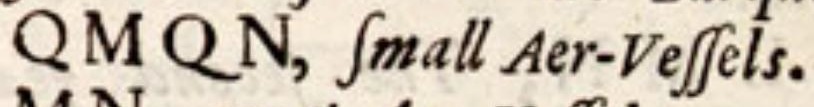

MN, great Aer-Veffels.

$\mathbf{R}$, the fmall Infertions.

$Q Q$, the great ones.

E F G, the Pith.

T A B. XXXIV. A B a a, the bairy skin.

A B C D, the Barque.

$\mathrm{H}$ w I, the Parenchyma.

D M C, the common Lympheducts.

K L, the Milk VefJels. $\mathbf{v}$, one VefSel.

$\mathrm{HI}$, Another fort of $L y m p h e d u c t s$, arched over the Milk Veffels.

$\mathrm{XX}$, feems to be athird fort of Lympheducts.

D CFE, the Wood. 


\section{The Explication of the Tables.}

$\mathrm{MM}$, the Infertions.

$\mathrm{XX}$, the true Wood. fels.

The Holes therein are the Aer.Vef-

E F, a Ring of Lympheducts.

E F G, the Pith.

T A B. XXXV. ABCD, the Barque.

A M B, the Parenchyma.

H MI, Balfam Veffels.

$\mathbf{K} \mathbf{L}$, another fort of Sap.Veffels in parcels.

K L D C, Lympheducts.

DCEF, The Wood.

In which the Holes are the AerVeffels.

$M \mathrm{M}$, the Infertions.

E F, more Balfame.Veffels.

E F G, the Pith.

T AB. XXXVI. a a, part of a Vine-Branch cut tranfver $\int y$, and alfo Split half way down the midle.

B B, The fame magnified. shewing the Pofition of the Bladders in the Barque and Pith in perpendicular Rows ; in the Infertions, in Horizontal Roms.

And the Vefjels or Parcels of Wood not raced as in many other Trees.

T A B. XXXVII. Sheweth the bracing of the Veffels. And hom the feveral Parcels of Veffels or Wood are interwoven with the infertions.

T A B. XXXVIII. A B C D, the Barque.

H I, The Parenchyma.

e e, A fort of $\mathcal{S}_{a p \text {-Veffels. }}$

a a, Another fort.

c c, Milk Vefels.

D CE F, the Wood.

$\mathrm{VV}$, the Aer.Veffels.

t t, More Lympheducts.

ff, More Milk-Veffels.

a t, The Infertions.

EF G, The Pith, composed of angular Bladders, the Bladders of Threds, and the Threds of fingle F $i$ bers.

$\rho$, One of the fingle Fibers.

T A B. XXXIX. Shemeth the Structure of the Lympheducts or of the Lignous Fibers both in the
Barque, and the Wood.

F. I. a, \& F. 2, A fingle $V_{e f f e l}$ in the Barque of Flax, compofed of a great number of other Lignous Fibers; with which alfo the Parn. chymous are intermixd. Not vifible, except very bighly magnified.

F. 3. A parcel of the fame $V_{e}$ fels in Wood.

F. 4, \& F. 5. Jhew the manner of the Afcent of the $S_{a p}$, both in the Lympheducts, and in the Ladiferous and other larger Veffels.

T A B. XL. The Fibers which bang down from the Barque are the Lympheducts; one of which is compofed of a great many other fmaller Fibers.

The large Tubes are the Milk-Vef fels compofed of Bladders.

The Fibers which hang down from the wood, are fome of them the old Lympheducts turn'd to wood.

And fome, Aer-Veffels unroav'd. The thin Plate between the two wedges of wood, is one of the InSertions, compofed of Bladders, and thofe Bladders of Threds.

The remainder, is part of the $P_{i t h}$, compofed of Thredy or Fibrous Bladders.

The TABLES to the Fourth BOOK are 42 .

$7 \begin{aligned} & \text { A B. XLI. b, a Dock-Leaf } \\ & \text { covered with the Veil. }\end{aligned}$ d, the Leaf naked.

a $c$, the Veil spred open.

In Clary, the Bud is embraced by the Curled Leavs.

In Sumach, the Bud lies within the Stalk, as an Egg or Kernel witbin a shell.

T A B. XLII. F. 1. Sheweth how the Pipes are inclofed one within another.

F. 2. a, the Leaf foulded up. b, opened.

F. 3. a b, the Bid. b, a little 


\section{The Explication of the Tables.}

magnified.

F. 4. $\mathbf{a} \mathrm{b}$, the Leaf rowled $u p$, invoard. c, a little magnified and cut tranfverfly, to fhew the Rowl.

F. 5. a, the Leaf rowled up. b, magnified and cut tranfverfly.

F.6.a, the Leaf rowled backward. b, magnified and cut tranfver ly.

T A B. XLIII. F. I. flieweth the Tenter-Hooks, by which the Leaf climbs.

F. 2. Shemeth the Globulets, turned to a white powder.

The Leaf of Ferufalem Complip. fremeth the Way of the Infect under the skin.

T A B. XLIV. \& XLV. Spenetb the Meajures of Leavs by the Circumference.

T A B.XLVI \& XLVII. Speweth the proportion between the chief $F i$ bers; and aljo the Angles they $u$ fually make together.

T A B. XLVIII. F. I, 2, \& 3 . fhew the Apertures in Several Leavs.

F. 4. Shemeth the fame. And likewife, the peculiar composure of the Bladders and Fibers of the Leaf.

T A B. XLIX. Shemeth the difference in the Bladders, and in the Pofition of the Lignous Fibers in the Stalks of Leavs.

TAB. L. flewetb the Pulp of $a$ Borage-Leaf and many others compofed of Bladders; the fides of zobich Bladder, are made of other fmaller ones.

And the distribution of the Lignous Fibers (and of the Aer-Veffels fouthed within them) not like that of Veins in Animals, but of the Nervs, erc. See the defcription of the Leaf.

T A B. LI. F.I. The appearance of the Aer-I'efjels like Cobwebs to the naked Eye, upon breaking the Leaf.

F. 2. A fmall peice cut off of the L.eaf.

F.3. The fame magnified in wbich the Some Veffels look like Jpiral wyers fretched out.

F. 4. The fame as they ftand entire within the Wood.

T A B. LII. Reprefenteth the Aer-Veffels of Scabious, as in Tab. LI.

T A B. LIII. Sheweth the manner of the Generation of the Leaf; chiefly, by the belp of feveral Salts, wherewith the Sap is impregnated.

F. 5. (I) The Foundation of the work.

F.6. ( I \& 2 ) frengtbned.

F. 7. ( 1 \& 3); in which (3) is fet with the Square end to end: and with the poynt-fide of one, to that of another.

F. 8. The fame, directing the $\mathrm{Po}$ fition of the Lignous Fibers at very Acute Angles.

F. 9. At lefs Acute Angles.

F. IO. The greater Fibers at Acute, and the fmaller at Right Angles.

F. 11. The greater at Right Angles with the belp of (I) (2) or (3).

F. I2. (3) directing the Fiber in the Edge of the Leaf into a greater Circle.

F. I 3. Into a le ss, and with divers Diameters.

F. I4. (4) derecting the Parenchymous Fibers in making the Bladders.

F. I 5.In winding from one Bladder to another.

F. 17. Or about the Lignous $F i$. bers.

F. I6. In making the Aer-Veffels.

T A B. LIV. Sheweth bow Nature manages the Folds of Flowers according to their Shape.

T A B. LV. F. I. freweth the Edges of the Leaf fastned by their Indented Hairs.

F.2. The Balfamick $K$ nobs in the place of Hairs.

F. 3. The number 5 running 3 times into its felf in 13 .

F.4. And five times in $2 \mathrm{r}$.

F. 5. \&c. The Seminiform Attire in clematis Anstriaca. With one of 


\section{The Explication of the Tables.}

the Thece magnified; of which, there are about 30 or 40 in cne Flower.

F.8, \&c. The fame in Blattaria, with one of the Thece magnified; of which are there about 5 in one Flower.

T A B. LVI. The fame in yellow Henbane.

With one of the Thece magnified; of which there are about 5 in one Flower.

And the Column on the top of the Seed-Caje.

TAB. LVII. The fame in St. Johns wort, entire, together with the Seed-Cafe or Uterus.

T A B. LVIII. The Varieties of the Spermatick Particles in the $S_{e-}$ miniform Attire.

T A B. LIX. The Florid Attire of Golden Rod;

In which, the feveral fuits confift but of two pieces. And of wobich Attire, the Flower doth almoft wholly $\operatorname{con} f i f$.

T A B. LX. F. I, \&c. The fame Attire in French Marigold or Flos Africanus, with one fuit magnified. of which, there are about 12 , in one Flower; and every fuit confifting of 3 Pieces.

F. 5. One of another Flower, confifting alfo of 3 Pieces.

TAB. LXI. One fuit of the fame Attire in Marigold, and Knapweed, each of them confifting of three Pieces.

F. 5. a, The Attire of one Piece, proper to each Leaf in a Marigold Flower, befides that in the bofome of the Flower.

F. 8. a b, the Seed-Cafe or Uterus at the bottom of every fuit.

T A B. LXII. The Attire (of 3 Pieces) proper to each Leaf in the Flower of Cichory.

T A B. LXIII. Sheweth the Flower of Mezereon perfectly formed in all its Parts, in the jear before it appears. But differs in Shape, as a $F Q$ tus doth when newly formed.

T A B. LXIV. joweth the fame in the Flower of Alarum.

T A B. LXV. Shemeth the pofition of the 20 chief Branches in an Apple.

Their Production from the Stalk to the Seeds and Flomer.

And a part of the Parenchyma magnified, fc. that wobich is pricked out from the Coar to the Skin; Jhewing the oblong Figure of the Bladders, and the Divifions in every Bladder.

T A B. LXVI. F. I,\&c. Sheweth the Bladders in the Rind of a $\mathrm{Li}$ mon conteining the Oyl.

The Bags and Bladders of the Pulp, conteining the fower Fuyce. And the Pofition of the Veffels belongeth to the Fruit, Seed, and Flower. F. 5. Joews the fame Vefjels, and treble Parenchyma in a Cucumer.

T A B. LXVII. Reprefsteth the Parts of a Pear.

The pofition and production of the Vefjets.

The Chanel from the top of the Pear to the botome of the Coar.

The Tartareous Knots. them.

And the Bladders radiated to

T A B. LXVIII. see the Defriptions of Fruits; and the laft Chapter of the Generation of the seed.

T A B. LXIX. F. 5. Sheweth the Parts of a Goosberry.

The darker part is the forver Rind. Confifting of two forts of Bladders, of which fome very fmall, and others very great.

The white pieces on the circumference of the Berry, are the Lignows Fibers.

The two oppofite white and radiated Bodys are the Midle Paren. chyma.

And the oblong Baggs round about the feveral Seeds or seed-Cafes, are the foeet Pulp.

T A B. LXX. Sheweth.the seedCafe of Radifh opened, and the Seeds hanging on two Ropes.

That of Poppey both entire, and

$$
\mathrm{Ccc} \text { Splis }
$$


Jplit down the midle.

A lice of the Cod of Garden-Bean, while veryyoung; and therein the Bladders and Threds of the spongy Parenchyma.

And the gratual ripening and opening of that of yellow Henbane.

T A B. LXXI. sheweth the seed Cafe of Tulip entire, cut tranfverfly, and $\int p l i t$ downe.

Aflice of Thorn-Apple, or of the Seed-Cafe of Stramonium, while young.

That of Pimpinel naturally divided into two Hemisphers; with the Button, on which the seeds grow, erected in the middle.

The manner of the ejaculation of the Seed, in Coded arjmart.

And the Coats of the seed of Aza. rum formed the year before it ripens.

T A B. LXXII. sheweth the meafures of $T$ lum-fiones.

The Apertures, and Divifions, of the covers of the Seed.

The Seed and Seed-Cafe of Harts rongue, opened with a spring.

And other contrivances both for the Motion, and Arreft of other seeds.

T A B. LXXIII \& LXXIV. see the Defcriptions.

In Tab. 74. the corners and edg. es of that of Fox-glove fhould bave been rounder.

The Figures are all done pretty near a Scale.

T A B. LXXV. The Belly and Back of a Dateftone, and the fmall Sprouting Node taken out of the Hole in the back cut open. seeds.

The Shapes and Foulds of divers

The Vitellum of orach, and Rhapontick.

In great blew-Lupine, d, the $\mathrm{Na}$ vle; $\mathrm{b}$, the defcending part of the Radicle.

T A B. LXXVI. Flag. I, the seed. 2, fylit open. 3, the true seed wbich lies in the bollow made in the Cover (2) 4 , one balf of
2) magnifyd. 5, the seed (3) magnifyd.

Purging Angola Nut. 1, with the Gell on.

2. taken off. 3, the foft Cover Split down. 4, the seed which lies in it; the Lobes hereof anfwerable to two Leaves, and Radicle to the Stalk.

And $f_{0}$ in the reft.

T A B. LXXVII. Coffee Beiry ftone. I, The belly of the Stone. 2, the Black. 3, pared a little. 4, the Kernel taken out of it. s, the fame magnifyd.

Goofgraß. 1, the entire seed. 2, the back of the hard Cover. 3, the belly. 4, cut in two 5 , the fame magnifyd. 6, the true Seed taken out of it.

Staphifagria. I, the entire Seed. 2 , the bard Cover. 3, Split in two. 4 , the true seed taken out of it. 5 , The fame magnifyd.

Peony, I, the Seed commonly fo call'd. 2 , one balf of it $\int$ plit down. 3 , the other balf. 4. the true feed taken out of it. 5, the fame magnifyd.

Stramonium. I, the Seed entire. 2 , the iner thick cover. 3 , the Jame split in two. 4, the true feed taken out of it. 5. half the thick Cover (3) magnifyd. 6, the seed (4) magnifyd.

T A B. LXXVIII. Some examples of the Buds of Seeds before they are fown.

Sena: 1, the naked Seed. 2, the Lobes divided to fhew the Bud. 3 , one Lobe with the Bud magnifyd.

Carduus Beneditius, 1 , the entire Seed. 2 , with the outer Covers off. 3 , naked. 4, divided. 5, that balf with the Bud, magnifyd.

Hemp. I, the naked Seed divided. 2,3 , the fame magnifyd.

Almond. 1. one balf of the Kernel. 2, the Radicle and Bud at the bottom of it. 3, the fame broken off. 4 , magnifyd. 5 , opened.

T A B. LXXIX. F. I. a b, Part of the onter Coat. 


\section{The Explication of the Tables.}

cd, Part of the Inner Coat. Skin.

c de, one Lobe cover'd with the

$\mathrm{f} g$, the other, with the skin and part of the Parenchyma pared off:

ff, the Skin.

$\mathrm{h}$ h. the Parenchyma.

i i. the Seminal Root.

$\mathrm{k} \mathrm{k}$, the Radicle.

$\mathrm{k} \mathrm{l}$, where it is cut off from the Lobss.

$\mathrm{M}$, the Plume or Bud

$\mathrm{N}$, The Cavitys in which it is lodg'd.

F. 2. Sheweth the Barque, Veffels and Pith of the Radicle.

T A B. LXXX. F. I. A Slice of a young Apricock, cut tranfver ly, near the lower end; fheming the duplicature of the Skin balf way through the Stone.

F. 2. A Slice, cut near the upper end; flowing the duplicature of the Skin quite throw the Stone

F. 3. A well-grown Apricock cut by the length.

F. 4, 5, The Membranes of a Filbert full rite.

F. 6, The Membranes of a young Apricock, with part of the Seedbranch.

F. 7. the two Membranes cat by the length.

T A B. LXXXI. F. I, The outer and midle Coats or Membranes; with the Chanel, oval at both ends, now formed in the latter.

f. 2 , Part of the fame, with the upper Oval grown larger, and the inmoft Cover now alfo formed therein.

f. 3. the fame with the inmolt cover grown larger.

f. 4. the Inmoft Cover more magnified, and the bollow in the fmaller end, laid open, to ghew the Seed it
Self, newly begun in a round Node.

f. 5. the Jame; in which the Node begins to be divided into two Lobes.

f. $6,7,8$, the gradual forming of the Lobes. dicle.

f. 9 , next the forming of the Ra-

f. 10,1 , Its gradual contraction at the point, into a flhort and flender Navle ftring.

Which in the further growth of the seed, breaks and difappears.

T A B. LXXXII. a a, the Pulp,or open Parenibyma.

$\mathrm{b} b$, the clofe Parenchyma or grownd of the Stone.

cc, the Flower-Branch running through the body of the Stone.

$\mathrm{d} d$, the Seed. Branch friking into the bollow of the Stone, and fo running round the outer Membrane ee. ff, the middle Membrane.

$\mathrm{g} g$, the Chanel.

$\mathrm{h}$, the inner Membrane, in wbich lies the Seed.

T A B. LXXXIII. f. I. the manner of the generation of the EfJential salts of Plants.

f. 2, a Crystal of the Efjential Salt of Rofemary, a little magnifyd.

f. 3 , a b, two of Wormwood, a, upon the fecond Solution; b upon the firft.

f. 4 , one of G. Scurvygrafs; a, one fide; b the other.

f. 5. a Crystal of the Marine salt of Rofemary.

f. b, of Garden scurvy-grafs; a the upper fide; $b$. the nether.

t. 7 , of Wormwood.

f. 8. of Black Thorne.

f. 9 . another of the fame.

f. $\mathrm{I} 0$, of Firne.

f. II, another of Wormwoods

\section{F I N I S.}




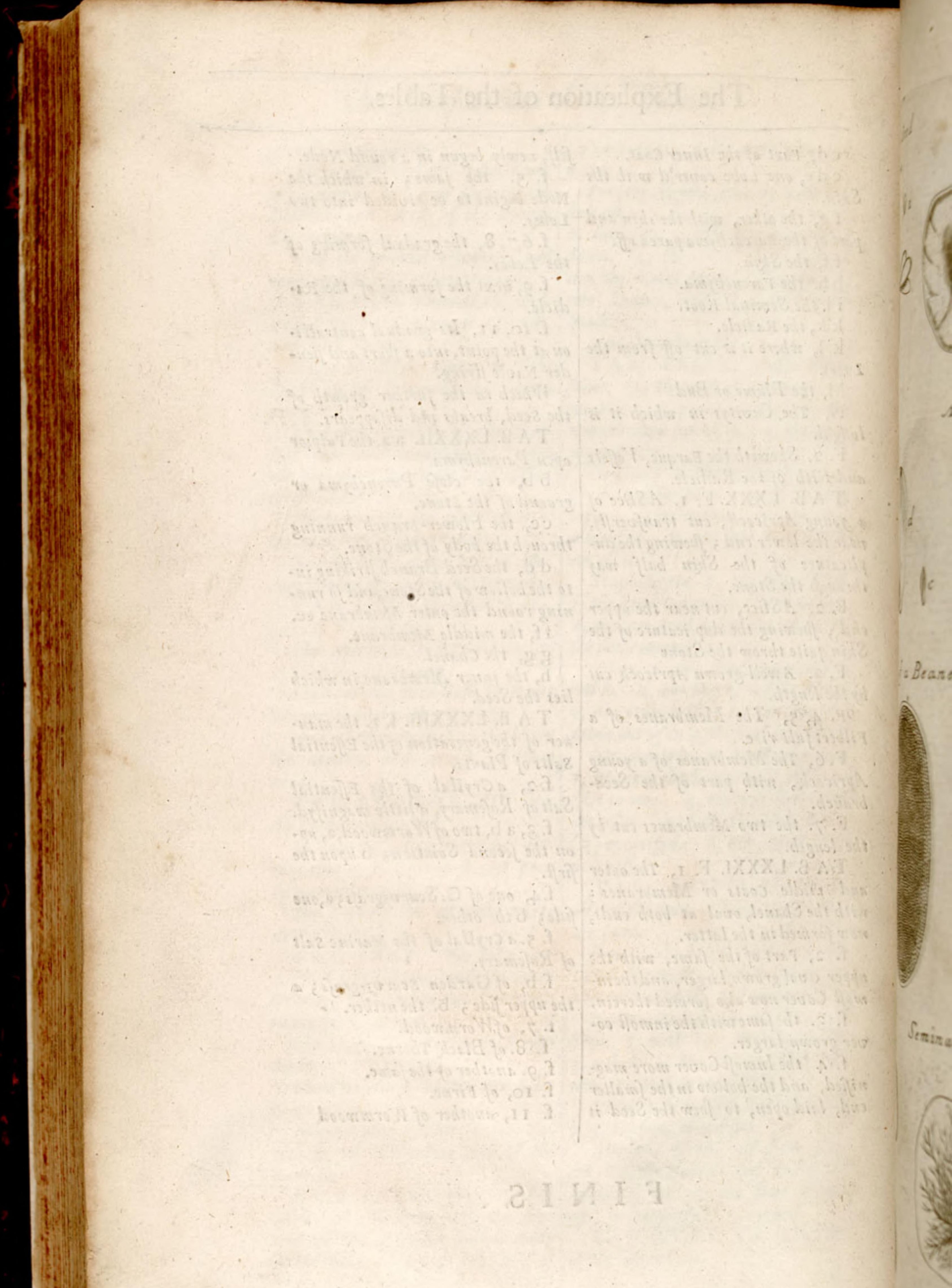




$$
\begin{aligned}
& 4800 \\
& 000 \\
& \text { (2) } \infty
\end{aligned}
$$

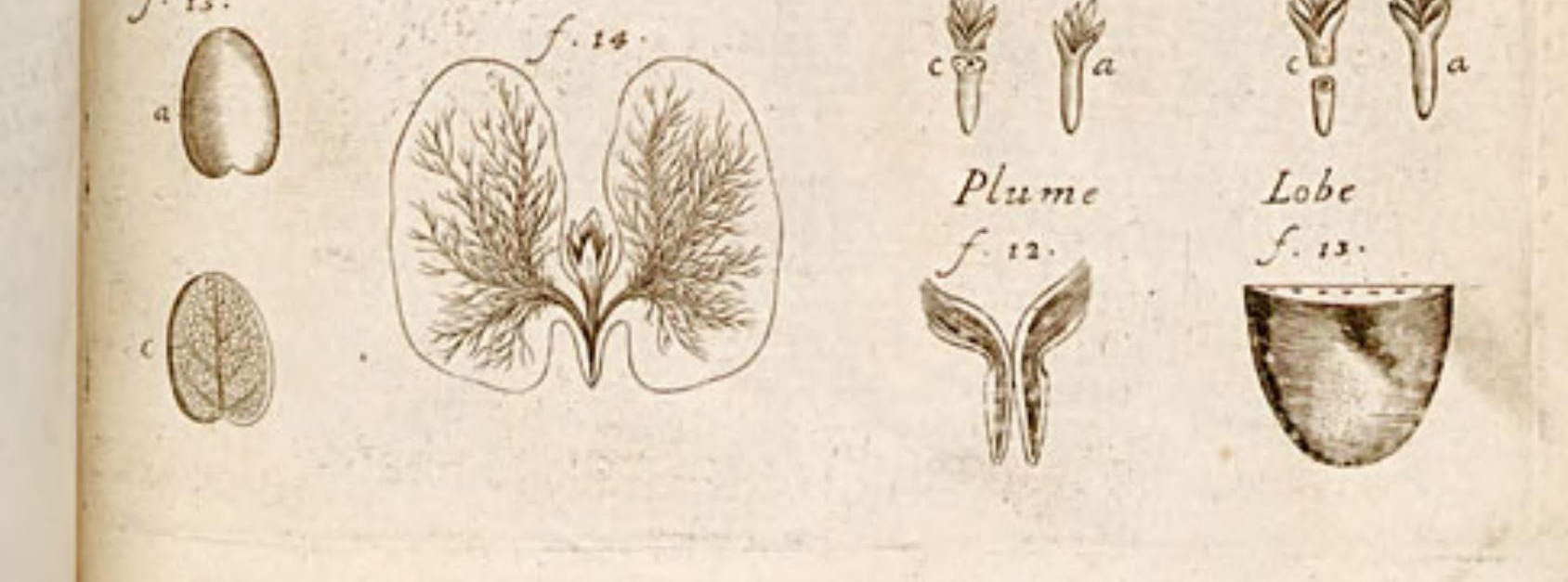




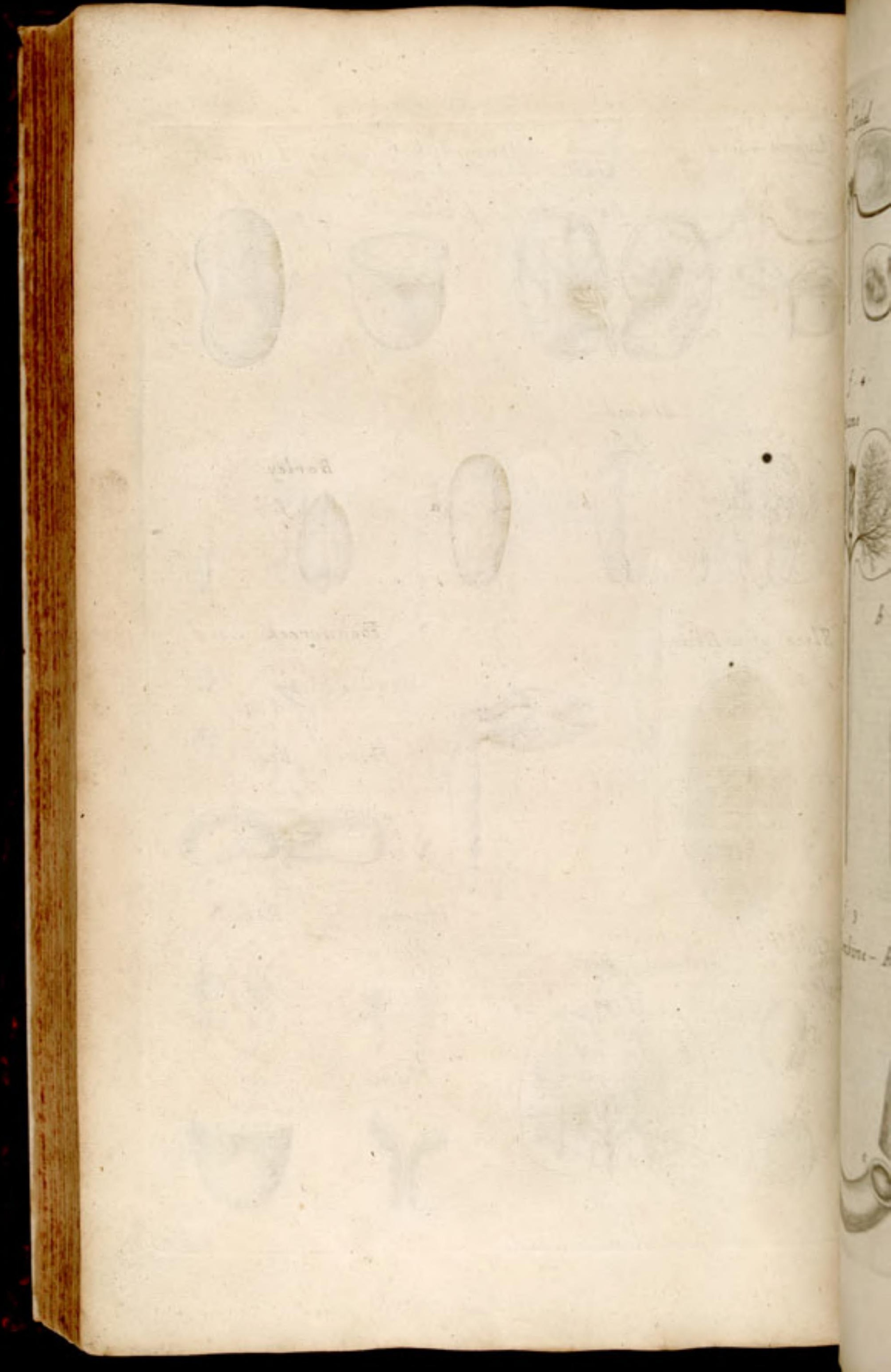


$\operatorname{sig} \cdot t$

Lupme-Seed

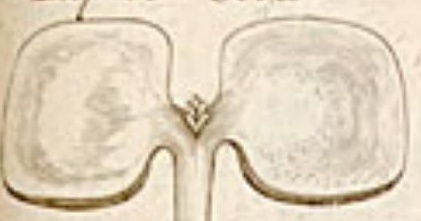

0. 8

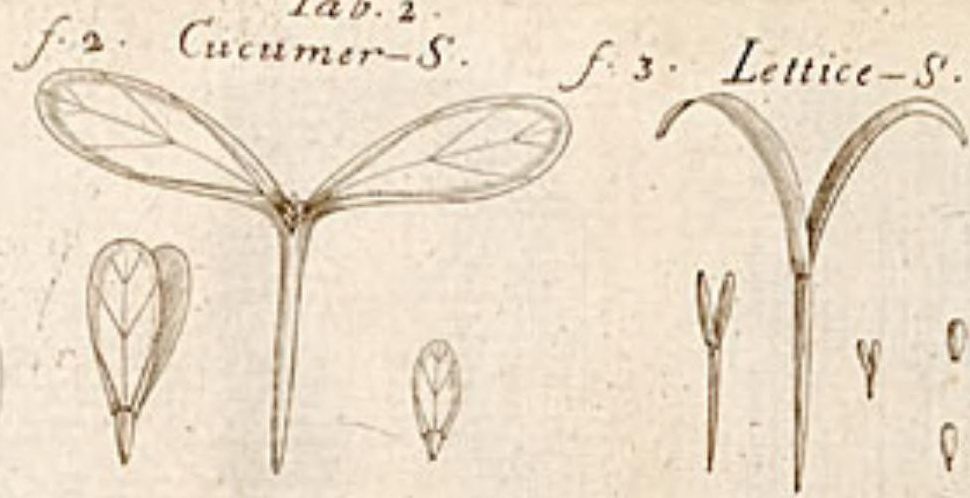

Tab. 2

- $f \cdot 4$
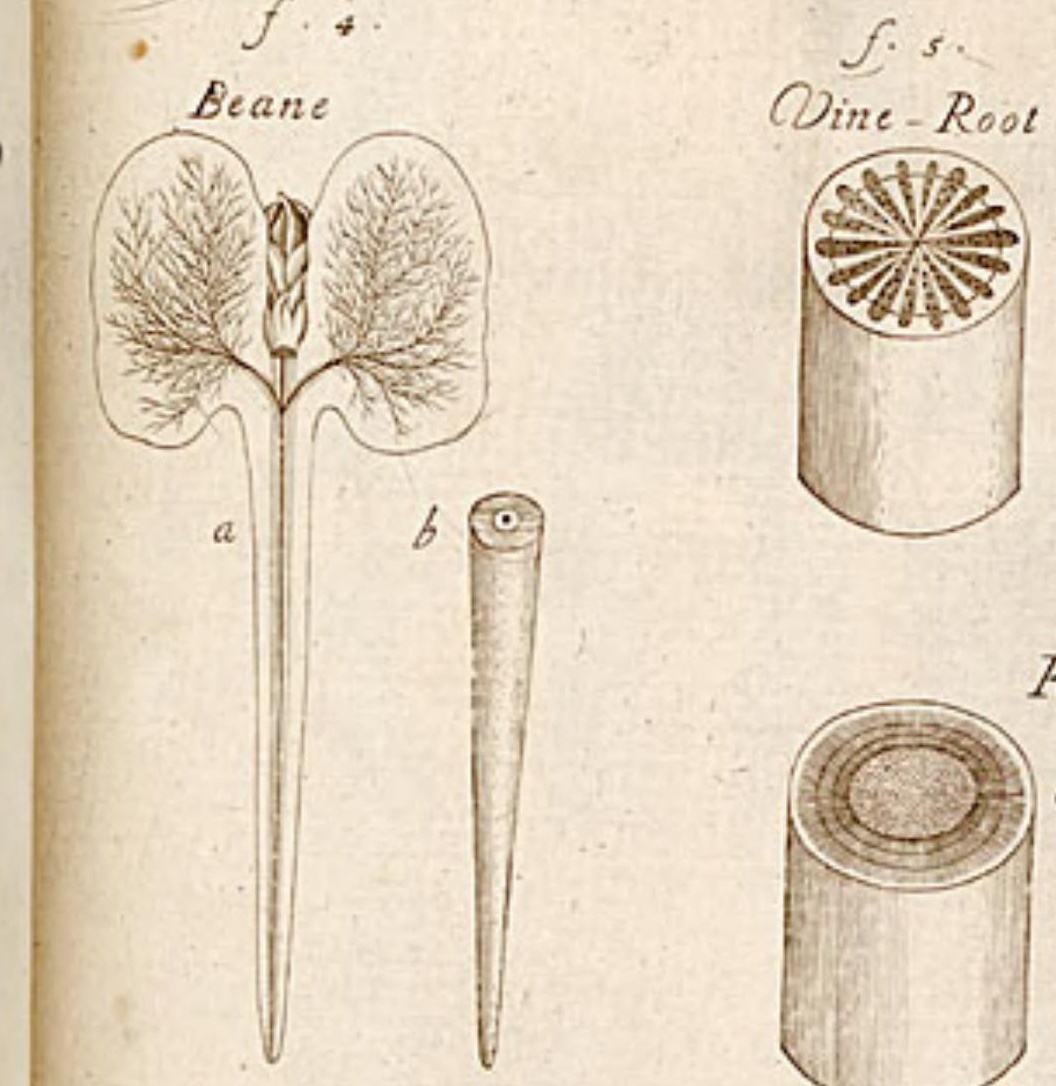

f. 6 .

P/ū̄e - Root
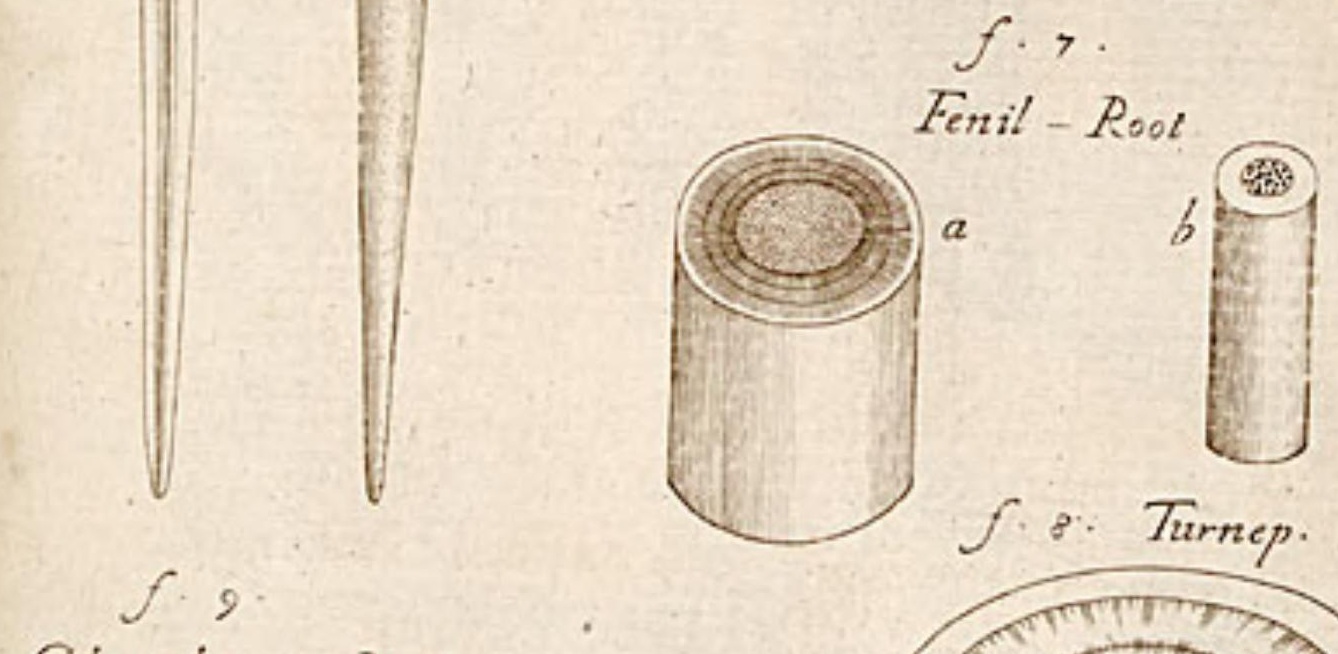

Columbine - Root

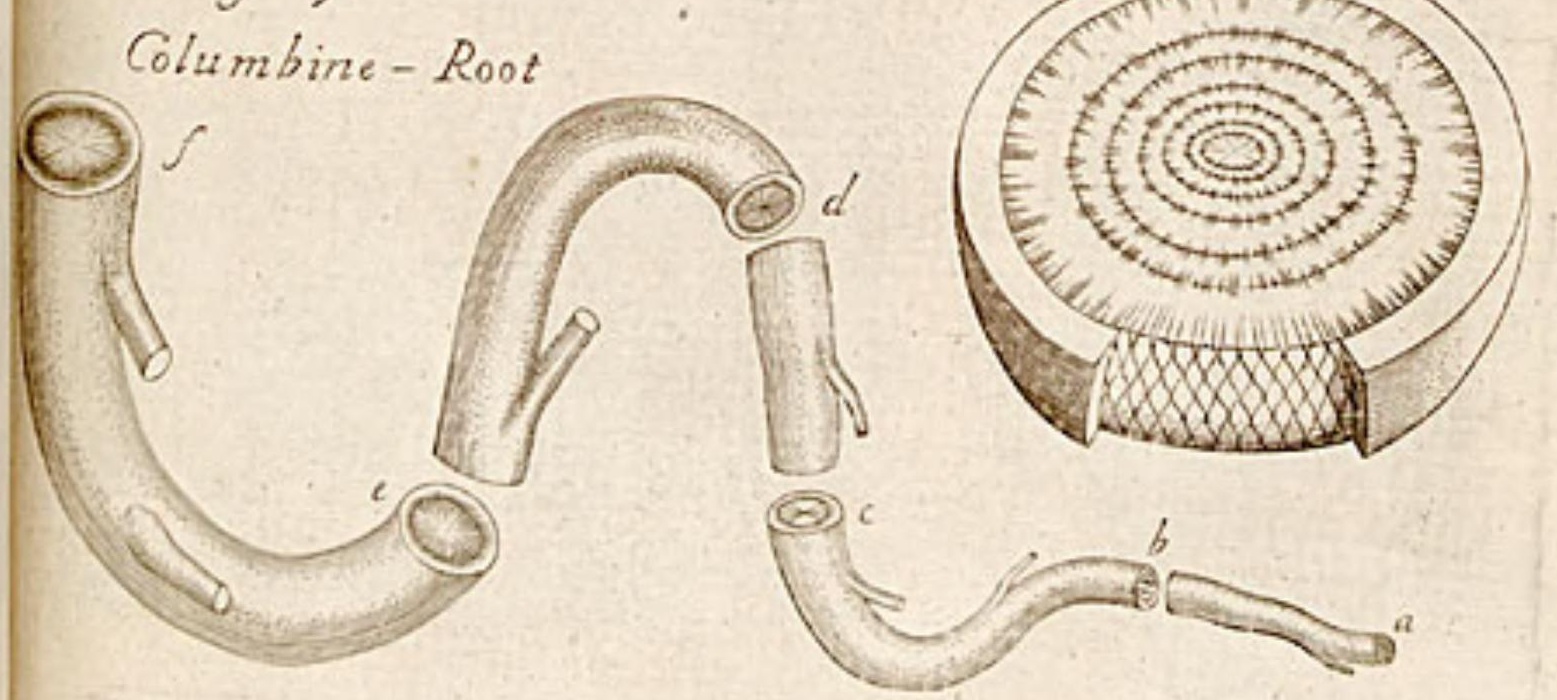


Tab.s. fig.t. a Beane f.2. Oak-Wood. fis. Peice of cane
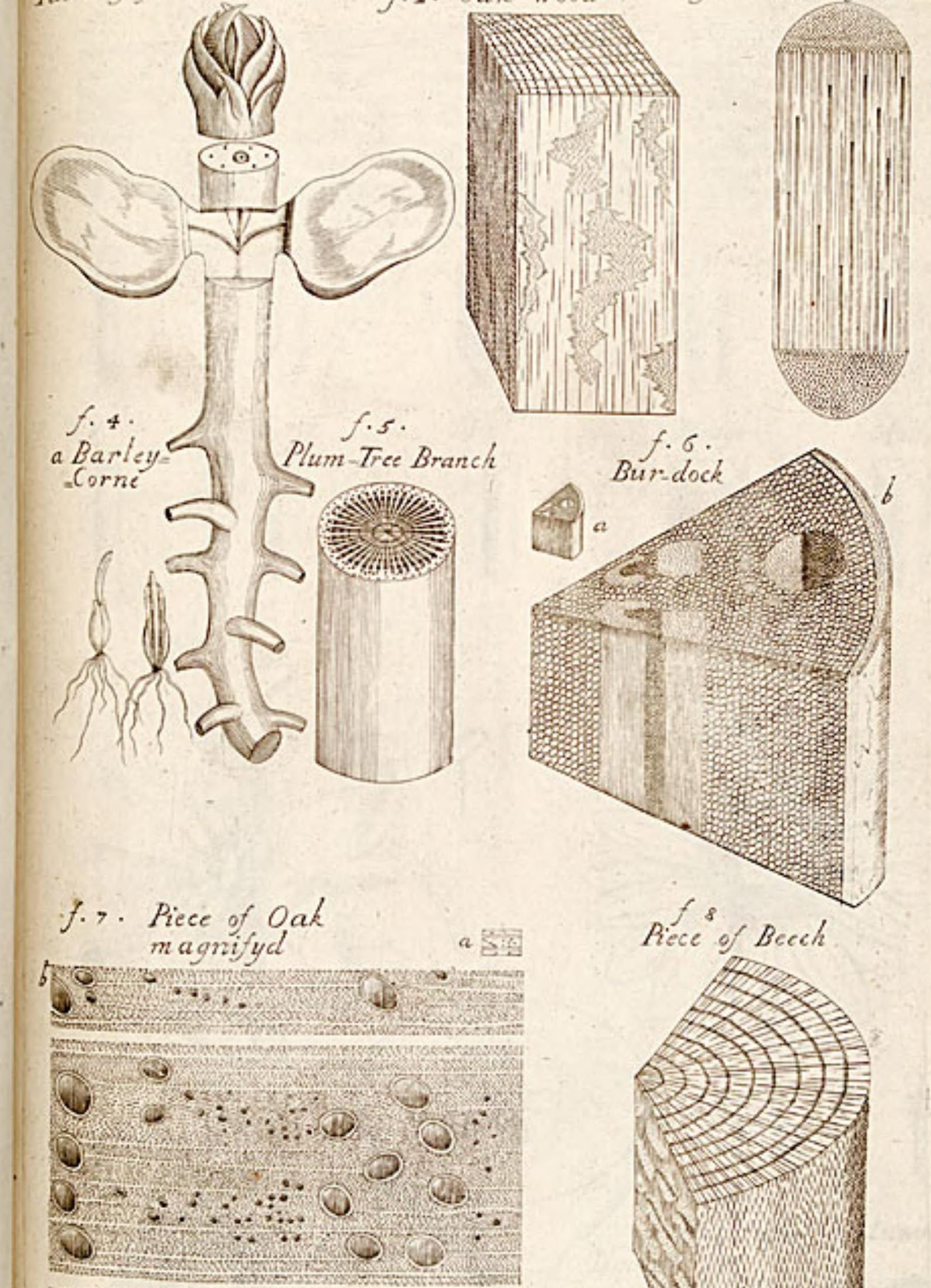

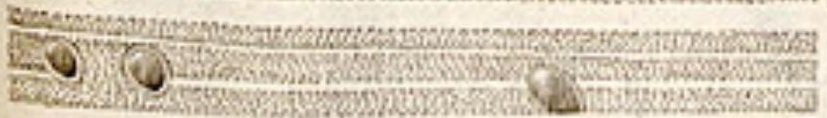

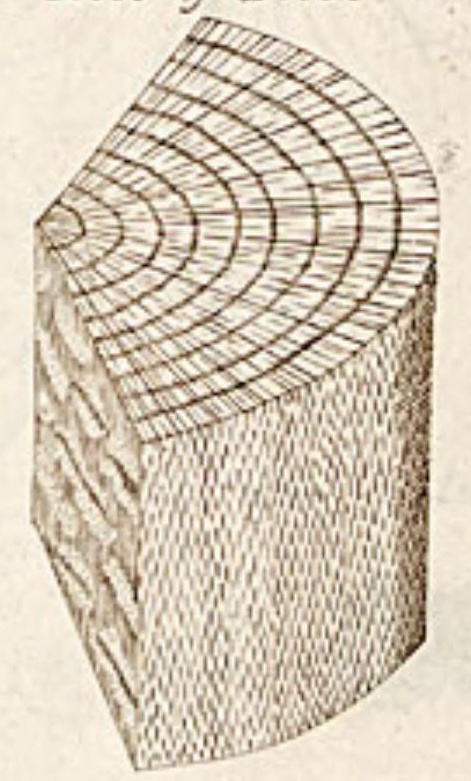


- Tab.tV. Picce of Beech Wood

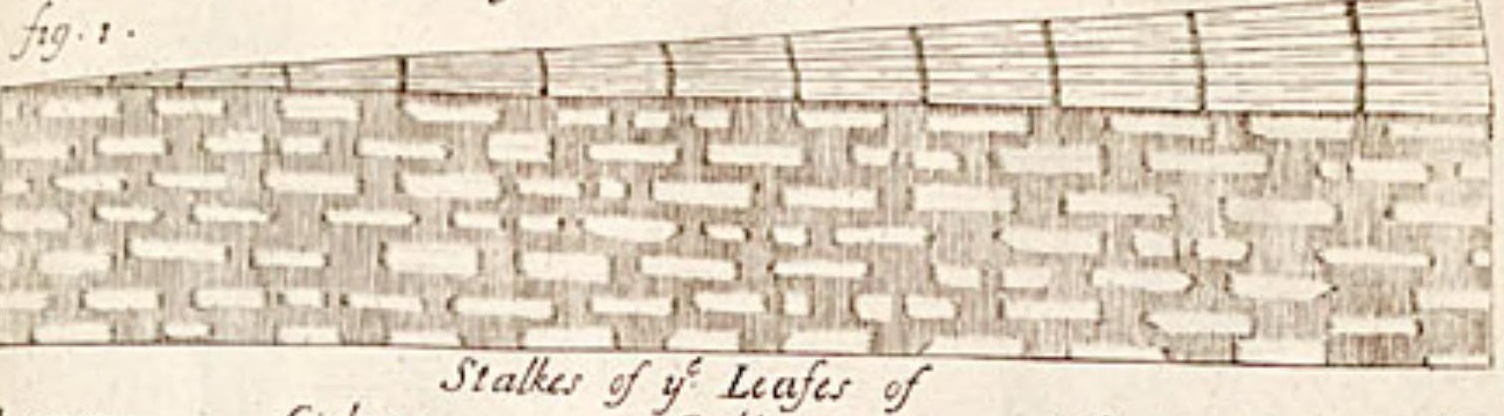
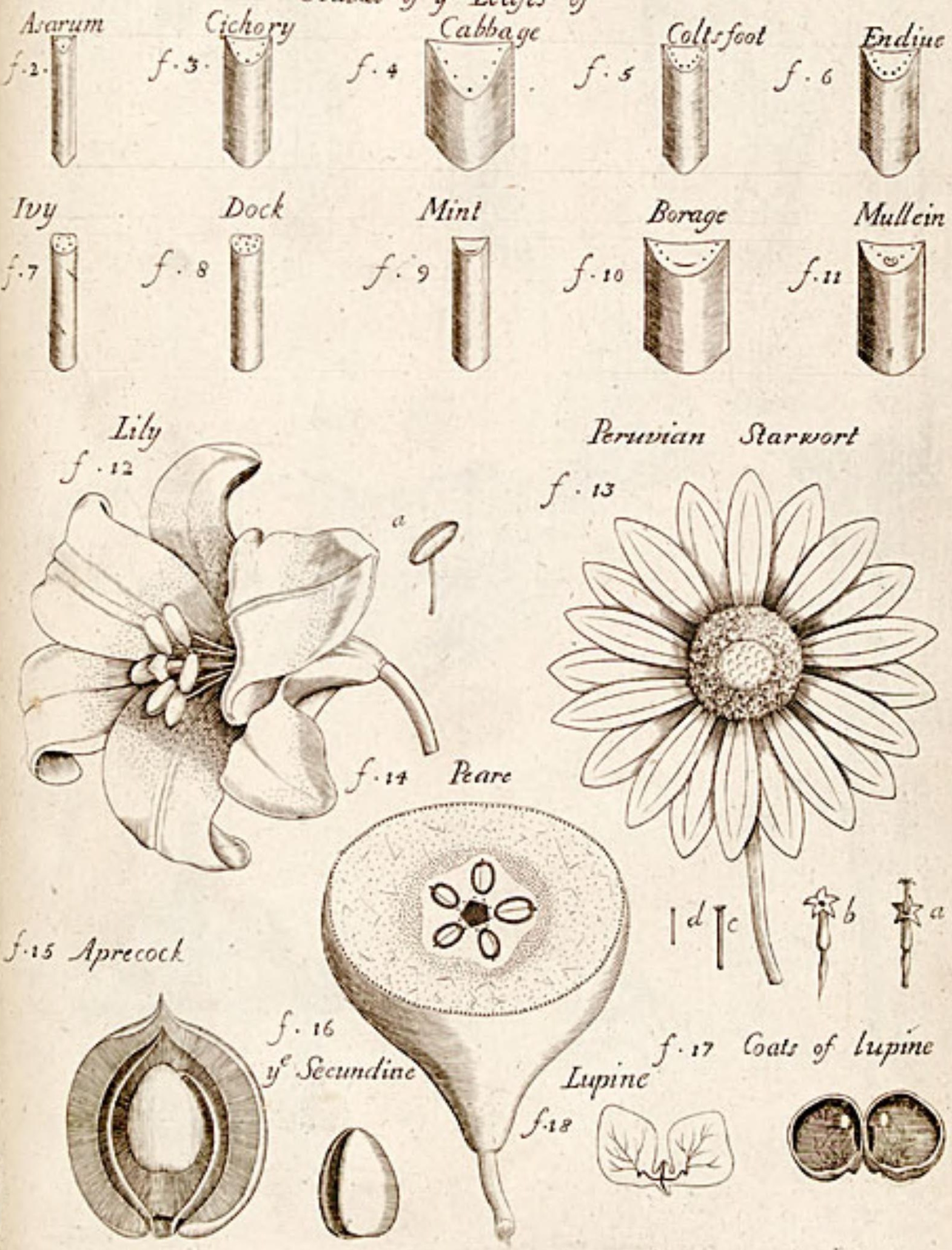


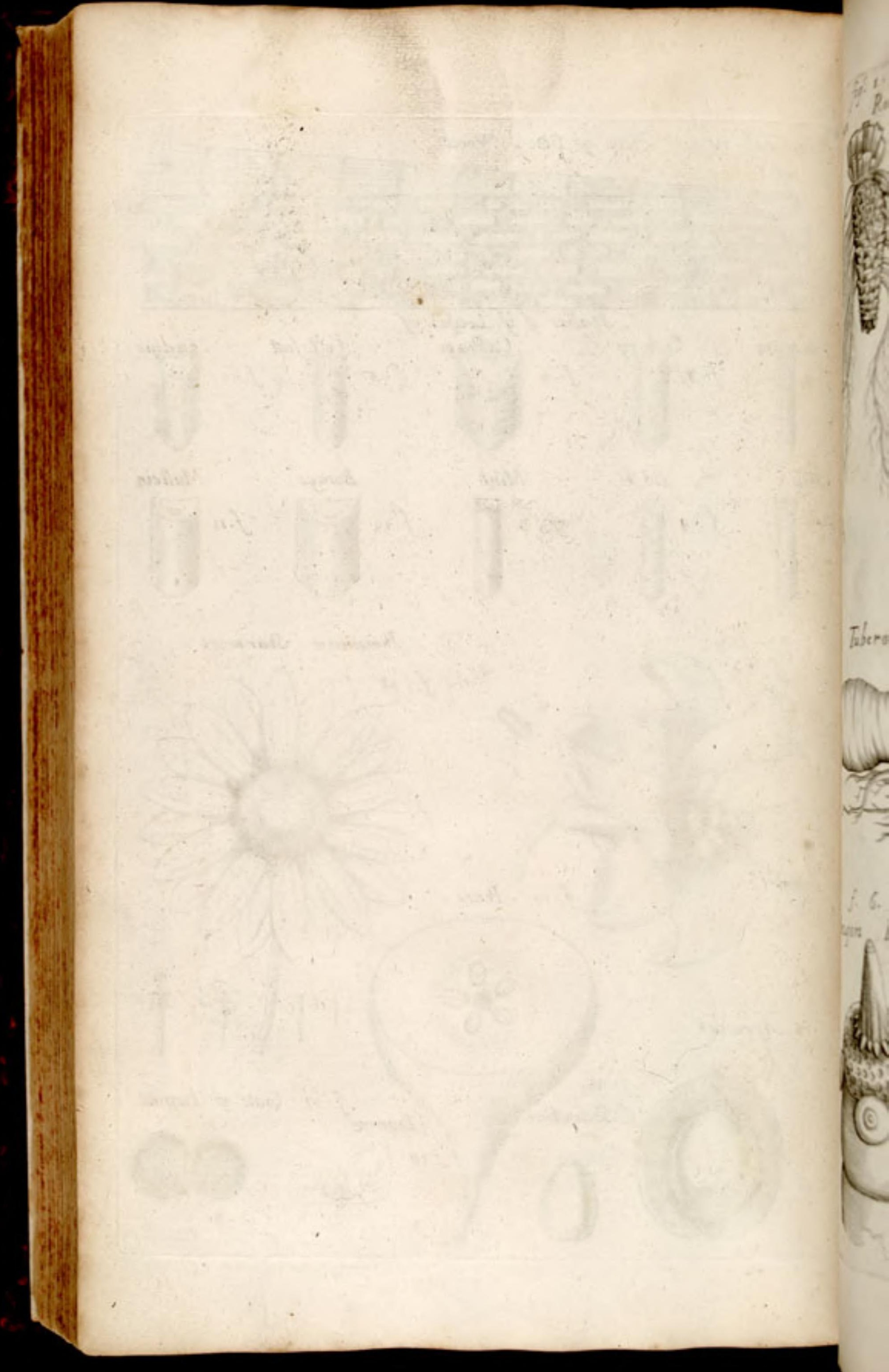




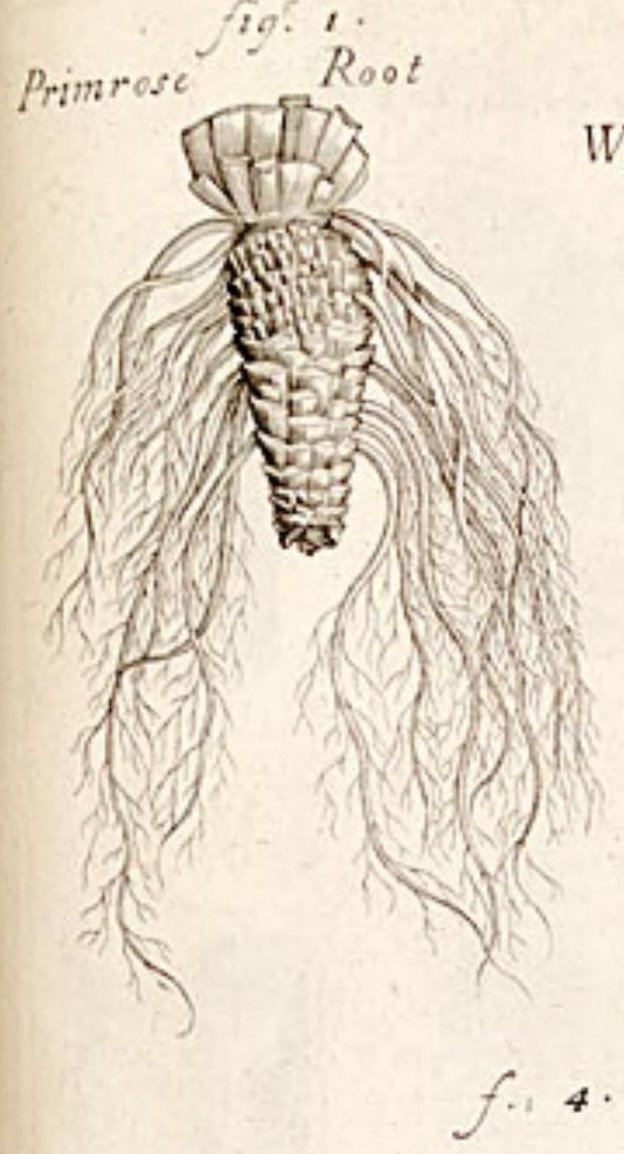

Tab: 5 . Wood-forrel $R$.

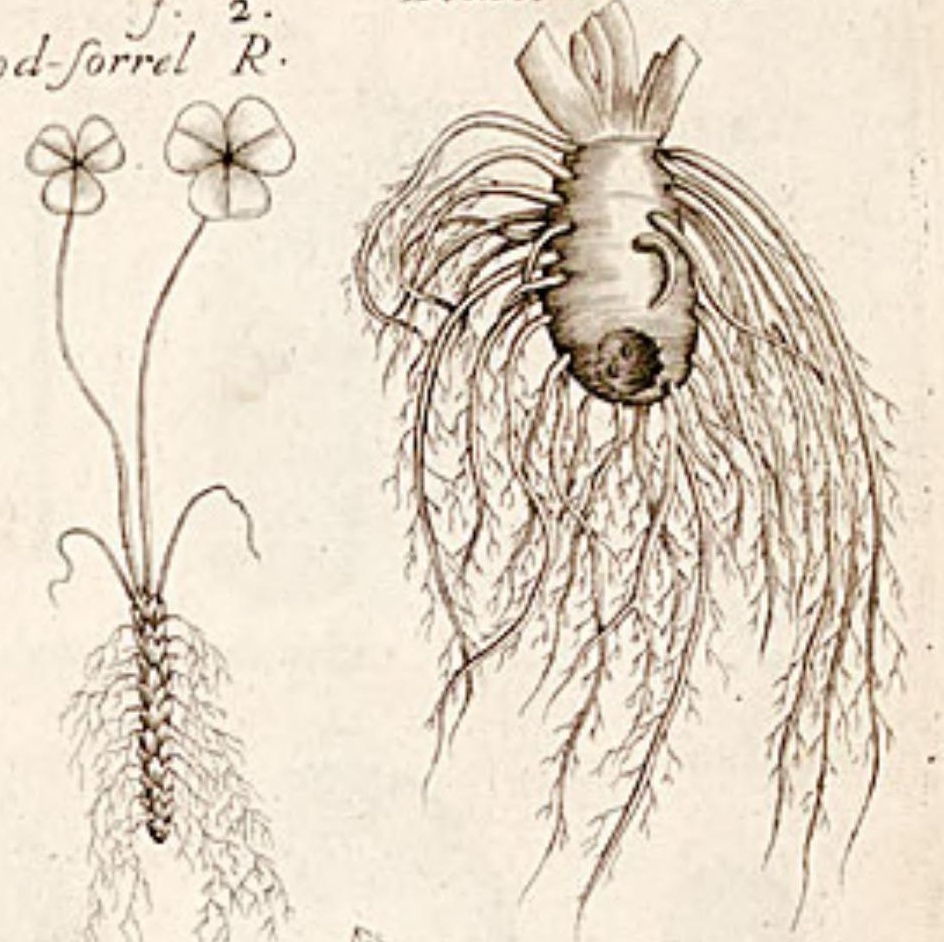

Dewils-bitt $R$.

Tuberous Iris $R$.

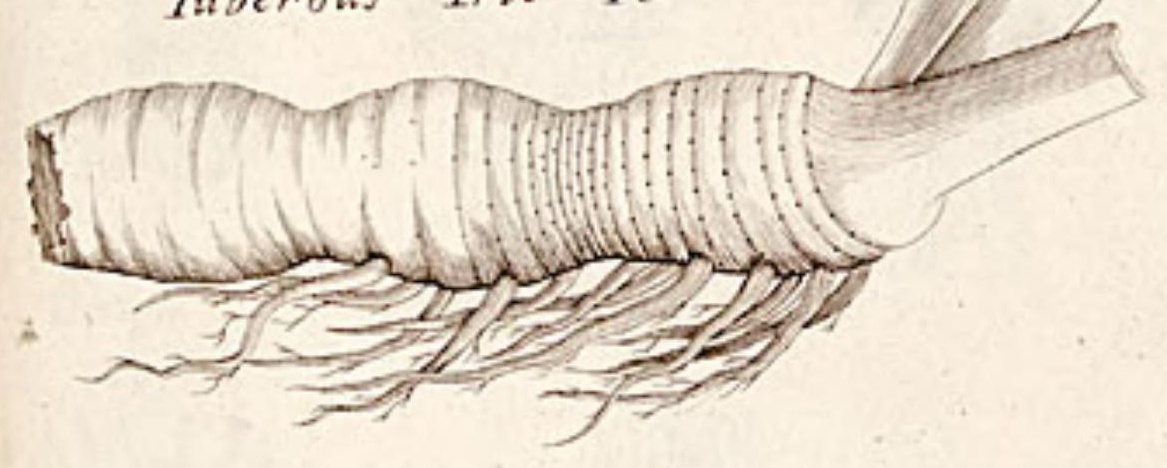

Dandelion $R$.
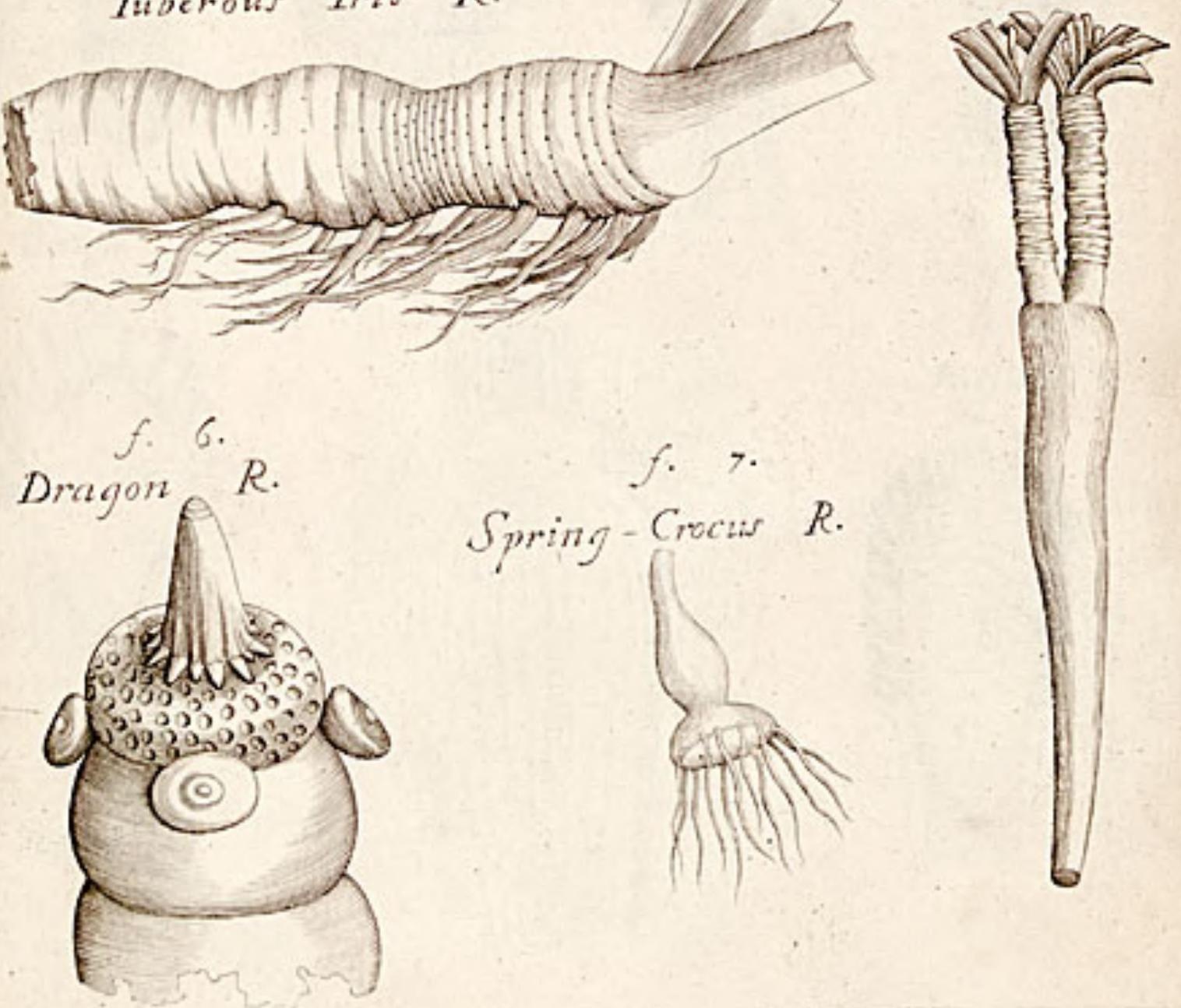


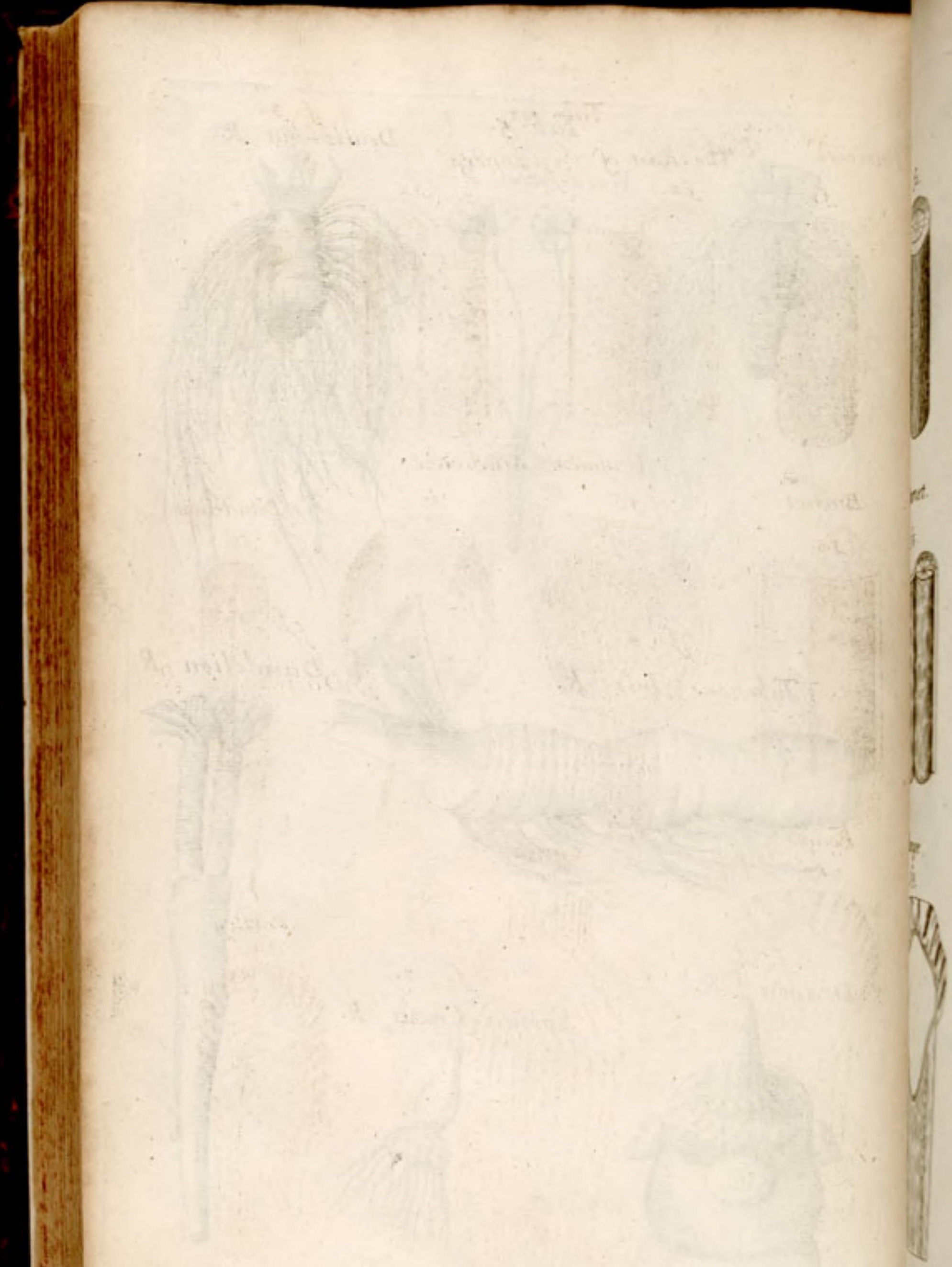


Tab: VI.

The Root of Scorzonera.
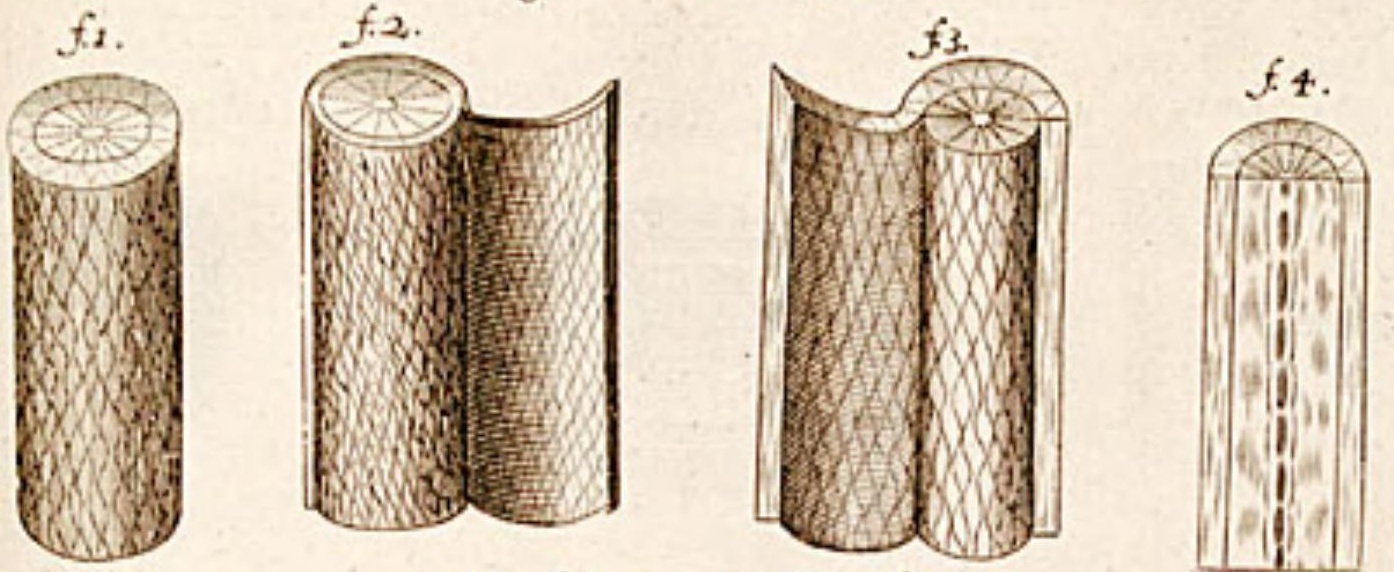

Jerufalem Artichoake.
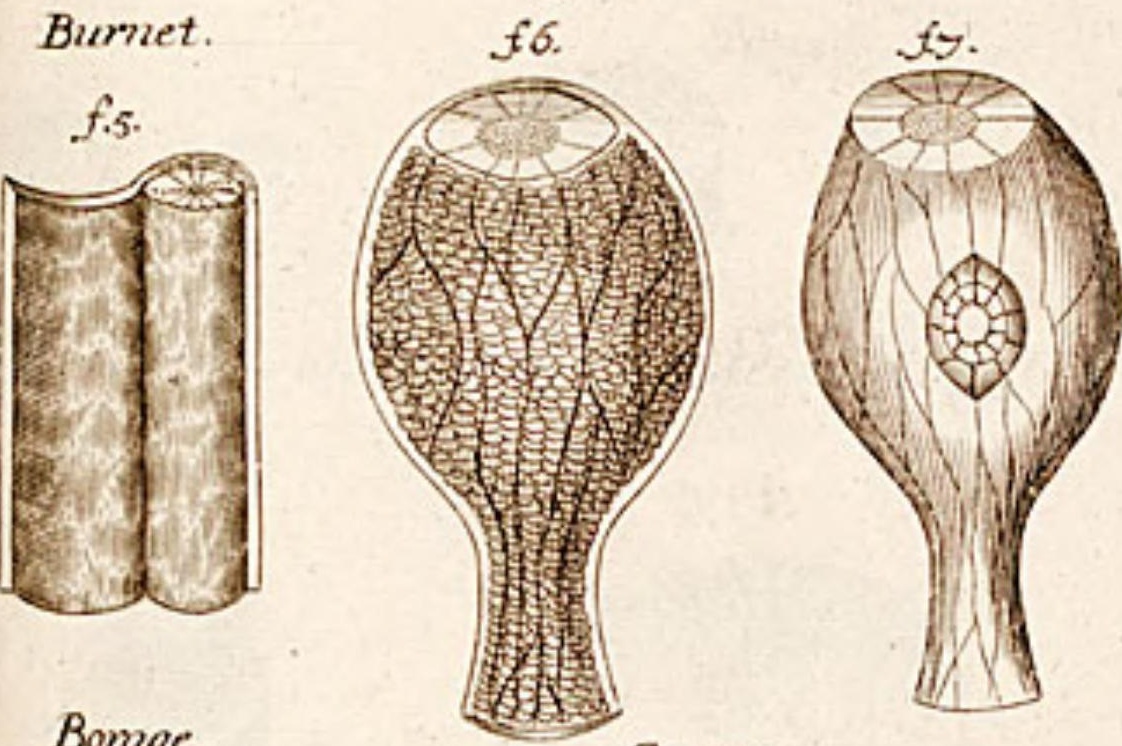

Dandelion.

Bonge .

f.9.

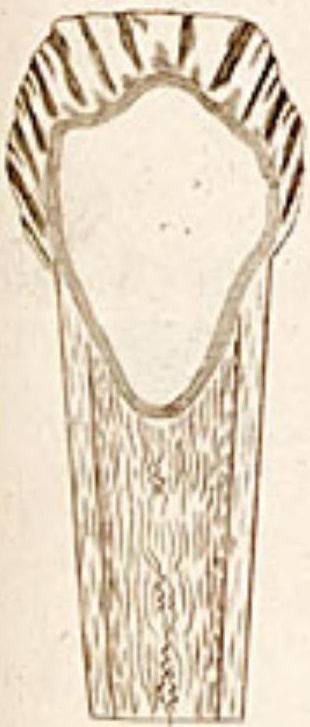

Carrot. fio.
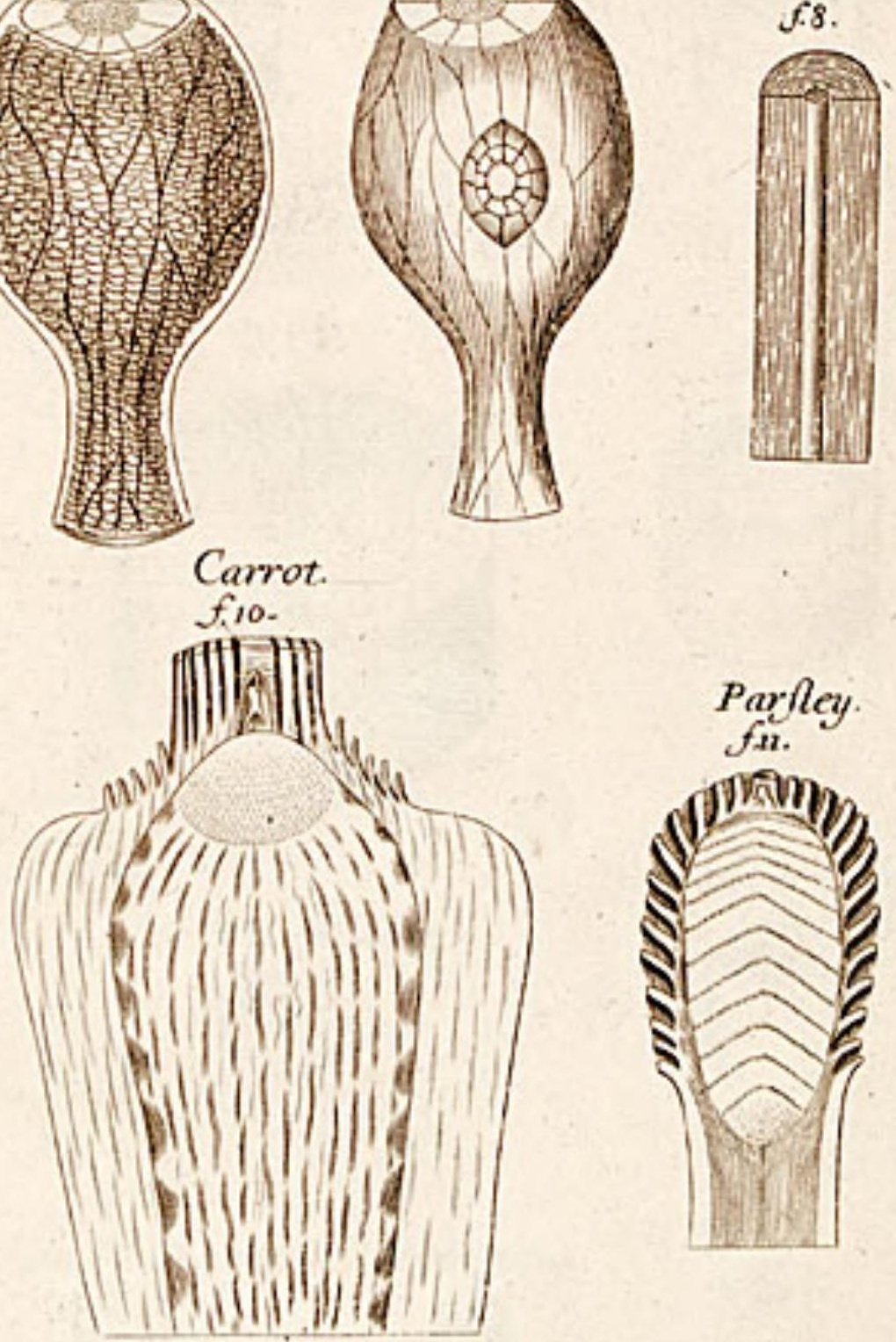


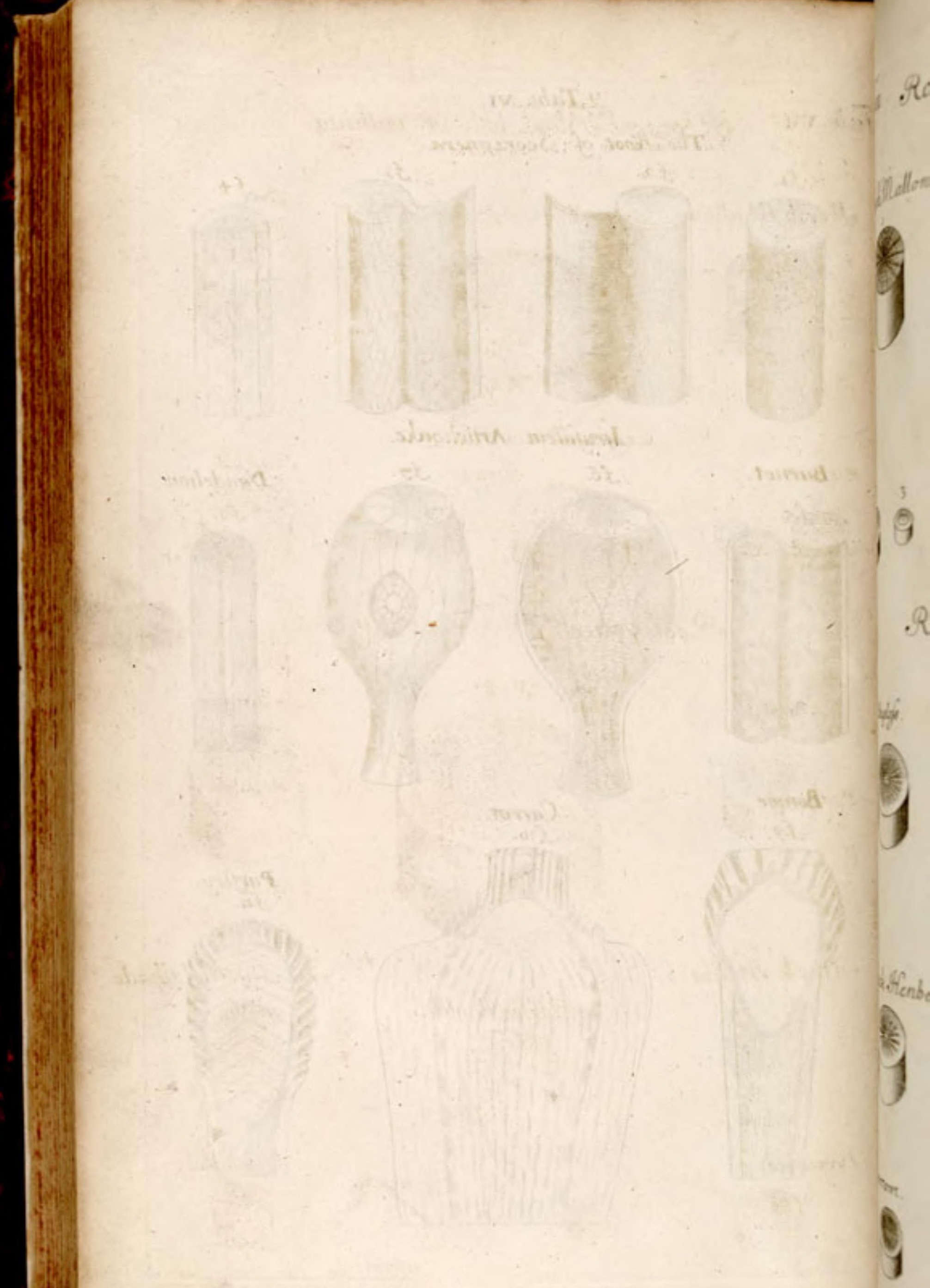


Tab. vil Roots w: Bleed little or nothing.

- llarsh Mallow

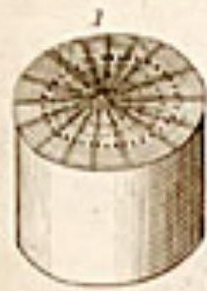

Patience

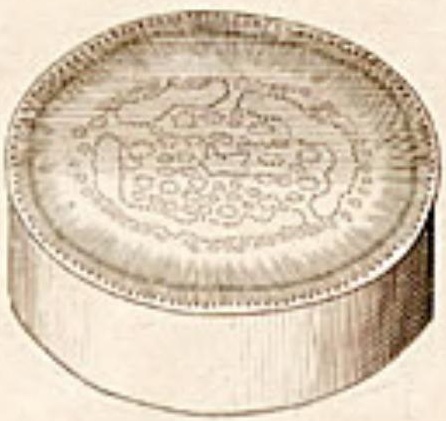

Peone.
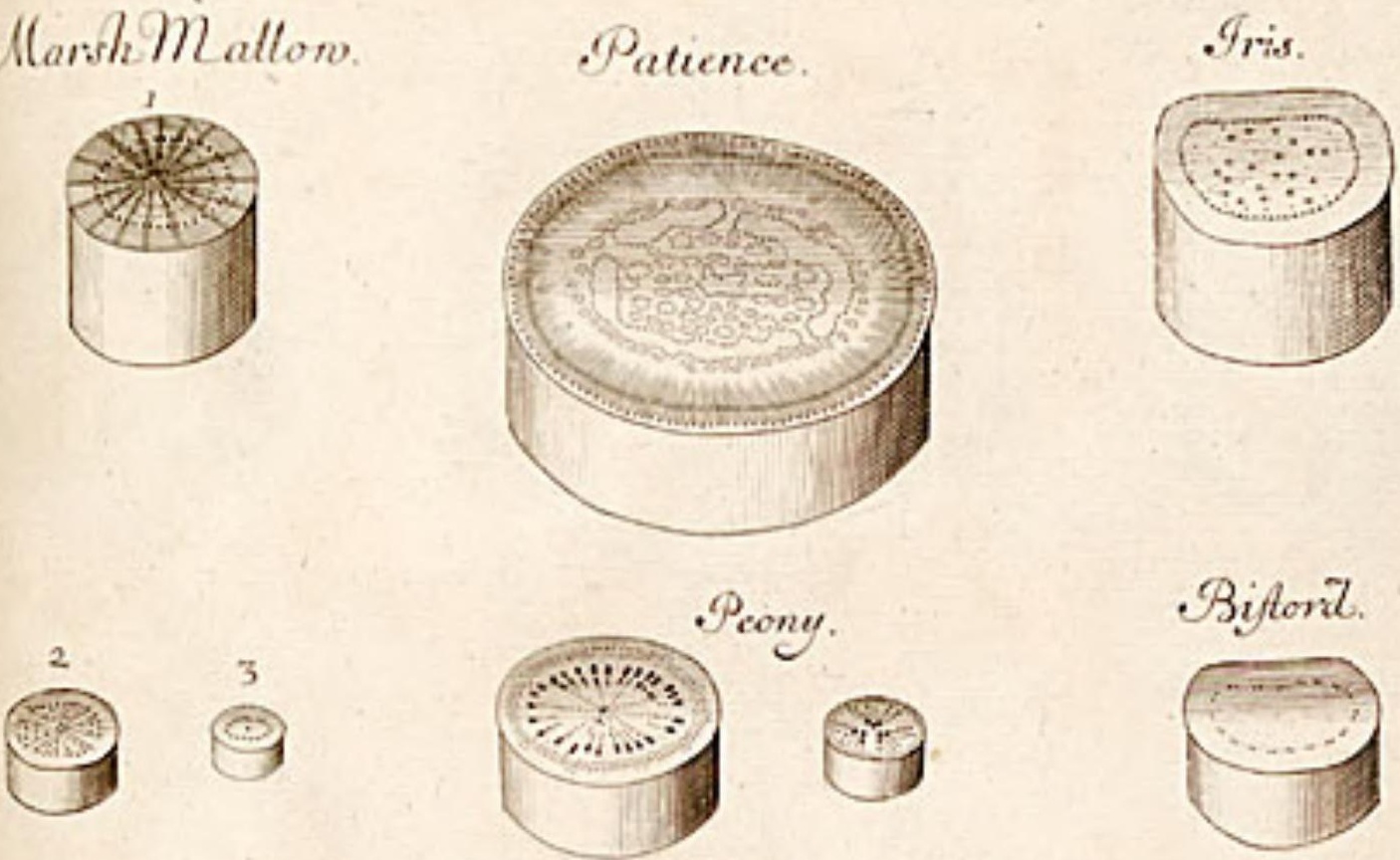

Bifonl.

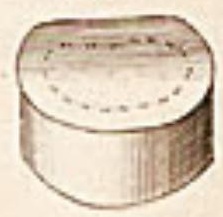

Rooternhich. Bled Lumpha.
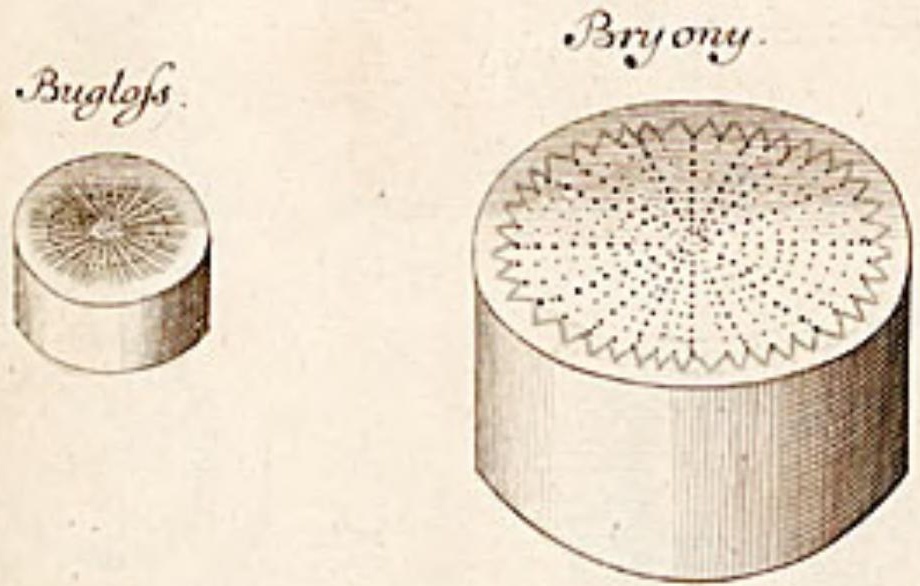

- Borage.

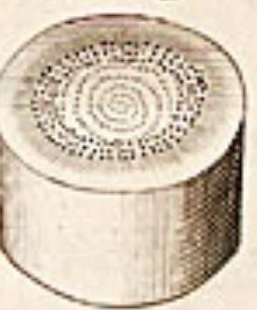

- Btact. Renbeane
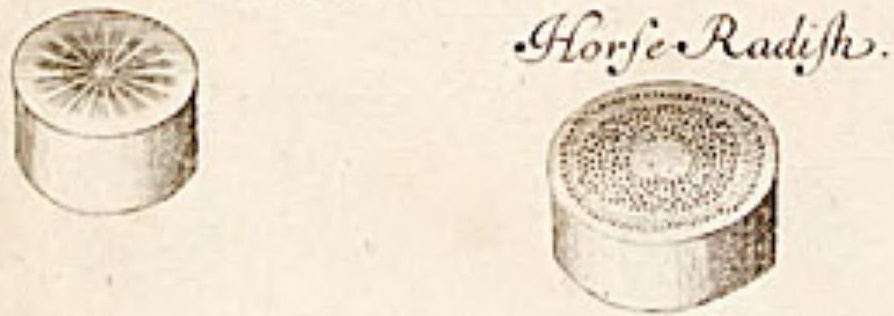

Deadlye Nighthade

- Bronnwort

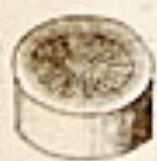

Wom. Butbons fily. diparzons.

Columbine.<smiles>[CH]1CCCC1</smiles>

(a)
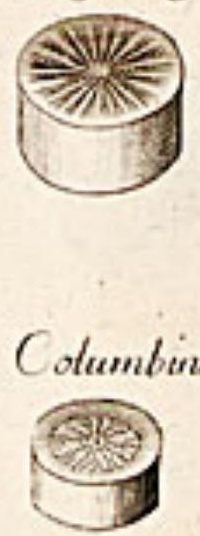
Tab. vilt Rooks which Biced a Lympha.

ft. Parmep

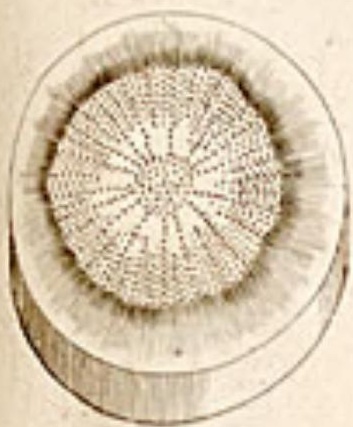

f.5. Nettle

(18)

f.6. Dalerian

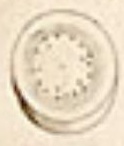

f.2. Carrot

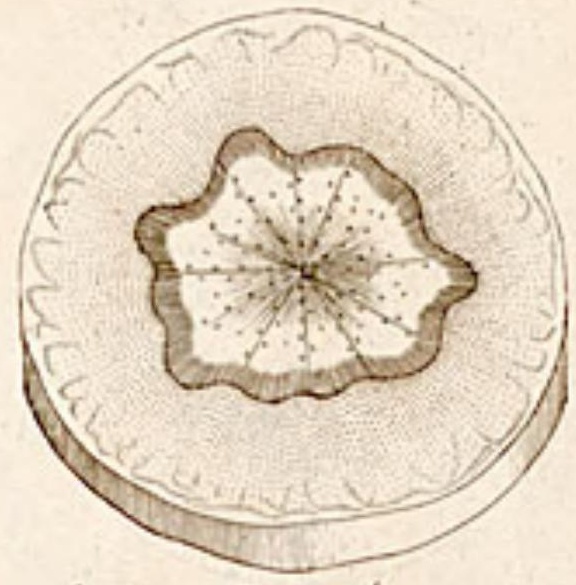

f.s. Beet

$f \cdot 4$ : Terusalem

$f \cdot>$ Dropert

(i)
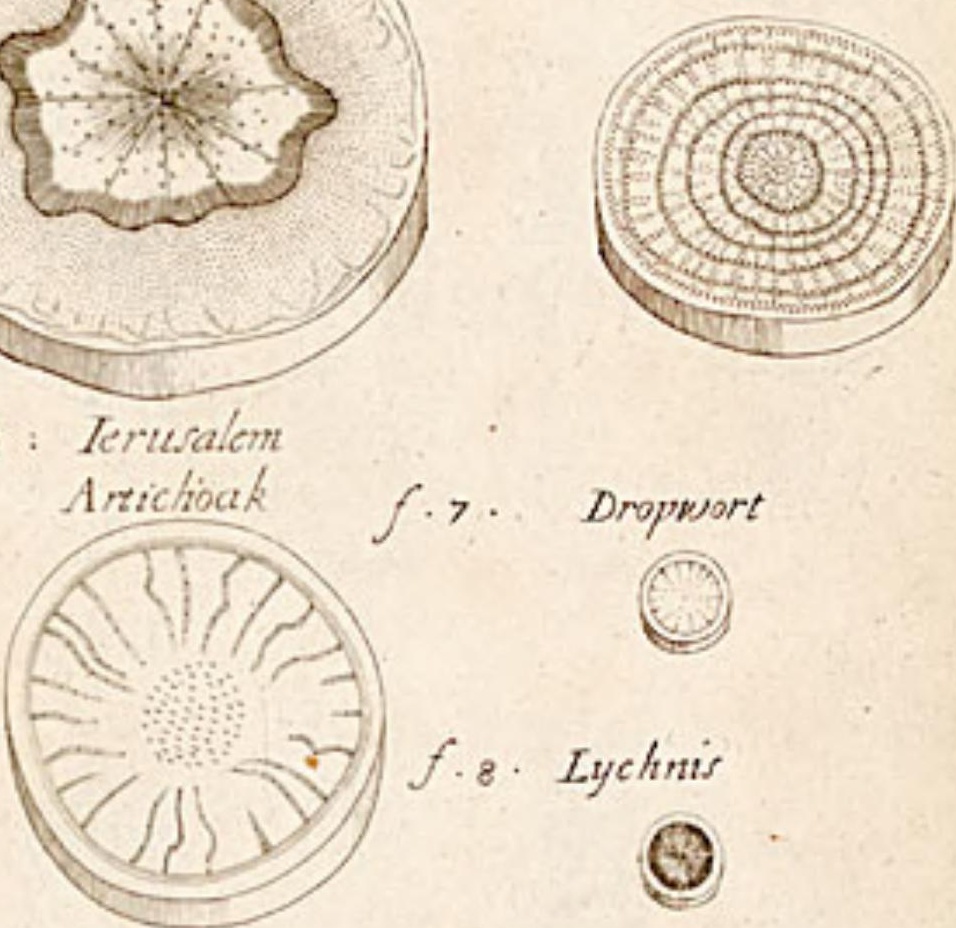

f.10. Butyr. Bur

Roots which Bleed a Milk or Oyly Sap

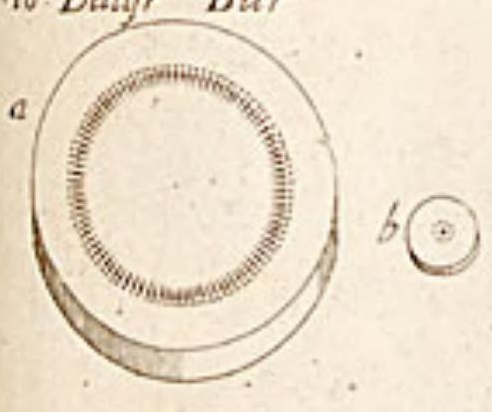

f.12. Great Celaudine

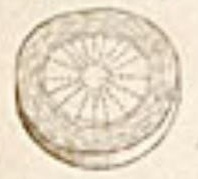

fis Bishopsweed

(.) (3)

•

S.14. Goatsbeard

(sid)
Lovage f. 9 .

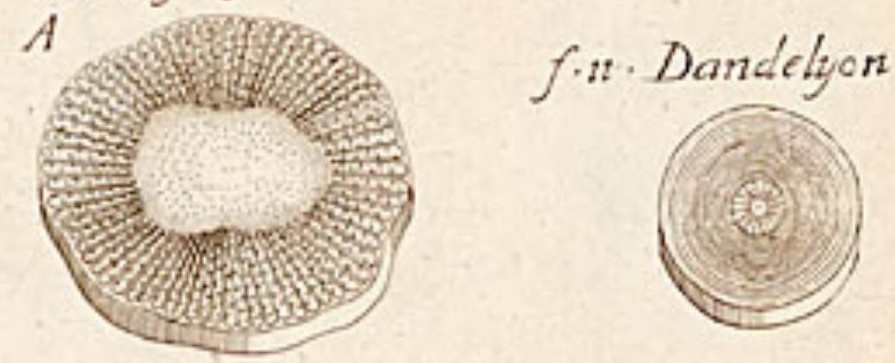

f. ${ }_{3}$. Cychory

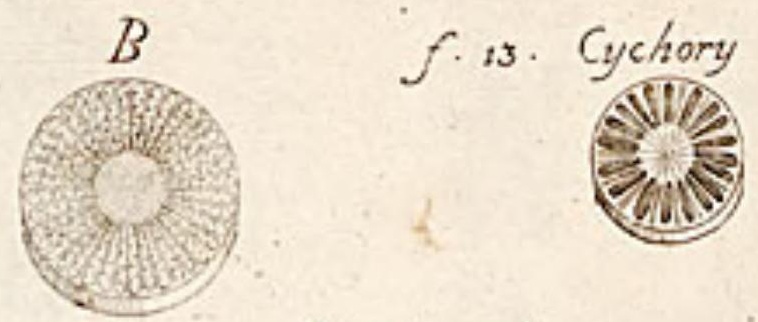




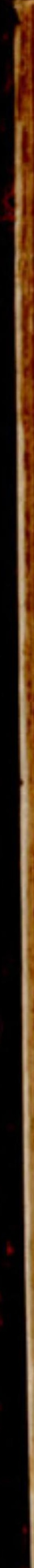

$y^{n} x^{n}$

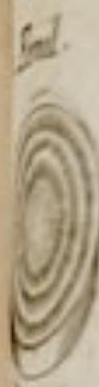

tont

betuct:

Elarray

8

Inte,

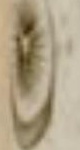

ton

te

$x_{9} 6$

28 


\section{Tab: 9 .}

Roots with Milky or Balfamick Vefsels, and Lymphreducts, both apparent .

F.1.Fenil. F:2. Enula camp :
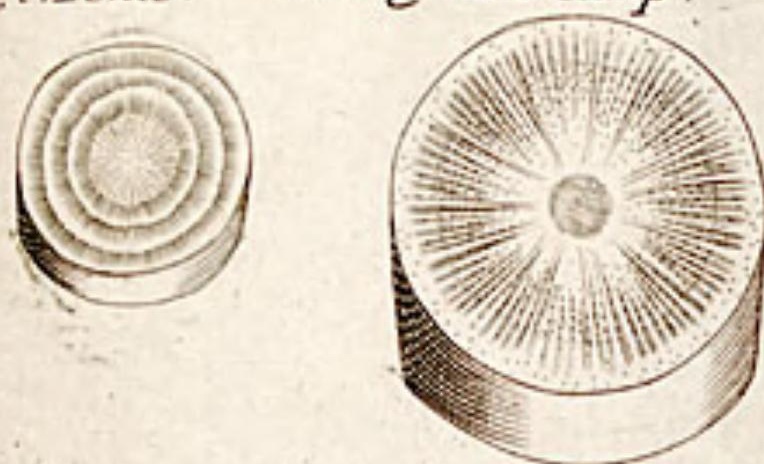

F: 3. Tracheliñ.

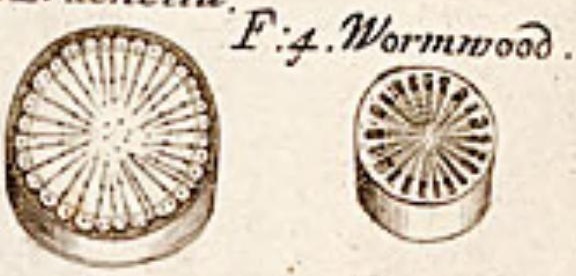

Roots with two sorts of Lymphaticks; in some, Aquaducts and Mucioucts.

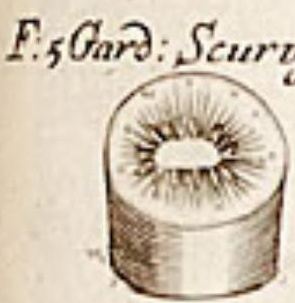

F. 7 Melilote

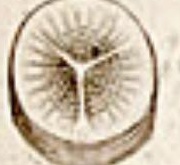

Fro. Cryngo

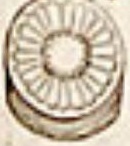

Fix. Cinquefoyle.

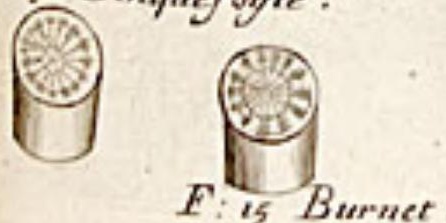

F6. Wild Cucumer.

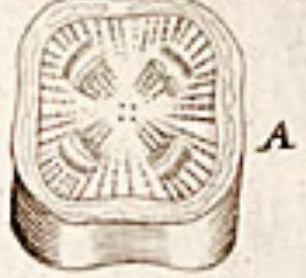

F.8. Potato
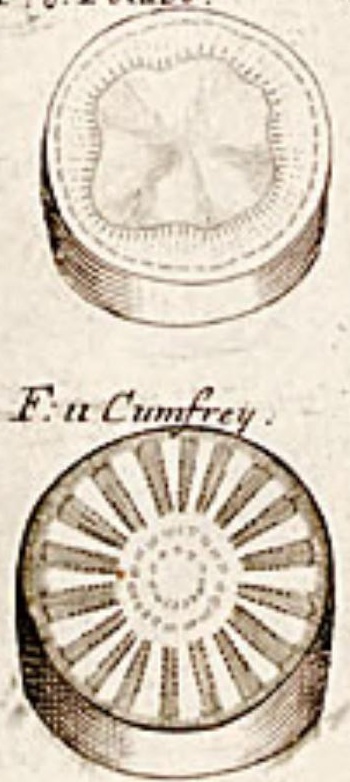

F: 22 Monk. Hood.

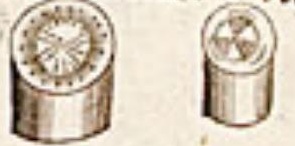

Fis. Dalerian.

9 


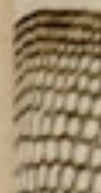

ex

20

20

02
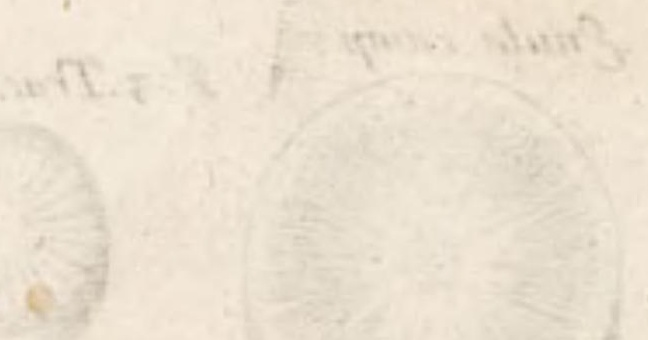
Tab. $x$.

Ty

$1309898806 \%$

to3 20889888

$20130008000 \%$ A

$20005050 \%$

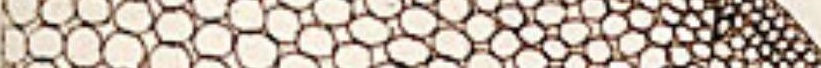

$12201001 \%$

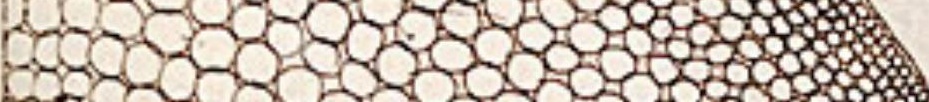

r.21201\%

-125-

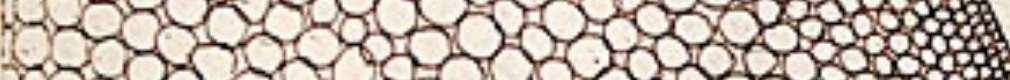

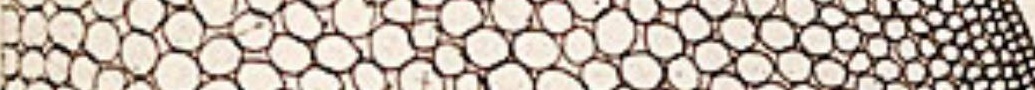

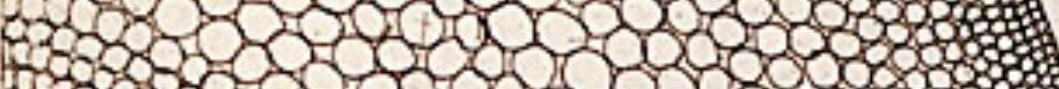

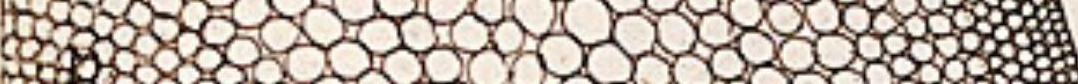

3030000 .

\%os

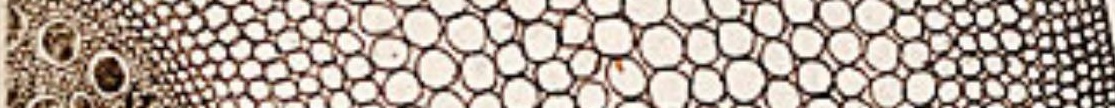

\%

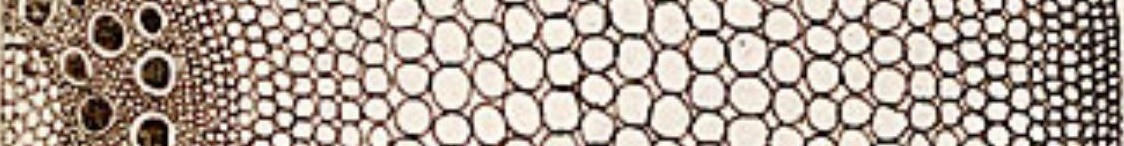

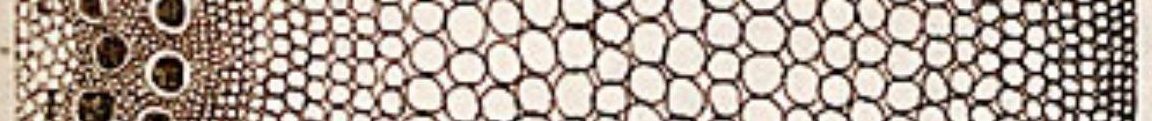

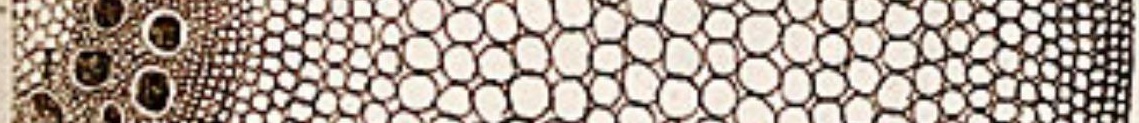

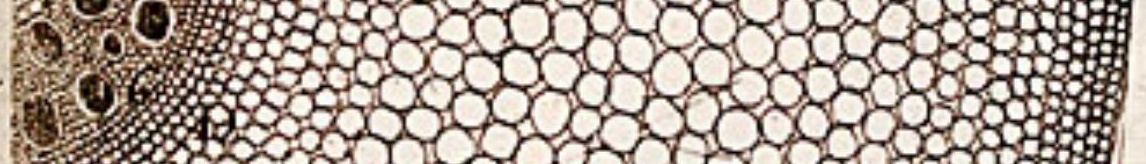

Figi

Small Root of

Asparagus

(9)
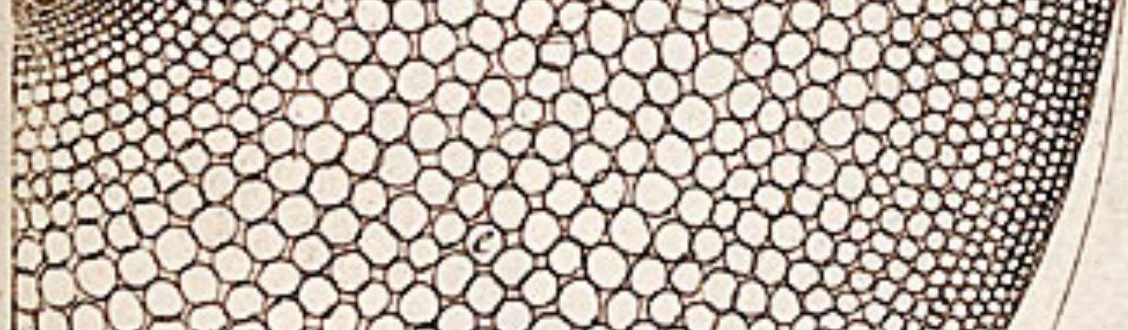

ras

itorobror

itrof

WOU

atho

$\cos$

- 100008080

1.

tifom

(s)

- T. 


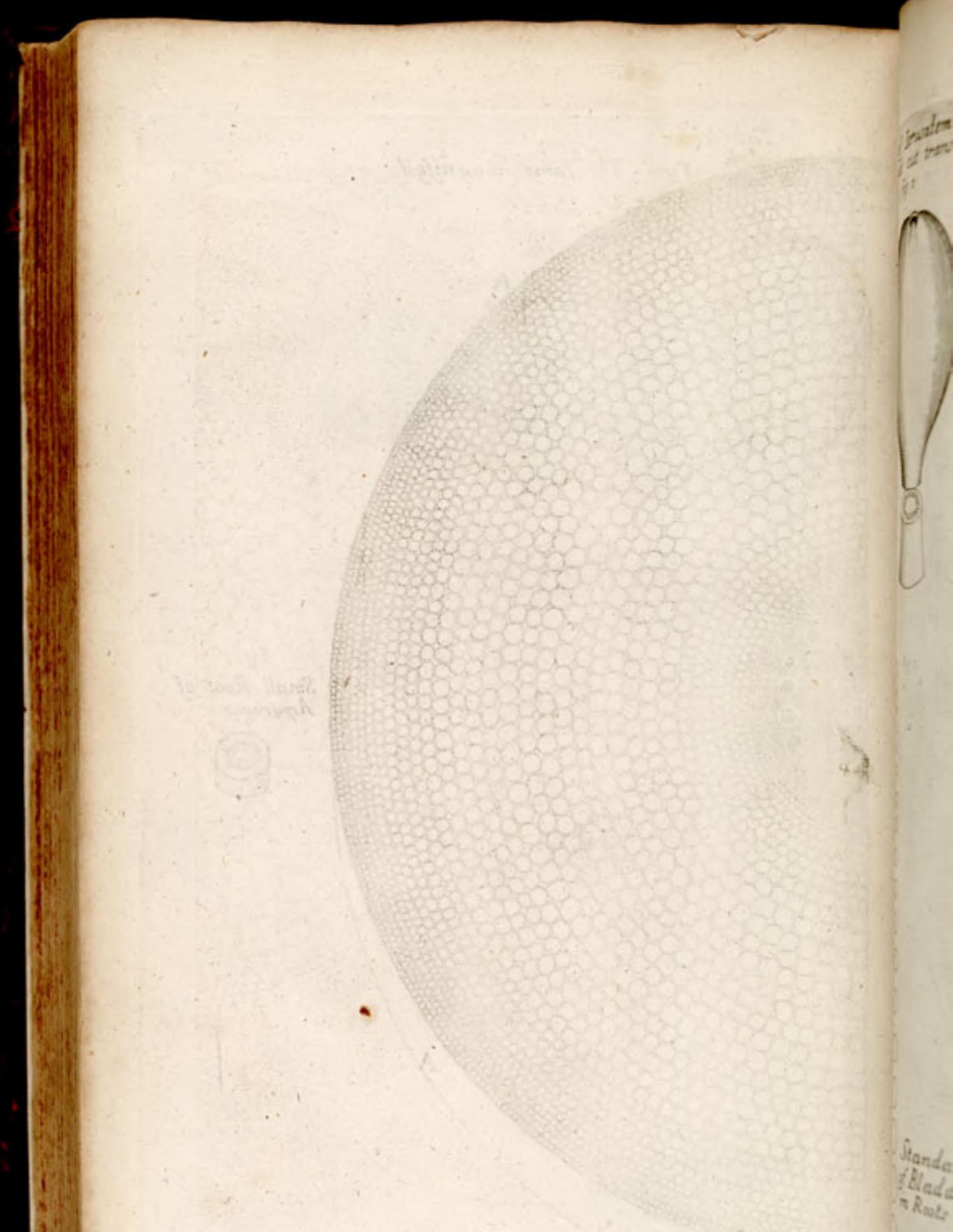


Reot of Icruvatem trichoak cut trans: wertly fig. $t$

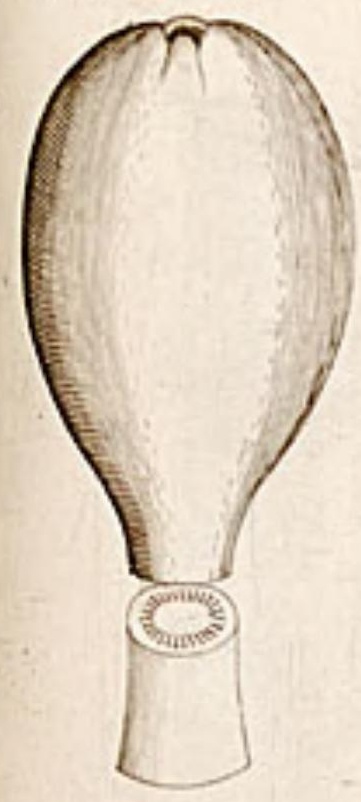

$5=$

30

40

50

60

$\rightarrow 0$

10

10

10

$: 0$

"

wO

40

s (

14

- Standard

"Of Bladders

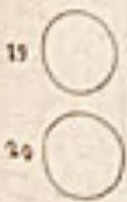

Tab.XI

Halfaslice Magnifyal Half a slice of

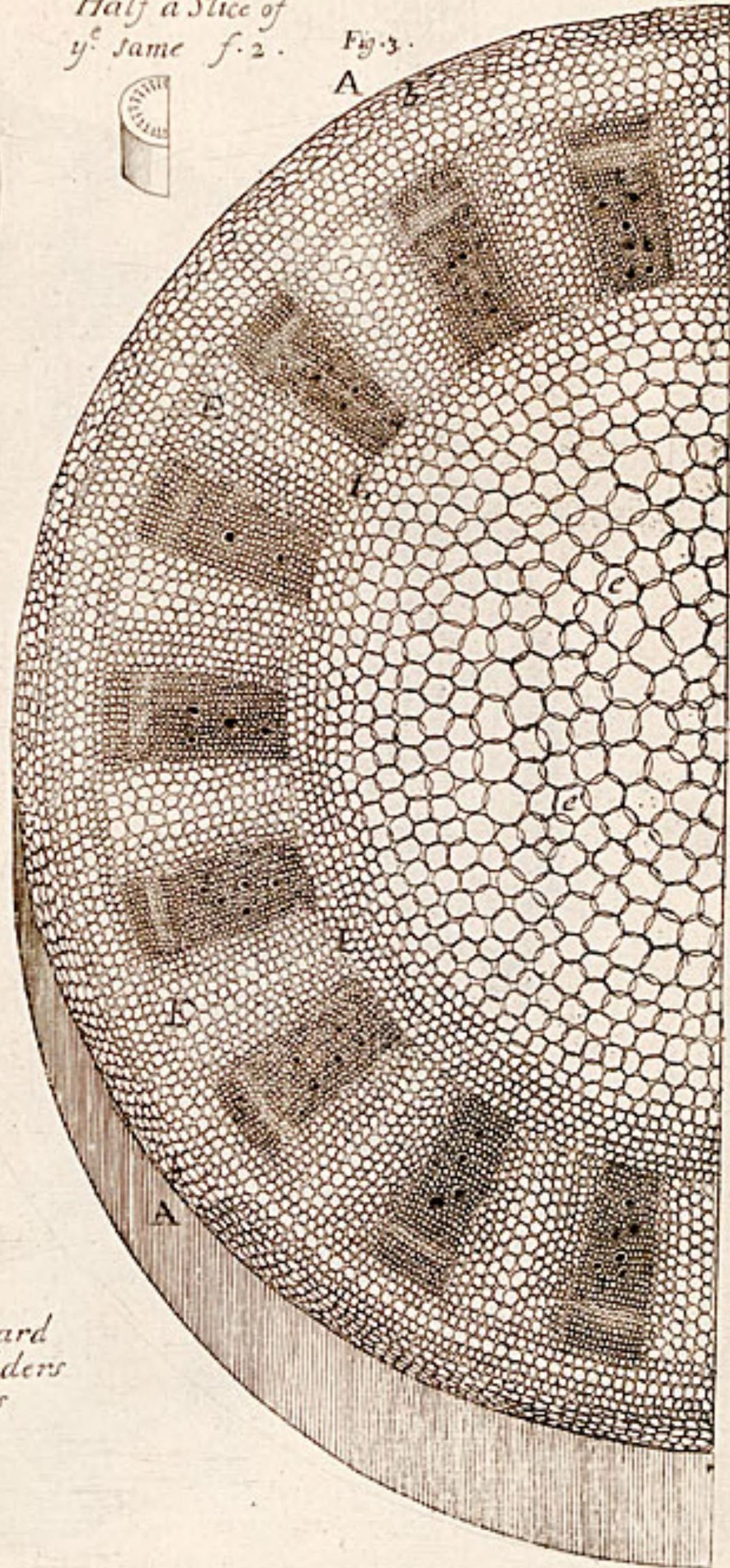




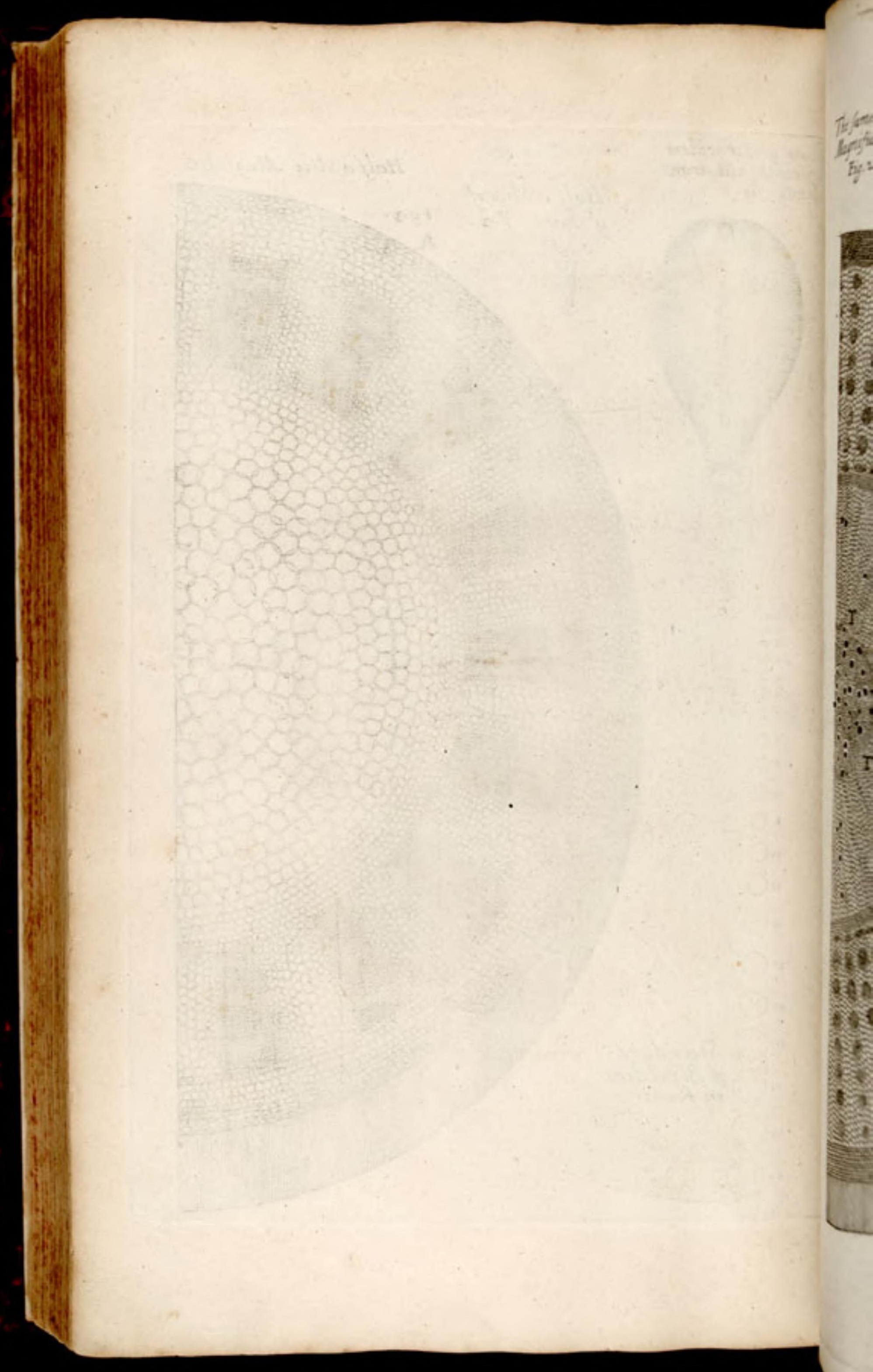


The fame

Magnifid

Fig. 2 .

Tab:XII

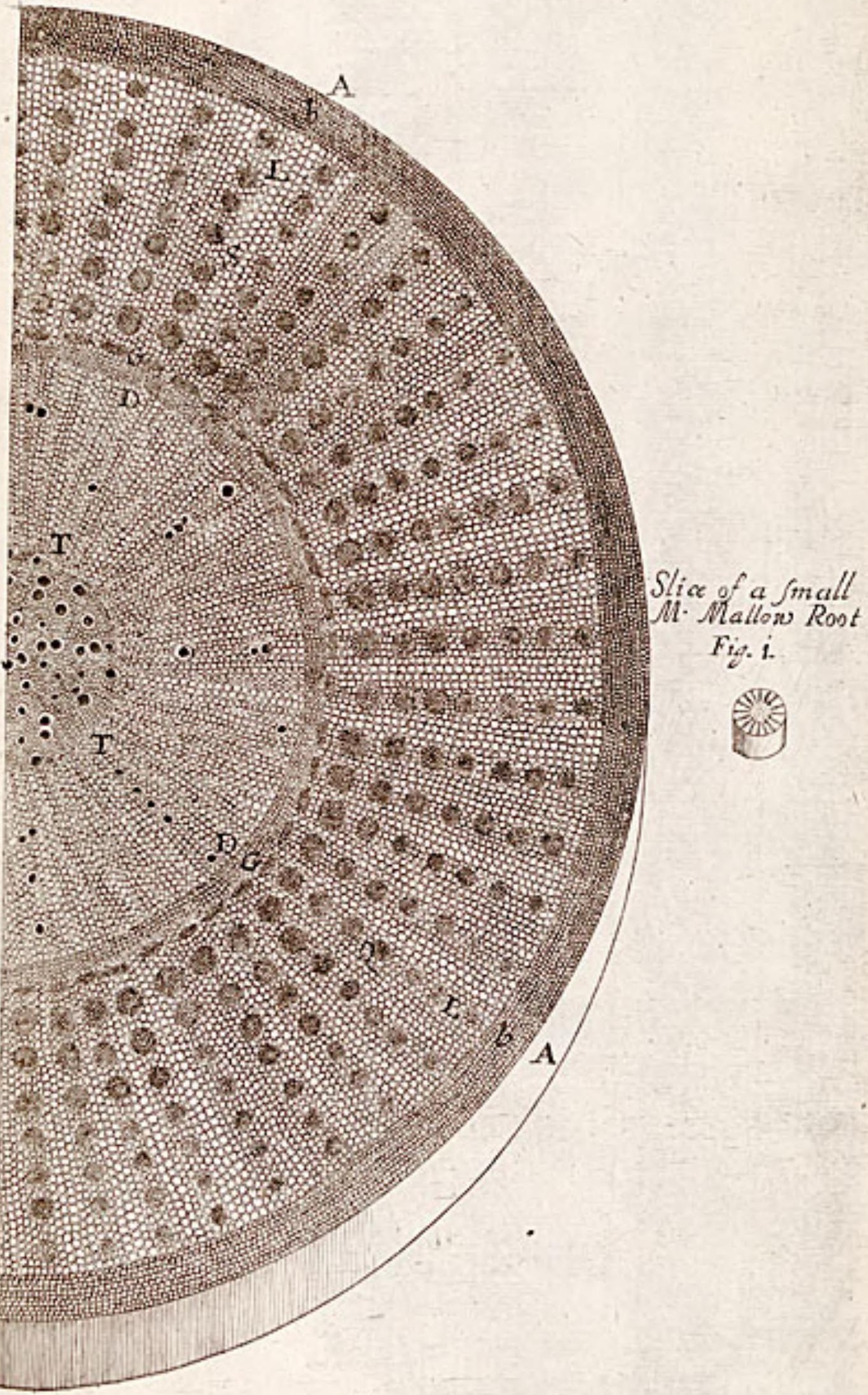


slice of Dandelyon

\section{Roof f: $t$ :

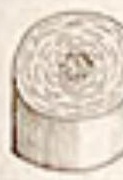

The same magnifyd Fig.2.

A .

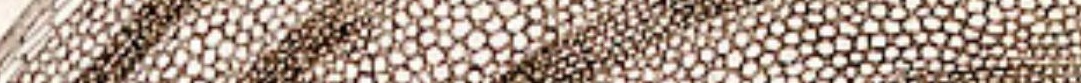

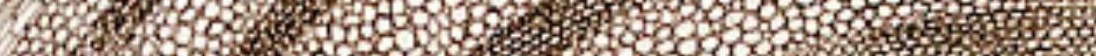

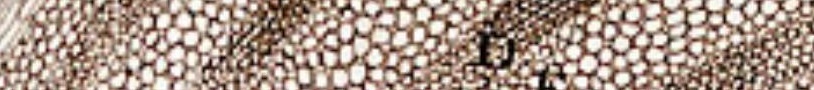

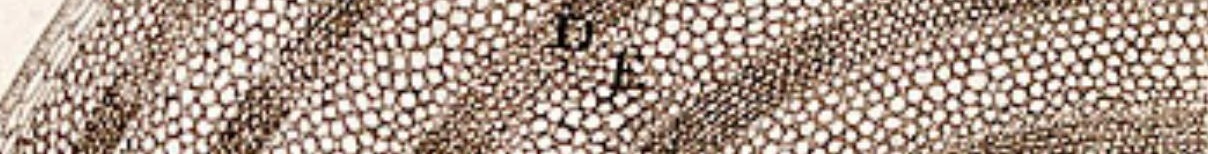

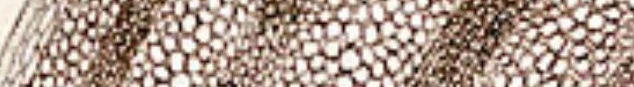

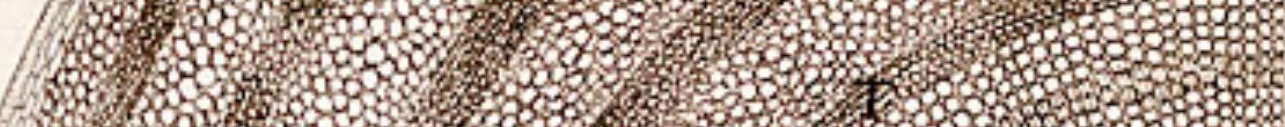

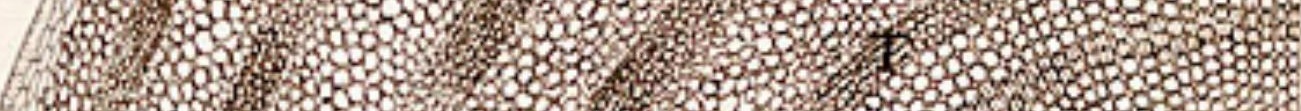

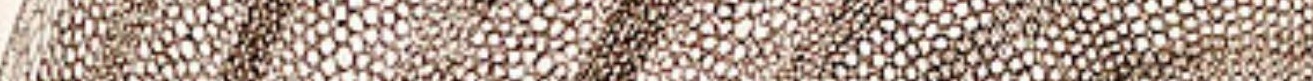

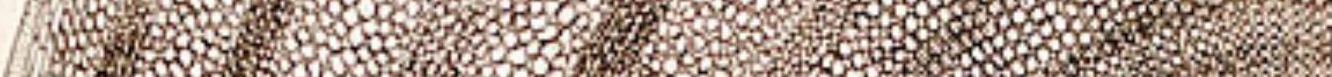

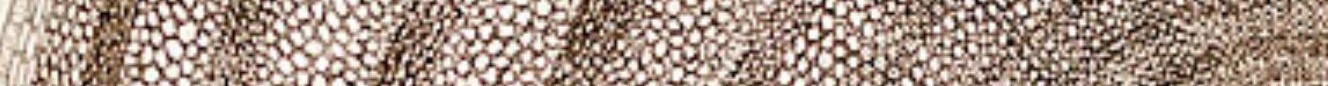

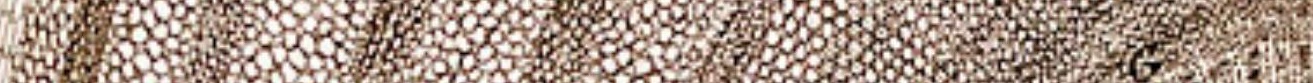

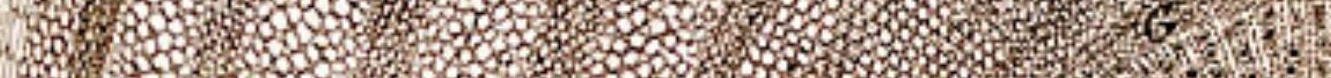

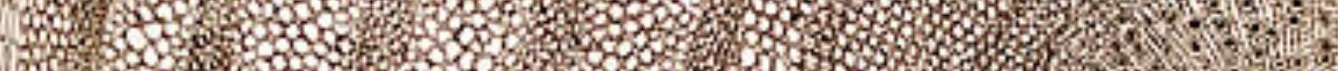

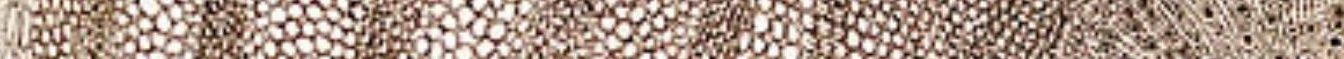

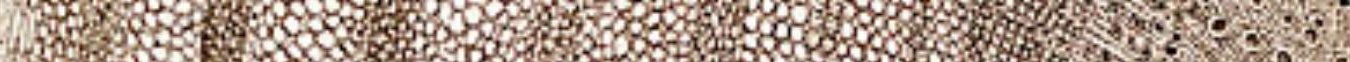

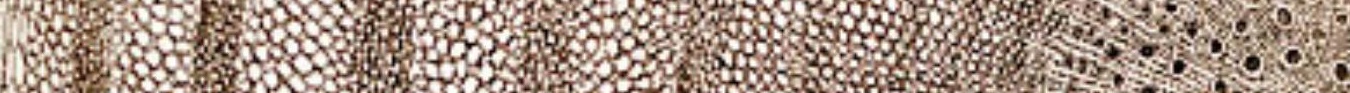

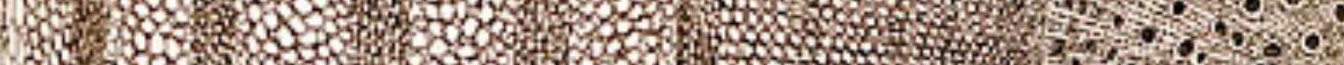

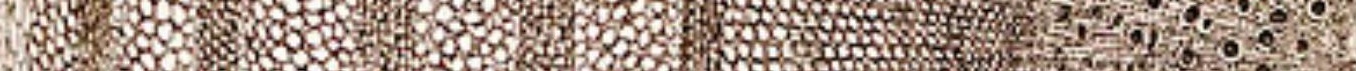

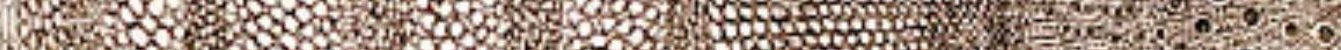

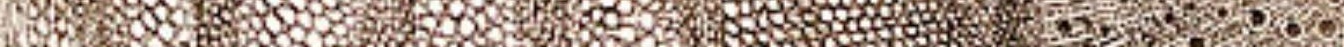

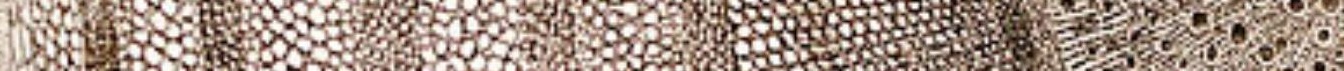

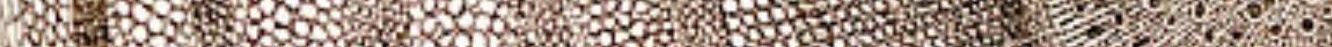

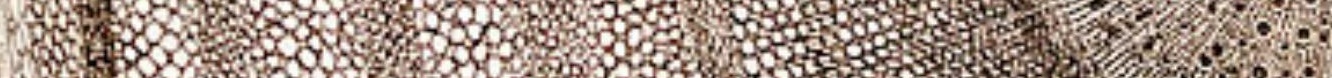

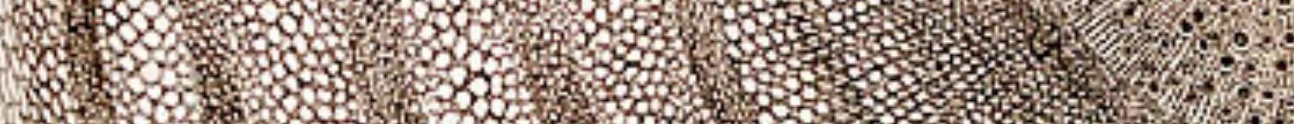

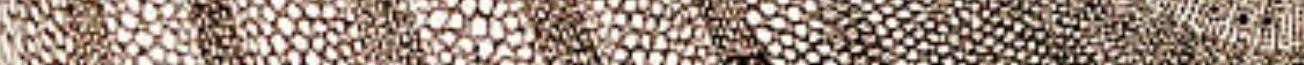

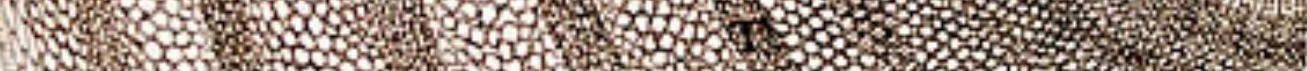

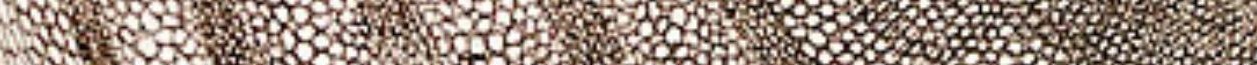

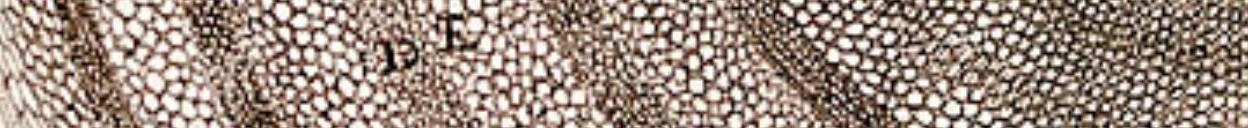

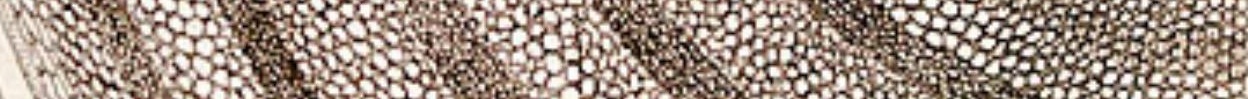

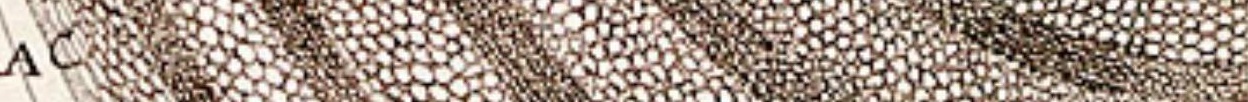

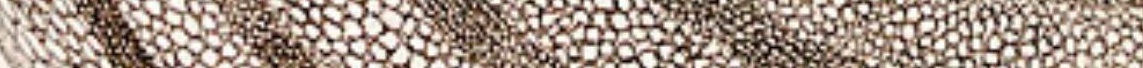

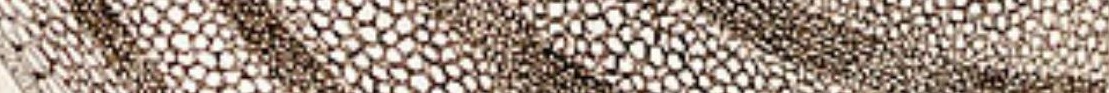

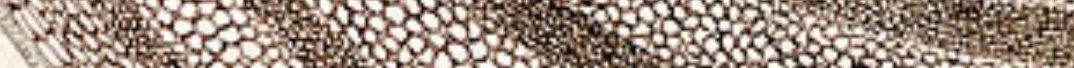

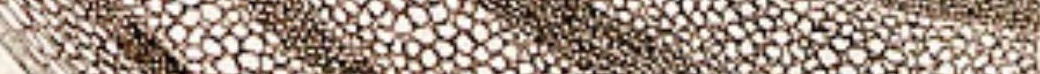

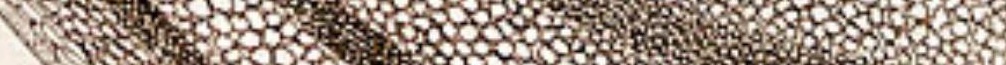

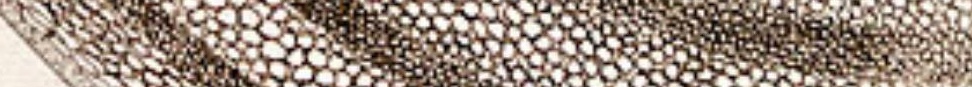

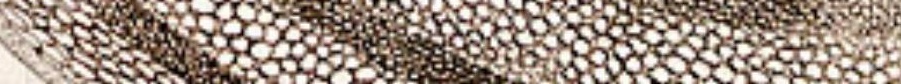

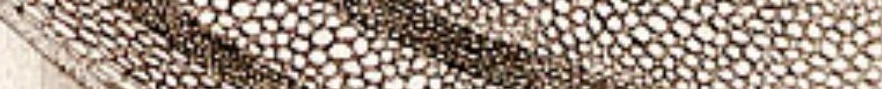

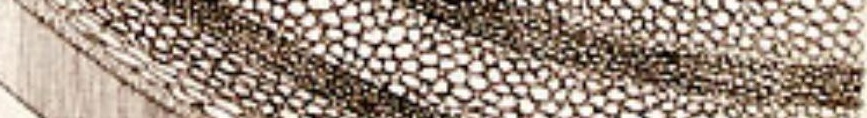

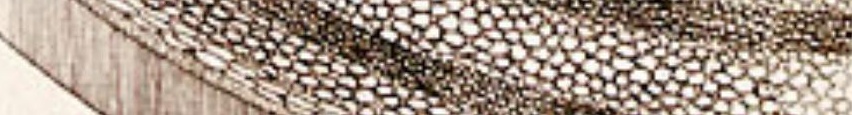

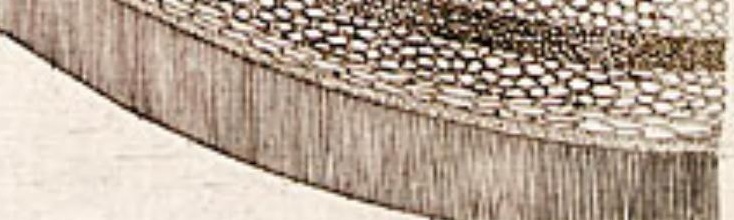




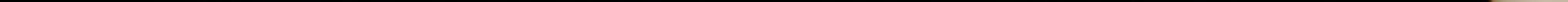




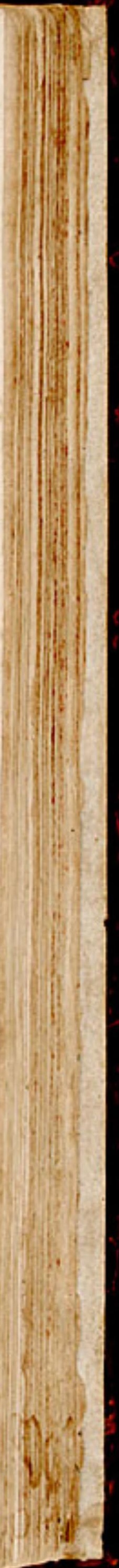



The small ond of
a Buglef Root Fig.1.

()

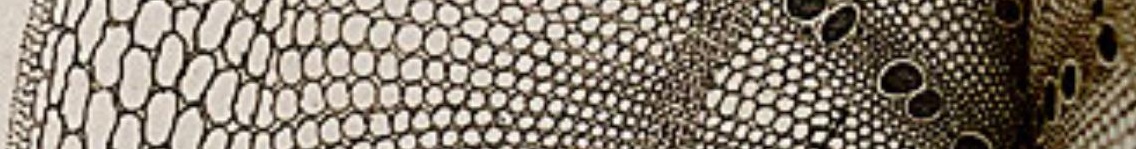

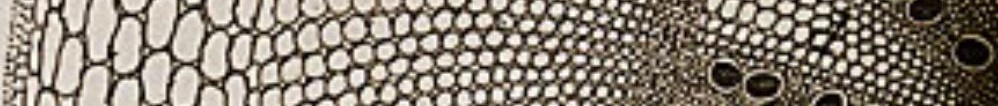

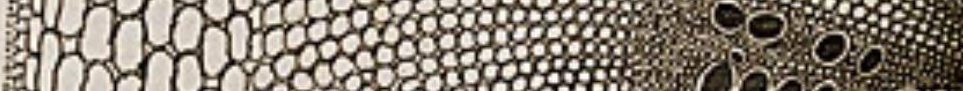

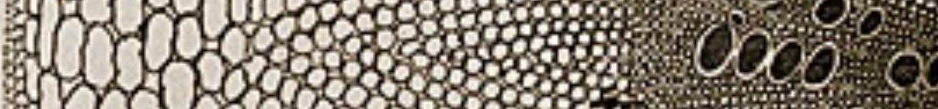

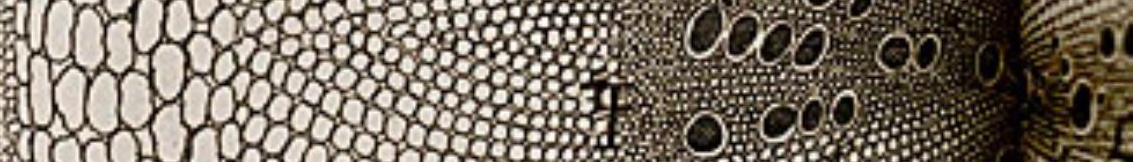

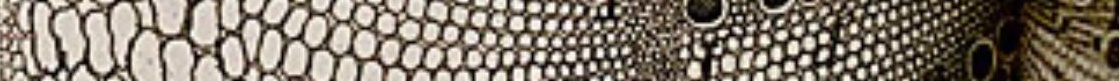

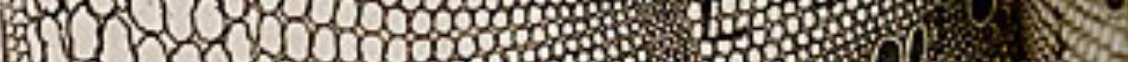

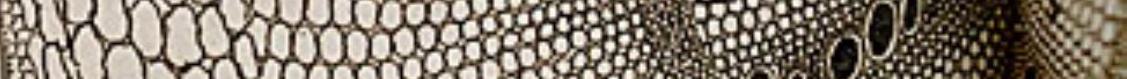
1. M N II T nto

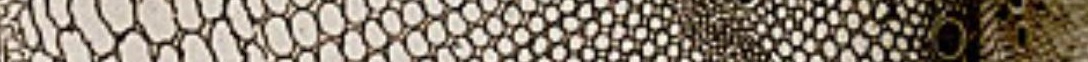

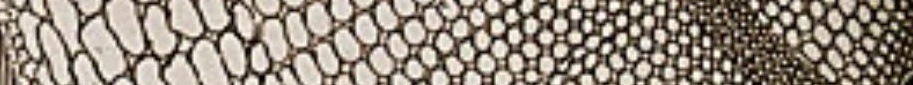

in 100000000 IN to 000080000 I I 00000000000 13 . N 1 .

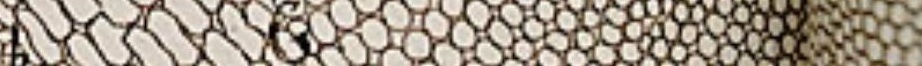
- $x$. i) $M$ o 50000000000 H N N 10000000

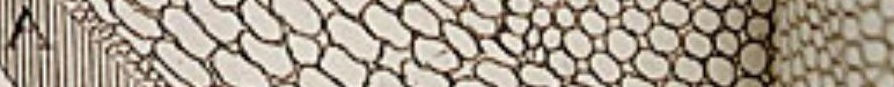
In 20050000 I. 
tanify'd

$T 2614$

$c$.

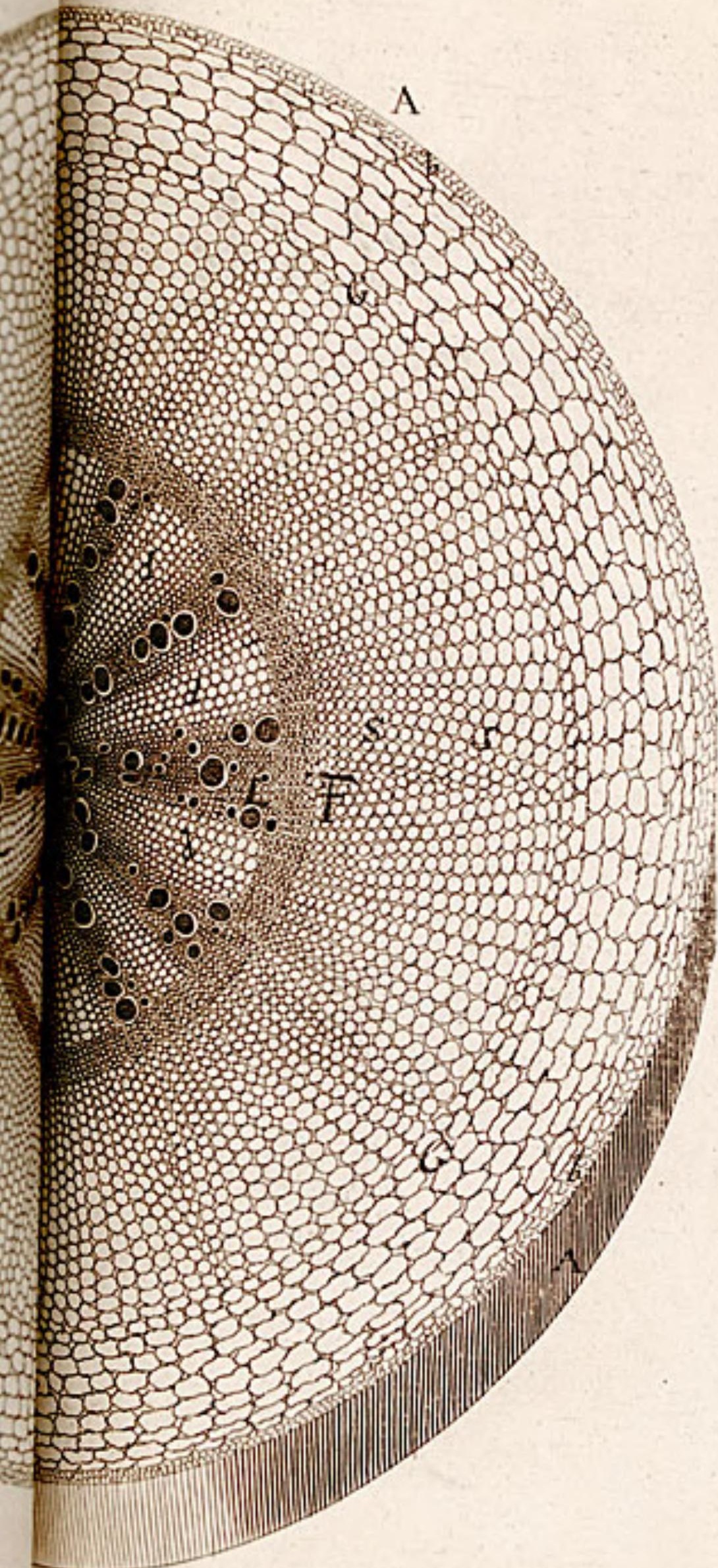




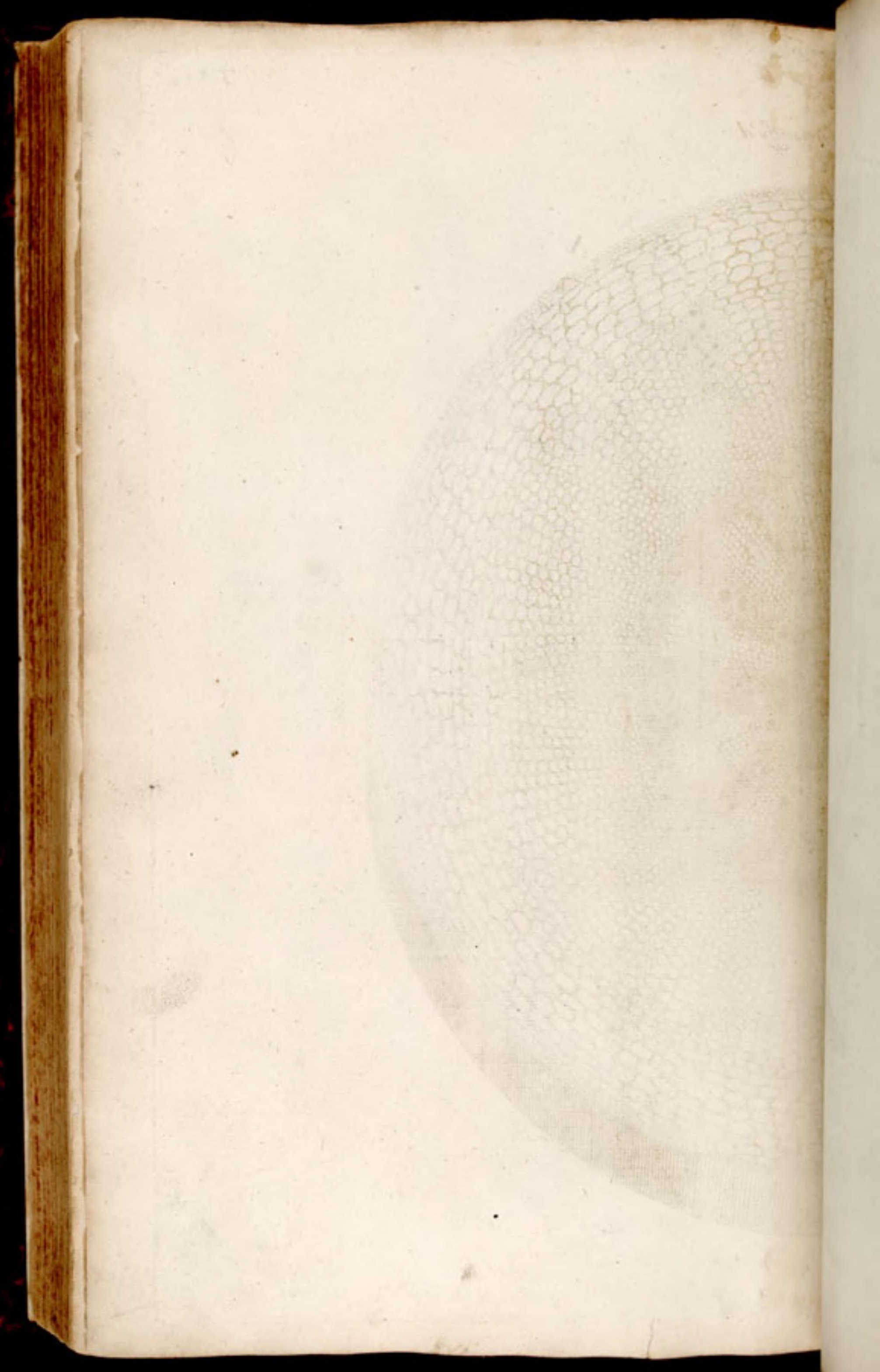




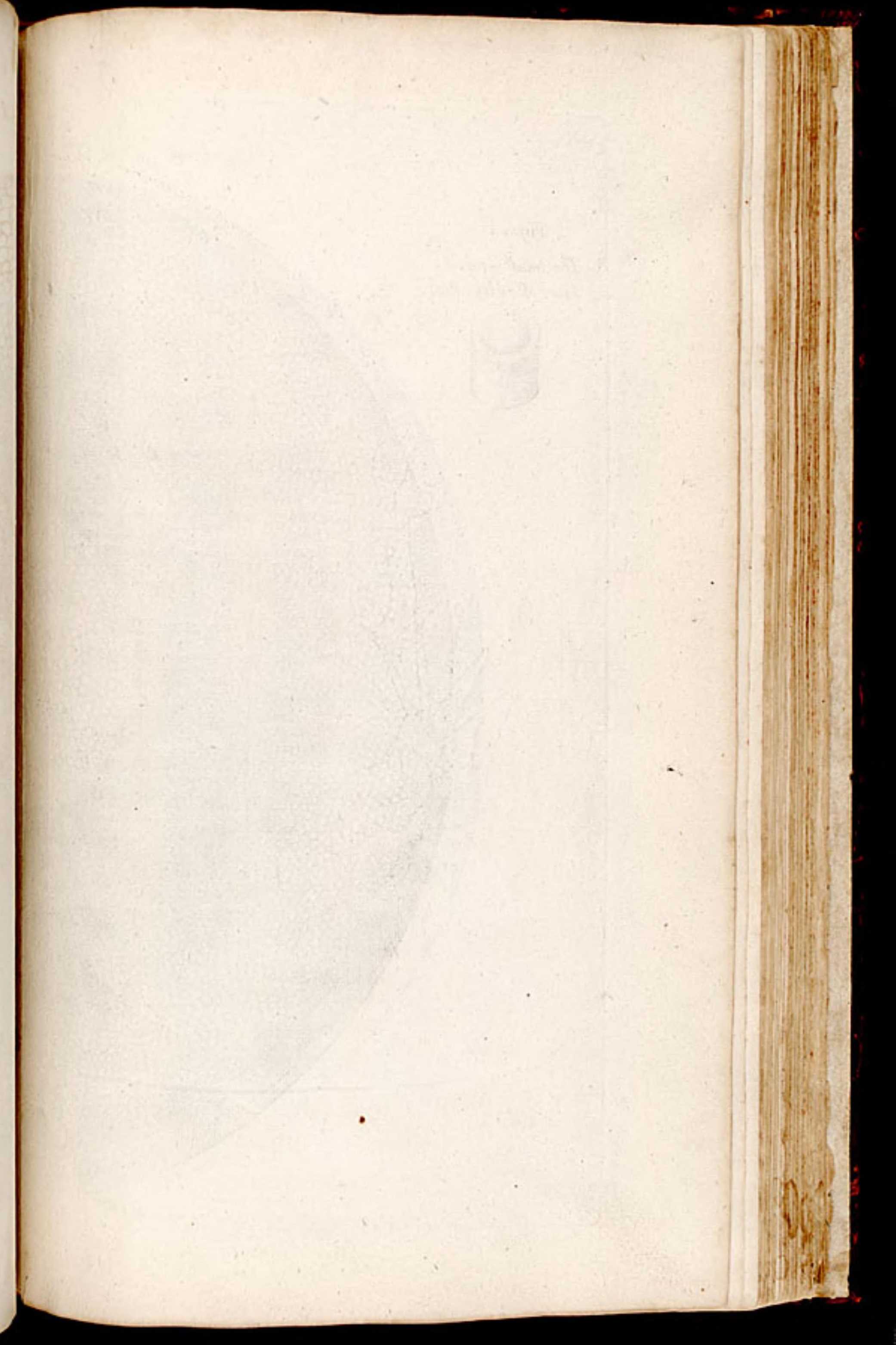


Fig.

Thie small end of

Hors-Radish Rool

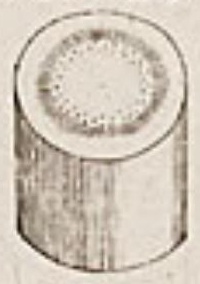

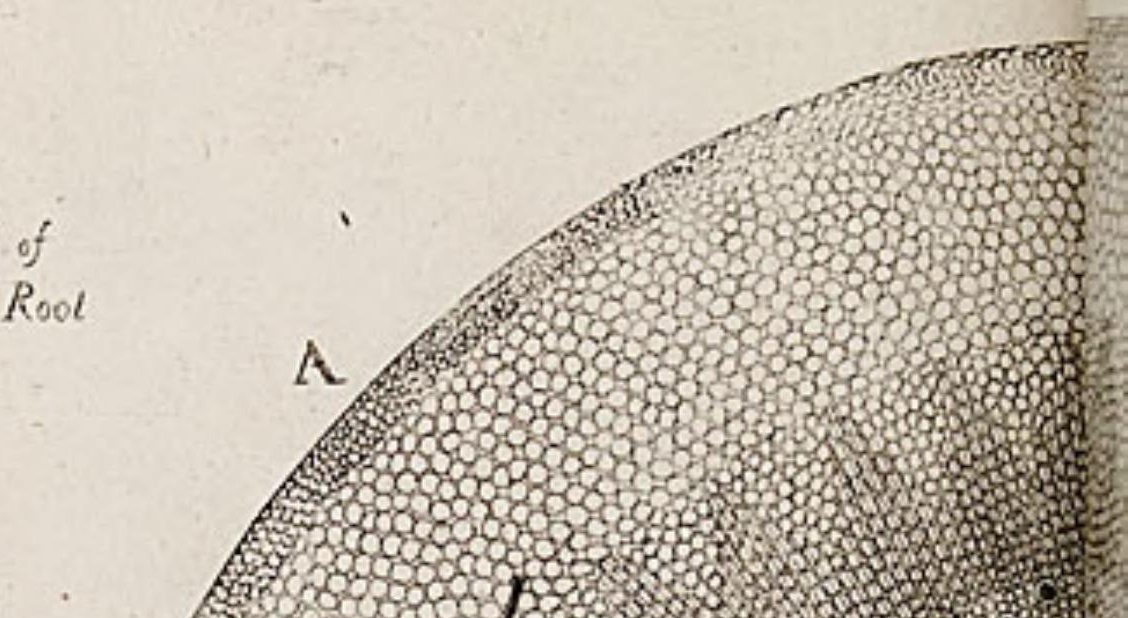

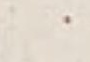




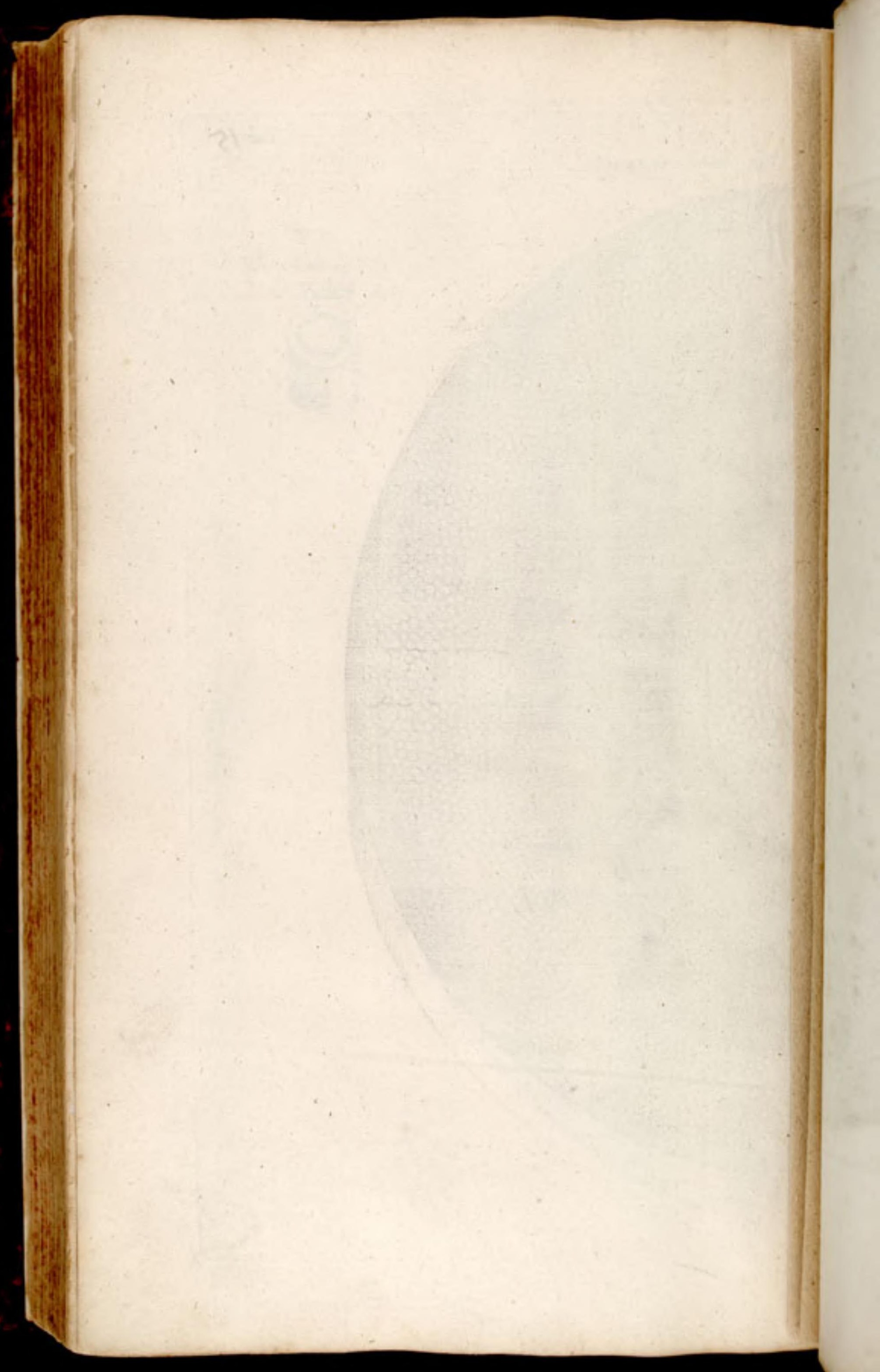




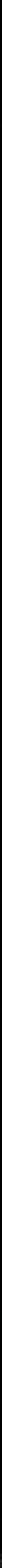




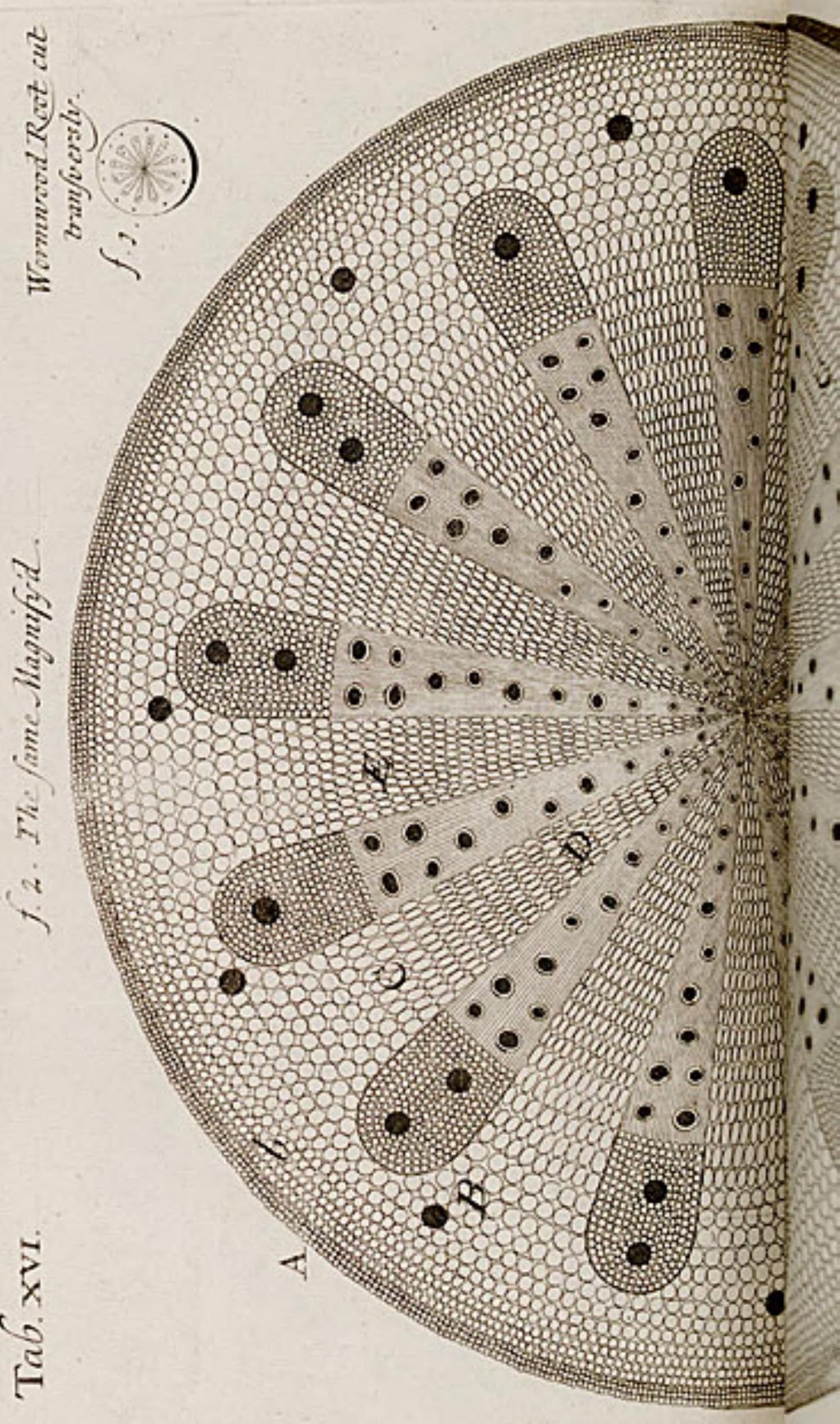




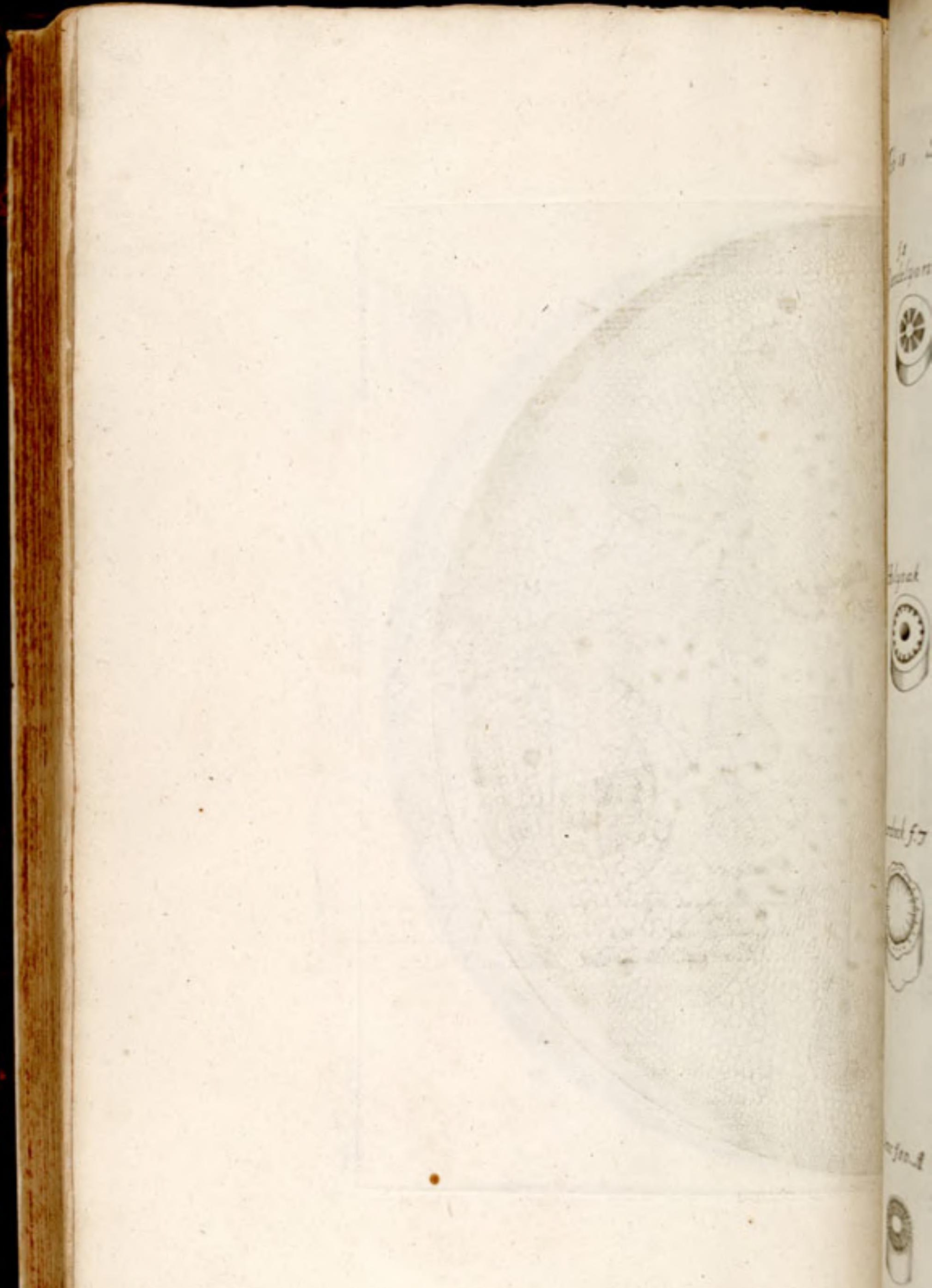


Tab is Stalks ox Branches cut transuersly Indian Wheat

Dandelyon
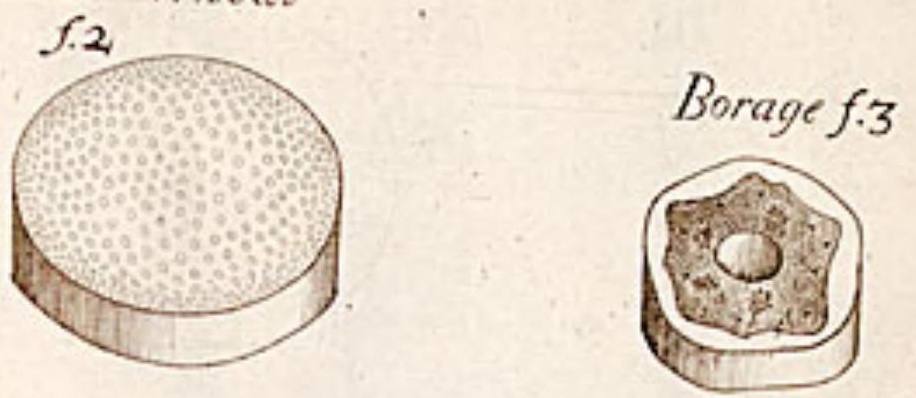

Colenort $f \cdot 5$

f.4 Holyoak
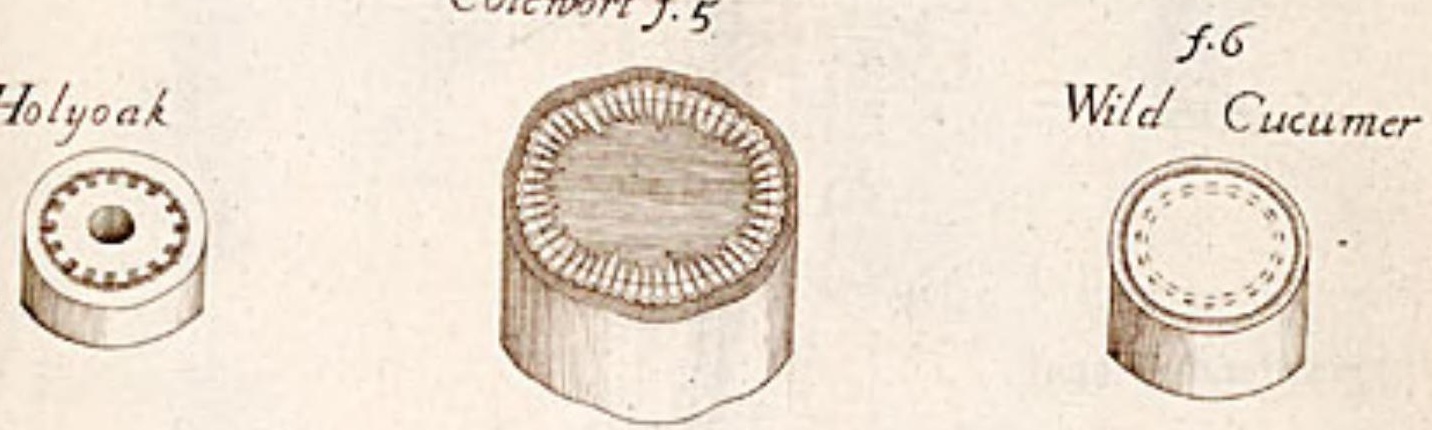

Burdock f.

Scorzonera $f .8$

Endiue f:g
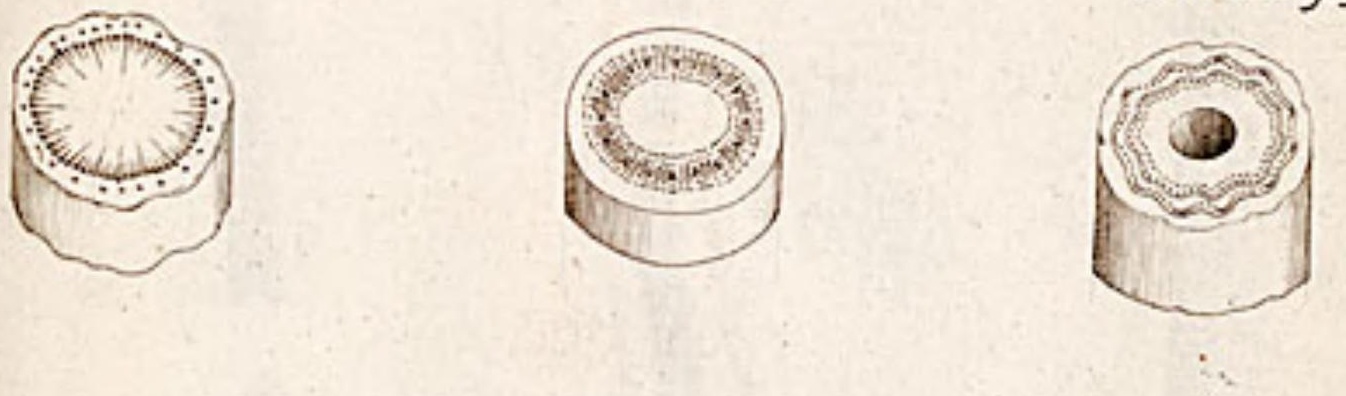

Vinefro.A

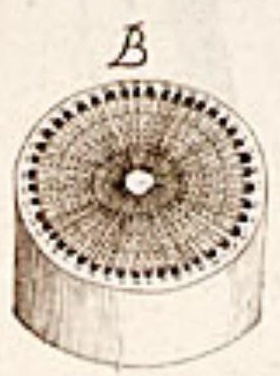

f.t. Sumach
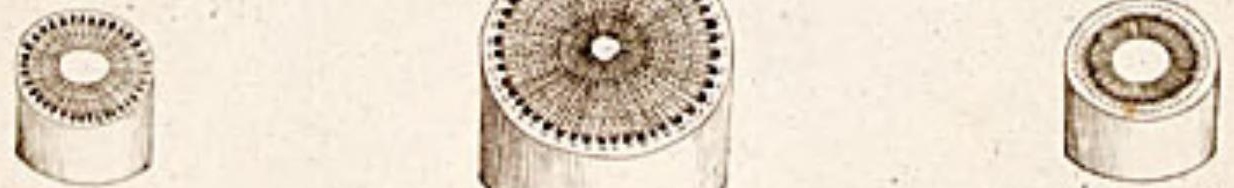


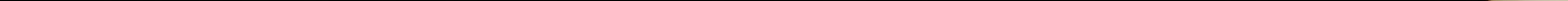


Tab 10.

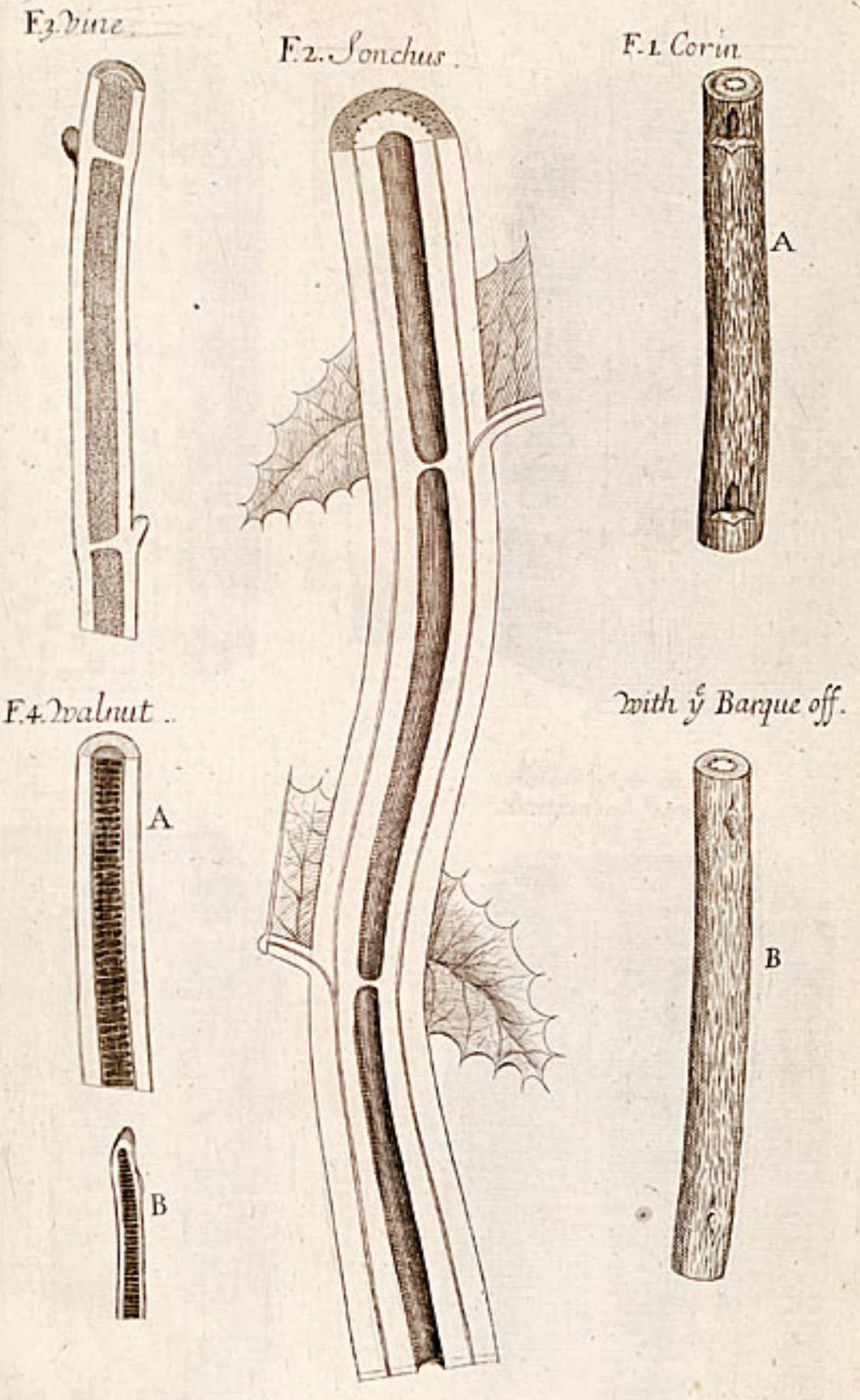


Tab. 20

A.Magnifyd.

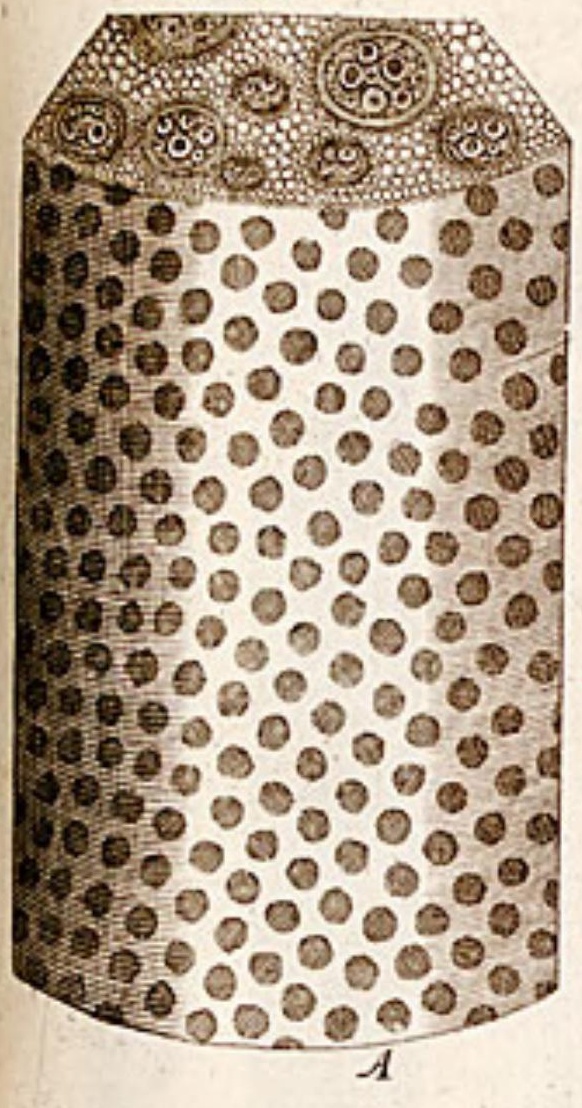

Turpentine-2) Vefels in the Barque of Pino.

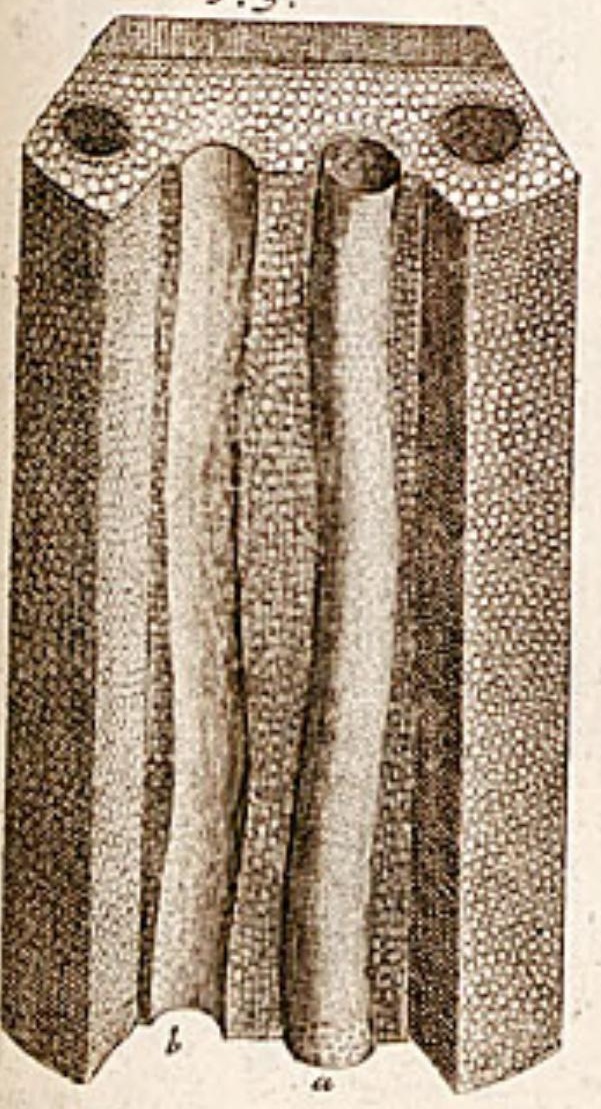

the Stuface of watkingaile. Fil. I.

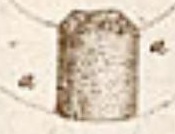

the Skan of

Borago vtalk. F. 2 .

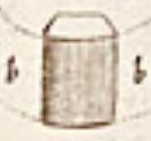

BHagnifyd.

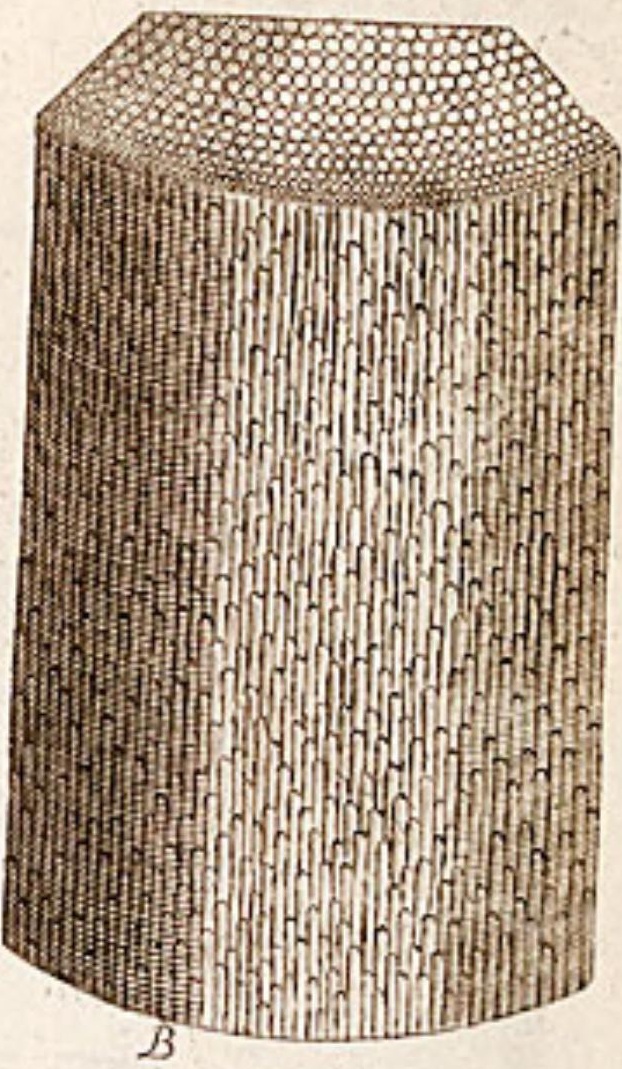

Ofitk-2 gects in the Barque of Stumach.

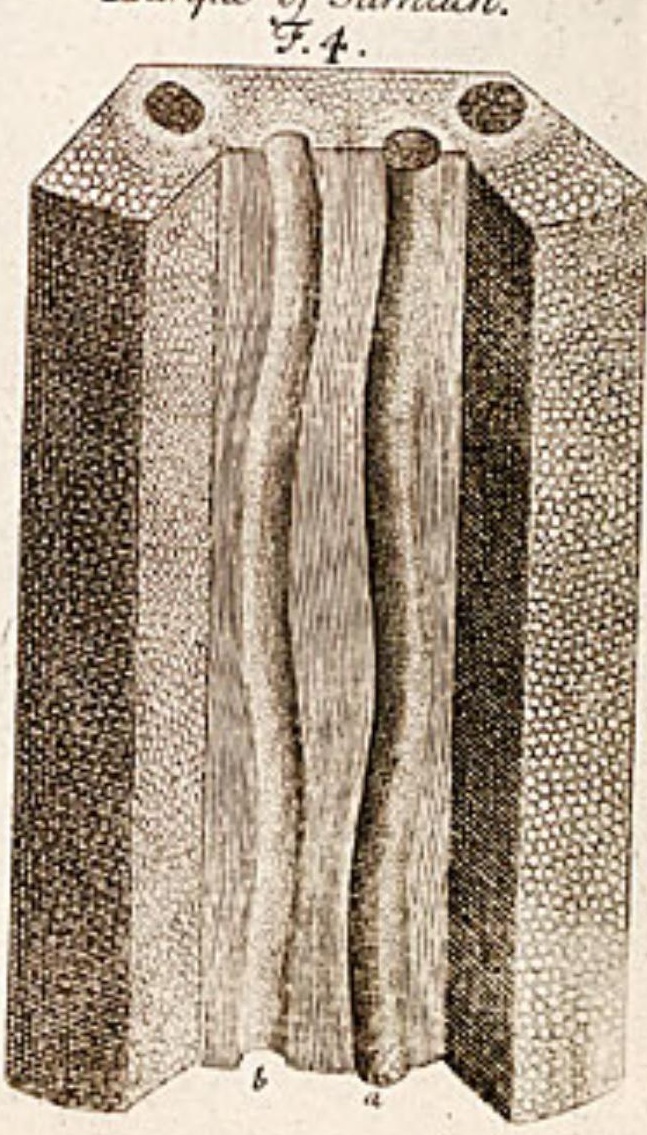




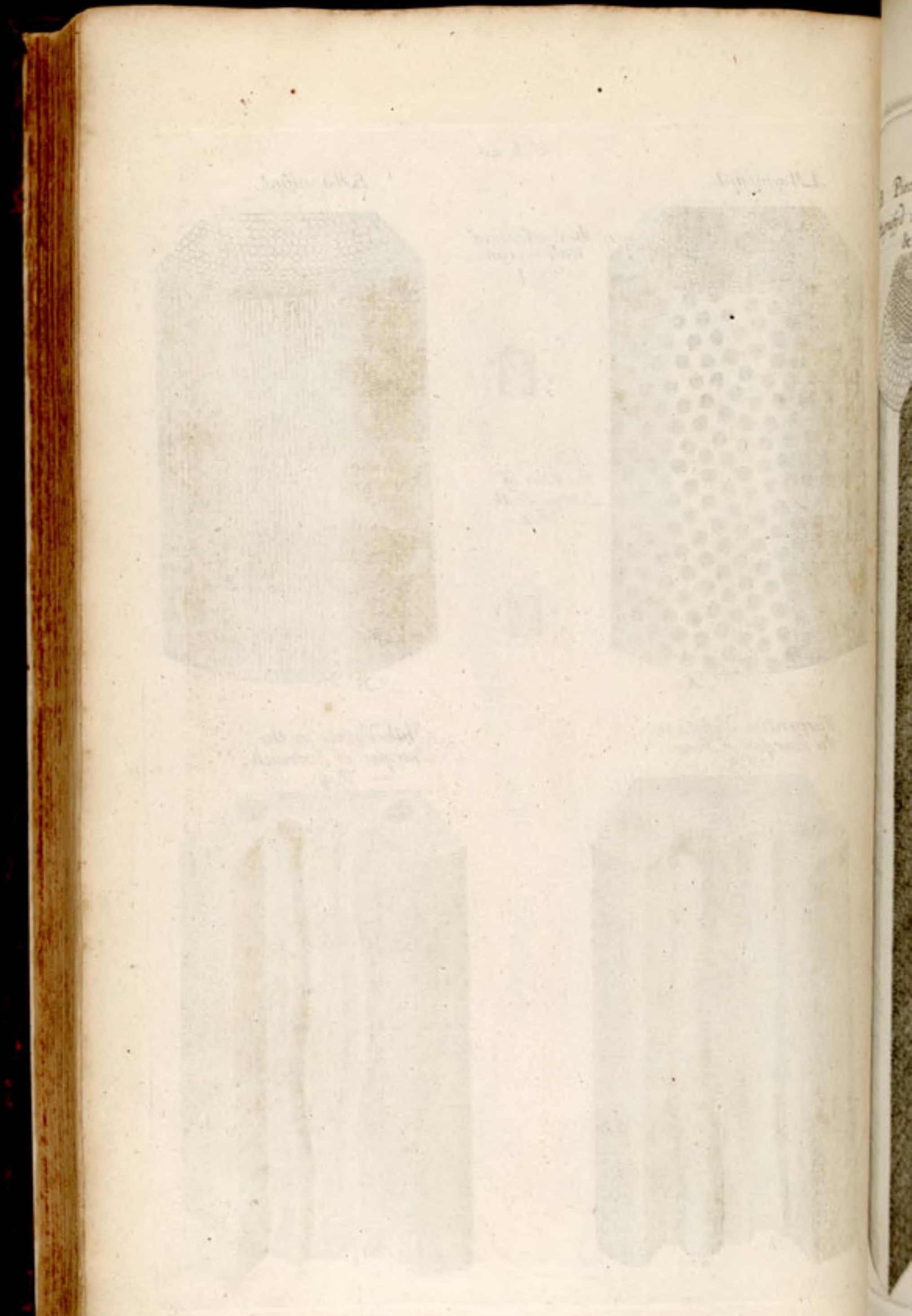


$T a b, 21$

A B Prece Cut out of $(a b)$ and

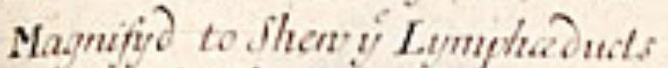

ab.Part of a Vime Brand

Cut tomsnerile

$$
\text { \&Aer-ieforts. }
$$

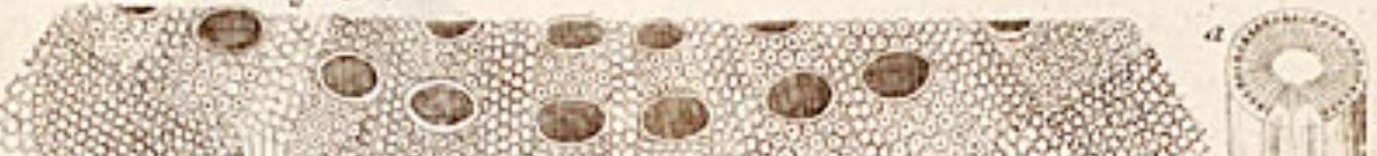

A

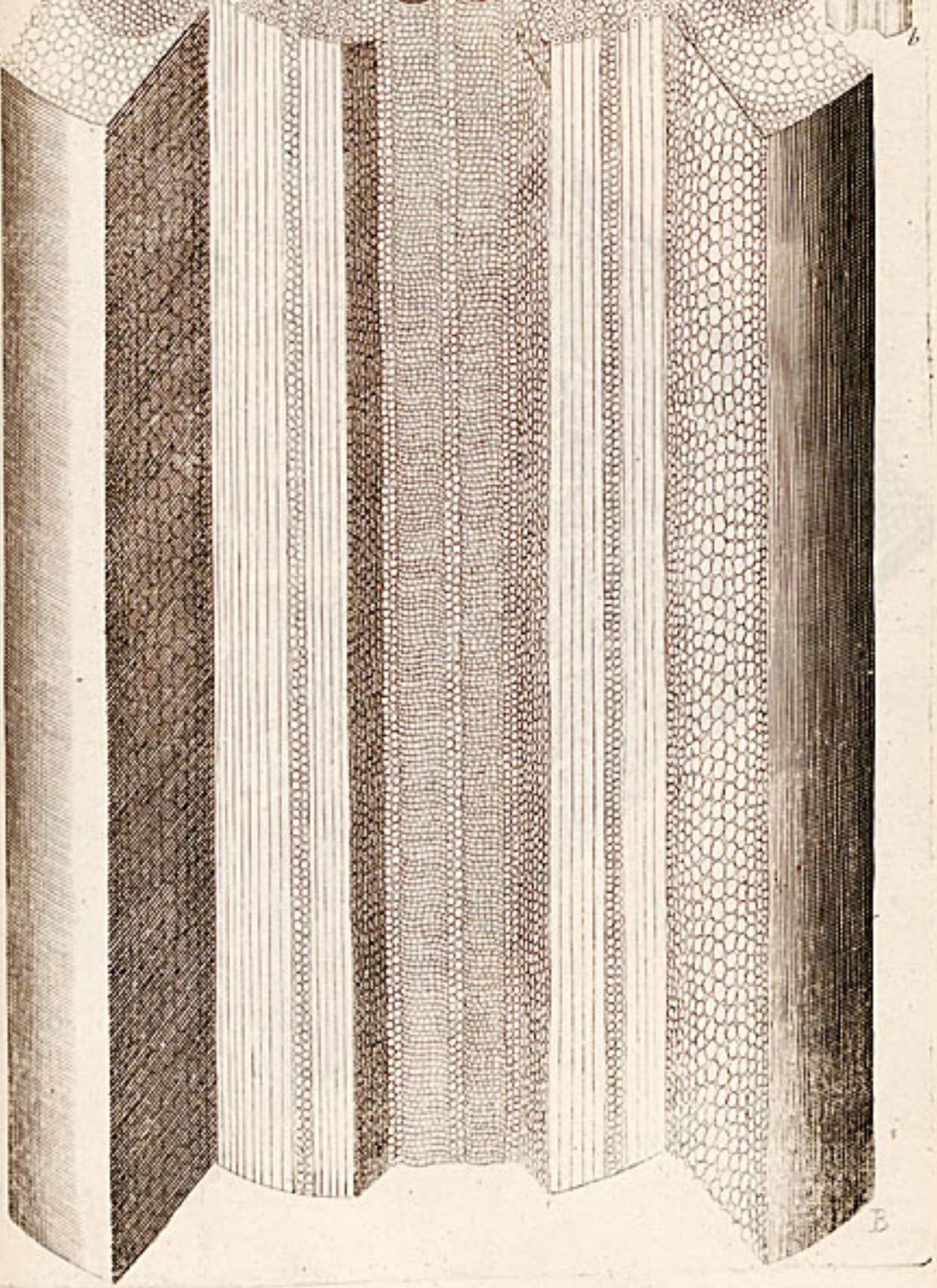




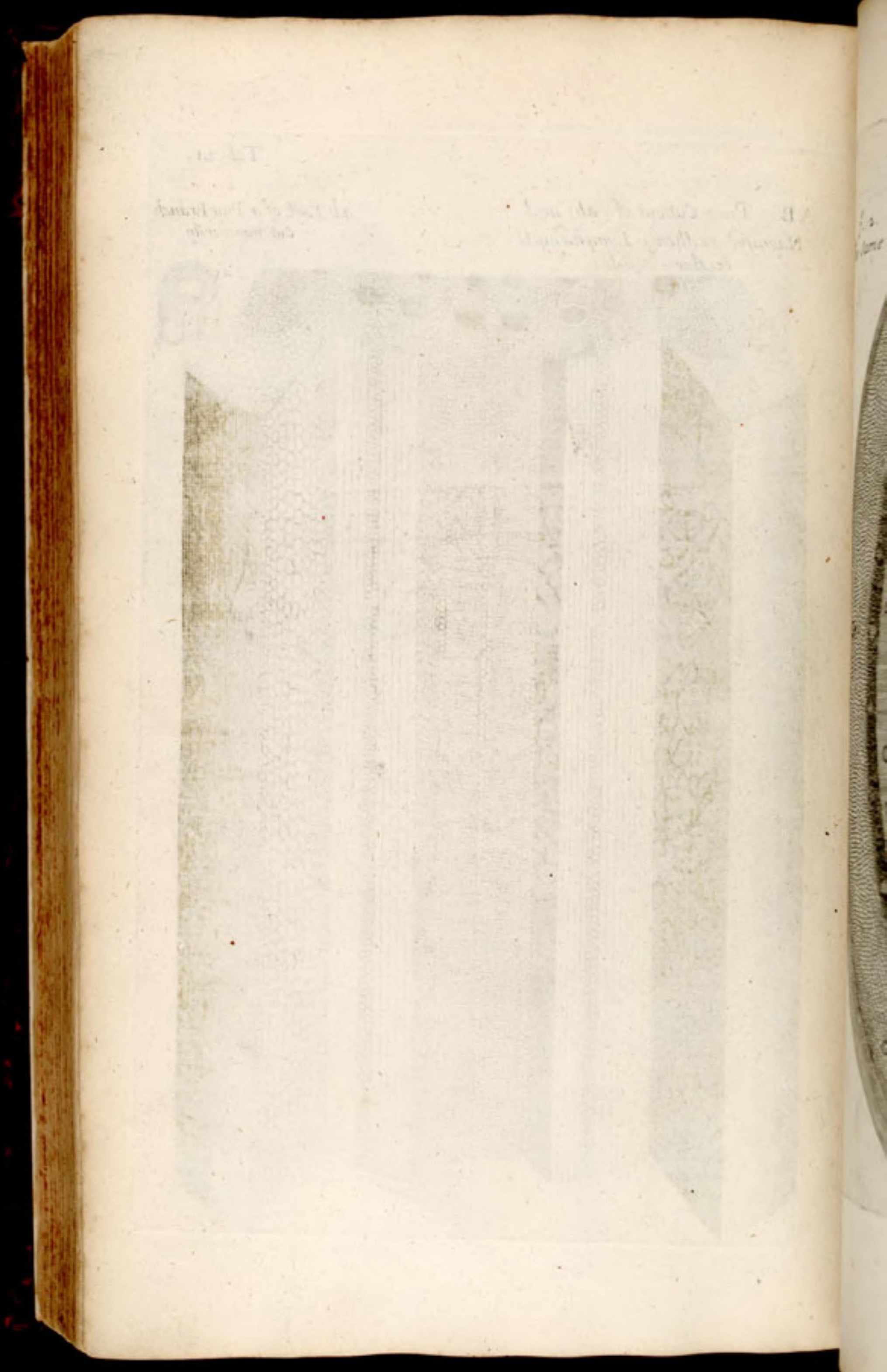




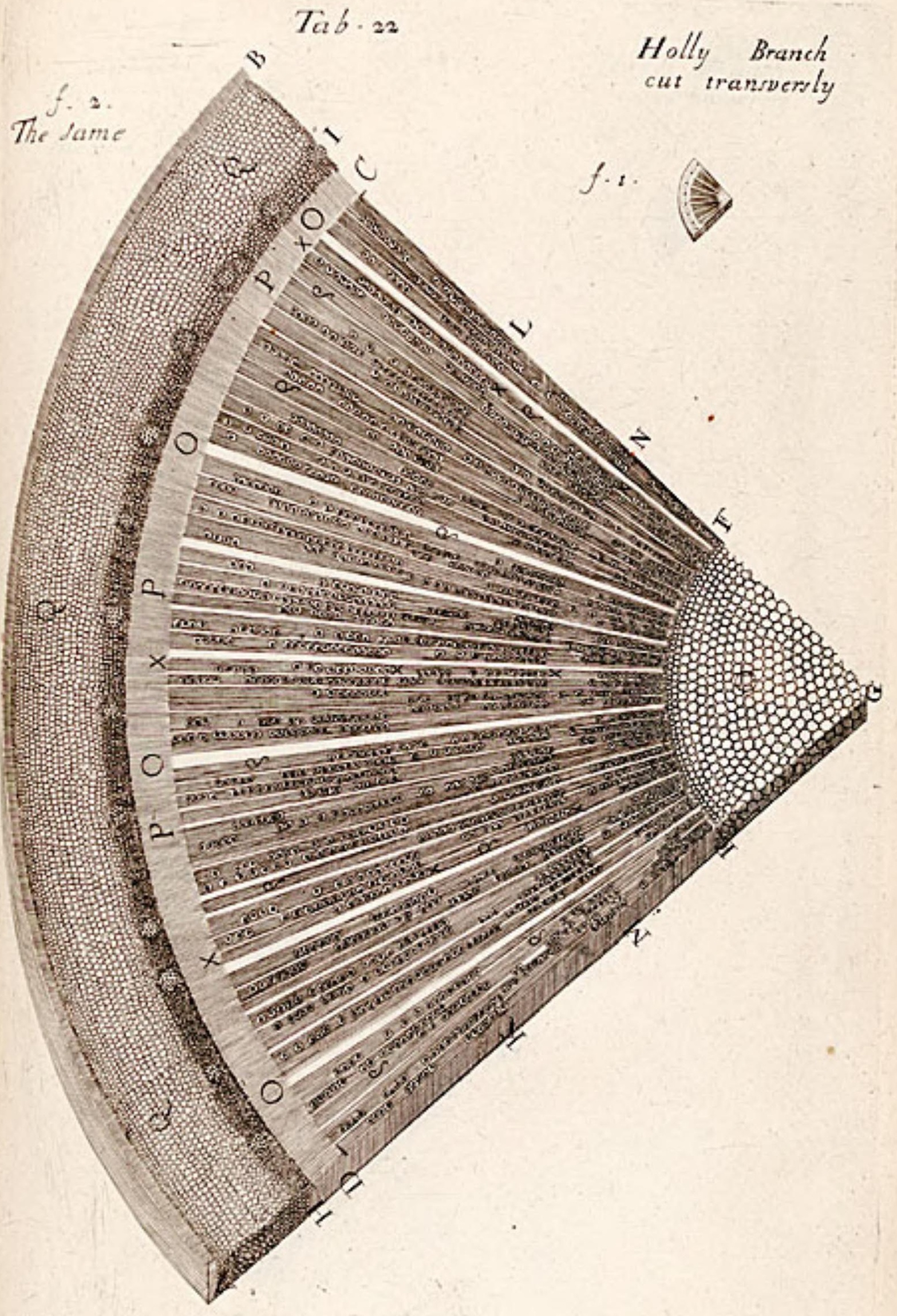




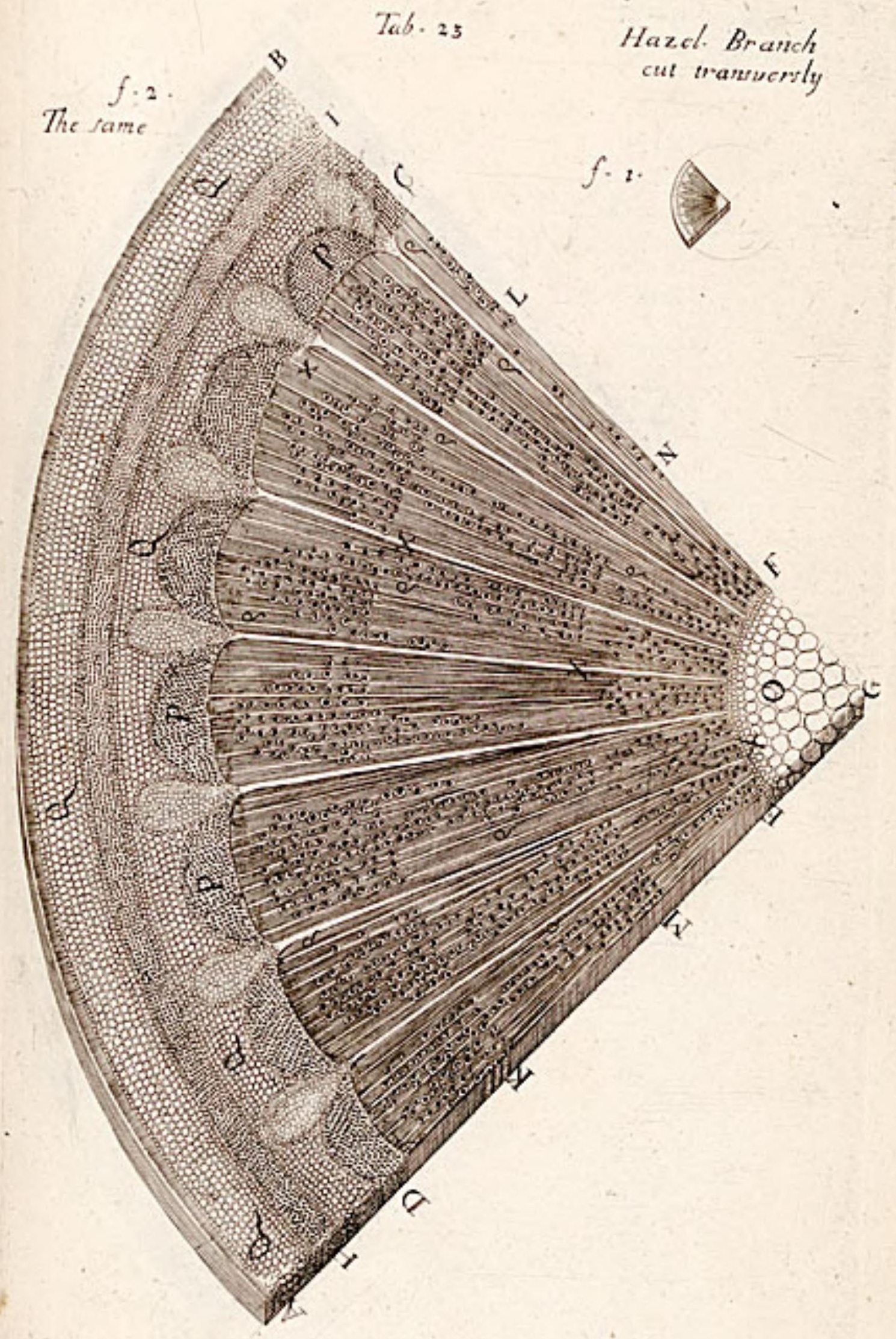




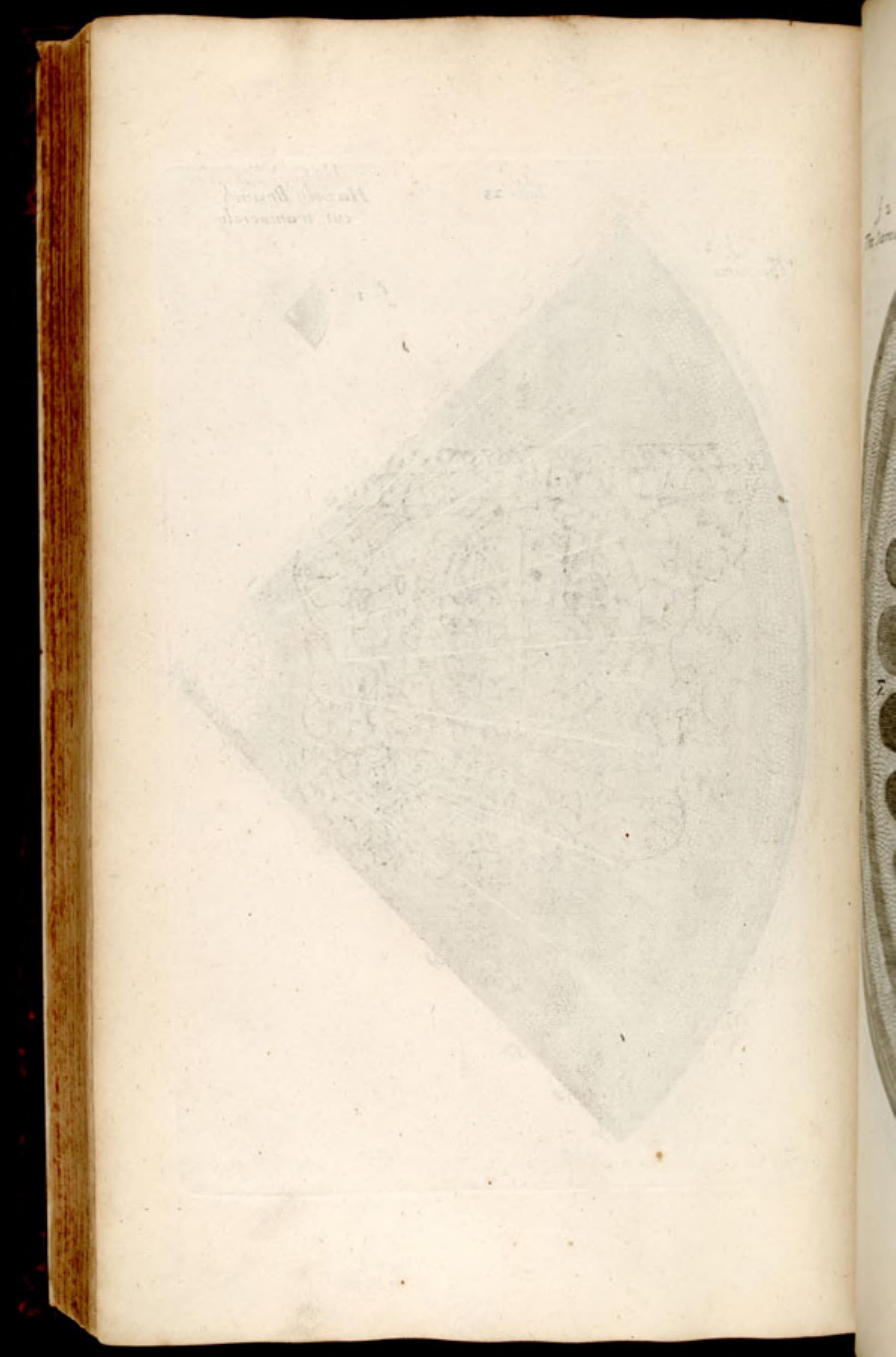




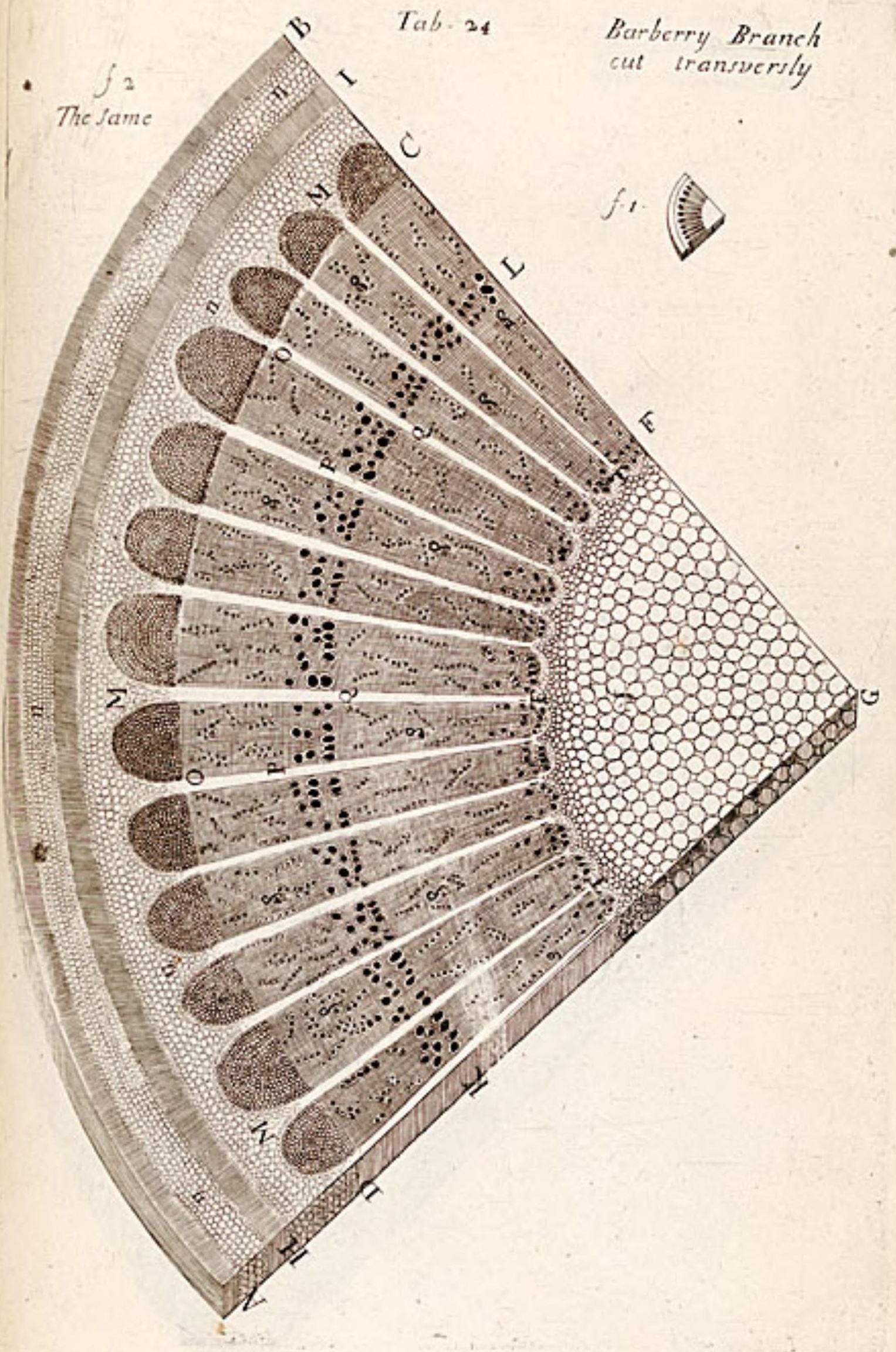




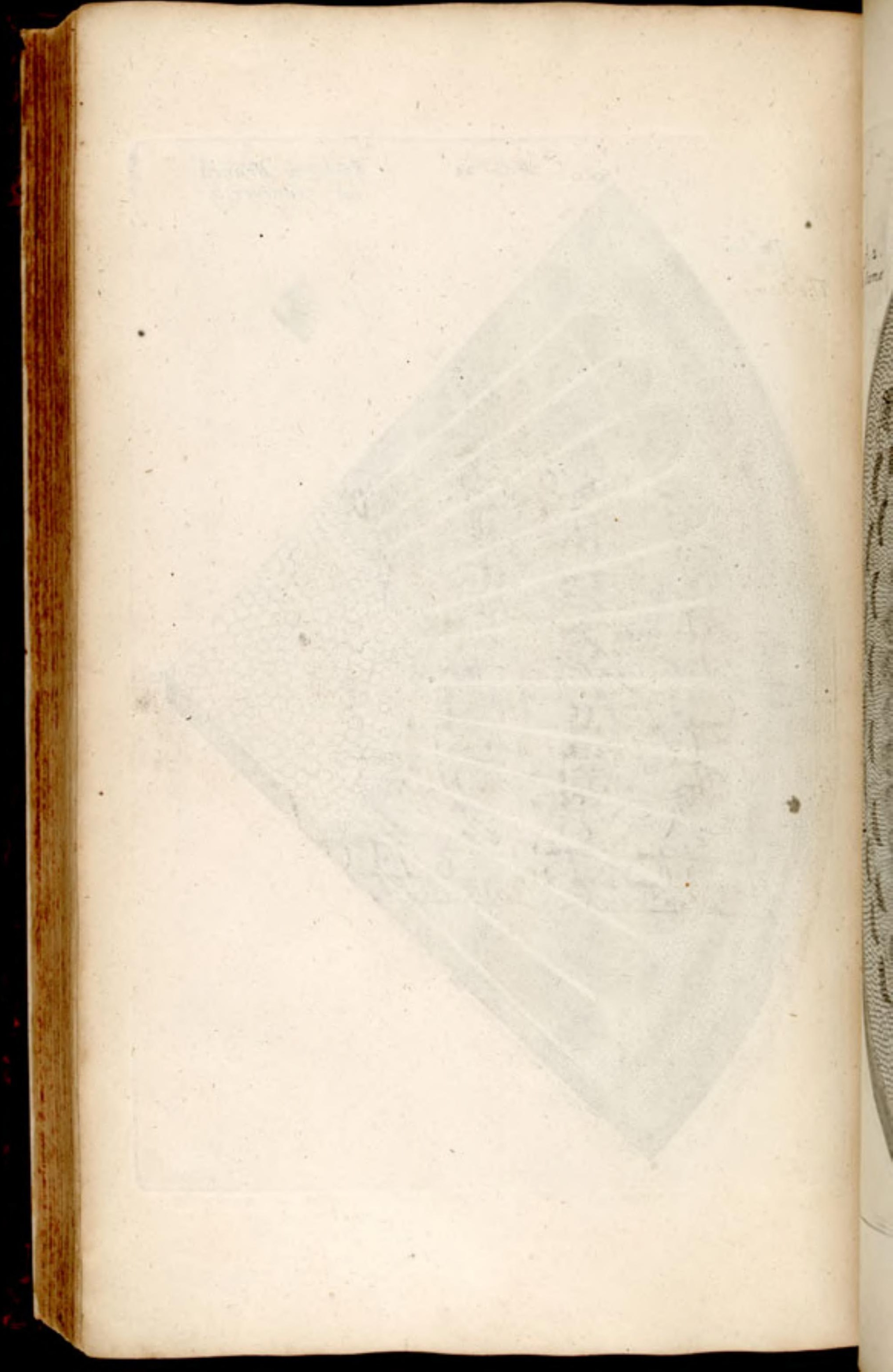




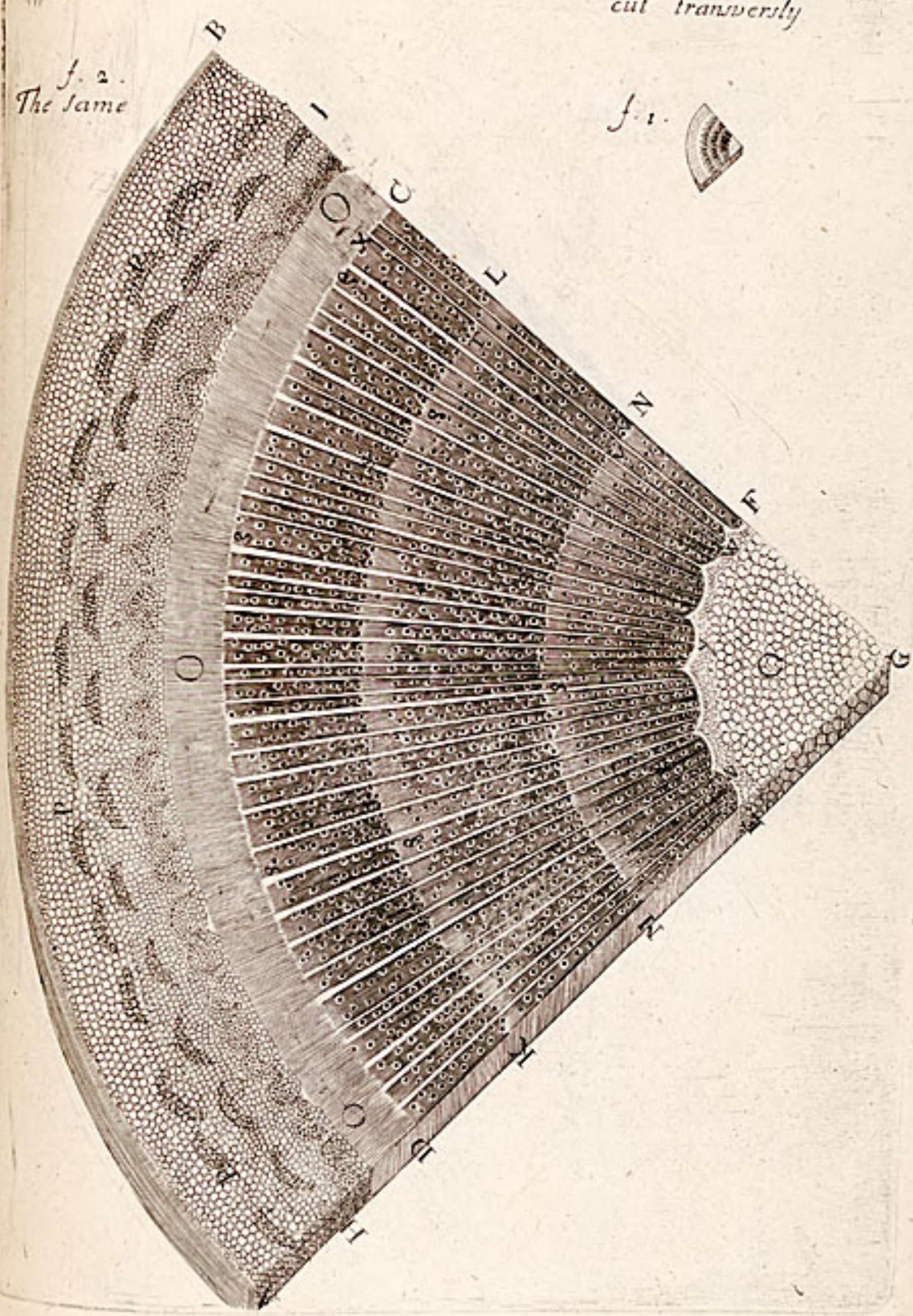




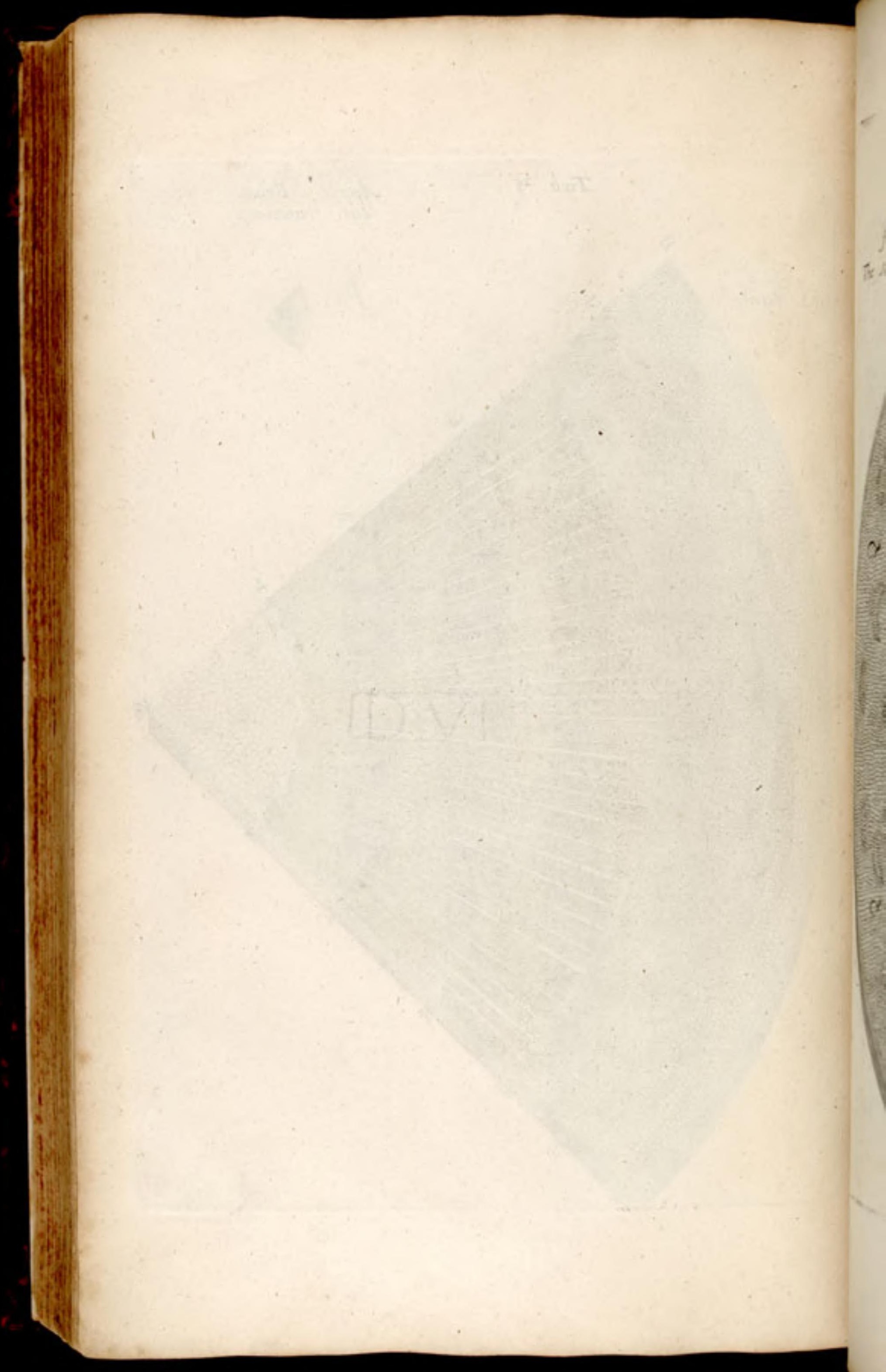




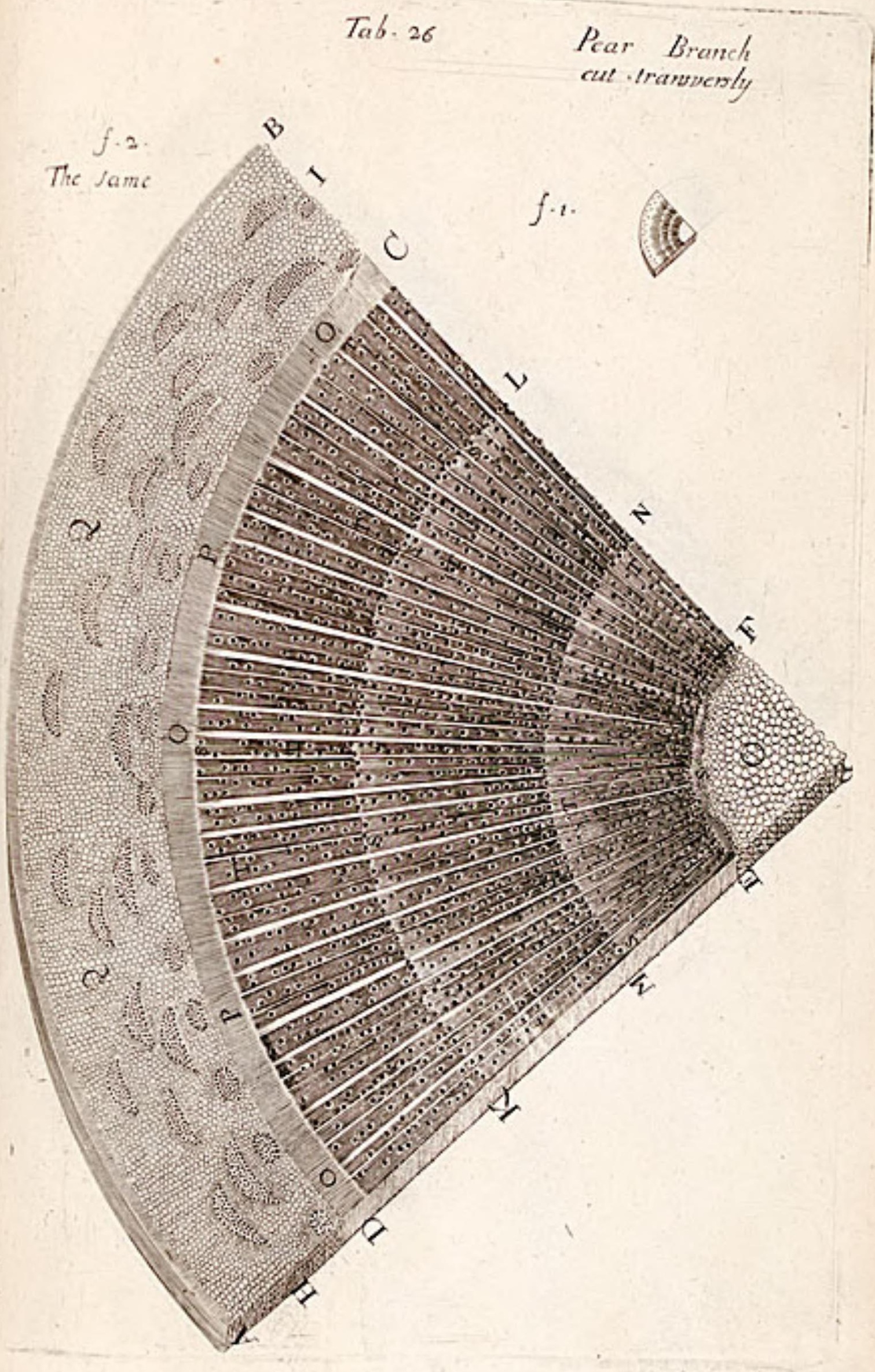




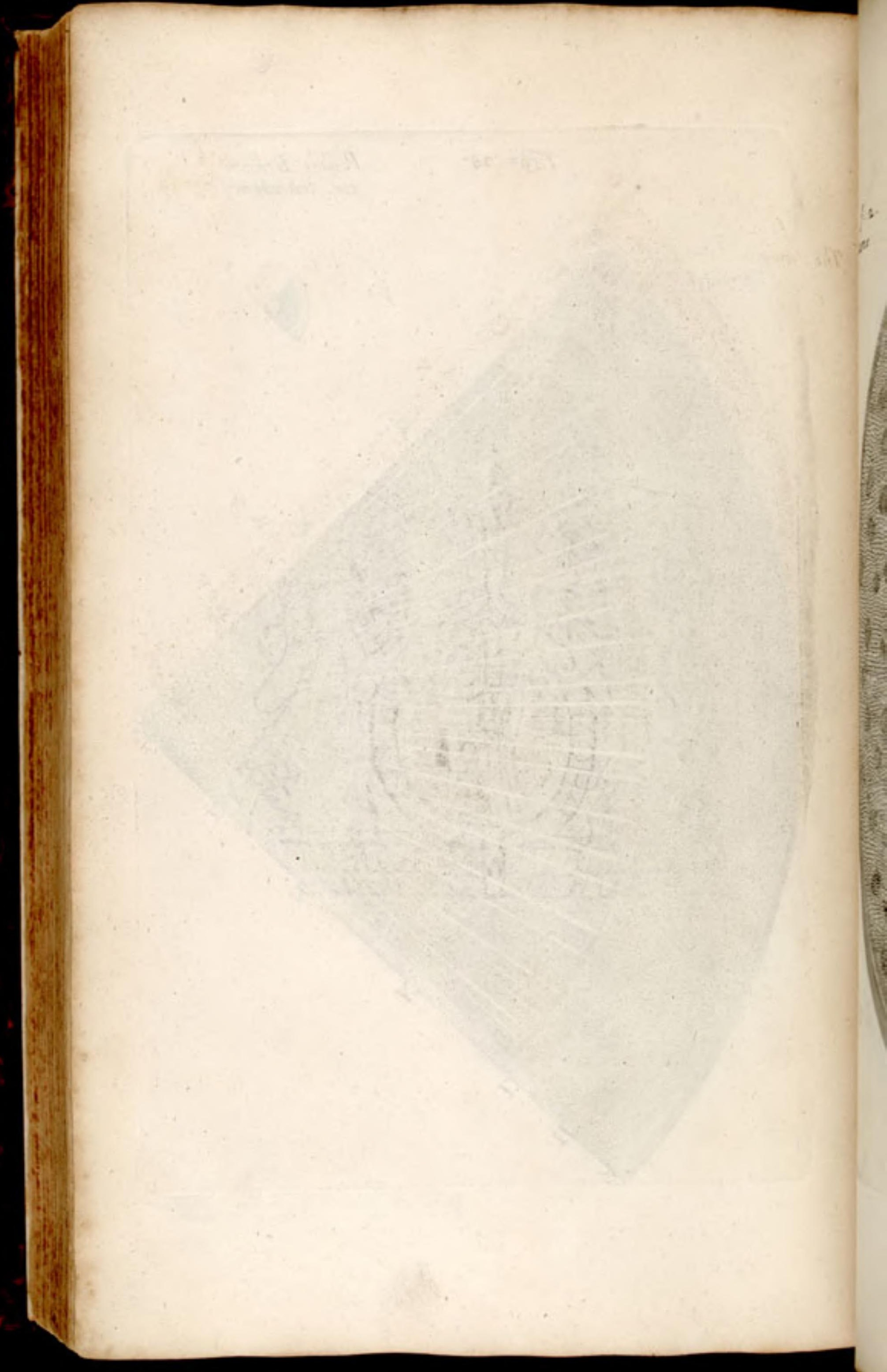




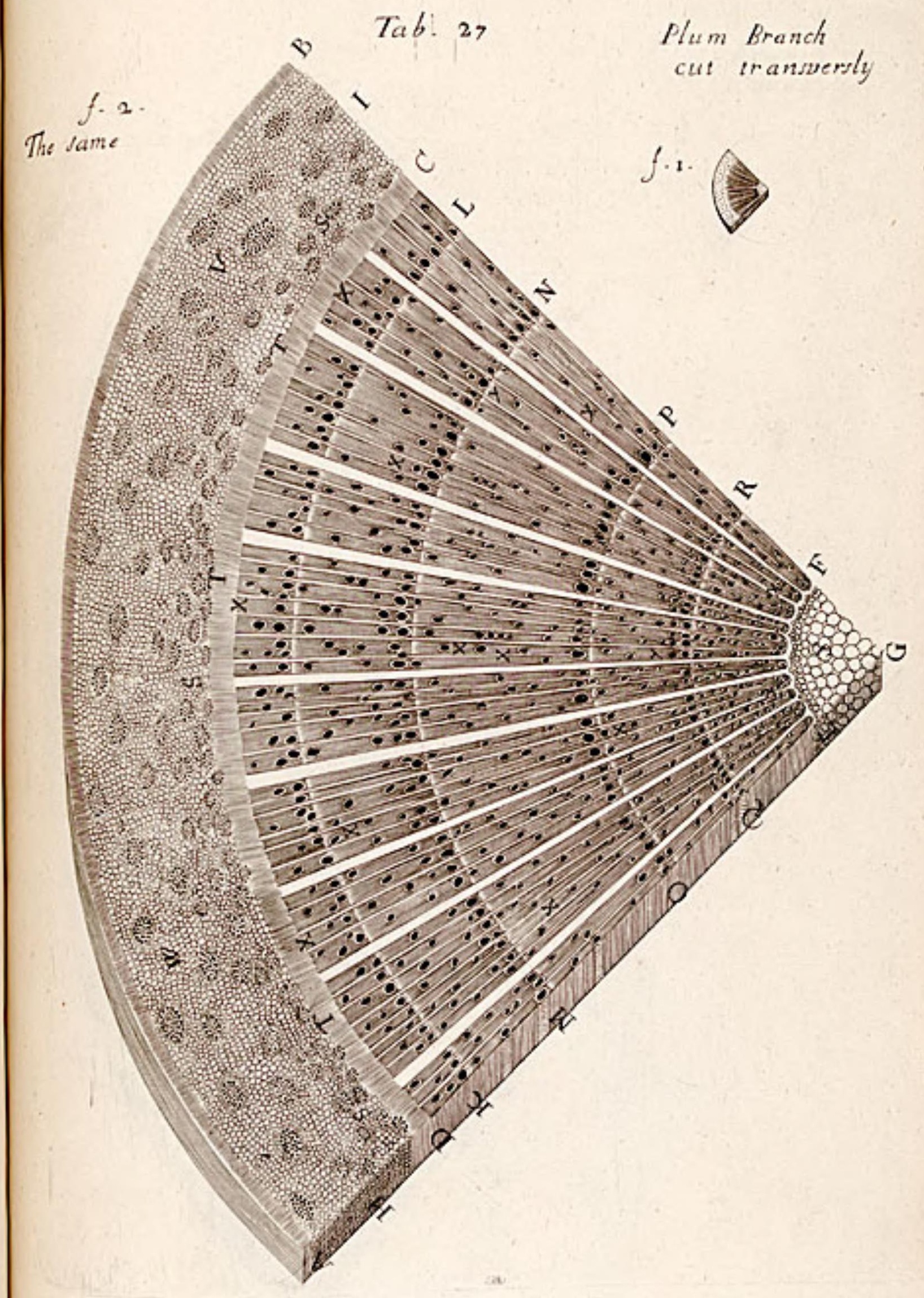




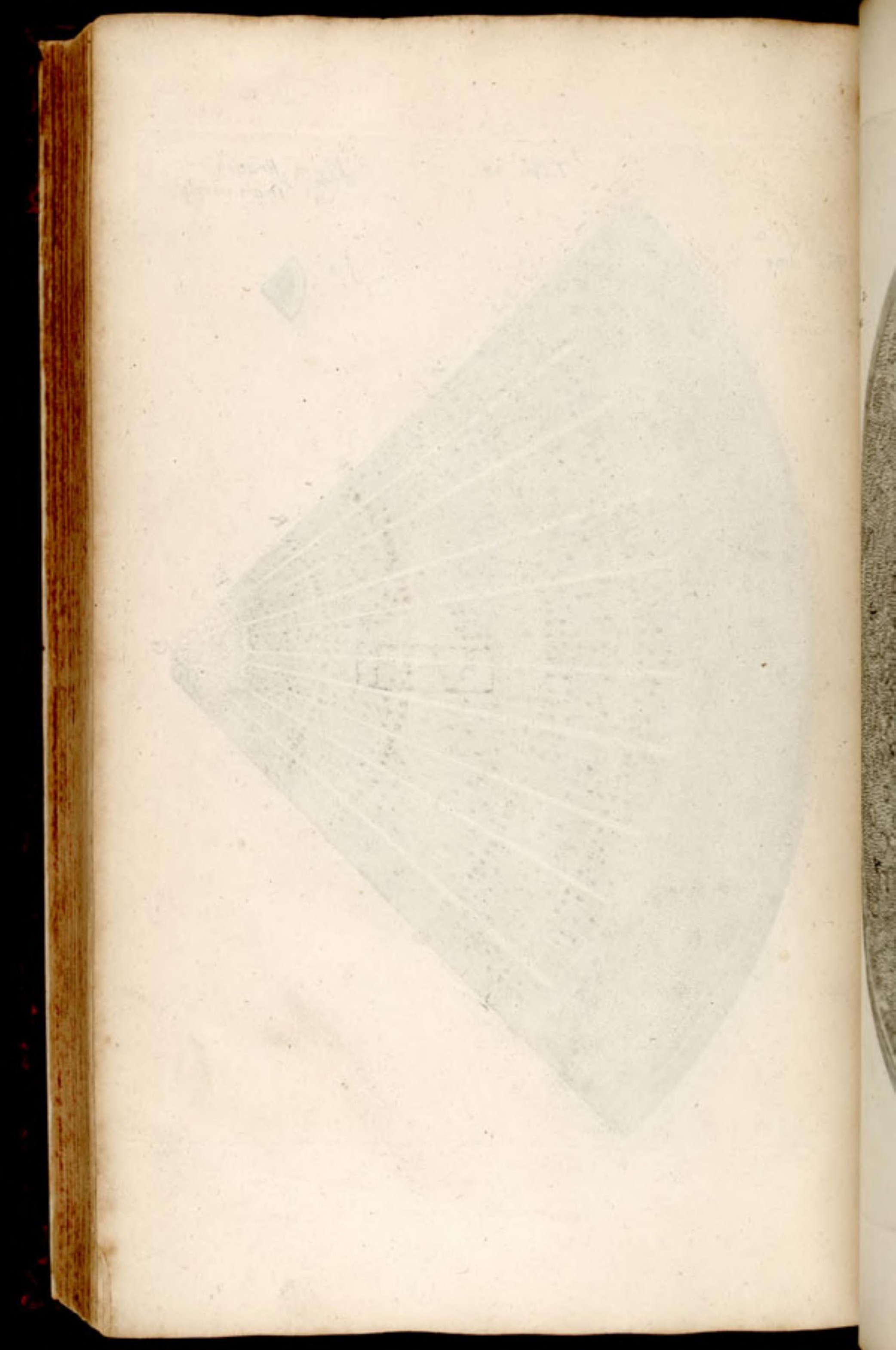




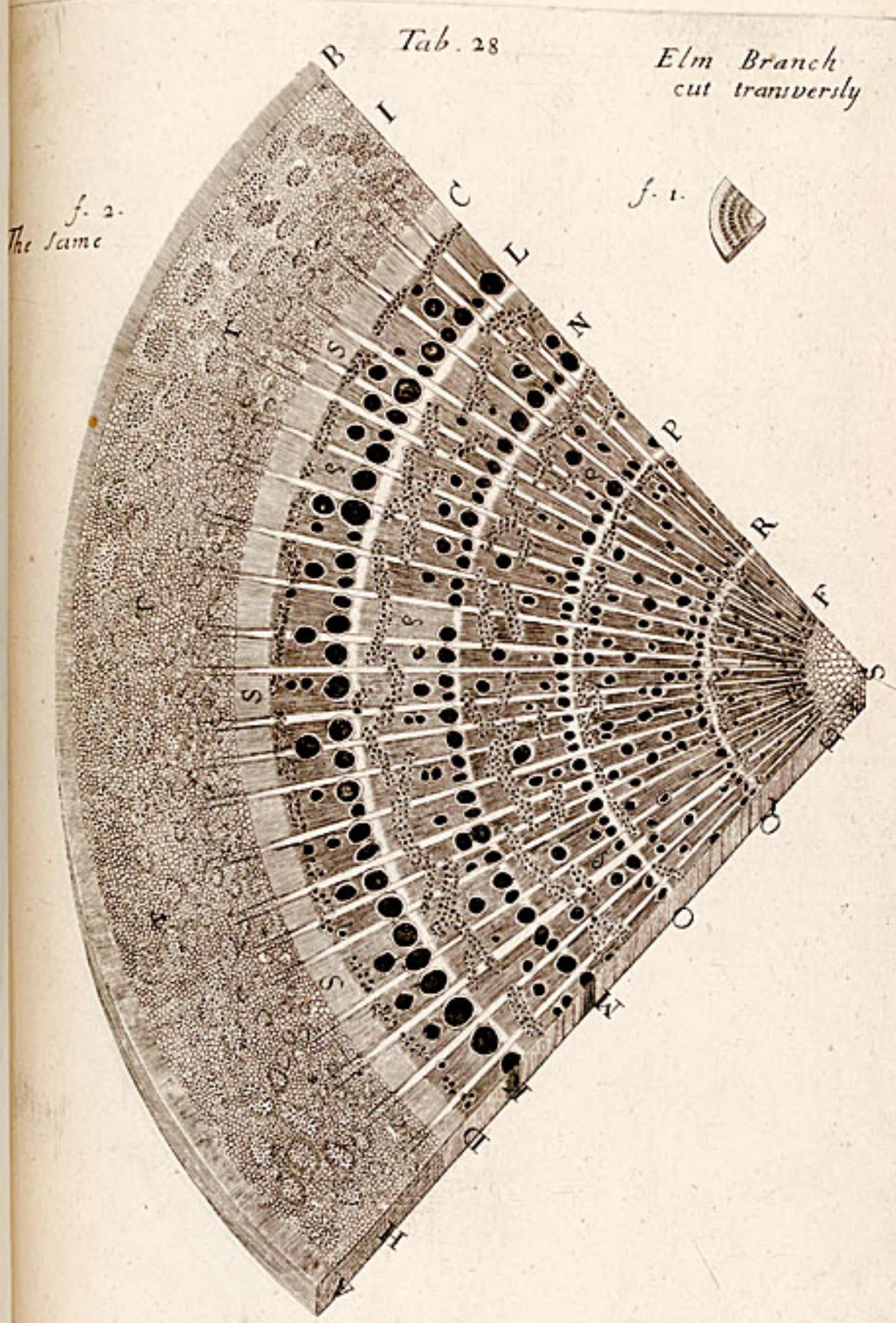




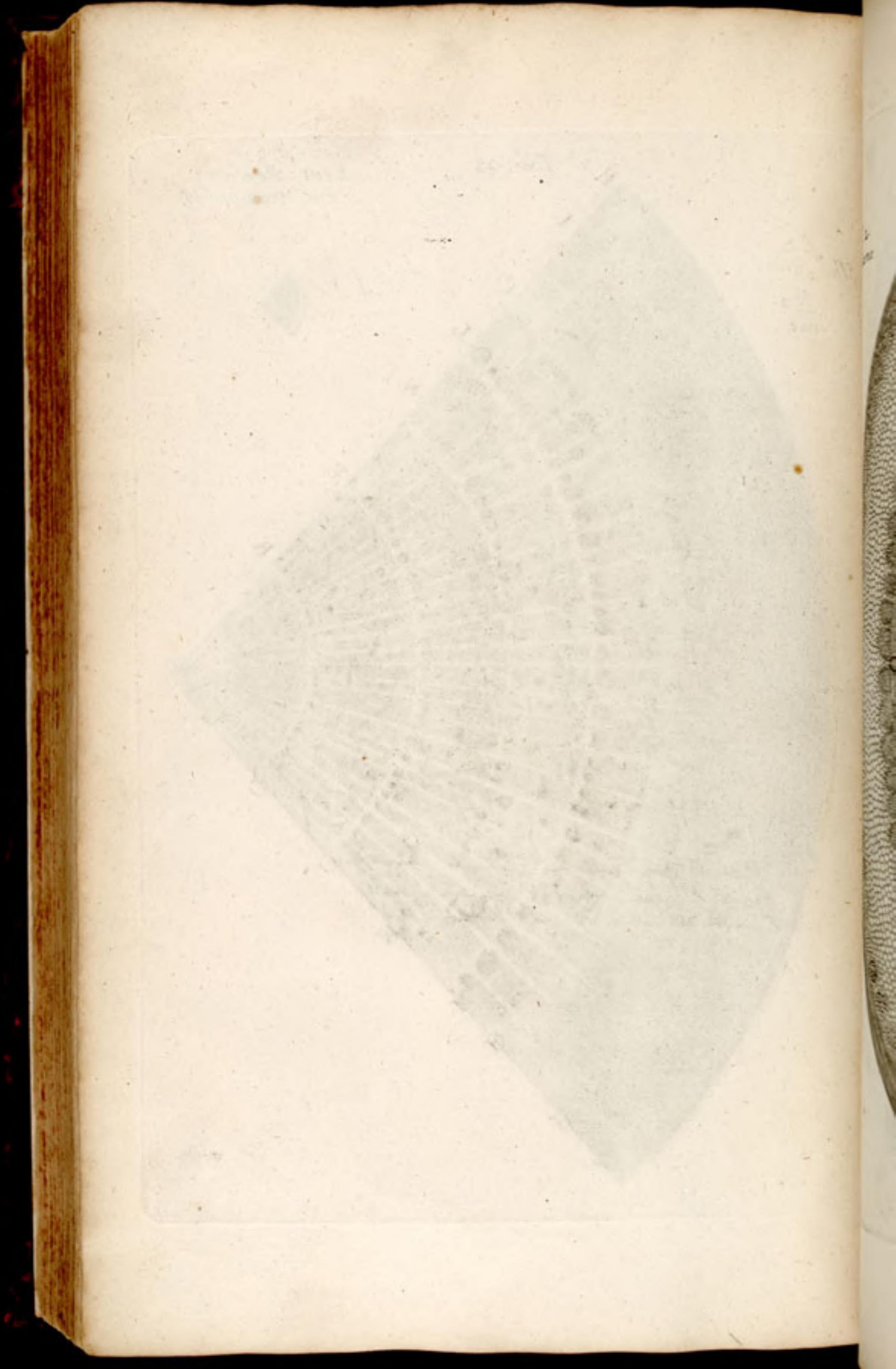


Tab. 29

s.

The fame

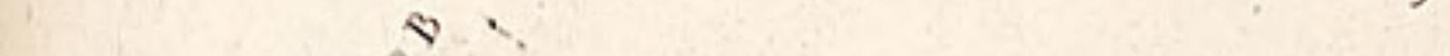

Ash Branch

cut transersly
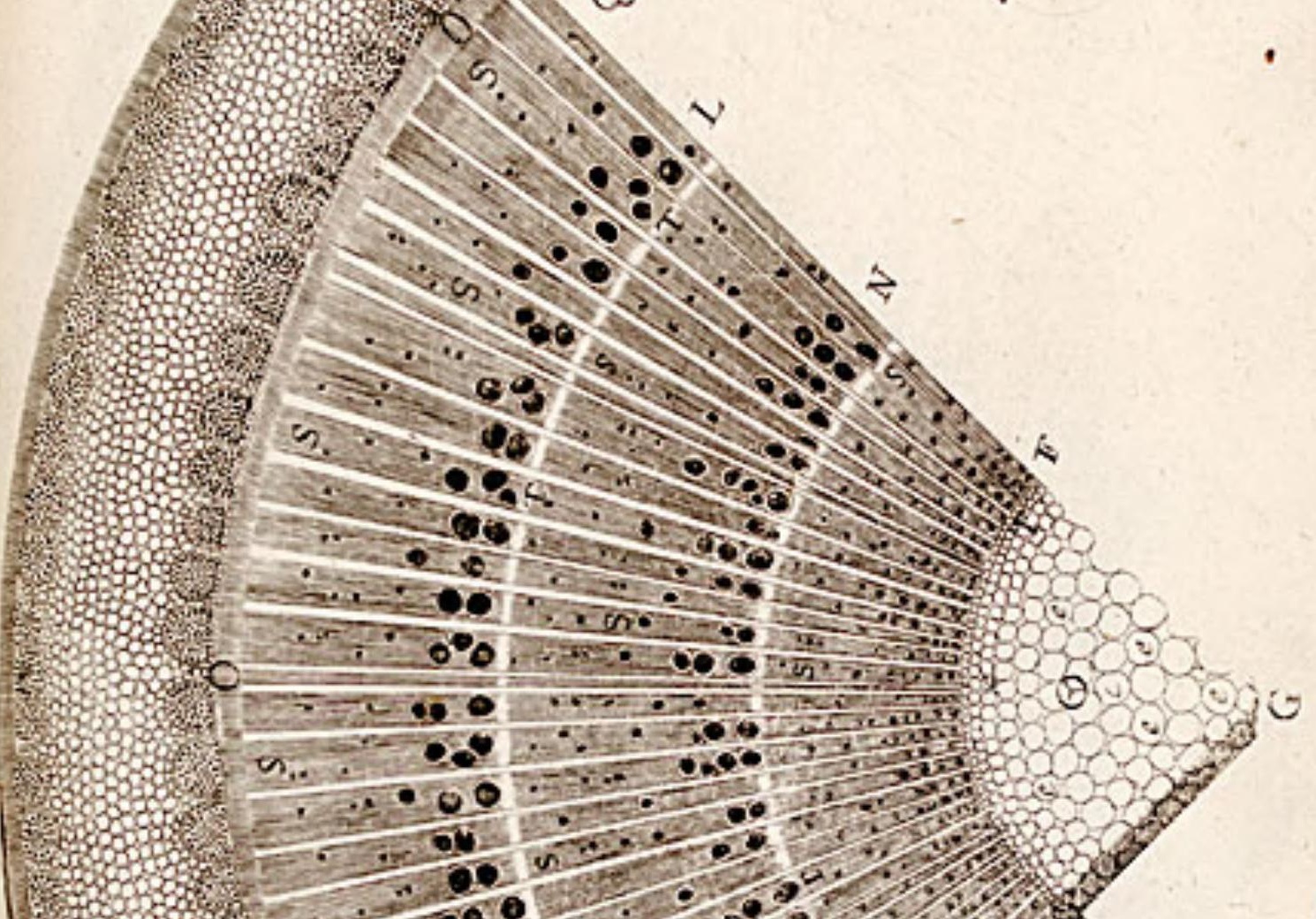

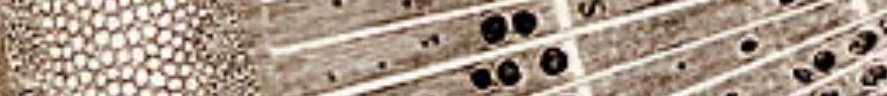

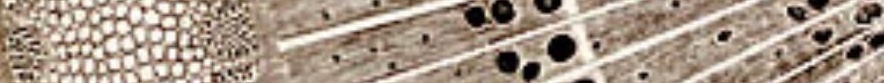

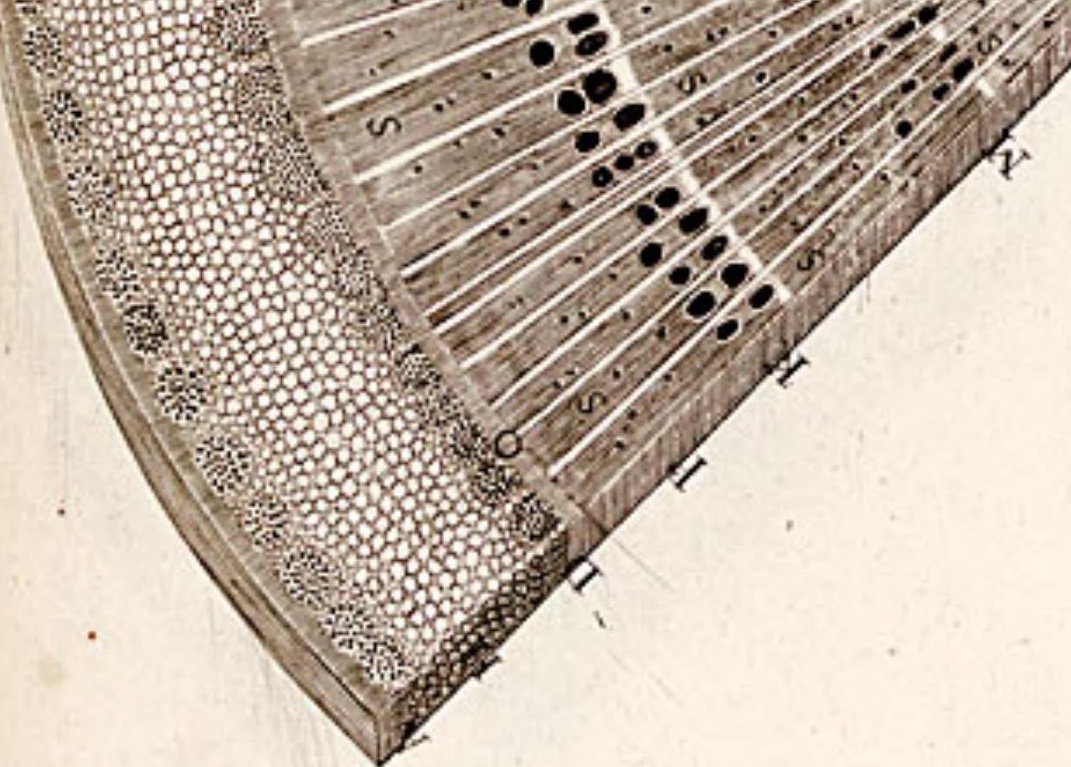




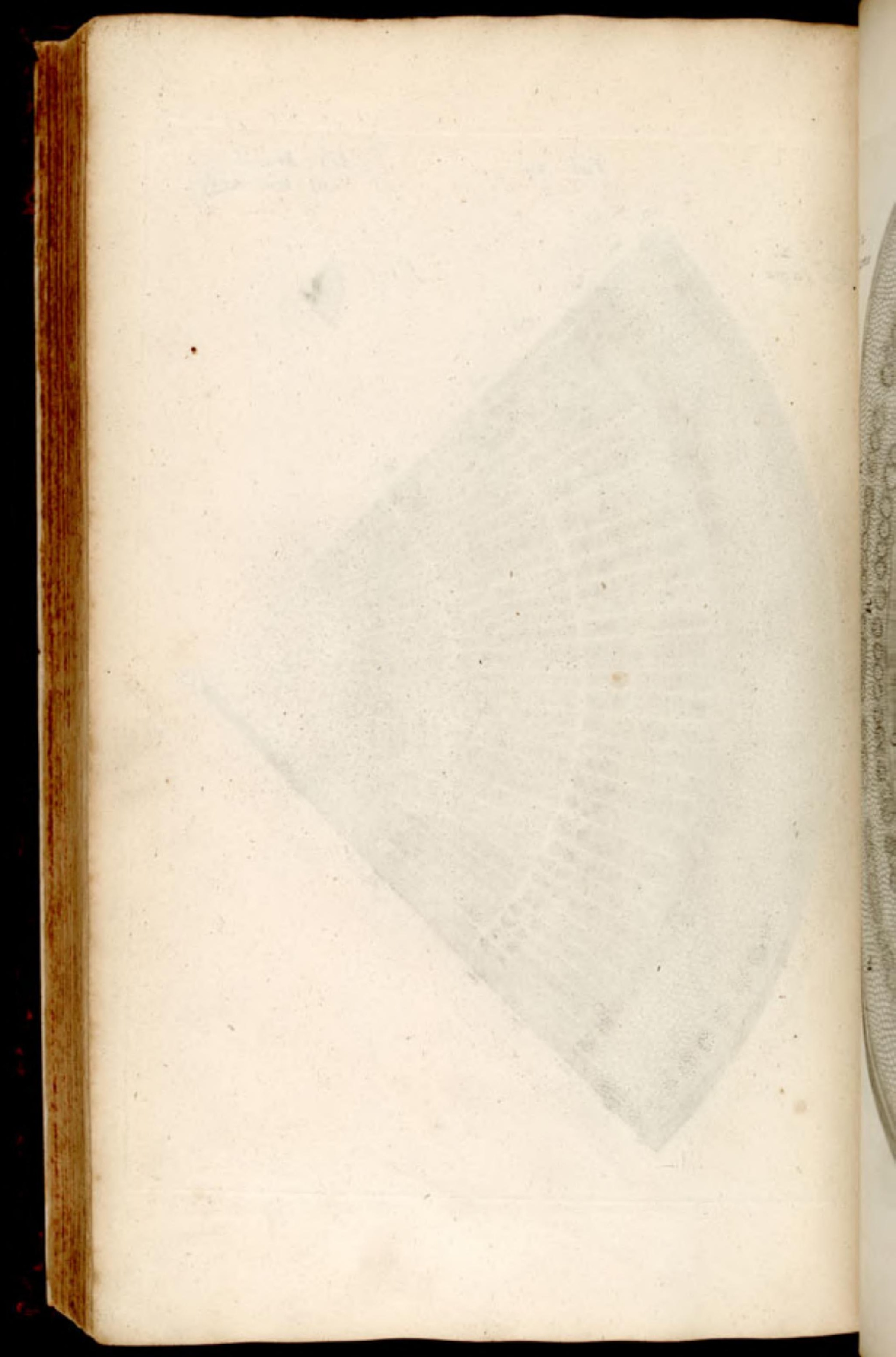




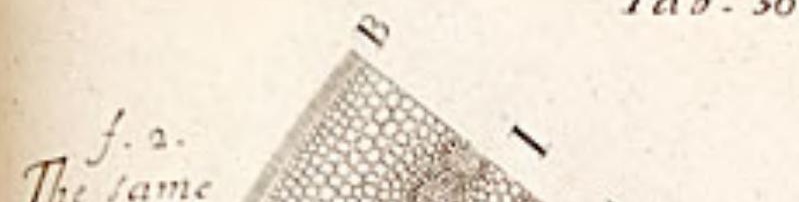

Tab. 30

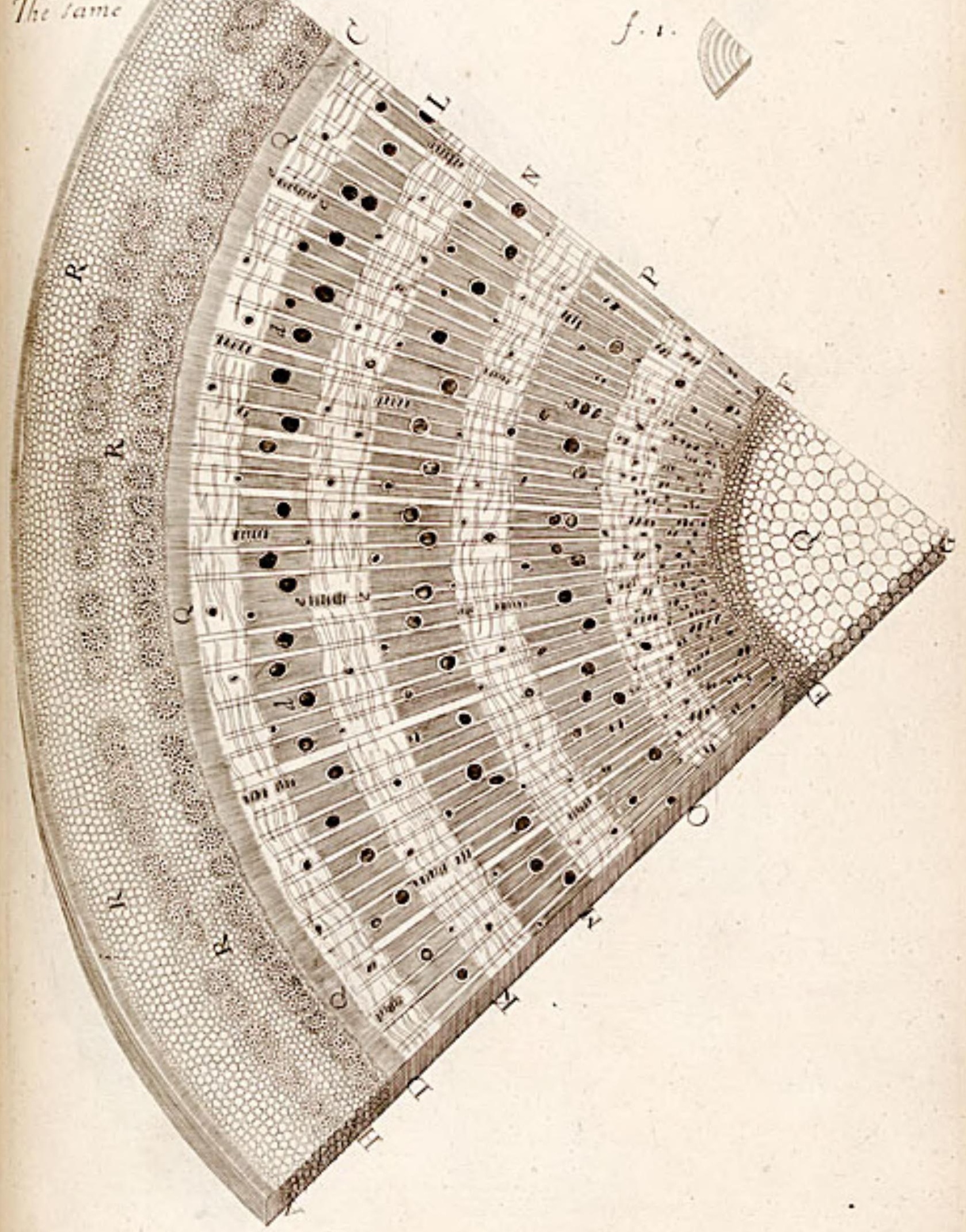

Wallnut Branclt

cut trannersly

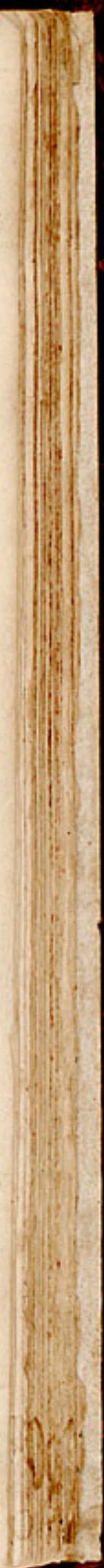




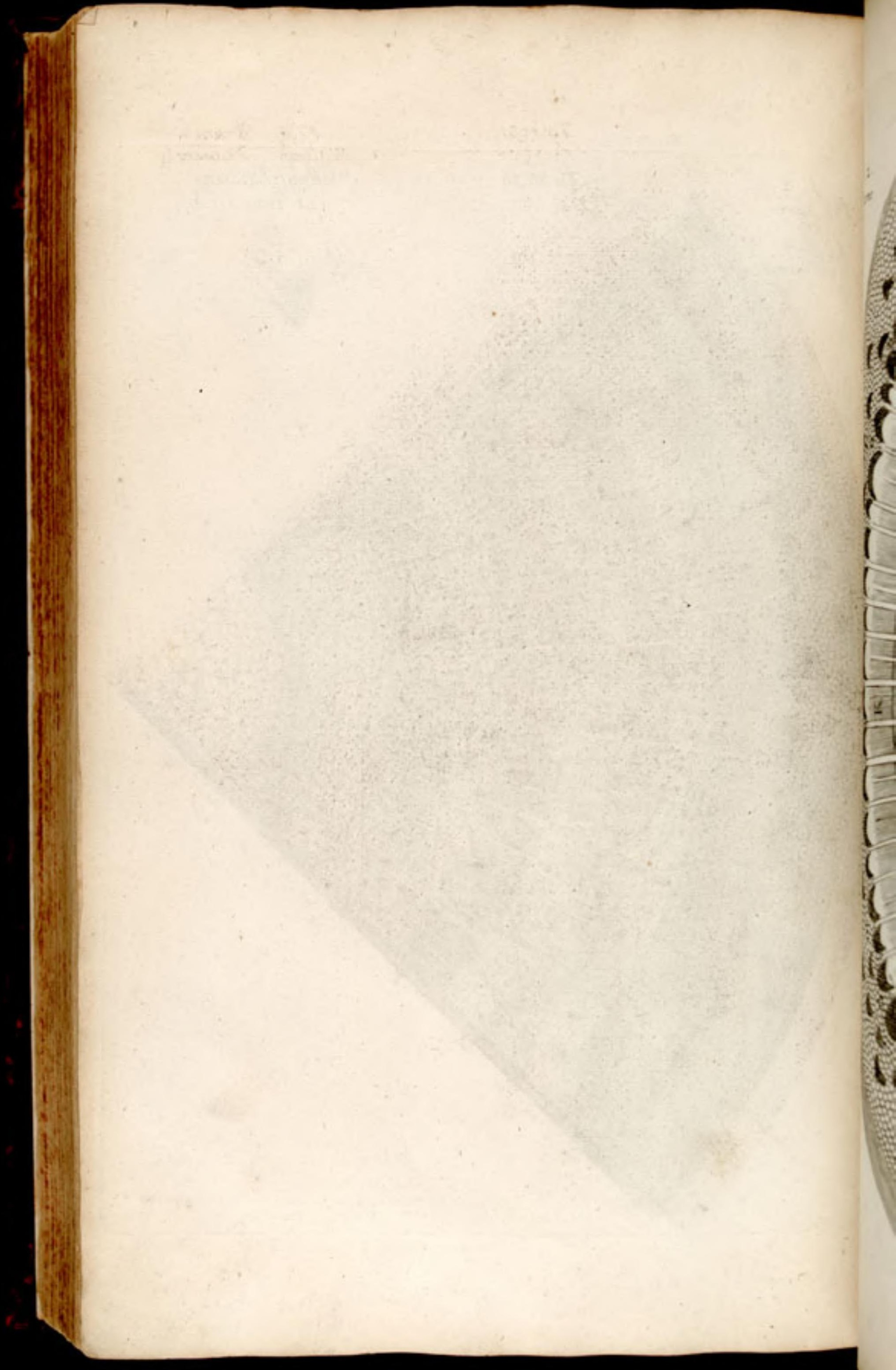


Tab.3t

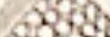

som

0,59

on

ogsh s

(j)

850

sin

sos

$630 \%$

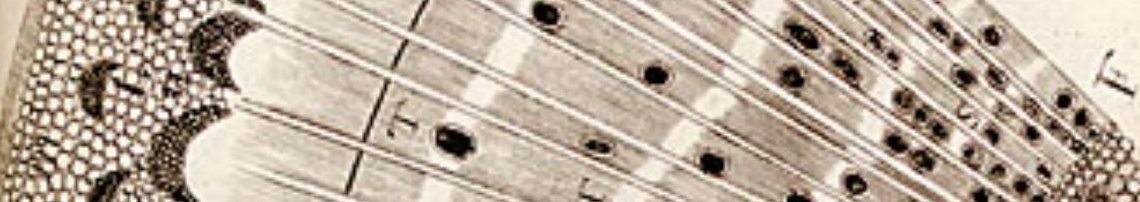

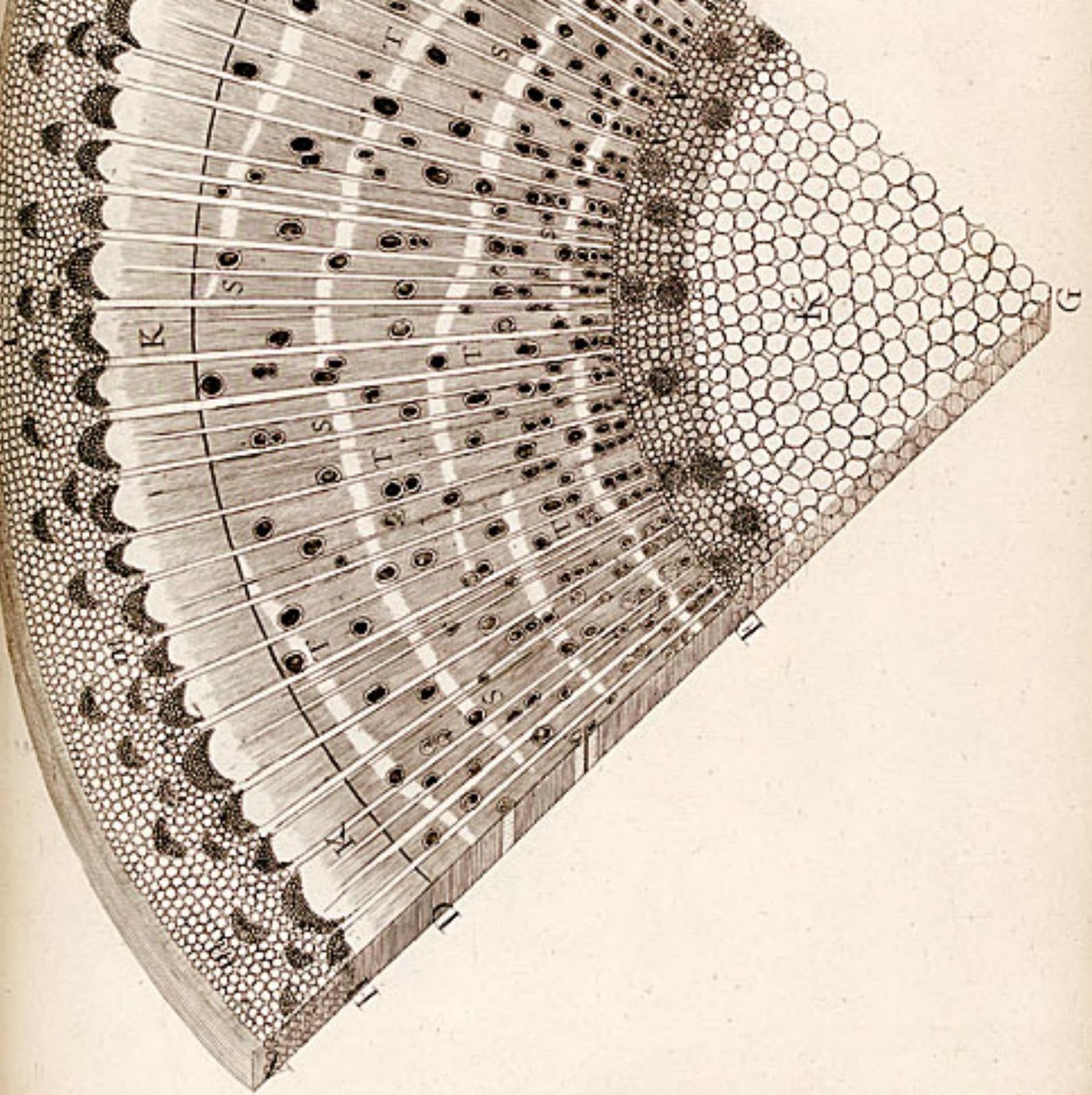



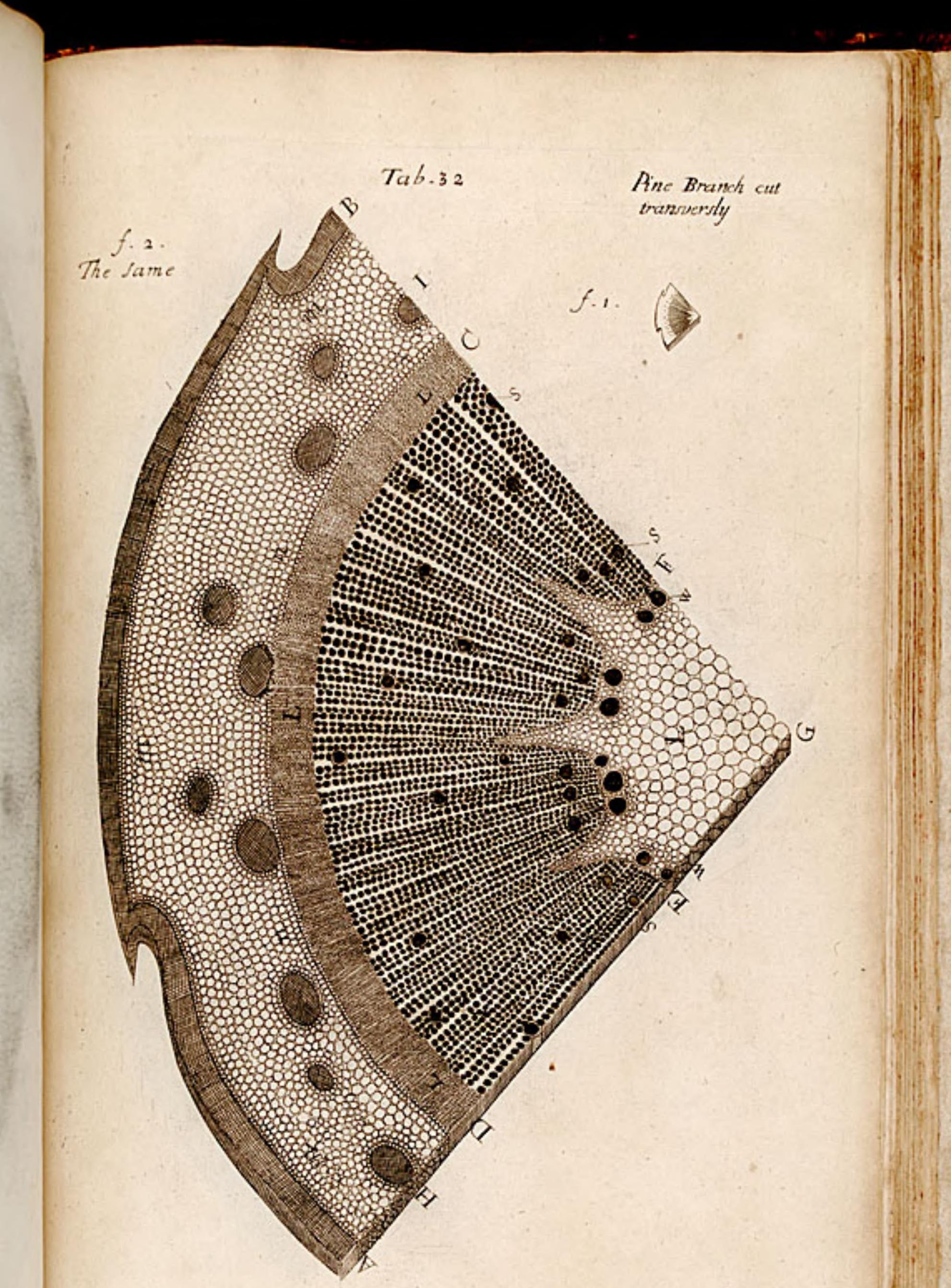


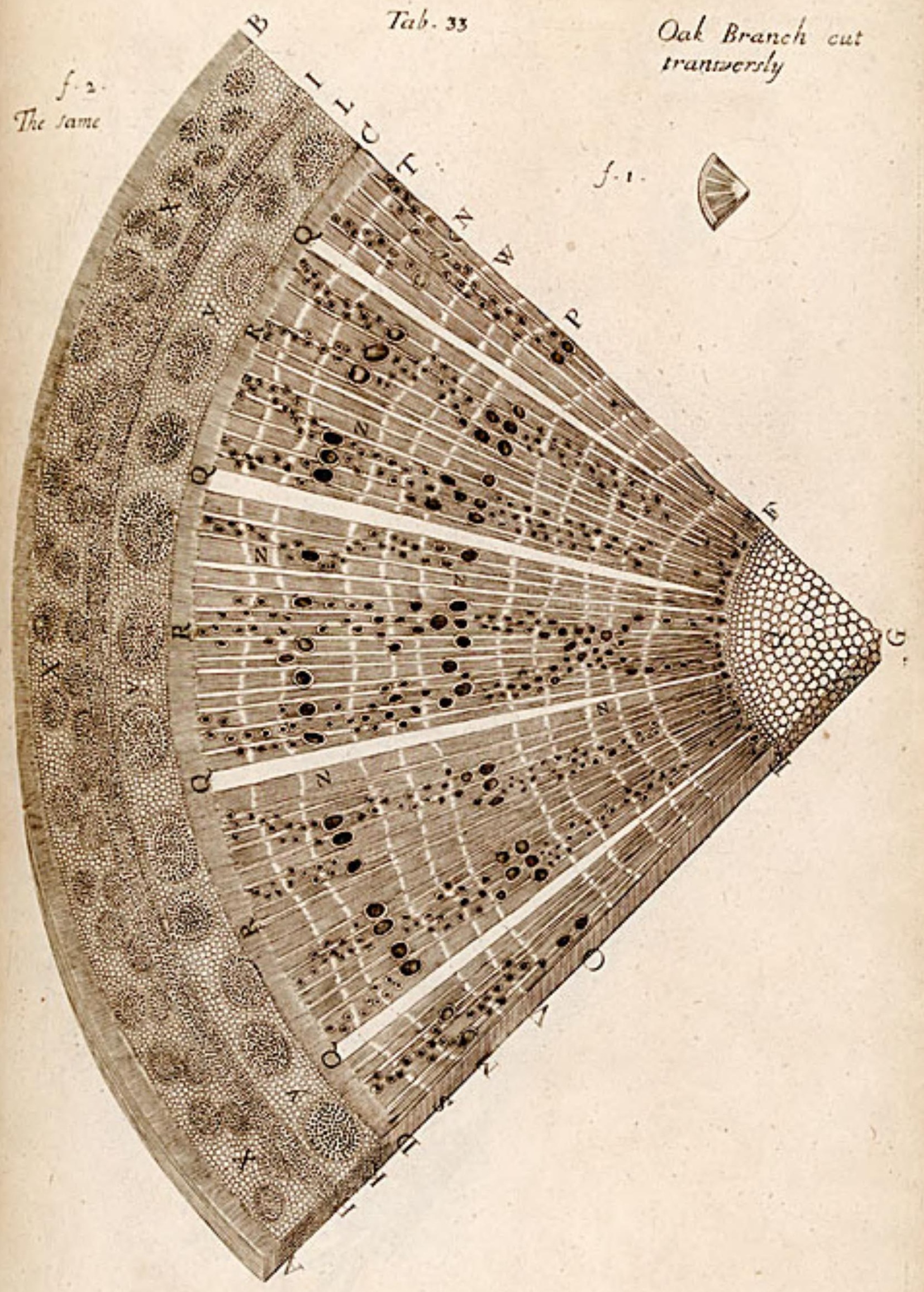




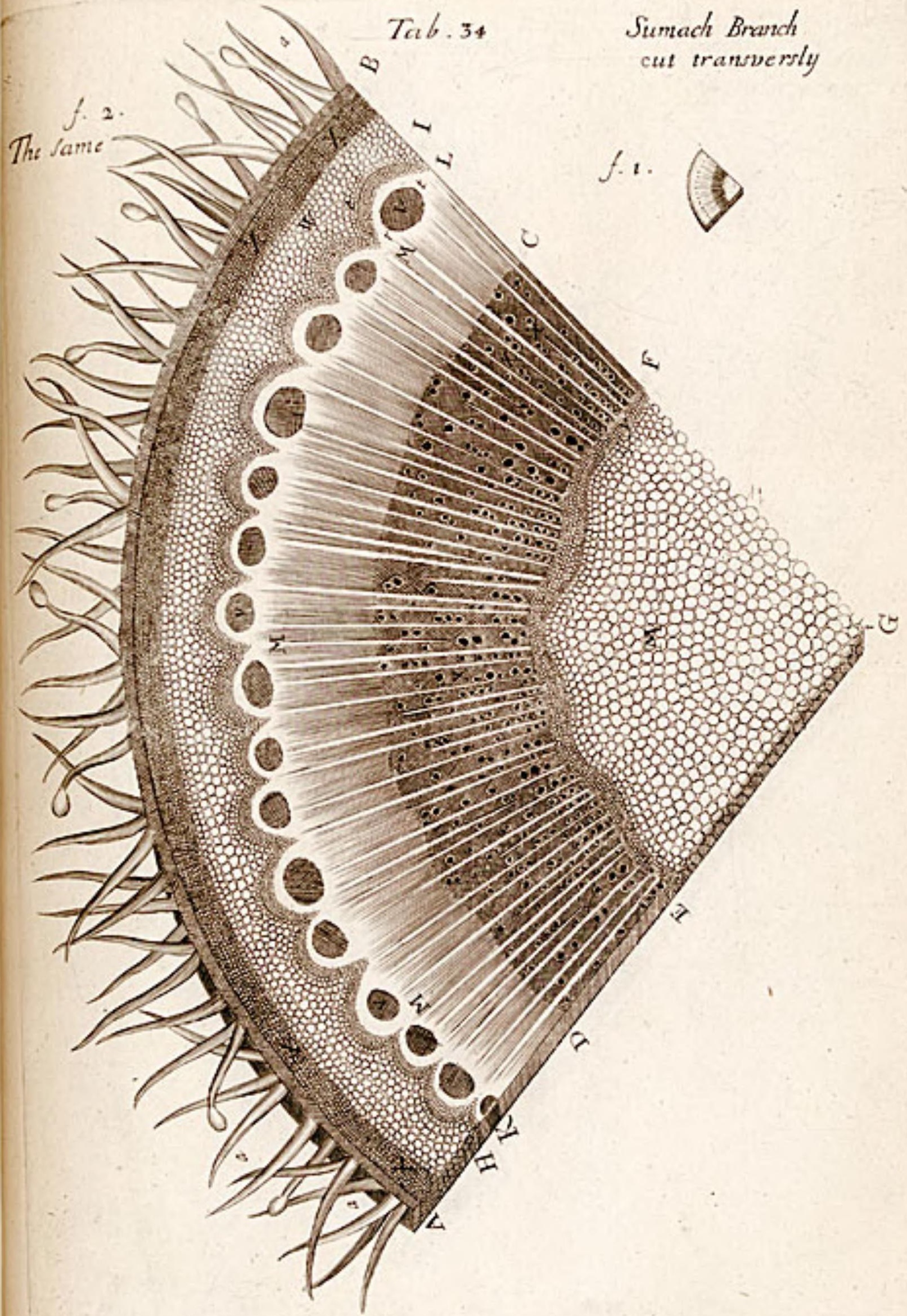




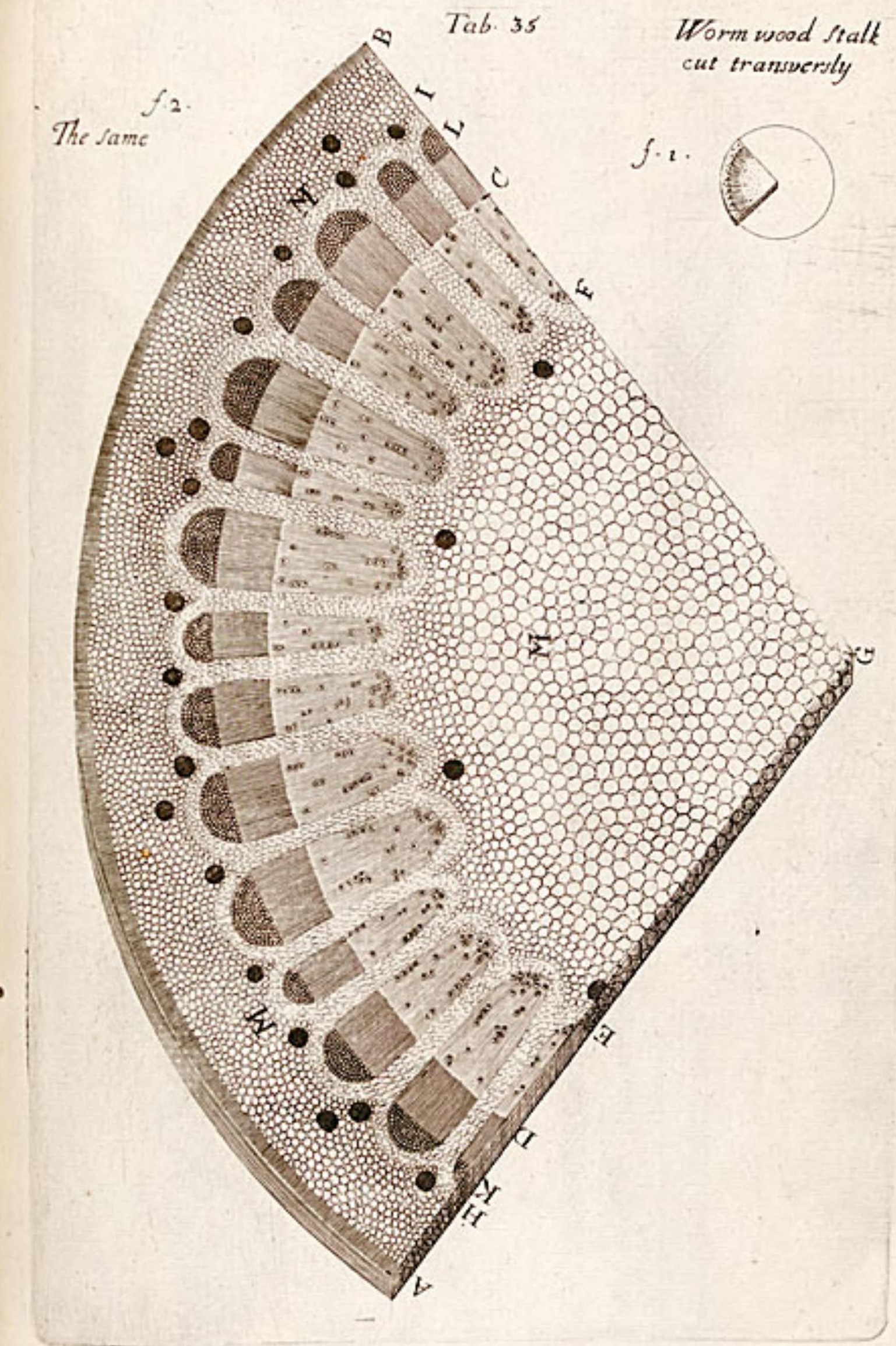


Mnd 

folll half way donue is walle

$\int \frac{1}{10}$

B 8

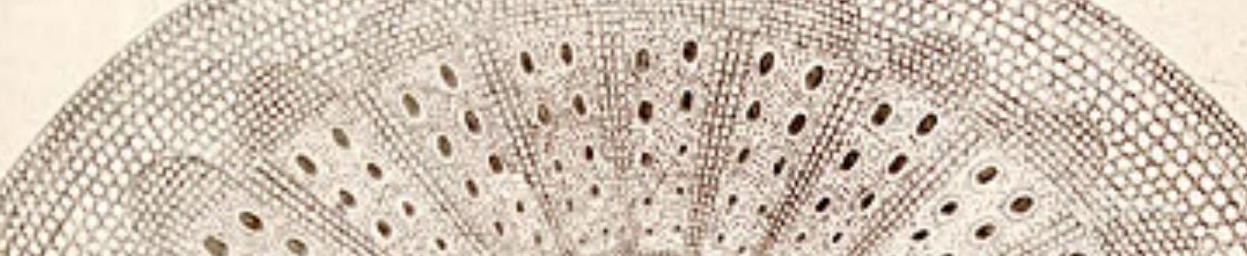
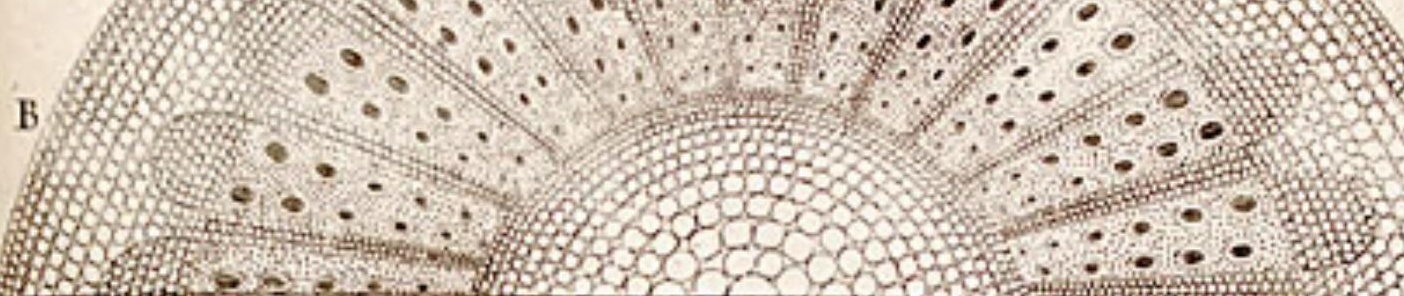

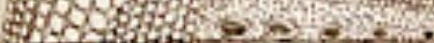

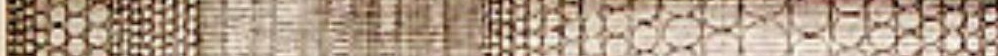

520

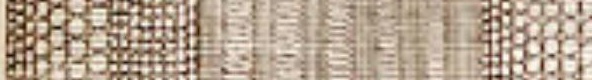

in

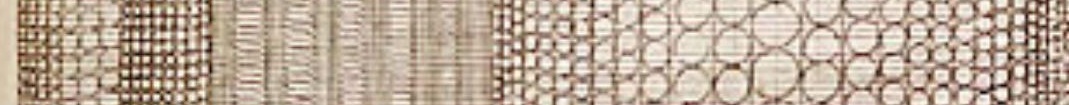

m.t.

H.

茄-

4.

\$30

速

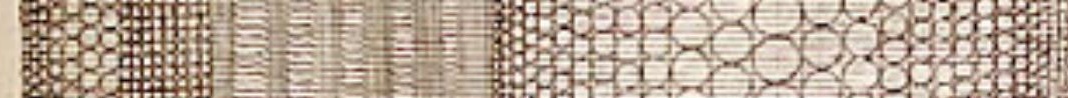

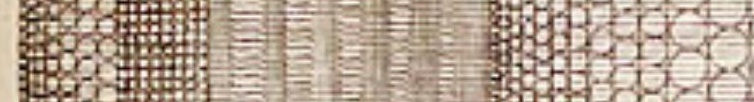

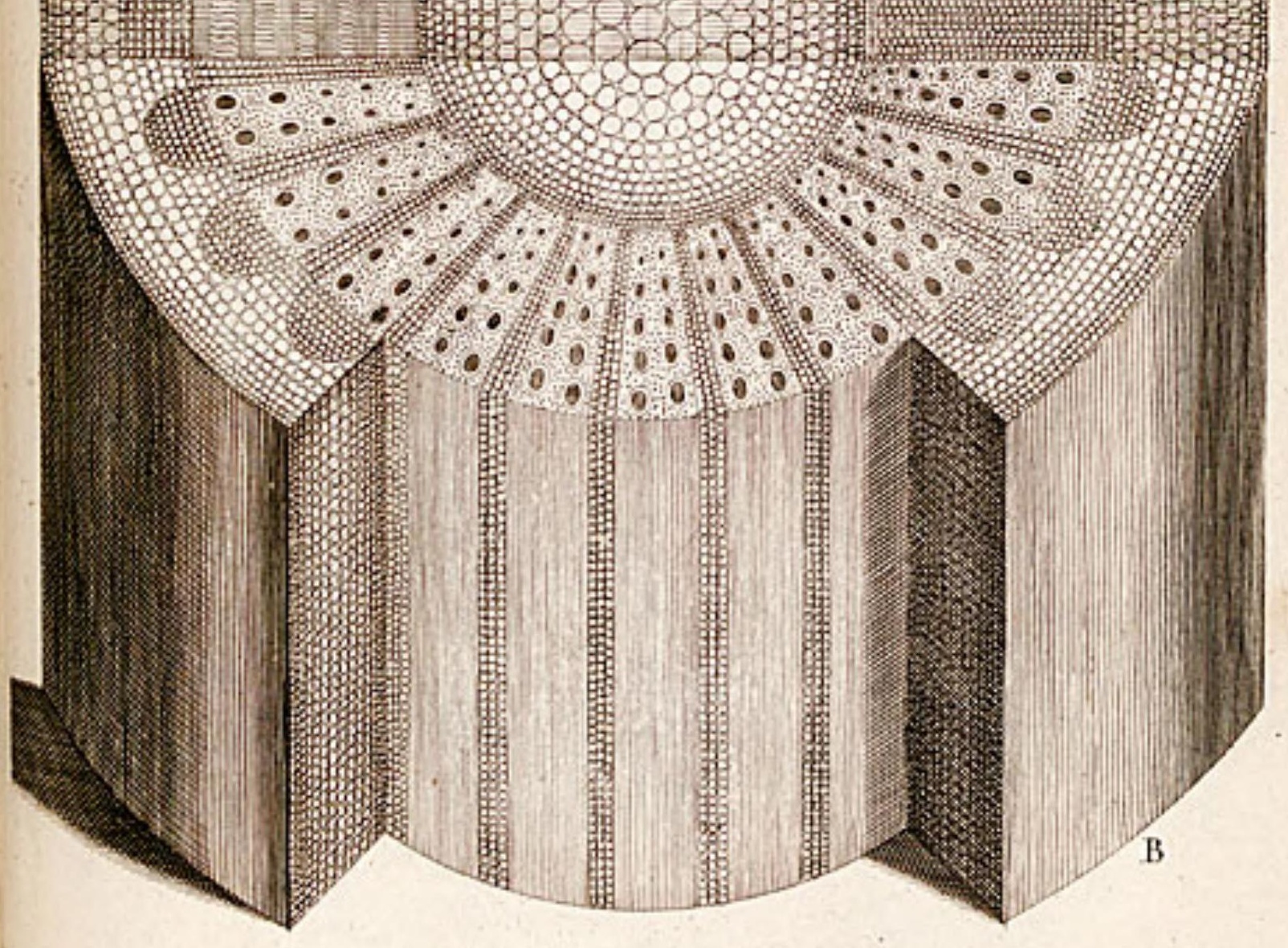




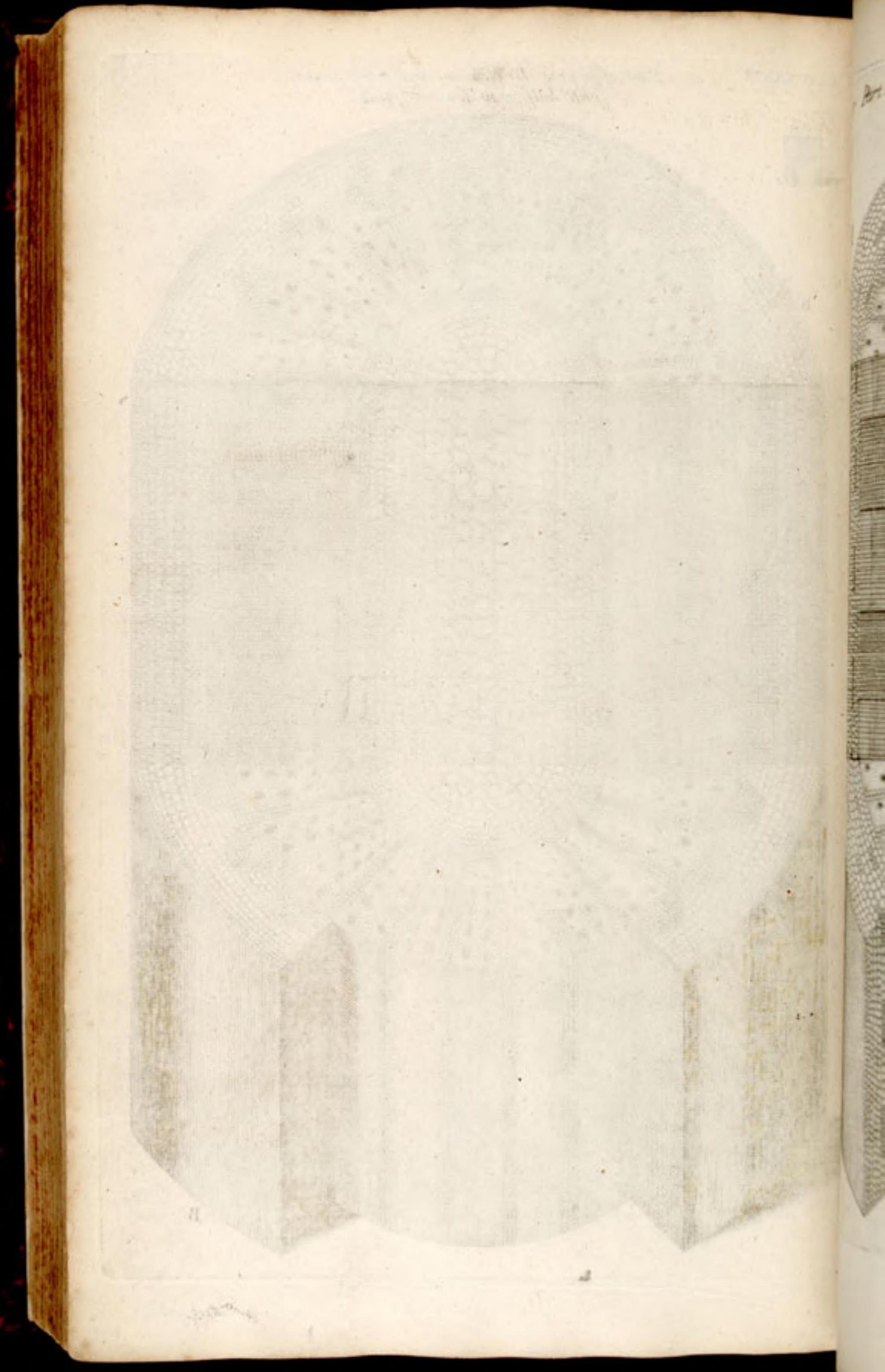


Tab:37. Purt of a Corin Branch cut as in Tab. 30

3.

a $(\mathrm{AO}$

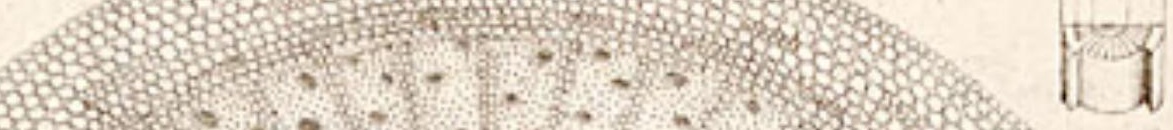

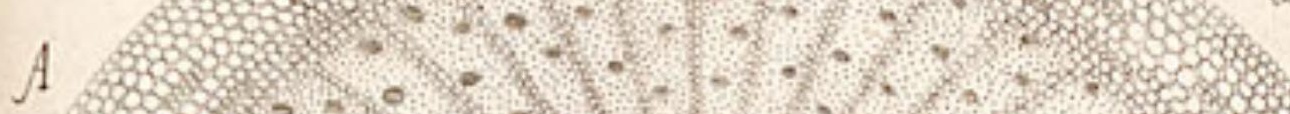

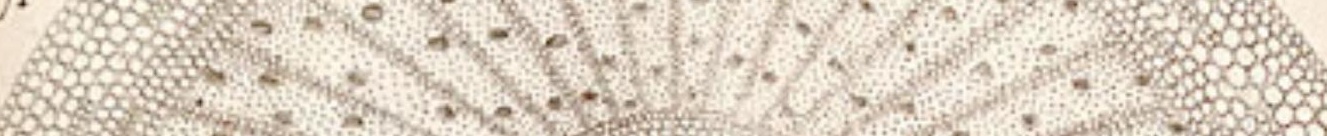

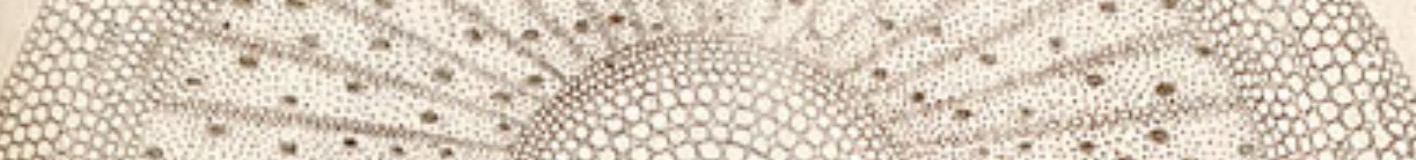

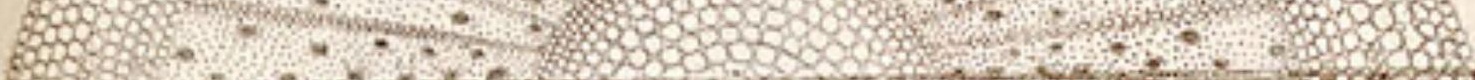

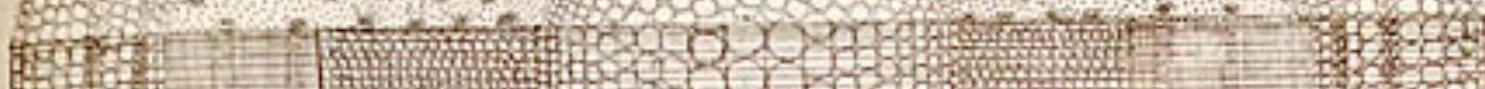

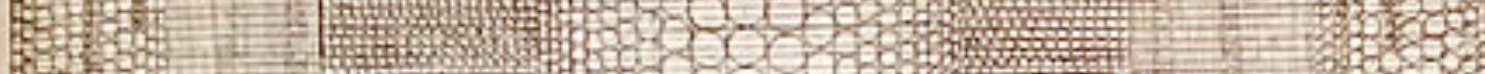

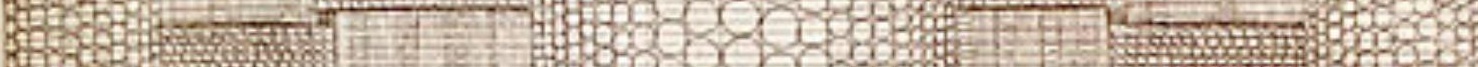

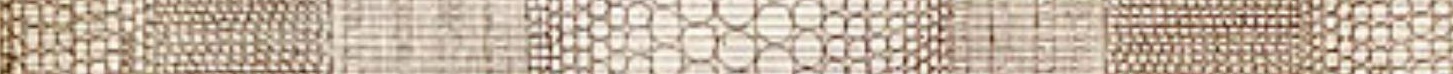
fing

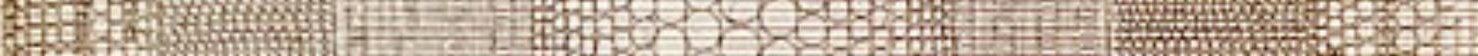

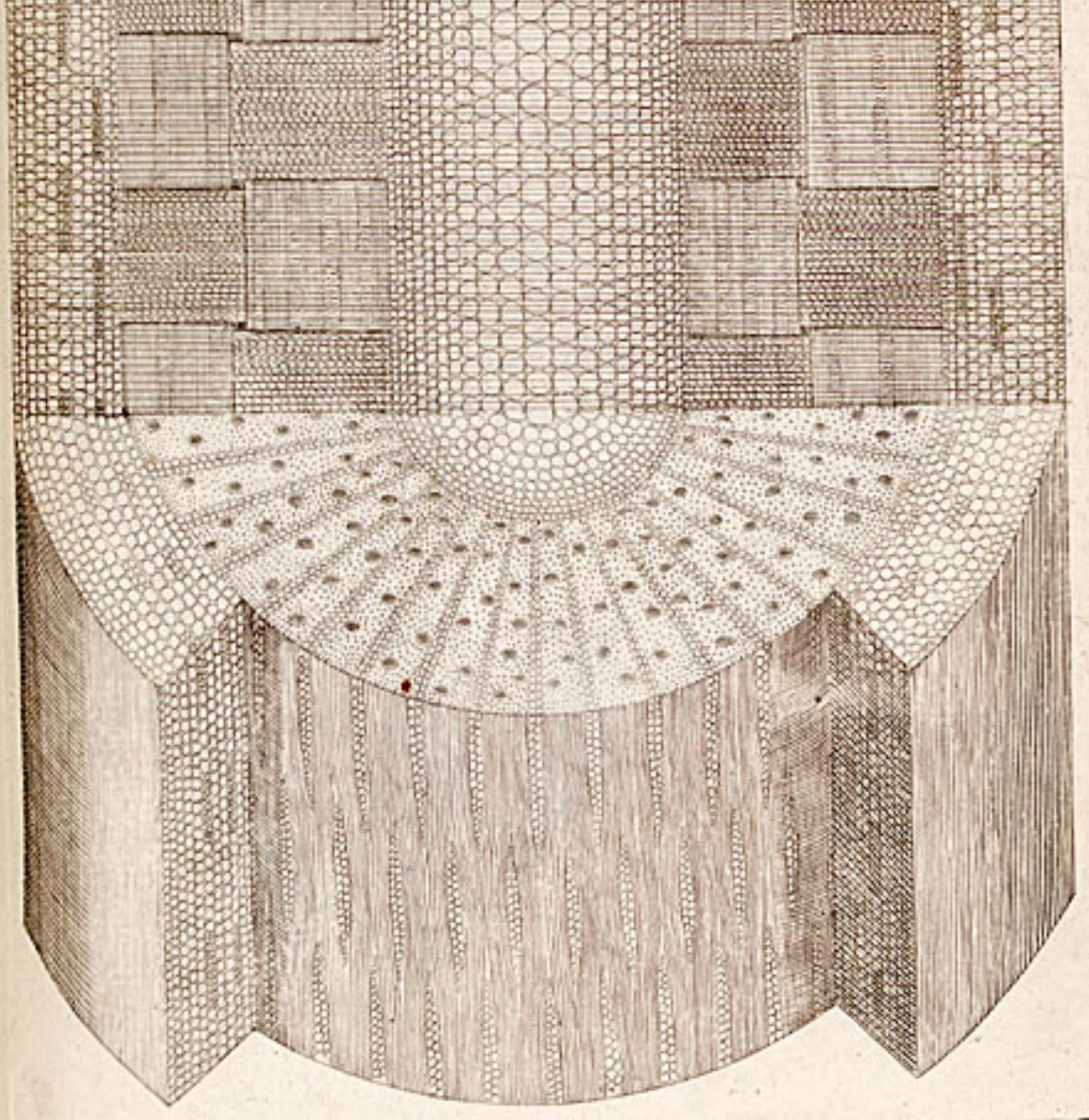




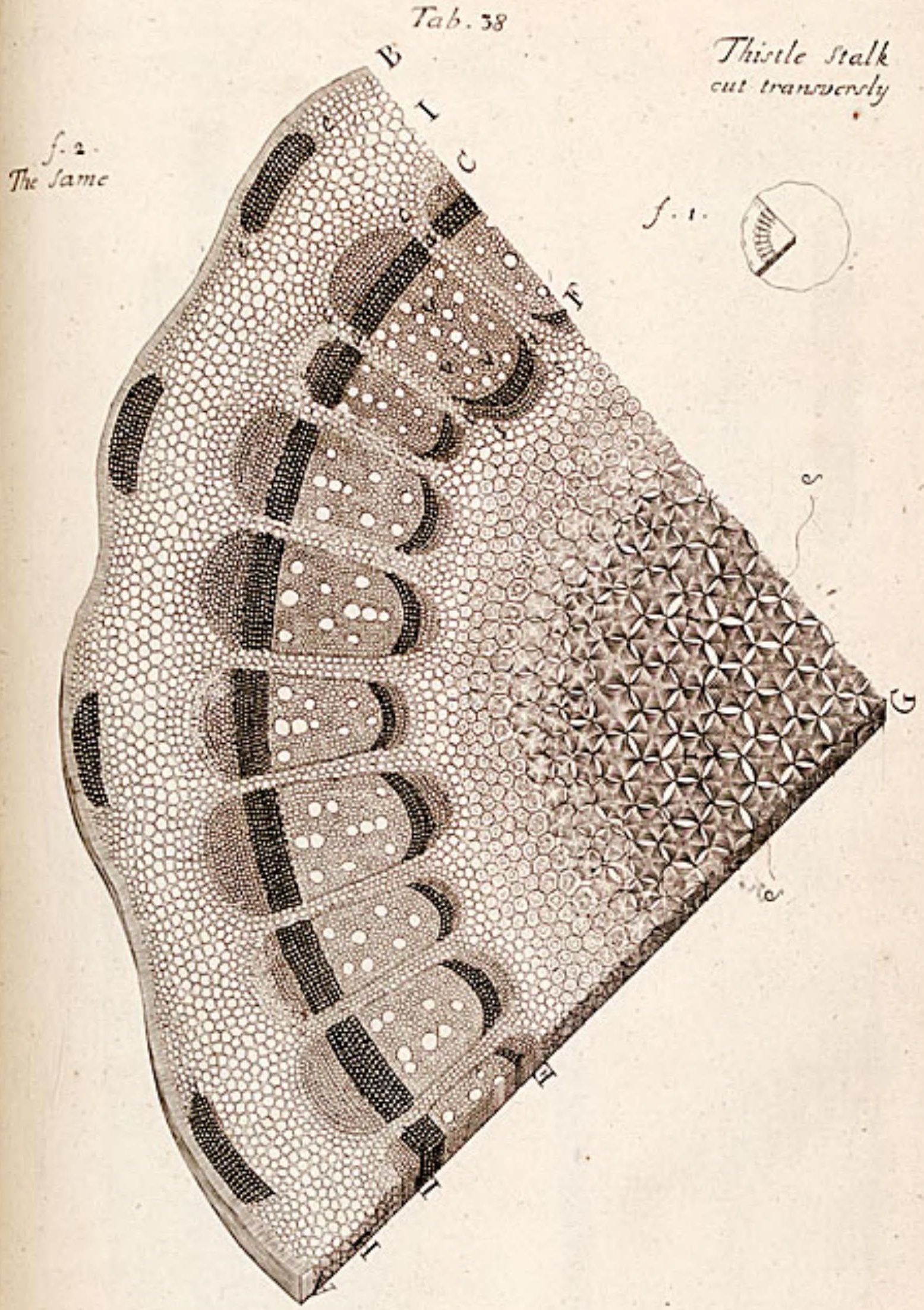




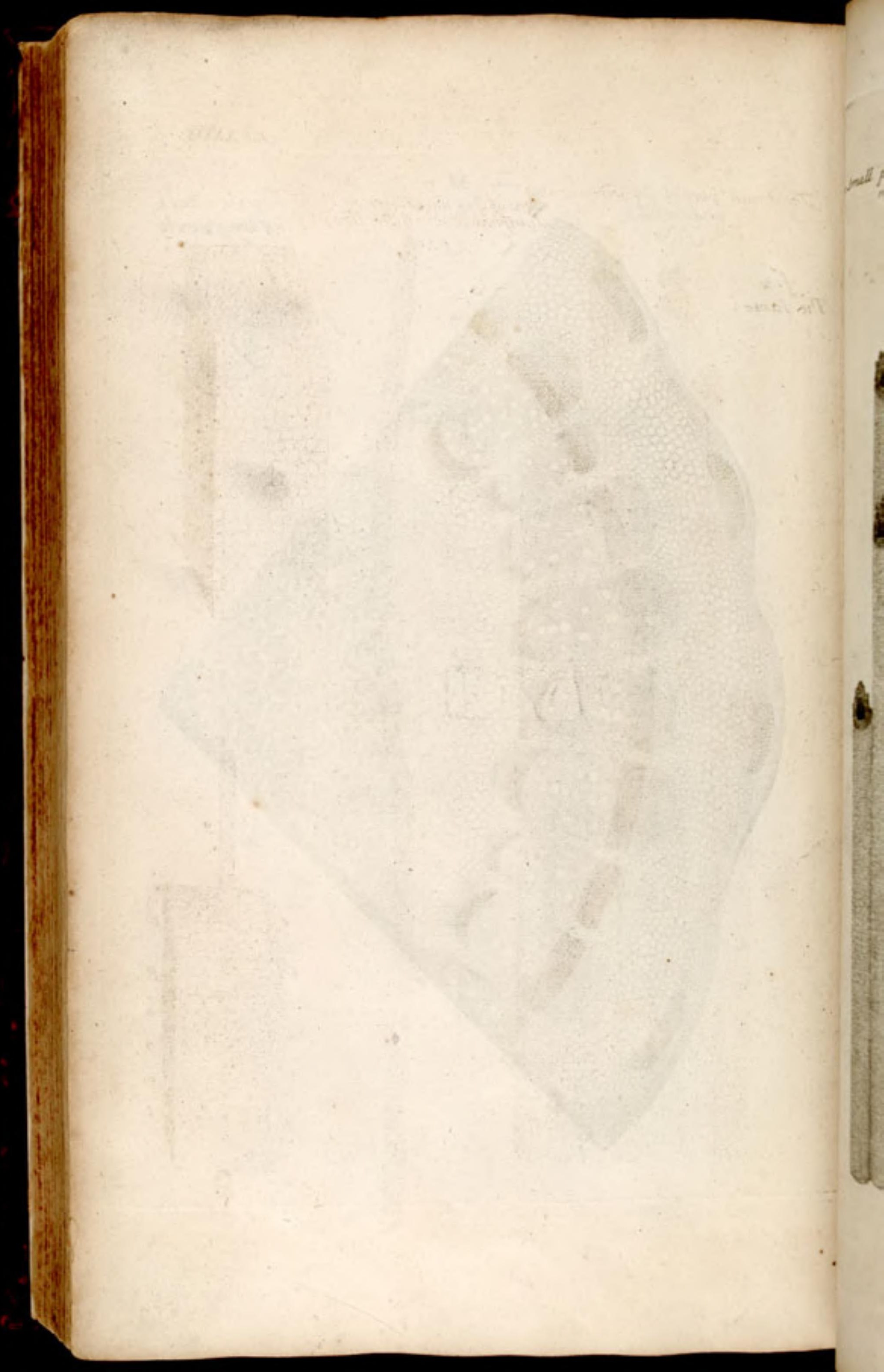


Tab XXXIX,

The small particle of Frenoov (a)

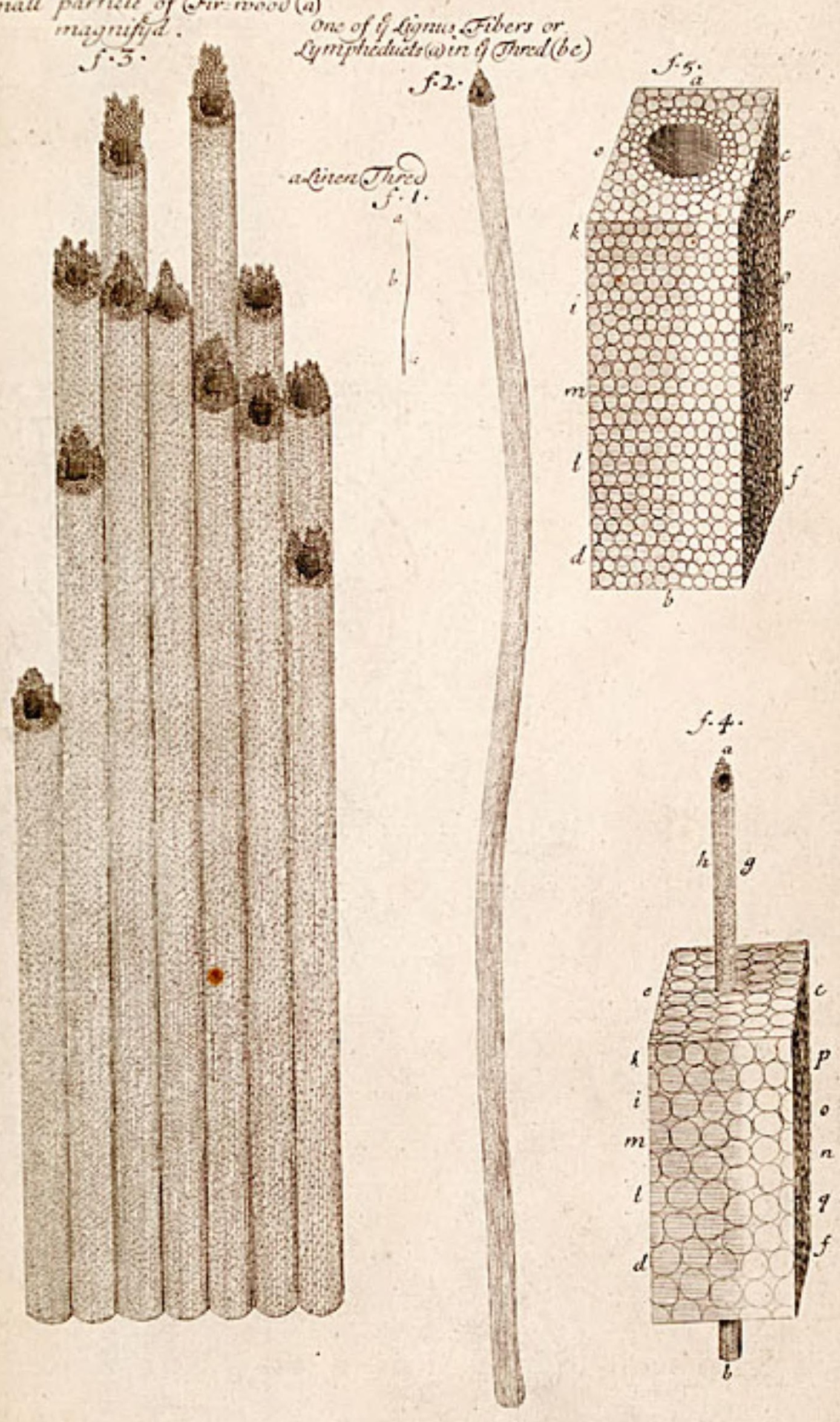




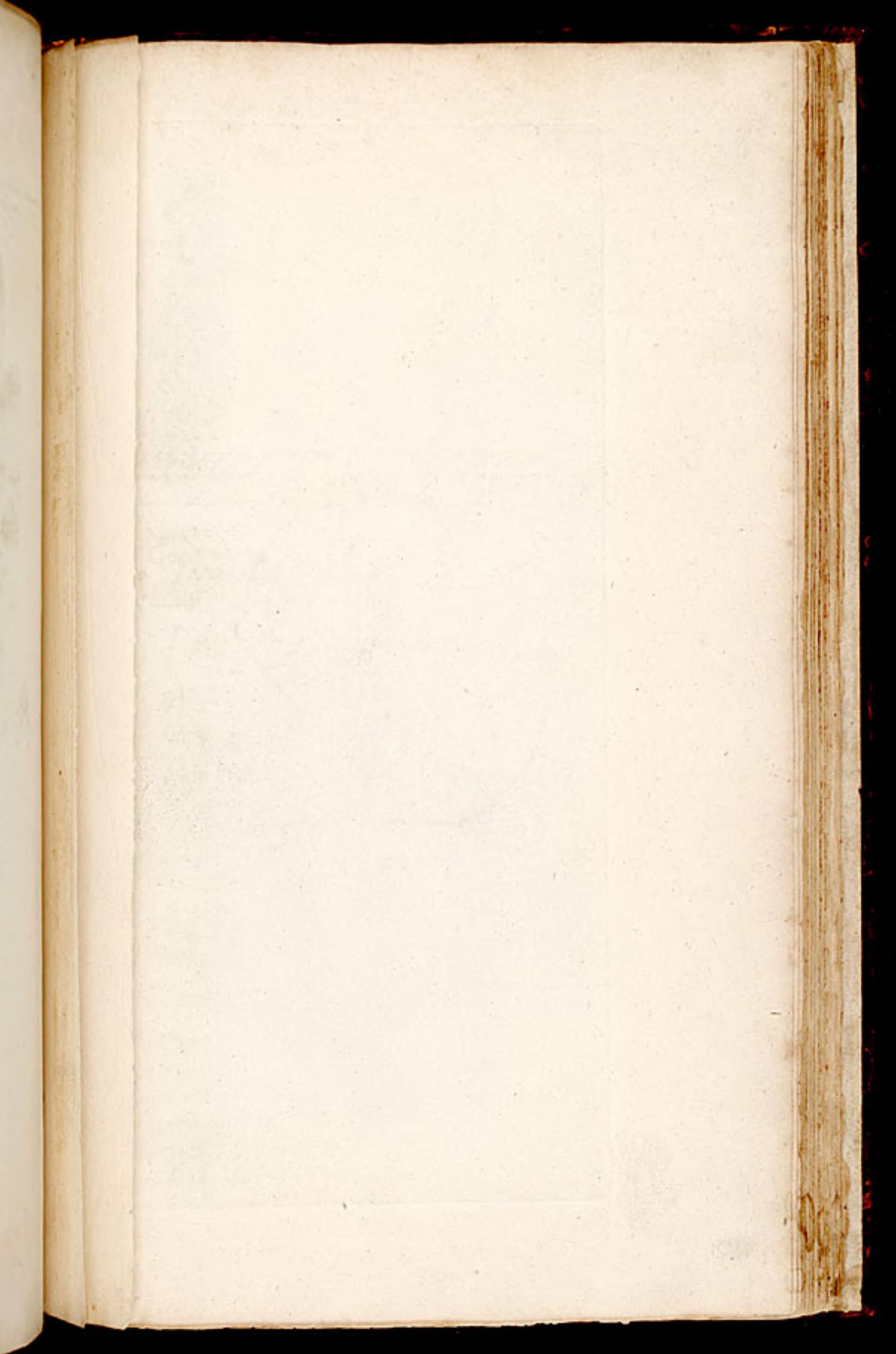




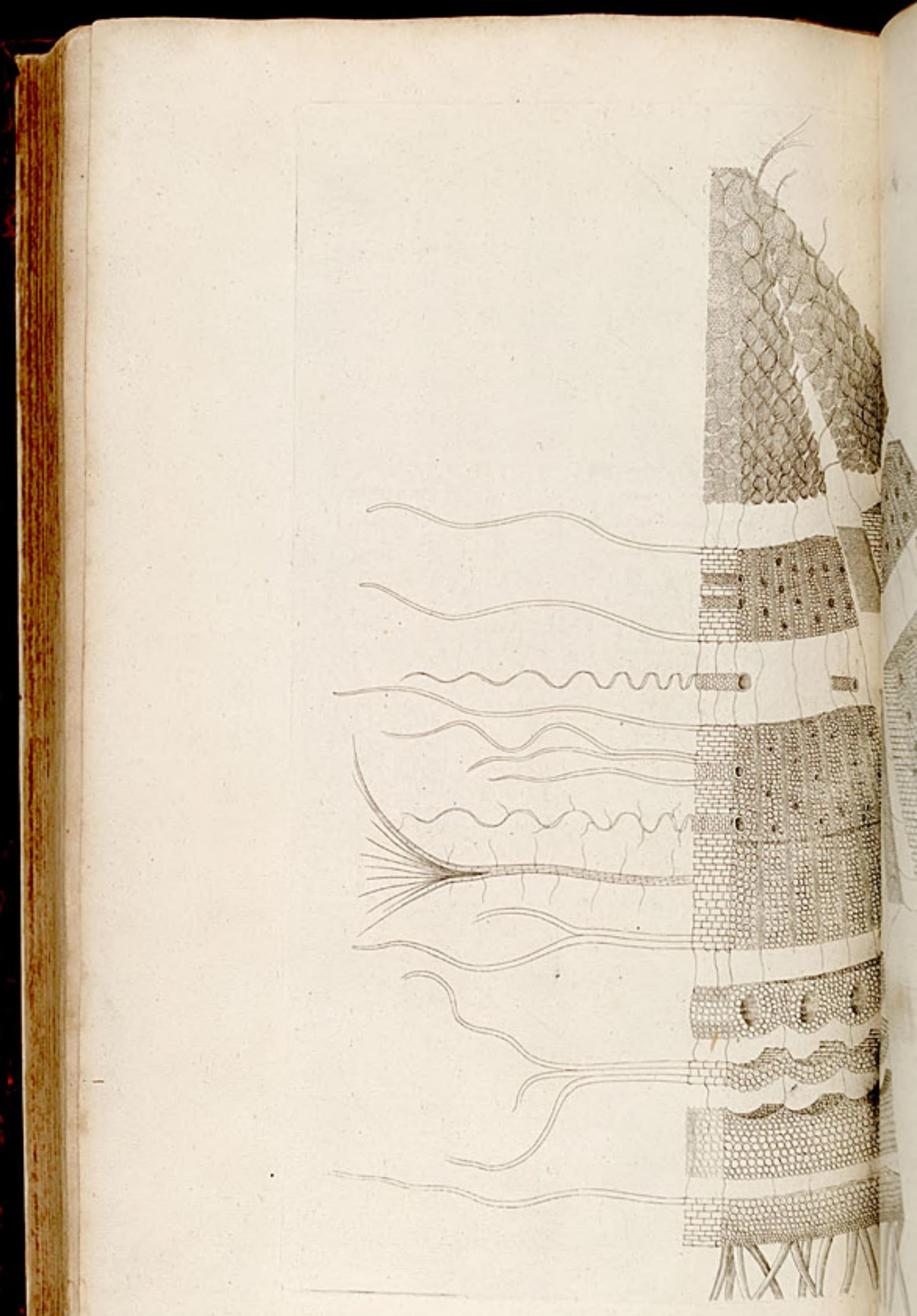




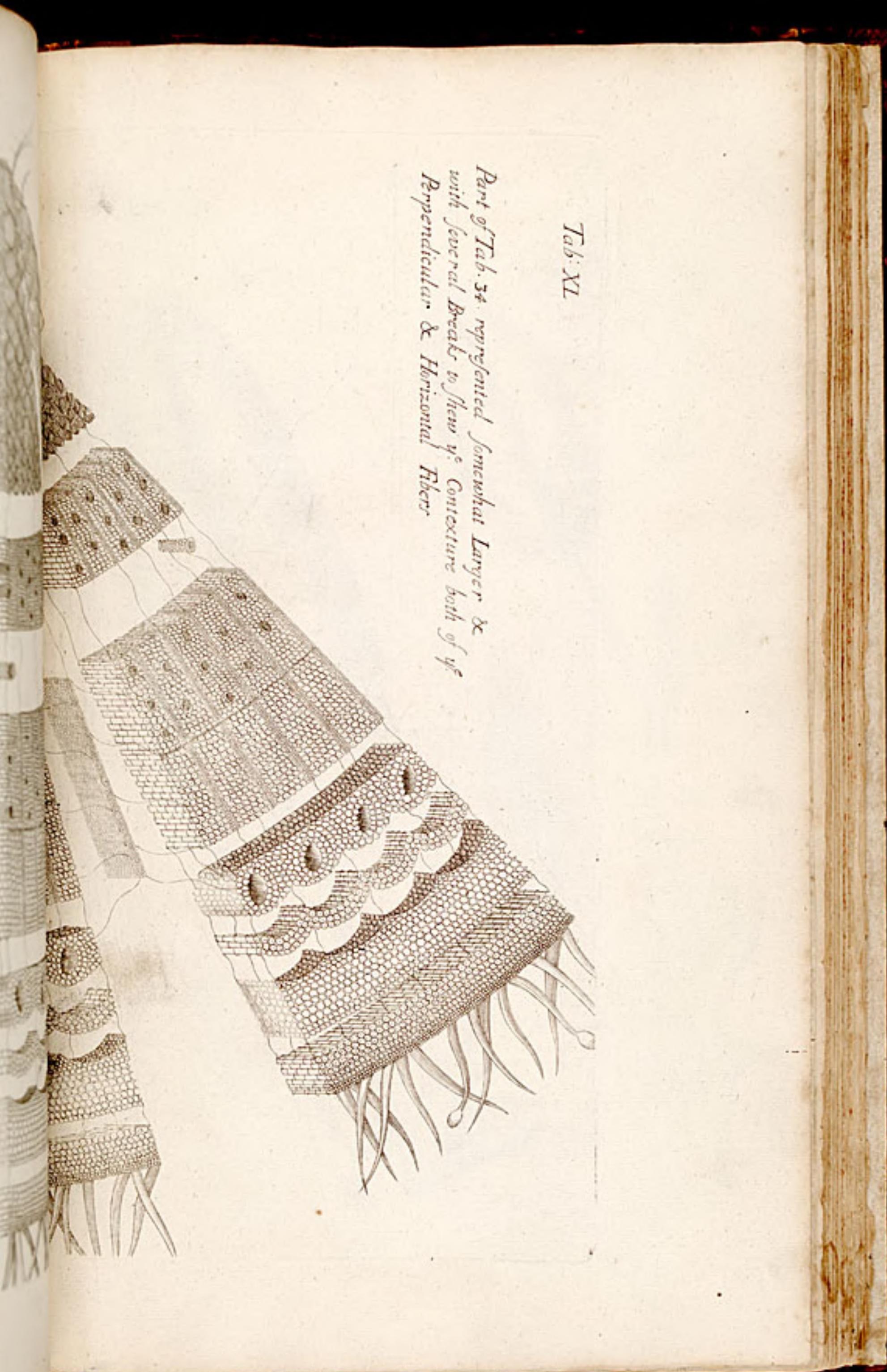


TAB, $\times X \times X I$

$\frac{\text { cat of }}{\text { Dock. }}$
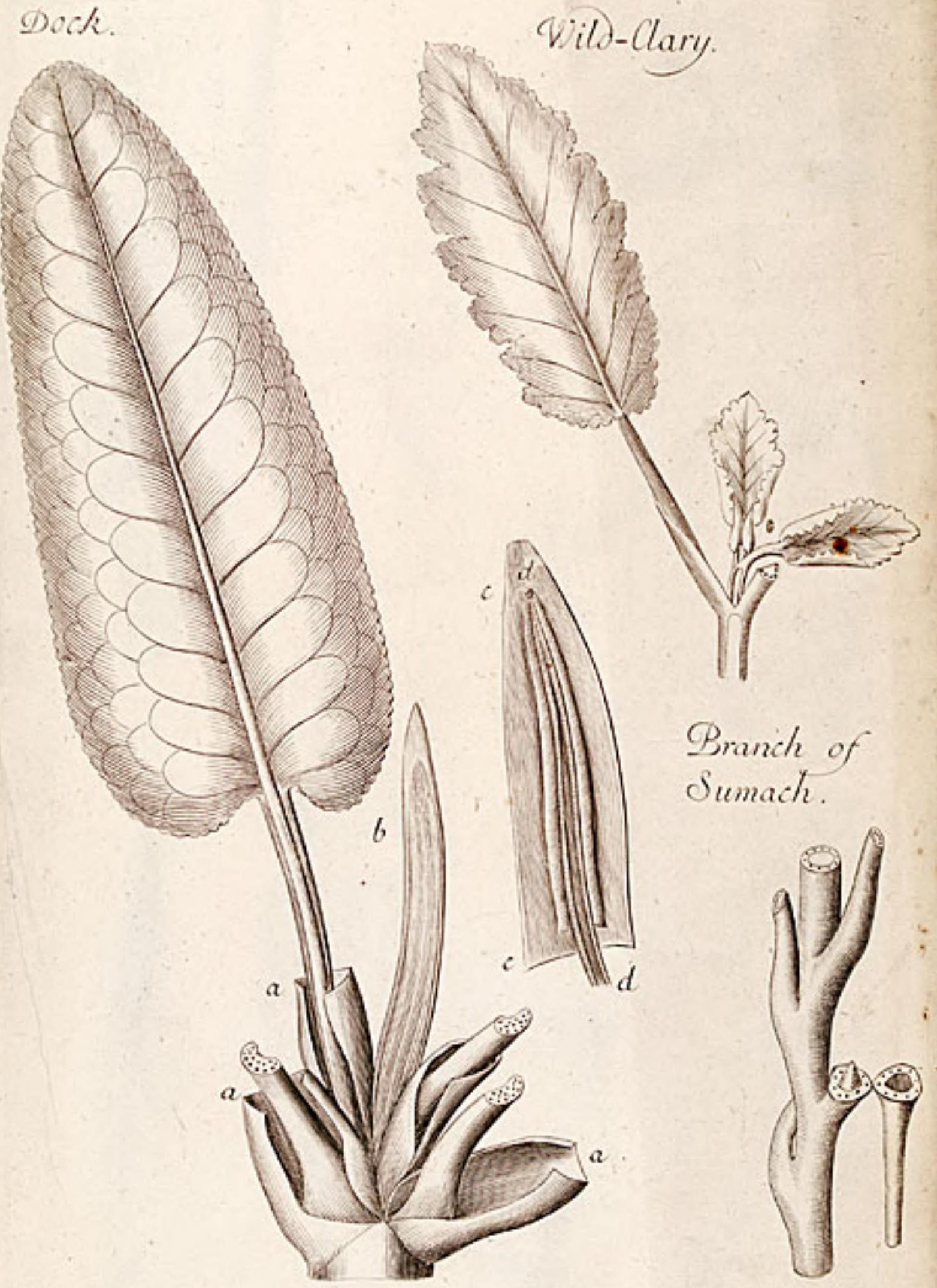


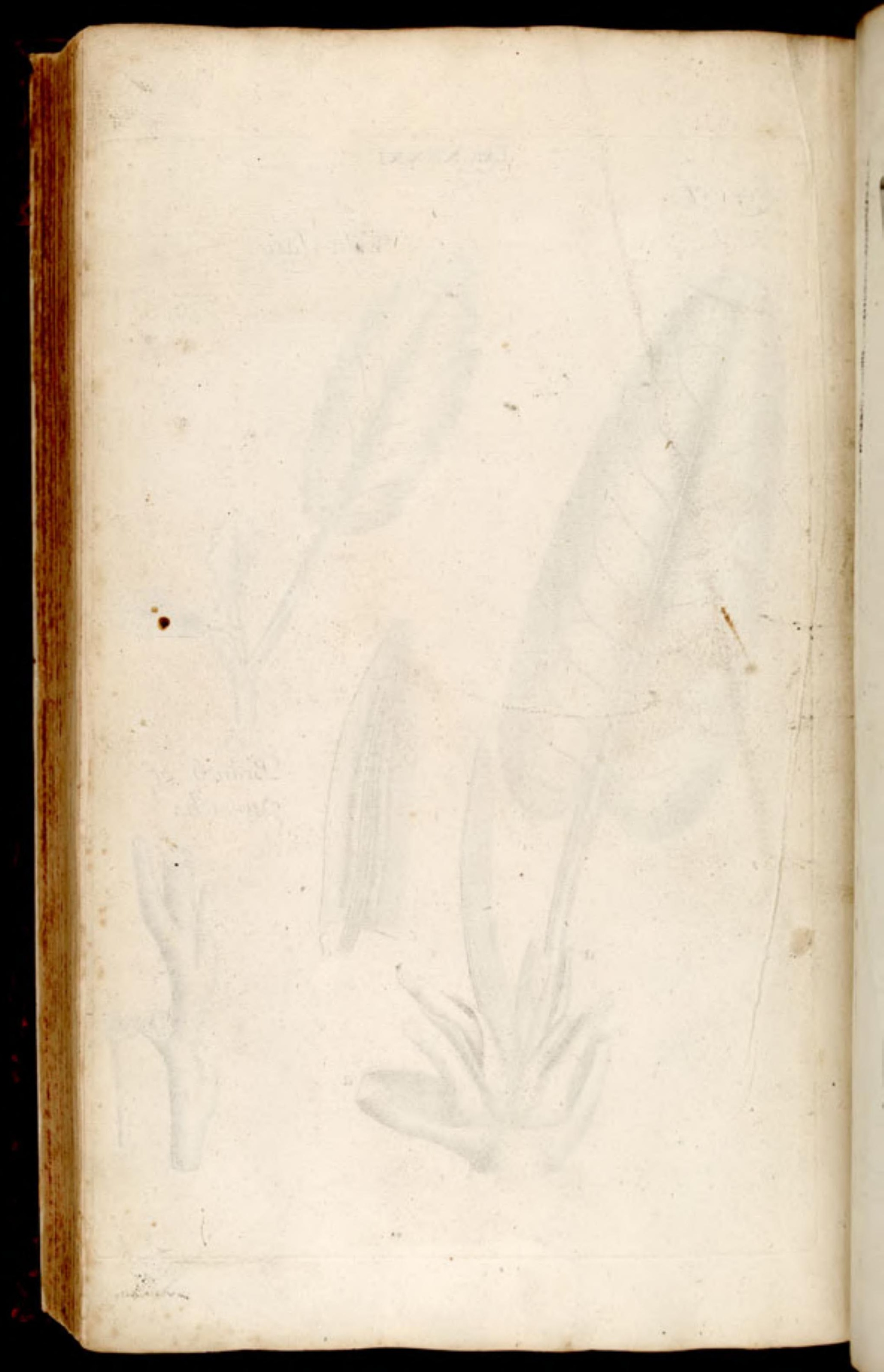




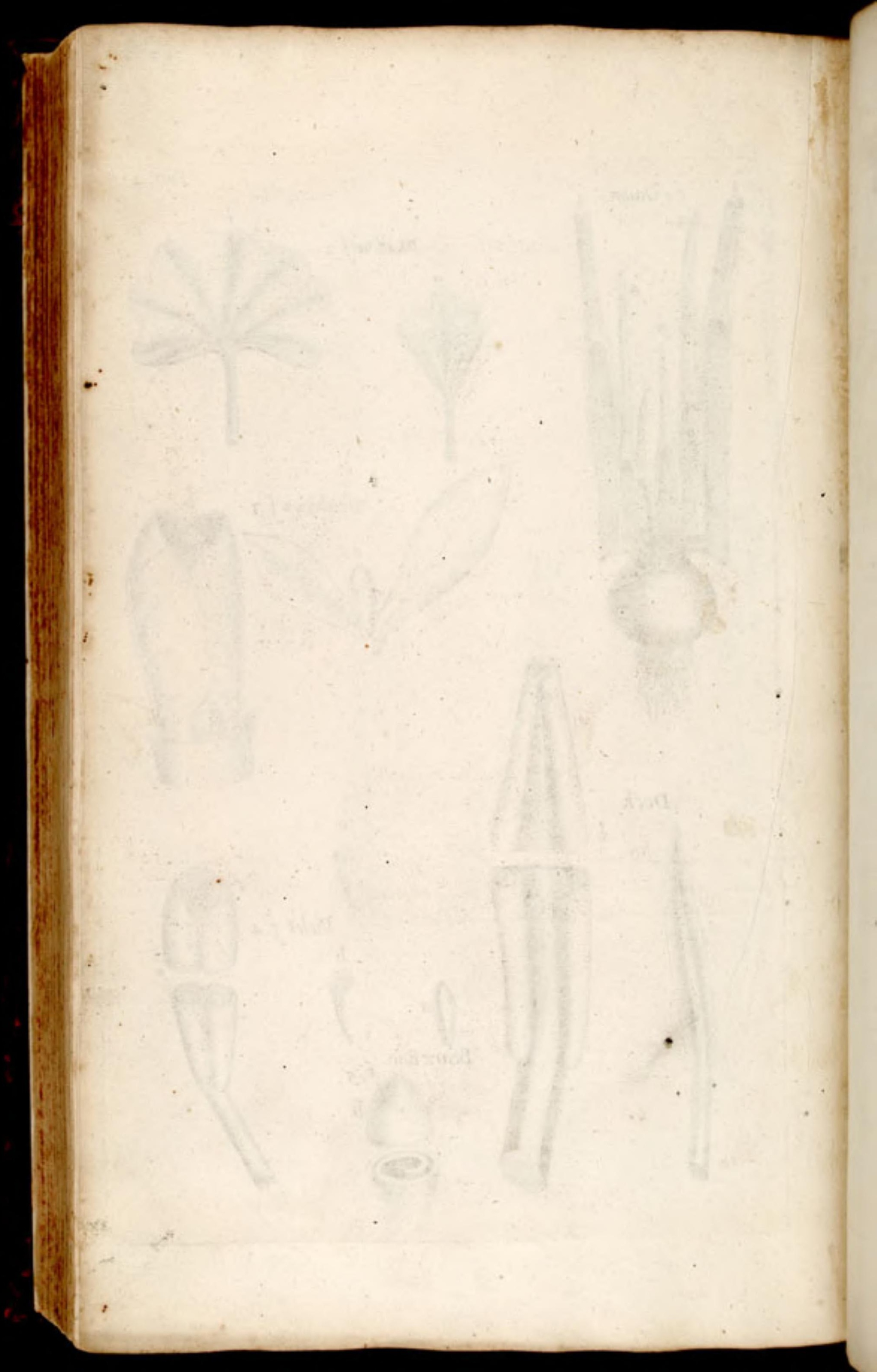


fy.t Natrify

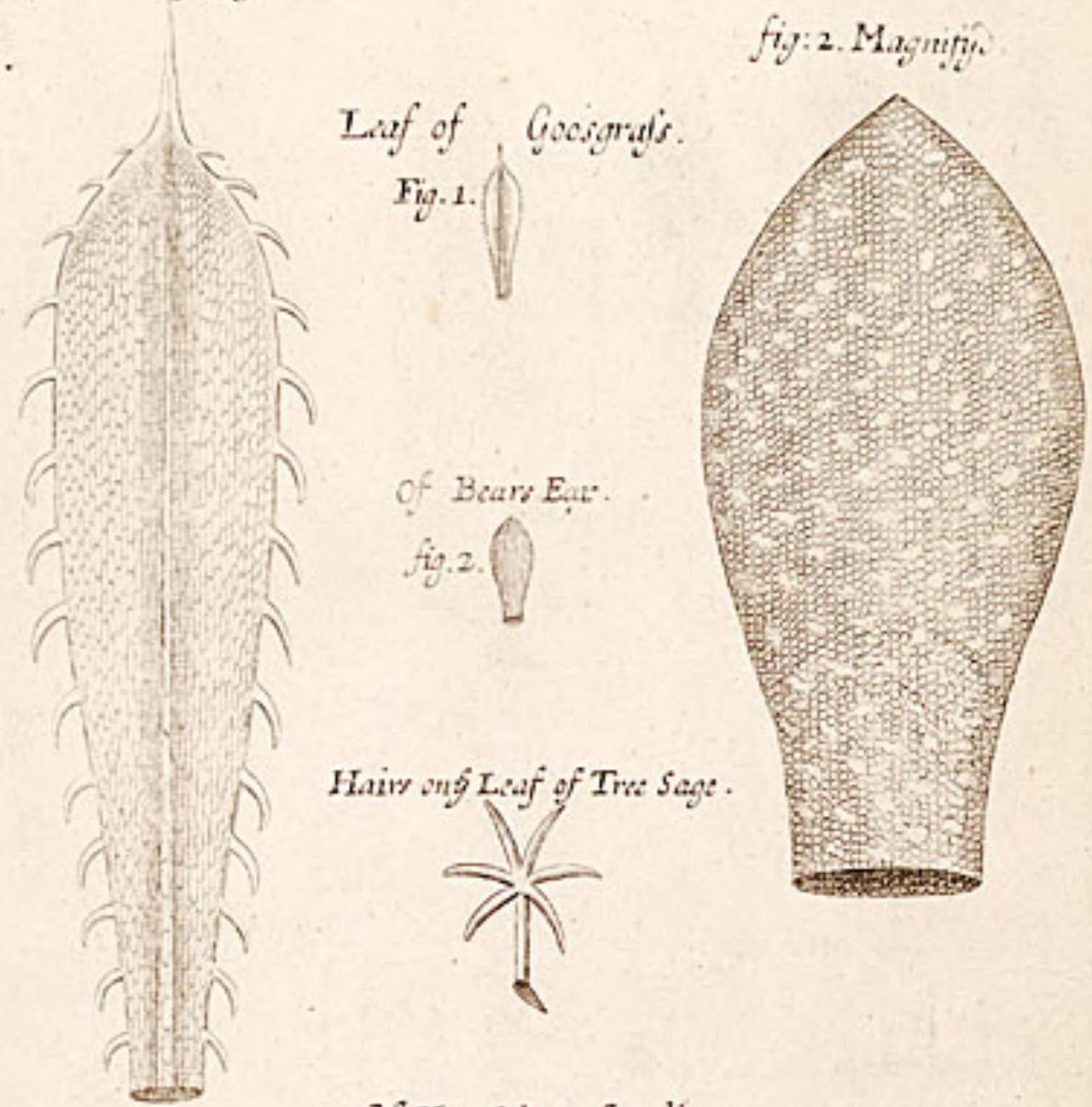

Of Herrfalem Conslip.
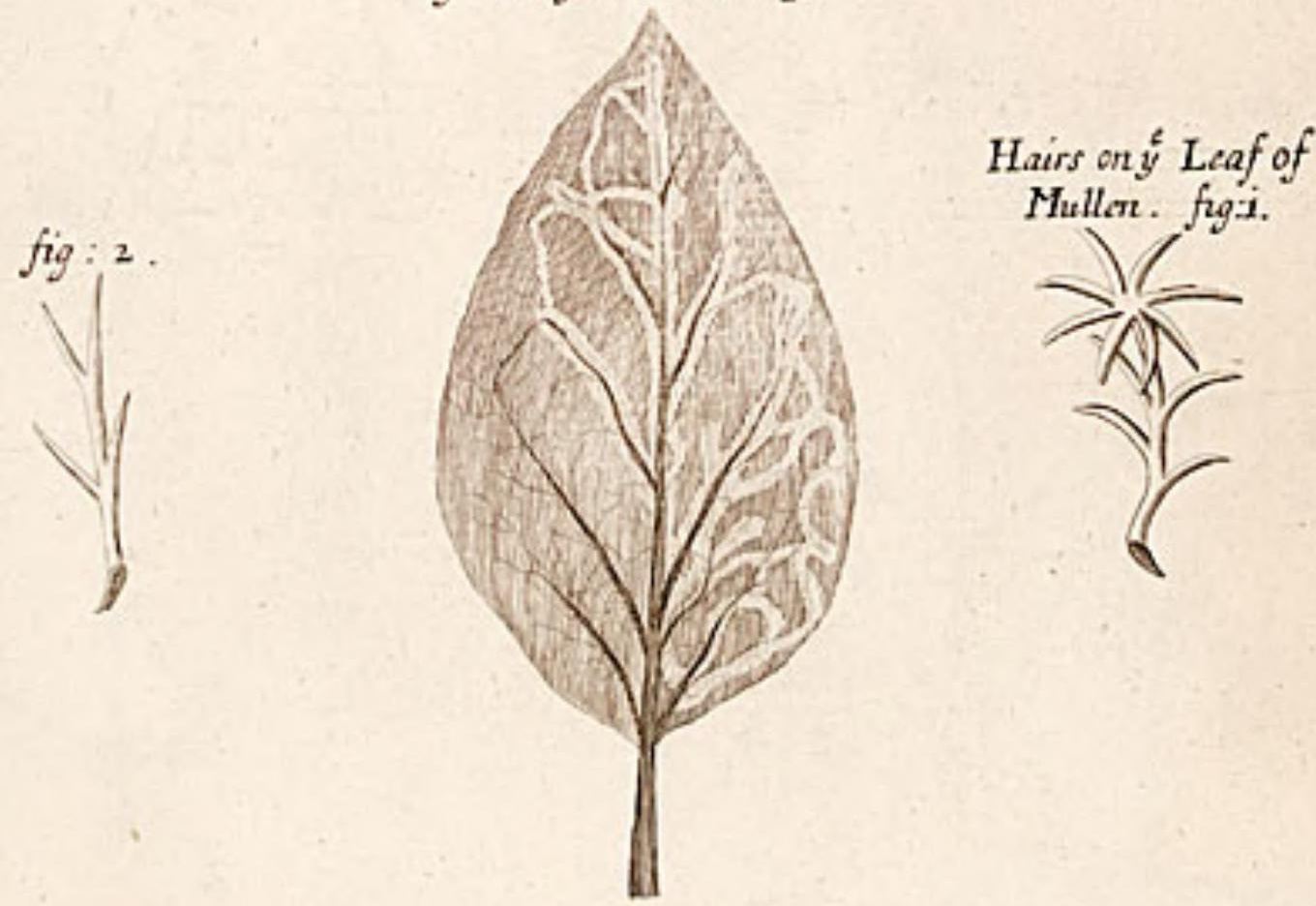
Lenf of Denetian Detch Tab XuIiI.

Orange

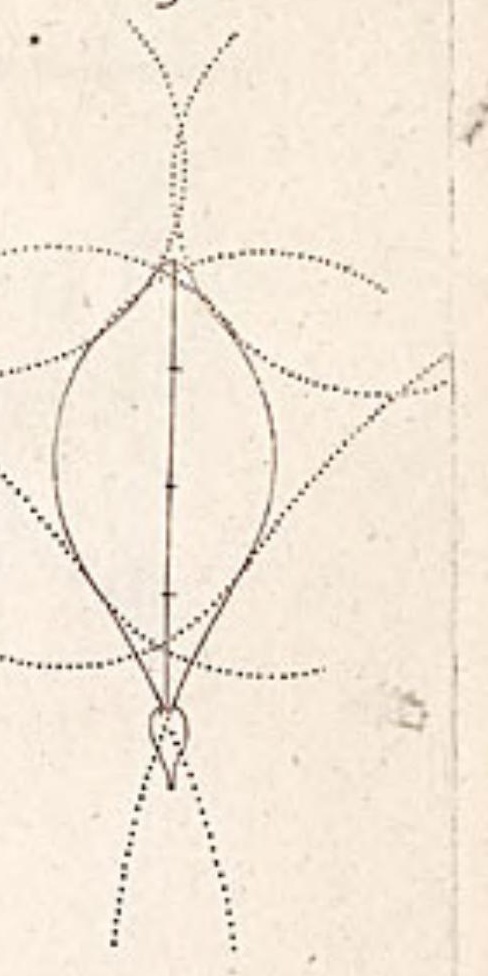

Sage-Leavd Ironvort

Comelan Cherry

Broad Leavio Lajer-nort

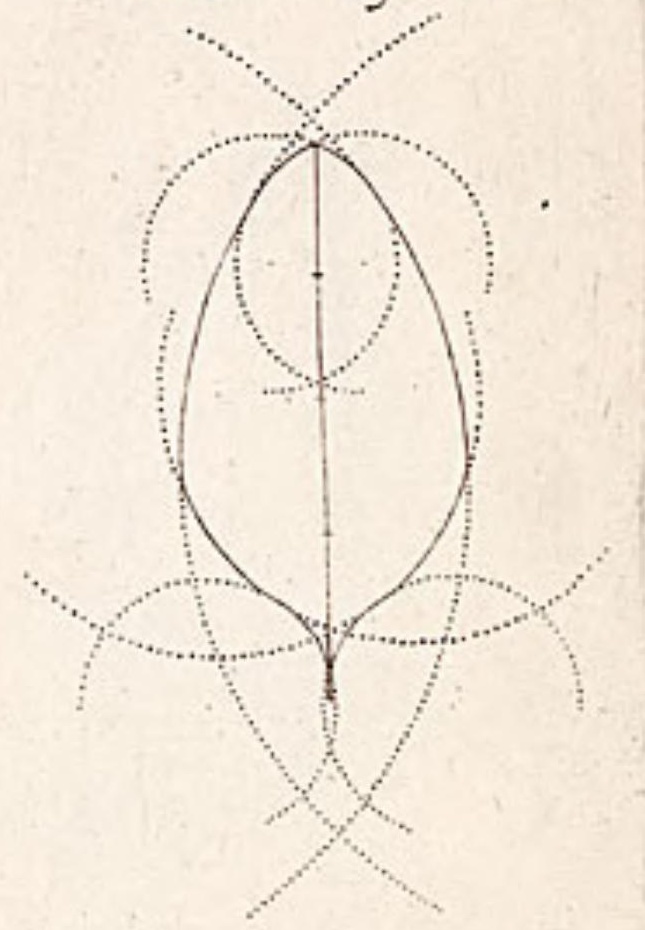




\section{Tab.XIV}

Lequards Bane

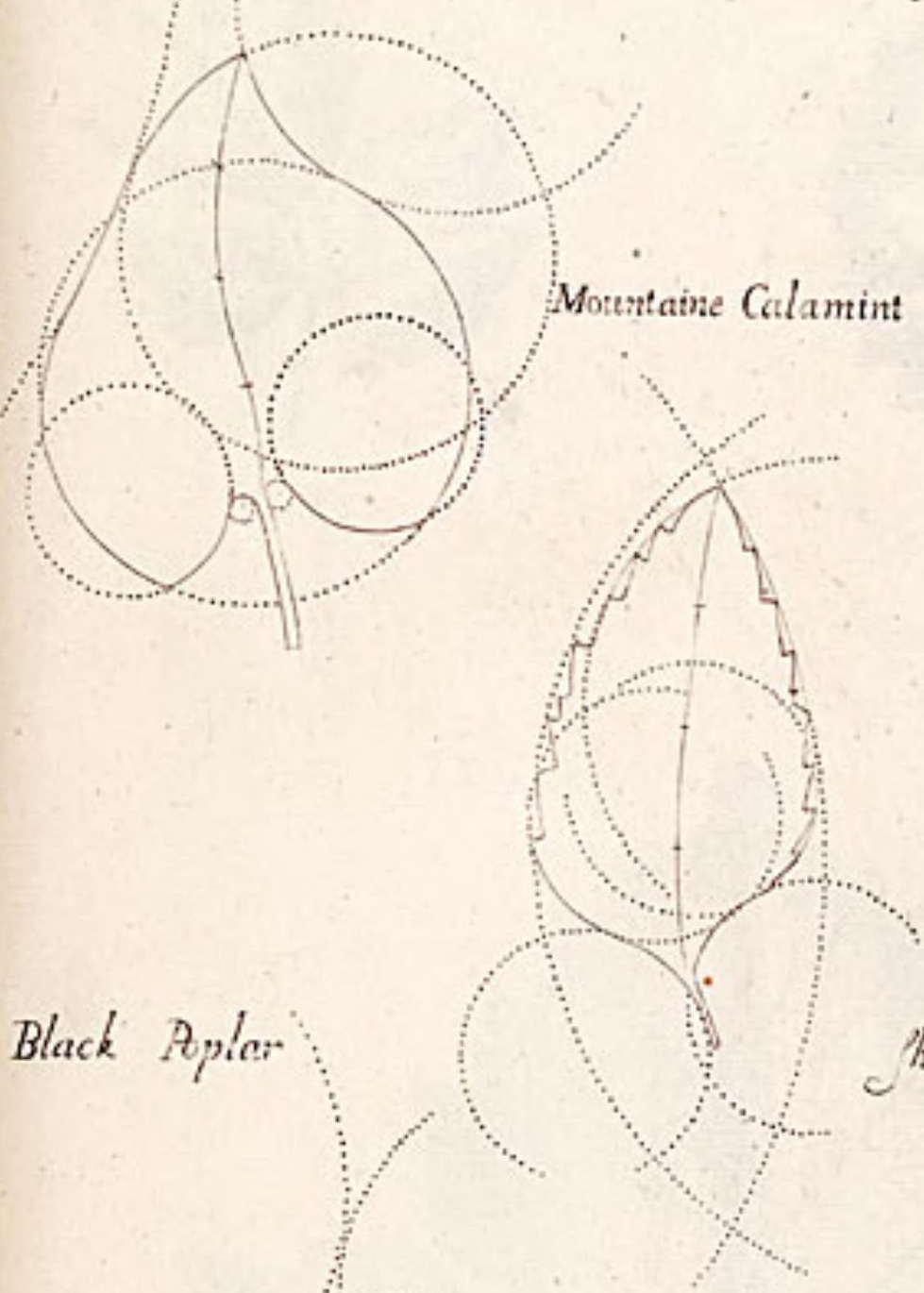

Great Lofernort

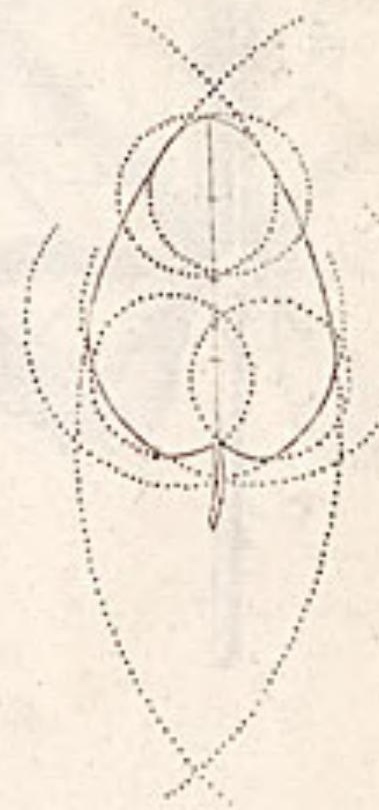

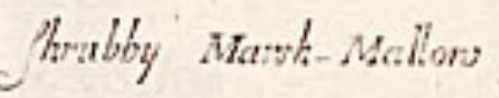

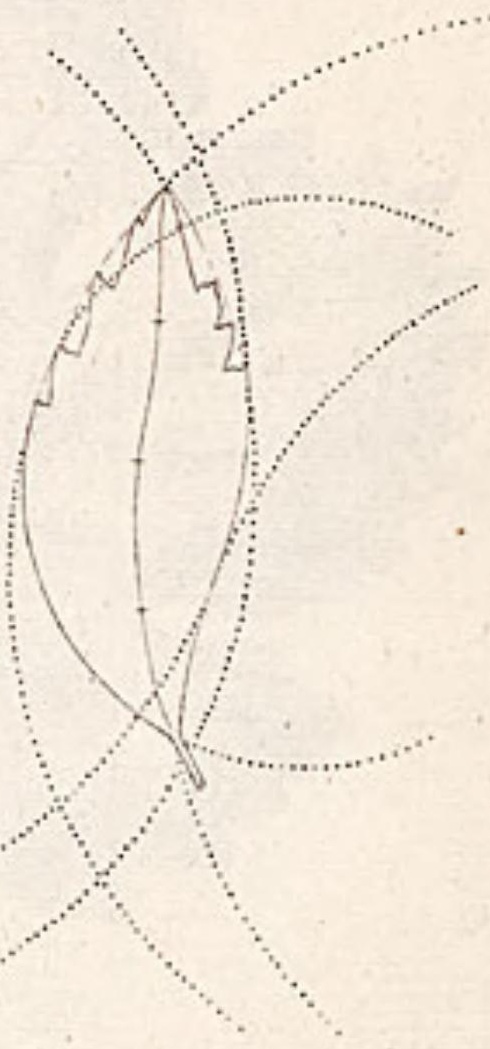





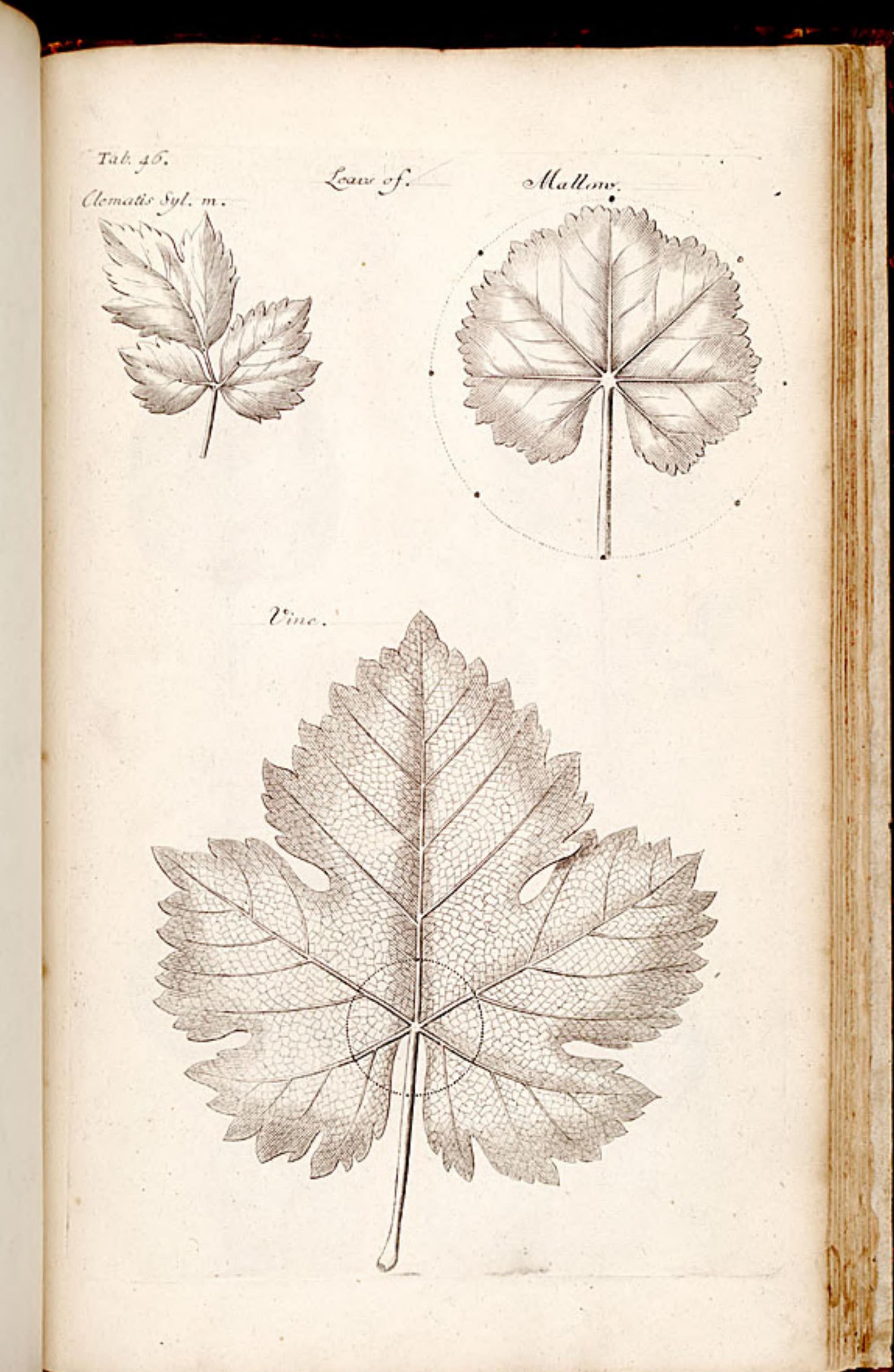




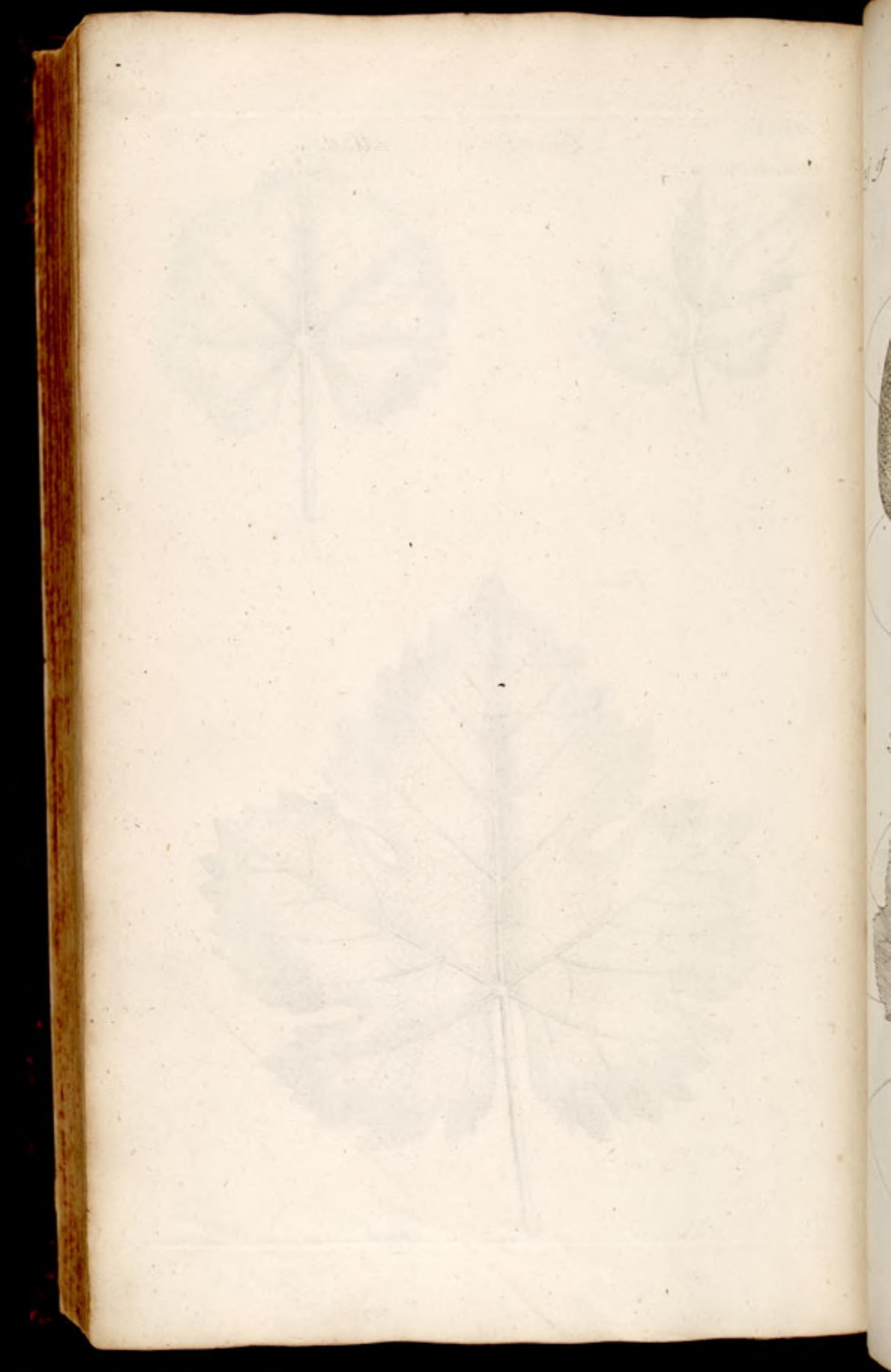



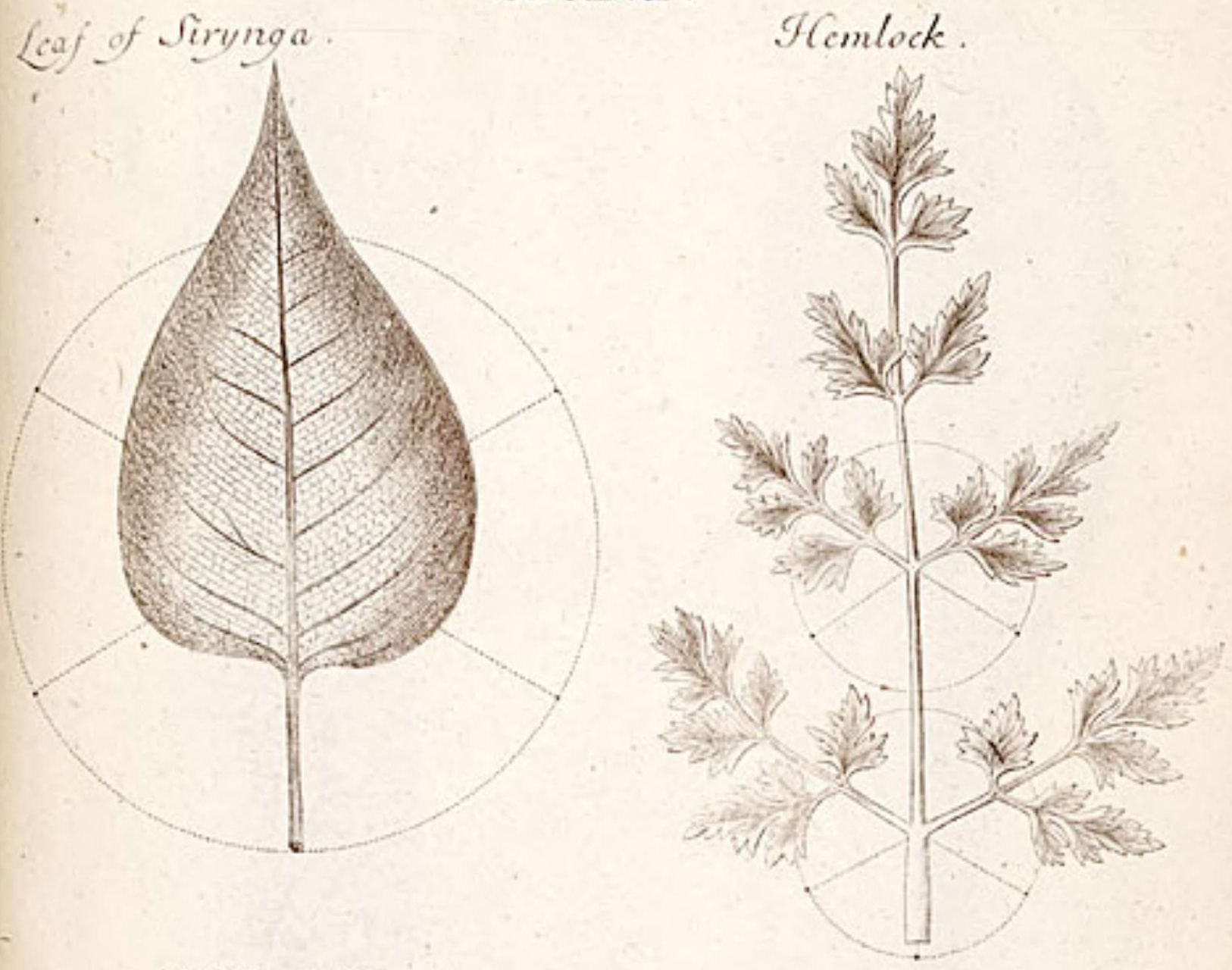

Holyoak.

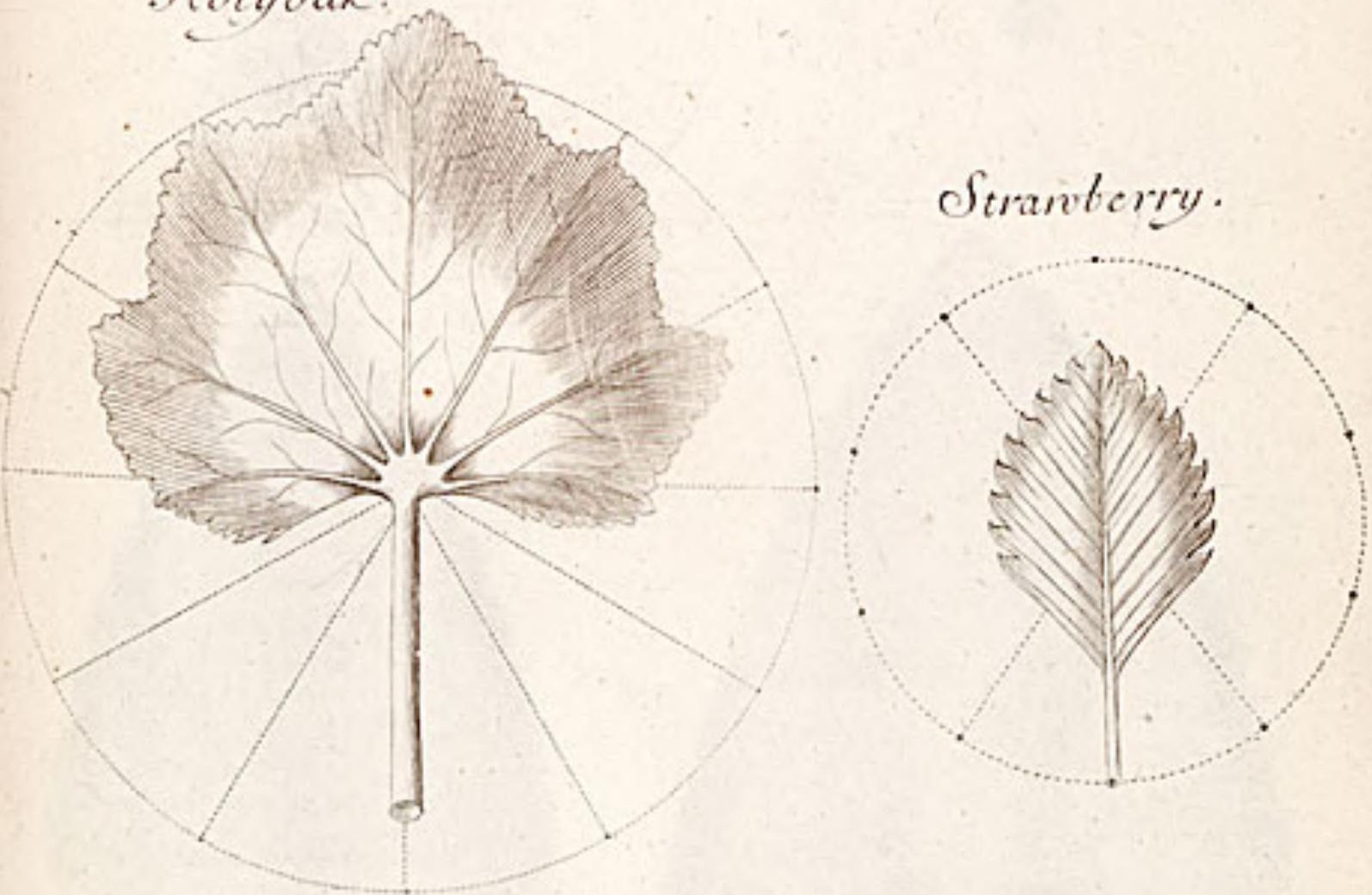




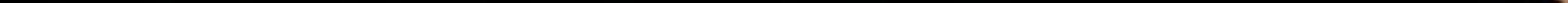


TAB. XIVIII .

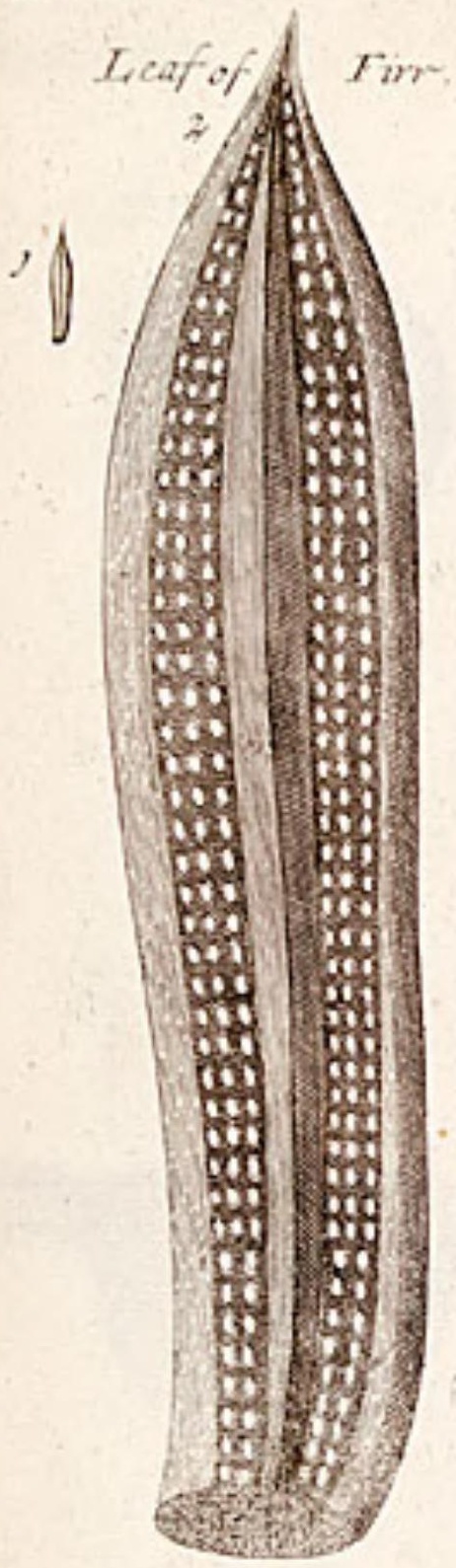

The top of Pine Leaf.

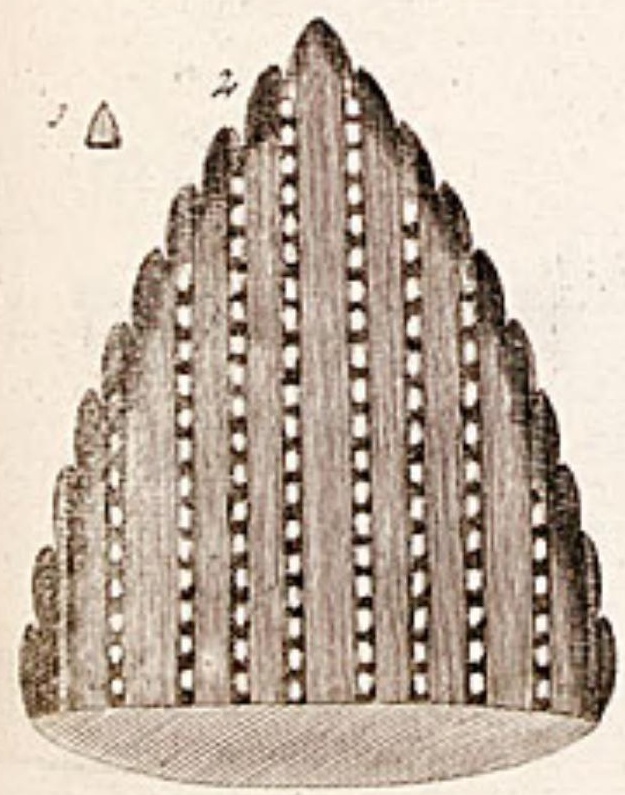

Rhammus Salias Folio.

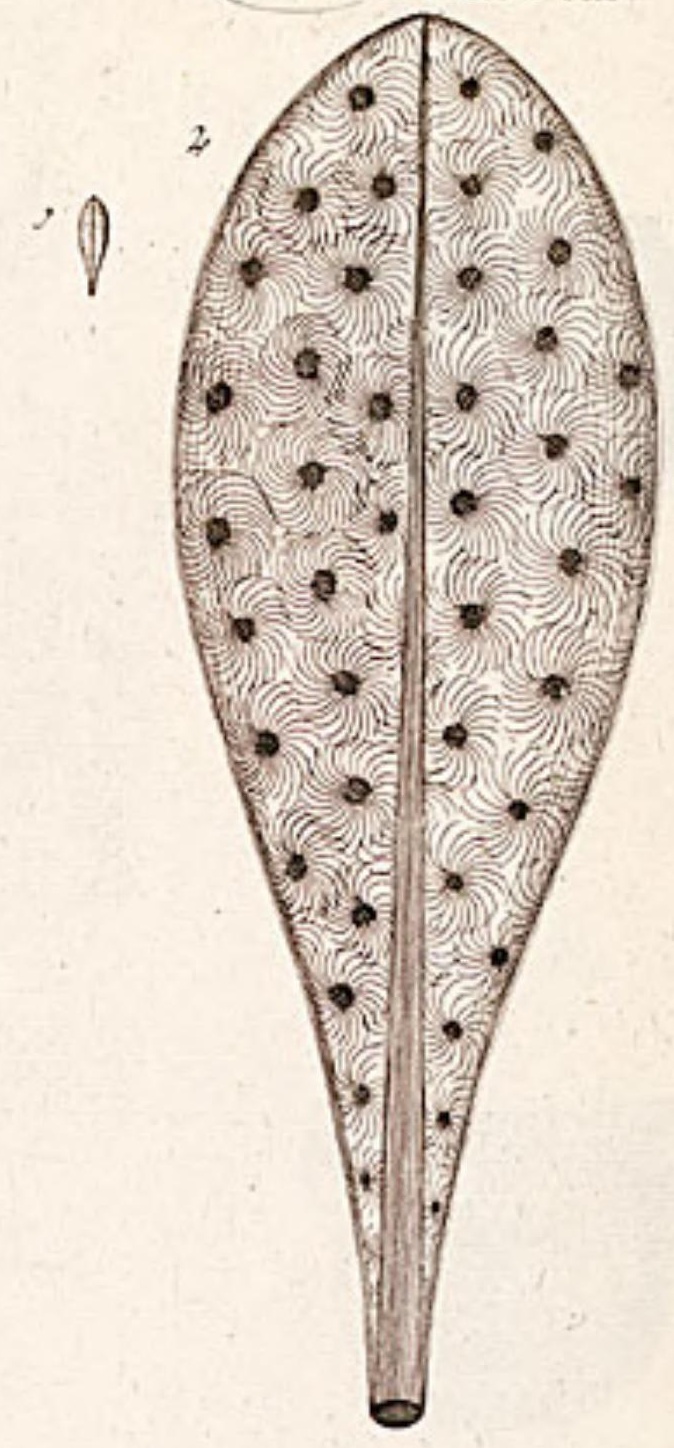

The lop of Litly leaf.

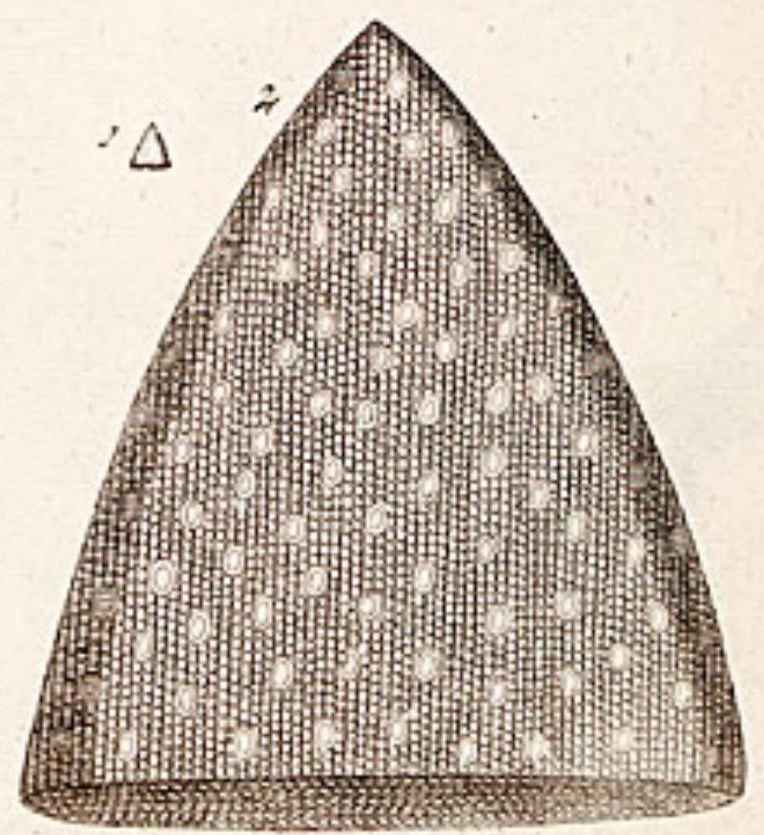


TAB. XLIX .

Mallon

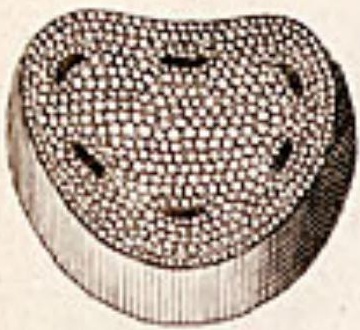

Dandelion.

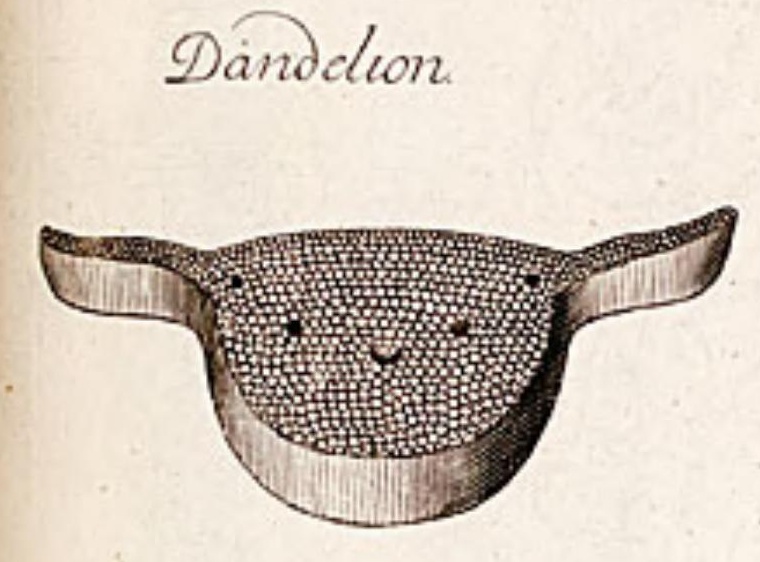

Borage.

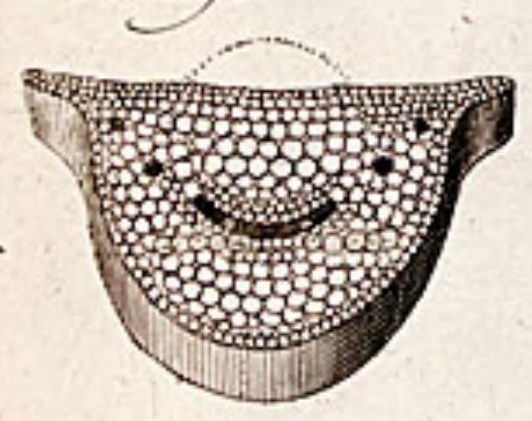

Otalks of

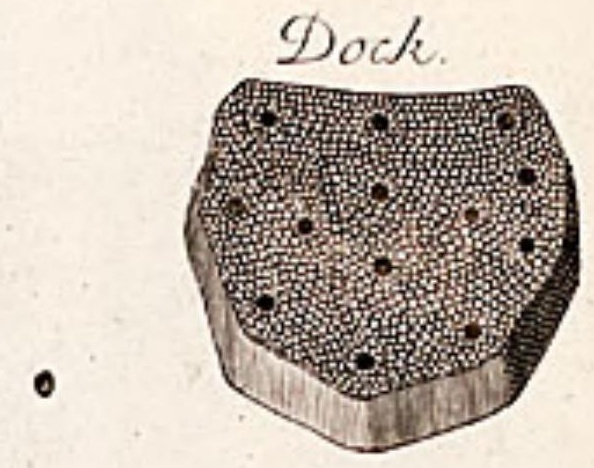

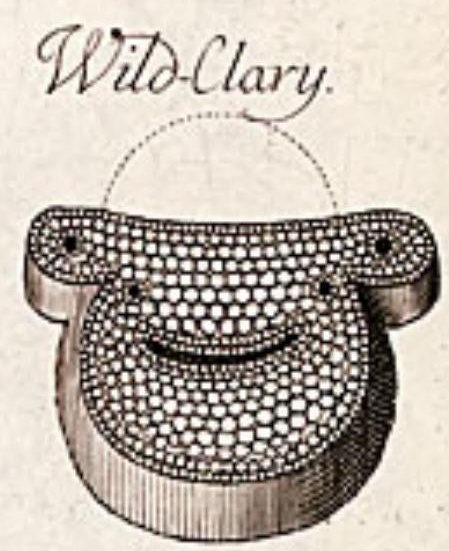

$$
\text { cllullon. }
$$

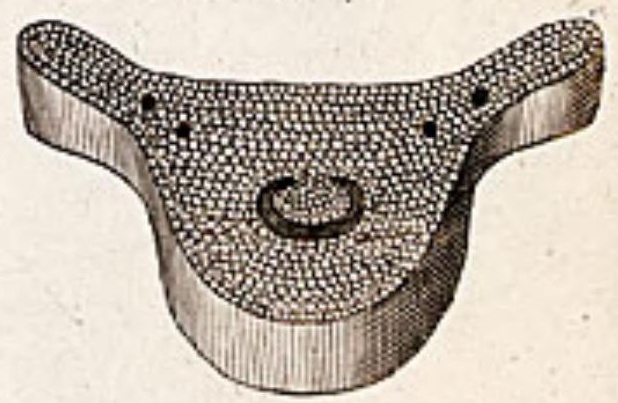


Tal. 50.

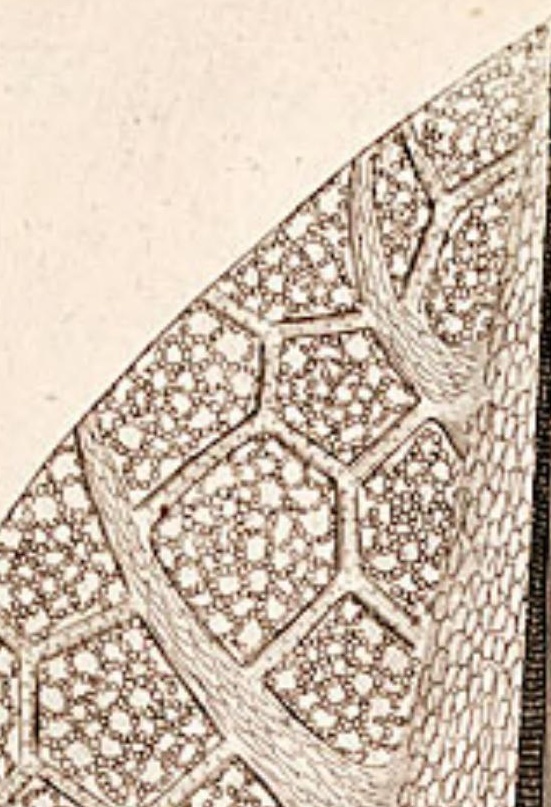

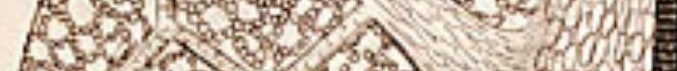
20\% 2 \% $\%$ के H.

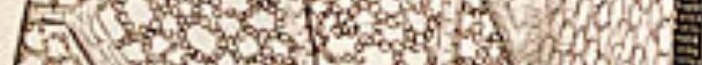

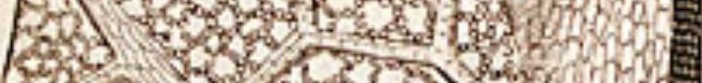
6.

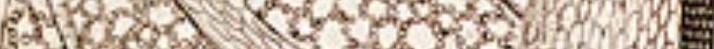

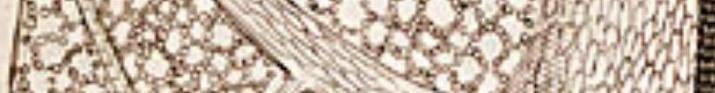

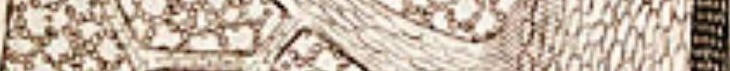
3.5.

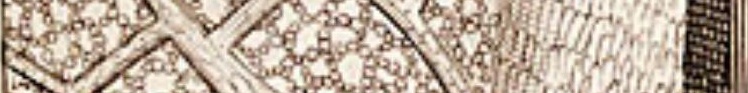

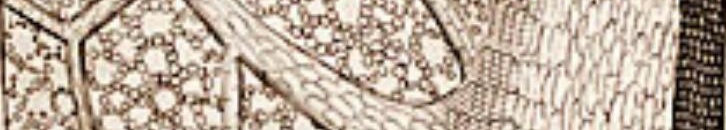

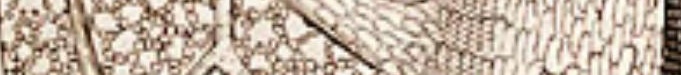
1050 and H.

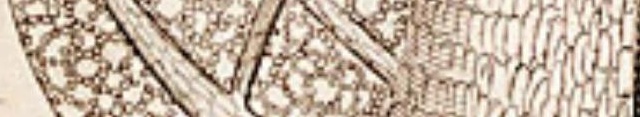

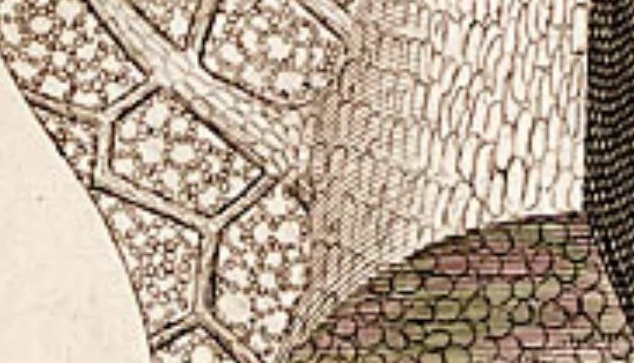

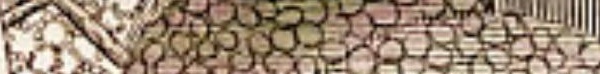

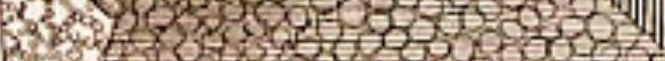

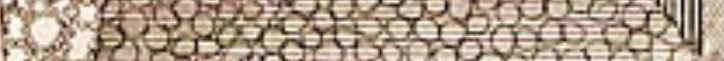

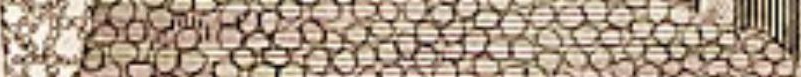

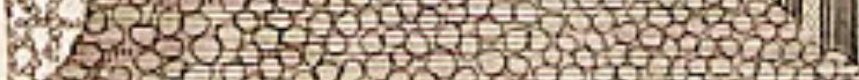

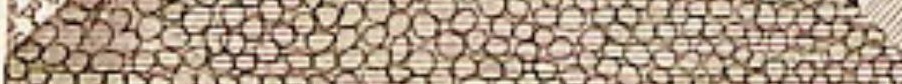

A young Borage Laf

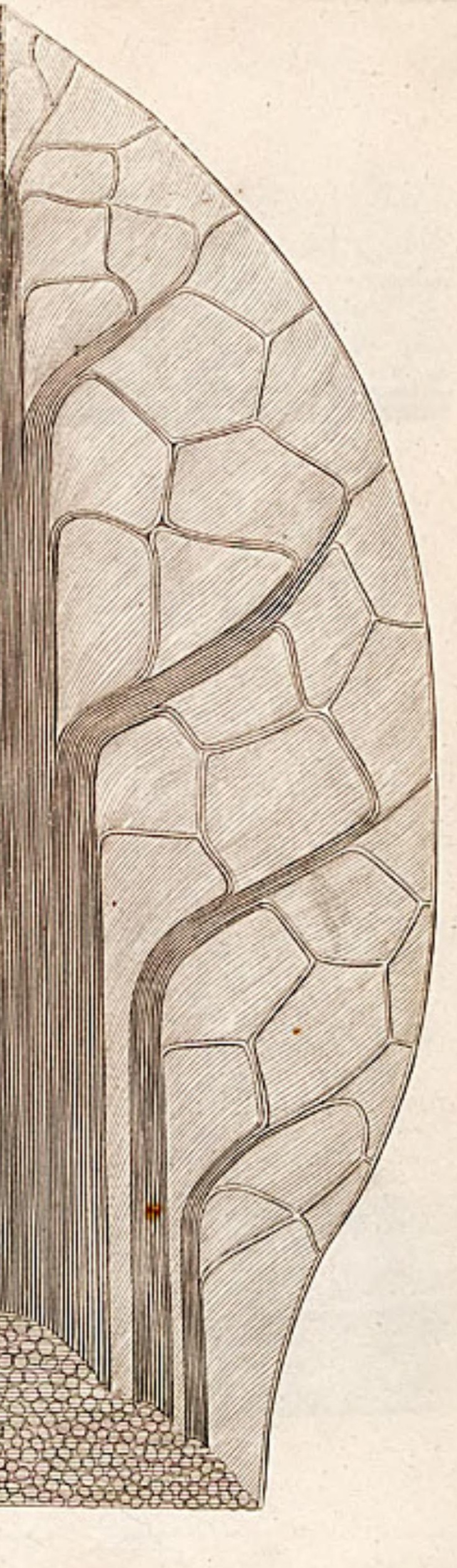




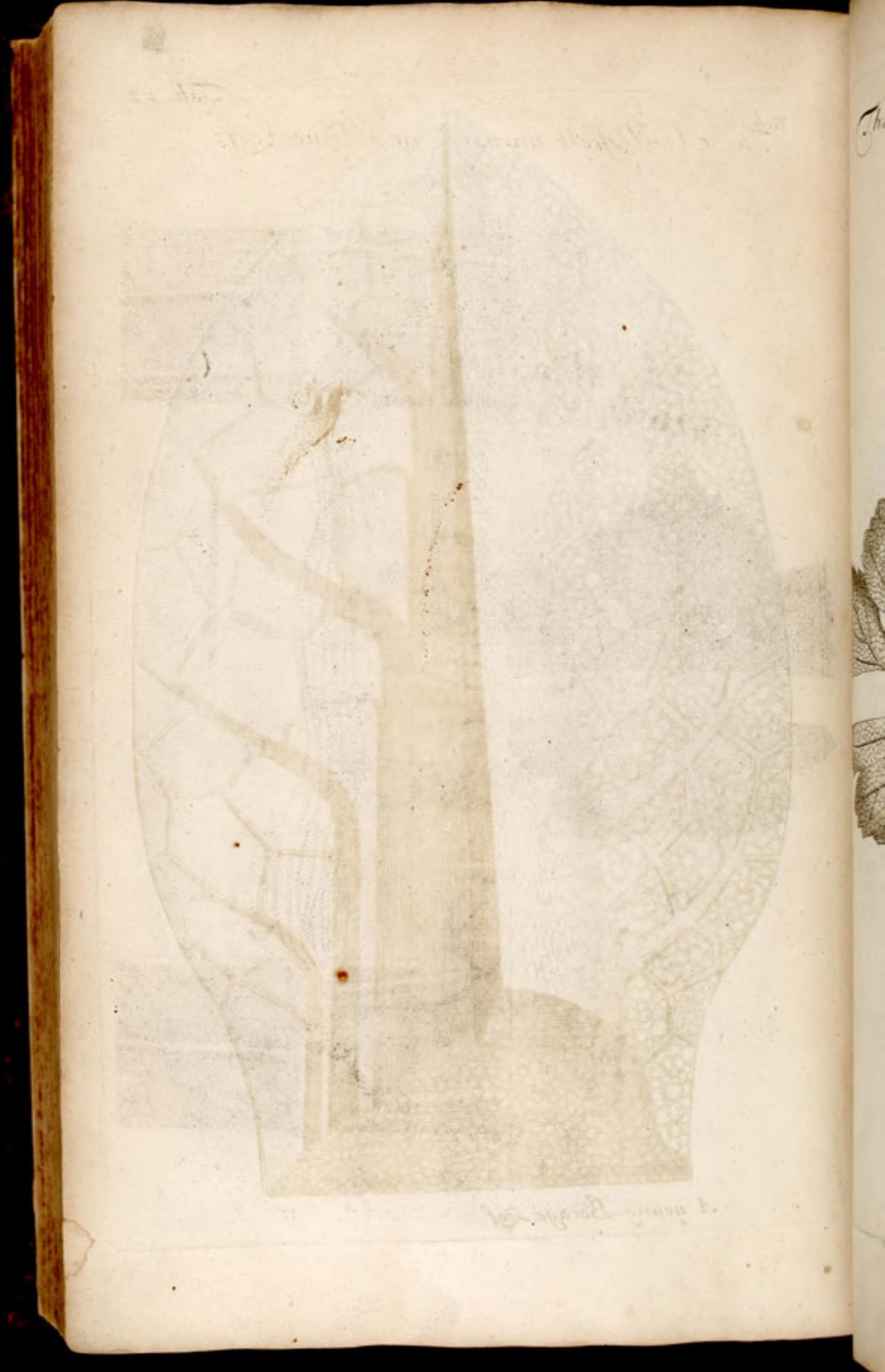


Tab: 51

The Aerolefels unrvaved in a Vine Leafe.

Fig: 3.

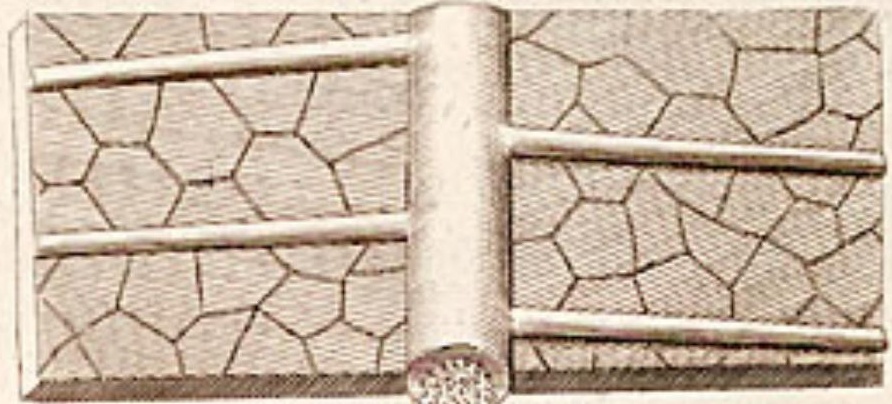

$F_{i g: 1}$
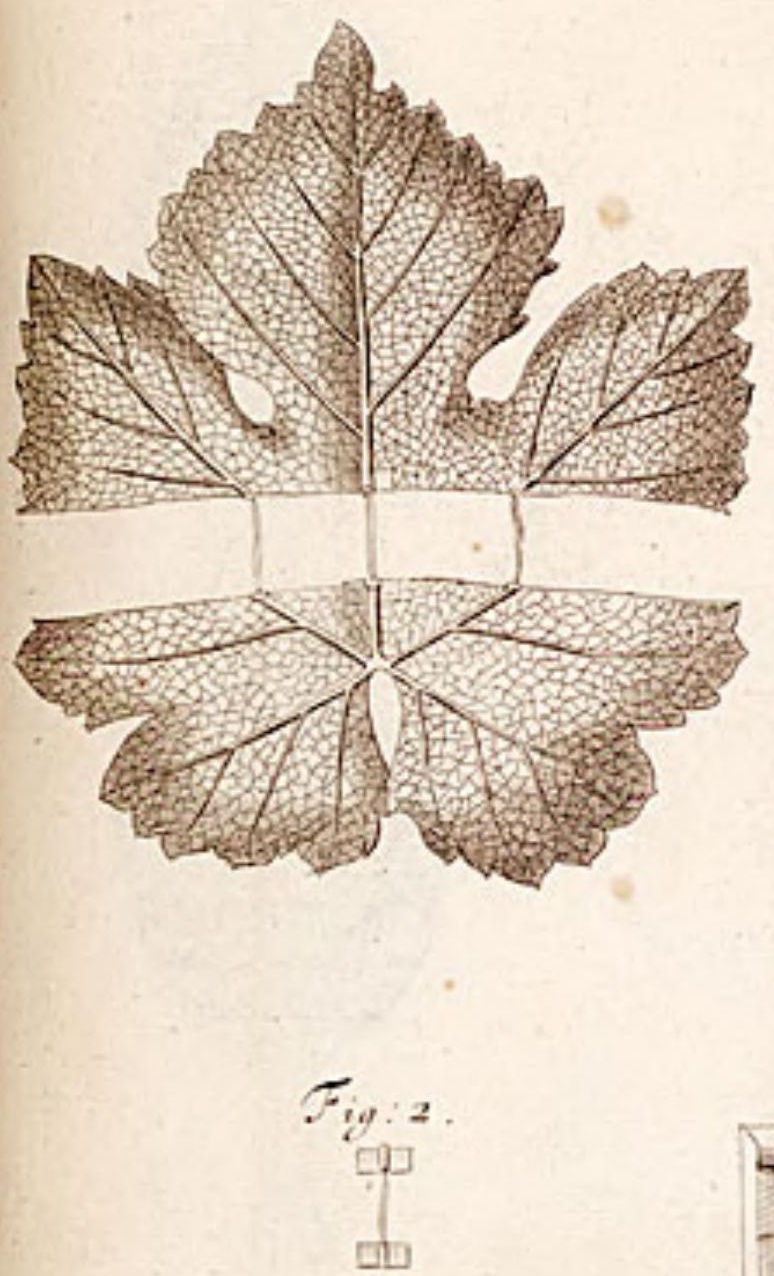

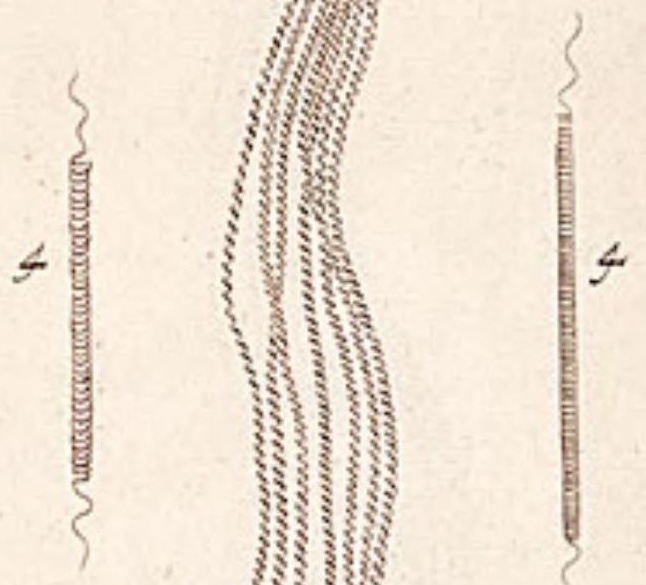

s

s.

3

玹桨

in

\}幺,

纹!

3)

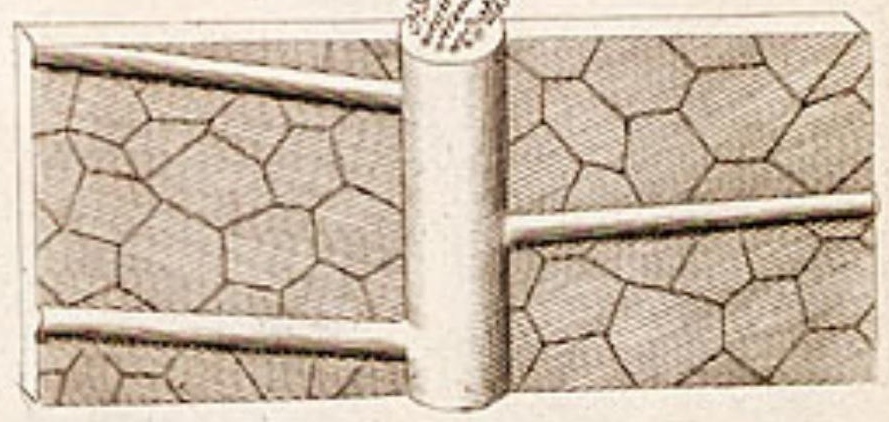




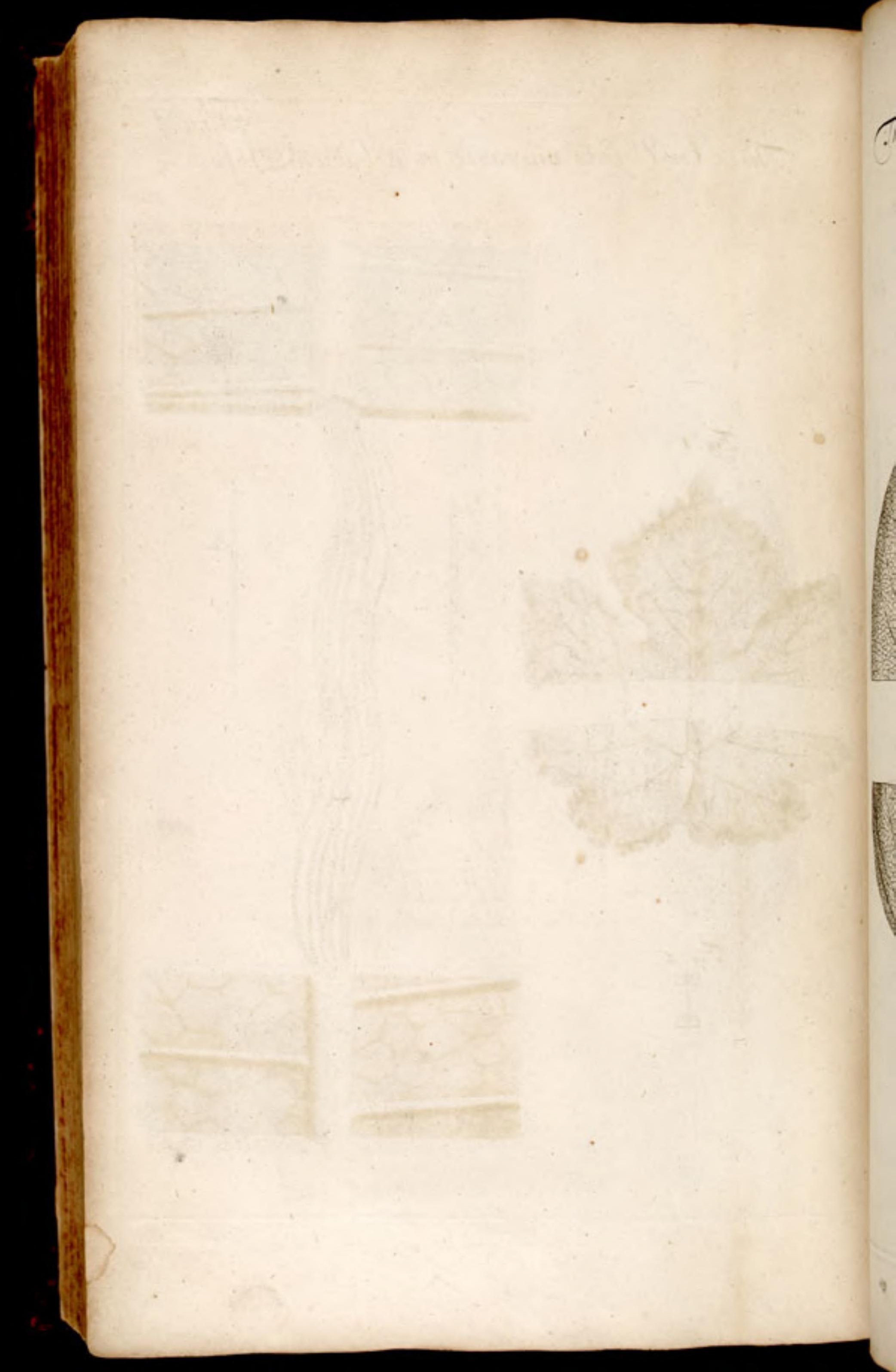


The Acr-Vefsels unrvaved in adcabions Lugfe.
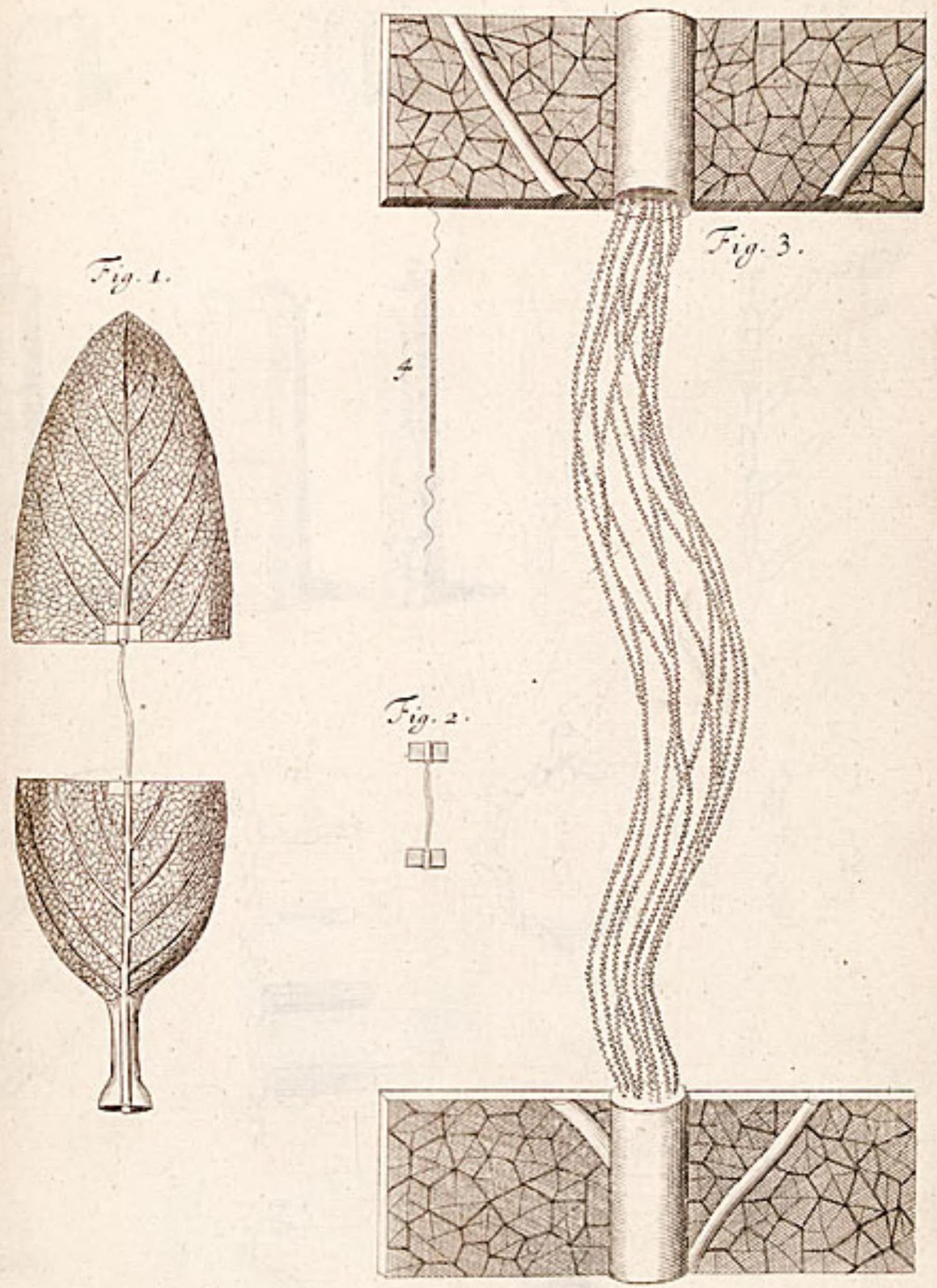


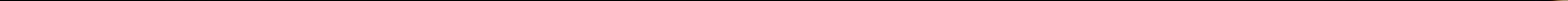



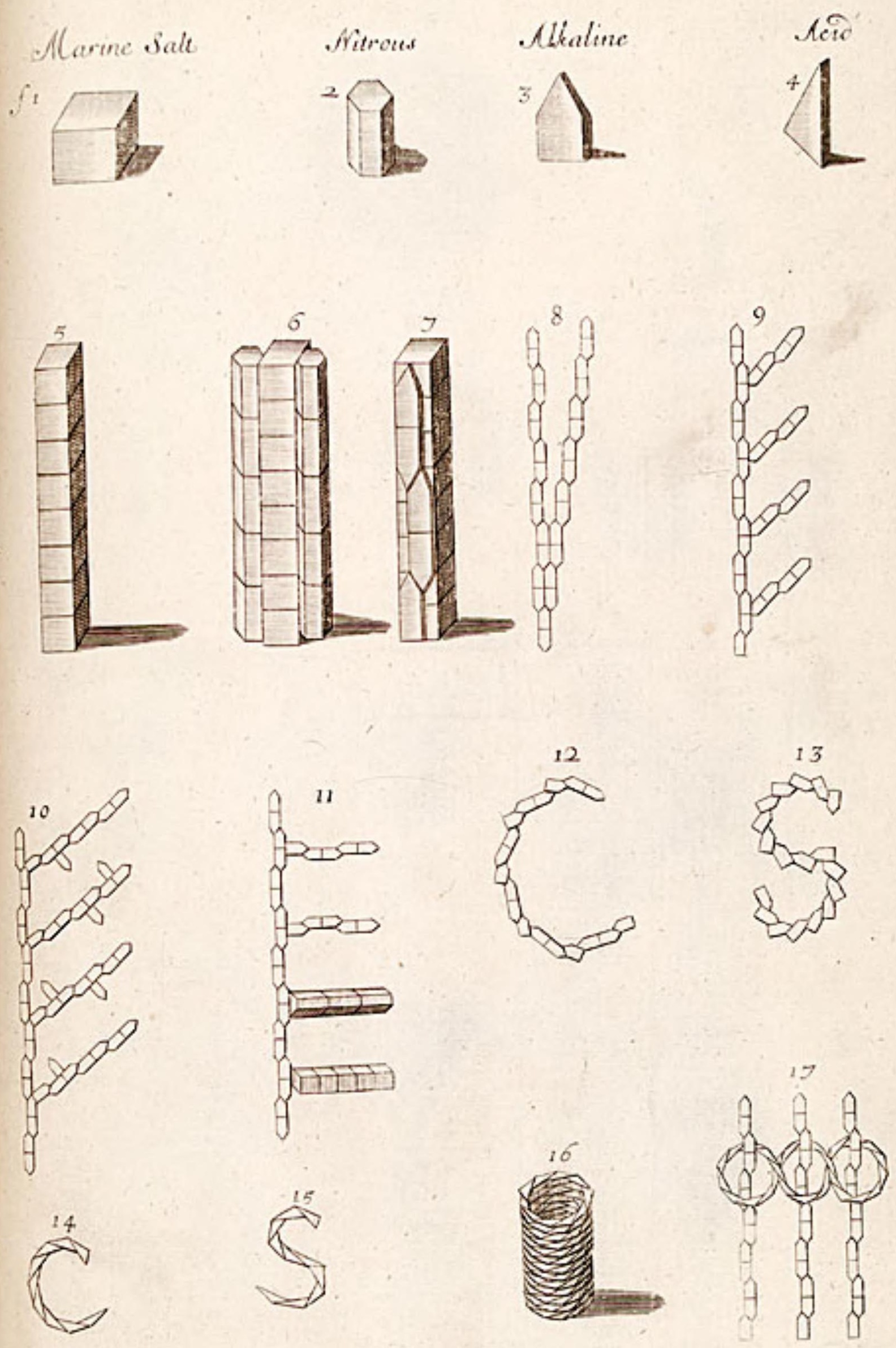


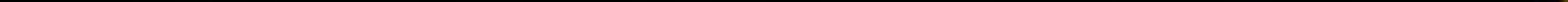




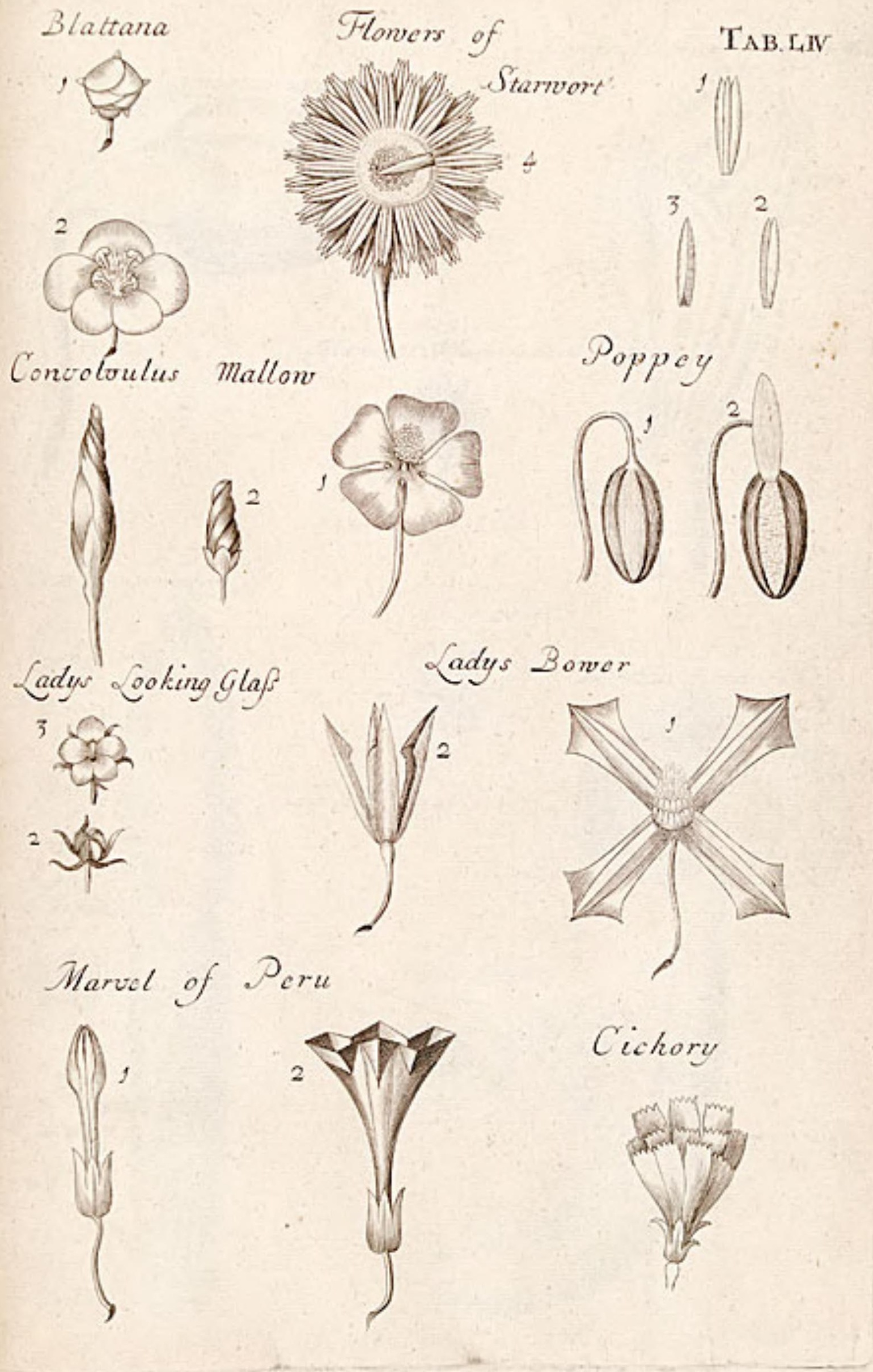




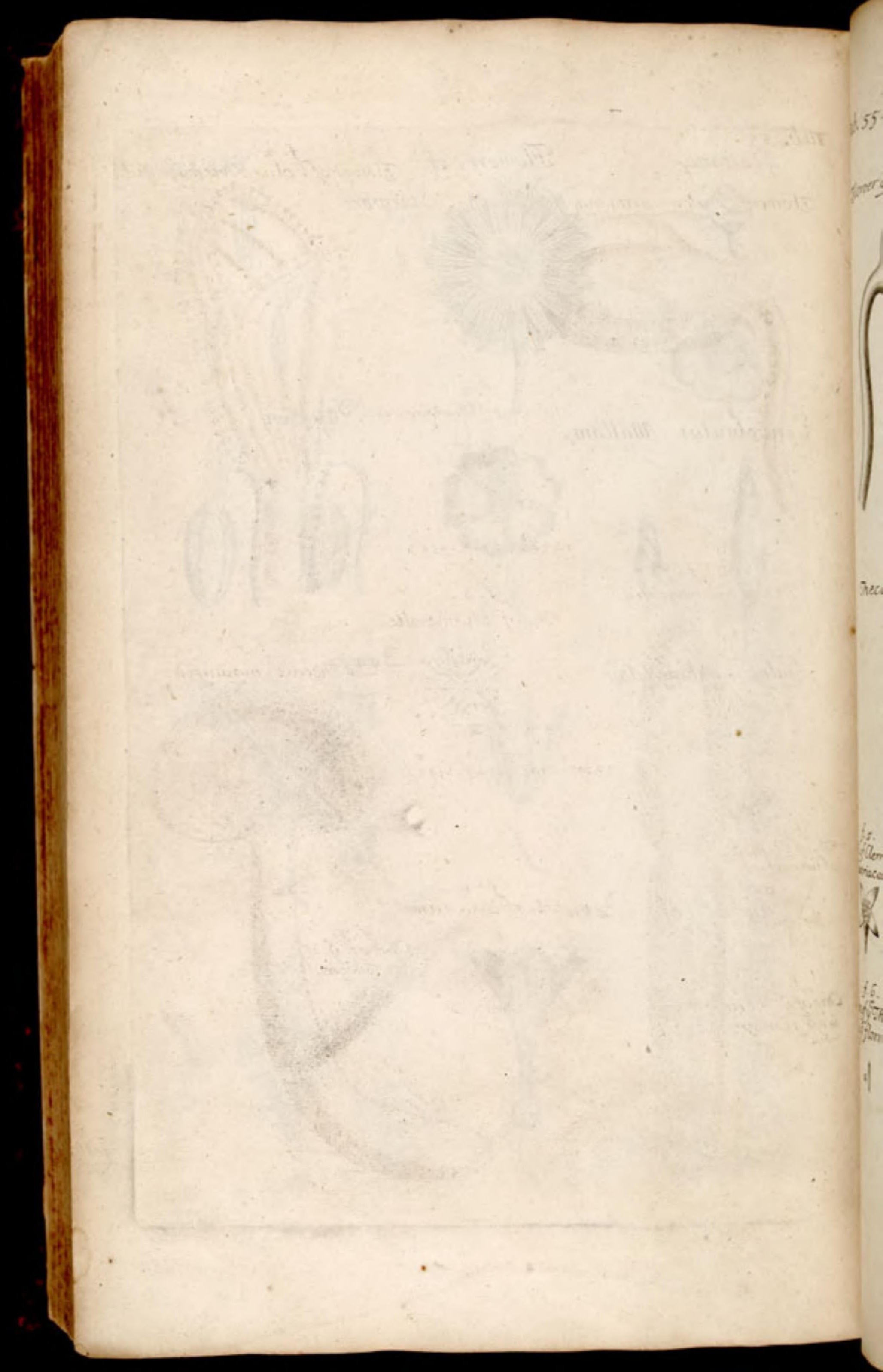


Tab. 55

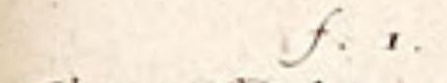

Glower of Dulcamaramagnifid.

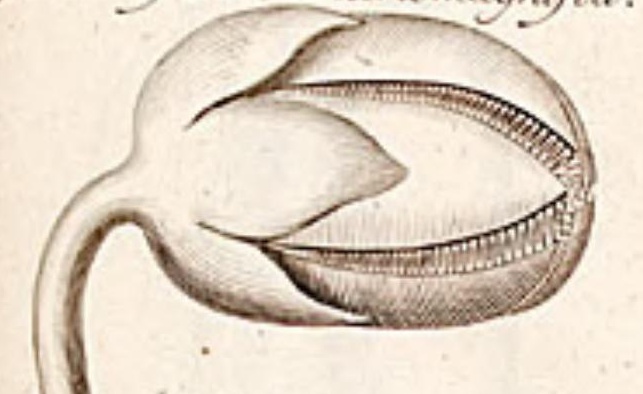

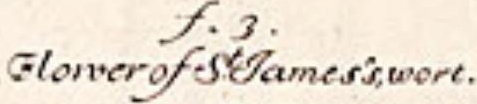

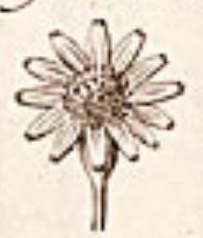

$12345 \cdot 2345+2345$

$f . J$.
Theca (a) maqnifid.

भ.of ilematis

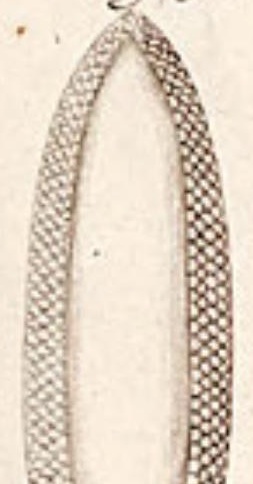

$12345 \cdot 2345+23+5 \cdot 2395$.

f. 4 . F. of Chamemile.
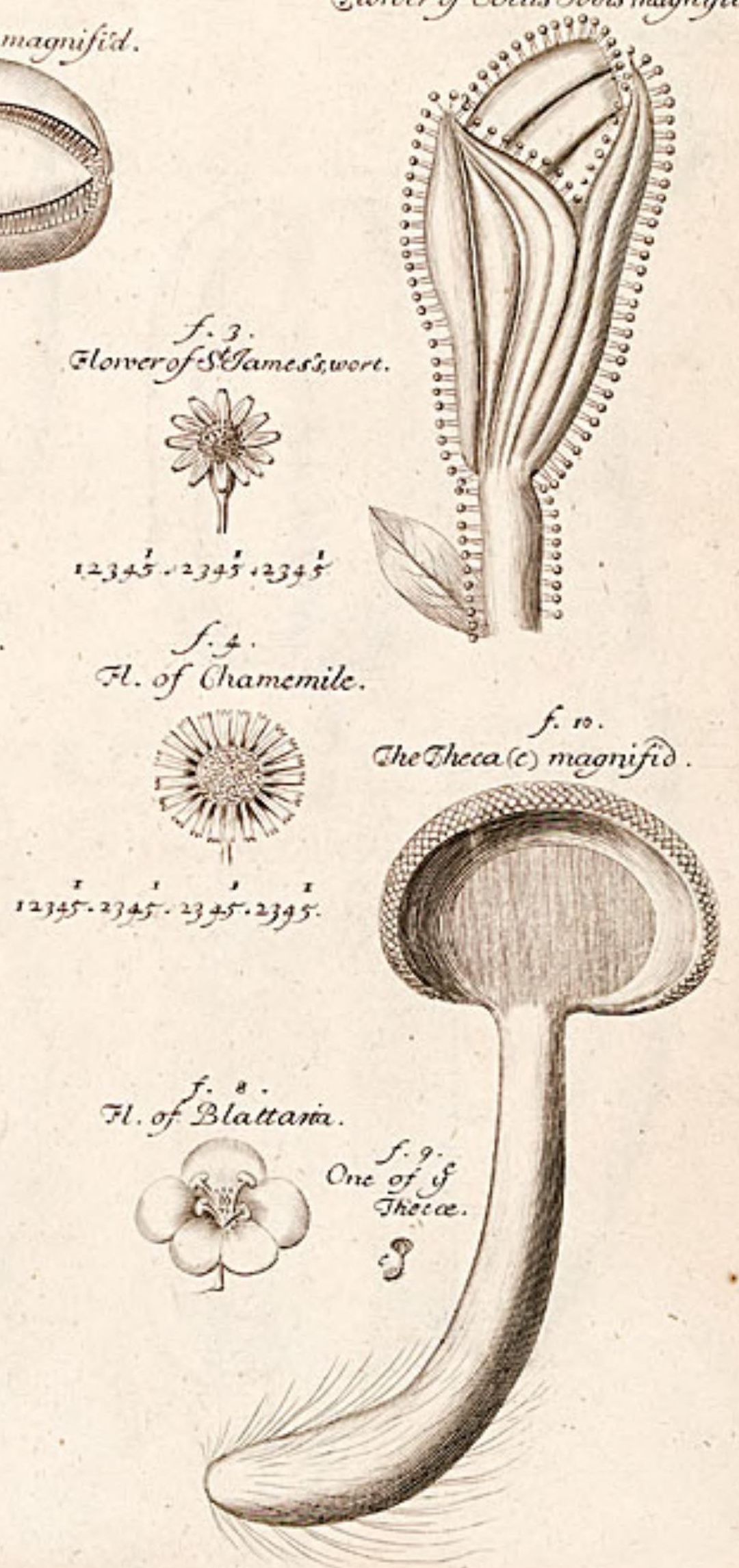

تtoner of Golus Tovismagnifit. 


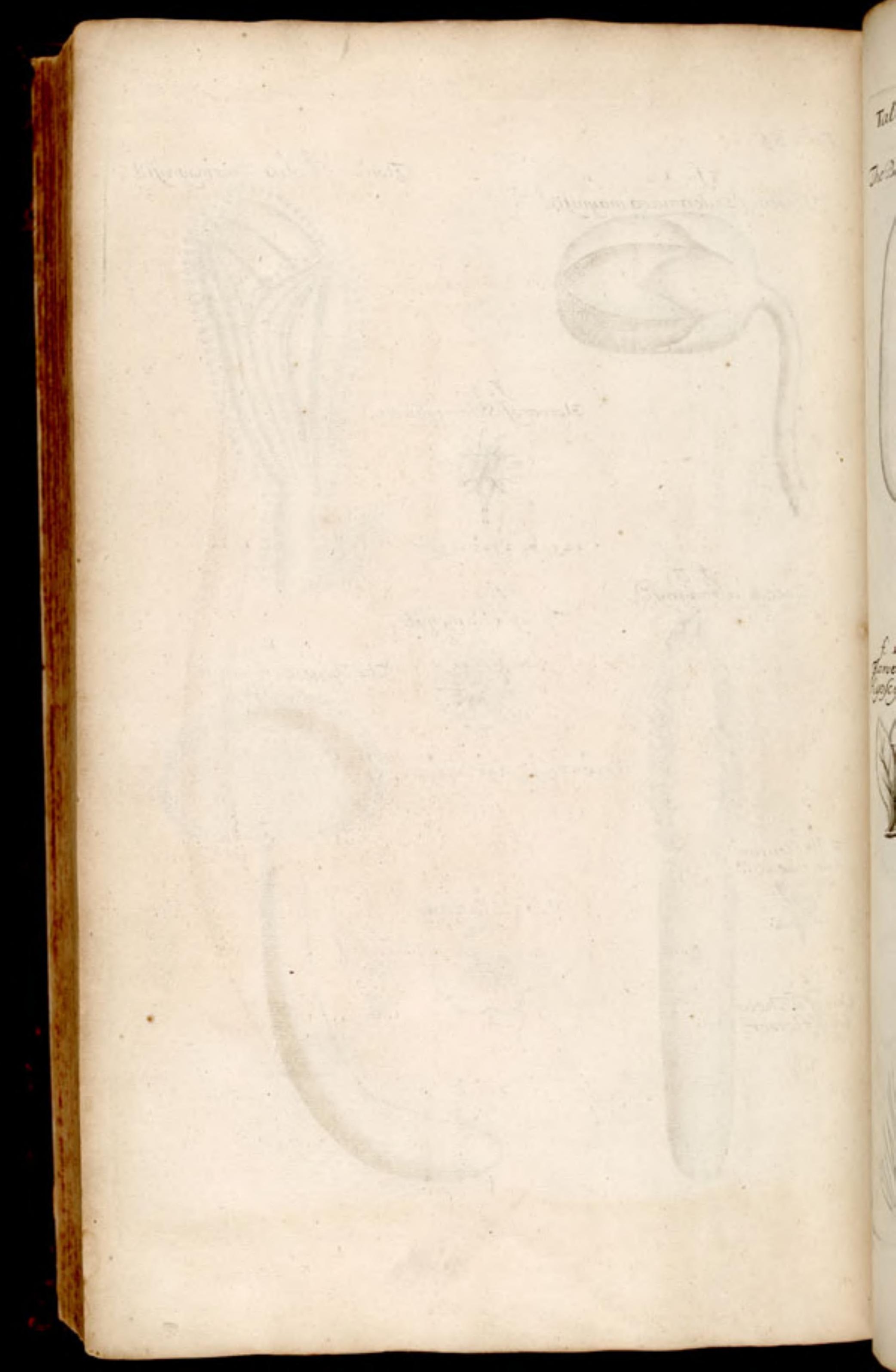


Tab.5\%.

The Buckide of ${ }^{\prime}$ Greca.(a)

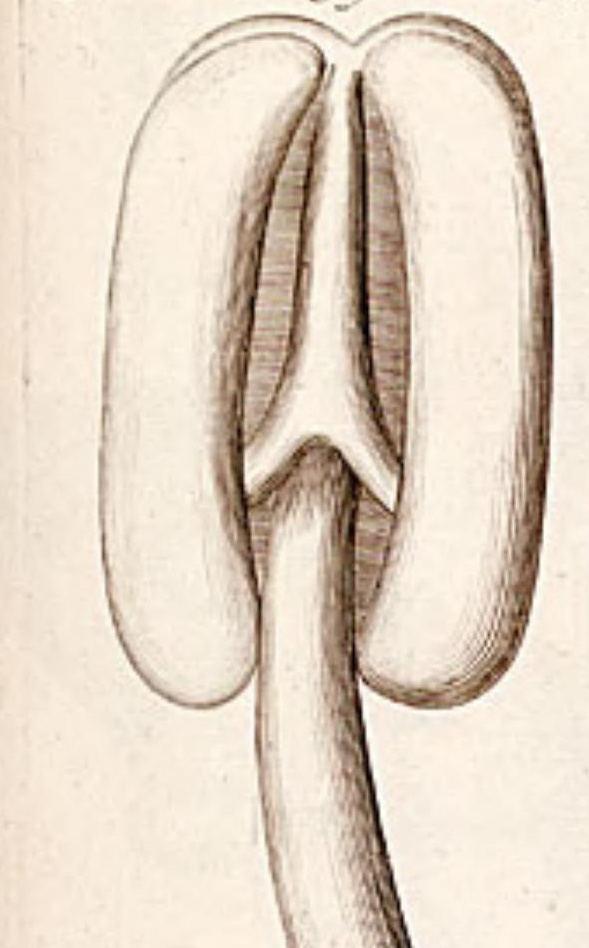

$f .7$.

Bre columm (c) Magnifid.

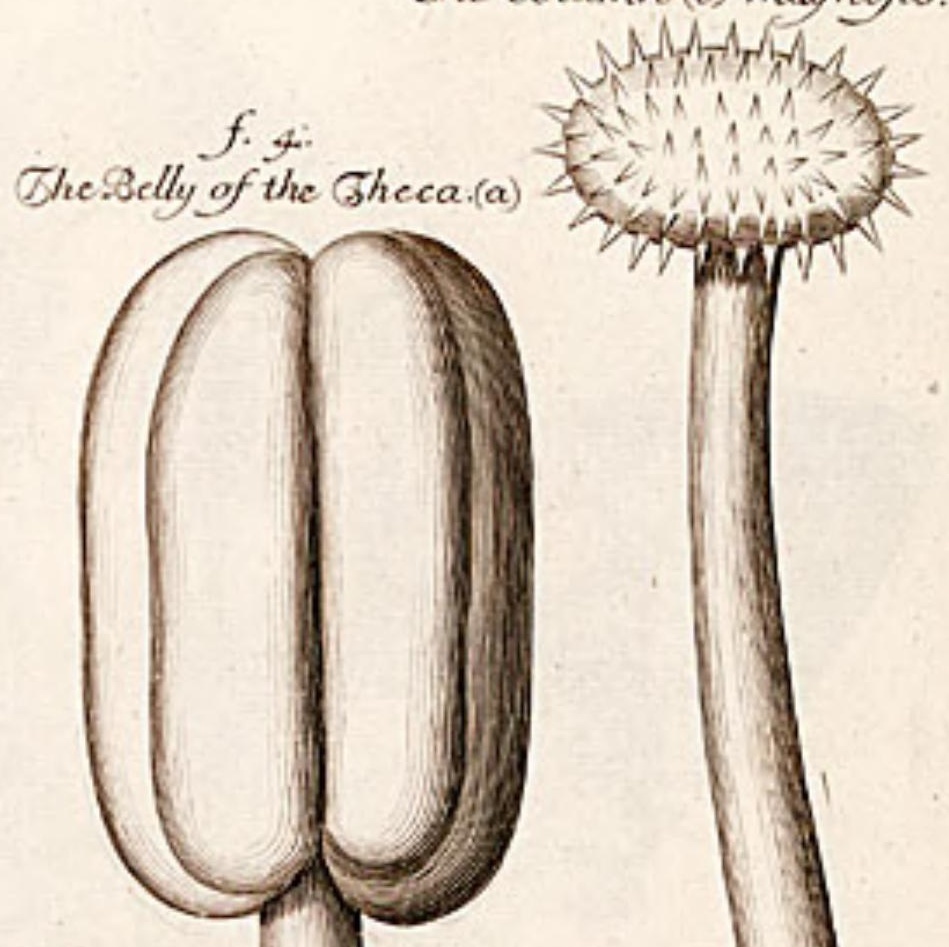

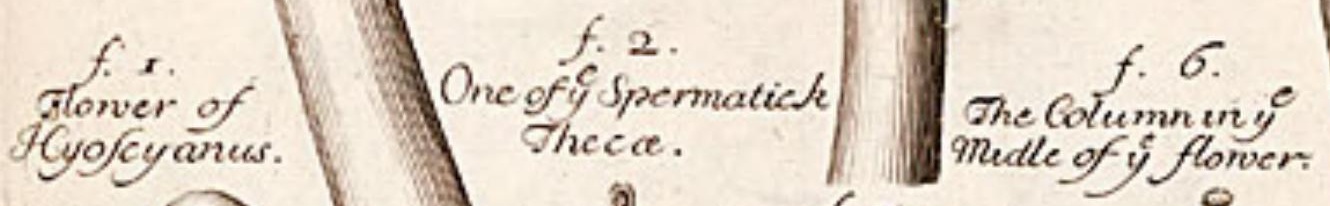

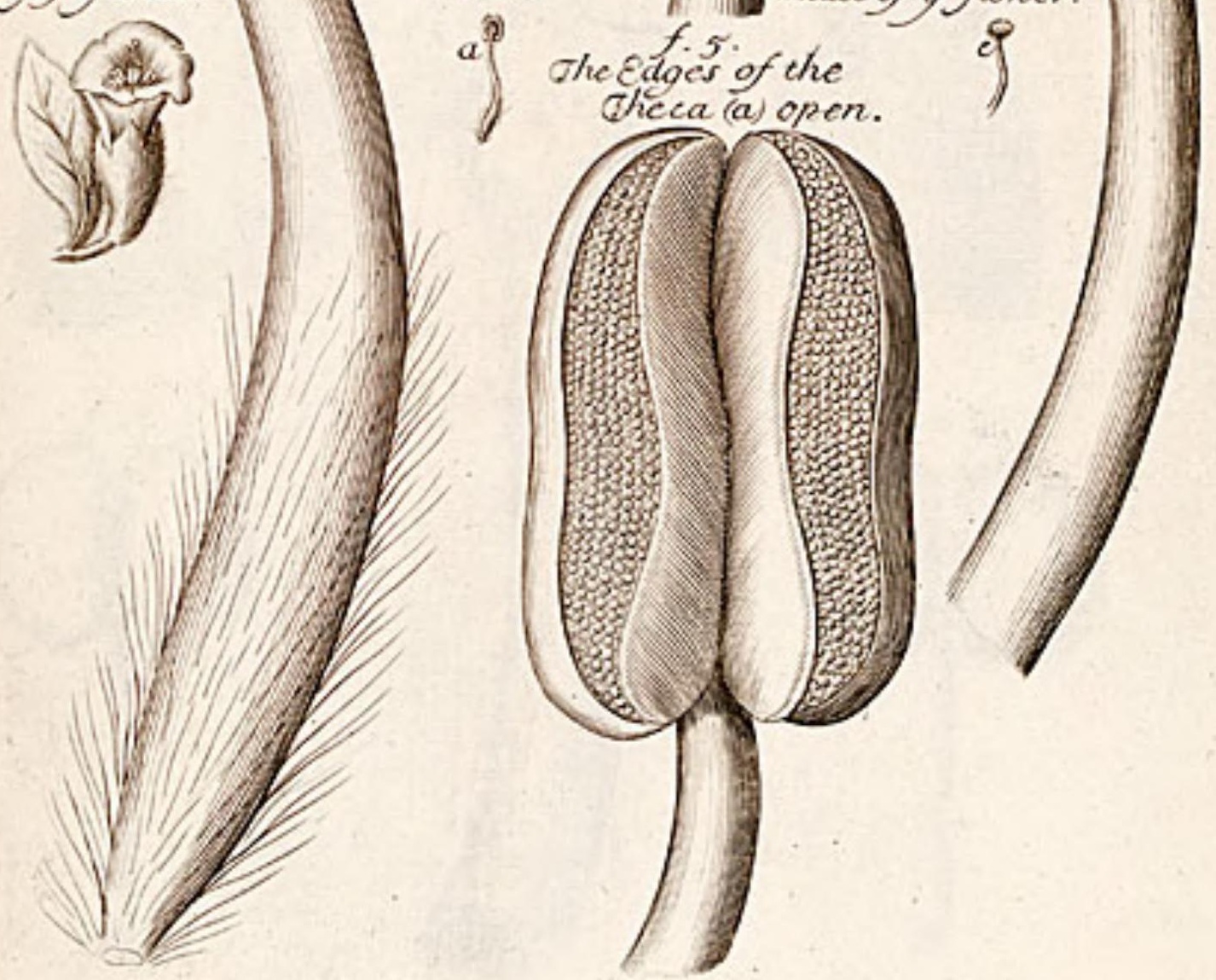


Tab.58.

Snapdragon

f.

$\therefore 3$

athe:

$\because \therefore:$

Derils-bit f.6.

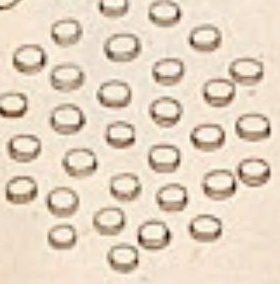

$f \cdot 3$.

One of $y$ Theca (t)

in f.s. 2 .

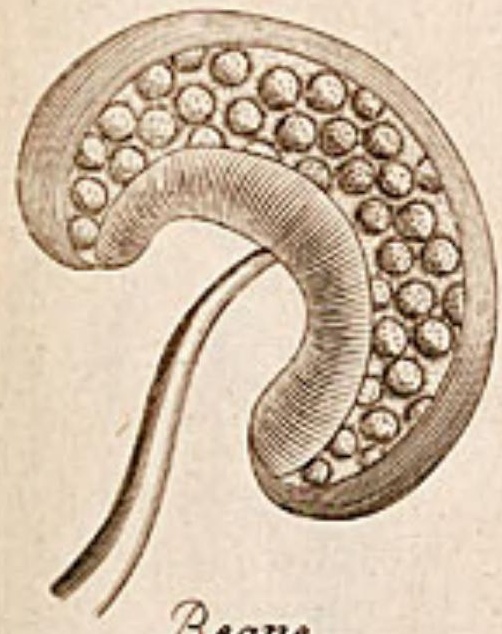

Beane

$\begin{array}{cccc}0.7 & 0 & 0 & 0 \\ 0 & 0 & 0 & 0\end{array}$

000000

000000

$00_{0}^{0} 0.8^{\alpha i z y}$

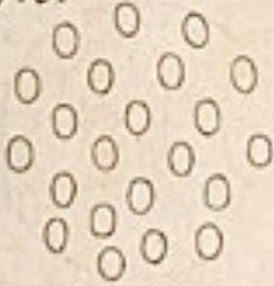

The Sperme of

Plantaine Bearsfoot

$f: 2.00$

$00 \% 000$

$0 \% 000$

$000 \%$

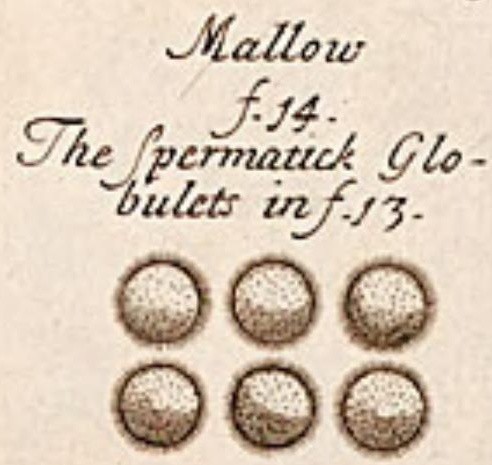

fis.
The Ative (e)
in f.st.
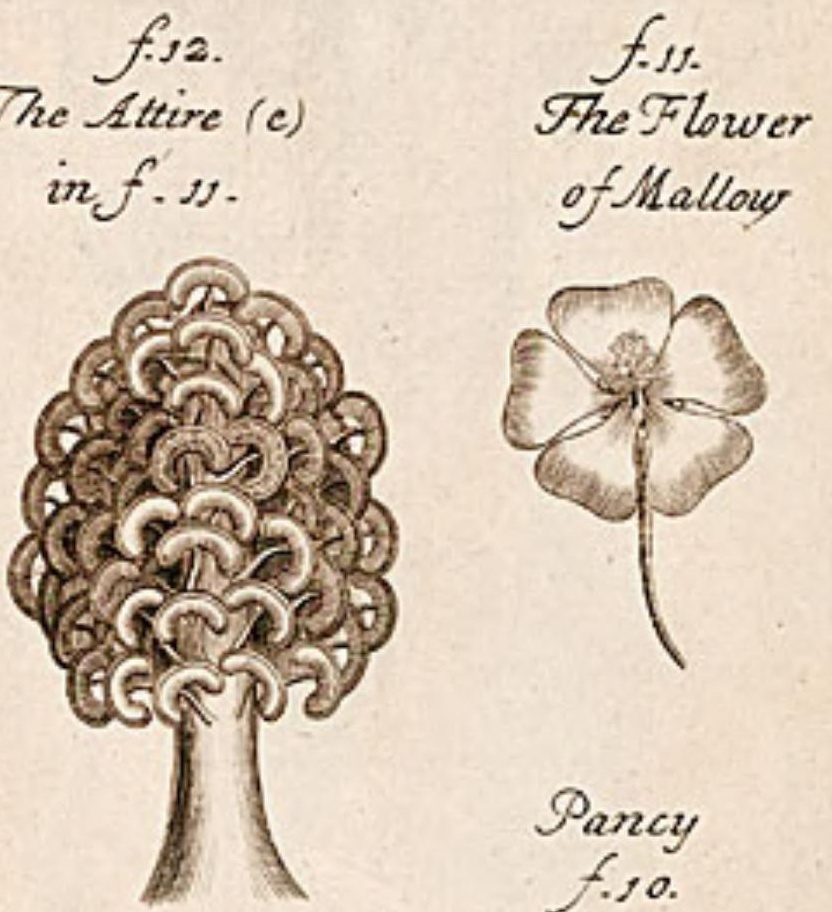

Pancy

1.00

[ 0

$\square \diamond \square \diamond$

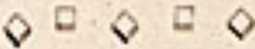

Deadly Night Shade $\diamond \square \diamond$

ㅁ $\square$

Carnation

0.000
0000 

Bindweed

f.5.008 .00000
00000
00000
0000

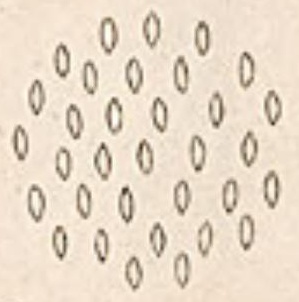




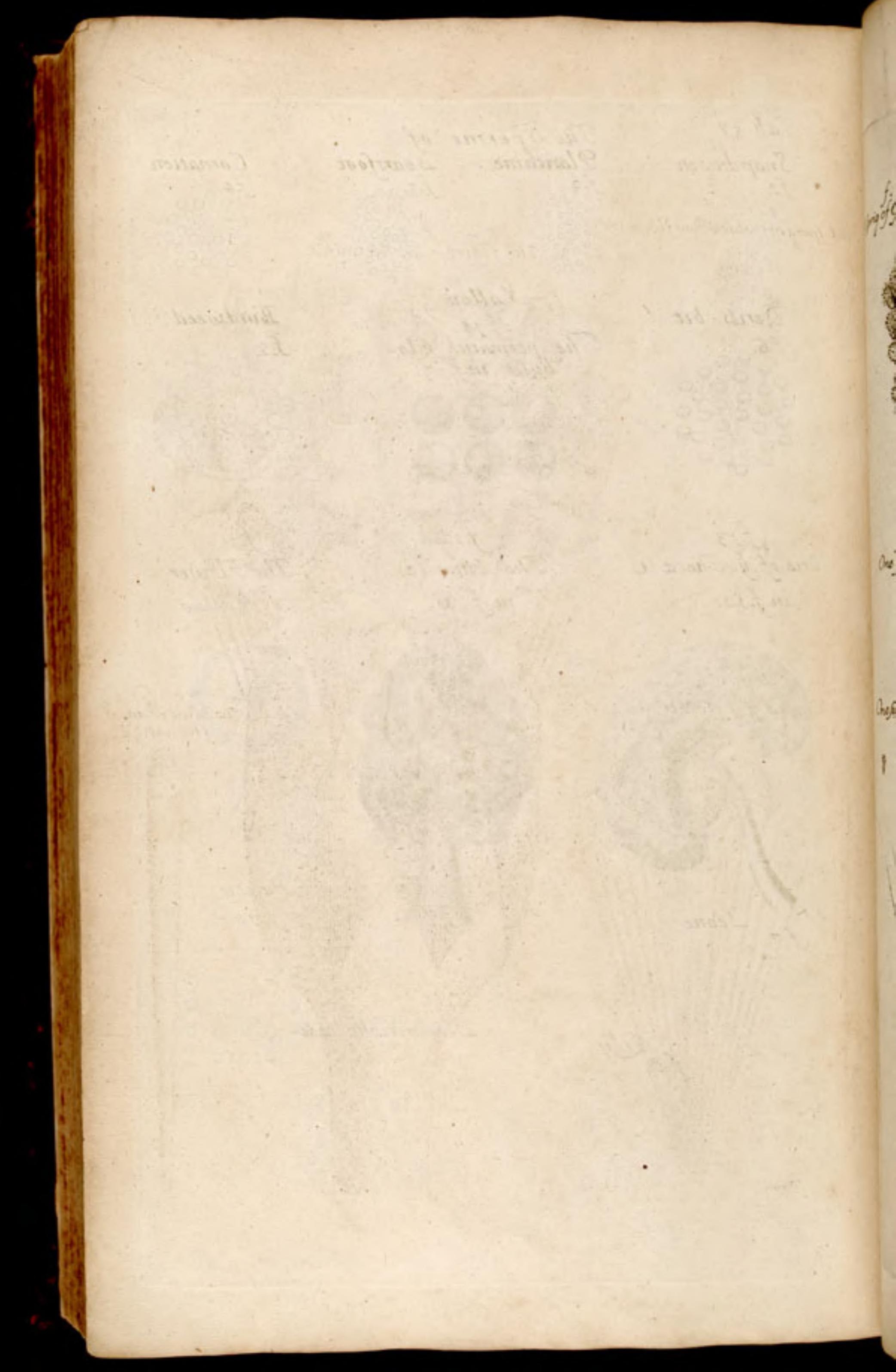



Tab. 6o.

1 Frnelingarigold.

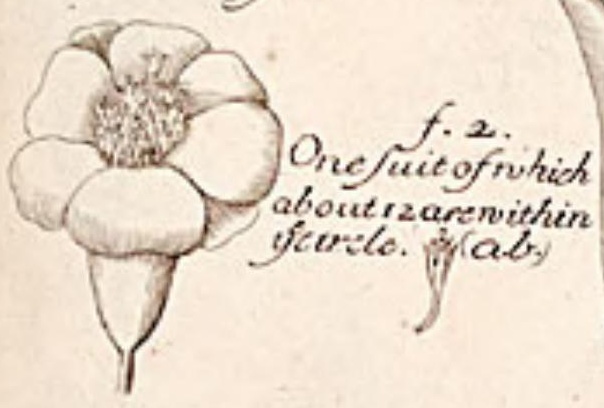

Onefuit of Chinjain

on andemem Cone If about eo areun cvery florver.

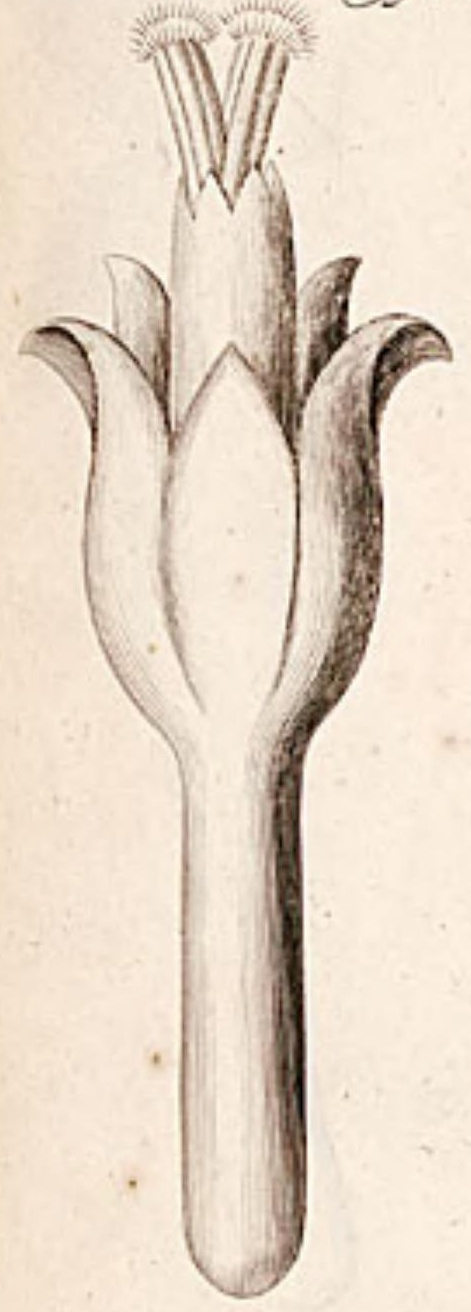

ohe fuetej magnifid. 3ie
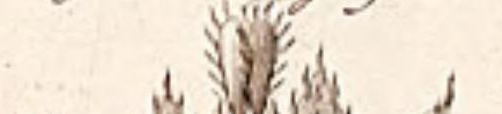

wheslateted taken out of 5 healhice. और $:$ :

g. $10.0 \%$

9. $)^{\circ} 90$

x. $0^{\circ}{ }^{\circ}$

Why

की

ah:

aोy :

- g.

2h:

ม.

a)

3ी:

3:

99

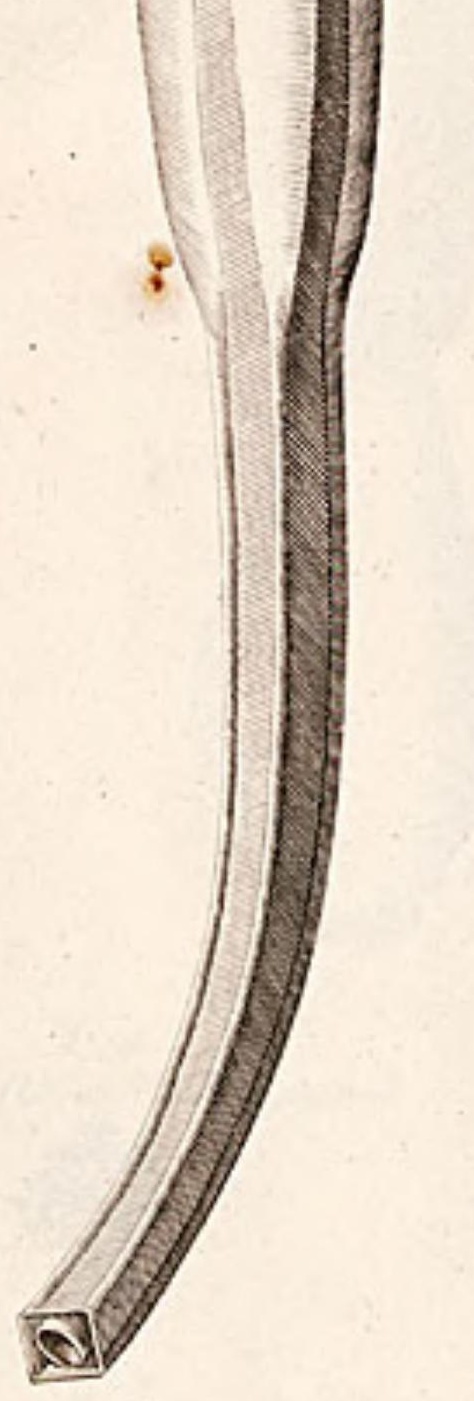




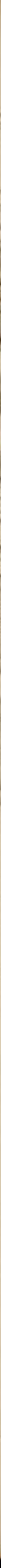


Tab. G

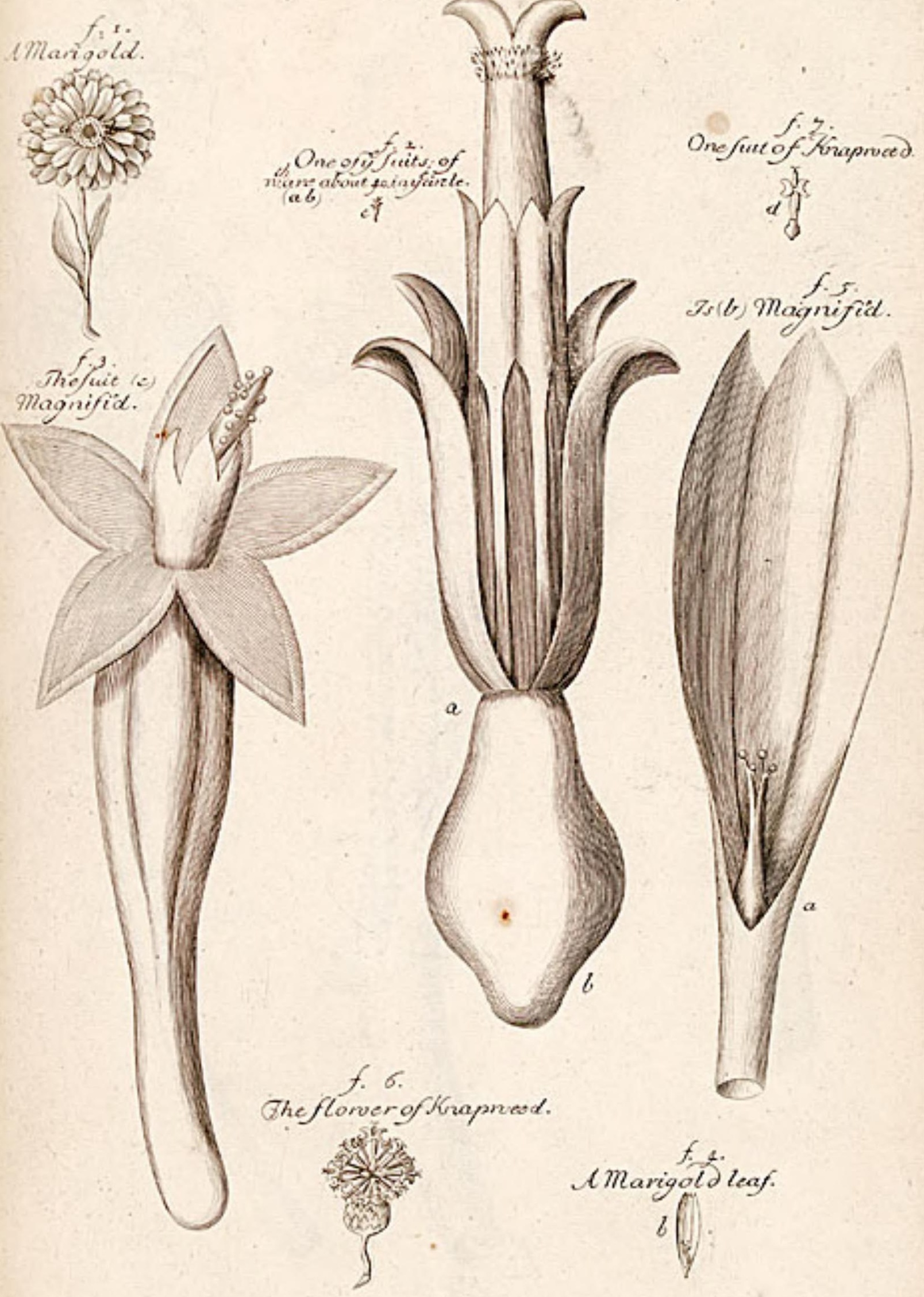




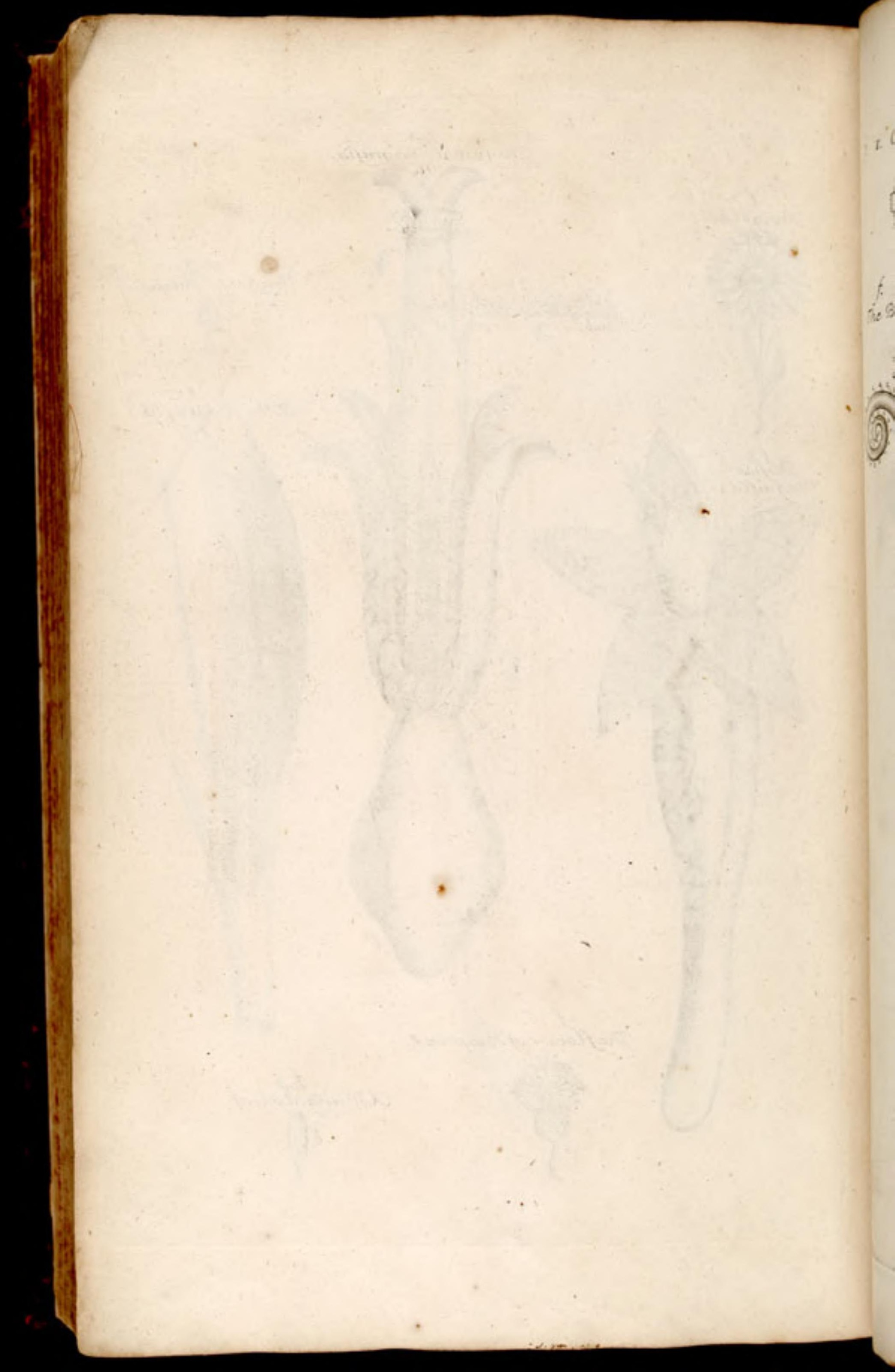




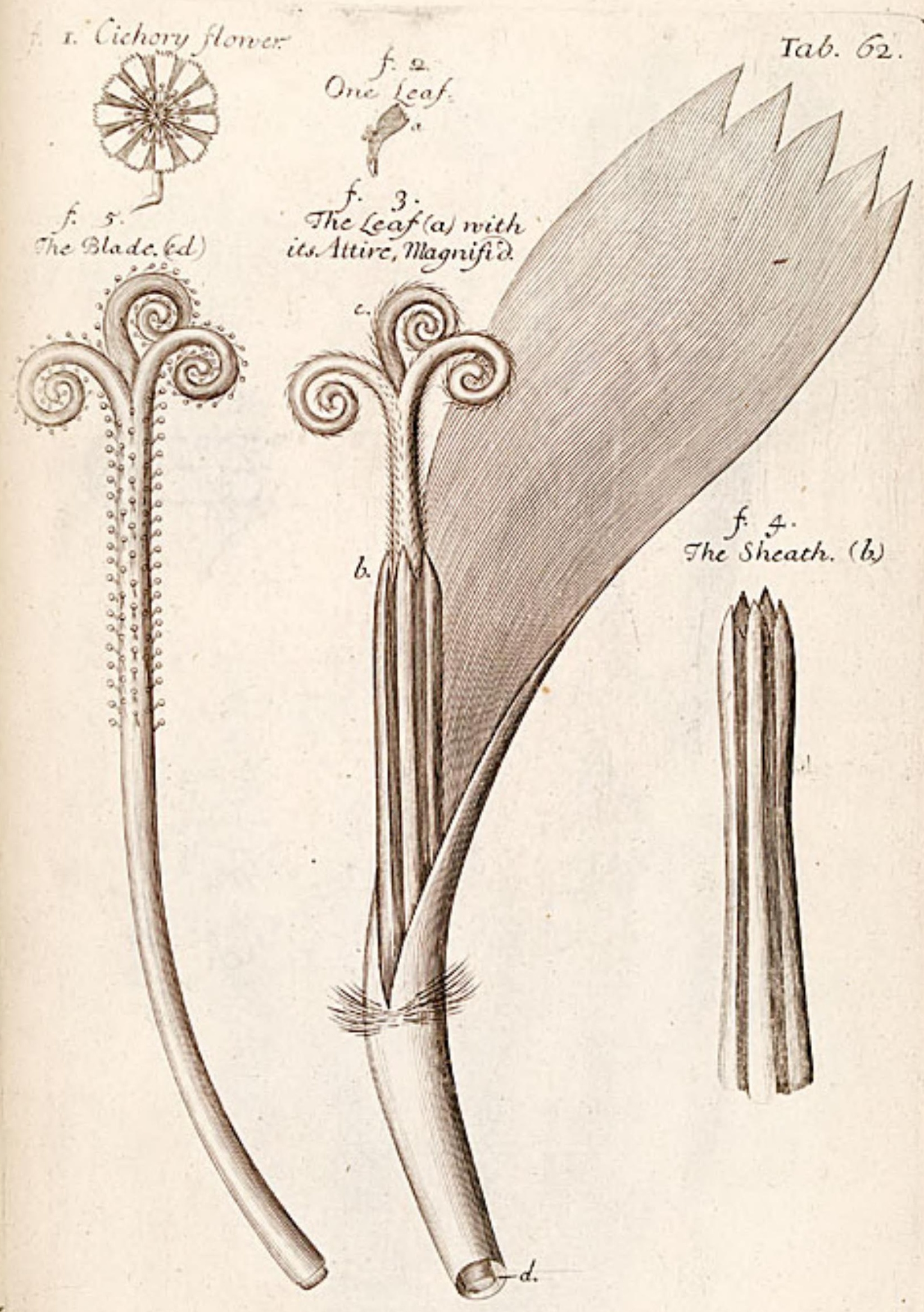




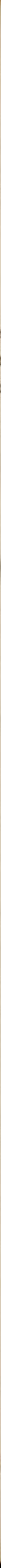


Sheneli ay a asit is fonnd ing oulip of ynoot in sepecmber.

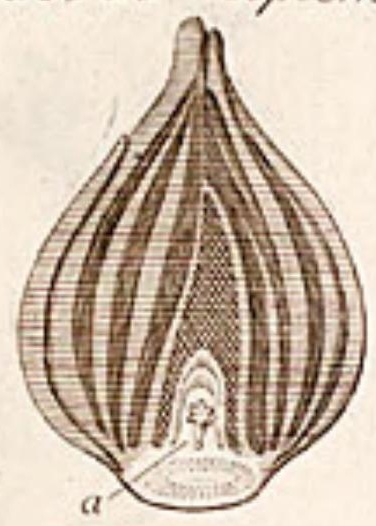

$$
\begin{aligned}
& \text { Tab } 6.3 \\
& \text { One off olorversing }
\end{aligned}
$$
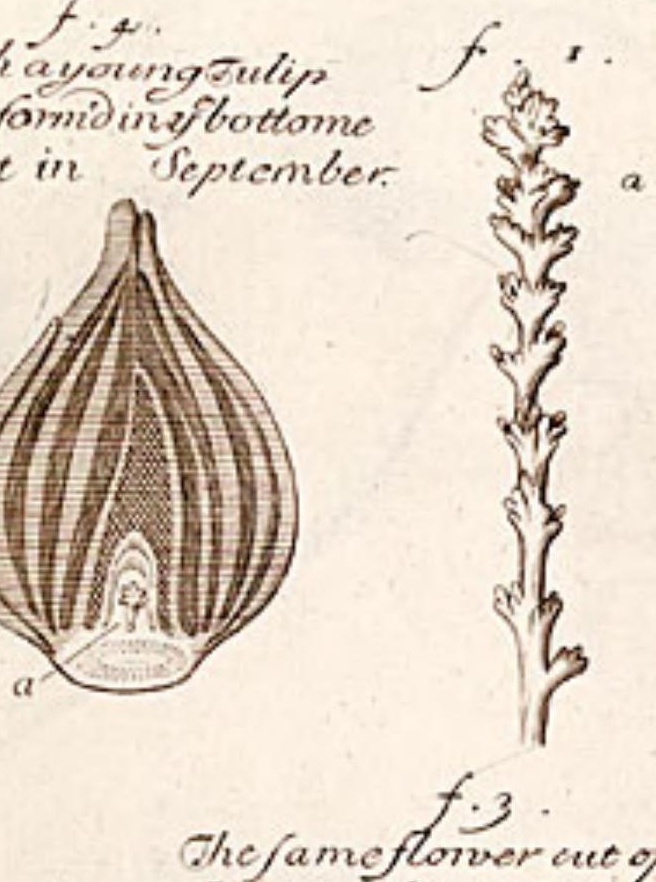

Thameflonver net open.
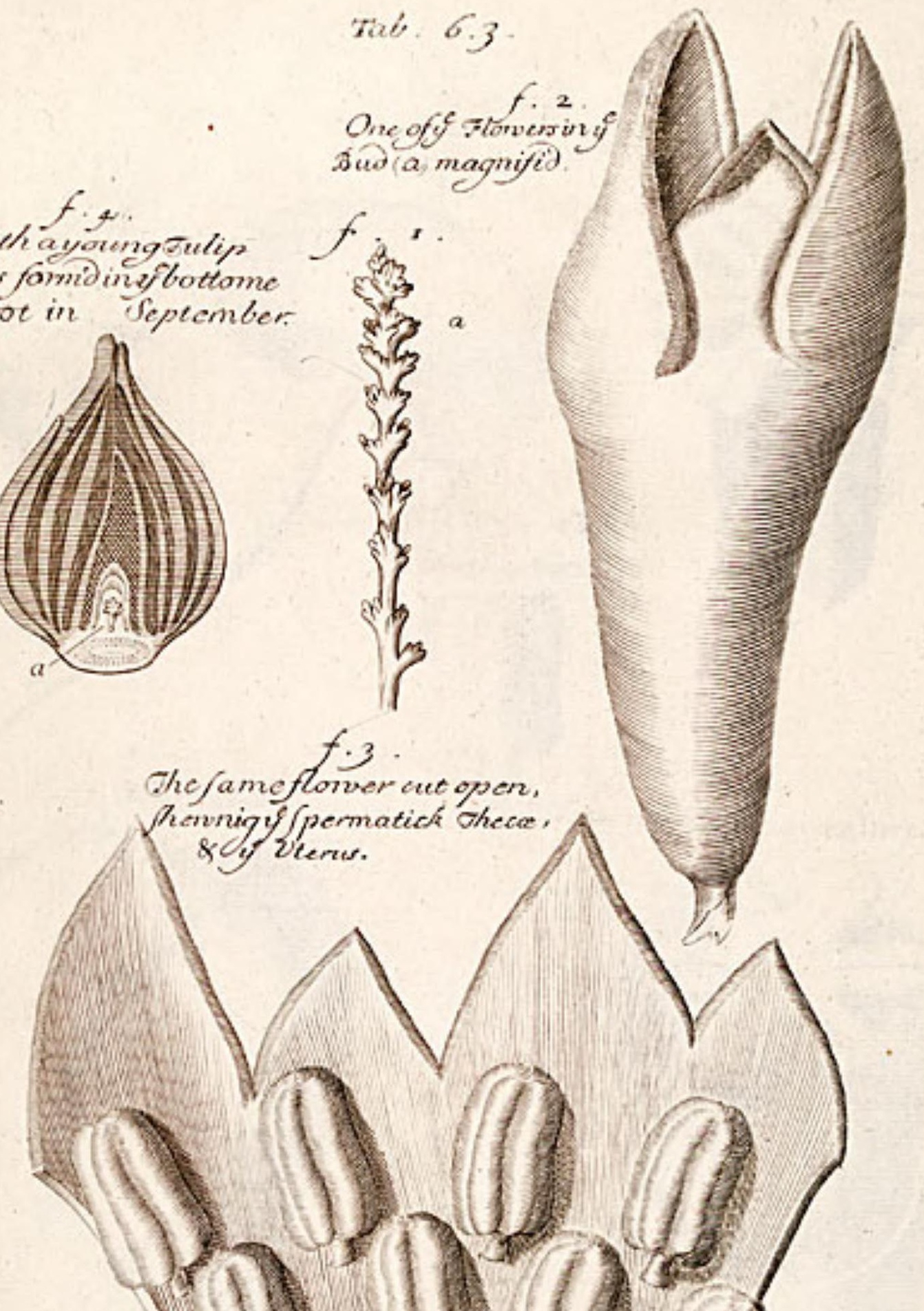
Tab. Gf.

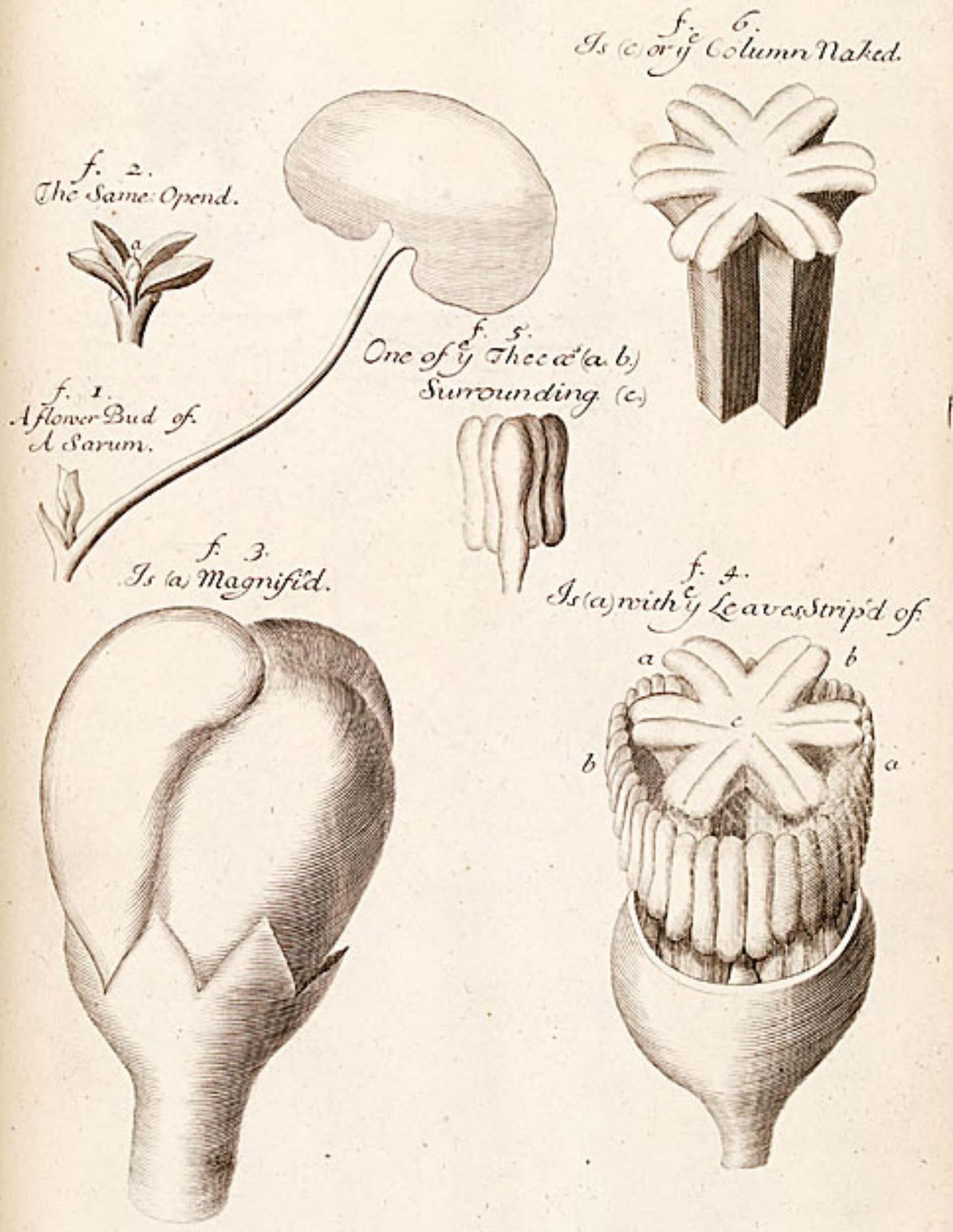




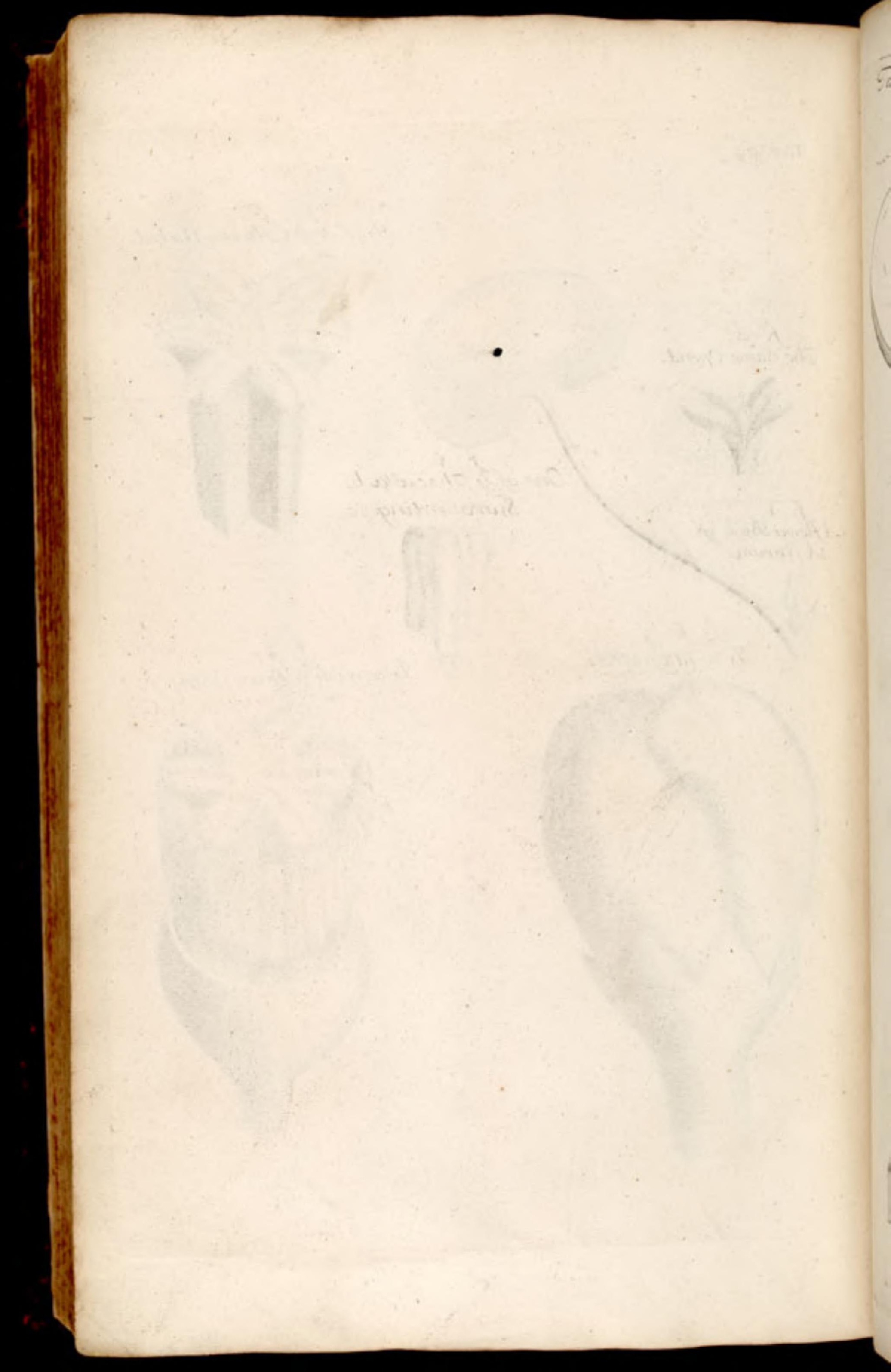




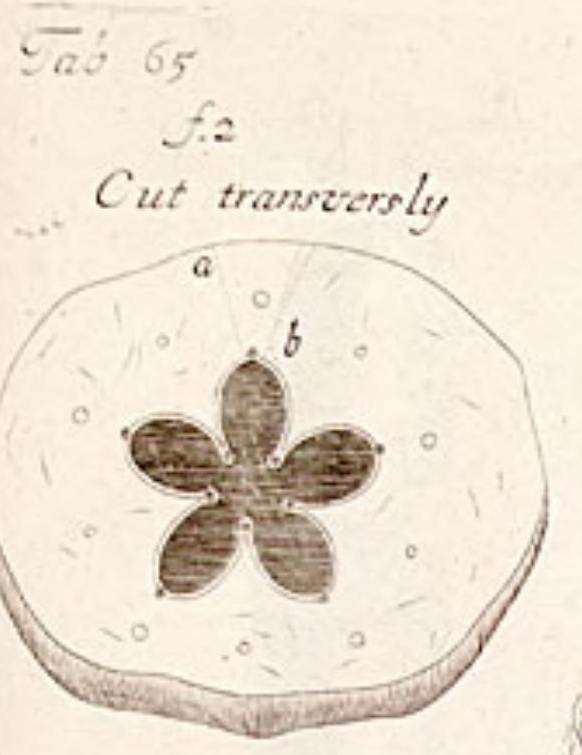
Thepiece (ab)
manified

f.t an Apple cut by the lenoth

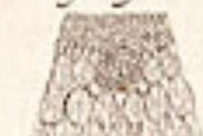
resen. expe:

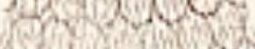
rom nolumen: (his wow

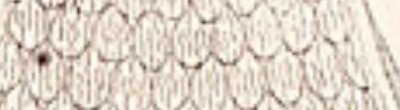
$30+1$ com ons 3. 20 rum 2. or $n=1$ 2.

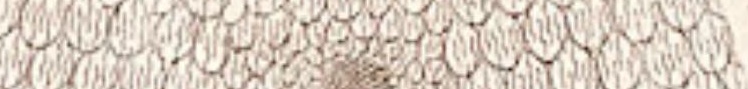

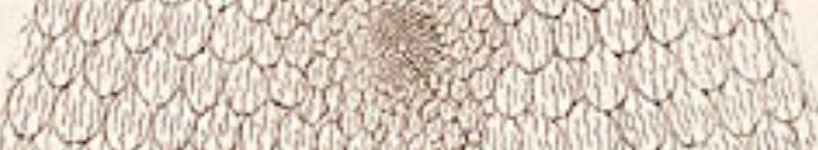

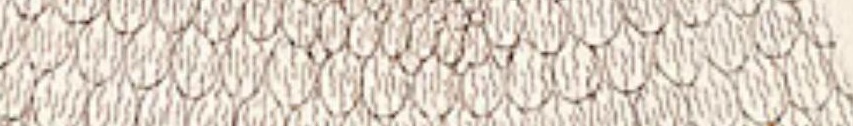

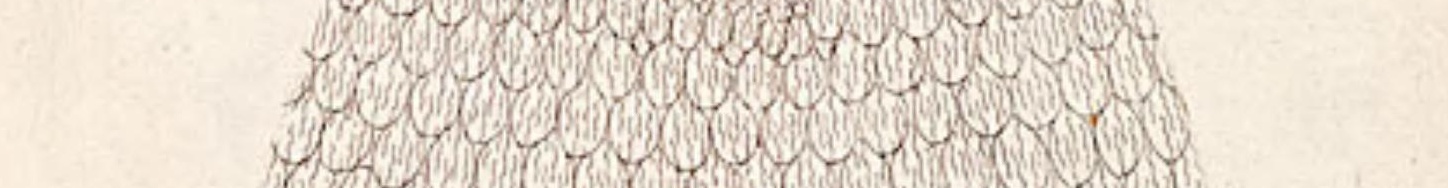




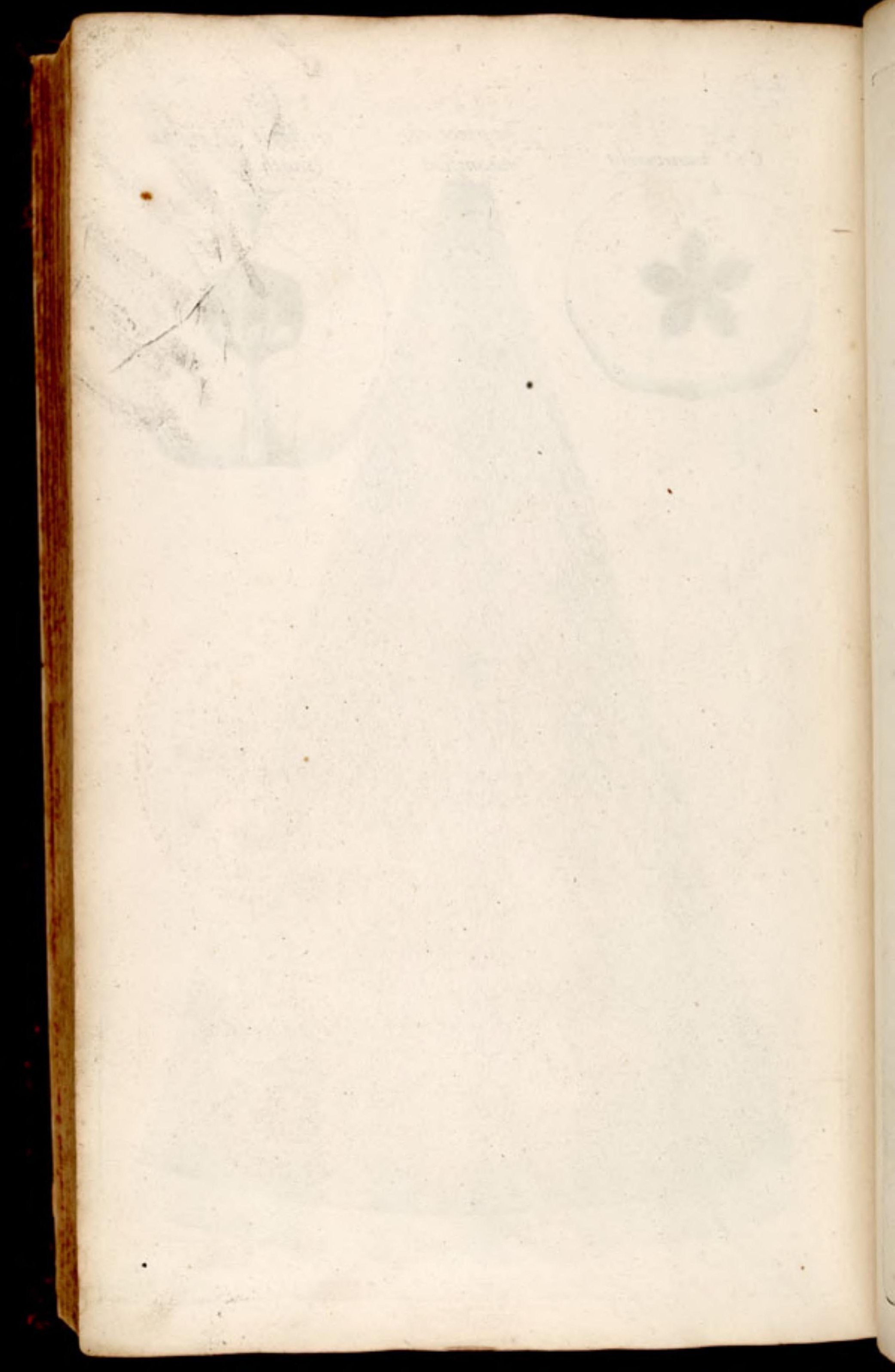


f. 3 great $\quad$ Tab. 66 . one of the Baggs, a.c.e.

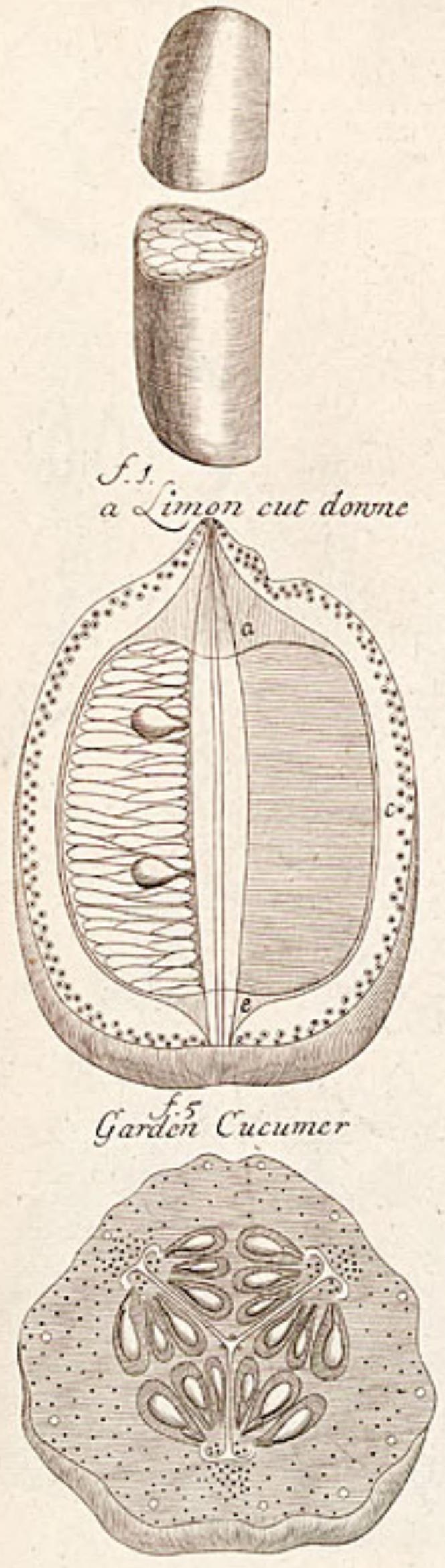

f. 4 One of the little Baggs c.e. cue transversly

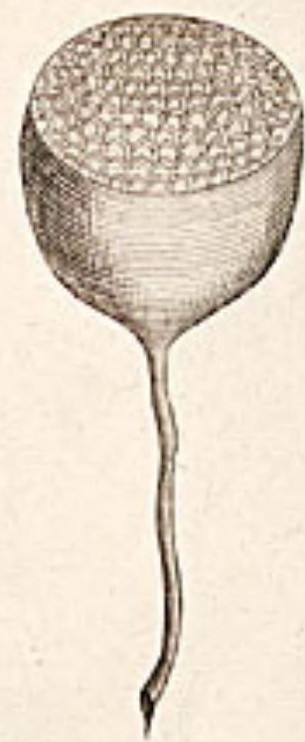

f. 2 .

cut transeversly

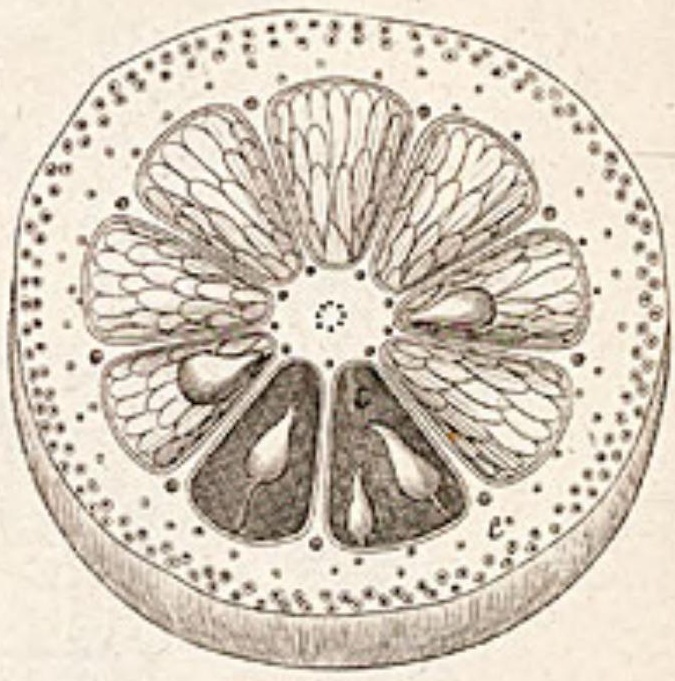

f. 6

Wilc Cucumer

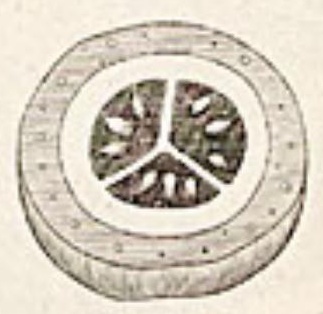


1
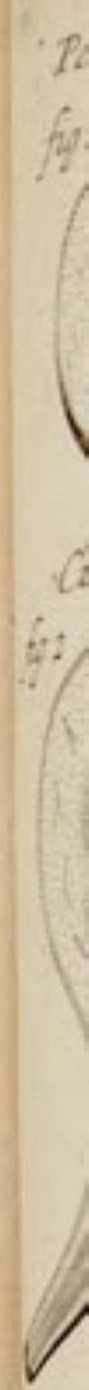
f. $\%$

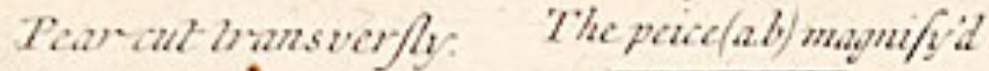

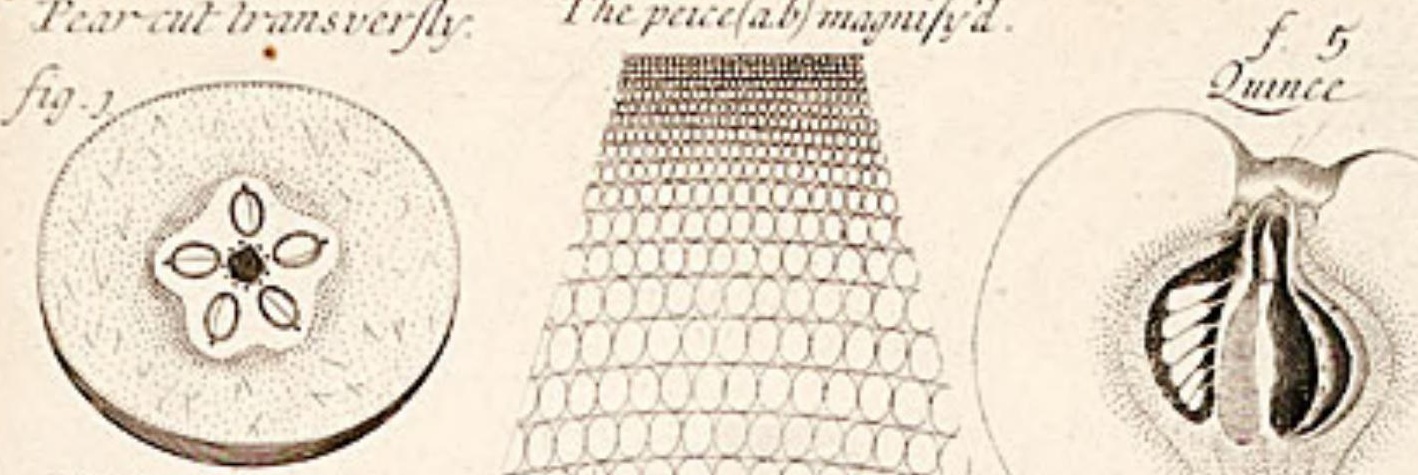

Cul by if $\mathrm{lonolh}$
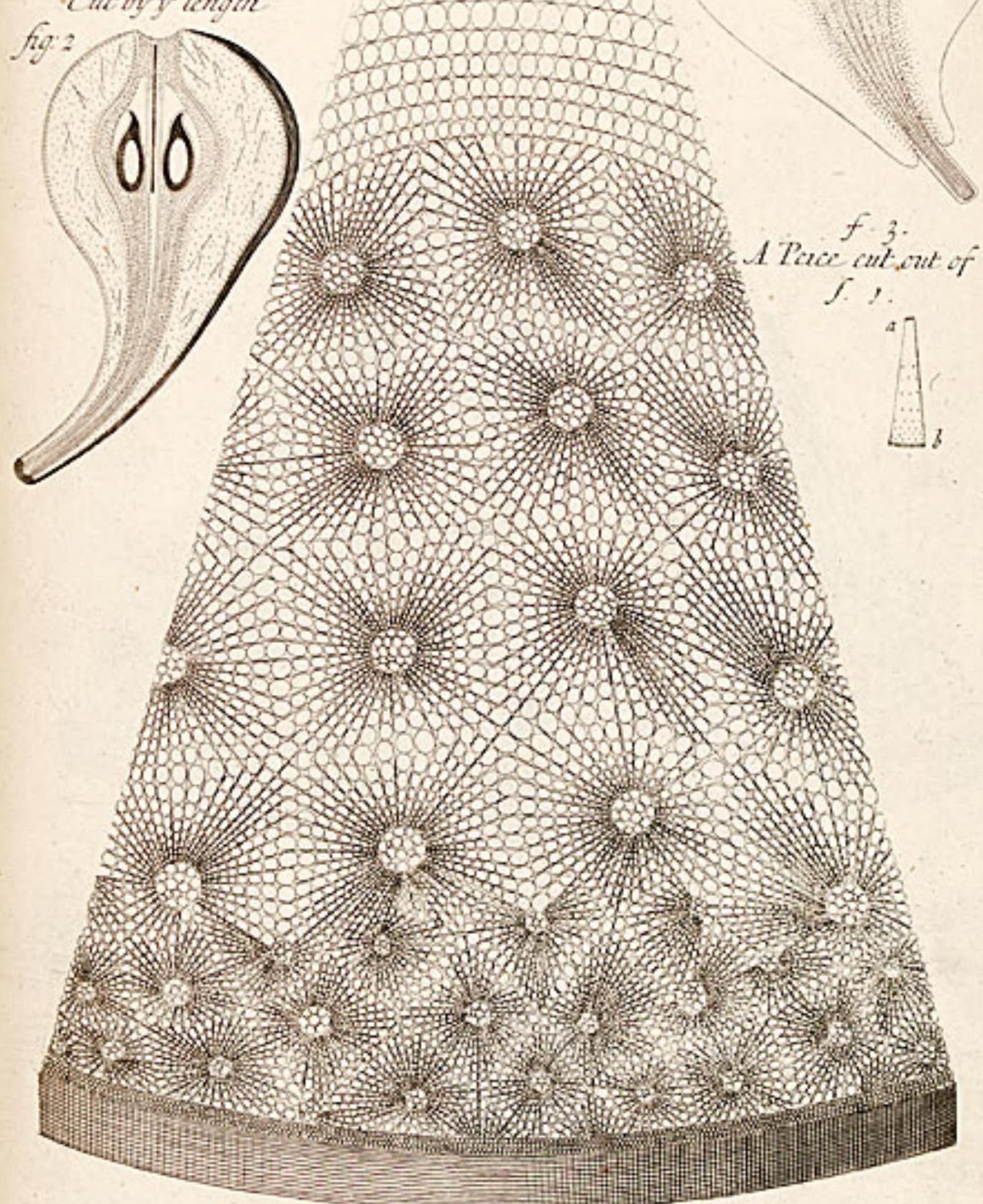


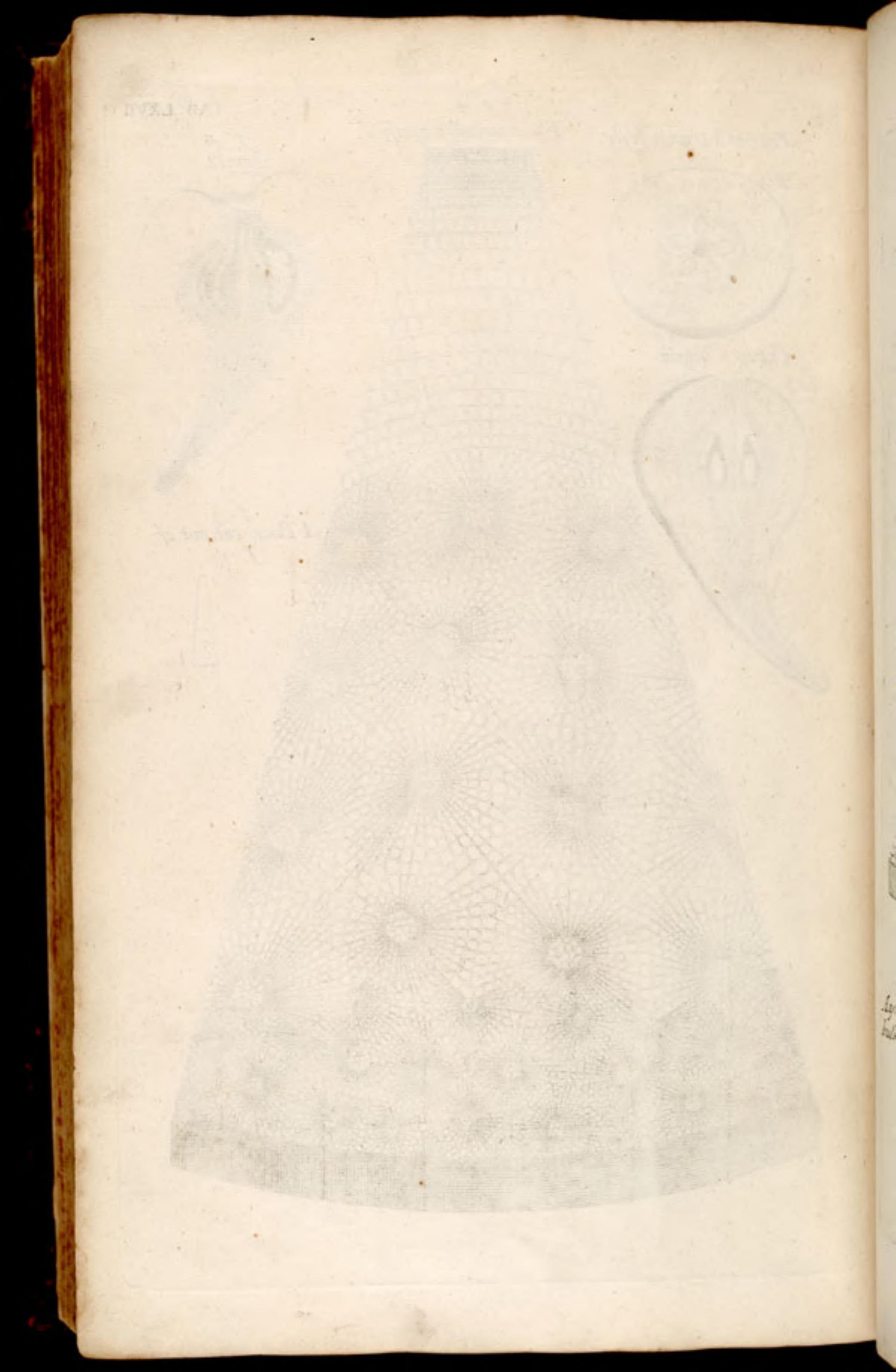





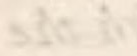


Tab. 6 .

f.3.

a Goosbony cut zoune.

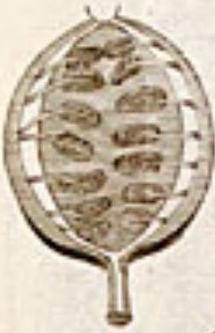

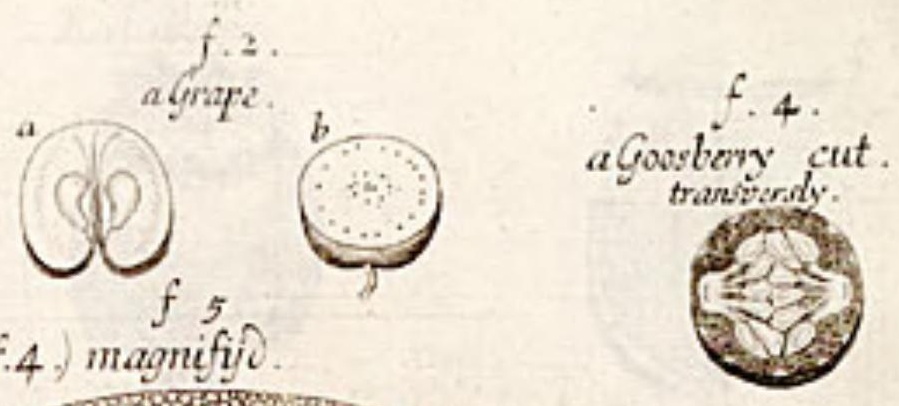

$60.0 \%$ (1)

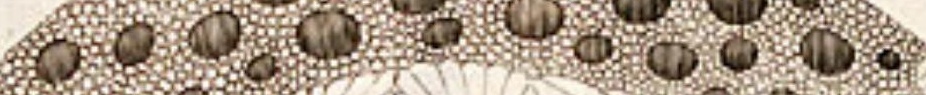

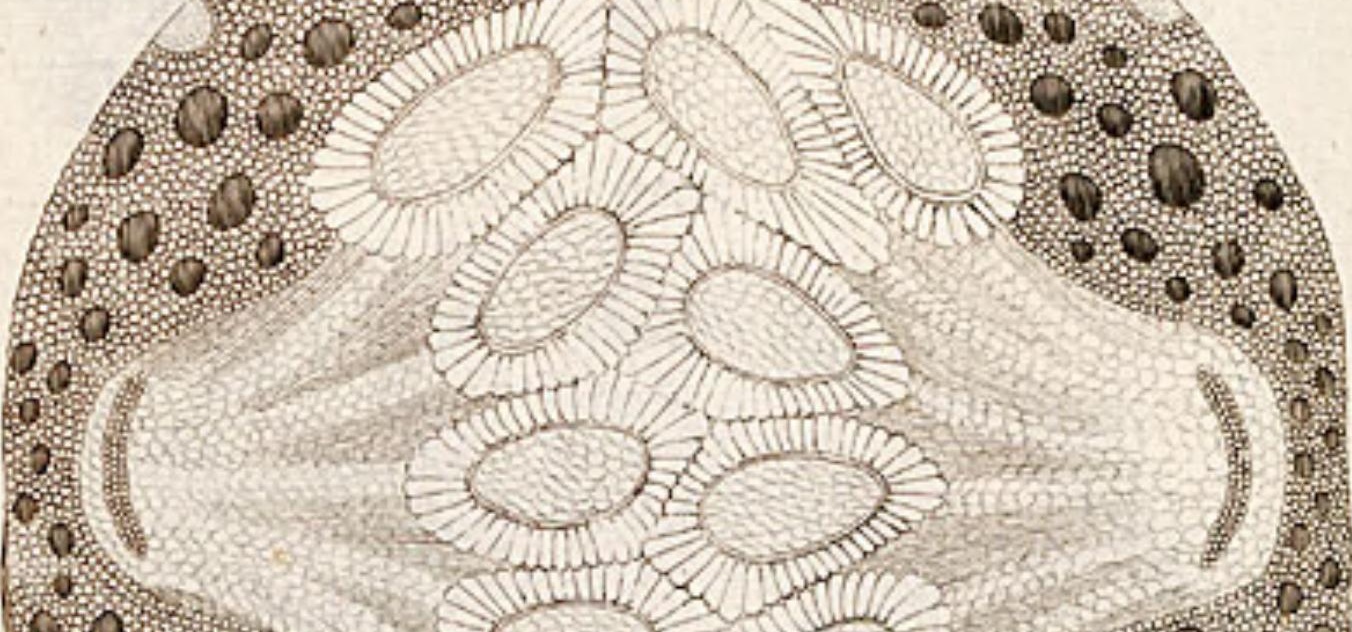

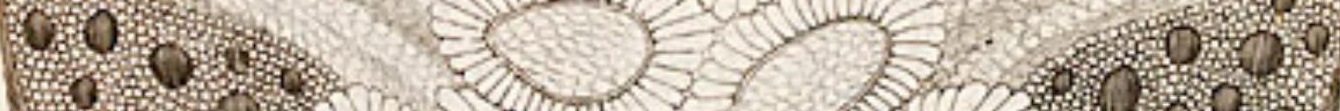
2. 2.

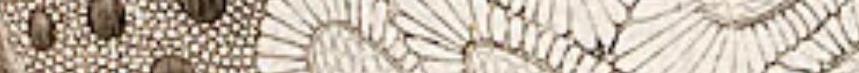

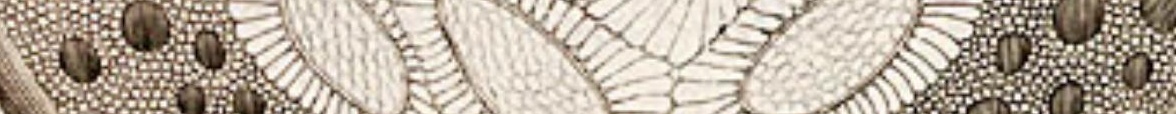

(

s.

(3)

1.

acharyuuvitin?

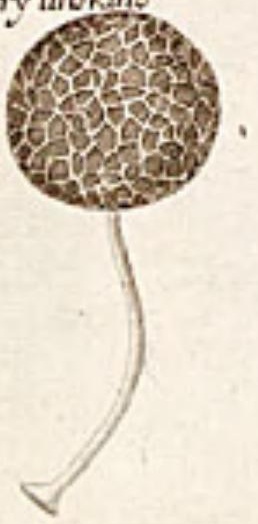

f.6.
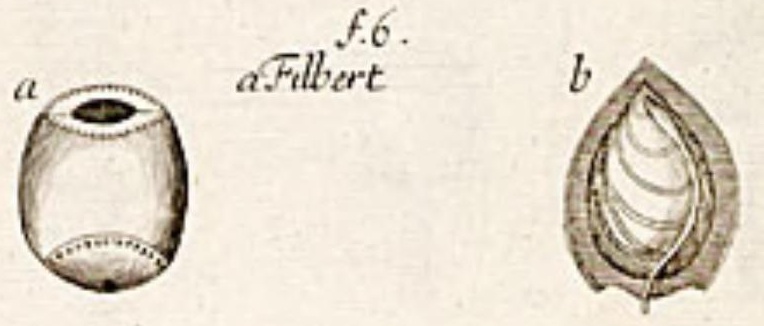


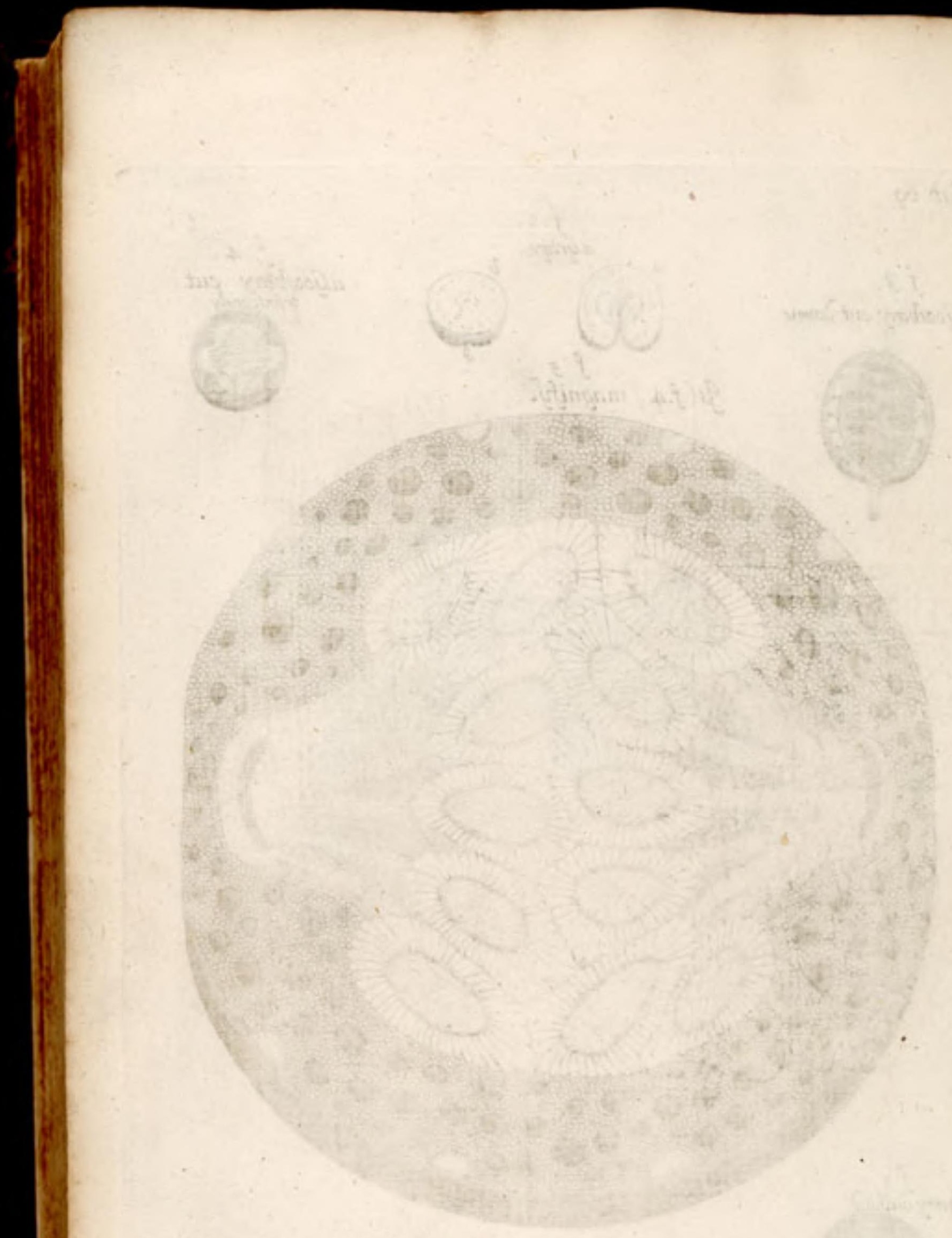




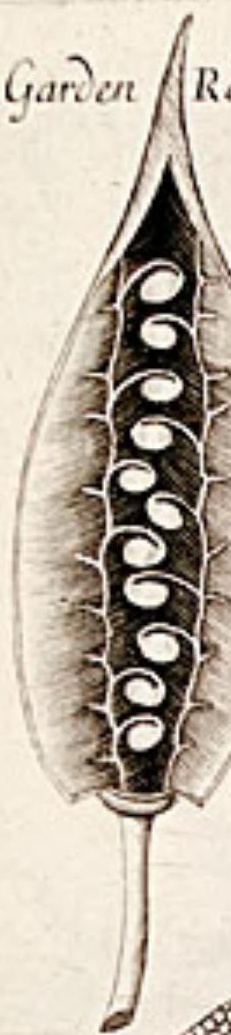

Sed-care of Red Poyy.

Tablyo.
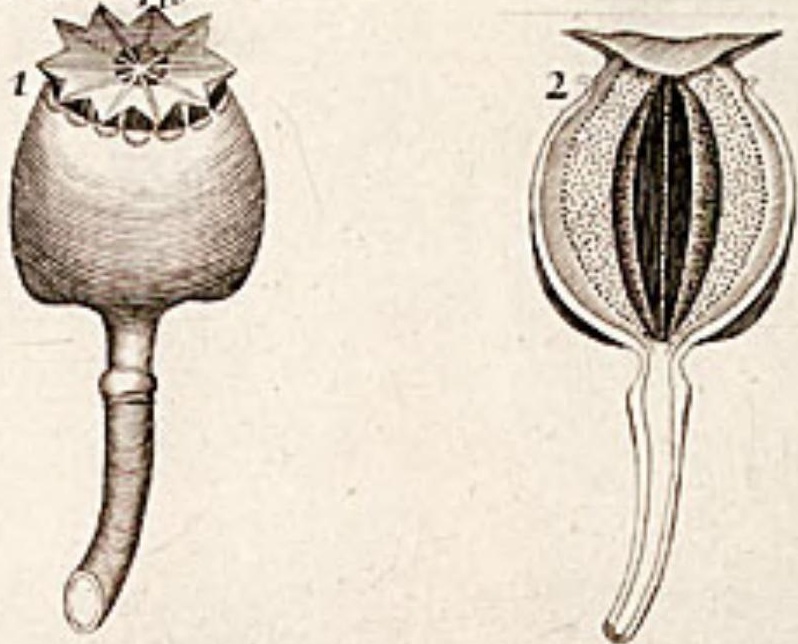

Garden Bean

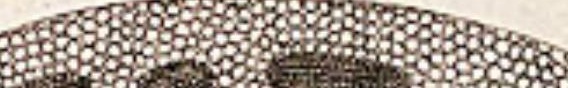

copeses
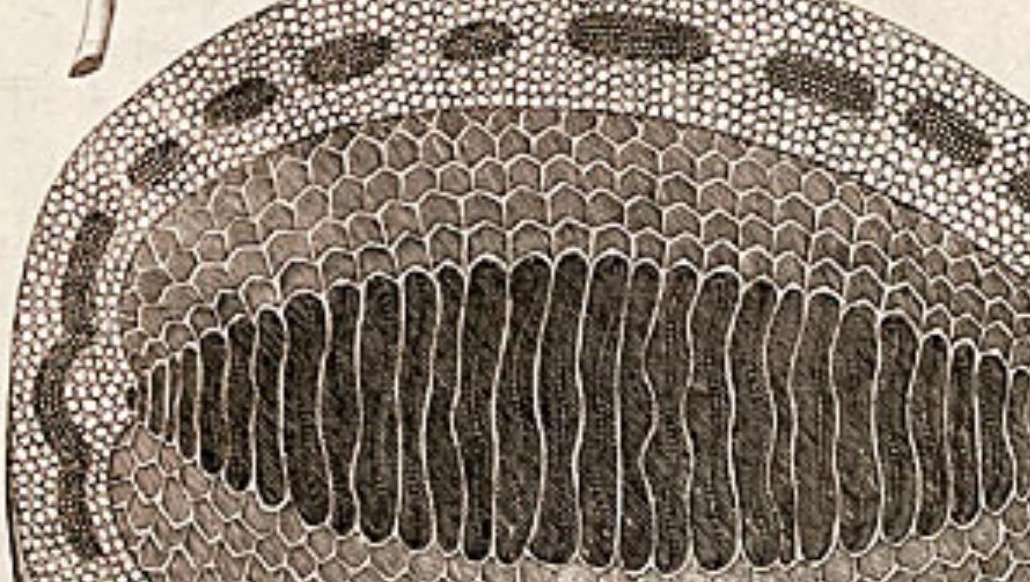

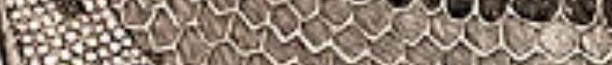

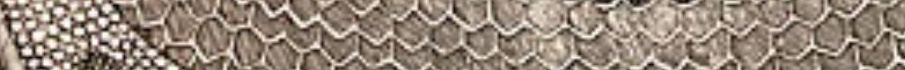

ranta

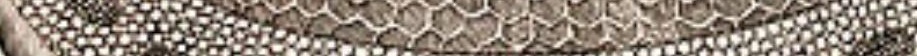

V

(4)

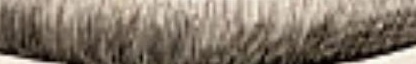

Yellom Henbeane.
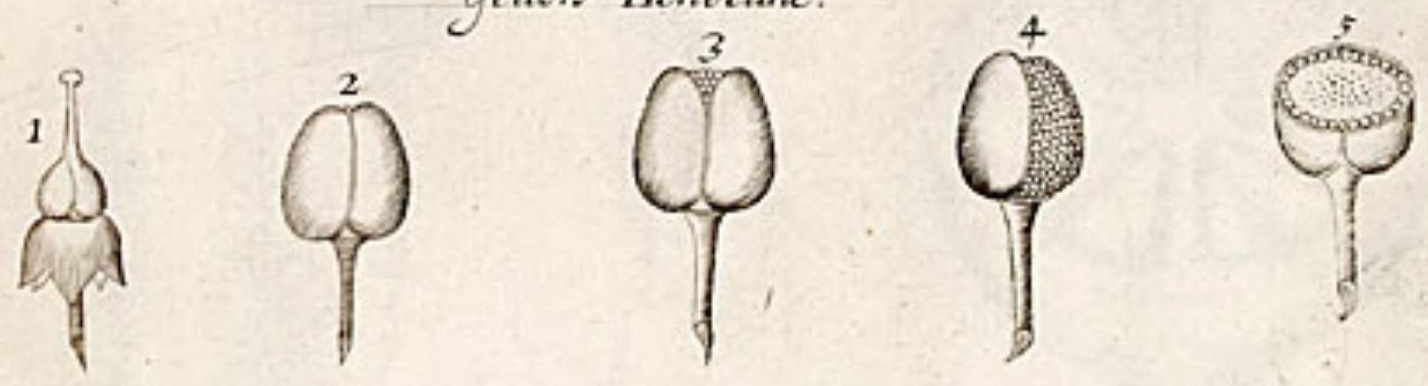


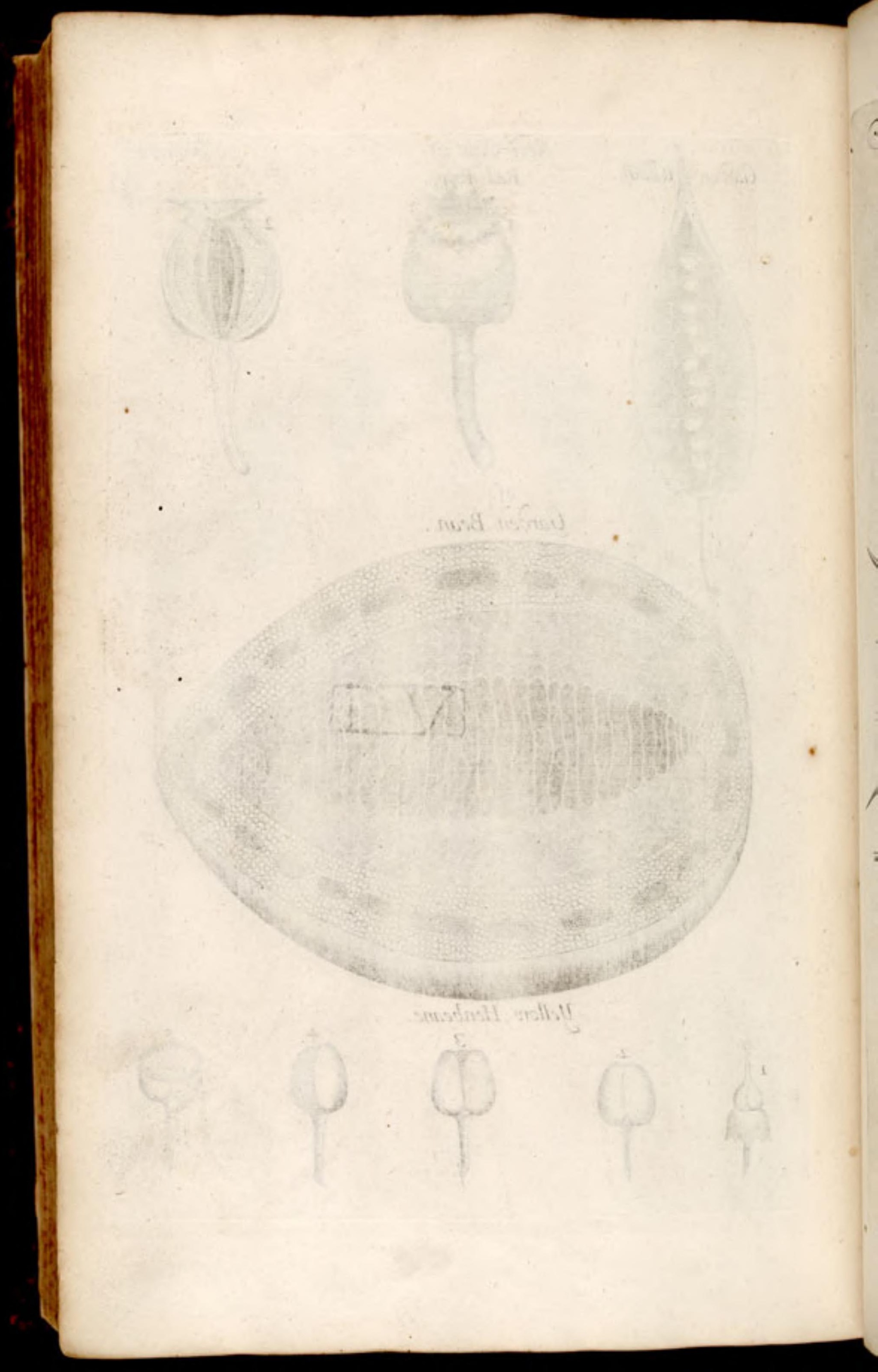




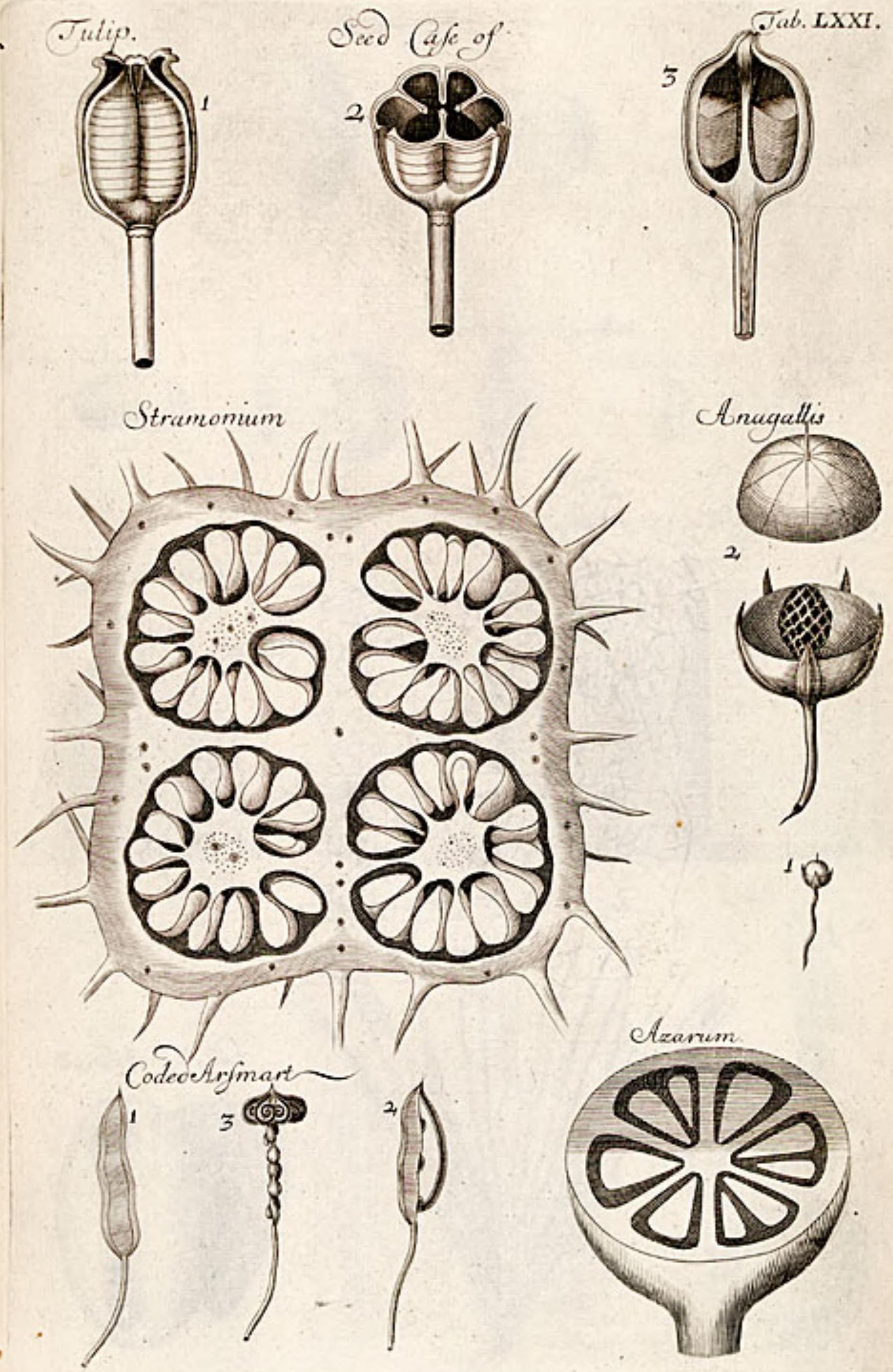





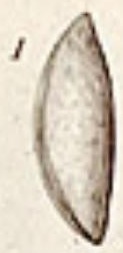

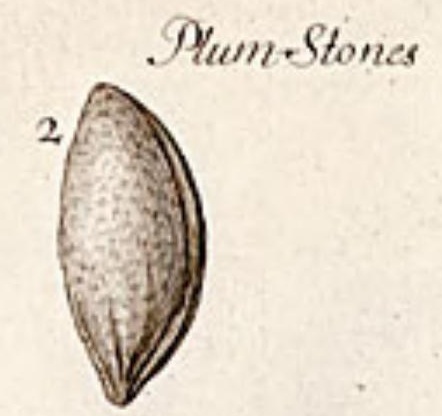

Fab LXXII

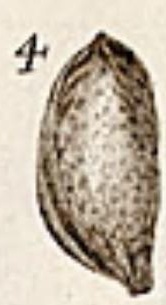

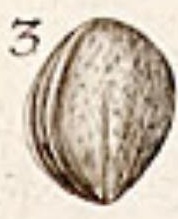

French- $\mathscr{B}_{\text {can }}$

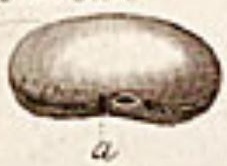

Scaf of Harls tongue

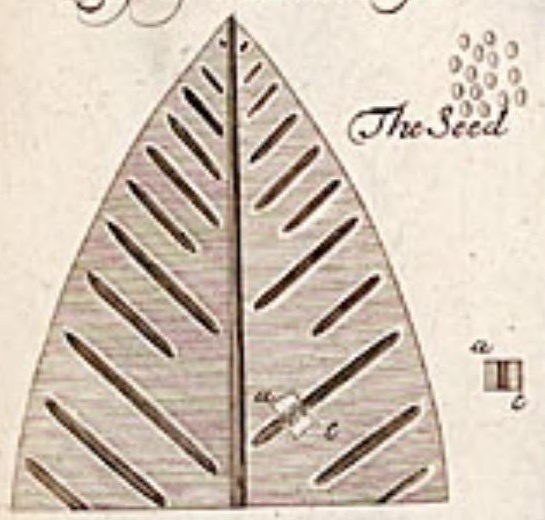

Chanut a Stone of Bellir:Mgrobal

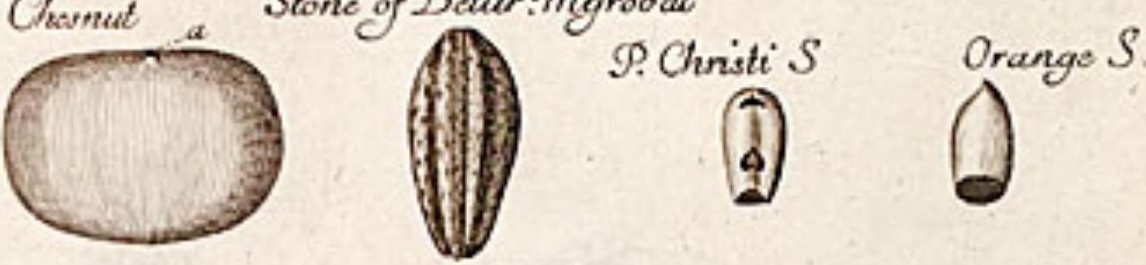

The imall piese (a c) taken out of the feyes somagnifyd

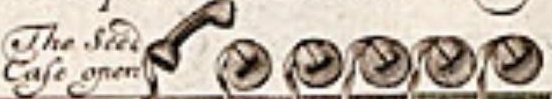

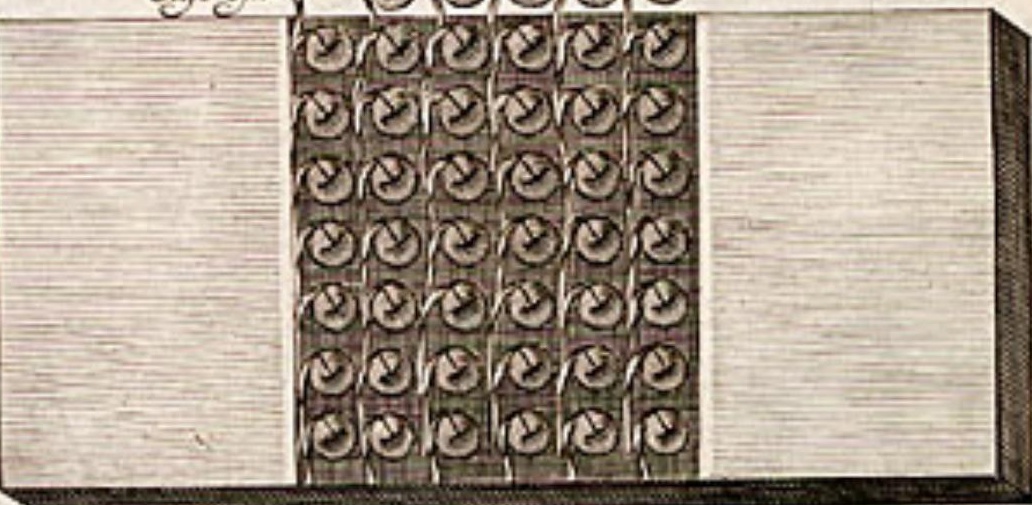

sed of Typha maior

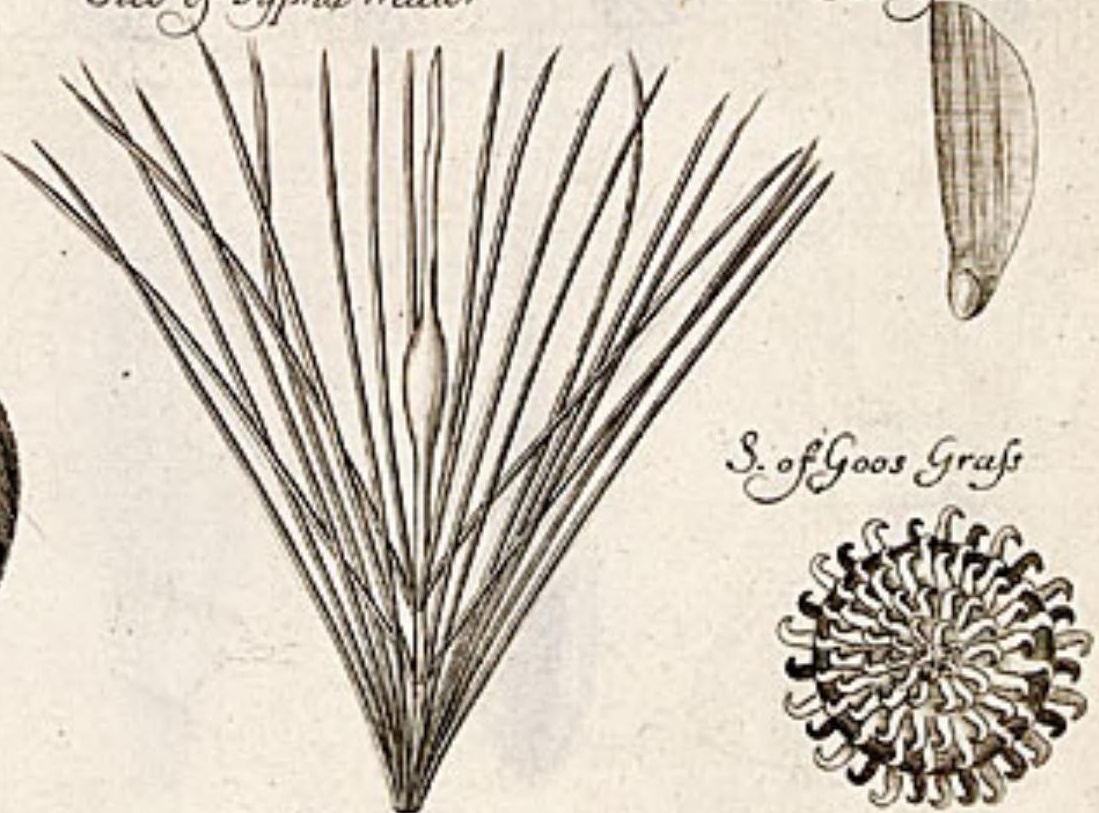


TA131.XXII

$$
\text { Secds of: }
$$

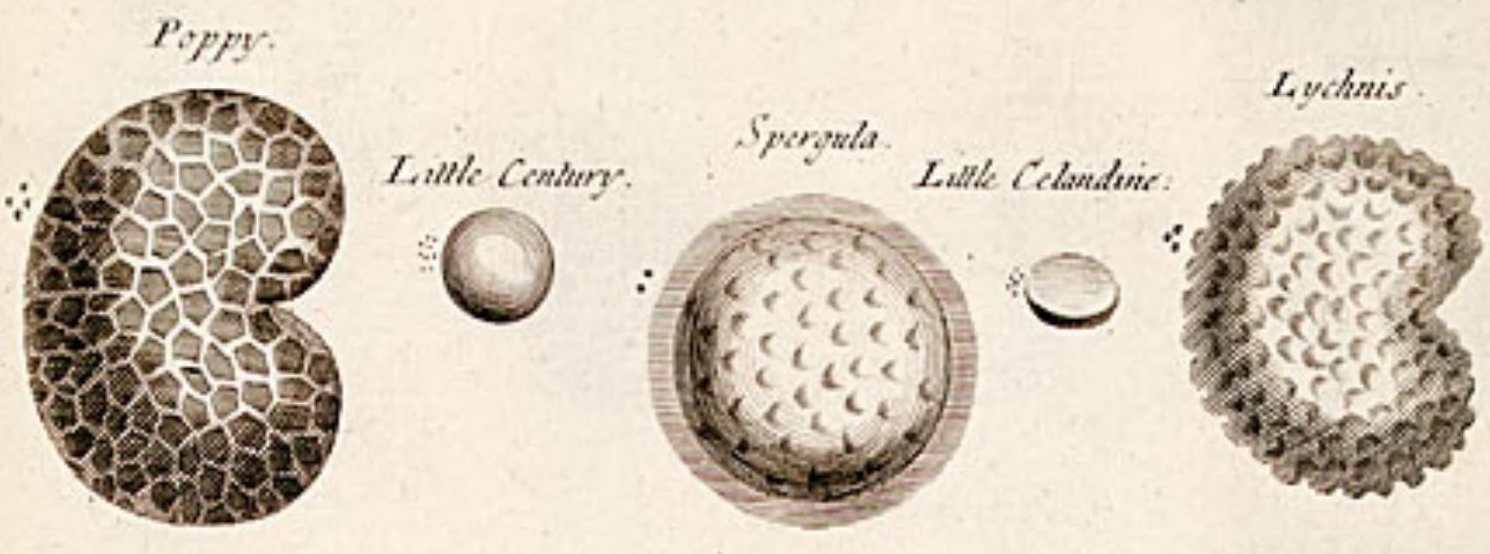

Grot Celantine
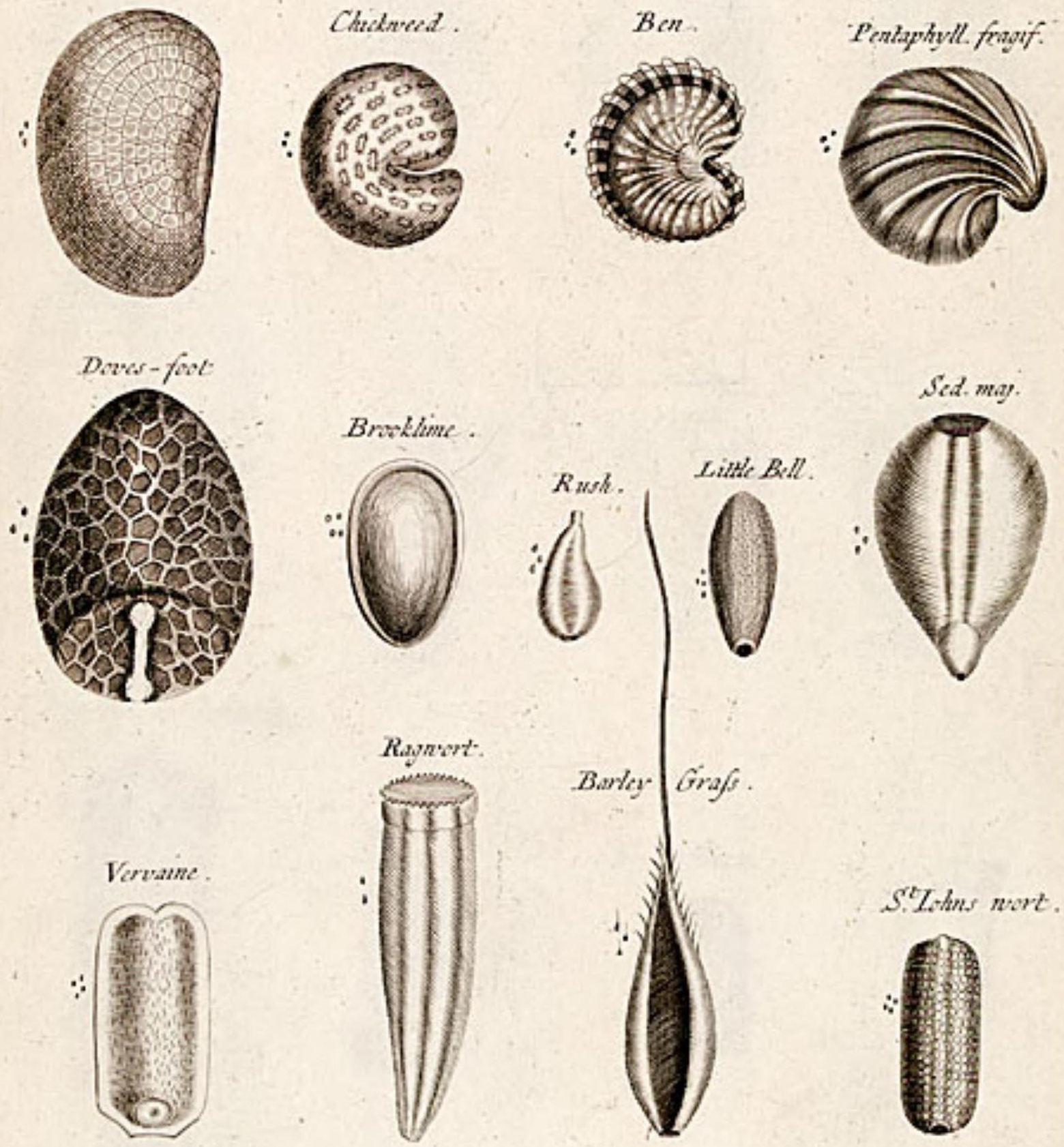


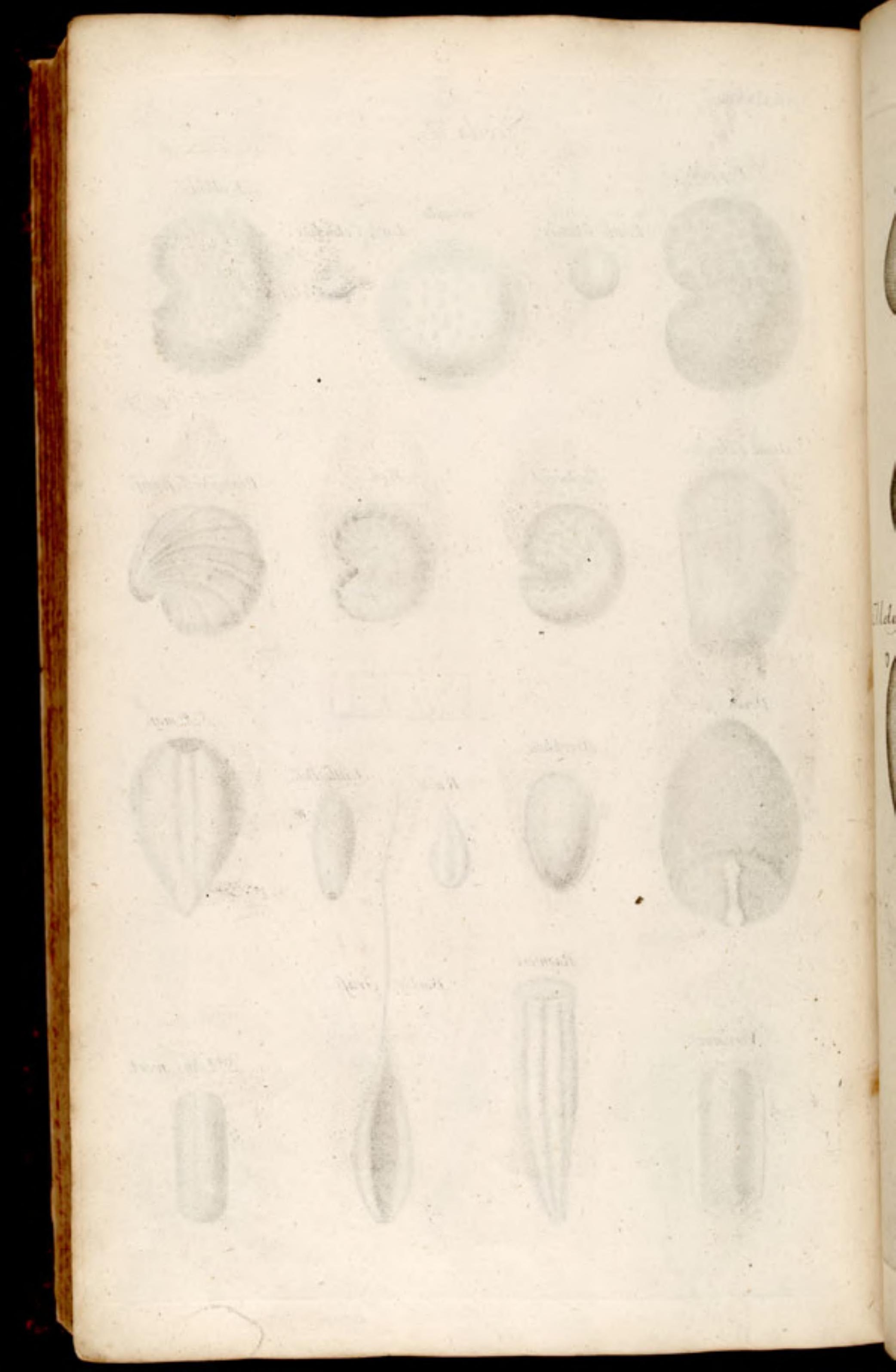




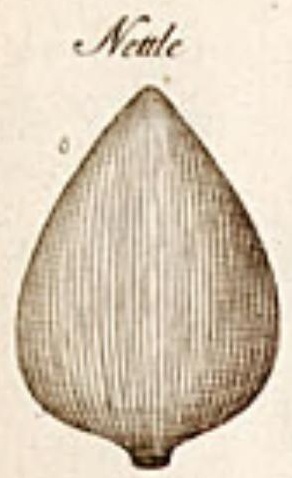

$$
\text { Etyebright }
$$

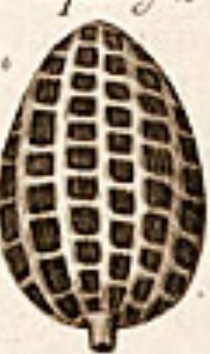

Syomeos

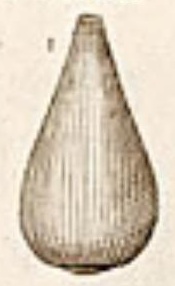

गवb LxxדI
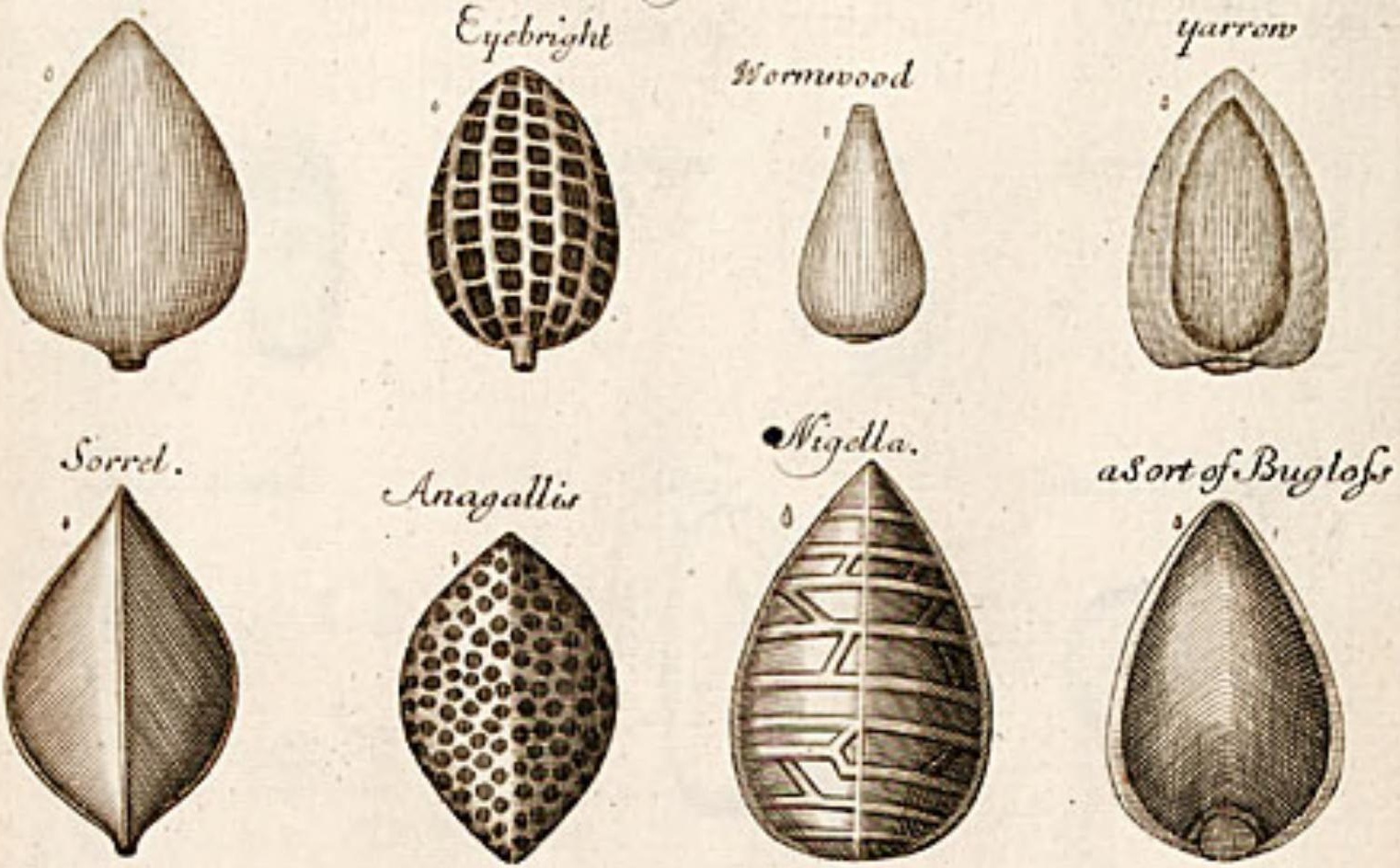

Ollifia Moldavioa.

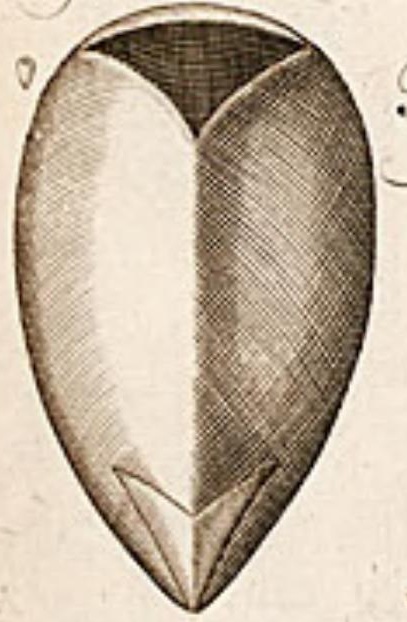

Bcllis Tanaceti folio annua.

Stächas Arabiza.

Fiartiont.
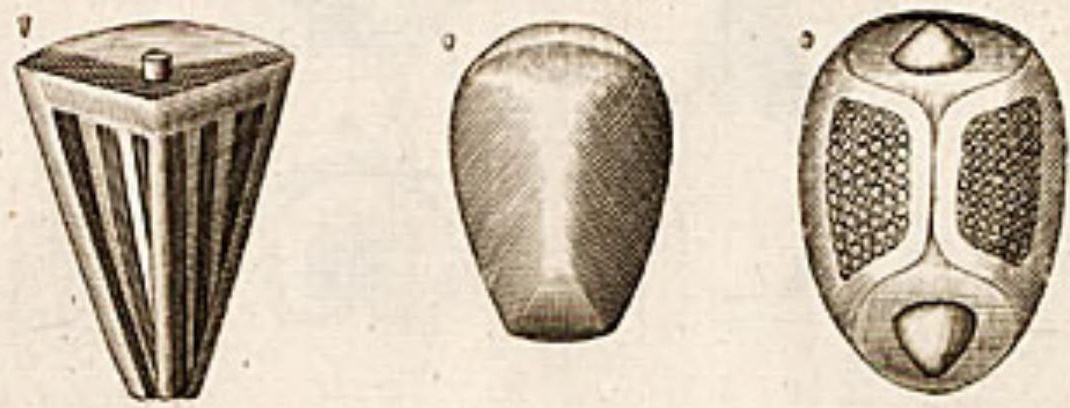

Chyfanth: Amerie:

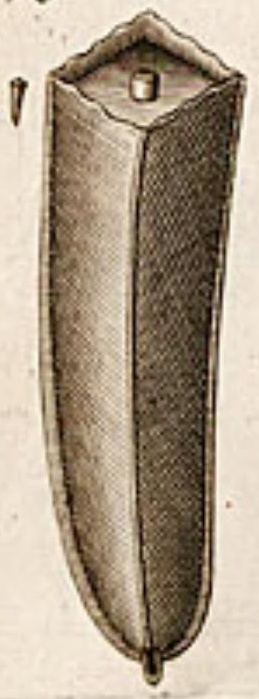

Blattaria.

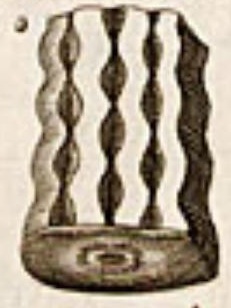

Frose Glove.

Tansey.

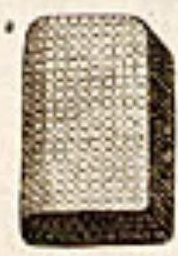

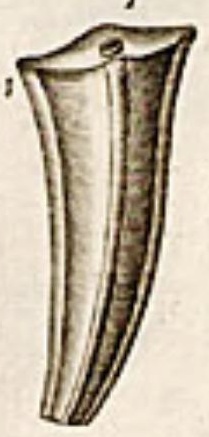



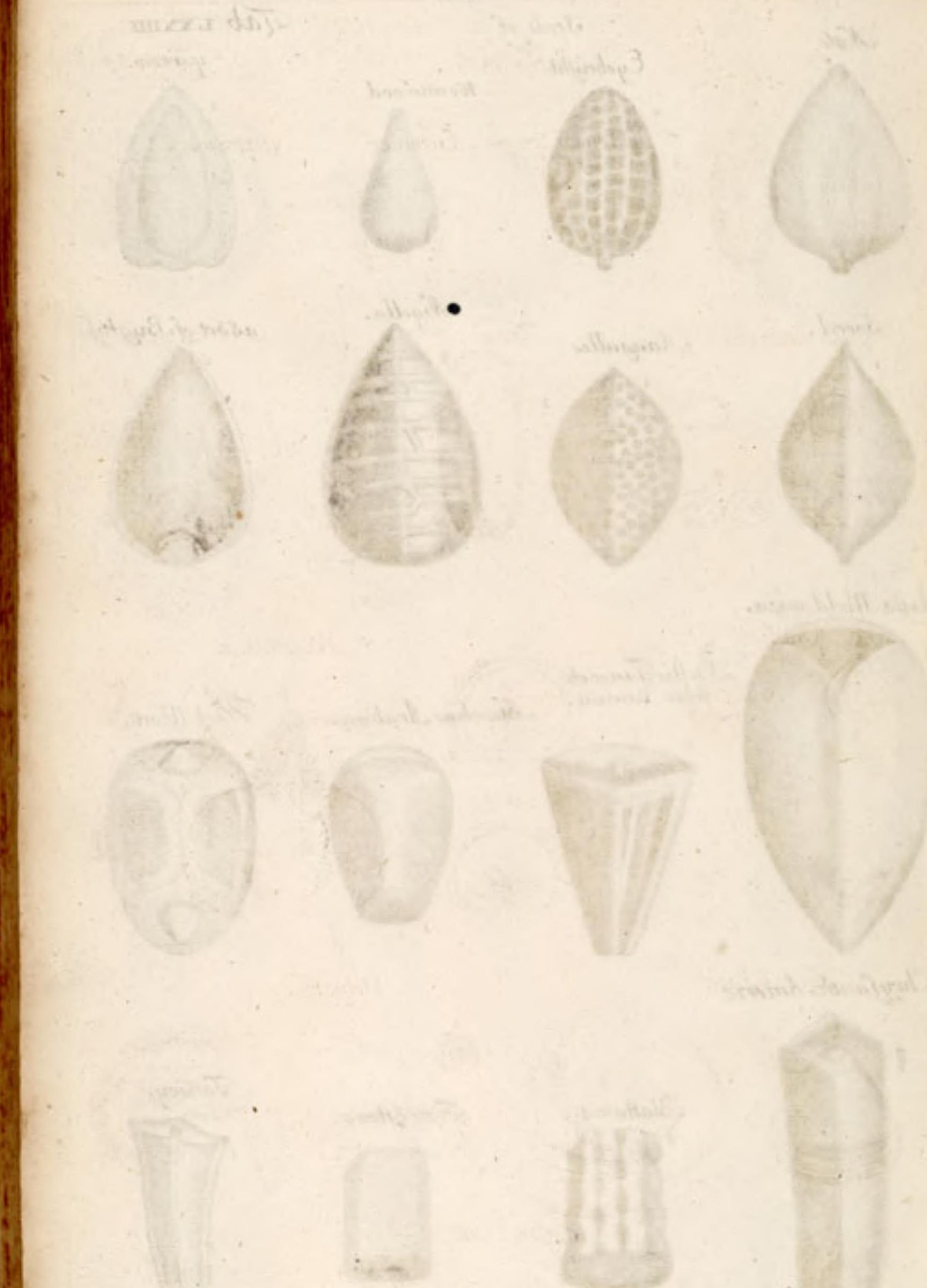
Date. : Seeds of

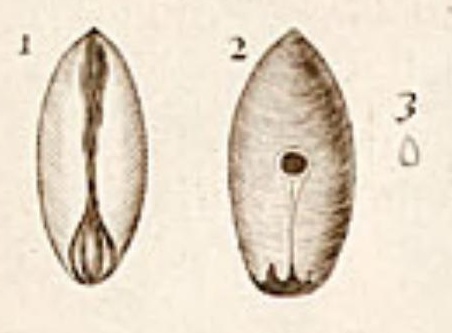

Viola lunaris.

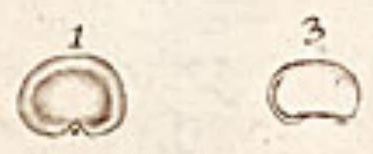

(
Hounds tougne. Cucturer.
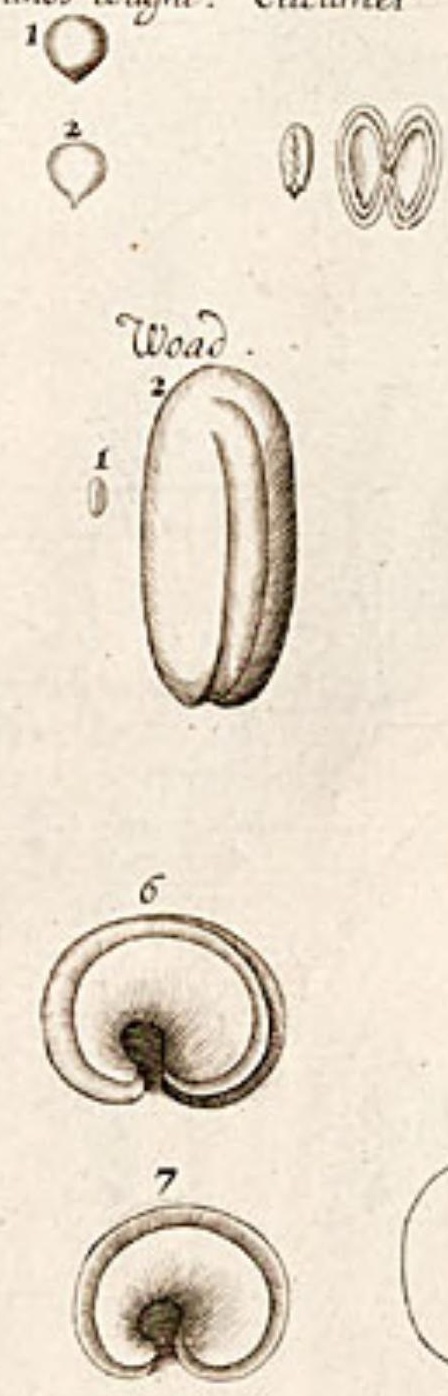

Tab: 75 :

ferzonera.

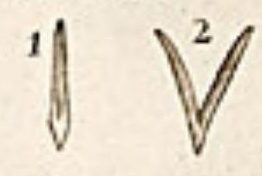

Grat blew Lupine.

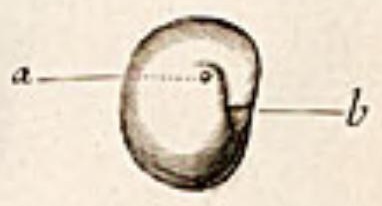

Rhapontick

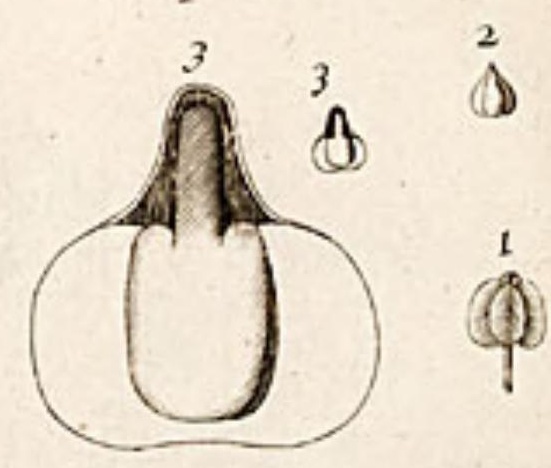

Holyoak

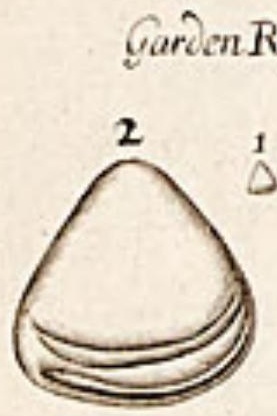

ish

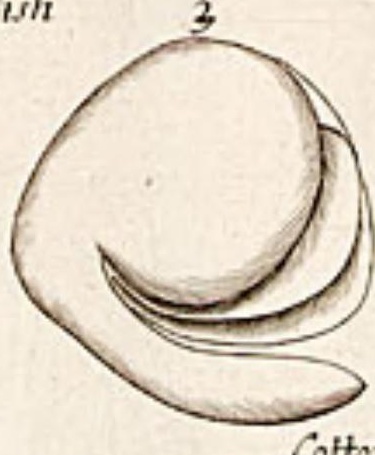

穴

高台向

के

Colton Plant

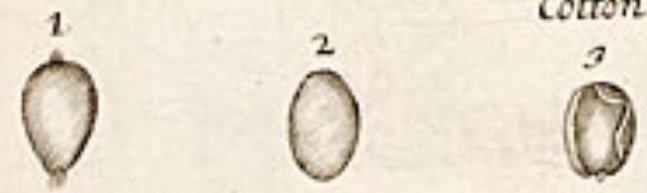

(4)

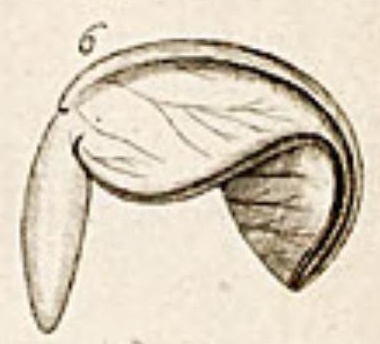




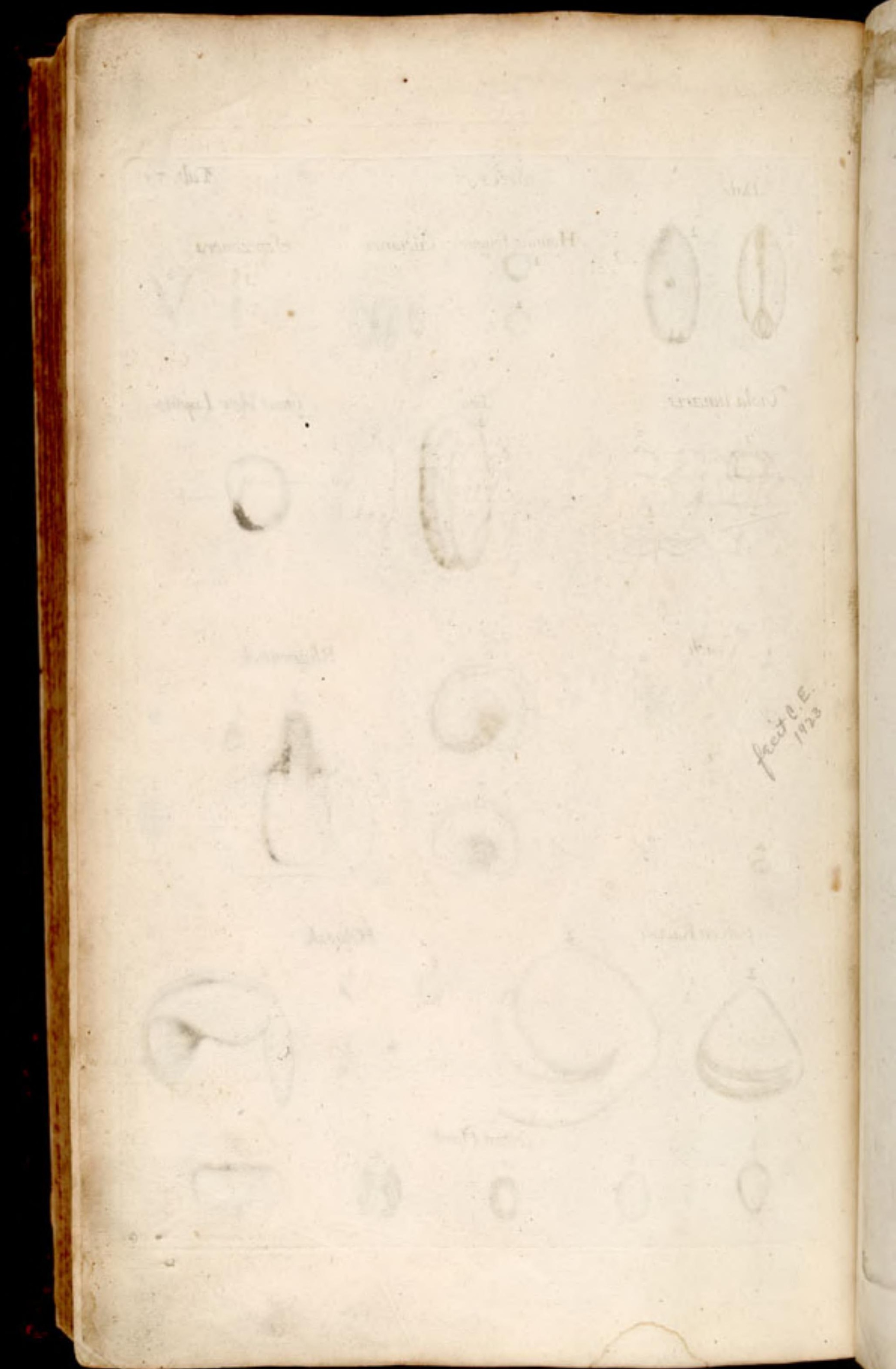


$7 a b:>6$

Secels of
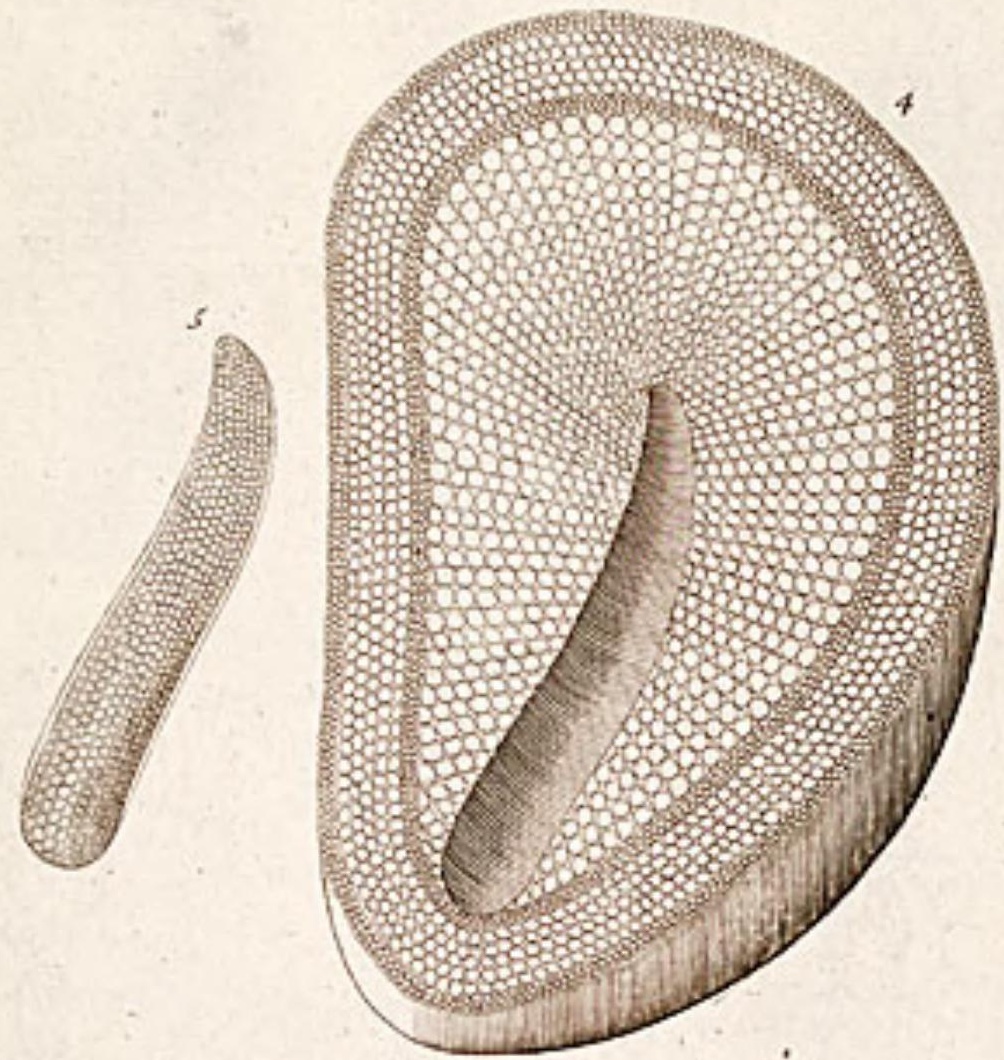

Flag

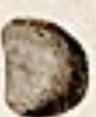

(Q):

(1) (D)

Rursing Ingola-Nut
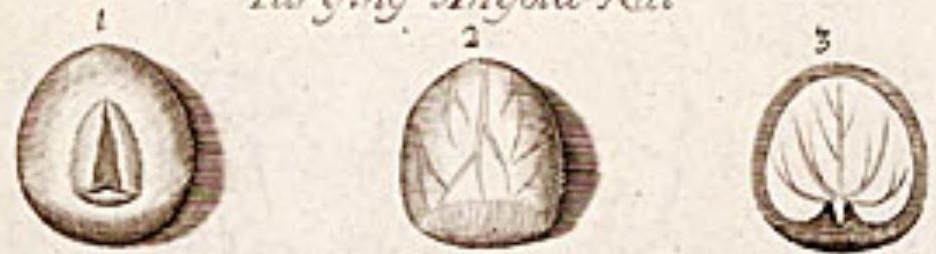

$(1 / 2)$

Rurging Bermbado-Xut
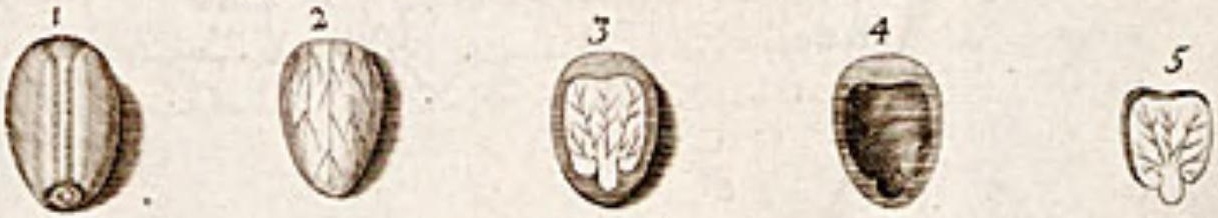

Ricinus Americanus
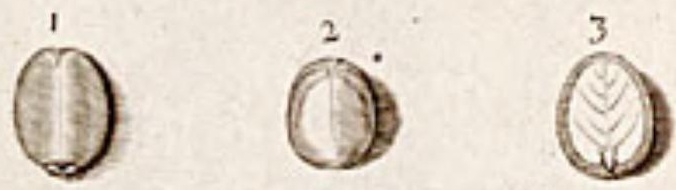

랄)

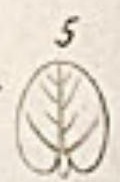

Nux 2onica oficin:
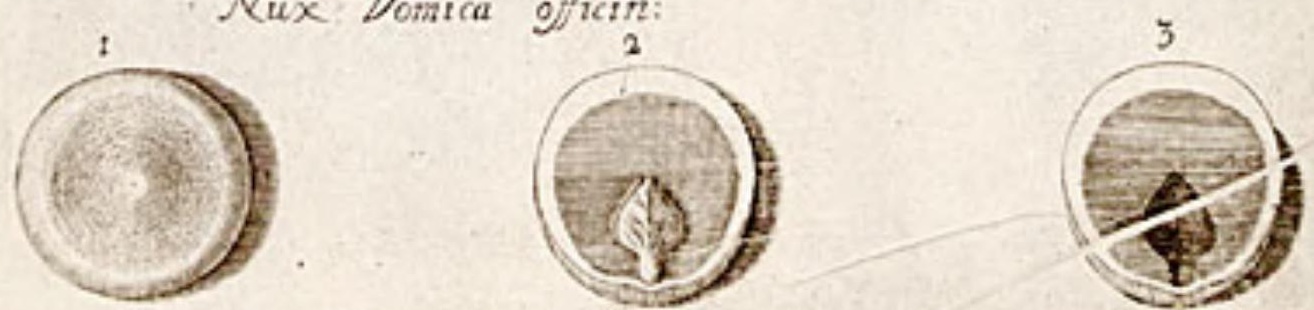

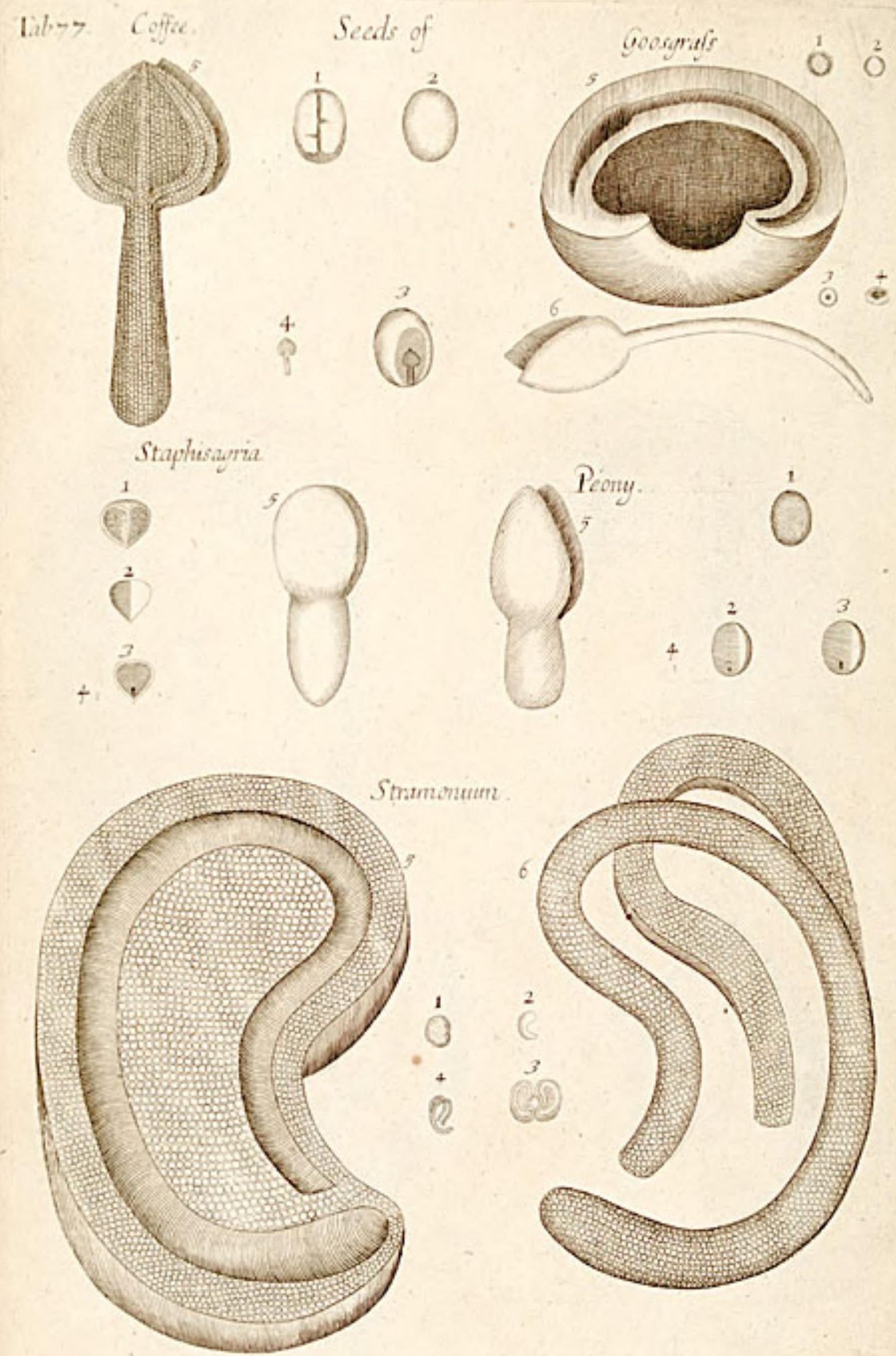
$\Im_{a b} \cdot 78$.

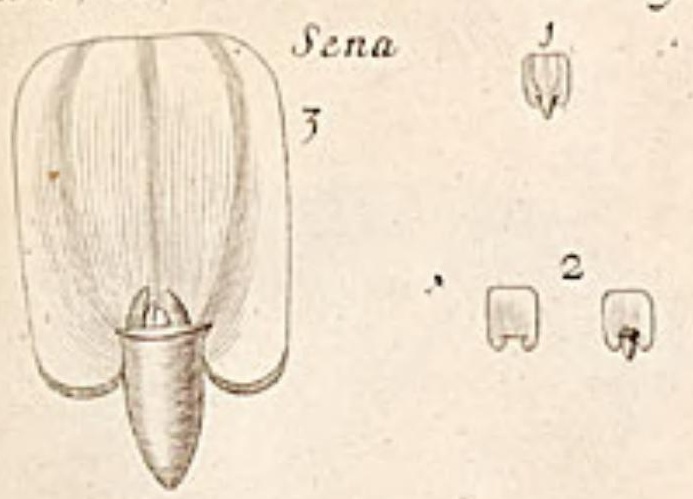

Hemp
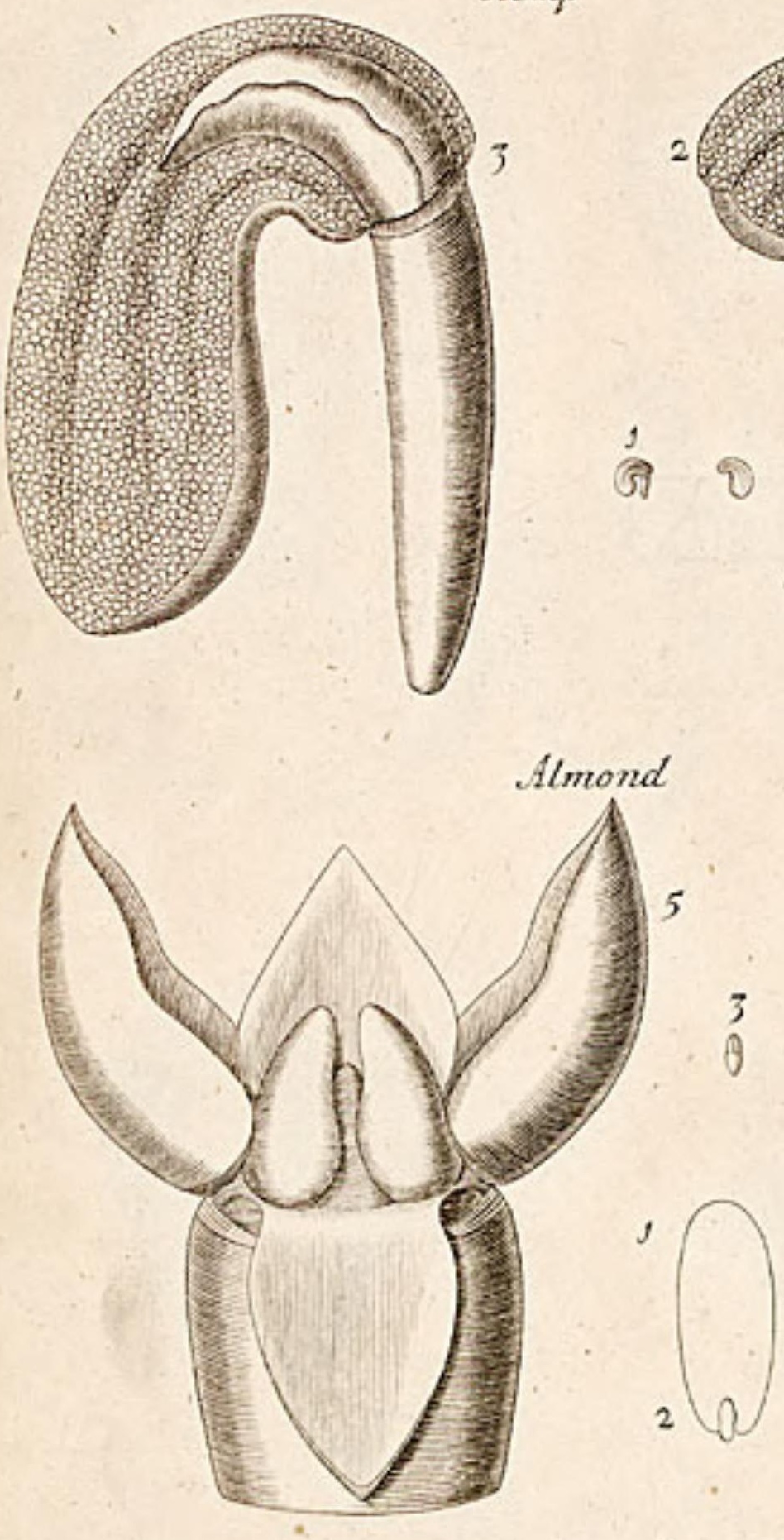

Cardtus bened
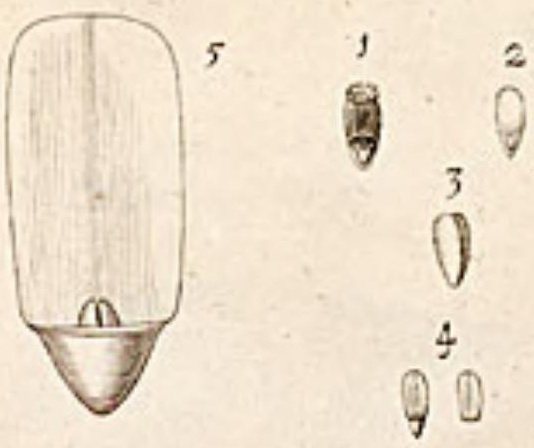


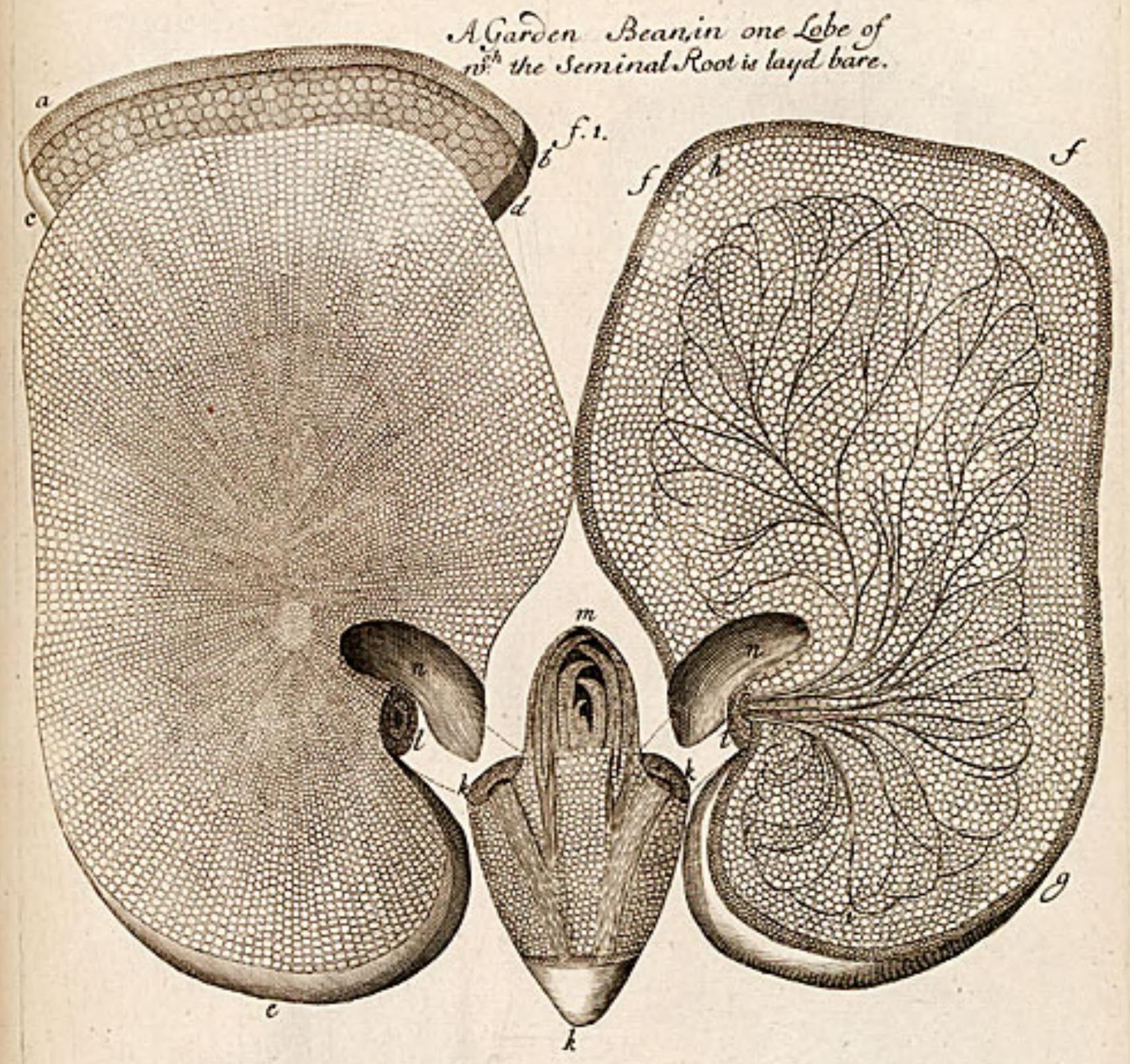

The Radide cut trans versly.
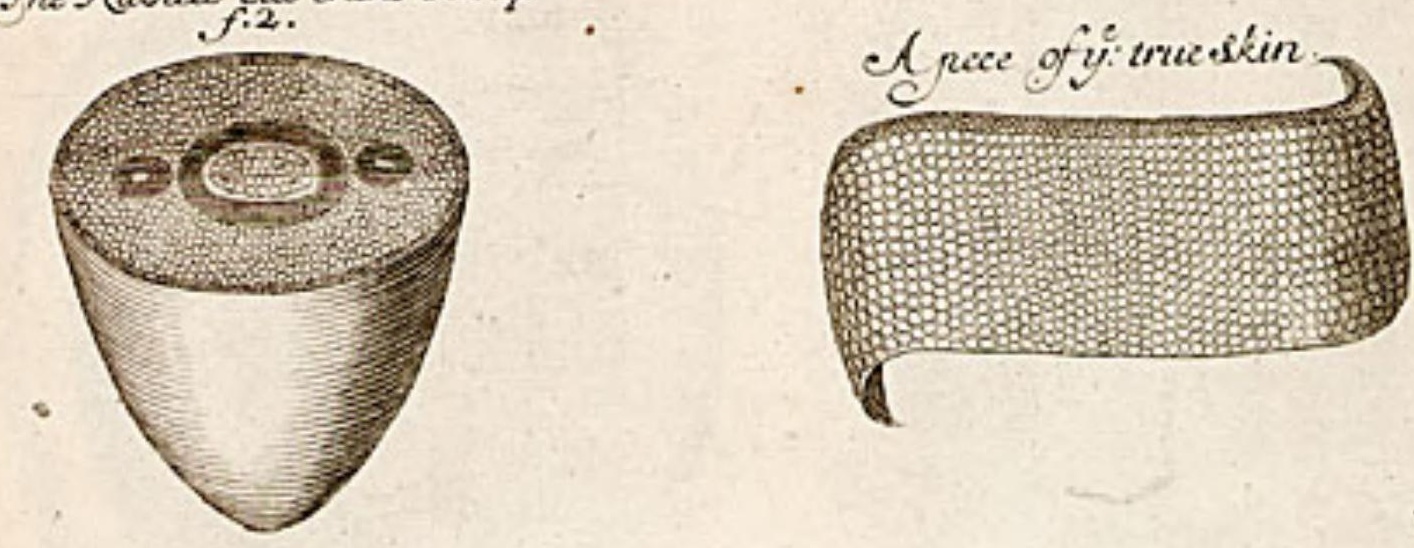


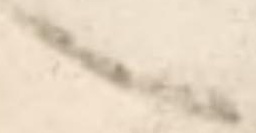

- tánaran 

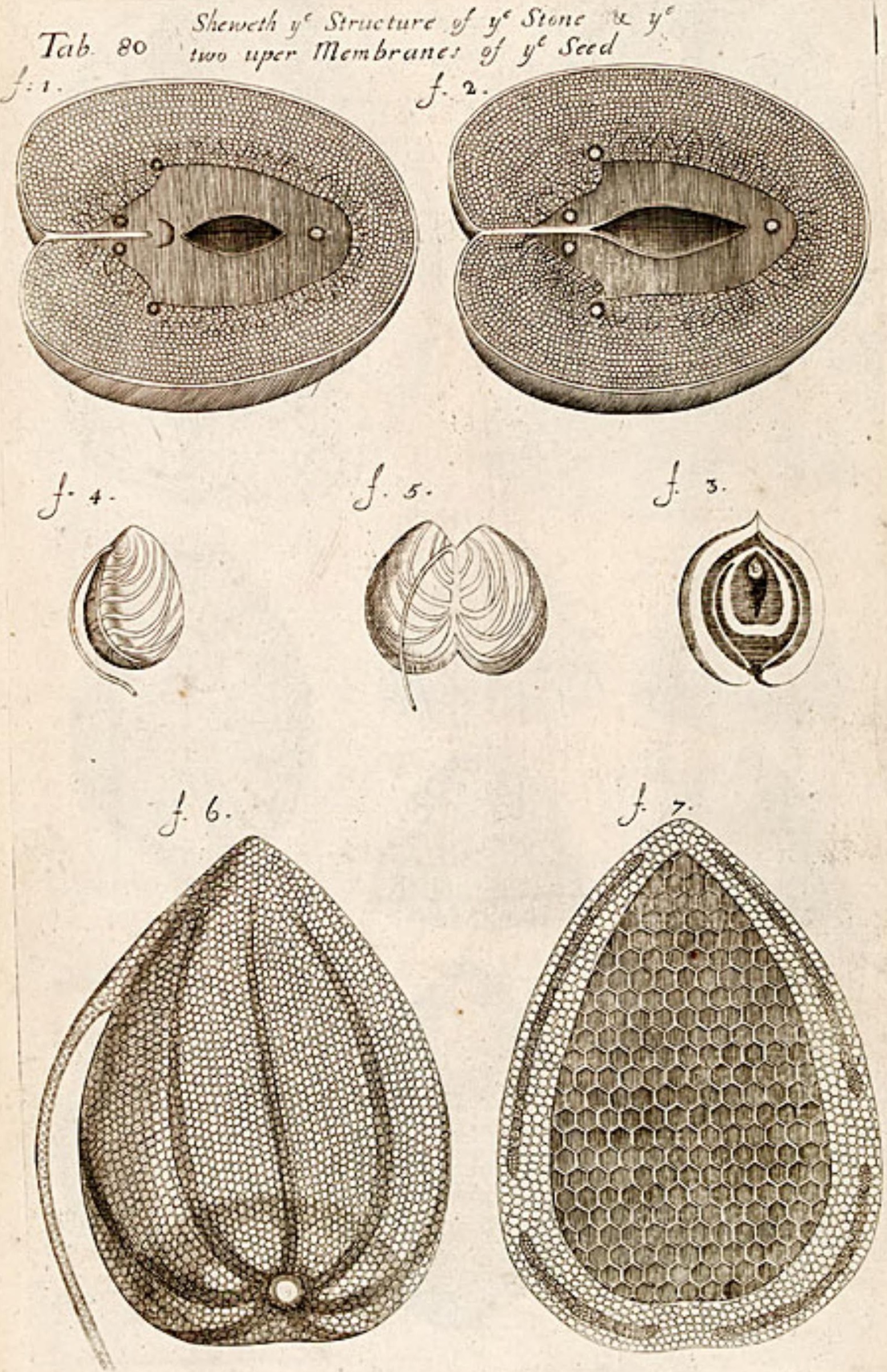



$$
\text { पab. 8f. }
$$

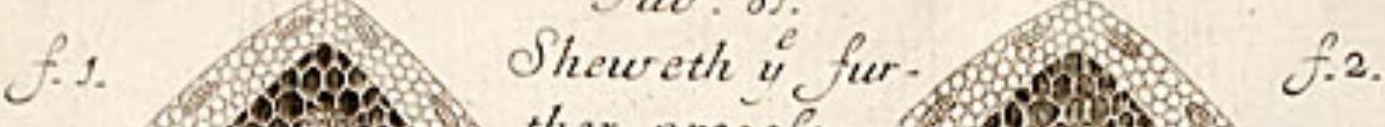

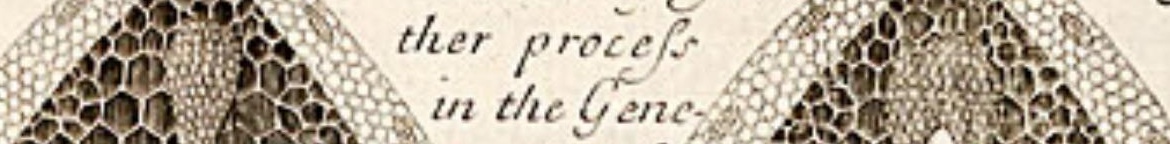

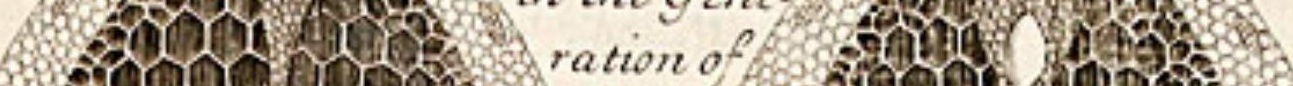

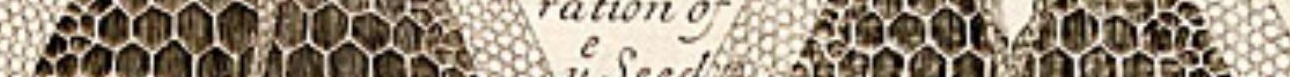

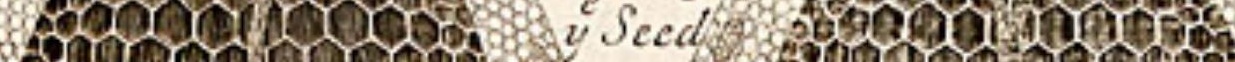
onorerom E001 mon
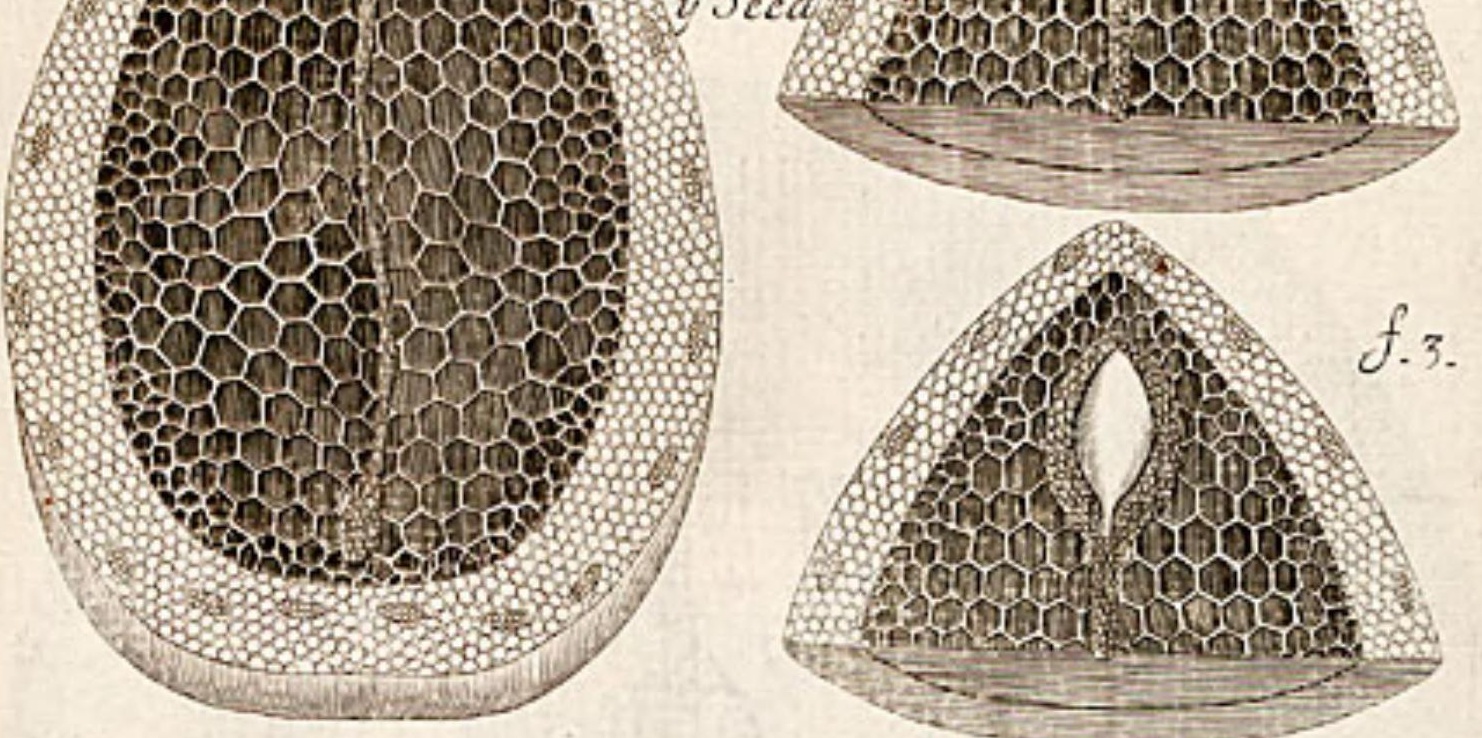

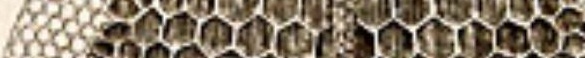

f. 1 .
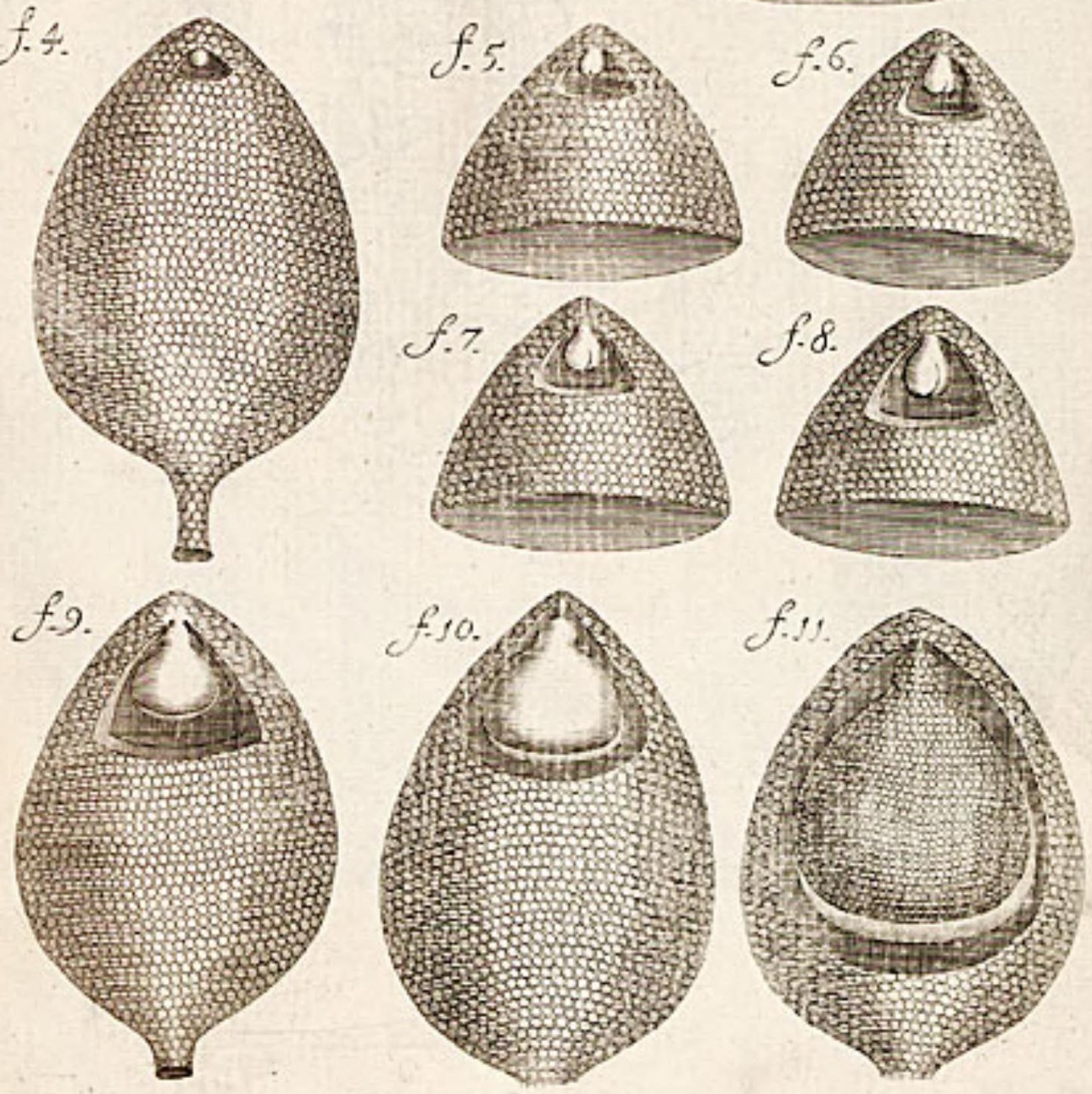


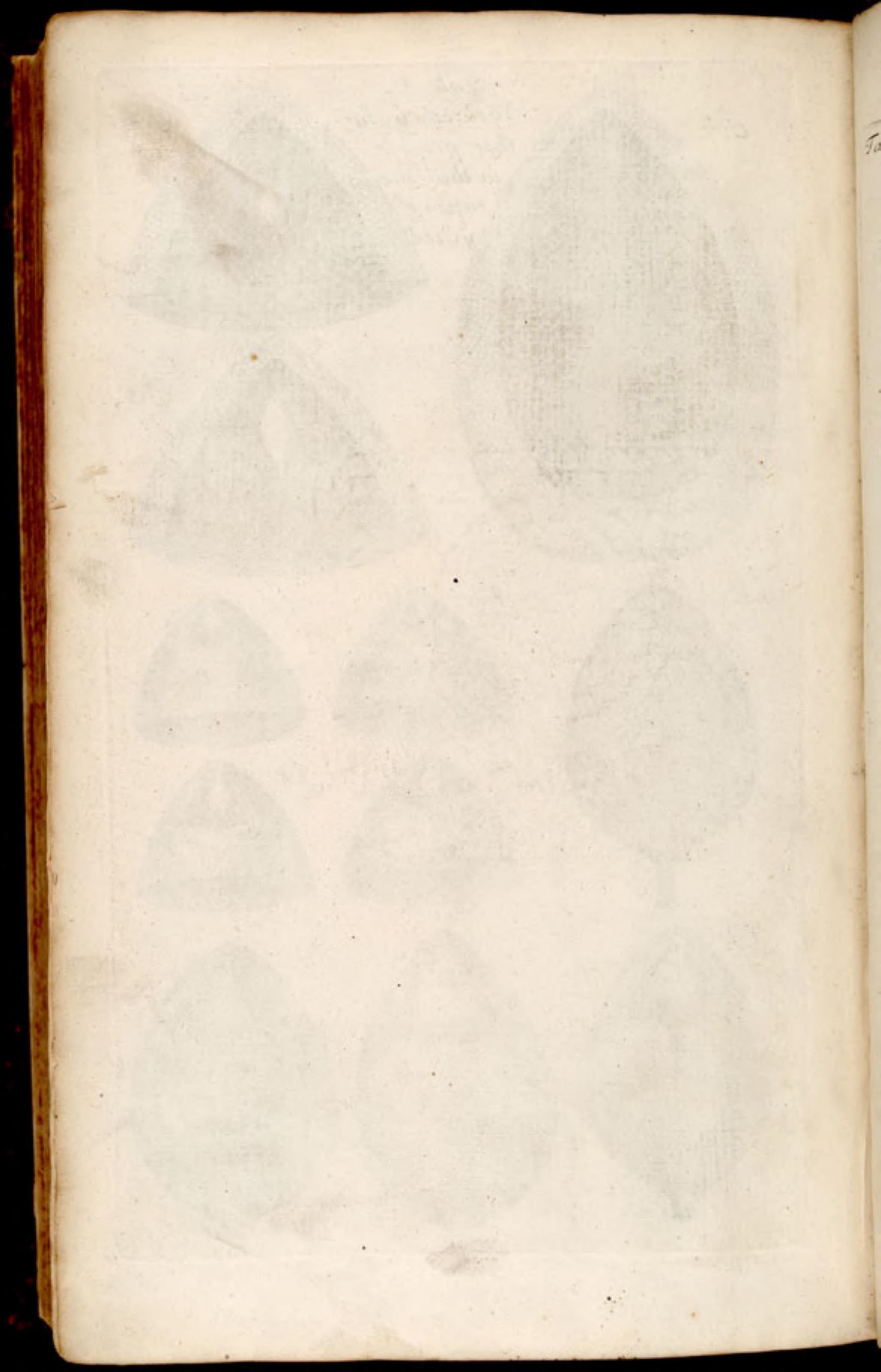


Tab 82

The young Fruit, Theas Menbranes, \& clead now looje,

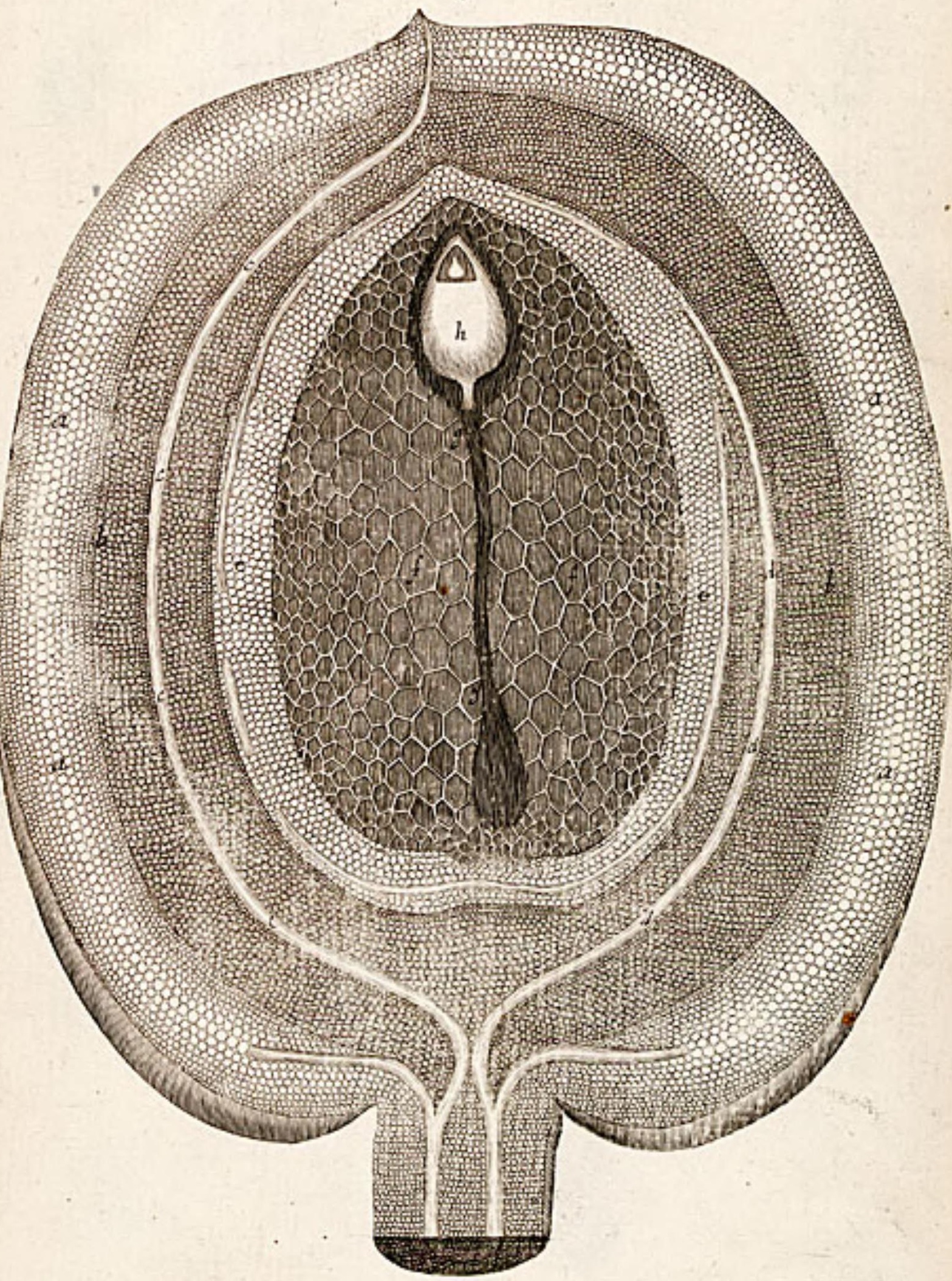


Tab. 83

Errent: Salts of Plants.
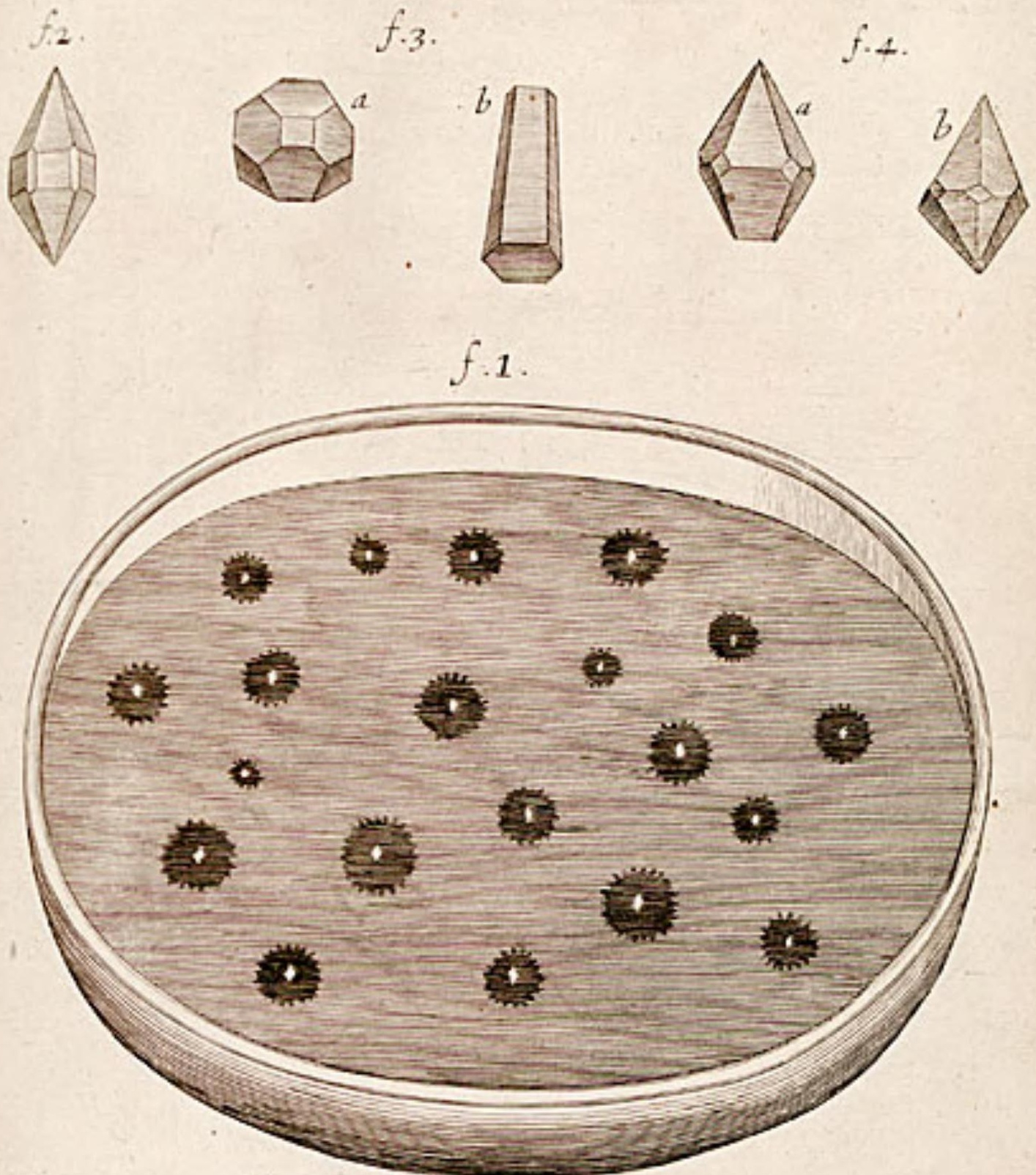

f.5. Manne Salts of Plants.

$\sqrt{i n}$
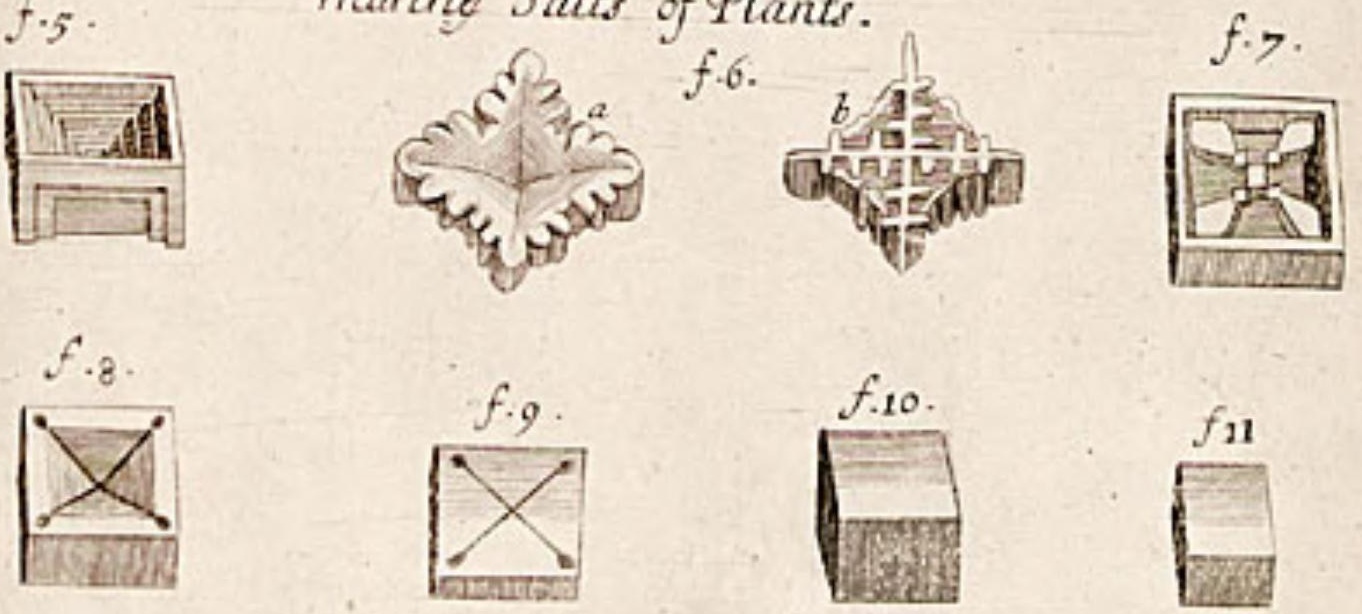


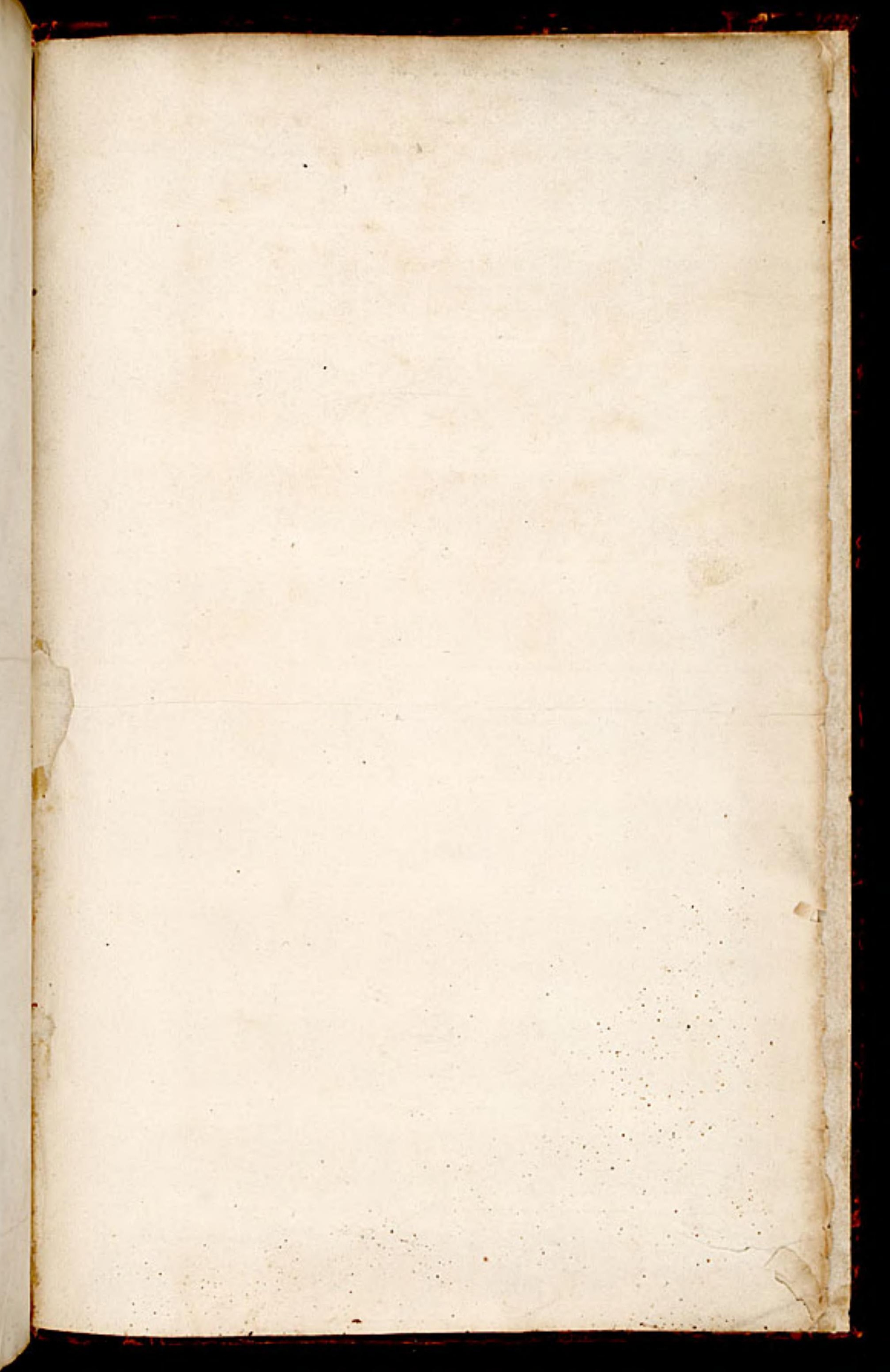




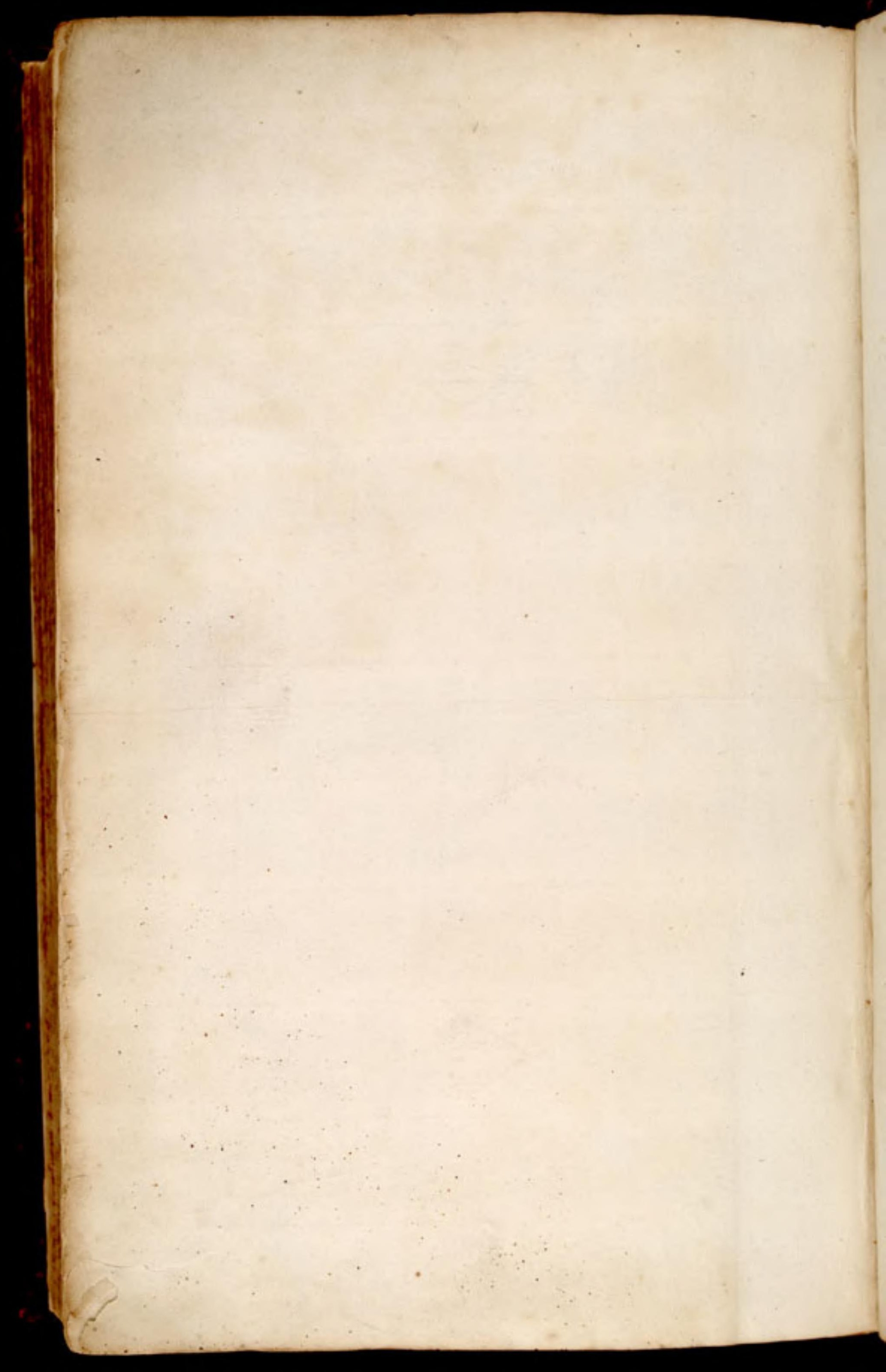




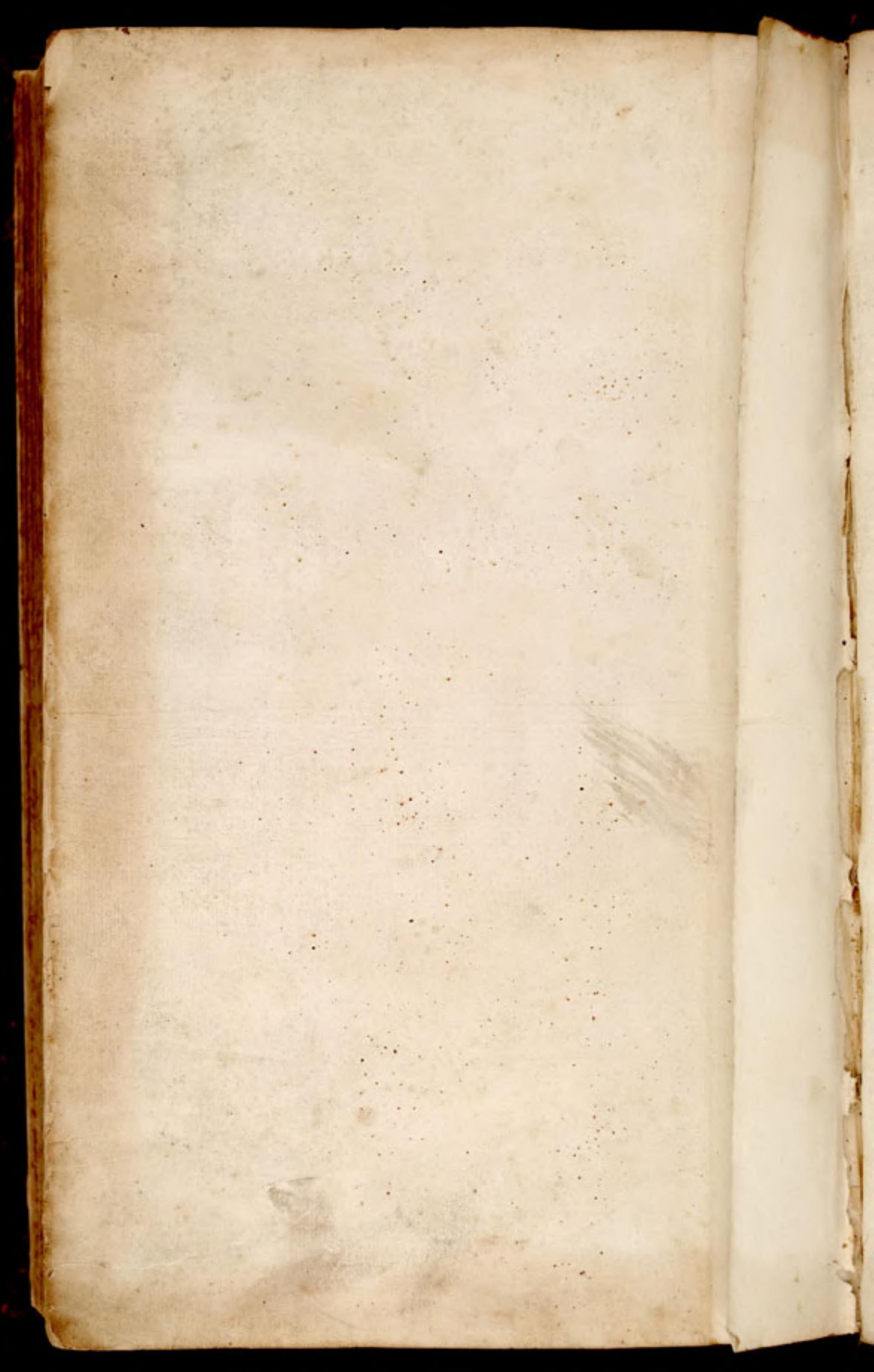





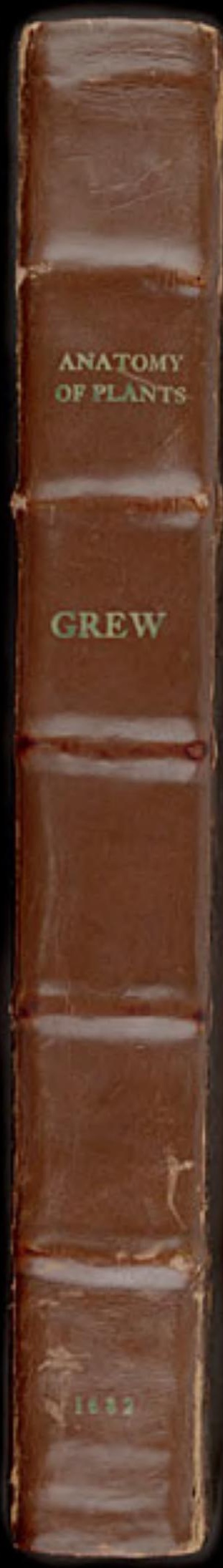

Spine
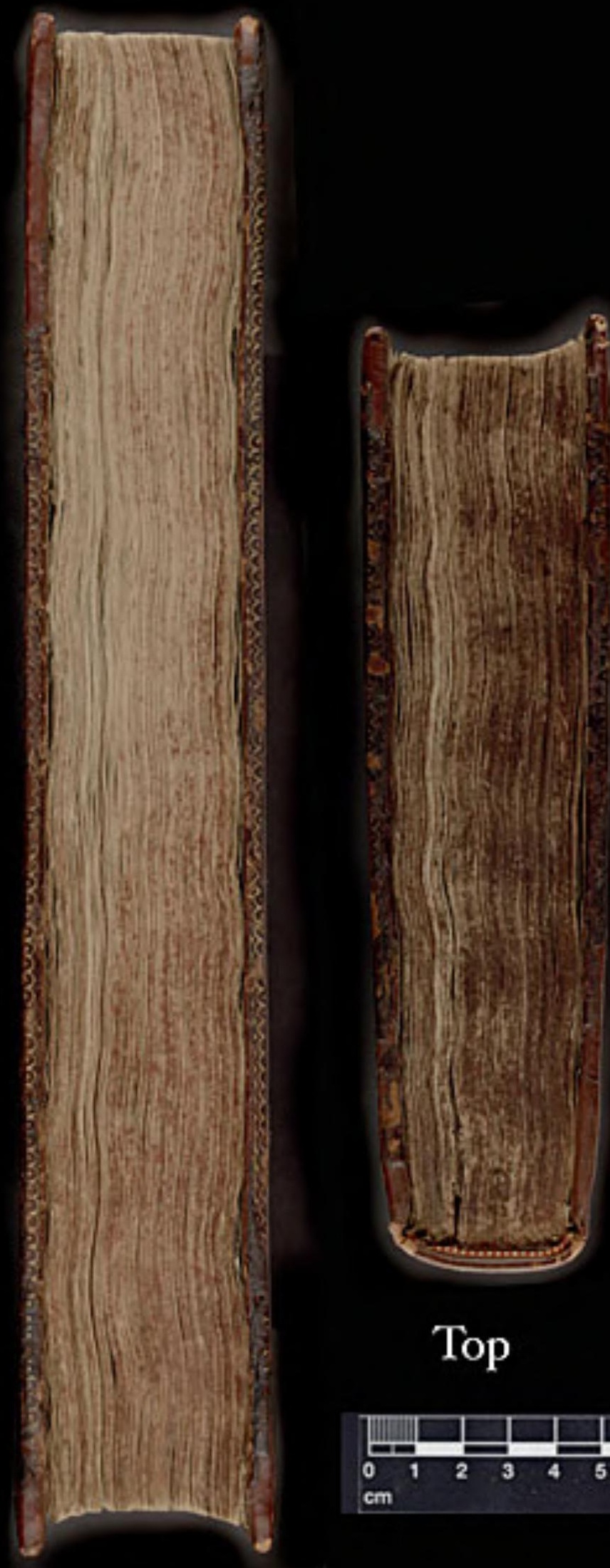

Top

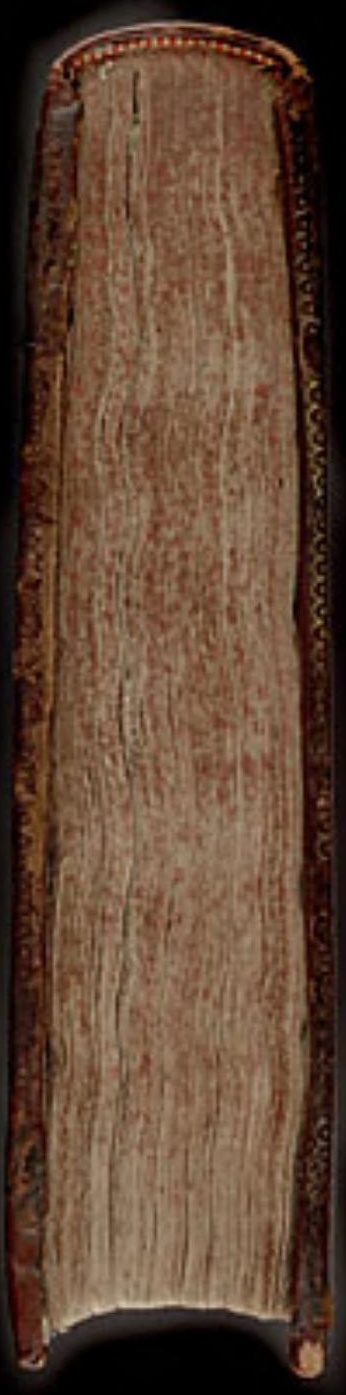

Foot

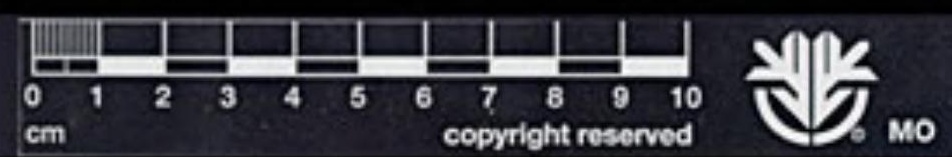

Fore 


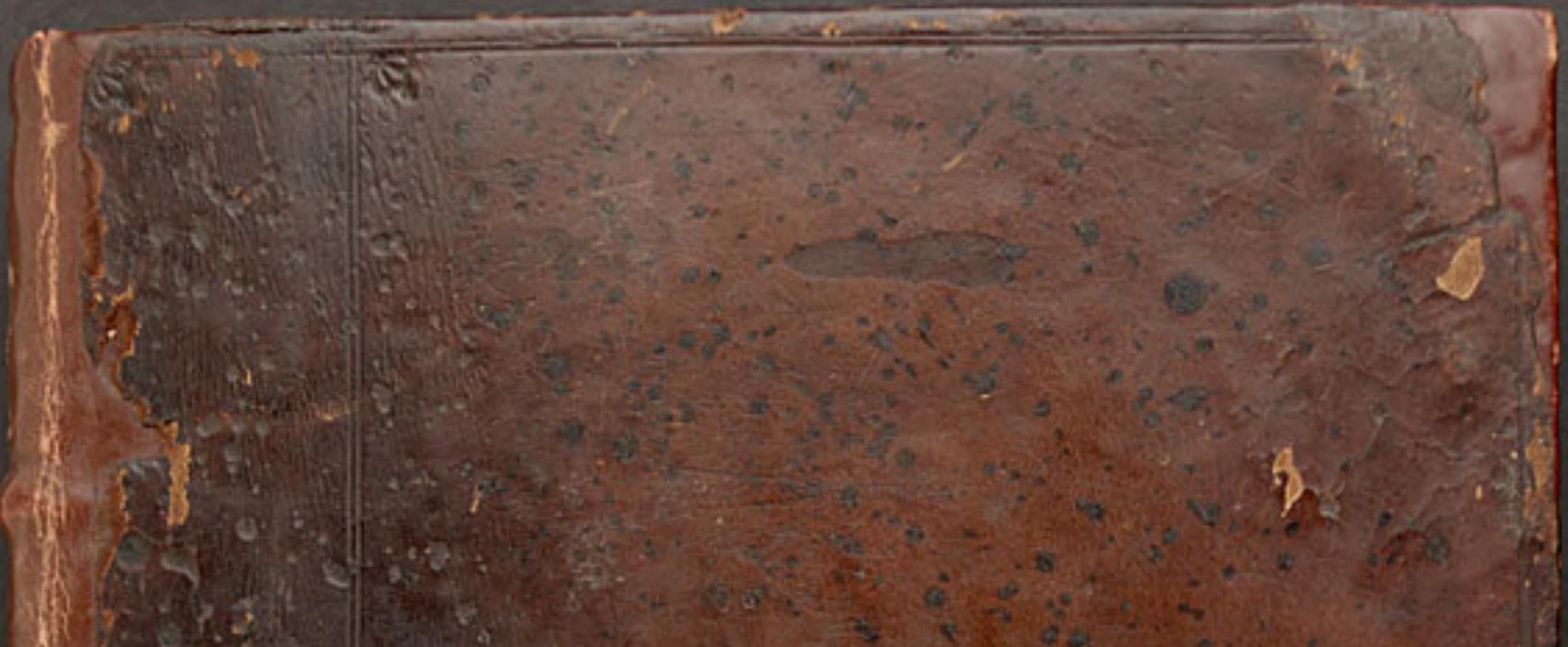

if $y=2$.

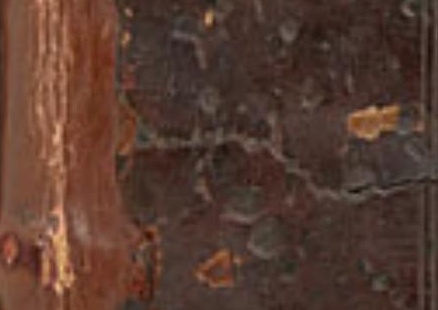

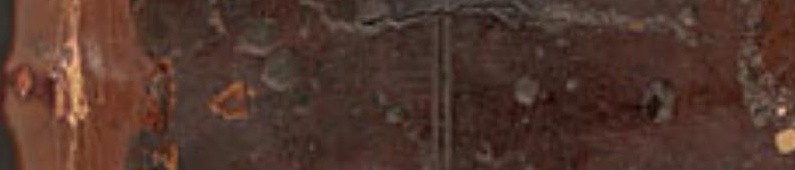

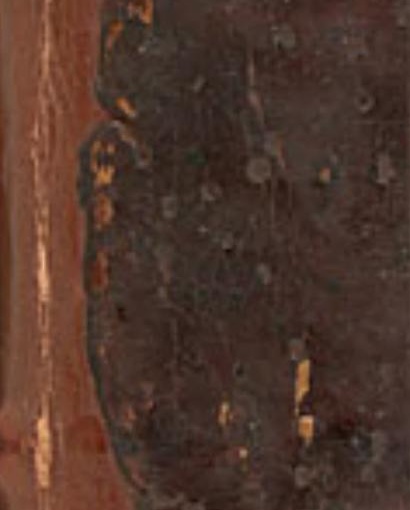

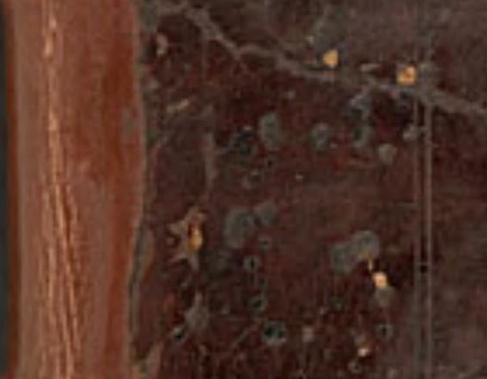

abe

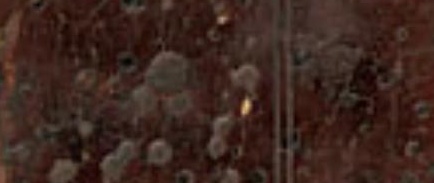

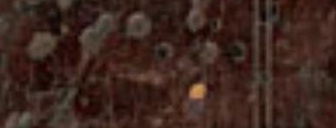

(3)

3.

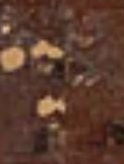




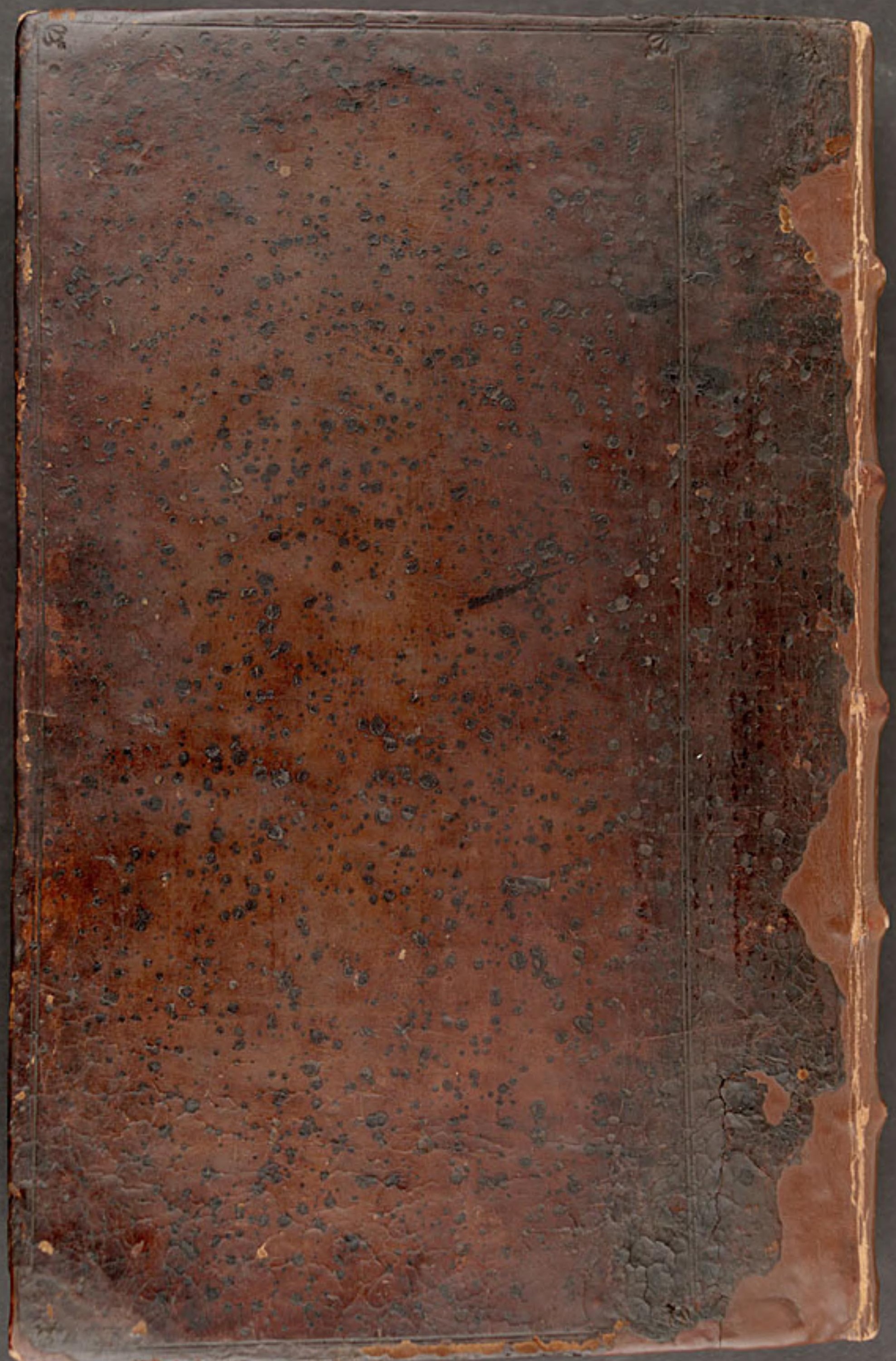

